\title{
Universiteit
}

Leiden

The Netherlands

\section{Stone artefact production and exchange among the Lesser Antilles}

Knippenberg, Sebastiaan

\section{Citation}

Knippenberg, S. (2007). Stone artefact production and exchange among the Lesser Antilles. Leiden University Press. Retrieved from https://hdl.handle.net/1887/27385

Version: $\quad$ Not Applicable (or Unknown)

License: $\quad$ Leiden University Non-exclusive license

Downloaded from: $\quad$ https://hdl.handle.net/1887/27385

Note: To cite this publication please use the final published version (if applicable). 

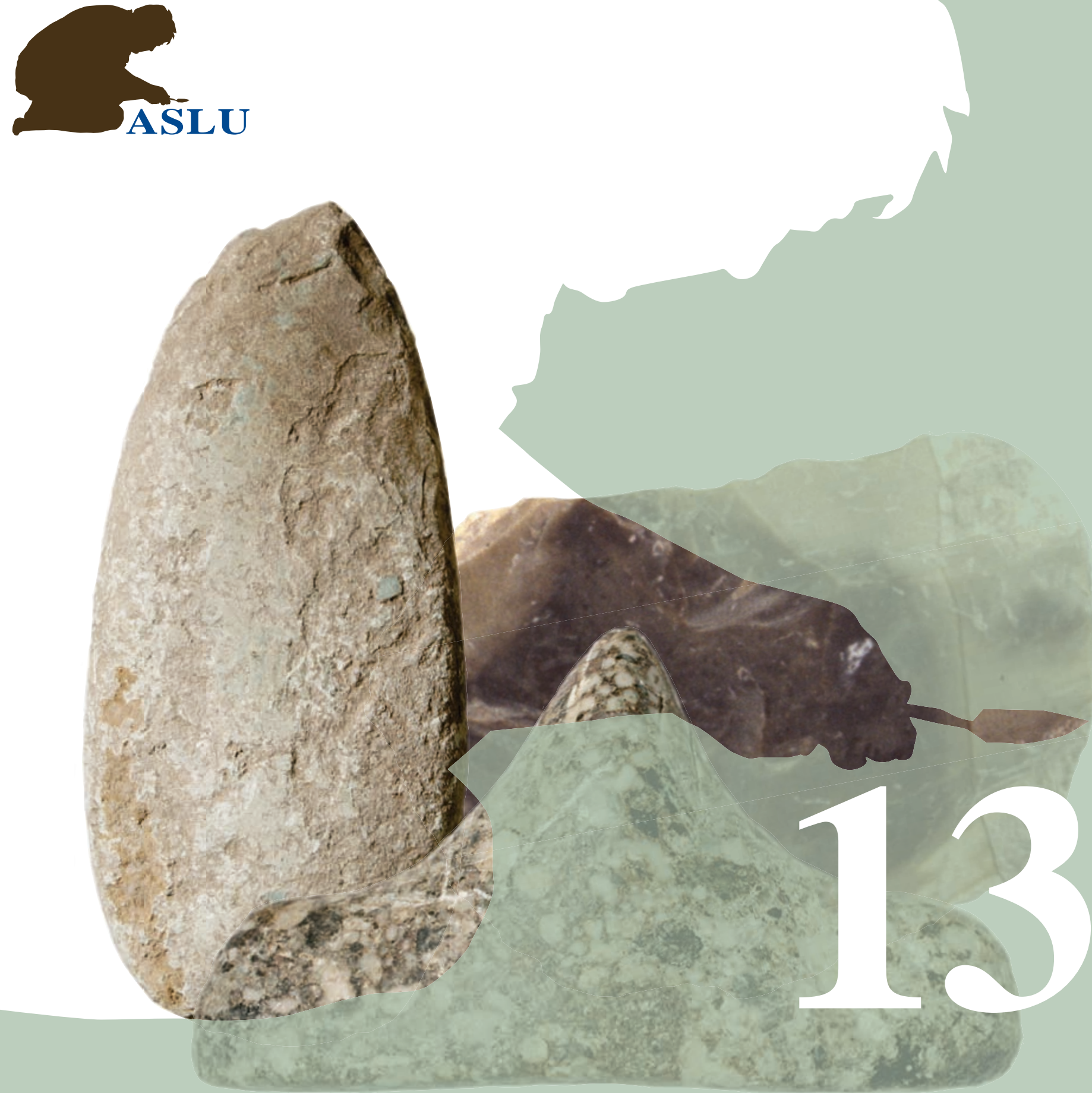

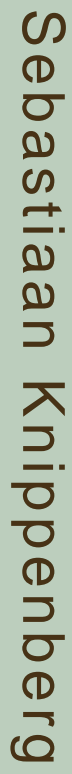

STONE ARTEFACT PRODUCTION AND EXCHANGE AMONG THE NORTHERN LESSER ANTILLES 


\section{STONE ARTEFACT PRODUCTION AND EXCHANGE AMONG THE NORTHERN LESSEN ANTILLES}

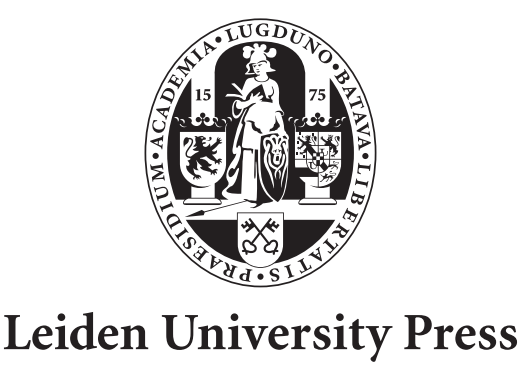


This book originally appeared as a Ph.D. thesis, Leiden University, The Netherlands

Series editors: Corrie bakels / Hans Kamermans

Cover photo’s: B. Grishaaver and J. Pauptit

Cover design: Medy Oberendorff

Lay out: Sebastiaan Knippenberg

ISBN 9789087280086

NUR 682

(C) Sebastiaan Knippenberg / Leiden University Press.

2007

All rights reserved. Without limiting the rights under copyright reserved above, no part of this book may be reproduced, stored in or introduced into a retrieval system, or transmitted, in any form or by any means (electronic, mechanical, photocopying, recording or otherwise) without the written permission of both the copyright owner and the author of the book. 
ARCHAEOLOGICAL STUDIES LEIDEN UNIVERSITY

\section{STONE ARTEFACT PRODUCTION AND EXCHANGE AMONG THE NORTHERN LESSEN ANTILLES}

Sebastiaan Knippenberg 

To Jim 



\section{Contents}

\section{Acknowledgements}

$1 \quad$ Introduction and research Objectives $r$

$\begin{array}{ll}1.1 & \text { Short background of the research } \\ 1.2\end{array}$

1.2 Short history of Caribbean archaeology 15

1.3 Socio-political organisation in Caribbean prehistory: current state of affairs 16

1.3.1 Early Ceramic Age societies

$\begin{array}{ll}\text { 1.3.2 Late Ceramic Age societies } & 17\end{array}$

$\begin{array}{lll}1.4 & \text { Socio-political organisation: tribal versus chiefdom societies } & 21\end{array}$

$\begin{array}{ll}1.5 & \text { Study of exchange: an anthropological perspective } \\ 1.6 & 21\end{array}$

$\begin{array}{ll}1.6 & \text { Exchange studies within Caribbean archaeology }\end{array}$

$\begin{array}{ll}1.7 & \text { Research objectives } \\ 1.8 & 25\end{array}$

$\begin{array}{llr}1.8 & \text { Methodology } & 27\end{array}$

2 Raw material sources and rock characterisation 29

$\begin{array}{llr}2.1 & \text { Introduction } & 29\end{array}$

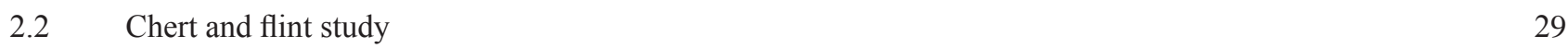

2.2.1 Introduction $\quad 29$

2.2.2 Chert nomenclature $\quad 30$

2.2.3 Cherts in the region 31

2.2.4 Methodology of the characterisation study 33

$\begin{array}{lll}2.3 & \text { Description of sources and related geology } & 34\end{array}$

$\begin{array}{lll}\text { 2.3.1 Introduction } & 34\end{array}$

2.3.2 Chert sources $\quad 36$

2.4 Chemical characterisation $\quad 52$

2.4.1 Introduction $\quad 52$

2.4.2 Origin of the trace-elements

2.4.3 Weathering $\quad 54$

2.4.4 Results $\quad 54$

$\begin{array}{lll}2.5 & \text { Discrimination of sources } & 71\end{array}$

$\begin{array}{lll}\text { 2.5.1 Discriminant Analysis } & 71\end{array}$

2.5.2 Results

$\begin{array}{lll}2.6 & \text { Source identification of artefacts. } & 77\end{array}$

2.6.1 Introduction $\quad 77$

2.6.2 Source assignment $\quad 79$

2.7 Conclusion 282

2.8 Other raw materials: calci-rudite and greenstone 82

2.8.1 A multicoloured conglomerate: calci-rudite zemi-stone from St. Martin 82

2.8.2 A grey-green mudstone: greenstone from St. Martin 86

2.8.3 Concluding remarks 92

$3 \quad$ Lithic analysis $\quad 93$

$\begin{array}{llr}3.1 & \text { Methodology } & 93\end{array}$

3.1.1 Introduction $\quad 93$

3.1.2 Aims $\quad 96$

$\begin{array}{ll}\text { 3.1.3 Data analysis } & 97\end{array}$ 
3.1.4 The attribute analysis form 102

3.2 Cultural setting of sampled sites 103

3.2.1 Sample of sites $\quad 103$

3.2.2 Chronology 104

$\begin{array}{lll}3.2 .3 & \text { Sampling and bias } & 109\end{array}$

$4 \quad$ Acquisition and lithic reduction at the source: Long Island 121

4.1 Introduction 121

4.2 Previous archaeological research on Long Island 121

4.3 The 2000-field campaign 123

4.4 Results of the 2000-field campaign 124

4.4.1 Jumby Bay

4.4.2 Sugar Mill 136

4.4.3 Buckley Bay $\quad 142$

4.4.4 "Site 32” 144

4.4.5 Flint scatters in the eastern area of Long Island 147

4.5 Discussion of results 147

$5 \quad$ Stone acquisition and working at habitation sites 151

5.1 Geology and occurrence of rock materials 151

$5.2 \quad$ Stone material use 156

$\begin{array}{lll}\text { 5.2.1 Introduction } & 156\end{array}$

$\begin{array}{lll}\text { 5.2.2 Early Ceramic A } & 157\end{array}$

5.2.3 Early Ceramic B 174

5.2.4 Late Ceramic A 193

5.2.5 Late Ceramic B 214

5.3 Discussion 217

5.3.1 Diachronic summary 217

$\begin{array}{lll}\text { 5.3.2 Organization of production } & 220\end{array}$

5.4 Conclusions 222

$6 \quad$ Production, distribution and exchange 223

6.1 Introduction 223

6.2 Distribution of lithic material 223

6.2.1 Long Island Flint 223

6.2.2 St. Martin greenstone 243

6.2.3 St. Martin calci-rudite 254

6.3 Exchange systems in the northern Lesser Antilles: some concluding remarks 261

$7 \quad$ Inter-island relationships 265

7.1 Summary of the data 265

7.2 Inter-island exchange networks and socio-political organisation 266

7.2.1 Introduction 266

7.2.2 The Early Ceramic Age 267

7.2.3 The Early to Late Ceramic Age transition 268

7.24 The Late Ceramic B phase 273

7.3 Concluding remarks 274 


\section{Appendix A Chert and flint sources}

References

Samenvatting 


\section{Acknowledgements}

In this context I wish to express my gratitude to all those individuals who have assisted me one way or another in the course of the present research. Participating in Caribbean archaeology and studying inter-island exchange networks starts by visiting as many islands as possible and cooperating with many local people, professional as well as avocational archaeologists. The regional scope of the research discussed in this study is well reflected in the large number of people from many different places who assisted my investigations. To stress the importance of "inter-island" contacts in particular and international cooperation in general, I would like to mention all of these individuals and acknowledge their help. I realize, though, that it is a long list.

Let me start by mentioning and thanking my supervisors Professor Leendert P. Louwe Kooijmans, Dr. Corinne L. Hofman, and Dr. Anne Louise van Gijn at Leiden University. Without their critical guidance this project would not have been possible. Furthermore, I wish to acknowledge the Netherlands Organisation for Scientific Research (NWO), The Hague, which made this research possible by allowing me a four-year's grant. This enabled me to conduct fieldwork at various islands and to study the collections of a number of institutions.

During the past few years I visited the islands of Puerto Rico, Anguilla, St. Martin, St. Eustatius, Antigua, Montserrat, Guadeloupe, La Désirade, Petite Terre, and Martinique. Furthermore, I spent some time at the Carnegie Museum of Natural History, Pittsburgh, USA. Each location introduced something of its own flavour to my research. I spent a wonderful time in Puerto Rico in 1998. Dr. Jeffery B. Walker of the USDA Forest Service in this island deserves special thanks for providing me lodging and a laboratory in one of the research facilities of the USDA Forest Service in El Yunque Forest Reserve. Besides, he critically reviewed my attribute code list, helped me out during my analysis of the Sorcé materials from the island of Vieques and took me to the chert sources of Southwest Puerto Rico. Also, I want to express my gratitude to Reniel Rodríguez Ramos, now a PhD student at the University of Florida, Gainesville, USA, for the many discussions we had on lithic technology, for sharing many of his unpublished data with me and for providing me with the Moca chert samples. Furthermore, I would like to thank Louis Chanlatte Baik and Yvonne Narganes Storde of the University of Puerto Rico, Río Piedras, for allowing me to study the lithic materials from the Sorcé site on Vieques and to analyse some of the flint and chert artefacts geochemically.

In 1999, I spent three weeks on Anguilla for the study of lithics from the Barnes Bay, Sandy Ground, and Shoal Bay East sites. Though remote and laidback, I had a great time working on this small island. First of all, I would like to thank Dr. John G. Crock, University of Vermont, USA, for generously allowing me to study these collections, sharing with me data acquired for his $\mathrm{PhD}$ research, and for all the help he gave me during my stay. Furthermore, I am indebted to Ijahny Christian, at that time director of the Anguilla Natural Trust, for providing me room to work.

During my various visits to the island of Antigua many individuals have assisted me. First of all, I wish to thank Dr. A. Reg Murphy, the state archaeologist of Antigua and Barbuda, for providing me permission to conduct archaeological fieldwork on Long Island, for pointing out to me the location of some of the local flint and chert sources, and for allowing me to use some of his data. Reg and his wife Nicky deserve special thanks for their great hospitality. Also, I would like to express my gratitude to Desmond V. Nicholson. Unfortunately, he will not see the results of my work, since he passed away recently. Nevertheless, I would like to mention him if only as a way of honouring him for his cheerful assistance during my stays on Antigua. With his death one of the most enthusiastic and joyful people of the Caribbean archaeological community has left us. In addition, I would like to thank the residents of Long Island, Jon and Karen Tate, for being most helpful during my fieldwork and for being excellent hosts to the islet. Also, Mr. Franklin and Mr. Swan, and the employees of the Long Island Resort are acknowledged for their hospitality. Mr. Stubbs deserves thanks for assisting in many ways. Finally, Monique de Rooij, Esther Mietes, Martijn van den Bel, and Tom Hamburg deserve special thanks for being such a great and enthusiastic fieldwork team on Long Island, and for producing so much work during our stay.

I visited Guadeloupe occasionally. At the time it formed the location of a University of Leiden archaeological field school. I would like to thank André Delpuech, the then director of the DRAC and at present curator of the Musée du quai Branly, 
for his support throughout the years and acknowledge him for providing such a great platform for executing large-scale archaeological fieldwork. This thesis has benefited in many ways from the work done on Guadeloupe.

In 2000, I visited Martinique in order to study the Vivé, Diamant, and Anse Trabaud collections. I would like to thank Dr. Benoit Bérard for allowing me to investigate these collections and helping me out during my stay on Martinique. I would like to mention the people of the DRAC for being great hosts.

My last foreign visit was to the Carnegie Museum of Natural History, Pittsburgh. Here the "journey" ended with one of the persons with whom it all started. I am very much indebted to Dr. David R. Watters. He inspired me by his enthusiasm during my first presentation on the subject on Guadeloupe in 1995, and afterwards "kept the fire burning". Partially by his interest and support this research has attained the present result. Besides, I would like to thank him for allowing me to study the Trants materials from Montserrat and providing such a great assistance during my stay in Pittsburgh. Finally, David and his wife Cathy deserve special thanks for letting me feel so welcome at their home.

Furthermore, I would like to mention and thank some of the people who have been helpful to me from a distance. First of all, I am indebted to Dr. Sandrine Grouard, Museúm National d'Histoire Naturelle, Paris, France, who analysed the animal bone materials from the Long Island habitation sites. I would like to thank also Dr. Christy N. de Mille, University of Calgary, Canada, for sharing with me data from her Antigua research. Professor Samuel M. Wilson, University of Texas at Austin, was so kind as to allow me to analyze the materials from the Hichman's site on the island of Nevis.

I spent considerable time at the Geology Department of the University of Utrecht, investigating the provenance of the flint and chert samples. Being an archaeologist while doing geological research, I was assisted by many people. First of all, I want to express my deepest gratitude to Dr. Johannes J.P. Zijlstra for teaching me the basics of flint and its formation, sharing his ideas, accompanying me to the chert and flint sources on Antigua, supervising my work on the provenance research, and critically reading and commenting on earlier versions of Chapter 2 and Appendix A.

Professor Bernard de Jong was always there to critically evaluate my research progress. In many ways he improved the work I did, for which I am deeply indebted. Furthermore, I would like to thank Helen de Waard who performed the ICPAES analyses and helped me out during the sample preparation procedure, Dr. Paul Mason, who performed LA-ICP-MS analyses on some of the flint samples, Dr. Tony Senior and Dr. Gerrit Klaver, who helped me identifying the minerals in the thinsections of the St. Martin greenstone, Dr. Cees Woensdrecht and Ir. Bertha Djee Kwee, who were helpful in many practical ways, and Otto Stiekema and Jan Drenth, who prepared many of the thin-sections.

At the home base, the Faculty of Archaeology, Leiden University, many people were helpful to me during different stages of this research. To start with the final stage, I would like to thank Medy Oberendorff for helping me out with the layout of the various maps and for creating the cover of this book. The work of Raf Timmermans and also Erick van Driel is much appreciated. They produced the beautiful artefact drawings which greatly improve the present work. Jan Pauptit and Ben Grishaaver made most of photos of the different artefacts. Dr. Alexander Verpoorte is thanked for critically reading and commenting on an earlier version of Chapter 4 and for sharing his ideas on the Long Island flint source. Dr. Menno L.P. Hoogland deserves thanks for the many discussions we had and for allowing me to study the lithic samples from Saba and Guadeloupe. Yvonne Lammers-Keyzers' willingness to share her knowledge on stone tool use and use-wear is greatly appreciated. Furthermore, I would like to thank Dr. Aad H. Versteeg for allowing me to analyse the Golden Rock, Godet and Smoke Alley collections from St. Eustatius, and A.J. Daan Isendoorn and Eelco Boomsma for allowing me to study the Anse à l'Eau finds from Guadeloupe. Special thanks are due to Frank Stevens, then MA student at Leiden University and at present employed by RAAP, Amsterdam, who analysed the Morel collection from Guadeloupe and generously allowed me to use his data for my research. The study by Joke and Harald, two BA students, of portions of the lithic sample from Golden Rock, St. Eustatius, is greatly appreciated.

Furthermore, I would like to thank Dr. Dave Hessen, University of Amsterdam, for helping me out with some issues related to the statistical analysis of the geochemical data.

My current employer, Archol BV, most kindly provided computer facilities to me, which allowed me to make and edit the 
various illustrations, and finalize the layout of the book. My colleagues at Archol are thanked for distracting me sometimes from Caribbean archaeology.

Dr. Maaike de Waal, co-participant in the project, has been a great colleague, with whom I had many professional discussions. She deserves special thanks for reading and commenting on earlier versions of this work and allowing me to study the materials she excavated on La Désirade, and Iles de la Petite Terre in the Guadeloupe region.

My friends Frank, Frits, Hans, Pieter, and Ruben have always been great distractions from my work and their letters written to me while doing archaeological research in the Caribbean are still very much appreciated - thanks guys.

My mother Rineke has always supported me during the different stages of the work, for which I am thankful. My father Hans has been a great stimulus in forming my analytical capabilities. My brother Olivier always critically observed my doings. Olivier, I hope I have convincingly demonstrated that "stone” turtles were not responsible for the transport of rocks among the islands.

I would like to express the deepest gratitude to my girlfriend Mireille Blom for being so patient and for showing me that archaeology is not everything.

I want to dedicate these final lines to the memory of Professor James B. Petersen, University of Vermont, USA, who so tragically was taken from us less than a year ago. Caribbean archaeology has lost of one of its finest researchers and one of its nicest individuals. Jim was the referent of this dissertation and has critically read and most thoroughly corrected the entire manuscript, for which I am deeply grateful. Just before his tragic death, I, fortunately, had the chance to see him and hear from him that he very much enjoyed reading the work. Therefore, this dissertation is dedicated to him. 


\section{Introduction and research Objectives}

\subsection{SHORT BACKGROUND OF THE RESEARCH}

The first impetus to the work described in this dissertation came during Masters fieldwork at two pre-Columbian sites on St. Martin in 1993 (Knippenberg 1995; Knippenberg et al. 1999; Nokkert et al. 1999). With three fellow students I did a site-survey at the Preceramic Age site of Norman Estate and the Saladoid site of Anse des Pères. After our interests were evaluated, we decided that I should analyse the lithic artefacts that were found. During this analysis I noted the presence of a large amount of artefacts made of chert materials not originating from St. Martin. Intrigued by this finding I initiated a preliminary study to identify the provenance of this type of stone. To my surprise I discovered that very little had been done on this topic in Caribbean archaeology, despite the often rich lithic artefact assemblages found. Fortunately some years prior to my St. Martin investigations, a team from Leiden University had excavated at Long Island, a small island off Antigua's northern coast, where significant amounts of natural flint material could easily be exploited (Van Gijn 1996). As numerous boxes of flint boulders and artefacts collected from the Long Island were stored at Leiden University, I was able to become very well acquainted with this variably coloured chert material. Visual similarity between this material and many of the artefacts excavated on St. Martin, encouraged me to find a method that could further confirm the Long Island origin of the St. Martin items. Applying geo-chemical techniques I was indeed able to confirm the close similarity. This, in turn, proved that Long Island flint had been transported over approximately $175 \mathrm{~km}$ from Antigua to its destination on St. Martin, suggesting exchange between the islands (Knippenberg 1995, 1999a).

Over the following years I discovered that many more sites in the region produced Long Island flint and that the St. Martin case was not the exceptional case. This persuaded me, supported by several colleagues working in the region, to set up a broad study aimed at the understanding of flint distribution and exchange in the northern Lesser Antilles and beyond. Fortunately, but totally unexpected, it appeared that the island of St. Martin itself hosts two other important sources for stone materials, namely a fine grey-green mudstone and a multicoloured conglomerate, calci-rudite. My initial archaeological work there had enabled me to become familiar with these materials but I was initially unaware of their significance within the surrounding area. Therefore the regional scope of the present research provided room for the study of the distributions of these materials as well and this dissertation is the outcome of this investigation. Before discussing the objectives and methodology followed, I will first present some issues in Caribbean archaeology, which are relevant for a proper understanding of my research.

\subsection{Short HISTORY OF CARIBBEAN ARCHAEOLOGY}

The history of Caribbean archaeology shows that it was untill recently dominated by a cultural-historic approach originally initiated by Professor Irving Rouse from Yale University. From the late 1930s onwards, Rouse developed a systematic line of research, focussed primarily on pottery typology (Rouse 1939, 1954, 1964, 1965, 1986, 1992). Armed with a thorough methodology, which was then very innovative within American archaeology (Willey \& Sabloff 1974), Rouse conducted numerous small scale excavations in cooperation with local archaeologists on many different Caribbean islands and the adjacent South American mainland (Rouse 1939, 1941, 1947, 1952, 1974; Rouse \& Alegria 1990; Rouse \& Cruxent 1963; Rouse \& Morse 1999). Rouse's work resulted in the construction of a chronological framework for the whole Caribbean region, which he continually refined until recently (Rouse 1992; Rouse \& Morse 1999).

During the 1970s attempts were made to change the attention in Carribean Archaeology from cultural chronology to other research objectives. Although some other lines of research had been previously applied, for example, subsistence studies, most of this research was still indirectly or directly related to characterising cultures and relating them to a chronological framework. Some new lines of research, however, had a more ecological, adaptive objective. For example, systematic surveys on an island level were conducted to determine adaptive changes through time (Goodwin 1979; Watters 1980). Also, midden material, which was formerly used to define cultural complexes in most cases, now became the subject

to objectives with a more ecological adaptive emphasis that aimed to reconstruct subsistence strategies (e.g. Reitz 1989; Wing 1991; Wing \& Reitz 1982). 
From approximately the 1990s onward, research has become more focused on understanding the social-political organisation of the Armeridian societies that inhabited the different islands (Curet 1992, 1996; Crock 2000; Haviser 1991; Delpuech \& Hofman 2004; Keegan 1992). The present study aimes to contribute to this recent investigation of socialpolitical organization by studying inter-island exchange. Before I go on to outline my research objectives, I need to first discuss the current state of affairs related to different views about Amerindian social-political organisation in the region. In addition, I will specify how the study of exchange contributes to this line of research.

\subsection{SOCIO-POLITICAL ORGANISATION IN CARIBBEAN PREHISTORY: CURRENT STATE OF AFFAIRS}

\subsubsection{Early Ceramic Age societies}

The pre-Columbian period in the Caribbean is generally divided into two major periods: the Preceramic and Ceramic Ages (Keegan 1994, 2000). The earlier period, which is outside the range of the present study, witnessed the first occupation of the Caribbean islands by nomadic foragers, roughly dated from 5000 to 500 BC (Keegan 1994; Rouse 1992). The first arrival of horticulturalists who migrated from the South American mainland, marks the end of the Preceramic Age. This second major migration did not pertain to the whole Caribbean at once, but initially only involved the populating of the Lesser Antilles, the Virgin Islands, and the eastern part of Puerto Rico (Haviser 1997; Hofman 1993; Keegan 2000; Rouse 1992). The remaining part of the Greater Antilles continued to be occupied by Preceramic Age residents, who were overtaken or driven toward the western end of the archipelago during the following centuries (Keegan 2000; Rouse 1992) (figures 1.1 and 1.2).

These first horticulturalists originated in the Orinoco delta, and entered the Caribbean islands through the southern Lesser Antilles. They quickly moved northwards, using the chain of islands as stepping-stones. Early dates from Trants on Montserrat, Hope Estate on St. Martin, and Fond Brulé on Martinique place this migration around 500 BC. Initially, only the relatively high fertile volcanic islands were settled, leaving many of the smaller and low-lying limestone Antilles vacant.

Up until the early 1980s all sites belonging to this so-called Early Ceramic Age were grouped under the Cedrosan Saladoid series, the Caribbean branch of the Saladoid culture related to the Ronquinan Saladoid complex on the South American mainland. The pottery of the Saladoid culture was well-made and characterized by typical use of White-onRed painted decoration and very characteristic modelled adornos (Hofman 1993, 1999; Rouse 1992). However, since the excavations at La Hueca on Vieques, where a distinctive style of pottery was discovered that had Zoned-IncisedCrosshatching and dog shaped adornos, a serious debate about the cultural and social interpretation of this difference has developed (Oliver 1999). The archaeologists working at La Hueca, Louis Chanlatte Baik and Yvonne Narganes Storde, ascribe the distinctive La Hueca ceramics, which were found spatially separated from Cedrosan ceramics at the same site, to an earlier migration into the Antilles by a culturally distinct group of people as compared to the "Saladoid" people. However, Rouse and others see the producers of the "La Hueca" ceramic style as a distinctive social group within the larger Saladoid culture (Chanlatte Baik \& Narganes Storde 1984; Rouse 1992). More recent excavations at sites producing Huecan ceramics did not provide a clear solution to this problem. In the Lesser Antilles all sites yielding Huecan type ceramics, such as Hope Estate, Morel, and Trants, also produced Saladoid ceramics in stratigraphically indistinguishable deposits. However, at the Punta Candelero site on the main island of Puerto Rico the Huecan deposits were again separated from the late Saladoid or Cuevas phase deposits (Chanlatte \& Narganes 1984; Hofman 1999, 2001; Reed \& Petersen 2001; Rodríguez Lopéz 1991; Watters \& Petersen 1999). These new findings have reinforced the original contrasting viewpoints rather than bringing scholars together in a theory, that explains these different situations (Oliver 1999).

Despite this debate about the cultural classification of Early Ceramic Age settlers, it is generally agreed that their sociopolitical organisation was on an egalitarian tribal level without hereditary stratification. This is suggested by absence of burial differentiation, relatively constant settlement sizes, and wide distribution of supposedly valuable artefacts, indicating non-restricted availability (e.g. Curet 1992; Siegel 1999). Notwithstanding this view, some scholars have emphasized certain features of Early Ceramic Age society that deserve additional mention. Boomert (2000, 2001a), for example, pleas for the existence of Big-Men, achieved leaders with some regional power, because in his eyes the wide distribution of semi-precious stone valuables is suggestive for frequent gift-giving activities, which would have taken place between competing Big-Men living on the different islands.

Hoogland (1996) and Siegel (1989) have adopted the term "complex tribe" to more precisely describe the situation. This term was first used in an unpublished paper by Hoopes (1988). It comprises a situation in which societies "conduct 


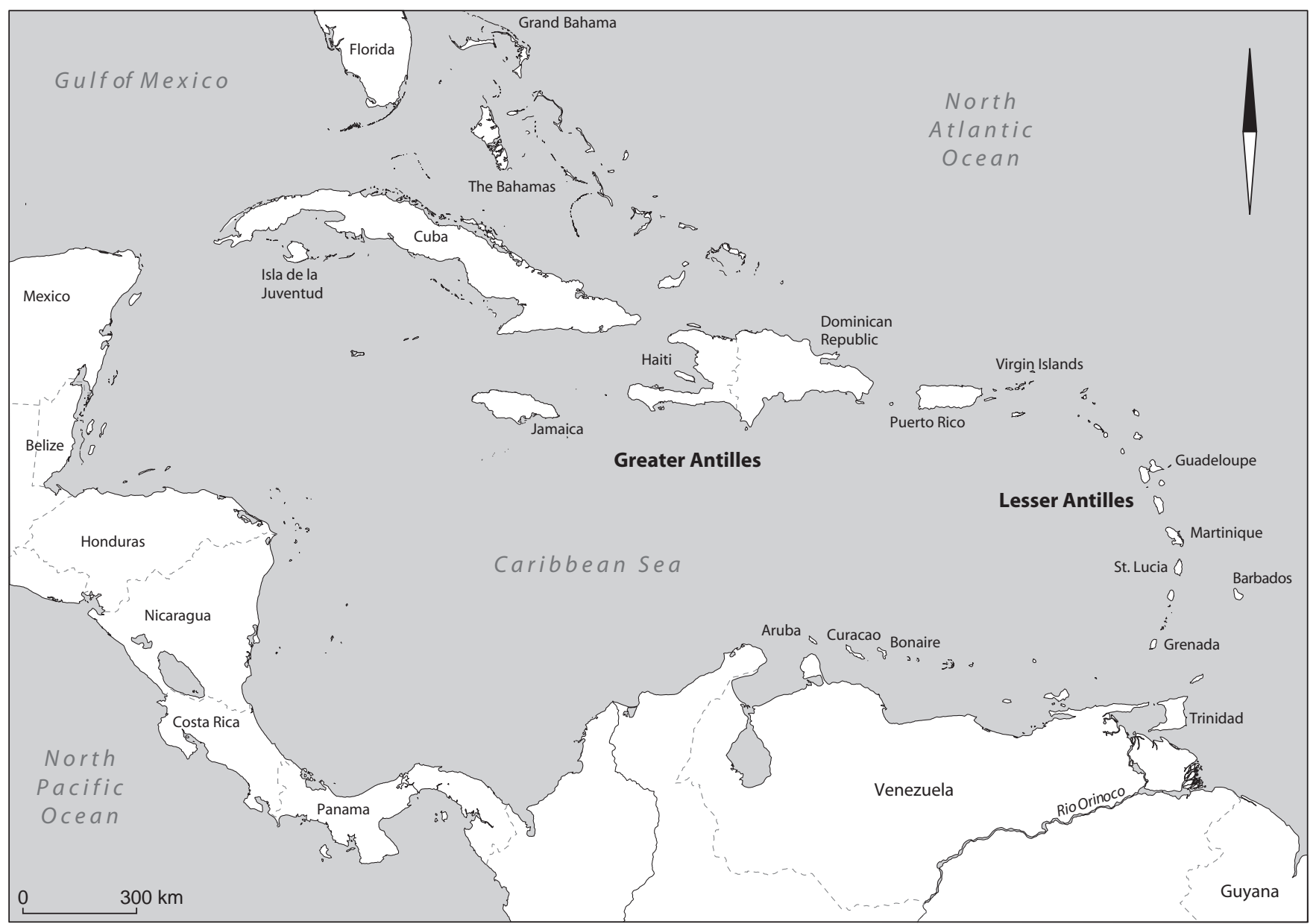

Figure 1.1. Map of the Caribbean.

communal activities, have status variation, but no centralized authority" (Siegel 1989, 202). Although burial differentiation and settlement hierarchy might be absent, they argue that the fast spread among the islands and relatively long uniformity in pottery decoration point to a society that was more complex than the tribal level (Hoogland 1996, 9). Thus, Boomert, as well as Hoogland and Siegel, stress the communal, connected character of Early Ceramic Age society, thereby contrasting it with the autonomous role that is usually attributed to villages in tribal societies (e.g., Carneiro 1998). Whether this communal character opened room for local village leaders to become regionally significant, in my opinion is not necessarily proven by the existence of a long-distance exchange network. Keegan et al. (1998) and Watters (1997a) argue that during first colonization this long-distance exchange network may have been crucial for the survival of different widespread villages in new environments. In this view, exchange functioned more as a means of bringing people together for purposes related to cooperation, rather than providing a platform for competing village leaders aiming at the acquisition of regional leadership.

\subsubsection{Late Ceramic Age societies}

From around AD 600 onward the typical traits of Saladoid pottery begin to disappear and new styles evolved. It is generally agreed that the transition toward new styles was a local process of acculturation and evolution, exhibiting regionally distinct developments. It did not involve a new migration of peoples from outside areas (Hofman 1993; Hofman \& Hoogland 2004; Keegan 2000). A detailed discussion of these local developments for the entire Caribbean archipelago is too extensive and too complex for my present purposes and in some cases they are not well understood (e.g. Haiti). For the present research I 


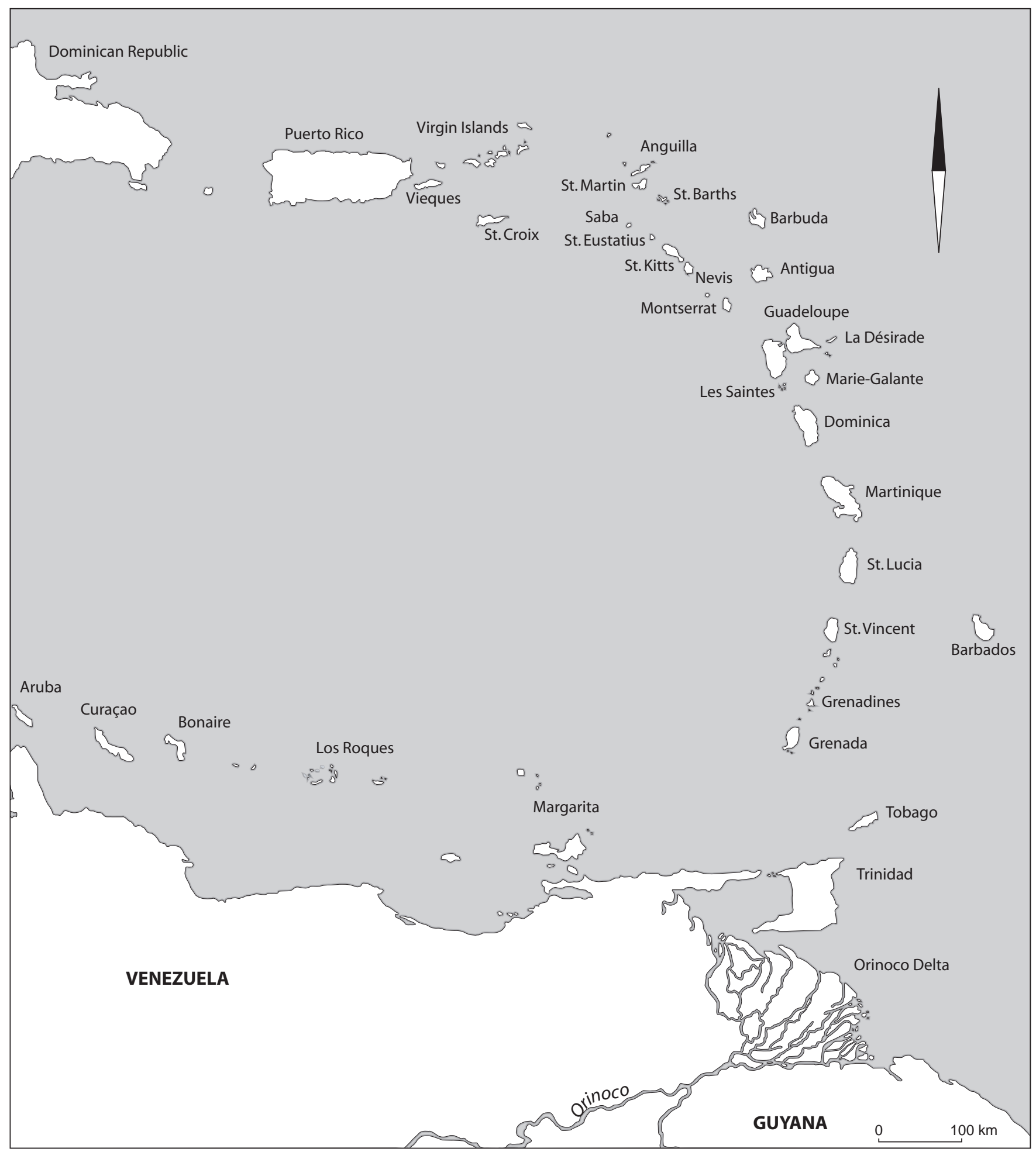

Figure 1.2. Map of the Lesser Antilles. 
have specifically restricted myself to the northern Lesser Antilles and the eastern Greater Antilles.

Regarding post-Saladoid developments, the Lesser Antilles are sub-divided into the southern Windward Islands, and the northern Leeward Islands, with the island of Guadeloupe marking the border between the two. This sub-division largely results from the work of Rouse (1992). Rouse notes that the southern islands experienced influence from the Barrancoid culture during late Saladoid times. This culture replaced the Saladoid culture in the Orinoco delta. A "modified" Saladoid sub-series arose, and it was in turn, replaced by the Troumassoid series, which lasted till around AD 1000. The Suazoid series represents the latest development in this southern region after AD 1000.

Data from the northern Lesser Antilles were relatively more limited at the time of Rouse's publication (1992) of his major overview. He saw this area as an eastern periphery under the influence of the Ostionoid series that arose on Puerto Rico after the Saladoid period. Recent investigations by Hofman on pottery styles in this northern region, however, revealed a more dynamic picture in which independent developments occurred, and style boundaries were somewhat fluid and changing (Hofman 1993; Hofman \& Hoogland 2004). In the first place, Saladoid pottery style persisted much longer on some of the western islands in this area than elsewhere. Late Saladoid sites have been identified on St. Eustatius, Saba, Anguilla and St. Martin (Hamburg 1999; Hofman 1993; Knippenberg 1999b; Knippenberg et al. 1999; Versteeg \& Schinkel 1992). Contemporary with this persistence, the more eastern islands of Antigua and Guadeloupe experienced local changes into post-Saladoid styles, called Mill Reef (Rouse 1992; Rouse \& Morse 1999).

After AD 900, local post-Saladoid pottery complexes had completely replaced the Saladoid style, although in some cases more regional affiliations with the southern Troumassoid and eastern Elenan Ostionoid are noticed. The final period of indigenous occupation displays some marked influences and intrusions from outside. Hofman and Hoogland reported the discovery of a Chican Ostionoid site at Kelbey's Ridge 2 on Saba, which appears to be affiliated with the Boca Chica style from Hispaniola. They argue for incorporation of Saba within the Greater Antilles interaction sphere (Hofman 1993; Hoogland \& Hofman 1999; Hoogland 1996). More to the southeast two sites were identified on la Désirade producing a pottery style not known within the local area, suggesting foreign intrusions from the south, possibly the South American mainland (De Waal 1999a, 2006.; Hofman 1999; Hofman et al. 2004).

Within the Greater Antilles, from the initially settled region in the eastern part of Puerto Rico, horticultural communities slowly started to occupy the western islands, at which time Preceramic groups disappeared. Whether this process involved acculturation, assimilation, hybridisation, or removal of the latter groups is still debated (Keegan 2000). The existence of proto-agricultural complexes on Cuba and Hispaniola contemporary with the Saladoid groups favours an acculturation model. From relatively a lot of research on Puerto Rico we know that the Saladoid series evolved into the Ostiones series after AD 600 on that island. From this period onward, expansion of Ostiones groups occurred toward the western islands, evidenced by small settlements on Hispaniola, Jamaica, Cuba and the Bahamas. Within the Greater Antilles, the Ostiones series is generally divided into four sub-series: Elenan, Ostionan, Meillacan and Chican (Hofman 1993; Petersen et al. 2004). The first two evolved out of the late Saladoid Cuevas style in the eastern and western part of Puerto Rico, respectively. The third evolved around AD 800 out of the western Ostionan sub-series, and spread towards the western Greater Antilles. Chican Ostionoid represents the latest development, first appearing around AD 1200 within the Dominican Republic, from where it spread into Puerto Rico and the Virgin Islands.

Regarding the socio-political organisation during this later period of Amerindian occupation, our knowledge was initially derived from historical documents written by the Spaniards directly after the discovery of the New World (Morosco 1981; Wilson 1990). There they first encountered the Taínos. From the writings of Columbus and later travellers it became clear that the Greater Antilles were divided into different cacicazgos. These were stratified polities under the reign of an ascribed leader, in the person of a cacique. The island of Hispaniola apparently hosted the most powerful and important polities in the region (Wilson 1990). It is now generally agreed that these Greater Antilles cacicazgos can be regarded as chiefdom type of societies.

Archaeological evidence is building up that supports the historical data with regard to the socio-political organisation of Taíno society (Curet 1992, 1996; Curet \& Oliver 1998; Siegel 1996, 1999). One of the most obvious cases is formed by the appearance of a clear site hierarchy and site functional variability starting during the early Ostiones period (Curet 1992). This period also shows the first evidence of ball-court sites, which clearly stand out from the regular settlement sites that were characteristic throughout the preceding Saladoid period (Alegría 1983). The ball-court sites, which become increasingly larger over time, are interpreted as regional centres, where leaders assembled the people living in small hamlets surrounding these central places for ritual, political and social activities (Oliver 1999; Siegel 1999).

There has been a recent increase in archaeological research centred on this topic. The focus of attention has shifted 
from an emphasis solely on the ball courts to the social environment related to these ball-courts and the forces that led to the development of socio-political stratification (Curet 1992, 1996; Curet \& Oliver 1998; Oliver 1999). During the late 1980s, Antonio Curet (1992) initiated a regional archaeological project with the aim of determining the nature of these forces. Curet focussed on one variable: population pressure. Population pressure is often considered within archaeology as (one of) the driving force(s) behind socio-political evolution. By showing that the population in the valley of Maunabo in southeast Puerto Rico never exceeded the carrying capacity during the Ostiones and later periods, Curet argued that population growth was not the prime mover by which people reorganized themselves into socially and politically different relations. After having suggested that, he hypothesized for a more politically influenced scenario, in which local chiefs modified existing cosmology with the aim of improving and maintaining their own position and that of their heirs (Curet 1992, 1996).

In the Lesser Antilles we are much less informed by the Spanish documents and we essentially have none for most islands. Based on the accounts of the Taínos, the Spaniards divided the Caribbean region into two areas, with the Greater Antilles including the Bahamas and the Virgin Islands as the region where the Taínos lived on the one end, and the Lesser Antilles, inhabited by hostile Island Caribs on the other end. Not much is known about these supposedly fierce Island Caribs. In particular, for political reasons the Spaniards refer to them as aggressive and more importantly, as cannibals. This designation enabled the Spanish to legally enslave these peoples, as they were not believed to be able to ever become Christians (Sued Badillo 1992).

Unlike the information on the Taíno cacicazgos, hardly anything is known about the socio-political organisation of the Caribs in the Lesser Antilles. Consequently statements regarding this subject have remained vague, and the area often was seen as a peripheral in relation to the Greater Antilles, thereby suggesting that society never surpassed tribal level. I think that the French documents describing the Island Carib inhabitants of some of the Lesser Antillean islands, written more than a century later, have often contributed to this picture, as they describe small-scale egalitarian societies there (Breton 1978; Moreau 1994). In the light of the considerable time period that elapsed between the first Spanish arrival and the writing of these French documents, it can be questioned whether these latter sources are reliable when attempting to reconstruct pre-Columbian socio-political organisation in the Lesser Antilles. The Spanish occupation of the Greater Antilles and enslavement of its local population not only had a dramatic effect on the Taínos themselves. The Taíno became culturally extinct within 50 years after Columbus and the Spanish first set foot on the islands. However, they also had a considerable impact on the surrounding region, because as a consequence of the disappearance of local work-power, the Spanish raided the Lesser Antilles and the northern South American coast in search of new slaves (Sued Badillo 1992). This must have resulted in significant depopulation of these regions, totally altering the existing socio-political situation.

As argued in the introductory paragraph, until recently archaeological research has not been able to make a significant contribution to the understanding of socio-political developments in the Lesser Antilles for the period after the disappearance of the Saladoid culture. Recently, however, this line of research has received more attention. Jay Haviser (1991) was one of the first to opt the existence of a lesser chiefdom in the Anguilla - St. Martin region along with the larger polities of the Greater Antilles. He based his interpretation on the presence of large settlement sites and a regular exchange network between these islands involving the distribution of various stone materials. Initially Hoogland questioned this conclusion arguing that the very limited archaeological evidence collected from this micro-region did not yet provide a solid basis for this interpretation related to the development of social complexity. In contrast, Hoogland concluded on basis of his own work on Saba that there was no evidence of hereditary leadership, and that society remained at a tribal level, oscillating "between both extremes in the range of tribal social organization" (Hoogland 1996, 220).

Very recently, Crock (2000) brought the concept of chiefdom again to the foreground, however, when he concluded from his excavation work on Anguilla that this island formed the centre of multi-island chiefdom in the Lesser Antilles. He showed that a number of sites on Anguilla differed in their artefact inventory, in particular with regard to high status items, exotic materials, and subsistence related artefacts. From this he argued that these sites had differential access to resources suggesting stratification. Moreover, he noted that Anguilla hosted some of the largest sites in the near region, signifying its central position.

The discovery of a similar large site at Anse à la Gourde, along the northern coast of Grande Terre (Guadeloupe), displaying a similar high status artefact inventory, did not lead Hofman and Hoogland (2004) to reach the same conclusions. Although they see that differentiation is becoming more evident between sites, they still did not identify conclusive evidence of hereditary status differences, one of the important characteristics of a chiefdom society. The burials found at the site suggest complex and differential rituals, but lack clear stratification in burial gifts. Moreover, Anse à la Gourde itself may be a large site seen within a composite regional perspective, in absolute size, but more importantly in absolute number of 
inhabitants during the different occupation phases it may be considered as a moderate village, not hosting more than a small number of houses.

This short introduction clearly shows that viewpoints regarding socio-political organisation within the region display considerable agreement when examining the egalitarian level attributed to the society of the first agriculturalists within the region, as well as to the chiefdom structure of Taíno society on the Greater Antilles prior to the arrival of the Spanish in the region. Controversy, however, exists surrounding the developments during post-Saladoid times on the Lesser Antilles, in particular the northern region. The debate mainly focuses on the question whether society reached a chiefdom level or it remained egalitarian.

\subsection{SOCIO-POLITICAL ORGANISATION: TRIBAL VERSUS CHIEFDOM SOCIETIES}

Before I continue with clarifying to what extent this study of exchange may contribute to this debate, let me first comment on what is exactly meant by "chiefdom" society and "egalitarian" society. An important volume edited by Redmond (1998a) recently appeared, which specifically relates to the change from egalitarian societies to chiefdoms in the Americas. This work, in particular, is important to the present study since it describes cases within the culturally related region of the Amazon. In this work, Spencer $(1998,105)$ defines a chiefdom society as "a human society that has centralized political authority and institutional social status differentiation but lacks an internally specialized central government". Despite an emphasis on social stratification in this definition Carneiro sees ranking only as an epiphenomenon of chiefdoms and not its central core. "A much more fruitful approach in characterizing a chiefdom is to look at its component units - a multiplicity of villages - and at the political means by which these villages are organized and integrated." So in Carneiro's eyes chiefdoms are rather political entities more than ranked societies. This is different from egalitarian tribal society, where village autonomy still plays an important role and that exhibits "a nested arrangement of consensual decision making" (Redmond 1998b, 3).

In Redmond's volume considerable attention is paid to the trajectory from egalitarian societies to the development of chiefdoms. The contributors, therefore, introduce the concept of "chieftaincy" to define the intermediate situation. It is considered as the more general equivalent of the Melanesian Big Man concept, which is abandoned because of its strong cultural connotation. Redmond (1998b) following Johnson (1982, 402-3) defines the chieftaincy as "a situational hierarchy occurring from time to time among nonhierarchical, uncentralized tribal societies". "Thus, the chieftaincy represents an emergent simultaneous hierarchy in which an achieved leader exercises hierarchically differentiated decision-making functions, albeit on a temporary basis". This situation is further illustrated in this book by cases among Amazon societies, in which strong village leaders are able to become regionally renowned and exercise control over a multi-village assemblage. Redmond further argues that if members of the leader's lineage are able to succeed him during the following generations and continue the regional hegemony, the path to a chiefdom is set.

It is evident from this short discussion of growing complexity from tribal towards chiefdom societies, that village autonomy versus regional centralization is an important distinction, which characterizes both extremes in this particular case. In relation to the study of exchange, which is the primary focus of the present work, this forms an interesting perspective, as these two cases primarily speak of changing inter-village relationships. Therefore, as part of a larger research project in which inter-island interaction is being studied from three different perspectives - with style affiliation and settlement patterns representing the other two besides exchange (De Waal 2006, Hofman \& Hoogland 2004) - the following chapters are devoted to study of stone material distribution as a means of understanding inter-island exchange within the northern Lesser Antilles. The derived exchange patterns may form a valuable contribution to a better understanding of inter-village relationships.

\subsection{StUdy OF EXCHANGE: AN ANTHROPOLOGICAL PERSPECTIVE}

Since the important work of Marcel Mauss (1990), first appearing in 1925, it has become clear that in non-western societies exchange in general has a different form and plays a different role than exchange in the capitalistic world. Through the analysis of agonistic and non-agonistic gift exchange rituals among the cultures of the American Northwest and the islands of Melanesia and Polynesia, Mauss clearly showed that exchange should not be merely considered as an economic relation, but that it is embedded in all aspects of society, including social, political, economic, as well as religious aspects. This work and later studies clearly highlighted some of the features that distinguish these gift exchange acts from exchange commonly 
found in Western (capitalistic) society. One of the most basic differences is that within gift exchanges the relationship between the persons exchanging is at stake, and not necessarily the items being exchanged, although they are often much valued too. In essence, these objects serve the goal of pleasing the other in the non-agonistic forms of exchange, or flattening the other in the agonistic forms of exchange. Given the important role attributed to the personal relationship, gift exchanges result in long lasting bonds between exchange partners. Furthermore, as the items merely function to please or beat the other, they do not necessarily represent economic value, but often have strong personal, religious, or historical connotations. Therefore, it is seen that the act of exchange itself occurs on special and important occasions, during which often large groups of people are assembled, and witness a sequence of acts involving highly normative behaviour, where ritual, dance, and feasting play an important role.

This is in sharp contrast to the essentially economic role fulfilled by exchange in capitalistic Western society, where the items form the main purpose of the transaction. Furthermore, both exchange partners in such cases do not necessarily have long lasting relationships. These relationships are often considered as impersonal. Although the act of exchange may be surrounded by highly normative behaviour, it often is part of everyday life and is considered to be purely economic.

The contrast I have sketched between non-Western societies and Western capitalistic society strongly follows Mauss' original distinction and is exaggerated (see Bazelmans 1996). ${ }^{1}$ Although exchange in both types of societies generally follows the descriptions written above, more economic forms of exchange also occur in non-Western societies, and gift exchange is obviously (still) part of Western capitalistic society as well. The former is usually grouped under the term "barter" and involves the exchange of commodities, a term generally used for items which are not considered to be gifts. Malinowski, in his important work on the Kula exchange of the Trobianders (1984), mentions the existence of gimwali, a form of barter, that was considered to be different from the Kula gift exchange. Malinowski specifically notes that it lacked ceremony, haggling was permitted, and it could be done between anyone, even between strangers (Malinowski 1984, 189-90). Chapman (1980) lists many other examples of barter among non-Western societies. Although barter may occur on different occasions than gift exchange ceremonies, it is often seen that during these ceremonies, which may last for several days and involve the gathering of many peoples, a lot of commodities are exchanged besides the actual gift exchange (Malinowski 1984; see also Thomas 1981, who explicitly notes the co-occurrence of different forms of exchange among the indigenous people of the Guyanas).

The modern capitalistic equivalent of gift exchange ("giving gifts"), e.g. at birthdays, Christmas, or other special occasions, still has many of the characteristics of gift-exchanges within non-Western societies, including the personal relationships involved, the transaction of special items with the aim to please the other, and the special occasion upon which it takes place. Considering the dual occurrence of both types of exchanges, anthropologists often make a distinction between societies in which gift-exchanges are predominant (non-Western society) and those in which the exchange of commodities is the most important form (capitalistic society) (Bazelmans 1996).

In the light of its embedded nature in all aspects of society, the study of exchange may provide information on a broad array of subjects. For example, T. Earle $(1999,608)$ has recently listed three broad perspectives from which exchange generally has been studied. The first perspective to a large degree corresponds with the role it fulfils in the adaptive strategies of societies, how humans "extract, process, and distribute the necessities of human existence". It sees exchange as a means of risk-controlling behaviour or the way in which products from localized resources were evenly distributed in sedentary societies (R. Kelly 1995; Thomas 1981). The second perspective focuses on the role exchange fulfils in the political economy, or how it "functions to finance the institutions of chiefdoms and states and to support the stratification on which these societies rest." (T. Earle 1999, 608). The third one studies "how a society's relationships and categories become objectified ('real' if you will) through the economic process... the production and distribution of material goods are part of a broad social process in which individuals actively construct systems of meaning and relationships" (T. Earle 1999, 608). "The important point from this perspective is that social structure and political process are the main determinants of economic organization and operation. Individuals act within this system to position themselves advantageously, and in these individual acts transform the system." (T. Earle 1999, 626)

The first and third perspectives form the most interesting ones in relation to this study. This can be mainly attributed to the small scale and primarily non-complex character of the societies under consideration, essentially ranging from tribal towards incipient chiefdoms, and the particular nature of the exchanged items being studied, ranging from ordinary tools to items with a very special cosmological value. The objects considered in the present investigation include chert and flint nodules used for making expedient flake tools, greenstone axes, and conglomeratic zemis, the latter which are three-pointed objects reported by the

\footnotetext{
1 Mauss' work on the "Gift" was not only an anthropological analysis of gift-exchanges, but also a critique of western capitalistic society, which in his view was becoming too individualistic.
} 
Spanish to be representations of the supra-natural entities and deified ancestors (Siegel 1997). The latter category of artefacts may, in theory, have been part of an elite exchange network involving wealth items, and thereby touching upon the subject of wealth finance supporting an elite (Brumfiel \& Earle 1987; T. Earle 1999). However, it is primarily this cosmological meaning with associated intrinsic power that was valued and constituted the important aspect when possessing or exchanging zemis.

The socially structuring aspect of exchange is also clearly evident within anthropological accounts for indigenous societies of the Amazonian rainforest. ${ }^{2}$ Chagnon (1983) explicitly notes in his famous work on the Yanomamö that exchange fulfilled a social-political role of bringing people together with the aim of forming allies in village raids, rather than an economic adaptive role, of distributing exotic artefacts across the region. Chagnon describes a situation in which each village is specialized in making a certain commodity, that no other village produces. This specialisation is not a result of uneven resource distribution, but it is an artificially maintained differentiation in order to secure the continuation of inter-village contacts. To support this notion Chagnon gives the example of a village that did not make pottery, as they "forgot" how to do it. After another village with which they were carefully initiating an alliance began asking for pots, the former community suddenly "remembered" how to produce them again (Chagnon 1983, 149-50).

This example illustrates another important aspect of exchange within Amazonian cultures, namely its relation to warfare. Kelekna (1985) has emphasized that warfare and exchange are seen as the two extreme forms of social relations: with friends one exchanges and with enemies one makes war. This important relation between exchange and warfare has also been highlighted by Redmond (1998c), among others. She pays specifically attention to this by showing how a war leader may be able to acquire the position of chieftain. Through distinguishing himself as a very strong person in war, a successful war leader may easily attract exchange partners who can become allies in raids and war. His ability to keep these people bonded through reciprocal exchange relationships is of pivotal significance in his wish to acquire and keep regional leadership and prestige.

Redmond presents another important individual in Amazon society, the spiritual specialist, who may become regionally known. He often holds a distinct place within his community as the only person who is able to communicate with and may actually obtain control over the supra-natural forces or entities that surround and influence every-day life. Strong spiritual specialists may become regionally renowned or feared for their ability to control and manipulate these powerful forces. As a result they attract apprentices from far around them. The specialist will teach them his knowledge in exchange for valuable objects, thereby creating a hierarchical relationship. By sustaining these relationships after the apprentices return to their home communities again, he may acquire a regional significance in local societies.

Apart from these essentially social-political and religious motives behind exchange relationships, more economic related reasons also may initiate exchange. For example, many communities in the Amazon host trade middle-men, who are persons standing in relatively frequent contact with the world outside the community, and therefore are able to obtain exotic objects or raw materials. These people may become important figures in the community, as they are able to acquire highlydesired items, that are not locally available. In contrast to the other two roles in Amazonian society, these trade middle-men are only important for this ability, and as they often lack the much rewarded strength in combat or power in spiritual matters, they never will be able to acquire a similar high position within society. These people, however, will ensure the flow of exotic goods. In relation to this Thomas (1981) notes an interesting feature of inter-village exchange among the indigenous peoples of the Guyanas. In many cases the real non-local items or raw materials are exchanged for items that are more commonly available, and may not necessarily be needed by the communities obtaining them. However, it is this seemingly unequal exchange of different valued objects that ensures the distribution of much desired exotics throughout the region.

In the preceding discussion I examined the role exchange fulfils in small-scale society. This discussion provides a starting point on how to view exchange and its relation to socio-political organisation. Next, I will describe the current state of knowledge about exchange within the archaeology of the Caribbean, followed by an explanation of this research's objectives and its methodology used to reach these goals.

\footnotetext{
2 Many anthropologists, linguists, and archaeologists have emphasized the cultural relatedness between the indigenous peoples of the Amazonian rainforest and the Caribbean archipelago. I will not go into much detail on the use of the anthropological accounts from the Amazon as analogies for the Caribbean pre-Columbian societies, as others have dealt with this before (cf. Hofman 1993; Hoogland 1996). It is generally considered that the first agriculturalists entering the Caribbean were speaking an Arawakan language, strongly related to some of the languages still spoken in the Guianas and Venezuela today. Furthermore, influences from Carib speaking peoples living in the Guianas have become evident during the latest phases of indigenous occupation of the islands (Taylor \& Hoff 1980).
} 


\subsection{EXCHANGE STUDIES WITHIN CARIBBEAN ARCHAEOLOGY}

The occurrence of artefacts and materials non-local to the island of discovery, hereafter referred to as exotics, is a common feature among excavated samples from Caribbean sites, and those within the Lesser Antilles in particular (Cody 1991, 1993; Crock \& Bartone 1998; Donahue et al. 1990; Fuess 2001; Knippenberg 2001a; Murphy et al. 2000; Narganes Storde 1995, 1999; Serrand 2001; Vescelius \& Robinson 1979; Walker 1980; Watters \& Scaglion 1994). In some cases these exotics make up a large part of a site's artefact inventory, as is shown by sites on Anguilla (Crock 2000), while in other cases it only concerns rare items, as is the case of sites on Antigua and St. Martin (De Mille 1996; Knippenberg 2001a). Materials that were identified as exotic include different varieties of stone (Watters \& Scaglion 1994; Knippenberg 2001a), specific species of worked shell (Serrand 2001), pottery temper (Fuess 2001), as well as ceramic pots (Crock 2000; Peterson \& Watters 1991).

Closely comparing the various types of exotic materials shows that stone artefacts make up the major part. In general, this predominance may be misleading to some degree since stones often are more easily recognized as exotic. This can be attributed to the fact that on the one hand specific types of stone materials can be restricted in occurrence, and on the other hand to the regional variability in geological composition of the different islands within the Caribbean archipelago, where limestone islands occur in close proximity to volcanic ones. This indicates that the presence of exotic rocks did not necessarily involve transport over large distances, although sometimes it did. As this study deals with the northern Lesser Antilles, it may be rewarding in this respect to distinguish materials, that are local within the Caribbean island archipelago, but were frequently transported between the different islands, and those that came from outside the Caribbean altogether, e.g. the South American mainland or the Yucatan Peninsula. These latter materials suggest long-distance transport, at least from this northern perspective point of view.

Among the long-distance materials, we may reckon certain varieties of semi-precious stone such as nephrite and turquoise used for making beads and pendants (Cody 1991; Rodríguez Lopéz 1993; Watters \& Scaglion 1994). A much larger variety of rock types can be named within the regionally available but restricted group of stones. Recurrent materials include cherts, flints, a limited variety of semi-precious stone (amethyst, carnelian, quartz, calcite, serpentinite), as well as varieties of igneous and metamorphic rock (Cody 1991; Crock 2000; Murphy et al. 2000; Rodríguez Lopéz 1993; Watters 1997a; see also this study). This large variation of rock types is also evident among the artefacts, which include beads, pendants, axes, zemis, flake tools, as well as all sorts of pebbles.

A second material category consists of ceramics and temper. Donahue et al. (1990) and Fuess (2001) have shown that ceramic pots from sites on the two limestone islands Anguilla and Barbuda, contain volcanic inclusions. As these islands are built up by carbonate rocks, these volcanic inclusions suggest three possible ways in which exotics were transported from volcanic or composite islands to these limestone islands: (1) volcanic sand was transported and added to local clays as temper; (2) clay naturally containing volcanic inclusions and originating from the volcanic or composite islands was transported and pots were locally produced; and (3) complete finished pots were transported between islands, which were made on the volcanic or composite islands. Thus far, a conclusive answer has not been given as to which type of material was transported. Given the occurrence of clay sources on all the islands, and lack of knowledge with regard to these sources, it is not possible to either exclude possibility 1 or $2 / 3$ at the moment. In addition, the difficulties of identifying the manufacture of ceramics on a household production level will often inhibit a distinction between 2 and 3. Faced with the same problem for material found on Anguilla, Crock (2000) assumes the $3^{\text {rd }}$ possibility was the case, considering the poor clay sources on the island, especially since non-volcanic, carbonate temper would have been easily available on the carbonate islands.

The clear identification of exotic stone and temper contrasts to artefacts made of shell material. Most shell species employed in artefact manufacture have broad, general occurrences along the coasts of most of the islands. Therefore, a prehistorically transported or exchanged shell artefact generally will not be recognized as exotic. This will only be the case when the species does not naturally occur in the islands local environment, as Serrand has shown for the Unionoida shells found at Hope Estate (2001). Still, there are indications, based on restricted shell bead and pendant manufacture, that shell items may have been more frequently transported and exchanged than has been suggested by the few examples of demonstrated exotic shell species usage (for studies of shell bead production, see Carlson (1995) and Lammers-Keijzers (2001a)).

The above-mentioned cases provide evidence that inter-island transport was a recurrent feature for the acquisition of materials used for ceremonial, and subsistence related activities. This inter-island transport, however, does not necessarily indicate the existence of inter-island exchange relationships, as the close proximity of islands hosting different types of 
resources may facilitate direct procurement by peoples living on the nearby islands. Although in many of these cases the exotic origin is acknowledged, attempts to integrate these data within a systematic and region wide study to better understand how these exotics were distributed are very scarce. Some scholars have hypothesized on basis of non-local material from a single site or island how its inhabitants obtained these exotics. Crock (2000), for example suggested for many of the lithics found on Anguilla and originating on nearby St. Martin that they were obtained by direct procurement. In case of the ceramics and some of the exotic chert varieties, however, including material from Antigua, exchange more likely formed the means of acquisition (for other examples see Crock \& Bartone 1998; Crock 1999, 2000; Murphy et al. 2000; Rodríguez Ramos 2001a).

Studies in which transport and exchange are seen within a regional Caribbean perspective are rare. Cody (1991), in her study on the distribution of semi-precious stone used for the making of beads and pendants, is one of the few scholars who has attempted to interpret this wide distribution. She links the occurrence of the wide spread of these lapidary items among Caribbean Early Ceramic Age sites with the existence of a long-distance exchange network, although she does no go any further into the type of exchange responsible for this distribution.

Another important aspect of rock material distribution studies, which has received very little attention in Caribbean archaeology, is the identification of raw material sources, the characterisation of source materials, and the comparison of these materials with artefacts (cf. Glascock et al. 1998). Although some attempts have been made (Pantel 1988; Walker 1980, 1985) and others are being elaborated (Walker et al. 2001), many studies so far have relied on written reports, which mention the occurrence of sources of specific rock types without actually comparing source materials with artefacts (Cody 1991; Rodríguez Lopéz 1993), as Watters specifically noted for the bead and pendant materials (Watters 1997b).

The lack of knowledge about regional distribution and prehistorically exploited sources, poses significant limitations about the understanding of past exchange relationships and networks. Furthermore, a better knowledge about regional variation in production and consumption behaviour might also identify commonly available materials as actual exchanged commodities. In this respect I refer to the above-mentioned example of limited shell artefact production places, which may have functioned as regionally important suppliers for such artefacts (Carlson 1995; Lammers-Keijzers 2001a; Watters 1997a).

\subsection{RESEARCH OBJECTIVES}

To start filling the knowledge gap about raw material sourcing, regional distribution and identification of exchange relationships within the Caribbean, this study will focus on three different rock materials, that have restricted occurrences but which were widely used within the northern Lesser Antilles during the pre-Columbian era. These materials include a variety of flint, a grey-green mudstone, and a conglomeratic pack-stone.

The objective of the present study is to specify the distribution of these specific rock materials within the northern Lesser Antilles during the different periods of the Ceramic Age. These distributions will be used to identify exchange patterns and possibly get at the underlying mechanisms behind them. In addition to these three rock materials, the use of several additional rock types is described and discussed as well to provide a more complete picture on rock material acquisition and usage. Finally, the results are evaluated against present knowledge about the development of socio-political complexity within this portion of the Caribbean region, as described in the introductory paragraphs.

Most attention will be given to the period that marks the transition from Saladoid into post-Saladoid society, i.e. AD $400-1200$. The study area includes the chain of islands lying between Puerto Rico on the west all the way to Martinique on the southeast (figure 1.3). This region largely corresponds with the distribution area of the three above-mentioned rock materials.

In order to reach these objectives a number of sub-goals are approached. These can be roughly divided into two parts, more or less corresponding with distinct data collecting episodes:

1) At first, sources need to be identified, mapped, and described, followed by a detailed study of material characterisation. This latter aspect also includes the search for a method by which inter-related rock varieties can be distinguished on the basis of objective criteria.

2) If materials can be distinguished and their provenance can be determined, then their distribution and use in the archaeological record need to be mapped through the study of numerous collections of samples from excavated sites. 


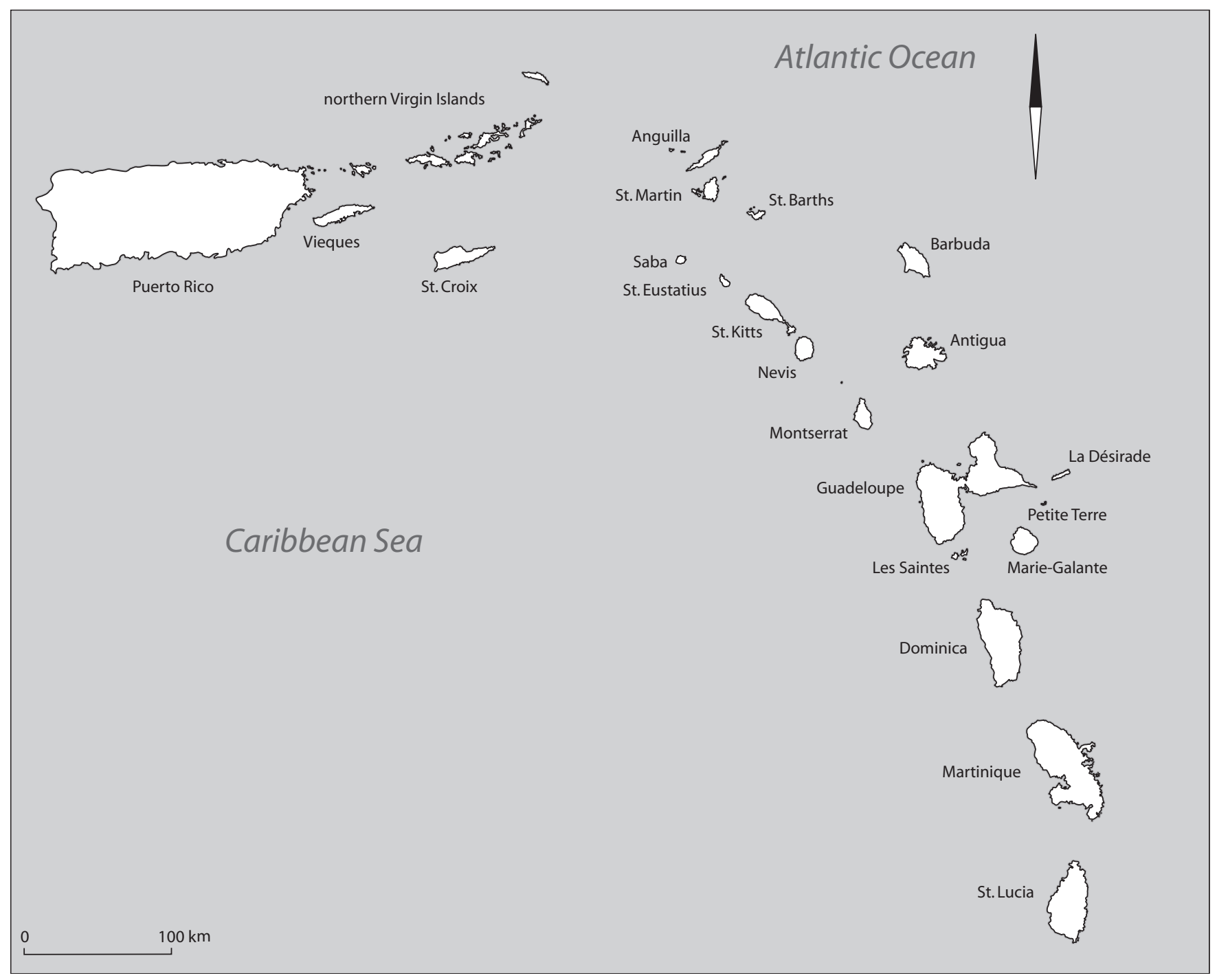

Figure 1.3. Map of the area studied in this work.

In relation to the first set of goals, known raw material source localities were visited and primary deposits of rock material (as well as secondary surface scatters), as likely available to the Amerindian settlers were mapped. Furthermore, evidence of actual Amerindian exploitation was recorded. For the characterisation study, macroscopic description, microscopic, and chemical analyses were employed in an attempt to find a method, that would discriminate among different inter-related rock varieties. Related to this characterisation and discrimination aspect, an additional subject was addressed that aimed at understanding how and why varieties differed. The reader is referred to Chapter 2 for a detailed description of the methodology employed. With regard to the study of distribution and the identification of exchange patterns, a more extensive discussion of the methodology is given below, as this part of the research guided the outline of this dissertation to a large degree. 


\subsection{Methodology}

The study of stone materials and artefacts to identify exchange relationships and patterns offers great advantages over some other materials commonly encountered during archaeological excavations. I have already mentioned the restricted occurrences of some stone varieties, as well as their specific characteristics, that enable reliable discrimination. Torrence (1986), however, also stresses the subtractive nature of stone tool making, during which each step of the production process (from acquisition to tool finishing) leaves residues within the archaeological record. These steps may be distinguished, at least on a general level, presenting the archaeologist with a situation where he or she can arrive at a relatively detailed knowledge of stone working behaviour.

Torrence, therefore, paid particular attention to the production process when studying the prehistoric exchange of obsidian among the Greek islands. This was different from many other studies on the exchange of stone artefacts, that primarily investigate the relative abundances of different materials. She correctly emphasizes the important role that the production process should receive when studying exchange, as she sees them interrelated. In the opening chapter of her book "Production and Exchange of Stone Tools" Torrence states one of her important premises:

"... artifact manufacture will vary according to the ease of access of the producer to the source of raw material, that is, the type of exchange" (Torrence 1986, 24). Further, "exchange as used here is seen as varying according to the amount of competition by actors for strictly material gains or profits", and "the degree of behavior directed toward the achievement of profits provides us with one fairly detailed description of the nature of exchange in question". Thus Torrence attempts to construct a middle range theory that provides links between the type of exchange, the associated stone tool production behaviour, and the actual material residues. To reach this goal Torrence presents a series of ethnographic case studies, that describe stone tool manufacture and exchange. By carefully selecting cases, that cover the whole continuum of exchange, from direct access, where there is no competition, to laissez-faire market exchange, she provides a relatively complete picture of stone tool production and exchange.

Torrence considers the efficiency of the production process as an important parameter for measuring competition. In other words, "as systems of exchange become more competitive and more profit-orientated, then one would expect that more types of behavior which were increasingly efficient would be adopted" (Torrence 1986, 40). To measure this efficiency, Torrence introduces a number of cost-control devices, which following Rathje (1975), are "methods which decrease time, energy and material inputs while at the same time increase the numbers and range of the distribution of the commodities". Torrence lists four devices:

1) Sophistication of technology, which relates to the use of a very specialized tool kit that may increase efficiency.

2) Simplification: simplifying the production process may increase efficiency.

3) Standardization: this will reduce the choices to be made during the production, and if trained, increase the speed at which products are made

4) Specialisation: important in considering specialisation is the type of specialist involved. Following Rathje, Torrence distinguishes craft production (craft specialists) and mass replication production (industrial specialists), the latter being able to make products at great efficiency, whereas the former is a very skilled craftsman producing highly individualistic products. Many of the ethnographic cases do conform to the general assumption that production becomes more efficient as exchange becomes more competitive, although it has to be noted that data on stone tool production, in particular regarding efficiency, are limited. In this respect intensive time and labour input, as shown for New Guinea mine shafts, does not necessarily indicate higher levels of socio-economic complexity, since the quantity of time and labour invested is not as important as the quality of the input, in other words the efficiency (Torrence 1986).

I want to make a few additional comments on how to relate these premises to the issue of socio-political organisation within the northern Lesser Antilles. Specifically looking at artefact production, the distinction between egalitarian and chiefdom societies is gradual, and organisation of production may in some cases be rather similar. Generally, it is agreed that within egalitarian societies most production occurs at the household level, in which certain individuals in each household are responsible for the specific productions of different things. Craft-specialisation in a village may occur, but usually is on a part-time basis. Considering the fact that exchange generally takes place on a reciprocal basis, it is assumed, following Torrence, that the application of cost-control devices only minimally took place. In chiefdom societies these features to a large degree may be encountered as well, in particular when looking at a single village on the periphery of the polity. However, the existence of a hereditary elite may have induced the appearance of full-time specialists operating in the service of this elite.

The research of Torrence provides a series of important guidelines for the study of stone tool production and 
exchange. For my study I used her key argument considering that production is a parameter of exchange. This study also uses an approach more on the consumption side as an additional line of research because it is the first within the region, that pays particular attention to stone tool production and distribution. However, many scholars have criticized this approach, where raw material abundance is a key variable (see Torrence 1986 for a discussion). Still, it was made necessary by the limited data on production behaviour. "Fall-off" analysis forms one of the most widely applied methods within this general approach.

Colin Renfrew (1977; Renfrew \& Dixon 1976; Renfrew et al. 1968) has paid much attention to this method in his work. Although later work by Hodder \& Orton (1976) amongst others, showed that different mechanisms of distribution may produce similar fall-off curves, this form of analysis is still regarded as a first base-line and informative way of analysing material distribution, in particular where island environments are involved. The central premise in the study of fall-off curves is the Law of Monotonic Decrement (LMD), that states:

"In circumstances of uniform loss or deposition, and in the absence of highly organized directional (i.e. preferential, nonhomogeneous) exchange, the curve of frequency or abundance of occurrence of an exchanged commodity against effective distance from a localised source will be a monotonic decreasing one" (Renfrew 1977: 72).

Basing himself on earlier work within geography, Renfrew regarded two models as significant for the study of falloff patterns because they can be mathematically described. These are the "down-the-line" and "random walk" models. The first relates to the exchange of a commodity between villages, that are linked in a linear chain, and where the abundance of the commodity exponentially decreases after each exchange transaction, in other words by moving further from the source. This case assumes that reduction of the material is dependent on the number that will be left at an exchange point, e.g. a village keeps half of what it acquires and passes the other half to the next village in line, which in its turn keeps half of that (a quarter of the original quantity) and passes the other half to the next one, etc.. If one modifies this assumption to the situation in which this reduction is independent on the amount that is exchanged (direct access to the source), then abundance will solely be dependent on distance to the source and the fall-off curve will transform into a simply linear one.

In the random walk model, which has been formulated and mathematically analysed by Pearson studying infiltration of a new species into a habitat, each exchange transaction is seen as a step. If these steps are assumed to be ordered randomly from a given centre point, a "coherent, quantifiable fall-off curve" will be produced that will follow a Gaussian distribution (Renfrew 1977: 80).

Mathematically, both exponential and Gaussian curves can be described by the following general equation:

$$
\mathrm{I}=\mathrm{m} \cdot \mathrm{e}^{-\mathrm{kx} \mathrm{x}^{\mathrm{a}}}
$$

In this I stands for Interaction/Abundance, $\mathrm{x}$ for distance to the source, and $\mathrm{a}, \mathrm{m}$ and $\mathrm{k}$ are constants. If $\mathrm{a}=1 \mathrm{we}$ obtain an exponential distribution (down-the-line model), and if $\mathrm{a}=2$ the distribution becomes Gaussian (Random walk).

As these cases assume transport or steps in one dimension, Renfrew also listed the distributions in case of two dimensions. Such a case would alter the curve belonging to a down-the-line mode of exchange from an exponential one into a Gaussian one, and in case of a linear curve (reduction is not proportional to quantity left) it would become a parabolic one. Any deficiencies from the law in general and these curves in particular may point to other means of exchanging the item. Notably, directional trade and central place pooling were considered to be responsible for different curves.

These two approaches to the study of exchange guided the outline of the second part of this research, which is focussed on the distribution of the particular stone materials and artefacts. As a result, this part was not only centred on the presence or absence of a stone artefact in the archaeological record, but also was aimed at understanding its production process. Therefore, to obtain a full overview of this process it was decided to look both at stone working activities at the source sites along with at settlement sites in the surrounding region.

For each of the sites a sample of lithic artefacts was studied using a pre-defined set of variables. The methodology of this analysis is discussed in Chapter 3. The results obtained from these analyses provided the necessary data to determine the presence of a specific stone type at a particular site, the form in which it had reached a site, how it was reduced on site, and what the aim of the production was. Chapter 4 discusses stone working at the flint source on Long Island and Chapter 5 presents an overview of stone working at settlement sites on the surrounding islands for each period within the Ceramic Age. This is followed by a description of regional patterns in Chapter 6. For each of the three materials, its distribution is outlined followed by a discussion of the exchange mechanism responsible for it. In conclusion the understanding of the type of exchange resulting from this analysis is discussed in light of current knowledge about socio-political organisation within the study (Chapter 7). 


\section{Raw material sources and rock characterisation}

\subsection{INTRODUCTION}

This chapter discusses the occurrence and characterisation of specific rock sources within the northern Lesser Antilles and Puerto Rico to identify Amerindian exploited localities and rock distribution patterns throughout the region. Three distinct rock types will be studied, as they commonly occur within the archaeological record of the region. They all can be classified as sedimentary rocks and include different varieties of chert, a grey-green mudstone and a multi-coloured conglomerate. The most significant part of this chapter is dedicated to the study of cherts. ${ }^{1}$ The indigenous peoples of the Lesser Antilles used multiple varieties of chert, that are often difficult to distinguish, but which originate from different areas. Therefore, I paid special attention to the mapping of the different sources and the characterisation of the material with the aim of identifying distinguishable features.

This contrasts to the other two materials commonly encountered within the archaeological record, the conglomerate and the mudstone. Both possess very striking characteristics making them easily distinguishable from other rock varieties used for the same purposes. Therefore, these latter characterisation studies only include the microscopic and macroscopic description of both materials and a discussion of their provenances.

\subsection{CHERT AND FLINT STUDY}

\subsubsection{Introduction}

Chert has been one of the most widely used rock materials for making stone tools during world prehistory and history. Its usage has been identified from Early Paleolithic times, up to today. It functioned as an important raw material, in particular for making flake and blade tools. Earliest evidence of chert usage in the Caribbean corresponds with the first colonization of the islands by Preceramic foragers. These so called Casimiroid people occupied the Greater Antilles and are well known for their blade industries (Keegan 1994; Kozlowski 1974; Rouse 1992). This study will show that chert remained a commonly employed rock type until the end of the indigenous occupation of the islands.

Despite the general utilization of this material, chert was not commonly available to all the region's inhabitants. Its restricted occurrence can to a large degree be explained by the diverse geological build-up of the different islands, in which the Greater Antilles, including the Virgin Islands, experienced a longer, more complex and varied geological formation history than the younger predominantly volcanic Lesser Antilles. As a result, chert is more commonly available in the Greater Antilles than in the Lesser Antilles.

The study of chert distribution provides an excellent case for the identification of inter-island rock material transport and exchange relationships, considering the relatively rare, and more importantly, its very restricted natural occurrences on the Lesser Antilles and its common usage by the indigenous inhabitants. Before chert artefacts excavated at archaeological sites can be assigned to a specific source and before the distribution of a chert material can be mapped, it is first necessary to distinguish a particular chert material from other cherts. Therefore, this chapter will pay particular attention to the sourcing of chert in the northern Lesser Antilles (figure 2.1). To accomplish this, a number of goals have been formulated prior to this research. These include:

a) The mapping of available chert sources and the context(s) in which the chert is found. The islands under consideration included Antigua, St. Kitts and Puerto Rico.

b) The morphological and geo-chemical characterisation of source material to identify criteria by which sources can be discriminated.

c) In addition to the characterisation study, which focuses on the geochemistry of the chert, I also attempted to find explanation(s) for why sources differ chemically. This provides a stronger empirical basis for source discrimination, and may yield guidelines for future research. I attempted to formulate hypotheses about the origin of most of the important trace elements, that are of importance to this study. In addition, special attention was given to the change in composition affected by weathering of the chert because it is believed that weathering played a significant role in this particular region given, the

\footnotetext{
${ }^{1}$ See the next paragraph for a definition of cherts, followed by a discussion of varieties, which are included within this study.
} 


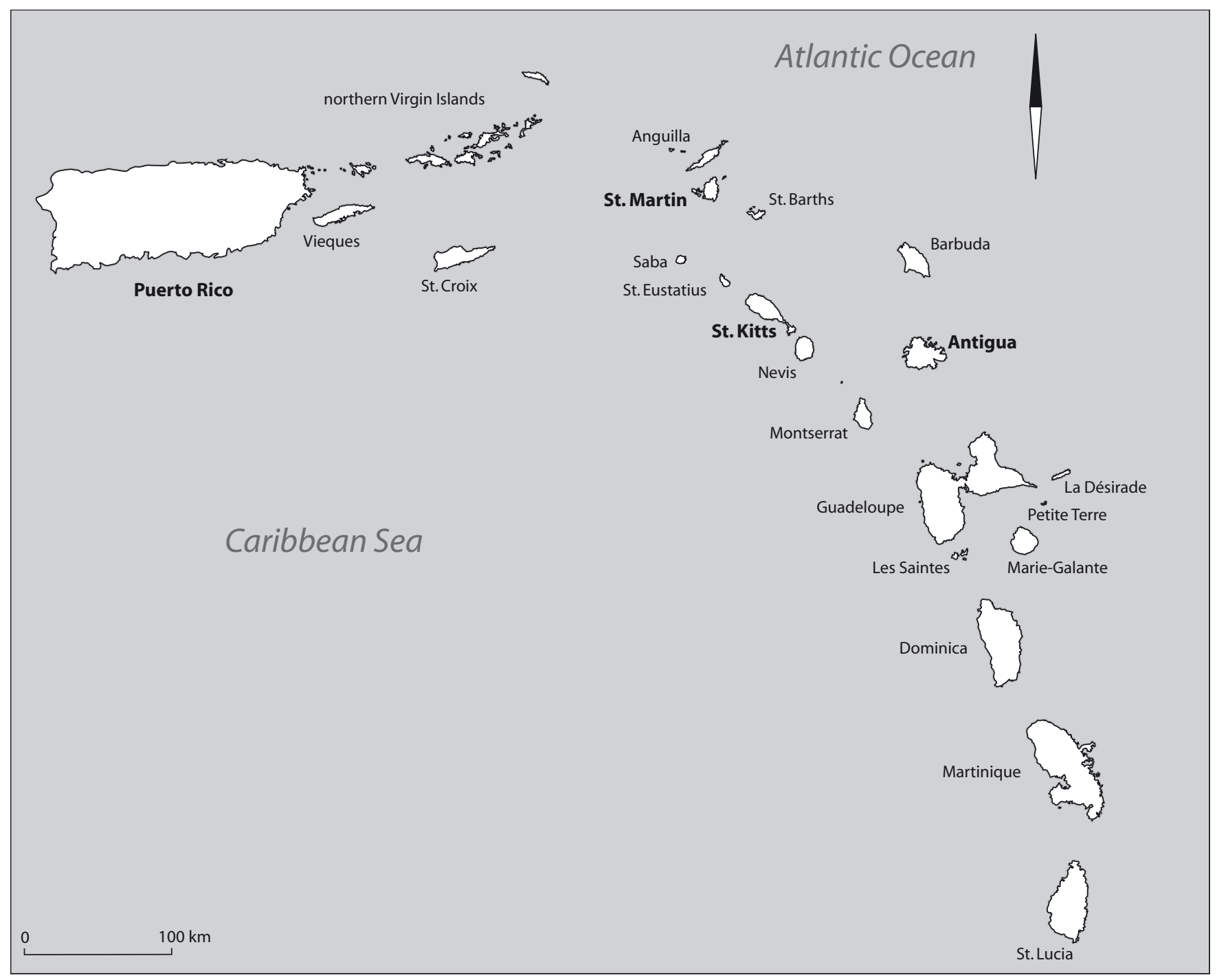

Figure 2.1. Map of the area studied in this work showing the source islands in bold.

fact that many of the sources are secondary surface scatters. It should be specified that only weathering of material on the sources themselves before acquisition is at issue here, that is, the weathering of geological material (see Lavin \& Prothero 1992), and that the weathering of artefacts after manufacture is not dealt with. It is assumed that post-depositional weathering had not significantly altered the chemical composition of the manufactured material, given the short period of burial of the artefacts related to the Ceramic Age. Sheppard and Pavlish (1992), however, have presented an example to the contrary. In their case from the Pacific islands, the chert artefacts display a macroscopically identifiable change in their appearance, which has not occurred for the large majority of chert materials from Caribbean archaeological sites. Besides, the chemical changes of the Pacific artefacts can be mainly attributed to interaction with relatively extreme types of soils, such as bauxitic ones.

\subsubsection{Chert nomenclature}

Before I go into the methodology that was used during mapping of the chert sources, I need to clarify what I define to be chert and what considerations guided the choice to include specific chert sources in this research and not others. Chert generally is used as the overall name for micro- to crypto-crystalline varieties of sedimentary silica in the form of the most 
stable crystal variety quartz, often including minor amounts of less stable crystal varieties of opal and chalcedony (Luedtke 1992). According to Hauptmann (1980), this is a narrow definition, since it only includes sedimentary varieties of silica. In addition, crypto-crystalline silica varieties can also occur in volcanic rocks as inclusions or in hydro-thermally altered veins such as, for example, agate, jasper, or chalcedony (figure 2.2).

In relation to the sedimentary varieties of chert, geological handbooks generally distinguish two types of chert: nodular and bedded cherts (Blatt 1992; Nockolds et al. 1978; Pettijohn 1975). According to this distinction, flint is seen as variety of chert and used to denote the nodular cherts which form authigenically in limestone and that are usually dark in colour. Bedded cherts, on the other hand, display a range of colours. They comprise the pure silica deposits often formed in deep marine environments and found in proximity to volcanic formations. In many cases, they contain remnants of siliceous biogenic tests, such as radiolaria. These latter cherts can have different names such as, for example, novaculite or radiolarian chert (Blatt 1992; Luedtke 1992; Nockolds et al. 1978; Pettijohn 1975).2

Apart from these micro- to crypto-crystalline varieties of quartz, quartz can also occur as a macro crystal variety, often present as inclusions in igneous or metamorphic rock. In this case it is simply called (smoky) quartz, or amethyst, aventurine, citrine, and rose quartz, depending on its colour.

These distinctions are based on different geological contexts of formation, and often are difficult to recognize when one is only confronted with isolated rock specimen, as archaeologists generally are. Therefore, it should be noted that within archaeological literature name giving does not always bear a relation to geological origin, and that it may be the result of the use of folkloric names, or even may correspond to quality differences of the rock. ${ }^{3}$

In this thesis, I follow the broad geological distinction between sedimentary nodular and bedded cherts, and other non-sedimentary types of chert. I classify a siliceous piece of rock as flint when it has been formed authigenically in carbonate rock, usually in a nodular form. ${ }^{4}$ For all bedded siliceous rocks, I use the term bedded chert. The more general term chert is reserved for all varieties of fine-crystalline siliceous rock, for which the geological relation to its formation is not specifically defined. For these, I sometimes use the term chalcedony to cover all opaque, fine-grained, often white, silica varieties, that do not contain any macroscopically visible biogenic clasts (fossils or fragments of fossils) or carbonate grains, so suggesting a possible non-biogenic origin. The use of the term chalcedony in this case should not be confused with the fibrous crystal variety, that can occur in most cherts, but which is only visible through microscopic study.

\subsubsection{Cherts in the region}

A large number of silica varieties, as specified above, occur in the Antilles and were used by the indigenous peoples over a long period. These include both macro as well as micro- to crypto-crystalline quartz rocks. This chapter, however, focuses on the micro- to crypto-crystalline varieties, as they were more specifically used for making flake tools, whereas the macro varieties were predominantly used for making lapidary artefacts, although exceptions occur.

Given the occurrence of a broad range of chert types within the Antilles (Bérard 1999; Bérard \& Vernet 1997; Bodu 1984; De Mille 1995; Knippenberg 1997, 1999a; Murphy 1999; Pantel 1988; Pike \& Pantel 1974; Walker 1980), a choice was made about which material varieties were to be included in the characterisation study and which were not. This choice was necessary to avoid having the series of source locations be too large, which would make success in petrographically or chemically distinguishing the different source types less probable. From a macroscopic analysis, it became clear that colour easily distinguishes the cherts into three general groups. Within these broad groups chert differs in appearance but is less easily distinguishable, especially for an untrained eye. These three groups are:

a) A multi-coloured group, including cherts ranging in colour from white, yellow, brown, grey to almost black. This group represents most of the chert varieties used within the northern Lesser Antilles, and therefore will be studied in this research. Cherts include flints, bedded cherts, other cherts, and silicified corals.

\footnotetext{
2 Despite this general distinction, European geologists often use the word flint only for the nodular cherts from the Northwestern Cretaceous Chalk formations (Hauptmann 1980; Schmid 1986). This is a pure regional distinction and the flints from these formations do not differ in properties and genesis from other nodular cherts in carbonate host-rock elsewhere in the world.

${ }^{3}$ Luedtke, for example, mentions the use of the name Knife River flint from North Dakota for a chert which actually is a silicified bedded lignite and not a nodular chert (Luedtke 1992, 124). In this respect the habit of many North American archaeologists to name high quality silica varieties "flint" and the poorer quality ones "chert" must be mentioned as well (Haviser, personal communication 1993).

4 Authigenic chert in carbonate rock can have a variety of forms, the most common one is in bands of nodules. Other forms are around burrows, or occasionally as thin beds or irregularly shaped concretions (Clayton 1986; Zijlstra 1994; Felder \& Bosch 1998; Schins 1998).
} 


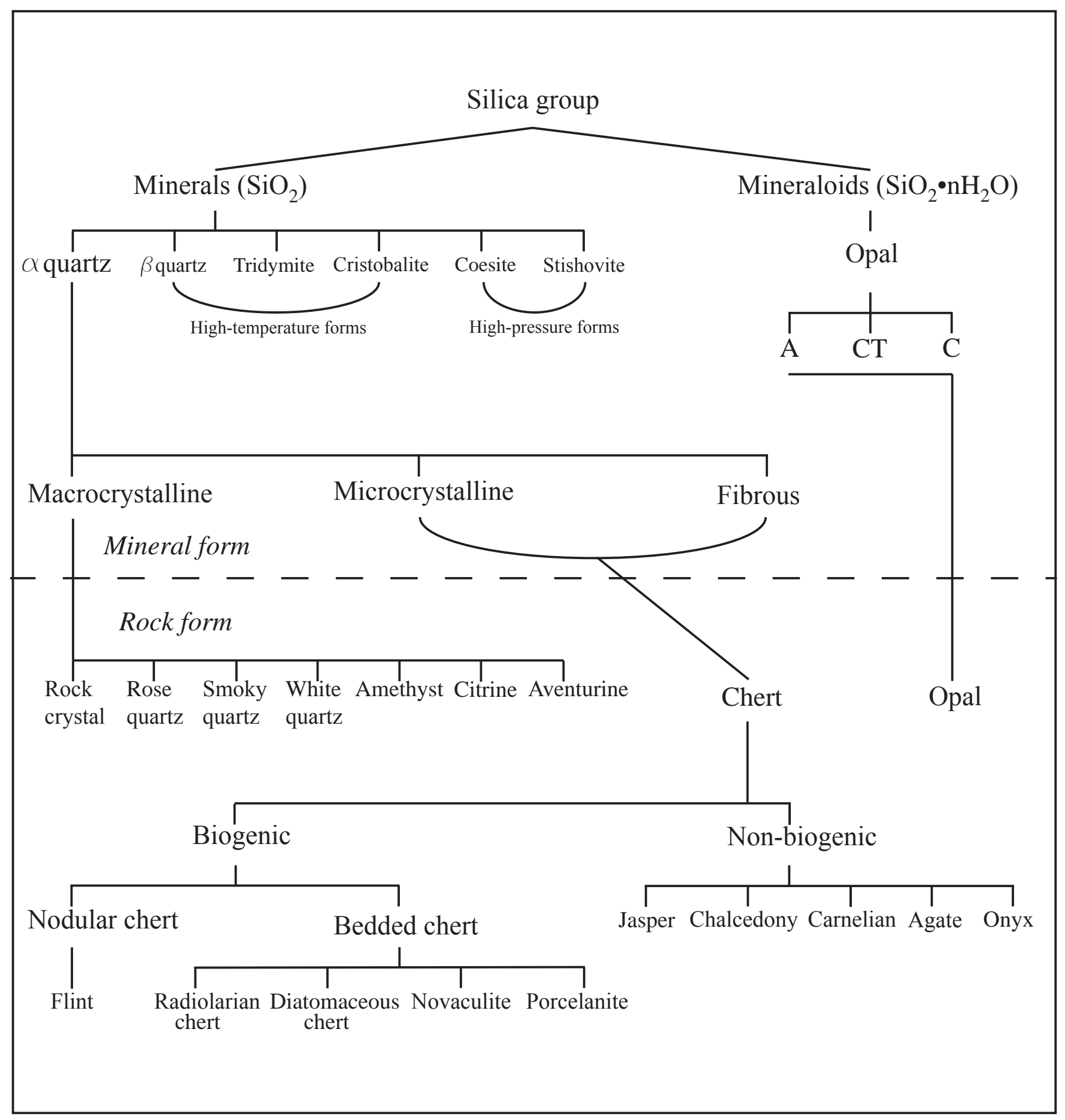

Figure 2.2. Relationship between silica minerals and related rock varieties (based on Leudtke 1992 with modifications).

b) A green-coloured group, including light to dark grey-green varieties. This group of cherts is rare among flaked material within the northern Lesser Antilles. It predominantly can be found at Puerto Rican sites (Rodríguez Ramos 2001a; see Chapter 5). The only known source locality thus far is the bedded chert from the Mariquita Chert Formation in southwest Puerto Rico (Volckmann 1984a,b). 
c) A red-coloured group. This group of cherts is rare as well among flaked material from northwestern Lesser Antilles sites, although more frequently occurring than the green cherts. On Martinique, however, local red jasper was the most widely used material on the island (Bérard 1997). Other sources include a red radiolarian bedded chert on La Désirade (Bodu 1985; Bouysse et al. 1983; De Waal 1999a; Montgomery et al. 1992), jasper on St. Martin (Christman 1953), and bedded cherts within the eastern part of Puerto Rico (Rodríguez Ramos, personal communication 2000).

In addition to these three colour groups, some clear petrographically distinguishable varieties of chert can be picked out beforehand. These include, for example, a white and translucent macro-crystal variety of quartz, which behaved differently during flaking than the cherts, as well as petrified wood, which still has its very characteristic wood structure preserved.

\subsubsection{Methodology of the characterisation study}

\section{Mapping of sources and sample taking}

Focussing on the multi-coloured group meant that basically three islands are of interest. These islands have chert occurrences that might have functioned as source locations for the materials used by the Amerindians in the surrounding region. These islands include the following ones:

1) Antigua, where the Long Island source is situated (Nicholson 1974; Olson 1973; Van Gijn 1989), as well as other flint and (bedded) chert occurrences (Martin-Kaye 1959; Watters \& Donahue 1990; Weiss 1994).

2) St. Kitts, where archaeological work by Arizona State University identified several natural surface scatters of flint (Walker 1980, 1981).

3) The southwest area of Puerto Rico near Cabo Rojo, where the existence of chert sources has become known during the past decennia (Pantel 1988; Pike \& Pantel 1974).

Based on my previous research aimed at sourcing of flint and chert in the region (Knippenberg 1995, 1997, 1999a), the island of Antigua and in particular the Long island flint source is believed to be the most important locality where material was obtained. This prior knowledge guided to a certain extent my search and mapping of unknown sources. Given the existence of high quality flint within the limestone district of Antigua, major attention was dedicated to this part of the island. In addition to reported and known flint localities, rock sections along the eastern and western coasts where inspected to search for unknown flint nodule bands. Within the other parts of Antigua, as well as the islands of St. Kitts and Puerto Rico, only reported and known localities were visited. These were considered to be possible source areas where material might have been obtained during pre-Columbian times. In addition, some present-day quarries were visited and sampled as well, but only if they were believed to provide additional information regarding the chert characterisation.

In the characterisation of chert material attention was devoted to the relation of the chert with its environment during its formation. I tried in the field to identify the type of host-rock, where chert was formed, as it is believed that the type of host-rock in large part determines variability in the chert's characteristics. However, the relation with its environment of formation was not always straight forward and this, became clear when analysing the numerous secondary chert scatters in Puerto Rico (see below).

At each location, samples were taken from all possible contexts, that is, from original layers, bands or nodules still preserved in rock sections (primary context), from natural surface scatters (secondary context) as well as from work-shop sites or flaked scatters of material in the source area (tertiary context). In many cases, it appeared that only the secondary context was present. Collection of rock samples occurred haphazardly, during which textural variation, as well as variation in clast content (particles such as fossils or remnants of carbonate in the matrix) and colour of the chert material were taken in consideration. Only in a few instances more systematic sample collection was performed. This usually occurred if material was still available in a primary context, allowing the possibility of taking several samples from one layer at certain distances or to sample different layers present.

Rock samples were initially described macroscopically on the following features: (a) colour, (b) type of cortex, (c) presence of clasts, (d) lustre, (e) grain size, and (f) texture. 


\section{Characterising cherts}

Similar to characterisation studies performed on cherts in other parts of the world (see Church 1994 for overview), that searched for methods more objective than common macroscopic classification, this study made use of geochemical techniques. The use of macroscopic analysis, which is still widely applied in chert sourcing, was considered to be a poor option in this particular case. This is because of the significant variation in the macroscopic appearance of samples within a single source, as a result of the secondary nature of many of them. Apparently weathering had significantly altered many of the rocks macroscopically, making it difficult even for the trained eye to classify individual artefacts. ${ }^{5}$

Following work by Kars et al. (Kars et al. 1990; see Thompson 1986) and continuing earlier research (Knippenberg 1995, 1997, 1999a), the determination of trace element composition using Inductively Coupled Atomic Emission Spectroscopy (ICPAES) was chosen as a promising method. This method allowed the determination of a number of different variables in the form of the trace-element concentrations, increasing the possibility of discrimination. Furthermore, actual sample preparation was relatively straightforward and not very time-consuming. A draw-back of the method included the destruction of the rock sample. I refer to the Appendix $\mathrm{C}$ for a more detailed description of sample preparation.

In addition to the chemical analysis using ICPAES, a number of samples from each source were thin-sectioned allowing microscopic analysis. These sections were studied to obtain a better understanding of the nature of the chert in question, and to link certain macroscopic and microscopic features with chemical characteristics.

Considering the aims outlined in paragraph 2.2.1, the following procedure was followed when taking samples for chemical analysis and microscopic analysis:

a) From the collection of chert rock specimens gathered during the different field-trips to the sources, a minimum of 8 samples per source were chosen, allowing statistical treatment of the data. In some cases, the final number of samples exceeded this initial standard number (see tables 2.5-9 for the total number of samples per source).

b) Samples were taken from, if available, a primary, secondary, and tertiary context. In case of secondary and tertiary scatters, attention was given to weathering of the rock by choosing additional samples.

c) The sample covered the full range of textures, colours, and clast contents encountered within a source.

d) A sub-sample, including at least 4 specimens per source, was prepared for thin-section study using the petrographic microscope.

e) In addition to the chert samples, a very limited number of samples from host-rock, if present, were chosen as well for chemical analysis. Generally, this number did not exceed one or two specimens per source.

Apart from these possible sources, present day-quarry sites or other localities where flint is exposed were sampled as well. This was primarily done to obtain a better understanding of chemical variation among cherts from similar host-rocks within similar formations.

\subsection{DESCRIPTION OF SOURCES AND RELATED GEOLOGY}

\subsubsection{Introduction}

To understand more about the natural distribution of the chert varieties discussed in this research a short description of the geological history of the region is presented here. The Caribbean islands have been formed as a result of plate tectonics, more precisely as a result of the collision of the Atlantic and the Caribbean plates. Despite this general underlying cause of formation we encounter significant variation in evolution of the individual islands (Donavon \& Jackson 1994; Weyl 1966). Basically, the Greater Antilles, including the Virgin Islands, can be grouped to the oldest land masses dating back to Upper Cretaceous or even Upper Jurassic, possessing a composite history of volcanism, marine sedimentation and metamorphism (figure 2.3) (Draper et al. 1994). ${ }^{6}$

The Lesser Antilles chain of islands is significantly younger than the Greater Antilles, generally not older than the

\footnotetext{
5 As will be shown in the next chapter, lithic samples from settlement sites in the Lesser Antilles often consist of a variety of flint materials originating from different sources. This makes it necessary that individual pieces should be classified to sources, rather than whole samples being assumed to come from a single source.

${ }^{6}$ Considering this complex general geological history, during which the different Greater Antillean islands each experienced local variation as well, a discussion of this is left out. The primary focus is on the Lesser Antilles.
} 
Eocene, and can be divided into two island arcs of volcanic origin (figure 2.4). An older outer arc extends from Anguilla in the north and moves along St. Martin, St. Barths, Barbuda, Antigua, and Grande Terre (Guadeloupe), to Marie Galante in the south, after which it joins the inner arc. This younger inner one, which lies to the southwest of its neighbour, signifies the present zone of convergence, where the Atlantic plate moves under the Caribbean plate. This arc includes the islands of Saba, St. Eustatius, St. Kitts, Nevis, Montserrat, Basse Terre (Guadeloupe), Dominica, Martinique, St. Lucia, St. Vincent, the Grenadines, and Grenada (Wadge 1994; Westermann 1957). The change of arc is thought to have taken place around 9 Ma and involved only the northern portion, while the southern part remained in place (Baker 1984). The inner arc islands are predominantly volcanic in nature, whereas the outer arc islands vary more in geological build-up. Most exhibit a composite nature of old arc-volcanics, non-carbonate marine deposition, as well as relatively large carbonate formations, that usually post-date the old arc-volcanism (Christman 1953; Westermann 1957; Martin-Kaye 1959; Weiss et al. 1986).

The islands of La Désirade, Barbados, Trinidad and Tobago do not belong to either of the arcs. The origin of La Désirade is still debated: it either represents an "ophiolitic complex," "an orogenic series," or "a primitive island arc fragment detached from the eastern Greater Antilles" (Montgomery et al. 1992). Trinidad and Tobago geologically form part of the South American mainland, and Barbados is "the exposed top of the accretionary wedge of sediments that have been scraped off by the subduction (of the Atlantic plate underneath the Caribbean one)" (Wadge 1994).

Chert and flint sources relevant to this study can be found on three islands, Antigua, St. Kitts, and the south-western part of Puerto Rico. These islands present totally different geological settings.

Antigua, lying in the northeastern corner of the Lesser Antilles, is one of the composite islands formed during oldarc volcanism. Basically, the island can be divided into three geological different regions (figure 2.5). The Basal Volcanic Suite covers the southwestern part of the island. It primarily consists of pyroclastic and igneous material of Oligocene age. The Central Plain group, also Oligocene in age, consists of stratified series of agglomerates, agglomerative tuffs, sandy tuffs, shaly rocks, and cherts (Martin-Kaye 1959), and covers the middle strip of the island, extending from the northwest to the southeast. The northeast part, including the many bays and islands, belongs to the Antigua Formation, an Oligocene series of limestone depositions, consisting of biomicrites, reef limestones, and limy mudstones (Weiss 1994).

St. Kitts is situated along the younger inner arc of the Lesser Antilles. It is a true volcanic island, with basically four regions of past and sub-recent volcanic activity (figure 2.6). The igneous rocks within the Southeast peninsula have been dated as the oldest rocks, around 2.3 Ma (Baker 1984). Later activity shifted towards the northeast, where the South East range and the Middle range centres are estimated to have erupted around 1-2 Ma. Mount Misery represents the area of lates activity, with still active fumaroles in its crater and a possible historic eruption in 1692 (Baker 1980). The volcanic rocks on the island mainly consist of pyroxene andesites, with smaller amounts of basalt and basaltic andesites.

In addition to these volcanic rocks, small limestone formations occur at several places on the island. The limestone at Brimstone Hill, on the leeward side, is best preserved and most extensive. This Brimstone Hill formation is considered to be a marine floor that has been uplifted by volcanic activity of the youngest centres. Its formation is dated prior to these eruptions but after the arising of volcanoes at the Southeast peninsula (Trenchmann 1932; Westermann \& Kiel 1961). Other limestone occurrences on St. Kitts are reported at Goodwin gut and as small outcrops scattered over the island.

Puerto Rico can be geologically classified to the Greater Antilles Orogenic Belt, a geological region that includes the Virgin Islands, a major part of Hispaniola and the southeastern end of Cuba as well (Draper et al. 1994). Its history of formation presents a long succession of volcanic, intrusive, metamorphic, sedimentary and tectonic processes (Larue 1994). Recently, Larue $(1994,161)$ presented a general summary of the island's geological history based on an extensive series of earlier work. He has listed 9 important phases and has divided the island into several zones (figure 2.7). The oldest rocks, dating to the late Jurassic present old oceanic crustal development. This is followed in the early Cretaceous by the first island arc volcanism. This arc is considered to be the ancestral arc of the Caribbean region and predates the Lesser Antillean ones. Arc build-up, interrupted by two phases, continued until the late Eocene, after which a period of uplift, deformation and rotation lasted until the middle Oligocene. Significant carbonate platform development occurred from the late Oligocene to Miocene, and the last phase is characterised by a series of tectonic rotational events.

The region where most chert occurrences are formed, is called the Southwest block. This block is part of the whole middle range of the island, which exposes rocks related to the crustal development and island arc volcanism events. Within the Southwest block, the oldest rock formations are found in the Bermeja complex, "a serpentinite melange consisting of dismembered ocean floor (including cherts) and island arc derivatives such as volcanic and volcaniclastic rocks" (Larue 


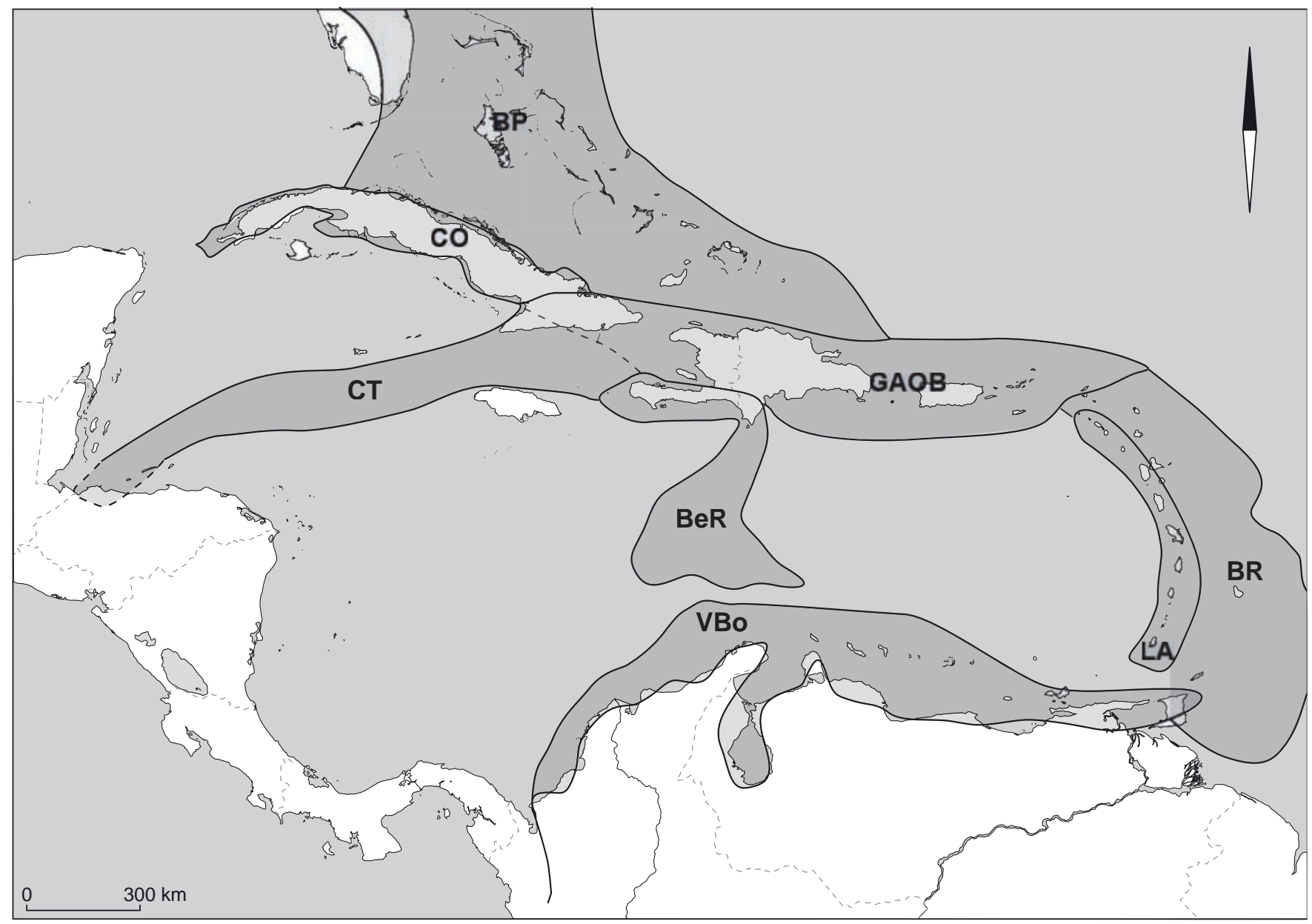

Figure 2.3. Map of the Caribbean region showing some of the geological provinces (redrawn after Draper et al. 1994, fig. 1.1 and based on Case and Dengo 1982; Case et al. 1990). BeR = Beata ridge; BP = Bahamas platform; BR = Barbados ridge and Lesser Antilles deformed belt; $\mathrm{CO}=$ Cuban Orogenic belt; $\mathrm{CT}=$ Cayman trough; $\mathrm{GAOB}=$ Greater Antilles Orogenic belt; LA = Lesser Antilles; VBo = Venezuelan borderland.

1994, 156). This region includes major occurrences of bedded chert grouped within the Mariquita Chert Formation. Two major limestone facies originate in a later period.

\subsubsection{Chert sources}

Field-walking of potential source areas, close reading of geological and archaeological reports, and consulting with local archaeologists has resulted in the identification of 15 potential source locations from where Amerindians may have acquired material for stone tool production in the overall study area. These locations either have remains of prehistoric exploitation in the form of scatters of flakes, blades and cores, or still bear chert in host-rock, which must have been available to the indigenous inhabitants. The reader is referred to Appendix A for a more detailed description of each source individually. In addition to these 15 sources, one location at Hughes Bay along Antigua's northeastern coast, where flint was found, probably represents an artificial flint occurrence, the result of stone ballast droppings during historical times (see figure 2.5; see Appendix B). Furthermore, at another three locations on Antigua, chert and flint material was also identified, inspected and sampled. At these locations chert and flint is exposed as a result of contemporary stone quarrying or house construction and therefore these localities should not be considered as potential prehistoric source areas. 


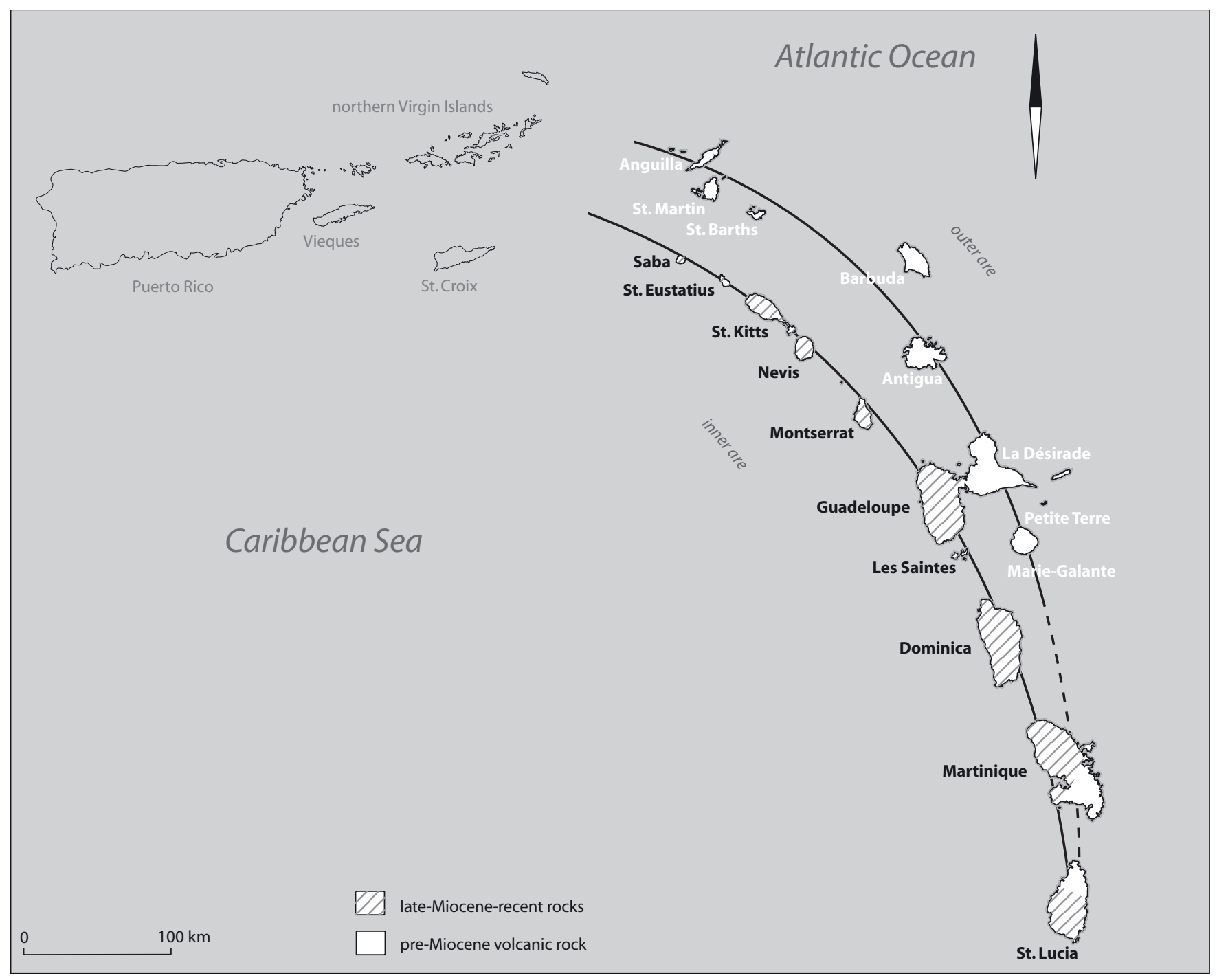

Figure 2.4. Map of the Lesser Antilles inner and outer volcanic arcs (redrawn after Multer et al. 1986, fig. 1.1).

Table 2.1 lists all 15 sources. It is immediately noticed that the majority are found on Antigua (see figure 2.5). Five localities geologically form part of the Antigua Formation, the extensive limestone formation covering the northeastern part of the island. Two are associated with tuff deposits from the Central Plain Group, and one is found among tuffs belonging to the Basal Volcanic Suite. It should be pointed out that for all these sources a clear association with their direct geological surroundings can be established: the sources either represent primary occurrences, where chert or flint still can be found in its rock of formation, or they represent secondary sources where a relation with its direct surroundings can be established on basis of material characteristics. This contrasts to the sources found on St. Kitts, as well as those in the southwestern part of Puerto Rico, where such relation proves more difficult to ascertain (see below).

As outlined above the Antigua flint sources in this region are considered to have been of primary importance to the Amerindians. Therefore, rock sections exposed along the eastern and western shores were inspected, as well as modern inland quarry sites in search of unreported flint occurrences, to gain a better understanding of the stratigraphy of the Antigua Formation and in particular, the stratigraphical position of the flint bearing layers in this formation (figures 2.5, 2.8-11). Inspection of a large section at the contemporary Piggott's Hill quarry site, which reveals a significant part of the stratigraphy of the Antigua Formation, shows that the flint bearing limestone layers are very restricted and that basically one deposit, which consists of fine-grained calcareous mudstone, contains nodule layers (see figure 2.11). The idea of restricted 


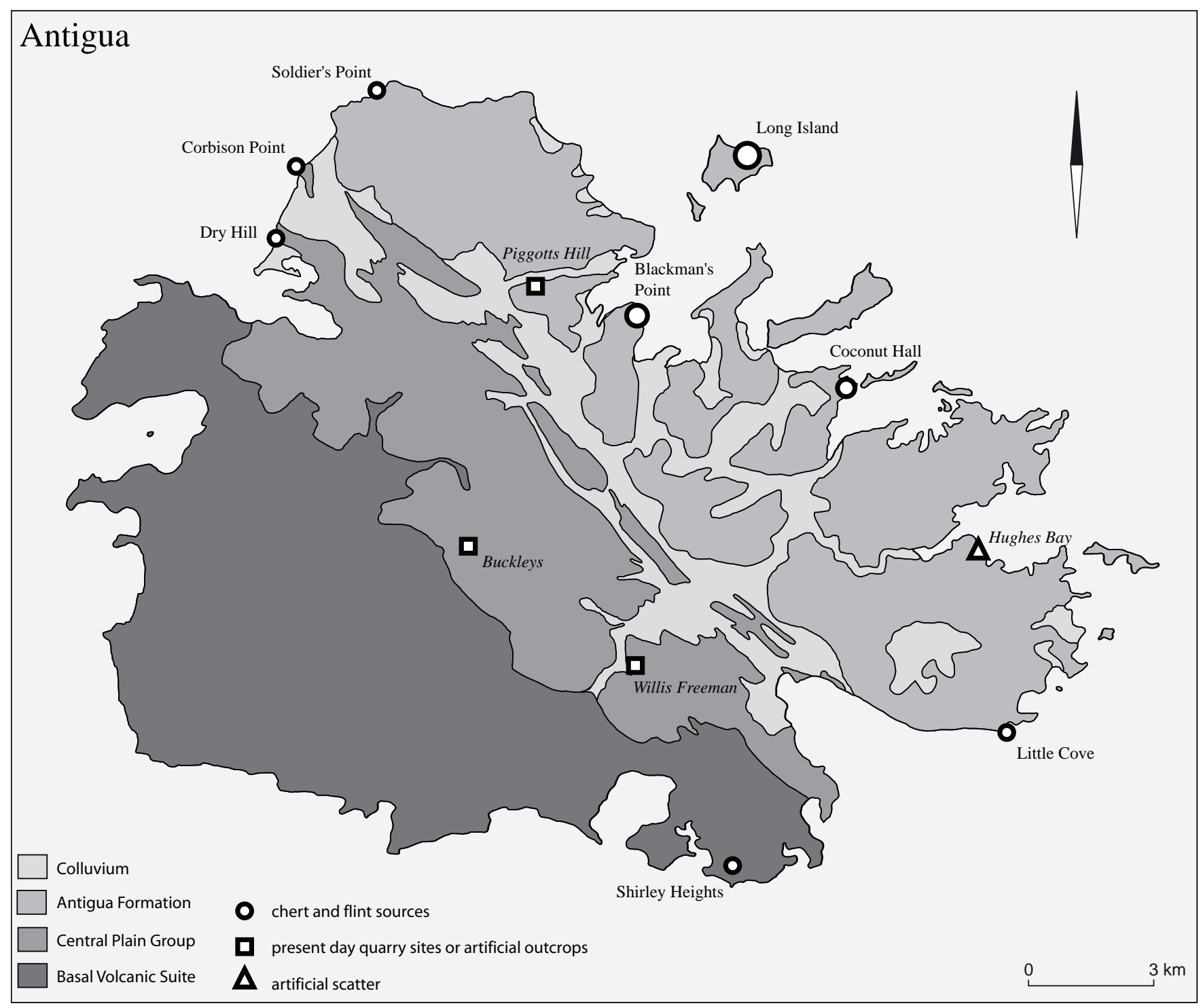

Figure 2.5: Geological map of Antigua showing the three main geological regions and the location of flint and chert sources, including the location of the artificial flint scatter at Hughes Bay, the limestone present day quarry site at Piggotts Hill, and chert outcrops at Buckleys and Willis Freeman (geological map based on Multer et al. 1986, fig. 2.1).

occurrence is also supported by the absence of flint within the many sections inspected along the eastern and western coasts.

During the survey a recurrent stratigraphy emerged, which was applicable to the different flint bearing rock sections. In short, it can be said that calcareous packstones, with high concentrations of foraminifers and usually indicating relatively high energy circumstances of deposition, underlie the flint bearing limestone layer. This latter layer generally consists of calcareous mud- or wackstones, which were deposited in a low energy environment. The number of flint nodule layers generally does not surpasses three. On top of this deposit reef limestones formed during relative high energy deposition.

Based on this stratigraphy, Hans Zijlstra (personal communication 2000) formulated a possible explanation for the rare occurrence of the flint bearing limestone layers, restricted to the middle of the Antigua Formation. He noted that the Antigua Formation is an Oligocene rhythmically bedded transgressive-regressive succession, reflecting an initial flooding of a steep, rapidly subsiding volcanic island, followed by a gradual shallowing again, due to decrease of subsidence rate and sediment deposition at the island margins. During this evolution, coral reefs moved from the coast seawards and back to the 


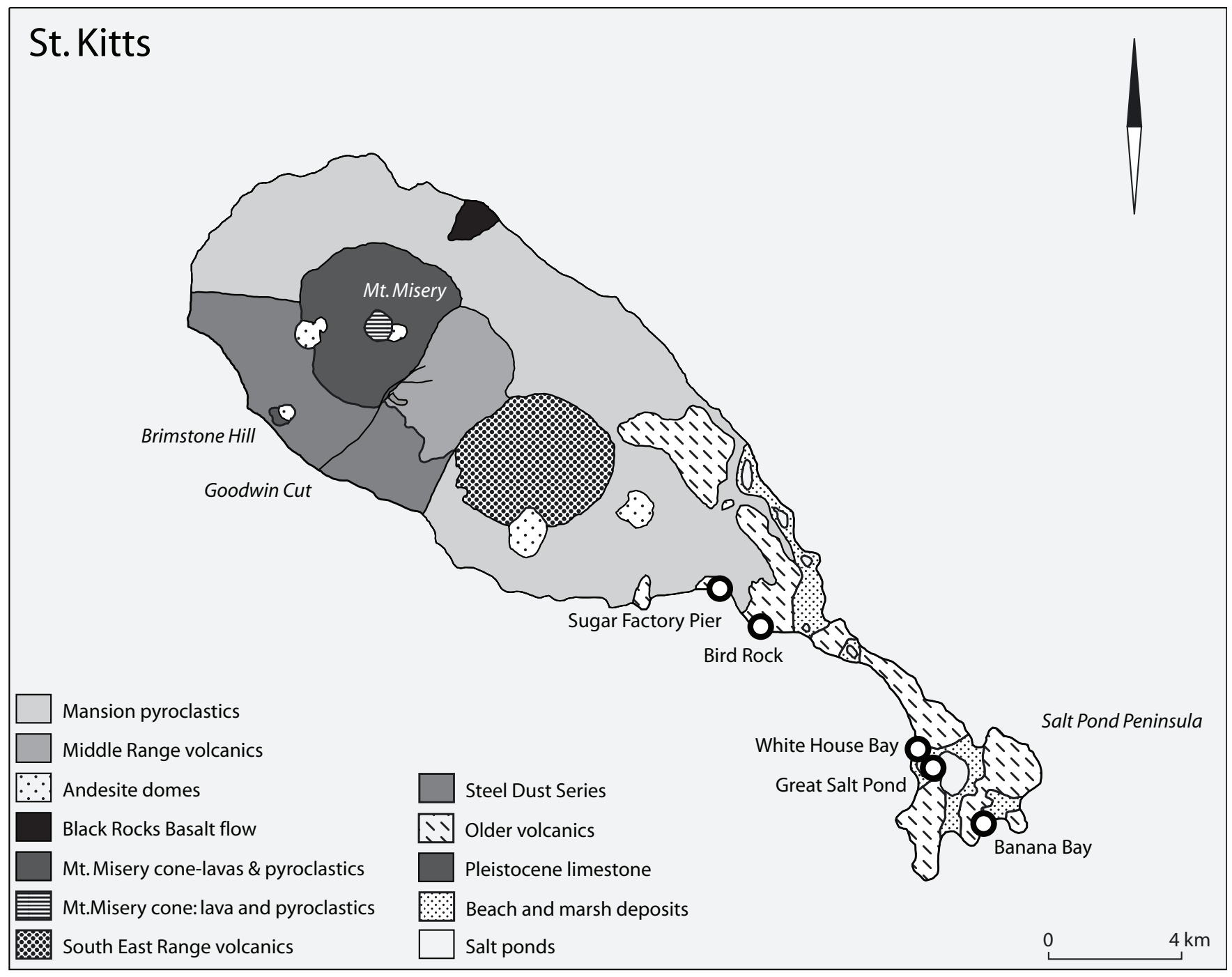

Figure 2.6. Geological map of St. Kitts, showing the location of flint scatters (geological map based on Baker 1968, fig.1).

coast again, forming an opening and closing restricted lagoon between land and open sea. As flint nodule layer genesis is understood to occur during conditions of rather low water energy in combination with relatively low deposition rate (Zijlstra 1994), only during the maximum extension of the lagoon, siliceous opal-rich flint layers should have been formed and preserved, allowing the much later genesis of flint nodule layers, probably during a Pleistocene sea-level fall.

The inspection of the Piggots Hill quarry rock section revealed a thin clay layer only $1 \mathrm{~m}$ below the flint bearing limestone layers, which had a high concentration of detrital quartz grains. It may be that this clay layer is another proof for relatively low deposition rates of carbonates and concentration (condensation) of quartz grains, constantly swept in from land by wind or water. Alternatively, the flint and clay layers in the middle of the Antigua Formation may reflect a period of excessive influx of siliceous material from land, either deposited directly or after uptake by biogenic opal producers.

In any case, it is suggested that the flint nodule layers have a very restricted occurrence in the stratigraphic succession and therefore, a detailed knowledge of the stratigraphy of the Antigua Formation enables the recognition of areas where flint is likely to be exposed, and were sources can be found.

The Central Plain Group and the Basal Volcanic suite represent the other two geological regions on the island of Antigua. Both pre-date the Antigua Formation, but are also Oligocene in age. The Basal Volcanic suite was formed by 


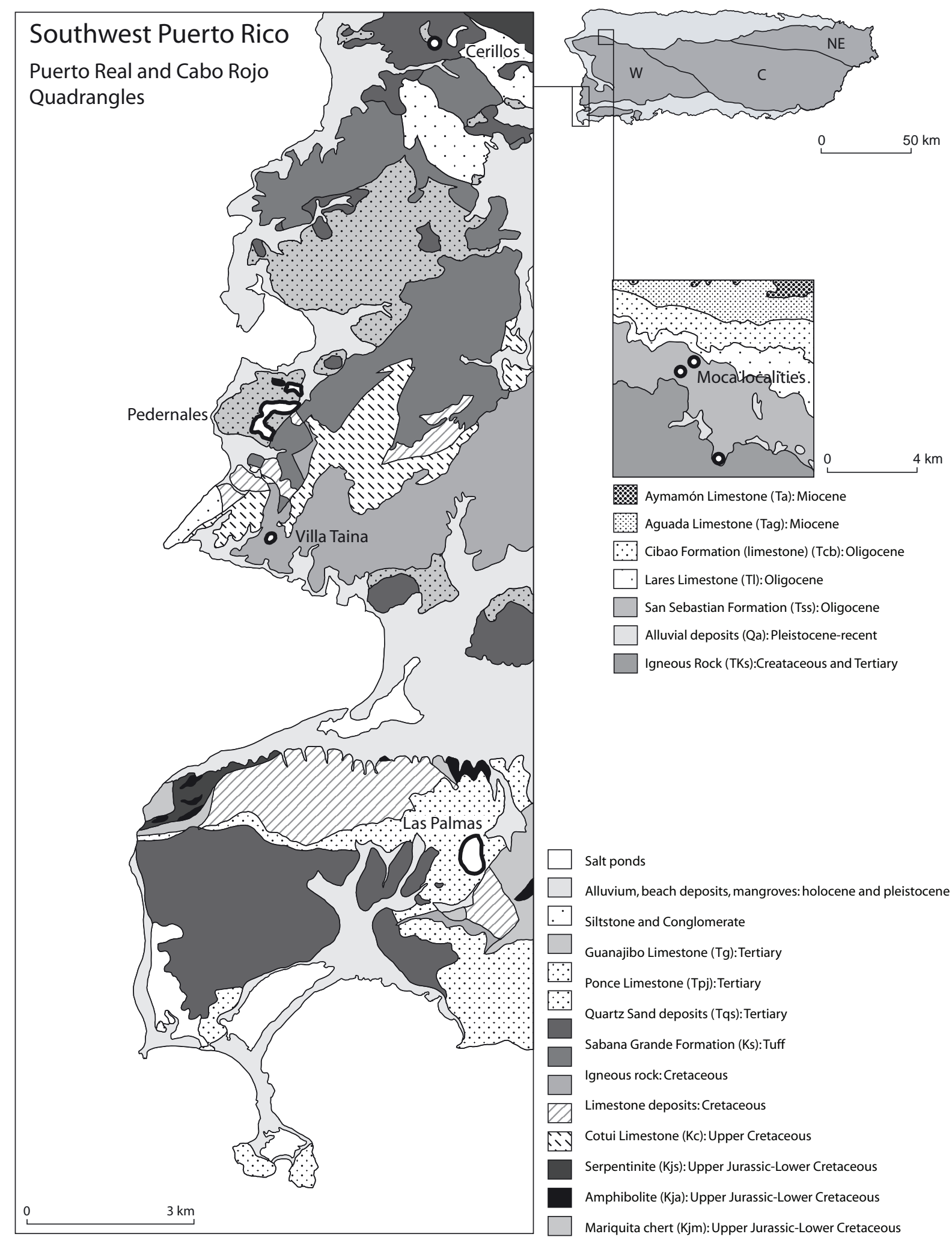

Figure 2.7. Geological map of the southwestern part of Puerto Rico showing the location of chert sources in white (geological map based on Volckman 1984a,b). 


\begin{tabular}{|c|c|c|c|c|c|}
\hline Island & Source Locality & Geological setting & $\begin{array}{l}\text { Type of (original) } \\
\text { hostrock }\end{array}$ & Type of occurrence & Description \\
\hline \multirow[t]{8}{*}{ Antigua } & Long Island (LI) & Antigua Formation & Limestone & $\begin{array}{l}\text { primary, secondary, } \\
\text { tertiary }\end{array}$ & $\begin{array}{l}\text { Major flint occurrence on small island off } \\
\text { Antigua's northern coast. Flint is scattered } \\
\text { along the islet's northern shore and at surface } \\
\text { scatters on large portions of the island. }\end{array}$ \\
\hline & Little Cove (LC) & Antigua Formation & Limestone & primary, secondary & $\begin{array}{l}\text { Limestone section and cobble beach along } \\
\text { Antigua's eastern coast. Flint can be found on } \\
\text { the cobble beach and in limestone sections }\end{array}$ \\
\hline & Soldier Point (SP) & Antigua Formation & Limestone & primary, secondary & $\begin{array}{l}\text { Extended rock point along Antigua's } \\
\text { northwestern coast. Flint can be found within } \\
\text { limestone of this rock point as well as at both } \\
\text { cobble beaches enclosing it. }\end{array}$ \\
\hline & Blackman's Point (BP) & Antigua Formation & Limestone & secondary, tertiary & $\begin{array}{l}\text { Bxclusive secondary occurrence of flint at the } \\
\text { northern shore. Flint can be found scattered } \\
\text { on the surface and along an eroded coast-line. }\end{array}$ \\
\hline & Coconut Hall $(\mathrm{CH})$ & Antigua Formation & Limestone & secondary, tertiary & $\begin{array}{l}\text { Exclusive secondary occurrence of inland } \\
\text { scatters of flint at Coconut Hall along } \\
\text { Antigua's northern coast. }\end{array}$ \\
\hline & Shirley Heights (SH) & Basal Volcanic Suite & Tuff & primary, secondary & $\begin{array}{l}\text { Chert boulders are exposed at the flanks of } \\
\text { Shirley Heights in the southeastern part of } \\
\text { Antigua, surrounded by secondary surface } \\
\text { scatters. }\end{array}$ \\
\hline & Corbison Point (CP) & Central Plain group & Tuff & primary, secondary & $\begin{array}{l}\text { Bedded chert layers exposed at a rock-point } \\
\text { along Antigua's northwestern coast. } \\
\text { Secondary chert is lying on the adjacent } \\
\text { cobble beach. }\end{array}$ \\
\hline & Dry Hill (DH) & Central Plain group & Tuff & primary, secondary & $\begin{array}{l}\text { Bedded chert layers exposed at a rock-section } \\
\text { along Antigua's northwestern coast, } \\
\text { secondary chert is lying on the adjacent } \\
\text { cobble beach. }\end{array}$ \\
\hline \multirow[t]{2}{*}{ St. Kitts } & Great Salt Pond (GSP) & Unknown & Limestone & secondary & $\begin{array}{l}\text { Secondary surface scatter of small cobbles } \\
\text { situated along an artificial dam separating two } \\
\text { salt lakes in the southwest peninsula of St. } \\
\text { Kitts. }\end{array}$ \\
\hline & Sugar Factory Pier (SFP) & Unknown & Limestone & secondary & $\begin{array}{l}\text { Small cobbles scattered on a cobble beach } \\
\text { predominantly consisting of igneous rock, } \\
\text { along St. Kitts southern shore near the capital } \\
\text { of Basse Terre. }\end{array}$ \\
\hline \multirow[t]{5}{*}{ Puerto Rico } & Cerrillos (CE) & Guanajibo Formation & Limestone & secondary, tertiary & $\begin{array}{l}\text { Significantly destroyed inland surface scatter } \\
\text { near the village of Conde Avila within the } \\
\text { southwestern part of Puerto Rico. }\end{array}$ \\
\hline & Pedernales (PE) & Guanajibo Formation & Limestone & secondary & $\begin{array}{l}\text { Extensive inland surface scatter of relatively } \\
\text { large irregularly chert boulders in the } \\
\text { immediate surroundings of the village of El } \\
\text { Cerro in the southwestern part of Puerto Rico. }\end{array}$ \\
\hline & Las Palmas (LP) & $\begin{array}{l}\text { Ponce Formation } \\
\text { Mariquita Chert }\end{array}$ & $\begin{array}{l}\text { Limestone } \\
\text { Chert }\end{array}$ & secondary, tertiary & $\begin{array}{l}\text { Extensive inland surface scatter near the } \\
\text { village of Las Palmas in the southwestern part } \\
\text { of Puerto Rico. The surface scatter includes } \\
\text { secondary green chert material from the } \\
\text { Mariquita Chert Formation as well. }\end{array}$ \\
\hline & Villa Taina (VT) & Cotui Fromation & Limestone & secondary & $\begin{array}{l}\text { Small inland surface scatter of relatively large } \\
\text { irregularly shaped chert boulders } 2.5 \mathrm{~km} \text { west } \\
\text { to the village of Boqueron in the southwestern } \\
\text { part of Puerto Rico. }\end{array}$ \\
\hline & Moca (MO) & San Sebastián Formation & Conglomerrate & secondary, tertiary & $\begin{array}{l}\text { Inland surface scatters of chert within the } \\
\text { valley of the Culebrinans river in the western } \\
\text { part of Puerto Rico. }\end{array}$ \\
\hline
\end{tabular}

Table 2.1. Description of chert and flint sources within the northern Lesser Antilles and Puerto Rico, included within this study. Note that primary stands for chert or flint material still present in its original host-rock, secondary for eroded material out of the host-rock and tertiary for evidence of exploitation or working of the material at the locality in the form of scatters of flaked stone. 


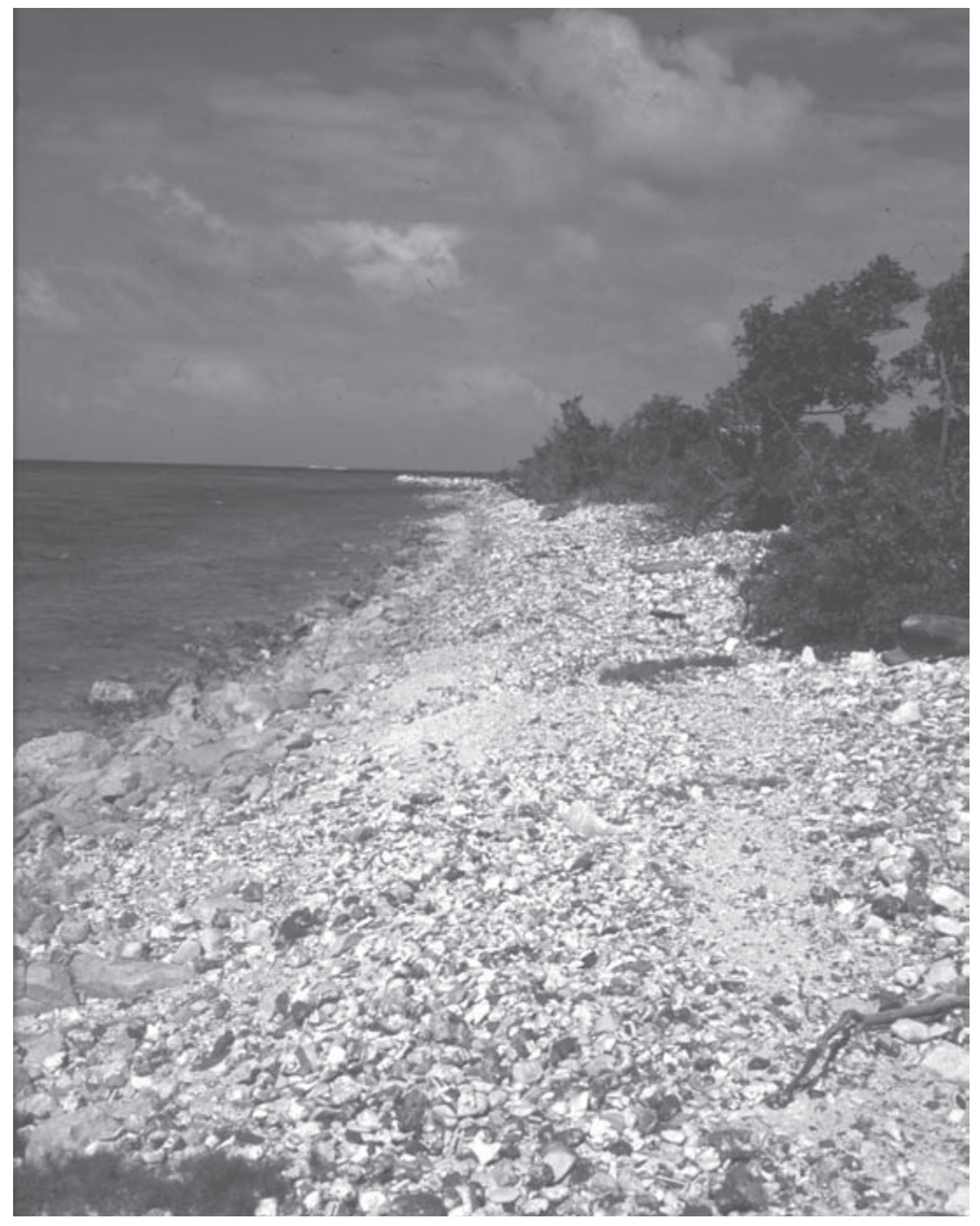

Figure 2.8. The Flinty Bay cobble beach along Long Island's northern coast.

predominantly calc-alkaline igneous rocks, with smaller volumes of limestone and other sedimentary rocks such as tuffs, tuffaceous mudstone, smectite and chlorite mudstone, and clay stone (Weiss 1994, 4). This area of the island either represents "the northeastern quadrant of a once-giant volcano that is now mostly blown away or eroded, and also drowned" (Weiss 1994, 4; see also Multer et al. 1986), or "the flank of the rising edge of the Caribbean plate" (Weiss 1994, 4; see also Mascle \& Westercamp 1983).

The Central Plain Group consists of a thick sequence of mixed marine and non-marine rocks of both sedimentary and volcanoclastic origin, which extends itself across the island from the northwest to the southeast (Weiss 1994, 5). Rock materials include limestones, cherts, shales (marine), mudstones, arenite, tuff, and conglomerate (non-marine) (Weiss 1994, 5). Both regions contain occurrences of chert. In particular the Central Plain Group hosts different types of chert, of which extensive beds are most common, but also nodule shaped cherts, ranging from the size of golf-balls to that of soccer balls are present (Martin-Kaye 1959; Multer et al. 1986).

During my fieldwork, no attempt was made to locate additional sources, as this would require an enormous amount of field-walking. Therefore, I relied on the observations of Martin-Kaye (1959) and Weiss (1994), as well as from personal communication with Reg Murphy (1997). The occurrences sampled include Shirley Heights, Dry Hill, Corbison Point, Buckleys, and Willis Freeman (figures 2.12 and 2.13). At the latter two localities present day building and quarry activities expose chert, making it unlikely that Amerindians had used these specific materials. Future research should attempt to locate 

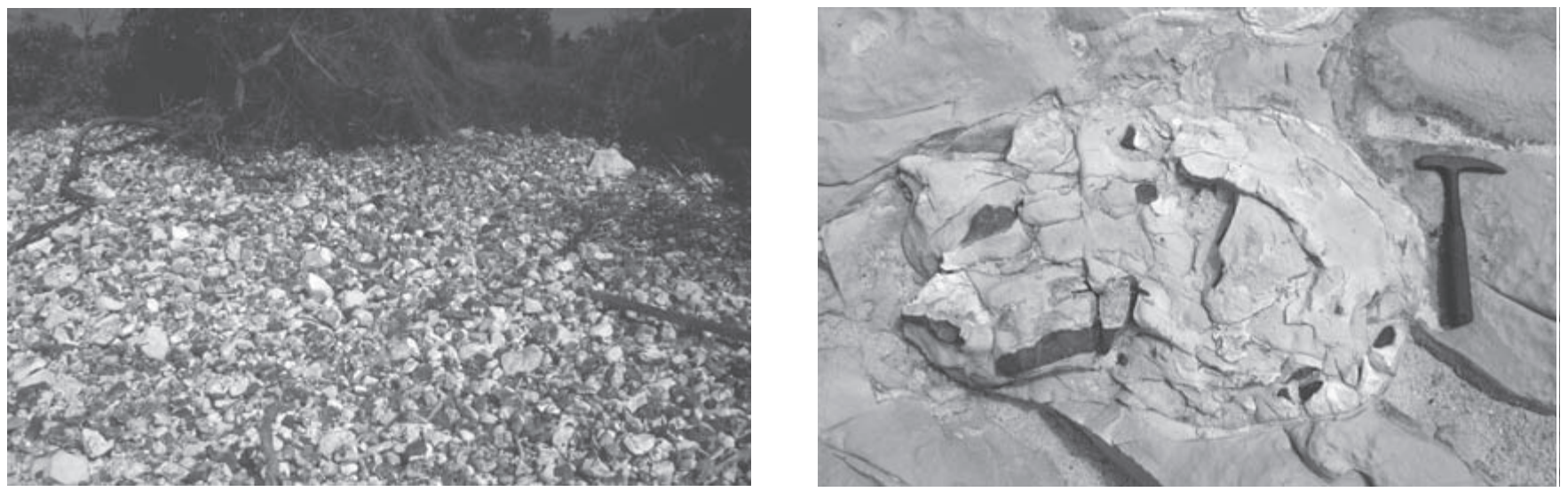

Figure 2.9. Flint cobbles rich area along Flinty Bay (left) and primary flint outcrop at Flinty Bay with cylindrical flint formed around a burrow of Bathichnus paramoudrea (right).

natural outcrops as well as possible archaeological evidence of exploitation, as Weiss (1994) reports natural outcrops of chert in both areas.

The presence of flint (limestone chert) on St. Kitts, which is predominantly a volcanic island, is odd and raises many questions. In total five flint occurrences were reported after research by the Arizona State University (see figure 2.6) (Armstrong 1978; Walker 1980, 64). All are secondary occurrences of flint pebbles found in areas where the older volcanics of the Southeast peninsula surface. Flint can be picked up scattered along igneous rock beaches at White House Bay, Banana Bay, and Sugar Factory Pier, below a rock cliff at Bird Rock, or on an artificial dam that has been erected to divide two salt ponds at Great Salt Pond. I only took samples at Sugar Factory Pier and Great Salt Pond.

In Appendix A, I go into more detail on this unexpected relation. From this evaluation it can be concluded that the flint scatters on St. Kitts actually are not likely natural to the island. The inability to identify its geological origin on the island and the possibly rare occurrence of St. Kitts flints within the archaeological record form the main arguments for this hypothesis. Similar to Hughes Bay on Antigua, a historic dropping as ballast load may be a possibility. Still, I am not able to find definite proof for an artificial occurrence and therefore these flint sources remain included within the following study (see figure 2.6).

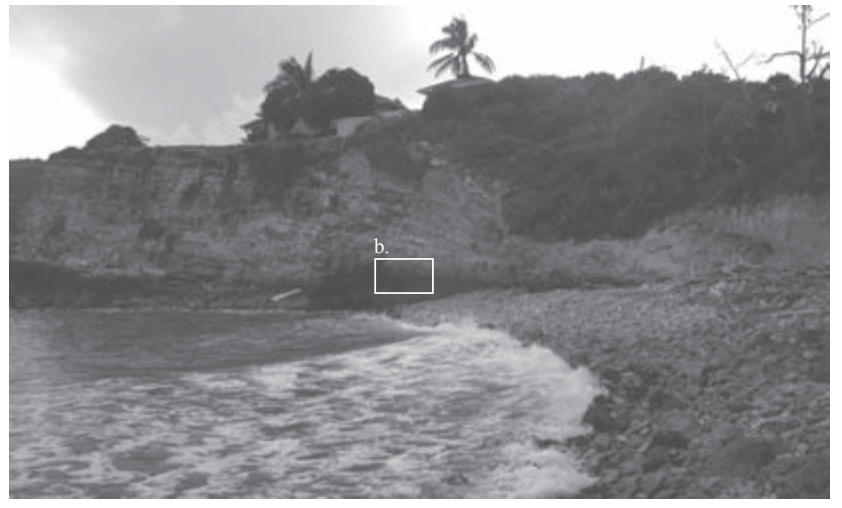

a

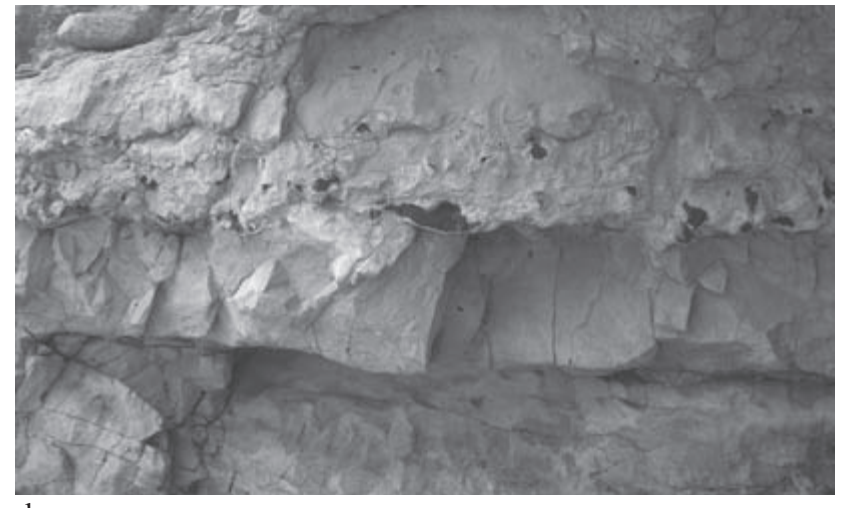

Figure 2.10. The Little Cove Bay (a) along Antigua's eastern coast, viewing the limestone section exposing flint nodule layers (b). Note that cobble beach primarily consists of flint pebbles. 


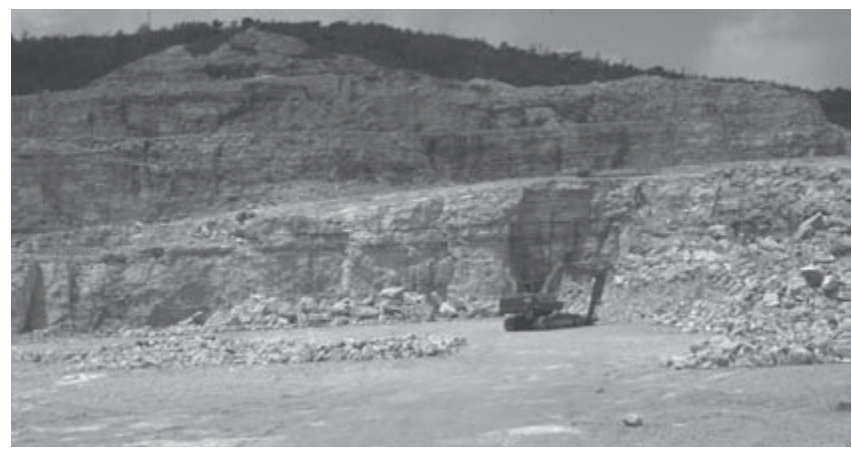

a

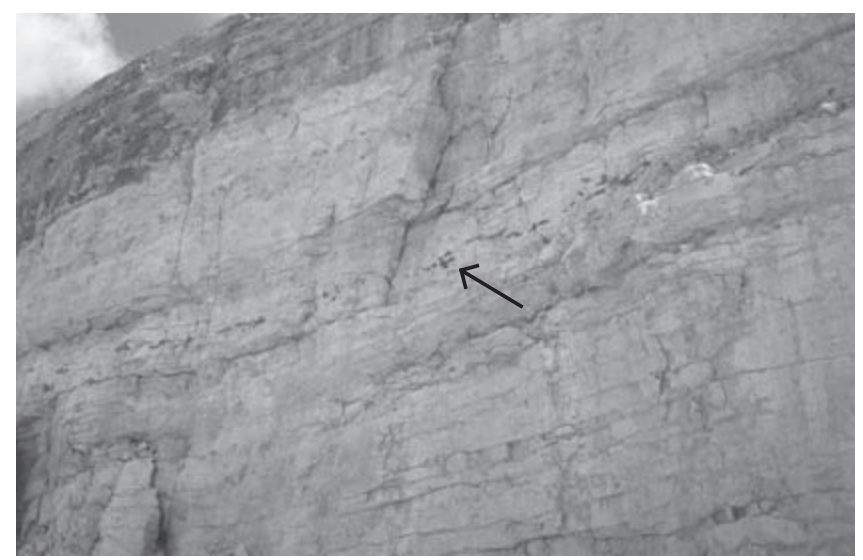

b

Figure 2.11. The limestone section exposed at the contemporaneous limestone quarry site at Piggots Hill (a), with a close-up of the section exposing rarely formed flint nodule layers, indicated by arrow in figure $b$.

On Puerto Rico, we are faced with another problem regarding the geological understanding of the sources. All sources are secondary in nature, that is, they only represent surface scatters of material (figure 2.14). For two sources, Cerrillos and Las Palmas, Volckmann (1984b, personal communication cited in Ortiz 1976) provides a possible geological relation, but it proved to be difficult to confirm this relation. In most cases, scatters of material are either lying in a limestone region or limestone formations are situated close-by. This suggests that the cherts should be considered as flints, i.e. formed in limestone. However, the structural absence of bioclasts and calcite indicate that these cherts are not flints in which quartz has replaced the original carbonate. They are more similar to the non-fossiliferous tuff cherts found on Antigua. Tuff rock, however, does not occur within vicinity to the chert localities, making this relation very unlikely. Another possible origin may be the formation of cherts in karstic carbonate rock (Thiry \& Ribet 1999). In such a case the chert does not represent a replacement, as with flints, but is an infilling of original voids present in the limestone. This would entail that the final chert does not contain any fossils. This may also explain the presence of differently silicified veins and areas in the flint. These should be seen as incompletely silicified areas during first silification, after which they became silicified during a second phase. Still the data at present are inconclusive to fully understand the formation and presence of chert at these different localities. Future research should focus on the identification of any primary deposits of chert in or near the vicinity of the different scatters.

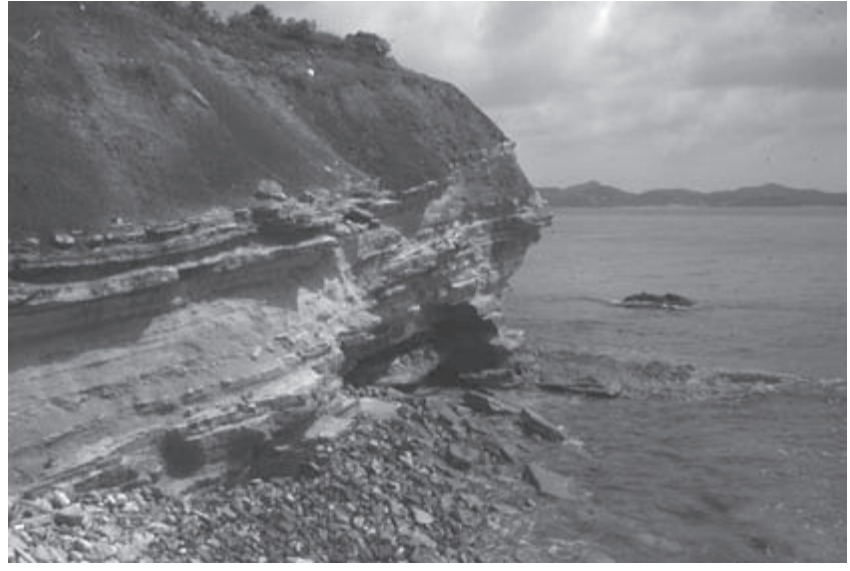

a

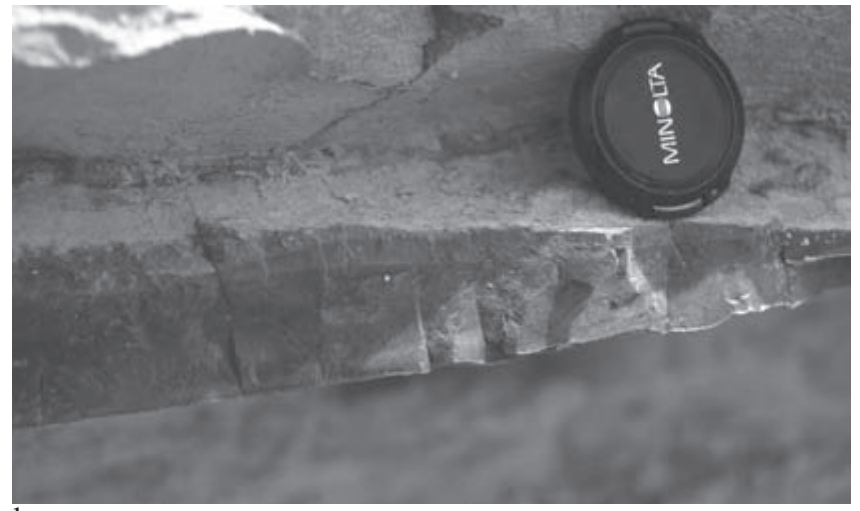

b

Figure 2.12. Rock section at Corbison point exposing less eroded chert layers within tuff deposits (a), with a close-up of one of these chert layers (b). 

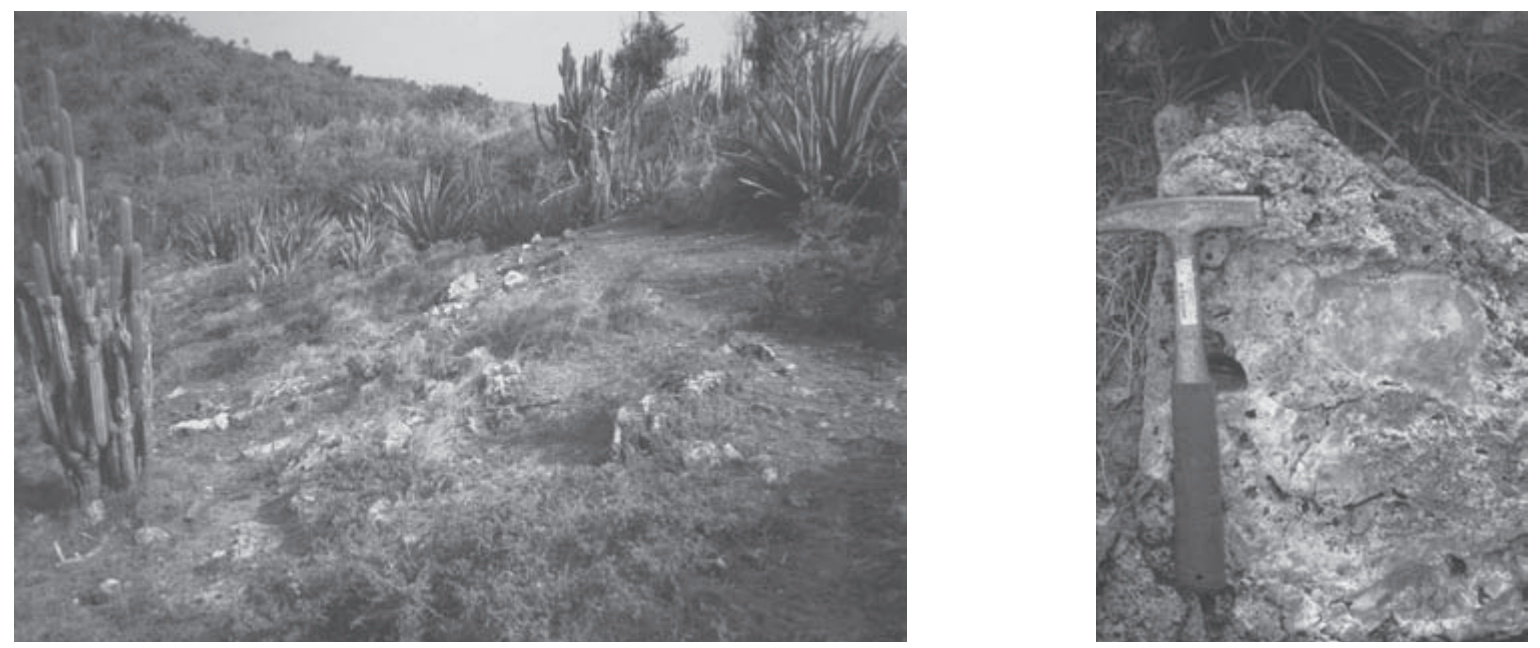

Figure 2.13. Chert outcrops at Shirley Heights (a) with a close-up of one of these chert outcrops (b).

\section{Macroscopic and microscopic characteristics}

The macroscopic and microscopic study of the different cherts and flints provides a first basis for explaining the variability between and within sources. Furthermore, it contributes to the understanding of the trace-element composition, discussed within the next sections. Tables 2.2 and 2.3 list the most important macro- as well as microscopic features of the cherts and flints for each source separately. The reader is again referred to Appendix A for a more detailed description of material characteristics per source. The photographs in figures 2.15-17 present an overview of the microscopic textures of the different flints and cherts.

Summarising the macroscopic comparison between and within the sources, it can be concluded that intra-source variability generally is high, apart from a few exceptions. This high variability can for the most part be attributed to the secondary nature of all sources, where chemical weathering has altered the original appearance significantly. This is particularly evident in the wide range of colours, predominantly of a (light) brown and reddish brown hue among many source varieties. On a microscopic level, intra-source variability is less significant, although weathering has also contributed to some intra-source differentiation. Still, on this level, cherts and flints from related geological settings exhibit similar features. This suggests that source groups comprising geologically related sources can be distinguished in most cases.

Taking a closer look at the macroscopic characteristics, it is noted that the primary flint varieties in Antigua display strong similarities. In particular, primary flint nodules at Soldier Point and Little Cove, as well as at the contemporary quarry site of Piggots Hill possess a similar colour, grain-size, and clast-contents. Primary flint at the related source of Long Island

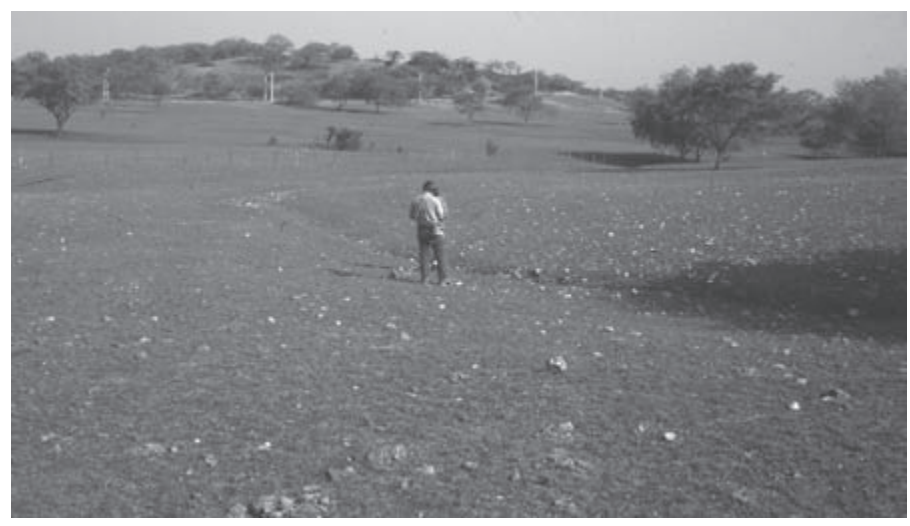

Figure 2.14. Overview of the natural chert scatter at Las Palmas, Puerto Rico. 


\begin{tabular}{|c|c|c|c|c|c|}
\hline $\begin{array}{l}\text { Island and geological } \\
\text { setting }\end{array}$ & Source & Colour & grain-size & $\begin{array}{l}\text { fossils and other } \\
\text { clasts }\end{array}$ & remarks \\
\hline \multirow[t]{5}{*}{$\begin{array}{c}\text { Antigua } \\
\text { (Antigua Formation) } \\
\text { (primary) }\end{array}$} & Long Island & $\begin{array}{l}\text { * primary: very dark grey } \\
* \text { secondary: (yellowish) brown - } \\
\text { greyish brown }\end{array}$ & very fine & $\begin{array}{l}* \text { haze of fine white } \\
\text { calsts } \\
* \text { rarely visible fossils }\end{array}$ & $\begin{array}{l}\text { large range of } \\
\text { colours }\end{array}$ \\
\hline & Little Cove & $\begin{array}{l}\text { * primary: (dark) brown - (dark) } \\
\text { grey } \\
\text { * secondary: (pale) brown - greyish } \\
\text { brown }\end{array}$ & fine & $\begin{array}{l}* \text { low concentration } \\
\text { of fossils }\end{array}$ & \\
\hline & Soldier Point & (dark) greyish brown - (pale) brown & fine & $\begin{array}{l}\text { * low concentration } \\
\text { of fossils }\end{array}$ & \\
\hline & $\begin{array}{l}\text { Blackman's } \\
\text { Point }\end{array}$ & $\begin{array}{l}\text { 1:light to dark grey } \\
\text { (yellowish) brown, pale yellow } \\
\text { light brownish grey } \\
\text { 2:pink, reddish brown, weak/pale } \\
\text { red }\end{array}$ & fine to moderate & $\begin{array}{l}* \text { varied } \\
\text { concentration of } \\
\text { fossils }\end{array}$ & $\begin{array}{l}\text { large range of } \\
\text { colours }\end{array}$ \\
\hline & Coconut Hall & $\begin{array}{l}\text { 1:dark greyish brown to pale brown } \\
\text { 2: yellowish brown to light grey } \\
3 \text { : grey to white }\end{array}$ & fine to moderate & $\begin{array}{l}* \text { varied } \\
\text { concentration of } \\
\text { fossils }\end{array}$ & $\begin{array}{l}\text { large range of } \\
\text { colours }\end{array}$ \\
\hline $\begin{array}{c}\text { Antigua } \\
\text { (Basal Volcanic Suite) }\end{array}$ & Shirley Heights & (light) grey to white & fine & * absent & \\
\hline \multirow[t]{2}{*}{$\begin{array}{c}\text { Antigua } \\
\text { (Central Plain group) }\end{array}$} & Corbison Point & $\begin{array}{l}* \text { primary: (very) dark grey } \\
* \text { secondary: grey - pinkish grey - } \\
\text { white }\end{array}$ & fine to moderate & $\begin{array}{l}* \text { varied } \\
\text { concentration of } \\
\text { fossils }\end{array}$ & variation by bed \\
\hline & Dry Hill & $\begin{array}{l}\text { (very) dark grey - grey - (light) } \\
\text { greyish brown }\end{array}$ & fine to moderate & $\begin{array}{l}* \text { varied } \\
\text { concentration of } \\
\text { fossils }\end{array}$ & variation by bed \\
\hline $\begin{array}{c}\text { St. Kitts } \\
\text { (unknown geological } \\
\text { origin) }\end{array}$ & $\begin{array}{l}\text { Great Salt Pond } \\
\text { and Sugar } \\
\text { Factory Pier }\end{array}$ & $\begin{array}{l}\text { 1: black - dark grey - greyish } \\
\text { brown - olive brown - yellowish } \\
\text { brown - brownish yellow } \\
\text { 2: (light) grey - light brownish grey }\end{array}$ & very fine & * fossils rarely visible & $\begin{array}{l}\text { *slightly } \\
\text { translucent } \\
\text { * large light } \\
\text { coloured areas }\end{array}$ \\
\hline \multirow[t]{2}{*}{$\begin{array}{l}\text { Puerto Rico } \\
\text { (Guanajibo } \\
\text { Formation) }\end{array}$} & Cerrillos & $\begin{array}{l}\text { (pale) brown - yellowish brown - } \\
\text { (light grey) - white } \\
\text { red }\end{array}$ & fine to moderate & $\begin{array}{l}* \text { no fossils } \\
* \text { iron oxides } \\
\text { * rare round clasts } \\
\text { (chalcedony) }\end{array}$ & veined rock \\
\hline & Pedernales & $\begin{array}{l}\text { brown - brownish grey - grey - } \\
\text { white }\end{array}$ & fine to moderate & * no fossils & veined rock \\
\hline $\begin{array}{c}\text { Puerto Rico } \\
\text { (Ponce Formation) }\end{array}$ & Las Palmas & $\begin{array}{l}\text { * pale brown - greyish brown - } \\
\text { grey - white } \\
\text { * dark grey } \\
\text { * yellow } \\
* \text { white pinkish/red }\end{array}$ & fine to moderate & $\begin{array}{l}* \text { no fossils } \\
* \text { iron oxides }\end{array}$ & $\begin{array}{l}* \text { large range of } \\
\text { colours } \\
* \text { varied textures } \\
\text { veined rock }\end{array}$ \\
\hline $\begin{array}{c}\text { Puerto Rico } \\
\text { (Cotui Formation) }\end{array}$ & Villa Taina & greyish brown - (light) grey - white & moderate & $*$ no fossils & $*_{\text {veined rock }}$ \\
\hline $\begin{array}{l}\text { Puerto Rico } \\
\text { (San Sebastián } \\
\text { Formation) }\end{array}$ & Moca & brown - yellowish brown - white & fine to moderate & * no fossils & clastic texture \\
\hline
\end{tabular}

Table 2.2. Macroscopic characteristics of flint and chert by source. 


\begin{tabular}{|c|c|c|c|c|c|c|c|}
\hline $\begin{array}{l}\text { Island and } \\
\text { geological } \\
\text { setting }\end{array}$ & Source & $\mathrm{N}$ & crypto-crystalline quartz matrix & carbonate & fossils & $\begin{array}{l}\text { detrital } \\
\text { minerals }\end{array}$ & other inclusions \\
\hline \multirow[t]{3}{*}{$\begin{array}{c}\text { Antigua } \\
\text { (Antigua } \\
\text { Formation) } \\
\text { (primary) }\end{array}$} & Long Island & 15 & $\begin{array}{l}\text { homogeneous fine size with larger } \\
\text { crystals }\end{array}$ & $\begin{array}{l}* \text { varied } \\
\text { concentration of } \\
\text { calcite crystals } \\
* \text { carbonate } \\
\text { fossils }\end{array}$ & $\begin{array}{l}\text { moderate } \\
\text { concentration }\end{array}$ & not visible & $\begin{array}{l}\text { *organic matter } \\
\text { *iron oxides }\end{array}$ \\
\hline & Little Cove & 11 & $\begin{array}{l}\text { homogeneous fine size with larger } \\
\text { crystals }\end{array}$ & $\begin{array}{l}* \text { varied } \\
\text { concentration of } \\
\text { calcite crystals } \\
* \text { carbonate } \\
\text { fossils }\end{array}$ & $\begin{array}{l}\text { moderate } \\
\text { concentration }\end{array}$ & not visible & $\begin{array}{l}\text { * organic matter } \\
\text { * iron oxides }\end{array}$ \\
\hline & $\begin{array}{l}\text { Soldier } \\
\text { Point }\end{array}$ & 3 & $\begin{array}{l}\text { homogeneous fine size with larger } \\
\text { crystals }\end{array}$ & $\begin{array}{l}* \text { varied } \\
\text { concentration of } \\
\text { calcite crystals } \\
* \text { carbonate } \\
\text { fossils }\end{array}$ & $\begin{array}{l}\text { moderate } \\
\text { concentration }\end{array}$ & not visible & $\begin{array}{l}* \text { organic matter } \\
* \text { iron oxides }\end{array}$ \\
\hline$\overline{\text { (secondary) }}$ & $\begin{array}{l}\text { Blackman's } \\
\text { Point }\end{array}$ & 8 & $\begin{array}{l}\text { homogeneous fine size with larger } \\
\text { crystals }\end{array}$ & $\begin{array}{l}* \text { low } \\
\text { concentration } \\
* \text { some fossils }\end{array}$ & $\begin{array}{l}\text { varying } \\
\text { concentration } \\
\text { low to high }\end{array}$ & $\overline{\text { not visible }}$ & $\begin{array}{l}* \text { organic matter } \\
* \text { iron oxides } \\
* \text { rectangular } \\
\text { voids }\end{array}$ \\
\hline & $\begin{array}{l}\text { Coconut } \\
\text { Hall }\end{array}$ & 7 & $\begin{array}{l}* \text { fine size with larger crystals } \\
* \text { very fine size } \\
* \text { veined rock with significant } \\
\text { presence of length-slow and radial } \\
\text { fibrous chalcedony and macro- } \\
\text { quartz }\end{array}$ & $\begin{array}{l}* \text { varied } \\
\text { concentration of } \\
\text { calcite and } \\
\text { carbonate } \\
\text { fossils }\end{array}$ & $\begin{array}{l}\text { varying } \\
\text { concentration } \\
\text { low to high }\end{array}$ & not visible & $\begin{array}{l}\text { * organic matter } \\
\text { * iron oxides }\end{array}$ \\
\hline $\begin{array}{c}\text { Antigua } \\
\text { (Basal } \\
\text { Volcanic Suite) }\end{array}$ & $\begin{array}{l}\text { Shirley } \\
\text { Heights }\end{array}$ & 3 & homogeneous coarse crystal size & absent & absent & not visible & - \\
\hline \multirow[t]{2}{*}{$\begin{array}{c}\text { Antigua } \\
\text { (Central Plain } \\
\text { group) }\end{array}$} & $\begin{array}{l}\text { Corbison } \\
\text { Point }\end{array}$ & 9 & $\begin{array}{l}\text { varied sizes from very fine to } \\
\text { coarse }\end{array}$ & $\begin{array}{l}* \text { varying by bed } \\
* \text { carbonate } \\
\text { fossils }\end{array}$ & $\begin{array}{l}\text { varying } \\
\text { concentration } \\
\text { low to high }\end{array}$ & not visible & $\begin{array}{l}\text { varying } \\
\text { concentrations } \\
\text { of mud }\end{array}$ \\
\hline & Dry Hill & 4 & $\begin{array}{l}\text { varied sizes from very fine to } \\
\text { coarse }\end{array}$ & $\begin{array}{l}* \text { varying by bed } \\
* \text { carbonate } \\
\text { fossils }\end{array}$ & $\begin{array}{l}\text { varying } \\
\text { concentration } \\
\text { low to high }\end{array}$ & not visible & $\begin{array}{l}\text { varying } \\
\text { concentrations } \\
\text { of mud }\end{array}$ \\
\hline $\begin{array}{l}\text { St. Kitts } \\
\text { (unknown } \\
\text { geological } \\
\text { origin) }\end{array}$ & $\begin{array}{l}\text { Great Salt } \\
\text { Pond and } \\
\text { Sugar } \\
\text { Factory Pier }\end{array}$ & 10 & homogeneous very fine size & $\begin{array}{l}* \text { low } \\
\text { concentration } \\
* \text { some carbonate } \\
\text { fossils }\end{array}$ & $\begin{array}{l}\text { low } \\
\text { concentration }\end{array}$ & not visible & organic matter \\
\hline \multirow[t]{2}{*}{$\begin{array}{l}\text { Puerto Rico } \\
\text { (Guanajibo } \\
\text { Formation) }\end{array}$} & Cerrillos & 4 & $\begin{array}{l}\text { * varied quartz sizes from very } \\
\text { fine to coarse } \\
\text { * veined rock with significant } \\
\text { presence of length slow } \\
\text { chalcedony and macro-quartz }\end{array}$ & absent & absent & not visible & iron oxides \\
\hline & Pedernales & 4 & $\begin{array}{l}* \text { homogeneous fine size } \\
* \text { veins with length slow } \\
\text { chalcedony and macro-quartz }\end{array}$ & absent & absent & not visible & - \\
\hline $\begin{array}{l}\text { Puerto Rico } \\
\text { (Ponce } \\
\text { Formation) }\end{array}$ & Las Palmas & 7 & $\begin{array}{l}* \text { varied sizes from very fine to } \\
\text { coarse } \\
* \text { significant presence of length- } \\
\text { slow and radial fibrous } \\
\text { chalcedony and macro-quartz }\end{array}$ & absent & absent & not visible & iron oxides \\
\hline $\begin{array}{l}\text { Puerto Rico } \\
\text { (Cotui } \\
\text { Formation) }\end{array}$ & Villa Taina & 4 & $\begin{array}{l}\text { * varied sizes from very fine to } \\
\text { coarse } \\
* \text { significant presence of length- } \\
\text { slow and radial fibrous } \\
\text { chalcedony and macro-quartz }\end{array}$ & absent & absent & not visible & iron oxides \\
\hline $\begin{array}{c}\text { Puerto Rico } \\
\text { (San Sebastián } \\
\text { Formation) }\end{array}$ & Moca & 3 & $\begin{array}{l}* \text { varied sizes from very fine to } \\
\text { coarse } \\
* \text { veined rock with presence of } \\
\text { radial fibrous and length-slow } \\
\text { chalcedony and macro-quartz }\end{array}$ & absent & absent & not visible & $\begin{array}{l}\text { varying } \\
\text { concentrations } \\
\text { of mud }\end{array}$ \\
\hline
\end{tabular}

Table 2.3. Microscopic characteristics of the flint and chert by source. $\mathrm{N}$ denotes the number of thin-sections analysed. 


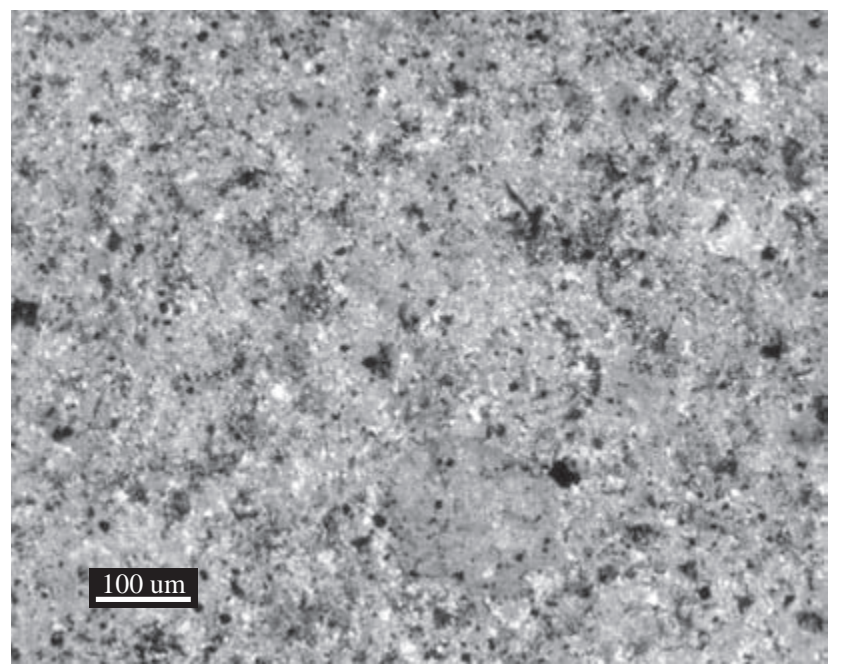

a. Long Island, flint matrix in ANLI-02 (CP).

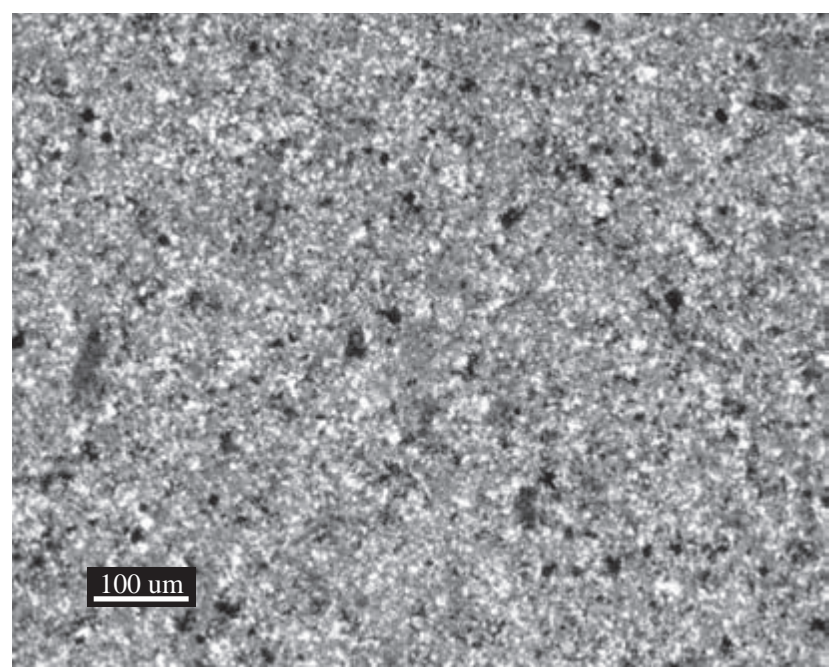

b. Long Island, flint matrix in sample ANLI-11 (CP).

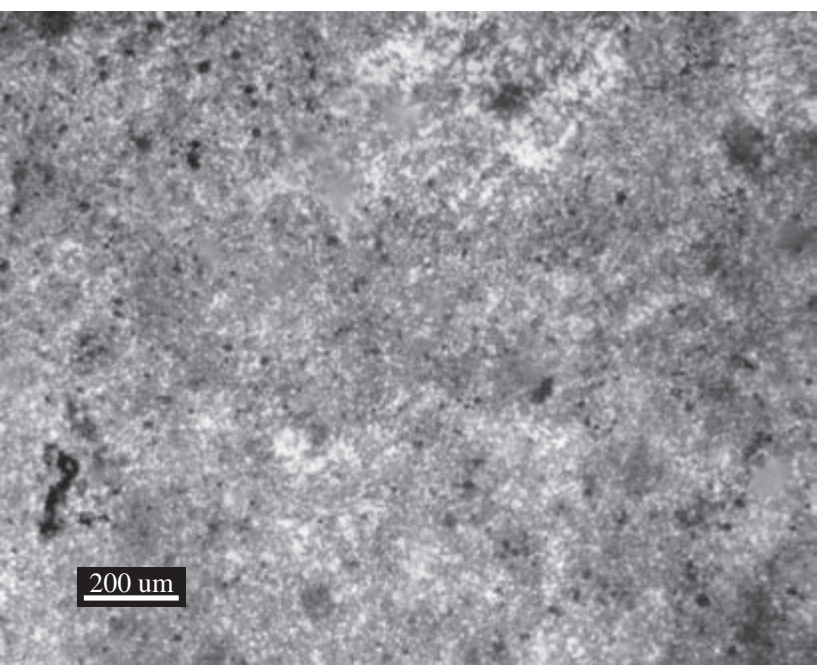

d. Soldier Point, Flint matrix in sample ANSPa-07 (CP).

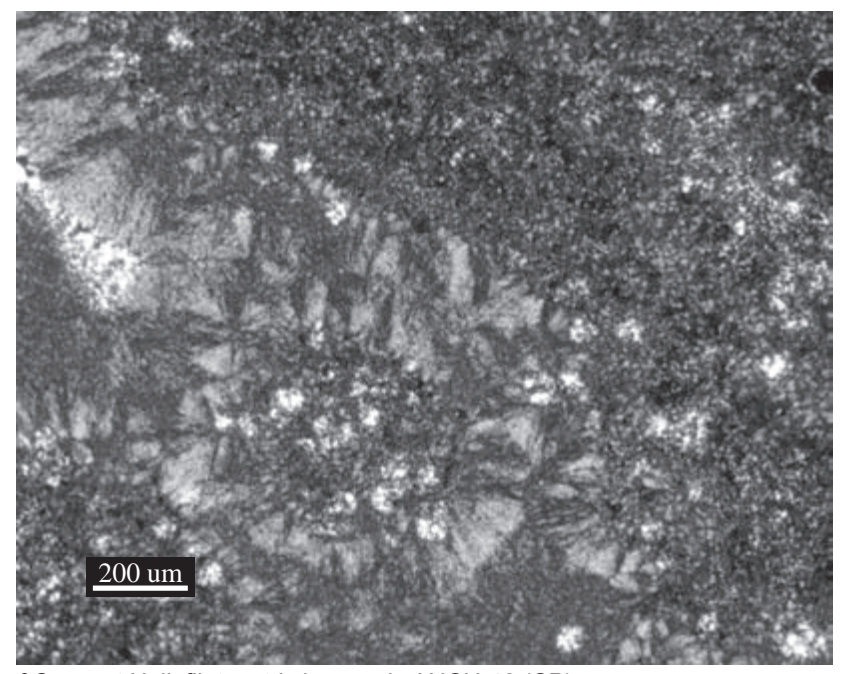

f.Coconut Hall, flint matrix in sample ANCH-42 (CP).

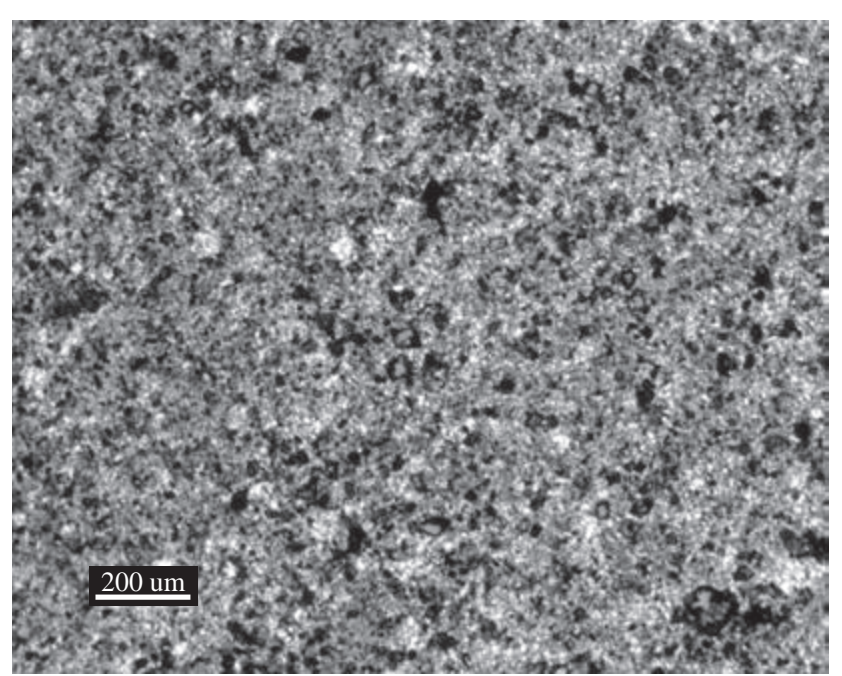

e. Blackman's Point, flint matrix in sample ANBP-01 (CP).

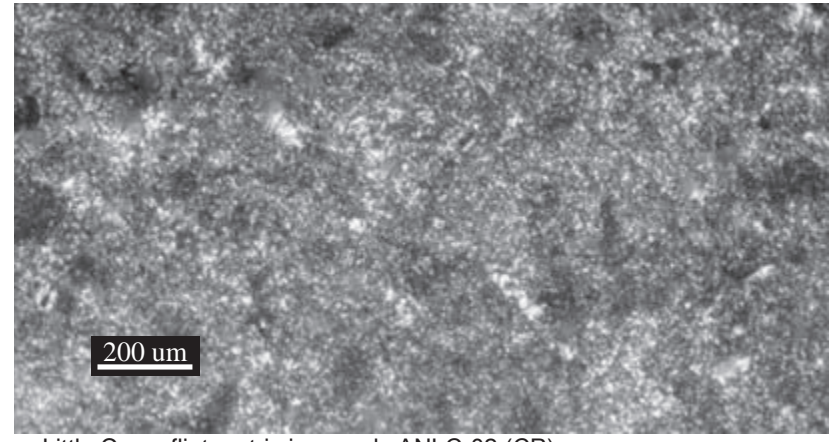

c. Little Cove, flint matrix in sample ANLC-02 (CP).

Figure 2.15. Thin-section photos of Antigua Formation flints in crossed polars (CP). 


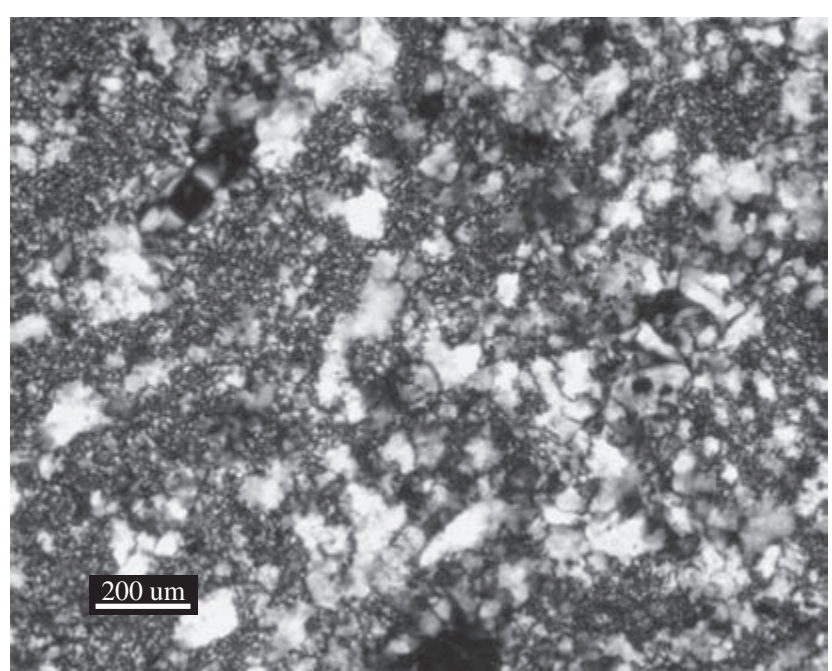

a. Shirley Height, Antigua, chert matrix in sample ANSH-01 (CP).

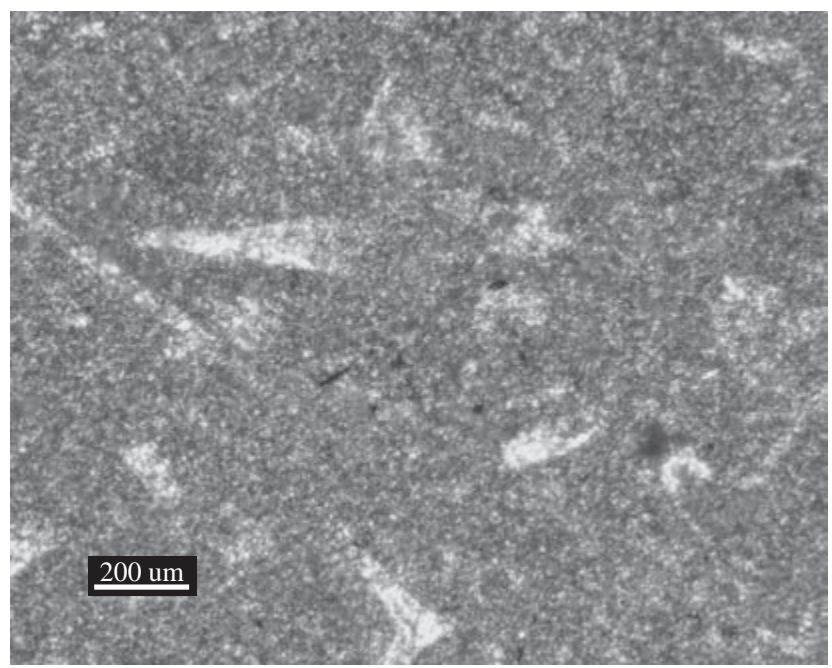

c. Dry Hill, Antigua, chert matrix in sample ANDH-12 (CP).

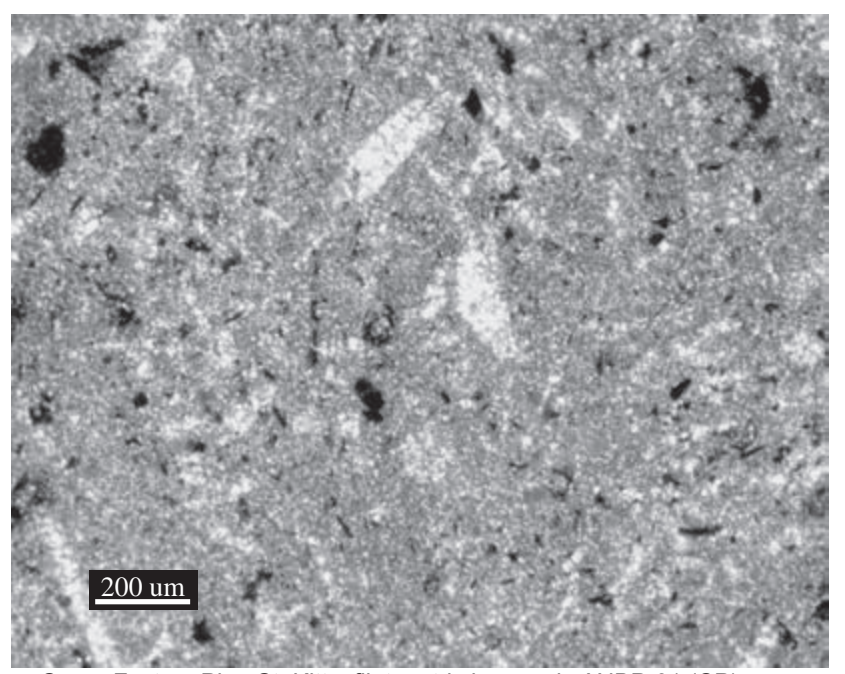

e. Sugar Factory Pier, St. Kitts, flint matrix in sample ANBP-01 (CP).

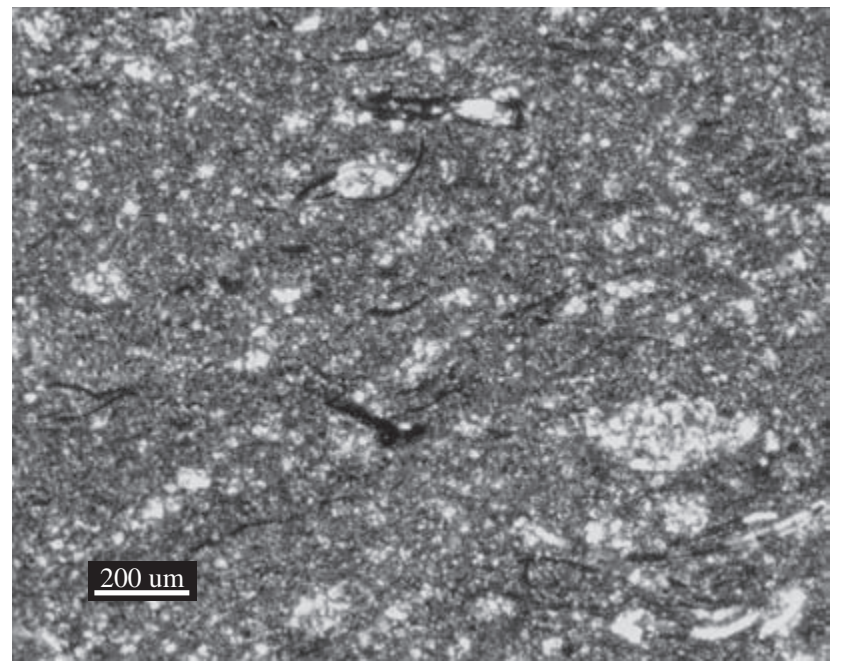

b. Corbison Point, Antigua, chert matrix in sample ANCP-05 (CP).

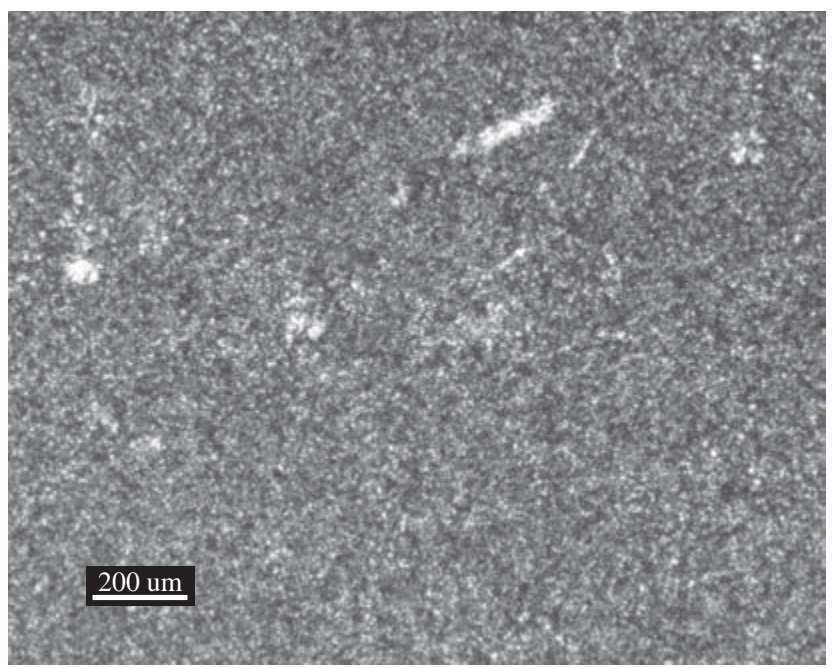

d. Sugar Factory Pier, St. Kitts, flint matrix in sample ANSPa-07 (CP).

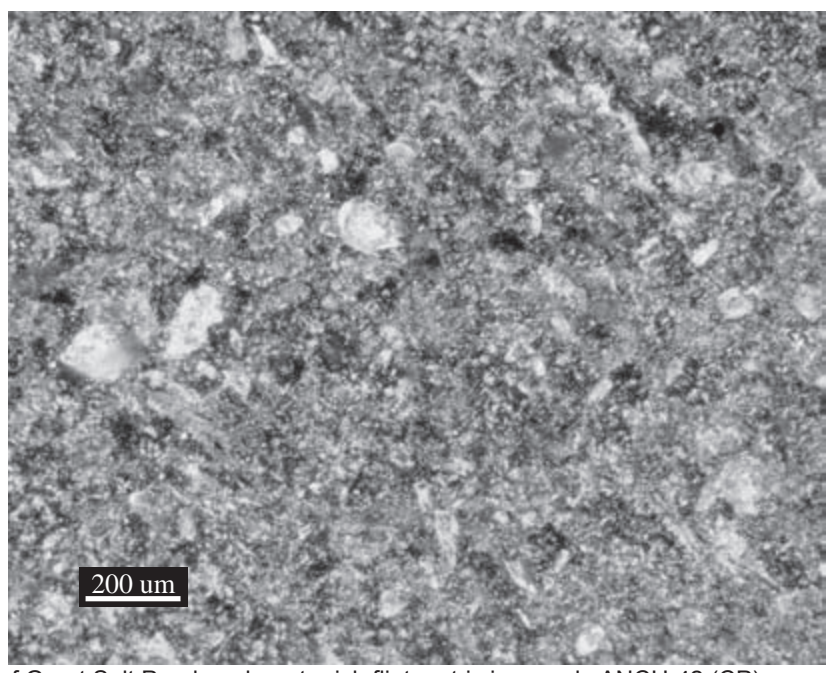

f.Great Salt Pond, carbonate rich flint matrix in sample ANCH-42 (CP).

Figure 2.16. Thin-section photos of Antigua tuff cherts and St. Kitts flints in crossed polars (CP). 


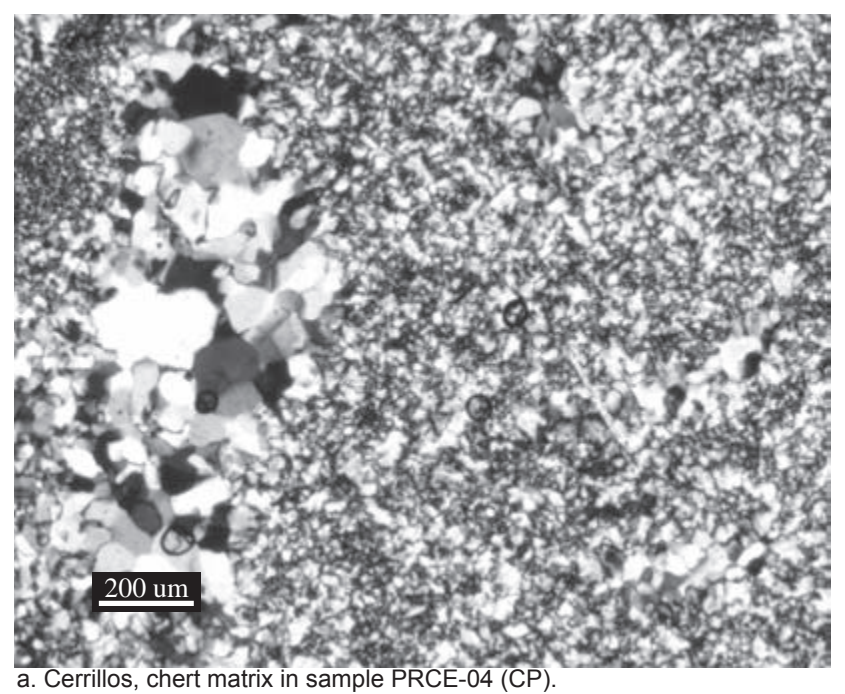

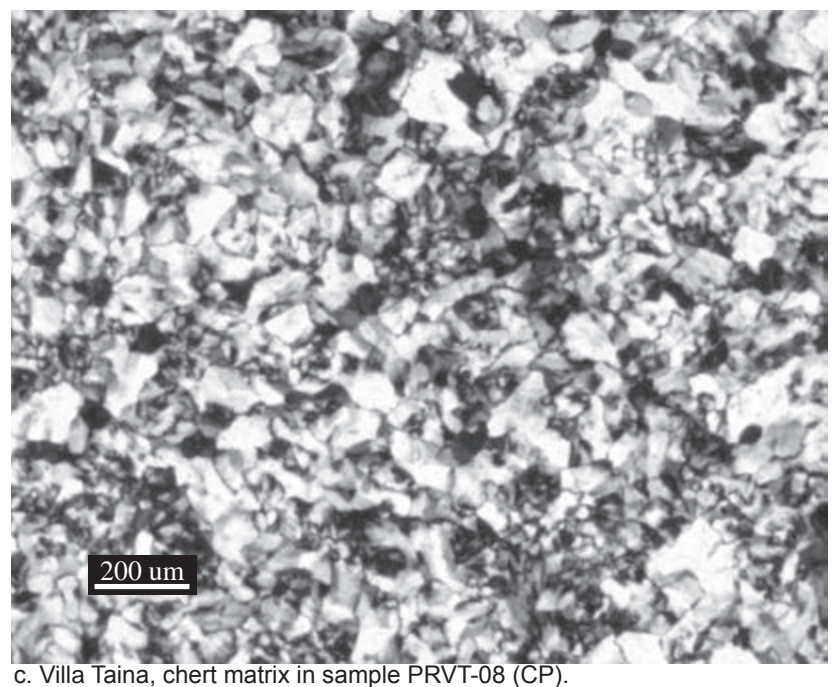

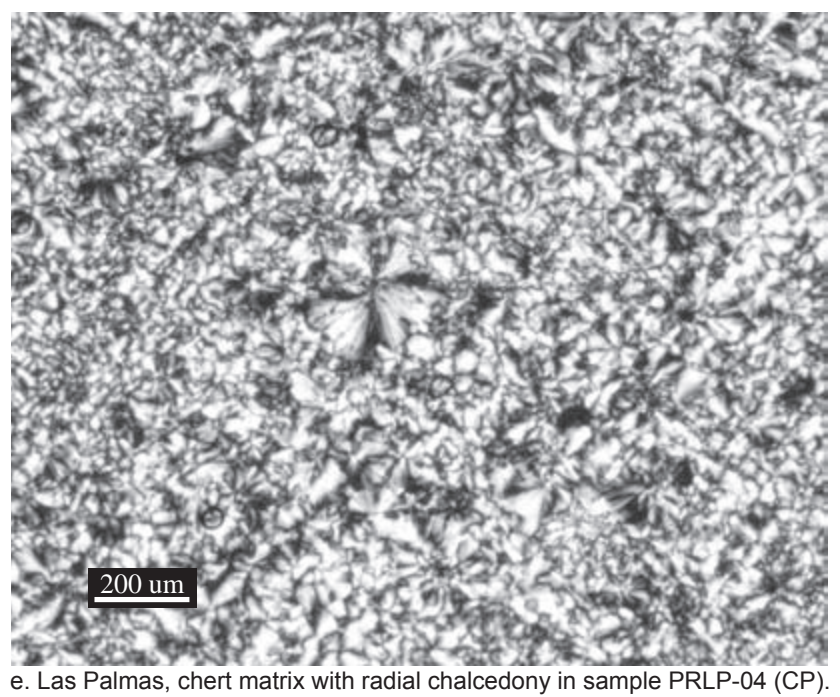

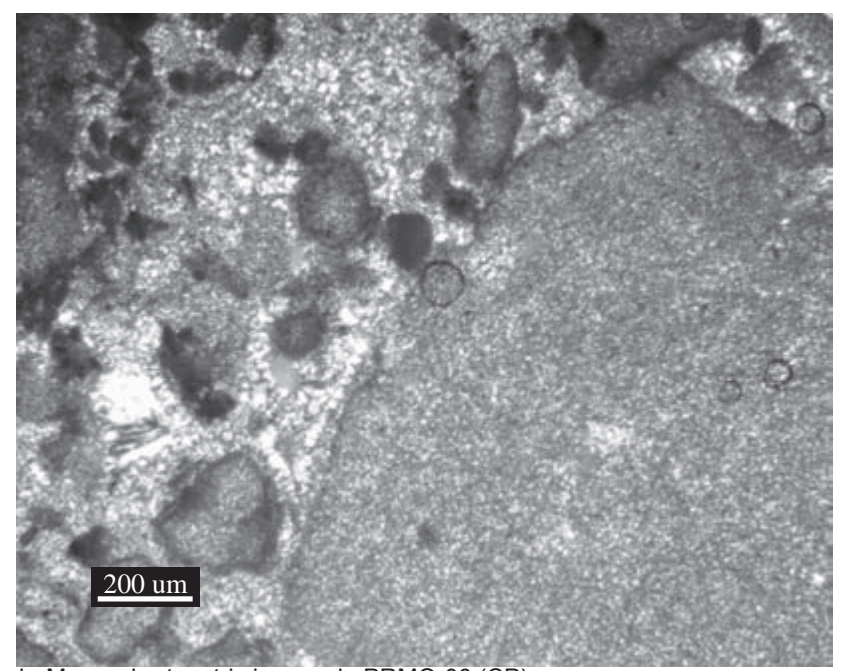

boca, chert matrix in sample PRMO-06 (CP).
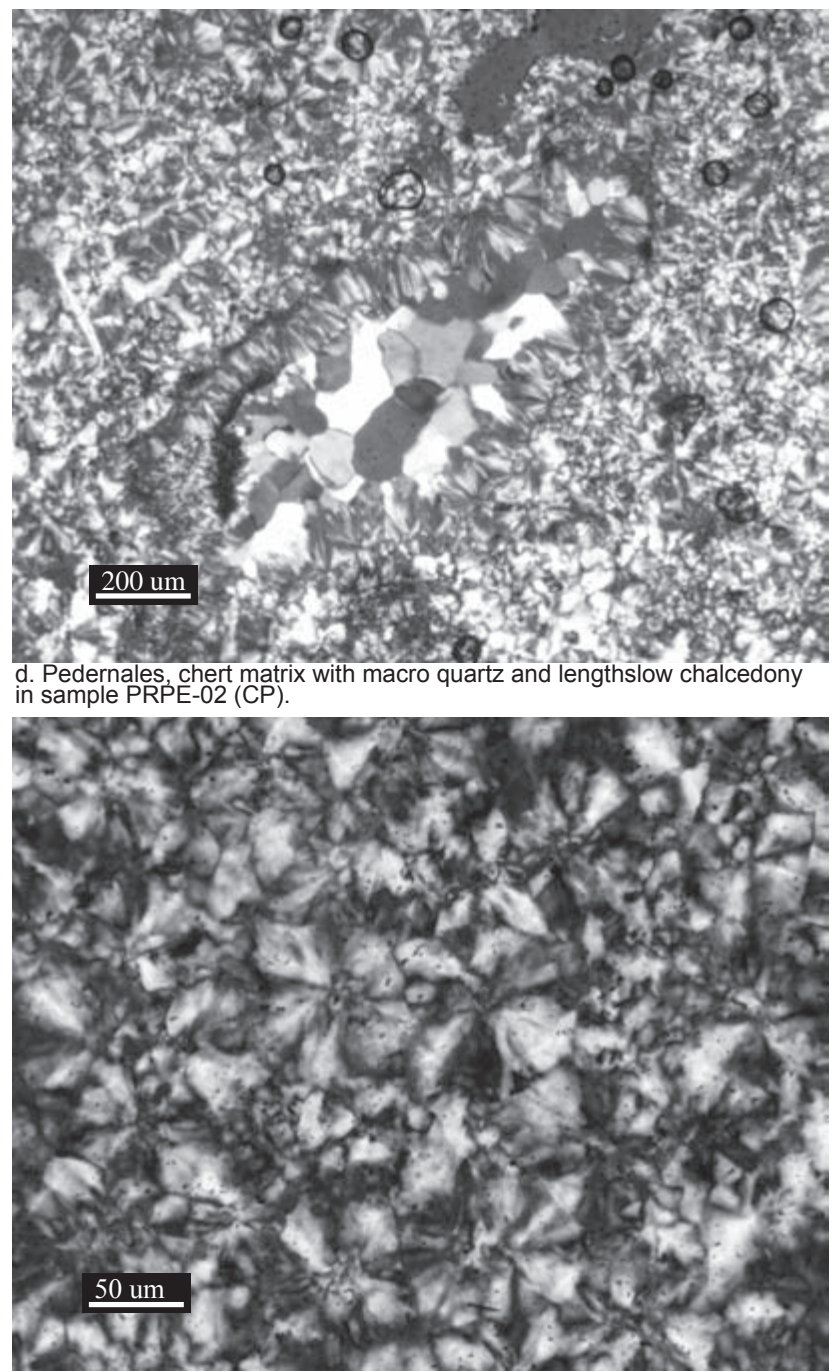

f. Las Palmas, close-up of radial chalcedony in sample PRLPa-13 (CP).

Figure 2.17. Thin-section photos of Puerto Rican cherts in crossed polars (CP). 
is generally darker and grain-size is finer. Furthermore, the flint displays a haze of fine calcite particles in its matrix, which makes it different from the other Antigua Formation flints. These differences may be explained by the fact that primary flint at Long Island is predominantly found in another form (around U-shaped burrow tubes; see figure 2.9) and within another limestone deposit than the Antigua flints mentioned above (see Appendix A). One primary outcrop on Long Island, however, is present in nodule form as well, and more closely resembles these other flints.

Contrary to the primary Antigua Formation flints, the same flint type from a secondary context displays much more variation. In particular, flint from Long Island, as well as material from the exclusive secondary sources of Blackman's Point and Coconut Hall, had experienced clear macroscopic change in colour, as well as grain-size as a result of weathering. Change has also been noted for the Little Cove and Soldier Point flints. However, here it has less significant implications, as the secondary flints solely exhibit lighter hues within the same colour range. Flint at Blackman's Point and Coconut Hall also has varying grain-sizes, including coarser varieties not encountered among the other Antigua Formation sources. Among the Blackman's Point flint, the influence of weathering is clearly visible under the microscope. Generally, this flint type has a very low calcite contents. Original calcite in the matrix has been lost as a result of dissolution, making the flint porous and therefore, giving it a lighter colour. At Coconut Hall, the flint matrix displays additional features not encountered among the other Antigua Formation flints. Some of the samples possess veined areas in which the quartz crystal size and type is different. This differentiation suggests multiple episodes of silification. Similar veined areas are present among some of the Puerto Rican cherts as well. Both groups also share the occurrence of a radial fibrous type of chalcedony (see Schubel \& Simonson 1990 for a similar example), in which chalcedony building occurs from a centre point, in contrast to length-slow chalcedony, in which chalcedony growth is along a boundary. The presence of these features in the Coconut Hall flint is not fully understood. It is at least clear that the formation of this flint underwent a slightly different trajectory than the other Antigua Formation flints.

The tuff cherts from Antigua can be divided into two groups: (1) the cherts formed in calcareous tuff at Corbison Point and Dry Hill; and (2) the cherts formed in non-calcareous tuff at Shirley Heights. The latter type is clearly distinguishable by its light grey to almost white colour, a feature rarely found among the other chert and flint sources. Furthermore it does not contain visible inclusions, unlike the other tuff cherts, which in some cases display clear fossils. Therefore, these fossil rich tuff cherts in some way resemble the flints from Antigua. In the first place, their dark grey brown colour is much more similar to the Antigua flints. In the second place, the presence of fossils resembles the flints as well, although it has to be remarked that fossil types differ. Close intra-source comparison of the Corbison Point locality in particular shows that the different beds exposed at this rock point vary. In combination with the chemical data, four subvarieties, each corresponding with a single bed can be distinguished. These are (A) a pure quartz chert without inclusions, (B) a bioclast rich and carbonate poor chert, (C) a bioclast rich and carbonate rich chert, and (D) a dirty bioclast poor chert, much resembling some of the Antigua Formation flints. Chert at Dry Hill is only similar to two out of these four varieties. Analogous to the Little Cove and Soldier Point flints, secondary chert at the cobble beaches of Corbison Point and Dry Hill, has turned lighter in colour.

Flint from St. Kitts clearly possesses features, that suggest its formation within limestone host-rock. First of all, many of the samples display the presence of fossils. Second of all, microscopic analysis confirmed the presence of calcite. These two features were both found among the material from the two sampled localities. The detailed analysis of this material also revealed that material from both localities is to be considered the same. Flint from both sources displays the same colour range, grain-size, and clast contents. This similarity is confirmed by the chemical data. This suggests that flint on St. Kitts originates from the same geological setting.

Compared to the Antigua cherts and flints, as well as the Puerto Rico cherts, the flint from St. Kitts is clearly distinguishable by its fine crystalline texture, as seen under the microscope. All samples exhibit a very fine homogeneous matrix, which is different from the other cherts within this research, which generally possess a broader range of grain-sizes, giving the rocks a varied appearance under the microscope.

Cherts from the different sources in Puerto Rico for their part display considerable intra-source variation, probably owing to their exclusive secondary nature in which weathering must have had a significant effect. This is in the first place clearly evidenced by the broad range of colours encountered, which generally lie in the red to reddish brown to light brown hue types.

Also, on a microscopic level variation is notable. The chert matrix differs a lot. Many samples are built up by quartz, which is larger in crystal size than most of the other sources within the study. Only Shirley Heights chert from Antigua possesses a similarly large crystal size. Many samples are veined as well, in which vein filling is different from the surrounding matrix. In most cases, macro-quartz fills these veins, surrounded by a chalcedony rim, which marks the 
boundary between matrix and vein filling. In some cases, veins are either completely filled with chalcedony or very fine quartz similar to the St. Kitts matrix. As in the Coconut Hall flints, these veins represent later phases of silification compared to the matrix. In addition to these types of quartz, the radial fibrous type of chalcedony, also present within the Coconut Hall flint, was identified (see above).

Comparing the different chert sources, it can be noted that despite the intra-source variation the cherts from the different localities share a number of features. These include: (a) absence of bioclasts, (b) absence of detrital litho-casts, (c) absence of calcite, and (d) a variable chert matrix, including veins or areas, which had been silicified during a later phase of silicification. Furthermore, a large portion displays the influence of iron staining and oxidation. The structural absence of bioclasts and calcite indicate that the cherts are not true flints similar to the Antigua Formation and St. Kitts ones, in which quartz has replaced original carbonate host-rock. Still the data at present are inconclusive to fully understand the formation and presence of chert at these different localities. Future research should focus on the identification of any primary deposits of chert in close vicinity to the different scatters.

\subsection{CHEMICAL CHARACTERISATION}

\subsubsection{Introduction}

In this section, I will highlight and explain some of the differences between the chert varieties that were encountered during this research. The aim here is to understand why chert localities vary. In general, it can be stated that variation among chert sources may be caused by the difference in the processes that are associated with its formation and its post-formational history. Chert formation in all its different forms is not fully understood. However, it is generally agreed that it represents a replacement of the original host-rock. Therefore, differences in composition can be a result of the variation in original sediment/host-rock, which may vary in time and space (Bush \& Sieveking 1986).

The post-formational history relates to all processes that operated on the rock after its formation, and mainly can be summarised under the name "weathering". Weathering may primarily vary, depending on the type of soil and agents occurring in the soil (e.g., plants), as well on the atmospheric conditions under which and time period during which a rock has been exposed to these processes. The subject of weathering is of primary interest as many of the sources in this study are secondary in nature. In some cases, this has resulted in clearly distinct looking cherts. Others have already shown that secondary material may differ from primary material in macroscopic, microscopic, as well as chemical features (Lavin \& Prothero 1992).

1) Environment of formation

a. type of host-rock (carbonate/tuff/volcanic)

i. time (layer/formation)

ii. place (location within layer/formation)

2) Environment of weathering

a. type of soil/surface (carbonate soils/tropical ferric soils/clayey soils/beach environment)

b. atmospheric condition (climate)

i. speed - time (period of exposure to weathering)

\subsubsection{Origin of the trace-elements}

Chert rocks almost exclusively consist of quartz, in micro- to crypto-crystalline form. This means that silicon $(\mathrm{Si})$ and oxygen (O) atoms mainly make up the rock. They usually account for more than $95 \%$ of the total constituents agents. Other elements may occur in minor amounts, however. Usually the variation of the concentration of these trace-elements provides the basis on which sources can be distinguished. Therefore, major attention needs to be devoted to the understanding of the traceelement composition of the different cherts. Earlier work has summarised the following main fractions in which the traceelements, used in this study, can occur (Bush \& Sieveking 1986; Cowell 1981; Kars et al. 1990; Luedtke 1992): 
1) As impurities (cations) within the quartz structure. Usually this is in very low concentrations. Major portions of $\mathrm{Li}$ and $\mathrm{Cr}$ may be attributed to this fraction, but also minor amounts of $\mathrm{K}, \mathrm{Al}$, and $\mathrm{Na}$.

2) Within the remaining relics of the original host-rock, e.g., carbonate, which has not been replaced. Primary elements associated with a carbonate fraction are $\mathrm{Ca}, \mathrm{Mg}$, and $\mathrm{Sr}$.

3) Within rock-forming minerals with a terrestrial or marine authigenic origin, e.g., clays, tuffs, detrital minerals. This fraction is responsible for the main portion of the trace elements such as $\mathrm{Al}, \mathrm{K}, \mathrm{Ti}$, and $\mathrm{Cr}$, but also for minor portions of Fe, $\mathrm{Ca}, \mathrm{Mg}, \mathrm{Sr}$, and $\mathrm{Na}$.

4) In iron minerals, e.g., pyrite. Fe, Mn, and $\mathrm{S}$

5) Within organic material, $S$

6) As salts in the remaining interstitial water. This is the main origin for $\mathrm{Na}$.

Apart from carbonate material, which can be present in significant amounts within flints (nodular cherts formed in limestone) (Kars et al. 1993), resulting in high $\mathrm{Ca}, \mathrm{Mg}$, and $\mathrm{Sr}$ concentrations, the main origin of most of the other trace-elements in cherts are clay-minerals or other fine (detrital) rock-minerals. These minerals may have different origins. They may be terrestrial, i.e. tuffs or the products of weathered rock, transported to the sea by rivers, or by volcanic or eolian processes. Alternatively, they may be clay minerals that have an authigenic marine origin (Weaver 1989). Usually, authigenic marine clay minerals are formed from available terrestrial minerals, which are changed in structure as a result of the difference in chemistry between fresh water and the newly encountered saline marine environment (Weaver 1989).

With regard to the terrestrial origin of the clay mineral suite, a nearby volcanic origin was probably of more influence than a distant eolian transport in case of the islands of Antigua and St. Kitts. ${ }^{7}$ This in particular accounts for the Antigua cherts formed in tuffs. As a consequence, this means that the type of clay-minerals formed must be related to the igneous rock that became exposed to weathering.

Igneous rock in Antigua and St. Kitts are both calc-alkaline in nature. These have low K, moderate Fe and Mg, and high $\mathrm{Al}$ contents. The most common clay mineral formed as a weathering product is a smectite, an Al-rich silicate with small amounts of $\mathrm{Fe}$ and $\mathrm{Mg}$ (Weaver 1989). This is a frequently encountered clay mineral within igneous rock regions. The fact that Weiss (1994) reports smectitic clay deposits on Antigua confirms this hypothesis. If this smectite is transported to the sea, a change in composition will occur when it reaches the new saline environment. As a result of the change in water chemistry, the smectite will incorporate $\mathrm{K}$ and $\mathrm{Mg}$, which are more available in marine waters, into their expanded layers (Weaver 1989). Illites and chlorites are likely to be formed then. This means that the clay mineral suite associated with the igneous origin of both islands will most likely consist of a mixture of smectite, derived illite, and derived chlorite.

In addition to these minerals, a common clay-mineral in sedimentary rocks is glauconite. It can form authigenically in marine environments where it is found in different forms, as fecal pellets from filter feeding organisms, as internal molds or casts of carbonate microfossils, and as biogenic carbonate debris. Comparing the structure and chemistry, it can be noted that glauconites are 2:1 layer clay-minerals, similar to smectites and illites. In fact, it can be considered as a Fe-rich illite or mica (Weaver 1989).

When it is formed authigenically in seawater, generally it can be said that the $\mathrm{Al}$ and Si may be derived from other clay-minerals, e.g., fecal pellets or detrital clays. First, Fe is incorporated, then K. As glauconite is actually a rich Fe-mica (illite), this might suggest that it formed either from available illite (see above) by only incorporating Fe, or that it may have formed from smectite by incorporating Fe and $\mathrm{K}$.

From this it can be outlined that a high detrital terrestrial input will result in relative high amount of smectite. In contrast, significant marine influence on the mineral suite will produce high amounts of illite, chlorite, and glauconite. Translated to the trace-element chemistry of the cherts, this means that relatively high terrestrial input results in a high concentration of $\mathrm{Al}$ with respect to $\mathrm{K}, \mathrm{Mg}$ and $\mathrm{Fe}$, whereas a high marine derived input will either result in relatively high $\mathrm{K}$, $\mathrm{Mg}$, and $\mathrm{Fe}$, depending on the type of mineral present.

Considering the fact that significant amounts of $\mathrm{Mg}$ and $\mathrm{Fe}$ can originate from fractions other than a clay-mineral one, respectively carbonates $(\mathrm{Mg})$ and iron minerals in the form of pyrite $(\mathrm{Fe})$, these two elements form poor indicators of clay-mineral presence. Therefore, major attention will be devoted to the Al-and-K-comparison.

\footnotetext{
7 Due to the unclear relation between the Puerto Rican cherts and their environment of formation, a discussion of the terrestrial and authigenic origin of the elements will not be included for this island.
} 


\subsubsection{Weathering}

Once rock formations erode and cherts are exposed to oxidizing conditions, they become subject to weathering. Weathering will be of significant influence from the moment they are totally eroded out of their bedrock. With regard to the weathering that can alter a rock, Brownlow (1979) considers the five following principle reactions:

1) (dis)solution

2) hydrolysis

3) ion-exchange

4) oxidation

5) organic reactions

From these, dissolution is of main concern to this research, since it represents the reaction by which relatively resistant quartz is lost following the equation.

$\mathrm{Si}_{2} \mathrm{O}+2 \mathrm{H}_{2} \mathrm{O} \rightarrow \mathrm{H}_{4} \mathrm{SiO}_{4}$

This process only occurs very slowly under neutral or high $\mathrm{pH}$. The dissolution rate of quartz under these conditions does not exceed $10 \mathrm{ppm}$. If the $\mathrm{pH}$, however, rises above 9, the dissolution of quartz displays a very steep increase, as result of the dissociation of silicic acid.

$\mathrm{H}_{4} \mathrm{SiO}_{4} \rightarrow \mathrm{H}^{+}+\mathrm{H}_{3} \mathrm{SiO}_{4}^{-}$

Röttlander (1975a, b, 1989) also found out that certain humic acids, containing a (1,2-dihydroxidebenzene) group, more easily dissolve quartz than would be expected on the basis of this behaviour, even under decreasing $\mathrm{pH}$ conditions.

Calcite, one of the important minor constituents of flint, is lost as well by dissolution. This mineral relatively easily dissolves in nature as a result of the presence of dissolved carbon dioxide in most waters. The dissolution rate increases with low $\mathrm{pH}$.

$\mathrm{CaCO}_{3}+\mathrm{H}_{2} \mathrm{CO}_{3} \rightarrow 2 \mathrm{HCO}_{3}^{-}+\mathrm{Ca}^{2+}$

It should be noted that at low $\mathrm{pH}$ silica precipitates and carbonate dissolves, explaining the replacement of carbonate by silica, in particular upon exposure to carbon-dioxide rich rainwater and groundwater in contact with oxidising organic matter.

Other weathering reactions that may occur are oxidation and to a lesser extent, hydrolysis. The primary oxidation reactions mainly involve iron or manganese in flints and cherts. Pyrite, for example, is oxidized by the following reaction:

$4 \mathrm{FeS}_{2}+15 \mathrm{O}_{2}+8 \mathrm{H}_{2} \mathrm{O} \rightarrow 2 \mathrm{Fe}_{2} \mathrm{O}_{3}+8 \mathrm{SO}_{4}^{2-}+16 \mathrm{H}^{+}$

The resulting agents are a very insoluble ferric oxide and a soluble sulphate. The ferric oxide gives the typical red-brown colour to the rock.

\subsubsection{Results}

\section{Introduction}

Considering the chert sources within the northern Lesser Antilles and Puerto Rico, table 2.4 summarizes the different variables for the different localities. The reader is referred to Appendix $\mathrm{C}$ for a complete list of all concentration values found within the different samples. Basically, two types of host-rock occur among the sources: (a) limestone and (b) tuff, with some localities being formed in a mixture of the two, e.g., Corbison Point and Dry Hill. For the sources formed within a similar host-rock, the limestone flints can be divided into the Antigua Formation flints and the St. Kitts flints, both groups of sources being formed within different geological formations. Unfortunately, the exact nature of the original carbonate host-rock of the St. Kitts remains unclear. Among the tuff cherts, localities can be found within the Basal Volcanic Suite and the Central 


\begin{tabular}{|c|c|c|c|c|}
\hline Island & Source Locality & $\begin{array}{l}\text { Type of (original) } \\
\text { hostrock }\end{array}$ & Type of occurrence & Weathering environment \\
\hline \multirow{6}{*}{ Antigua } & Little Cove (LC) & Limestone & primary, secondary & beach \\
\hline & Soldier Point (SP) & Limestone & primary, secondary & beach \\
\hline & Blackman's Point (BP) & Limestone & secondary, tertiary & beach and soil \\
\hline & Shirley Heights (SH) & Tuff & primary, secondary & soil \\
\hline & Corbison Point (CP) & Carboneous Tuff & primary, secondary & beach \\
\hline & Dry Hill (DH) & Carboneous Tuff & primary, secondary & beach \\
\hline \multirow[t]{5}{*}{ Puerto Rico } & Cerrillos (CE) & Limestone? & secondary, tertiary & soil \\
\hline & Pedernales (PE) & Limestone? & secondary & soil \\
\hline & Las Palmas (LP) & Limestone? & secondary, tertiary & soil \\
\hline & Villa Taina (VT) & Limestone? & secondary & soil \\
\hline & Moca (MO) & Conglomerrate? & secondary, tertiary & soil \\
\hline
\end{tabular}

Table 2.4. Weathering environment at 15 different Caribbean chert and flint sources.

Plain Group on Antigua. Within the latter geological formation, tuffs vary in their carbonate contents. Uncertainties relating to the original host-rock exist only for the Puerto Rican cherts.

At a number of the localities in this study, primary deposits co-occurred alongside secondary ones. They will be called primary sources hereafter. Only the already mentioned Puerto Rico localities, the St. Kitts ones as well as the Coconut Hall and Blackman's Point scatters are completely secondary in nature. That is, at these localities secondary material is the only material readily available. They will be referred to as secondary sources. This means that at all localities rocks have been exposed to weathering. Only the "primary" sources provide the opportunity to compare relatively little weathered primary material ${ }^{8}$ with more weathered secondary material.

In agreement with what would be expected, variation among cherts is smallest if they originate from a similar host-rock, within a similar geological formation (tables 2.5-9; figures 2.18-20). Variation between different host-rock cherts is more evident. The results also show that weathering may have a very significant effect on the original trace-element composition, severely altering the existing values and as a consequence, increasing intra-source variability, but also intersource variability in some cases. This is particularly noticed for cherts that have exposed to weathering for a considerable period.

\section{Antigua Formation flints}

The Antigua Formation flints, in particular, provide good opportunities to study the variability among localities originating from a similar geological formation, as well as the effects weathering has on the flints. Primary rock samples originating from different localities can be compared. Furthermore, for some localities primary samples can be compared with secondary

${ }^{8}$ Primary material may have undergone some weathering in the form of oxidation. However, this will have changed the chemical composition of the rock only very slightly. 


\begin{tabular}{|c|c|c|c|c|c|c|c|c|c|c|c|c|c|}
\hline \multirow[b]{2}{*}{ Sources } & \multirow[b]{2}{*}{$\mathrm{N}$} & \multicolumn{3}{|c|}{$\mathrm{Al}$} & \multicolumn{3}{|c|}{ K } & \multicolumn{3}{|c|}{$\mathrm{Na}$} & \multicolumn{3}{|c|}{$\mathrm{Ti}$} \\
\hline & & mean & sd & $\overline{\mathrm{RSD}}$ & mean & sd & $\overline{\mathrm{RSD}}$ & mean & $\mathrm{sd}$ & $\overline{\mathrm{RSD}}$ & mean & $\mathrm{sd}$ & RSD \\
\hline Long Island & 21 & 1590.26 & 309.16 & 19.44 & 494.38 & 83.91 & 16.97 & 924.45 & 193.47 & 20.93 & 66.74 & 13.58 & 20.34 \\
\hline Little Cove & 13 & 1117.03 & 282.40 & 25.28 & 329.72 & 80.49 & 24.41 & 768.01 & 265.65 & 34.59 & 35.17 & 10.33 & 29.38 \\
\hline Soldier Point & 10 & 876.76 & 167.66 & 19.12 & 289.94 & 66.17 & 22.82 & 604.20 & 147.73 & 24.45 & 33.40 & 9.91 & 29.68 \\
\hline Blackman's Point & 12 & 519.19 & 219.43 & 42.26 & 127.80 & 80.33 & 62.86 & 400.13 & 328.06 & 81.99 & 17.19 & 9.60 & 55.85 \\
\hline Coconut Hall & 11 & 335.82 & 162.67 & 48.44 & 106.59 & 42.38 & 39.76 & 155.33 & 60.74 & 39.10 & 27.99 & 49.53 & 176.97 \\
\hline Corbison Point & 7 & 880.42 & 790.06 & 89.74 & 196.07 & 158.77 & 80.98 & 489.74 & 405.90 & 82.88 & 59.03 & 41.63 & 70.52 \\
\hline Dry Hill & 13 & 309.54 & 122.32 & 39.52 & 84.63 & 46.61 & 55.07 & 491.16 & 184.68 & 37.60 & 13.01 & 7.20 & 55.33 \\
\hline Shirley Heights & 9 & 1716.62 & 1301.74 & 75.83 & 336.70 & 191.86 & 56.98 & 329.30 & 161.83 & 49.14 & 75.41 & 68.33 & 90.61 \\
\hline Cerillo & 13 & 287.10 & 147.98 & 51.54 & 58.30 & 26.41 & 45.29 & 61.07 & 32.58 & 53.35 & 9.29 & 5.74 & 61.83 \\
\hline Las Palmas & 8 & 141.13 & 100.37 & 71.12 & 79.74 & 41.32 & 51.82 & 113.21 & 63.79 & 56.34 & 5.83 & 8.98 & 154.17 \\
\hline Pedernales & 6 & 214.62 & 72.69 & 33.87 & 111.79 & 71.35 & 63.82 & 103.98 & 67.38 & 64.80 & 10.70 & 7.87 & 73.56 \\
\hline Villa Taina & 11 & 284.64 & 114.44 & 40.20 & 48.20 & 20.64 & 42.83 & 99.97 & 23.62 & 23.63 & 4.51 & 2.63 & 58.27 \\
\hline Moca & 8 & 281.20 & 240.16 & 85.40 & 113.50 & 78.30 & 68.98 & 165.93 & 97.25 & 58.61 & 14.12 & 17.19 & 121.76 \\
\hline St. Kitts & 15 & 471.04 & 208.91 & 44.35 & 272.06 & 86.96 & 31.96 & 574.71 & 180.21 & 31.36 & 16.92 & 8.95 & 52.92 \\
\hline
\end{tabular}

Table 2.5. Average values $(\mathrm{mg} / \mathrm{kg}(\mathrm{ppm}))$, standard deviations $(\mathrm{mg} / \mathrm{kg}(\mathrm{ppm}))$, and relative standard deviations (RSD) of trace-element concentrations within Caribbean flints and cherts by source.

\begin{tabular}{|c|c|c|c|c|c|c|c|c|c|c|c|c|c|}
\hline \multirow[b]{2}{*}{ Sources } & \multirow[b]{2}{*}{$\mathrm{N}$} & \multicolumn{3}{|c|}{$\mathrm{Li}$} & \multicolumn{3}{|c|}{$\mathrm{Cr}$} & \multicolumn{3}{|c|}{$\mathrm{Fe}$} & \multicolumn{3}{|c|}{$\mathrm{Mn}$} \\
\hline & & mean & sd & RSD & mean & sd & RSD & mean & sd & RSD & mean & sd & RSD \\
\hline Long Island & 21 & 13.88 & 2.67 & 19.20 & 6.72 & 1.53 & 22.80 & 459.60 & 190.10 & 41.36 & 2.76 & 2.51 & 90.96 \\
\hline Little Cove & 13 & 13.68 & 4.21 & 30.79 & 4.47 & 1.09 & 24.34 & 204.38 & 110.46 & 54.05 & 0.69 & 0.28 & 40.77 \\
\hline Soldier Point & 10 & 11.29 & 1.63 & 14.45 & 3.48 & 0.80 & 22.99 & 234.22 & 69.83 & 29.81 & 1.32 & 0.64 & 48.26 \\
\hline Blackman's Point & 12 & 10.46 & 6.02 & 57.54 & 4.57 & 1.13 & 24.66 & 1126.81 & 1278.08 & 113.43 & 6.12 & 8.59 & 140.28 \\
\hline Coconut Hall & 11 & 3.49 & 3.18 & 91.16 & 4.05 & 1.85 & 45.79 & 788.75 & 617.49 & 78.29 & 41.44 & 123.99 & 299.20 \\
\hline Corbison Point & 7 & 14.84 & 11.76 & 79.28 & 1.40 & 0.43 & 31.02 & 401.97 & 873.94 & 217.41 & 3.55 & 3.61 & 101.67 \\
\hline Dry Hill & 13 & 4.96 & 4.06 & 81.92 & - & - & - & 647.77 & 457.07 & 70.56 & 25.82 & 54.07 & 209.44 \\
\hline Shirley Heights & 9 & 6.76 & 4.40 & 65.11 & 5.42 & 3.34 & 61.53 & 1370.41 & 2159.52 & 157.58 & 166.08 & 295.16 & 177.73 \\
\hline Cerillo & 13 & 6.40 & 6.39 & 99.87 & 47.27 & 51.48 & 108.92 & 1498.80 & 1519.24 & 101.36 & 7.95 & 4.92 & 61.93 \\
\hline Las Palmas & 8 & 1.67 & 1.03 & 61.80 & 19.73 & 21.70 & 109.97 & 3062.67 & 3462.91 & 113.07 & 32.04 & 52.85 & 164.96 \\
\hline Pedernales & 6 & 2.55 & 1.21 & 47.53 & 7.55 & 7.64 & 101.11 & 1825.92 & 1048.16 & 57.40 & 16.61 & 10.27 & 61.85 \\
\hline Villa Taina & 11 & 4.68 & 2.89 & 61.70 & 22.29 & 10.10 & 45.32 & 730.94 & 1200.80 & 164.28 & 6.67 & 11.78 & 176.68 \\
\hline Моса & 8 & 8.14 & 3.23 & 39.69 & 14.40 & 16.30 & 113.21 & 226.91 & 123.30 & 54.34 & 2.25 & 1.77 & 78.68 \\
\hline St. Kitts & 15 & 3.73 & 3.47 & 93.05 & 14.01 & 40.57 & 289.54 & 309.52 & 322.99 & 104.35 & 3.99 & 5.43 & 136.16 \\
\hline
\end{tabular}

Table 2.6. Average values $(\mathrm{mg} / \mathrm{kg}(\mathrm{ppm}))$, standard deviations $(\mathrm{mg} / \mathrm{kg}(\mathrm{ppm}))$, and relative standard deviations (RSD) of trace-element concentrations within Caribbean flints and cherts by source. 


\begin{tabular}{|c|c|c|c|c|c|c|c|c|c|c|c|c|c|}
\hline \multirow[b]{2}{*}{ Sources } & \multirow[b]{2}{*}{$\mathrm{N}$} & \multicolumn{3}{|c|}{ S } & \multicolumn{3}{|c|}{$\mathrm{Al} / \mathrm{K}$} & \multicolumn{3}{|c|}{$\mathrm{Al} / \mathrm{Fe}$} & \multicolumn{3}{|c|}{$\mathrm{Al} / \mathrm{Li}$} \\
\hline & & mean & sd & RSD & mean & $\mathrm{sd}$ & $\overline{\mathrm{RSD}}$ & mean & $\mathrm{sd}$ & $\overline{\mathrm{RSD}}$ & mean & sd & RSD \\
\hline Long Island & 21 & 356.30 & 238.88 & 67.05 & 3.21 & 0.26 & 8.16 & 4.16 & 2.66 & 64.07 & 114.91 & 11.86 & 10.32 \\
\hline Little Cove & 13 & 50.18 & 12.34 & 24.60 & 3.39 & 0.18 & 5.25 & 8.29 & 7.22 & 87.14 & 84.13 & 12.85 & 15.28 \\
\hline Soldier Point & 10 & 89.33 & 61.52 & 68.87 & 3.08 & 0.42 & 13.68 & 3.94 & 1.06 & 26.98 & 78.64 & 16.51 & 21.00 \\
\hline Blackman's Point & 12 & 63.26 & 76.63 & 121.15 & 4.60 & 1.52 & 32.97 & 0.84 & 0.68 & 81.49 & 121.38 & 25.14 & 20.72 \\
\hline Coconut Hall & 11 & 306.25 & 464.12 & 151.55 & 3.26 & 1.03 & 31.62 & 0.73 & 0.67 & 92.05 & 74.93 & 61.56 & 82.16 \\
\hline Corbison Point & 7 & - & - & - & 4.50 & 1.27 & 28.13 & 18.19 & 8.18 & 44.99 & 146.93 & 79.84 & 54.34 \\
\hline Dry Hill & 13 & 135.15 & 167.33 & 123.81 & 4.50 & 1.58 & 35.14 & 3.30 & 2.84 & 86.15 & 233.85 & 50.77 & 21.71 \\
\hline Shirley Heights & 9 & 155.61 & 302.04 & 194.10 & 4.66 & 3.87 & 83.00 & 1.89 & 2.33 & 122.83 & 67.68 & 15.95 & 23.57 \\
\hline Cerillo & 13 & 37.44 & 14.48 & 38.68 & 5.26 & 3.04 & 57.77 & 0.43 & 0.52 & 120.76 & 120.46 & 112.42 & 93.33 \\
\hline Las Palmas & 8 & 23.64 & 9.28 & 39.25 & 7.02 & 4.07 & 58.07 & 0.34 & 0.31 & 90.67 & 69.09 & 45.32 & 65.59 \\
\hline Pedernales & 6 & - & - & - & 2.77 & 0.68 & 24.75 & 0.26 & 0.31 & 120.59 & 94.62 & 92.10 & 97.34 \\
\hline Villa Taina & 11 & 43.88 & 11.91 & 27.15 & 1.85 & 0.86 & 46.49 & 0.40 & 0.35 & 88.12 & 59.85 & 6.69 & 11.18 \\
\hline Мoca & 8 & 16.36 & - & - & 2.36 & 1.31 & 55.41 & 1.15 & 0.49 & 42.91 & 146.94 & 159.04 & 108.23 \\
\hline St. Kitts & 15 & 131.91 & 149.30 & 113.18 & 1.73 & 0.49 & 28.09 & 2.77 & 2.05 & 74.05 & 94.06 & 46.34 & 49.27 \\
\hline
\end{tabular}

Table 2.7. Average values $(\mathrm{mg} / \mathrm{kg}(\mathrm{ppm}))$, standard deviations $(\mathrm{mg} / \mathrm{kg}(\mathrm{ppm}))$, and relative standard deviations (RSD) of trace-element concentrations within Caribbean flints and cherts by source.

\begin{tabular}{|c|c|c|c|c|c|c|c|c|c|c|c|c|c|}
\hline \multirow[b]{2}{*}{ Sources } & \multirow[b]{2}{*}{$\mathrm{N}$} & \multicolumn{3}{|c|}{$\mathrm{Ca}$} & \multicolumn{3}{|c|}{$\mathrm{Mg}$} & \multicolumn{3}{|c|}{$\mathrm{Ba}$} & \multicolumn{3}{|c|}{$\mathrm{Sr}$} \\
\hline & & mean & sd & RSD & mean & sd & RSD & mean & sd & RSD & mean & sd & RSD \\
\hline Long Island & 21 & 1805.73 & 2203.06 & 122.00 & 457.26 & 714.58 & 156.27 & 41.20 & 66.88 & 162.36 & 16.58 & 10.36 & 62.48 \\
\hline Little Cove & 13 & 2551.44 & 2994.93 & 117.38 & 107.29 & 35.47 & 33.06 & 35.24 & 43.56 & 123.61 & 10.31 & 4.63 & 44.94 \\
\hline Soldier Point & 10 & 2749.95 & 3660.49 & 133.11 & 73.99 & 19.18 & 25.92 & 3.01 & 1.57 & 52.28 & 12.29 & 10.33 & 84.00 \\
\hline Blackman's Point & 12 & 266.66 & 137.19 & 51.45 & 71.78 & 72.21 & 100.59 & 10.57 & 14.36 & 135.83 & 9.95 & 9.50 & 95.44 \\
\hline Coconut Hall & 11 & 336.99 & 391.76 & 116.25 & 129.83 & 403.18 & 310.54 & 8.82 & 8.74 & 99.03 & 19.33 & 49.85 & 257.90 \\
\hline Corbison Point & 7 & 219.76 & 127.63 & 58.08 & 32.75 & 17.05 & 52.07 & 59.24 & 63.56 & 107.29 & 28.74 & 26.72 & 92.97 \\
\hline Dry Hill & 13 & 8007.52 & 12356.1 & 154.31 & 200.97 & 207.19 & 103.10 & 33.07 & 38.93 & 117.74 & 30.63 & 24.64 & 80.45 \\
\hline Shirley Heights & 9 & 12816.0 & 16008.8 & 124.91 & 532.17 & 473.71 & 89.01 & 3.96 & 4.16 & 105.16 & 26.12 & 26.09 & 99.90 \\
\hline Cerillo & 13 & 49.71 & 89.70 & 180.44 & 352.95 & 244.98 & 69.41 & 8.06 & 10.61 & 131.53 & 1.82 & 1.62 & 89.30 \\
\hline Las Palmas & 8 & 228.73 & 235.68 & 103.04 & 199.93 & 181.49 & 90.77 & 25.06 & 24.46 & 97.63 & 2.29 & 0.95 & 41.51 \\
\hline Pedernales & 6 & 126.27 & 104.41 & 82.68 & 186.13 & 244.03 & 131.11 & 12.51 & 11.67 & 93.30 & 1.77 & 0.86 & 48.91 \\
\hline Villa Taina & 11 & 193.46 & 235.49 & 121.72 & 163.53 & 184.22 & 112.65 & 19.28 & 39.74 & 206.17 & 2.24 & 2.01 & 89.70 \\
\hline Мoca & 8 & 144.67 & 148.31 & 102.52 & 86.56 & 88.91 & 102.72 & 3.34 & 3.41 & 102.04 & 1.32 & 0.42 & 32.14 \\
\hline St. Kitts & 15 & 3636.95 & 9892.82 & 272.01 & 177.60 & 217.61 & 122.53 & 4.72 & 5.38 & 113.96 & 10.30 & 17.66 & 171.44 \\
\hline
\end{tabular}

Table 2.8. Average values $(\mathrm{mg} / \mathrm{kg}(\mathrm{ppm}))$, standard deviations $(\mathrm{mg} / \mathrm{kg}(\mathrm{ppm}))$, and relative standard deviations (RSD) of trace-element concentrations within Caribbean flints and cherts by source. 


\begin{tabular}{ccrrr}
\hline & & \multicolumn{3}{c}{$\mathrm{Ca} / \mathrm{Mg}$} \\
\cline { 3 - 5 } Sources & $\mathrm{N}$ & mean & sd & $\mathrm{RSD}$ \\
\hline Long Island & 21 & 5.82 & 4.38 & 75.28 \\
Little Cove & 13 & 20.35 & 15.01 & 73.75 \\
Soldier Point & 10 & 32.26 & 30.75 & 95.32 \\
Blackman's Point & 12 & 6.52 & 5.28 & 81.00 \\
Coconut Hall & 11 & 22.87 & 17.46 & 76.35 \\
Corbison Point & 7 & 7.37 & 3.56 & 48.26 \\
Dry Hill & 13 & 21.67 & 21.01 & 96.96 \\
Shirley Heights & 9 & 19.17 & 16.17 & 84.34 \\
Cerillo & 13 & 0.17 & 0.22 & 128.75 \\
Las Palmas & 8 & 1.35 & 0.68 & 50.43 \\
Pedernales & 6 & 1.64 & 1.24 & 75.38 \\
Villa Taina & 11 & 1.48 & 0.67 & 45.34 \\
Moca & 8 & 1.80 & 0.49 & 27.24 \\
St. Kitts & 15 & 9.76 & 17.12 & 175.40 \\
\hline
\end{tabular}

Table 2.9. Average values (mg/kg (ppm)), standard deviations ( $\mathrm{mg} / \mathrm{kg}(\mathrm{ppm}))$, and relative standard deviations (RSD) of $\mathrm{Ca} / \mathrm{Mg}$ concentration ratio within Caribbean flints and cherts by source.

ones, and the heavily weathered samples from Blackman's Point provide an opportunity to study the effects of prolonged alteration.

Not considering the secondary sources for the moment, flint from the Antigua Formation is similar in microscopic and geo-chemical composition. The primary sources possess a similar texture of heterogeneously sized microcrystalline quartz crystals, with the presence of varying amounts of calcite, carbonate fossils as well as silicified ones. Furthermore, matrices exhibit a "dirty" appearance with small dark inclusions. Similarity is also attested for the geo-chemical data (tables 2.5-9). Most striking resemblances are: (1) relatively constant values of clay-related elements, such as Al, K, Ti, and Fe, (2) very constant $\mathrm{Al} / \mathrm{K}$ ratios (suggesting the origin from a similar suite of minerals) (figure 2.21 ), (3) varying $\mathrm{Ca}$ and $\mathrm{Mg}$ values, including very high concentrated samples, and (4) relatively high Li values.

This similarity suggests that despite geographical differences (different localities on the island) the environment of formation was relatively similar, in which notably the terrestrial and authigenic mineral inputs were the same.

Notwithstanding these similarities, occasional differences are noted as well. These primarily are highlighted when the Long Island flint source is compared to the other localities. Within the Long Island flint, the clay-mineral related group of elements (Al, K, Ti, Cr), as well as the pyrite elements (Fe, S) is significantly higher than within the other Antigua flints. Apparently, the concentration of non-carbonate impurities within the host-rock is higher at Long Island as compared to the other sources. The type of impurities, however, is the same as similarity in the $\mathrm{Al} / \mathrm{K}$, but also shown by $\mathrm{Al} / \mathrm{Ti}$, and $\mathrm{Al} / \mathrm{Cr}$ ratios between the localities.

Comparing these data to northwestern European flints, which were formed in a similar environment, the clayderived elements have on average a higher concentration within the Antigua flints. This may be related to the smaller size of the carbonate platform on Antigua when compared to that for northwestern Europe, making the terrestrial influx more predominant. Bush and Sieveking $(1986,134)$ noted that some of the European sources with relatively high concentrations probably were situated along the margin of the carbonate platform.

Closely studying the $\mathrm{Al} / \mathrm{K}$ ratios of the Antigua flints, it is noted that they vary from 2.67 to 4.23 , with the majority of the values falling in the 3.0 to 3.5 range (see Appendix C). From the above introduction it became clear that the most likely clay minerals that occurred within shallow marine waters, below which the mudstone carbonate material was deposited, include smectite, illite, chlorite and glauconite. The $\mathrm{Al} / \mathrm{K}$ ratio of 3.0 to 3.5 is found in neither of the minerals individually, a mixture, however, can produce such values (table 2.10). Such a mixture contains relatively more illite and smectite compared to chlorite, or glauconite, considering the low Fe-values of the former two. As the Fe in the flints is significantly less concentrated than the Al, glauconite may have been rare, especially if we take into account that part of the Fe in the flint has originated from pyrite. A similar argument can be suggested for chlorite. Probably most of the $\mathrm{Mg}$ originated from the 

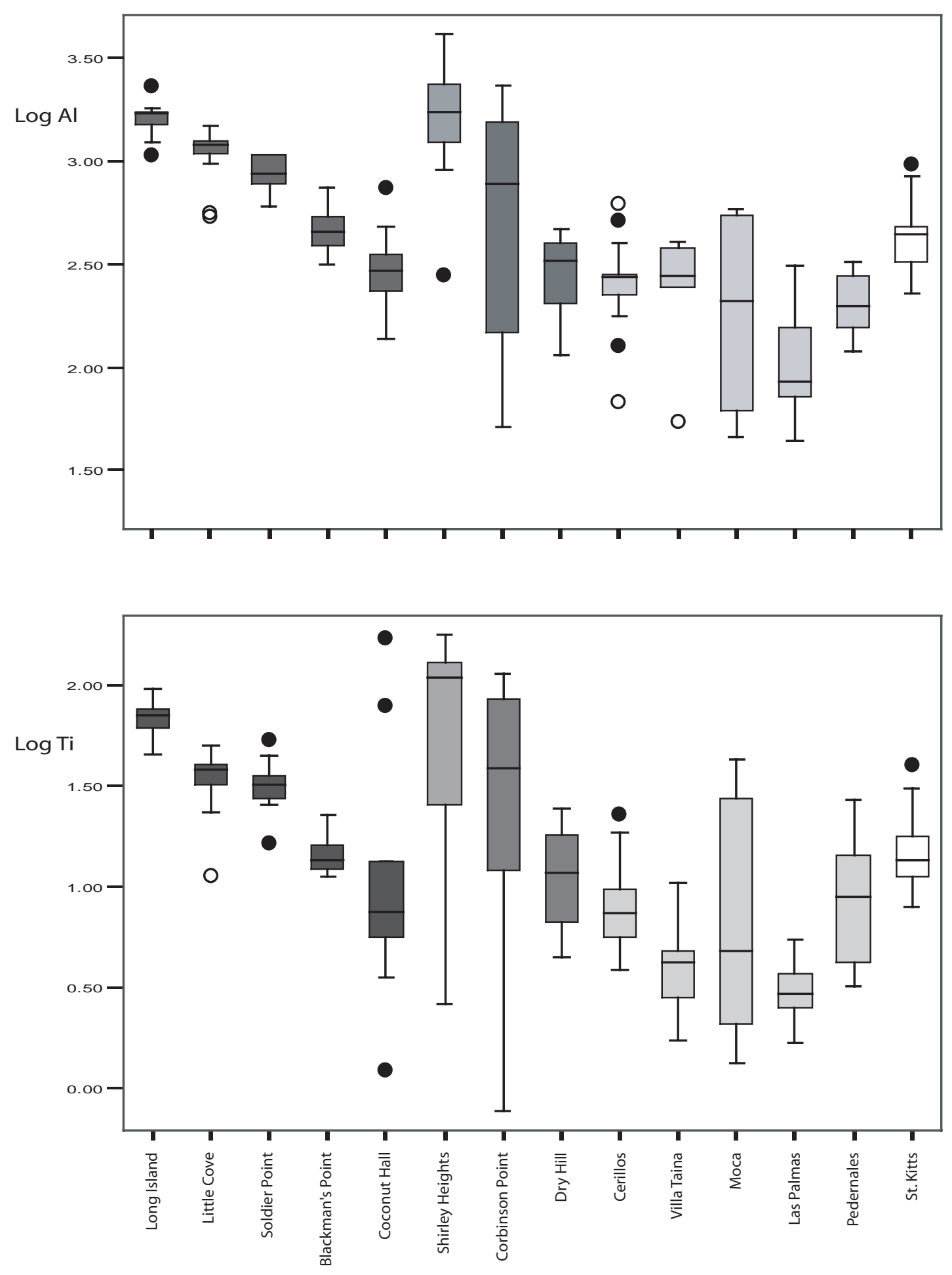

Figure 2.18. Boxplot graphs showing the log-values of Al and Ti concentrations by source grouped according to geology. Solid circles are outliers, open circles are extremes. 

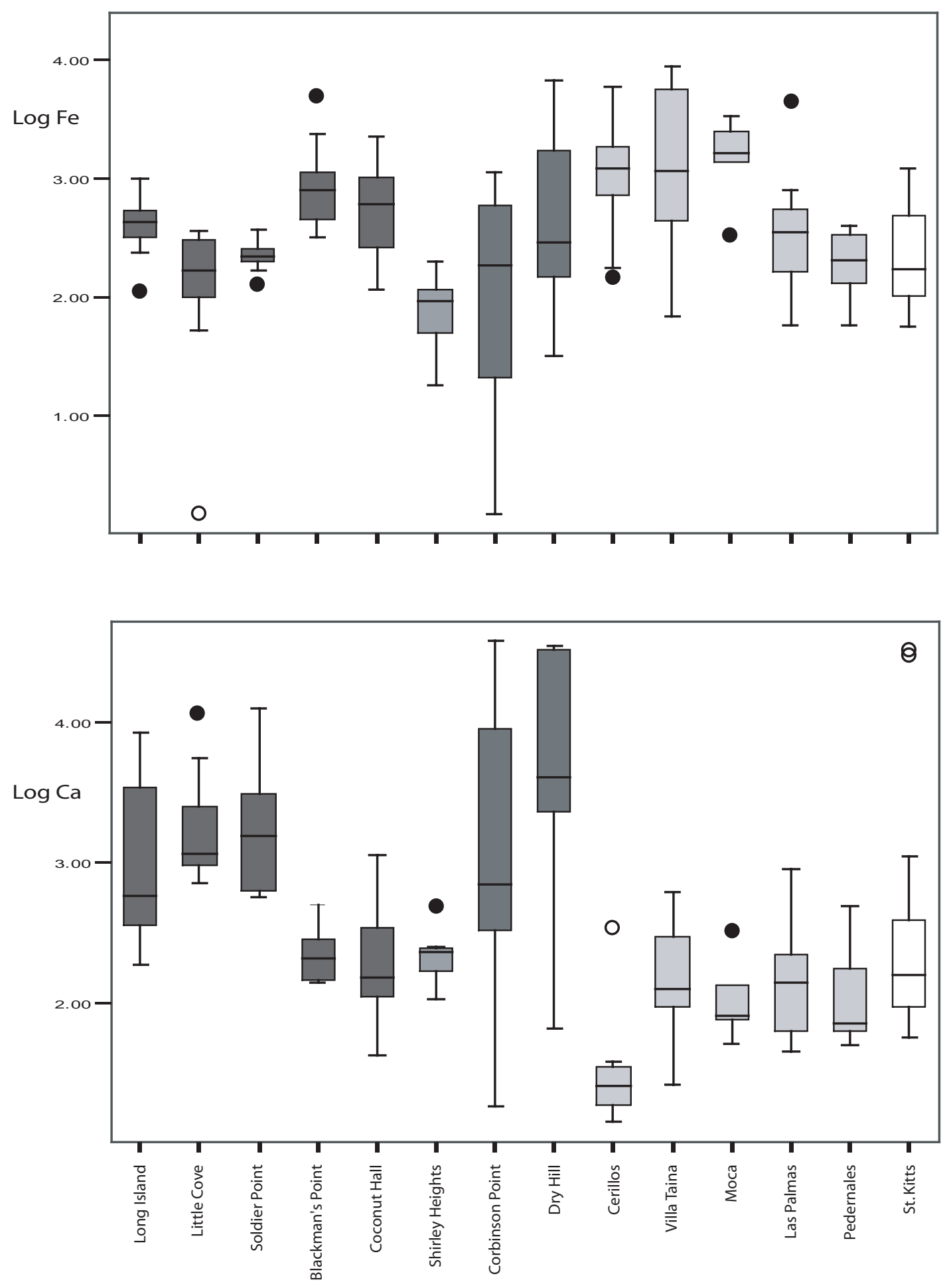

Figure 2.19. Boxplot graphs showing the log-values of Fe and Ca concentrations by source grouped according to geology. Solid circles are outliers, open circles are extremes. 

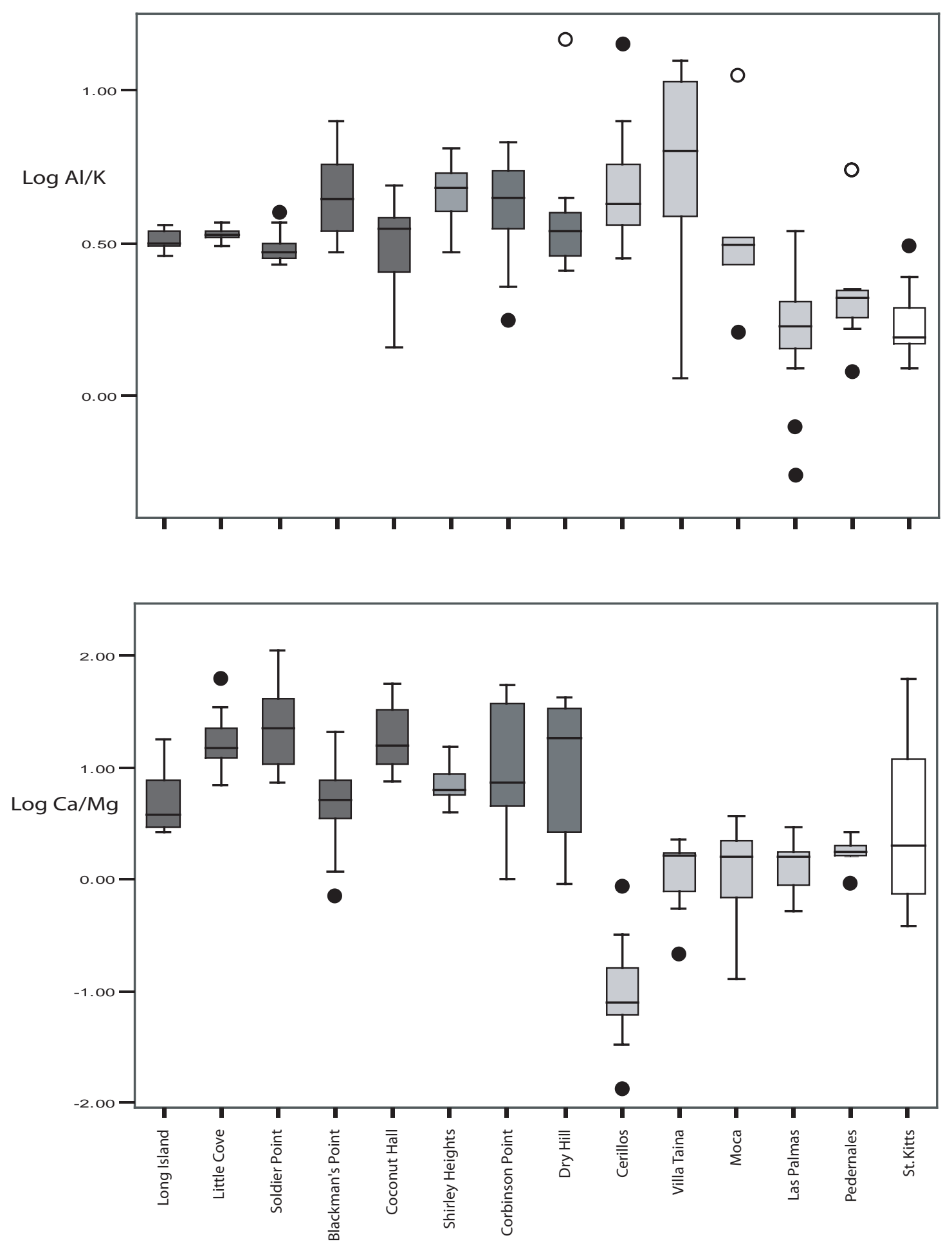

Figure 2.20. Boxplot graphs showing the log-values of $\mathrm{Al} / \mathrm{K}$ and $\mathrm{Ca} / \mathrm{Mg}$ concentration ratios by source grouped according to geology. Solid circles are outliers, open circles are extremes. 


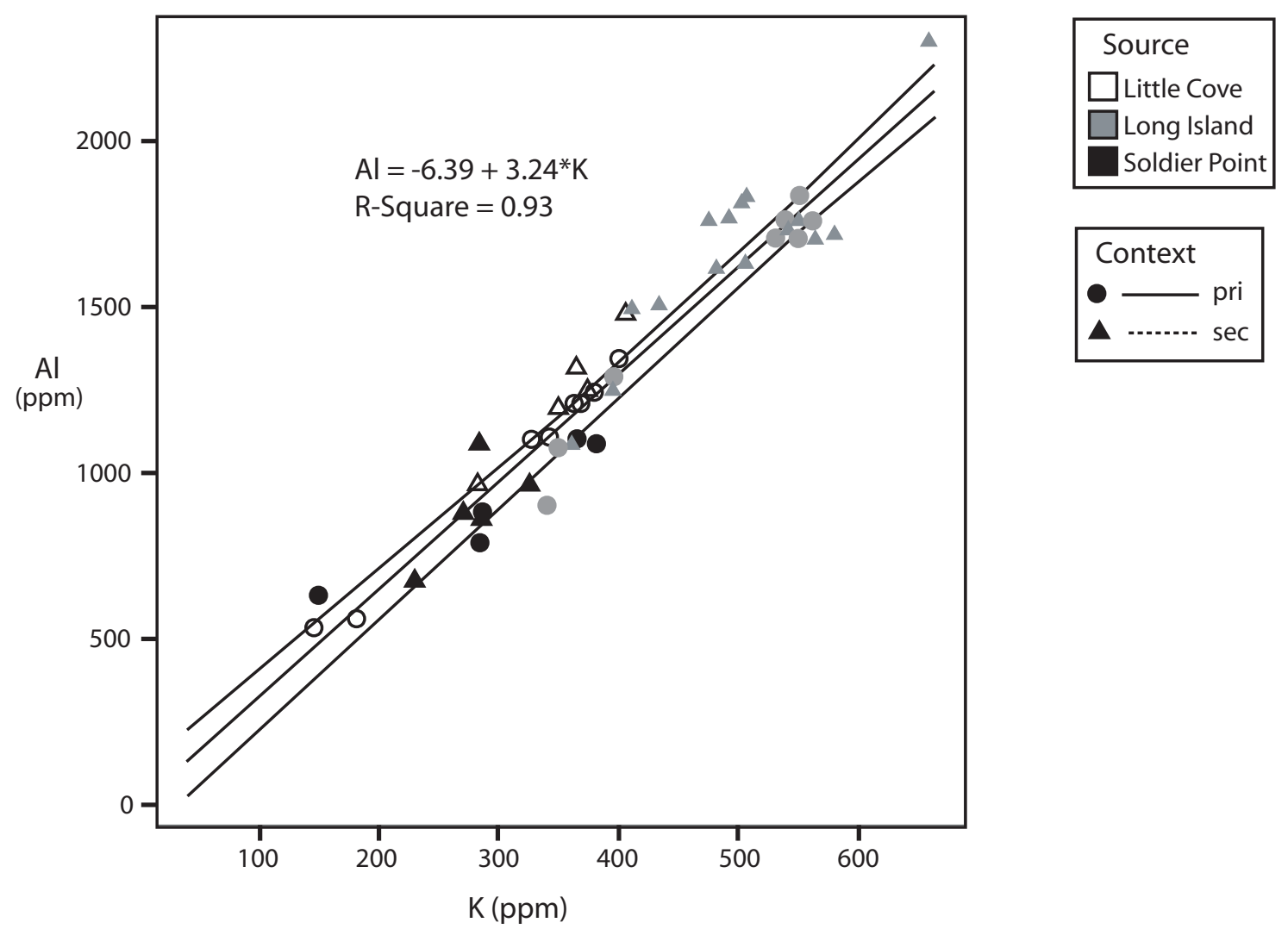

Figure 2.21. Antigua flints from primary sources. Linear regression of Al by $\mathrm{K}$ with $95 \%$ mean prediction interval. "Pri" stands for primary flint samples and "sec" for secondary flint samples.

carbonate grains that are still present in the flint. This suggests that a detrital smectite influx, which is for a great part changed into illite, and to a lesser extent chlorite, prevailed.

Given this resemblance in trace-element composition, additional support is provided for the fact that the flint bearing limestone layer on Antigua may have been deposited during a single event, if the points on its restricted occurrence and its similar stratigraphical position within the Antigua Formation, made earlier, are also considered. This chemical similarity, however, has negative consequences for source discrimination, in particular the Soldier Point and Little Cove flints significantly overlap in concentration values. Luckily, overlap with the Long Island material is considerably less.

Both the Long Island, Soldier Point and Little Cove sources provide data with which the influences of flint weathering can be studied. Basically, two weathering environments occur: (1) a coastal one in which sea-water is the primary agent; and (2) an inland location in which rain water and soil chemistry play the decisive role. In the former location, simple dissolution of rock material has been the primary mechanism by which the rock changes, whereas within the latter one dissolution and chemical interaction with the surrounding soil may be of significance.

The analysis of both primary and secondary samples from the Soldier Point and Little Cove localities shows that in these cases of beach weathering the trace-element composition only slightly changed. For most elements there is no significant difference between primary and secondary samples, although values of primary samples may in some cases be higher on average. Closer study of the values shows, however, that at Little Cove Na significantly, (but minimally) decreased as compared to $\mathrm{Al}$ and $\mathrm{K}$, as is clear from higher $\mathrm{Al} / \mathrm{Na}$ and $\mathrm{K} / \mathrm{Na}$ ratios in the secondary flints (table 2.11). This decrease of $\mathrm{Na}$ must be ascribed to loss of interstitial sea-water, which stayed trapped in the flint during its formation. This decrease in $\mathrm{Na}$ with respect to $\mathrm{Al}$ and $\mathrm{K}$ is not present in the Soldier Point-flints, where the opposite is the case.

The analysis of secondary material from the inland soils at Long Island provides other results. Already suggested by 


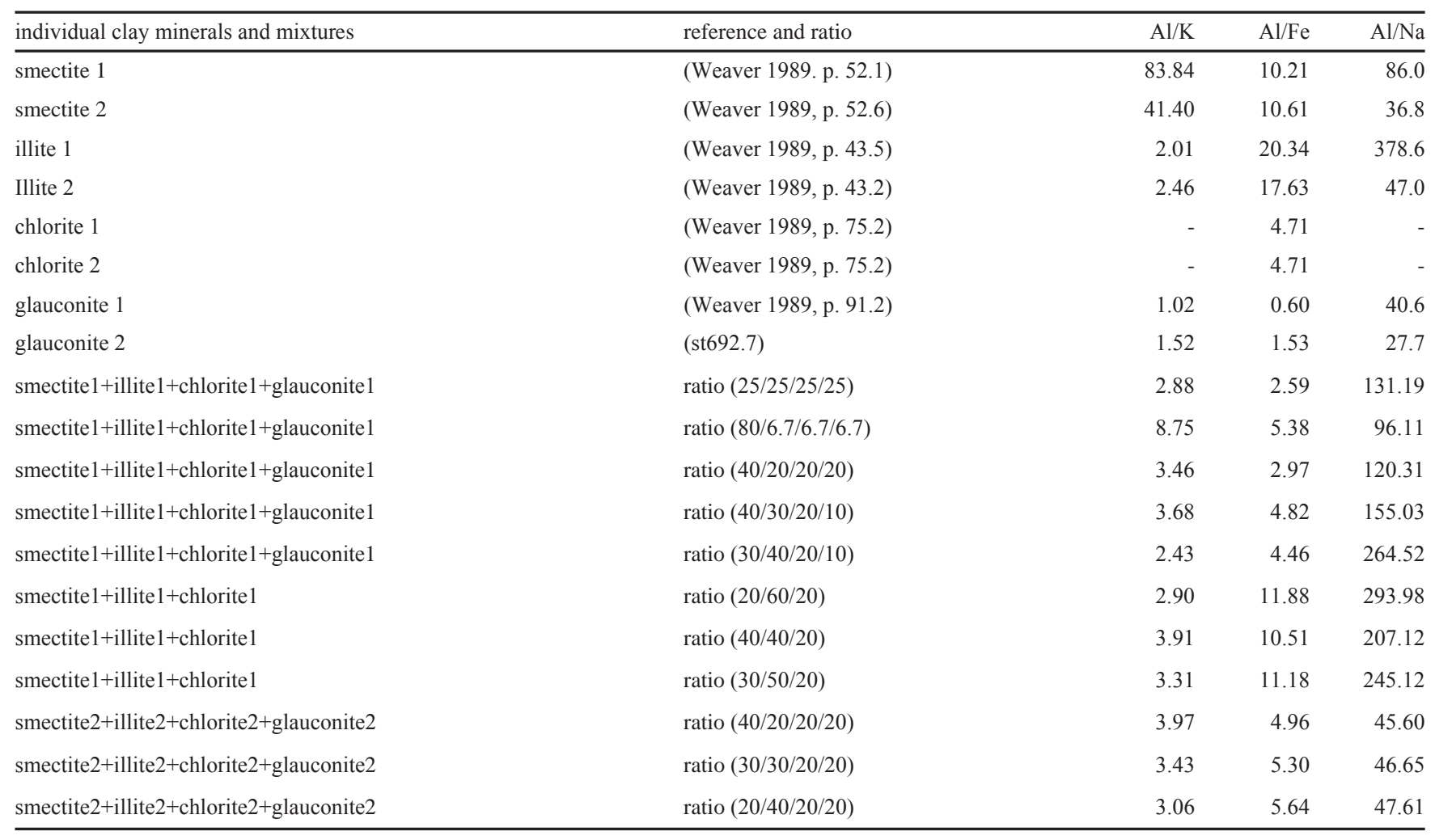

Table 2.10. Trace element ratios in clays. Ratios from single clays are from Weaver (1989). The ratios of the mixtures are artificial and based on the single clay data with weighing factors between brackets.

the colour change among a significant part of the secondary material, where the dark greyish brown has turned into yellowish brown, chemical alteration is more significant within these inland flints than among beach-flints from the other localities. ${ }^{9}$ Notable changes are a significant decrease of $\mathrm{Ca}, \mathrm{Mg}$, and $\mathrm{S}$, and a local increase of $\mathrm{Fe}, \mathrm{Ba}$, and $\mathrm{Sr}$ (table 2.11). Close examination of $\mathrm{Fe}$, which usually is affected as a result of oxidation, reveals that the Fe-concentration values in secondary flints are not lower on average. Variation, however, between samples has increased, as is suggested by higher RSD (relative standard deviation) values, 30.6 for primary flints and 46.7 for secondary ones. This suggests that the Fe-concentration is affected by weathering but that weathering does not necessarily work in one direction and merely redistributes the $\mathrm{Fe}$ within the flint concretions. Preliminary analysis of individual specimens using Laser Ablation Inductively Coupled Mass Spectroscopy (LA-ICP-MS), during which certain isolated areas can be sampled, indicates that highly concentrated $\mathrm{Fe}-$ bands are present in the outer part of the rock, which displays also a browner colour (figure 2.22). These bands represent $\mathrm{Fe}$-oxidation borders, and may have formed as a result of Fe-transport from the inner part of the nodules. Concurrent with dissolution and transport of Fe to the outer parts, $\mathrm{S}$ from the pyrite is lost as well

From the Long Island samples it is also clear that $\mathrm{Ca}$ and associated $\mathrm{Mg}$ are lost in secondary flints as a result of carbonate dissolution, which was also attested among the different thin-sections. This loss is not always evident from the chemical data, as the amount of carbonate can vary a lot in limestone flints. A comparison of the primary sample LI-53, with other primary Long Island samples clearly demonstrates this variation (see table C.1 in Appendix C).

These results show that weathering only affects trace-element composition to a minor extent in case of beach weathering, whereas the soils at Long Island had a more significant effect. Most influence can be noticed in the $\mathrm{Na}$, and carbonate related element $(\mathrm{Ca}, \mathrm{Mg})$ concentrations, which on average decrease. The clay and quartz related elements, such as $\mathrm{Al}, \mathrm{K}, \mathrm{Li}, \mathrm{Cr}$, and Ti remain relatively constant.

9 A systematic comparison between secondary beach flints and inland flints from Long Island has not been performed, as significant erosion of the coastline during the past eroded a lot of inland buried flint material on the beach. This hampered a sound designation of weathering environment as both flint groups became mixed on the beach. 


\begin{tabular}{lrrrrrrrrrrrrrrr}
\hline \multicolumn{1}{c}{ source } & $\mathrm{Al}$ & $\mathrm{K}$ & $\mathrm{Na}$ & $\mathrm{Ti}$ & $\mathrm{Li}$ & $\mathrm{Cr}$ & $\mathrm{Fe}$ & $\mathrm{Ca}$ & $\mathrm{Al} / \mathrm{K}$ & $\mathrm{Al} / \mathrm{Na}$ & $\mathrm{K} / \mathrm{Na}$ & $\mathrm{Al} / \mathrm{Fe}$ & $\mathrm{Al} / \mathrm{Li}$ & $\mathrm{Al} / \mathrm{Ti}$ & $\mathrm{Al} / \mathrm{Cr}$ \\
\hline $\begin{array}{l}\text { Long Island } \\
\text { primary }\end{array}$ & 1484 & 481 & 1029 & 58.1 & 12.7 & 5.80 & 482 & 3303 & 3.06 & 1.45 & 0.47 & 3.23 & 115.4 & 25.52 & 254 \\
secondary & 1647 & 502 & 868 & 71.3 & 14.5 & 7.21 & 447 & 1007 & 3.29 & 1.94 & 0.60 & 4.65 & 114.6 & 23.15 & 234 \\
Little Cove & & & & & & & & & & & & & & & \\
primary & 1037 & 314 & 822 & 35.9 & 13.1 & 4.51 & 235 & 3121 & 3.32 & 1.33 & 0.40 & 5.98 & 81.4 & 30.35 & 231 \\
secondary & 1246 & 355 & 682 & 34.1 & 14.7 & 4.40 & 162 & 1640 & 3.50 & 1.88 & 0.54 & 11.52 & 88.5 & 37.15 & 337 \\
Soldier Point & & & & & & & & & & & & & & \\
primary & 875 & 297 & 528 & 32.1 & 11.2 & 3.34 & 227 & 3570 & 3.06 & 1.72 & 0.59 & 3.97 & 79.8 & 28.29 & 268 \\
secondary & 878 & 283 & 680 & 34.6 & 11.4 & 3.62 & 241 & 1930 & 3.10 & 1.30 & 0.42 & 3.91 & 77.5 & 26.60 & 262 \\
\hline
\end{tabular}

Table 2.11. Antigua Formation flints. Average values of trace-element concentrations (in $\mathrm{mg} / \mathrm{kg}(\mathrm{ppm})$ ) and their ratios within flints from a primary context compared to flints from a secondary context by source.

Considering the presence of primary material in clear association and near vicinity to secondary material at these sources, it can be argued that the erosion processes are still occurring and that secondary material has not been exposed to weathering for long periods on average. This may be in contrast to the other two localities within the Antigua Formation, Blackman's Point and Coconut Hall. Here the presence of primary material cannot be identified. In addition, flint material generally possesses lighter colours and in case of Blackman's Point, grain-size is coarser, possibly due to re-crystallisation. These are all features, that suggest that the rock material had been exposed to a longer period of weathering, or more severe weathering processes. ${ }^{10}$

In particular, comparison between the Blackman's Point flint on one hand and the Long Island, Little Cove, and Soldier Point on the other, is most instructive. Blackman's Point flint resembles the other Antigua Formation flints in many respects. Close similarity in microscopic texture suggests a similar history of formation. Only its prolonged exposure to weathering gives the flint certain different characteristics.

During the microscopic analysis, it became soon clear that most of the Blackman's Point flint samples are poor in calcite. One sample (BP-1) exhibits clear rectangular voids, $0.05 \mathrm{~mm}$ in length, similar in shape and size to most of the calcite minerals present in the Long Island flint samples (see figure 2.22). Close comparison of different thin-sections from Long Island and Blackman's Point reveals a continuous sequence of calcite rich non-weathered primary Long Island samples, to samples exhibiting very small voids, and finally to Blackman's Point samples with clear rectangular voids in which calcite was completely weathered out. The smaller voids are places where iron oxides were precipitated, indicated by red-brown to dark brown fillings. It should be noted that, similar to most of the secondary Long Island material, the Blackman's Point flint had been buried in soils for prolonged periods. Only along the coast-line, where the sea is gradually gaining on the land, is flint exposed.

This more significant weathering at Blackman's Point resulted in an overall decrease in trace-element concentration values for almost all analysed elements, compared to the primary flints from the other localities (see tables 2.5-9, 11). Exceptions include $\mathrm{Fe}$ and $\mathrm{Mn}$, which generally have higher values, as well as $\mathrm{Li}$, and $\mathrm{Cr}$, which are less affected by the weathering. From this the following weathering sequence for all the Antigua Formation flints can be postulated.

In the first instance some $\mathrm{Na}$, trapped as interstitial water, is lost. This is accompanied by the dissolution of calcite in the rock, indicated by a decrease of $\mathrm{Ca}$ and $\mathrm{Mg}$. Slowly, the flint becomes more porous due to calcite dissolution and quartz may be more easily dissolved as a result of a higher specific surface. Porosity of the rock also induces iron and manganese oxidation. Depending on the water transport in the flint, Fe (and $\mathrm{Mn}$ ) may be precipitated in bands in the outer parts of the rock (see Cackler et al. (1999a) for an example in which Mn-rich bands were formed in weathered chert). Slowly, clay minerals and other terrestrial minerals trapped in the quartz and calcite, are dissolved, resulting in lower $\mathrm{Al}, \mathrm{K}$, and $\mathrm{Ti}$ concentrations. $\mathrm{K}$ and $\mathrm{Ti}$ decrease relatively more in concentration than $\mathrm{Al}$, as they are more reactive (Brownlow 1979), resulting in higher $\mathrm{Al} / \mathrm{K}$ and $\mathrm{Al} / \mathrm{Ti}$ ratios. $\mathrm{A}$ decrease in $\mathrm{Li}$ and $\mathrm{Cr}$ indicate actual quartz dissolution. These elements are least affected by weathering ( $\mathrm{Al} / \mathrm{Li}$ and $\mathrm{Al} / \mathrm{Cr}$ ratios decrease in secondary flints), suggesting relatively little quartz is dissolved. Depending on the Fe contents in the surrounding soil, new Fe (and $\mathrm{Mn}$ ) may be precipitated in the voids that are formed after solution. If Fe-content is higher in the surrounding soil than in the flint, this will result in an increase of Fe in the flint.

10 In theory it may be hypothesized that speed at which the weathering reactions occurred might have been higher at these localities. However, there are no indications, that suggest this, so for now I will assume that the period during which these flints were exposed to weathering is longer. 
These results show that the concentration of trace-elements generally drops in weathered cherts, and only in case of high availability in surrounding soils may rise. Sheppard and Pavlish (1992) present an example of trace-element concentration rise in cherts due to high availability in surrounding soils. In their study of Pacific cherts, they attribute the increase of $\mathrm{Al}$ to bauxitic soils in which the flints were buried.

Considering the fact that the flints buried in soils, both at Blackman's Point as well as at Long Island, display the most significant changes, this weathering environment is more severe than the alteration on the beach. This can be related to a generally higher acidity, dissolving the calcite in the rock. The possible presence of humic acids in these soils, primarily responsible for quartz dissolution may have contributed as well to the general loss of most elements.

From this it is clear that in addition to a decrease of many trace-element values, the variation, measured by the RSD, increases in secondary flints. Apparently, individual rocks are altered differently depending on the time they are buried in soils. This means that on the one hand the weathering has a positive effect on discrimination, as secondary sources can be distinguished from primary ones originating from the same geological formation. On the other hand, it has a negative effect, as variation within a source becomes considerably larger, increasing the chance of overlap between sources.

On first sight, the Coconut Hall flints display a similar decrease in concentration of most of the elements related to clay minerals and calcite, as in case of the Blackman's Point material. More detailed comparison, however, reveals some differences, which cannot be explained by the weathering process described above. In the first place some of the flints still contain considerable quantities of carbonate material, indicated by high Ca-concentration and the presence of calcite crystals (tables 2.5-9). In correspondence with this presence of calcite is the significant lower number of voids visible than within the Blackman's Point rocks. This suggests markedly less dissolution of calcite, which may be an indication of a lesser degree of overall weathering, keeping in mind the generally higher solubility of calcite compared to quartz.

The second difference relates to the clay-associated elements. Although the concentration values of $\mathrm{Al}$ are in the range of those found in the Blackman's Point rocks, they vary more and more importantly, the relative amount in comparison with $\mathrm{K}$ is on average lower, suggested by low $\mathrm{Al} / \mathrm{K}$ ratios. The Blackman's Point flints show a structural decrease of $\mathrm{K}$ relative to Al, when compared with the primary Antigua Formation flint sources. Some of the Coconut Hall samples, however, have $\mathrm{Al} / \mathrm{K}$ ratios that are lower than any of the other Antigua Formation flints. This indicates a different original $\mathrm{Al}$ and $\mathrm{K}$ relation. If this latter characteristic is combined with the different quartz matrix fillings that some samples display, including high amounts of chalcedony, then the evidence suggests that the formation of the Coconut Hall flints had occurred in a slightly different geological environment, where $\mathrm{K}$ was more abundant than within the limestone of the other Antigua Formation sources.

With regard to the quartz matrix, the Coconut Hall flints resemble the Puerto Rican cherts, which also exhibit significant occurrence of chalcedony in the matrix (see figures 2.15 and 2.17). Considering the secondary nature of all these cherts, as well as the Coconut Hall flint, it is hypothesized that this chalcedony represents a secondary phase of silicification. This secondary phase may have altered original trace-element composition, making a sound comparison impossible.

\section{St. Kitts flints}

The other definite limestone chert (flint) is found on St. Kitts. Earlier, I already assumed, based on similarity in macroscopic and microscopic features, that material from the different localities on the island probably were formed within the same limestone formation. The chemical data confirm this assumption. Trace-element concentrations of the different elements fall within the same range, and $\mathrm{Al} / \mathrm{K}$ ratios do not vary between the sources, suggesting a similar clay origin (figure 2.23; see Appendix C).

Only from Great Salt Pond, two poorly silicified, carbonate rich samples were analysed, and none were analysed for Sugar Factory Pier. Despite the secondary nature of the flints on St. Kitts, they do not exhibit clear signs of significant weathering, as some of the Antigua Formation flints do: (1) voids are not visible under the microscope, (2) no high Feconcentration as a result of iron oxide precipitation is present, and (3) some samples still contain a lot of calcite, which is not expected if significant weathering had taken place. Two possible explanations may be suggested for this absence of alteration: (a) the low porosity of the quartz in matrix, which will make dissolution of quartz and subsequent weathering more difficult, or (b) the weathering that predominantly had taken place was within a beach environment, which appears to be a less destructive environment than certain soils, where the existence of humic acid is the primary cause for weathering. 


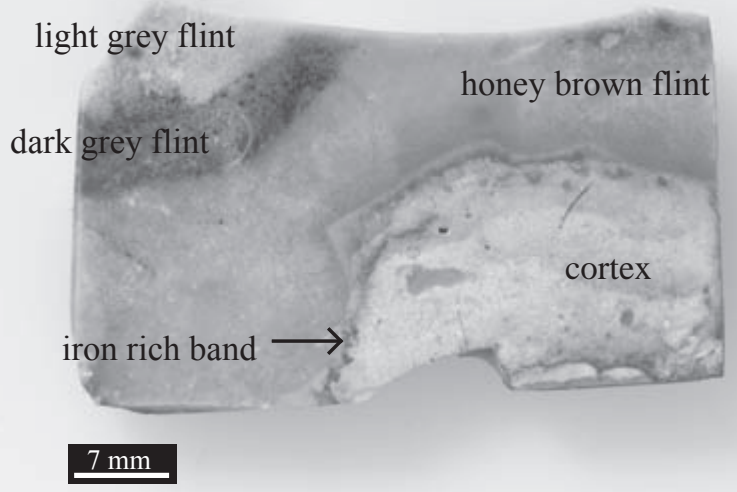

a. Long Island, cut flint sample ANLI-02.
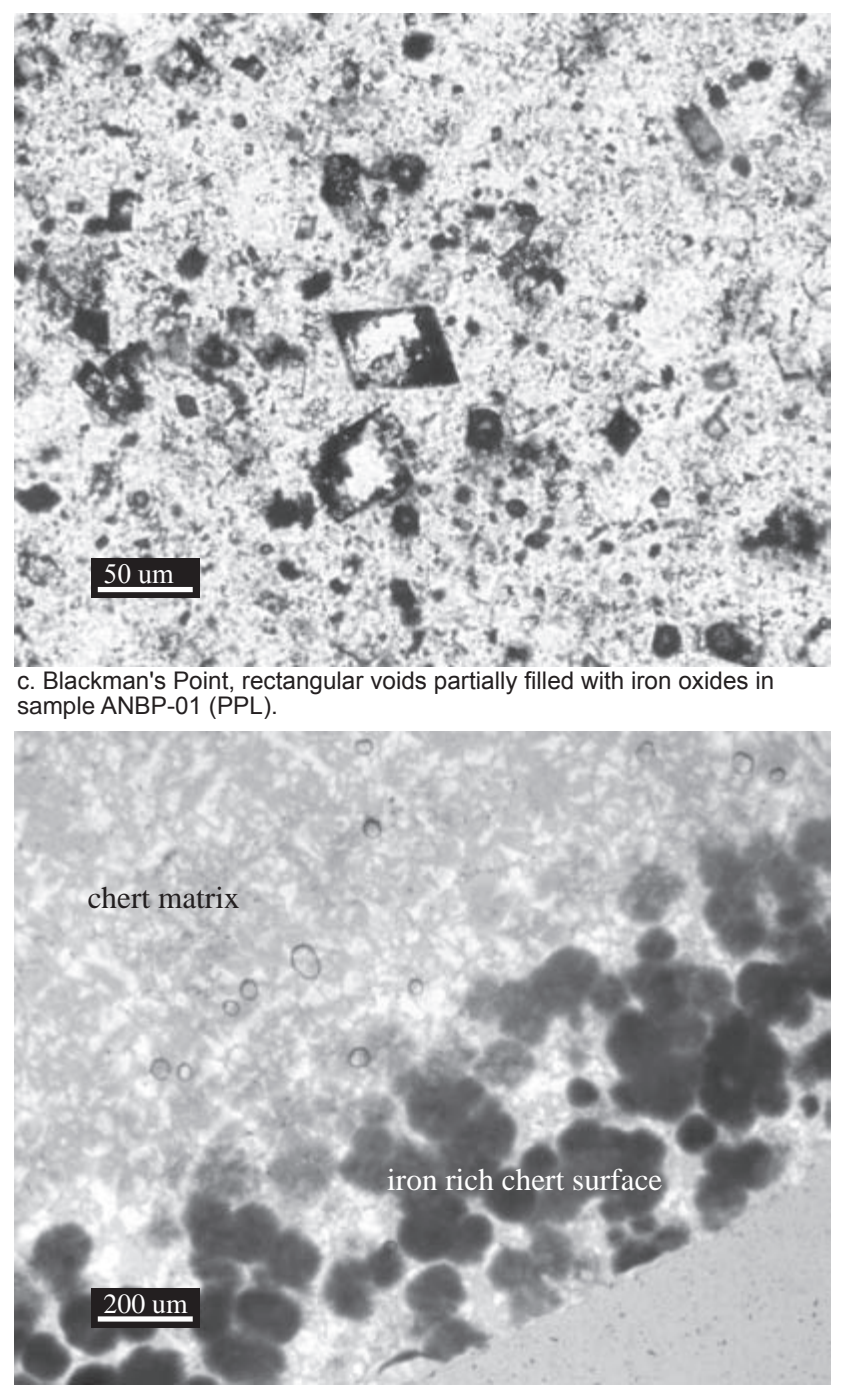

e. Moca, iron rich outer part of chert sample PRMO-04 (PPL).

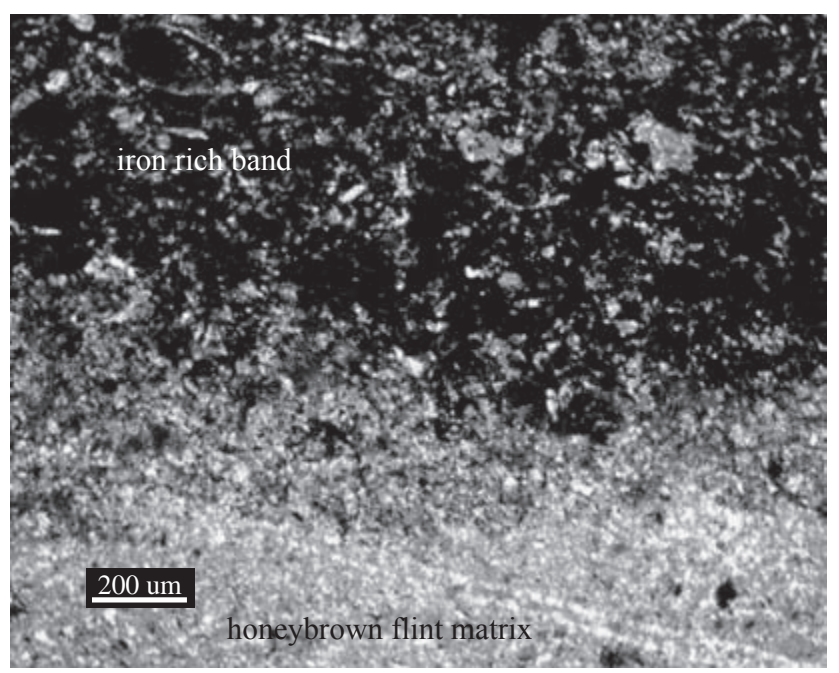

b. Long Island, iron rich band in sample ANLI-02 (CP)

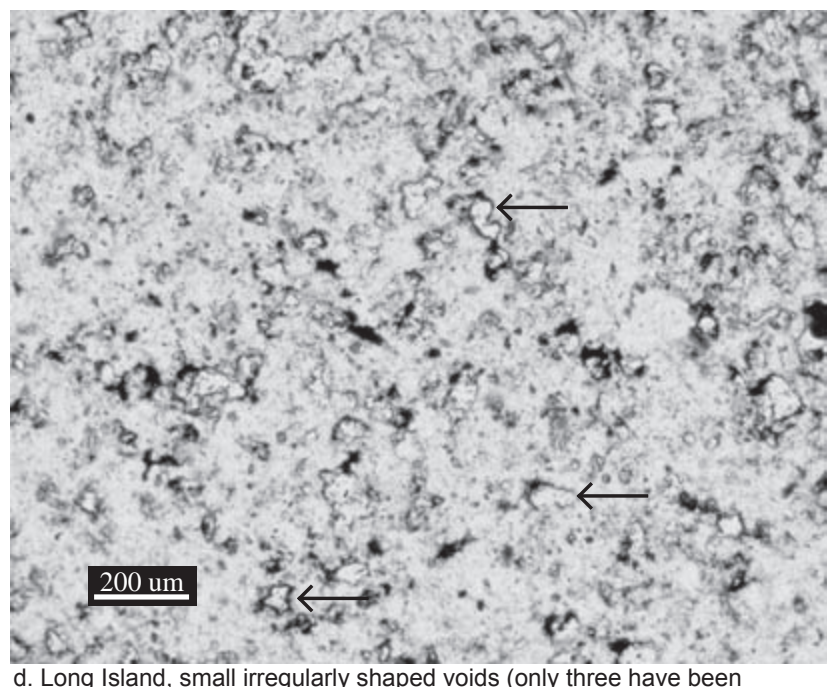
d. Long Island, small irregularly shaped voids (only three have been indicated by arrows) in sample ANLI-09 (PPL).

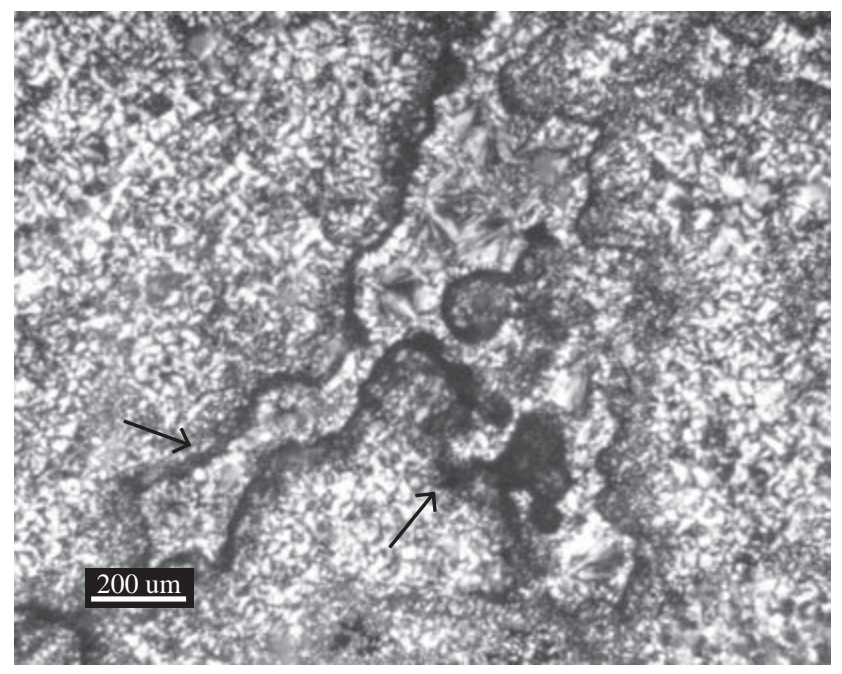

f.Villa Taina, iron rich bands along vein boundaries in matrix of sample PRVT-02 (CP). 


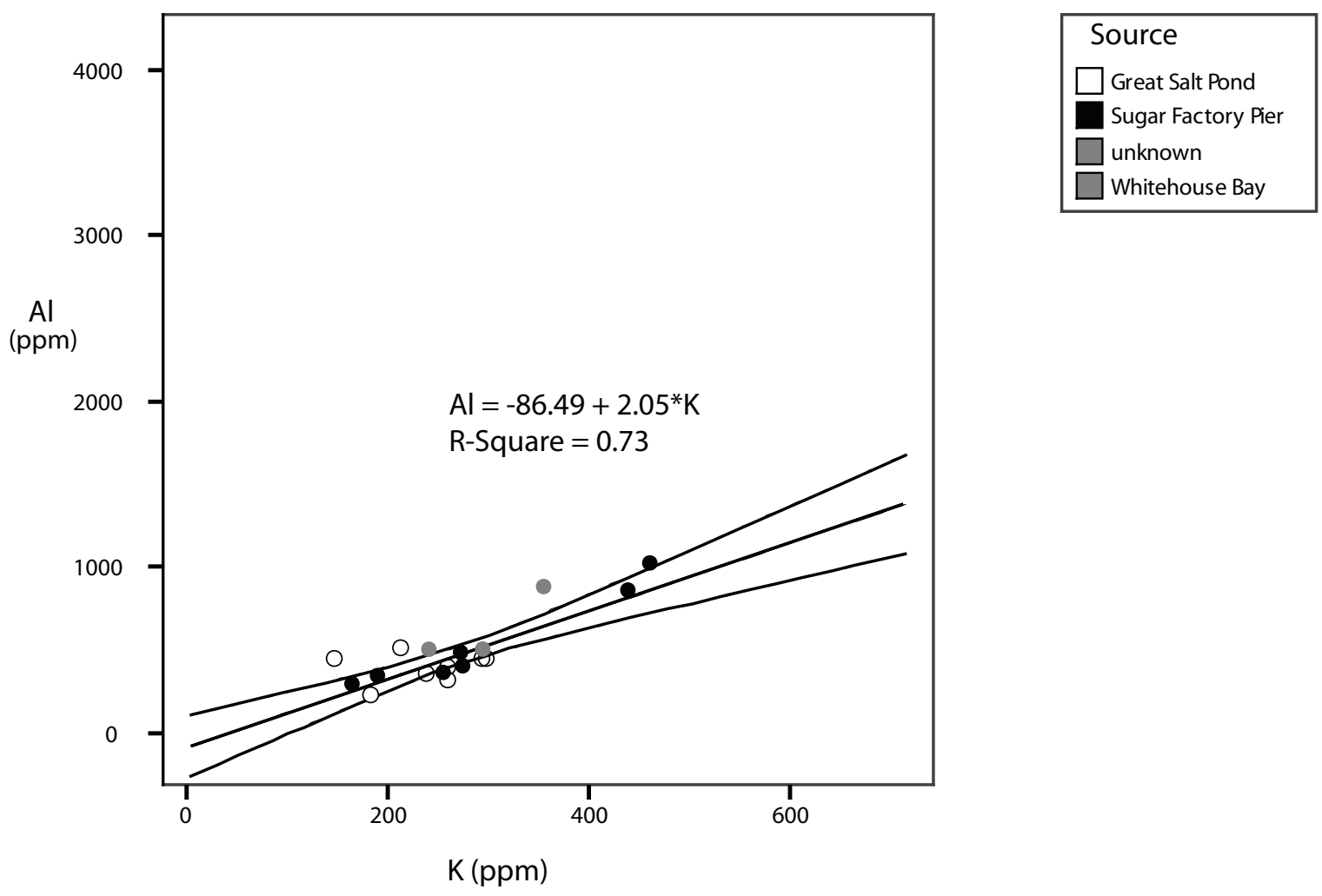

Figure 2.23. St. Kitts flints. Linear regression of Al by $\mathrm{K}$ with $95 \%$ mean prediction interval.

Comparing the St. Kitts material to the Antigua Formation flints, the following is noted (tables 2.5-9):

- Trace-element concentrations are in general lower than on Antigua, notably the elements $\mathrm{Al}, \mathrm{K}, \mathrm{Li}, \mathrm{Cr}, \mathrm{Fe}$, and $\mathrm{Ca}$, making the flints purer.

- The $\mathrm{Al} / \mathrm{K}$ ratio is lower than within the Antigua Formation flints, indicating that clay minerals richer in $\mathrm{K}$ were responsible for the impurities in the St. Kitts flint. Considering the fact that terrestrial minerals likely are similar at St. Kitts, as igneous rock is similar, the higher K contents must be attributed to a larger portion of marine derived or authigenic minerals. Probably the illite and maybe the glauconite contents relative to smectite are higher in these flints.

These two facts relating to the flint from St. Kitts, that is lower trace-element concentrations and higher proportion of marine clays, may be inter-related. As authigenic marine clay-mineral formation is dependent on the availability of terrestrial minerals, a lower concentrated terrestrial input in the marine waters of St. Kitts will lead, in case of equal Kavailability in marine waters, to a more complete conversion of the terrestrial clay-minerals into marine ones. This more complete conversion will result in a lower $\mathrm{Al} / \mathrm{K}$ ratio.

Similar trends can be found among the northwestern European flints (Bush \& Sieveking 1986; Sieveking et al. 1972). Although not mentioned by the authors, close inspection of their data reveals that flints with relatively high concentrations of clay related elements, for example those from the mine of Beer, have relatively higher $\mathrm{Al} / \mathrm{K}$ ratios, than those with relatively low trace-element concentrations, most of the other mines (Bush \& Sieveking 1986, 134 table 14.1; Sieveking et al. 1972). Al/K ratios fall in a similar range as the ones found in this study, suggesting environments of formation are similar between the Caribbean flints and these European ones.

Figure 2.22 (opposite page). One normal and five thin-section photos of different flints and cherts showing evidence of weathering. Thinsection photos in crossed polars (CP) and plain polarized light (PPL). 


\section{Antigua tuff cherts}

Through comparison of the different flints, it is noted that variation between sources originating within a similar geological formation is small, although exceptions may occur. Variation between flints from different formations can be more significant, however. Furthermore, weathering may considerably alter the trace-element concentration values of particular flints, thereby increasing variation, both between as well as within sources. Knowing this, it is expected that general differences between flints formed within limestone, and cherts formed within tuffs will be significant as well. This has been confirmed. It has also become clear that variation among cherts formed within tuffs can be considerable.

Based on host-rock and chemical composition, the Central Plain and Basic Volcanic Suite cherts can be divided into two groups: (1) the Shirley Heights and Buckleys cherts, and (2) the Corbison Point and Dry Hill cherts. ${ }^{11}$ The first group includes relatively pure cherts possibly formed from non-biogenic silica, and the second group represents bedded cherts in carbonate-rich and bioclast rich tuffs, possibly formed from biogenic silica.

Despite their pure appearance under the microscope in which only quartz is identified, the first group of cherts contains significant amounts of trace-elements, in particular the Shirley Heights locality. Within this group, the Buckleys chert data are only limited because the material gathered is not likely source material, given their artificial scattering. The data suggest that tuff at Buckleys may have been richer in carbonate material than the Shirley Heights cherts, as Ca is higher with respect to the concentration of Al. Furthermore, there is a correlation between $\mathrm{Ca}, \mathrm{Mg}$, $\mathrm{Sr}$, and $\mathrm{Ba}$. At Shirley Heights, a correlation between these latter elements is less evident, whereas a correlation between $\mathrm{Al}$ and $\mathrm{Ca}$ indicates that $\mathrm{Ca}$ is primarily associated with clays or tuffs.

A closer look at the Shirley Heights data reveals that a large group of elements is correlated (Al-Fe-Li-Ca-K-Na$\mathrm{Mg}$ ), which can be sub-divided into two groups, exhibiting an even stronger correlation (table 2.12). These two sub-groups are Al-Fe-Li-Ca on the one hand and $\mathrm{K}-\mathrm{Na}-\mathrm{Mg}$ on the other. With increasing Al-Fe-Li-Ca, the K-Na-Mg concentrations become higher as well; these latter ones increase proportionally less, however. This is indicated by different ratios: $\mathrm{Al} / \mathrm{Fe}$, $\mathrm{A} / \mathrm{Li}$, and $\mathrm{Al} / \mathrm{Ca}$ remain constant with increasing concentration of $\mathrm{Al}$, whereas $\mathrm{Al} / \mathrm{K}, \mathrm{Al} / \mathrm{Na}$, and $\mathrm{Al} / \mathrm{Mg}$ become higher when $\mathrm{Al}$ increases. Both groups apparently represent two different mineral fractions from which they originate.

As already pointed out, igneous rocks on Antigua are calc-alkaline in nature, with relatively abundant $\mathrm{Ca}, \mathrm{Fe}$ and $\mathrm{Mg}$ in addition to $\mathrm{Al}$ (chemical data from Christman 1972). Except for $\mathrm{Mg}$, the element composition of the igneous rocks correlates well with the first group of elements. As I specified above, $\mathrm{Mg}$ may have a major marine origin (chlorite), in addition to an igneous one. The close similarity between both sets of elements suggests that they may directly originate from the tuff. On the other hand, $\mathrm{K}$ is rare among the igneous rocks, and its origin is therefore likely marine in the form of clays, such as illite (K). Combining this, it can be concluded that both cherts were likely formed within a carbonate poor (Ca is low compared to the flints, for example) marine deposition of tuffs and clays, which is notably different from the carbonate pure environment of the Antigua Formation flints.

Difference in solubility may explain the proportional differences of both fractions within the low trace-element and high trace-element samples. Apparently, the clay fraction has a lower solubility grade, as is suggested by proportionally higher concentrations of $\mathrm{K}, \mathrm{Mg}$, and $\mathrm{Na}$ compared to the $\mathrm{Al}, \mathrm{Fe}, \mathrm{Ca}$, and $\mathrm{Li}$ concentrations (expressed by low $\mathrm{A} / \mathrm{K}, \mathrm{Al} / \mathrm{Mg}$, and $\mathrm{Al} / \mathrm{Na}$ ) in the relatively pure cherts. In a more pure chert the silica has replaced the host-rock to a greater extent.

The cherts from Corbison Point and Dry Hill resemble the Antigua Formation flints more in their trace-element composition, notably in their high $\mathrm{Ca}$ and $\mathrm{Mg}$ concentrations (tables 2.5-9). This is expected given their carbonate rich environment of formation. Still, differences are apparent. In particular, the relatively high variation within the Corbison Point chert is striking. I already noted that the Corbison Point cherts can be divided into four different varieties based on similarity in microscopic characteristics, as well as chemical composition. These four varieties each originate within one of the different beds identified at the Corbison Point rock section. Comparison of the chemical data shows that variation within each variety (so, within each bed) was low, whereas variation between beds is high with regard to $\mathrm{Al}$ and Li concentration and $\mathrm{Al} / \mathrm{K}$ ratios, suggesting a different mineral suite origin for each bed.

The most striking differences are tabulated in table 2.13. The most extreme varieties are represented by a calcareous poor and $\mathrm{Al}-\mathrm{K}-\mathrm{Na}$ poor pure chert, with high $\mathrm{Al} / \mathrm{K}$ ratios on one end and a bioclast rich, calcareous rich, chert with low $\mathrm{Al} / \mathrm{K}$

\footnotetext{
11 The limited data obtained on the Willis Freeman chert are left out of this discussion, as the available results do not provide any clear patterns in the form of correlated groups of trace elements, hampering the understanding of trace element origin. Additional sample taking in the future, combined with an extensive series of chemical analyses, should clarify whether this lack of correlation is real or whether it is a result of poor sampling.
} 


\begin{tabular}{|c|c|c|c|c|c|c|c|c|c|c|c|c|c|}
\hline \multirow[t]{2}{*}{ sample number } & \multicolumn{4}{|c|}{ tuff group } & \multicolumn{3}{|c|}{ clay group } & \multicolumn{3}{|c|}{ tuff group } & \multicolumn{3}{|c|}{ clay group } \\
\hline & $\mathrm{Al}$ & $\mathrm{Fe}$ & $\mathrm{Li}$ & $\mathrm{Ca}$ & $\mathrm{K}$ & $\mathrm{Na}$ & $\mathrm{Mg}$ & $\mathrm{Al} / \mathrm{Fe}$ & $\mathrm{Al} / \mathrm{Li}$ & $\mathrm{Al} / \mathrm{Ca}$ & $\mathrm{Al} / \mathrm{K}$ & $\mathrm{Al} / \mathrm{Na}$ & $\mathrm{Al} / \mathrm{Mg}$ \\
\hline C-ANSH-01 & 4168.2 & 198.5 & 14.2 & 489.7 & 649.8 & 576.4 & 62.7 & 21.0 & 294.4 & 8.5 & 6.4 & 7.2 & 66.5 \\
\hline C-ANSH-09 & 2192.1 & 93.6 & 9.1 & 227.2 & 458.9 & 410.4 & 39.8 & 23.4 & 241.2 & 9.7 & 4.8 & 5.3 & 55.0 \\
\hline C-ANSH-11 & 1735.3 & 71.1 & 6.7 & 229.2 & 374.6 & 357.6 & 36.1 & 24.4 & 258.2 & 7.6 & 4.6 & 4.9 & 48.1 \\
\hline C-ANSH-12b & 278.9 & 18.1 & 1.4 & 123.1 & 93.9 & 97.2 & 8.2 & 15.4 & 193.7 & 2.3 & 3.0 & 2.9 & 34.0 \\
\hline
\end{tabular}

Table 2.12. Concentration values (in $\mathrm{mg} / \mathrm{kg}(\mathrm{ppm})$ ) and ratios of main correlated trace-elements in Shirley Heights chert. Note that samples are tabulated in decreasing order of Al.

ratio and moderate Al-K-Na concentrations on the other end. These chemical data suggest alternation between one period of low carbonate and high clay and tuff deposition resulting in a proportionally high terrestrial input, and consequently a high $\mathrm{Al} / \mathrm{K}$ ratio (variety $\mathrm{C})^{12}$, and periods of high carbonate deposition and relatively lower, but varying terrestrial inputs, with lower $\mathrm{Al} / \mathrm{K}$ ratios (varieties $\mathrm{A}, \mathrm{B}$, and $\mathrm{D}$ ). Within these latter carbonate chert varieties, it is noted that they follow the trend observed for the limestone flints: the sequence from $\mathrm{D} \rightarrow \mathrm{B} \rightarrow \mathrm{A}$ corresponds with increasing $\mathrm{Al}$ concentrations, indicating higher terrestrial input, resulting in higher $\mathrm{Al} / \mathrm{K}$ ratios. Close comparison with the limestone flints, however, shows that the $\mathrm{Al} / \mathrm{K}$ ratios within the Corbison Point cherts on average are higher, given a certain level of Al-concentration.

In this regard, the Dry Hill cherts exhibit considerably less variation; the samples basically resemble the B and D varieties of the Corbison Point chert in microscopic features and chemical composition. However, it has to be pointed out that the $\mathrm{Al} / \mathrm{K}$ ratio generally is higher than most of the $\mathrm{B}$ and $\mathrm{D}$ cherts at Corbison Point. This similarity suggests that although the beds exposed at Dry Hill correspond with beds at Corbison Point, the individual beds are not completely similar.

Unlike minor variation between Antigua Formation flints from different localities, cherts within the Central Plain Group and Basal Volcanic Suite exhibit considerable variation, even within single localities that only expose small portions of a formation. At some localities variation is continuous such as Shirley Heights, corresponding with the degree of silification, while at others it is discrete, corresponding with different beds, such as Corbison Point. This contrast between the limestone flints and the tuff cherts may well be explained by the different conditions under which they were formed. The origin of the silica plays a decisive role in this respect.

\begin{tabular}{|c|c|c|c|c|c|c|c|c|c|c|}
\hline number & & type & $\mathrm{Al} / \mathrm{K}$ & $\mathrm{Al}$ & $\mathrm{K}$ & $\mathrm{Na}$ & $\mathrm{Li}$ & $\mathrm{Ti}$ & $\mathrm{Ca}$ & $\mathrm{Mg}$ \\
\hline ANCP-20 & bioclast poor and carbonate rich & $\mathrm{D}$ & 1.78 & 51.76 & 29.02 & 252.78 & 0.93 & 12.02 & 8828.38 & 238.62 \\
\hline ANCP-02 & bioclast rich and carbonate rich & $\mathrm{B}$ & 3.40 & 773.59 & 227.34 & 488.46 & 17.22 & 113.53 & 695.73 & 96.00 \\
\hline ANCP-13. & & B. & 3.70 & 570.29 & 154.08 & 1299.00. & 11.36 & 33.43 & 30698.85 & 554.58 \\
\hline ANCP-11.2 (pri) & bioclast rich chert with varied & A & 4.30 & 1611.41 & 374.63 & 1128.09 & 25.40 & 80.17 & 9579.71 & 267.19 \\
\hline ANCP-11.1 (pri) & carbonate concentrations and & A & 4.45 & 1551.94 & 348.72 & 1077.58 & 23.81 & 82.63 & 6434.20 & 205.41 \\
\hline ANCP-05 & & A. & 5.54 & 2332.44 & 420.80 & 861.35. & 33.73 & 110.10 & 437.77 & 99.01. \\
\hline ANCP-04 & bioclast poor and carbonate poor & $\mathrm{C}$ & 6.34 & 169.98 & 26.80 & 103.89 & 1.58 & 10.90 & 54.91 & 54.56 \\
\hline ANCP-06 & pure chert with low trace-element & $\mathrm{C}$ & 6.70 & 81.08 & 12.11 & 52.78 & $<$ d.1. & $<$ d.1. & 18.27 & 14.64 \\
\hline ANCP-03 & concentrations & $\mathrm{C}$ & 6.79 & 148.57 & 21.87 & 156.82 & 1.86 & 23.98 & 80.24 & 61.57 \\
\hline
\end{tabular}

Table 2.13. Sub-varieties of chert based on microscopic as well as chemical characteristics within Corbison Point chert. Trace-element concentrations in $\mathrm{mg} / \mathrm{kg}$ (ppm), "pri" denoted primary sample taken from one of the beds.

\footnotetext{
12 Note that $\mathrm{Ca}$ is correlated with $\mathrm{Al}$, and that the $\mathrm{Ca} / \mathrm{Mg}$ ratio is much lower than in the carbonate rich varieties. This suggests that $\mathrm{Ca}$ is primarily associated with the clays and tuffs, and not with a carbonate fraction.
} 
Nodular chert in limestone derives its silica from small organisms, consisting of opal (amorphous silica) such as diatoms, or radiolarians. These fine organisms will be only deposited in a low-energetic marine environment (Zijlstra 1994). Usually, this is a protected basin, which receives little terrestrial inputs (clays, tuffs, or detrital minerals). This means that these environments are relatively pure in carbonate (silica concentration may even be low as well), which makes them very similar and leaves little room for variation.

In contrast cherts in tuffs or volcanic rocks derive their silica from the Si abundantly present in the tuff or volcanic host-rock. Although the specific mechanism by which silicification occurs has not been fully understood, it has become clear that host-rock can vary considerable in composition, with respect to elements such as $\mathrm{Al}, \mathrm{K}, \mathrm{Mg}, \mathrm{Ca}, \mathrm{Fe}$, and $\mathrm{Na}$. As a result, the chert may differ in trace-element composition as well.

\section{Puerto Rico cherts}

A proper understanding of the trace-element composition of the Puerto Rican cherts is complicated by their unclear geological origin. From the ICPAES analysis it is clear that the different localities share a number of features (table 2.59): (1) a very low $\mathrm{Ca} / \mathrm{Mg}$ ratio, (2) low Al-K-Na concentrations, (3) high Fe and $\mathrm{Mn}$ concentrations for a large number of samples, and (4) a generally poor correlation between the different elements. These latter three characteristics suggest that chemical weathering has affected the rocks. This is already evident from the general light colour of most cherts, and the microscopic identification of clear concentrations of iron oxide, notably in the outer rim of most samples. The formation of voids, similar to some of the secondary Antigua flints, had not occurred, however. Combined with the fact that calcite is not present in the Puerto Rico cherts, this again supports the notion that within the Antigua Formation flints these visible voids primarily have to be related to calcite dissolution.

Table 2.14 lists some specific characteristics for each location individually. It has to be stressed again that in comparison to the Antigua Formation flints, for example, the correlation is generally weaker, or only applies to a part of the samples from within the source.

\section{Summary}

Close comparison of lithic sources originating from the different islands shows that they vary in their trace element composition if they originate from different host-rocks. In particular, the concentration ratios of elements associated with a clay, tuff, and carbonate fraction exhibit diversification, and suggest the presence of different types of impurities (figure 2.24). Furthermore, the results show that inter-source (between) and intra-source (within) similarity can be considerable for flint varieties originating within the same limestone formation. In particular, constant $\mathrm{Al} / \mathrm{K}$ ratios suggest that the clays, from which a substantial portion of the elements originate, are the same.

Cherts formed within tuffs generally vary more, both in concentration values and the type of terrigenous input, as suggested by varying $\mathrm{Al} / \mathrm{K}$ ratios. This variation is not only evident between sources, but may be even the case within a single source. This can occur if different beds are exposed, which were formed in varying host-rock types, as is the case at Corbison Point and Dry Hill. Furthermore, the data suggest that weathering may have a significant influence on the original trace-element composition. Such is particularly evident for cherts and flints that have been buried in soils for long periods. Beach environments, where salt water is the primary weathering agent, have less significant effect. The more severe weathering characteristic of soils can be attributed to significant calcite dissolution, making the flints more porous and increasing the quartz surface exposed to weathering agents. This larger surface exposure will increase the weathering rate of quartz as well as impurities in it by available humic acids.

Overall, different forms of weathering have a negative effect on source discrimination. Weathering produces high variation among concentration values within sources, making the chance of overlap between sources more likely. In specific cases, however, it may differentiate localities, which were originally similar. This only accounts for sources where all available material, spatially constrained, has been exposed to a similar weathering environment for a considerable period, as is the case at Blackman's Point. 


\begin{tabular}{ll}
\hline Source & Specific features \\
\hline Cerillos & $*$ high but varied $\mathrm{Al} / \mathrm{K}$ ratio \\
& $*$ very low Ca/Mg ratio \\
& $*$ Fe-Mn-V correlation \\
& $*$ Mg-Li correlation \\
& $*$ Al-Ti correlation \\
Villa Taina & $*$ varied, but on average high Fe concentration \\
& $*$ high but varied Al/K ratio \\
& $*$ Al-Fe-V-Zn correlation \\
& $*$ Ca-Mg correlation \\
& $*$ high Fe concentration \\
& $*$ Al-K-Na-Ti-Cr-Sr correlation: clay/tuff \\
& $*$ P-Fe-Zn correlation: iron minerals \\
& $*$ varied, but on average low Fe concentration \\
& $*$ Al-Fe correlation \\
& $*$ Ti-Mn correlation \\
& $*$ Ca-Mg correlation \\
& $*$ low Fe concentration \\
& $*$ Al-K-Na correlation \\
& $*$ Ca-Mg correlation
\end{tabular}

Table 2.14. Puerto Rican cherts. Specific chemical characteristics for each source.

\subsection{DisCRIMINATION OF SOURCES}

\subsubsection{Discriminant Analysis}

Source characterisation and discrimination using trace-element concentrations has become a common method within archaeology (Cackler et al. 1999b; Craddock et al. 1982; De Bruin et al. 1982; Glascock et al. 1998; Luedtke 1978, 1979, 1992; Shackley 1998; Sieveking et al. 1972; Sieveking \& Thompson 1986; see Church 1994 for an overview). The possibility of obtaining a large number of variables (the concentrations of the different elements) as well as their quantification (the concentration values), gives a great advantage over traditional macroscopic and microscopic techniques. These latter techniques often involve a more limited number of variables, which are typically hard to quantify.

Acquisition of numerous and quantifiable variables makes it possible to employ multi-variable statistical techniques to differentiate sources and provenance artefacts. Following Luedtke (1979), who tested different identification methods, the application of Discriminant Analysis is most suited to this purpose. The recurrent use of this technique supports this notion (Craddock et al. 1983; De Bruin et al. 1972; Glascock et al. 1998; Sieveking et al. 1972).

Keckla $(1980,7)$ defines Discriminant Analysis as "a statistical technique which allows the researcher to study the differences between two or more groups of objects, with respect to several variables simultaneously." In relation to this study, the sources of chert material are the groups, and the different trace-element concentration values represent the variables. This technique can be applied in two different ways: (1) Descriptive Discriminant Analysis is used in interpreting group differences; and (2) Predictive Discriminant Analysis in classifying (assigning ${ }^{13}$ ) cases to groups. The latter application has been widely used in provenance studies for stone materials.

In short, Discriminant Analysis (DA) determines which factors contribute most to group separation. It identifies functions, called canonical discriminant functions, that are linear combinations of the original variables. These functions maximally enhance group separation. The classification technique of DA calculates a centroid for each group, which is the mean value in multi-dimensional space based on values obtained from the canonical discriminant functions. It then compares the distance of the canonical value of an unknown case (an artefact for which one wants to identify the source) to the centroids of the different groups. This distance is called the Mahalanobis distance. The Mahalanobis distance $\left(\mathrm{D}^{2}\right)$ is defined as the "squared Euclidean distance between a group centroid and an individual specimen divided by the group standard deviation in that direction" (Glascock et al. 1998). The artefact will be assigned to the group for which the $\mathrm{D}^{2}$ is smallest.

\footnotetext{
13 In this chapter I use the word "assign" for placing an unknown case (i.e. artefact) within a pre-defined group (a source) and the word "classify" for grouping a number of cases based on predefined criteria. Confusingly, in predictive Discriminant Analysis the term classify is often used for assigning unknown cases to known groups (e.g., Duarte Silva \& Stam 1995).
} 


\section{Chert occurrences in the Northern Lesser Antilles and Puerto Rico}
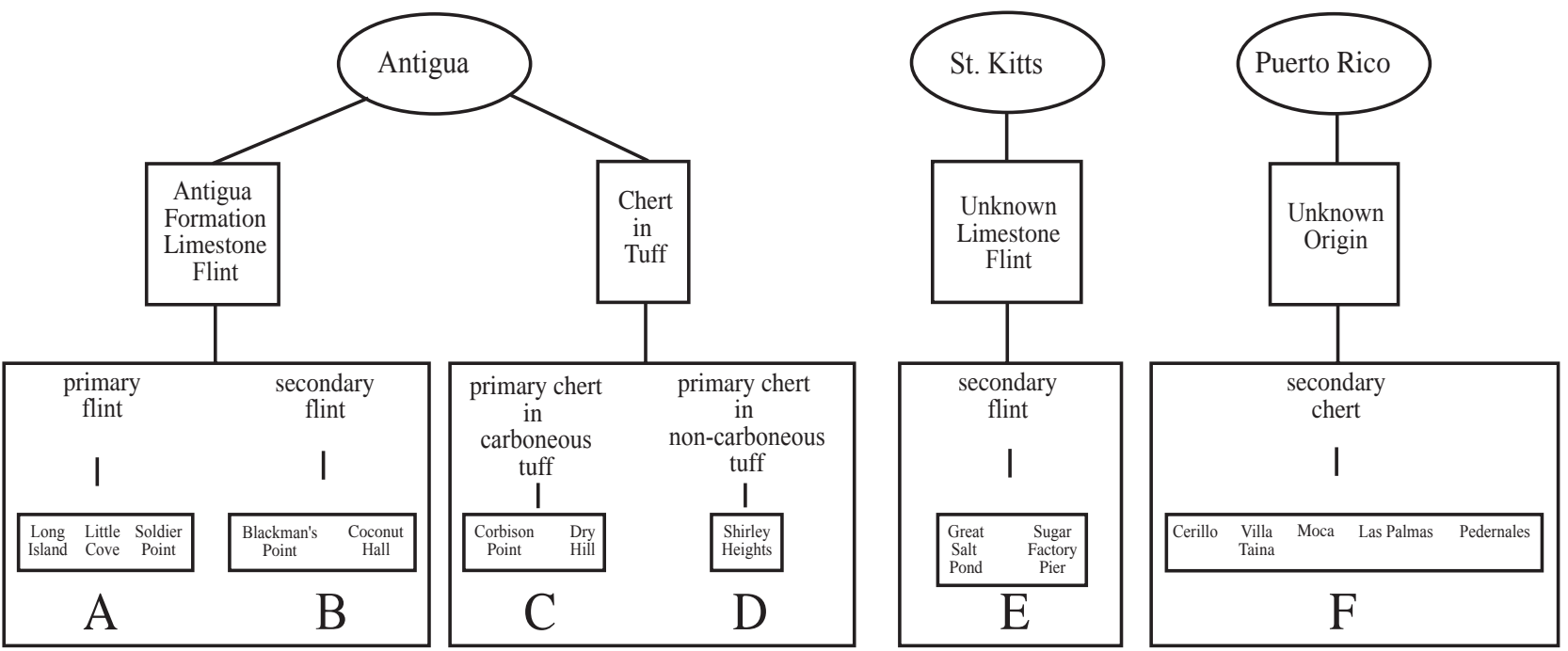

A \& E: Correlated Al-K-Ti-(Fe); Constant $\mathrm{Al} / \mathrm{K} \longrightarrow$ terrestrial and marine clays High but varied $\mathrm{Ca}$-concentration $\longrightarrow$ carbonate

B: $\quad$ Weakly correlated Al-K-Ti; Varying Al/K $\rightarrow$ terrestrial and marine clays, which partly have been dissolved Low Ca-concentration $\longrightarrow$ dissolved carbonate; Varying but high $\mathrm{Fe} \longrightarrow$ iron from surrounding soil

$\mathrm{C}: \quad$ Varied $\mathrm{Al} / \mathrm{K} \longrightarrow$ terrestrial, marine clays and tuff in varying compositions by layer High but varied $\mathrm{Ca}$-concentration $\longrightarrow$ carbonate

D: $\quad$ Correlated Al-Fe-Li-Ca group $\longrightarrow$ tuff

Correlated K-Na-Mg group $\longrightarrow$ marine clays

F: $\quad$ Poorly correlated elements, generally low concentrations; Fe may high $\longrightarrow$ weathering Origin of the elements is unclear; no carbonate

Figure 2.24. Overview of flint and chert geochemistry in the Lesser Antilles and Puerto Rico.

Glascock et al. (1998, 31), following Keckla (1980) and Hughes (1986), have listed the statistical assumptions, that need to be fulfilled when the classification aspect of DA is used:

"(1) there are two or more groups;

(2) there are at least two observations in each group;

(3) the number of discriminating variables must be at least two less than the total number of specimens;

(4) the discriminating variables are measured at the interval level;

(5) the discriminating variables must not be linear combinations of other discriminating variables;

(6) each group is drawn from a sample population with a multivariate normal distribution on the discriminating variables; and

(7) the variance-covariance matrices for each group must approximately be equal." 


\subsubsection{Results}

In this study, 12 elements were used for the discrimination of sources and assigning artefacts to sources, as they proved to be above the detection limit in most cases and produced relatively precise results. They include the following:

Lithium (Li), Sodium (Na), Potassium (K), Magnesium (Mg), Calcium (Ca), Barium (Ba), Titanium (Ti), Vanadium (V), Chromium (Cr), Manganese (Mn), Iron (Fe), and Aluminium (Al).

Of these, $\mathrm{V}, \mathrm{Cr}$, and $\mathrm{Mn}$ concentrations were occasionally below the detection limit, and this missing value was given an arbitrary value of $10 \%$ lower than the detection limit (see Rock 1988 for how to handle missing values). Five samples from five different sources were omitted, as they possessed outliers for different elements.

In this study, the first five requirements as specified and listed by Glascock et al. (1998) are met. Absolute values of some elements, however, are not always distributed normally. Therefore, a log-transformation of each value was performed to obtain a distribution more similar to a normal one, following earlier studies relying on compositional data (Glascock et al. 1998; Luedtke 1979; De Bruin et al. 1972). Furthermore, the variance-covariance matrices are not equal for all sources. In particular, the Corbison Point and Shirley Heights cherts are different in this respect from the Antigua Formation flints. This inequality may have consequences for the final assignment of the artefacts.

To evaluate how well sources in this study are discriminated, in the first instance only the source samples were entered and tests were performed on classification results, following Glascock et al. (1998). Luedkte (1979) named three different types of errors that occur when assigning artefacts to sources. Her type one error corresponds with assignment of a case to a source when it is actually from another source (figure 2.25). The SPSS computer program (version 9.0 for Windows) provides the option of treating source samples as unknown cases and this can be used as an estimator of how well the elements separate the different sources, and the rate of successful assignment. This can be considered as an estimator of type one error. There are two "classification" possibilities in SPSS: (a) one source sample at a time is treated as unknown, when all information is used in separating the sources, including the information on this "unknown" sample, or (b) one source sample at a time is treated as unknown, when information on this sample is not used in the source separation. This latter type of classification is referred to as cross-validation in the SPSS program, and it also called the leave-one-out, or jack-knife method (Duarte Silva \& Stam 1995; Glascock et al. 1998)). According to Duarte Silva \& Stam (1995, 301-304), the first estimator of the correct classification rate is optimistically biased. They prefer the cross-validation type of classification. This one, however, is a poor estimator if small sample sizes have to be dealt with, which is the case in this research ${ }^{14}$ Still, Glascock et al. (1998) used this latter option in their provenance study of Meso-American obsidians to see how well the different sources were discriminated.

The other types of error are each other's opposites. Error 2 is defined as assigning an artefact to a source not included in the study when in reality it belongs to a source within the study (see figure 2.25). Error 3, then, is defined as assigning an artefact to one of the sources within the study when it actually is from a source not part of the study (see figure 2.25). Error 3 is considered by Luedtke as "potentially the most serious type" $(1979,751)$ because the number of these unknown sources can be significant. Her study on comparing different identification techniques confirms this. The difficulty with studying these latter two errors lies in the way the classification aspect of DA functions. The analysis does not consider the possibility of a source outside the study and will always assign an artefact to one of the sources included within it. One way of overcoming this problem is by defining an arbitrary value of the Mahalanobis distance as the cut-off point beyond which artefacts are classified as unknown. However, the difficulty remains, that a too high $\mathrm{D}^{2}$ value, will result in a large error 3 type, whereas a value too low will result in a large error 2 type.

Different levels of source discrimination can be applied in this study. In the most detailed level, each locality on each island is treated as a separate source (group), resulting in 15 groups. A more general level puts the sources into larger groups on the basis of their shared geological history, e.g. all sources from the Antigua formation in one group, all the Central Plain sources in one group, etc. The most general level treats the different islands each as separate groups.

Of course, the most specific level would be the most desirable level, in particular if lithic procurement behaviour by the inhabitants of the source islands themselves is under investigation and there are indications that utilized cherts may have come from different islands. In such a case, it may be meaningful to differentiate between different regions across an

\footnotetext{
14 The leave-one-out principle is one specific type of cross-validation. Duarte Silva \& Stam (1995) state that a common practice of cross-validation in the social sciences is to divide the groups (sources) into two, after which one half is used to determine the discriminant functions, and the other half is used as a test sample which is treated as unknowns. This, off-course, can only be done when sample sizes for groups are considerable.
} 


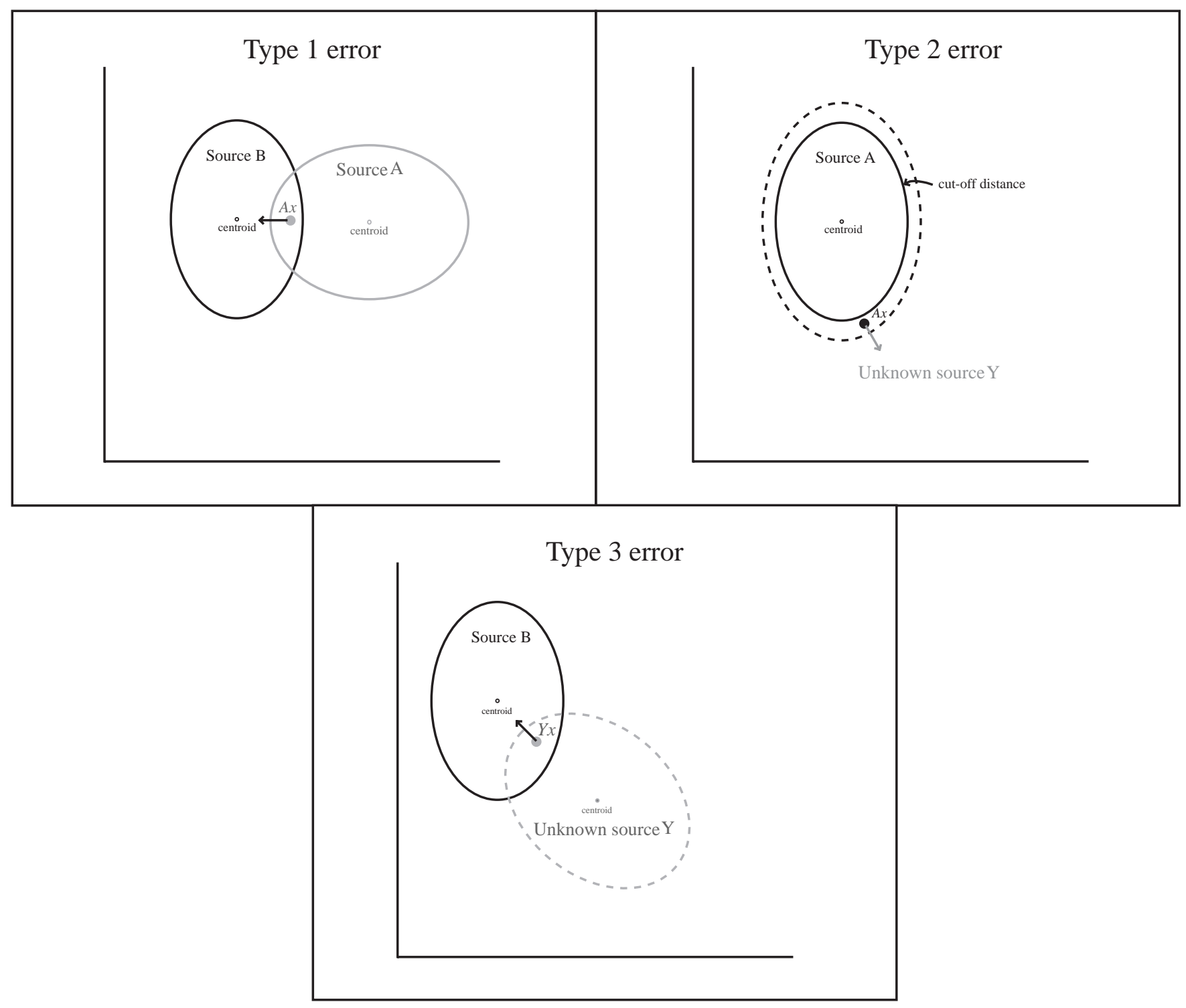

Figure 2.25. Graphic depiction of error types according to Luedtke (1979).

individual island. On a larger scale, however, if the regional distribution of chert materials among the different islands is at issue, the provenance only specified to the island level may well be sufficient.

I tested these different levels on their correct assignment rate using both classification procedures in the SPSS program. For each level, I searched for the element combination, that gave the highest rate, by the backward stepwise method, as described by Keckla (1980). It appeared that using all 12 elements did not necessarily produce best results in most cases, again supporting the notion that intra-source variability is high for some elements. Furthermore, it should be emphasized that high intra-source variability will significantly lower the correct assignment rates in the case of leave-one-out cross-validation, in particular for sources characterized by low number of samples.

The most detailed level of source separation using cross-validation classification in the SPSS program shows that the correct assignment rate is relatively poor, a little above 73\%. Different researchers working on northwestern European flints found similarly low or even lower success rates (Craddock et al. 1983; De Bruin et al. 1983). This poor assignment rate compared to, for example, obsidian studies (see Glascock et al. 1998) can be attributed to large intra-source variation of some sources 
in particular and low inter-source variation in general in the case of cherts and flints. ${ }^{15}$

Looking in detail at assignments within this study, many of the incorrectly assigned samples are assigned to sources with a similar geological context. Many of the Dry Hill samples, for example, are assigned to the Corbison Point locality. Furthermore, it is noted that the particular sources from Puerto Rico and St. Kitts give poor results. Many of the samples from a locality on these the islands are misclassified to another source on the same island, showing that for these two islands inter-source compared to intra-source variation is low. If each of the islands is studied separately using discriminant analysis, assuming that chert can only come from this island, St. Kitts gives a correct assignment rate of only around $60 \%$ for the Great Salt Pond and Sugar Factory Pier localities. This means that geo-chemical characterisation only barely provides better assignment results than randomly grouping the artefacts to one of the two sources, which would give a rate of $50 \%$. Above I noted that the St. Kitts flint is similar in its macroscopic and microscopic appearance, suggesting a common origin. The geochemical results further support this. In statistical terms both sources can be nearly considered as two samples derived from the same population. Consequently, it means that St. Kitts flint cannot be assigned with any accuracy to either of the two localities.

For Puerto Rico, the situation is different. Although the correct assignment rate is low (74\%), the fact that we are dealing with 5 sources makes this $74 \%$ significantly higher than $20 \%$ that would be obtained when randomly grouping the samples. Furthermore, if different discriminant analyses are performed in which sources are compared two at a time, almost $100 \%$ correct assignment can be achieved for almost every pair. This clearly supports the existence of differences between sources despite the low overall rate of correct assignments. Still, determining the exact provenance of Puerto Rican artefacts on the basis of geo-chemical characterisation will be inaccurate for most localities. Accuracy will be improved if, a priori, localities are excluded on the basis of macroscopic features or unlikely use.

On Antigua, source assignment is also not perfect. However, it is evident that most misclassified samples are ascribed to a source, that can be considered similar in geological terms (see above). Discrimination in Antigua on a broader scale, in which sources are grouped following the different geological regions, roughly between the northeastern and southwestern parts, produces better results. However, a 100\% correct assignment rate cannot be obtained. This is partly due to the broad variation within the Corbison Point chert. Given discontinuous variation between different layers within it, additional sample taking in the future will probably make it possible to divide the Corbison Point source into several subsources, each corresponding with a single layer. These sub-sources, treated as separate groups, will probably together exhibit less overlap with other Antigua sources than grouping them as one source.

Considering this poor correct assignment rate on a source specific level, the next step is to see how well the three islands can be discriminated. It appears that approaching this problem using two steps produces the best results. By first discriminating Puerto Rico from the two Lesser Antillean islands, a 100\% correct assignment rate is nearly obtained. One sample from Puerto Rico out of 46 samples is assigned to the Lesser Antilles, and two samples from the Lesser Antilles out of 96 samples in total (one from Antigua and one from St. Kitts) are assigned to Puerto Rico. The next step of discriminating Antigua from St. Kitts results in two St. Kitts samples assigned to Antigua, while all Antigua samples are correctly identified, corresponding with an $95.7 \%$ overall correct classification rate.

The problem with applying discriminant analysis in this manner is that errors made during the first analysis will be of significance during the following analyses. This means that the total error during the last analysis is the sum of all errors made during the earlier ones, plus the last one. However, it appeared that the overall correct assignment rate is higher in the case of doing two separate analyses than separating the three islands during a single analysis.

Looking at discrimination within the island of Antigua, a similar series of discriminant analyses was attempted, which will ultimately produce higher rates of correct assignment. During each such analysis, source groups are separated from each other, reducing the number of sources to be discriminated in the next analysis. So, in the first analysis the Shirley Heights source can be separated from the rest with 100\% accuracy. In the following analysis, the Dry Hill and Corbison Point sources discriminate from the Antigua Formation flints. The Antigua Formation flints can then be divided into the Long Island source, the pair of Little Cove and Soldier Point, and the pair of secondary Antigua Formation flints from Blackman's Point and Coconut Hall. Only during the last round of analyses problems arose in distinguishing the Little

\footnotetext{
15 This may well by explained by the different environments of genesis between both rock materials. In the case of obsidian, sources usually correspond with specific volcanic outburst events. These events generally vary significantly in chemical characteristics, even between events from a single volcano. Furthermore, obsidian contains higher concentrations of trace- and rare-earth elements in general than does flint, which makes the possibilities of finding discriminating variables higher for obsidian.
} 
Cove from the Soldier Point, the Blackman's Point from the Coconut Hall, and the Dry Hill from the Corbison Point flints. Correct assignment, however, still is above $90 \%$ for the first pair, and even above $95 \%$ for the latter two cases. Furthermore, the inability to completely distinguish Corbison Point from Dry Hill has less significant archaeological implications as both localities are only at $1.5 \mathrm{~km}$ distance from each other along Antigua's western coast. On the other hand, the different analyses show that when it would be possible to exclude certain origins a priori, very accurate assignments may be given for the cherts and flints on Antigua.

This discussion shows that correct assignment cannot be achieved on a $100 \%$ basis for all sources. This analysis includes a number of lithic localities, that were not certainly exploited during the past. For a small number of other sources, in particular the Long Island source, clear evidence of exploitation in the form of flake scatters has been identified. Furthermore macroscopic inspection of a number of artefact collections from sites in the near region had already demonstrated that the Long Island source might have been of great significance during the pre-Columbian era, as these artefacts strongly resemble the source material. In the next few chapters I demonstrate that Long Island actually was the primary fine-grained material for making flake tools within the northern Lesser Antilles. Given this a priori knowledge and the fact that all sources are difficult to discriminate, I have approached the problem of discrimination and assignment differently, following a procedure in which the Long Island source obtains a central role. The primary question asked is: can a way be found to discriminate Long Island from other flint and chert sources, with a 100\% percent accuracy using cross-validation as the estimator? During such a procedure, all Long Island source samples have to be assigned to Long Island and all non-Long Island source samples have to be assigned to one of the other sources or source groups. Correct assignment to the other sources is desired, but not of primary importance. It appears that grouping the sources, based on similarity in geological formation and post-formation history as specified above, produces best results (figure 2.26).

In this grouping, a division is made between the primary Antigua Formation sources (LC and SP), the secondary Antigua Formation sources (BP and CH), the Central Plain Tuff cherts (DH and CP), the Basal Volcanic Suite cherts (SH), the sources from St. Kitts (GSP and SFP) and the sources from Puerto Rico (CE, VT, MO, LP, and PE). Table 2.15 lists the assignment results using these groupings. From this it is clear that almost a 100\% correct assignment rate can be obtained for the Long Island samples, and that none of the other source samples are assigned to Long Island. Only one Long Island source sample is assigned to the other primary Antigua sources, which is a likely mistake considering their similar geological origin. A second analysis then separates the Long Island source from the two other primary Antigua Formation flint sources. Using only four elements, a $100 \%$ correct assignment rate is obtained.

This procedure also allows a better evaluation of the type 2 and 3 errors, as only the Long Island source is relevant. The Mahalanobis distance values of the Long Island source samples do not vary much and are relatively low, which is in contrast to the high variation among some of the other sources. This low variation suggests that the chance of finding either significant amounts of type 2 or 3 errors are unlikely. Therefore, taking the highest value as cut-off point may in this case provide a means of avoiding samples from unknown sources (not included in the study) being assigned to the Long Island source. Such a source is likely situated within the Antigua Limestone Formation, given the similarity in trace-element composition of the primary sources from this formation.

As the above discussion shows, this method does not provide an absolute $100 \%$ certainty with regard to correctly assigning the source samples to each source, clearly indicating that the geochemistry of the different cherts overlap. Therefore, it is recommended that in each case of matching an artefact, sources preferably need to be excluded beforehand if possible, to minimize the chance of incorrect assignment. For example, in the case of dark coloured cherts or flints, the white to light grey coloured Shirley Heights source can be excluded.

Close inspection of the $\mathrm{D}^{2}$ values within this source study shows that some source samples have high values, suggesting that these sources are varied and these samples lie at the extremes of the within-source distribution. These $\mathrm{D}^{2}$ values, for example, can be higher than some other samples' "second source" $\mathrm{D}^{2}$ values (that is, the value of the Mahalanobis distance to the second best source, which is often tabulated in SPSS next to the first source $\mathrm{D}^{2}$ ). If one of the sources, of which some samples have low "second source" $\mathrm{D}^{2}$ values (for another source), has not been included in this study and if these high $\mathrm{D}^{2}$ values of the group of samples mentioned in the beginning are used as the cut-off points, it is immediately clear that there will be a number of type 3 errors. On the other hand, if the low "second source" $\mathrm{D}^{2}$ values guide the choice of the cut-off point, there will be a number of type 2 errors. Therefore, it is likely, considering the fact that not all sources are included, that if a specific $\mathrm{D}^{2}$ value is chosen, either considerable type 2 or 3 errors will arise in this study. 


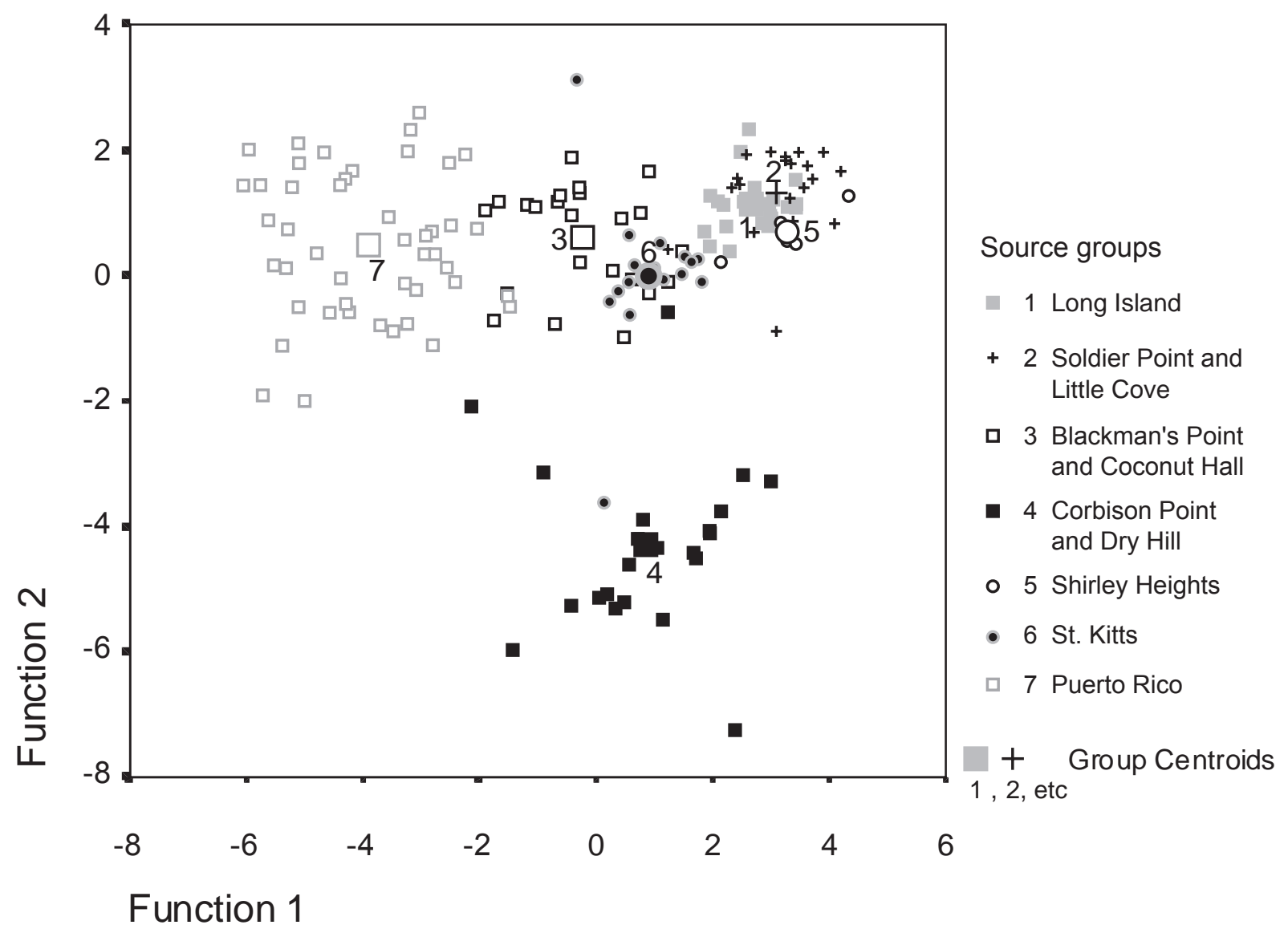

Figure 2.26. Scatter plot of the first two caniconal discriminant functions by source groups.

\subsection{SOURCE IDENTIFICATION OF ARTEFACTS.}

\subsubsection{Introduction}

During the analysis of a number of collections of excavated lithic artefacts from habitation sites on the different islands of the northwestern Lesser Antilles and Puerto Rico (see Chapters 3 and 5 for the complete list and description of the artefacts), chert artefacts were grouped into distinct varieties on basis of their macroscopic similarity. Usually, characteristics of each variety were defined on the basis of the different source groups, which are incorporated in this study. This means that if the macroscopic characteristics of a number of chert artefacts, or simply just one artefact, correspond with those characteristics of a source group they are grouped to a chert variety ${ }^{16}$ named after the source locality, e.g., Little Cove flint. In case of highly variable source groups, sub-varieties can be distinguished, e.g., Coconut Hall flint A, corresponding with the grey flints, and Coconut Hall flint B, corresponding with the brown flints. So, on the basis of macroscopic similarity, artefacts had already received a source assignment.

In case artefacts do not match these pre-defined source varieties, or similarity with these varieties is questionable, they were grouped into a new variety. Grouping ${ }^{17}$ and defining unknown chert varieties is an arbitrary process, which largely depends on the number of artefacts exhibiting similarity and the variation similar chert pieces exhibit. When one encounters unknown varieties, it is important to make a distinction between a variety based on similarity among artefacts and

\footnotetext{
16 Luedtke $(1992,6)$ uses the term chert type for a chert variety that originates from a single source location.

${ }^{17}$ I use the word grouping here, instead of classifying, because defining the variety occurred after putting the artefacts together, and not a priori, as should have been the case during classification.
} 


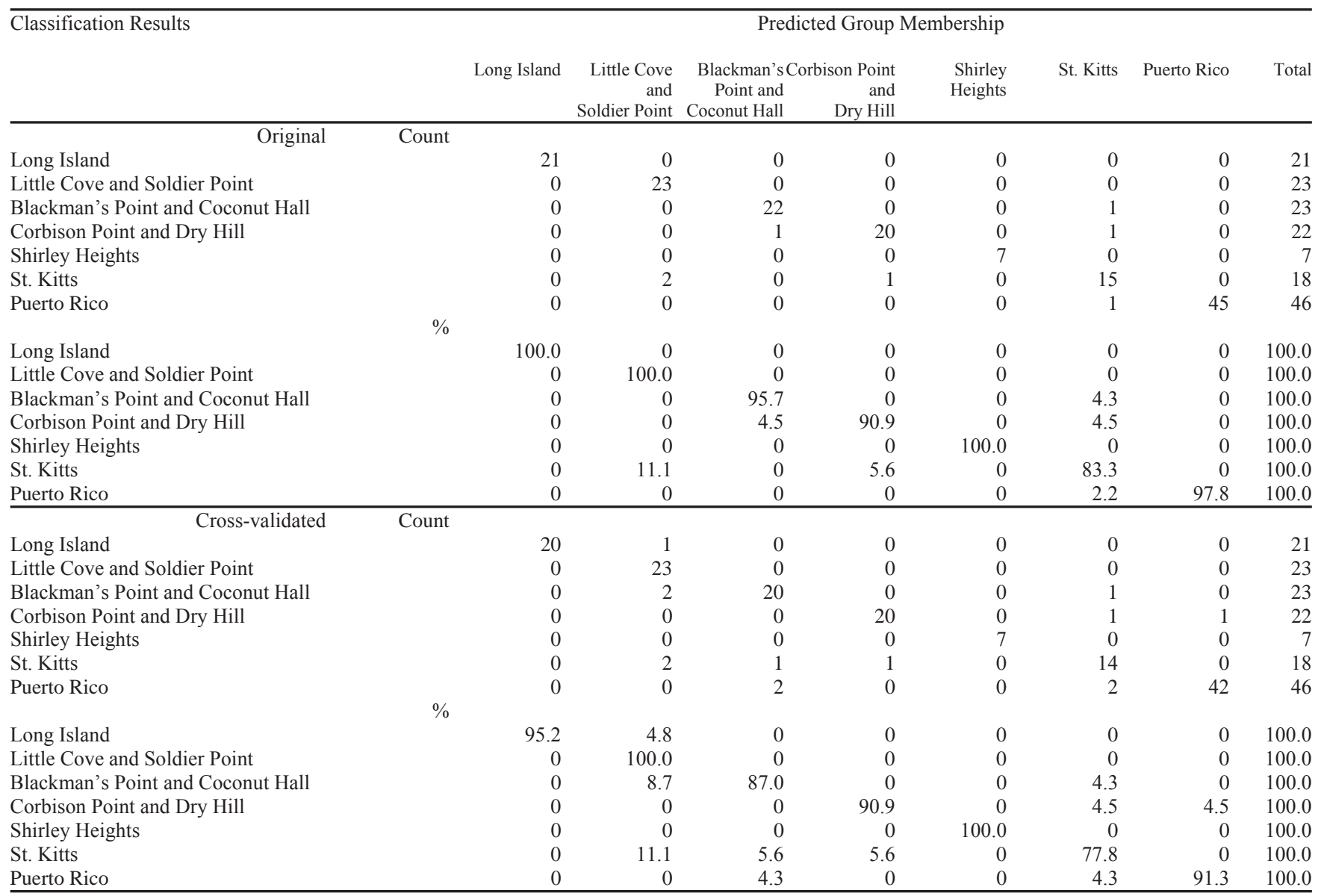

Table 2.15. Assignment results of DA analysis. In total, $95.6 \%$ of original grouped cases is correctly classified and $91.3 \%$ of cross-validated grouped cases is correctly classified.

a variety based on similarities with actual source materials, a chert type. The first one is an artificial group constructed by the researcher, whereas the second one is a real (natural) group. Usually the first one will be narrowly defined, only incorporating chert pieces, that are very similar in colour, clast contents, grainsize, and texture, whereas the latter one may cover a broad variation of colours, grainsizes, and textures, depending on the variability of the source. To give an example of the difficulties that may be encountered, I found a specific dull light coloured chert variety and a more translucent brown one among the artefacts of the Saladoid site of Sorcé on Vieques. Initially using a sub-sample, I defined two varieties, thereby suggesting more or less that they originate from two sources. Studying more artefacts, however, I discovered that both varieties were occurring in a single artefact, meaning that they actually represent two sub-varieties of a single source. If these unknown varieties were encountered, I usually specified whether or not they exhibited similarity with one or more of the known source varieties. In this way, I had some direction in evaluating likely source origins, and more importantly, I could exclude a number of source localities a priori, facilitating the evaluation.

Only a few archaeological sites were chosen, from which artefacts were selected for chemical analysis. These include the ones that produced relatively large samples of flake tool related materials. Furthermore, I attempted to include a site from every of the four temporal phases distinguished for the Ceramic period, as well as sites that would cover the Long Island flint distribution (see Chapter 3). Table 2.16 lists the selected sites.

Having assigned the artefacts to known or new varieties, I chose one artefact from the Long Island variety in addition to one each from the most important other varieties for chemical analysis. The selection of the latter artefacts was optional. Selection did not occur randomly, but was guided by the following principles: (a) the mass of the artefact preferably 


\begin{tabular}{lllr}
\hline Site & Island & phase & $N$ \\
\hline Sorcé & & Early Ceramic A & 6 \\
Anse des Pères* & Vieques & Early Ceramic B & 6 \\
Spring Bay 3* & St. Martin & Late Ceramic A & 1 \\
Kelbey's Ridge 2* & Saba & Late Ceramic B & 1 \\
Golden Rock & Saba & Early Ceramic B & 4 \\
Sugar Factory Pier & St. Eustatius & Early Ceramic B & 3 \\
Trants & St. Kitts & Early Ceramic A & 6 \\
Morel & Montserrat & Early Ceramic A & 3 \\
Anse à la Gourde & Guadeloupe & Early Ceramic B (early occupation phase) & 1 \\
& Guadeloupe & Late Ceramic A (middle occupation phase) & 1 \\
\hline
\end{tabular}

Table 2.16. Sites from which artefacts have been analysed using ICPAES. Artefacts from sites with * have been analysed during earlier research described in Knippenberg (1995, 1999a). N denotes the number of artefacts analysed for each site.

had to be heavier than $5 \mathrm{~g}$, facilitating sample preparation for ICPAES ${ }^{18}$; (b) the sample had to be a true representative of the variety in question, that is, its macroscopic characteristics were shared with the majority of the artefacts assigned to that variety, and (c) the artefact preferably did not entail technologically or functionally important information, in other words shatter was preferred over flake cores and utilized flakes (flakes with use or intentional retouch).

\subsubsection{Source assignment}

The concentration values of the different elements for the artefacts are listed in Appendix C. The DA analysis of the artefacts was divided into two series. A separate analysis was performed for the artefacts grouped to the Long Island variety. The remaining artefacts were analysed using two different procedures. During the first analysis, a priori knowledge on macroscopic characteristics was not used, whereas during the second analysis specific sources were excluded based on a priori information.

Twelve samples classified as Long Island flint and originating from different habitation sites were selected for ICPAES analysis. These samples were all part of larger sets of Long Island artefacts excavated at each of the sites. The sample of Vieques had been part of a larger sample of only seven artefacts, whereas the sample from Trants had been part of a sample of more than 550 Long Island artefacts. Using DA, during which a distinction was made between Long Island, the other two primary Antigua Formation sources, the secondary Antigua Formation sources, the Central Plain bedded chert sources, the Basal Volcanic Suite source from Shirley Heights, the St. Kitts sources, and the Puerto Rico ones, resulted in group of 10 samples assigned to Long Island (85\%), one sample (A-F-StEGR-01) assigned to the closely related primary Antigua Formation source group (Little Cove and Soldier Point), and one sample (A-F-VISO-01) assigned to the Shirley Heights source. Closer look at the first and second choice source assignments learned that the second source assignment for this Golden Rock sample (A-F-StEGR-01) was Long Island, and almost all but one of the second source assignments of the other artefacts were the LC-SP source group. The close similarity among the three primary Antigua Formation sources was further supported by the small difference in $\mathrm{D}^{2}$ values between the first source and second source for most of the samples.

As Keckla (1980) noted, if the variance-covariance matrices for each group are not equal, this will likely result in wrong assignments in case of similar $\mathrm{D}^{2}$ values for the first and second source assignment. Above, I stated that the variancecovariance matrix is not equal when all the sources are included, primarily owing to significant variation differences between the tuff cherts on one hand and on the limestone flints on the other. Considering the small difference in $\mathrm{D}^{2}$ values between the Long Island assignment and the Little Cove-Soldier Point assignment, I performed another DA analysis, using only the Long Island source and the Little Cove-Soldier Point sources as groups. The variance-covariance matrix is equal in this analysis. Using only four elements both source groups were separated, in which a $100 \%$ correct assignment of the source samples was obtained with cross-validation.

The results showed that all the artefacts were assigned to Long Island in this case. Furthermore, the $\mathrm{D}^{2}$ values were

18 If the artefact possessed much cortex, the mass had to be higher, depending on the amount of cortex. 
much lower for the Long Island source than for the Little Cove-Soldier Point source group, strongly suggesting that at least these 11 samples all originated from Long Island, thereby supporting the macroscopic identification (table 2.17).

The Vieques sample (A-F-VISO-01), however, formed an anomaly. Its first source assignment was Shirley Heights, whereas its second source assignment was St. Kitts. In particular, the first source choice was not expected based on the distinct macroscopic appearance of the Shirley Heights material when compared the Long Island one. Inspection of the concentration values for this sample showed that they all fell within the range of Long Island values, except for Mn, which was significantly higher in the artefact sample. Based on the chemical similarity with Long Island, two additional DA analyses were performed: one in which only Long Island and Shirley Heights were included, and the other in which only Long Island and St. Kitts were included. Contrary to the first analysis, these two produced a Long Island assignment for the artefact, even if $\mathrm{Mn}$ was included. The chance that the artefact originated from Long Island became considerably higher when $\mathrm{Mn}$ was excluded from the analysis. ${ }^{19}$

In case of the source identification of the other samples several questions were at issue. First, a number of different source varieties were included, demanding a DA analysis that incorporated all the available sources. Secondly, a number of unknown varieties were also among the samples. This required a means by which it would be possible to ascribe the sample to an unknown source not included in this study. The attempt to find a method of overcoming the second problem revealed that the chemical data for the Caribbean cherts and flints do not properly lend themselves to this purpose. As I noted above, the high $\mathrm{D}^{2}$ values for first choice source assignments for some of the source samples, in particular those from the Puerto Rican sources, pose difficulties in choosing specific cut-off values, as Luedtke (1979) recommended.

Therefore, other means were sought to see whether samples might be excluded from assignment to one of the sources in the study. An informative way is to evaluate the $\mathrm{Al}$ and $\mathrm{K}$ concentrations and especially the $\mathrm{Al} / \mathrm{K}$ ratios. In some sources $\mathrm{Al} / \mathrm{K}$ is very constant, making it possible to exclude source assignment with relatively good accuracy on the basis of this value alone. Where more variation is present in other sources, $\mathrm{Al}$ and $\mathrm{K}$ can be correlated with the majority of the other elements. Therefore, on the basis of a combination of $\mathrm{Al}$ and $\mathrm{K}$ with these correlated elements, certain samples can be excluded from assignment to these sources. This appears to be useful when samples contain very low $\mathrm{Al}$ and $\mathrm{K}$ values, which in some artefacts were below all values found for the sources. ${ }^{20}$ Considering the high variation of $\mathrm{Al}$ and $\mathrm{K}$ in some of the sources, it seems likely that some rock pieces from such a source, not included in the present sample, actually contain such very low values.

A procedure, in which the different islands were first discriminated before samples were assigned to different sources produced the following results. All samples, except one, were either assigned to the Antigua or St. Kitts sources. The single artefact assigned to the Puerto Rico localities came from the Sorcé site (A-C-VISO-04), which is reasonable considering the fact that Sorcé is situated closest to these localities. However, despite this assignment to the Puerto Rico sources, the concentrations of the elements did not perfectly correspond with the concentrations from one of these sources. In particular, the low $\mathrm{Al}$ and $\mathrm{K}$ concentrations of the artefact are not present among the Puerto Rico localities. This means that the possibility of an unknown source origin cannot be excluded. Interestingly, the other chert artefacts from Sorcé do not originate from the Puerto Rico sources. This signifies that the southwestern Puerto Rican chert localities were not important in chert procurement on Vieques.

Among the 19 artefacts ascribed to either Antigua or St. Kitts, eventually three groups could be distinguished after assignment to the source level had occurred. For the first group of artefacts, the macroscopic identification corresponds with the chemical one, while in the case of the second group of artefacts macroscopic identification does not correspond with the chemical assignment. The third group included artefacts that were initially grouped as unknown varieties. Each group can be subdivided into samples for which the Mahalanobis distance does not exceed the maximum value found among the source samples themselves (low $\mathrm{D}^{2}$ ), and samples for which it does (high $\mathrm{D}^{2}$ ).

In particular, the last two groups present difficulties in deciding whether they should be assigned to the source based on DA analysis, or whether they should be assigned to an unknown source. On the basis of low $\mathrm{Al}$ and $\mathrm{K}$ concentrations, and low $\mathrm{Al} / \mathrm{K}$ ratios, which are not represented among the sources, four samples are ascribed to unknown sources (StMAP-03 and StEGR-05; GUMO-02 and GUMO-03). The latter two samples from Morel are from the same variety of white chert, but are assigned to two different source localities. This assignment suggests that at least one source has been mistakenly chosen.

19 Excluding Mn during the initial analysis produced a Long Island assignment for this source as well. However, this diminished the overall correct assignment rate of this analysis, as was shown by cross-validation.

20 The opposite, that is very high values above the ranges found for all sources, did not occur. 


\begin{tabular}{|c|c|c|c|}
\hline Sample number & Site & Source assignment & Comments \\
\hline A-F-VISO-01 & Sorcé & Long Island & - \\
\hline A-F-StMAP-02 & Anse des Pères & Long Island & - \\
\hline A-F-StMAP-06 & Anse des Pères & Long Island & - \\
\hline A-F-SaSB3-01 & Spring Bay 3 & Long Island & - \\
\hline A-F-SaKB2-01 & Kelbey's Ridge 2 & Long Island & - \\
\hline A-F-STKSFP.a-01 & Sugar Factory Pier & Long Island & - \\
\hline A-F-MOTR-01 & Trants & Long Island & - \\
\hline A-F-GUMO-01 & Morel & Long Island & - \\
\hline A-F-GUAAG-01 & Anse à la Gourde & Long Island & - \\
\hline A-C-VISO-05 & Sorcé & Soldier Point & - \\
\hline A-C-MOTR-02 & Trants & Dry Hill & - \\
\hline A-C-VISO-03 & Sorcé & St. Kitts? & low $\mathrm{D}^{2}$ \\
\hline A-F-StMAP-01 & Anse des Pères & St. Kitts? & low $\mathrm{D}^{2}$ \\
\hline A-C-VISO-06 & Sorcé & Coconut Hall & low $\mathrm{D}^{2}$ \\
\hline A-F-StMAP-05 & Anse des Pères & primary Antigua Flint & low $\mathrm{D}^{2}$ \\
\hline A-C-MOTR-03 & Trants & Shirley Heights? & low $\mathrm{D}^{2}$ \\
\hline A-C-VISO-04 & Sorcé & unknown & low $\mathrm{Al}$ and $\mathrm{K}$ \\
\hline A-F-StMAP-03 & Anse des Pères & unknown & low $\mathrm{Al} / \mathrm{K}$ \\
\hline A-C-StEGR-05 & Golden Rock & unknown & low $\mathrm{Al} / \mathrm{K}$ \\
\hline A-C-GUMO-02 & Morel & unknown & low $\mathrm{Al} / \mathrm{K}$ \\
\hline A-C-GUMO-03 & Morel & unknown & low $\mathrm{Al} / \mathrm{K}$ \\
\hline A-C-VISO-02 & Sorcé & unknown & high $D^{2}$ \\
\hline
\end{tabular}

Table 2.17. Source assignment for chert artefacts found at different habitation sites.

In relation to the remaining samples, those with Mahalanobis distances not exceeding the largest Mahalanobis distance of the source samples for that particular source are ascribed to the source provided by the DA-analysis. In the other cases, samples are from unknown sources.

After these assignments, the group of identified sources include Coconut Hall, Blackman's Point, Soldier Point, Dry Hill, Shirley Heights, and St. Kitts (tables 2.17-18). In particular, the identification of the first four sources should be considered certain, whereas some doubts pertain to the latter two.

\begin{tabular}{lll}
\hline Site & Island & Identified sources \\
\hline Sorcè & Vieques & Long Island, Soldier Point, Coconut Hall, St. Kitts (?), unknown \\
Anse des Pères & St. Martin & Long Island, primary Antigua flint sources, St. Kitts (?), unknown \\
Spring Bay 3 & Saba & Long Island \\
Kelbey's Ridge 2 & Saba & Long Island \\
Golden Rock & St. Eustatius & Long Island, unknown \\
Sugar Factory Pier & St. Kitts & Long Island, Soldier Point, Coconut Hall \\
Trants & Montserrat & Long Island, Blackman's Point, Dry Hill, Shirley Heights (?), unknown \\
Morel & Guadeloupe & Long Island, unknown \\
Anse à la Gourde & Guadeloupe & Long Island, Coconut Hall \\
\hline
\end{tabular}

Table 2.18. Identified source localities for flint and chert artefacts by settlement site. 


\subsection{CONCLUSION}

In this chapter I have reviewed a number of potential chert sources within the northern Lesser Antilles and Puerto Rico. It appears that chert and flint varieties relevant to this study have restricted natural occurrences, which basically can found on three islands: Antigua, St. Kitts, and Puerto Rico. The small geographical extent and their rare presence offered great opportunities for a regional research aiming at raw material distribution among the different islands of the Lesser Antilles. Therefore, this research has attempted to find a means to distinguish the different chert and flint occurrences on the island, facilitating the determination of provenance for the individual artefacts.

The determination of trace-element concentrations using ICPAES provides objective criteria for reaching this goal. From careful comparison of data between the sources, it is evident that inter-source variation is primarily a result of host-rock variability and to a lesser degree dependent on variation in time and space. Differences can be related to different terrigeneous and marine authigenic mineral presence in the chert rocks. Flint outcropping in different areas but formed in the same limestone will contain similar mineral inputs, and only the concentration values may be variable. Chert in tuffs, however, differ in mineral inputs. Furthermore, it is clear that cherts in tuff display large intra-source variability owing to diverse origins for the silica. Weathering also has a significant effect on trace-element composition. Generally, the final effect is disadvantageous for source discrimination, as intra-source variability increases. Under specific circumstances, however, as is shown by the Blackman's Point material, it can have a differentiating effect.

Correct artefact assignment to the level of source locations proves to be difficult due to significant overlap between sources from similar geological origins. Discriminating geologically related source groups, or distinguishing the three different islands, produces better results. Another problem with regard to the artefact assignment, is related to the evaluation on the use of sources not included in this study. It proves to be very difficult to determine whether unknown varieties originate from one of the sources included in this study or from another unknown source. Generally, this is further complicated by the rare occurrence of such varieties among archaeological samples within the study area. To partly overcome this problem, it is recommended that several samples be taken from such an unknown archaeological variety. This will provide a trace-element pattern that facilitates comparison with known sources.

Other recommendations for future research, should improve the correct assignment rates. These include additional sample taking at the Dry Hill and Corbison Point localities, for example. By more thoroughly analysing different beds, researchers should be able to define sub-sources within these localities, significantly diminishing overall overlap with other source localities and consequently improving assignment results. Also, the Shirley Heights source and other localities within the Central Plain and Basal Volcanic Suite regions of Antigua require additional surveying and sample taking. Among the artefact samples still unknown varieties are encountered and based on the large variety of cherts, that turn up in excavations on Antigua, these areas are the most likely ones where additional sources will be found.

In relation to the St. Kitts sources, future research should attempt to determine the age of these flints by analysing Dinoflagellates. This will provide data by which it will be possible to see if these flints were, in fact, formed on St. Kitts, or whether they represent artificial scatters dropped during Historic times (see Appendix A for a discussion on the origin of St. Kitts flints). Additional research among Puerto Rican chert sources should focus on the geological origin of the cherts and more attention should be paid to rock weathering by taking samples from the surrounding soils.

\subsection{OTHER RAW MATERIALS: CALCI-RUDITE AND GREENSTONE}

\subsubsection{A multicoloured conglomerate: calci-rudite zemi-stone from St. Martin}

During the study of different collections of archaeological lithic artefacts (see Chapter 5), a very characteristic raw material was repeatedly present. Others before me have occasionally reported finding it at various sites within the northern Lesser Antilles (Crock 2000; Crock \& Petersen 1999; Haviser 1987,1993, 1999; Hoffman 1963, 81, plates V.B, VI.B; see also Hoffman 1970; Hoogland 1996; Versteeg 1999). The indigenous populations of the northwestern Lesser Antilles used this material to manufacture zemi three-pointer stones, important objects with religious and spiritual significance (figure 2.27)(McGinnis 1997; Pané 1999; Siegel 1997).

The lithic material in question can be described as a mixture of round and angular particles (clasts) cemented by a fine-grained limestone matrix (figures 2.27-29). Among the clasts a distinction can be made between round to oval white (N8) to light grey (N7) and occasional pale red (10R 6/2) grains, and dark (black (N2.5) to greenish black 5G 2.5/1) rounded 

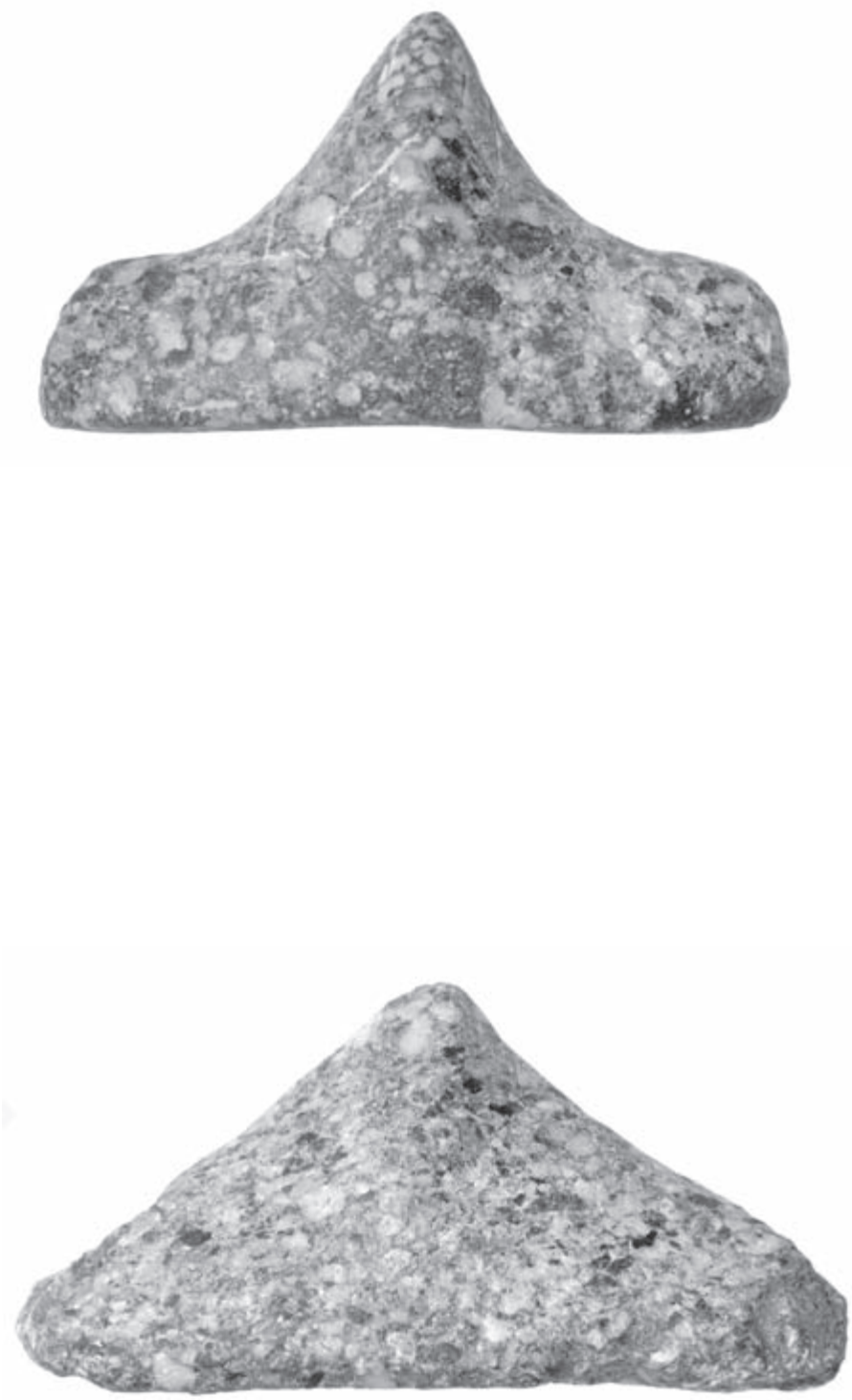

Figure 2.27. Two calci-rudite zemi three pointer stones found at the Anse à la Gourde site, Guadeloupe. See figure 5.32 for the drawing of both zemis. (Photos Ben Grishaaver) 

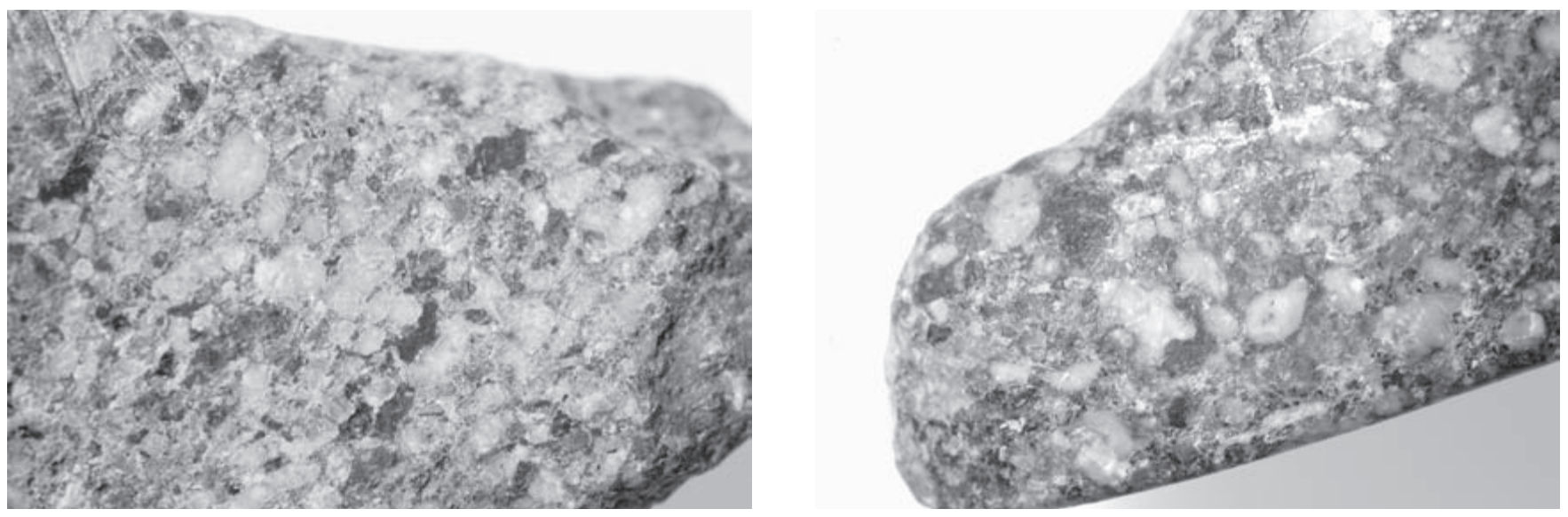

Figure 2.28. Close-up of the conglomeratic texture of both calci-rudite zemi three pointer stones depicted in figure 2.27. (Photo Ben Grishaaver)

to angular particles (Van Tooren 1993). This rock has a very distinctive overall appearance, making it easily recognizable. However, variation can occur in the size of the grains and particles. The distinct combination of light and dark clasts and low variation among different artefacts suggest that this material originates from one and the same source location.

To date, a single artefact of this rock, found at the Early Ceramic Age Hope Estate site, has been studied petrographically using standard microscopic techniques (Haviser 1993, 1999; Van Tooren \& Haviser 1999). Van Tooren, working in the Laboratory of Engineering Geology at Delft University of Technology, has called the rock, calci-rudite, a conglomerate, which should be classified as a packstone following the classification scheme for sedimentary rock by Dunham (1962). ${ }^{21}$ Within the rock, she identified the light coloured grey pebbles, making up $70 \%$ of the total sample as bioclasts (fossil fragments), including in diminishing order the following genera: red algae, Discocyclinae, Lepidocyclinae, Nummulites, as well as some unidentifiable fossils (figure 2.29). The dark coloured, grey pebbles are lithoclasts (rock fragments and detrital minerals), making up $25 \%$ of the total. Identified fragments include andesite fragments, glass,

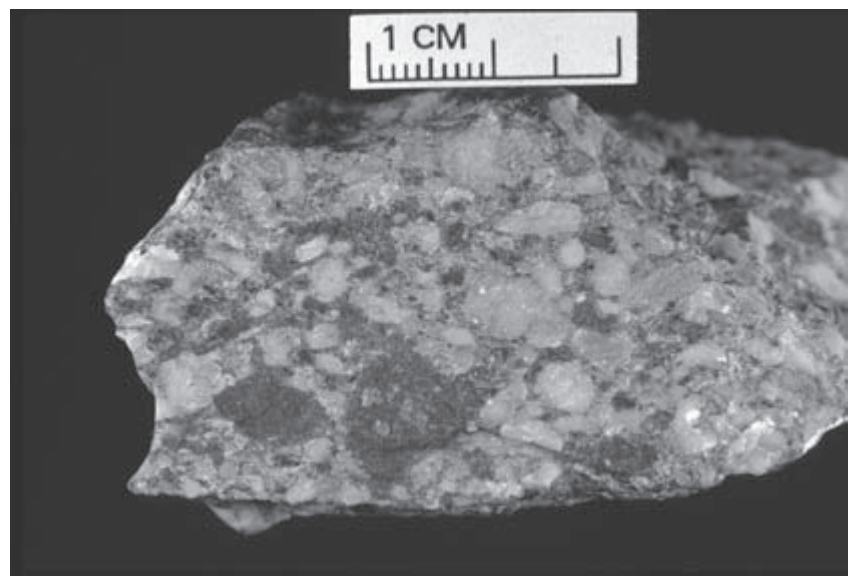

a

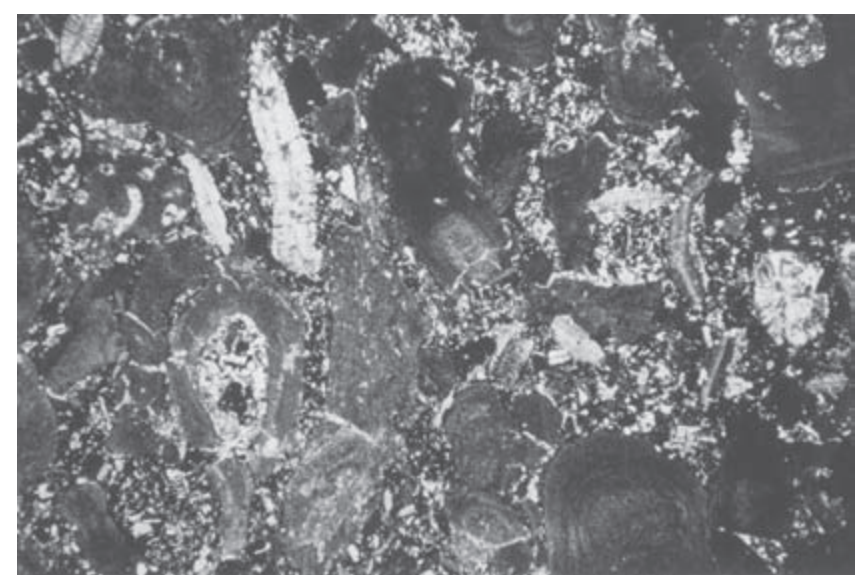

b. Magnification $8 \mathrm{x}$

Figure 2.29. Normal photo and thin-section photo of the calci-rudite sample analyzed by van Tooren (taken from van Tooren and Haviser 1999 , 259 photos 6 and 7 ).

21 Based on the granular texture of the rock, it has earlier been called porphyrite or porphyry by others (Crock 2000; Haviser 1987). This name is misleading since it would place it among igneous rocks. Although igneous particles are present within the rock, it should be classified as a sedimentary rock based on its formation. 


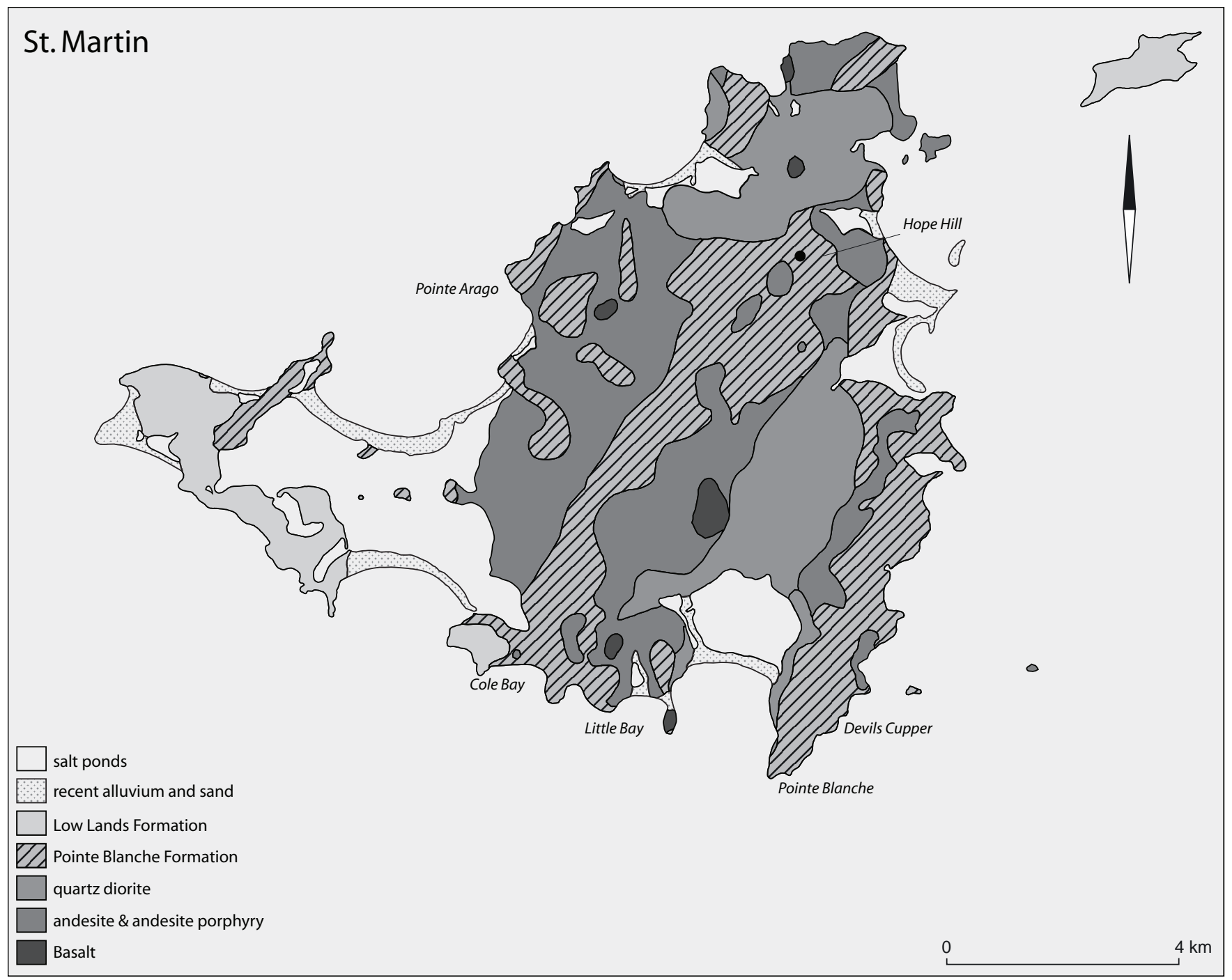

Figure 2.30. Geological map of St. Martin showing the regions where the Pointe Blanche Formation is the underlying rock formation (map based on Christman 1953). Indicated are the calci-rudite source at Pointe Arago and some other significant Pointe Blanche Formation outcrops.

hornblende and plagioclase minerals. The cement, $5 \%$ of the total, consists of micrite (fine-grained calcite), sparite, and iron hydroxides (Van Tooren 1993, 3-4). Based on the occurrence of Discocyclinae and Lepidocyclinae sp., she dated the rock to the Upper Eocene and placed the possible source of this rock on Jamaica, where Upper Eocene sedimentary formations occur (Van Tooren 1993, 4). ${ }^{22}$

Haviser later pointed out that Upper Eocene sedimentary occurrences are present on St. Martin and assumed the material to be local. A following report by Stouvenot supported this notion. He identified its source at Pointe Arago, a rock cliff between Baie de la Potence and Anse des Pères (figure 2.30) (Stouvenot 1999, personal communication 2001). Sections there reveal outcrops of sedimentary depositions belonging to the Pointe Blanche Formation, which is dated between at least Middle Eocene to Upper Eocene (Bonneton \& Vila 1983). Bonneton and Vila have divided the Pointe Blanche Formation into three sequences. The middle sequence, which can be characterised as volcanic-sedimentary in nature in which andesitic rocks dominate ("série volcano-sédimentaire à dominante andésitique" (Bonneton \& Vila 1983, 868)), is found at Pointe

22 She based this observation on an old overview of Caribbean geology written by a German geologist, Weyl (1966). 
Arago, and has hereafter been named the Pointe Arago Formation by the authors. In addition to nicely stratified pyroclastics, inter-bedded with tuffs and siliceous beds, large deposits of conglomerates and micro-conglomerates occur. These latter can be characterised by cementation of lava debris (lithoclasts) with fossils (bioclasts), such as Mélobisiees, Enchinoderms, Lamellibranches, and Nummulites. Some rare deposits contain Lepidoclyna sp. and Discocyclina sp. (Bonneton \& Vila 1983, 884), the species that occur in the calci-rudite studied by Van Tooren.

Based on the similarities in composition between the analysed artefact and the description of the conglomerate rocks at Pointe Arago, both contain lithoclasts, predominantly in andesite form, and the same fossil species: Discocyclinae, Lepidocyclinae, and Nummulites, the source of this rock material must be assigned to this area along the western coast of St. Martin..$^{23}$ This locality correlates well with the archaeological data (see Chapter 5), which show that sites on Anguilla, the neighbouring island to the western side of St. Martin, produced large quantities of this material. Unfortunately, evidence of pre-Columbian exploitation at Pointe Arago locality itself has yet to be demonstrated.

\subsubsection{A grey-green mudstone: greenstone from St. Martin}

Despite the fact that I have called this material "greenstone", the rock discussed here often does not look at all like a greenstone within the archaeological record. In many cases it is white, sometimes very corroded and chalky, and it easily loses pieces of its outer surface-layer (figure 2.31). The colour of this corroded surface varies from true white to very pale brown (10YR 7/3-7/4) to light grey (10YR 7/1) to light brownish grey (10YR 6/2), probably to some degree depending on the influence of the surrounding soil on the different archaeological sites. The crumbling outer surface likely suggests that chemical weathering has altered the rock. This is made clear by some specimens, which still possess remnants of their original texture, often found in the form of thin layers following natural bedding within the rock itself (figure 2.32). The original texture can be described as dull, homogenous, and fine-grained, resembling chert and flint in its flaking characteristics. Its colour varies from light greenish grey $(5 \mathrm{GY} 7 / 1,5 \mathrm{G} 7 / 1,10 \mathrm{GY} 7 / 1,10 \mathrm{BG} 7 / 1)$ to greenish grey $(5 \mathrm{G} 6 / 1$ 5/1, 5BG 6/1, 10Y 5/1). Colour variations can occur within single specimens, which follow the internal layering of the rock.

Many archaeologists working on St. Martin and its surrounding islands have reported finding this rock during their excavations. The earliest account goes back to the work of Josselin de Jong at Golden Rock on St. Eustatius, where he discovered numerous axe and "chisel" fragments, with a characteristic "crust of earth", or "loam-like earth" (Josselin de Jong 1947, 42, PlateXII.30,37-40,48, PlateXIV.1-4,15-16). Many years later Haviser (1987) mentioned the finding of a "chalky grey-green chert" celt production at Cupecoy Bay on St. Martin, followed by similar discoveries at Hope Estate (Haviser 1988, 1991, 1999). Watters, performing small-scale excavations within Fountain Cavern on Anguilla in 1986, found 5 core artefacts, of which at least one was a celt bit, made of similar material as the Hope Estate and Cupecoy Bay material reported by Haviser (Watters 1991, 279-282, 291). Recently, John Crock, University of Pittsburgh, has identified large quantities of artefacts relating to an axe production at numerous sites on Anguilla (Crock 1999, 2000; Crock \& Petersen 1999).

Classification of the rock type in question has been difficult due to the material's weathered nature. This uncertainty is well reflected by the number of names it has previously been given. Initially, Haviser called it grey-green chalky chert in his Cupecoy Bay report (Haviser 1987). He later changed its name to radiolarian limestone ${ }^{24}$, after "casual identification" by B. Fouke of Stony Brook University of New York (Haviser 1993, 2; Haviser 1999, 189). Following the 1993 excavations at Hope Estate, Haviser sent an archaeological sample specimen of this rock (6-C-6) to M. Van Tooren for petrographic analysis, in addition to a calci-rudite artefact, as discussed above.

Van Tooren distinguished two different parts in the specimen from Haviser, a light red rock and grey-green rock. She identified the former under the microscope as being of biogenic origin. It mainly consists of a micrite (fine-grained calcite) matrix, in which many canals are present, probably the result of some organism. The grey-green part of the rock was identified as an altered tephrite, built-up by fine crystalline minerals, which include plagioclase, leucite, chlorite, hornblende, titanite, calcite, and unidentified opaque minerals. Based on these results, Haviser started to make a distinction between tephrite A and tephrite B in his description of the lithic artefacts from Hope Estate, the A-type being the limestone rock and the B-type being the altered volcanic rock, or the true tephrite (Haviser 1993, 1999). Although van Tooren does not mention

\footnotetext{
${ }^{23}$ In addition to Pointe Arago, another Middle Eocene sequence is reported on St. Martin at Red Pond Bay, where conglomerates occur. These conglomerates are coarser in nature, however, and the occurrence of two fossil species (Lepidocyclina and Discocyclina) is not noted.

24 French reports on later Hope Estate excavations use the related term "radiolarite" for this material (Chauviere 1998).
} 


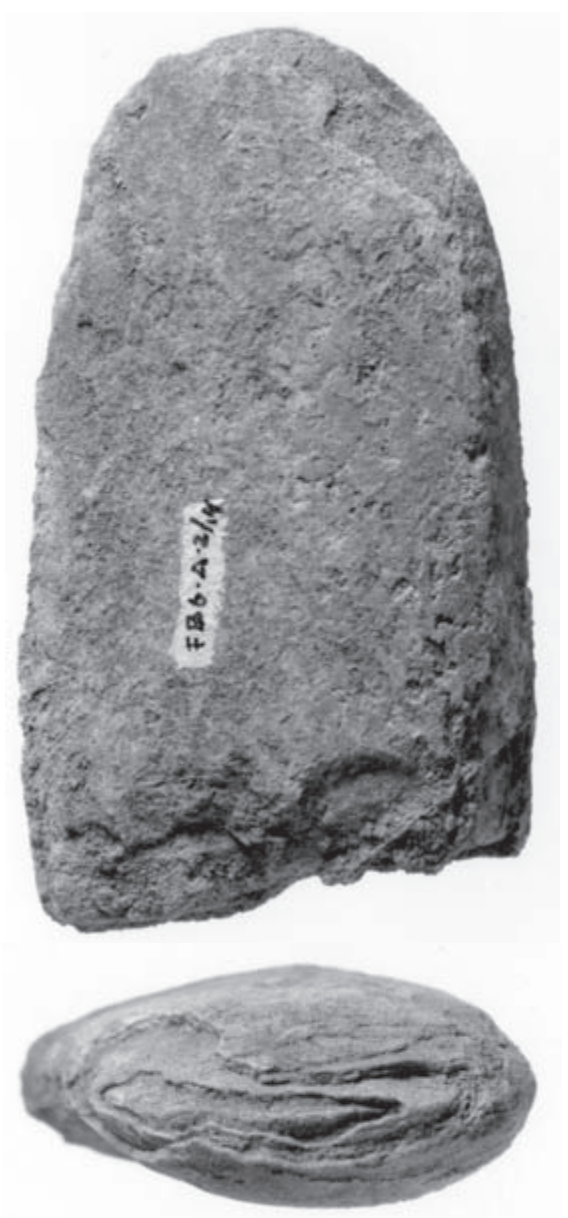

Figure 2.31. Corroded greenstone artefact from the Early Ceramic Age Anse des Pères site, St. Martin, showing extensive weathering (scale 1:1). (Photo Jan Pauptit)

it, it is of interest to specify that the "red" limestone part corrodes into the typical chalky rock, while the grey-green part does not. ${ }^{25}$

Following my earlier Master thesis research related to the lithic artefacts from Anse des Pères, a late Saladoid site on the west coast of St. Martin, I performed a re-analysis of a series of thin-section samples for artefacts from this site with the help of Tony Senior and Gerrit Klaver. ${ }^{26}$ These samples included five weathered and three partly weathered examples of this grey-green material, a non-weathered dark green sample, as well as four rock samples from a geological context on St. Martin. Based on the analysis of the artefacts, we concluded that the weathered grey-green rock should be classified as a mudstone, following Dunham (1962), as it is essentially a sedimentary rock, rather than an igneous one. The non-weathered dark green piece appeared to be a totally different type of rock, which already was clear to some extent when comparing it macroscopically. This latter sample consists of garnet and quartz, and can be classified as a metamorphic rock. ${ }^{27}$

Closely comparing the corroded and partly corroded grey-green samples showed that they are similar, although some contain features not shared by others. More specifically, they are sedimentary rocks with a volcanoclastic component, suggesting sedimentation occurred during active volcanic periods. The matrix of this rock consists of very fine-grained,

\footnotetext{
25 This macroscopic identification of corrosion was based on the original colour pictures, which were taken of the rock sample. A black and white duplicate has been published in Van Tooren and Haviser (1999, 257, Photo 1).

26 During my PhD-work, the samples from my Master Thesis work were re-analysed by Tony Senior (Faculty of Earth Sciences, University of Utrecht) and Gerrit Klaver (Institute of Applied GeoScience (TNO-NITG, Utrecht).

27 Careful reading of geological works on St. Martin demonstrates that this sample may have been local to the island, as garnet is reported in the metamorphosed contact zone between the plutonic rock and the Pointe Blanche formation tuffs (Molengraaff 1931; Staargaard 1952).
} 

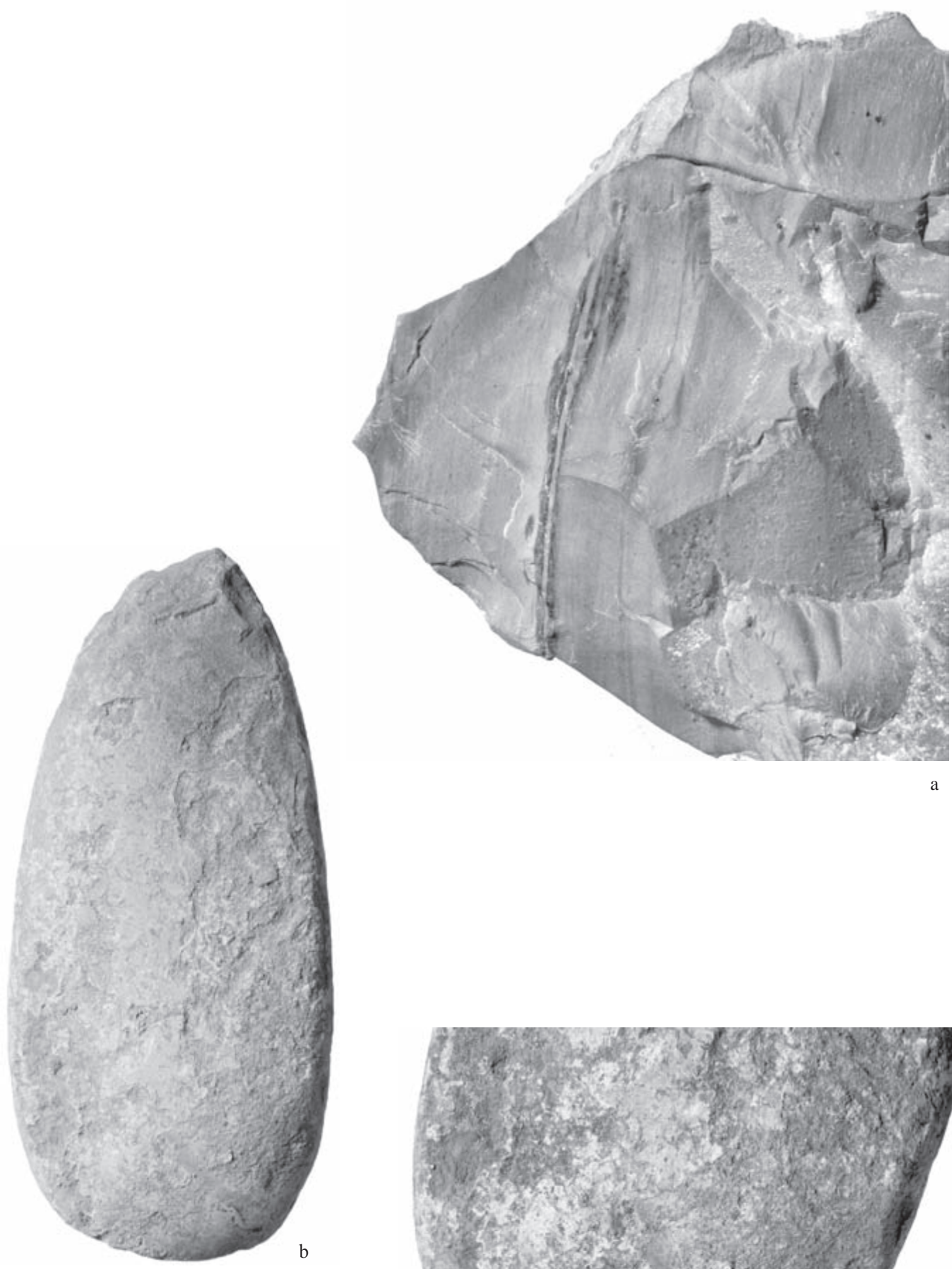

a

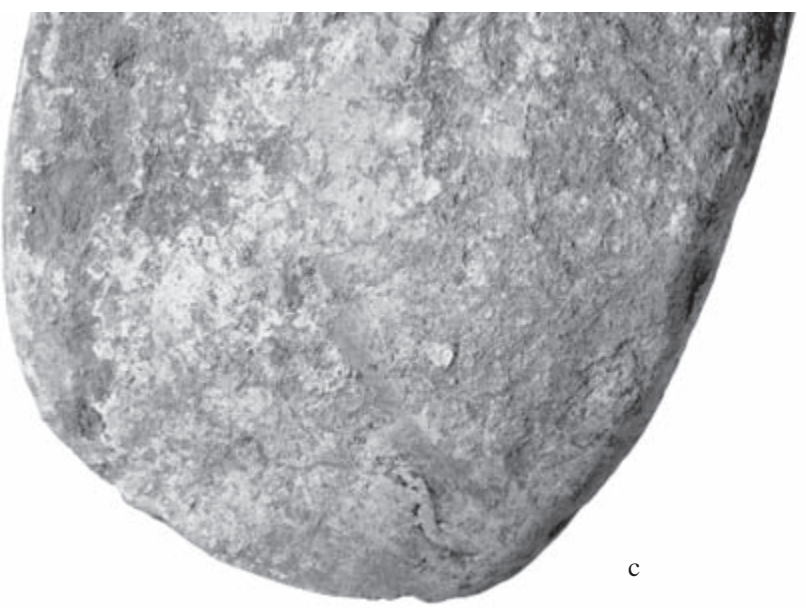

Figure 2.32. Uncorroded greenstone rock sample from the Hope Hill contemporaneous quarry site (a) and partially corroded greenstone axe from the Late Ceramic Age Anse à la Gourde occupation phase (b) and close-up showing a thin uncorroded band (c).(Photos Ben Grishaaver) 
partly re-crystallised material, which could not be identified on the basis of the thin-section study (figure 2.33). Chemical analyses of a sub-sample of four archaeological samples, using ICPAES and earlier microprobe data (see Knippenberg 1995), indicates that the amount of $\mathrm{Ca}$ is very high, suggesting that it mainly consists of very fine carbonate mud. High $\mathrm{Al}, \mathrm{K}$, and $\mathrm{Na}$ values suggest that there is likely a tuff and/or clay component present as well. These fine materials were deposited in a marine environment, as indicated by the presence of rare fossils, such as foraminifers and radiolarians. In addition to the possible tuff, rare occurrences of larger and identifiable igneous rock fragments, in the form of probable wind-blown plagioclase minerals, provide additional evidence for volcanic influences during deposition (see figure 2.33).

The high concentrations of $\mathrm{Ca}$ must be associated with the characteristic surface corrosion of this rock, which makes the material so easily recognizable. It is probably a process where the less stable components dissolve and the carbonate remains.

Notwithstanding this classification, there remains a discrepancy between Van Tooren's identification of this rock as tephrite and our petrological results. If both data are compared, the following points emerge:

1) Both the corroded part of the specimen studied by Van Tooren and my corroded samples contain significant amounts of carbonate in the form of micrite, suggesting a marine origin.

2) The non-corroded part of Van Tooren's sample is identified as an altered tephrite, but none of my corroded samples can be classified as such. However, considering the variable nature of its origin within the Pointe Blanche Formation (see below), where sedimentary rocks occur inter-bedded with tuffs and igneous rock, the existence of two different rock-types in one piece likely represents the interface of two beds, in which the non-corroded part belongs to a layer consisting of igneous rock, whereas the corroded part belongs to a sediment overlying it.

This means that only corroded specimens contain carbonate in the form of micrite and that the development of the chalky surface is associated with this content. This also means that naming this corroded stone as tephrite A, as Haviser does in his Hope Estate lithics report (Haviser 1993, 1999; Van Tooren \& Haviser 1999), is erroneous because it is primarily a marine sediment and not an igneous rock. The name tephrite should be reserved only for non-weathered artefacts corresponding with the proper mineral composition..$^{28}$ Non-corroded artefacts, however, only form a small part of the archaeological samples ${ }^{29}$, probably owing to its inferior flaking characteristics. This suggests that the Amerindians specifically preferred and used the calcareous beds within the Pointe Blanche formation, and not the igneous ones.

Contrary to what Van Tooren and Haviser (1999) claim after their analysis of a single sample, namely that the material is well defined, I conclude that although they correctly described this sample, Haviser unhappily chose a complex specimen, which cannot be considered as representative for the majority of the archaeological materials. This led to the use of an incorrect name, tephrite, for the rock category as a whole.

With regard to the source of this material, the Middle to Late Eocene Pointe Blanche Formation on St. Martin is considered the most likely origin. This geological unit outcrops at many places on St. Martin, with notable locations at Little Bay, Pointe Blanche, Red Pond, Devils Cupper, and Cole Bay (see figure 2.30) (Bonneton \& Vila 1983; Christman 1953). Generally, this formation consists of a bedded sequence of fine-grained re-crystallised green and white tuffs. In some places tuffs are calcareous or cherty in nature, or lack re-crystallisation. True cherts are reported at Devils Cupper and north of Marigot. Coarser grained tuffs occur along the coast between Oyster Pond and Geneve Bay (Christman 1953). At some places, andesite and dacite dykes and sills inter-bed the tuffs, such as at Pointe Arago (Bonneton \& Vila 1983).

Considering this, Haviser and I took geological samples for comparison from a present day quarry site at Hope Hill, where a significant part of the Pointe Blanche Formation is exposed, providing easy access and good stratigraphic visibility (see figure 2.30). From a rock section in which thin (dark) green and grey-green beds of cherty material are present, four samples were taken from four different beds (figure 2.34). Within this sequence of beds, there are beds with rock material that exhibits good conchoidal flaking characteristics and there are other beds where the material is unsuitable for flaking, as it easily falls apart. The good quality material is usually (light) grey-green in colour and resembles a dull chert (see figure 2.33), while the poor quality material usually can be found among the (dark) green materials, which are coarser grained.

Two out of the four geological samples (the light grey-green ones) display similarity with the archaeological specimen under the microscope, although close similarity is not shared with all archaeological samples (see figure 2.33).

\footnotetext{
28 The highly variable build-up of the Pointe Blanche Formation, including the occurrence of different beds of igneous rock, suggests that other tuff or igneous rock varieties than the identified tephrite may be present among non-corroded specimens. Therefore, in case of the significant use of non-corroded rock, such possible variation should be studied by analysing several samples.

${ }^{29}$ Within all assemblages that I studied, the weathered artefacts make up the large majority, often more than $90 \%$ of this category.
} 


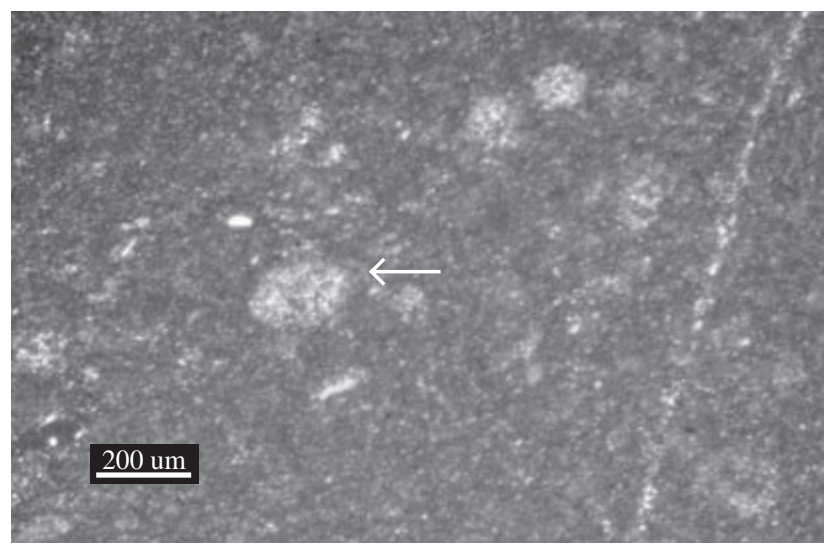

a. Hope Hill greenstone, geological sample StMHH-02 (CP).

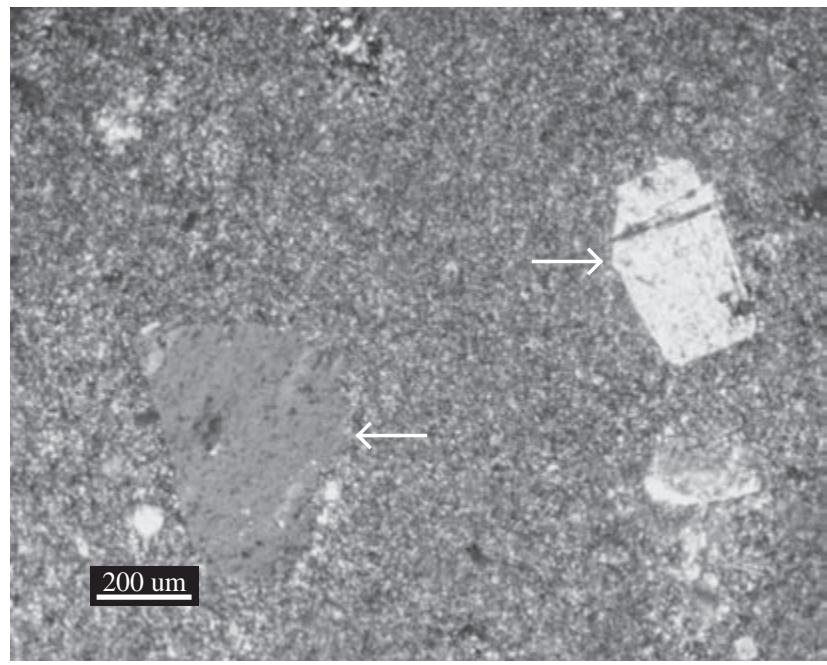

c. Anse des Peres greenstone, artefact sample StMAP-01 (CP).

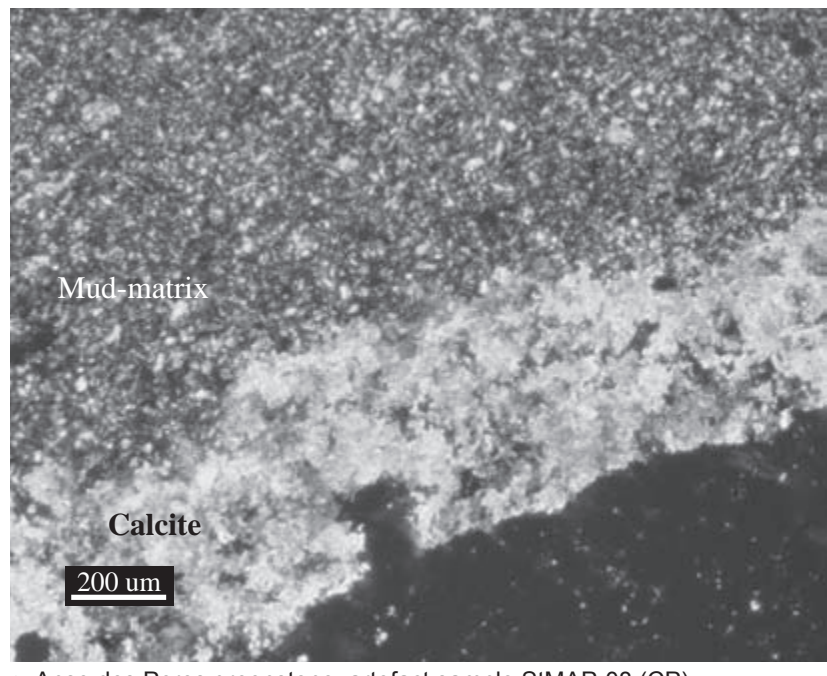

e. Anse des Peres greenstone, artefact sample StMAP-08 (CP).

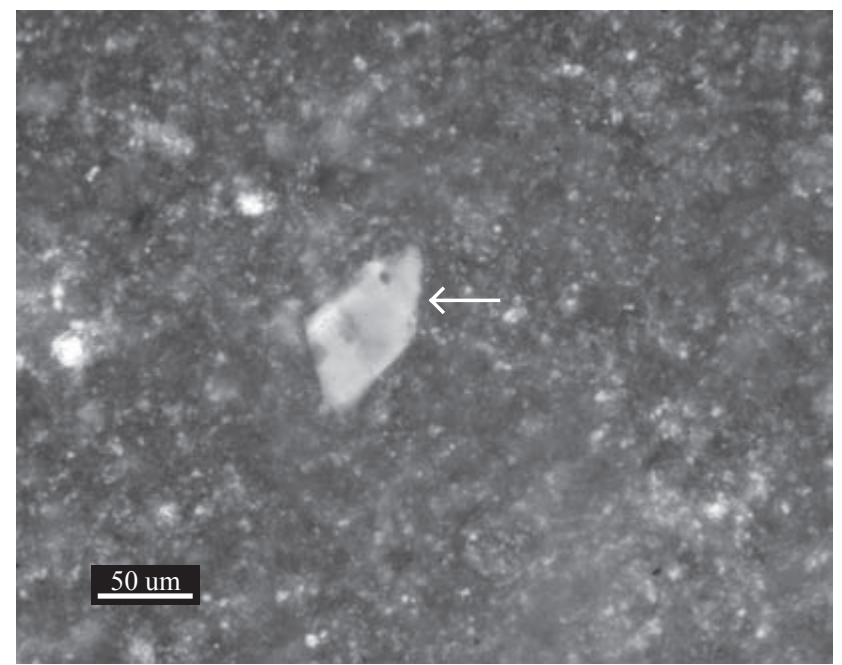

b. Hope Hill greenstone, geological sample StMHH-02 (CP).

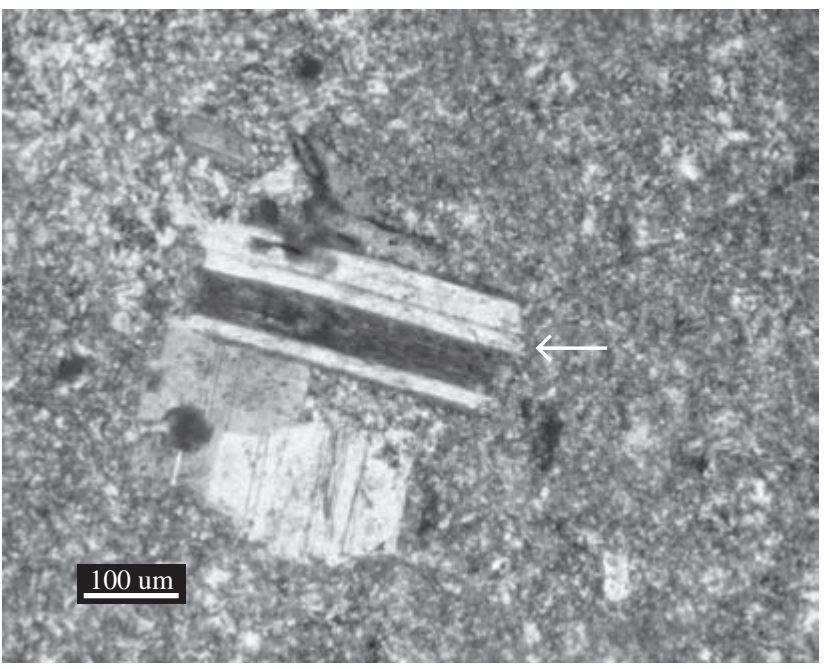

d. Anse des Peres greenstone, artefact sample StMAP-01 (CP).

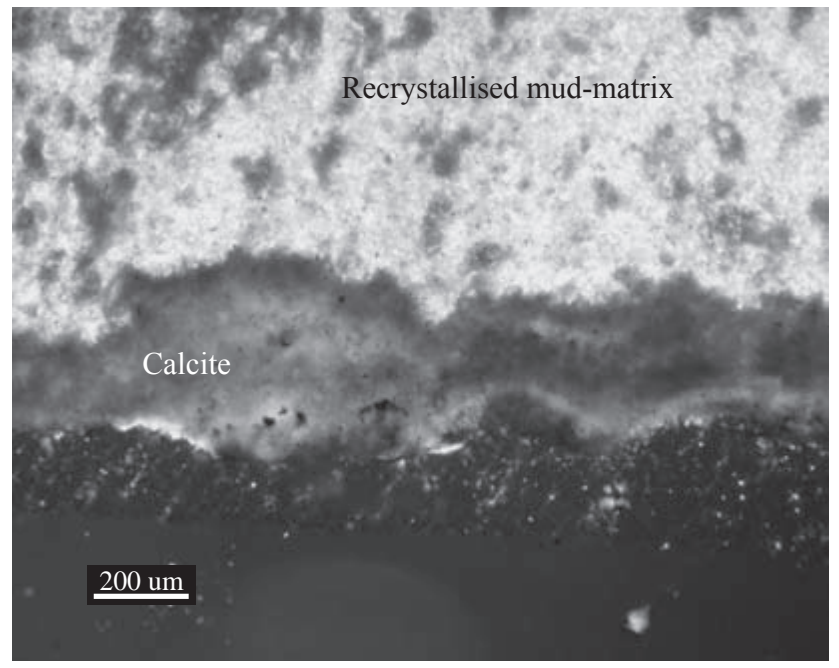

f. Anse des Peres greenstone, artefact sample StMAP-08 (CP). 


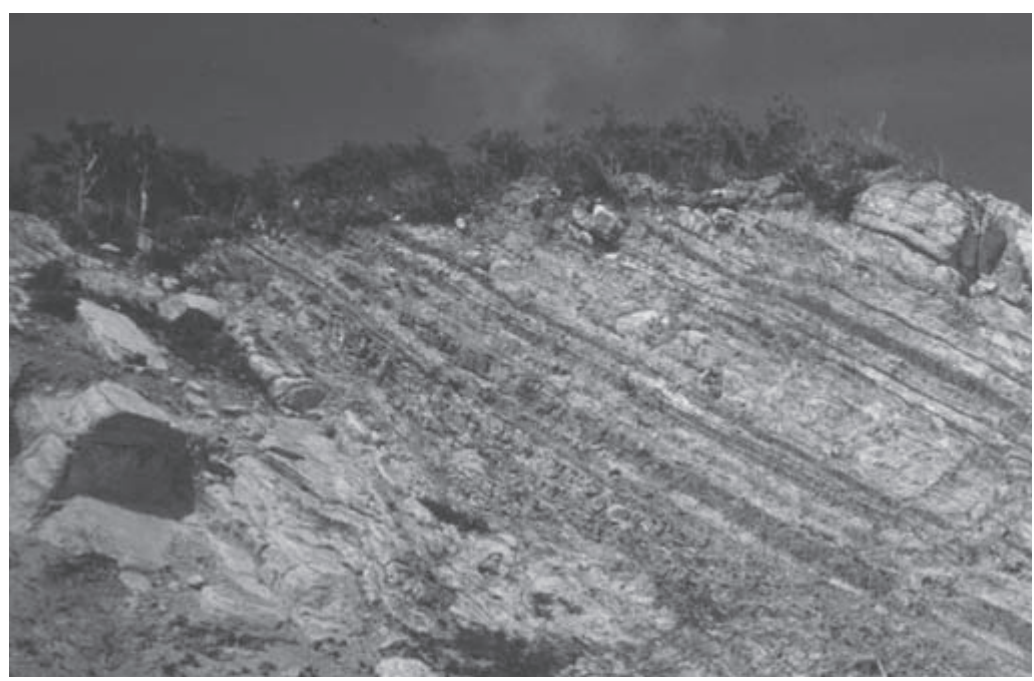

Figure 2.34. Rock section at the contemporary Hope Hill stone quarry exposing a significant portion of the bedded sequence of the Pointe Blanche Formation.

Both geological samples have very fine re-crystallised matrices, in which fossils and volcanic fragments (plagioclase and quartz) can be identified. In one of the samples, the matrix probably contains tuff as well.

The other two samples are of a different nature. One is a tuff, consisting of very fine homogenous distributed material. The other is a true igneous rock of the hypabyssal type, with clino-pyroxene and plagioclase phenocrysts, which had been partially replaced by amphibole and kali-feldspar, respectively. This variation in rock-types clearly corresponds with descriptions of the Pointe Blanche Formation provided by the different geological reports, in which igneous rock, tuffs, and calcareous sediments are distinguished (Bonneton \& Vidal 1983; Christman 1953).

The two samples displaying similarity with the archaeological samples were submitted for chemical analysis, using ICPAES. These data were compared with the data from four chemically analysed archaeological samples (table 2.19). This comparison shows that the geological samples differ from the archaeological ones, despite their similarity under the microscope. Both groups of samples contain high concentrations of $\mathrm{Ca}$, suggesting carbonate formed a major constituent of the rock. The archaeological samples, however, contain two to three times more $\mathrm{Ca}$ than the geological ones. The geological samples are richer in $\mathrm{Al}, \mathrm{K}, \mathrm{Na}, \mathrm{Fe}$, Ti, and $\mathrm{Mg}$, suggesting that the igneous-tuff-clay fraction is more significantly represented. This minimally indicates that the archaeological samples excavated at Anse des Pères did not originate within the two analysed beds at Hope Hill. Considering that the Hope Hill samples were obtained from a contemporary stone quarry, it was not expected that Hope Hill was necessarily the source or the archaeological specimen. Given the similar nature of both groups, and the common occurrence of the Point Blanche Formation at many outcrops, it is likely that the Anse des Pères inhabitants obtained this material elsewhere on St. Martin.

Another striking feature of the comparison between the geological and archaeological samples needs to be mentioned. Variation among most of the elements in the two geological samples (in particular Al, $\mathrm{K}$ and $\mathrm{Na}$ ) is more significant than within the four archaeological samples. Since both geological samples originated in two different beds (layers) at Hope Hill, the relatively closer similarity between the archaeological samples may suggest that they originated within a single bed. If it is true that inter-bed variation is significant and intra-bed variation is not, this may guide the search for possible prehistorically quarried outcrops on St. Martin. For example, it would suggest that the outcrops along St. Martin's southern coast, e.g., Little Bay, were not likely exploited by the Anse des Pères inhabitants, as rock sections here expose numerous beds of flakable grey-green material. A more inland outcrop, where only limited portions of the Pointe Blanche Formation come to the surface, may be a more likely quarry locality.

However, this low chemical variability among the grey-green rock only accounts for this small sample from the Anse des Pères site. A more extensive sampling program might produce different results. Furthermore, the study of other

Figure 2.33 (opposite page). Thin-section photos of St. Martin greenstone in crossed polars (CP). a. Arrow points to radiolarian fossil floating in a fine matrix; b. Arrow points to small plagioclase fragment floating in a fine matrix; $c$ and $d$. Arrows point to larger plagioclase fragments floating in a fine matrix; e and f. Corroded outer surface in thin-section clearly showing the corroded outer surface consists of calcite. 


\begin{tabular}{|c|c|c|c|c|c|c|c|c|}
\hline Sample number & $\mathrm{Al}$ & $\mathrm{K}$ & $\mathrm{Na}$ & $\mathrm{Ti}$ & $\mathrm{Fe}$ & $\mathrm{Mg}$ & $\mathrm{Ca}$ & $\mathrm{Ba}$ \\
\hline \multicolumn{9}{|l|}{ geological samples } \\
\hline BC-StMHH-01.1av & 46604 & 8878.0 & 14208.7 & 1810.6 & 37322 & 16942 & 114160 & 578.91 \\
\hline $\begin{array}{l}\text { BC-StMHH-02 } \\
\text { artefact samples }\end{array}$ & 27221 & 29251.9 & 3380.4 & 966.4 & 13836 & 11708 & 131089 & 1061.12 \\
\hline A-BC-StMAP-08 & 18137 & 536.9 & 525.6 & 810.0 & 12355 & 5063 & 331073 & 21.73 \\
\hline A-BC-StMAP-04.1av & 16933 & 1106.5 & 2518.3 & 851.5 & 25834 & 8508 & 290204 & 4.80 \\
\hline
\end{tabular}

Table 2.19. Trace-element concentration values (in $\mathrm{mg} / \mathrm{kg}(\mathrm{ppm})$ ) within St. Martin greenstone geological (Hope Hill) and artefact (Anse des Pères) samples. Suffix "-av" denote average values from multiple analyses.

grey-green axe production sites on St. Martin and surrounding islands (see Chapters 5 and 6) may well yield different results as well, if these axe producers came from different directions and visited different outcrops on St. Martin.

\subsubsection{Concluding remarks}

Petrographic analysis of two frequent rock types among archaeological samples from pre-Columbian sites within the northern Lesser Antilles, demonstrated that both materials originate on St. Martin. They are easily recognized due to specific features, that are solely related to them. The first variety, used for making three-pointer zemis, is a conglomeratic packstone, named calci-rudite, and it displays a very characteristic mixture of dark igneous rock clasts and light coloured fossils. The other, used for making axes, is a fine-grained grey-green re-crystallised mudstone, named (St. Martin) greenstone hereafter. The St. Martin greenstone is easily recognized as a result of its susceptibility to weathering which turns it into crumbly and chalky on its exterior.

The natural occurrences of both rock types on St. Martin are variable. Calci-rudite has been solely identified at Pointe Arago, a rock cliff along the west coast of St. Martin. Greenstone, however, has a wider distribution on the island, as it is generally associated with the Pointe Blanche Formation, which covers an extensive part of St. Martin's surface. Its common presence and the fact that greenstone quarry sites have not been identified, make it impossible to pinpoint just where pre-Columbian people obtained this material. In relation to the calci-rudite packstone, data on its exploitation activities remain limited to one geographical location only, since related artefact scatters have not been reported on St. Martin. 


\section{$3 \quad$ Lithic analysis}

\subsection{Methodology}

\subsubsection{Introduction}

The analysis of lithic artefacts and related technology dating to the Ceramic period has remained a poorly studied field within Caribbean archaeology. This is in sharp contrast to more abundant knowledge related to Preceramic Age stone tools and their industries (Davis 1982, 1993, 2000; Kozlowski 1974; Lundberg 1989; C. Moore 1982, 1991; Veloz Maggiolo 1991; Wilson et al. 1998). To a large extent, this discrepancy can be attributed to the emphasis put on cultural chronology within the regional archaeology. As lithic artefacts form very important cultural remains for the Preceramic period by the virtue of the absence of ceramics, most attention has been directed towards this category. With the appearance of the first ceramics, stone tools are considered to be inferior for this purpose and lost their central research position, especially because of the overall paucity of standardized tool types among flaked stone specimens of the Ceramic Age. It is noteworthy that some of the earlier studies devoted to lithic artefacts from the Ceramic Age had a strong cultural chronological objective (Allaire 1983).

Fortunately a change has been occurring over the past ten years or so, given an increase in research related to lithics (Bérard 1997, 1999a, 2001; De Mille 1996; De Waal 1999b; Haviser 1999; Knippenberg 1995, 1999c; Rodríguez Ramos 2001a,b). Initiated by the important work of Jeff Walker (1980, 1981, 1983), who was one of the first to specifically pay attention to stone tool technology and organization of production, recent research has directed attention toward the production sequences of stone artefacts, rather than merely describing formal tool types or artefact shapes. Unfortunately, the other important part of Walker's work, the determination of the function of tools through use-wear analysis, has not received much emphasis (Crock \& Bartone 1998; Berman et al. 1999, 2000) and this field still remains largely neglected. ${ }^{1}$

This study analyses the distribution and exchange of lithic materials by focussing on the production of the lithic artefacts. Therefore, a short summary of stone tool production and the range of lithic artefacts among Ceramic Age sites within the region needs to be presented. Furthermore the technologies by which tools were produced, characterisation of the different stages of the production process, and the products and debitage must be considered. In this way, trajectories can be modelled for different stone tool production processes and all possible instances for which materials were transported need to be listed, closely following the work of De Grooth (1991).

Overlooking Caribbean stone tool technology and lithic artefacts in general, a number of recurrent groups of artefacts can be distinguished. These form part of a coherent reduction sequence aimed at the production of a specific set of end products. In addition, there are groups of artefacts that have not undergone such production process and were directly used. Before discussing the wide range of these artefact sets, I first need to define the term "artefact" as used throughout this work. I consider a piece of stone to be an artefact when it was either modified by humans and/or when it was brought to a site by humans as it does not naturally occur in the site area. I regard modification here in the broadest sense. This not only includes general stone working techniques such as flaking, pecking, grinding, and sawing, but also use related modifications as a result of abrading, hammering, and polishing, as well as modifications in shape and colour due to intentional burning of the piece of rock.

To provide a better understanding, I begin with a description and short discussion of the different groups of lithic artefacts. From the above definition it is clear that a first general distinction can be made between artefacts, that have undergone modification and those that have not. The former group of artefacts is further subdivided and discussed below. To the latter group belong all lithic specimens that do not naturally occur within a given site area, and that do not exhibit any form of obvious human modification. These artefacts are often referred to as manuports. Within the Caribbean, basically two groups of manuports occur: (1) various sorts of water-worn stone pebbles, and (2) red ochre. ${ }^{2}$

\footnotetext{
${ }^{1}$ Currently, Yvonne Lammers-Keijzers (Leiden University) is studying use-wear on a broad range of artefacts, including different stone materials, pottery, shell, and coral (Lammers-Keijzers 2001b, in prep.).

${ }^{2}$ A third group of artefacts can be potentially added to this group. This is the range of unmodified raw materials, which had not been (yet) reduced. As it is often possible to link such material with artefacts from the same material, that clearly belong to a certain production process, these materials are considered part of such technology and will be classified as unmodified raw material intended for reduction.
} 
The pebble-category is somewhat problematical in its interpretation. Lithic samples from Caribbean sites often contain a large number of water-worn pebbles. Many of these exhibit some kind of modification in the form of use-wear and can be definitely considered as tools (see below). However, there are often some items that do not exhibit such use-wear, even when viewed under a microscope. Two possible interpretations of these specimens can be presented: (1) they served tasks, that did not leave any detectable traces. Either the type of task was responsible for that (see Chapter 5; Stevens 2002; Lammers-Keijzers in prep. for an example of use-residue, which easily could have been removed), or the type of rock made it difficult for use-wear to form; or, (2) these specimens were intended to be used, but were never used. As these items have exotic origins the first option seems more likely.

Red ochre is a raw material used for making paints or pigments. As this material is ground to fine size before being used as a colorant, it will not often enter the archaeological record as a stone material. Sometimes, however, natural pieces or fragments are identified. Due to its low frequency in the archaeological record, little is known about its natural shape, making full interpretation of its modification difficult. Modified pieces can be only identified if they exhibit ground surfaces, and the distinction between a natural unmodified piece or a crushed piece for grinding (which can be considered as human modification) is hard to make.

Regarding the humanly modified items a distinction can be made between: (1) lithic specimens that have been shaped to serve certain tasks; (2) lithic specimens that can be considered as the debitage of that shaping process; (3) lithic specimens that have been only modified through its use, hereafter referred to as use-modified artefacts (see Rodríguez Ramos 2001a; Walker 1997); and (4) lithic specimens that were burnt and not otherwise modified. To start with the latter group, these include intentionally burnt artefacts, such as cooking stones or stones used to prop up pots during cooking. Unintentionally burnt artefacts need to be considered as well. It is often very difficult to distinguish between intentionally burnt stones, or unintentionally and/or naturally burnt stone, if the use-context of the rocks is unknown. The shape of the object will be the best clue to interpretation then. Considering this and the fact that burnt rock, if not fire-cracked, can be difficult to recognize and therefore easily missed when excavating, systematic discussion of these artefacts will be left out of this work.

This brings me to the three other groups of items, that make up the majority of artefacts within Caribbean lithic assemblages. In fact, the first two groups listed above can be contrasted to the third group, the use-modified specimens. In case of this latter group, the process of intentional shaping (the production process) is absent, whereas the other two are interrelated because the second one forms the waste from production of the first one.

Among the use-modified materials, a range of artefacts can be included. These artefacts all share the characteristic that they have been collected as natural rocks and were used without being shaped beforehand by flaking, pecking, sawing or grinding. In the Caribbean, the majority of use-modified artefacts consist of beach or river cobbles, hereafter referred to as water-worn pebbles. Raw materials that are usually found among use-modified tools largely depend on local availability in the direct surroundings, but generally include igneous rock, fine-grained sedimentary rock, and limestone (Knippenberg 1999c; Rodriguez Ramos 2001). Pebbles were used for all kinds of tasks, depending on their natural shape. In addition, more angular rocks are occasionally found. I distinguish the following general types of tools (see Rostain (1994) for a more detailed discussion of use modes):

(1) hammer-stone: active tool for flaking, pecking, or crushing objects. Rock exhibits localised pits as use-wear, often on edges or high points.

(2) anvil stone: passive tool for supporting an object to be flaked or crushed. Generally flat rock surface exhibits localised pits as use-wear.

(3) rubbing/abrading stone or manos: active tool for grinding or abrading an object. Rock exhibits localised abraded or smoothed areas on convex to flat surfaces.

(4) polishing stone: active tool for polishing an object, likely pottery. Rock exhibits polish, often all over, as well as fine striations.

(5) grinding or milling (metate) stone: passive tool against which an object (for example an axe) or a substance (for example red ochre, or food stuffs) is ground. Object exhibits a concave or flat abraded or smoothed surface.

Focussing on shaped pieces and their related debitage, we enter the field of lithic technology. Within this field a distinction is often made between flake or blade tool technology on the one hand and core tool technology on the other (Collins 1975). Within the former technology, flakes, the detached pieces, are the aim of the production and the desired end products are tools in the form of these flakes, with secondary work or not. In core tool technology, the objective piece from which flakes 
are detached is the aim of production and the desired end products constitute various types of core tools and core objects. ${ }^{3}$ Unlike the Preceramic Age, during which flake as well as blade tool technologies were used (Armstrong 1978; Crock et al. 1995; Davis 1982, 1993, 2000; Knippenberg 1999d; Nodine 1991), the Ceramic Age exhibits little variation among flaked stone artefacts as only an expedient flake technology was utilized throughout the region (Bérard 1997, 2001; Berman 1995; Crock \& Bartone 1998; De Mille 1996; Knippenberg 1999c; Rodríguez Ramos 2001a; Rostain 1997; Walker 1980, 1985, 1997). A common feature of this technology is the use of direct freehand percussion as well the bipolar flaking technique. In addition, an absence of standardized tool shapes is characteristic and most tools lack intentional retouch. Identified artefacts include cutting, scraping, and drilling tools, as well as grater teeth (Walker 1980, 1983; Berman et al. 1999, 2000). Utilized raw materials include flint, chert, jasper, quartz, silicified wood, and silicified tuff (Bérard 1999; Bérard \& Vernet 1997; Crock \& Bartone 1998; De Mille 1996; Knippenberg 1999c; Rodríguez Ramos 2001a; Walker 1980, 1985, 1997).

Among the core artefacts, different production technologies can be mentioned, each having its own end product. These end products include true tools, hereafter referred to as core tools, as well as decorative and religious items, simply called core objects in this work for lack of proper denomination. Core tool technologies basically comprise axe (celt) or adze production (Crock 1999; Knippenberg 1999c, 2001a; Rodríguez Ramos 2001a; Walker 1985). In addition to these generally formal tool technologies several other utensils can be considered as human shaped core-tools. However, they lack extensive production processes, such as, for example, net-weights (Keegan 1997) or metates (see Chapter 5). Core object technologies comprise bead, pendant, zemi and rare stone collar productions (Cody 1991, 1993; Crock 1999; Crock \& Bartone 1998; Murphy et al. 2000; Narganes Storde 1999; Walker 1995; Watters \& Scaglion 1994). All share the characteristic that the core itself is to be shaped into an end product, either very small in case of beads ${ }^{4}$ or very large in case of metates (Knippenberg 2001a). The core tools and core objects are usually referred to as "ground stone" technologies as different from "flaked stone" technologies. Regarding the end products, this distinction is justified to some degree. However, it should be noted that in viewing the whole production sequence ground stone technologies generally start with a flaking stage, and some core tool productions do not include a final grinding phase, as is the case for net-weights and, for example, hand-axes or bifaces, to name a common world-wide non-ground core tool type (Newcomer 1970). Therefore, the major difference between flake tool and core tool technologies within the Caribbean is evident in the type of the core artefacts found in the first place. Important in this respect is to distinguish flake cores from preforms, as well as various finished products such as axes, beads, pendants, etc. Secondly, the presence or absence of use-wear and/or modification of flakes may also be a discriminating feature.

The variety among end products is also evident among their production sequences. Axe, adze, bead, pendant, and zemi technologies can be considered as ground stone technologies, while the metate, net-weight, and edge grinder productions lack a final grinding phase and only involve flaking and perhaps a pecking stage. In some cases the flaking stage might only include a few flake removals, as the original piece naturally resembles the desired end product in shape. This pertains to the production of axes and adzes from water-worn pebbles, and to the metate production, for example (Knippenberg 1999c, 2001a). In the case of net-weights, this is even more evident as the desired end product consists of a water-worn pebble with only two to four flake removals at the middle to make indentations, leaving the remainder of the piece untouched (Keegan 1997). ${ }^{5}$

Considering raw material choice, igneous and metamorphic rocks are generally used for making axes or adzes (Knippenberg 2001a; Murphy 1999; Rodríguez Ramos 2001a; Roobol \& Lee 1976; Walker 1980, 1985, 1997). Igneous rock is often used for metates (Knippenberg 2001a), while various rocks, including igneous rock, conglomerate, calcite and limestone are used for zemis. All sorts of semi-precious stones and rock crystals are used for making beads and pendants (Cody 1991, 1993; Murphy et al. 2000; Narganes Storde 1995, 1999; Watters \& Scaglion 1994). ${ }^{6}$

\footnotetext{
${ }^{3}$ In my definition, core tools include axes, adzes, metates, and net-weights. As (core) objects I consider: beads, pendants, and zemis.

${ }^{4}$ It can be argued in general that beads and, in particular, flat discoidal beads were made from small flakes, although Crock \& Bartone (1998) clearly show that carnelian beads at the Early Ceramic Age site of Trants were produced from small, blocky core pieces in most cases. The occasional shaping of flakes into beads does not significantly change the overall sequence and taking notion of the grinding process, this production is more similar to a core than to a flake artefact.

${ }^{5}$ The sites of Morel and Anse à la Gourde on Guadeloupe have also yielded examples of non-modified pebbles, probably used as net-weights (see Chapter 5).

${ }^{6}$ To complete this list of materials, shell and coral should be added as well because they were commonly used for making axes, adzes, beads, pendants (all shell), zemis (both shell and coral), and all sorts of active and passive grinding tools (coral) (see H. Kelly 2003; Lammers-Keijsers 2001b, in prep).
} 


\subsubsection{Aims}

From the preceding, it should be clear that lithic samples from habitation sites include a wide variety of stone artefacts, which form the remnants of different types of production processes. In addition, a large set of stone artefacts did not undergo any production process and was used as is. Following distinctions discussed above, I have divided lithic artefacts into five groups and have named them "technology sets". Subdivisions have been made only within the core tool/core artefact set, as variation in the production process justifies such a division. At the same time, I have grouped them so that each sub-set basically correlates with a recurring group of rock types. Therefore, I have put the production of beads and pendants, which are two different types of core artefacts, within one and the same sub-set because similar materials were used to make both items (Cody 1991; Narganes Storde 1995, 1999). Some core artefact technologies are not included as they rarely occur within the study area, such as net-weights and stone collars.

The following technology sets have been distinguished:

Technology set 1: artefacts related to flake tool technology.

Technology set 2: artefacts related to core tool or core object technology.

2a: artefacts related to axe or adze production.

2b: artefacts related to metate production.

2c: artefacts related to bead or pendant production.

2d: artefacts related to zemi production.

Technology set 3: use-modified materials.

Technology set 4: manuports, the non-modified exotic pieces of rock.

Technology set 5: burnt-modified artefacts.

It can be argued that these sets oversimplify the rather dynamic process of lithic tool production, which may take many forms, especially if re-use and re-shaping is a recurrent feature. Furthermore, the possibility exists that certain tool technologies yield various artefacts that served totally different tasks. Especially in the case of debitage it is not always possible to classify an artefact into a specific technology set. Considering the expedient nature of flake tool technology, in theory it is likely that proper flakes generated during the manufacture of, for example, an axe may have been used as flake tools. Fortunately, lithic tool production within the Caribbean, at least within the north-eastern Lesser Antilles study area, was relatively formal in its choice of raw materials. I mean here that certain specific rock types were generally chosen to make specific types of tools, despite the presence of alternatives. For example, flint, jasper, and chalcedony were always used for making flake tools, and are not found in the form of axes or adzes (see also Chapter 6 for discussion on the uses of St. Martin greenstone).

In Chapter 1, I emphasized the subtractive nature of stone tool production. This enables the archaeologist to study the whole production sequence (Ammerman \& Andrefsky 1982; De Grooth 1991; Torrence 1986). Such a sequence can be divided into different stages or activity sets, which can be considered as specific phases within the production process. The change from one phase to another may correlate with the use of a different flaking technique, or it may signify the change from reducing cores for flake production to reducing the flakes themselves. Such breaks in the stone working sequence potentially form moments before or after which items are transported. Collins (1975) has constructed general reduction sequences for flake tool and core tool productions. I take Collins' reduction sequences as the point of departure and simplify them so that they are applicable and useful for my purposes.

Having defined the different technology sets (TS), I have tabulated the different production trajectories for each set following the general scheme proposed by Collins (1975) (table 3.1). It should be remarked that these trajectories are simplified models of actual lithic artefact production. Furthermore TS 2 will exhibit variation depending on the type of core artefact made and nature of raw material available.

In her study on the organization of blade production during the Dutch Neolithic, De Grooth (1991) listed all the possible flows of flint materials and artefacts when this reduction sequence is coupled with all possible instances when lithic items are transported. She distinguishes transportation within a social group (direct access) and transportation between social groups (exchange). Translated to this case, a division should be made between TS 1 and 2 on the one hand, and TS 3, 4, and 5 on the other, as the sequence of the former sets is more complex and provides more possibilities than the latter ones do. Figure 3.1 presents the possible use-transport sequences for the latter technology sets. 


\begin{tabular}{|c|c|c|c|c|}
\hline $\begin{array}{c}\text { TS } 1 \\
\text { Flake tool production }\end{array}$ & $\begin{array}{c}\text { TS } 2 \\
\text { Core tool/core artefact } \\
\text { production } \\
\end{array}$ & $\begin{array}{c}\text { TS } 3 \\
\text { Use-modified tools }\end{array}$ & $\begin{array}{c}\text { TS } 4 \\
\text { Manuports }\end{array}$ & $\begin{array}{c}\text { TS } 5 \\
\text { Burnt-modified } \\
\text { artefacts } \\
\end{array}$ \\
\hline I & 1 & I & I & 1 \\
\hline v & $\mathrm{v}$ & I & I & I \\
\hline Primary reduction and core- & Primary reduction and core & I & I & i \\
\hline v & $\mathrm{v}$ & I & I & I \\
\hline Core reduction & Secondary reduction & I & I & I \\
\hline I & 1 & I & I & I \\
\hline $\mathrm{v}$ & $\mathrm{v}$ & 1 & 1 & I \\
\hline Shaping of flake-tools & Grinding/polishing & I & I & I \\
\hline 1 & 1 & I & i & i \\
\hline
\end{tabular}

Table 3.1. Production sequence, divided into different activity sets for each technology set, modified after Collins (1975).

Using these models as the starting point and bearing in mind the additional information that can be gathered from a subtractive process, the aim of the present technological analysis is to specify which stage(s) of the production process took place at a particular location. Regional comparison between different locations indicates in what form material was transported. This information will be further used in the following chapter to specify in which instances exchange was the mechanism by which items were transported, and what the type of exchange might have been.

\subsubsection{Data analysis}

Flake tool technology

To reach the goal specified above, I set up a data-collecting program. As this study was centred on flint and chert, in particular on Long Island flint flake tool production and its distributions, my data collecting strategy was organised around reduction of this material. As is clear above flake tool production can be divided into different activity sets, which may have been performed at different localities. All likely localities where these stone materials were worked should be investigated, to obtain a complete view of such a production process and its distribution. Within the Caribbean only two different types of sites at which flint and chert were worked have been reported thus far. These include lithic source areas and their direct surroundings (Pike \& Pantel 1974; Van Gijn 1996; Verpoorte 1993), and habitation sites (Crock \& Bartone 1998; De Mille 1996; Knippenberg 1999c, 2001a, b; Rodríguez Ramos 2001a; Walker 1980). So far, special flint and chert work camps other than those at lithic sources, have not been reported within the region. The sampling of habitation sites is discussed below in section 3.2.1.

Returning to the sequence of activity sets as proposed by Collins (1975), the data collecting strategy should be set up so that it is possible to determine for each site which parts of the production sequence took place and which parts not, using a specific number of related attributes. The following sections discuss the different broad phases in the production process separately. 

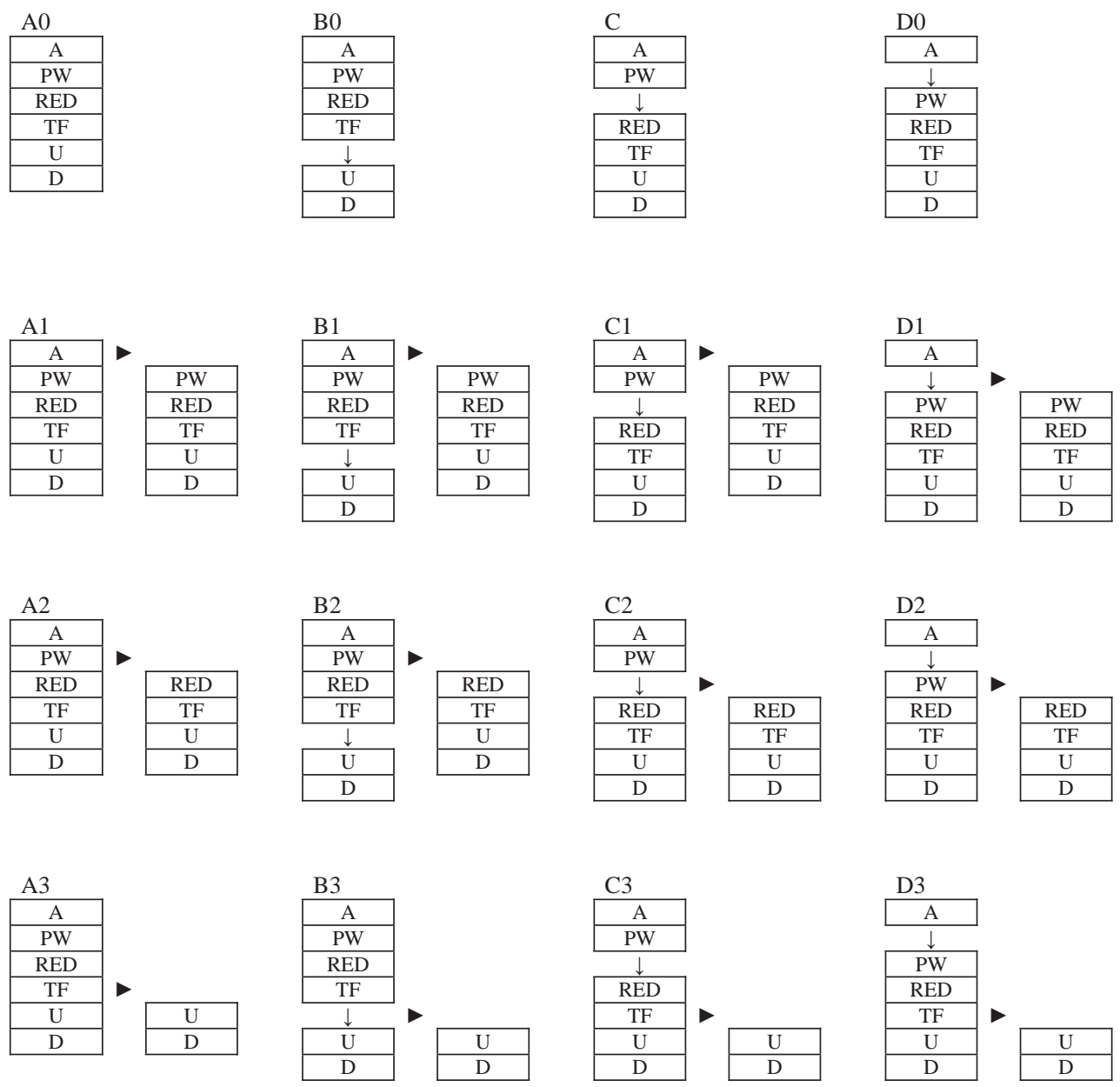

$$
\begin{aligned}
& \mathrm{A}=\text { Acquisition } \\
& \mathrm{PW}=\text { Pre-working } \\
& \text { RED }=\text { Reduction } \\
& \mathrm{TF}=\text { Tool finishing } \\
& \mathrm{U}=\text { Use } \\
& \mathrm{D}=\text { Discard }
\end{aligned}
$$

$\downarrow$ Within-group transport

- Between-group transport (Exchange)

Figure 3.1a. Specific models for acquisition and manufacture of stone tools (flake tools (TS 1) as well core tools (TS2)), allowing for transport at different stages in the production process, and distinguishing within-group en between-group transport (after De Grooth 1991, 170-171, with modifications). 

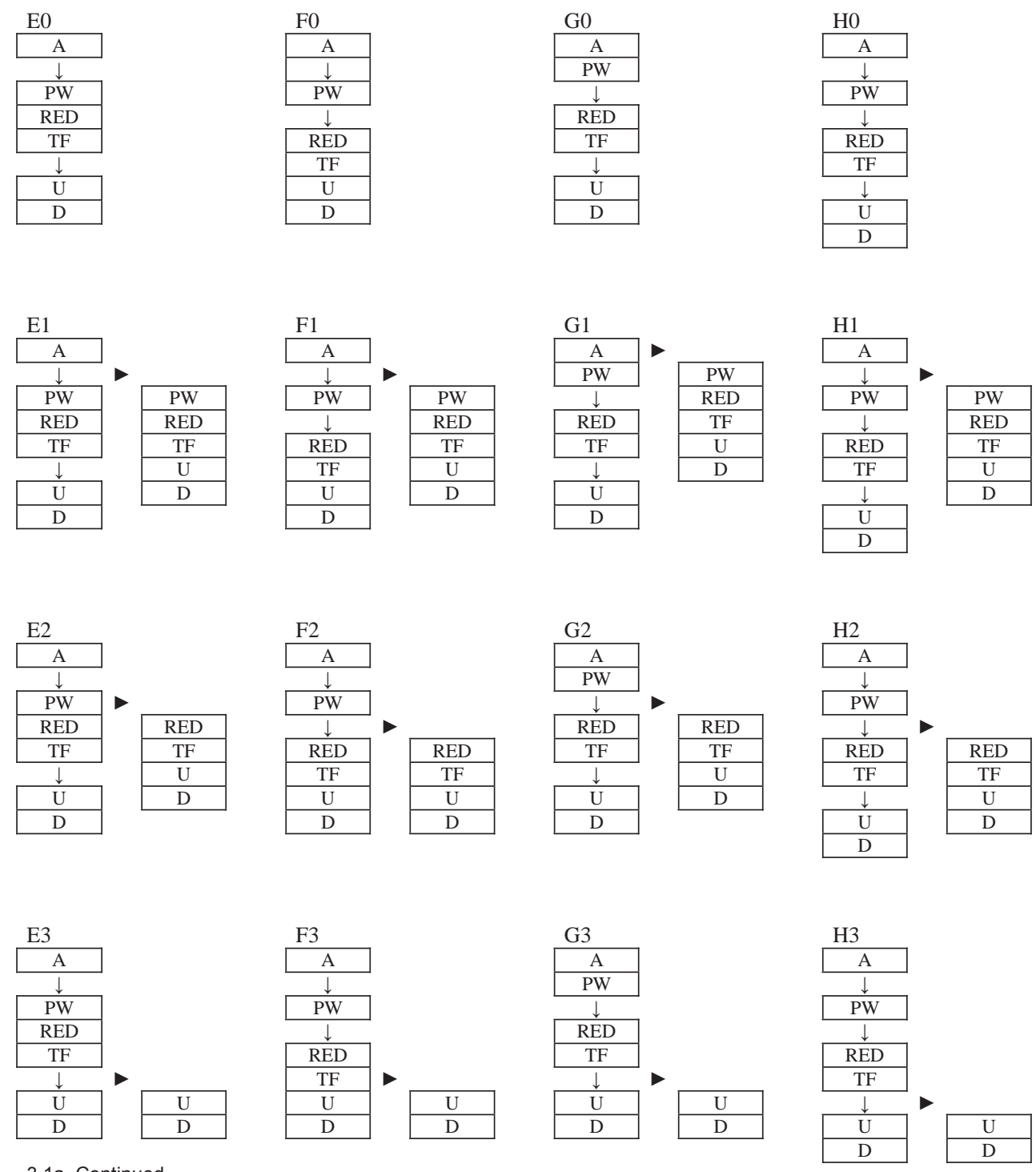

3.1a. Continued.
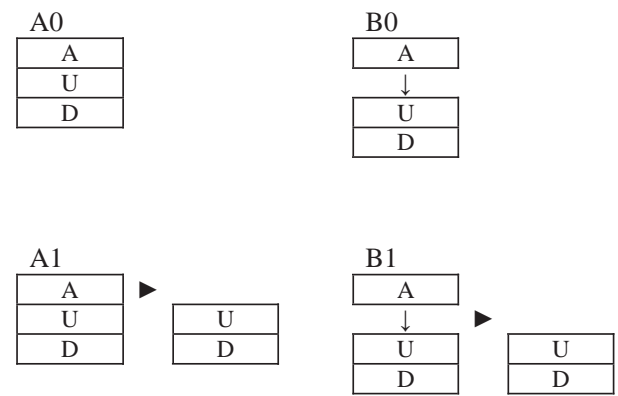

Figure 3.1b. Specific models for acquisition and use of use-modified and burnt rock (TS 3, 4 and 5), allowing for transport at different instances, and distinguishing within-group en between-group transport (see figure 3.1a for explanation). 


\section{Acquisition}

The first step in the lithic tool production process is the acquisition of raw material. This step needs to be studied at or near the source localities. To be able to make a proper distinction between production stages, detailed knowledge on the nature of the raw material is essential. Therefore the following questions are to be addressed first:

(1) How is the raw material naturally distributed and what are the characteristics of any natural form in which it occurs?

(2) Do the sources provide any evidence of quarrying strategies?

To answer question 1, the natural availability of the lithic material was studied and characteristic occurrences were noted. Special attention was addressed to whether the material was scattered on the surface, or still present in its primary bedrock deposition. Furthermore, shape, size, and outer surface of the natural material were recorded. The former two features significantly influence the nature of the debitage produced in the end. Experimental studies have demonstrated that the relative amount of cortical flakes, and the size and weight of the debitage are affected by the original size, form, and nature of the raw material. Therefore, knowledge on these features is essential when interpreting lithic samples (Amick \& Mauldin 1997; Bradbury and Carr 1995). As the outer surface or cortex on flakes plays a significant role in determining the reduction stage, good knowledge of the possible types is crucial for a proper determination.

After important information about natural availability and physical characteristics of the material has been collected, the next step is to see if any archaeological evidence can be gathered from the source itself to provide insight into the manner in which the material was obtained (question 2). Two types of quarrying are distinguished: (1) collecting surface material, or (2) mining primary deposits. Both types are likely to yield different raw materials.

\section{Reduction and tool finishing}

Knowledge gathered about the natural characteristics of the lithic material and the likely form in which it was quarried form the starting point for a proper analysis of lithic reduction and identification of different stages within the reduction process. This part of the analysis addresses for each site, habitation as well as source sites, the following questions:

(3) In which form did material arrive at the site?

(4) Was the material worked at the site, and if so, what stages of production were performed and what specific products were made?

(5) Was the material exported from the site, and if so, in what form was it transported?

In answering questions 3 and 5, the following possible forms of chert material are distinguished: (a) unmodified material, (b) pre-worked cores, and (c) flakes/flake tools. The following possibilities were evaluated as production stages: (a) testing, primary reduction and core-preparation; (b) core reduction; (c1) primary trimming/shaping of tools; (c2) reduction of flakes; and (d) use of tools (Collins 1975).

Due to the expedient nature of Ceramic Age Lesser Antilles lithic technology, the shaping of morphologically standardized flake tool types had not played a role (Bartone \& Crock 1993; De Mille 1996). In relation to reduction, Walker (1980) is the only one who has come up with a complete sequence for the tool production within the Caribbean. Supported by replication studies, Walker showed that at the Sugar Factory Pier site on St. Kitts, cores were reduced to produce flakes, which were either used as is or further reduced for the production of smaller flakes to be utilized as grater teeth (Walker 1980). This tool production did not involve any systematic secondary working in the form of edge modification or chipping, but occasionally flakes were modified by one or two flake removals to obtain a better edge. This absence of formal tool shapes poses difficulties in establishing the presence of actual tools at a site. For example, it has been very problematical for correct identification of grater teeth with any certainty (Crock \& Bartone 1998).

To answer the questions formulated above, certain attributes were chosen that would yield useful data. Starting with the artefact classification, I have chosen to use the scheme of Sullivan and Rozen (1985). This classification scheme is based on flake breakage patterns, and it was originally presented as an objective scheme for classifying debitage. The proportions of different flake types were seen as indicative of certain reduction technologies, e.g. core reduction, biface reduction, and bipolar reduction. Application of this scheme avoids the use of more subjective typologies.

Sullivan and Rozen's article (1985) has been a great stimulus for interpreting the debitage of lithic samples with 
respect to type of reduction. Although many lithic specialists questioned their interpretations (Amick \& Mauldin 1989; Ensor \& Roemer 1989), its less subjective method was subsequently used in many experimental studies to adjust these interpretations (Amick \& Mauldin 1997; Ingbar \& Bradley 1989; Kuijt et al. 1995; Prentiss \& Romanski 1989).

Recently it has been questioned whether distinct stages occur within stone tool production processes, and scholars have noted that lithic reduction should be seen more as a continuum (Bradburry \& Carr 1995; Shott 1996). From a knapper's point of view one can definitely point out certain stages between which a clear qualitative change occurs (e.g. change of hammer or reduction mode), but these changes can not always be significantly attested within the produced debitage (Shott 1996). Still, experiments have shown that there are some attributes, that show a rough correlation with reduction stage. These make it possible to distinguish early from late reduction phases (Bradbury \& Carr 1995; Shott 1996). As best indicators the following attributes are suggested: (1) amount of cortex on dorsal face, (2) scar count on dorsal face, and (3) weight (Andrefsky 1998; Shott 1996). Especially when a multivariate approach is used, high correlations between stage and attribute data are found (Bradbury \& Carr 1995). Therefore, these attributes play a central role within the present analysis.

\section{Flaking technique}

Determination of the manner of force application is essential for a better understanding of the core reduction technology. Caribbean lithic studies have shown that two manners of force application were used: direct freehand percussion and bipolar reduction (Bartone \& Crock 1993; Knippenberg 1995; Walker 1980). Both were used in the course of the same reduction process (Walker 1980).

Debitage will exhibit qualitative differences between these applications of force. Flakes from direct freehand percussion generally have a clear cone of percussion, a pronounced bulb of force, and may be curved in shape, whereas bipolar flakes have a diffuse bulb of percussion, diffuse or well pronounced percussion rings, and often are flat and straight (Kuijt et al. 1995). Sometimes, it is hard to distinguish interior from exterior faces on bipolar flakes (Walker 1980). Caution should be used when individual pieces are assigned to either of the two types of reduction because bipolar reduction can produce direct freehand percussion type of flakes and visa versa.

\section{Other technologies}

As pointed out above, lithic technology within the Caribbean and elsewhere comprises a number of different production processes. This analysis so far has mainly addressed the methodology for analysis of artefacts related to flake tool production. This section presents the strategy by which artefacts associated with other technologies can be studied. Data presented in Chapter 5 and 6 show that the outcomes relating to other lithic technologies are variable and different from the results from chert and flint research. This is attributed to the poor knowledge about source areas for many of these other materials. This was the case, in particular, at the start of this research, although positive exceptions occurred as well (Knippenberg 1995; Van Tooren and Haviser 1999; see also Chapter 2). Fortunately, this situation has been recently changing as works by Murphy et al. (2000), Bérard (1997, 1999), Bérard and Vernet (1997), and Rodríguez Ramos (2001a) have provided valuable new information on natural availability of different raw materials in the Caribbean. Still, crucial data on actual quarry areas is generally lacking since most references only report the general occurrence of specific materials on an island or within a certain geological formation, but without specifying actual quarry locations exploited by pre-Columbian inhabitants. ${ }^{7}$ Apart from these new findings, the provenance of many materials remains unidentified. In some cases it is possible to pinpoint areas or specific islands from which material likely originated, but in other cases only a "possibly local" or "possibly exotic" designation is feasible.

In addition to limited knowledge about sources, the low occurrence of a number of materials in the archaeological record hampers a detailed view about how they were worked, where they were worked, and over what distances they were distributed. A third feature that makes analysis of many of these technologies different from flake tool production is the less pronounced formation of technological features on the specimens due to the nature of the materials, as well as the fact that in some cases these features were blurred by later grinding or pecking within the production process.

Despite these inherent problems, an attempt was made to elucidate what stage material arrived at a particular site,

\footnotetext{
${ }^{7}$ The work of Bérard \& Vernet (1997), reporting on stone working at jasper quarry sites on Martinique, is a positive exception.
} 
which stages of the production process took place on-site, and whether any lithic items were transported elsewhere. In this case, a distinction was made between transport of (a) unmodified material, (b) preforms/blanks, and (c) tools or finished core artefacts. Stages were divided into (a) primary reduction of cores, (b) shaping of preforms, and (c) pecking and grinding of tools.

The debitage of the core-artefact production was analysed following the same scheme as was used to classify debitage of the flake tool production. I attempted to include as many of the attributes that were studied for the flake tool related artefacts, as possible. However, this was not always possible because determination of the flaking technique was very difficult in many cases. Furthermore, identification of outer surfaces was hampered due to ignorance about the original nature of such surfaces. Many rocks often lack a clearly distinct outer surface unlike, for example, flint where cortex rinds can be easily differentiated from the flint material itself. Finally, it should be noted that the amount of debitage related to these other productions was very small in many samples, thus complicating interpretation.

\subsubsection{The attribute analysis form}

To facilitate the analysis, a standard registration form was designed (see Appendix $\mathrm{C}$ for a complete presentation of the list of attributes, including definitions and codes). Each artefact was given an individual number and was studied for the following attributes: (a) raw material; (b) specific sub-variety of raw material; (c) artefact type; (d) length; (e) maximal dimension; (f) width; (g) thickness; (h) weight; (i) colour; (j) traces of burning; and (k) probable source.

Some remarks need to be made about the attributes a and b. I encountered a huge variety of rock materials during the analysis of the different lithic artefact collections and these can be attributed to the variable geological nature of the region. Materials include all sorts of igneous, metamorphic, and sedimentary rocks. Proper identification of every rock type would have required microscopic analysis, or the help of geologists familiar with regional rocks in most cases. Apart from the flints and cherts, this was beyond the scope of this research. Therefore general rock classes (e.g., igneous rock, metamorphic rock, and limestone) will often be used to denote raw materials in the following chapters. Only incidentally more specific rock classifications were recorded, if material was easily recognized or microscopic research had been previously performed (see Chapter 2).

After recording these attributes, core artefacts were separated from flake artefacts, and flake tool technology artefacts were distinguished from the artefacts associated with other production technologies. For all flake artefacts, (l) cortex count was coded as well as (m) reduction/modification, and (n) use-wear, if possible. All flake tool debitage was further analysed for the (o) scar count, (p) platform type, (q) distal end, and (r) flaking technique.

The "reduction/modification" and "use-wear" attributes need some additional clarification. Sullivan \& Rozen (1985) distinguish debitage from modified flakes. They consider the former to be the debitage of the production and the latter to be tools. This distinction is more difficult to make within Caribbean lithic assemblages because the expedient nature of the flake tool production, in which a portion of the flakes were used ad hoc without any further modification. Still, flakes were further modified in some instances. This modification served two purposes. Some flakes were modified to improve their overall shape or to create a specific edge to be able to (better) perform certain tasks. Other flakes, however, were modified (reduced is a better word in this case), for the production of smaller flakes. In fact, these flakes can be considered as a type of flake core, which Rodríguez Ramos (2001a) has termed "core on flake". To exclude these two types of modified flakes from the true debitage, they were given a special designation under the attribute "reduction". In this way, the modified could be distinguished from the non-modified artefacts.

Actual signs of use-wear were recorded under the "use-wear" attribute. The proper identification of use and function of flaked stone requires specialized analysis, involving different microscopic techniques and related experimental work (Van Gijn 1990). This was beyond the scope of the present study. Therefore, a means was sought to provide a general indication of the degree to which flakes were used. Use-wear in the form of edge damage or use retouch was taken as the measure. Use-wear was defined as a regularly patterned damage along edges in the form of small flake scar negatives or retouch. A distinction was made between intentional retouch, considered to be deliberate secondary working of the edge to improve its working capabilities, and use retouch, considered to be damage produced when an object was used. Discrimination between these two categories was sometimes hard to make, unlike stone tool technologies in other world areas, where clear formal tool types are often recognized. Therefore, an arbitrarily line was drawn between them based on the scar size within the retouch. 
All flake cores were categorised according to specific types defined by Hutcheson and Callow (1986). Furthermore, the presence of cortex and use-wear, and the type of flaking technique were recorded for the cores as well. Within the group of other core artefacts and core tools, a distinction was made between complete and fragmented items, as well as finished tools, and preforms. In addition, evidence about the mode of modification, such as pecking, grinding, and flaking, as well as evidence of used faces and type of use-wear was recorded. In the case of chopping tools, axes were distinguished from adzes based on the edge cross-section shape.

\subsection{CUltural SETTING OF SAMPLED SITES}

\subsubsection{Sample of sites}

Initially the distribution of chert and flint, and Long Island flint in particular, formed the central theme of this dissertation. This distribution forms one of the main databases from which statements about exchange can be deduced. Therefore, the choice of sites to be sampled was made with this issue in mind. Certain considerations played a role in the sampling. First, sites ideally should be distributed in such manner that they would cover the complete pre-Columbian distribution of the Long Island flint material. If such complete coverage could not be reached, then it should be at least possible to say where the distribution likely stopped from the pattern identified. Secondly, considering the fact we are dealing with island environments, an even distribution of sites across as many islands as possible was preferred over an in-depth study of many sites on a single island. Thirdly, the sample should include sites, be they workshops, extraction camps or habitation sites, on the Long Island source itself, keeping in mind the crucial information that can be gathered about the physical characteristics of the raw material, as well as collecting and primary reduction of flint material as discussed above (see section 3.1.3). Fourth, sites on the surrounding islands preferably should be habitation sites as they were the central locus within Amerindian social life. Camp or workshop sites, other than those at or near the source areas, are unlikely to be of major importance, as this study deals with exchange patterns, that result from social relations, rather than subsistence strategies. It should be added that the study of settlement patterns where attention is paid to possible site functional variation related to subsistence strategies is poorly developed within Caribbean archaeology. Most attention is paid to the relative large sites, which are generally considered permanent settlements, while temporary campsites and workshop sites are often neglected (for discussion of small sites, see De Waal 2006).

Regarding the focus on habitation sites, preference was given to sites, that have (a) produced radiocarbon dates, (b) from which a significant sample of lithic artefacts has been gathered, and (c) from which artefacts have been collected in a systematic procedure using screens, for example. Furthermore, (d) artefact samples should originate within similar contexts in a given site. As stated above, these requirements formed the starting point for sample selection and were considered as ideal conditions. In reality the ideal could not always be met and the actual choice of sites was much influenced by available sites that had been studied. Although this local region has had a lot of recent archaeological research (a project like this would not have been possible 20 years ago), there are still considerable gaps. In the first place, not every island has been studied archaeologically. For example, the islands of St. Barths and Dominica still remain relatively unexplored with only a small number of unsystematic site identifications and no large-scale archaeological excavations (Gassies 1999; Honeychurch 1995, 1997). Secondly, some of the islands have been unevenly explored, in which certain areas are systematically surveyed and others are not, as is the case for Guadeloupe, Montserrat and Barbuda. Such uneven focus also can be identified among the sites chosen for excavation. In general, relatively large settlement sites have been preferred, often with an extensive period of occupation such as, for example, Anse à la Gourde and Morel on Guadeloupe (Hofman et al. 2001; Hamburg 2000); Trants on Montserrat (Watters 1994; Watters \& Petersen 1999); Indian Creek on Antigua (Rouse \& Morse 1999); Hope Estate on St. Martin (Hoogland 1999); and Golden Rock on St. Eustatius (Versteeg \& Schinkel 1992). Exceptions, however, occur as well, such as small sites on Saba (Hoogland 1996).

In relation to chronology, sites dating to the earliest Ceramic period, i.e. Saladoid occupation, have received relatively more attention. This appears to be the case for St. Eustatius, St. Martin, Montserrat, and St. Kitts, which hosted 
Amerindian populations throughout the entire Ceramic period. ${ }^{8}$ Still, islands where this research bias is less evident also occur, such as Saba, Anguilla, Antigua, Nevis, and Guadeloupe.

Despite these and other biases more or less detailed archaeological maps exist for many local islands. These maps are in some cases based on a systematic survey in which the survey boundaries and methodology were clearly defined. In other cases, they have been drawn over the past years and are the result of more opportunistic data recovery methods. Still, in many of these latter cases site distribution maps provide almost complete coverage of individual islands and they apparently represent to a large degree the actual site distributions (e.g., Crock 2000).

Despite this variation in archaeological research within the northeastern Lesser Antilles, the past 20 years have certainly provided an enormous amount of new archaeological data, all of which has drastically changed the region's position within Caribbean archaeology (Crock 2000; Crock \& Petersen 1999; Hofman 1993; Hofman \& Hoogland 1999; Hofman et al. 2001; Hoogland 1996; Murphy 1996, 1999; Petersen 1996; Versteeg \& Schinkel 1992; Watters 1994; Wilson 1989; for an overview, see Delpuech \& Hofman 2004). Until the late 1970s, the northern Lesser Antilles were considered to be a marginal archaeological region between the relatively well-studied Greater Antilles and the Windward Islands. Now, however, they have been much better studied than many of the Windward Islands, and it is now believed that local developments played a much more important role in pre-Columbian times than previously thought (i.e. Hofman \& Hoogland 2004; Crock 2000), as born out by this study.

Table 3.2 lists the different sites included within the sample (figures 3.2-3.12 for location of the sites). The specified qualifications described above for the sample to a large degree have been met. In general, the region from eastern Puerto Rico to Martinique, assumed to include the entire distribution of Long Island flint, has been covered and a fair number of islands were included (N=14). These include Vieques, Anguilla, Saba, St. Martin, St. Eustatius, Nevis, Antigua, Long Island, Montserrat, La Désirade, Petite Terre, Guadeloupe, Marie Galante, and Martinique. It should be noted that samples from some of these islands are very limited, as was the case for Nevis, La Désirade, Petite Terre, and Marie Galante. Moreover, in many cases the studied samples only represented portions of the entire lithic artefact inventory excavated. For example, samples from Montserrat, from a number of sites on the main island of Antigua, and from sites on Saba basically only included flake-tool-technology-related artefacts. The main reasons why entire collections were not studied are related to the limited availability of materials at the institutions where they are stored. In a few cases, my analysis only involved the recording of a limited number of attributes due to time restraints. This accounted for samples from Antigua excavated by Fuess, material from La Désirade, Petite Terre, and the Anse à l'Eau, and Cocoyer sites on Guadeloupe and Marie Galante, respectively.

A close look at the distribution of the studied islands reveals that islands surrounding the source area of flint are under-represented, unfortunately. On Barbuda, St. Kitts, and St. Barths, materials were not accessible for varying reasons. To overcome this under-representation to some degree, data from the master's thesis by Jeff Walker (1980) was used to provide useful information from St. Kitts. As Walker is very familiar with the Long Island material, his source classifications are considered reliable. Also, data from sites on Antigua excavated and published by Reg Murphy and Christy De Mille in recent years (De Mille 1996, 2001; Murphy et al. 2000), have been used to supplement my finds from Long Island and results from the limited analysis of the Fuess' sites. In relation to published work on lithic materials, studies from Haviser on St. Martin, and Crock and Petersen on Anguilla were very helpful as well (Crock 1999, 2000; Crock \& Petersen 1999; Haviser 1987, 1988, 1991, 1993, 1999). In addition, co-operation with Reniel Rodríguez Ramos during my stay on Puerto Rico enabled us to set up an identical coding list of raw material types, with which we classified rock types encountered among the samples from the La Hueca and Sorcé sites on Vieques island, as well as some other Puerto Rican sites such as Punta Candelero and Paso del Indio (Rodríguez Ramos 2001a, b, 2005). We frequently exchanged data from these sites and others in the course of this research.

\subsubsection{Chronology}

The period between AD 400 and AD 1200 was considered to be most important to this research, because significant socialpolitical changes occurred during this period, which marks the transition from the Saladoid cultural tradition to localized post-Saladoid cultures. When viewing cultural chronology within the Caribbean, I see a fundamental problem for this study.

\footnotetext{
${ }^{8}$ A superficial evaluation of research on Anguilla and Barbuda might indicate the opposite, as sites under study were almost exclusively post-Saladoid (Crock 2000; Wattters et al. 1991). This focus on post-Saladoid sites, however, is not the result of specific research objectives and fully can be attributed to the almost exclusive presence of Late Ceramic Age sites on these islands.
} 


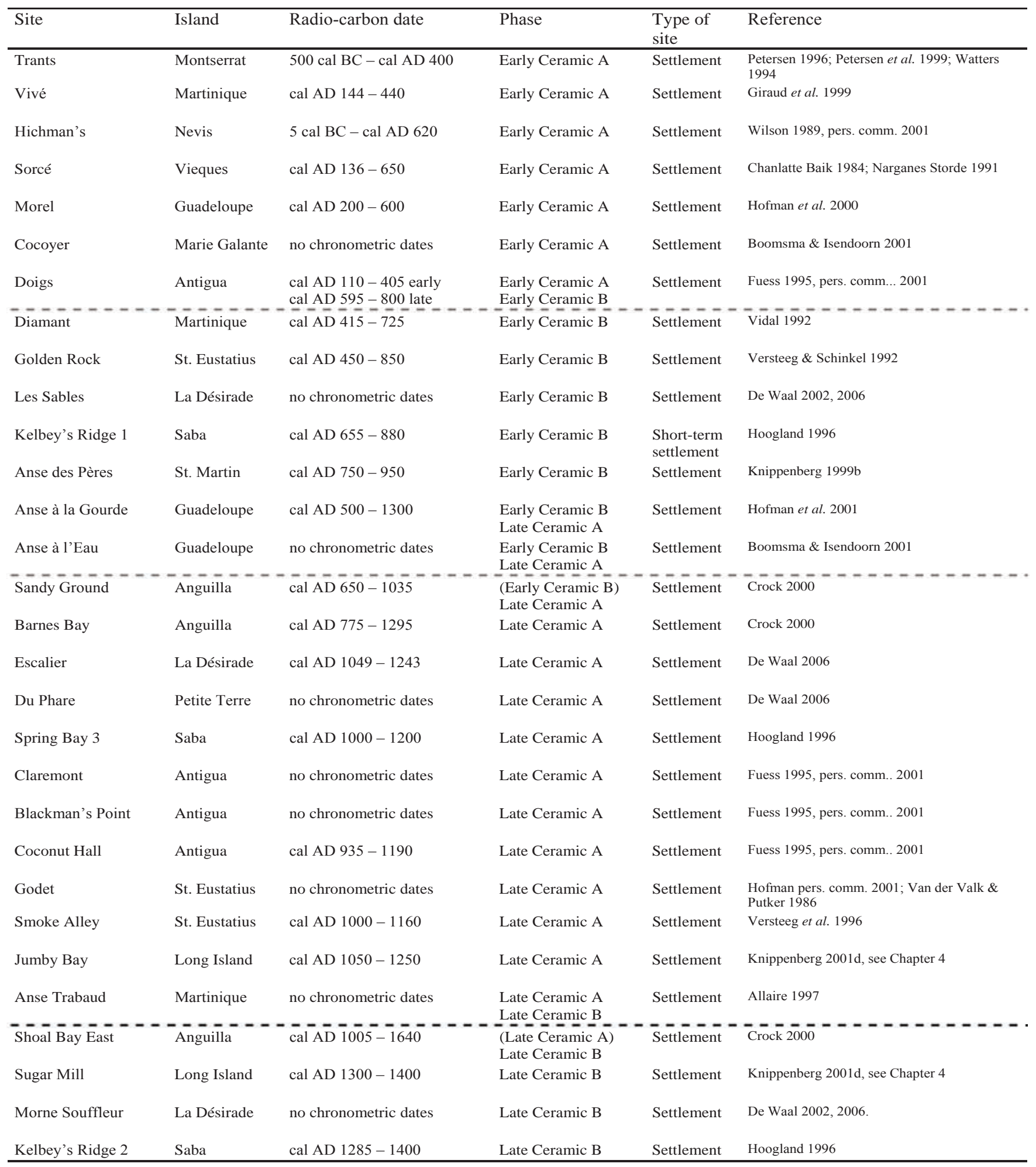

Table 3.2. Sample of Caribbean sites by period. For each site the range of radio-carbon dates has been specified. 


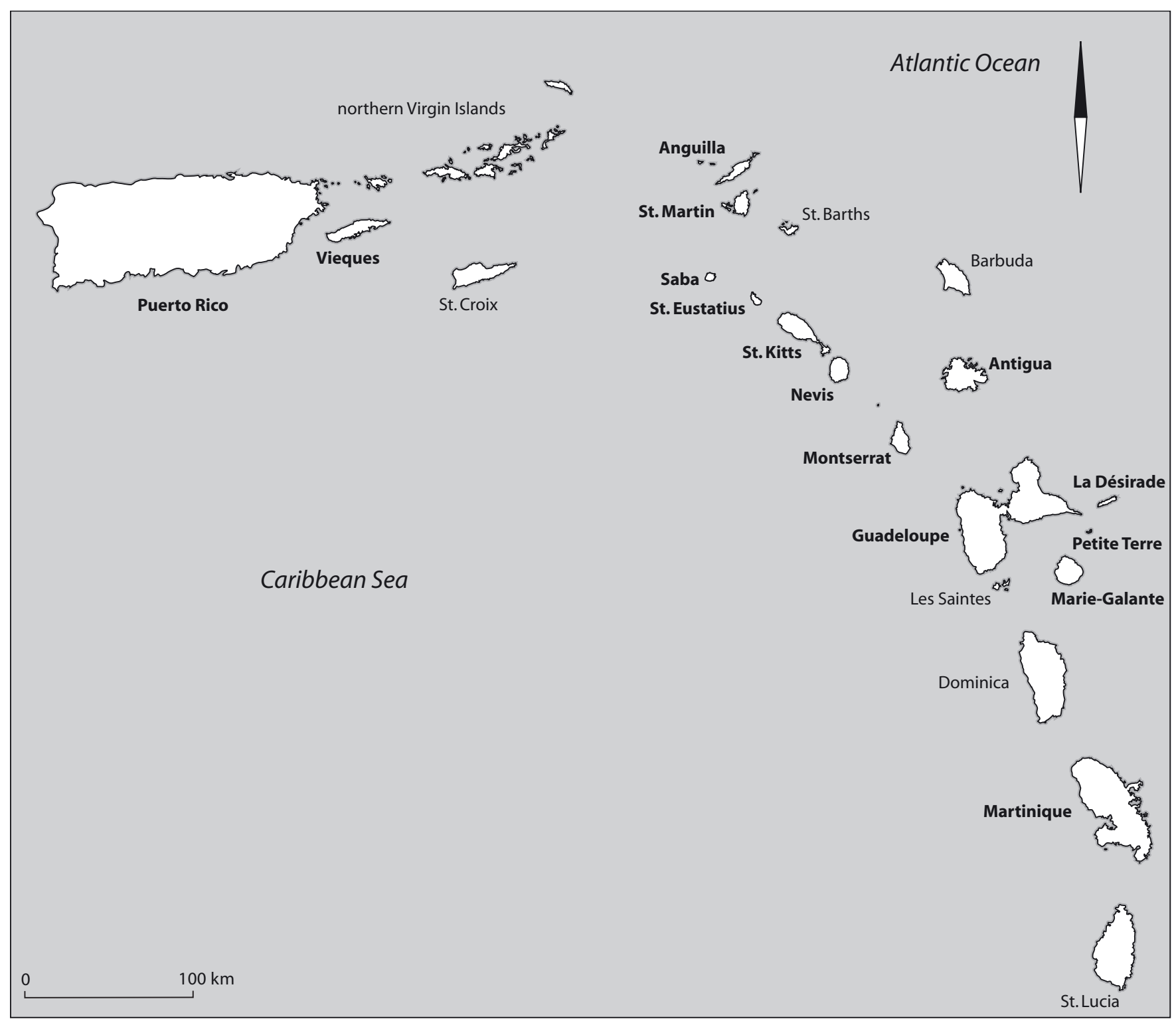

Figure 3.2. Map of the area studied in this work.

Rouse and many other Caribbean archaeologists have divided the chronology of the Caribbean within different cultural traditions, or to use the terminology of Rouse, Ceramic series and sub-series. Based on the absence or presence of certain ceramic modes, sites have been often classified to one of the different series and sub-series. Combined with stratigraphic data, Rouse was able to place these (sub)-series in relative chronological order. With the appearance of radiocarbon dating, this relative chronological division was supplemented and refined by absolute dates. However, rather than using the C14dates to define and refine his relative chronology, Rouse largely stuck to his original somewhat static cultural divisions and unilinear developments. This created a situation where general cultural traditions over large areas succeeded each other one at a time over large areas, neglecting cases where traditions coexisted within an area, or persisted in isolated regions.

For the study of exchange networks, the primary objective of this research, we need to know the contemporaneity of sites within a certain period and that is much more important than knowing their cultural similarity or affinity. Therefore, what is needed is an absolute site chronology, rather than a cultural chronology. This all seems very straightforward, but looking at Caribbean archaeological studies it can be noted that cultural divisions are still used to make temporal divisions, 


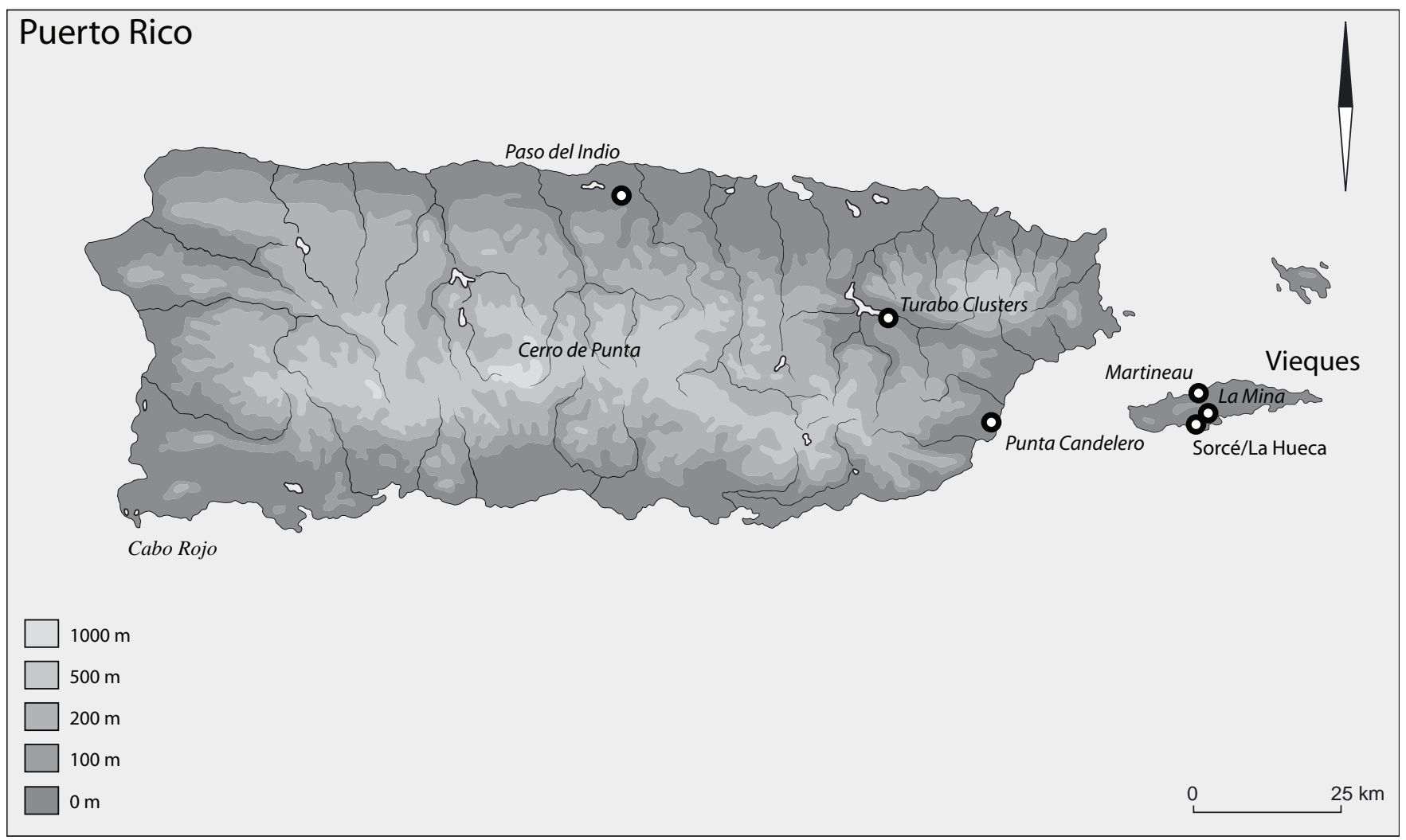

Figure 3.3. Map of Puerto Rico and Vieques showing the sites mentioned in this work. In normal font sites studied by myself, and in italic sites studied by others.

as in the case of the Saladoid and post-Saladoid period, which is based on ceramic traits, rather than on absolute dates. Therefore, in this study I distinguish certain phases in absolute years (see also Hofman 1993), which will lack a cultural connotation. Although they broadly follow the cultural chronology of Rouse, I avoid using terms such as the Saladoid period, for example. When I speak of Saladoid or Ostionoid sites, I mean sites that have produced ceramics possessing Saladoid or Ostionoid modes/traits, rather than sites belonging to the Saladoid or Ostionoid period.

I distinguish the following phases for the northern Lesser Antilles, following Hofman (1993, 28; see also Hofman and Hoogland 2004) to some extent and keeping in mind the aims of the present study:

The Preceramic Age: 3500 - 400 BC; during which ceramics were absent and fishermen and shell-fish collectors inhabited the islands.

The Early Ceramic A (early phase): $400 \mathrm{BC}-\mathrm{AD} 400$; period, during which the first horticulturalists arrived, and during which Huecan and Cedrosan Saladoid ceramics co-existed.

The Early Ceramic B (late phase): AD 400 - AD 850; this period corresponds with the final phase and end of the Cedrosan Saladoid sub-series and the appearance of the first post-Saladoid ceramic styles.

The Late Ceramic A (early phase): AD 850 - approx. 1250; this period corresponds with the decline of ceramic features, commonly grouped among the general name of post-Saladoid, and development of more localized styles.

The Late Ceramic B (late phase): approx. AD 1250 - 1492/early Historic period: period corresponds with a revival of pottery art and the full development of chiefdoms in the Greater Antilles. Especially during the later part, foreign styles within the Lesser Antilles made their first appearances. 


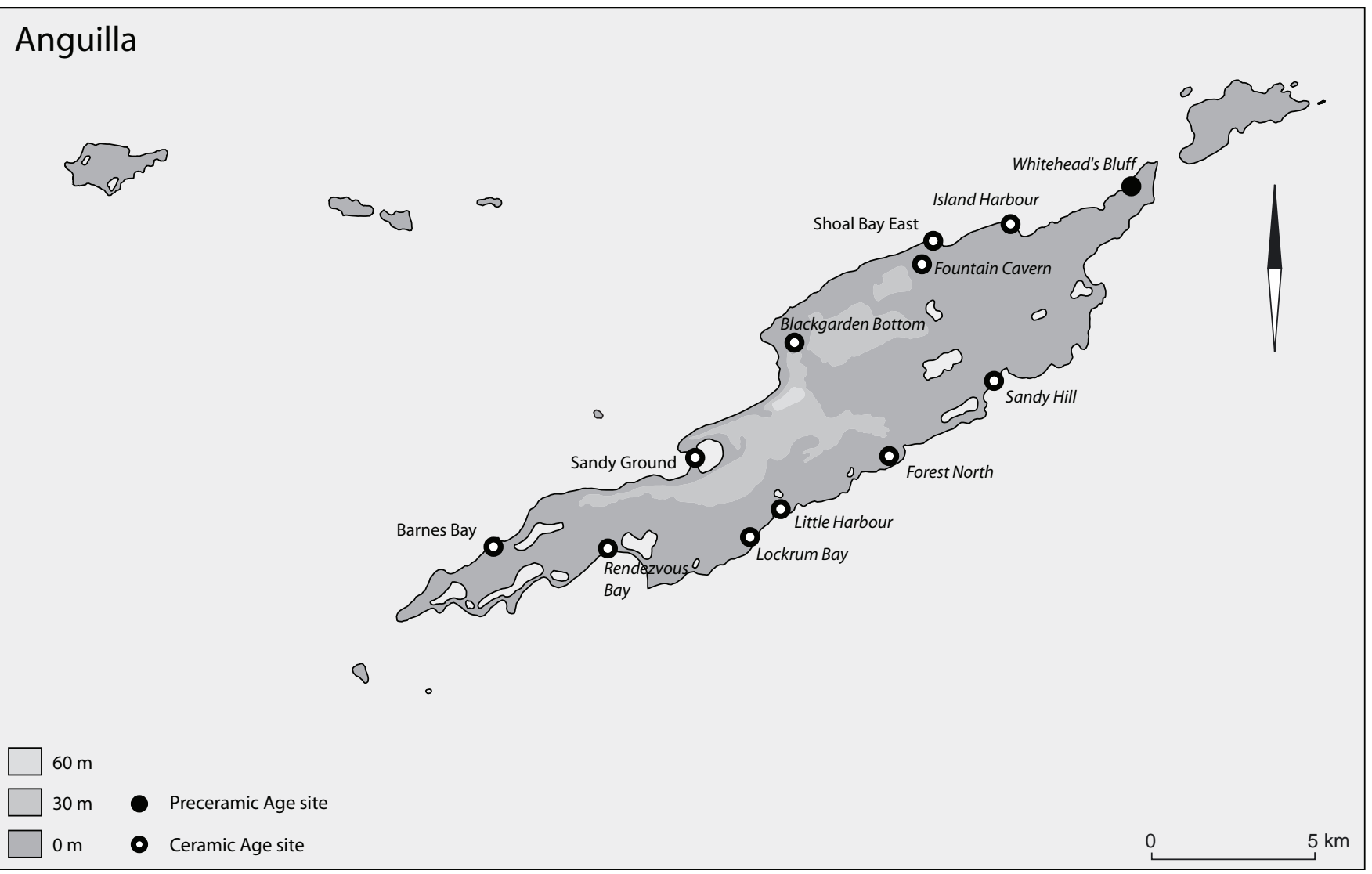

Figure 3.4. Map of Anguilla showing the sites mentioned in this work. In normal font sites studied by myself, and in italic sites studied by others.

Here, I mainly deal with the period extending from the Early Ceramic A to the Late Ceramic A phases, as they mark the period from Saladoid domination toward decline followed by local post-Saladoid developments. Attention is also devoted to the Late Ceramic B phase. However, knowledge about this phase is still poorly developed in the northern Lesser Antilles and mainly relates to materials from a very small number of sites.

Table 3.2 lists the absolute chronology of the different sites discussed in this study. The tabulated dates are associated with the material samples that were studied. So, in some cases these dates do not cover the entire period of occupation of a site, because the studied samples only formed a part of the total excavated collection. This is the case for Sorcé, Shoal Bay East, and Trants. In some cases absolute dates were not available, and sites were then given a probable date based on close similarities in ceramic modes with dated neighbouring sites. This is the case for Smoke Alley, Godet, Blackman's Point, Claremont, Anse à l'Eau, Cocoyer, and Anse Trabaud.

Trants, Vivé, Sorcé, Morel, Hichman's, and the early occupation at Doigs are the earliest sites used in this study, partly preceding AD 400 and therefore falling into the Early Ceramic A phase. Cocoyer has been placed within this period as well on basis of stylistic similarities. Late Saladoid sites belonging to the Early Ceramic B include Diamant, Golden Rock, Kelbey's Ridge 1, Anse des Pères, and the late occupation at Doigs. Les Sables has been classified as Late Saladoid as well on the basis of ceramic features. Multi-component sites with the earliest occpations during this same period are Sandy Ground, Anse à la Gourde, and Anse à l'Eau. Exclusive post-Saladoid sites belonging to the Late Ceramic A include Barnes Bay, Spring Bay 3, Smoke Alley, Escalier, Coconut Hall, and Jumby Bay. Godet, Blackman's Point, Claremont, Du Phare, and Anse Trabaud may be assigned to this period as well based on ceramic traits, although Anse Trabaud may also have been part of the Late Ceramic B. The excavators tentatively have dated this site between AD 1000 -1500 (Allaire 1997). The samples from Shoal Bay East, Kelbey's Ridge 2, and Sugar Mill are among the latest sites belonging to the Late Ceramic B, with the former extending to the early contact period. Morne Souffleur has been dated to this period as well on basis of strong similarity with Morne Cybèle, which has been radiocarbon dated between AD $1200-1460$. 


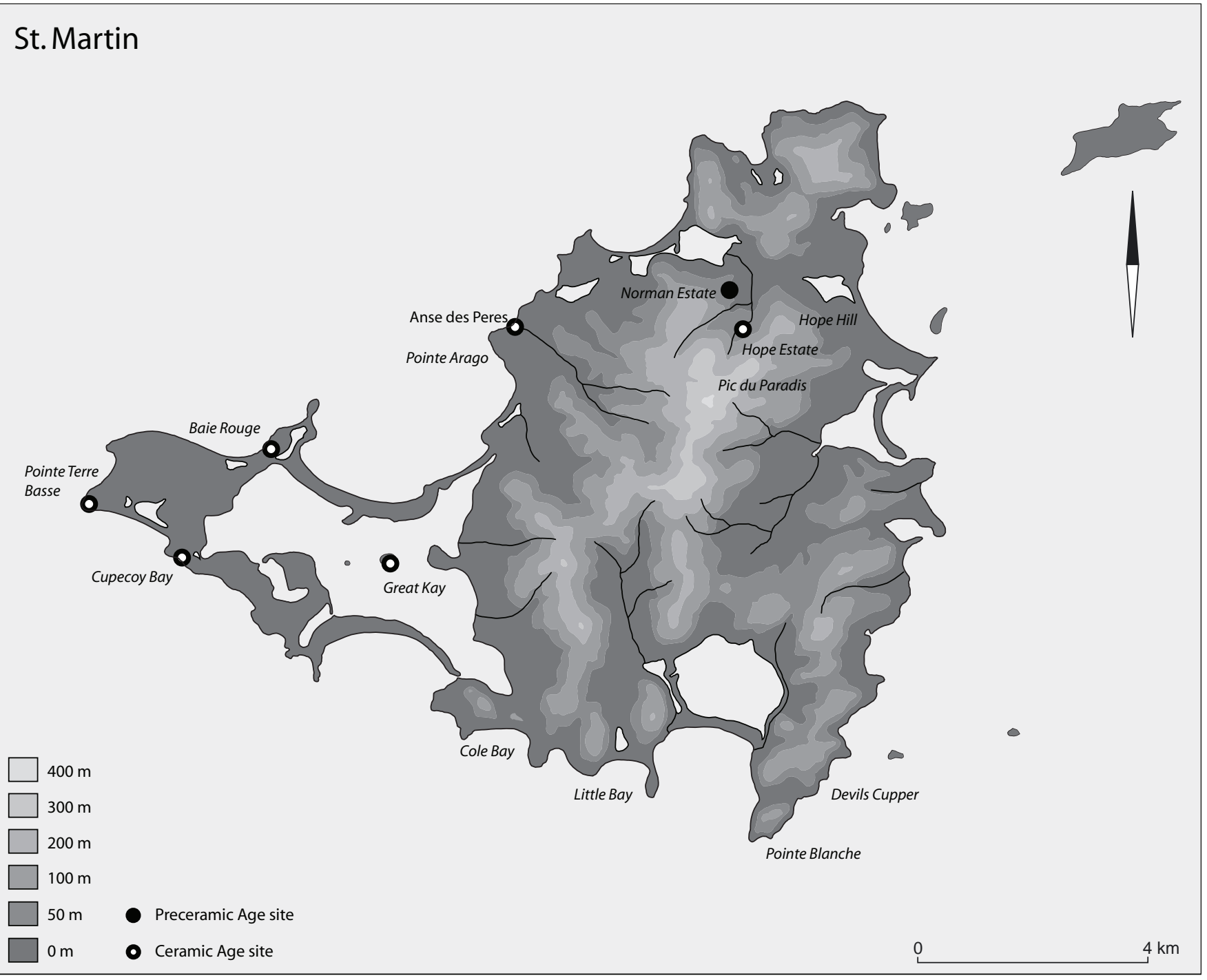

Figure 3.5. Map of St. Martin showing the sites mentioned in this work. In normal font sites studied by myself, and in italic sites studied by others.

\subsubsection{Sampling and bias}

Site sample

Above I explained the considerations that guided the selection of sites to be incorporated within the present research. It became clear that the amount of archaeological work done was limited for some islands, despite the significant overall increase of excavations during recent years in the region. This meant that site choice was generally dictated by availability of excavated material, and that sample taking did not follow rigid statistical procedures. Such a limited choice is not ideal because it hampers insight into sample bias. In order to get a better idea of what type(s) of sites were part of the sample and which were not, I looked at the results of archaeological survey work performed at the Pointe des Châteaux peninsula on Grande Terre, Guadeloupe (De Waal 2001, 2006), on Anguilla (Crock 2000; Crock \& Petersen 1999; Watters 1991) and on Saba (Hoogland 1996). Research on most of these islands has resulted in an almost complete knowledge of site distribution and variation on whole islands (Saba and Anguilla) or parts of them (Pointe des Chateaux on Grande Terre). These data enabled me to place the sites from these islands within my sample, against the complete population of these islands, and by doing that identify certain biases. 


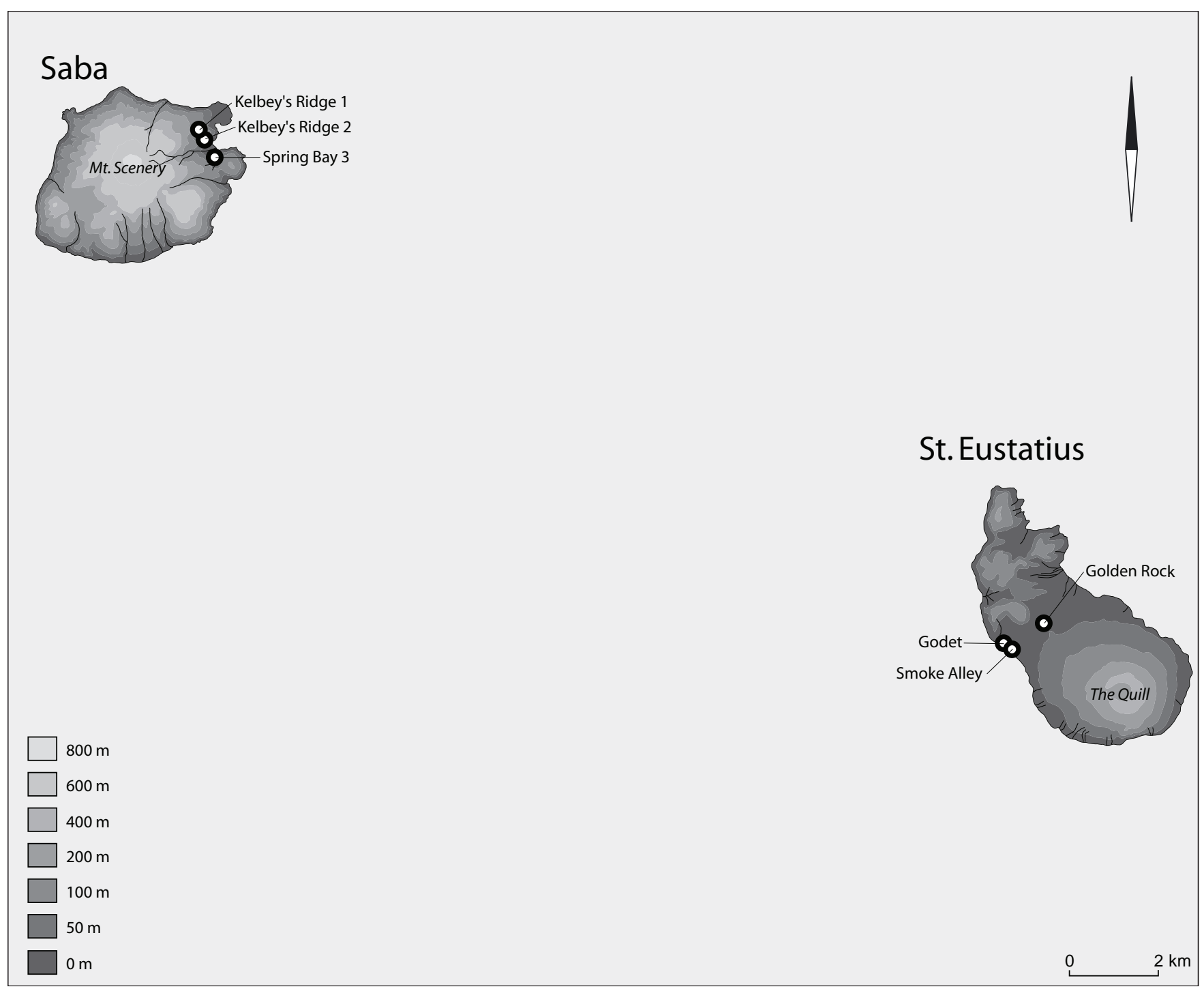

Figure 3.6. Map of Saba and St. Eustatius showing the sites mentioned in this work. In normal font sites studied by myself, and in italic sites studied by others.

The Anse à la Gourde site, for example, is a site within my sample situated on the Pointe des Chateaux peninsula on Grande Terre. It is a large settlement site dated between AD 500 and 1300 (Hofman et al. 2001). From the survey work by Maaike de Waal we know that this site can be considered as a major site within the near region, as none of the surrounding sites did equal Anse à la Gourde in size and, in particular, duration of occupation (De Waal 2001, 2006).

A similar situation exists for the island of Anguilla (Crock \& Petersen 1999; Crock 2000), where a long period of successive efforts by different researchers has led to a good knowledge of its site distribution (Crock 2000; Crock \& Petersen 1999; Dick et al. 1980; Douglas 1986, 1991). On this island too, excavation work has been directed at the relatively large and long occupied sites, as is evident from recurrent work at the large site of Rendezvous Bay (Watters \& Petersen 1993) and John Crock's sample choice for his dissertation research (Crock 2000, 50-53). The latter deliberately chose the larger and longer occupied sites from the available sample to gain insight into site hierarchy through time (Crock 2000). As a result, sites included in my sample follow this bias as well.

The situation is somewhat different on Saba (Hofman 1993; Hoogland 1996). In the first place, Saba has not produced large sites, as can be found on Guadeloupe, Anguilla, and St. Eustatius (Hoogland 1996, 208-13). Bearing this in 


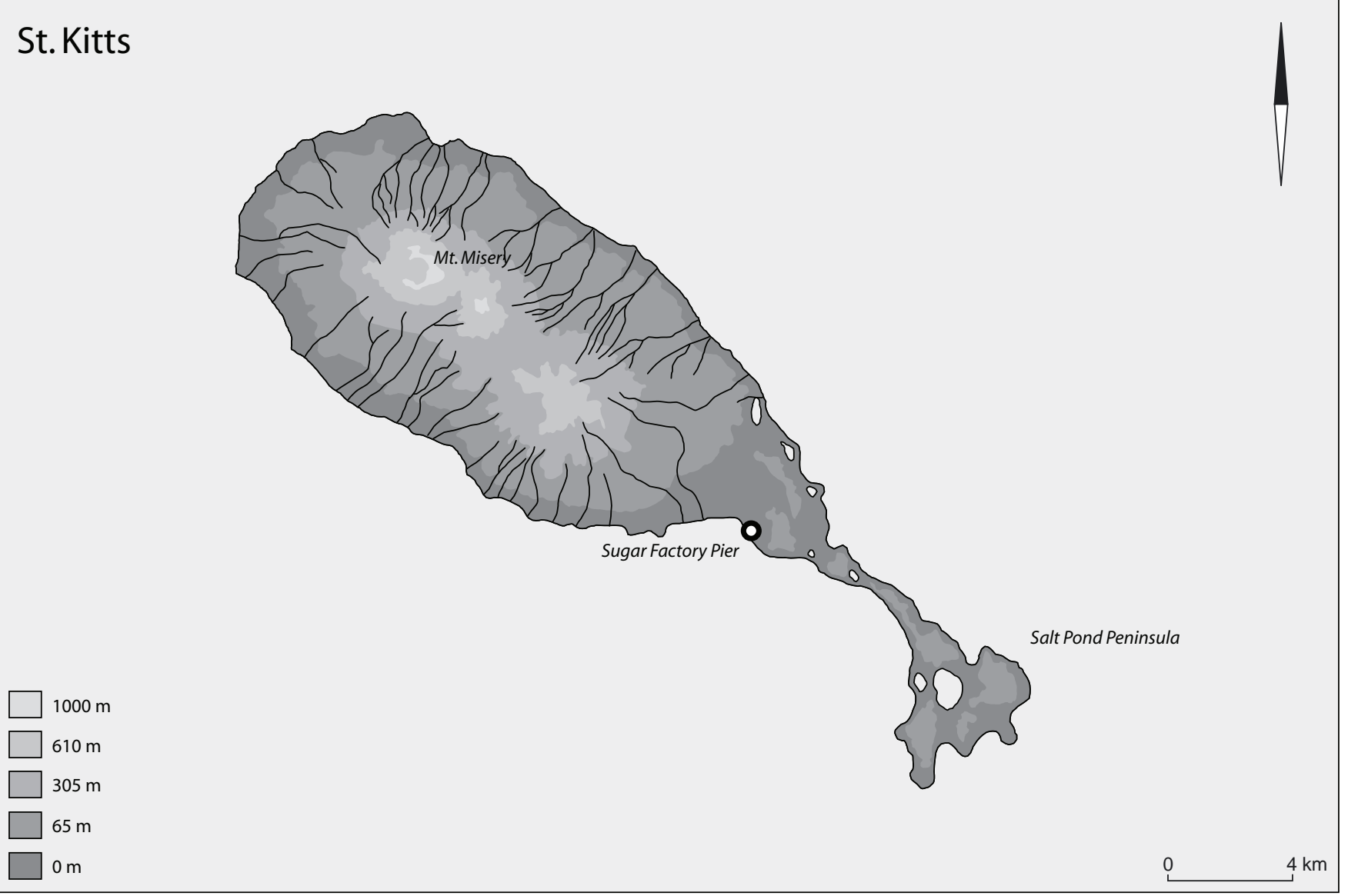

Figure 3.7. Map of St. Kitts showing the sites mentioned in this work. In normal font sites studied by myself, and in italic sites studied by others.

mind, the sample of settlement sites studied by Hofman and Hoogland probably forms a better representation of the total population of available sites on the island than is the case elsewhere. Both small sites, such as Kelbey's Ridge 1, as well as relatively large sites, such as Kelbey's Ridge 2, were included (Hoogland 1996, 208-13), but of course smaller populations may have been present on Saba.

Summarising, the relatively short history of archaeological research within the northeastern Lesser Antillean region has resulted in an overrepresentation of large and long-term occupied habitation sites. Small settlement sites are in general by-passed, but exceptions do occur as was shown by the research of Hofman and Hoogland on Saba (Hoogland 1996). Sites that are almost completely neglected in Caribbean archaeology include special activity sites (see for discussion De Waal 2006). Only on Anguilla a cave site was studied in more detail, the Fountain Cavern (Watters 1991; Petersen \& Watters 1991). This cave contains a fresh water source as well as a sculptured limestone stalagmite, and it has been interpreted as a place of ritual significance (Watters 1991).

An apparent bias toward large and long-term occupied settlements therefore is also represented within my sample of sites, and as such may hamper complete knowledge of the organization of stone tool production, involving the whole range of likely places were stone tools were worked and used. I have already noted that habitation sites form the most important localities when studying exchange in small-scale societies. Furthermore, only those special activity sites that are directly related to stone working or stone acquisition should be considered. As Torrence (1986) has shown, the organization of stone working sites is to a large extent related to the degree in which people have access to raw material sources, which is crucial for understanding of production and exchange. So, they all should be included when investigating exchange. These sites are often found near lithic source areas within small-scale societies. This is also the case for the Caribbean, where sites interpreted as stone working sites have never been reported outside source areas. 


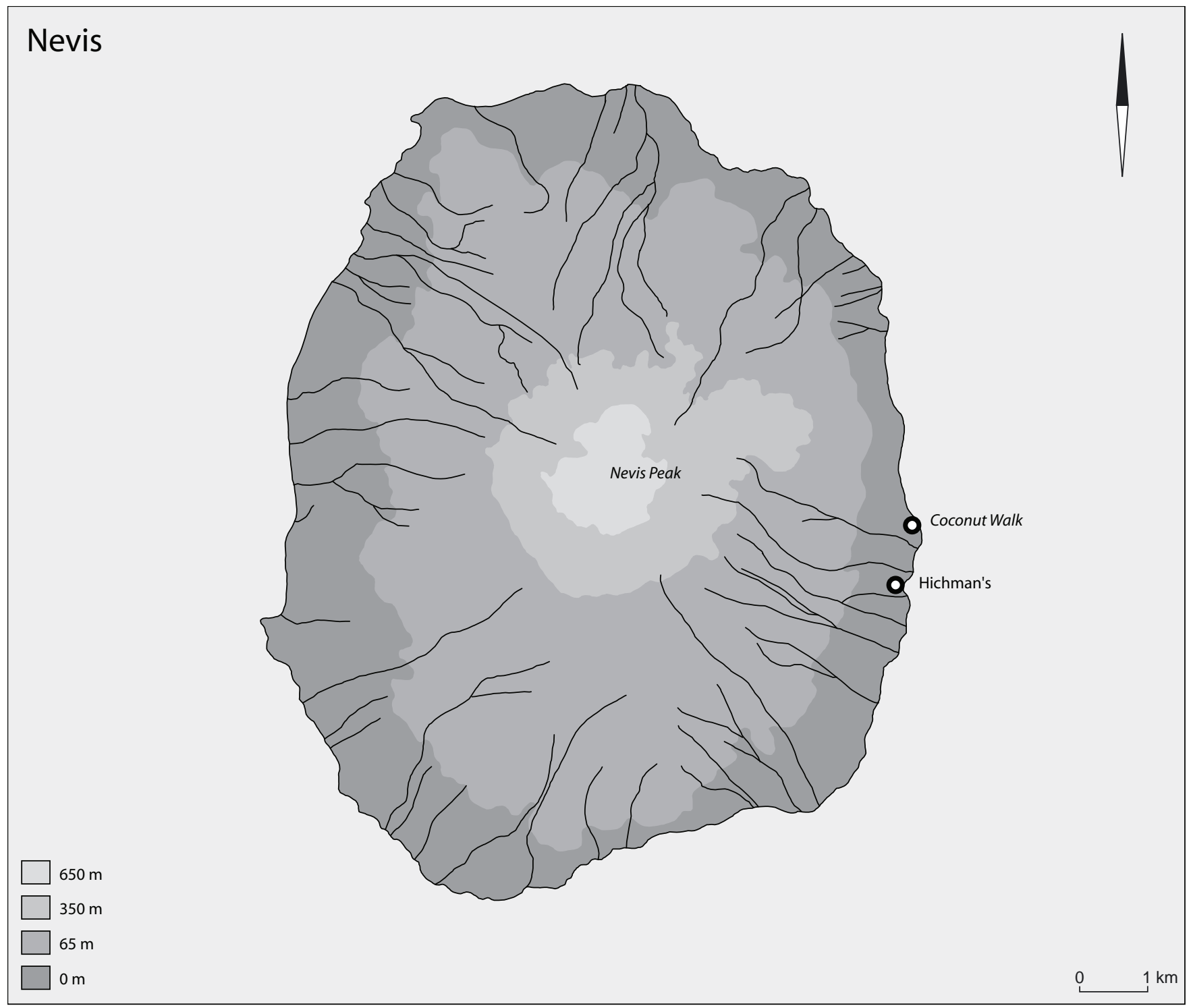

Figure 3.8. Map of Nevis showing the sites mentioned in this work. In normal font sites studied by myself, and in italic sites studied by others.

On the other hand, activity sites not directly related to stone working such as, for example, ritual places, water collecting localities, or camp sites where specific food resources were exploited will provide general knowledge about where material was worked and used within local societies. It will inform us about the different functions and values that the people attributed to stone. Such information is useful to the study of exchange, as it contributes to interpretation on another level, namely the motives behind the exchange systems at work. For this study, however, I am initially interested in the type of exchange that was responsible for the distribution of the lithic materials. So, the general behaviour toward production and use of the stone tools is my main focus.

As discussed above, I will evaluate whether cost-control devices were applied. Such an application will not necessarily exhibit variation between special activity sites and permanent settlement sites within small-scale societies as in the Caribbean. Therefore, in neglecting such special activity camps, other than stone workshop sites, the analysis of settlement sites should provide sufficient information on my initial purposes and there is no reason to state beforehand that excluding such special activity camps will significantly bias my results. This leaves a bias towards the larger settlements within the sample. Fortunately, some of the smaller sites on Saba are included. 


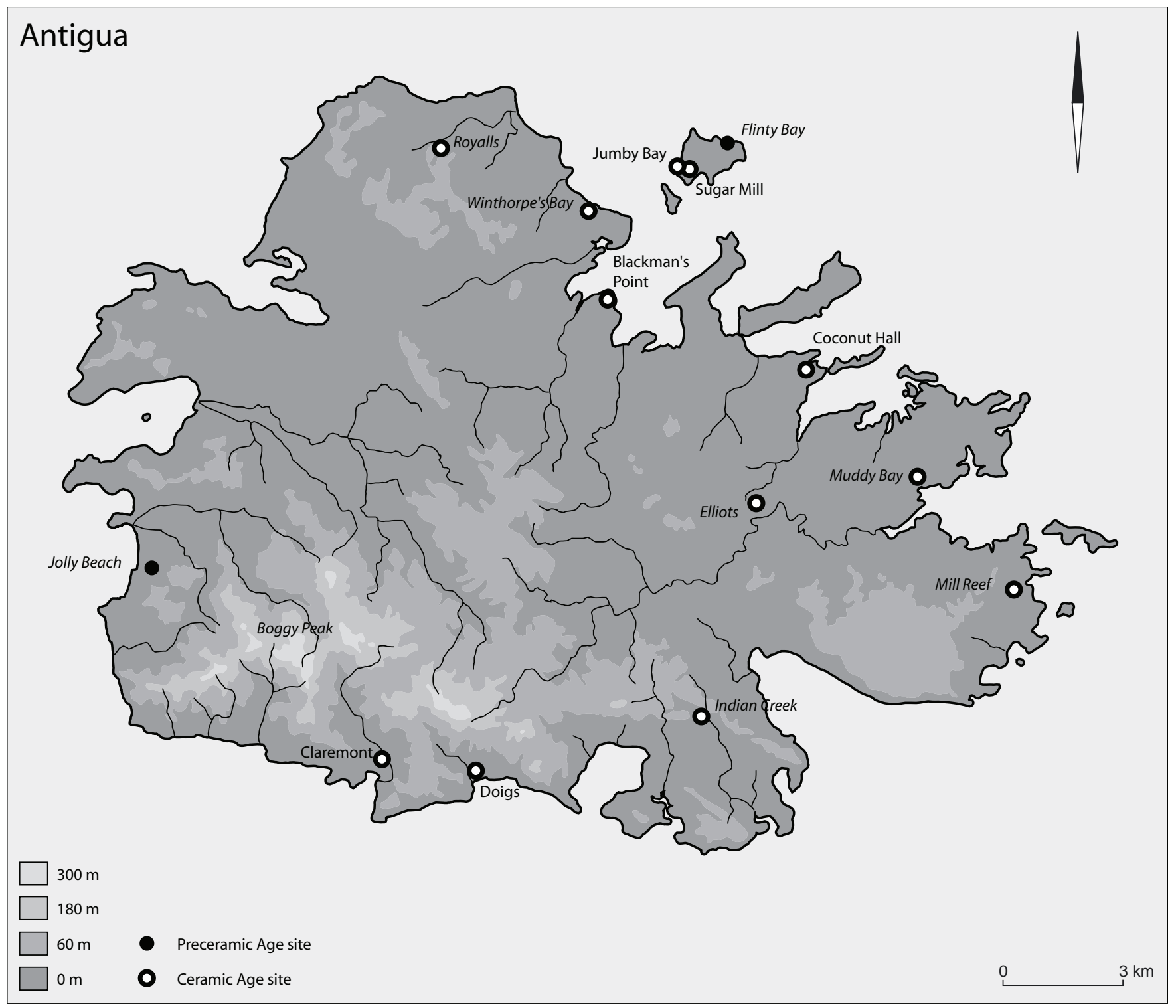

Figure 3.9. Map of Antigua showing the sites mentioned in this work. In normal font sites studied by myself, and in italic sites studied by others.

\section{Excavation methodology}

On another level, sampling bias can arise from variation within the excavation methodologies applied at different sites. This may well be a significant factor, considering the many different researchers and research institutions working within the region. I limit myself here to the discussion of the methodology that was used for the excavation of the lithic samples discussed within this study. This only involves the systematic excavation of test-units, varying in size from $0.5 \times 0.5 \mathrm{~m}$ to $4 \mathrm{x} 4 \mathrm{~m}$, as my samples only originated from such units. The methodology used when clearing large areas for house plan reconstruction need not be dealt with.

The common archaeological excavation methodology within the Caribbean is sometimes cynically called "phone booth archaeology" (Keegan 1994). This name is used to emphasize the total reliance on the excavation of (a limited number of) arbitrarily chosen test-units, preferably ranging from 1 × 1 to 2 × $2 \mathrm{~m}$, within large densely concentrated site areas. It was much employed by Rouse in the early days as a quick means to collect materials for his cultural chronological 


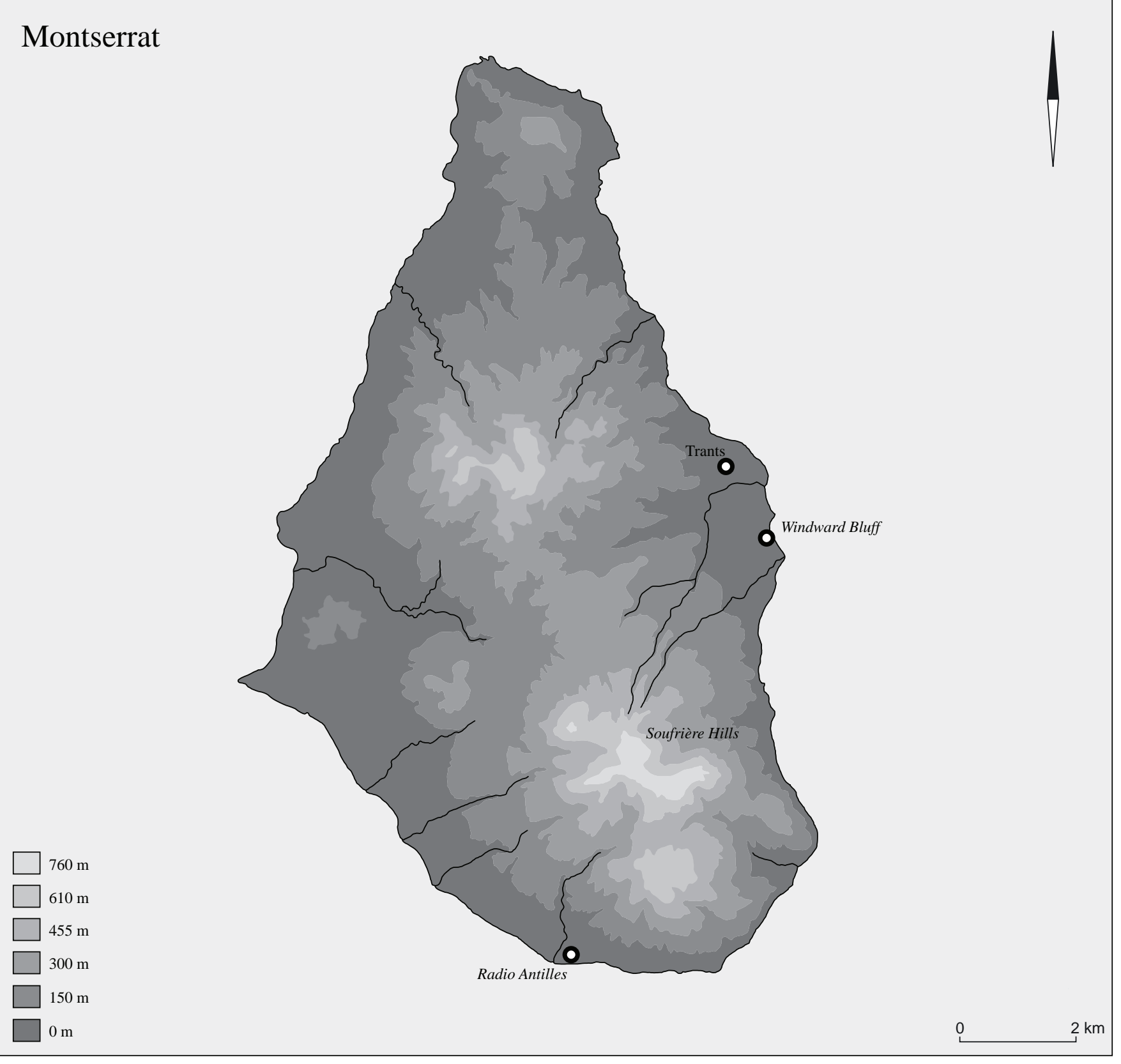

Figure 3.10. Map of Montserrat showing the sites mentioned in this work. In normal font sites studied by myself, and in italic sites studied by others.

characterisation, but it is an excavation method that is still widely used within the region for practical reasons. Nowadays, more systematic sampling (Crock 2000; Hoogland 1996; Versteeg \& Schinkel 1992; Watters 1994) and occasionally random sampling (Knippenberg 1999b) are also guiding the location and number of test-units excavated. Furthermore, excavation of test units is in many cases combined with clearing of larger areas for reconstruction of house plans and studying burial areas (Hofman et al. 2001; Hoogland 1996; Versteeg \& Schinkel 1992; Watters \& Petersen 1999). These latter trends result from changing research objectives, shifting from an emphasis on cultural chronology toward an emphasis on social behaviour (e.g., Hoogland 1996; Keegan 1992). 


\section{Guadeloupe}

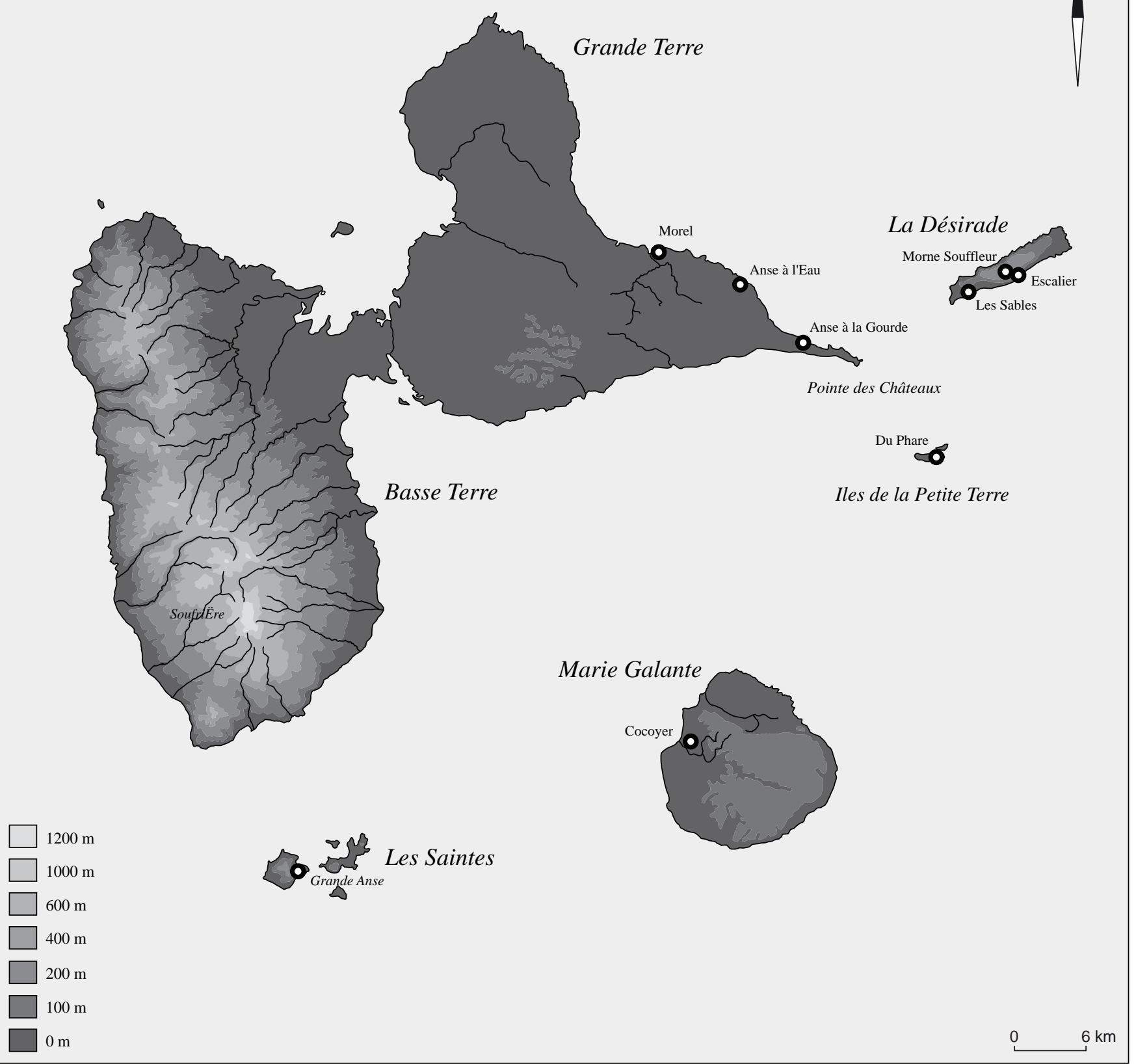

Figure 3.11. Map of Guadeloupe, La Désirade, Petite Terre, Marie Galante and Les Saintes showing the sites mentioned in this work. In normal font sites studied by myself, and in italic sites studied by others. 


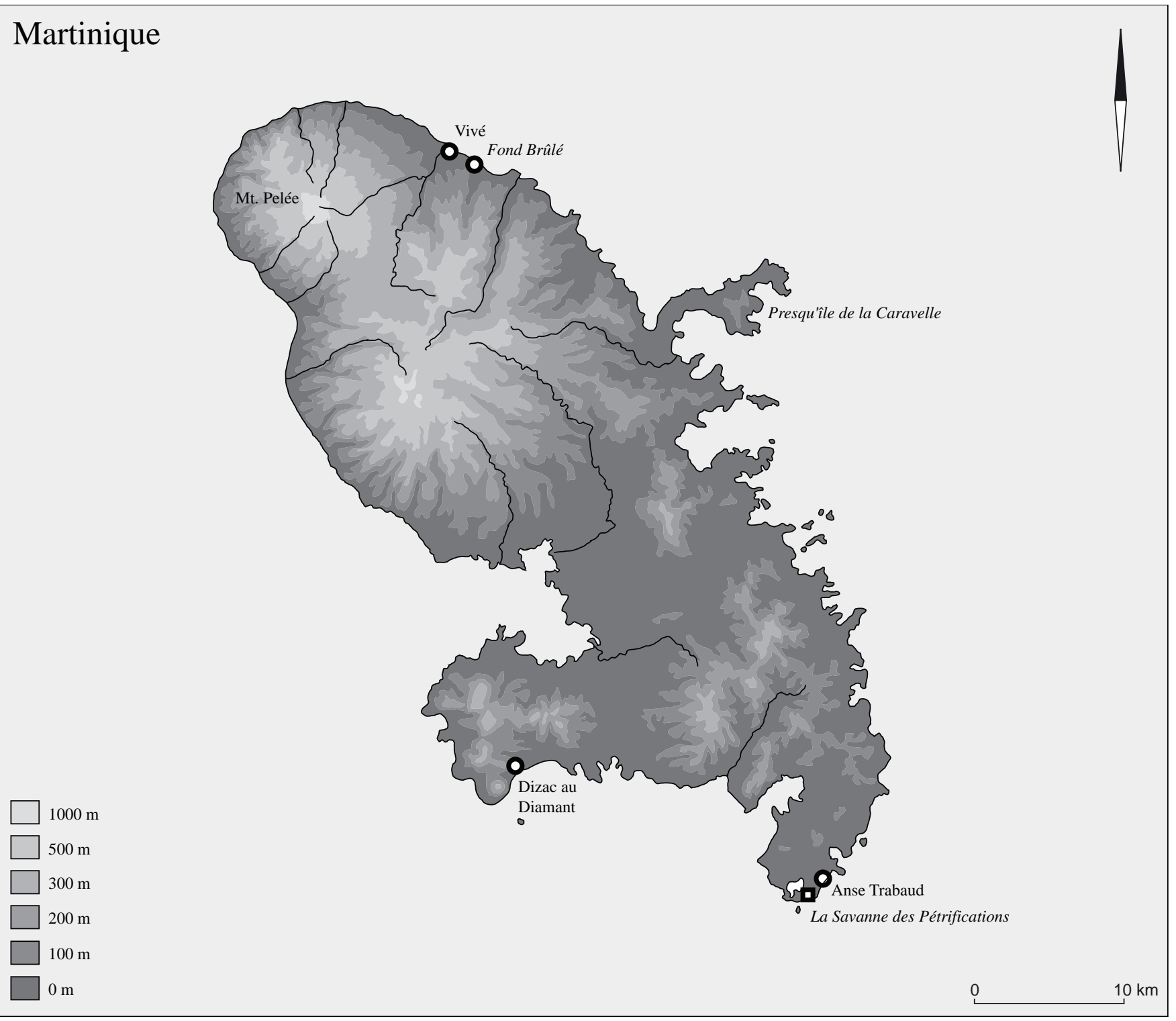

Figure 3.12. Map of Martinique showing the sites mentioned in this work. In normal font sites studied by myself, and in italic sites studied by others.

The continuous and frequent use of the test-unit excavation methodology is still a standard procedure in the region, in particular when excavating within deep, densely concentrated refuse areas. This provides an excellent situation where material has been collected in relatively similar manner and from similar contexts. Therefore, it makes it very useful for my present comparative purposes. Another concern regards whether the procedures followed in the field when excavating testunits are comparable. The following similarities are discerned, in the reports on the different sites used in this study (listed in table 3.2):

(a) all units were excavated in arbitrarily chosen levels (in some cases within natural strata);

(b) mesh screens were systematically used during excavation; and

(c) a similar range of materials was collected, including pottery, stone artefacts, shell artefacts, shell subsistence remains, coral, animal bone, and crab remains 
These similarities justify the comparability of collected samples. A number of differences, however, are noted as well:

(a) units varied in size from $0.5 \times 0.5 \mathrm{~m}$ to $4.0 \times 4.0 \mathrm{~m}$, including $1.0 \times 1.0 \mathrm{~m}, 1.0 \times 2.0 \mathrm{~m}$, and $2.0 \times 2.0 \mathrm{~m}$ sizes;

(b) mesh size of screens varied from $2 \mathrm{~mm}$ to $12 \mathrm{~mm}$, including $2.9 \mathrm{~mm}, 3.2 \mathrm{~mm}, 6.4 \mathrm{~mm}$, and $10 \mathrm{~mm}$ sizes;

(c) depth of arbitrary levels varied from 10 to $20 \mathrm{~cm}$;

(d) some excavators started new levels when a different archaeological/geological layer would start, making the level thinner than the average 10 or $20 \mathrm{~cm}$, but they could be combined within $10 \mathrm{~cm}$ levels in some cases, while others systematically stuck to the 10 or $20 \mathrm{~cm}$ levels;

(e) some excavators systematically included a sample square in each test unit for collecting small sized animal bone through fine mesh screening, while others sampled a small number of entire test units for this purpose.

These differences, especially the variation in mesh size, may well have a biasing effect. Therefore, I attempted to obtain some idea about how mesh size differences might bias the data. For this purpose the material from the Barnes Bay site, Anguilla, was subjected to a more detailed analysis, as it provided the best characteristics for such a test. Test-units at Barnes Bay were sub-divided into a fine sample part and a normal part (Crock 2000, 128). The fine sample part, a $0.5 \times 0.5 \mathrm{~m}$ square, was sieved through a $3.2 \mathrm{~mm}$ mesh-screen, while the remaining larger portion was sieved through a $6.4 \mathrm{~mm}$ mesh-screen. All possible stone artefacts were collected from both residues. These were compared in this case with respect to proportions of raw materials and types of flake artefacts. Furthermore, it was tested from what minimum size samples could be considered similar. In other words, I looked at which size classes of artefacts had to be excluded before both samples can be believed to be the same. This latter inquiry was designed to make the different samples comparable on a detailed level, as will be required in Chapter 6.

Looking at raw material percentages, three main raw materials were worked at Barnes Bay. These include chert, St. Martin greenstone, and calci-rudite (Crock 2000; see also Chapter 5). The first was used for flake tool production, the second for axe production, and the third for zemi production. All three materials produced debitage, and related flake cores and core artefacts. When comparing the mesh residues it was noted that the percentage of flake tool related material is significantly higher within the finer mesh residue when compared to the other two materials (table 3.3). When one considers that the flake tool production was aimed at producing small flakes, occasionally incorporating flake reduction, then this relative increase within the finer mesh residues follows one's expectations. The finer mesh screens also produced higher proportions of flake fragments (table 3.4). This was also expected, bearing in mind the broken nature of these types of flakes, which in general will be smaller.

The other test is described in Appendix E in more detail. The data suggest that 3.2 and $6.4 \mathrm{~mm}$ mesh screen residues become comparable if one excludes all artefacts, that either have a maximum dimension or a width smaller than $12 \mathrm{~mm}$. Although this number is significantly different than $6.4 \mathrm{~mm}$, the largest mesh size, this discrepancy to a large degree can be explained by shape variation of the artefacts and the fact that with a $6.4 \mathrm{~mm}$ mesh screen the largest opening amounts to 9.1 $\mathrm{mm}$, which is the diagonal between the corners of one mesh square opening $\left((6.4)^{2}+(6.4)^{2}=(9.1)^{2}\right)$. Thin, 6.4 by $6.4 \mathrm{~mm}$ artefacts, may then pass through the screen, while thick specimens with the same maximal dimensions will remain. Still, the preferred size from which a sample should be equal would be $9.1 \mathrm{~mm}$ by $9.1 \mathrm{~mm}$, or 10 by $10 \mathrm{~mm}$, if one takes rounding into account. ${ }^{9}$ Apparently, certain processes cause the items in size just larger than this maximum mesh-opening to be underrepresented within the residue. This might be ascribed to mesh-size variation within a screen (not all squares are equal squares, and occasionally iron wires of meshes can be broken), and collecting bias in which smaller items in a residue will be picked out less likely than larger items.

If we extrapolate these data to coarser mesh-screens, then in the case of a $12 \mathrm{~mm}$ mesh (the coarsest one found in this study), the maximum (diagonal) opening would be $17.0 \mathrm{~mm}$ and residues would be only comparable from a 19 by 19 or 20 by $20 \mathrm{~mm}$ or larger size class. It may be argued, however, that this difference between largest mesh-opening (17 $\mathrm{mm})$ and preferred size class $(19$ or $20 \mathrm{~mm}$ ) in this case might be smaller, as collecting bias will diminish when meshes become coarser, and as a consequence, artefacts become larger.

Another bias not mentioned yet involves collecting criteria. These are often closely related with the objective of the research and the definition of an artefact. The procedures concerning lithic artefact collection are usually not mentioned in excavation reports, despite the fact that criteria about what is an artefact are not as straight forward as for example in case of pottery, and may vary from site to site within the region. To a large degree this can be ascribed to differences in geological surroundings

\footnotetext{
$99 \mathrm{~mm}$ can stand for 8.5 to $9.4 \mathrm{~mm}$, when measuring size of an artefact. So, this includes a number of smaller artefacts than $9.1 \mathrm{~mm}$. Therefore, to be sure that all artefacts are definitely larger than $9.1 \mathrm{~mm}$ it is best to take the $10 \mathrm{~mm}$ size class, which includes 9.5 to $10.4 \mathrm{~mm}$ specimens.
} 


\begin{tabular}{|c|c|c|c|c|c|c|}
\hline \multirow[t]{4}{*}{ Raw material } & \multicolumn{2}{|c|}{ Unit 401/418 } & \multicolumn{2}{|c|}{ Unit $402 / 423$} & \multicolumn{2}{|c|}{ Average } \\
\hline & $6.4 \mathrm{~mm}$ & $3.2 \mathrm{~mm}$ & $6.4 \mathrm{~mm}$ & $3.2 \mathrm{~mm}$ & $6.4 \mathrm{~mm}$ & $3.2 \mathrm{~mm}$ \\
\hline & $\%$ & $\%$ & $\%$ & $\%$ & $\%$ & $\%$ \\
\hline & $\mathrm{N}=135$ & $\mathrm{~N}=125$ & $\mathrm{~N}=102$ & $\mathrm{~N}=139$ & $\mathrm{~N}=237$ & $\mathrm{~N}=264$ \\
\hline St. Martin greenstone & 12.6 & 7.2 & 13.7 & 10.1 & 23.2 & 8.7 \\
\hline St. Martin calci-rudite & 17.0 & 1.0 & 8.8 & 5.8 & 12.9 & 3.4 \\
\hline Igneous rock & 1.5 & - & - & 1.4 & 0.8 & 0.7 \\
\hline \multirow[t]{2}{*}{ Other rock } & 4.4 & - & 2.9 & 5.0 & 3.7 & 2.5 \\
\hline & 100.0 & 100.0 & 100.0 & 100.0 & 100.0 & 100.0 \\
\hline
\end{tabular}

Table 3.3. Barnes Bay. Raw material count and percentages by mesh-size.

\begin{tabular}{|c|c|c|c|c|c|c|}
\hline \multirow[t]{4}{*}{ Artefact type } & \multicolumn{3}{|c|}{ Unit 401/418 } & \multicolumn{3}{|c|}{ Unit 402/423 } \\
\hline & $6.4 \mathrm{~mm}$ & $3.2 \mathrm{~mm}$ & Total & $6.4 \mathrm{~mm}$ & $3.2 \mathrm{~mm}$ & Total \\
\hline & $\%$ & $\%$ & $\%$ & $\%$ & $\%$ & $\%$ \\
\hline & $\mathrm{N}=51$ & $\mathrm{~N}=82$ & $\mathrm{~N}=133$ & $\mathrm{~N}=42$ & $\mathrm{~N}=87$ & $\mathrm{~N}=129$ \\
\hline split flake & 2.0 & - & 0.8 & - & 1.1 & 0.8 \\
\hline broken flake & 2.0 & 1.2 & 1.5 & 2.4 & - & 0.8 \\
\hline flake fragment & 37.3 & 65.9 & 54.9 & 33.3 & 55.2 & 48.1 \\
\hline unidentified flake artefact & 11.8 & 4.9 & 7.5 & 9.5 & 6.9 & 7.8 \\
\hline flake core & 5.9 & - & 2.3 & 7.1 & 1.1 & 3.1 \\
\hline \multirow[t]{2}{*}{ unidentified } & 3.9 & 2.5 & 3.0 & 2.4 & - & 0.8 \\
\hline & 100.0 & 100.0 & 100.0 & 100.0 & 100.0 & 100.0 \\
\hline
\end{tabular}

Table 3.4. Barnes Bay, Anguilla. Number of flint and chert artefacts by type by mesh size.

of given sites, causing variation in raw material availability. This variation is best explained by an example. Anse à la Gourde, one of the major sites on Guadeloupe, is situated in an area completely consisting of limestone. Any non-limestone object therefore should be considered as an artefact (see my definition of an artefact in section 3.1.1), even if it does not exhibit any signs of use-wear or shaping. This is the case for many of the small igneous pebbles. These pebbles probably served in tasks that did not leave any traces, or in which case any traces were blurred (see Chapter 5). In addition, the Anse à la Gourde site has produced many small non-modified limestone pebbles, apart from flaked and use-modified examples. These pebbles are locally available near the site. This presents the problem that if one considers these pebbles as natural rock one may neglect the possibly used ones (used for functions similar to the igneous pebbles). In contrast, if one considers them as artefacts, then one may over-represent the used ones. This problem of interpretation is even more difficult at Anse des Pères on St. Martin, where the vast majority of all pebbles is locally occurring in the site area (Knippenberg 1999c).

To obtain a better insight into what may be deliberately collected and what not, raw material proportions of naturally occurring material can be compared with the proportions found within the archaeological samples. To my knowledge, such in-depth analysis of natural background scatters has not been performed within Caribbean archaeology to date. This last bias will mainly involve artefacts related to categories of use-modified, manuports and burnt rock (TS 3, 4, and 5), as they are often hard to identify as artefacts based on their shape alone. This is easier to do in case of flakes, flake cores, axes, and zemis, for example.

Another significant form of sample bias relates to the actual sample size of artefacts on which certain parameters are based such as, for example, average length and weight of flakes, percentage of chert types among chert artefacts, percentage of cortical flakes, etc. Sample size is surely a significant factor in archaeology, which is not always dealt with. To a large degree this may be a result of the nature of archaeological research. It is generally the case that excavation at a site can only be 
performed a single time. As a consequence, data are final for such a site and cannot be easily supplemented. Furthermore, in many cases sample size could not always be estimated a priori based on survey research.

My research was to a large degree dependent on existing collections, and only in certain instances could evaluate and determine the sample size of the artefacts to be studied. In many cases, the number of lithic artefacts studied equalled the total number of stone items excavated, but in other cases sub-samples of collections were chosen due to limited time available during a visit to foreign institutions where artefact collections were kept.

In order to obtain some idea of how accurate a certain sample size would be as an estimator of the true artefact population at a site, I performed a detailed analysis of the flake tool material from Golden Rock, St. Eustatius. Due to the fact that the refuse area at this site was systematically excavated in $1 \times 1 \mathrm{~m}$ test unit squares, I could easily construct a number of sub-samples ranging in size (see Appendix E).

Comparing the results of these sub-samples showed that sample sizes exceeding 100 artefacts generally provide accurate results, that is, the difference with the results from the complete sample of artefacts (here considered as the total population) remains small in such cases, most often not exceeding more than $10 \%$. Only the determination of average weight still exhibits considerable variation. In the case of the average maximum dimension and the percentage of Long Island flint, for example, smaller samples (down to 50 artefacts, and even 25 for average maximum dimension) produced generally accurate results as well.

The following Chapters will show that a number of samples produced fewer than 100 flake-tool associated artefacts in total, and in many cases less than 25 Long Island artefacts in particular. For these samples the final outcomes considering the different parameters should be treated with caution, as the difference between the sample value and the actual population value may be large. 


\section{$4 \quad$ Acquisition and lithic reduction at the source: Long Island}

\subsection{INTRODUCTION}

Situated on the north coast of Antigua, Long Island has been recognized as an important prehistoric flint source since the early 1970s. After several visits, Desmond Nicholson and Fred Olson were the first to report on the island's abundant flint and the special place in the region it likely had during prehistory (Nicholson 1974, 1976; Olson 1973). Since Jeff Walker's Master thesis on stone tool technology at the Sugar Factory Pier site on St. Kitts (Walker 1980a, b, 1981) followed by Crock \& Bartone's (1998) research on Montserrat and my own on St. Martin (Knippenberg 1999a, c), the presence of Long Island flint has been attested outside the Antigua area. This proved that Long Island functioned as a source of fine-grained stone with regional significance. Geo-chemical results discussed in Chapter 2 confirmed this. As is evident below, the present study shows that Long Island flint remained the most abundant flaked lithic material among the surrounding islands during the entire pre-Columbian era, despite the availability of other fine-grained siliceous materials on different locations in the region. Therefore, a close examination at pre-Columbian activities on this small island related to the exploitation of flint is justified.

This Chapter presents a discussion of prehistoric exploitation of flint and related activities on Long Island itself to provide knowledge about the initial stages of the flint production trajectory, namely quarrying and possible first stages of reduction. A discussion about further reduction and tool production among the surrounding islands follows in the next Chapters.

From examination of the natural distribution of flint on Long Island (Appendix A), it is clear that flint was mainly available in secondary form, that is, as individual pieces of rock, that had eroded out of the limestone bedrock. Two main environments can identified: one consists of a number of small cobble beaches along the northern coast, and the other consists of the inland part of the island, where a clayey soil of varying thickness covers the limestone bedrock. Both environments had different effects on the shape and appearance of the flint (see Chapter 2). This distinction is blurred to some extent by the erosion of the coast, resulting in the appearance of characteristic "inland" material, exhibiting typical features such as brown cortex, on the beaches. This mixing of material is probably not just a recent process, and likely occurred ever since Long Island appeared above sea level and flint began to erode out of the bedrock. However, it can be argued that the speed at which erosion occurred increased significantly as a result of disappearing vegetation during historic times. Nonetheless, if we assume that this mixing also took place during pre-Columbian times, the type of outer surface on flint is only partly indicative of a specific collecting environment. In case of water-worn surfaces, the likely collecting place would be the beach, while "inland" types of outer surface, such as brown and white chalky surfaces, could have both originated from the beach, where they ended up after erosion, or from a more inland location proper.

In addition to these secondary occurrences, flint can be found in primary context in the limestone bedrock in rare locations. Such in-situ occurrences are concentrated in the middle part of the Flinty Bay coast line, where ring-shaped flints are exposed to the surface. Other very isolated and small primary outcrops are situated along the coast between Buckley Bay and Cistern Point, and along the northern portions of Pond Bay and Pasture Bay (figure 4.1).

\subsection{Previous archaeOlogical RESEARCH ON Long Island}

Despite its regional significance, Long Island has experienced only small-scale archaeological work, which can be dated to the last 40 years. The first archaeologist to do any research there was Charles Hoffman in 1963. As part of his Master's research, Hoffman conducted small-scale test-excavations at three localities on the southwestern part of the island (Hoffman 1963, 32-35). Two of these localities proved to be Ceramic Age sites. He was not sure whether both localities belonged to one and the same site given their close proximity. Now, it is at least clear that the westernmost locality (LI 2) can be considered as the Jumby Bay site, which was later named by Desmond Nicholson, one of the members of the Archaeological and Historical Society of Antigua (Nicholson 1974). The other locality where Hoffman excavated (LI 1) most likely corresponds to the Sugar Mill site, situated to the southeast of the old Estate House (see below). From Hoffman's presentation of the ceramic data, we can conclude that both sites produced ceramics displaying similarities to the local Mill Reef style (Hoffman 1963, 32-33).

Following Hoffman's work, Desmond Nicholson and Fred Olson occasionally visited the island and reported 


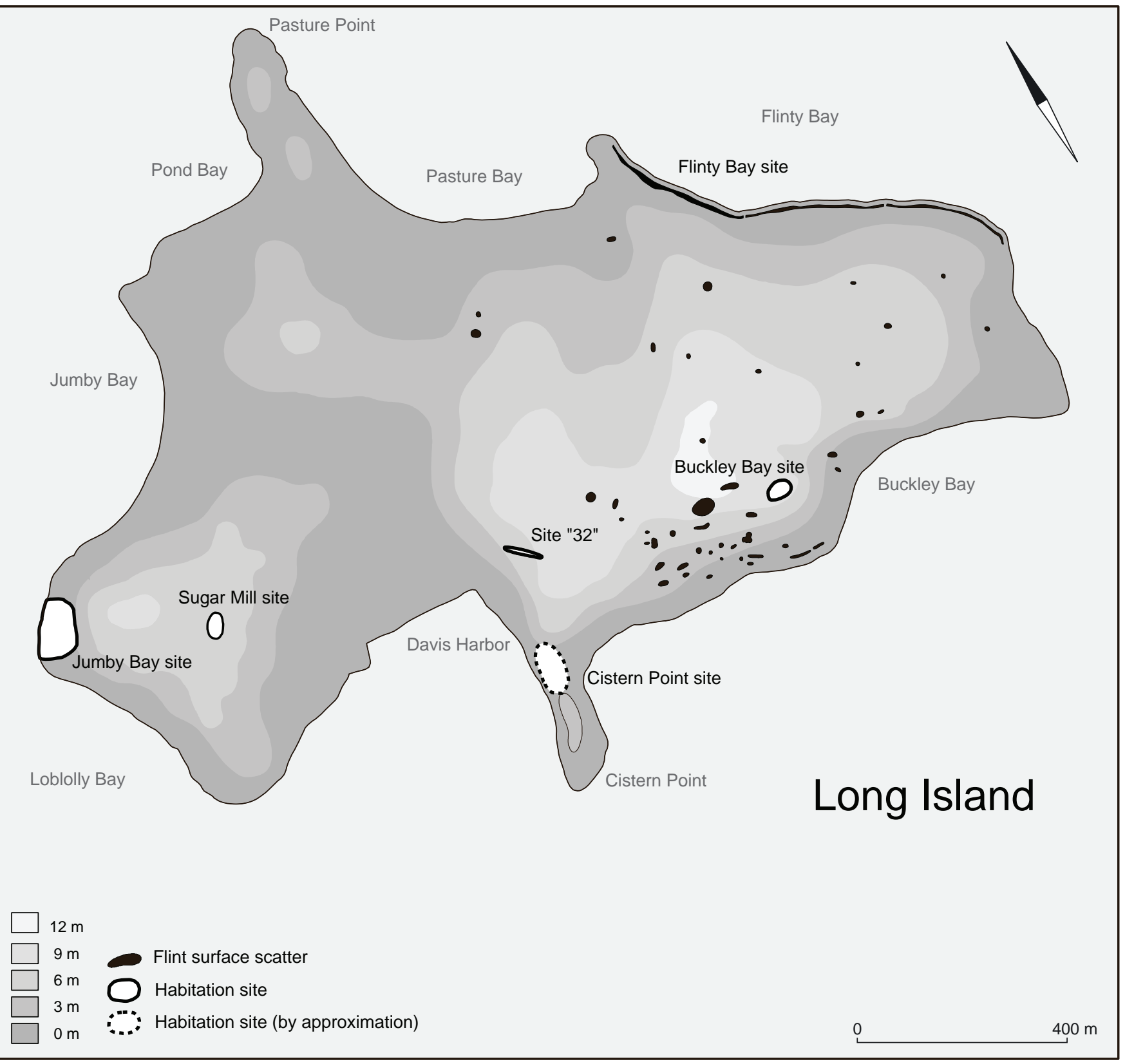

Figure 4.1. Map of Long Island showing location of archaeological sites (map partly based on Van Gijn (1996, fig.2)).

pre-Columbian sites during the early 1970s. In addition to Jumby Bay, they identified a "Ciboney" workshop site along Flinty Bay, a shell scatter at Cistern Point, scattered flint concentrations at Pasture Bay, Buckley Bay, and Highest Point, as well as a Ceramic Age site just to the north of Cistern Point (Nicholson 1974; Olson 1973). They also located a site on the south coast of the island, which disappeared after construction of the Dockyard (Olson 1973). Using the data from this site reconnaissance, Dave Davis decided to carry out a small-scale test-excavation at Cistern Point, a Preceramic Age habitation site as part of his research on the Archaic occupation of Antigua (Davis 1974, 2000). In his later monograph on Jolly Beach, Davis compares the Cistern Point flint assemblage with that from Jolly Beach, and he discerned such strong similarities that he concluded that both industries belong to a similar complex. As the greater blade length and thickness at Cistern Point were comparable with material from the younger deposits at Jolly Beach, he considered the former to be younger in age (Davis 2000, 76-77). 
In response to an invitation from Desmond Nicholson, a team of archaeologists from Leiden University executed a smallscale research campaign on Long Island in 1989 (Van Gijn 1996; Verpoorte 1993). Supervised by Annelou van Gijn, in co-operation with Corinne Hofman and Menno Hoogland, this team concentrated on the eastern part of Long Island, which is the less disturbed part. They mapped all surface scatters of flint that exhibited any signs of human activities in the form of working. Furthermore, they explored primary flint deposits. This mapping resulted in the reconnaissance of many flint concentrations, of which the majority produced debris related to a blade technology. Finally, the Leiden team conducted small-scale test-excavations at the most interesting site locations. These were the large workshop site along Flinty Bay and a Ceramic Age midden scatter, called "Site 32" (see figure 4.1). Data from the Flinty Bay site confirmed the earlier assumptions of Olson and Nicholson: it was an activity area where presumably Preceramic Age flint knappers pre-worked high quality blade cores. "Site 32 " is one of the very few settlement sites on Long Island. The shallow deposit produced a mixture of flake tools, blades, shell tools, shell subsistence remains, and pottery. Based on the co-occurrence of pottery and different flint working technologies, Site 32 was interpreted as a mixed Preceramic and Ceramic Age site (Van Gijn 1996; Verpoorte 1993).

From the resulting archaeological map of Long Island, it was clear that construction work and limestone quarrying already had a serious impact on the number of sites still present then. Furthermore, the Leiden team questioned the validity of the mapped scatters, as colonial agriculture and land clearing probably disturbed the original distribution. Another difficulty concerned the dating of the Flinty Bay workshop site, since no conventional ${ }^{14} \mathrm{C}$ dating material was available (Van Gijn 1996).

\subsection{The 2000-FIELD CAMPAigN}

Apart from work at Jumby Bay and "Site 32", all previous excavation research on Long Island was mainly directed toward the Preceramic Age, or sites yielding evidence of blade working. Data on the activities there during the Ceramic Age remain scarce, especially when one takes into account that the mixed nature of "Site 32" hampered detailed knowledge of that period, and the low number of flint artefacts first reported from Jumby Bay (Hoffman 1963, 32-35) suggest incomplete artefact collecting methods. Confronted with this I decided to set up a small-scale research project to study archaeological remains that could be related to activities during the Ceramic Age. As my time in the field was limited, I had to pinpoint areas of interest on the island beforehand, rather than extend earlier survey work in search of new sites by field-walking unstudied areas. The usefulness of such an extension would have been very questionable, bearing in mind the disturbed nature of large parts of the island, as suggested by Van Gijn (1996) and Verpoorte (1993). Furthermore, the majority of unstudied areas, located in the western part of the island, was covered by grassland, making surface inspection unreliable. A more reliable sub-surface method of systematically digging shovel test pits there was too time-consuming, and not feasible, since private hotel plots could be only minimally investigated.

Therefore I decided to base my research on the earlier work of Nicholson and the Leiden team. The work of Nicholson, in particular, provided the advantage that he had visited the island in the 1970s when destruction of sites by construction activities had just begun. Nicholson was still able to inspect areas, that were built over by the time of the 1989 research. A drawback of this earlier work was the unsystematic nature of the island inspection, making it likely that some sites were missed.

Even the 1989-survey does not claim to be systematic in the true sense of sampling in archaeology. Van Gijn (1996) admits that due to dense bush not all areas on the eastern part of the island could be systematically field-walked. Furthermore, she states that the mapping of surface scatters was a difficult and subjective process as the island was covered with a background of extensive flint debris, in particular in the interior, hampering proper identification of human-produced scatters. Therefore, the 1989-team focussed on lithic scatters near the coast-lines, while the centre of the island was inspected less thoroughly.

From the previously mapped sites, I choose possible Ceramic Age, preferably single component, sites for closer examination. I considered two characteristics important, for establishing a Ceramic date. These are: (1) the presence of pottery, and/or, (2) the presence of flint tools and debitage exclusively related to a flake tool technology. Concerning the latter characteristic, some precautionary remarks must be added. Within Caribbean prehistory, archaeologists make a clear distinction between Preceramic and Ceramic Age chipped stone technologies. The former can be characterized as a blade tool industry, while the latter is an expedient flake tool industry. However, this distinction is only applicable to some degree. All blade industries are definitely Preceramic in age, since a true blade technology has never been reported from Ceramic Age 
sites, but not all expedient flake assemblages are Ceramic in age. Especially in the Lesser Antilles some flaked stone samples from Preceramic Age sites have typical characteristics of expedient flake tool technologies. On that basis, they are grouped within the Ortoiroid series (Hofman \& Hoogland 2003; Knippenberg 1999d; Lundberg 1989, 1991; Nodine 1990; Nokkert et al. 1999; Rouse 1992). Detailed inspection has revealed that the use of the bipolar flaking technique, which was commonly used by people from the Ceramic Age, only played an insignificant role or was completely absent within Preceramic Age flake tool assemblages, but this difference is difficult to distinguish in the field. Such a distinction will be even harder to make at workshop sites near a lithic source, if one also bears in mind the following: the application of the bipolar industry was mainly directed towards the production of small flakes as grater teeth that could be inserted in a wooden board. This will not be an issue if one is only pre-working material at the source for further transport. Therefore, all sites or scatters yielding flake tool technologies are of interest to the present research. These include (see figure 4.1):

(a) The Jumby Bay site, which is designated in field notes of Desmond Nicholson as a true single component Ceramic Age site;

(b) The Sugar Mill site. During the 2000 field work an additional Ceramic Age site was discovered as a result of pipe-line construction near the "old" Sugar Mill, in the centre of the island;

(c) Scatter 36 at Buckley Bay, which also produced pottery (Verpoorte 1993, 51);

(d) "Site 32", located just to the north of Cistern Point; and

(e) The interior of the eastern part of the island. Although the large majority of the scatters in this part of Long Island were related to blade production, after discussion with Annelou van Gijn it was decided that they should be re-examined to see whether flake tool related material could be also identified there.

The aim of the 2000 field-campaign was to establish whether sites or scatters could be dated to the Ceramic Age and if so, to which particular phase. If a Ceramic Age date was established, the main objective was to determine what the purpose of flint production was at that specific location. The following three options were considered:

1) Flint was worked to prepare cores or flakes/flake tools for further transport. This would have resulted in a relatively high percentage of cortical flakes, a low number of cores compared to number of flakes, and the cores present would be predominantly exhausted, and should display flaws that made them unsuitable for further reduction (see Van Gijn 1996; Verpoorte 1993);

2) Flint was worked into tools for local use on Long Island only. This would have resulted in a sample suggesting that full reduction had occurred at the site, including the following features: (a) high numbers of cortical as well as non-cortical flakes; (b) high numbers of cores compared to flakes; (c) fully or at least significantly reduced cores, including flakes reduced as cores as well; and (d) clear presence of utilized flakes; and

3) A combination of options 1 and 2. Flint was worked both for further transport as well as local use on Long Island: this would have resulted in sample including the features mentioned for option 2 . The difference with this option would predominantly lie in a relatively lower number of cores, if cores had been transported, or a relatively lower number of tertiary flakes, if flakes or tools had been transported.

\subsection{Results of THE 2000-Field CAMPAign}

\subsubsection{Jumby Bay}

\section{Introduction}

In the early 1960s Charles Hoffman conducted test excavations at a Ceramic Age site at the southwest corner of Long Island (Hoffman 1963). Desmond Nicholson later called it the Jumby Bay site during his site reconnaissance. Nicholson marked a large site area in his field notes, almost completely covering this southwest point. Annelou van Gijn also mentions this site in her field notes, but did not include it within the 1989 field campaign (Van Gijn 1996). Upon my arrival in 2000, a dense shell scatter including pottery, flint, coral and animal bone, was identified along the coast immediately to the south of Jumby Bay beach. In one restricted location, a midden deposit up to $50 \mathrm{~cm}$ thick was visible within a rocky section eroded by the sea. The coast there is formed by a rocky shoreline, which slopes slightly in eastern direction toward one of the relatively higher points of the island around $9 \mathrm{~m}$ above sea level (figures 4.1 and 4.2). This relatively high point is marked by a flag 


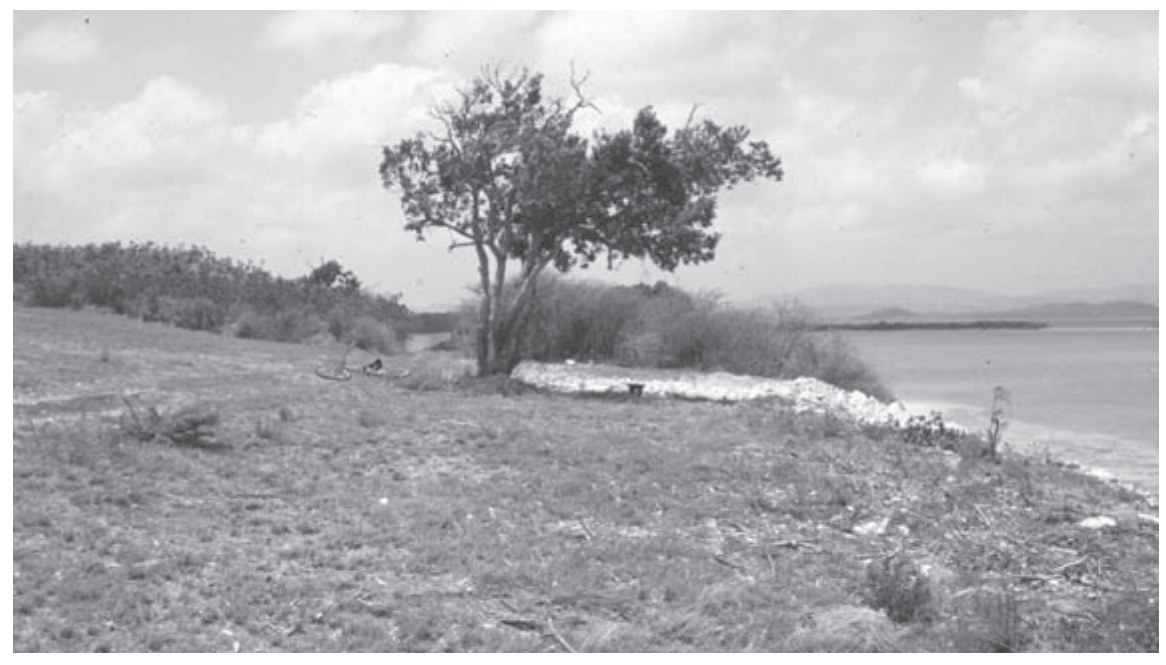

Figure 4.2. The Jumby Bay site facing south.

and lies adjacent to the old Estate House, originally the residence of the former owner of the island and nowadays one of the central buildings of the Jumby Bay Hotel resort. The areas surrounding this house belong to the hotel and are covered with grassland, while bush is still present in the coastal areas. Following this coastline to the south, the area has been used as modern refuse dump by the hotel, evidenced by piles of concrete, wood, iron and plastic. If one continues to walk along the coast one comes across the only remaining mangrove area of Long Island at Loblolly Bay.

To determine the extent of find distribution and preserved midden deposits, it was decided to systematically excavate $0.5 \times 0.5 \mathrm{~m}$ shovel test pits with $10 \mathrm{~m}$ intervals along transect lines (figure 4.3). As most of the archaeological material was situated along the coast a trench of shovel test pits was laid following the coastline. In addition, three transects were directed toward the top of the low hill perpendicular to the first line. The number of shovel test pits excavated totalled 28. Test pits were dug in arbitrary $10 \mathrm{~cm}$ levels, and dirt was sieved through $8 \mathrm{~mm}$ mesh screens. After the shovel test pits, one 1 x $1 \mathrm{~m}$ test-unit was excavated in the area with the thickest midden deposit. In addition to the procedures that were followed for the shovel test excavations, a $2.9 \mathrm{~mm}$ mesh screen was used to sieve a $0.5 \times 0.5 \mathrm{~m}$ column for recovering small faunal remains.

In the areas that produced artefacts the characteristics of the cultural remains are similar in spite of variation in the thickness of the archaeological deposits. Shell material, predominantly bivalves, was the most abundant, followed by flint artefacts and pottery. Only low concentrations of animal bone, coral, worked shell, and other worked stone materials were found.

The shovel testing showed that finds were scattered over an area of approximately $2500 \mathrm{~m}^{2}$ at Jumby Bay. The thickest deposits were found in the northern part, where a dense shell midden ranging in depth between 30 to $60 \mathrm{~cm}$, extended for approximately $20 \mathrm{~m}$ in a north-south direction and for only $11 \mathrm{~m}$ in an east-west direction (figure 4.4). Finds were more dispersed along the slopes of the hill to the east. No real midden was identified there and archaeological material was only present in a thin layer. Following this sloping part of the terrain to the south, the number of finds gradually increased and the cultural deposits became thicker. The deposit finally approached a depth of $25 \mathrm{~cm}$ adjacent to an area where recent activities related to garbage dumping and clearing had destroyed the original distribution. ${ }^{1}$ It is clear that this area of finds partly encircled an archaeologically empty space along the shoreline. The disturbed southern part impedes complete knowledge of the exact shape of the artefact distribution, as well as the dimensions of the empty space. It is likely that archaeological deposits continued south up to the coast, fully enclosing this vacant area. This configuration of a centre with hardly any finds surrounded by an area with typical refuse material, might reflect the place where the site's inhabitants

\footnotetext{
${ }^{1}$ Within this southern coastal area hotel workers have recently cleared refuse from the surface. In doing this they have initially removed all topsoil, after which the area was levelled again with soil from the direct surroundings. The soil apparently originated from a concentrated archaeological deposit, as the whole cleared part was covered with concentrations of all sorts of archaeological material on the surface. A number of auger tests was cored in this area to see if the original context of this material could be relocated. They did not provide any contextual information as topsoil had been disturbed down to the sterile chalk weathered bedrock. The location of archaeological material somewhere within this area would suggest that the scatter of material indeed continued to the south, where it probably stopped upon reaching the coastline.
} 


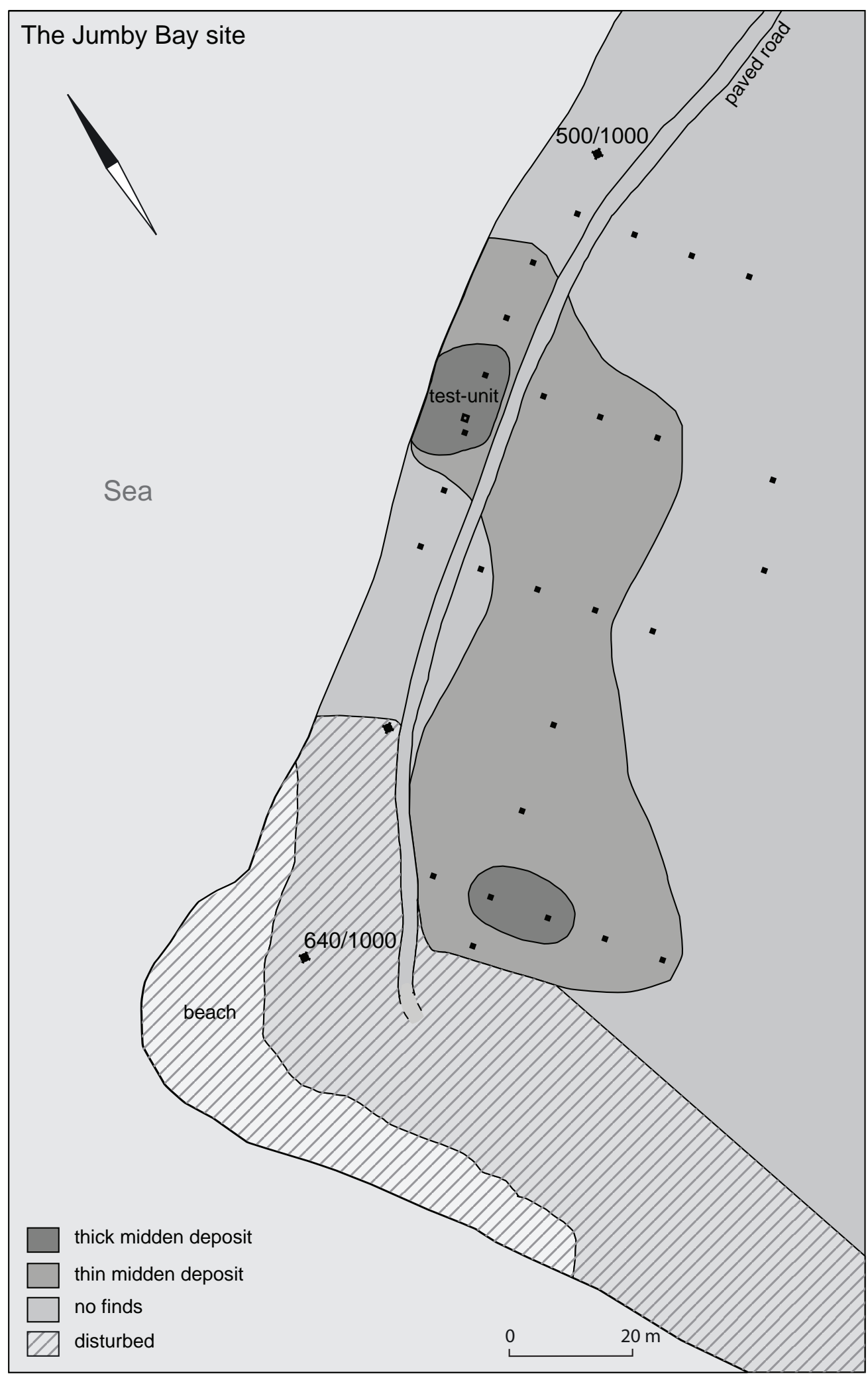

Figure 4.3. The Jumby Bay site with the location of the test pits (small rectangles) and the test-unit (large rectangle). The crosses indicate the location of site grid points. 

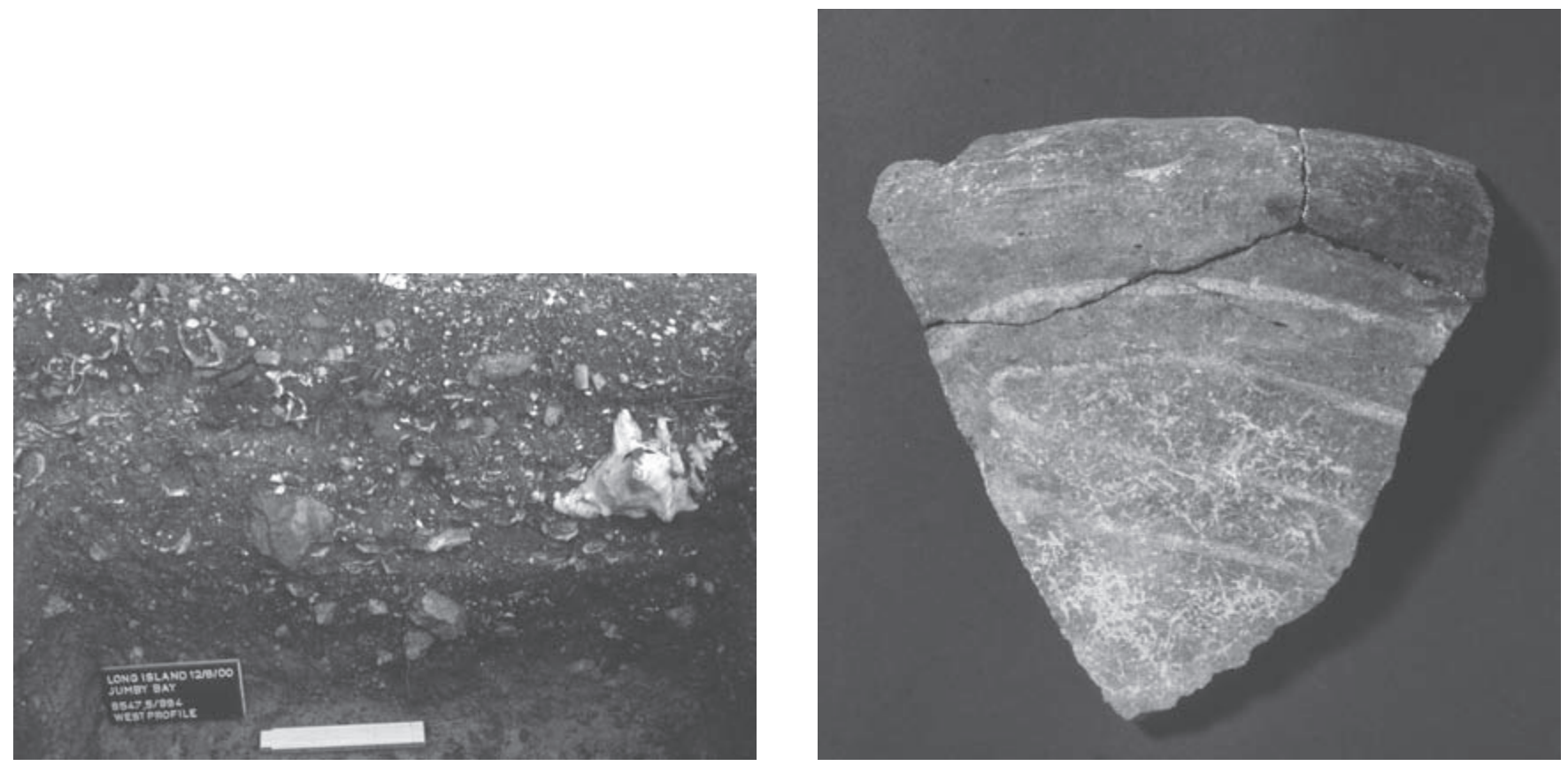

Figure 4.4. Section of the shell midden deposit exposed in the $1 \times 1 \mathrm{~m}$ test-unit at Jumby Bay (left). Large wall fragment with white line decoration (right) (fragment has a maximum dimension of $176 \mathrm{~mm}$ ). (right photo Jan Pauptit)

had erected their dwelling structure or other structures, similar to the situation found at Anse à la Gourde on Grande Terre and Trants on Montserrat (Hofman et al. 2001; Petersen 1996). As the 2000-field campaign was not aimed at studying house plans and intra-site organization, no effort was put into locating any habitation remains.

Since intra-site analysis demonstrated that different parts of the site do not exhibit much variation in the type of shell species nor in the characteristics of the pottery and flint technologies, this site was considered to be single component. Therefore, the cultural remains have been lumped and treated as one sample.

\section{Absolute dating}

One charcoal sample from a lens of burnt material within the $1 \mathrm{x} 1 \mathrm{~m}$ test-unit at the Jumby Bay site was submitted for AMSradiocarbon dating. It produced a ${ }^{14} \mathrm{C}$-age of $860 \pm 60 \mathrm{BP}(\mathrm{GrA}-18850)$. Calibrated, it falls between $\mathrm{AD} 1035$ and 1275, when a $95 \%$ confidence interval is used. ${ }^{2}$ This date places the site in the Late Ceramic A phase, approximately corresponding with the late part of the local Mamora Bay style (Nicholson 1994; Rouse 1992), and contemporaneous with the Muddy Bay site on the nearby main island of Antigua (Murphy 1996, 1999; Murphy \& Healy 1999).

\section{Ceramics}

The ceramic sample from the Jumby Bay site consists of 762 sherds weighing $14181 \mathrm{~g}$, of which 488 pieces originate from excavated contexts (307 from the different shovel test pits and 181 from the test unit) and 274 from unsystematic surface collections. ${ }^{3}$ This sample of pottery is too small to provide sufficient knowledge of its typo-morphological characteristics. In general, it consists of plain pottery sherds, with relative crude surface finishing, which is typical of post-Saladoid ceramics. Scratching is a very rare feature, however. Within the excavated and screened sample, three modes of decoration were

\footnotetext{
2 Stuiver et al. Intcal. 98 calibration curve was used, available in cal25, the Groningen Radiocarbon Calibration Program (1998).

${ }^{3}$ The pottery sample was analysed during the fieldwork by Tom Hamburg and Martijn van den Bel, following the methodology as described in Hofman (1993).
} 


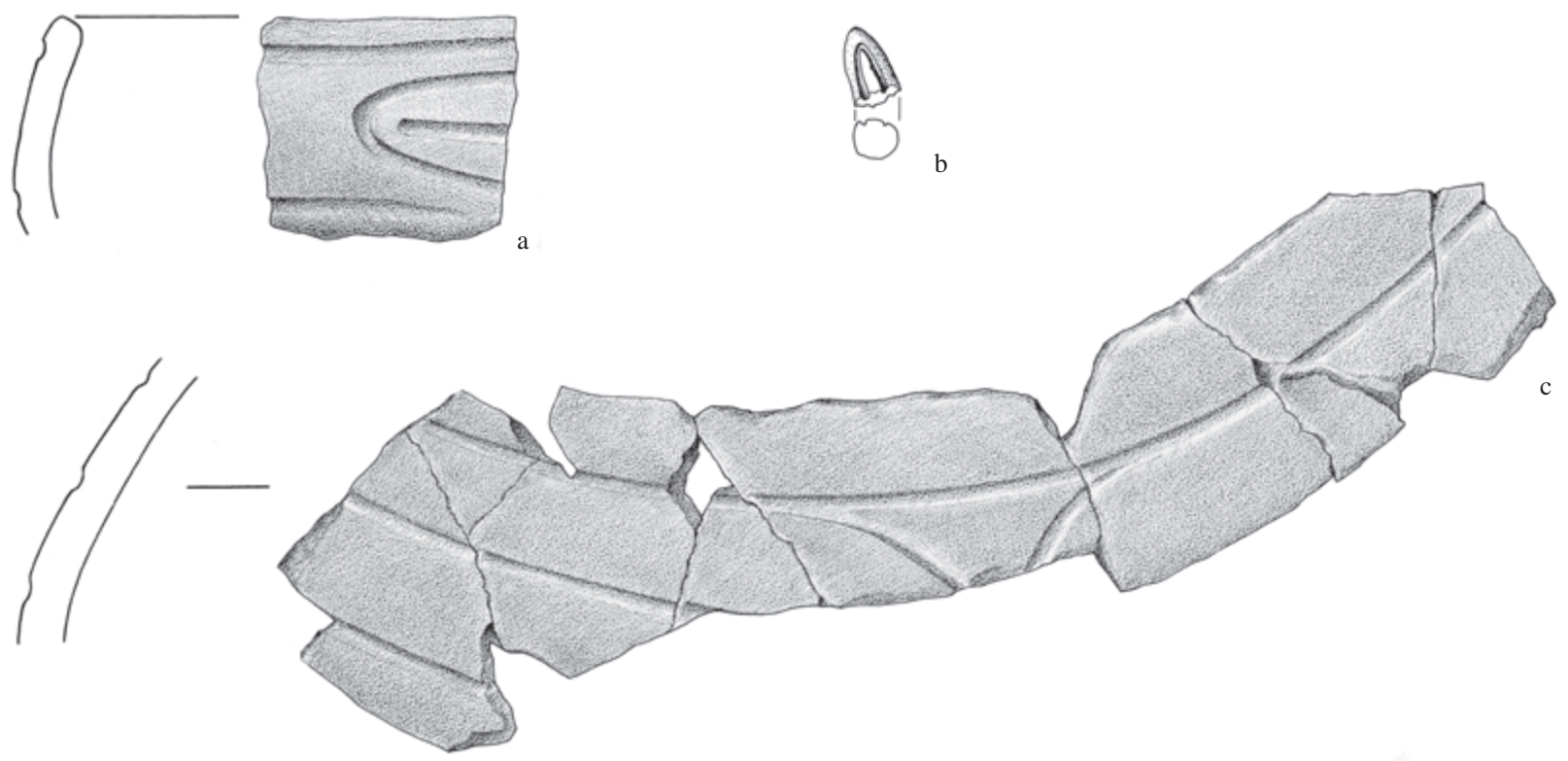

Figure 4.5. Jumby Bay. Broadline incision on a rim and wall sherd (a and c), and a body stamp fragment (b). (Drawings Erick van Driel (a and c) and Raf Timmermans (b))

identified. These include White-on-Red painting, or WOR (1.2\% of the total sample), incision (0.8\%), and red slip (19.1\%) (figure 4.6). The WOR painting mainly consists of thin white lines on a red slip or paint. On one specimen the white line is clearly curvilinear (see figure 4.4). All incision is broad-lined (figure 4.5), except for one sherd where a shallow incision has been cut just underneath the rim, probably to accentuate it. Among the surface material, similar decoration modes were identified. One curvilinear broad-lined incised specimen should be mentioned, as similar specimens were not encountered among the excavated sample.

Only two vessel shapes could be made out in the excavated sample: an unrestricted vessel with simple contour (67\%) and an independent restricted vessel with a composite contour (27\%) (figure 4.6). These also predominate among the surface material, although two other shapes can be added as well: a restricted vessel with a simple contour and an independent restricted vessel with a complex contour. Base shapes include the following types in order of diminishing frequency: concave, flat, and convex. The surface sample included one pedestal base.

In addition to the vessel sherds, several griddle fragments were also found. Among the excavated sample, two shapes were recorded, straight and overhanging, while the surface material includes two fragments of a legged griddle and one rounded griddle. Other non-vessel ceramics are spindle whorls and one fragment of a body stamp (see figure 4.5).

The presence of griddles, the predominance of non-decorated sherds, and spindle whorls among the ceramic assemblage, indicates that domestic activities occurred at the Jumby Bay site and may further support the presence of dwelling structures, as suggested above.

Based on the decoration modes, the material has both Mill Reef and Mamora Bay characteristics. White line designs on red paint or slip are common among Mill Reef style material (Hoffman 1963; Nicholson 1994; Rouse \& Morse 1999), although it also persisted within the later Mamora Bay style. Broad line incision on the other hand is more typical of the Mamora Bay style. Still, it can be found on Mill Reef ceramics, where it had its first appearance (Rouse \& Morse 1999). During the 2000 field campaign, it was decided to compare the pottery in more detail with ceramics from the radiocarbon dated Muddy Bay site (AD $1100-1300)^{4}$, after discussion with Murphy (Reg Murphy, personal communication 2000). Both sites exhibit close similarity in the presence of WOR painting, broad line incision, a high occurrence of red slip, crude surface finishing, and

\footnotetext{
4 Using the same calibration program as used for the Jumby Bay and Sugar Mill dates (note 2), the four dates from Muddy Bay cover the range from $999-1397 \mathrm{cal}$ AD $(95 \%$ interval).
} 

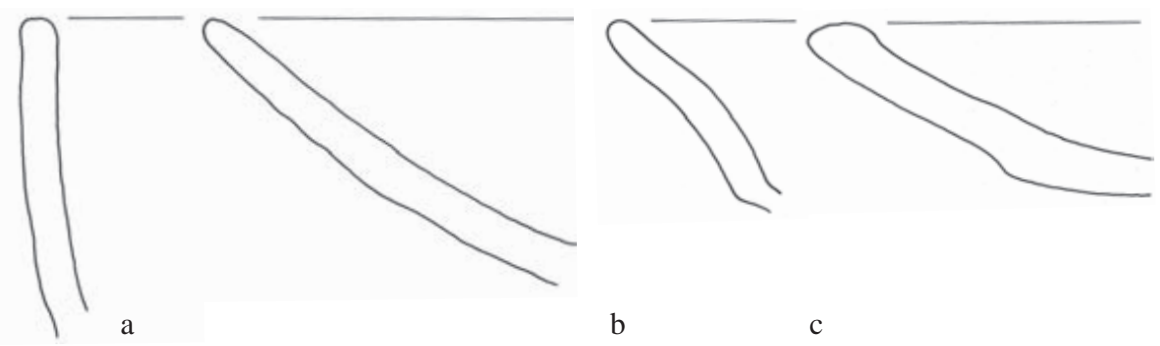

b

C

$\mathrm{d}$

Figure 4.6. Jumby Bay. Vessel shapes (scale 1:2): a and b. unrestricted simple contour; c and d. independent restricted composite contour. (Drawings Raf Timmermans)

similar vessel shapes (Murphy 1996, 42-69). ${ }^{5}$ This similarity is supported by its contemporaneity, as is evident from the ${ }^{14} \mathrm{C}$ date.

In addition to the Jumby Bay site another Late Ceramic Age site (GE-01, along Winthorpe's Bay) ${ }^{6}$ resembled the Muddy Bay and the Jumby Bay materials. Interestingly, this site lies along that part of the northern coast of Antigua that faces Long Island. One radiocarbon sample yielded a slightly younger date than that of the Jumby Bay site, but older than the one from Sugar Mill (Murphy personal communication 2003).

\section{Subsistence remains}

Shell debris made up the majority of the subsistence remains from the Jumby Bay site, while the quantity of animal bone varied significantly between the different excavated units. The analysis of shells has been very basic, only directed toward reconstructing the habitats that were exploited. For this purpose each shell was classified to the level of species and total weight, Minimum Number of Individduals (MNI), and Number of Identified Species (NISP) for each species was determined using the forms composed by Nieweg (2000).

Measuring and weighing individual shells for reconstructing diet has not been attempted. Although there is some variation in relative MNI counts per shovel test pit, the list of most frequent species is very similar for each test pit. Bivalves make up the large majority of the shells by MNI. Most important species by MNI are Chama sp., Arca zebra, and Pinctada imbricata. (tables 4.1 and 4.2) Other recurrent bivalve species are Anadara floridana and Brachidontes modiolus, while recurrent gastropods are Crepidula aculeate, Petaloconchus varians, Nerita versiculor and Nerita tessellata. The majority of these species point to a rocky littoral zone as the exploitation area. This environment can be found in the waters surrounding the island. Notable is the scarcity of Cittarium pica among the archaeological samples. This species is often well represented among shell subsistence remains from Ceramic Age sites (Brokke 1996, 1999a; Nieweg 2000; Taverne \& Versteeg 1992). Whether this low occurrence can be ascribed to poor natural availability or particular human choice is unclear. The list of most frequent shellfish species strongly correlates with that of the Muddy Bay site, situated along Antigua's northeastern coast in a similar low-lying limestone region with abundant reefs nearby (Murphy 1996), suggesting similar shell collecting behaviours.

In relation to the study of animal bone and crab material, Sandrine Grouard analysed a sample from the single $1 \mathrm{x}$ $1 \mathrm{~m}$ test-unit excavated, as well as one from one shovel test pit (550/995) (Grouard 2002). This total sample included both $2.9 \mathrm{~mm}$ and $8.0 \mathrm{~mm}$ mesh residues collected from one $0.5 \times 0.5 \mathrm{~m}$ square in the test-unit, and an $8.0 \mathrm{~mm}$ mesh residue only originating from the shovel test pit. In addition to the determination of MNI and NISP and evaluation of habitats exploited, Grouard looked at diversity and richness of taxa, completeness of skeletons, and average size of the animals that were caught. The Jumby Bay site produced almost 10000 bone fragments. Grouard's results show that the sample consists of

\footnotetext{
5 During the 2000 field campaign, time was spent on comparing recently discovered sherds from both sites. The similarity in reported data was also supported by this visual examination.

6 This site has not been reported in detail and therefore should not be confused with the neighbouring site of GE-06, situated along Winthorpe's Bay as well. Murphy has more extensively investigated and discussed this latter site in his Ph.D. dissertation (Murphy 1999).
} 


\begin{tabular}{|c|c|c|c|c|c|c|}
\hline Shell species & $\begin{array}{r}\mathrm{T} 547.5 \\
994 \\
\mathrm{~N}=514\end{array}$ & $\begin{array}{r}\mathrm{S} 550 \\
995 \\
\mathrm{~N}=116\end{array}$ & $\begin{array}{r}\mathrm{S} 540 \\
995 \\
\mathrm{~N}=159\end{array}$ & $\begin{array}{r}\mathrm{S} 620 \\
1025 \\
\mathrm{~N}=127\end{array}$ & $\begin{array}{l}\mathrm{S} 620 \\
1035 \\
\mathrm{~N}=49\end{array}$ & Overall \\
\hline Pinctada imbricata & 14.8 & 19.0 & 28.9 & 9.4 & 18.4 & 18.0 \\
\hline Chama sp. & 15.6 & 23.3 & 17.0 & 49.6 & 46.9 & 30.5 \\
\hline Chama macerophylla & 1.6 & 1.7 & 3.1 & - & - & 1.3 \\
\hline Anadara floridana & 1.2 & 2.6 & 1.9 & 4.7 & 0.0 & 2.1 \\
\hline Isognomon alutus & 1.2 & - & - & - & - & 0.2 \\
\hline Donax denticularis & 0.8 & - & - & - & - & 0.2 \\
\hline Lopha frons & 0.0 & 0.0 & 0.0 & 0.8 & 0.0 & 0.2 \\
\hline
\end{tabular}

Table 4.1. Jumby Bay, Long Island. \% MNI of bivalves by shovel (S) and test-unit (T). N comprises the total number of all shell MNI.

\begin{tabular}{|c|c|c|c|c|c|c|}
\hline Shell species & $\begin{array}{r}\mathrm{T} 547.5 \\
994 \\
\mathrm{~N}=514\end{array}$ & $\begin{array}{r}\mathrm{S} 550 \\
995 \\
\mathrm{~N}=116\end{array}$ & $\begin{array}{r}\mathrm{S} 540 \\
995 \\
\mathrm{~N}=159\end{array}$ & $\begin{array}{r}\mathrm{S} 620 \\
1025 \\
\mathrm{~N}=127\end{array}$ & $\begin{array}{l}\mathrm{S} 620 \\
1035 \\
\mathrm{~N}=49\end{array}$ & Overall \\
\hline Nerita versicolor & 19.5 & 0.8 & - & - & - & 4.1 \\
\hline Crepidula aculeata & 4.9 & 6.0 & 6.9 & 1.6 & - & 3.9 \\
\hline Petaloconchus varians & 3.1 & 1.7 & 3.8 & 11.0 & 0.0 & 3.9 \\
\hline Tectarius muricatus & 2.1 & 1.7 & - & - & - & 0.8 \\
\hline Cittarium pica & 0.4 & 0.8 & 0.0 & - & 0.0 & 0.2 \\
\hline Strombus gallus & 0.4 & 0.0 & 0.0 & - & 0.0 & 0.1 \\
\hline Strombus gigas & 0.2 & 0.0 & 0.6 & 0.0 & 0.0 & 0.2 \\
\hline Murex (phyll.) pomum & 0.4 & 0.8 & 1.3 & 4.7 & 0.0 & 1.4 \\
\hline Murex florifer & 0.2 & - & - & - & 2.0 & 0.4 \\
\hline Columbella mercatoria & 0.4 & - & 1.3 & - & 2.0 & 0.7 \\
\hline
\end{tabular}

Table 4.2. Jumby Bay, Long Island. \% MNI of gastropods by shovel (S) and test-unit (T). N comprises the total number of all shell MNI.

more than $90 \%$ (NISP) fish. Of the fish-bones that could be identified to the family or species level, the following families were attested, in decreasing order (by MNI): Scaridae (Parrotfish), Acanturidae (Surgeonfish), Haemulidae (Grunts), Lutjanidae (Snapper), and Serranidae (Seabass). This suggests that predominantly reefs and rocky banks were exploited. Species caught in an offshore-pelagic habitat contributed less than $3 \%$ of the total. In addition to fish, very small amounts of remains of crab, mammals, birds, reptiles, and amphibians were also identified.

The representation of skeletal parts found in the samples showed that entire reef fish and crabs were taken to the site. The limited sample of offshore-pelagic fish, as well as rodents, on the other hand, suggests that these animals were trimmed of their less edible parts, before being transported to the site. The small size of especially the reef-fish suggests that nets were used for catching them.

\section{Flint working}

The lithic sample from the Jumby Bay site almost exclusively consists of flint artefacts. In addition, a small number of other lithic artefacts was found. These include 29 flakes, 4 shattered pieces and 1 core piece, all made out of limestone, a St. Martin greenstone axe fragment, 2 calcite crystal pieces, an igneous rock flake, and one quartz-diorite bead. All flint was counted and weighed. In total, 1896 flint artefacts were collected from all shovel test pits and the test-unit. These all belong to the $8 \mathrm{~mm}$ 


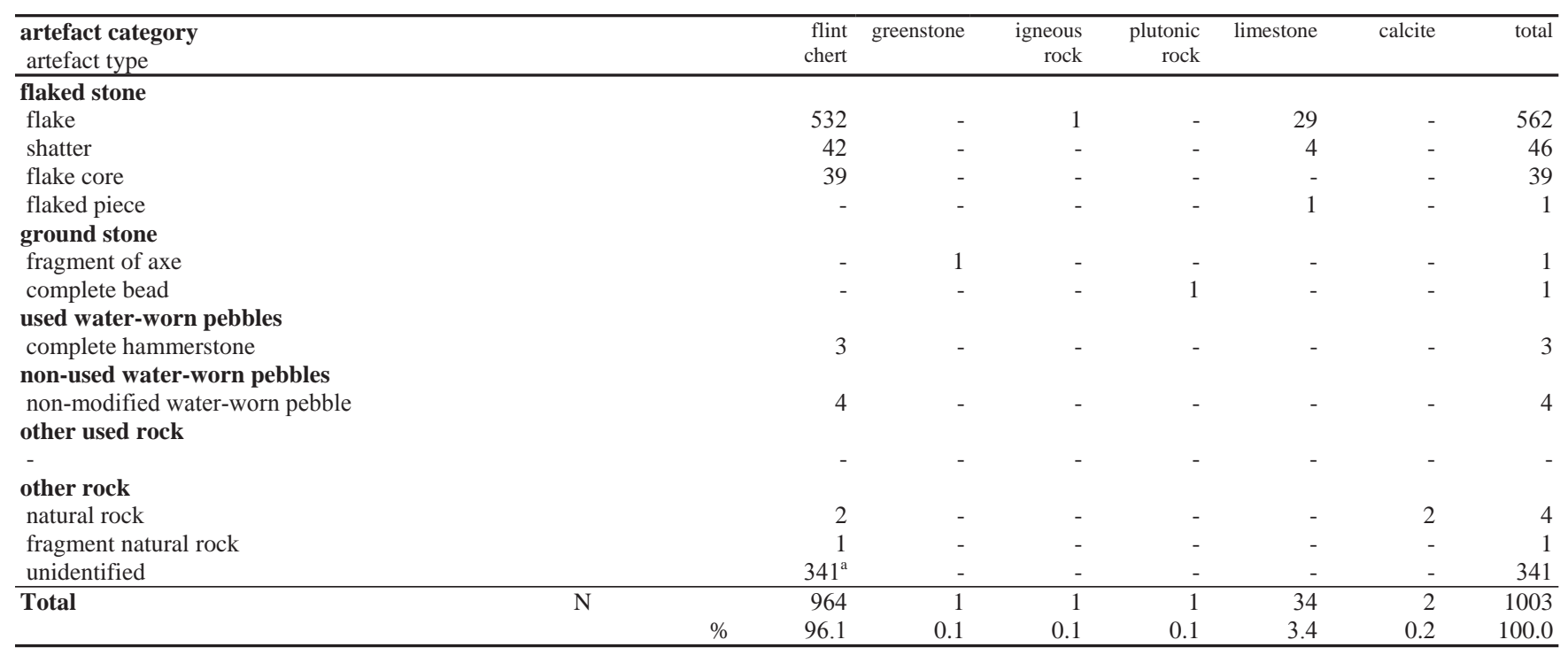

Table 4.3. Jumby Bay, Long Island. Number of artefacts by type and by raw material. a predominantly includes fire-cracked flint rock.

mesh-screen residues. A subsample from a well-defined midden context was chosen for more detailed analysis (table 4.3). ${ }^{7}$

The subsample consisted of 964 flint artefacts. These were studied in more detail following the methodology described in Chapter 3. The flint analysis was hampered by the high proportion of fire-cracked pieces. Especially in test-unit 547.5/994, part of the deposit had been burnt, probably as the result of a hearth there. This hearth or burnt layer cannot be related to heat-treatment of flint material. In the first place the expedient technology with which the flint was worked without making formal tools does not require a subtle technique such as heat-treatment, which is of use in sophisticated biface reduction. Furthermore the fact that many pieces were cracked in tens of small pieces indicates that the burning was too intense to be of any help in improving the flint quality for working. Another indication is the wide variety of artefact types exposed to the firing, which points to an absence of deliberate choices in artefact selection. This is highly uncommon for heat-treatment. Therefore, it is most likely that these firing locations were related to either food preparation or refuse burning activities. $^{8}$

As expected the large majority of the flint had a local Long Island origin. However, there are a few pieces (1.1\%), that originated either definitely outside Long Island, as their characteristics are different from Long Island material, or which might be non-local, where a Long Island-origin is still a possibility. One dull white chert piece, resembling quartz, and three pieces of translucent cherts, likely from a re-crystallized coral as evidenced by their internal structure, are definitely not from Long Island, but probably come from the main island of Antigua. Among the "probable exotic" flint pieces are coarser varieties or those possessing different inclusions than the common Long Island flints.

This small number indicates that the flint knappers at Jumby Bay almost solely relied on Long Island flint. Although such reliance would conform to expectations, some sites on Antigua situated in areas where other raw materials occur do not exhibit such exclusive utilization of local material, as discussed below in Chapter 5.

The outer surface of the Long Island flint artefacts points to different types of raw material. The majority consists of a dark grey flint, with a white "chalky" cortex. In addition, specimens with dark grey cores surrounded by brown bands, or completely brown specimens occur, both possessing a more brown "chalky" cortex. Both the white as well as the brown cortex have been worn to some degree, indicating that original cobbles were from secondary contexts, and not cut from the

\footnotetext{
7 This sample comprised those shovel test pits that were situated in areas that had a clear shell deposit, which varied in thickness from $5 \mathrm{~cm}$ to $60 \mathrm{~cm}$. This sampling ascertained that material came from undisturbed Amerindian contexts. The following test pits and test-unit were included: S 540/995, S 550/995, S 570/1015, S 570/1025, S 620/1035, S 620/1045, S 620/1055, S 628/1025, and test-unit 547.5/994.

8 These fire-cracked pieces were only counted and not further analysed, as this post-depositional alteration reshaped the object and blurred original flaking characteristics. Burnt pieces that were not cracked were included, however, as burning in these cases did not have any negative effect on the identification of original flaking characteristics.
} 
limestone bedrock. Occasionally, some of these pieces also had white and brown patinated surfaces on faces where cobbles had been naturally broken. As already mentioned, these particular outer surfaces were originally formed within the inland part of the island. However, whether they were actually collected within these areas cannot be determined, as erosion might have moved them to the cobble beaches. Cobble beaches were certainly exploited, as suggested by the presence of waterworn outer surfaces on many flakes and the use of flint pebbles as hammerstones.

In addition to these natural types of raw material, the Jumby Bay site also produced previously flaked material. Among the overall sample, there is a small number of completely white patinated artefacts $(\mathrm{N}=5)$. This complete patination distinguishes them from the large majority of artefacts that are not patinated at all, or which only exhibit patination on (part of) their dorsal face. In the case of complete coverage, the patination must have developed after flaking. Therefore, it suggests that flaking occurred earlier than is the case with the majority of the other (non-patinated, or partly patinated) artefacts, as the find contexts can be considered similar.

The origin of these white artefacts was easily found, as surface scatters on the eastern part of the island, mapped by the 1989 Leiden-team, contain many patinated pieces. Considering that most of these scatters are associated with a blade technology (Verpoorte 1993), these artefacts would be dated to the Preceramic Age. Apart from the patination there is another feature, less clear and therefore subject to more discussion, that points to a Preceramic origin. This is the more sophisticated flaking technology by which these artefacts were produced. All patinated flakes are relatively large, thin, and regular in shape, and possess a regularly shaped platform. Furthermore, their bulb of force and cone of percussion are clearer and more pronounced than is generally the case for the other lithic artefacts. Finally, none of the five flakes have been further reduced, a feature commonly found among Ceramic Age flaked material. I have noted such difference in flaking characteristics between Preceramic and Ceramic Age technologies on St. Martin (Knippenberg 1999c, d), as well as during a recent analysis of Preceramic Age material from Barbuda (Watters 2001; Watters et al. in prep.). Although others have reported scavenging of Preceramic Age material within a Ceramic Age context on Antigua (De Mille 1996; Murphy 1999), the presence of these Preceramic Age artefacts does not necessarily point to such behaviour in this case. The wide occurrence of scattered Preceramic Age material on Long Island makes it likely that the patinated artefacts at Jumby Bay just represent material that ended up in the deposits by accident after clearing parts of the site area. Furthermore, there is no evidence on the artefacts themselves, such as secondary working that suggests re-use of these items during the Ceramic Age. Such edge working was identified on a blade at the Ceramic Age site of Royall's on the main island of Antigua, for example (Murphy 1999, 158-159).

In any case, the variation in outer surfaces suggests that Amerindians at Jumby Bay did not prefer a specific type of raw material, as has been reported for knappers at Flinty Bay (Van Gijn 1996). Furthermore, the few slightly reduced cores at Jumby Bay are relatively small in size, minimally indicating that large nodules were not specifically desired. Such choice is similar to choices made at sample area 36 near Buckley Bay, where small nodules of an inferior quality flint were used (Verpoorte 1993). This behaviour directly may have been a result of the scarcity of large nodules there, which were widely used during the Preceramic Age.

If we look at the technological features of the sample, the flint was clearly worked using an expedient flake tool technology. Cores were reduced from any platform available and flakes were used ad hoc or only after minimal modification in the form of one or two flake removals (figure 4.7). Another aim of reducing flakes was to produce smaller flakes.

Typical intentional retouch in which edges were systematically chipped to shape and strengthen them is absent. Formal tool shapes have not been identified. Only $4.3 \%$ of the flakes had use wear in the form of small edge retouch (figure 4.8). One core exhibited such retouch as well. In addition, four artefacts $(0.7 \%)$ had retouch, that was considered to be intentional based on size of the scar negatives. However, it lacked a regular pattern.

The use of hard hammer percussion is evidenced by clear points and cones of percussion on many flakes. The application of this technique was supported by the presence of several flint pebbles with pitted areas at their sides or ends, clearly indicating use as hammer-stones (figure 4.9). Direct freehand percussion flaking was the predominant flaking technique. The majority of the flakes had a pronounced bulb of force, were curved in shape, and had single scarred platforms. Unlike many Ceramic Age sites, the use of the bipolar technique only played a minor role in core reduction at Jumby Bay. Out of the studied flakes, only $5 \%$ was identified as truly bipolar flakes, possessing a flat bulb of force and being straight in shape. Also, the low occurrence of pointed and edge type of striking platforms suggest the minor significance of this flaking technique. However, the site produced a number of flakes, that were bipolarly split. They were placed on an anvil either on their dorsal or ventral face, and struck into more pieces. 

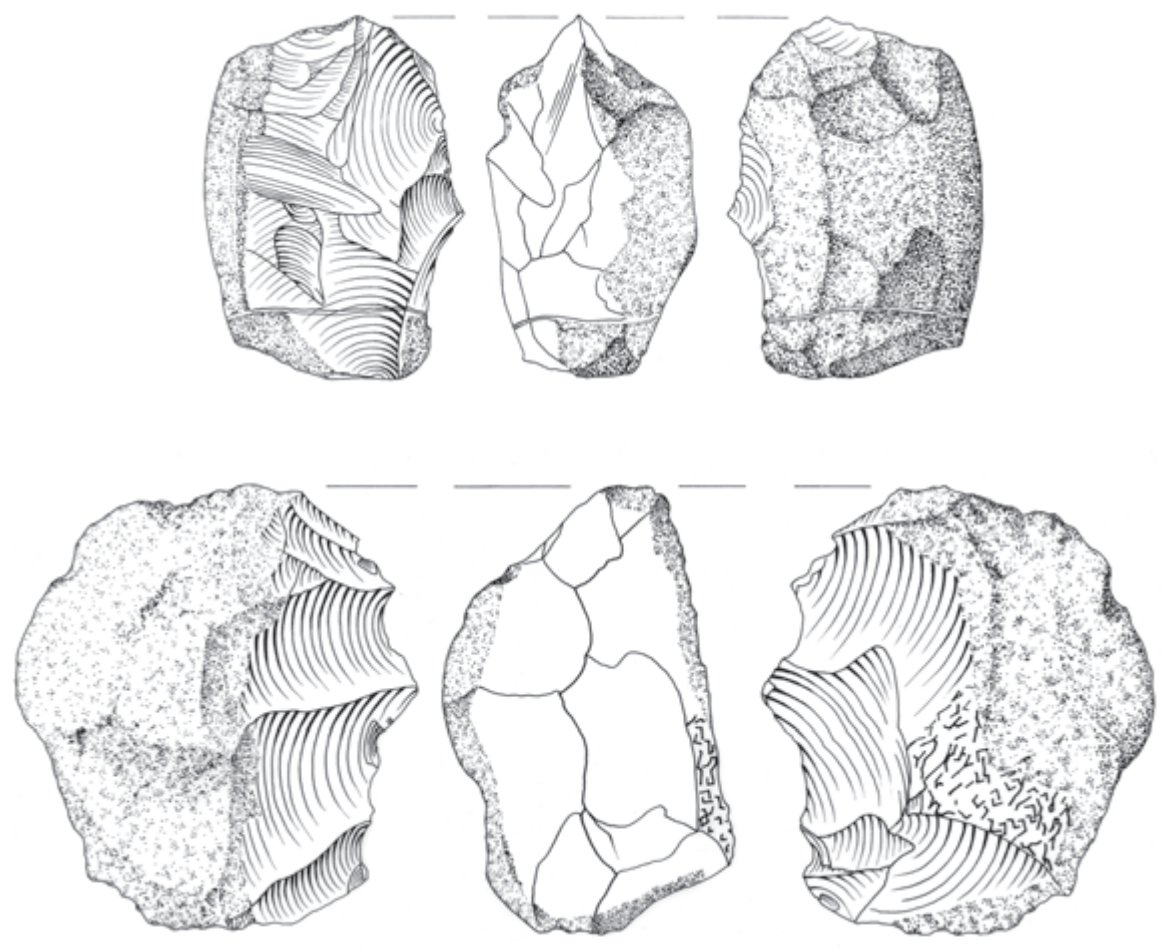

Figure 4.7. Jumby Bay. Expedient flint cores (scale 1:2). (Drawings Raf Timmermans)

The characteristics of the flint sample from Jumby Bay clearly point to an expedient production of flakes for local use. The whole repertoire belonging to such a production was recovered including cores, shatter, and primary, secondary and tertiary flakes, as well as flakes with use wear. If we consider the settlement context of the materials associated with this production, then the local use of the flint does not present an anomaly. Still, it is a possible that in addition to the production for local use people at Jumby Bay were pre-working material for transport to or exchange with other sites. In other words, it should be studied whether there is evidence for the missing or under-representation of certain artefact categories. The flake/core ratios of the different clusters vary between 5 and 20. Such low values do not indicate that cores are underrepresented in the sample and therefore, it is not likely that they were taken somewhere else. Rather, such a low ratio would suggest the opposite, that flakes were transported. For this latter option, however, additional evidence is hard to find. The low values may be understood in view of the small size of the cores and the initial reduction stage in which some of these cores were found. Furthermore, the possibility that some of the cores originally were flakes should also be considered, which would decrease the ratio as well. With the absence of formal tool types, tertiary flakes would be the most likely candidate for further transport, as they generally possess the most suitable working edges. The frequency distribution of cortical flakes, however, shows that tertiary flakes are well represented at Jumby Bay, and that there is no clear evidence for systematic displacement of such flakes (table 4.4). Infrequent transport of individual flakes cannot be excluded with these numbers, however. In

\begin{tabular}{lrr}
\hline cortex count & $\mathrm{N}$ & $\%$ \\
\hline $0 \%$ & 75 & 37.3 \\
$1-24 \%$ & 52 & 25.9 \\
$25-49 \%$ & 34 & 16.9 \\
$50-74 \%$ & 25 & 12.4 \\
$75-99 \%$ & 9 & 4.5 \\
$100 \%$ & 6 & 3.0 \\
\hline total & 201 & 100.0 \\
\hline
\end{tabular}



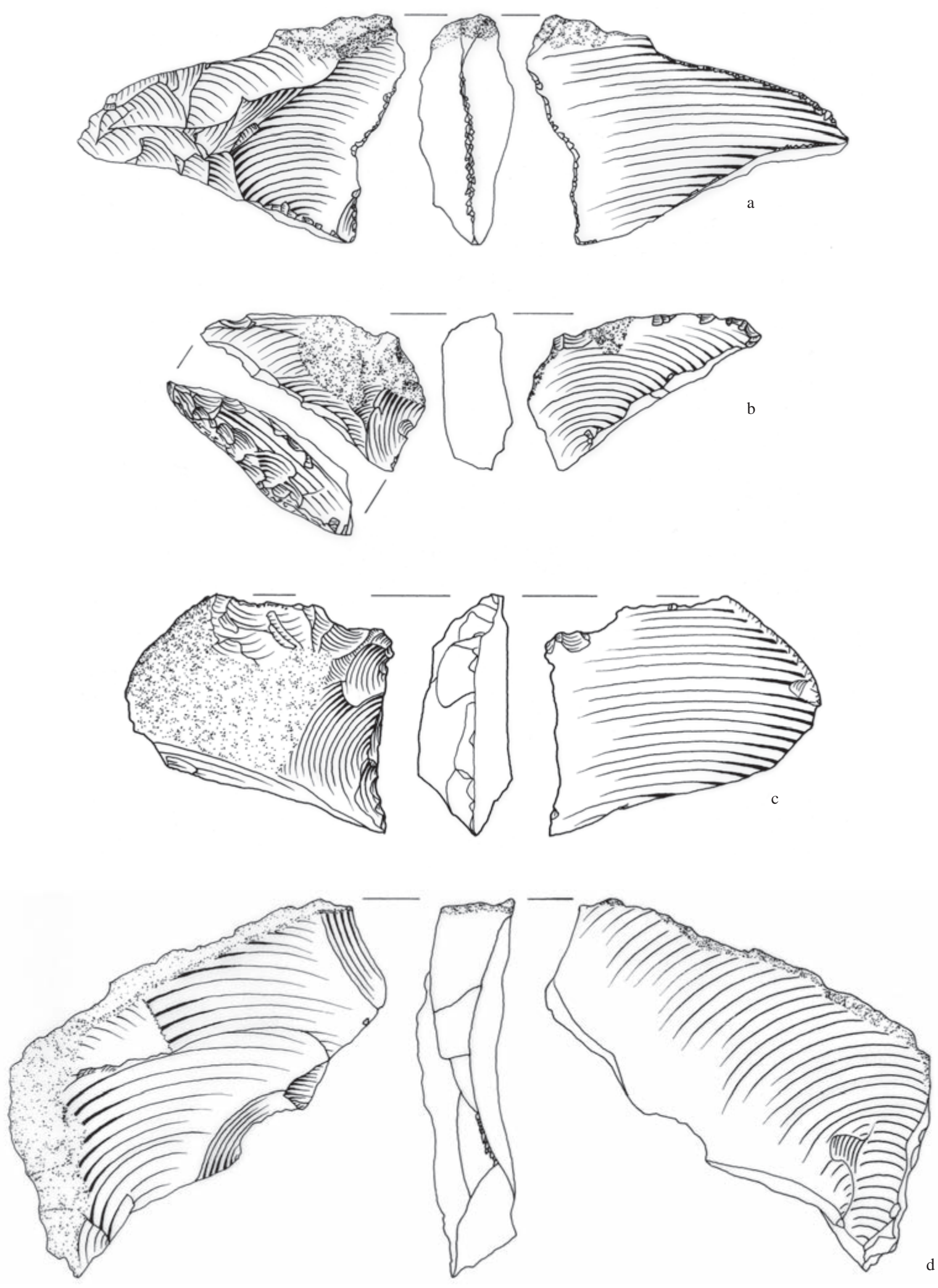


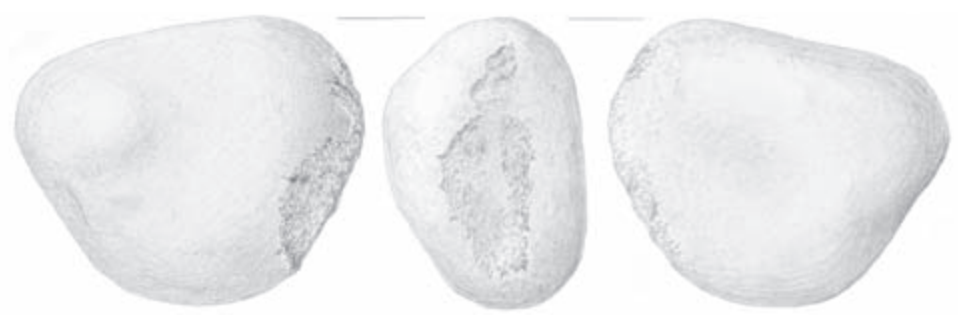

Figure 4.9. Jumby Bay. Flint pebble hammerstone (scale 1:2). (Drawing Raf Timmermans)

light of these considerations, it should be concluded that there is no clear evidence that people staying at Jumby Bay were involved in systematic flint working of cores or flakes to be transported to or exchanged with other sites. The data support on-site production and use of expedient flake tools.

\section{Other stone and coral}

The other stone materials form only a very small portion of the lithic sample, less than $3 \%$. Raw materials include limestone, greenstone, igneous rock, calcite, and diorite. Limestone is most abundant, comprising 29 flakes, 4 shatter pieces and 1 core artefact. Most likely, the material was local to Long Island, as its medium coarse-grained homogeneous texture is common there. The flakes suggest that limestone was worked at the Jumby Bay site, but it is hard to specify the purpose behind this reduction. The only core artefact is not very indicative. It is an irregularly shaped cobble with a few flake removals, likely an initial flake core. The flakes suggest that limestone was not reduced much, as most of the pieces have remnants of outer surface on their dorsal face. In fact, it is possible that some of these cortical pieces actually were removed from flint cobbles with a thick cortex rind, as they closely resemble flint cortex. Still, some flakes do not exhibit such a similarity. From the low numbers, it is clear that limestone working did not play an important role at Jumby Bay.

In addition to the local limestone, two calcite crystal fragments were found. These might have a local provenance, although no calcite has been identified on the island yet. Having only two pieces and because it is unclear if they were modified, the use of calcite is hard to explain. From Saladoid sites on Antigua we know that this material was used for making beads (Murphy et al. 2000). On Anguilla, a predominantly limestone island, this material was also found at a number of other sites, mainly in crystal or unmodified form (Crock 2000; see Chapter 5). Rare examples of calcite bead pre-forms suggest bead production there as well.

Obvious exotic artefacts include the diorite bead, the greenstone axe fragment, and the igneous rock flake fragment. Being finished items and lacking any material that might point to production, the former two suggest that these artefacts were imported in this form. The diorite resembles bead material at other local sites, such as the Elliot's site (Murphy et al. 2000). However, its source is unknown. The axe fragment, in the form of an edge bit, has a typically corroded surface, which is common for the greenstone variety originating from St. Martin (see Chapter 2). The igneous flake fragment consists of dark coloured rock, with small light mineral inclusions. Its provenance is unknown. Having only one piece, it is hard to tell if this rock was worked at the Jumby Bay site and for what purpose.

In addition to stone, coral material was also collected to be used as tools (table 4.5). Among the collected pieces, a small portion displayed evidence of use-wear, predominantly in the form of abraded areas present on restricted parts of the often fragmented items. ${ }^{9}$ Identified species exhibiting such use-wear are in the majority Acropora palmata, Acropora cervicornis, and Porites sp. In addition, only a single Montastrea annularis artefact was identified. The cylinder-shaped branches with a

Figure 4.8. Jumby Bay (opposite page). Flint flakes showing evidence of utlization. a. flint fragment with bifacial use retouch; b. modified flake with intentional retouch; c. modified flake with unifacial steep use retouch; d. flake fragment (scale 1:1). (Drawings Raf Timmermans)

9 The identification of use-wear was made using the naked eye or a hand lense (up to 10x magnification). 


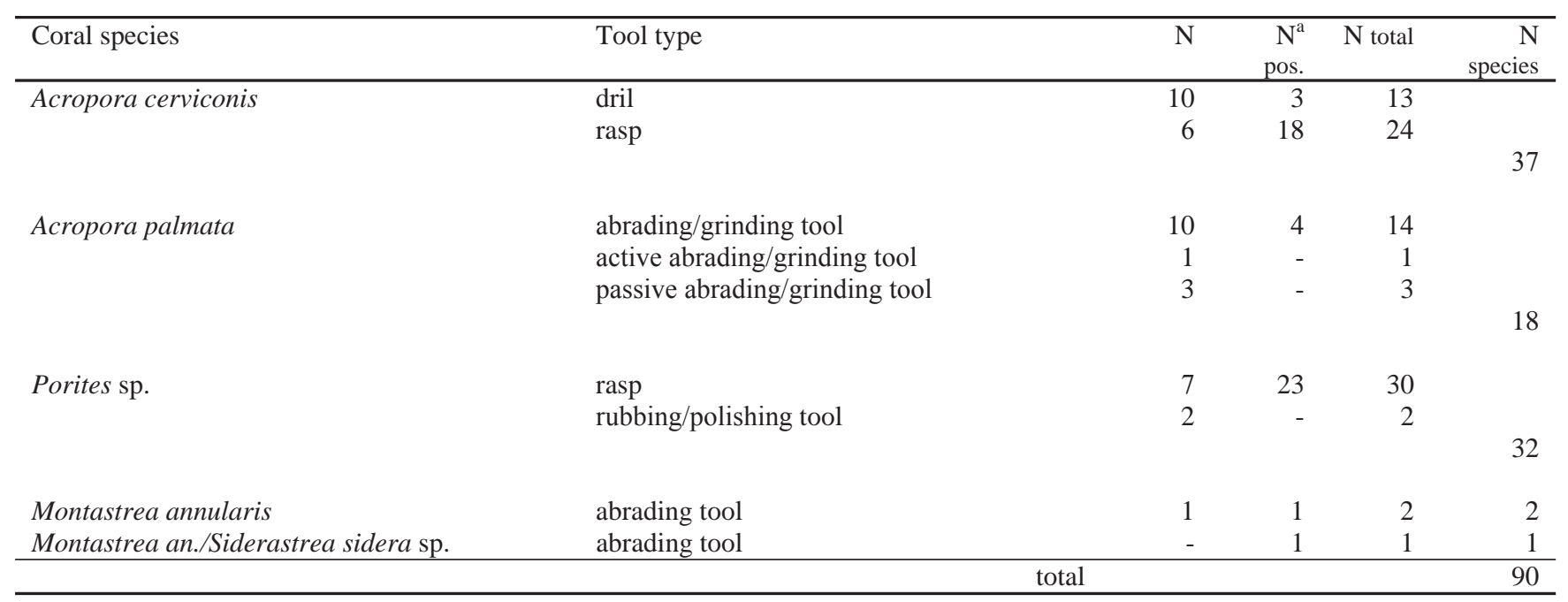

Table 4.5. Jumby Bay. Number of identified coral tools by species from test-unit and shovel excavations. a This column tabulates possible artefacts, for which use-wear is not very pronounced.

slightly pointed top of the Acropora cerviconis coral almost all display parts with abraded areas completely surrounding the branch, suggesting that the tools were used as drilling devices. Rare pieces, however, exhibit abraded surfaces on one side only, suggesting use as an active abrading tool, e.g. a rasp (see also Steenvoorden 1992).

The flattened branches of the Acropora palmata predominantly display abrasion on a single face. Both concave as well as convex faces possessed this use-wear, suggesting that this species was used as an active and a passive grinding/ abrading tool. In case of the Porites sp., the identification of any possible use-wear was complicated by the presence of less pronounced protruding polyps. Cylinder-shaped and flat items were seen among the used specimens. Most artefacts suggest use as an active abrader.

\section{Summary}

From this small scale field research, it is evident that the area to the south of Jumby Bay was settled for some time during the Late Ceramic A, somewhere between AD 1100 and 1200. The material remains point to domestic activities related to exploitation of local resources. Rocky inter-tidal habitats close to the shore were exploited for collecting shells and catching fish. The abundant flint available on the island was primarily worked at the site for local purposes. Small cores were reduced following an expedient technology for the production of sharp-edged flakes, which underwent little if any secondary working before use. Clear evidence for systematic pre-working of cores or flakes to be transported to or exchanged with other sites is lacking.

\subsubsection{Sugar Mill}

\section{Introduction}

The Sugar Mill site only lies approximately $270 \mathrm{~m}$ to the east of the Jumby Bay site, at the other end of the highest point in this area of Long Island. The site is located on a slightly sloping grassland bordered by the Old Estate House to the west and a replication of an old Sugar Mill to the north (figure 4.1 and 4.10). About $250 \mathrm{~m}$ to the southwest the present dockyard is situated. This site probably corresponds with locality LI 1 of Hoffman's fieldwork in the 1960s. However, Nicholson was not familiar with the presence of an archaeological site at this specific location (Nicholson, personal communication 2000), although in his field-notes he indicates a wider distribution of the Jumby Bay site, which partly includes the area of the Sugar Mill site. Sugar Mill was discovered during initial inspection of the island as preparation for the field-work in 2000. A small 


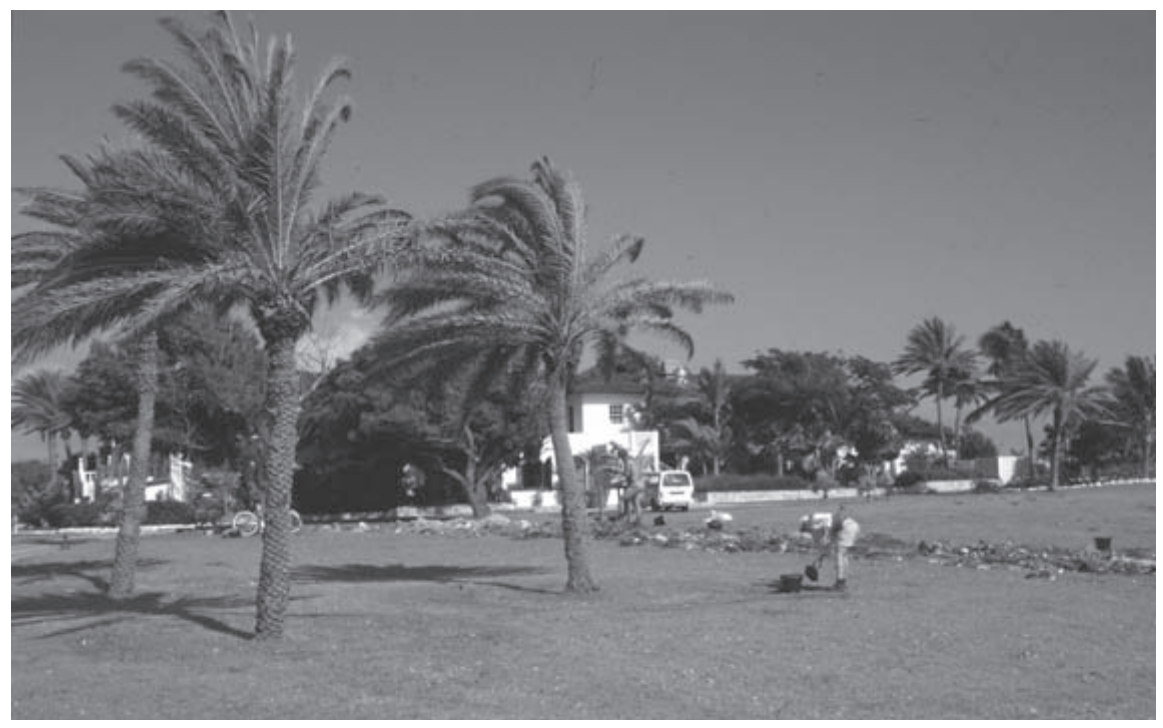

Figure 4.10. The Sugar Mill site facing north.

trench dug for pipeline construction uncovered a concentrated Amerindian midden deposit. Lots of shell debris in addition to pottery, flint, and small amounts of coral could be identified on the spoil heap. Inspection of the trench profiles showed that archaeological material did not go deeper than 30 to $40 \mathrm{~cm}$ below the surface and that the higher concentration only extended for approximately $10 \mathrm{~m}$, while more dispersed concentrations could be found over a length of $80 \mathrm{~m}$.

It was decided to place a $10 \mathrm{~m}$ grid over the site area, and systematically excavate $0.5 \times 0.5 \mathrm{~m}$ shovel test pits every $10 \mathrm{~m}$, as the laying-out of a grass-field had hidden archaeological material on the surface in the surroundings of the trench. Each test pit was excavated in arbitrary $10 \mathrm{~cm}$ levels, using $8 \mathrm{~mm}$ mesh screens, similar to the methodology employed at Jumby Bay. Figure 4.11 shows the location of the 18 shovel test pits. The extension of the grid was limited to the west by the presence of a putting green and the beginning of a stone pavement as part of the Old Estate House. No obstructions were present in the other directions.

Figure 4.11 also shows the extension of the shell deposit as identified, which has an approximate size of 20 to 28 $\mathrm{m}$. This is believed to represent the original extent of the deposit, despite the fact that the shovel test pits in the western area revealed considerable disturbances, likely associated with the construction of the old Estate House and connecting stone paths. However, it is possible that additional shell deposits or scatters are situated further to the west, as test pits produced archaeological material in disturbed topsoil there.

The cultural deposit can be considered rather shallow at the Sugar Mill site never exceeding $25 \mathrm{~cm}$ in thickness. In the eastern part it resides on a dark humic clayey subsoil, which gradually becomes more chalky to the west, likely associated with the rise of the terrain in this direction. In the higher parts surrounding the old Estate House, only relatively thin topsoil covered limestone bedrock. The clayey deposits in the lower surroundings, therefore are likely to be slope-wash. The inhabitants of the Sugar Mill locality probably placed their dwellings in the higher parts and threw their refuse to the lowlying peripheries.

Disturbance from recent and Historic times are also visible in the area of the shell deposit itself. These are localised, however. At test pit 1029/510, an erosive transition was noted between the topsoil and the beginning of the shell deposit. Here the topsoil contains hundreds of small flint pebbles, in addition to some colonial artefacts, such as fragments of mortar, brick, glass, and glazed pottery. The fact that none of the small pebbles exhibit any signs of use wear or reduction, that they are highly concentrated, and that they all fall within a restricted size range suggest that they might be related to construction activities, in which they functioned as some sort of foundation or filling material. In addition to this shovel test pit other test pits also produced colonial material in the top 10 to $20 \mathrm{~cm}$ of the soil. In these cases, however, the erosive transition between topsoil and archaeological material is not apparent, which indicates that later activities did not intrude much into the Amerindian deposit. 


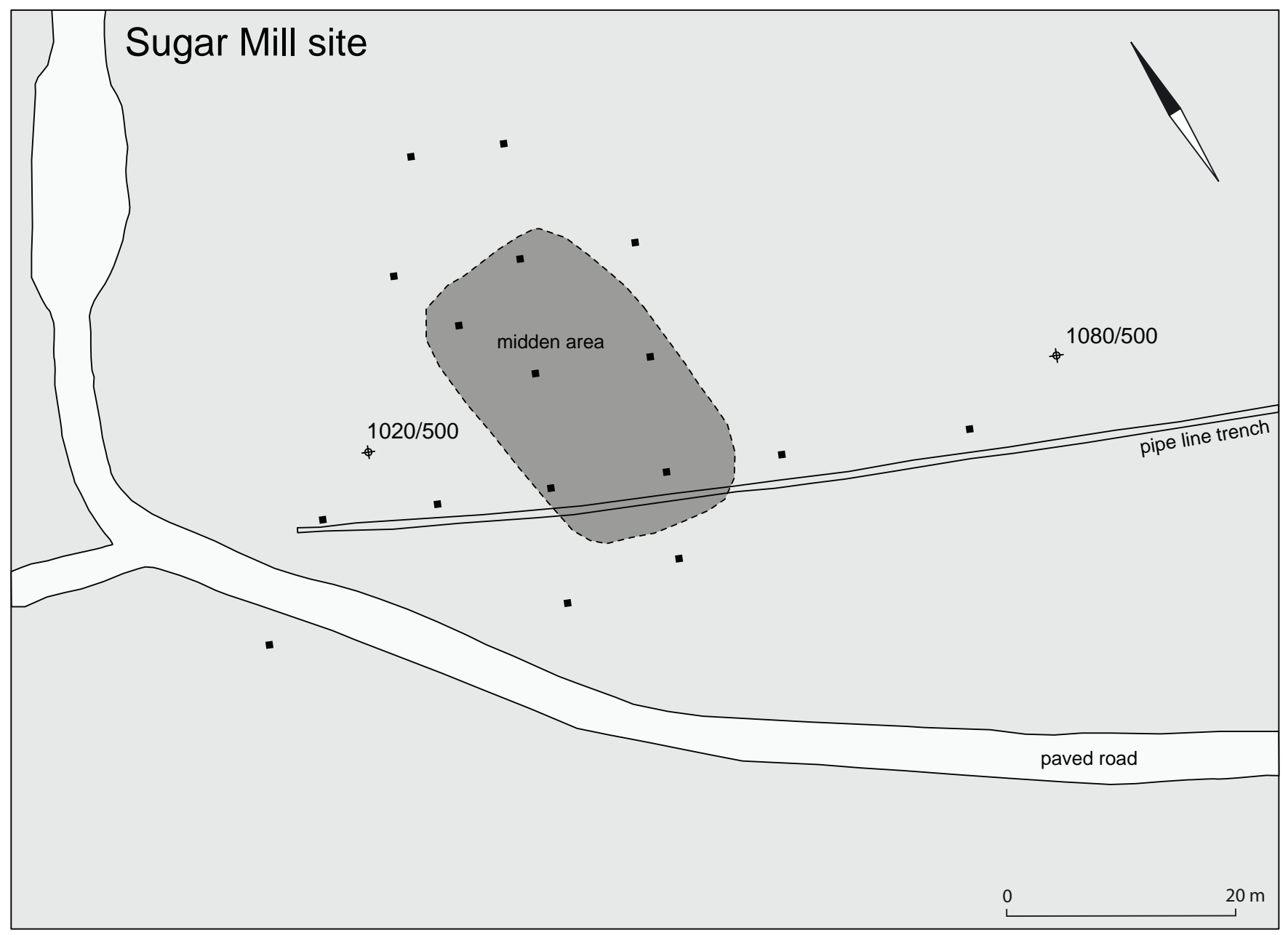

Figure 4.11. The Sugar Mill site with the location of the test pits (small rectangles) and site grid points.

\section{Absolute dating}

One charcoal sample from a lens of burnt material within shovel test 1045/495 has been submitted for AMS-radiocarbon dating for the Sugar Mill site. This sample produced a ${ }^{14} \mathrm{C}$ age of $600 \pm 60 \mathrm{BP}$ (GrA-18849). Calibrated, the date falls between AD 1291 and 1421, when a 95\% confidence interval is used. This places the site within the Late Ceramic B phase, corresponding with the local Freeman’s Bay style (Nicholson 1994).

\section{Ceramics}

The ceramics of the Sugar Mill site have a similar low occurrence compared to shell debris, as found at Jumby Bay. The total excavated sample consists of 277 sherds. In addition, 148 ceramic pieces were collected from the heap that resulted from the pipeline trench. ${ }^{10}$ The characteristics of the Sugar Mill pottery ${ }^{11}$ resemble those from the Jumby Bay site based on the following features: relative crude surface finishing on the majority of the pottery, a high occurrence of red slip (27.1\%), a low occurrence of other forms of decoration (1.8\%), and the predominance of the same two vessel shapes (figure 4.12). A notable difference is the absence of WOR painting within the Sugar Mill material, which only produced broad line and

\footnotetext{
10 Considering the clear association of this spoil heap with the archaeological deposits identified in the profile sections of the trench, this material definitely can be ascribed to this site.

11 The ceramics were analysed during the fieldwork by Tom Hamburg and Martijn van den Bel, following the methodology described by Hofman (1993).
} 

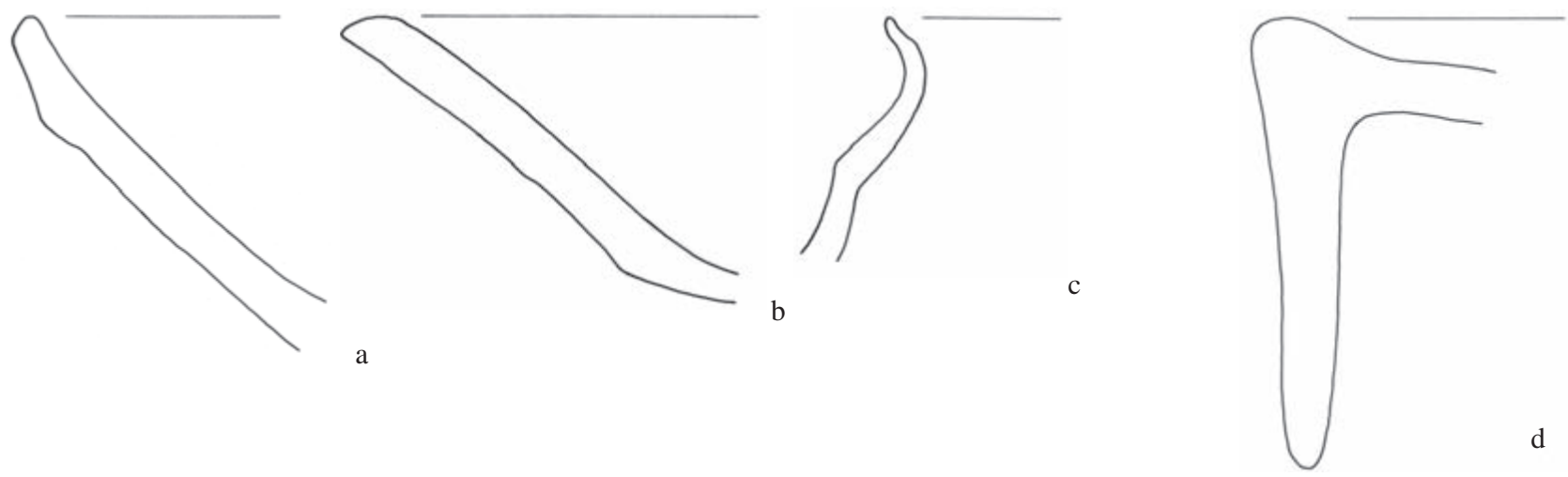

Figure 4.12. Sugar Mill. Unrestricted simple contour vessel shapes (a and b), restricted complex vessel shape (c) and a legged griddle (d) (scale 1:2). (Drawings Raf Timmermans)

fine line incision as decoration modes. It has to be mentioned that the small sample size, particularly in case of the Sugar Mill material, hampers sound statistical comparison and therefore, these differences and similarities have to be treated with caution.

The absence of WOR is supportive of the later occupation at Sugar Mill relative to Jumby Bay and Muddy Bay, despite the many similarities. On the other hand the sample does not typically represent the Freeman Bay style, as is suggested by its ${ }^{14} \mathrm{C}$ date. Rather, the occurrence of broad line incision places it in the earlier Mamora Bay style. Murphy (1999) has recently pleaded for redefinition of the local pottery styles, as the recent data do not correlate well with the original distinction of three subsequent post-Saladoid styles originally brought forward by Rouse (1992; see also Rouse \& Morse 1999).

\section{Subsistence remains}

A close similarity between Jumby Bay and Sugar Mill is also evident within the shell subsistence remains (table 4.6 and 4.7). Bivalves predominate and the three most common species by MNI are the same: Chama sp., Arca zebra, and Pinctada imbricata. The relative proportions differ, however, with Pinctada imbricata occurring more and Chama sp. less at Sugar Mill. Among the other less common species a close similarity is noticed again; of a list of around 30 species present at both sites, only three species exhibit significantly different proportions by MNI. In addition, each site yielded nine species that do not occur at the other site, but these species are so rare that this difference likely can be attributed to sample bias. Table 4.7 shows that the common Cittarium pica is also relatively rare at Sugar Mill. From the species identified, the rocky littoral zone again appears as the most commonly exploited habitat, which is quite similar to both Jumby Bay and Muddy Bay (Murphy 1996).

The amount of animal bone and crab remains at Sugar Mill are much smaller than the samples from Jumby Bay. This can be largely attributed to the use of only an $8 \mathrm{~mm}$ mesh-screen when collecting bone material from Sugar Mill. The residues from two test pits were analysed, following a similar methodology as for the Jumby Bay material (Grouard 2002). The total number of analysed bone specimens inlcuded 648 pieces.

The results from this limited sample display many similarities to the Jumby Bay results. Fish, almost exclusively caught from the reefs and rocky banks, forms the predominant animal class present at the Sugar Mill site (more than $95 \%$ by NISP). Identified fish species belong to similar families as at Jumby Bay, including in decreasing order by MNI: Scaridae (Parrotfish), Acanturidae (Surgeonfish), Haemulidae (Grunts), Serranidae (Seabass), and Lutjanidae (Snapper). In addition, very small amounts of crab, mammal bone and bird bone were found as well (Grouard 2002).

\section{Flint working}

Like the Jumby Bay site, the Sugar Mill site produced a high quantity of flint artefacts as compared to other stone materials. From the shovel test pits, 1207 flint artefacts were collected, while only 36 limestone, one calcite crystal piece, and one 


\begin{tabular}{|c|c|c|c|c|c|c|c|}
\hline Shell species & $\begin{array}{r}\mathrm{S} 1045 \\
495 \\
\mathrm{~N}=303\end{array}$ & $\begin{array}{r}\mathrm{S} 1045 \\
505 \\
\mathrm{~N}=102\end{array}$ & $\begin{array}{r}\mathrm{S} 1035 \\
495 \\
\mathrm{~N}=223\end{array}$ & $\begin{array}{r}\mathrm{S} 1035 \\
505 \\
\mathrm{~N}=107\end{array}$ & $\begin{array}{r}\mathrm{S} 1035 \\
515 \\
\mathrm{~N}=91\end{array}$ & $\begin{array}{r}\mathrm{S} 1029 \\
510 \\
\mathrm{~N}=57\end{array}$ & Overall \\
\hline Pinctada imbricata & 17.8 & 21.6 & 29.1 & 32.7 & 24.2 & 29.8 & 25.9 \\
\hline Chama sp. & 19.1 & 23.5 & 16.1 & 14.0 & 14.3 & 15.8 & 17.1 \\
\hline Anadara floridana & 2.0 & - & 0.4 & 0.9 & 3.3 & 3.5 & 1.7 \\
\hline Brachidontes modiolus & 7.6 & 2.0 & 1.3 & 0.0 & 0.0 & 0.0 & 2.0 \\
\hline Donax denticulatus & - & 1.0 & 5.4 & - & - & - & 1.1 \\
\hline Modiolus americanus & 1.0 & 0.0 & 0.0 & 0.0 & 0.0 & 0.0 & 0.2 \\
\hline
\end{tabular}

Table 4.6. Sugar Mill, Long Island. \% MNI of bivalves by shovel (S). N comprises the total number of all shell MNI.

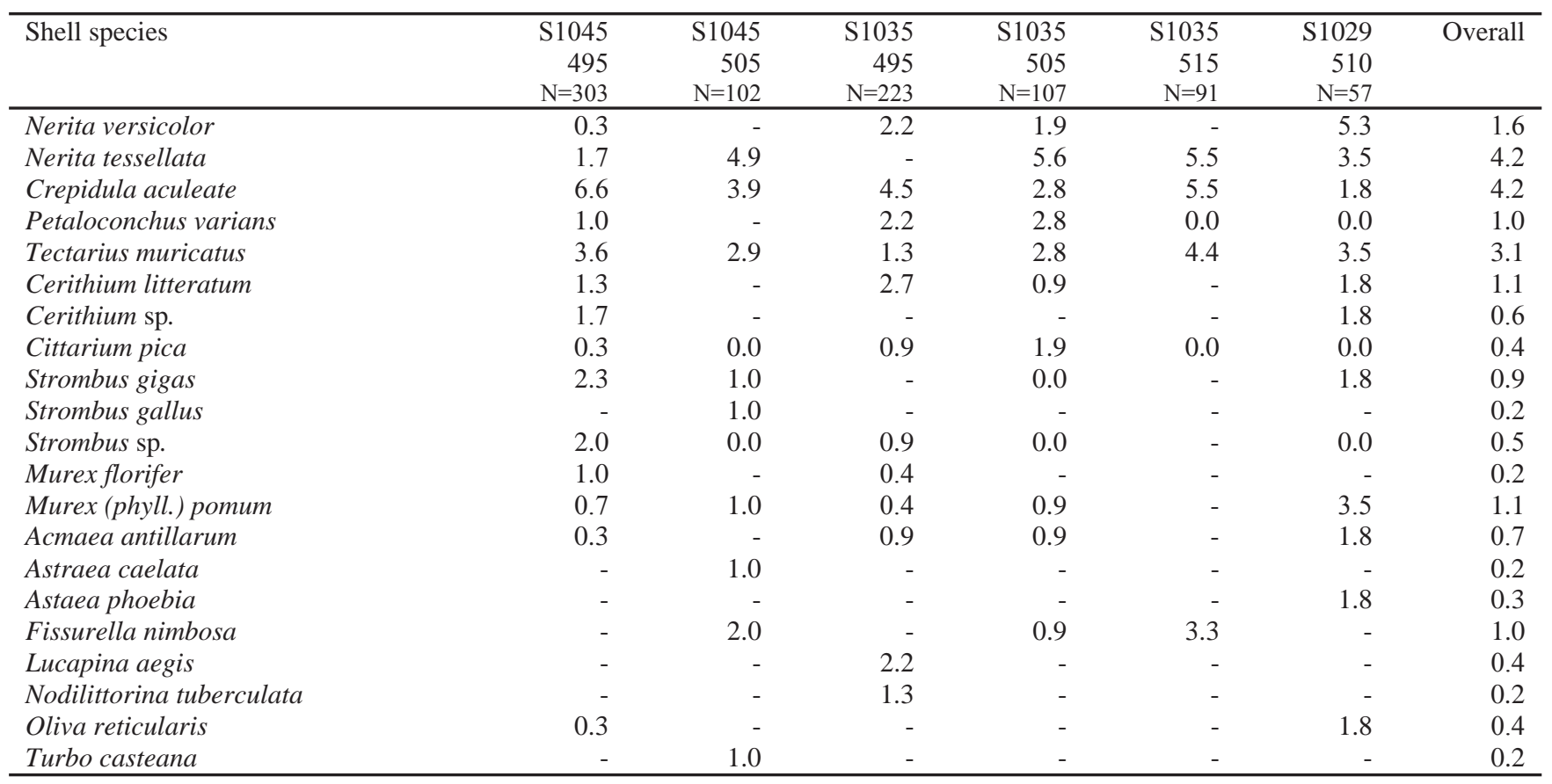

Table 4.7. Sugar Mill, Long Island. \% MNI of gastropods by shovel (S). N comprises the total number of all shell MNI.

igneous pebble hammerstone were retrieved. ${ }^{12}$ A sample of flint artefacts was analysed following similar procedures as for the Jumby Bay site ${ }^{13}$ (table 4.8). This sample consists of 427 flint artefacts in total. Again, many of the artefacts are fire-cracked, impeding analysis. The percentages of fire-cracked material within the test pits vary between 11 and $76 \%$.

The flint sample in many other ways resembles that from Jumby Bay as well. Sugar Mill displays a $100 \%$ use of local flint material; no exotic flint or chert varieties were identified. The sample also contains a very small percentage of Preceramic Age material in the form of two flakes. They do not exhibit secondary working, similar to the Jumby Bay material. Therefore, they may not have been left at Sugar Mill as a result of deliberate scavenging, but rather their presence may be attributed to clearing habitation areas. Among the flake material, the outer surface types include the wide range found

\footnotetext{
12 In addition, many shovel test pits yielded high quantities of small (in general, not larger than $3 \mathrm{~cm}$ ) flint pebbles. As these probably date to the later historic period, they are not included in the discussion.

13 Shovel test pits, which were excavated within the shell refuse deposit, were selected. The analysis included the following ones: 1027/525, 1029/510, $1035 / 495,1035 / 505,1035 / 515,1035 / 525,1045 / 495,1045 / 505,1045 / 515,1055 / 495$, and 1071.5/495.
} 


\begin{tabular}{|c|c|c|c|c|c|c|}
\hline $\begin{array}{l}\text { artefact category } \\
\text { artefact type }\end{array}$ & raw material & flint and chert & igneous rock & limestone & calcite & total \\
\hline \multicolumn{7}{|l|}{ flaked stone } \\
\hline flake & & 199 & - & 35 & - & 234 \\
\hline flake core & & 13 & - & - & - & 13 \\
\hline flaked piece & & - & - & 1 & - & 1 \\
\hline \multicolumn{7}{|l|}{ ground stone } \\
\hline \multicolumn{7}{|l|}{ non-used water-worn pebbles } \\
\hline non-modified water-worn pebble & & 1 & - & - & - & 1 \\
\hline \multicolumn{7}{|l|}{ other used rock } \\
\hline \multicolumn{7}{|l|}{ - } \\
\hline natural rock & & - & - & - & 1 & 1 \\
\hline
\end{tabular}

Table 4.8. Sugar Mill, Long Island. Number of artefacts by type and by raw material. a predominantly includes fire-cracked flint.

on Long Island, such as water-worn, brown and white patinated, and white and brown chalky surfaces. The majority of the flint is dark grey in colour, but brown banded and completely brown varieties were also identified.

From the few slightly reduced cores it is evident that size of raw material is not very large, at least for part of the material. These cores can be largely considered as poor in quality. This poorness does not reflect flaking properties, but rather has to do with the low flint content of the cobbles, as indicated by relatively thick cortex rinds compared to their small overall size. This wide variety in cortex and small size of sometimes poor cobbles indicates that the knappers at Sugar Mill did not select specificly large or high grade flint nodules, as, for example, was done by the Preceramic Age knappers at Flinty Bay. Such behaviour might be related to the expedient nature of the reduction at Sugar Mill, aimed at the production of flakes for use as ad-hoc tools, as was the case at Jumby Bay.

Only 3.5\% of the Sugar Mill flakes possess use retouch, and one artefact was found with intentional retouch around a steep angled edge. This specimen probably functioned as a scraper. The percussion tool was a hard hammer, evidenced by clear percussion points and pronounced cones. The flaking technique was predominantly direct freehand percussion, although $9.3 \%$ of the flakes exhibit features that indicate bipolar reduction. For the flake cores this percentage is even higher, $35.7 \%$. Many of the flake cores are small in size, suggesting that this flaking technique was applied during the later stages of reduction.

It is very unlikely that cores were systematically pre-worked at Sugar Mill for further transport, considering the relative high number of cores. The ratio of flakes/cores is around 15:1. The presence of some hardly reduced cobbles with only a few scar negatives, is responsible for this low ratio value; these were probably tested and discarded without much flaking on them.

Looking at the proportions of cortical flakes the percentage of non-cortical flakes is relatively small, only $30 \%$ (table 4.9). This can imply three things: (a) the reduction of cores was not done exhaustively; (b) only small cobbles were reduced; or (c) tertiary flakes were transported to other locations. The presence of a few hardly reduced small cobbles suggests that a combination of (a) and (b) is responsible for these low frequencies of tertiary flakes. Jeff Walker (1980a) also found similar

\begin{tabular}{lrr}
\hline cortex count & $\mathbf{N}$ & $\mathbf{\%}$ \\
\hline $0 \%$ & 20 & 30.0 \\
$1-24 \%$ & 21 & 30.4 \\
$25-49 \%$ & 10 & 14.5 \\
$50-74 \%$ & 9 & 13.0 \\
$75-99 \%$ & 5 & 7.2 \\
$100 \%$ & 4 & 5.8 \\
\hline total & 69 & 100.0 \\
\hline
\end{tabular}

Table 4.9. Sugar Mill. Cortex count on complete flint flakes excluding one possible pre-Ceramic artefact. 
proportions during his reduction experiments using small St. Kitts nodules. However, if larger nodules were also reduced at Sugar Mill, which cannot be completely excluded, then it is likely that some tertiary flakes were transported from this site to other localities.

\section{Other stone and coral}

The number of other stone materials is small compared to flint at Sugar Mill. Materials include limestone, calcite, and igneous rock. Limestone is present in the highest number, including 35 flakes and 1 core piece. As is the case with Jumby Bay, it is difficult to specify the purpose of working the limestone. The absence of indicative core artefacts is primarily responsible for this. The only core-specimen present is a limestone cobble with one flake removal. Again, this raises the question whether we are dealing with the debris of a specific separate production or with the debris belonging to the testing and initial reduction of flint cobbles, during which occasionally limestone pieces were tested as well. The latter option is quite possible, considering the close resemblance of many of the limestone flakes to the cortex of the flint, and the high percentage of outer surface on the dorsal face.

The only calcite piece has a crystal structure, on which modification is difficult to identify. Use of this piece may be related to bead making, as suggested for similar material from the Jumby Bay site. The remaining artefact is an elongated igneous pebble used as a hammerstone. Unlike Jumby Bay where flint pebbles were used for this purpose, Sugar Mill has not produced any such specimen, apart from only a few unused specimens.

Among the coral material, a small number of the pieces exhibit traces of usage in the form of abrasion (table 4.10). Similar to Jumby Bay, Acropora cervicornis and Porites sp. are the predominant species used as tools. In contrast to Jumby Bay, Acropora palmata is much more rare. Among the Acropora cervicornis artefacts the abrading type of tool, exhibiting abrasion on a single face, outnumbers the drill-type. However, among the former tools, use-wear is less pronounced and in some cases more doubtful than among the latter type. This accounts as well for the Porites sp. rasps, which predominantly display minor abrasion. The two Acropora palmata artefacts both display use-wear on one of the single flat faces, suggesting utilization as grinding or abrading tools.

\section{Summary}

Archaeological fieldwork at Sugar Mill resulted in the discovery of a restricted area where refuse was deposited, mainly in the form of shell debris, flint, and pottery. This area likely belonged to small-scale settlement activities on Long Island. A dated sample suggests occupation sometime between AD 1300 and 1400, which is later than the settlement at Jumby Bay. Similar to Jumby Bay, activities At Sugar Mill were related to the use of local resources. Shell and bone remains point to the exploitation of the rocky inter-tidal habitat close to the shore and commonly available around the island. Flint exploitation and working was primarily related to purposes on site, and cannot be associated with systematic pre-working of material for transport to or exchange with other sites.

\subsubsection{Buckley Bay}

Alexander Verpoorte $(1993,51)$ mentions the occurrence of pottery, along with shell, coral and flint at "sample area 36 " near Buckley Bay (see figure 4.1; Van Gijn 1996, fig.2). The overall dimension of the scatter of the finds there is reported to be 30 by $30 \mathrm{~m}$, with a modest concentration of archaeological material. Upon arrival during the 2000-campaign, major construction activities had taken place near this scatter. At the east side closer to the coast, a house has been built including the pavement of a drive-way, that runs along the south side of the scatter. In the area of the previous finds, the land had been cleared for future gardening. With this clearing, approximately $25 \mathrm{~cm}$ of topsoil had been removed, as is evident by the higher level of the ground surface around several large trees, that were left standing. Despite the removal of topsoil, archaeological material is still lying on the surface. Low concentrations of pottery, coral, shell and flint were identified.

As some archaeological material was still present, six $0.5 \times 0.5 \mathrm{~m}$ shovel test pits were excavated at locations where surface material was most abundant to see if any in situ archaeological deposits could be identified. In addition, the surface was inspected for the presence of pottery as relative dating material. 


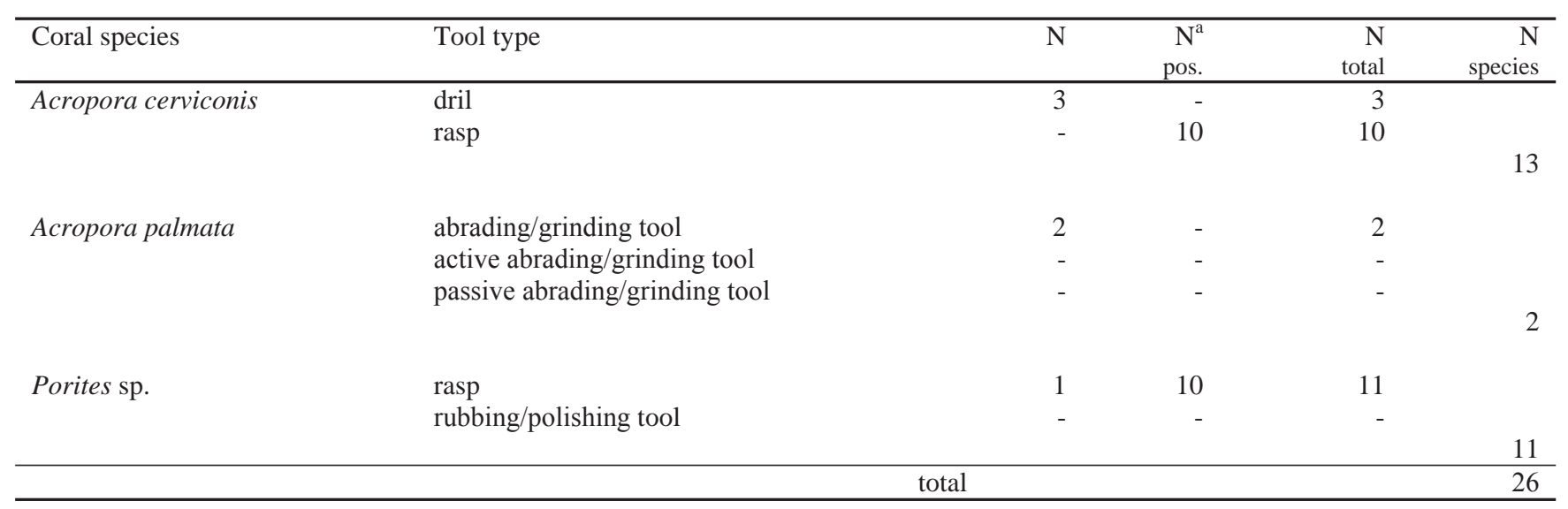

Table 4.10. Sugar Mill. Number of identified coral tools by species from test-unit and shovel excavations. a Tabulates possible artefacts, for which use-wear is not very pronounced.

The subsurface tests showed that true midden deposits or clear distinct occupation layers are no longer present. The western area of the present surface scatter did not produce any finds. A sterile deposit of grey clay is the topsoil at this point. More to the east the topsoil consists of dark humic sandy clay, $25 \mathrm{~cm}$ thick with low concentrations of artefacts throughout the layer. This covers a sterile fine-grained chalk dust layer, which is the weathered top layer of the chalk bedrock. This dispersed distribution of finds suggests a mixed horizon, likely a plough-zone or the base of one.

The collected pottery sample is very small, including only 44 sherds from the shovel excavations and an additional 26 pieces from unsystematic surface collections. This small sample limits proper comparison with other samples in the region. The pottery sample basically consists of undecorated and crudely finished sherds. No decorated pottery was excavated from the test pits and the surface collecting yielded only one body sherd with broad line incision. In addition, five sherds from the test pits, $11.4 \%$ of the total, and one sherd from the surface have red slip. The presence of broad line incision and relative crude finishing of most of the undecorated sherds suggest a post-Saladoid attribution. Both the local Mill Reef and later Mamora Bay styles include such broad line incision, which especially became an important decoration mode during the latter one (Nicholson 1994). Based on this, the site must be dated somewhere between AD 600 - 1200.

The sample of flint collected from this site is also very limited. The shovel test pits produced mostly naturally broken, fire cracked and un-worked cobbles. Between 15 to $25 \%$ was classified as true artefacts. The number of diagnostic core artefacts, which provide some data on type of technology, is small. Most of the cores are either shapeless (see Appendix D for definition), possessing only one or two flake removals, or multi-directional. These cores are rather small cobbles, not greater than $10 \mathrm{~cm}$. These characteristics suggest that only initial stages of flake core reduction are represented, as expected for the Ceramic Age date of this site. Verpoorte $(1993,51)$ also noted the high number of burnt and naturally broken flint pieces. However, he remarked that small flakes predominate among his collected sample, which is contradicted by my findings. This difference may be attributed to the recent post-depositional activities, since the site was less disturbed when he studied it.

Another difference concerns the finding of blade technology artefacts during the 2000-fieldwork. Within test pit 834.7, one clear patinated blade was recovered. In addition, two flakes, which are likely related considering their similar nature and degree of patination, were found in that test pit. In the view of the patination and blade technology, these artefacts can be ascribed to the Preceramic Age. More patinated artefacts, including blades were seen on the surface during the 2000campaign. On the contrary, Verpoorte explicitly states that blades or blade related materials were absent within the surface scatter that he inspected. This difference likely is attributed to one of the following reasons: (a) blade material was originally present in the deeper strata and therefore was not seen by the 1989-team; (b) recent construction activities after 1989 have disturbed the site more than previously thought, and have completely mixed material from nearby surface scatters with site material to a considerable depth; or (c) the small sample studied by Verpoorte biased his results, making it likely that the low percentage of blade material was not identified. Of these three possibilities, at least the second one probably can be excluded, as material seems only to have been removed and not added to the site. Furthermore the test pits excavated do not indicate 
that the topsoil was completely disturbed and mixed very recently, in this case only one to three years ago. In relation to the first and third possibilities, it is more difficult to decide how they may be relevant.

Based on this, we can assume that the Buckley Bay site is a multi-component one, with a mixture of Preceramic and Ceramic Age occupation remains. However, this disregards the possibility that the Preceramic Age blades, which are abundantly available locally, might have been collected by Ceramic Age settlers and used without modification. Such behaviour has been suggested for the occurrence of true "Preceramic" Age blades within Ceramic Age archaeological contexts at Muddy Bay (De Mille 1996) and Royall's (Murphy 1999). As Buckley Bay lacks intact archaeological deposits now, such re-use is difficult to prove or disprove. In any case, the Muddy Bay and Royalls examples only concern a few individual pieces out of a sample of a few hundred and these bear signs of re-use in the form of secondary working, while here the proportion is higher, and the artefacts do not display any evidence of re-use. Since blade material is abundantly present on this part of the island Preceramic Age evidence at Buckley Bay can likely be related to these occurrences. This suggests that material from at least two distinct periods of occupation are mixed at this site.

In addition to these artefacts, the test pits yielded subsistence debris in the form of shells, a few animal bones, and some crab fragments. Only the shell were classified into species and counted. Keeping in mind that the amounts of shell are relatively small, the major species by MNI include Nerita tessalata, Nerita versicolor, Tectarius muricatus, Chama species, Donax denticulatus, Cittarium pica, Arca zebra, and Strombus gigas (table 4.11). The majority point to the exploitation of a rocky littoral zone, whereas Donax denticulatis indicates collecting on a sandy littoral zone and the Strombus gigas suggests exploitation of sea grass beds (Murphy 1996; Nieweg 2000). These zones are well represented near Long Island. Comparing these species with the most common species within the Sugar Mill and Jumby Bay sites shows that although all samples are similar in types of species, proportions differ at Buckley Bay. At Buckley Bay, gastropods form the most important shells, such as the Nerita, Cittarium and Strombus species, whereas at Jumby Bay and Sugar Mill bivalves predominate and the gastropods only make up a small part of the total sample. Considering this predominance of gastropods, the shell debris is likely related to the Ceramic Age component of this site, as during the Preceramic Age shell exploitation was mainly directed toward collecting bivalves (Brokke 1996). Furthermore, this predominance resembles shell collecting behaviour of early Ceramic Age sites on the main island of Antigua and elsewhere (Brokke 1999a; Murphy 1999; Taverne \& Versteeg 1992), but also some Late Ceramic Age sites (Nieweg 2000). This difference is likely the result of changing preferences, if it is assumed that shell-fish availability was similar for the occupants of different sites on this small island. This may suggest that the occupation at Buckley Bay occurred at a different time than at Jumby Bay and Sugar Mill, probably earlier. Combined with the pottery characteristics, an early Late Ceramic A date is most probable for Buckley Bay.

My concluding remarks remain limited for this site, due to the absence of intact archaeological deposits. The collected materials suggest that this location was probably used both during the Preceramic and the Ceramic Ages, likely the later phases. Post-depositional processes such as ploughing and plant growth first disturbed the original deposits and mixed up finds from different periods. Disturbance was continued by recent land clearing and removing of part of the topsoil.

Most activities during the Preceramic Age were probably related to flint working and are similar to those at many other flint scatters distributed across this part of the island. For the Ceramic Age, the co-occurrence of pottery, flint, coral, shell, and animal bone suggests settlement at this location. These activities must have been very small-scale and short-term, based on the small distribution originally seen by the 1989-team, the dispersed nature of the finds identified in 2000, and the absence of a concentrated midden deposit. A one-time campsite is a likely possibility for the Ceramic Age. The small sample of flint material suggests only initial reduction of poor quality cobbles. There is no indication that specific items were taken elsewhere.

\subsection{4 "Site 32"}

The Leiden team discovered a relatively elongated surface scatter of flint material, pottery, and shell remains, approximately $240 \mathrm{~m}^{2}$ in size, along the south side of an unpaved road near Cistern Point in 1989 (see figure 4.1; Van Gijn 1996; Verpoorte 1993). ${ }^{14}$ Threatened by new road construction, the team decided to systematically collect all material from the surface in $1 \times 1$ $\mathrm{m}$ squares and excavate a $1 \mathrm{x} 1 \mathrm{~m}$ test-unit for establishing the depth of the cultural deposits. The subsoil testing confirmed the

\footnotetext{
14 Desmond Nicholson told me that a group of students worked on the locality of "Site 32" in 1972 as part of a Proctor Academy summer camp (Nicholson personal communication 2000). Unfortunately, I was not able to study reported results and therefore this work is left out of this discussion.
} 


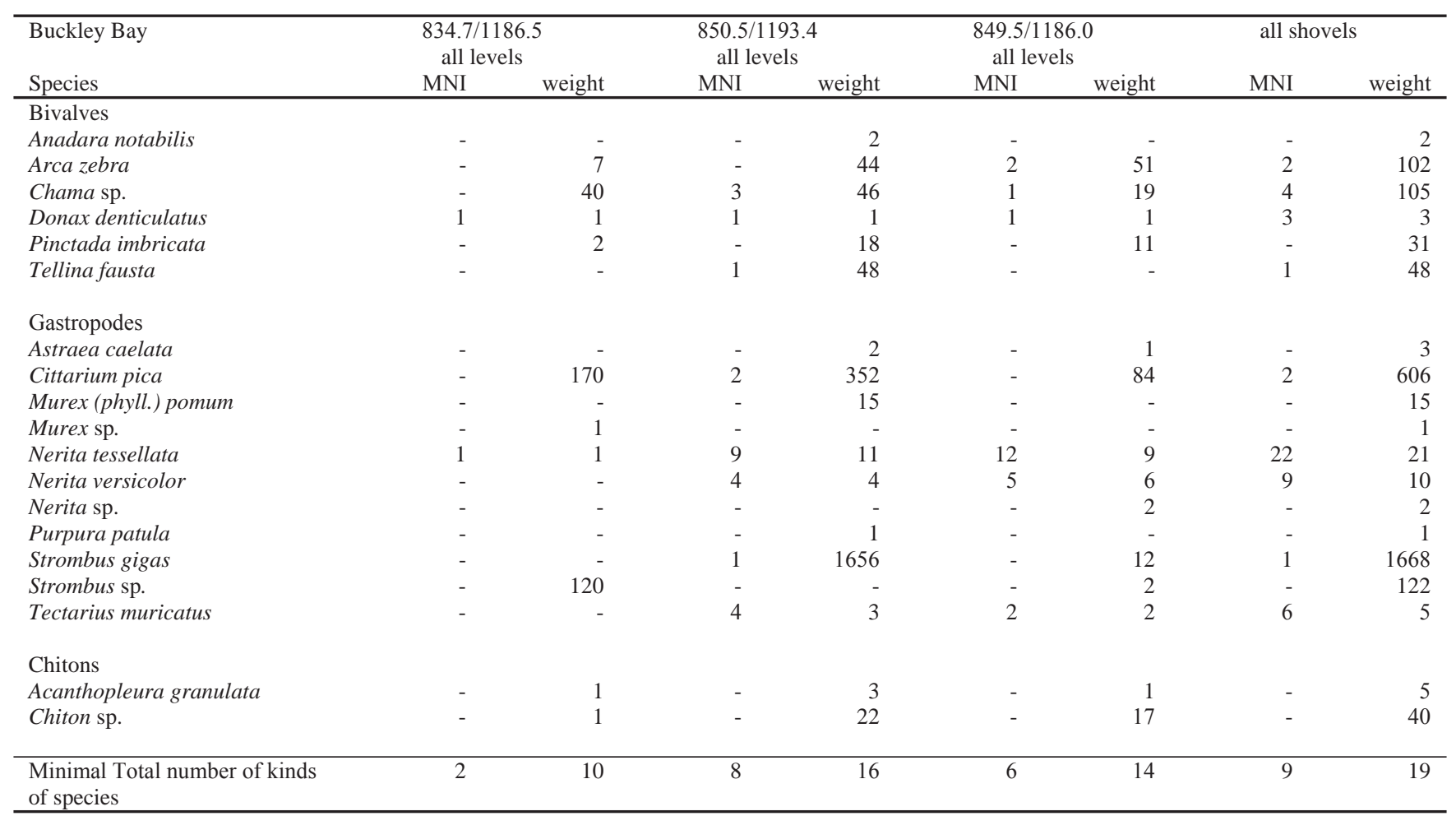

Table 4.11. Buckley Bay, Long Island. MNI and weight (g) of shell remains by species and by shovel.

earlier assumption that material was largely located on the site surface.

Upon my re-visit in 2000, significant construction activities were evident in the area. A new road was paved on the track of the former one. This construction also incorporated some digging work for widening and laying out road foundations. In addition to the road construction, a pipeline for water transport had been laid out in the site area. After close inspection of the site surface it appeared that most of it had been destroyed, as indicated by recently disturbed topsoil. Only toward the southern border of the area were still low concentrations of flint identifiable, not extending more than $40 \mathrm{~m}^{2}$ in size. The subsoil seemed different in nature in this area, and may have remained undisturbed. Therefore two $0.5 \times 0.5 \mathrm{~m}$ shovel test pits were excavated. One test pit excavated within an undisturbed context produced hardly any finds, only a few flint artefacts were found. The other test pit yielded more flint artefacts, but the topsoil was very loose and most probably thrown up. Both test pits did not produce any pottery and shell remains were almost absent. From these findings it is clear that recent construction activities basically destroyed this site and only a very low artefact concentration remained in the southern area.

This situation means that the data from Van Gijn's article and Verpoorte's thesis are the only information available for "Site 32" (Van Gijn 1996; Verpoorte 1993). They both reported that this locality was probably a multi-component site. The co-occurrence of pottery, small in number, and blade production strongly points to this. In addition, an expedient flake tool technology, and shell remains, including two conch celts, were identified. Due to its shallow nature, the different site components could not be separated on the basis of stratigraphy. Verpoorte attempted to distinguish the different flint technologies on basis of raw material choice. Hampered by the patinated nature of the artefacts, he still could see an association of blades and blade cores with what he called "raw material unit 1" (RMU 1). Some flake cores were also assigned to RMU 1, and they were interpreted as "failed pre-worked blade cores" (Verpoorte 1993, 43). Most artefacts could not be grouped to a specific RMU due to patination, but they exhibited mutually similar characteristics and therefore, were considered to represent an undefined RMU (nr.9). A small portion of the sample was classified to RMU 2, a raw material originating from the hard ledges near Buckley Bay, basically consisting of brown coloured small sized nodules (Verpoorte 1993, 24). Unfortunately no core artefacts were included in the small RMU 2-group. The absence of blades within this RMU, minimally suggests that this material was not used for blade production. 
After having studied a sample from the 1989 collected material more closely, Verpoorte $(1993,48)$ concluded that the debris can be ascribed to two types of technologies. One is related to the production of blades, of which a part exhibits traces of use-wear that suggests use at the site and the other is an expedient flake tool technology, including many small, almost exhausted cores. The first sequence is associated with RMU 1, while the second probably includes RMU 2, among other raw materials. Verpoorte noted that the specific blade production is different from the one found at Flinty Bay with respect to reduction stage. At Flinty Bay, the high proportions of artefacts suggesting initial reduction, such as primary blades, secondary blades, and core caps, sharply contrast with the proportions found at "Site 32", where core caps are scarce and tertiary blades predominate. Therefore, "Site 32 " is interpreted as an occupation site where flint was worked for local use, whereas Flinty Bay can be considered as a flint workshop site, solely for the preparation of blade cores that were further transported elsewhere. The flake tool technology at "Site 32" exhibits a similar exhaustive use of material indicated by the small flake cores. In this respect, both technologies suggest reduction for local use.

Not being able to spatially separate both technologies and unfamiliar with Ceramic Age flake tool production, Verpoorte did not assign the samples to specific occupation periods (Verpoorte 1993, 48; Van Gijn 1996, 190-1). With the new available data from Ceramic Age sites, Jumby Bay and Sugar Mill on Long Island, as well as experience with Ceramic Age flint working on surrounding islands, I have tried to date the material. I inspected part of the material stored at Leiden University to do this. This examination did not involve systematic coding of artefacts, but was addressed toward qualitative aspects of the sample. ${ }^{15}$

From this re-study of the material, I conclude that the blade technology artefacts and the majority of the flake technology artefacts must be ascribed to the Preceramic Age. Only a very small portion, likely to be less than $10 \%$, can be assigned to the Ceramic Age. The following arguments were decisive in this assignment. First, most artefacts are patinated. As all artefacts from the Jumby Bay and the Sugar Mill site do not exhibit such patination, this suggests that either artefacts at "Site 32" were exposed to weathering processes for a considerable longer time, or that the weathering processes operating at "Site 32" were different from those at the other two sites, resulting in a faster patination. Considering that non-patinated artefacts also occurred at "Site 32" and assuming that all artefacts at this site experienced the same weathering, this implies that the period of weathering was different for both groups (the patinated and non-patinated), and that the patinated ones thus originated from an older occupation. The technological features of the patinated artefacts provide additional support for this time differentiation. These features are different from those common among Ceramic Age flake technologies. Most striking characteristics of the patinated artefacts at "Site 32" are predominance of single to multifaceted striking platforms on flakes, pronounced bulbs of force, more regularity in flake shape, and larger average size of flake scars on the cores.

Within Ceramic Age flake technologies the use of the bipolar technique resulted in the formation of edged or pointed platforms, less pronounced bulbs of force, a large variety of flake shapes, and exhaustive use of the flake cores, often possessing very small flake scars and scars with hinged distal ends. A difference between Preceramic and Ceramic Age expedient flake tool technologies is also reported on St. Martin for the Preceramic Norman Estate site and the Saladoid Anse des Pères site (Knippenberg 1995). Recent study of Preceramic flaked stone assemblages from Barbuda further supports this difference (Watters 2001; Watters et al. in prep.). In general, it can be said that Preceramic expedient flake tool technologies exhibit more control in the reduction process, which can be likely attributed to the absence of the bipolar technique. When examining the few non-patinated cores from "Site 32" with these characteristics in mind they exhibit more similarities to features associated with the Ceramic Age. This correlation between the presence and absence of patina and specific technological features supports the correlation between the degree of patination and age in the case of this site. ${ }^{16}$

Knowing that most flint artefacts are Preceramic in age, it is justifiable to ask how the co-occurrence of blade and flake technologies can be explained. There are a few possible solutions: (a) they were two different technologies serving different demands by the occupants of the site; (b) they belong to two different groups of people, possessing different kinds of stone working protocols; or (c) the flake technology represents the last stages of a reduction sequence that started as a blade technology. The evidence is too limited to provide any definite answer, but the co-occurrence of both technologies is not uncommon at Preceramic Age settlement sites on Antigua. For example, Davis reports such a situation for the Jolly Beach

\footnotetext{
15 As only a part of the original collected sample was taken to Leiden University, there was no use in quantitatively studying the remains. The sample that was inspected included the excavated test unit (Verpoorte 1993), the only unit that was completely shipped to Leiden University, as well as some additional surface collected units to see if the findings from the excavated unit were consistent with the rest of the material. Furthermore, all cores were studied.

${ }^{16} \mathrm{I}$ am aware that this correlation is not a general one, as each site may provide different weathering conditions. Therefore within each context it should be tested anew.
} 
site, as well for Cistern Point, which is situated only 100 to $200 \mathrm{~m}$ from "Site 32" (Davis 2000). Although Davis does not specifically indicate whether this flake technology has to be considered apart from the blade technology, his size comparison of blade and flake cores suggests such a case, as both artefact categories are similar in this respect. Flake cores would have been smaller if they were to be associated with the last stages of reduction. On the other hand, Crock et al. (1995) present a case from Anguilla, Whitehead's Bluff, where they identified a flake technology, that likely started as a blade technology, indicated by blade-like scars on a small portion of the cores.

If we combine the limited data from "Site 32", the following probable scenario emerges. During the Preceramic Age, a group of foragers settled this location for a some period of time. Considering their exhaustive reduction of flint material, this stone was used for purposes on site that were related to habitation and subsistence activities, including shell-fish consumption. As such, this site must have been similar to the Cistern Point site excavated by Davis (1974) and interpreted as a small Preceramic Age settlement. During the Ceramic Age this location was also visited, but less extensive. As the amount of Ceramic Age associated flint material is small, and there are few ceramics, site activities must have been limited, i.e. short term camping, similar to Buckley Bay.

\subsubsection{Flint scatters in the eastern area of Long Island}

The 1989 field-campaign had put a lot of effort in mapping surface scatters of worked flint material on the eastern part of Long Island (see figure 4.1; Van Gijn 1996, fig. 2). Verpoorte (1993) listed these in more detail. Based on estimated proportions of cores, primary, secondary and tertiary flakes and blades, he categorised the scatters according to predominant reduction stage (Verpoorte 1993, 63). Scatters where cobble testing and initial reduction were performed made up the majority, while another significant group is formed by scatters where all stages of production are represented. Verpoorte mainly attributed these scatters to blade producing knappers, as evidence of systematic flake core reduction is scarce.

During the 2000-field campaign the previously listed scatters were hard to relocate due to dense and long grass covering most of the area. In addition, large areas in the middle of the island had been significantly disturbed, as evidenced by large erected piles of flint, likely attributed to land clearing. Certain scatters, however, were found and inspected in 2000. These confirmed the interpretations of Verpoorte.

In addition, transect lines, which were cleared in the eastern part of the island to designate plot boundaries, were field walked. Not hampered by any vegetation, these transects clearly affirmed the difficulties the 1989-team faced in distinguishing artefact scatters, as flint cobbles and artefacts are lying everywhere, with occasionally higher concentrations of material. Furthermore, the inspection of the cleared transects showed that blade related artefacts also exhibit this same overall distribution, suggesting that pre-working of this material was probably responsible for the majority of the artefact distributions. Evidence of systematic flake core reduction was not identified. Therefore, Verpoorte (1993) saw this distribution as typical of open quarry sites where people paid recurrent visits to collect, test, and pre-work material, leaving a "back ground noise" of flint debris widely scattered.

If any occasional pre-working of flake cores had taken place within this area, it would be very difficult to ascertain considering the disturbed nature of the area in which ploughing affected the original artefact distribution and the fact that the overall presence of blade working makes it hard to isolate flake production from it. In any case, it is clear from the 1989 survey and my own inspections that there is no evidence of systematic flake core preparation or reduction within this part of Long Island, as was found at Flinty Bay for blade core preparation.

\subsection{DisCUSSION OF RESULTS}

The data presented above and elsewhere (Davis 1974, 2000; Hoffman 1963; Nicholson 1974, 1976; Olson 1973; Van Gijn 1996; Verpoorte 1993) enable me to provide a general picture of flint working activities on Long Island through time. An extraordinary case exists there in that the least known period within the Lesser Antilles, the Preceramic Age, is relatively well represented and documented on this small island. Based on the assumption that blade industries are Preceramic in age, an assumption well shared among Caribbean archaeologists (e.g., Keegan 1994; Rouse 1992; Veloz Maggiolo 1991), a number of Preceramic Age localities have been identified on Long Island. As true sites, Cistern Point, "Site 32", and Flinty Bay are so designated. At the former two, the co-occurrence of subsistence remains in the form of shells and animal bone, and blade technology flint debris suggests local settlement of Preceramic Age shell fish collectors and fishermen on the island. Flint was worked for local use at these sites. Flinty Bay only produced flint debris and has been interpreted as a flint workshop 
site. The high percentage of primary and secondary blades, the absence of retouched implements, and the presence of many blade cores, most of which bear some sort of flaw, is supportive of the interpretation that blade cores were pre-worked at this locality for transport elsewhere (Van Gijn 1996, 191-3). Furthermore, small variation in the size of the blades and platforms, as well as among flaking angles, all suggest a large degree of standardisation within this technology (Verpoorte 1993).

For the subsequent Early Ceramic Age (400 BC - AD 850, Phases 2 and 3) there is an absence of clear evidence. Typical Saladoid ceramics have not been found on Long Island. Despite similarities in shell collecting behaviour at Buckley Bay to some Saladoid sites, including the Antigua site of Royal's, this site was more post-Saladoid-like in its pottery characteristics. Furthermore the identified flint scatters do not suggest that Ceramic Age knappers performed systematic reduction at their workshop sites. Still, it cannot be excluded that some of the scatters with evidence of raw material testing might be attributed to Early Ceramic Age knappers. However, in these cases it will not be necessarily possible to distinguish between Early Ceramic and Late Ceramic Age activities, bearing in mind the similar technologies that were employed throughout the whole Ceramic Age (see Chapter 5). It is also important to note that on the nearby island of Antigua there are still few known Saldoid sites relative to Preceramic and Late Ceramic Age sites (cf. Davis 1982, 2000; Murphy 1999).

In contrast to an apparent absence of evidence of Saladoid activities on Long Island, the Late Ceramic Age (Phases 4 and 5) has demonstrated settlement activities at Jumby Bay and Sugar Mill, at least sometime between AD 1100 and 1400. Occupation might have occurred earlier at Buckley Bay, and "Site 32". Generally this was small-scale settlement, although Jumby Bay can be considered a site of some significance. As Long Island lacks permanent natural water sources, it is puzzling that people settled there at all. This immediately raises the question whether we are dealing here with more permanent forms of settlement or with short-term visits to Long Island. The dispersed scatters of archaeological remains and their restricted distribution at Buckley Bay and "Site 32" as well strongly suggest the latter option. Jumby Bay and Sugar Mill, however, are larger sites with a high find density. So, it can be concluded that settlement must have been more extensive at these latter sites than at Buckley Bay or "Site 32". This may have been the result of a longer period of occupation or a larger group of people inhabiting these sites. As we do not possess information on dwelling structures, we must solely rely on size of the deposits. When compared to other sites on the main island of Antigua, the Long Island sites are relatively small. For example, at the settlement of Muddy Bay, which likely is contemporary with one of the sites on Long Island, a thick shell midden was identified, that covers an area of nearly $20000 \mathrm{~m}^{2}$ (Murphy 1999, 222). From this it seems justified to consider the Jumby Bay and Sugar Mill sites, either as a short term occupied sites or a repeatedly visited campsites. The clear discrepancy in dates between the Jumby Bay (1035 - 1275 cal AD) and Sugar Mill (1291 - 1421 cal AD) sites suggests that occupation on the island remained small-scale with habitation activities at only one site at a time, probably relating to the minimal basic resources that were provided.

Assuming this short-term settlement on Long Island, one may wonder what the purpose was of being there. It is quite clear from the present study that Long Island flint was highly valued as raw material for flake tool production in this region, as is evidenced by its wide distribution among the surrounding islands (see Chapters 5 and 6). Therefore Long Island must have been visited many times for exploiting this fine-grained material. From the above discussion, it is clear that during the Ceramic Age these exploitation activities did not leave any evidence in the form of pre-working raw material in the areas of natural raw material distribution and related habitation sites. Flint was probably collected and mainly exported from the island in unmodified form at this time.

If the settlement activities cannot be related to flint reduction activities, how then can we explain their occurrence on Long Island? Based on the available evidence from the shovel test pits and other excavations, shell collection and fishing seem to have played a significant role. One would be inclined to suggest that local settlement might have been related to the abundance of shells and fish in the surrounding waters. During the Ceramic Age, an increase in reliance on marine resources is noticed through time and it is especially apparent within the Late Ceramic Age (Petersen 1997). The beginning of this period marked a considerable increase in the number of sites on the various local islands, such as for example Anguilla, Nevis, and la Désirade (Crock 2000; Crock \& Petersen 1999; De Waal 1999a, 2006; Wilson 1989). Furthermore, we see the appearance of an overall distribution of sites on all regional islands, including ones that were formerly unoccupied (Crock 2000; Petersen 1997; Watters 1980). In such a scenario, where all primary resource areas have become occupied, the settlement of less desirable small islands, with no fresh water resources but situated within shell and fish rich areas is easily comprehensible and this may in part pertain to Long Island. These settlements must then be considered as a means to guarantee subsistence returns in situations where demands on surrounding environments became considerable larger.

Another possible scenario relates to the presence of flint in a more indirect manner. In this scenario, the settlement is seen as some sort of outpost from where the source of valued material was controlled, or guarded. There are numerous 
examples from ethnography that mention the territorial control of local resources (e.g., McBryde 1984). Such control has effects on the access to local raw materials, which would become more restricted. Whether the settlement at Jumby Bay, Sugar Mill, or Buckley Bay was associated with local resource control is difficult to prove by analysing the data from these sites alone. The small scale of the archaeological investigations at each makes it very difficult to find evidence to support such an explanation. It can be even doubted whether such control would leave specific evidence on Long Island itself, if it only concerned small camps where people stayed and guarded the lithic source. It would be more rewarding to study this from a regional perspective. If it indeed was the case that Long Island became controlled by a specific community during the Late Ceramic Age who limited access to it, then this should become visible by changes in distribution of the material and changes in degree of its use at sites further away (Torrence 1986; see below). 


\section{$5 \quad$ Stone acquisition and working at habitation sites}

\subsection{GEOLOGY AND OCCURRENCE OF ROCK MATERIALS}

In this section, particular attention is paid to raw material occurrences on the various islands within the northern Lesser Antilles in a more general sense, to complement the description and characterisation of the three rock varieties in Chapter 2. It should be read as an introduction to the following sections, in which I present a diachronic picture of stone procurement and use at different habitation sites.

From a geological point of view the Caribbean can be basically divided into the Greater and Lesser Antilles (see figure 2.3) (Draper et al. 1994). The Greater Antilles possesses a relatively longer geological history during which volcanism, marine sedimentation, and metamorphism all have played a significant role. The Lesser Antilles are generally much younger. Among this group of small islands, the rock material provenances can be meaningfully distinguished between the islands of the younger inner volcanic arc and older outer volcanic arc (see figure 2.4). This division groups the predominantly volcanic islands on the inner arc together on the one hand, including the following islands relevant to this study: Saba, St. Eustatius, St. Kitts, Nevis, Montserrat, Basse Terre (Guadeloupe), Les Saintes, Dominica, and Martinique. ${ }^{1}$ The more complex outer arc islands include Anguilla, St. Martin, St. Barths, Barbuda, Antigua, Grande Terre, and Marie Galante. La Désirade belongs to neither of the arcs. This latter island is much older in age and its formation is not related to the Lesser Antilles arc volcanism.

Tables 5.1a and b list rock material occurrences for each island. It is clear that among the inner arc islands less variation exists among rock types. These islands are predominantly volcanic in nature, in which igneous rock types fall within the calc-alkaline group. The major occurring rock variety is porphyritic andesite, in addition to minor amounts of basalts, basaltic andesite, dacite, and rhyolite (Rea \& Baker 1980; Smith et al. 1980). Based on differences in the occurrences of the latter rock types, three groups of islands can be distinguished. One group comprises Saba, St. Eustatius, and Nevis, which almost lack basalt rocks. St. Kitts and Montserrat form the second group, with significant basalt occurrences, related to the Mt. Misery and South Soufriere eruption centres. The third group includes Basse Terre, Dominica, and Martinique, which possess higher proportions of more acidic rock types, such as rhyolites and dacites (Rea \& Baker 1980).

Apart from these igneous rock types, on most islands rare limestone deposits are found, varying in size. The Brimstone Hill Formation on St. Kitts and the White Wall Formation on St. Eustatius, as well as Miocene limestone depositions on Martinique are the best-known and most extensive examples of such non-volcanic occurrences of limestone. Most of the other inner arc islands display at least minor limestone deposits as well.

An additional feature of concern to the present study relates to the longer geological history of Martinique relative to its northern volcanic neighbours. As a result of several episodes of volcanic activity, the oldest igneous rock series on Martinique have been exposed to hydrothermal alteration during later phases, changing original rock composition in these areas. This hydrothermal alteration has produced jasper, chalcedony, and other quartz crystal varieties inter-veined or included within the original igneous rock (Bérard \& Vernet 1997; Westercamp \& Tazieff 1980). Other local quartz or micro-quartz crystal varieties occurring as isolated inclusions are known on Dominica as well (Honeychurch 1995, personal communication 2000). Additional occurrences of such materials may not be excluded, given the often isolated occurrence of these crystal varieties and crystals in general, combined with sometimes limited geological work done on the islands.

The outer arc islands and La Désirade exhibit more variability in rock types, not only on an inter-island but also on an intra-island level. The outer arc islands can broadly be divided into the limestone Antilles, and the composite islands. The former group includes islands that are almost exclusively built-up by a series of limestone deposits. These include Anguilla, Barbuda, Grande Terre, and Marie Galante. The composite group of islands possess more complex geological regions, which can be either volcanic or marine in origin. This group includes St. Martin, St. Barths, Antigua, and La Désirade. ${ }^{2}$

Comparing the limestone Antilles shows that most of them are not totally built up by limestone, but also have isolated outcrops of underlying igneous rock, volcanic debris or tuffs, as is the case for Anguilla, Marie-Galante, and Grande Terre. Furthermore the limestone formations on the different islands vary in nature and age, and must be related to deposition

\footnotetext{
${ }^{1}$ Only islands the area from Puerto Rico to Martinique are discussed.

${ }^{2}$ Usually, the whole group of outer arc islands are referred to as limestone Antilles, given the presence of extensive limestone formations on all of them.

However, I reserve this term for the islands almost exclusively consisting of limestone formations.
} 


\begin{tabular}{|c|c|c|c|c|c|c|c|}
\hline & Island & $\begin{array}{l}\text { Igneous and intrusive } \\
\text { rocks }\end{array}$ & $\begin{array}{l}\text { Carbonaceous } \\
\text { sedimentary rocks }\end{array}$ & $\begin{array}{l}\text { Other sedimentary } \\
\text { rocks }\end{array}$ & Metamorphic rocks & Other & References \\
\hline $\begin{array}{l}\mathrm{G} \\
\mathrm{r} \\
\mathrm{e} \\
\mathrm{a} \\
\mathrm{t} \\
\mathrm{e} \\
\mathrm{r}\end{array}$ & Puerto Rico & $\begin{array}{l}\text { basalt } \\
\text { andesite } \\
\text { porphyry } \\
\text { dacite } \\
\text { basalt porphery } \\
\text { basaltic andesite } \\
\text { quartz diorite } \\
\text { granodiorite } \\
\text { grabbo } \\
\text { serpetinite }\end{array}$ & $\begin{array}{l}\text { different types of } \\
\text { limestone }\end{array}$ & $\begin{array}{l}\text { bedded chert } \\
\text { mudstone } \\
\text { sandstone } \\
\text { tuff } \\
\text { conglomerate } \\
\text { breccia }\end{array}$ & amphibolite & $\begin{array}{l}\text { quartz } \\
\text { serpentine }\end{array}$ & $\begin{array}{l}\text { Volckmann } \\
1984^{\text {a, b, c }}\end{array}$ \\
\hline \multirow{7}{*}{$\begin{array}{l}\text { A } \\
\mathrm{n} \\
\mathrm{t} \\
\mathrm{i} \\
\mathrm{l} \\
\mathrm{l} \\
\mathrm{e} \\
\mathrm{s}\end{array}$} & Vieques $^{\mathrm{a}}$ & $\begin{array}{l}\text { igneous rock } \\
\text { andesitic tuff } \\
\text { (quartz) diorite }\end{array}$ & $\begin{array}{l}\text { different types of } \\
\text { limestone }\end{array}$ & - & - & quartz & Meijerhoff 1926 \\
\hline & St. Thomas & $\begin{array}{l}\text { keratophyres } \\
\text { spilite } \\
\text { porphyry } \\
\text { volcanic wacke } \\
\text { tuff } \\
\text { diorite }\end{array}$ & siliceous limestone & $\begin{array}{l}\text { radiolarian tuff and chert } \\
\text { breccia } \\
\text { andesite breccia }\end{array}$ & $\begin{array}{l}\text { albite-epidote hornfels } \\
\text { hornblende hornfels } \\
\text { marble }\end{array}$ & jasper & $\begin{array}{l}\text { Alminas et al. 1994, } \\
\text { Donnelly } 1966\end{array}$ \\
\hline & St. John & $\begin{array}{l}\text { keratophyre } \\
\text { spilite } \\
\text { volcanic wacke } \\
\text { andesite breccia } \\
\text { tuff } \\
\text { breccia } \\
\text { pegmatite } \\
\text { diorite }\end{array}$ & $\begin{array}{l}\text { siliceous limestone } \\
\text { limestone }\end{array}$ & radiolarian tuff and chert & $\begin{array}{l}\text { calcic bytownite-hornblende } \\
\text { albite-epidote hornfels } \\
\text { hornblende hornfels }\end{array}$ & $\begin{array}{l}\text { turquoise } \\
\text { barite } \\
\text { alunite } \\
\text { jarosite } \\
\text { quartz }\end{array}$ & $\begin{array}{l}\text { Alminas et al. 1994, } \\
\text { Donnelly } 1966\end{array}$ \\
\hline & Tortola & $\begin{array}{l}\text { basaltic anglomerrate } \\
\text { andesitic- anglomerate } \\
\text { (porphyritic) basalt } \\
\text { volcanic breccia } \\
\text { chert-like basalt } \\
\text { bedded tuff } \\
\text { diorite } \\
\text { tonalites (grabbo to diorite) } \\
\text { dolerite (diabase) }\end{array}$ & $\begin{array}{l}\text { coarse recrystallized } \\
\text { limestone }\end{array}$ & $\begin{array}{l}\text { ashy mudstone } \\
\text { porcellanitic rock } \\
\text { chert }\end{array}$ & marble & $\begin{array}{l}\text { felsite* } \\
\text { quartz veins }\end{array}$ & $\begin{array}{l}\text { Martin-Kaye 1959, } \\
\text { Earle } 1924\end{array}$ \\
\hline & Virgin Gorda & $\begin{array}{l}\text { diorite (tonalite) } \\
\text { pegmatite }\end{array}$ & siliceous limestone & - & $\begin{array}{l}\text { amphibolite* } \\
\text { (pyritiferous) -quartzite* } \\
\text { granulite* } \\
\text { slate } \\
\text { phyllite } \\
\text { amphibolitic and feldspathic } \\
\text { flagstone* } \\
\text { felsitic rock } \\
\text { epidosite } \\
\text { hornblendic rock } \\
\text { recrystallised limestone } \\
\text { schist } \\
\text { marble }\end{array}$ & $\begin{array}{l}\text { garnet } \\
\text { quartz } \\
\text { malachite } \\
\text { chalcopyrite } \\
\text { copper } \\
\text { molybdenite } \\
\text { haematite }\end{array}$ & $\begin{array}{l}\text { Martin-Kaye 1959, } \\
\text { Earle } 1924\end{array}$ \\
\hline & Anegada & - & $\begin{array}{l}\text { gray, cream, yellow } \\
\text { limestone }\end{array}$ & - & - & - & Martin-Kaye 1959 \\
\hline & St. Croix & $\begin{array}{l}\text { grabbo } \\
\text { grabboic diorite } \\
\text { basaltic-andesite- porphyry } \\
\text { (augite)-hornblende } \\
\text { diabase } \\
\text { pyroxene porphyry } \\
\text { dacite }\end{array}$ & $\begin{array}{l}\text { coral limestone } \\
\text { (tuffaceous) limestone } \\
\text { marl } \\
\text { beach rock }\end{array}$ & $\begin{array}{l}\text { montmorillonitic mudstone } \\
\text { bedded chert } \\
\text { (tuffaceous) mudstone } \\
\text { volcanic sandstone } \\
\text { tuffaceous sandstone } \\
\text { volcanic conglomerate } \\
\text { (including spilite and } \\
\text { keratophyre) }\end{array}$ & $\begin{array}{l}\text { pyroxene hornfels } \\
\text { hornblende } \\
\text { albite-epidote } \\
\text { hornfels } \\
\text { turbidite* }\end{array}$ & barite & $\begin{array}{l}\text { Alminas et al. 1994, } \\
\text { Lidiak \& Jolly } \\
\text { 1998, } \\
\text { Whetten } 1966\end{array}$ \\
\hline
\end{tabular}

Table 5.1a. Rock material occurrences by island within the Virgin Islands and Puerto Rico. Data have been derived from geological reports. In a few occasions archaeological reports and personal observations provided additional information on rock material occurrences. ${ }^{a}$ Literature on the geology of Vieques is incomplete and rarely reports rock type occurrences.

Table 5.1b (opposite page). Rock material occurrences by island within northern Lesser Antilles. Data have been derived from geological reports. In a few occasions archaeological reports and personal observations provided additional information on rock material occurrences. 


\begin{tabular}{|c|c|c|c|c|c|c|c|}
\hline & Island & $\begin{array}{l}\text { Igneous and intrusive } \\
\text { rocks }\end{array}$ & $\begin{array}{l}\text { Carbonaceous } \\
\text { sedimentary rocks }\end{array}$ & $\begin{array}{l}\text { Other sedimentary } \\
\text { rocks }\end{array}$ & Metamorphic rocks & Other & References \\
\hline $\begin{array}{l}\mathrm{L} \\
\mathrm{e} \\
\mathrm{s}\end{array}$ & Anguilla & $\begin{array}{l}\text { basalt } \\
\text { andesite } \\
\text { tuff } \\
\text { tuff breccia }\end{array}$ & $\begin{array}{l}\text { different types of } \\
\text { limestone }\end{array}$ & - & - & & Christman 1953 \\
\hline $\begin{array}{l}\mathrm{S} \\
\mathrm{e} \\
\mathrm{r}\end{array}$ & St. Martin & $\begin{array}{l}\text { (quartz) basalt } \\
\text { andesite (porphyry) } \\
\text { quartz diorite } \\
\text { granite aplite } \\
\text { tuff (cherty, calcareous, crystal, } \\
\text { shaly, vitric, lithic) }\end{array}$ & limestone & $\begin{array}{l}\text { chert } \\
\text { calcareous chert } \\
\text { white, green, and dark green } \\
\text { chert-like material } \\
\text { recrystallised tuff } \\
\text { conglomerate }\end{array}$ & - & $\begin{array}{l}\text { jasper } \\
\text { quartz } \\
\text { manganese }\end{array}$ & $\begin{array}{l}\text { Christman 1953, } \\
\text { Bonneton \& Vila } \\
1983\end{array}$ \\
\hline $\begin{array}{l}\mathrm{t} \\
\mathrm{i} \\
\mathrm{l} \\
\mathrm{l} \\
\mathrm{e} \\
\mathrm{s}\end{array}$ & St. Barths & $\begin{array}{l}\text { quartz diorite } \\
\text { andesite porphyry } \\
\text { quartz diorite porphyry } \\
\text { dacite } \\
\text { basalt } \\
\text { basalt porphyry } \\
\text { breccia } \\
\text { (calcareous) tuff }\end{array}$ & $\begin{array}{l}\text { limestone } \\
\text { calcareous sandstone }\end{array}$ & silicified tuff & - & $\begin{array}{l}\text { malachite } \\
\text { limonite }\end{array}$ & Christman 1953 \\
\hline $\begin{array}{l}\mathrm{o} \\
\mathrm{u}\end{array}$ & Barbuda & - & $\begin{array}{l}\text { different types of } \\
\text { limestone }\end{array}$ & - & - & - & $\begin{array}{l}\text { Brasier \& Marther } \\
1975\end{array}$ \\
\hline $\begin{array}{l}\mathrm{t} \\
\mathrm{e} \\
\mathrm{r}\end{array}$ & Antigua & $\begin{array}{l}\text { quartz diorite } \\
\text { felsite } \\
\text { dacite porphyry } \\
\text { andesite } \\
\text { basalt } \\
\text { tuff } \\
\text { agglomerate }\end{array}$ & $\begin{array}{l}\text { different types of } \\
\text { limestone }\end{array}$ & $\begin{array}{l}\text { flint } \\
\text { chert } \\
\text { tuff }\end{array}$ & - & $\begin{array}{l}\text { carnelian } \\
\text { malachite } \\
\text { calcite } \\
\text { quartz } \\
\text { jasper } \\
\text { barite } \\
\text { silicified wood }\end{array}$ & $\begin{array}{l}\text { Martin-Kaye 1959, } \\
\text { Mascle \& } \\
\text { Westercamp 1983, } \\
\text { Murphy et al. 2000, } \\
\text { Weiss 1994; } \\
\text { Christman 1972 }\end{array}$ \\
\hline $\mathrm{C}$ & $\begin{array}{l}\text { Grande Terre } \\
\text { (Guadeloupe) }\end{array}$ & $\begin{array}{l}\text { tuff } \\
\text { volcanic debris }\end{array}$ & $\begin{array}{l}\text { coral limestone } \\
\text { calcarenite } \\
\text { beach rock }\end{array}$ & $\begin{array}{l}\text { calcareous tuff } \\
\text { conglomerate }\end{array}$ & & calcite & Lasserre 1975 \\
\hline & Marie Galante & tuff & coral limestone & - & - & - & $\begin{array}{l}\text { Andreieff et al. } \\
1983\end{array}$ \\
\hline $\begin{array}{l}\mathrm{L} \\
\mathrm{e} \\
\mathrm{s}\end{array}$ & Saba & $\begin{array}{l}\text { andesite } \\
\text { agglomerate } \\
\text { tuff }\end{array}$ & $\overline{-}$ & $\overline{-}$ & $\overline{-}$ & $\overline{-}$ & $\begin{array}{l}\text { Westermann \& Kiel } \\
1963\end{array}$ \\
\hline $\begin{array}{l}\mathrm{s} \\
\mathrm{e} \\
\mathrm{r}\end{array}$ & St. Eustatius & $\begin{array}{l}\text { andesite } \\
\text { pumice } \\
\text { rhyolite } \\
\text { diorite }\end{array}$ & $\begin{array}{l}\text { different types of } \\
\text { limestone }\end{array}$ & - & - & - & $\begin{array}{l}\text { Rea \& Baker } 1980 \\
\text { Westermann \& Kiel } \\
1963\end{array}$ \\
\hline $\begin{array}{l}\mathrm{A} \\
\mathrm{n} \\
\mathrm{t}\end{array}$ & St. Kitts & $\begin{array}{l}\text { basalt } \\
\text { basaltic andesite } \\
\text { andesite } \\
\text { rhyolite }\end{array}$ & $\begin{array}{l}\text { different types of } \\
\text { limestone }\end{array}$ & - & - & - & Rea \& Baker 1980 \\
\hline $\begin{array}{l}\mathrm{i} \\
\mathrm{l} \\
\mathrm{l}\end{array}$ & Nevis & $\begin{array}{l}\text { basaltic andesite } \\
\text { andesite } \\
\text { andesitic tuff }\end{array}$ & - & - & - & copper & $\begin{array}{l}\text { Martin-Kaye 1958a, } \\
1969\end{array}$ \\
\hline $\mathrm{e}$ & Montserrat & $\begin{array}{l}\text { basalt } \\
\text { basaltic andesite } \\
\text { andesite } \\
\text { andesitic pumice }\end{array}$ & calcerous tuff & - & - & - & Rea 1974 \\
\hline $\begin{array}{l}\mathrm{n} \\
\mathrm{n} \\
\mathrm{e} \\
\mathrm{r}\end{array}$ & $\begin{array}{l}\text { Basse Terre } \\
\text { (Guadeloupe) }\end{array}$ & $\begin{array}{l}\text { basalt } \\
\text { basaltic andesite } \\
\text { andesite } \\
\text { dacite } \\
\text { pumice }\end{array}$ & - & - & - & - & Lasserre 1975 \\
\hline \multirow{4}{*}{$\begin{array}{l}\mathrm{a} \\
\mathrm{r} \\
\mathrm{c}\end{array}$} & Les Saintes & andesite & - & - & - & - & Lasserre 1975 \\
\hline & Dominica & $\begin{array}{l}\text { andesite } \\
\text { andesite breccia }\end{array}$ & limestone & & & & Sigurdsson 1973 \\
\hline & Martinique & $\begin{array}{l}\text { basalt } \\
\text { tholeíite } \\
\text { andesite } \\
\text { dacite } \\
\text { tuff }\end{array}$ & $\begin{array}{l}\text { coral limestone } \\
\text { calcareous tuff }\end{array}$ & - & - & $\begin{array}{l}\text { amethyst } \\
\text { jasper } \\
\text { chalcedony } \\
\text { silicified wood } \\
\text { calcite }\end{array}$ & $\begin{array}{l}\text { Westercamp \& } \\
\text { Tazieff } 1980\end{array}$ \\
\hline & La Désirade & $\begin{array}{l}\text { basalt } \\
\text { rhyolite } \\
\text { tronjhemite } \\
\text { quartz diorite } \\
\text { plagiogranite }\end{array}$ & limestone & radiolarian chert & $\begin{array}{l}\text { meta-basalt } \\
\text { metatonalite } \\
\text { meta diorite } \\
\text { metadacite } \\
\text { metarhyolite } \\
\text { meta-andesite }\end{array}$ & copper & Bouysse et al. 1983 \\
\hline
\end{tabular}


of carbonate material on locally raised ocean floors or on top of erupted volcanic material.

Inter-island variability is also notable among the composite islands. La Désirade stands by itself in this repect. It is the oldest Lesser Antillean island, with basement rock predating the formation of the outer arc. Its formation is still debated: it either represents an "ophiolitic complex," "an orogenic series," or "a primitive island arc fragment detached from the eastern Greater Antilles" (Montgomery et al. 1992). The oldest rock, in the form of radiolarian cherts, dates to the Upper Jurrasic, that is ca. 161.2 - 145.5 million years ago. Other basement rock types include varieties of igneous rock and plutonic rock (quartz diorite) and slightly metamorphosed igneous rock types. Pliocene limestone deposits, similar in age to major limestone formations on neighbouring Grande Terre and Marie-Galante, overlie this basement on la Désirade.

Generally, the oldest rocks on the other composite islands relate to the era of outer arc calc-alkaline volcanic activity, which started during the Eocene, as is evidenced on St. Martin and St. Barths. Antigua, the other composite island, is somewhat younger in age, with Oligocene volcanic and plutonic rock. All three islands to some extent display a similar pattern of formation despite these chronological differences. The oldest rocks relate to periods of increased eruptive activities alternated with periods of marine sedimentation, resulting in predominantly non-carboneous marine bedded depositions (Pointe Blanche Formation on St. Martin, St. Barths Formation on St. Barths, and Central Plain Group on Antigua). After volcanic activity ceased, more extensive carbonate platforms were able to form (Oligocene Antigua Formation on Antigua, Miocene Lowlands Formation on St. Martin). Final formation of present-day outline of the islands resulted from tectonic activity, exposing the submarine rocks, and subsequent erosion.

This more "composite" history of formation resulted in a much wider range of rock materials found on the islands of the outer arc. Plutonic rock in the form of diorite, varieties of calc-alkaline igneous rock, and a whole series of sedimentary rock ranging from (re-crystallised) tuffs, carboneous tuffs, bedded cherts, and different types of limestone occur. In addition, crystal varieties are reported. Notably, the island of Antigua seems to be relatively rich in this regard. Petrified wood, quartz, chalcedony, jasper, flint, barite, malachite, and possibly carnelian are reported to occur. On St. Martin, the presence of jasper and on St. Barths the occurrence of malachite need mention as well. ${ }^{3}$

In relation to the rare regional occurrence of flint (see Chapter 2) the common presence of limestone formations on the different islands is intriguing. Careful comparisons of the different limestone occurrences are listed in table 5.2. These show that carbonate deposition was a local process in close relation to the existence of locally shallow marine waters resulting from island formation and/or raised marine floors. Large submarine carbonate platforms connecting different islands are rare within this region. One example is the Anguilla bank, which possibly connects the St. Martin Lowlands Formation with the Anguilla Formation. In most other cases, carbonate deposition has been related to individual islands. From this it is clear that the Oligocene limestone formation on Antigua stands by itself, as no contemporary limestone deposits are known. This means that flint formation on and near Antigua does not necessarily entail flint formation on other islands. Furthermore, flint likely forms in limestone rock, which has been deposited in low-energetic marine environments. These environments rarely occurred, or at least are seldom preserved on these islands, as is clear from abundant reef limestone deposits on many of them. This helps to explain the infrequent occurrence of flint in the region.

The western part of the study area includes the group of the Virgin Islands and Puerto Rico. These islands were formed during the older Greater Antilles island arc volcanism and as a result, most of the rocks exposed are Cretaceous to Eocene in age, or Cretaceous to Oligocene in the northern Virgin Islands (Larue 1994). Only on Puerto Rico is this island arc of volcanism pre-dated by the southwestern Bermeja Complex, which is Upper Jurrasic in age. It consists of a "dismembered ocean floor and island arc derivates" (Larue 1994,156). Cherts representing the former have been dated to the Kimmeridgian stage $(153-156 \mathrm{Ma})$.

Notably, Puerto Rico exposes a very long succession of different volcanic episodes, covering the entire central strip of the island, where different volcanic centres have been identified. On the Virgin Islands, such eruptive centres were most likely not represented and the oldest volcanic rock relates to sub-marine deposited material from a nearby eruption centre (Donnely 1966; Whetten 1966). On the northern Virgin islands, the rocks are both igneous and sedimentary in nature (tuffs).

Table 5.2 (opposite page). Limestone formations by island by age within the northern Lesser Antilles, the Virgin Islands and Puerto Rico. Data have been derived from geological reports.

\footnotetext{
${ }^{3}$ It must be pointed out that among these crystal varieties, the size of crystals is sometimes too small to provide sufficient raw material for stone tool or other artefact making. For example, this accounts for the malachite on Antigua (personal observation 1998).
} 


\begin{tabular}{|c|c|c|c|}
\hline Island & Limestone Formation & Age & References \\
\hline Puerto Rico & $\begin{array}{l}\text { Parguera Limestone } \\
\text { Cotui Limestone } \\
\text { Melones Limestone } \\
\text { Small lenses in Volcaniclastic rock } \\
\text { Lares Limestone } \\
\text { Montebello Limestone } \\
\text { Angola Limestone } \\
\text { Cibao Limestone } \\
\text { Los Puertos Limestone } \\
\text { Ponce Limestone } \\
\text { Aymamon Limestone } \\
\text { Quebradillas Limestone }\end{array}$ & $\begin{array}{l}\text { Turanian-Maastrichtian } \\
\text { Campanian } \\
\text { Maastrichtian } \\
\text { Eocene } \\
\text { Late Oligocene } \\
\text { Early Miocene } \\
\text { Early Miocene } \\
\text { Early Miocene } \\
\text { Middle Miocene } \\
\text { Middle Miocene - Early Pliocene } \\
\text { Middle Miocene - Late Miocene } \\
\text { Early Pliocene }\end{array}$ & Larue 1994 \\
\hline Vieques & no data available & - & - \\
\hline St. Thomas & Outer Brass Limestone & Lower Cretaceous & Alminas et al. 1994 \\
\hline St. John & $\begin{array}{l}\text { Congo Cay Limenstone Member } \\
\text { Outer Brass Limestone }\end{array}$ & $\begin{array}{l}\text { Lower Cretaceous } \\
\text { Lower Cretaceous }\end{array}$ & Alminas et al. 1994 \\
\hline Tortola & Towers Limestone & Upper Cretaceous & Martin-Kaye 1959 \\
\hline Virgin Gorda & Minor formations & - & \\
\hline Anegada & Anegada Limestone & Pleistocene & Martin-Kaye 1959 \\
\hline St. Croix & $\begin{array}{l}\text { Mudball } \\
\text { Jealousy Formation } \\
\text { Kingshill Limestone } \\
\text { Blessing Formation }\end{array}$ & $\begin{array}{l}\text { Eocene - Oligocene } \\
\text { Early - Middle Miocene } \\
\text { Middle Miocene - Early Pliocene } \\
\text { Pliocene }\end{array}$ & Larue 1994 \\
\hline Anguilla & Anguilla formation & Early Miocene & Drooger 1951, Christman 1953 \\
\hline St. Martin & Low Lands Formation & Early Miocene & Drooger 1951, Christman 1953 \\
\hline Saba & No limestone formation & - & Westermann \& Kiel 1961 \\
\hline St. Barths & $\begin{array}{l}\text { St. Barths Formation } \\
\text { Occasional limestone lenses }\end{array}$ & $\begin{array}{l}\text { Middle - Late Eocene } \\
\text { Miocene }\end{array}$ & Christman 1953 \\
\hline St. Eustatius & $\begin{array}{l}\text { Sugar Loaf } \\
\text { White Wall Formation }\end{array}$ & $\begin{array}{l}\text { Pleistocene } \\
\text { Pleistocene }\end{array}$ & Westermann \& Kiel 1961 \\
\hline St. Kitts & $\begin{array}{l}\text { Brimstone Hill Formation } \\
\text { Godwin Gut }\end{array}$ & $\begin{array}{l}\text { Pleistocene } \\
\text { Pleistocene (?) }\end{array}$ & Westermann \& Kiel 1961 \\
\hline Nevis & No limestone formation & - & Martin-Kaye 1958, 1969 \\
\hline Barbuda & $\begin{array}{l}\text { Codrington Formation } \\
\text { Beazer Formation } \\
\text { Highlands Formation }\end{array}$ & $\begin{array}{l}\text { Pleistocene } \\
\text { Pleistocene } \\
\text { Middle Miocene }\end{array}$ & Brasier \& Mather 1975 \\
\hline Antigua & $\begin{array}{l}\text { Antigua Formation } \\
\text { Limestone in Volcanic Suite }\end{array}$ & $\begin{array}{l}\text { Oligocene } \\
\text { Oligocene }\end{array}$ & Martin-Kaye 1959, Weiss 1994 \\
\hline Montserrat & $\begin{array}{l}\text { Roche Buff } \\
\text { Sweeney's Bay }\end{array}$ & $\begin{array}{l}\text { Pleistocene } \\
\text { Pleistocene }\end{array}$ & Westermann \& Kiel 1961 \\
\hline Grande Terre & $\begin{array}{l}\text { Coral limestone } \\
\text { Grand Fonds area }\end{array}$ & $\begin{array}{l}\text { Pliocene - Pleistocene } \\
\text { Pliocene }\end{array}$ & Lasserre 1975 \\
\hline Basse Terre & No limestone formation & - & Laserre 1975 \\
\hline La Désirade & Central limestone plateau & Pliocene & Lasserre 1975 \\
\hline Marie Galante & Coral and tuffaceous limestone & Pliocene - Quarternary & Laserre 1975 \\
\hline Les Saintes & No limestone formation & - & Westercamp \& Tazieff 1980 \\
\hline Dominica & Limestone lenses & Pleistocene & Sigurdsson 1973 \\
\hline Martinique & $\begin{array}{l}\text { Coral limestone } \\
\text { Calcareous tuff }\end{array}$ & $\begin{array}{l}\text { Miocene } \\
\text { Miocene }\end{array}$ & Westercamp \& Tazieff 1980 \\
\hline
\end{tabular}


In contrast, St. Croix, which was likely farther from these eruptive centres, predominantly consists of sediments in the form of tuffs, volcanic sandstones, agglomerates, and mudstones.

Arc volcanism ended during the late Cretaceous (Maastrichtian) on St. Croix, during the Eocene in Puerto Rico, and probably the Oligocene in the northern Virgin Islands. This was followed by uplifting, deformation, and rotation of the arc formations. The youngest major depositional events corresponded with carbonate platform development, which was late Oligocene to Miocene on Puerto Rico, and late Miocene in the northern Virgin Islands. On St. Croix, early Miocene carbonate was formed in a sedimentation basin.

This longer and more complex geological history has resulted in a wider range of rock materials occurring on these islands. Igneous rock includes keratophyres and spillites (Virgin Islands) along with calc-alkaline rock, basalt, andesite, porphyry, dacite, and serpetinite (Puerto Rico), as well as different plutonic rocks, such as quartz diorite and rare granodiorite and gabbro. Associated sedimentary rocks are tuffs, volcanic sandstones, breccias, agglomerates, mudstones, and bedded cherts. The latter rock can found in the southwestern region of Puerto Rico, as well as in rare outcrops on St. Croix. Almina et al. (1994) speak of radiolarian chert occurrences in the northern Virgin Islands, but Donnelly (1966) classifies these rocks as radiolarian tuffs. Moreover, Puerto Rico has an extensive amphibolite occurrence in the southwest, whereas the Virgin Islands have localized metamorphic rocks in the form of hornfels and marble.

This short presentation of rock type occurrences shows that inter-island variability is considerable within the study area, and as a result, the islands provide quite different environments for stone tool making people. The limestone Antilles can be considered as poor environments in this case, as they are generally deprived of relatively hard rock materials. In contrast, a much wider variety of suitable stone materials is available on the composite islands, as well as in the Virgin Islands and Puerto Rico, where both hard siliceous rocks with conchoidal fracturing as well as hard though more random fracturing igneous materials occur. In addition, variation is noticed between the Lesser Antillean and the Greater Antillean islands. In the latter, specific rock types display greater variation, including metamorphic rocks and sandstones, which do not occur on the Lesser Antilles.

\subsection{StONE MATERIAL USE}

\subsubsection{Introduction}

The following part of this Chapter provides a description of stone material use and tool production on the different islands within the study area. The presentation is divided into four parts, corresponding with the four main phases of indigenous occupation during the Ceramic Age, from Early Ceramic A to Late Ceramic B. For each of the four phases, I systematically present data on the four main technology sets, as defined in Chapter 3. The fifth technology set consisting of rock material solely modified from burning, whether intentional or not, is left out of the discussion. Furthermore, the data on lithic bead and pendant industries (technology set 2c) are primarily derived from previous research by others.

As outlined above in Chapter 3, data gathered through the systematic analysis of samples of lithic artefacts from different regional sites form the core of this presentation and the data are tabulated in Appendix F. Details on the provenience of the samples within the sites and excavation methodologies applied are presented in Appendix F as well.

If available, published results on other relevant sites are mentioned, primarily for purposes of comparison. In some cases, a detailed level of comparison was possible when researchers used similar methodologies or were familiar with at least some of the raw materials encountered during the present study. 


\begin{tabular}{|c|c|c|c|}
\hline Site & Island & Type of sample & reference \\
\hline Pearls & Grenada & bead and pendant related artefacts & Cody 1991 \\
\hline Vivé & Martinique & all lithics (including lapidary items) & Berard et al. 2001 \\
\hline Cocoyer & Marie-Galante & all lithics & - \\
\hline Morel & Guadeloupe & all lithics & - \\
\hline Doigs early & Antigua & flake tool related artefacts & - \\
\hline Royalls & Antigua & flake tool, axe, bead and pendant related artefacts & Murphy 1999; Murphy et al. 2000 \\
\hline Elliots & Antigua & flake tool, axe, bead and pendant related artefacts & Murphy 1999; Murphy et al. 2000 \\
\hline Sorcé & Vieques & all lithics (including lapidary items) & Narganes 1999 \\
\hline La Ниеса & Vieques & all lithics & Narganes 1995; Rodríguez Ramos 2001 \\
\hline Punta Candelero & Puerto Rico & all lithics & Rodríguez Lopez 1993; Rodríguez Ramos 2001 \\
\hline
\end{tabular}

Table 5.3. Studied sites from the Early Ceramic A phase. Data from sites in italic have been obtained from literature.

\subsubsection{Early Ceramic A}

\section{Introduction}

Collections varying in size have been studied from five sites dating to this earliest phase of the Ceramic Age. In addition, others have reported on lithic material from another seven sites. Their data are included in this section and used for comparison. Table 5.3 specifies the exact nature of each sample. It shows that in many cases not all lithic artefacts originally collected were studied for the present research.

\section{Flake tool production}

\section{Raw materials}

Materials used to produce flake tools include a wide variety of fine-grained rock materials, basically falling in the broad group of cherts and chert related rocks. Identified materials are flint, bedded chert, chert, jasper, chalcedony, petrified wood, quartz, and probably a silicified tuff (table 5.4). Looking in detail at the percentages of material per site, it is immediately clear that Long Island flint is predominant at sites on Antigua and on the islands directly surrounding Antigua, such as Montserrat, Guadeloupe, and Nevis. Haviser $(1993,1999)$ does not distinguish chert varieties for Hope Estate, but mentions that a large part of the flake material may have originated from Long Island there as well. In addition to Long Island flint, a white chert type with an unknown provenance is the second most common variety at most of these sites. I identified this type of chert at Cocoyer, Morel, Trants, Doigs, and Hichman's. In particular, the large samples from Trants and Morel produced significant amounts of this chert, enabling a more detailed description. The white chert varies in texture and grain-size, both within sites as well as between sites. This makes it difficult to say whether this white chert should be considered as a single chert type originating from only one source. Based on its white colour, the absence of clear cortex, and the absence of inclusions, I assumed that this type is not a flint or other biogenic type of chert. It exhibits some similarities with the cherts formed in the tuffs at Shirley Heights on Antigua, although a perfect resemblance with this source material was not established. The high abundance of this chert type at Doigs on Antigua, which is relatively close to Shirley Heights supports this origin, however. 


\begin{tabular}{|c|c|c|c|c|c|c|c|c|c|c|}
\hline Chert type & Site & $\begin{array}{l}\text { Punta } \\
\text { Candelero } \\
\mathrm{N}=1041 \\
\%\end{array}$ & $\begin{array}{r}\text { La Hueca } \\
\mathrm{N}=1472 \\
\%\end{array}$ & $\begin{array}{l}\text { Sorcé } \\
\qquad \begin{array}{r}\mathrm{N}=468 \\
\%\end{array}\end{array}$ & $\begin{array}{l}\text { Hich- } \\
\text { mann's } \\
\mathrm{N}=38 \\
\%\end{array}$ & $\begin{array}{l}\text { Doigs early } \\
\qquad \begin{array}{r}\mathrm{N}=234 \\
\%\end{array}\end{array}$ & $\begin{array}{l}\text { Trants } \\
\begin{array}{r}\mathrm{N}=996 \\
0\end{array}\end{array}$ & $\begin{array}{l}\text { Morel } \\
\begin{array}{r}\mathrm{N}=1388 \\
\%\end{array}\end{array}$ & $\begin{array}{l}\text { Cocoyer } \\
\qquad \begin{array}{r}\mathrm{N}=62 \\
\%\end{array}\end{array}$ & $\begin{array}{l}\text { Vivé } \\
\qquad \begin{array}{r}\mathrm{N}=285 \\
\text { \% } 0\end{array}\end{array}$ \\
\hline Long Island flint & & 3.0 & 7.7 & 1.4 & 63.2 & 31.6 & 57.5 & 78.0 & 37.1 & 0.4 \\
\hline Blackman’s Point flint & & - & - & - & - & - & 0.1 & 0.1 & - & - \\
\hline Coconut Hall flint & & - & - & - & - & - & - & - & - & - \\
\hline Antigua Form. flint & & - & - & - & - & - & 0.2 & - & 1.6 & - \\
\hline White chert & & - & - & - & 7.9 & 31.6 & 27.6 & 12.1 & 14.4 & - \\
\hline Petrified wood & & - & - & - & - & - & 0.3 & 0.1 & - & - \\
\hline Other chert & & 46.0 & 31.8 & 44.8 & 15.8 & 36.8 & 4.7 & 9.1 & 17.7 & 41.7 \\
\hline Désirade red chert & & - & - & - & - & - & - & - & - & - \\
\hline Jasper & & - & & - & - & - & 0.5 & 0.6 & - & 57.9 \\
\hline White quartz & & 5.3 & 14.1 & 43.2 & - & - & - & - & - & - \\
\hline Unidentified chert & & - & - & - & 13.2 & - & 5.2 & - & 29.0 & - \\
\hline Other materials & & 45.5 & 45.1 & 10.5 & - & - & - & - & - & - \\
\hline
\end{tabular}

Table 5.4. Early Ceramic A phase. Relative amount of identified chert types by site.

Unfortunately, chemical analysis did not provide a clear answer to this provenance problem. In the first place, the Discriminant Analysis did not assign analysed artefacts from Trants and Morel to the Shirley Heights source. In addition, the artefacts from Trants and Morel differ with respect to each other. This suggests that multiple sources of white chert were likely exploited during this earlier phase of the Early Ceramic Age. The most likely location of these sources would still be Antigua, where non-biogenic cherts are numerous. The common occurrence of white chert in archaeological contexts on Antigua and islands directly surrounding it, supports this view. Trants, for example produced higher percentages of this material than Morel and Trants is closer. Honeychurch, however, reports the occurrence of non-biogenic types of chert on the more southern part of Dominica as well (1995, personal communication 2000). Archaeological data that would favour such a more southern provenance are lacking for the white chert at the moment.

Apart from these two predominant varieties of chert, the regional sites produced other less abundant cherts, as well. An origin could be specified for some varieties. Trants yielded Corbison Point/Dry Hill Antiguan chert, which was confirmed by chemical analysis. In addition, petrified wood was identified at Trants. It is likely that the petrified wood originates from this locality in Antigua as well, considering the fact that the Trants inhabitants were familiar with the Corbison Point/Dry Hill locality, where petrified wood can be also found. Both varieties only include $1.7 \%$ of all flake tool material, however. A slightly more abundant variety (2.4\%) likely originates from Blackman's Point in Antigua. At Morel, only a single Blackman's Point specimen (0.1\%), two red bedded radiolarian chert pieces originating from La Désirade, and nine red jasper pieces with a possible Martinique provenance were also identified.

It is interesting to note that chert varieties at sites on Antigua itself display a larger variability than at the sites on the other islands discussed above. DeMille (1999) reports for Royalls finding of 15 chert varieties, along with Long Island flint. These have probably all, or at least mostly have an Antiguan origin. At Doigs, Long Island flint only forms a small portion of the sample (32\%), whereas white chert is significant as well (32\%), along with other varieties (36\%). Apparently, the Antigua inhabitants obtained material from different localities on the island, which were all close and relatively easy accessible, whereas the inhabitants on the neighbouring islands only chose or had access to a few specific sources, among which Long Island formed the most important one.

Relatively extensive excavation work at Trants showed that the site was continuously occupied for a considerable period, from approximately $500 \mathrm{BC}$ to AD 400, or later. As the samples I studied came from relatively deep units largely covering this complete period of occupation, I was able to study possible diachronic changes in relation to raw material choice. The results showed that during this long occupational history the use of different stone materials was not significant variable through time. This suggests a very constant and stable social environment, in which access to raw material sources remained the same for hundreds of years. Such a scenario supports the idea of a static circular village lay-out, which also seems to have remained unchanged (Petersen 1996, 354-56). In contrast to the absence of chronological variation in use of stone materials, some spatial variation has been noted. A northern excavation unit N596E571 produced significantly more Long Island flint throughout all its different levels than the three southern units. Whether this means that the village was subdivided into spatially separated social groups, which acted more or less independently and occupied certain areas within the settlement throughout different generations, is open to discussion and needs additional evidence from more lithic studies, as well as analysis of other categories of material culture. 
The percentage of Long Island flint becomes considerably lower and white chert is not encountered any more at sites located farther away from Long Island and Antigua, such as Vivé, Sorcé, La Hueca, and Punta Candelero. At Vivé, materials local to Martinique make up the large majority of the flake tool materials. These include red and yellow jaspers, different coloured cherts and a translucent more chalcedonic type of chert. These materials naturally occur at several places on the Martinique, but the closest source can be found at Presqu'île de Caravelle, around $20 \mathrm{~km}$ from Vivé (Bérard 1997, 1999).

In addition to these chert varieties, Bérard (1997) has argued that igneous rock was also used for making flake tools, as the Vivé excavations produced a number of flakes made of fine-grained varieties. Despite the fact that associated core artefacts made of a similar igneous rock are lacking, Bérard suggests that these flakes represent a separate production, aimed at the manufacture of large flakes in contrast to the small equivalents made of jasper, chert, and chalcedony. There are no clear indications from Vivé that would disprove this argument (or strongly support it for that matter), but I am not inclined to follow this conclusion. I have several arguments: (a) flake tool production at other sites from the same phase and later phases are not associated with igneous rock; (b) igneous rock is usually associated with the manufacture and use of axes; (c) one igneous rock axe fragment and a single axe preform were identified at Vivé, these two artefacts are made of a different igneous rock variety, more porphyritic in nature; and (d) the igneous flakes lack typical features common among flake tool material, such as reduction of flakes and clear use-wear. Bérard, however, does mention the presence of one flake with possible use-wear. This use-wear is doubtful, as it may be merely ripple marks.

The common association of igneous rock and axe production and the fact that at least some varieties of igneous rock were reduced to produce axes on site at Vivé suggest that the finer grained igneous rock flakes were part of a similar production as well. This interpretation is more in agreement with the fact that fine-grained igneous rock cores are missing at Vivé. Axes, rather than flake cores, were more likely discarded at places outside the village, places where they were used, broken, and lost (e.g., the forest).

At Sorcé on Vieques, the sourcing of different varieties of chert types is more problematic, as source locations cannot always be specified. Apart from the Long island material and a very distinct type of white quartz, which is local to Vieques, I distinguished ten varieties of chert at Sorcé. Two can be easily discriminated, as they are green and red in colour and do not have clear cortical rinds. The analysis of the Punta Candelero and La Hueca lithic artefacts from Puerto Rico and Vieques respectively, by Rodríguez Ramos revealed both of these materials as well (Rodríguez Ramos 2001a). Rodríguez Ramos located a possible source area in the eastern part of Puerto Rico in the municipality of Ceiba, where similar rocks occur in a bedded sequence. These are classified as silicified tuffs. In addition, the green variety also resembles green Mariquita chert from the southwestern part of Puerto Rico. In Chapter 2, I mentioned the occurrence of this material at the Las Palmas source.

The remaining eight chert varieties fall within the group of cherts that form the objective of my chert sourcing research described above (see Chapter 2). Despite the large number of potential sources, the majority of these eight chert varieties are not similar to any of the characterised sources. Only two exhibit some similarity with the southwestern Puerto Rico sources, in particular the Las Palmas locality. For five chert varieties I submitted artefacts for geochemical research. The results showed that only one possibly originates from the southwestern Puerto Rican sources, although complete chemical similarity with one of these localities was not obtained. The other four are more similar to the Antigua and St. Kitts sources than to the Puerto Rico ones. One of these probably originates from Little Cove, although this source was not initially identified. However, its macroscopic characteristics do not display definite anomalies with Little Cove material. For the others the source assignment remains unknown, as the outcomes of the Discriminant Analysis yielded sources for which macroscopic characteristics were quite different from the artefacts. This minimally suggests that additional lithic sources are present in the study area or nearby, which are not included in this research. These sources probably should not be sought in the southwestern area of Puerto Rico, as the structural low $\mathrm{Ca} / \mathrm{Mg}$ ratio for the cherts from this region does not correspond with the artefact data. Considering the low Long Island flint occurrence at Sorcé, an Antigua origin for these cherts is not likely either. Source areas probably are situated closer-by, either in eastern Puerto Rico, on Vieques itself (Rodríguez Ramos personal communication 2000), or in the Virgin Islands, where cherts have been also reported (Almina et al. 1994).

Close comparison with the data from La Hueca and Punta Candelero, two sites yielding Huecan style ceramics, shows that they exhibit a similarly large range of chert varieties. The large majority resembles varieties encountered at Sorcé. Still, some differences are noted as well, and these are not only related to raw material choice but also to reduction behaviour (Rodríguez Ramos 2001a). 
Reduction and tool production

The technological analysis of the flake tool material from the different sites shows that the lithic materials were worked using an expedient technology, in which both bipolar and direct freehand percussion techniques were employed. Other characteristics shared by the different samples include the production of both large and small flakes, the ad-hoc use of flakes without any further modification in the form of intentional retouch, and the exhaustive reduction of the material in nearly all cases.

Furthermore, it became clear that material was reduced on site and probably was not imported in the form of flakes in most cases. The study of cortical surfaces indicates that in many cases water-worn cobbles, either originating from cobble beaches or streambeds, were collected, along with more inland surface scatters. Small sample size and my unfamiliarity with the nature of the sources for some varieties, including lack of knowledge about cortex or outer surfaces, make it difficult to identify in what form these different chert varieties arrived at the various sites. Long Island flint constitutes an exception in this respect. Cortex count data for this flint type, as discussed in the next Chapter, shows that this flint material arrived at most of the sites in largely unmodified form. Only the Cocoyer material suggests a different situation. There, Long Island flint material might have arrived in the form of large flakes, rather than pre-worked cores, to be reduced for the production of smaller flakes.

An additional feature needs to be mentioned in relation to the acquisition of lithic material and that is possible re-use of Preceramic Age flaked material during the Ceramic Age. Murphy (1999) reports the finding of a Preceramic Age blade from Long Island, that was re-used by the inhabitants of the Royalls site on Antigua. My analysis of flake tool material revealed the very rare occurrence of true blades as well, which definitely cannot be associated with the expedient technology employed during the Early Ceramic phase. This is evident for a blade fragment found at Sorcé because the raw material is unique among the sample studied. At Trants, however, a Long Island blade fragment from the intermediate excavation levels exhibits very worn and blunt edges, which is quite unlike the rest of the Long Island material at this site. This suggests long exposure to wind and water erosion before being collected. In this latter, case the presence of this blade artefact may be attributed to scavenging of Preceramic Age surface material, probably taken from scatters on Long Island, whereas in case of the Sorcé artefact the possibility of exchange with still existing Preceramic Age settlers on the neighbouring island of Puerto Rico should be considered as well.

All samples include flakes displaying use-wear. In the majority, the edges were not modified prior to usage, but in some cases some minor modifications occurred. Recurrent is a single small flake removal creating a concave edge, similar to examples reported by Crock and Bartone (1998), Murphy (1999, 237), and De Mille (1996). Other modifications primarily were intended to change or reduce overall flake shape, rather than work the edge (figures 5.1 and 5.2).

In addition to this production of expedient flake tools, the lithic reduction was aimed at making small flakes. This is clearly shown by a significant number of flakes among the large samples that were reduced to obtain smaller flakes. Clear bi-directional flaking is the predominant form used for reducing these flakes, but more unsystematic reduction was also used, particularly in the form of removing a few flakes from whatever direction possible (figures 5.3 and 5.4). This production of smaller flakes may be related to the making of boards for grating cassava. However, I did not identify any small flakes with actual use-wear, that could be the result of their use as grater teeth. This absence of clear use-wear on smaller flakes is widely recurrent, as also encountered in the study of later material. Crock and Bartone noted a similar absence in their use-wear study for a larger sample from the Trants site $(1998,209-12)$. They offered two reasons that might explain the absence of the grater board teeth: (a) either the use-wear is too subtle for the identification methods used in their work (and also mine) ${ }^{4}$, or (b) the location within the site, where such teeth were used in the grater board has yet to be identified.

Currently Yvonne Lammers-Keijzers (Leiden University) is doing experimental studies and microscopic usewear analysis, including work specifically related to this type of function. Preliminary results favour the first explanation (Lammers-Keijzers in prep, personal communication 2004). The second explanation, however, should not totally be excluded. Grater boards are usually valued items (Butt Colson 1973; Myers 1981; Thomas 1972, 1981). Modern ethnographic wooden boards are often decorated with painted motifs (Crock and Bartone 1998), making it likely that they will be kept as long as possible. Therefore, the stone teeth will be only renewed in case of malfunctioning or loss. This should result in occasional discard and accidental loss of stone grater teeth at the locations where they are used. Considering their small size, lithic grater teeth will more likely remain there, rather than being swept to surrounding peripheries of the site where other refuse is located and most test-units were excavated in sampling the site.

\footnotetext{
${ }^{4}$ Crock and Bartone used a 10-30x Bausch and Lomb binocular microscope $(1998,201)$ and I used a 10x hand lens to identify traces of use-wear.
} 

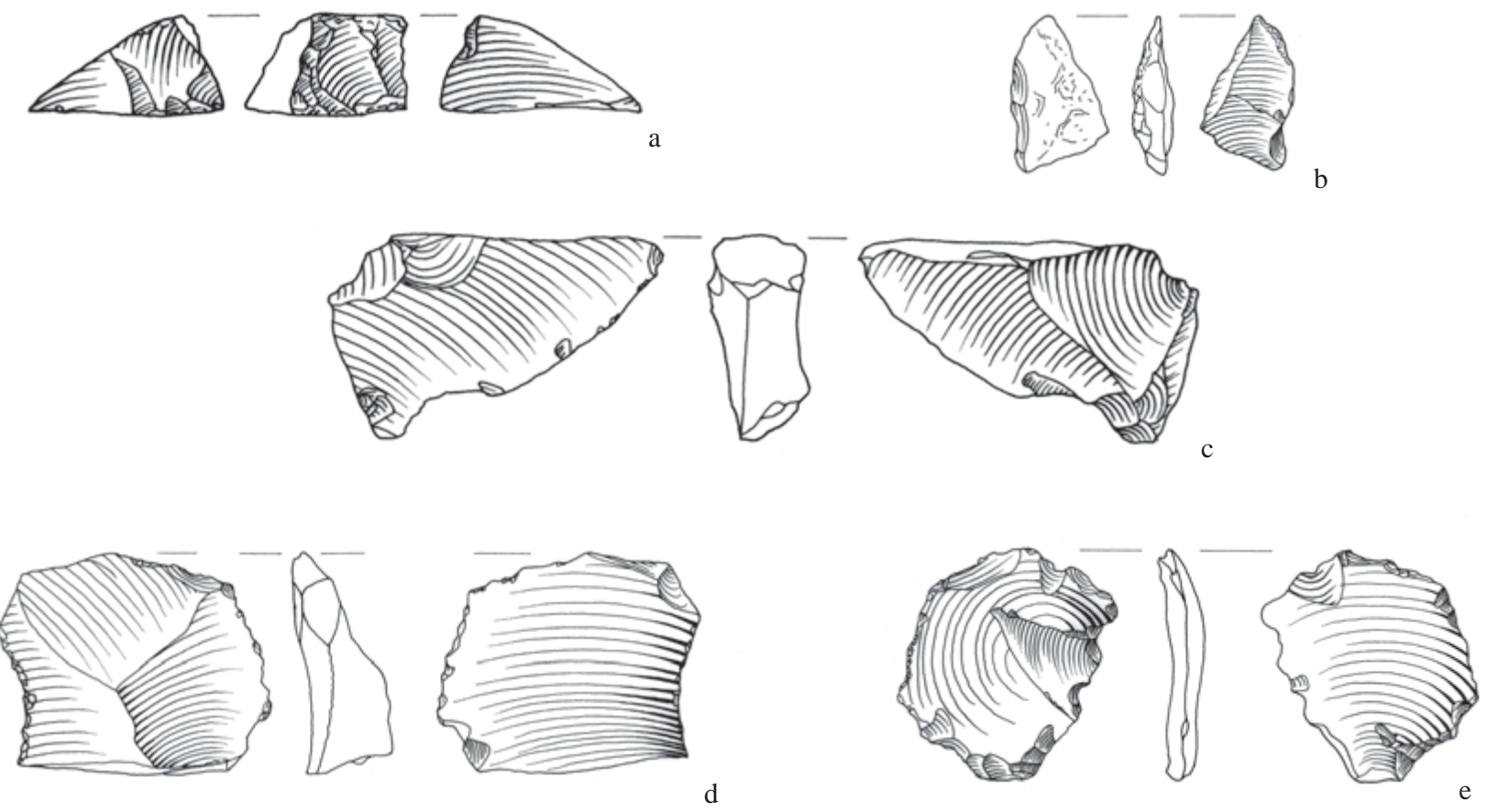

Figure 5.1. Trants, Monserrat. Utilized and modified flakes: a. core on flake; b. flake fragment with unifacial use retouch; c. modified flake with fine use retouch; $d$. flake fragment with unifacial use retouch; e. complete flake with unifacial intentional retouch (scale 1:1). (Drawings Raf Timmermans)

\section{Core tool production}

\section{Axes and Adzes}

All sites dating to this early phase of the Early Ceramic Age yielded evidence for the use of axes and/or adzes, although in most cases it only concerns a few artefacts (table 5.5). Interestingly, this phase is the only phase of the Ceramic Age during which adzes (plano-convex edged) were found in considerable numbers alongside axes (biconvex edged). Still, axes clearly outnumber adzes on all sites. Sites yielding these latter tools are basically restricted to the western part of the study area, on the islands of Vieques and Puerto Rico (Rodríguez Ramos 2001a). Also, the Hope Estate site on St. Martin yielded this type of tool (De Waal 1999b). This geographical and chronological trend has only recently been identified, and may be related to different stone working protocols between different regions and through time. It is also intriguing that almost all adzes found on the Lesser Antilles are made of conch shell.

Stone type variability is much larger among the axe and adze category than in case of the flake tool artefacts. Rock type classification by necessity, however, remained at a very general level, i.e. only distinguishing igneous from metamorphic rock, for reasons mentioned in Chapter 3. In most cases, it was possible to specify whether the material is locally occurring in the direct site surroundings or even on the island of discovery, or not. In combination with the production data, this evidence provides strong support for the operation of exchange systems as the means by which local social groups had obtained lithic raw materials and/or finished tools (see below).

Looking at evidence for local production of axes, actual working of lithic material into finished axes took place only at a very limited number of settlements. This contrasts significantly to the general occurrence of on-site flake tool production. Sites yielding such evidence include Vivé, Cocoyer, Sorcé, and Hope Estate. At Vivé, Sorcé, and Hope Estate probable local material was worked. In case of Cocoyer and in case of some of the rock materials found at Sorcé, rocks were used that may not have been local to the island. A difference is noticed in comparing the sites. At first three localities, production debris is not abundant, and basically only includes unfinished preforms. Related flake material is very rare compared to the number of preforms and axes found at Sorcé and absent at Cocoyer. At Vivé, the relation between flake material and preforms is not clear, as a result of various raw materials (see above discussion of igneous flakes at Vivé). This low occurrence of flakes becomes even more striking once it is realised that the formation of flakes may be related to accidental breakage in some 


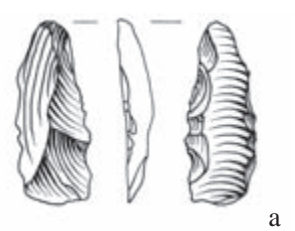

a
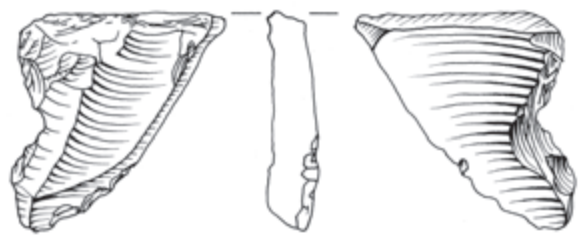

d
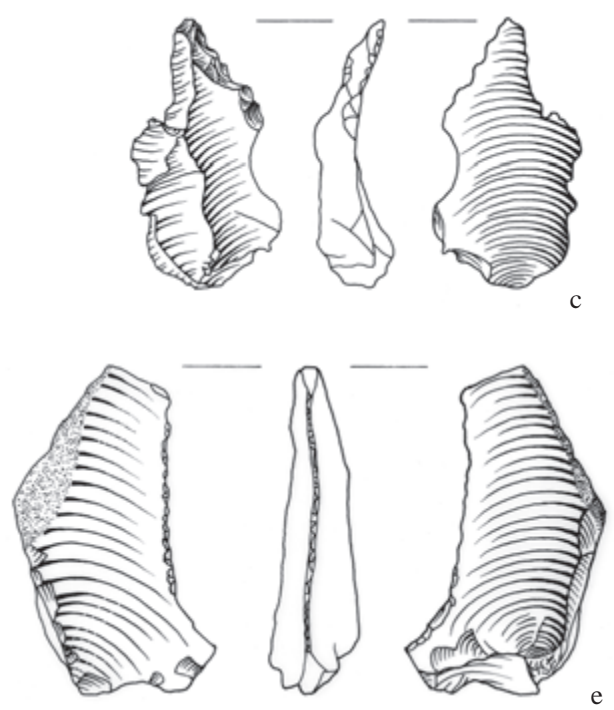
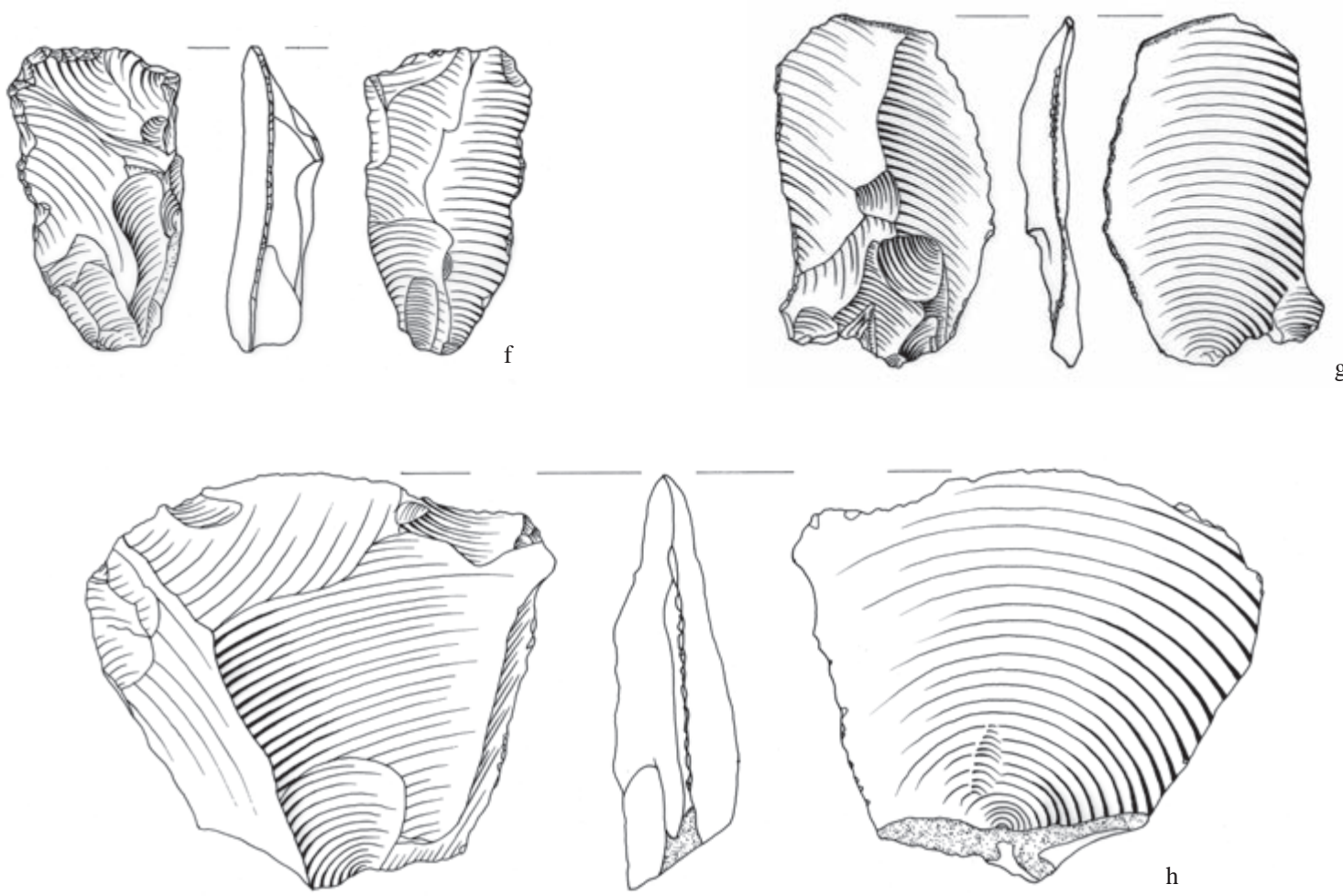

Figure 5.2. Morel, Guadeloupe. Utilized flakes: a. flake fragment with intentional retouch; b. flake fragment with use retouch; c. complete flake with intentional retouch (drill); e. modified flake with utilized curvate edge; e. complete flake with unifacial use retouch; f. modified flake with intentional retouch; g. complete flake with use retouch; h. complete flake with use retouch (scale 1:1). (Drawings Raf Timmermans)

cases as a result of the (heavy) use of axes, rather than intentional formation related to their manufacture. Another cause of these flakes may have been the re-shaping or re-sharpening of exhaustively used axes or adzes. A third possible origin may be related to the use of water-worn pebbles, as this generates flakes with seemingly "ground" dorsal faces, making their 

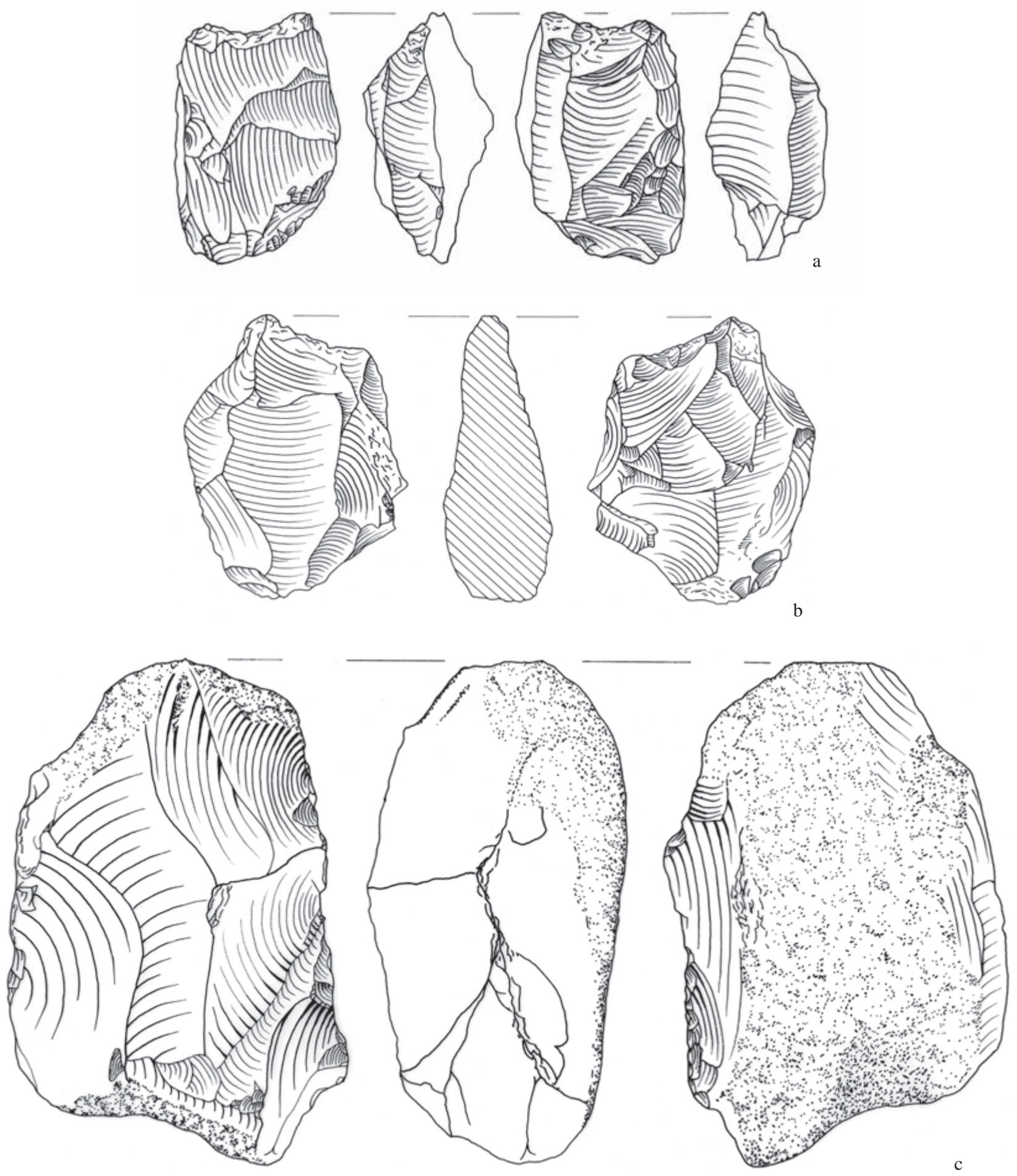

Figure 5.3. Trants, Montserrat. Flake cores: a en b. bipolar cores; c. multiple platformed flake core (scale 1:1). (Drawings Raf Timmermans) 

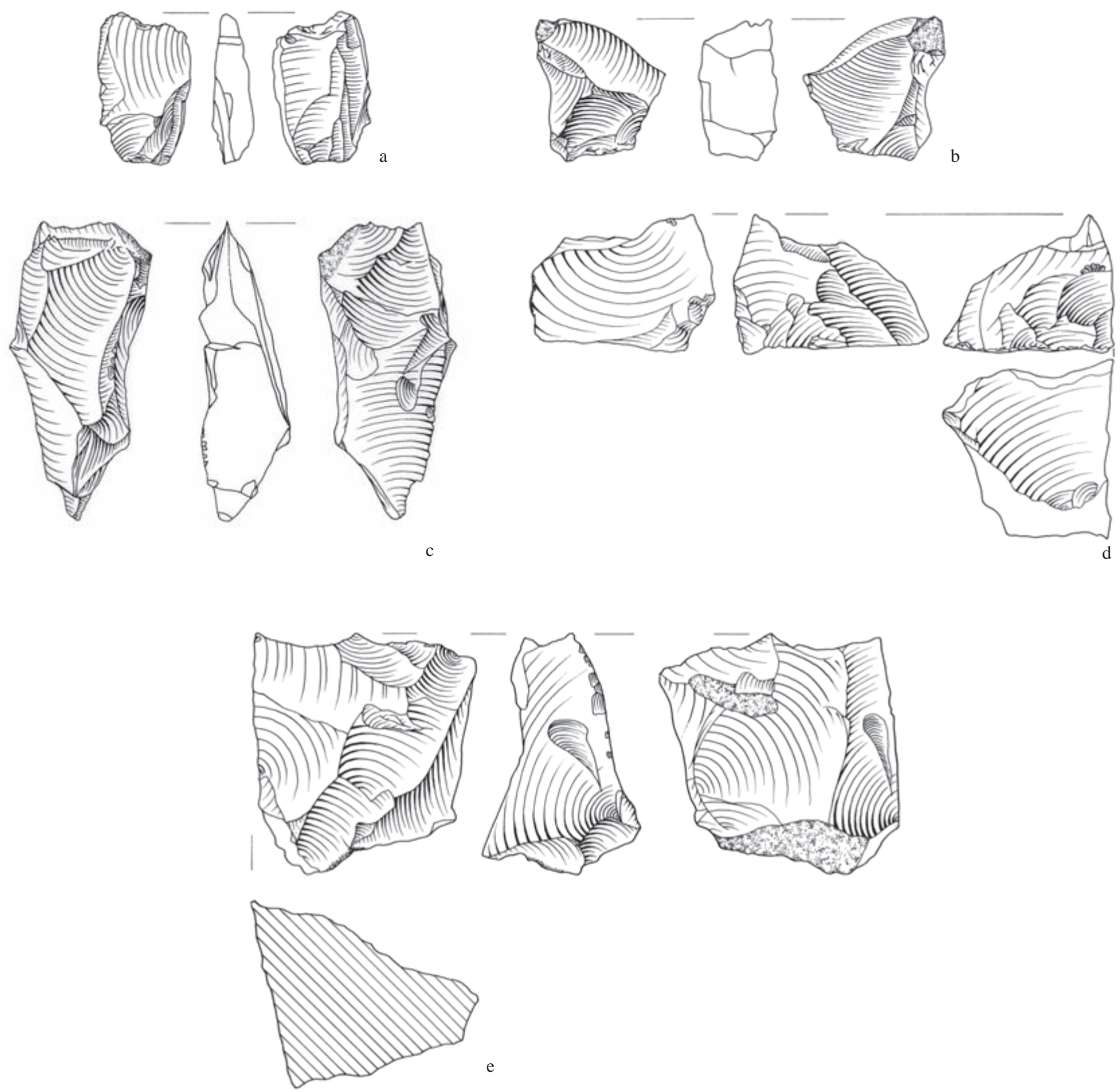

Figure 5.4. Morel, Guadeloupe. Flake cores: a and b. bipolar cores; c and d. cores on flake; e. polyhedral core (scale 1:1). (Drawings Raf Timmermans)

distinction from axe related flakes difficult. This clearly suggests that in case of these three sites the flaking stage of axe and adze manufacture is poorly represented and probably did not solely occur on site, but likely took place elsewhere. This might have been at the source or some other special work-shop site. Archaeological evidence for this latter option is lacking in the region for this phase, however.

Apart from these rock materials used to make axes and adzes, the Sorcé excavations yielded a very specific raw material, a silicified shale (or phyllite), which was worked at the site. It was not possible to specify why this material was reduced due to a lack of finished artefacts, as well as clear preforms. The artefacts include a number of large and relatively flat, flaked core artefacts. Flakes and a few water-worn pebbles were also identified. The pebbles might have served as the 


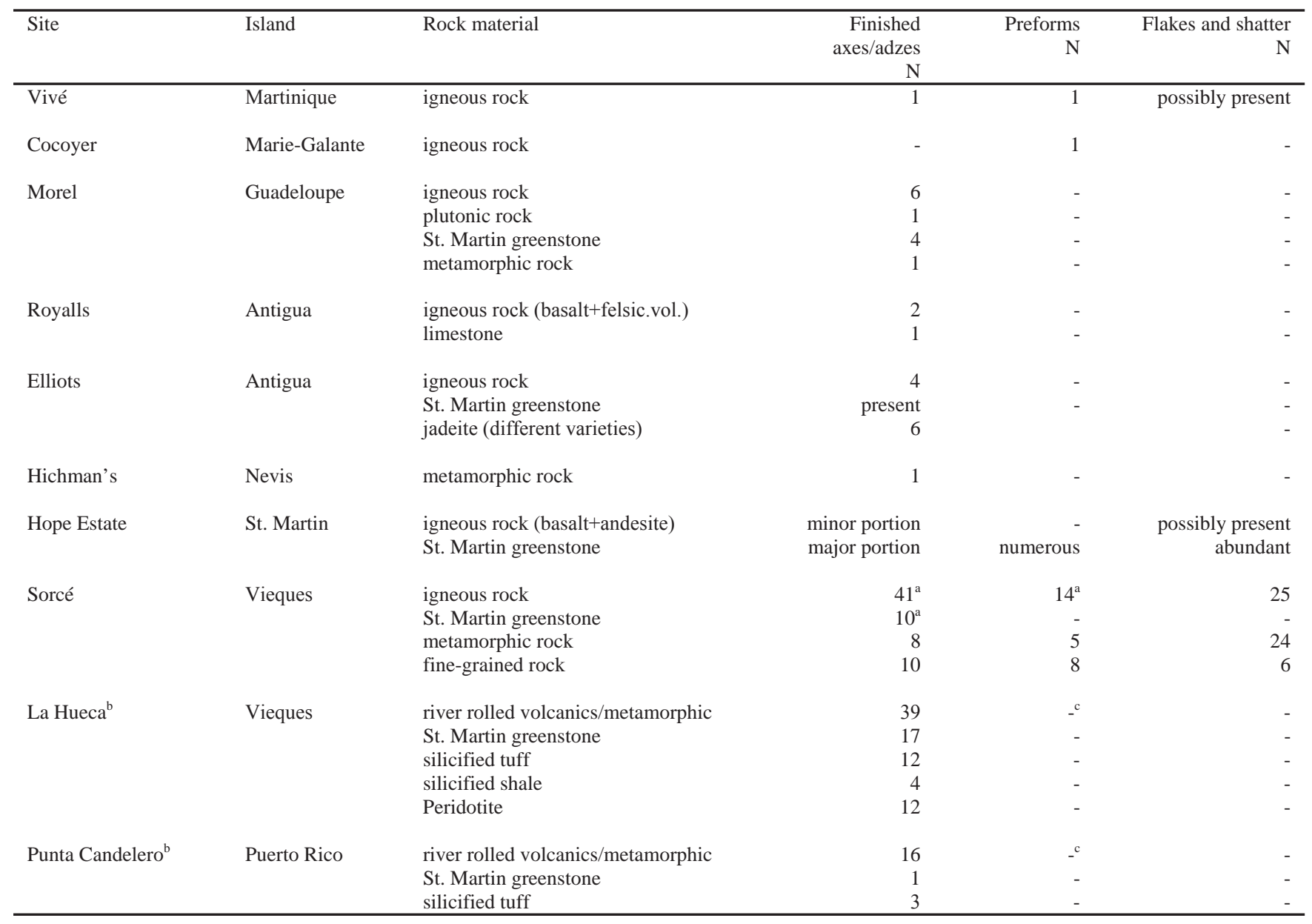

Table 5.5. Early Ceramic A phase. Identified axes and axe manufacture related artefacts by raw material by site. a includes both axes as well as adzes; b In case of La Hueca and Punta Candelero no distinction was made between axe and adze types, although Rodríguez Ramos (2001) distinguishes 6 different axe and adze forms: La Hueca axe/adze ratio 67/17; Punta Candelero axe/adze ratio 15/5; c Rodríguez Ramos $(2001,176)$ explicitly states that production of ground stone material was not occurring on site, both for local as well for non-local materials.

raw material from which production started. Similar material was identified at the Huecan component of the site as studied by Rodríguez Ramos (2001a), where it was used for making axes. Rodríguez Ramos mentions that this material might be locally available, but he has not been able to identify truly identical materials in the site area.

The Hope Estate site is the only settlement with abundant evidence for axe and adze production activities. Two lithic materials are associated with axe manufacture on site, including the local greenstone and a possibly local andesite. Haviser (1999) explicitly states that the Hope Estate dwellers brought the local greenstone to the site in natural form and worked it into completely finished axes and adzes (see also De Waal (1999b) for different axe and adze types). The number of flakes, blocky fragments, and preforms found at Hope Estate is strikingly high and supports this complete production sequence.

With regard to the andesite, it should be pointed out that Hope Estate did not yield many artefacts relating to the manufacture of igneous rock axes (Chauviere 1998). Only a few andesite core fragments were found, alongside with some flakes. The low number of manufacturing debris resembles igneous rock axe evidence at many other sites and stands in marked contrast to the greenstone material at Hope Estate.

This scanty evidence about the production of axes made of igneous rock, as well as some other materials in the region, demands additional explanation. One of the reasons that igneous debitage is considerably lower in number than in 

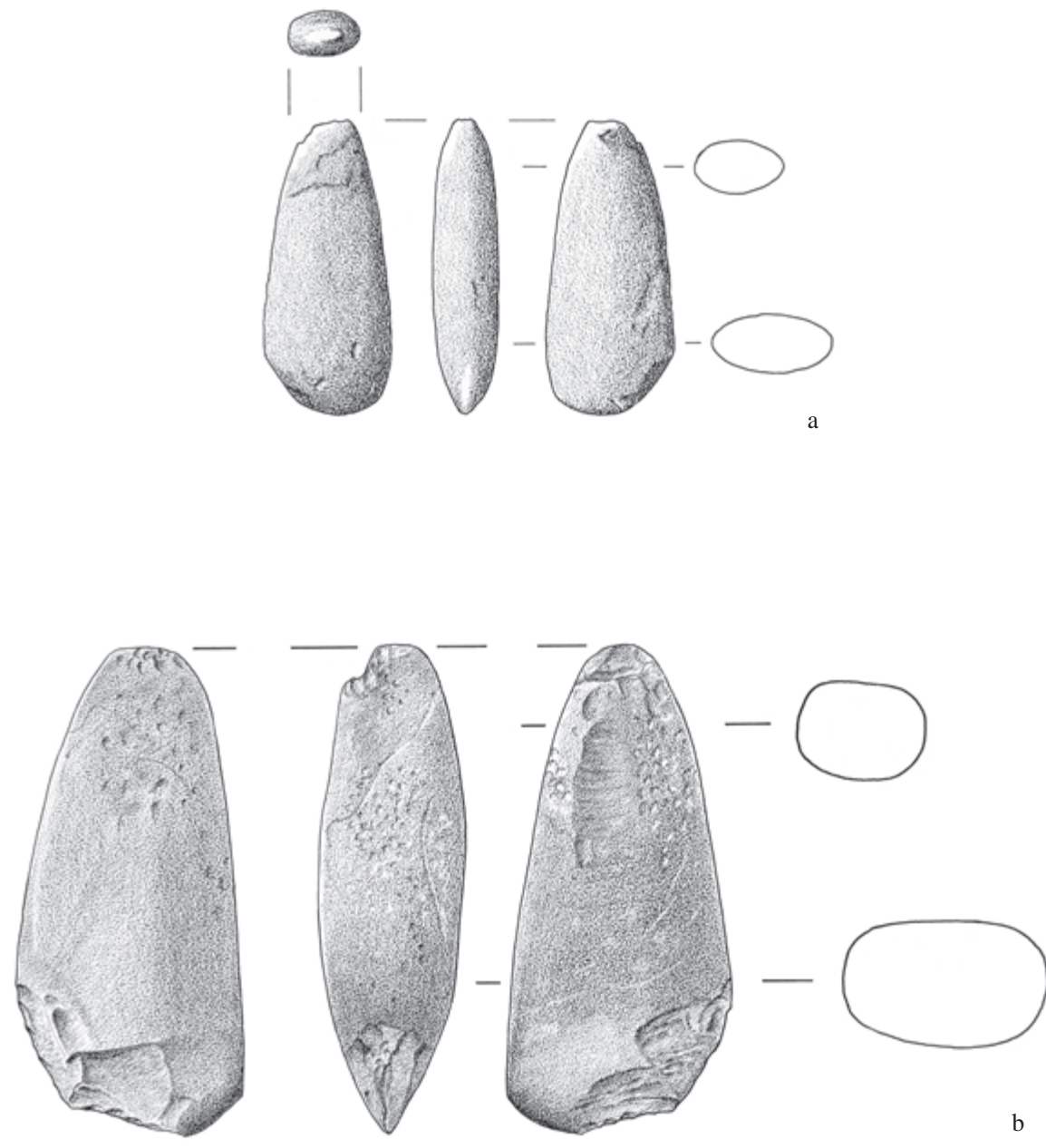

b

Figure 5.5. Morel, Guadeloupe. Axes: a. St. Martin greenstone complete axe; b. igneous rock axe with damaged edge and signs of hammering at the poll and sides (scale 1:2). (Drawings Raf Timmermans)

case of the greenstone may be related to a difference in the form by which both materials were collected. The presence of water-worn surfaces on some of the igneous rock flakes suggests collection of pebbles from beaches and streambeds. As these pebbles in many cases can have shapes, that (closely) resemble final axe or adze forms, reduction by flaking may have been limited to thinning the object and subsequent edge shaping. The greenstone, on the other hand, was probably obtained in the form of blocks, which is suggested by its clearly bedded nature. The large amount of blocky fragments, probably belonging to an earlier stage of shaping the greenstone also suggests this.

In addition to evidence about the local production of axes and adzes at habitation sites, many sites produced finished tools, for which local production was not identified. These tools probably represent items obtained through exchange in most cases (figure 5.5). In particularly, this accounts for the greenstone axe material originating on St. Martin, for which clear production at Hope Estate and the distribution of finished tools on surrounding islands provides good support for regional exchange (see next Chapter for further description and discussion). In the case of most other materials no such production loci were identified. In this instance it may be useful to distinguish the igneous rock axes from the metamorphic ones. The former lithics may originate on many of the northern Lesser Antillean islands, where igneous rock is quite abundant. In contrast, metamorphic rock is not reported within the Lesser Antilles, and only occurs on or near the South American mainland (including Trinidad and Tobago) and the Greater Antilles (including the Virgin Islands) and beyond. 
This means that the metamorphic axes found at Morel, Royalls, Elliots and Hichman's have rather distant sources. Exact provenance determination is not possible yet, as a result of poor knowledge about sources and broad, non-specific petrographic classification of these artefacts. With regard to sources, ample use of greenstone axes is reported from the South American mainland (Boomert 1979), but also from Jamaica for example (Roobol \& Smith 1976). Whether Jamaica possibly provided the source of such axes is unknown, but seems highly unlikely due to late human occupation post-dating this early phase of the Early Ceramic Age. Murphy (1999) even considers a Guatemala origin for one of the greenstone jadeite axes found at Royalls, since it is a jadeite variety that includes pyrite inclusions, only known from that specific Meso-American region (Hargett 1990, 138; Murphy 1999, 122). If this indeed proves to be the actual provenance of this artefact, it provides a very intriguing case, since the transportation route must have gone through the Greater Antilles and they were still occupied by Preceramic Age inhabitants at the time. These people in the Greater Antilles must then have stood in contact with both the Meso-American cultures and the first Ceramic Age settlers of the Antillean islands.

Much work still needs to be done as related to the igneous rock axes found within the Lesser Antilles, specifically for provenance and island distribution. Vivé might have been a site where different varieties of igneous rock were reduced into axes for further exchange to one of the islands deprived of igneous rock, such as for example Morel on Grande Terre. The archaeological data are still too poor to definitely prove this, however. It may be hypothesized that sites on more nearby volcanic islands, such as Basse Terre or Dominica, which so far have received little archaeological investigation, functioned as suppliers for this latter site.

The large number of imported axes and adzes found at Sorcé, La Hueca, and Punta Candelero display various rock types. Exotic varieties include the St. Martin greenstone, as well as fine-grained black igneous rock, identified as peridotite (Rodríguez Ramos 2001a). This latter rock may originate from the Cretaceous serpentine belt of southwestern Puerto Rico. In addition, other rock varieties include green metamorphic rock, silicified tuff, and meta-volcanics. Their exact provenance remains unclear, but most of them likely originate nearby, either in Puerto Rico or the Virgin Islands.

Another subject to be approached is the occurrence of two distal fragments originally part of so called "eared" axes among the Morel and Hope Estate collections. These axe types are well known from museum collections, especially on Guadeloupe and St. Vincent, but are very rare from archaeological excavations (Harris 1983). They are believed to be one of the few remaining cultural traits that persisted from the Preceramic Age. Both specimens have two indentations on both sides and a straight butt-end (figure 5.6). Classified in the scheme of Harris, they either fall in the Butt type 3, "flat cutaway beak" (Harris 1983, 275) (specimen K7, K6), or Butt type 12, "two ears" (ibid, 278) (specimen F15.C). From Harris (1983) we also learn that Edgar Clerc found another specimen at Morel 2 during his excavations in the early 1960s.

The raw material of the recently found axe fragment at Morel is quite rare as most of these types of axes are from a finegrained dark basalt type of rock, lacking the clear phenocrysts of the Morel specimen. Basse Terre may be a possible source, as Guadeloupe is one of the few islands, that yielded large amounts of this artefact type. Unfortunately most examples lack known find contexts. Furthermore, we do not possess any evidence of local production for these axes. Therefore, it remains unclear how the Morel inhabitants obtained this axe. Given the occurrence of Preceramic Age flint blades at Ceramic Age sites, it is clear that Ceramic Age settlers occasionally scavenged Preceramic Age material. Thus, it is possible that that this axe originated from a Preceramic Age context. It could have been picked up there by the Morel inhabitants, or perhaps obtained through exchange with other communities.

Beads and pendants

One of the most striking features of the Early Ceramic A phase involves the manufacture and use of beads and pendants from various semi-precious stones, of which some originate beyond the Antillean islands. I will not provide an extensive discussion of this industry, as others before me have begun to do so. In particular, I refer to the works of Bérard et al. (2001), Haviser (1999), Murphy (1999, Murphy et al. 2000), Narganes (1995, 1999), Vescelius \& Robinson (1979), and Watters and Scaglion (1994), who presented descriptions of lithic materials and finished items from different sites. In addition, the work of Cody (1991, 1993) and Rodríguez Lopez (1993) are important because they studied the provenance and regional distribution of these materials, including the identification of production loci. Despite these works, various issues still need to be addressed, as Watters (1997b) pointed out before me. These particularly relate to comparing archaeological materials with known sources, to be able to identify with more accuracy the actual provenance of the artefacts and the distribution trajectories that they may have followed. 


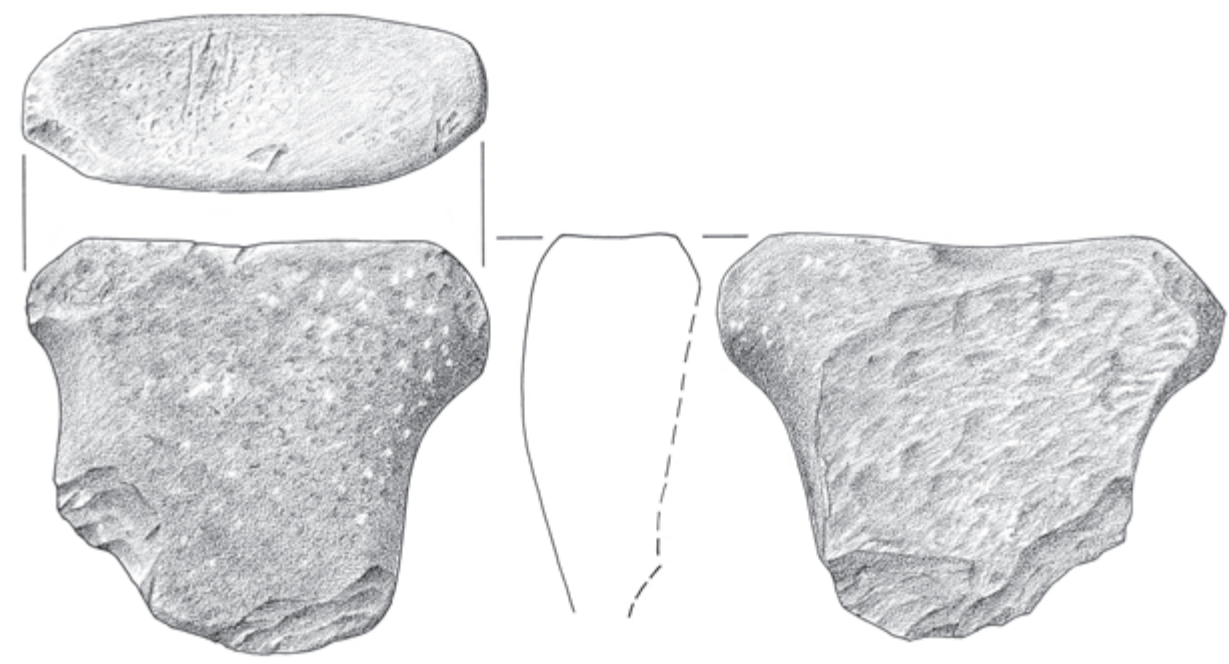

Figure 5.6. Morel, Guadeloupe. Poll part of an igneous rock eared axe (scale 1:2). (Drawing Raf Timmermans)

In short, identified materials include a wide variety of quartz related rocks, such as carnelian, amethyst, citrine, chalcedony, jasper, aventurine, and (milky) quartz. In addition, other gem stone varieties such as turquoise, nephrite, jadeite, amazonite, emerald, malachite, serpentine, barite, and calcite regularly turn up as well. Other rock varieties include diorite, quartzite, marble and different types of limestone (table 5.6 and figure 5.7 for bead examples from Morel). Cody (1991, 1993) has listed possible sources for most of these rock types. As she points out, the difficulty in tracing crystal sources is due to the fact that they are often small in size and volume, and therefore may have disappeared in some places as a result of exhaustive usage during pre-Columbian or historic times. Also, the limited geological work for some islands is another hindrance in finding possible source locations for the semi-precious rocks.

The majority of the listed gem and rock types occur naturally on one or more of the Caribbean islands. Among these "local" materials, however, a few are found in such forms that local exploitation for bead and pendant production during this early times can be questioned. A limited group of materials, on the other hand, reportedly originates only on the South American mainland, where possible sources have been identified in the Guyanas, Brazil, and Venezuela. These materials suggestive of very long distance relations include citrine, nephrite, amazonite, aventurine, and turquoise (Cody 1991, 1993; Rodríguez Lopez 1993). Despite this general agreement on the latter material being foreign to the Caribbean islands, Alminas et al. $(1994,31)$ recently reported the presence of thin veins of turquoise in fine-grained hydrothermal quartz at White Cliffs, St. Johns (US Virgin Islands). Whether the size of the crystals at this locality is large enough to be exploited for bead and pendant production is not clear from this report, but it signifies the possible occurrence of this type of rock in the Antilles.

The finding of similar, rarely occurring materials at a number of sites on different islands supposes the existence of inter-island exchange. This is further supported by differentiation in production activities of materials between these sites. Carnelian bead production, for example, is concentrated around the island of Antigua, where Murphy et al. (2000) assumes this variety naturally occurs. At more distant localities, such as Prosperity on the Virgin Islands, only finished beads have been reported.

This inter-island exchange connected a lot of the Lesser Antilles and Virgin Islands and the eastern part of Puerto Rico with the South American mainland. This is not only evidenced by the discovery of South American gem varieties such as nephrite at sites on Puerto Rico, but also from the depiction of animals in pendant form, such as the Andean vulture, a species not endemic to the Caribbean islands (Boomert 2001b). 


\begin{tabular}{|c|c|c|c|c|c|}
\hline Site & Island & Rock material & Finished only & Production & Reference \\
\hline Pearls & Grenada & $\begin{array}{l}\text { diorite, amethyst, chalcedony, citrine, } \\
\text { (milky) quartz, rock crystal turquoise, } \\
\text { nephrite, serpentine }\end{array}$ & - & $\begin{array}{l}\text { diorite, amethyst, } \\
\text { chalcedony, citrine, } \\
\text { (milky) quartz, rock } \\
\text { crystal, turquoise, nephrite, } \\
\text { serpentine }\end{array}$ & Cody 1991 \\
\hline Vivé & Martinique & $\begin{array}{l}\text { diorite, carnelian, amethyst, chalcedony, } \\
\text { jasper, quartz, quartzite, turquoise, } \\
\text { amazonite, jadeite (?), jade, emerald, } \\
\text { marble (?) }\end{array}$ & most are finished & is not specified & $\begin{array}{l}\text { Bérard et al. } \\
2001\end{array}$ \\
\hline Morel & Guadeloupe & $\begin{array}{l}\text { carnelian, amethyst, citrine (?) } \\
\text { quartz/chalcedony, limestone }\end{array}$ & citrine & $\begin{array}{l}\text { carnelian, amethyst (?), } \\
\text { quartz/chalcedony, } \\
\text { limestone (?) }\end{array}$ & Stevens 2002 \\
\hline Trants & Trants & $\begin{array}{l}\text { diorite, carnelian, amethysts, chalcedony, } \\
\text { quartz (rock crystal), quartzite, } \\
\text { aventurine (?), turquoise, nephrite/jade, } \\
\text { serpentine (?), limestone (?) }\end{array}$ & $\begin{array}{l}\text { amethyst, aventurine, } \\
\text { turqoise, nephrite/jade, } \\
\text { serpentine }\end{array}$ & $\begin{array}{l}\text { diorite, carnelian, quartz } \\
\text { (rock crystal) }\end{array}$ & $\begin{array}{l}\text { Watters \& } \\
\text { Scaglion } 1994\end{array}$ \\
\hline Royalls & Antigua & $\begin{array}{l}\text { diorite, tuff (?), carnelian, chalcedony, chert, } \\
\text { jasper (?), quartz, turquoise, nephrite, } \\
\text { serpentine, barite, calcite, limestone }\end{array}$ & $\begin{array}{l}\text { diorite, turquoise, nephrite, } \\
\text { serpentine }\end{array}$ & $\begin{array}{l}\text { tuff(?), carnelian, jasper(?) } \\
\text { chert, chalcedony, quartz, } \\
\text { barite, calcite, limestone }\end{array}$ & $\begin{array}{l}\text { Murphy et al. } \\
2000\end{array}$ \\
\hline Elliots & Antigua & $\begin{array}{l}\text { diorite, tuff, carnelian, amethyst, } \\
\text { chalcedony, chert (?), quartz, malachite, } \\
\text { nephrite, serpentine, barite, calcite, } \\
\text { limestone }\end{array}$ & $\begin{array}{l}\text { diorite, tuff, amethyst, } \\
\text { nephrite, serpentine }\end{array}$ & $\begin{array}{l}\text { carnelian, chalcedony, } \\
\text { quartz, malachite, barite, } \\
\text { calcite, limestone }\end{array}$ & $\begin{array}{l}\text { Murphy et al. } \\
2000\end{array}$ \\
\hline Hope Estate & St. Martin & $\begin{array}{l}\text { diorite, carnelian, amethyst, quartz, } \\
\text { jadeite/nephrite, calcite }\end{array}$ & $\begin{array}{l}\text { amethyst, quartz, } \\
\text { jadeite/nephrite }\end{array}$ & diorite, carnelian, calcite & Haviser 1999 \\
\hline Prosperity & St. Croix & $\begin{array}{l}\text { carnelian, amethyst, (bull) quartz, } \\
\text { magnetite quartz, quartz/hornblende, } \\
\text { aventurine, turquoise, serpentine, peridot } \\
\text { (form of olivine), garnet, actinolite, } \\
\text { metamorphosed marl, calcite }\end{array}$ & is not specified & $\begin{array}{l}\text { (bull) quartz, } \\
\text { quartz/hornblende, } \\
\text { turquoise, calcite }\end{array}$ & $\begin{array}{l}\text { Vescelius \& } \\
\text { Robinson } 1979\end{array}$ \\
\hline La Hueca & Vieques & $\begin{array}{l}\text { diorite, agate, carnelian, amethyst, green } \\
\text { quartz, rock crystal, aventurine, turquoise, } \\
\text { topaz, malachite, nephrite, jadeite, } \\
\text { serpentine, calcite }\end{array}$ & $\begin{array}{l}\text { agate, carnelian, amethyst, } \\
\text { green quartz, aventurine, } \\
\text { turquoise, topaz }\end{array}$ & $\begin{array}{l}\text { rock crystal, malachite, } \\
\text { nephrite, jadeite, } \\
\text { serpentine, calcite }\end{array}$ & Narganes 1995 \\
\hline Sorcé & Vieques & $\begin{array}{l}\text { diorite, periodotite, carnelian, amethyst, } \\
\text { agate, green quartz, rock crystal, aventurine, } \\
\text { malachite, turquoise, nephrite, jade(ite?), } \\
\text { serpentine, calcite marble }\end{array}$ & $\begin{array}{l}\text { periodotite, carnelian, } \\
\text { amethyst, agate, green } \\
\text { quartz, aventurine, } \\
\text { malachite, turquoise }\end{array}$ & $\begin{array}{l}\text { diorite, rock crystal, } \\
\text { nephrite, jade(ite?), } \\
\text { serpentine, calcite marble }\end{array}$ & Narganes 1999 \\
\hline Punta Candelero & Puerto Rico & $\begin{array}{l}\text { citrine, (milky) quartz, aventurine, } \\
\text { turquoise, local molted jadeite, exotic } \\
\text { nephrite (?), serpentine }\end{array}$ & is not specified & is not specified & $\begin{array}{l}\text { Rodríguez } \\
\text { Lopez } 1993\end{array}$ \\
\hline
\end{tabular}

Table 5.6. Early Ceramic A phase. Identified lapidary items and production remains by raw material by site.

Zemi three-pointer stones

Apart from axes, adzes, beads, and pendants, not many other items where worked into core tools or artefacts during the Early Ceramic A phase. The frequency of stone three-pointer zemis is strikingly low at this time. Only Morel, Elliots, and Sorcé have yielded finished zemis from excavated contexts (figure 5.8). From Trants, a complete calci-rudite zemi is known, but from an un-provenienced context. At Hope Estate, calci-rudite fragments were found that possibly originated from finished zemis. However, these items are associated with the later occupation phase at this site, which coincides with the Early Ceramic B phase.

Narganes Storde (1999) reports the occurrence of four zemis within the cultural deposits at the Sorcé site, in addition to five examples encountered at Tecla, a site situated on Puerto Rico and attributed to the same phase as Sorcé (Narganes Storde 1999). Among both groups of zemis, she identified four different materials, diorite, serpentine, periodotite, and marble. Although Narganes Storde does not specify a provenance for these materials, similar rock varieties occur in Puerto Rico and the Virgin Islands. 

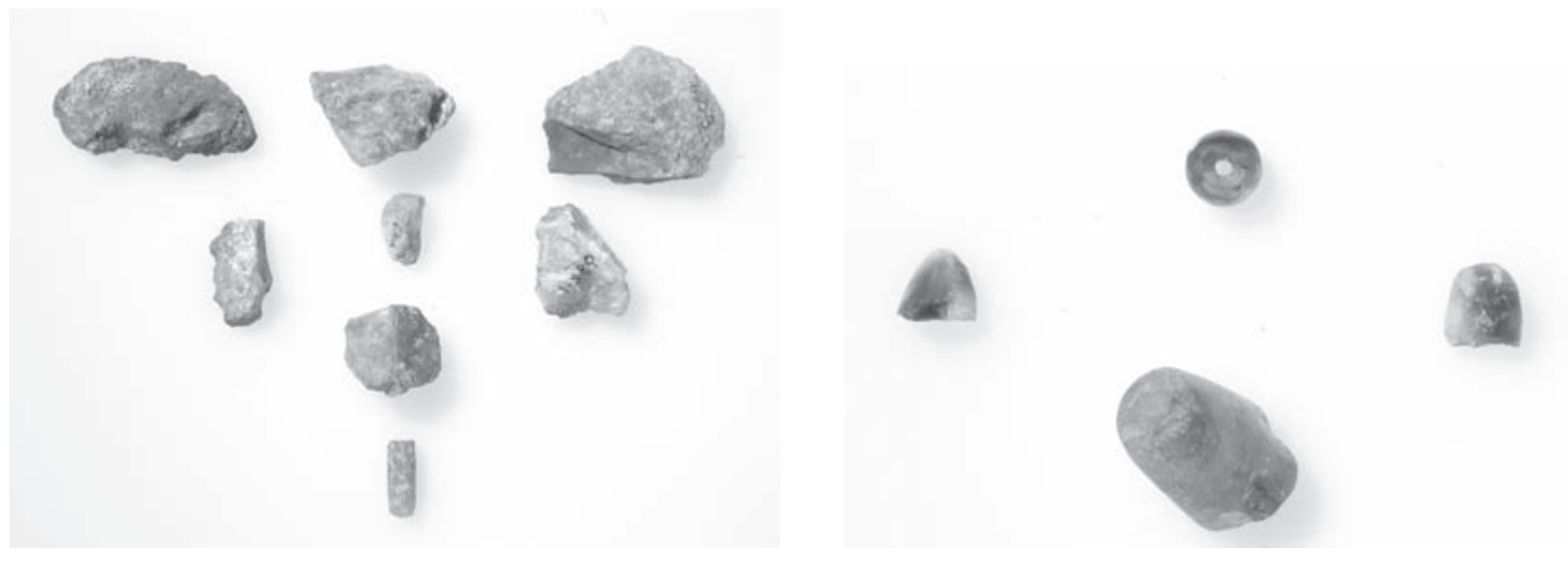

Figure 5.7. Morel, Guadeloupe. Left: a carnelian barrel bead (below; $15 \mathrm{~mm}$ length) and related manufacture debitage; Right: amethyst bead and bead fragments (lower fragment has a maximum dimension of $23 \mathrm{~mm}$ ). (Photos Ben Grishaaver)

A closer look at the sites where stone three-pointers were found reveals that they predominantly fall within the later part of this early phase. Early sites such as Fond Brûlé, but also the first occupation phases at Vivé and Hope Estate, have not yielded these stone artefacts. Apparently, the introduction is a typical Antillean phenomenon and occurred with the first migration of horticulturalists into the area. From its absence at the Martinican sites, its first appearance may be dated somewhere after $\mathrm{AD} 300$. All sites yielding these artefacts have a long occupation, which at least partly post-date AD 300.

Shaped grinding and abrading stones

The number of artefacts in this class is low (table 5.7). Vivé yielded some fragments of passive grinding/abrading stones made of a porphyritic igneous rock. These items originally belonged to large flat stones. One of these exhibits evidence of modification prior to being used, considering its unnatural shaped sides. The Morel sample includes a few very flat igneous passive abrading tools as well. Strikingly, the other sites in my study area did not yield any similar artefacts. Some produced tools that can be classified as passive grinding stones, but these are pebbles that were not shaped prior to use. Rodríguez Ramos (2001a) studied large lithic samples from La Hueca and Punta Candelero and he does not report any of these types of grinding and abrading stones.

Morel yielded another type of tool: it is a broken, flat, light green igneous granular rock with its unbroken end running into a blunt point (figure 5.9). Both sides are ground or abraded into flat and thin, (but blunt) edges. Both faces also

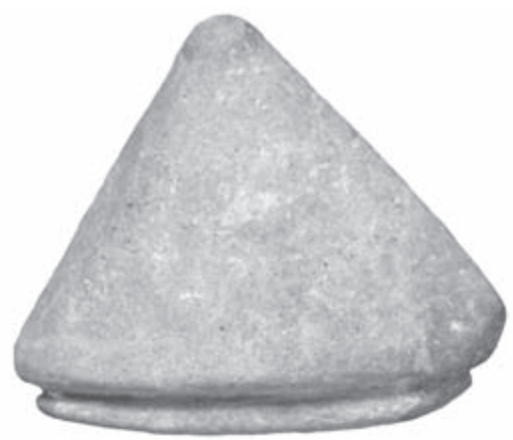

Figure 5.8. Morel, Guadeloupe. Igneous rock zemi three-pointer stone (scale 1:1). (Photo Jan Pauptit) 


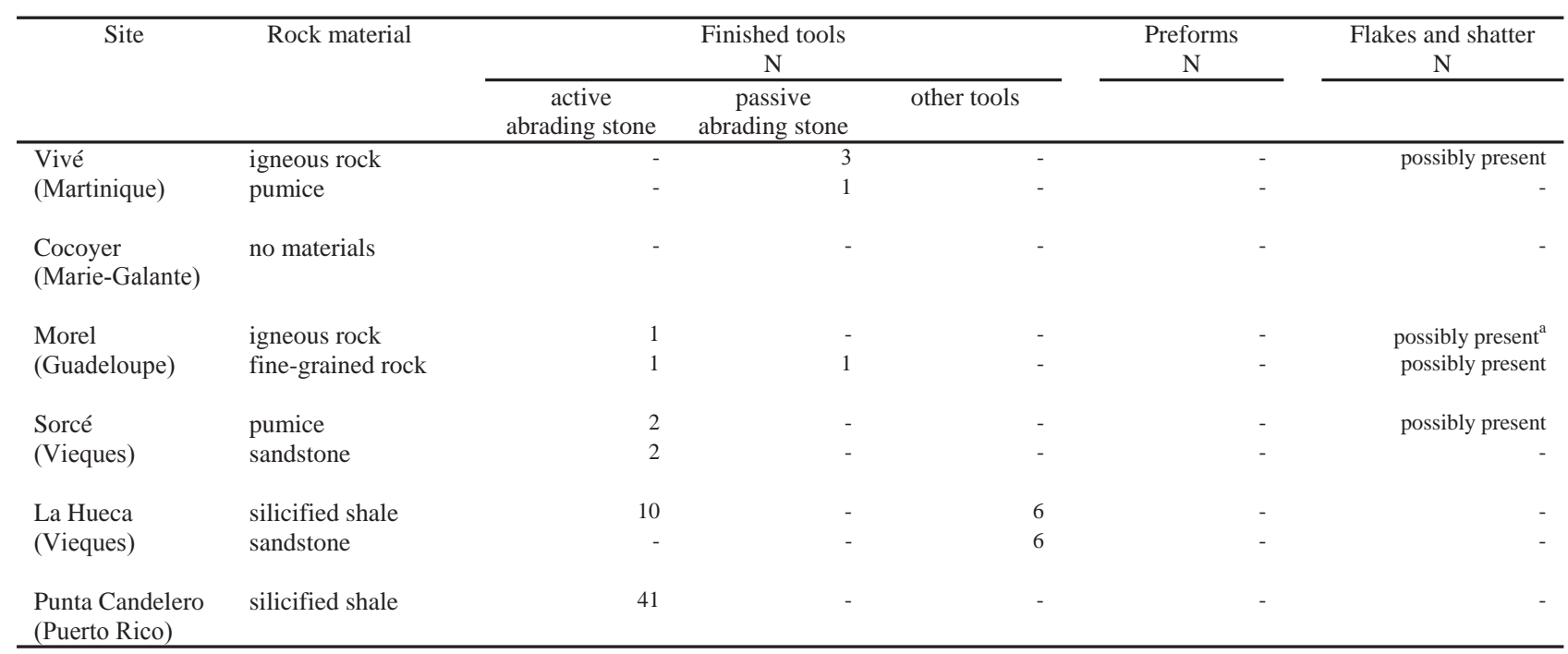

Table 5.7. Early Ceramic A phase. Number of identified shaped grinding and abrading tools and related manufacture debris by raw material by site. a Morel: minor amounts of flake and shatter are present, these, however, can also be related to the manufacture of axes.

display evidence of modification. The faces may have been ground to make the object thinner or abraded through some repetitive usage. In the case of the second modification, this object may have served as an active abrading tool similar to the use of a mano in grinding vegetable substances on a metate. If the modification marks are only related to the shaping of the object, then its function remains unclear. The source of this light green rock remains unspecified. La Désirade, where a huge variety of igneous rocks occur, including green ones, as well as Antigua, where green igneous rock is known, may be possible sources for this material.

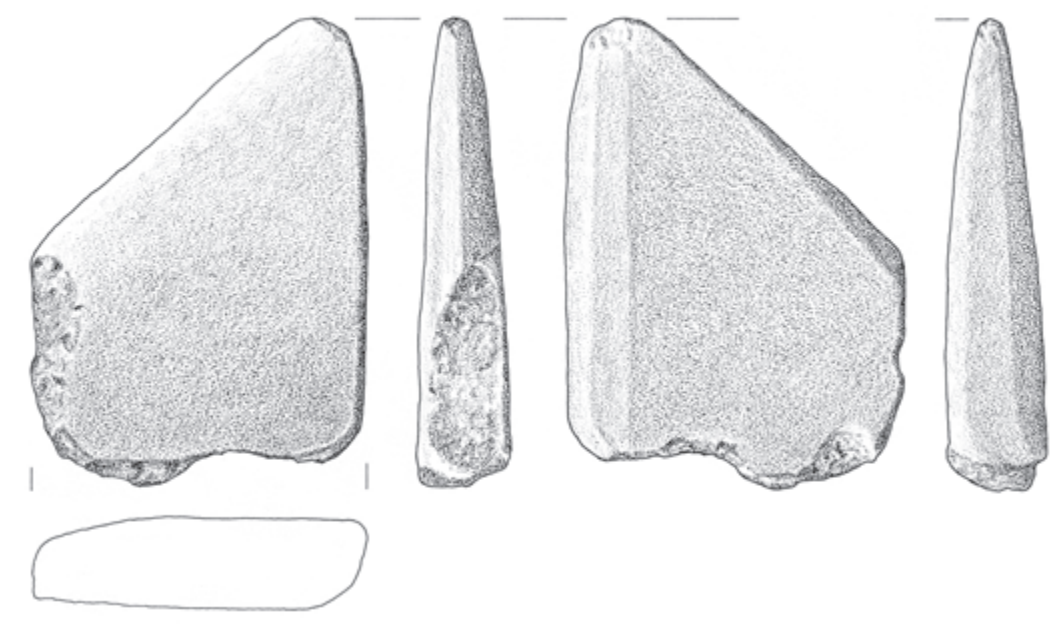

Figure 5.9. Morel, Guadeloupe. Igneous rock fragment of a flat possibly active abrading tool (scale 1:2). (Drawing Raf Timmermans) 
Use-modified rock and manuports

Use-modified tools, predominantly in the form of utilized water-worn pebbles, form a significant segment of the lithic collections studied. In addition, the number of pebbles without any evidence of usage is also striking. These latter pebbles represent true manuports originating from elsewhere, as well as pebbles naturally occurring in the site area.

Table 5.8 lists the different tool-types. Following the classification methodology discussed in Chapter 3, only macroscopic identifiable traces of modification were recorded and artefacts were classified to broad functional categories without specifying direction and depth of traces. Preliminary results from microscopic use-wear analysis have shown that many traces resulted from more than a single functional activity (Lammers-Keijzers in prep., personal communication 2001).

Raw materials at the different sites predominantly fall within the igneous rock class for this category of lithic specimens. In addition, limestone, plutonic rock, metamorphic rock, sandstone, chert, quartz, and other fine-grained varieties of an undefined nature occur as well. Igneous rock artefacts display the largest variety of functions. Among the pebbles, the following tool types were identified: hammerstones, anvils, polishing stones, and active and passive abrading stones. Limestone, metamorphic, plutonic, chert, quartz, and jasper pebbles were mainly collected for usage as hammerstones. Rare examples of polishing stones were seen among the limestone, chert, and quartz pebbles. This latter type of tool is commonly associated with fine-grained rock of an undefined nature. Rare sandstone artefacts were used as active and passive abrading stones.

\begin{tabular}{|c|c|c|c|c|c|c|c|c|}
\hline \multirow[b]{2}{*}{ Site } & \multirow[b]{2}{*}{ Pebble Material } & \multicolumn{7}{|c|}{ Tool types $(\mathrm{N})$} \\
\hline & & $\begin{array}{l}\text { non-utilized } \\
\text { pebble }\end{array}$ & $\begin{array}{l}\text { hammer } \\
\text { stone }\end{array}$ & anvil & $\begin{array}{l}\text { passive } \\
\text { abrading } \\
\text { stone }\end{array}$ & $\begin{array}{l}\text { active } \\
\text { abrading } \\
\text { stone }\end{array}$ & $\begin{array}{l}\text { polishing } \\
\text { stone }\end{array}$ & other tool \\
\hline $\begin{array}{l}\text { Vivé } \\
\text { (Martinique) }\end{array}$ & igneous rock & 6 & 1 & 1 & 2 & - & - & - \\
\hline $\begin{array}{l}\text { Cocoyer } \\
\text { (Marie-Galante) }\end{array}$ & igneous rock & - & 1 & - & - & - & - & - \\
\hline \multirow{9}{*}{$\begin{array}{l}\text { Morel } \\
\text { (Guadeloupe) }\end{array}$} & igneous rock & 429 & 20 & 3 & - & 26 & 1 & 21 \\
\hline & plutonic & 52 & - & - & - & 1 & - & - \\
\hline & metamorphic rock & 23 & 5 & - & - & - & - & 1 \\
\hline & sandstone & 3 & - & - & - & 1 & - & - \\
\hline & fine-grained rock & - & - & 1 & - & 5 & - & - \\
\hline & chert & 3 & 1 & - & - & - & - & - \\
\hline & quartz & - & 1 & - & - & - & - & - \\
\hline & limestone & 16 & 1 & - & - & 1 & - & 1 \\
\hline & unidentified rock & 1 & - & - & - & - & - & - \\
\hline \multirow{10}{*}{$\begin{array}{l}\text { Sorcé } \\
\text { (Vieques) }\end{array}$} & igneous rock & 72 & 4 & 2 & - & 1 & 26 & - \\
\hline & plutonic & 3 & 1 & - & - & - & - & - \\
\hline & pumice & 1 & - & - & - & - & - & - \\
\hline & metamorphic rock & 2 & - & - & - & - & - & - \\
\hline & sandstone & - & 1 & - & - & - & - & - \\
\hline & fine-grained rock & 32 & 1 & - & - & - & 9 & - \\
\hline & chert & 3 & 2 & - & - & - & 2 & - \\
\hline & quartz & 25 & 3 & - & - & - & - & - \\
\hline & limestone & 4 & - & 1 & - & - & - & - \\
\hline & unidentified rock & 11 & 3 & - & - & 2 & 4 & - \\
\hline \multirow{5}{*}{$\begin{array}{l}\text { La Hueca } \\
\text { (Vieques) }\end{array}$} & igneous rock & n.s. & present & present & - & - & present & - \\
\hline & sandstone & n.s. & - & - & present & - & - & - \\
\hline & fine-grained rock & n.s. & - & - & - & - & present & - \\
\hline & chert & n.s. & present & - & - & - & - & - \\
\hline & quartz & n.s. & present & - & - & - & - & - \\
\hline \multirow{5}{*}{$\begin{array}{l}\text { Punta Candelero } \\
\text { (Puerto Rico) }\end{array}$} & igneous rock & n.s. & present & present & - & - & present & - \\
\hline & sandstone & n.s. & - & - & present & - & - & - \\
\hline & fine-grained rock & n.s. & - & - & - & - & - & - \\
\hline & chert & n.s. & present & - & - & - & - & - \\
\hline & quartz & n.s. & present & - & - & - & - & - \\
\hline
\end{tabular}

Table 5.8. Early Ceramic A phase. Number of identified use modified rocks and manuports by raw material, by site. n.s. $=$ not specified. 
Contrary to the flake tool and axe/adze materials, many of the lithic varieties at the studied sites either have a local provenance, possibly in the immediate site surroundings, or originate from localities in relatively close proximity. For example, many of the igneous materials found at Vivé and too a lesser degree at Sorcé, La Hueca and Punta Candelero, were probably collected from beaches or stream beds in the vicinity of each site. In the case of Morel, however, as well for the single igneous rock artefact from Cocoyer, the inhabitants had to make boat-trips to the small island of La Désirade or neighbouring volcanic islands such as Basse Terre or les Saintes for the procurement of igneous pebbles. In particular, at the Morel site the majority of the igneous rock resembles the large variety of this rock class natural to the island of La Désirade and easily accessible along many of its beaches. Travel to La Désirade only involves a $25 \mathrm{~km}$ boat trip.

Apart from the locally available rock pebbles, the samples from Sorcé, La Hueca and Punta Candelero include some non-local rocks as well. Predominant is the fine-grained black peridotite, similar to the materials used for the axes and adzes, which probably originates in southwestern Puerto Rico. In addition, the chert pebbles and some fine-grained green and light coloured rock varieties likely come from unspecified exotic sources.

Within the class of use-modified artefacts the hammerstones and polishing stones predominate. The Early Ceramic A phase yielded various hammerstone shapes not encountered during later phases. In particular, within the Sorcé and to a lesser degree the Morel sample these different types are well represented. Rodríguez Ramos (2001a) reports a similar variety of hammerstone types for the La Hueca and the Punta Candelero samples:

(a) A round ball shape with use-wear in the form of pits almost totally covering the stone. Only quartz and flint were used for this type of hammer tool.

(b) A round flat shape with six possible locations of use-wear: on both ends, the middle of both faces, and both sides. Igneous rock is predominant among this group; and

(c) An elongated shape with use-wear on one or both ends, and in some cases also on both sides. Igneous rock predominates as well. It should be further noted that a number of re-used artefacts corresponds with this type of hammer tool (figure 5.10).

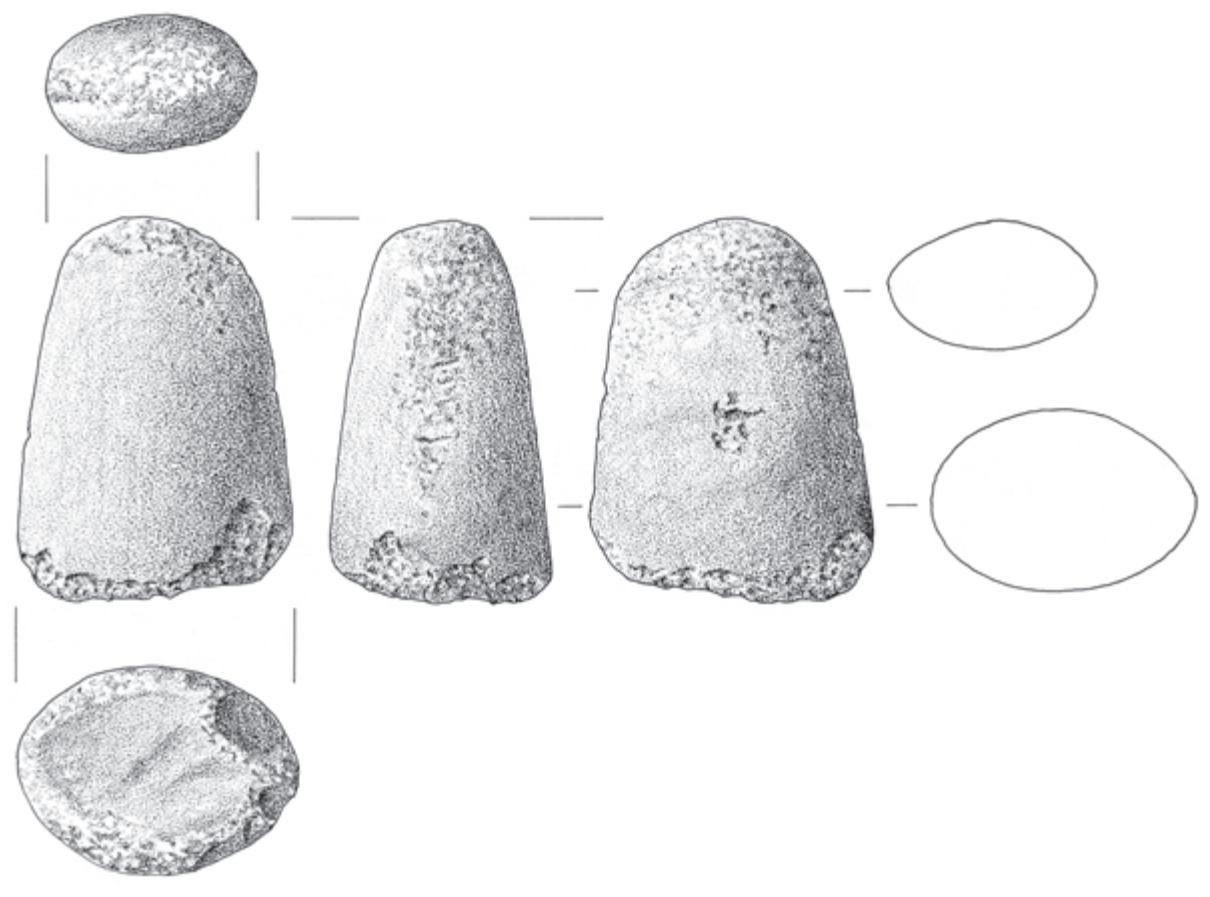

Figure 5.10. Morel, Guadeloupe. Heavily utilized igneous rock hammerstone, exhibiting usewear on both ends, sides and one face (scale 1:2). (Drawing Raf Timmermans) 
Polishing stones are relatively small in size and basically only include fine-grained rock varieties. Black igneous examples from Sorcé, La Hueca, and Punta Candelero, all display clear striated areas (see also Rodríguez Ramos 2001a). In the case of other examples, striations are more difficult to identify.

A variety of abrading stones and rare examples of anvils and passive grinding/abrading stones occur as well. The former group is characterised by significant variation in raw material, size, and location of use marks, suggesting different functions. Anvils are largely made of flat igneous rock pebbles. This is also the case for the passive grinding stones.

Close inspection of the large group of small igneous pebbles found at Morel and originating on La Désirade revealed a black residue, present in a thin band around the stone (figure 5.11) (Stevens 2002). Microscopic analysis of this black residue showed that the substance is organic in nature, and probably was an adhesive to firmly attach something around the rock (Lammers-Keijsers in prep., personal communication 2001). This may have been a rope, suggesting these pebbles may have functioned as fish-net weights, which had firmly been tied to the nets.

The small group of 23 artefacts displaying black residue resembles a larger group, found at Morel, of more than 400 pebbles in size and raw material. These pebbles were mostly excavated in concentrations and may have served the same purpose. In particular, this becomes evident when it is considered that this black residue may have easily eroded from the artefact. For example, some pebbles only have small segments of the original bands displaying this black substance. Another possibility is that this resin was not used on every pebble or that some pebbles were never used and had been collected for future usage. Despite the fact that none of the other sites dating to this phase yielded comparable black residue on pebbles, this particular function may partly explain the strikingly large number of non-modified pebbles excavated at Sorcé.

Comparing the tools among the sites showed that La Hueca and Punta Candelero yielded additional types of lithic tools not encountered at other sites (Rodríguez Ramos 2001a). The most striking example is the edge ground cobble, which is also reported from Preceramic Age contexts. Rodríguez Ramos (2001a) considers the presence of this artefact at these sites as an indication that these two Huecan Saladoid settlements were culturally distinct from their Cedrosan Saladoid neighbours. Again, it is possible that this tool type was picked up by Early Ceramic Age people at a Preceramic Age site. The number of other forms of naturally shaped rock classified as artefacts is small. Only the Sorcé site included a number of red ochre pieces, which probably served as raw material to be pulverised for use as a pigment.

\subsubsection{Early Ceramic B}

\section{Introduction}

Collections varying in size have been studied from nine sites dating to this phase of the Early Ceramic Age (table 5.9). In addition to these sites, Walker (1980) and Crock \& Petersen (1999) have reported on lithic samples from another two sites: Sugar Factory Pier and Rendezvous Bay. Furthermore, I exchanged data with Rodríguez Ramos about the later phase of the Punta Candelero site, as well as on the second occupation phase of the Paso del Indio site. Similar to the preceding section the studied samples do not represent all of the complete lithic inventory excavated at these sites (see table 5.9).

\section{Flake tool production}

Raw materials

Various fine-grained materials falling into the class of cherts and chert related rocks were again reduced to produce flake tools. Detailed comparison with the previous phase, however, shows that minor changes occurred in some areas with regard to the use of specific chert varieties (table 5.10). This is most apparent in the Guadeloupe - Antigua area, where the white chert almost completely disappeared among most collections. Only at Doigs was a significant number encountered ( $\mathrm{N}=40$; $14 \%)$. At Anse à l'Eau, the other site with white chert finds, the amount is significantly lower $(\mathrm{N}=2 ; 3.3 \%)$. Likewise, Corbison Point/Dry Hill chert was not identified in this phase either. In the case of this latter material, its frequency within the Early Ceramic A phase is very low and the difference identified may be merely a result of sample bias.

As a consequence, Early Ceramic B sites on Guadeloupe display a much higher reliance on Long Island flint than before. Similar high percentages of Long Island flint were encountered at sites on St. Kitts, St. Eustatius, and Saba, islands not represented within the earlier phase samples. The abundance of Long Island flint considerably diminishes on St. Martin and beyond, however. At Anse des Pères, for example, only 45\% came from Long Island, whereas limited material from the 

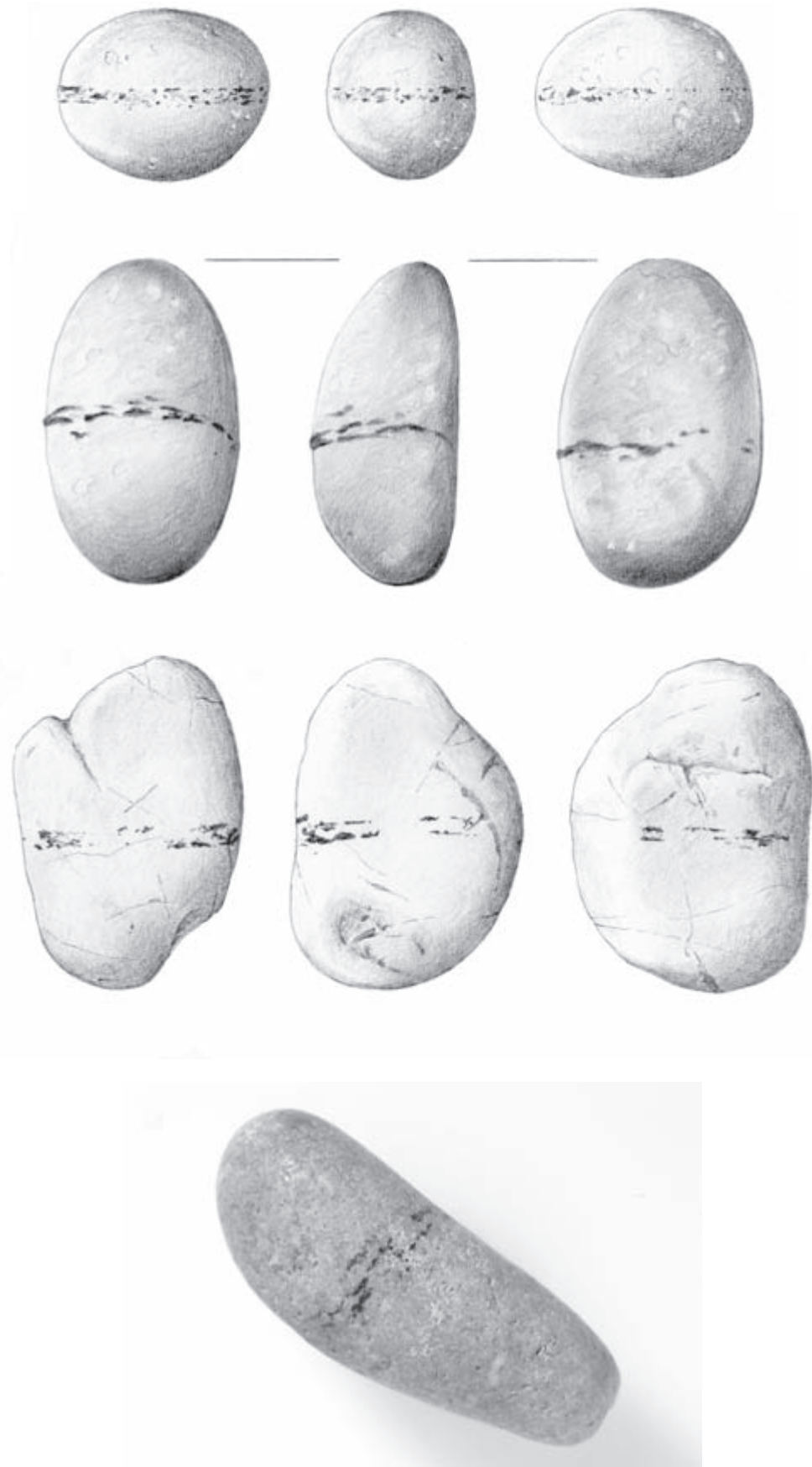

Figure 5.11. Morel, Guadeloupe. Igneous rock pebbles with a thin band of black residue, possibly used as net-weights (scale 1:1). (Drawings Raf Timmermans and photo Ben Grishaaver) 


\begin{tabular}{llll}
\hline Site & Island & Type of sample & Reference \\
\hline Diamant & Martinique & all lithics & - \\
Anse à la Gourde early & Grande Terre & all lithics & - \\
Anse à l'Eau early & Grande Terre & all lithics & - \\
Les Sables & La Désirade & all lithics & - \\
Doigs late & Antigua & flake tool related artefacts & - \\
Sugar Factory Pier & St. Kitts & all lithics & Walker 1980a \\
Golden Rock & St. Eustatius & all lithics & - \\
Kelbey’s Ridge 1 & Saba & flake tool related artefacts & - \\
Anse des Pères & St. Martin & all lithics & Crock \& Petersen 1999 \\
Rendezvous Bay & Anguilla & all lithics & \\
\hline
\end{tabular}

Table 5.9. Studied sites from the Early Ceramic B phase. Data from sites in italic have been obtained from literature.

early occupation phases at Rendezvous Bay and Sandy Ground on Anguilla display similar percentages.

In relation to the use of Long Island flint on the island of Antigua itself, the picture is still somewhat vague due to the limited data available. Diachronic variability at the Doigs site along the south coast shows that its percentage increases within the later deposits within a single test-unit analysed, corresponding with this phase. At Mill Reef, where occupation started around this phase well into the Late Ceramic Age, around $68 \%$ of flake material is from Long Island, while the remainder originated from other sources local to the island (De Mille 2001).

Data from sites within the Saba - Guadeloupe region show that the exploitation of other Antigua sources and chert materials from other islands remained very limited during this phase. Generally individual varieties other than Long Island do not exceed 5\% for most sites. Identified sources include Little Cove or Soldier Point, Blackman's Point, the northeastern part of La Désirade, possibly St. Kitts, and possibly Martinique. With regard to these latter origins, the possible low occurrence of St. Kitts flint at Sugar Factory Pier and on the surrounding islands is striking. Unlike Martinique, where the use of local material inferior to Long island flint is predominant (see below), this is not the case on St. Kitts. I have questioned the true natural nature of the Great Salt Pond and Sugar Factory Pier flint sources on St. Kitts (see Appendix A). However, I was unable to find definite proof for an artificial origin (i.e. ballast dropping during Historic times). If these flint varieties are indeed natural to St. Kitts, this would suggest that the Sugar Factory Pier inhabitants had much easier access to the Long Island material than did the Martinicans. This easy access allowed them to almost totally neglect their Kittian flints, which are scattered in the immediate surroundings of the Sugar Factory Pier settlement. In addition, most sites yielded chert

\begin{tabular}{|c|c|c|c|c|c|c|c|c|}
\hline Chert type & Site & $\begin{array}{l}\text { Anse des Pères } \\
\begin{array}{c}\text { N=201 } \\
\text { \% }\end{array}\end{array}$ & $\begin{array}{c}\text { Kelbey's } \\
\text { Ridge } 1 \\
\mathrm{~N}=80 \\
\%\end{array}$ & $\begin{array}{c}\text { Golden Rock } \\
\begin{array}{c}\text { N=676 } \\
\%\end{array}\end{array}$ & $\begin{array}{c}\text { Doigs late } \\
\begin{array}{c}\text { N=292 } \\
\%\end{array}\end{array}$ & $\begin{array}{c}\text { Anse à l'Eau } \\
\text { early } \\
\mathrm{N}=119 \\
\%\end{array}$ & $\begin{array}{c}\text { Anse à la } \\
\text { Gourde early } \\
\mathrm{N}=15 \\
\%\end{array}$ & $\begin{array}{c}\text { Diamant } \\
\text { N=177 } \\
\%\end{array}$ \\
\hline Long Island flint & & 45.3 & 62.5 & 71.3 & 54.8 & 50.4 & 100 & 0.6 \\
\hline Blackman's Point flint & & - & - & 0.3 & 0.7 & 0.8 & - & - \\
\hline Coconut Hall flint & & - & - & 0.4 & - & - & - & - \\
\hline Antigua Form. flint & & - & - & 1.4 & - & 0.8 & - & - \\
\hline White chert & & - & - & - & 13.7 & 1.7 & - & - \\
\hline Petrified wood & & - & - & - & - & 1.7 & - & 6.2 \\
\hline Other chert & & 35.8 & 26.3 & 19.8 & 30.8 & 18.6 & - & 32.8 \\
\hline Désirade red chert & & - & - & - & - & 1.7 & - & - \\
\hline Jasper & & 1.5 & - & 0.6 & - & - & - & 55.9 \\
\hline White quartz & & 8.0 & - & - & - & - & - & 4.5 \\
\hline Unidentified chert & & 9.5 & 11.3 & 6.1 & - & 25.2 & - & - \\
\hline
\end{tabular}

Table 5.10. Early Ceramic B phase. Relative amount of identified chert types by site. 
varieties for which I could not specify a source. In general, these are (slightly) translucent ones, to some extent resembling chalcedony.

On Martinique, the heavy reliance on local chert varieties continued during this phase, similar to the earlier occupation at Vivé. The total amount of local rock at Diamant is approximately $100 \%$, which is similar to Vivé, although the Diamant site differed in the ratios of local materials, probably as a result of the exploitation of other source areas on Martinique, closer to the Diamant site itself. The presence of only one Long Island flake points to the limited acquisition of exotic cherts.

Within the western part of the study area (Puerto Rico and the Virgin Islands), comparison with the earlier phase is hampered by the absence of analysed samples. Rodríguez Ramos, who examined some material from the Cuevas occupation at both Punta Candelero and Paso del Indio sites, noted continuation of the use of chert and flint materials for flake tool production. Despite this continuation, Rodríguez Ramos saw some changes in the raw materials used, with the later phase exhibiting a smaller range. Still, he also identified the use of Long Island flint at both sites (Rodríguez Ramos 2001a, 2005).

\section{Reduction and tool production}

Technological analysis did not reveal a significant change from the preceding phase for the Early Ceramic phase B. Chert was reduced on site following a similar expedient technology, both employing bipolar and direct freehand percussion techniques (figure 5.12). The small average size of flake material and cores found on islands surrounding Antigua shows that the materials were worked exhaustively, during which reduction of large flakes to obtain smaller flakes was a commonly employed strategy. At Diamant, a similar small size of flaked materials was encountered, probably due to small natural size of local material available.

Use of flakes occurred in most cases without prior edge modification, although rare examples of secondary edge working were identified. Formal tool types, however, are again lacking. The relatively large flaked lithic sample from Golden Rock includes a wide variety of utilized flakes (figure 5.13). Edge shapes exhibiting use-wear suggest that cutting, scraping, and drilling formed recurrent tasks for which these tools were employed. The presence of utilized cores at Golden Rock provides a good example of the opportunistic usage of these fine-grained materials even after they served as cores.

Cortex data on flakes show that Long Island flint arrived at Golden Rock in unmodified form (see next Chapter). With regard to other varieties, the limited number of artefacts, and the limited knowledge of cortical surfaces for unknown varieties hampered proper insight into the reduction stage at which material arrived on site. Generally, cortical flakes are present among the different samples, suggesting that arrival of unmodified material should be considered as a likely option.

\section{Core tool production}

Axes and adzes

The number of axes and adzes found is generally low at each site, but there are a few exceptions (table 5.11). Anse des Pères and Golden Rock yielded a relatively high number of artefacts, which can be largely attributed to local axe manufacture. Comparison with the preceding phase reveals both differences and similarities. Again, the absence of adzes within the Lesser Antilles sites is notable, whereas on Puerto Rico the use of this plano-convex tool still occurred, as is shown by its presence within the corresponding phase at Paso del Indio (Rodríguez Ramos, personal communication 2001). Furthermore, greenstone from St. Martin and different varieties of igneous rock are the predominant rock types at the different sites. In contrast, metamorphic rock is less generally present. Only the Golden Rock site yielded several examples, whereas in the preceding phase all Puerto Rican sites and most Lesser Antilles sites produced some such artefacts. As a result of the low numbers generally it is difficult to establish whether this difference is significant or not.

In contrast to the Early Ceramic A phase, the Early Ceramic B phase yielded considerable evidence of on-site axe manufacture. This increase can be mainly attributed to the expansion of St. Martin greenstone axe fabrication to islands surrounding St. Martin. Sites yielding evidence of axe production are Golden Rock on St. Eustatius (figure 5.14), Rendezvous Bay on Anguilla (Crock \& Petersen 1999), and Sugar factory Pier on St. Kitts (Walker 1980). Saba may be included as well, and more detailed analysis of a complete sample of lithic artefacts may attest this in the future.

Evidence relating to the working of igneous rocks is more abundant as well. In particular, the Anse des Pères site on St. Martin yielded a considerable number of preforms and flakes. Within this group, a distinction can be made between the working of water-worn pebbles into axes, including a variety of rock types (figure 5.15), and the reduction of dark coloured fine-grained basalt blocks. The former group probably was obtained from the cobble beach adjacent to the site, whereas 

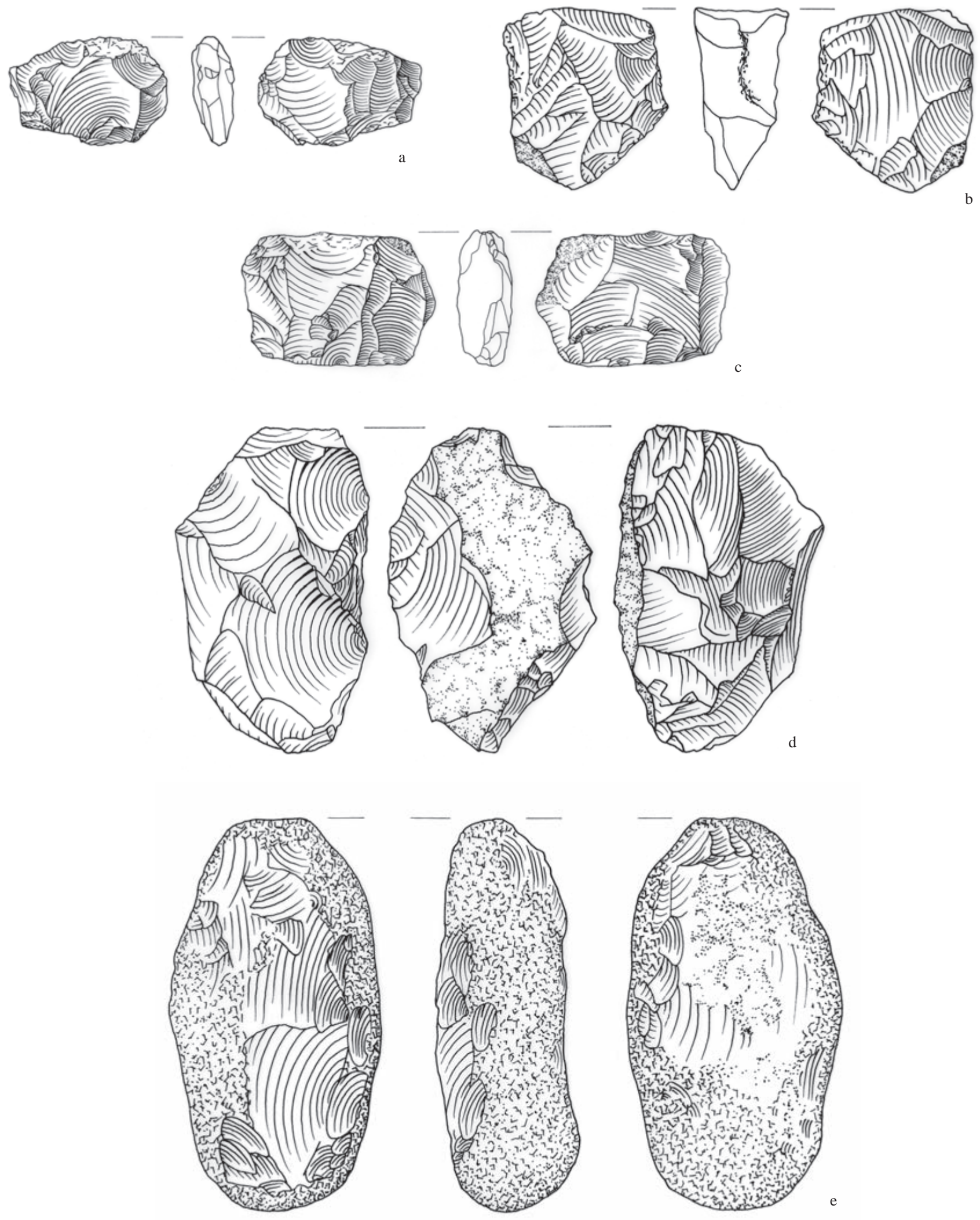

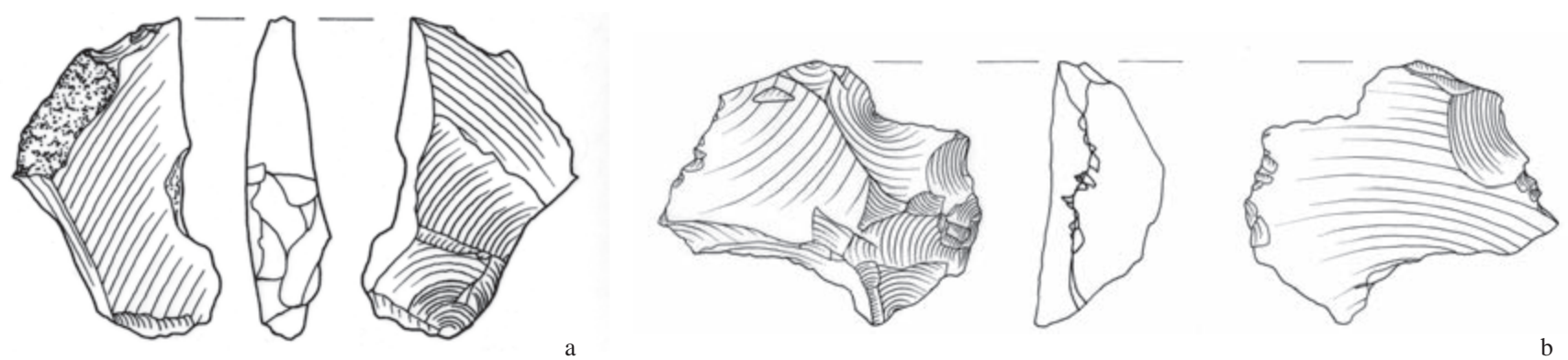

a
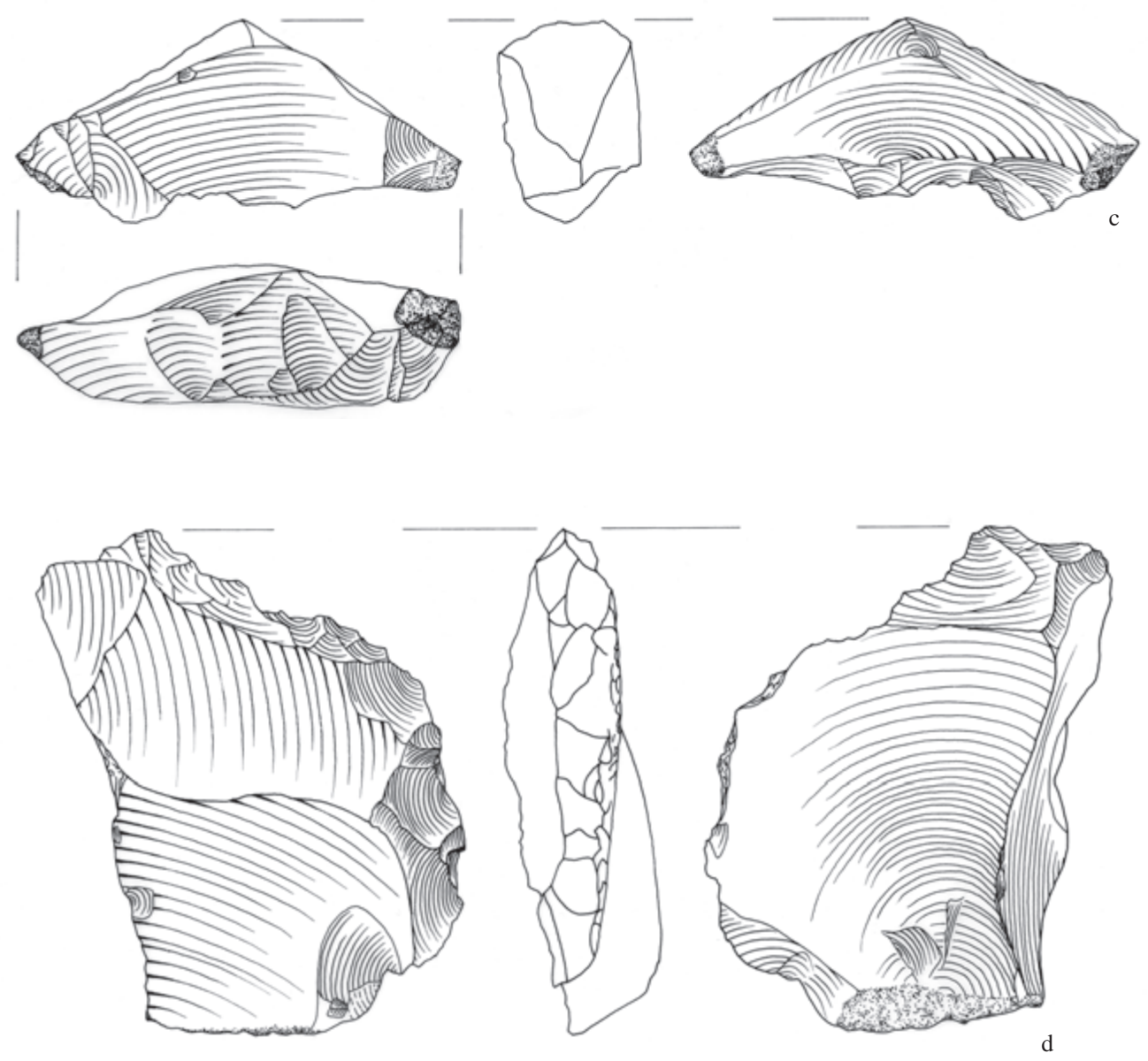

Figure 5.13. Golden Rock, St. Eustatius. Utilized and modified flakes; a. modified flake with use-retouch along a curvate edge; b. core on flake with use retouch; c. bipolarly split flake; d. modified flake with unifacial intentional retouch (scale 1:1). (Drawings Raf Timmermans)

Figure 5.12 (opposite page). Golden Rock, St. Eustatius. Flake cores: a, b, and c. bidirectional bipolar cores; d. polyhedral core; e. flake core later used as hammerstone with use-wear along the entire circumference of the stone (scale 1:1). (Drawings Raf Timmermans) 


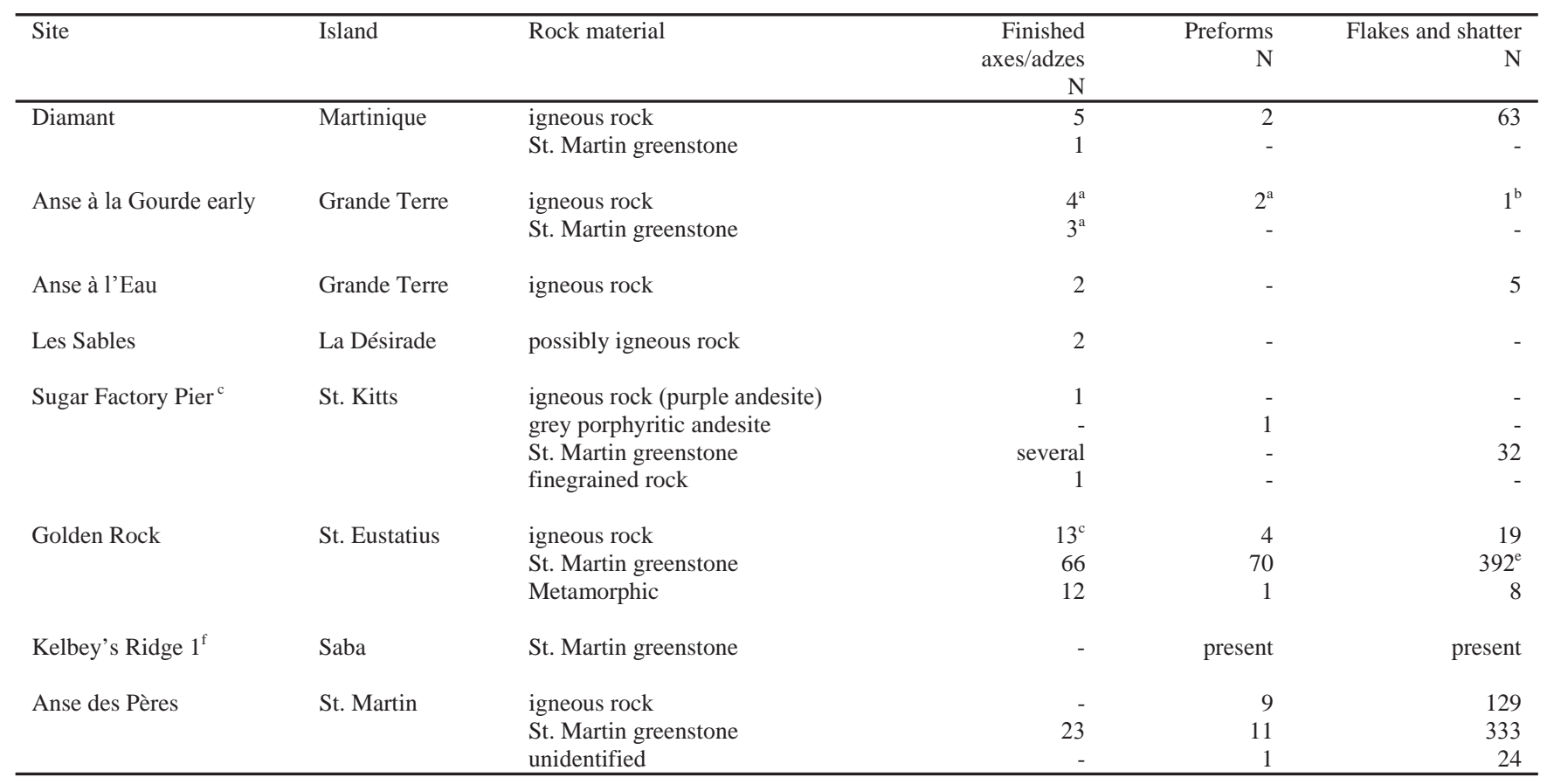

Table 5.11. Early Ceramic B phase. Identified axes and axe production related artefacts by raw material by site. a Anse à la Gourde: three igneous rock and three greenstone axes are not from test-unit sample, but from other contexts; $b$ igneous rock flake is from other material than finished axes; c Data from Walker (1980); d The Golden Rock sample includes 2 tuff axes; e Greenstone shatter and flakes does not include 61 (fragmentary) unidentified core artefacts; ${ }^{f}$ Material from Kelbey's Ridge 1 has only been superficially and very minimally looked at, this initial inspection, however, confirmed the presence of St. Martin greenstone axe manufacture debris.

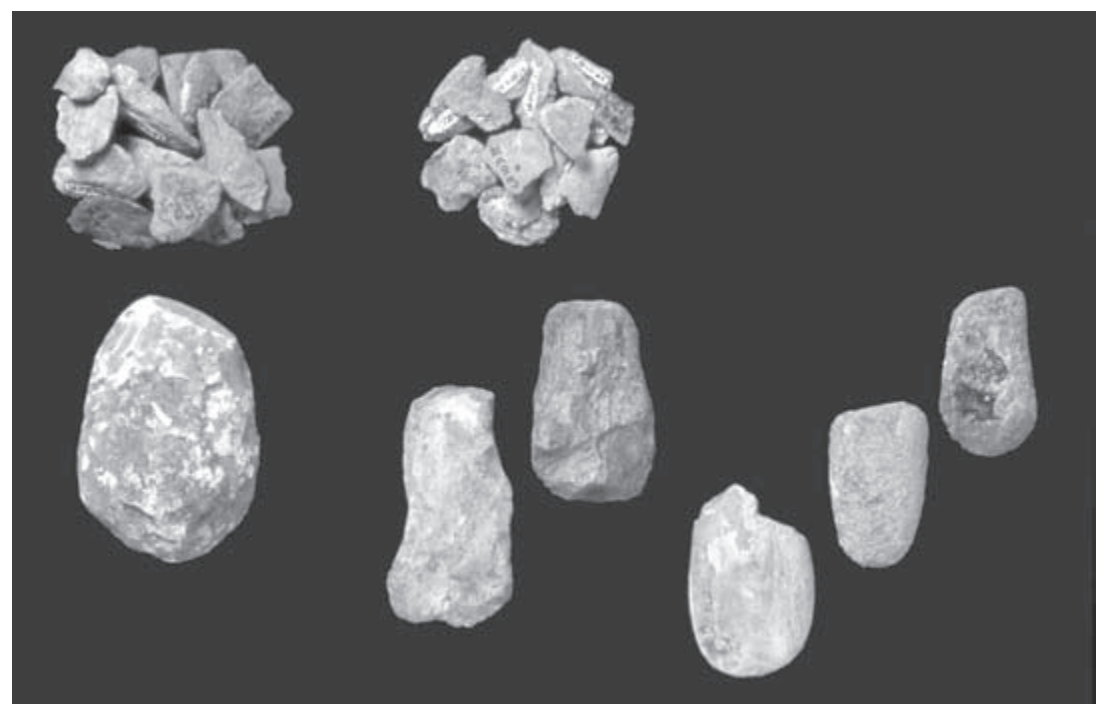

Figure 5.14. Golden Rock, St. Eustatius. St. Martin greenstone axes (lower right) and related manufacture debitage comprising preforms (centre and lower left) and flakes (top). (Photo Jan Pauptit) 

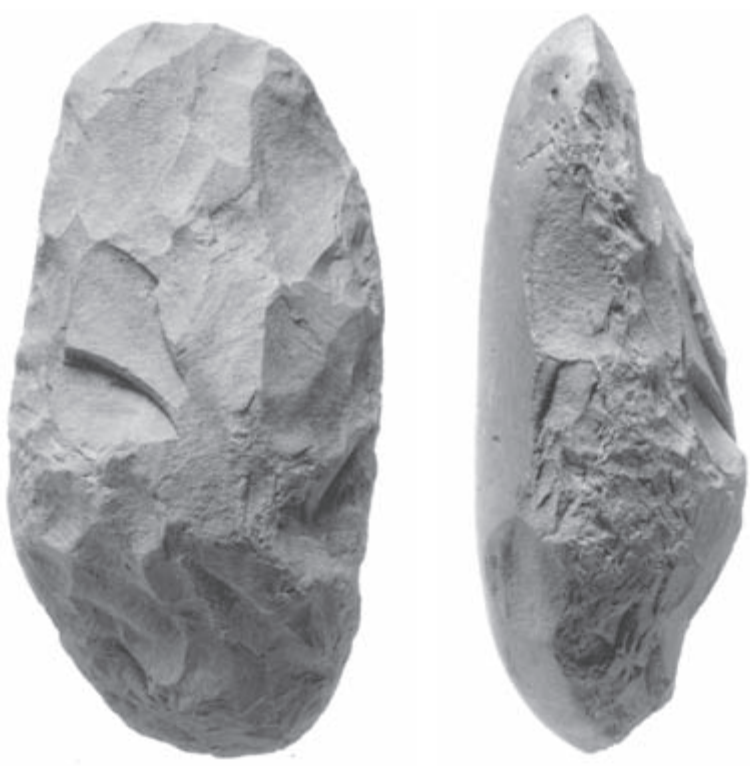

Figure 5.15. Anse des Pères, St. Martin. Igneous rock axe preform with one face still bearing the original water-worn surface suggesting procurement of pebbles as raw material for axe manufacture (scale 1:2). (Photos jan Pauptit)

the latter group resembles local material originating on the northern part of the island, as mentioned by Haviser (1999, 200 fig.13.6).

In addition, two other sites produced igneous rock debitage associated with axe production. The Diamant site on Martinique produced clear evidence of axe making out of local igneous water-worn pebbles. At Golden Rock, only some fine-grained flakes resembling a small number of axe preforms can be related to local axe making.

The acquisition of finished tools was attested to at the majority of sites and these not only include sites lacking evidence of local production. Also, settlements with evidence for on-site axe making yielded finished items for which no related debitage was found and which were made from exotic rocks. In particular, the high number of imported tools at the Golden Rock site is striking, when it is recognised that local greenstone and igneous rock were worked into axes as well (figure 5.16). This combination of import and local production may indicate various things. Either distinct materials were used for different purposes, or their presence is explainable from a social perspective. It was a result of the participation of Statia inhabitants in a regular exchange network, in which these items did not necessarily meet a functional demand, but rather, they fulfilled a predominant social role, as gifts to bind exchange partners, for example.

Some sites point to the import of axes made out of a fine-grained variety of greenstone that is different from the St. Martin greenstone, and which probably represents an igneous rock. This shows that this material had a regional importance within the northern Lesser Antilles more broadly. Sites yielding these finished items included Anse à la Gourde, les Sables, and Diamant (figure 5.17).

Beads and pendants

One of the most striking differences in stone working between the Early Ceramic A and later phases relates to the making of stone beads and pendants. The difference is twofold. Firstly, stone beads and in particular stone pendants become less frequent during later phases, particularly in the Early Ceramic B phase. Secondly, a number of specific gem stone varieties disappeared, with predominantly local varieties remaining as raw materials for bead making (table 5.12).

The first difference is most clearly shown by a comparison of the Golden Rock site dating to the Early Ceramic B phase with the sites on Vieques and Puerto Rico dating to the preceding phase. Not a single pendant and only two beads 

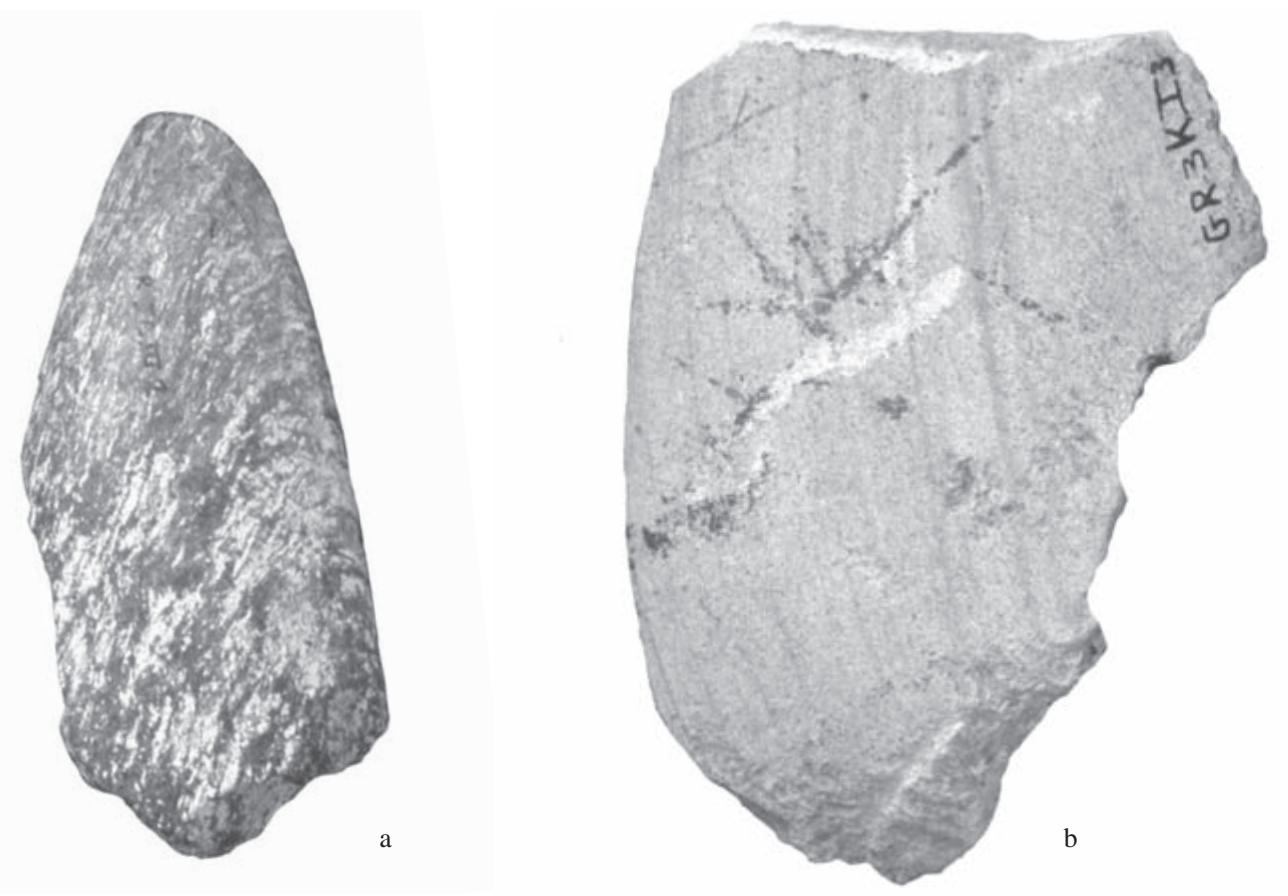

Figure 5.16. Golden Rock, St. Eustatius. Two axe fragments made of exotic metamorphic rocks (scale 1:1). (Photos Jan Pauptit)
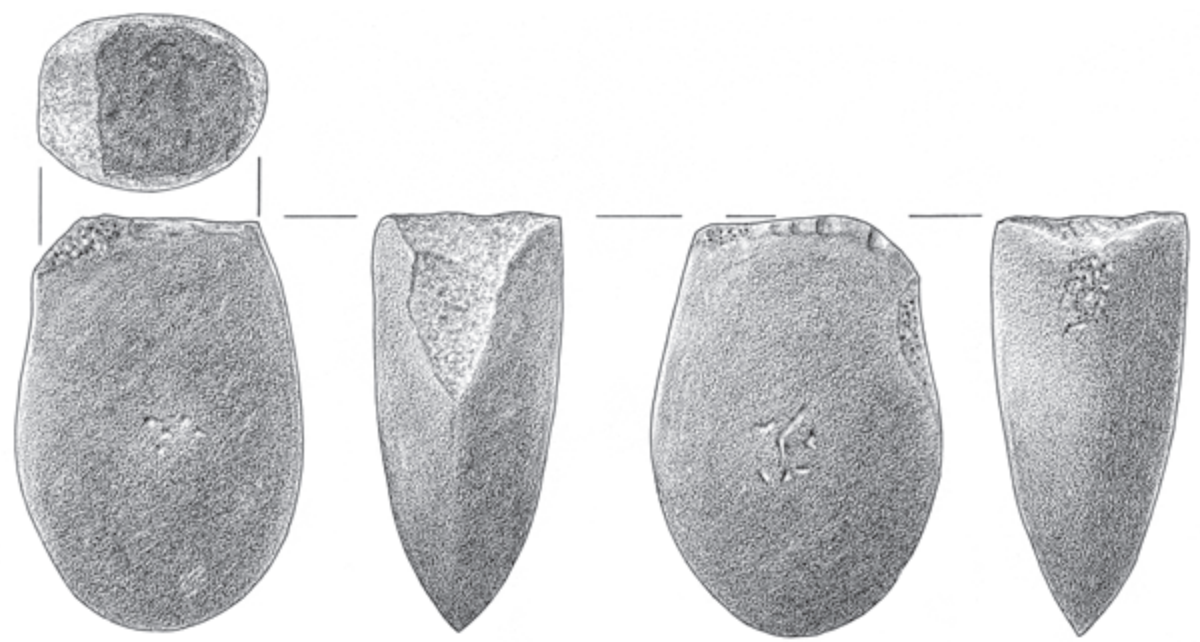

Figure 5.17. Anse à la Gourde early occupation phase, Guadeloupe. Igneous rock axe fragment with evidence of use-wear suggesting later use as a hammerstone (scale 1:2). (Drawing Erick van Driel)

were recovered at Golden Rock out of a total of more than 3500 stone artefacts excavated from a $352 \mathrm{~m}^{2}$ midden area. ${ }^{5}$ This markedly contrasts to a reported average density of 2.3 lapidary items per $\mathrm{m}^{2}$ found at La Hueca (Oliver 1999, 293). The

\footnotetext{
${ }^{5}$ These do not include the numerous quartz beads originally part of a necklace, which were found at one of the burials (Versteeg \& Schinkel 1992).
} 


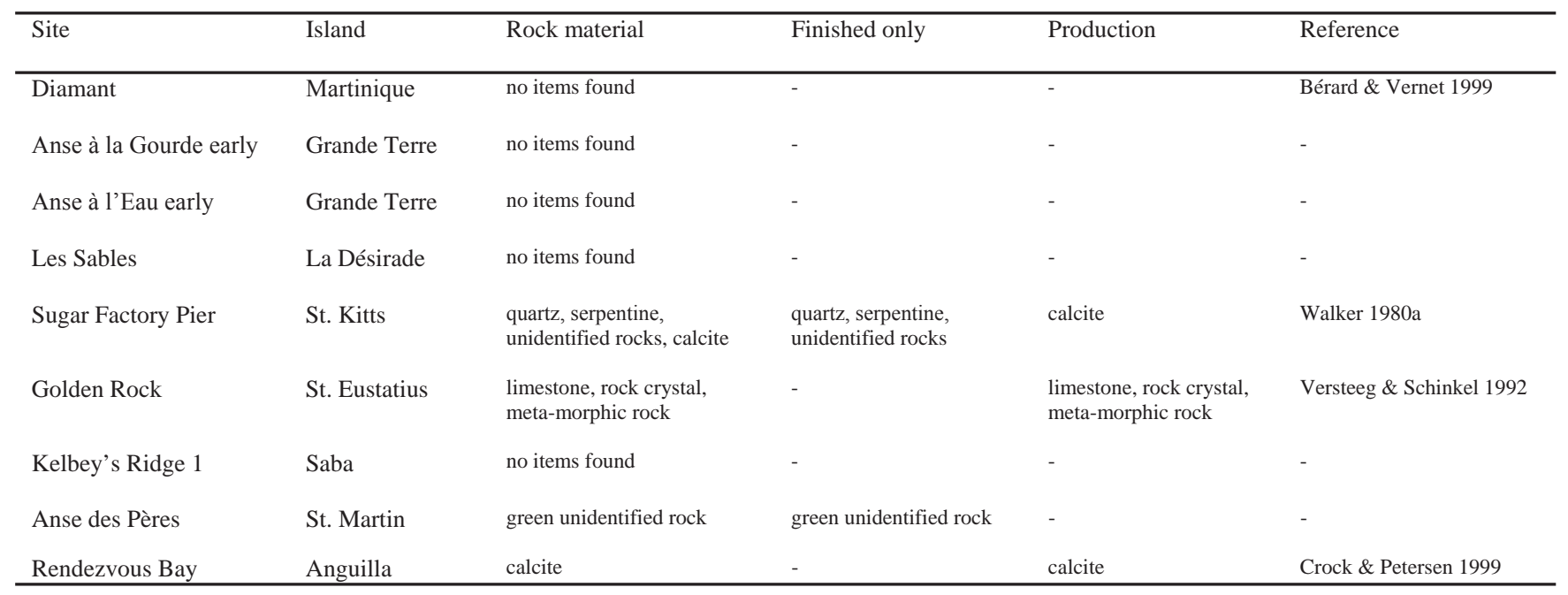

Table 5.12. Early Ceramic B phase. Identified lapidary items and production remains by raw material by site.

difference is exaggerated to some extent by the use of a larger mesh-size at Golden Rock. However, it cannot explain the total absence of pendants and barrel beads, which largely exceed the Golden Rock mesh-size in their dimensions. Low occurrence of beads and an absence of pendants are attested as well during limited test-excavations at Anse des Pères, where smaller mesh-sizes were used (Knippenberg 1999b, c).

With regard to stone varieties, the following repetitively used ones during the Early Ceramic A disappeared, or became considerably rare within the second phase: carnelian, amethyst, citrine, aventurine, and turquoise. Considering their disappearance at around $\mathrm{AD} 400$, these varieties can be used as chronological markers.

The few beads related to the Early Ceramic B phase are made of quartz (Golden Rock) and a green stone variety (Anse des Pères). In addition, Walker (1980, 177-179) reports the finding of several beads made of quartz, a white and a green rock, as well as one greenstone pendant at the Sugar Factory Pier site. Furthermore, he mentions the occurrence of some calcite crystals. With regard to this latter crystal variety, it is yet unclear whether calcite beads found at Rendezvous Bay and Sandy Ground should be attributed to this phase as well (Crock 2000; Crock \& Petersen 1999). They probably belong to the later occupations at these sites, as is suggested by the finding of calcite in only the upper levels of Sandy Ground. Furthermore, relatively large quantities of calcite crystals and amorphous pieces found at later sites on Anguilla, such as Barnes Bay and Shoal Bay East, may suggest that local calcite production is mainly attributable to the following Late Ceramic A phase (see below). Local bead production using any of other rock varieties was not identified among the different studied samples for this phase.

This marked difference with the preceding phase, in particular the disappearance of certain gem stones possibly originating in South America, as well as certain pendant forms with a South American "signature," suggests the termination of most long-distance contacts, which were characteristic during the Early Ceramic A phase.

\section{Zemi three-pointer stones}

In contrast to the preceding phase, during which zemis and zemi making were only rarely practised, one site dated to the the Early Ceramic B produced clear evidence of stone zemi usage and probable manufacture as well (table 5.13). At the Golden Rock site, zemis are recurrent and include a number of different stone varieties, both local and non-local. Among the 11 complete and 2 fragmentary examples, limestone, calci-rudite, pumice, igneous rock, and an unidentified rock variety, probably a tuff or igneous rock, are found (figure 5.18). Debitage relating to the manufacture of zemis is rare. Still, some of the items may have been locally fabricated. This particularly accounts for the pumice. This material occurs on the island and its relatively soft nature may have made grinding it a relatively easy task, and as a result evidence of any preceding flaking stage probably was limited or totally absent.

Limestone and igneous rock are also available on St. Eustatius (Westermann \& Kiel 1961). At present, however, it cannot be stated whether the specific raw materials used for the zemis have a local origin or not. The variety of limestone 


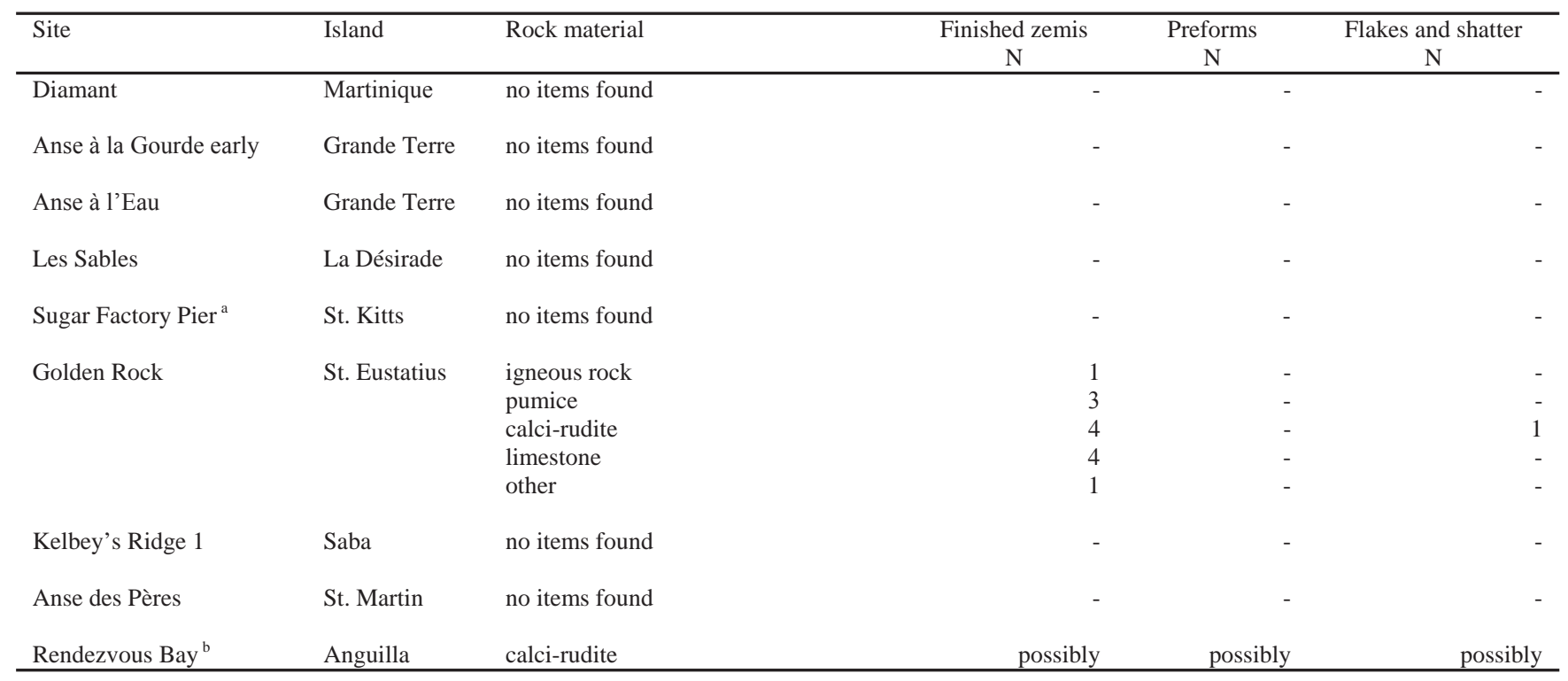

Table 5.13. Early Ceramic B phase. Identified zemi three pointer stones and production remains by raw material by site. ${ }^{a}$ Data from Walker (1980a); b Data from Crock \& Petersen (1999).

types among the zemis may suggest that at least some of them were obtained from elsewhere. Also, the two igneous rock zemis differ in material and these materials are distinct from the large bulk of igneous rock used at Golden Rock. In addition, related debitage in the form of flakes and preforms is absent, also suggesting an exotic provenance for these zemis. The four calci-rudite artefacts clearly resemble the material from St. Martin, exhibiting the typical mixture of light and dark grains cemented in a fine-grained matrix. In addition to the calci-rudite zemis, one undifferentiated flat piece of rock, probably a flake fragment, made of similar material was also identified. This rarity of debitage points to arrival of finished calci-rudite zemis at Golden Rock.

A striking feature of the group of zemis at Golden Rock is their relatively small size, with the maximum dimension ranging from 21 to $52 \mathrm{~mm}$. This finding is supportive of the general notion that the oldest zemis are small and generally become larger during Late Ceramic times. Three recurrent shapes were identified: a simple one, a zemi with an incision on its base, and one with an inflected base. Only among this latter type, two examples have thin incisions at the top.

A considerable number of zemis have been found at Rendezvous Bay on Anguilla (Crock \& Petersen 1999). Particularly in relation to calci-rudite zemi manufacture, this site must have played an important role, as argued by Crock and Petersen. The long occupation encompassing large portions of the Early Ceramic B and Late Ceramic A, makes it difficult to precisely date the recovered artefacts, however. A major portion of the zemi production and finished zemis probably can be dated to the Late Ceramic Age occupation. Still, Crock and Petersen also mention the finding of a pedestalled example, which they consider to be Saladoid, so falling within the Early Ceramic B phase. Ongoing research at this site may well specify if calci-rudite zemi production actually can be dated this early. If this can be established, it would provide a possible explanation for the origin of the finished Golden Rock examples, for which a production place has not to be identified (see next Chapter).

Apart from these two sites, zemis are absent among the other collections dated to this phase. This may be a result of sample bias, considering the generally rare occurrence of this type of artefact. Collections of most sites do include more than 250 lithic artefacts, the average number of stone items per zemi at Golden Rock. The sample size at the Anse des Pères site, however, exceeds this number by far and the absence suggests a clear difference. This becomes even more striking if one realises that Anse des Pères is situated only a few hundred metres from the Pointe Arago locality, the present source of the calci-rudite material. 

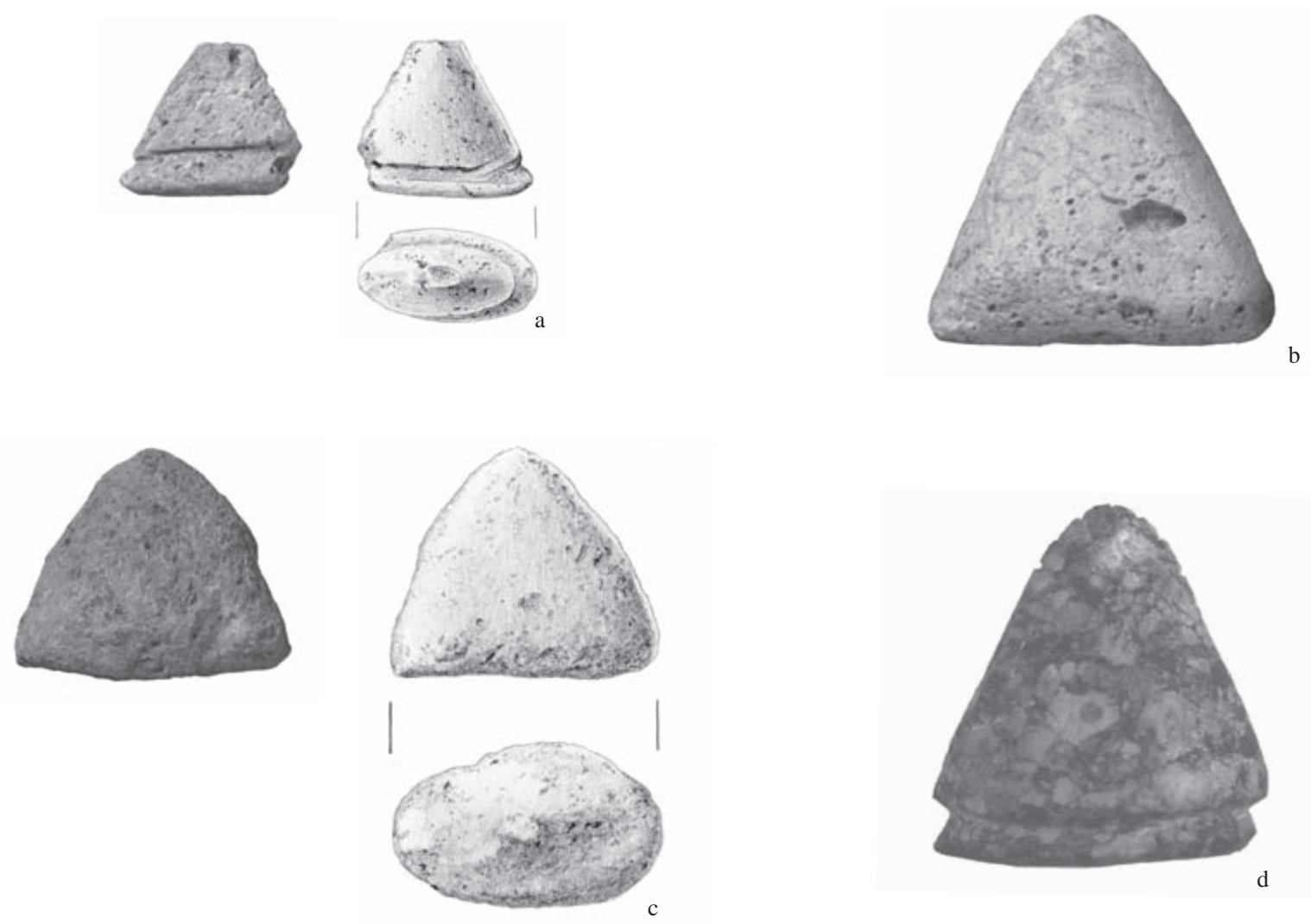

Figure 5.18. Golden Rock, St. Eustatius. Zemi three-pointer stones: a. pumice zemi with inflected base; b. limestone zemi; c. igneous rock zemi; d. calci-rudite zemi with incision on the top (scale 1:1). (Photos a, b and c Jan Pauptit; Drawings Raf Timmermans)

Shaped grinding and abrading stones

This phase includes a number of sites where relatively extensive use was made of shaped passive grinding stones and usemodified examples (tables 5.14 and 15). Being rare during the preceding phase, the large sample from Golden Rock, and the much smaller sample from the Saladoid occupation at Anse à la Gourde contain a significant number of predominantly fragmentary grinding slabs. The even smaller lithic sample from Diamant yielded a few fragmentary artefacts as well. Golden Rock is remarkable because of its high abundance of grinding and abrading stones and by the fact that these tools were locally made. Despite the notion that the number of complete items is very small, the large number of rock fragments with a flat or concave smooth surface clearly resulting from abrasion, points to a common use of passive grinding or abrading slabs at this village.

Different materials were identified among these artefacts. The largest group is formed by igneous rock, which includes two recurrent rock varieties and a large group of mainly individual pieces. Among the igneous rocks, a dark porphyritic variety is predominant, exhibiting clear and large phenocrysts, whereas the other variety is light coloured, containing small phenocrysts. Other recurrent materials are beach-rock and a yellow crumbly rock, which possibly represents a weathered igneous rock. Most of these materials are local to St. Eustatius. The beach-rock, which is built up by a mixture of calcareous and volcanic sand grains, exhibits similarities with the present sand composition along the eastern coast of St. Eustatius (personal observation 1999), although the actual occurrence of beach-rock has not been reported on the island (Westerman \& Kiel 1961). The light igneous rock has been identified among rock material scattered on the surface within the Cultuurvlakte (personal observation 1999). For the dark coloured rock, no specific source location can be specified, although some of the phenocrysts identified in it, such as feldspar and hornblende, correspond with mineral contents of igneous rock on the island (Westermann \& Kiel 1961). 


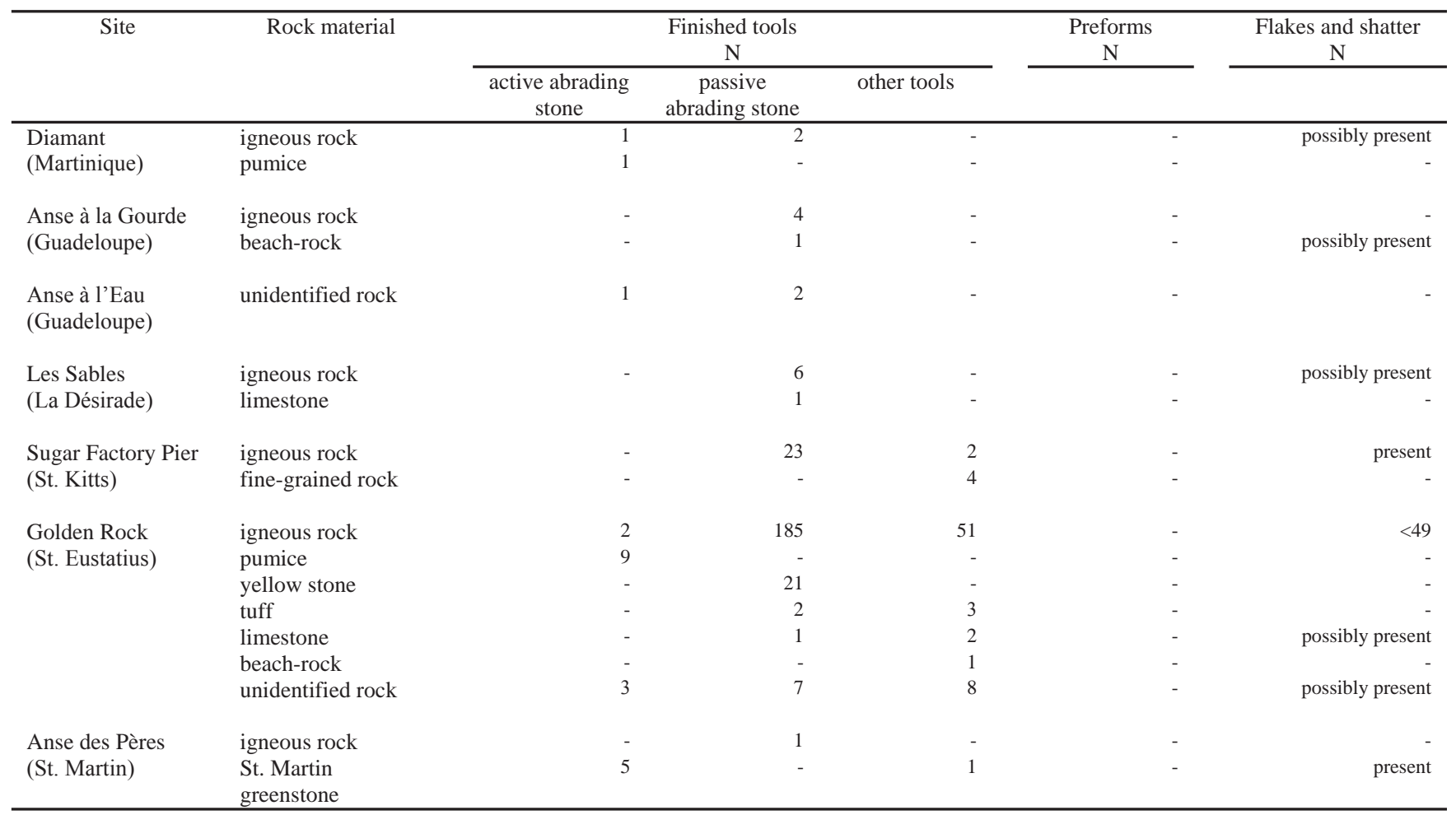

Table 5.14. Early Ceramic B phase. Number of identified shaped grinding and abrading tools and related manufacture debris by raw material by site.

Among these tools broadly, four types of abrading stones can be distinguished:

1) Large flat stone pieces with a concave abraded surface and slightly raised rim part. An almost complete example originated in one of the posthole features (F 201) within the habitation area of the site (figures 5.19 and 5.20). After its use as a grinding stone, it functioned as stone packing around the wooden post of this feature (Schinkel 1992, 159 fig. 131). Generally, the dark porphyritic as well as the yellow crumbly rock are associated with this shape;

2) Flat stone pieces with flat abraded surfaces without a raised or a distinct rim part. This type is mainly found among both igneous varieties;

3) Large flat water-worn pebbles, often exhibiting a slightly convex used surface. This type is mainly found among the beach-rock artefacts. One example provides insight to its original function, as it exhibits residue of red ochre on its used face. Rare examples were found among the porphyritic igneous variety. This type of tool actually belongs to the use-modified group of artefacts, but it is discussed here for a better overview of passive grinding stones; and

4) Flat stones with an oblique abraded face. Only a few examples were identified and predominantly include rare, often finegrained rock varieties.

Some uncertainties remain concerning the making and shaping of these artefacts. The fragmentary nature and the extended use-life of most of them have blurred most evidence of any shaping activities. Also, the sample does not include large numbers of clear manufacturing debitage in the form of flakes or shatter. This does not account for the light igneous rock variety, which includes a major portion of small blocky pieces and some flat rocks with abraded surfaces. As this rock variety occurs nearby the site, it is not always easy to distinguish production debris from natural rock. Some pieces suggest artificial breaking. Combined with the few passive abrading stones with clearly used surfaces, some evidence suggests that the rocks were shaped to some extent.

For the other rock categories, especially the dark porphyritic one, some artefacts suggest intentional shaping as well. For the most part, their unnatural flat shapes and the presence of steep angles between sides and used faces indicate this. Depending on the nature of the source localities visited, rock slabs were removed from outcrops, in the case of primary 


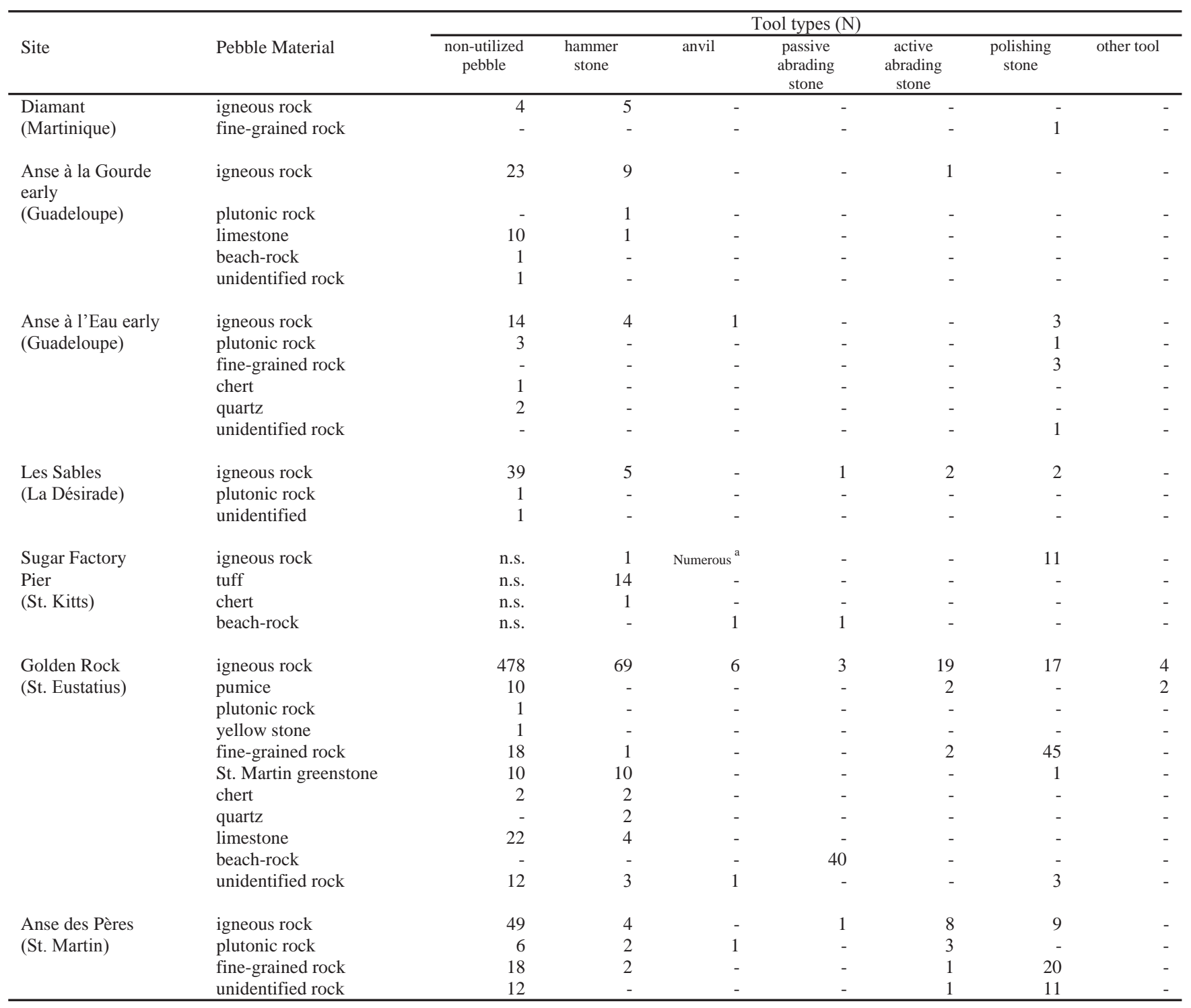

Table 5.15. Early Ceramic B phase. Number of identified use modified rocks and manuports by raw material, by site. ${ }^{a}$ Walker (1980a) mentions 13 anvils, both water-worn as well as tabular shaped; n.s. = not specified.

sources with the help of rock splitting through rapid heating and cooling. Alternatively, in the case of secondary scatters, large boulders were split and shaped by removing a few large flakes. The absence of irregularities in the form of ridges from original flaking scars suggests that the toolmakers employed some kind of pecking technique to remove these irregularities.

The initial shaping stage, in which large flakes were removed to give the tool its overall shape, probably did not occur at Golden Rock itself and was likely done at the source location. This would explain the low occurrence of related flakes, which cannot account for the large number of metate fragments found. Considering the large size of at least some of the tools, this behaviour would have reduced a lot of unnecessary weight to be carried.

In contrast to the use of predominant local rock at Golden Rock, most passive grinding stones made of igneous rock at Anse à la Gourde have an exotic origin. One complete example and five fragments were identified. The neighbouring island of La Désirade is the most likely origin. The shape of the complete example, made of a green rock, is rather exceptional, being 


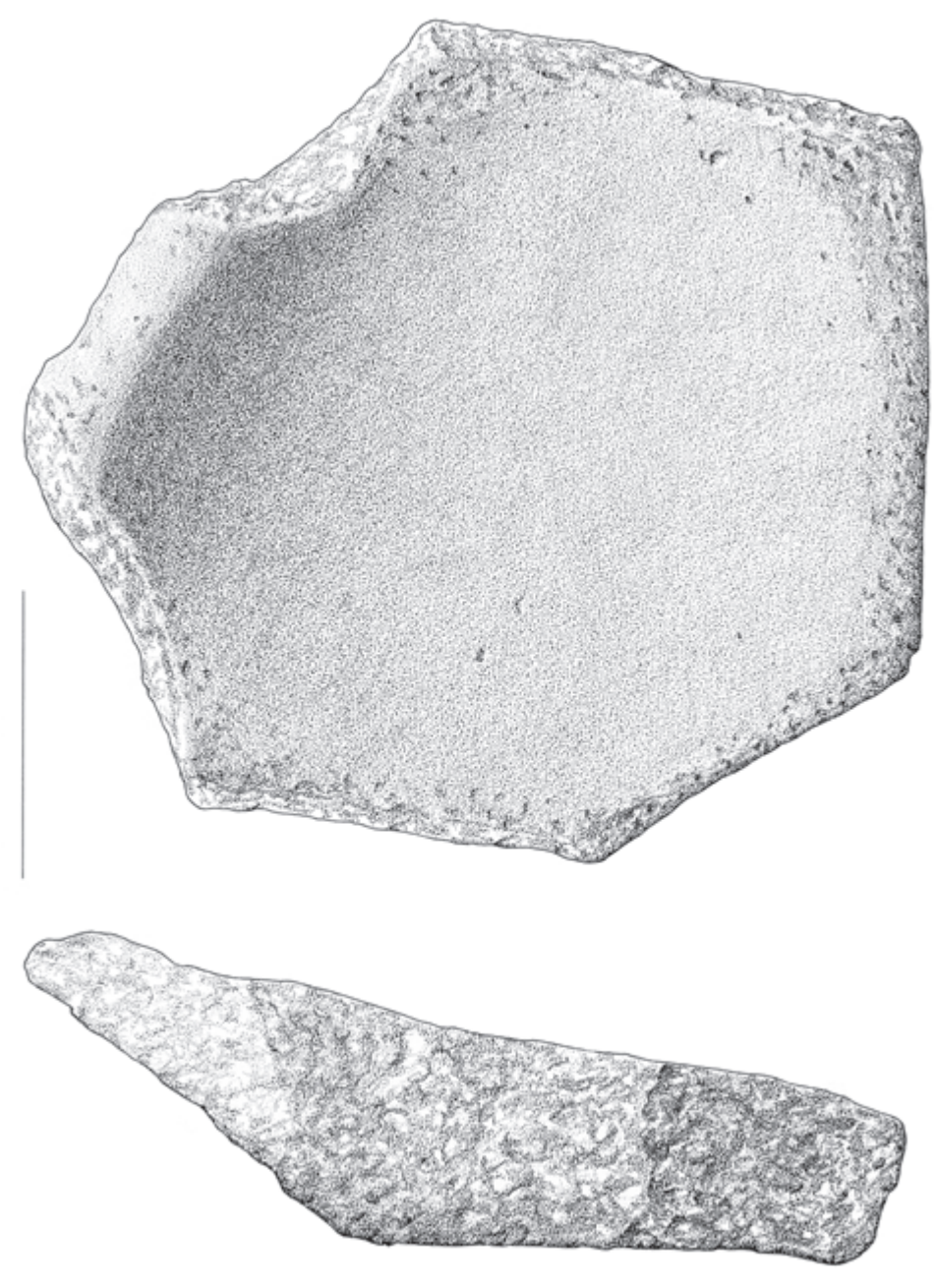

Figure 5.19. Golden Rock, St. Eustatius. Passive grinding slab (metate) made of igneous rock (scale 1:4). (Drawing Raf Timmermans)

thick with an elongated abraded area (figure 5.21). This suggests its use as passive tool, against which axes or other objects were ground. Originally, the stone must have been a large, slightly rounded boulder, which likely was split in two, to create a grinding face. The non-used surfaces of this rock are irregular, suggesting that it was not elaborately shaped and finished. Some of the ridges at least suggest that the raw material underwent some crude shaping by removing large portions.

The other fragments are made of various rock types and originally belonged to thinner tools. One artefact is made of a somewhat crumbly yellow stone material, possibly a weathered igneous rock that resembles some material encountered at Golden Rock. Its provenance, however, remains unknown. Other rock materials include probable local limestone beachrock and exotic dark granular igneous rock. The granular igneous rock was also identified among some fragments of passive grinding stones found at Les Sables on La Désirade. The Diamant collection only includes two passive grinding stone fragments of local igneous rock.

A striking artefact type at Anse à la Gourde is a flat ground or abraded object made of a moderate grained, light greenish grey, possibly igneous rock (figure 5.22). It resembles the flat green artefact found at Morel, which was described above. This flat object exhibits traces of abrasion or grinding on the two faces, both convex in outline, which meet in a blunt edge-like end. Similar to the Morel example, it is difficult to discern to what extent this object was intentionally ground, or whether repetitive usage caused its present form. The excavations yielded more and larger examples of these flat tools from un- 


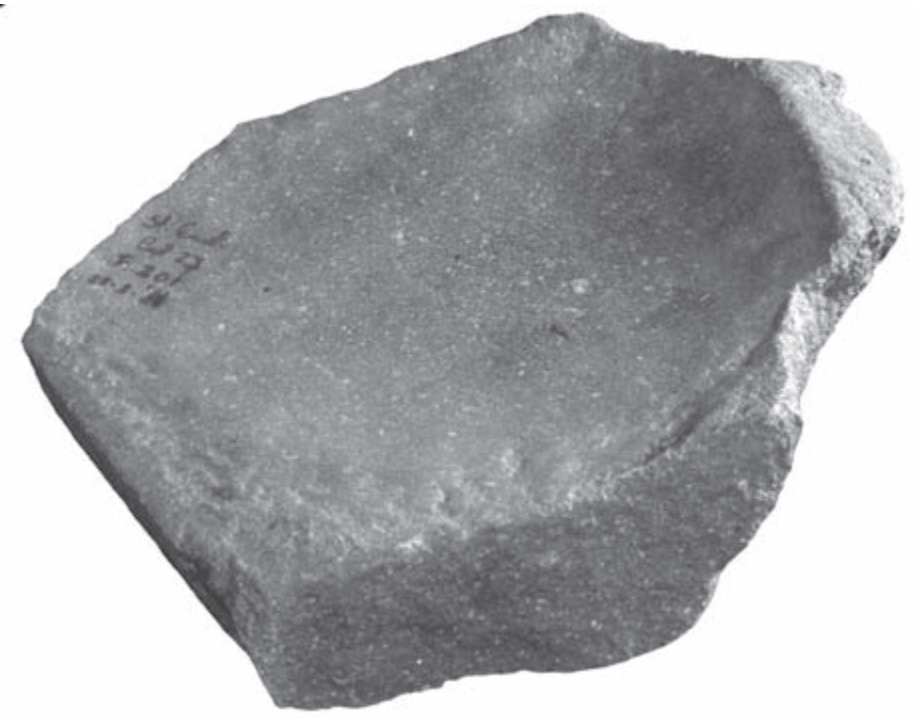

Figure 5.20. Golden Rock, St. Eustatius. Photo of passive grinding slab (metate) made of igneous rock (scale 1:4). (Photo Jan Pauptit)
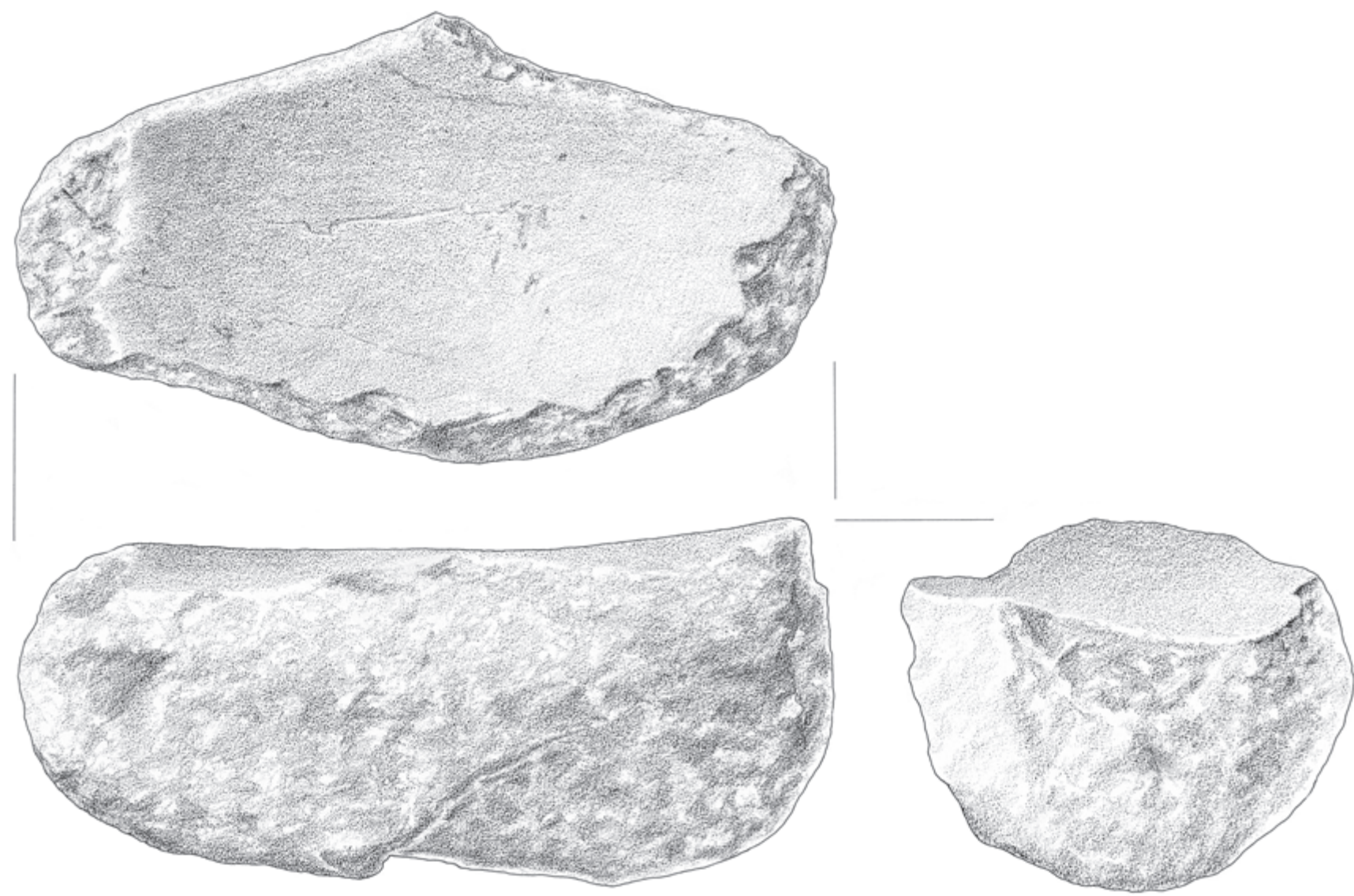

Figure 5.21. Anse à la Gourde early occupation phase, Guadeloupe. Igneous rock passive grinding stone (scale 1:2). (Drawing Raf Timmermans) 

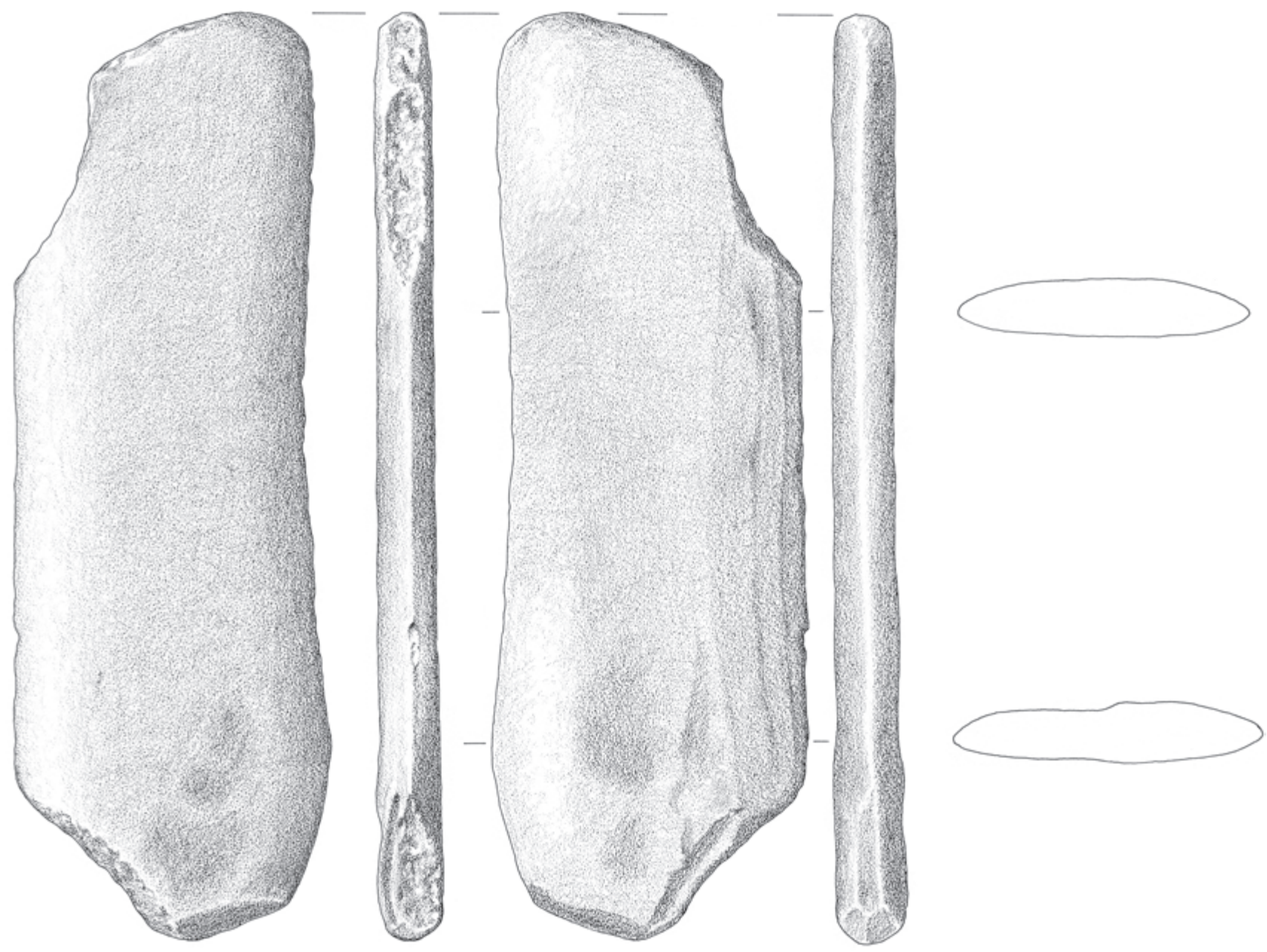

Figure 5.22. Anse à la Gourde early occupation phase, Guadeloupe. Igneous rock flat possible active grinding stone (scale 1:2). (Drawing Raf Timmermans)

screened and less well-dated contexts. All are complete or fragments of finished artefacts. An exceptional example measures $350 \times 132 \times 20 \mathrm{~mm}$, with one round and a one pointed end. Initial shaping through grinding must have certainly played a role in the formation of this artefact (figure 5.23).

The most likely function of this kind of tool would have been hand-held as an active grinder for grinding vegetal substances, similar to manos in Meso-America. The complete and almost complete passive grinding/abrading stones found at Anse à la Gourde, however, do not correspond with these green flat artefacts in size and concavity, suggesting that the function of these flat rocks is not related to the passive tools. The origin of this material remains to be identified, but green, light coloured igneous rocks are found on La Désirade and Antigua (personal observation 1998, 1999).

Looking broadly at the relatively rich sample of passive grinding stones from this phase, many have a local origin and inter-island transport and exchange of these tools does not seem to have been common. Despite the significant presence of locally made dark igneous tools on Golden Rock, examples made of this variety were not found at other sites. This suggests that the making of these tools at Golden Rock was for local use only. The only varieties that have turned up at more than one site are the granular igneous rock, probably originating from La Désirade and found at Les Sables and Anse à la Gourde, and the yellow crumbly rock found at Golden Rock and Anse à la Gourde.

Figure 5.23 (opposite page). Anse à la Gourde early occupation phase, Guadeloupe. Igneous rock flat possible active grinding stone (scale 1:3). (Photo Ben Grishaaver and Drawing Raf Timmermans) 

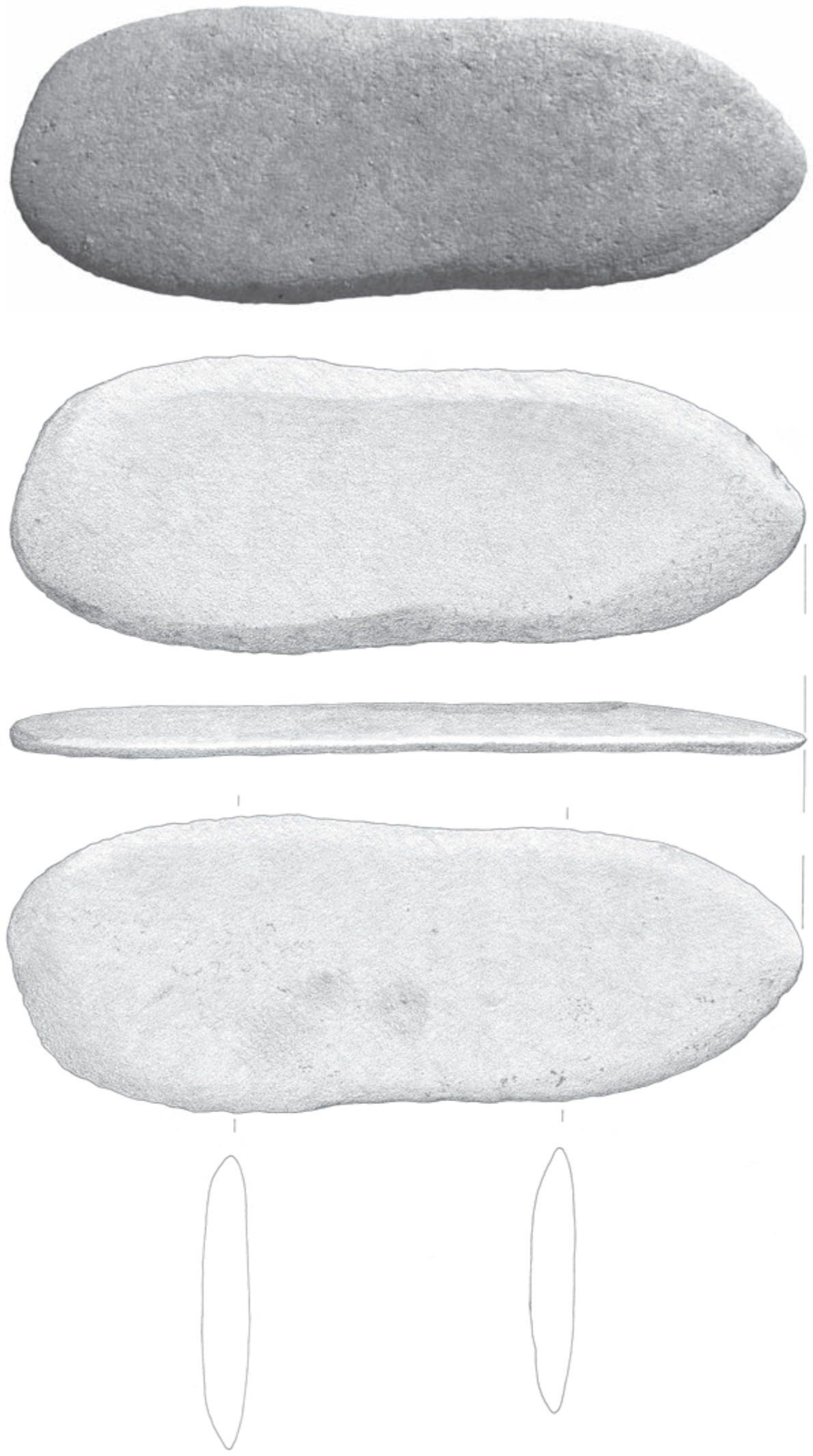
Use-modified rock and manuports

Use-modified materials and manuports continued to form a significant part of the archaeological collections studied in this phase. Most of these items are water-worn pebbles of many different sizes. In relation to the first group, igneous rock represents the largest group of used pebbles, but other types of rock include limestone, beach-rock, fine-grained rock, and rarely plutonic rock, metamorphic rock, chert, quartz, greenstone, and pumice (table 5.15). The largest variety in tools is seen among the igneous rocks, evident as hammerstones, anvils, active abrading stones, polishing stones, and passive abrading stones. Fine-grained rock is predominantly associated with the use of polishing stones, whereas the rare materials, such as plutonic rock, limestone, chert, greenstone, and quartz, were used as hammerstones. Pumice and beach-rock respectively, were used as active and passive abrading/grinding stones. Metamorphic rocks were used for hammering, polishing, and abrading. A closer look reveals that generally the hard and tough materials are associated with hammering tools, a notable exception being limestone. Fine-grained hard rock was used for polishing, and the coarser varieties of igneous rock, vesicular pumice, and granular beach-rock were basically found among the abrading or grinding tools.

Comparison of the different sites reveals significant inter-site variation with regard to raw materials. Although igneous rock occurs at most sites, the actual varieties encountered differ among sites. This inter-site variation is likely the result of the variation in local island specific geology. This group of artefacts, more than the tools from other technology sets, was obtained from nearby localities. Therefore, its usage was strongly dependent on local geology. These nearby sources were not necessarily situated within the immediate site surroundings, however. Anse à la Gourde and Anse à l'Eau, for example, are situated within an almost exclusively limestone region along the northern coast of Grande Terre. This was as a poor setting for procurement of these types of tools. As a result, the local inhabitants, like their Morel predecessors, obtained most of their use-modified and non-modified pebbles from the small island of La Désirade.

At Golden Rock, the situation is totally different. Most of the rock varieties encountered are igneous in nature, and can be found on St. Eustatius itself relatively close to the site (figure 5.24). Also, pebbles found at Anse des Pères fall within the relatively large range of varieties scattered on the cobble beach adjacent to the site. In the case of this site, therefore, it should be questioned whether the non-modified pebbles are actually manuports, or whether they simply represent natural material scattered in the site-area.

Apart from transport of pebbles from La Désirade to the Grande Terre sites, there is one recurrent pebble variety that generally does not occur locally on many of the islands of discovery and which probably was transported over considerable distances. These are the fine-grained pebbles used as polishing stones. The Golden Rock and Anse des Pères sites yielded a considerable number of small polished pebbles displaying very fine striae, made of green, grey-green, grey, to almost white varieties. A few resembled the greenstone from St. Martin used for making axes, while others were almost cherty in nature. Considering the large variety of fine-grained rock on St. Martin in the form of re-crystallised tuffs or cherty tuffs displaying these colours (Christman 1953; personal observation 1993, 1999), St. Martin is a likely source for these pebbles. This may also account for some of the pebbles found at the Grande Terre sites, although other varieties not resembling the possible St. Martin ones were seen as well. This exotic nature of many of the polishing stones relates well with anthropological reports about indigenous peoples in the Amazon, who highly value these objects (figure 5.25) (e.g., Yde 1965; Renzo Duin, personal communication 1999).

Pebbles without any signs of modification or use can be considered as true manuports in many cases, because they were brought from elsewhere. This applies to most of the rocks found at Anse à la Gourde, Anse à l'Eau, and Golden Rock. Only at Anse des Pères and possibly Diamant, pebbles are naturally occurring in the site area. Therefore, it can be questioned whether they were deliberately collected and taken to the site in these cases.

The possible usage of non-modified pebbles as fish-net weights, as was argued for a large portion of pebbles at Morel, should be considered again. Among the pebbles found at Anse à la Gourde, one actually contains the remains of a similar black residue, as was encountered at Morel. Furthermore, many of the pebbles from Anse à la Gourde and Anse à l'Eau fall in the size range and are of the same material as the black residue pebbles. At Golden Rock, large numbers of similar small sized pebbles also occur, which may suggest a similar usage. If these pebbles were indeed used for this purpose, it would explain their high frequency in the archaeological record, in particular at the Grande Terre sites. 


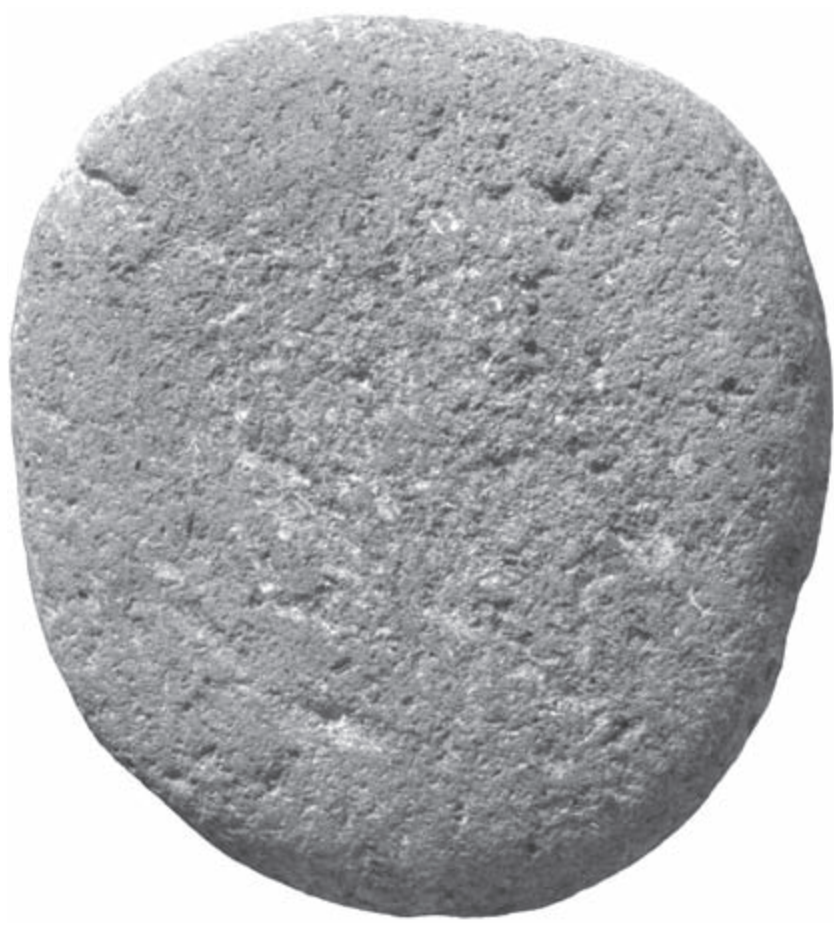

Figure 5.24. Golden Rock, St. Eustatius. Flat igneous rock pebble used as an anvil (scale 1:2). (Photo Jan Pauptit)

\subsubsection{Late Ceramic A}

\section{Introduction}

A total of 13 Late Ceramic A sites were studied in the present research, which is considerably more than from the other phases. However, many of the samples analysed only consist of a relatively small number of artefacts, largely a result of limited excavations (table 5.16). Written reports provided additional data about six sites. In addition, Rodríguez Ramos (personal communication 2000) exchanged data on the Paso del Indio site and Mark Nokkert (personal communication 2002) informed me about the finding of St. Martin greenstone axes at Coconut Walk on Nevis.

\section{Flake tool production}

Raw materials

The data on flake tool production activities relating to Late Ceramic A phase in many ways resemble those from the preceding phase. Some differences are also noted. Chert and chert related varieties continue to be the basic rock materials used for making flake tools (table 5.17). Only in case of the Paso del Indio site, Rodríguez Ramos (2005) reports the use of cobbles from meta-volcanic material. Among the samples, flint, chert, bedded chert, jasper, petrified wood, quartz, and chalcedony were identified. Again, Long Island flint continues to be the major flake tool material in the Anguilla - Guadeloupe region. However, beyond this region this high quality flint is not reported anymore. This clearly contrasts with the preceding phases.

Within the Anguilla - Guadeloupe region, Long Island flint was identified among all samples in varying percentages. It accounts for more than 50\% of all flake tool material for sites on Antigua, Guadeloupe, St. Eustatius, and Saba, and it is less frequent at sites on Anguilla and at the Godet site on St. Eustatius. The percentage found at this latter site must be treated with caution, however, as the sample size is very small. Inter-site variation with regard to raw material 


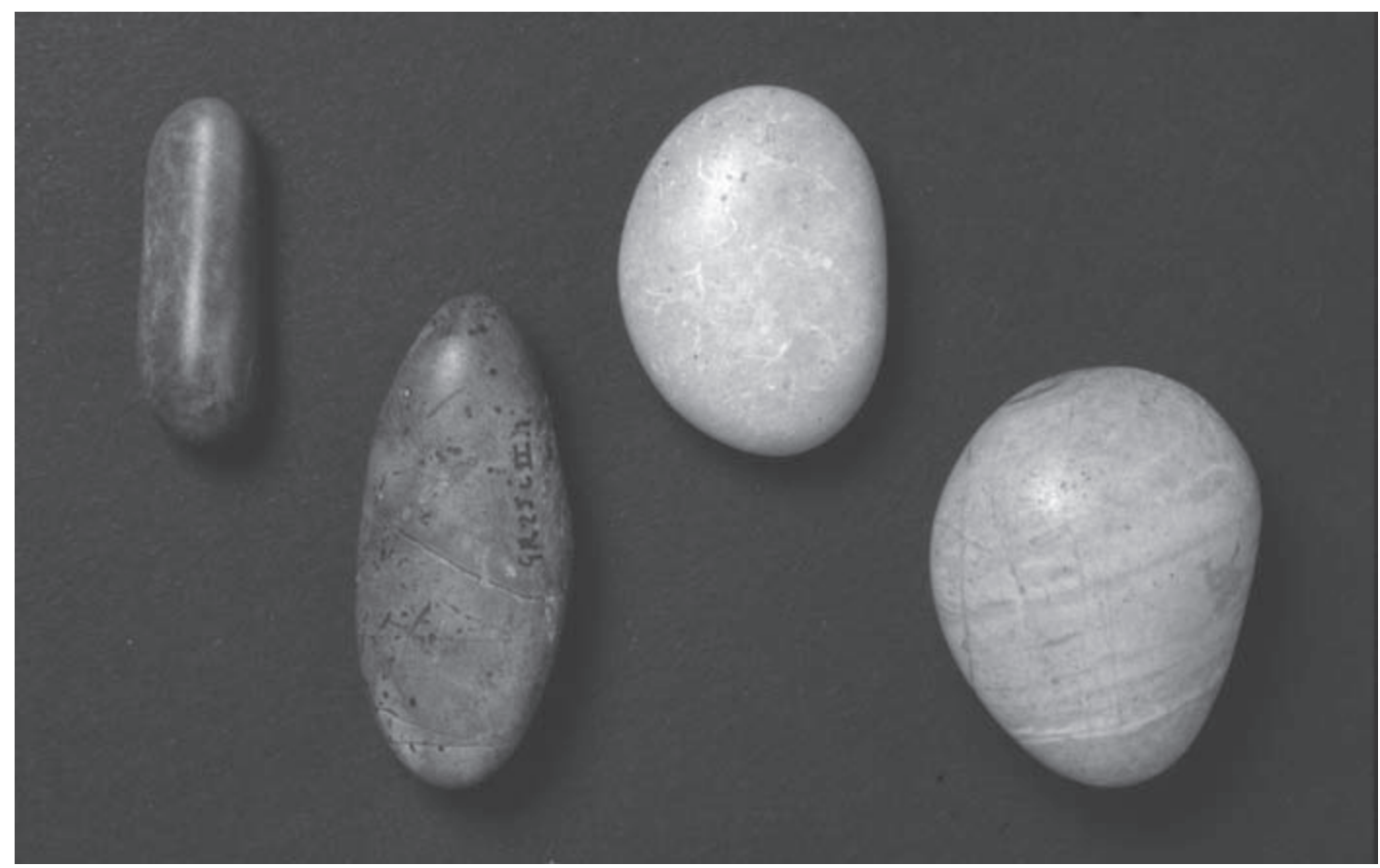

Figure 5.25. Golden Rock, St. Eustatius. Small fine-grained rock pebbles used as polishing stones (scale 1:1). (Photo Jan Pauptit)

frequencies reveals some interesting results, despite the predominance of Long Island flint at most sites. Looking at the different Antigua sites, considerable variation occurs in the abundance of Long Island flint. The Blackman's Point and the Coconut Hall settlements display a markedly lower percentage of Long Island flint than the Jumby Bay and Claremont sites. This difference can be attributed to the availability of local flint material in the immediate surroundings of Blackman's Point and Coconut Hall (see Chapter 2 and appendix A). As a result, almost equal amounts of these local flints, Coconut Hall flint in case of the Coconut Hall site and Blackman's Point flint in case of the Blackman's Point site, are represented, along with the use of Long Island flint.

Claremont, situated on the southern coast of Antigua in a region devoid of flint and chert, displays an almost exclusive usage of Long Island flint. This evidently shows that on a regional scale Long Island remained the most desired material, but apparently people were searching for nearby alternatives and exploiting these, if possible. The fact that procurement of local sources became an integral part of Ceramic Age flake tool production behaviour is most clearly evidenced at the Blackman’s Point site. This site yielded a Preceramic Age occupation as well (Nicholson 1976; Martin Fuess, personal communication 2001). Study of the lithic material from this phase revealed two interesting differences. One was related to a change in lithic technology. Reduction of flint during the Preceramic Age was focussed on the production of blades, a recurrent feature during this era, contrasting with the expedient flake tool technology of the Ceramic Age. The second difference relates to the use of raw materials. During the Preceramic Age, the Blackman's Point dwellers had only reduced Long Island flint. No local Blackman's Point material was encountered, which significantly differs from its high abundance within the Ceramic Age occupation of this site.

This change in raw material choice may have had a social cause, apart from the fact that the Ceramic Age expedient flake technology hardly poses any limitations on raw material qualities. Settlement on Long Island, evidenced by the Jumby Bay site, may have restricted their access to the Long Island flint. This may have induced people to use alternatives when available. Therefore, it may have also formed one of the reasons for settlement at Blackman's Point and Coconut Hall.

Similar to the Claremont site, the settlements on the surrounding islands also displayed a preference for Long Island flint, in most cases possessing higher percentages of this flint type than the Blackman's Point and Coconut Hall sites. Interestingly, however, flints from these latter two sources also turn up in low abundances at a number of sites. Coconut Hall flint forms a relatively large portion of the flake tool material at the Late Ceramic A occupation phases of the two sites studied 


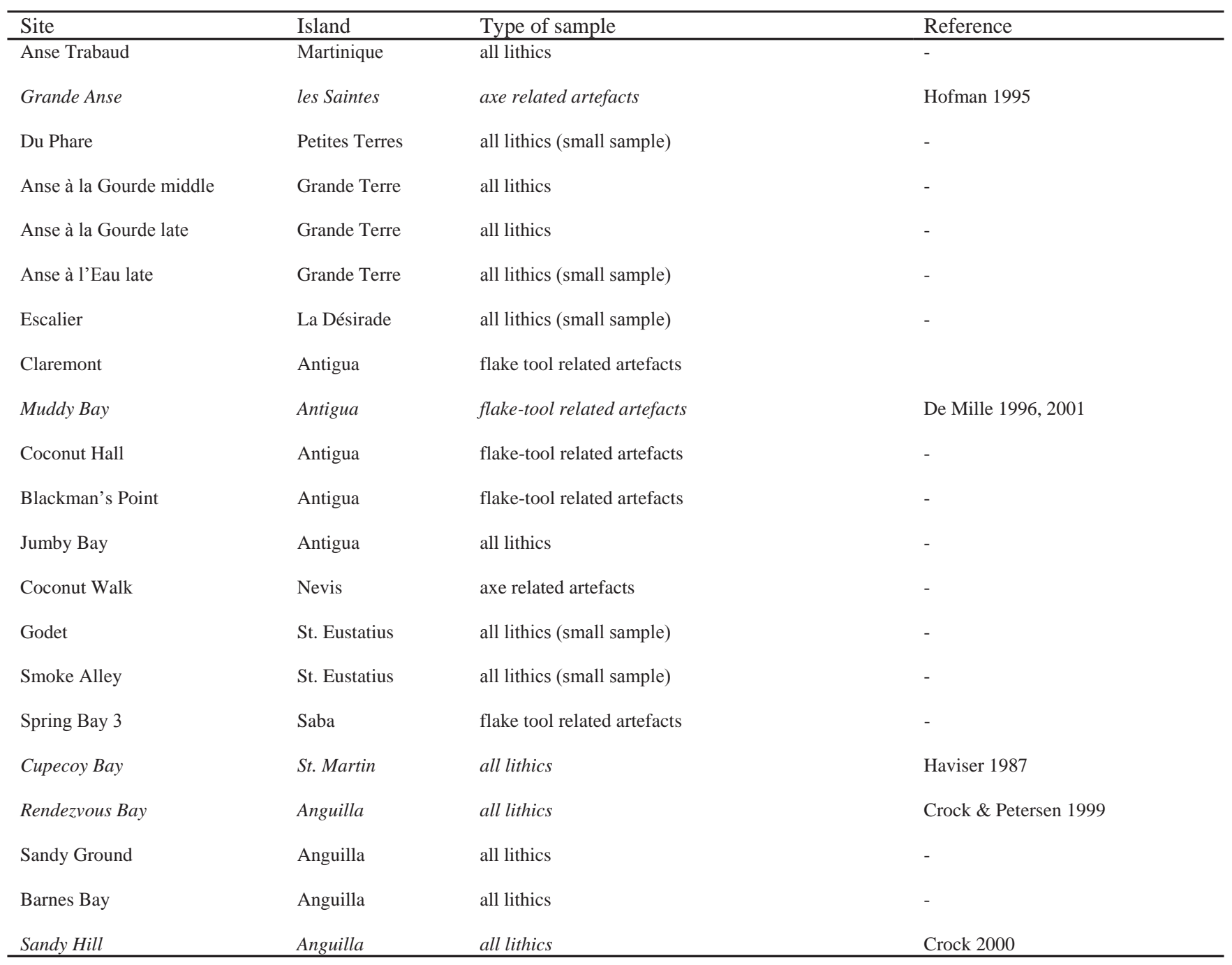

Table 5.16. Studied sites from the Late Ceramic A phase. Data from sites in italic have been obtained from literature.

from the northern coast of Grande Terre, Anse à la Gourde (both main occupation phases) and Anse à l'Eau. It was also found, in smaller quantities though, at Blackman's Point, Spring Bay 3, Smoke Alley, Godet, Sandy Ground and possibly, Barnes Bay. Blackman's Point flint is generally less abundant and shows up at Anse à la Gourde, Smoke Alley, Spring Bay 3, Barnes Bay, and possibly Sandy Ground. Other Antigua varieties that were identified among the different samples include Little Cove/Soldier Point flint (at Anse à la Gourde and Sandy Ground) and possibly Corbison Point/Dry Hill (at Godet).

In addition to these Antigua cherts and flints, various sites produced other cherts and possibly flints, varying in amount. In most cases, sources for these siliceous rocks could not be established; only one red chert artefact from Anse à la Gourde is assigned to the bedded radiolarian chert source in the northeastern part of La Désirade (Bodu 1984; Montgomery et al. 1992). Initially, Bodu (1984) regarded this source as possibly of regional significance, based on evidence of lithic exploitation at the locality itself. Recent research on La Désirade by De Waal (2006) and my findings on raw material usage in the surrounding region shows that the local red chert did not constitute a frequently used material on La Désirade itself and beyond. This suggests that the red chert was only rarely exploited during this phase, which immediately raises the question of how to interpret the data about exploitation activities of Bodu (1984). Studying his results in detail reveals that locally flaked red chert is not present in such high concentrations, as encountered at other exploited lithic sources, which is shown by work on Martinique (La Savanne des Pétrifications) and Long Island, for example (Bérard \& Vernet 1997; Van Gijn 1996; 


\begin{tabular}{|c|c|c|c|c|c|c|c|c|c|c|c|c|}
\hline Chert type & $\begin{array}{c}\text { Barnes } \\
\text { Bay } \\
\\
\mathrm{N}=420 \\
\%\end{array}$ & $\begin{array}{c}\text { Sandy } \\
\text { Ground } \\
\begin{array}{c}\mathrm{N}=316 \\
\%\end{array}\end{array}$ & $\begin{array}{c}\text { Spring } \\
\text { Bay } 3 \\
\\
\mathrm{~N}=149 \\
\%\end{array}$ & $\begin{array}{c}\text { Smoke } \\
\text { Alley } \\
\\
\mathrm{N}=28 \\
\%\end{array}$ & $\begin{array}{c}\mathrm{N}=24 \\
\%\end{array}$ & $\begin{array}{c}\text { Jumby } \\
\text { Bay } \\
\\
\mathrm{N}=953 \\
\%\end{array}$ & 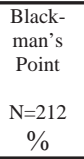 & $\begin{array}{c}\text { Coconut } \\
\text { Hall } \\
\\
\mathrm{N}=229 \\
\%\end{array}$ & $\begin{array}{c}\begin{array}{c}\text { Clare- } \\
\text { mont }\end{array} \\
\mathrm{N}=40 \\
\%\end{array}$ & 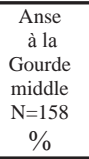 & $\begin{array}{c}\text { Anse } \\
\text { à la } \\
\text { Gourde } \\
\text { late } \\
\mathrm{N}=38 \\
\%\end{array}$ & $\begin{array}{c}\text { Anse } \\
\text { Trabaud }\end{array}$ \\
\hline Long Island flint & 20.7 & 18.7 & 73.8 & 71.4 & 37.5 & 98.8 & 40.1 & 54.6 & 80.0 & 53.8 & 55.3 & - \\
\hline Blackman’s Point flint & 0.2 & - & 2.0 & - & - & - & 48.1 & - & - & 2.5 & - & - \\
\hline Coconut Hall flint & 1.7 & 1.3 & 2.7 & - & 8.3 & - & 0.5 & 34.5 & - & 12.0 & 5.3 & - \\
\hline Antigua Form. flint & 0.5 & 2.5 & - & - & - & - & - & - & - & 3.2 & - & - \\
\hline White chert & 55.7 & 14.6 & - & - & 4.2 & - & 1.4 & - & - & - & - & 64.4 \\
\hline Petrified wood & - & - & - & - & - & - & - & - & - & - & - & 22.2 \\
\hline Other chert & 16.7 & 46.5 & 15.4 & 21.4 & 41.7 & 0.2 & 1.4 & 0.4 & 2.5 & 18.9 & 18.4 & 13.3 \\
\hline Désirade red chert & - & - & - & - & - & - & - & - & - & 0.6 & 5.3 & - \\
\hline Jasper & - & - & - & - & 4.2 & - & 0.5 & - & 5.0 & 5.1 & - & - \\
\hline White quartz & 4.5 & 14.6 & 0.7 & - & - & - & - & - & 2.5 & - & - & - \\
\hline Unidentified chert & - & 1.6 & 5.4 & 7.1 & 4.2 & - & 8.0 & 10.5 & 10.0 & 3.8 & 15.8 & - \\
\hline
\end{tabular}

Table 5.17. Late Ceramic A phase. Relative amount of identified chert types by site.

Verpoorte 1993; see Chapter 4). Therefore, these low-density flake scatters may have been a result of chert working for local use at the source area itself, rather than systematic exploitation involving pre-working of large quantities of material for use elsewhere. Attributing these flake scatters to Preceramic Age usage of this source may be another explanation. Unfortunately, this cannot be tested archaeologically as a result of the likely disappearance of local habitation sites dated to this phase (De Waal 2006).

Among the large group of unknown other chert varieties, two found at the Sandy Ground and Barnes Bay sites on Anguilla deserve additional attention, as they make up relatively significant portions of the samples. A translucent brown chert with white inclusions (possibly fossils) is the most common variety at Sandy Ground (more than 40\%), but it only accounts for around 5\% of all flake material at Barnes Bay. A white dull chert, of which the predominant part is relatively fine-grained but which has a coarser variety almost quartzite like in texture, dominates the Barnes Bay flake tool material $(60 \%)$. At Sandy Ground, only the finer variety was found, accounting for a little less than $15 \%$.

The brown translucent chert exhibits some similarities to a variety encountered at Sorcé. This suggests that its source might be sought more in a western direction from Anguilla, among the Virgin Islands and Puerto Rico, for example, rather than among the Lesser Antilles. On the other hand, among the Sandy Ground sample flaked artefacts from this material are on average larger in size and possess more cortex, relative to the Long Island artefacts there. This may suggest a source in closer proximity to Anguilla than Long Island and raises the question whether it might be local to the island itself. This is a possibility, considering the almost exclusive limestone geological build-up of the island. Crock, however, did not encounter any natural occurrences of chert or flint when doing his archaeological fieldwork on the island during the past ten years (Crock personal communication 1999; see also Crock 2000), nor has anyone else ever reported local flint on Anguilla (e.g, Christman 1953; Douglas 1986, 1991).

The white chert likely originates from a non-biogenic geological formation, similar to the cherts formed in the tuffs near Shirley Heights on Antigua. It is therefore probably not natural to Anguilla. A near-by St. Martin origin, where nonbiogenic chert varieties such as jasper occur (Christman 1953; Staargaard 1952) may not be excluded a priori, but it is not supported by archaeological evidence. Natural occurrence of this type of material on Vieques, which was used by the Sorcé and La Hueca inhabitants during the Early Ceramic A phase, in any case suggests similar materials may also occur there, although the white chert does not resemble the locally available quartz (see Early Ceramic A section; Rodríguez Ramos 2001a). Unfortunately, the poor knowledge of the occurrence of regional rock types in general and my unfamiliarity with archaeological material from the Virgin Islands and Puerto Rico suggests that additional study is needed.

At the multi-component site of Paso del Indio, in the middle of Puerto Rico, the Late Ceramic A phase displays a marked change from the preceding one in the almost sole use of the meta-volcanics, available nearby the site. During the earlier Cuevas occupation, imported chert and flint varieties are the predominant group of rocks among the flake tools (Rodríguez Ramos 2005). At Anse Trabaud on Martinique, on the southern border of my study area, the flaked stone consists exclusively of local chert, which were obtained from the nearby Savannes des Pétrification locality, only 1 to $2 \mathrm{~km}$ from the site (Bérard 1999, 2001; Bérard \& Vernet 1997). 

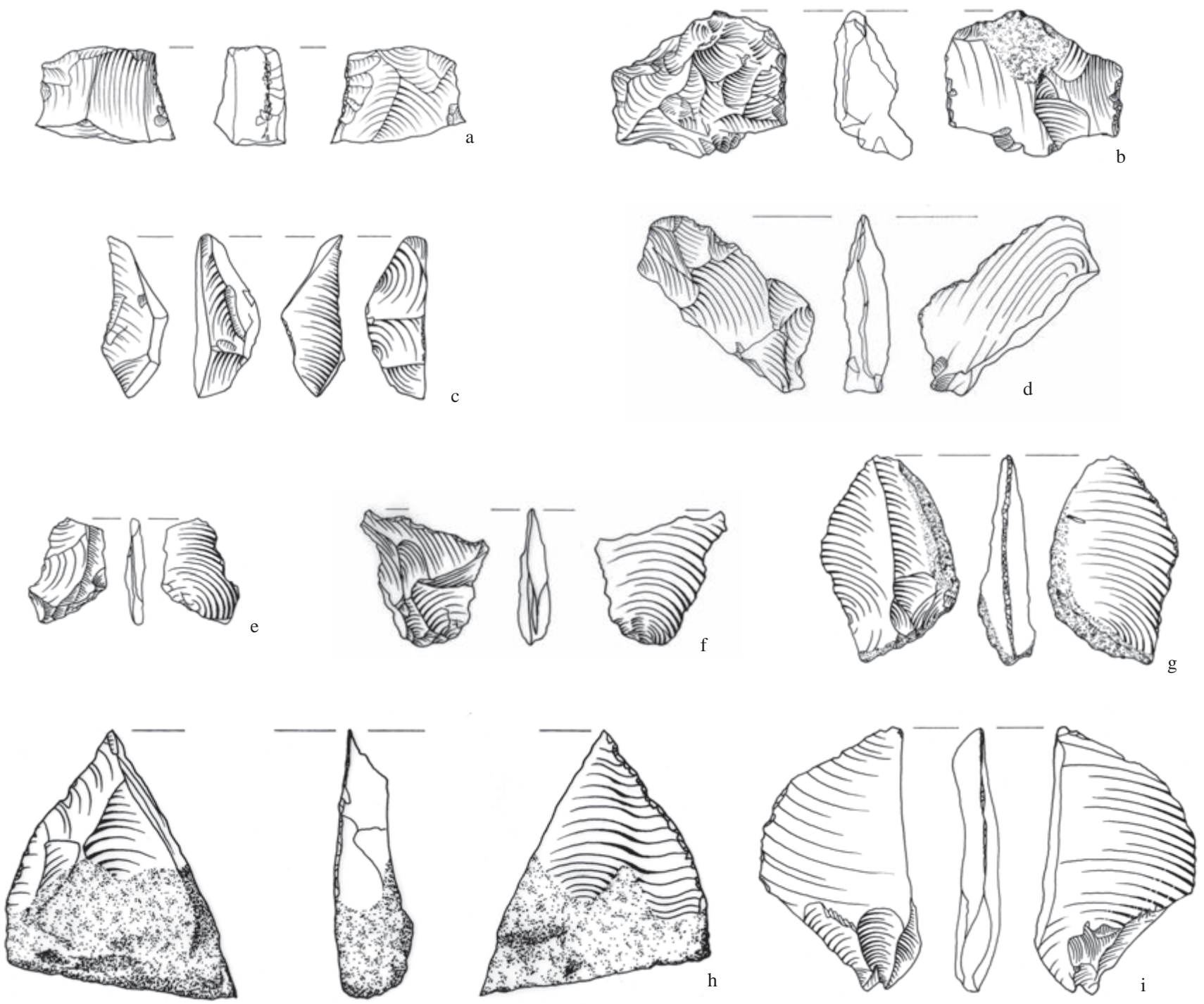

Figure 5.26. Anse à la Gourde middle (a,b,d,e,g-i) and late $(c, f)$ occupation phases, Guadeloupe. Flint cores and flakes: a en b. bipolar cores; c. bipolarly split flake fragment ; d. flake fragment with use retouch; e-h. complete flakes with use retouch; i. modified flake with use reouch (scale 1:1). (Drawings Raf Timmermans)

Reduction and tool production

The flake tool production during this phase continues to be expedient, aimed at production of a variable set of flakes to be used without any or minimal modification. Identified flaking techniques include the direct freehand percussion and bipolar ones (figure 5.26). Contrary to this view of continuity, Bérard (2001; Bérard \& Vernet 1997) argues for a change in reduction during this phase toward the production of predominantly large flakes, instead of small ones. He bases this primarily on the larger average flake size at the Anse Trabaud site, as compared to those from the preceding occupations at Vivé and Diamant. Taking mesh-size differences into account, larger flakes are indeed more predominant at Anse Trabaud and cores do not suggest production of small flakes. Notwithstanding these differences, the larger size of flaked material may have been the result of the availability of larger cobbles at La Savanne des Pétrifications and the close proximity of this source to the Anse Trabaud site, when compared to source areas exploited by the Vivé and Diamant dwellers. Moreover, easy availability to source areas is of significance when studying size differences, as is clear from flake size comparison of the Jumby Bay and Sugar Mill sites on Long Island with settlements on surrounding islands (see below). If it is further noted that among the 
samples of the northern Lesser Antilles, small flake production still was part of the objective of the chert and flint reduction, there is no clear evidence that technology indeed experienced changes from the Early Ceramic B phase to Late Ceramic A phase.

Similar to the preceding phase, the limited data suggest core reduction and flake production on-site, indicated by the presence of cores, flakes and shatter at the studied settlements. Looking at Long Island flint, the recurrent high percentages of flakes displaying cortex on their dorsal surfaces suggest arrival of unmodified cobbles. Only the lower percentages of cortex at Spring Bay 3 on Saba and Barnes Bay on Anguilla suggest pre-worked material arrived at these sites (see Chapter 6).

\section{Core tool production}

Axes and adzes

This phase marks the extensive usage of St. Martin greenstone as raw material for axes within the northern Lesser Antilles relative to the other materials. It was already noted that the number of habitation sites where this greenstone material was worked increased during the preceding Early Ceramic B phase and that it expanded regionally over a larger area during that period. The Late Ceramic A phase specifically exhibits a marked increase of habitation sites on Anguilla with evidence of axe production. However, the total region where greenstone axes were made had not become larger relative to the Early Ceramic B phase.

This significance of greenstone axes immediately becomes evident when comparing the axe occurrences from both phases (tables 5.11 and 5.18). Within the northern Lesser Antilles, notably the region from Anguilla to Guadeloupe, it was now the predominant axe material, even appearing in very small excavated samples. Other materials occur only rarely.

In relation to the use of other materials, the latest three occupations at Anse à la Gourde, all falling within the Late Ceramic A phase, provide the richest inventory of used axes. In addition to a considerable number of St. Martin greenstone axes (figure 5.27), over 40 specimens, the excavations produced a limited number of metamorphic examples, predominantly green in colour, a plutonic one, and some fine-grained igneous rock ones (figures 5.28). Comparison of this sample with material from the preceding Early Ceramic B occupation shows that greenstone increased relatively during the later phases. This holds also for metamorphic materials, which are rarely found among Early Ceramic B samples.

Sandy Ground and Barnes Bay are, apart from Anse à la Gourde, the only two sites in the Anguilla-Guadeloupe region, that yielded axe artefacts of a rock type other than the St. Martin greenstone. The materials used are fine-grained dark grey rock types, probably of an igneous nature. The number of such items, however, is very small.

The provenance of many of these other axes remains unknown. The metamorphic items originate from regions beyond the northern Lesser Antilles, either the Greater Antilles or the South American mainland. The igneous rock specimens probably come from less distant sources. St. Martin is the likely source for the Anguilla sites, as materials resembling these fine-grained igneous rock varieties were seen on this neighbouring island. The provenance of the igneous axes from Anse à la Gourde remains unspecified. The nearby islands of La Désirade, Basse Terre, or Montserrat should be considered as most likely sources. In relation to these latter varieties, it should be noted that the plutonic rock axe closely resembles an axe found at Morel. This suggests that in addition to the continuous use of St. Martin greenstone for axe making, other materials were utilized as well for considerable periods.

The abundance of greenstone axes decreases beyond the Anguilla - Guadeloupe region. At the Paso del Indio site, a single such axe was found among many other materials. At Anse Trabaud, a single such fragment was identified among other local varieties. This site on Martinique is one of the few sites from this phase that actually produced evidence of axe manufacture from raw materials other than St. Martin greenstone. Barnes Bay and Sandy Ground are the other sites that yielded such evidence. The worked material consisted in all cases of igneous rock, which was primarily obtained as water-worn cobles. In general, the production debris is limited. Such a low occurrence resembles evidence at sites reported from the earlier phases. It apparently is a common feature that may be a result of the similarity between raw material shape (rounded pebbles), and the desired final axe shape. Material likely originated from local sources at the Anse Trabaud site, and in the case of Anguilla, the sources were on nearby St. Martin, as suggested above.

Beads and pendants

Beads form the major category of decorative lapidary items during the Late Ceramic A phase, similar to the preceding Early Ceramic B phase. The large number of excavated examples suggests an increased usage during this phase. The recurrent 


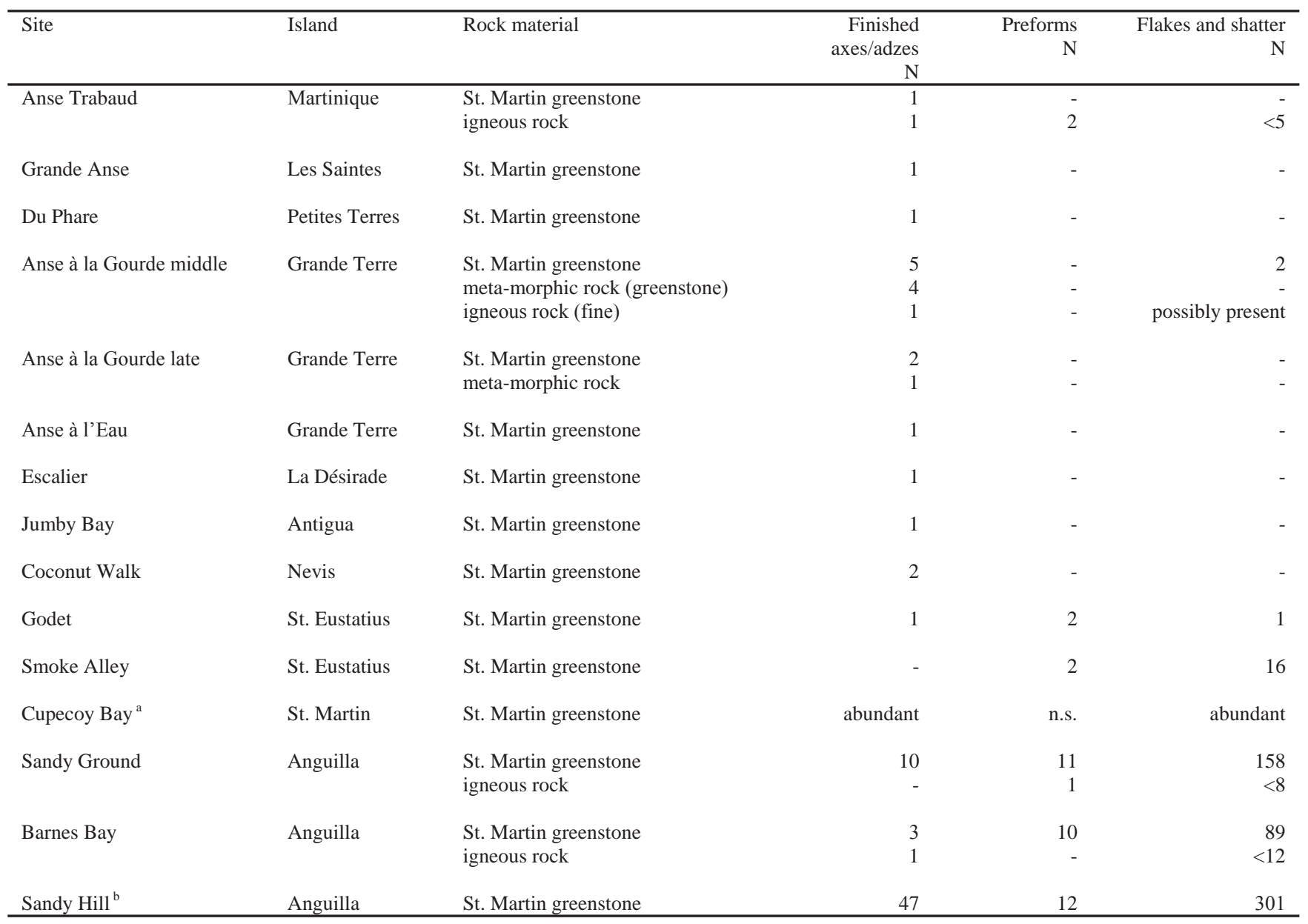

Table 5.18. Late Ceramic A phase. Identified axes and axe production related artefacts by raw material by site. a Data from Haviser (1987); b Data from Crock \& Petersen (1999).

appearance on Anguilla particularly supports this. Comparison of the sites within the northern Lesser Antilles shows that basically two raw material varieties are predominant: calcite and diorite (table 5.19 and figure 5.29). In addition, limestone rarely occurs as well, while for a small number of beads the raw materials were not identified (Crock 2000).

It can be assumed that calcite was commonly available within the Lesser Antilles, considering the extensive presence of limestone deposits on many of the islands. The local provenance of this crystal variety is supported by the relatively high abundance of calcite among archaeological material from sites on Anguilla and also Cupecoy Bay on St. Martin, both islands with extensive limestone (Crock 2000; Crock \& Petersen 1999; Haviser 1987). Samples from Sandy Ground, Barnes Bay, and Shoal Bay East are characterised by a high number of small natural (fragmentary) pieces in the form of angular crystals, as well as more amorphous calcite. These latter pieces resemble stalagmites in shape, but generally do not exceed $2.7 \mathrm{~cm}$ in size. In addition, rare worked pieces, in the form of flaked items, ground but unfinished bead preforms, and finished beads complement the collections, clearly suggesting local calcite bead production at these sites. Whether the relatively abundant pieces of unworked natural calcite served as a raw material for future bead making is unclear. The high number clearly contrasts with the low amount of worked material and this differs from reported frequencies related to, for example, carnelian bead working material at the Early Ceramic A site of Trants (Crock \& Bartone 1998). Therefore, the unworked materials may have served other purposes, or simply represent a natural scattering of calcite within the soils of Anguilla.

In contrast to the clear evidence of calcite bead making on Anguilla and to a lesser extent on St. Martin, loci of diorite bead making have not been identified in the study area. All reported and identified diorite beads within the collections 

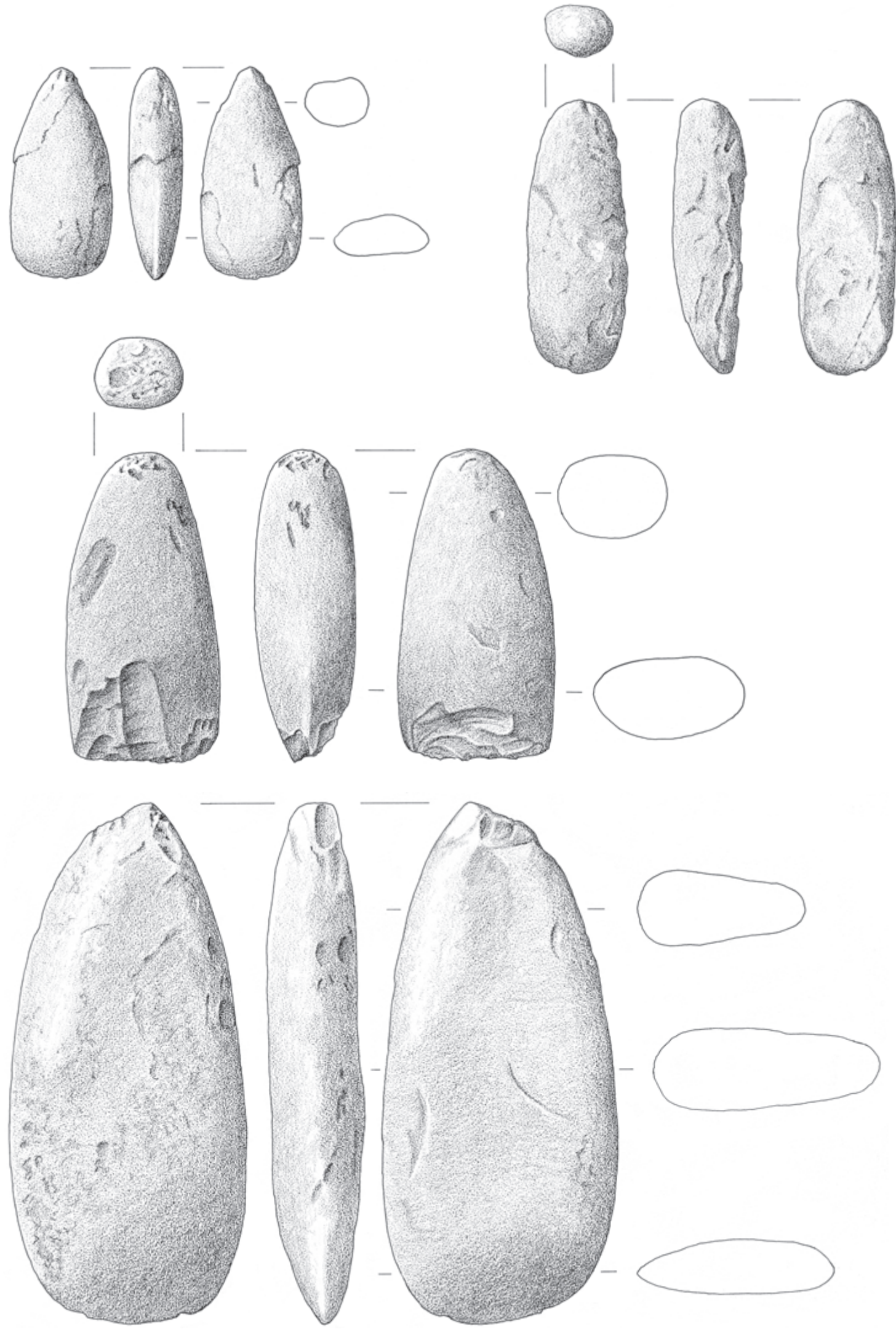

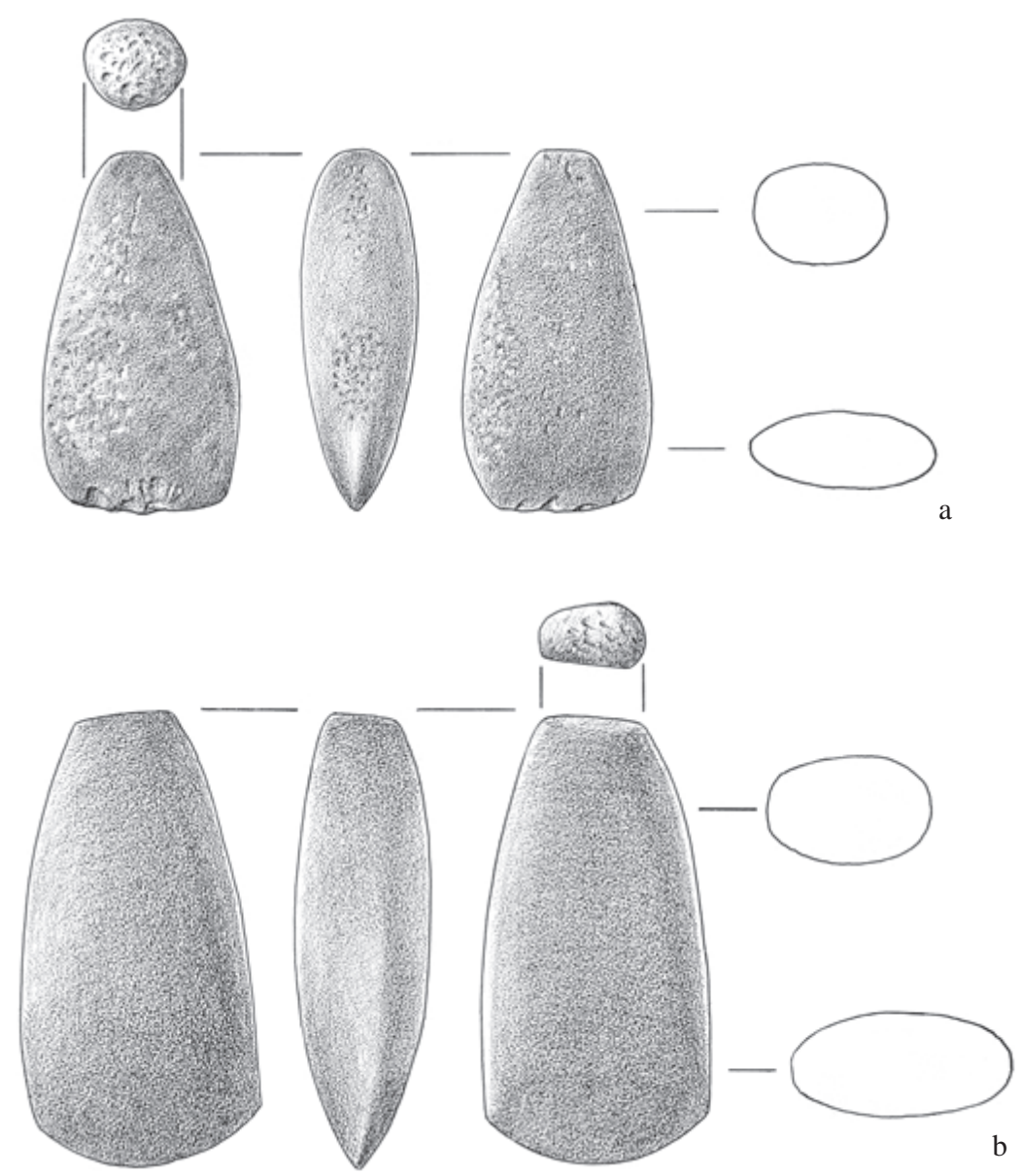

Figure 5.28. Anse à la Gourde middle occupation phase, Guadeloupe. a. Green metamorphic rock axe; b. Dark igneous rock axe (scale 1:2). (Drawings Erick van Driel)

are finished items. Close Similarities among the different beads suggest a single origin. The absence of any production on these islands makes it likely that its source has to be sought outside the region of the northern Lesser Antilles, although diorite can be naturally found on some of the islands, for example, St. Martin, Antigua, and La Désirade (Christman 1953, 1972; Bouysse et al. 1983). Close comparison with published illustrations of diorite beads dated to the Early Ceramic A phase (Watters \& Scaglion 1994, figures 5, 6, 8, and 12) shows that this diorite may represent another variety, in which the proportion of white crystals is considerably larger than within the variety of the Late Ceramic A samples encountered at Anse à la Gourde, Jumby Bay, and Kelbey's Ridge 2. Furthermore, the material from Trants indicates that diorite beads were finished on site, as evidenced by the presence of a number of unfinished examples (Watters \& Scaglion 1994). In combination with the high abundance among lapidary items at Trants and general occurrence at Royalls and Elliots on Antigua, these observations suggest that during the Early Ceramic A, rock local to the Lesser Antilles was used. 


\begin{tabular}{|c|c|c|c|c|c|}
\hline Site & Island & Rock material & Finished only & Production & Reference \\
\hline Anse Trabaud & Martinique & no items found & - & - & \\
\hline Du Phare & Petite Terre & no items found & - & - & \\
\hline Anse à la Gourde middle & Grande Terre & $\begin{array}{l}\text { calcite, rock crystal, } \\
\text { igneous rock }\end{array}$ & $\begin{array}{l}\text { rock crystal, } \\
\text { igneous rock }\end{array}$ & possibly calcite & \\
\hline Anse à la Gourde late & Grande Terre & no items found & - & - & \\
\hline Anse à l'Eau late & Grande Terre & no items found & - & - & \\
\hline Escalier & La Désirade & no items found & - & - & \\
\hline Muddy Bay & Antigua & no items found & - & - & Murphy 1999 \\
\hline Mill Reef & Antigua & diorite & diorite & - & \\
\hline Jumby Bay & Antigua & diorite & diorite & - & \\
\hline Godet & St. Eustatius & no items found & - & - & \\
\hline Smoke Alley & St. Eustatius & no items found & - & - & \\
\hline Spring Bay 3 & Saba & diorite & diorite & - & Hoogland 1996 \\
\hline Cupecoy Bay & St. Martin & calcite & - & calcite & Haviser 1987 \\
\hline Sandy Ground & Anguilla & $\begin{array}{l}\text { calcite, diorite, } \\
\text { unidentified rock }\end{array}$ & diorite & calcite & \\
\hline Barnes Bay & Anguilla & $\begin{array}{l}\text { calcite, diorite, feldspar, } \\
\text { unidentified rock }\end{array}$ & diorite & calcite & Crock 2000 \\
\hline Sandy Hill & Anguilla & $\begin{array}{l}\text { calcite, limestone, diorite, } \\
\text { unidentified rock }\end{array}$ & $\begin{array}{l}\text { limestone, diorite, } \\
\text { unidentified rock }\end{array}$ & calcite & Crock 2000 \\
\hline
\end{tabular}

Table 5.19. Late Ceramic A phase. Identified lapidary items and production remains by raw material by site.

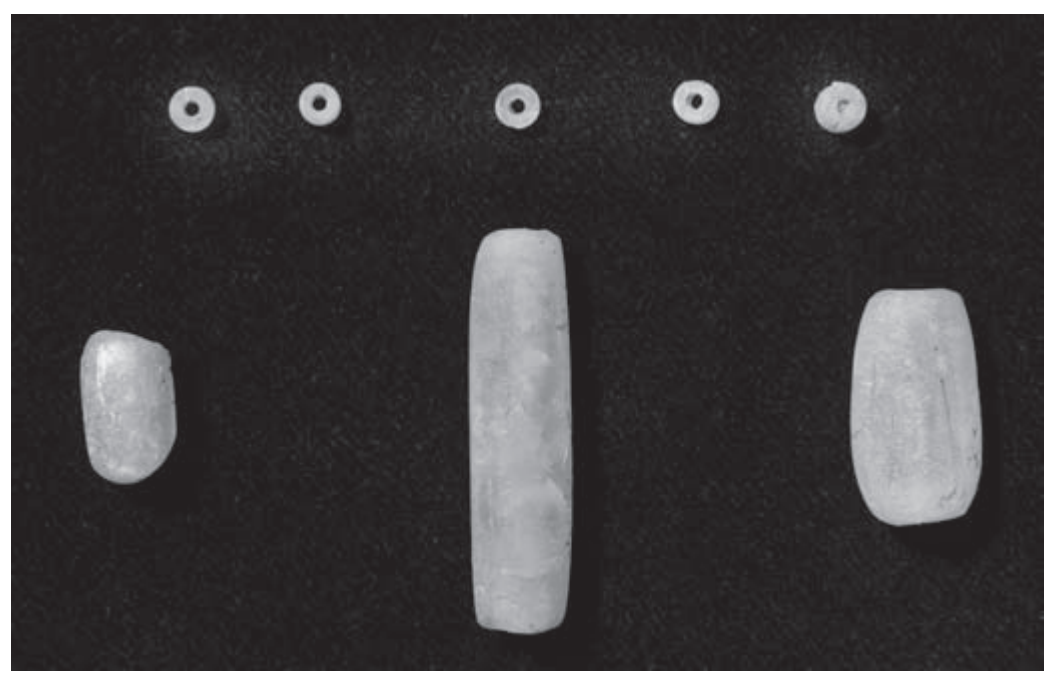

Figure 5.29. Anse à la Gourde middle occupation phase, Guadeloupe. Calcite beads (scale 1:1). (Photo Ben Grishaaver) 
Zemi three-pointer stones

The Late Ceramic A phase marks one of the most productive periods with regard to zemi usage within the northern Lesser Antilles. In particular, the island of Anguilla stands out on the basis of its zemi-rich artefact collections from different island sites. This may be partly a result of the repeated efforts of the Anguilla Archaeological and Historical Society (AAHS) followed by research of John Crock and Jim Petersen, who all put a lot of work into mapping sites, surveying sites, and cataloguing artefact collections (Crock 2000; Crock \& Petersen 1999; Douglas 1986, 1991). On the other hand, local production of these artefacts on Anguilla also likely produced a much higher actual frequency, than, for example, on Saba that did not yield such a rich zemi artefact inventory, in spite of extensive systematic archaeological research (Hofman 1993; Hoogland 1996).

Looking at zemi raw materials, basically three rock types stand out: calci-rudite, calcite, and limestone (table 5.20). The former two rock types are distinct varieties, while the latter represents a rock class, covering a broad range of varieties. In addition igneous rock and quartz examples were occasionally identified as well. These materials largely resemble the variety of rock types used at the Early Ceramic B site of Golden Rock and suggest continuation of raw material choice. Only the presence of pumice at Golden Rock, which was not found anywhere during the phase discussed here and calcite, which was not encountered at Golden Rock, are the marked differences. These are likely the result of the local geological environment at Golden Rock, where pumice is available and calcite is not.

This phase provides the first unequivocal evidence of local on site working of raw material into three-pointers. Worked materials include both calci-rudite and limestone. With regard to the former rock type, sites on Anguilla and to a lesser extent on St. Martin produced abundant artefactual data relating to zemi production in the form of flakes, unspecified fragments, preforms, and finished zemis (figure 5.30). Sites with abundant evidence of zemi manufacture are Rendezvous Bay, Sandy Ground, and Barnes Bay on Anguilla, and Cupecoy Bay on St. Martin. In addition, limited samples from surface collecting at Island Harbour, Little Harbour, and Lockrum on Anguilla (Crock \& Petersen 1999) and possibly at Pointe Terre Basse, Red Bay, and Great Kay on St. Martin (Haviser 1987) also suggest on-site working. These sites perfectly surround the Pointe Arago source on St. Martin (figure 5.31). It should be noted that only sites on the western part of St. Martin have yielded evidence of zemi production. This indicates that access to Pointe Arago was only possible from within a limited region. A closer look at the calci-rudite artefacts from Sandy Ground and Barnes Bay reveals that part of the material was collected from a secondary context, as indicated by worn outer surfaces. Considering the low occurrence of distinguishable outer surfaces, it may well be that primary material was commonly obtained as well.

The recovery of finished calci-rudite items at a number of sites, such as Spring Bay, Anse à la Gourde (figure 5.32), Anse à l'Eau, and Paso del Indio (Rodríguez Ramos 2005), all far from the Pointe Arago source, in combination with these production places, demonstrates the existence of exchange relationships between these two groups of sites. This is an important topic for further discussion (see next Chapter).

Limestone is the other predominant material that available evidence suggests that it was worked into zemi threepointers at a number of sites. Correct identification of such local production is to some degree hampered by variability in limestone rock varieties encountered among the different zemis at a single site, making it difficult to relate flake material with preforms and finished objects. Sites that minimally yielded evidence of limestone working and the presence of preforms and finished limestone zemis comprise Anse à la Gourde on Grande Terre, and Sandy Ground, Barnes Bay, Sandy Hill, and Rendezvous Bay on Anguilla. All these sites are situated within limestone regions and rock varieties are likely local to the direct site surroundings

At Anse à la Gourde, basically two types of limestone were found: a calcareous sandstone (beach rock) (figures 5.33 and 5.34) and a calcareous mudstone. The sandstone variety likely is local to the area in view of the common availability of beach rock along the northern coast of Grande Terre (Russell 1960; Troelstra \& Beets 2001). However, this type of beach-rock differs from the common underlying bedrock in the site area by its stronger cementation, in which the carbonate sandstone grains were "melted" and cannot be separated individually. The other limestone type resembles limestone available in the direct site vicinity. The majority of the limestone zemis from this site can be attributed to the Troumassoid 1 and 2 occupations, the latest Suazan Troumassoid occupation only yielded a single fragmentary artefact. Furthermore, these zemis generally exceed their Saladoid equivalents in size and are more variable in shape, which is shown by a comparison with the Golden Rock artefacts (see figure 5.18 and 5.32-34).

In the case of the Anguilla artefacts, material variability is obvious, but the different limestone varieties are macroscopically less distinct than among the Anse à la Gourde artefacts. Most of the material was likely locally obtained, but exact source locations cannot be specified. Some of the flaked material exhibits water-worn surfaces, indicating that cobble beaches were exploited. With regard to the calcite zemis from Anguilla, the data are very scanty. The high numbers of 


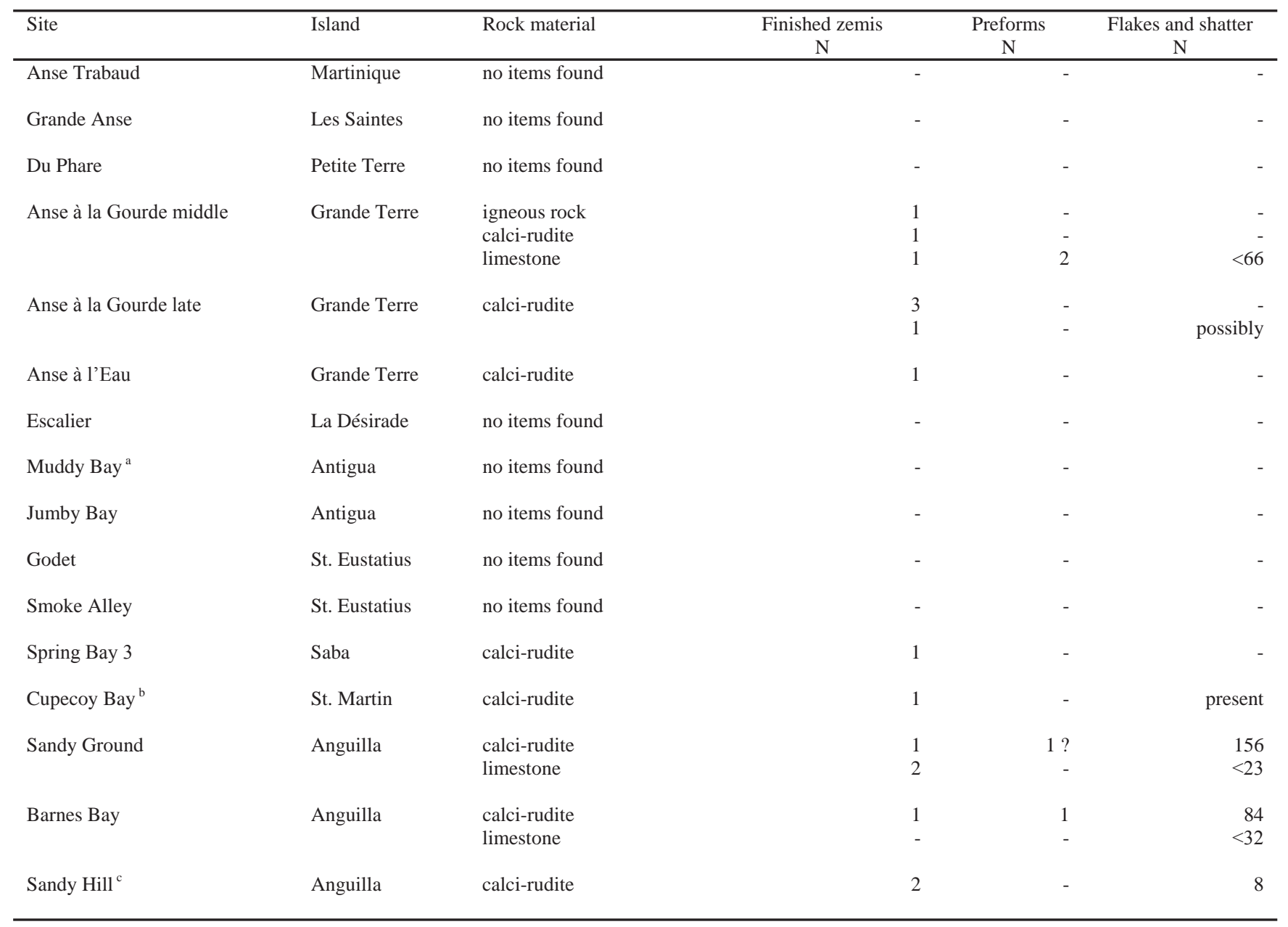

Table 5.20. Late Ceramic A phase. Identified zemi three pointer stones and production remains by raw material by site. a Data from Murphy (1999); b Data from Haviser (1987); c Data from Crock \& Petersen (1999).
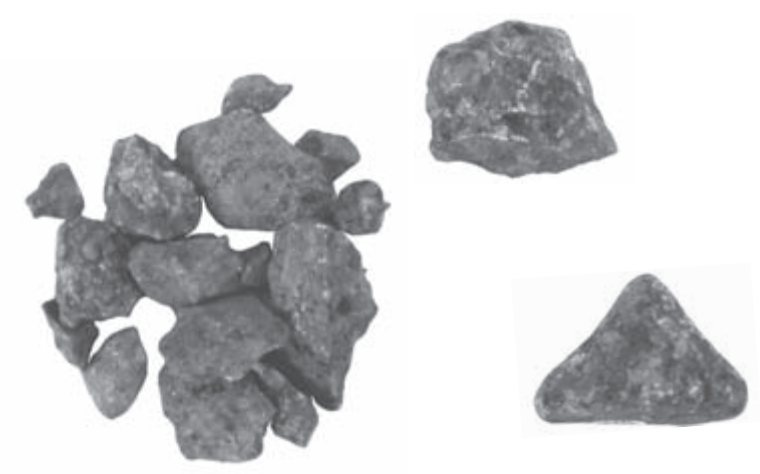

Figure 5.30. Sandy Ground, Anguilla. Calci-rudite zemi three pointer manufacture remains: debris (on the left), a preform (on the top right) and a single finished example (at the bottom right) (scale 1:2). 


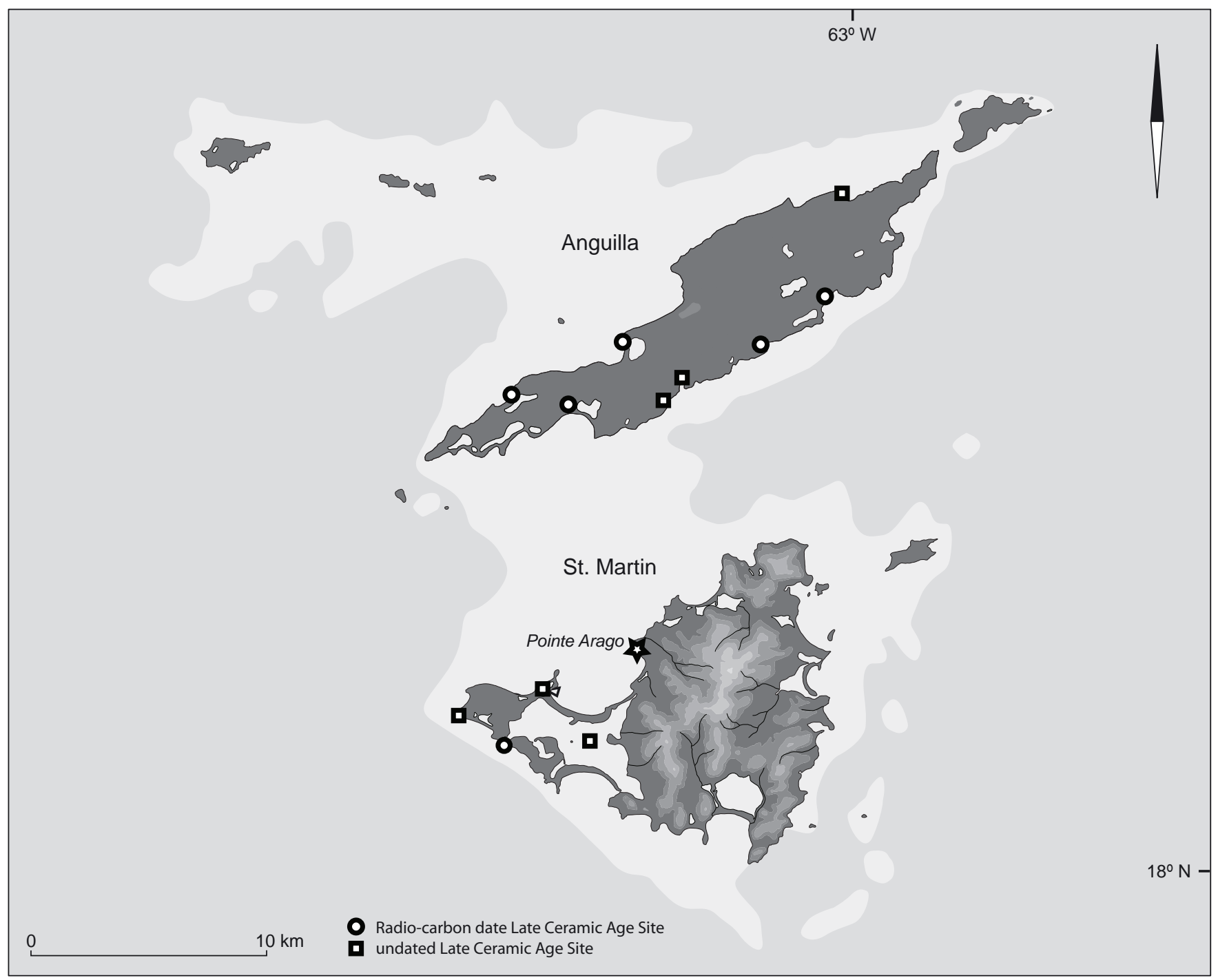

Figure 5.31. Map of Anguilla and St. Martin showing the location of Late Ceramic Age sites with evidence of calci-rudite zemi manufacture.

calcite pieces mentioned in the previous section on bead manufacture cannot be related to calcite zemi manufacture, because of their significantly smaller size. Only one site, Forest North produced a calcite-zemi preform (Crock 2000). Still, a local provenance of the material should be considered as very likely.

In addition to these materials, igneous rock and quartz zemis were only found as finished items at the site of Anse à la Gourde (figure 5.35). Considering the absence of related debitage and their exotic provenance, they were likely imported from yet unknown origins.

\section{Shaped grinding and abrading stones}

This phase does not include a similarly rich site like Golden Rock attributable to the preceding phase with regard to passive grinding stones. Studied sites on the same island of St. Eustatius, Godet and Smoke Alley, did not yield any complete examples, nor fragments of rock types associated with these artefacts (table 5.21). Although the small sample size from both sites hinders sound comparison, each of the two samples should have at least contained four to five such artefacts, if a similarly abundant occurrence as at Golden Rock was the case. 

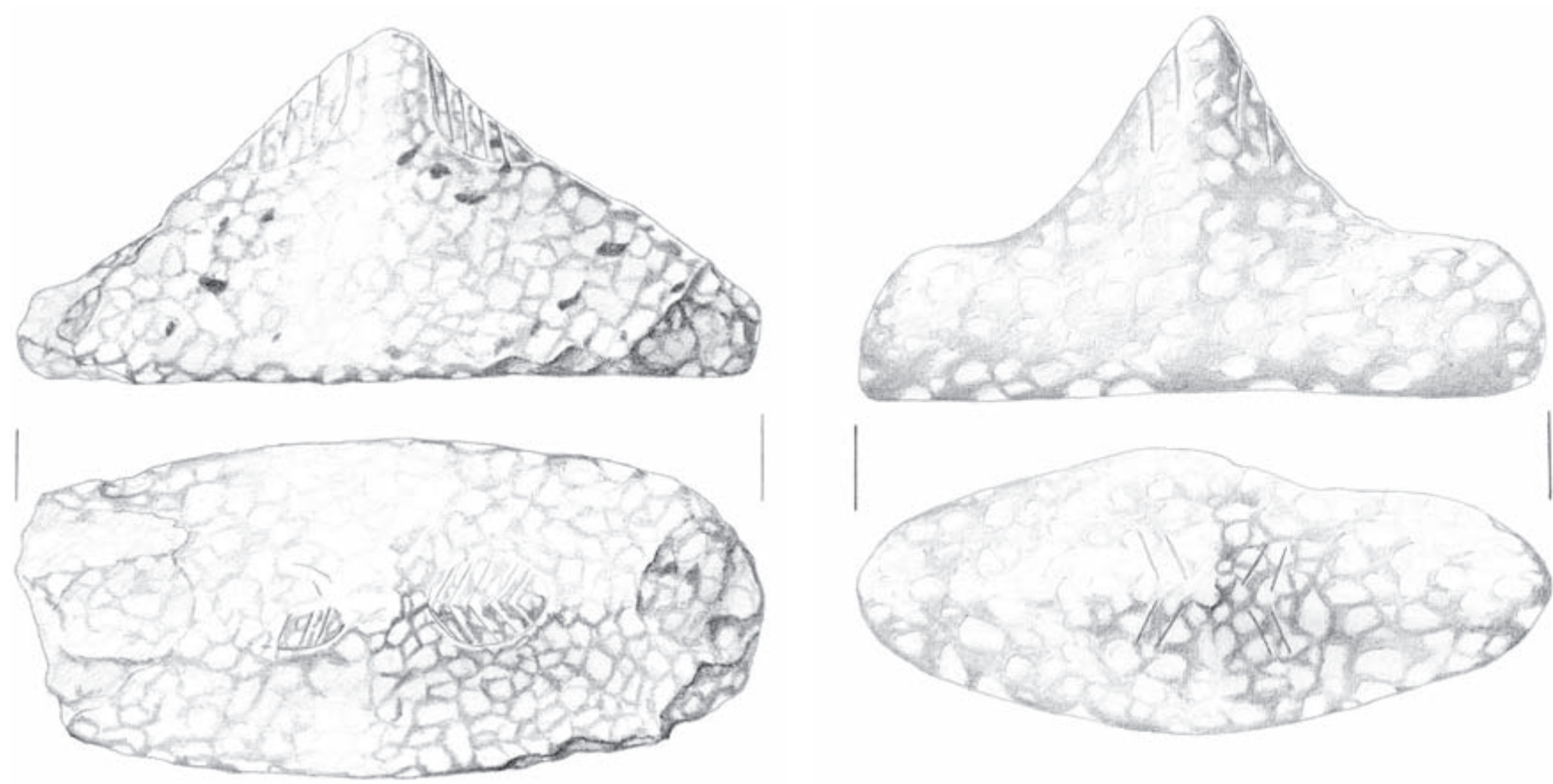

Figure 5.32. Anse à la Gourde middle and late occupation phases, Guadeloupe. Calci-rudite zemi three pointer stones (scale 1:1). (Drawings Raf Timmermans) See figure 2.27 for photos of both zemis.

Only excavations at Anse à la Gourde produced a significant number of such artefacts, largely fragments (figure 5.36). Due to their incomplete nature, it was often difficult to determine whether these rocks were shaped prior to use or not. It was minimally obvious that they did not originate from water-worn pebbles. Fragments with a concave smooth surface, clearly the result of abrasion, are predominant and include coarse grained igneous rock varieties, beach-rock, and a number of unidentified often burnt rock, also likely igneous in nature. Clear stones for the grinding of tools, such as axes, were not identified.

Other sites that only yielded a small number of passive grinding stone fragments are Anse Trabaud, where local igneous rock was used, and Sandy Ground and Barnes Bay, where igneous rock was obtained from elsewhere. Interestingly, Sandy Ground yielded one artefact made of yellow rock, which is similar to a variety infrequently encountered at the Early Ceramic B site of Golden Rock.

Limited excavations on the small island of La Désirade yielded additional examples of passive grinding stones. Within the sample of the Aéroport site, a granular material, likely igneous rock, was encountered that was almost identical to a variety repeatedly used at Anse à la Gourde and the Early Ceramic B site of Les Sables. In addition to the yellow rock, this again supports continued use of a limited number of raw material types for the making of these tools. Unfortunately, a source location cannot be specified for this material, but it was probably situated on La Désirade.

The relatively large sample from Anse à la Gourde included a small number of light green fragments exhibiting a convex abraded surface, similar to examples found within the Early Ceramic B occupation of this site and at Morel. I hypothesized above that they may have been used as active abrading or grinding stones resembling manos tools in MesoAmerica. This type of tool was only found at the northern Grande Terre sites of Morel and Anse à la Gourde. In particular, in light of their absence among some large artefact samples, as at Golden Rock and Sorcé, for example, a very localized appearance can be suggested. Whether this difference relates to different functional activities at these Grande Terre sites, or it relates to different stone working habits, is unclear and needs to be studied in the future. 

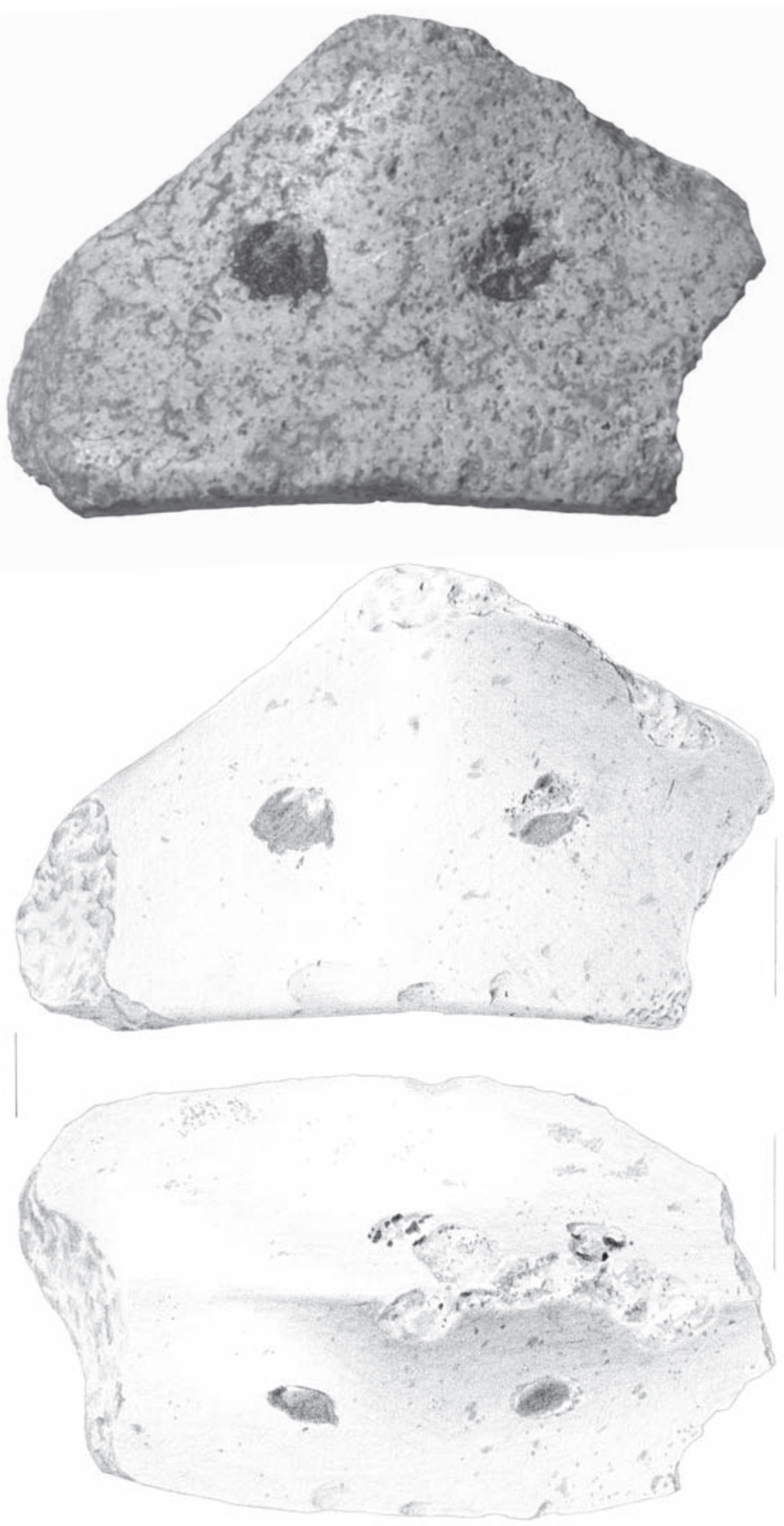

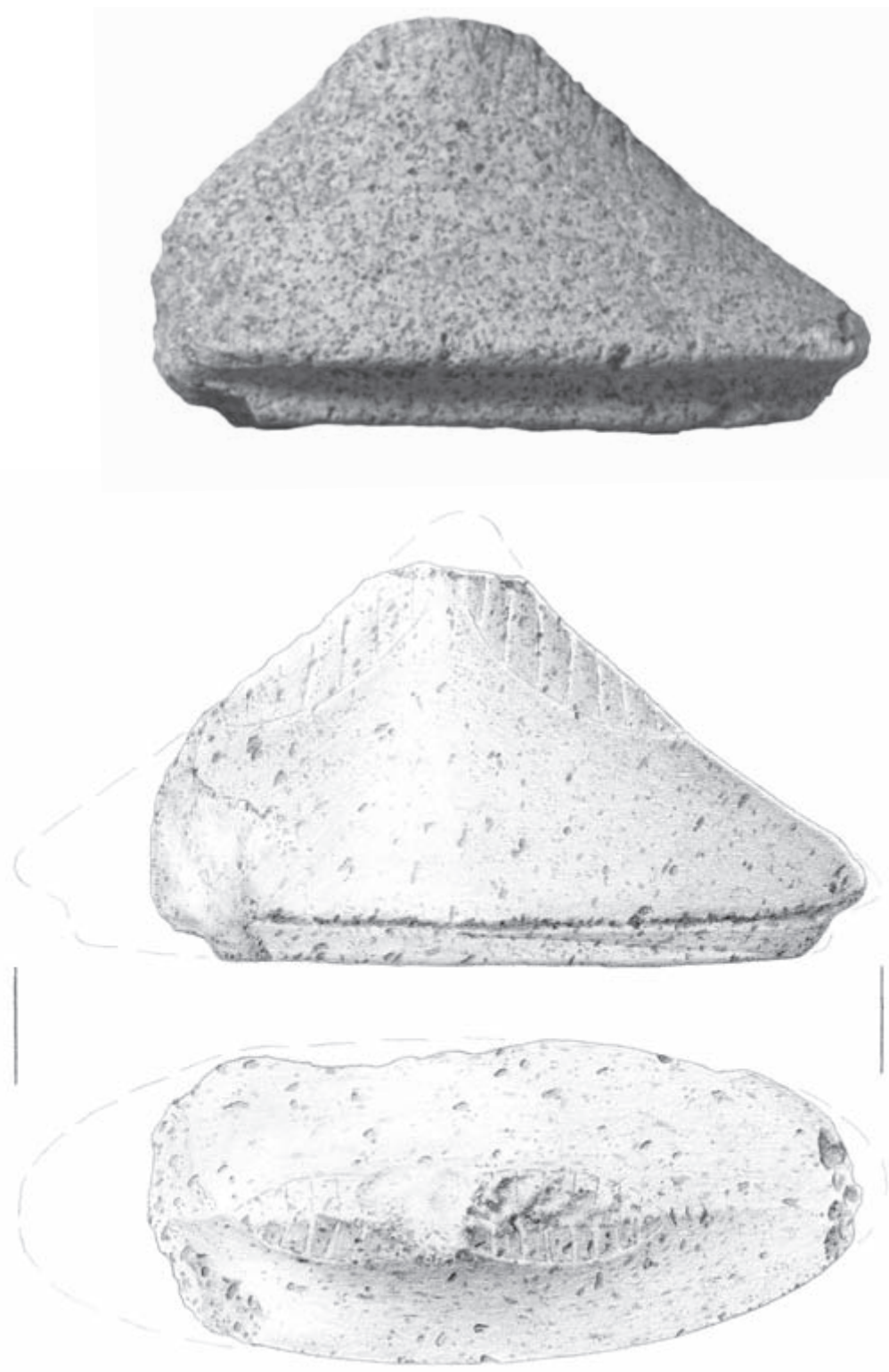

Figure 5.34. Anse à la Gourde middle and late occupation phases, Guadeloupe. Beach-rock zemi three pointer stone (scale 1:1). (Photo Jan Pauptit and drawing Raf Timmermans)

Figure 5.35 (opposite page). Anse à la Gourde middle and late occupation phases, Guadeloupe. Igneous rock zemi three pointer stones (scale 1:1). (Drawings Raf Timmermans and photo Jan Pauptit) 

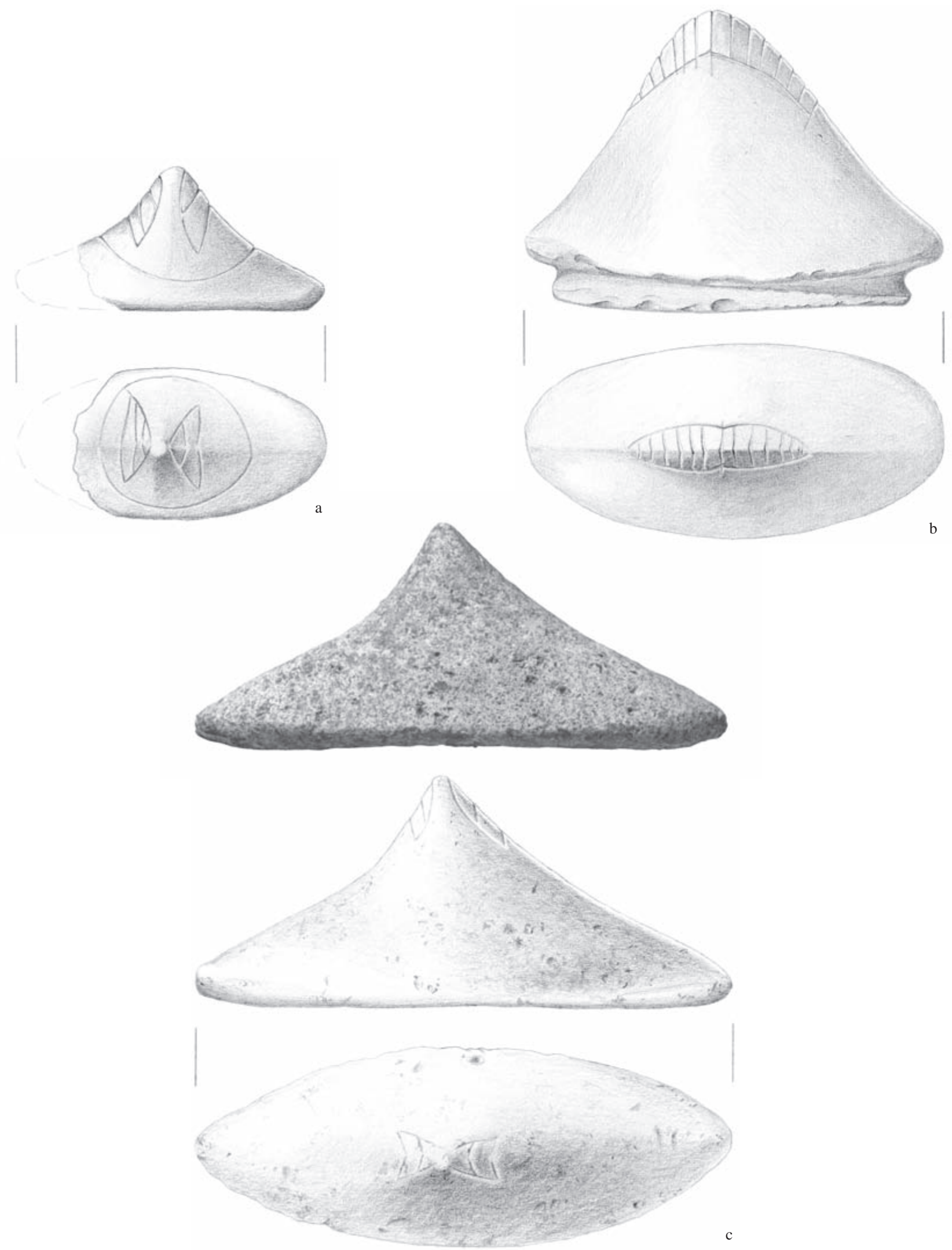


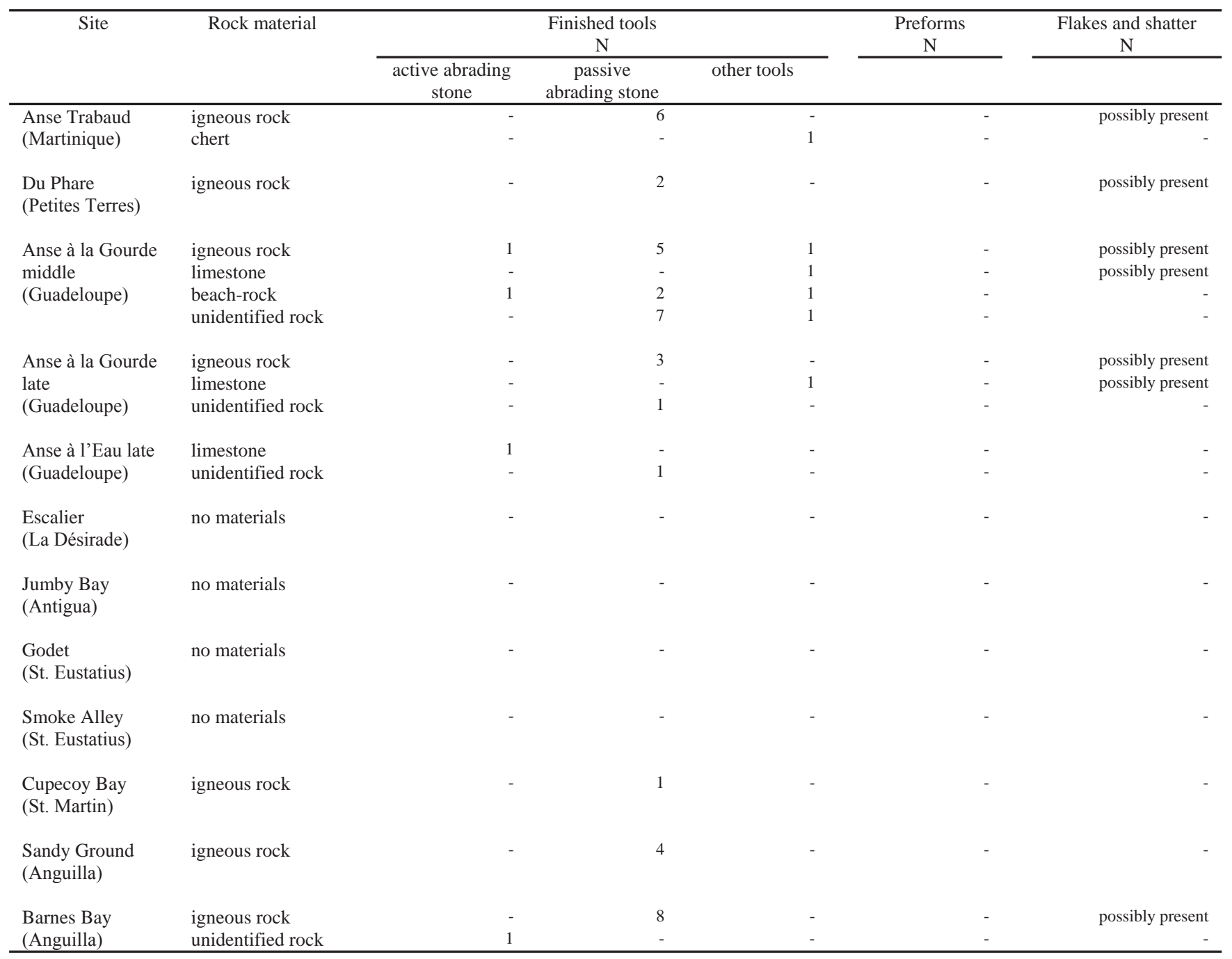

Table 5.21. Late Ceramic A phase. Number of identified shaped grinding and abrading tools and related manufacture debris by raw material by site.

Use-modified rock and manuports

Characteristics relating to use-modified pebbles and pebbles without any modification from this phase resemble in many ways the situation of the preceding period. Notable similarities include the use of rocks originating from nearby sources, the predominance of igneous rock artefacts among this group, and association of specific tool types with certain rock types. In detail, the rock types identified besides igneous rock include limestone, beach-rock, undefined fine-grained rock, chert, plutonic rock, and possibly sandstone (table 5.22). Apart from limestone, the occurrence of these latter types among the collections is rare.

Igneous rock again displays the most variability in tool types, including hammerstones, anvils, active and passive abrading/grinding stones, and polishing stones (figure 5.37 and 5.38). Among the limestone pebbles more tool types were found than in the preceding phase, probably owing to the fact that most studied collections come from limestone islands. Tool types include hammerstones, active abrading/grinding stone, a polishing stone and a passive abrading/grinding stone. Fine-grained rock is only associated with the polishing stones as was the case within the preceding phase. These fine-grained polishing stones were not identified much, probably owing to the small size of the lithic samples from sites on and nearby St. Martin. 


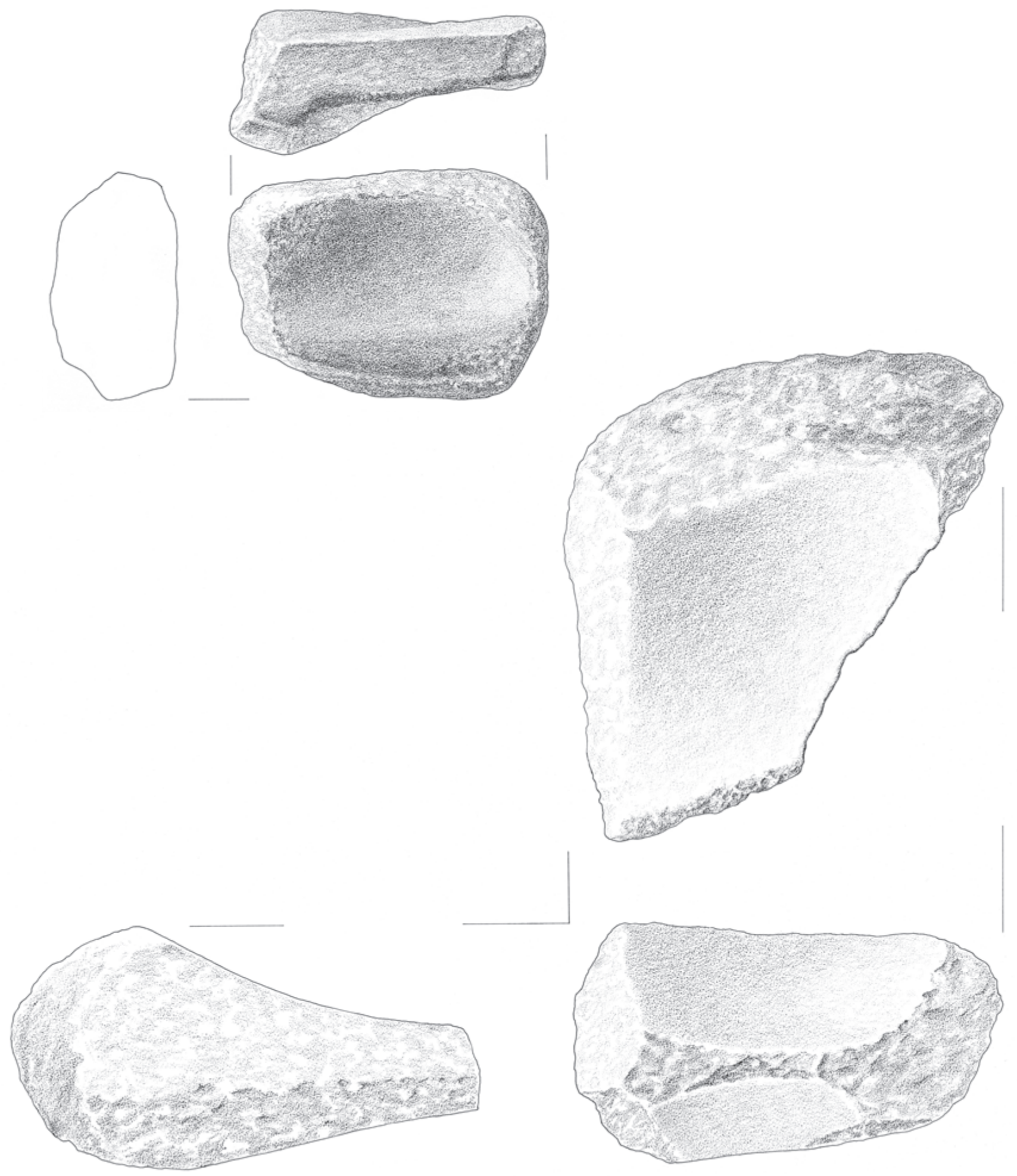

Figure 5.36. Anse à la Gourde middle and late occupation phases, Guadeloupe. Igneous rock passive grinding stones (scale 1:2). (Drawings Raf Timmermans) 


\begin{tabular}{|c|c|c|c|c|c|c|c|c|c|}
\hline \multirow[b]{2}{*}{ Site } & \multirow[b]{2}{*}{ Pebble Material } & \multicolumn{8}{|c|}{ Tool types (N) } \\
\hline & & $\begin{array}{l}\text { non- } \\
\text { utilized } \\
\text { pebble }\end{array}$ & $\begin{array}{l}\text { hammer } \\
\text { stone }\end{array}$ & anvil & & $\begin{array}{l}\text { passive } \\
\text { abrading } \\
\text { stone }\end{array}$ & $\begin{array}{l}\text { active } \\
\text { abrading } \\
\text { stone }\end{array}$ & $\begin{array}{l}\text { polishing } \\
\text { stone }\end{array}$ & other tool \\
\hline $\begin{array}{l}\text { Anse Trabaud } \\
\text { (Martinique) }\end{array}$ & igneous rock & 23 & 2 & & - & 1 & 2 & 4 & - \\
\hline $\begin{array}{l}\text { Du Phare } \\
\text { (Petite Terre) }\end{array}$ & igneous rock & 3 & - & & - & - & - & - & - \\
\hline \multirow{6}{*}{$\begin{array}{l}\text { Anse à la Gourde middle } \\
\text { (Guadeloupe) }\end{array}$} & pumice & 1 & - & & - & - & - & - & - \\
\hline & fine-grained rock & 18 & _ & & _ & - & - & 1 & - \\
\hline & sandstone & 1 & 1 & & _- & - & 1 & - & _ \\
\hline & limestone & 212 & 6 & & - & - & 1 & 1 & - \\
\hline & beach-rock & 2 & - & & - & 1 & 2 & - & - \\
\hline & unidentified rock & 15 & - & & - & - & - & - & - \\
\hline $\begin{array}{l}\text { Anse à la Gourde late } \\
\text { (Guadeloupe) }\end{array}$ & unidentified rock & 3 & - & & - & - & 1 & - & - \\
\hline \multirow{2}{*}{$\begin{array}{l}\text { Anse à l'Eau late } \\
\text { (Guadeloupe) }\end{array}$} & igneous rock & 7 & - & & - & - & - & 1 & - \\
\hline & plutonic rock & 1 & - & & - & - & - & - & - \\
\hline \multirow{2}{*}{$\begin{array}{l}\text { Escalier } \\
\text { (La Désirade) }\end{array}$} & igenous rock & 69 & 2 & & - & - & 5 & 1 & 1 \\
\hline & limestone & 1 & - & & - & - & 1 & - & - \\
\hline $\begin{array}{l}\text { Jumby Bay } \\
\text { (Antigua) }\end{array}$ & flint & 4 & 3 & & - & - & - & - & - \\
\hline \multirow{2}{*}{$\begin{array}{l}\text { Godet } \\
\text { (St. Eustatius) }\end{array}$} & igenous rock & 22 & 10 & & 1 & - & 1 & - & - \\
\hline & fine-grained rock & - & - & & - & - & - & 2 & - \\
\hline \multirow{5}{*}{$\begin{array}{l}\text { Sandy Ground } \\
\text { (Anguilla) }\end{array}$} & igneous rock & 3 & 1 & & - & - & 1 & 1 & - \\
\hline & St. Martin greenstone & 1 & - & & - & - & - & - & - \\
\hline & chert & - & - & & - & - & 1 & - & - \\
\hline & limestone & 3 & 1 & & - & - & - & - & - \\
\hline & unidentified rock & 1 & - & & - & - & - & - & - \\
\hline \multirow{3}{*}{$\begin{array}{l}\text { Barnes Bay } \\
\text { (Anguilla) }\end{array}$} & igneous rock & 4 & 1 & & - & - & - & - & - \\
\hline & St. Martin greenstone & 3 & 1 & & - & - & - & - & - \\
\hline & limestone & 7 & 2 & & - & 1 & - & - & - \\
\hline
\end{tabular}

Table 5.22. Late Ceramic A phase. Number of identified use modified rocks and manuports by raw material, by site. n.s. $=$ not specified.

As already pointed out, procurement of most of such pebbles occurred at localities relatively close to the sites. The Anse Trabaud, Godet, and Smoke Alley inhabitants, living on the coasts of volcanic islands, probably obtained their pebbles from the immediate site surroundings. In contrast, the inhabitants of the Grande Terre and Anguilla sites made boat-trips to nearby islands for pebble collecting. The Anse à la Gourde and Anse à l'Eau people continued to largely collect their needed materials from La Désirade, as evident in the low diachronic variation among rocks from these sites. Still other islands providing igneous rock such as Basse Terre and Montserrat may have been visited on rare occasions as well. The Sandy Ground and Barnes Bay inhabitants probably collected their pebbles from St. Martin, where a large variety can be found. 

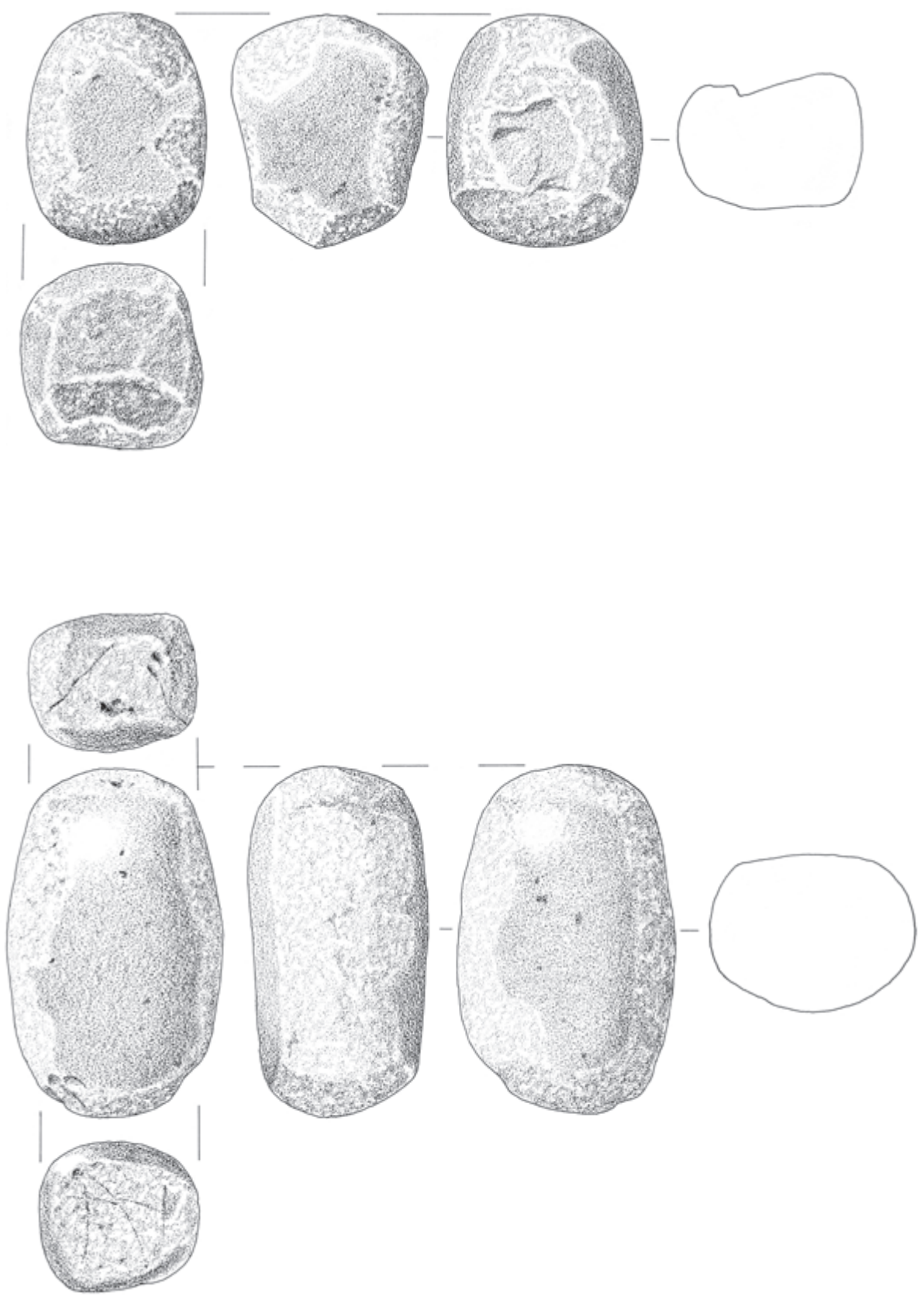

Figure 5.37. Anse à la Gourde middle and late occupation phases, Guadeloupe. Igneous rock hammerstones (scale 1:2). (Drawings Raf Timmermans)

This collecting may have co-occurred with procurement of greenstone material used for axe-manufacture. A minor portion of pebbles used at the Anguilla and Grande Terre sites, represented by the limestone and rare beach-rock examples, were obtained locally, probably within the immediate site surroundings.

In addition to the use-modified pebbles, non-modified pebbles were also found, particularly at the Anse à la Gourde site, where their occurrence continued to be a striking feature of the site inventory. Unlike the earlier occupation phase at this site and at Morel, the later phases of Anse à la Gourde did not yield any pebbles with remains of black residue, interpreted 

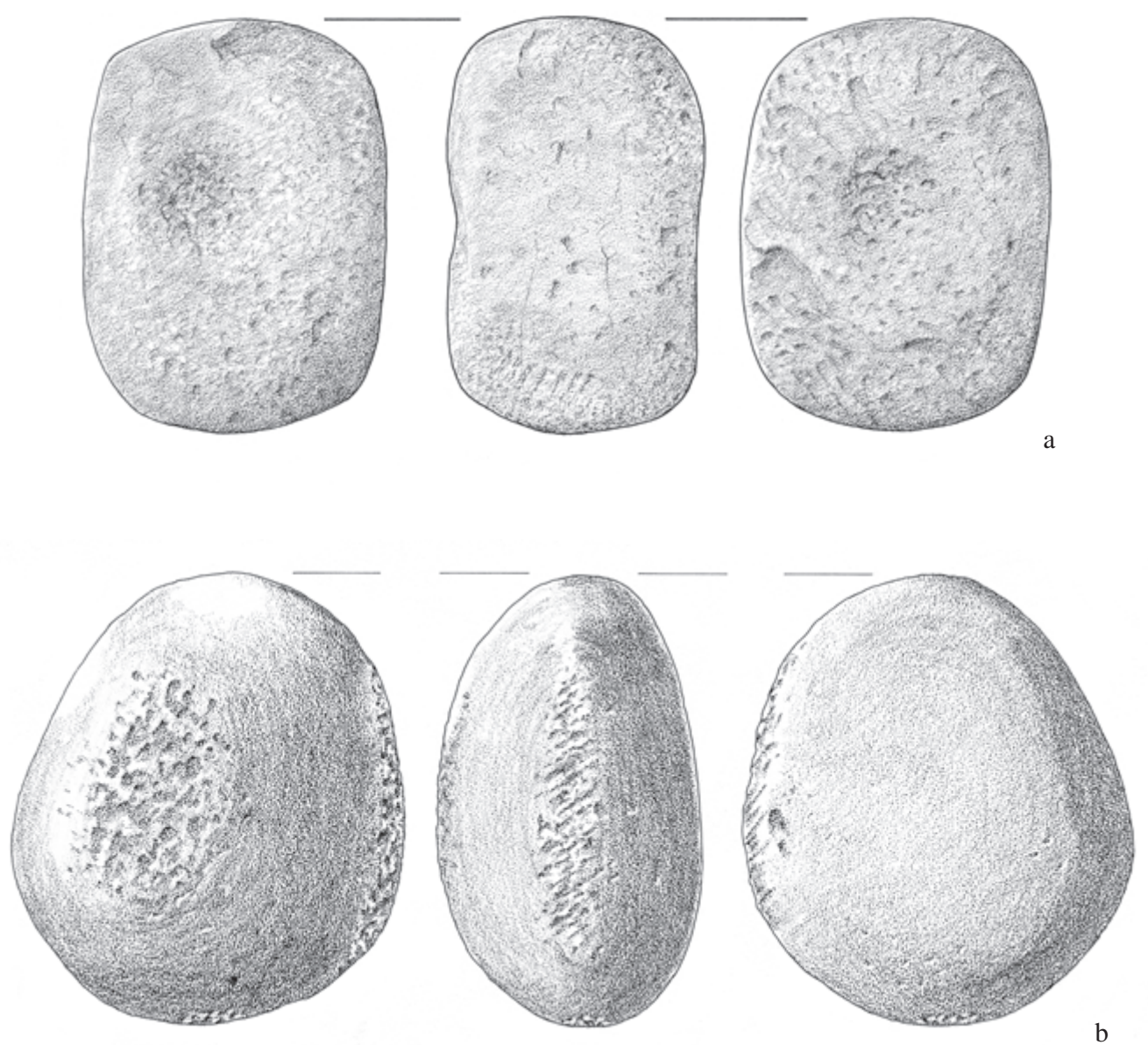

Figure 5.38. Anse à la Gourde middle and late occupation phases, Guadeloupe. Igneous rock hammerstone (b) and hammerstone/anvil (a) (scale 1:2). (Drawings Raf Timmermans)

as fish-net weights. Similar to the earlier phases, however, was the small pebble size and use of the same rock types. This indicates that either the black adhesive was no longer used to attach the pebbles, or post-depositional processes removed the residues from the pebbles in these deposits. Considering the rare finding of this black residue within the earlier phase at Anse à la Gourde, it is likely that post-depositional processes are responsible for its absence in this phase.

\subsubsection{Late Ceramic B}

\section{Introduction}

The number of sites attributed to the Late Ceramic B phase is small within the northern Lesser Antilles in general, and as a result not many sites dated to this phase could be analysed. A total of only four sites were studied, while Rodríguez Ramos (2005, personal communication 2001) provided data on the latest occupation phase of the Paso del Indio site (table 5.23). Moreover, some sites include a small number of artefacts, limiting overall comparison and conclusions. 


\begin{tabular}{llll}
\hline Site & Island & Type of sample & Reference \\
\hline Morne Souffleur & La Désirade & all lithics & - \\
Sugar Mill & Long Island & all lithics & - \\
Kelbey's Ridge 2 & Saba & flake tool related artefacts & - \\
Shoal Bay East & Anguilla & all lithics & - \\
\hline
\end{tabular}

Table 5.23. Studied sites from the Late Ceramic B phase.

\section{Flake tool production}

The limited sample from the latest phase of the pre-Columbian era does not deviate significantly from the preceding one relative to flake tool production. Varieties of chert continue to form the predominant material used within the northern Lesser Antilles (table 5.24) and on Puerto Rico, the Paso del Indio site displays the exploitation of similar local meta-volcanic materials (Rodríguez Ramos 2005, personal communication 2001). A closer look at the Kelbey's Ridge site reveals an almost identical abundance of Long Island flint (70.5\%) compared to older sites on Saba, suggesting that the use of and access to this material remained the same. In contrast, the limited data from Anguilla point to an increasing abundance of Long Island flint through time. Shoal Bay East produced higher percentages of Long Island flint than the earlier Barnes Bay and Sandy Ground sites. Furthermore, comparison of the material within Shoal Bay East itself displays an increase of Long Island within the upper site levels, although these levels produced very little material in general.

At Morne Souffleur, the absence of Long Island flint is striking, but the size of the sample excavated is small. Most flaked material is made of local red chert or local igneous rock. Due to the small number of artefacts, it could not be specified with what kind of production these latter igneous flakes are related to. In addition, Kelbey's Ridge 2 yielded still some other chert and flint types. Other than Long Island flint, this group displays considerable variability, which made it difficult to distinguish discrete varieties. Interestingly, the use of other Antigua sources was not identified.

As discussed above in Chapter 4, stone working at both sites on Long Island was very similar with regard to the choice of raw material, expedient reduction, and low occurrence of bipolar flaking, suggesting that the technological behaviour did not change through time. This is supported by data from Saba as well, which resemble the technological features of the earlier Spring Bay 3 site in many respects. Again, the smaller size of flaked material on sites further away from Long Island is noticed when compared to the material found of the source itself. A higher abundance of bipolar flakes is present as well, clearly supporting the view that the presence or absence of the use of this technique not necessarily is related to a cultural difference, but rather is dependent on availability of raw material. Similar to the earlier phases, Long Island flint was transported in unmodified natural form to Saba, as indicated by high percentage of cortical flake at Kelbey's Ridge 2.

\begin{tabular}{|c|c|c|c|c|}
\hline Chert type & Site & $\begin{array}{c}\text { Shoal Bay } \\
\text { East } \\
\mathrm{N}=26 \\
\% \\
\%\end{array}$ & $\begin{array}{c}\text { Kelbey's } \\
\text { Ridge 2 } \\
\mathrm{N}=112 \\
\% \\
\end{array}$ & $\begin{array}{c}\text { Sugar Mill } \\
\qquad \begin{array}{c}\mathrm{N}=432 \\
\%\end{array}\end{array}$ \\
\hline Long Island flint & & 65.4 & 70.5 & 100.0 \\
\hline Blackman's Point flint & & - & - & - \\
\hline Coconut Hall flint & & 3.8 & - & - \\
\hline Antigua Form. flint & & 3.8 & - & - \\
\hline White chert & & - & - & - \\
\hline Petrified wood & & - & - & - \\
\hline Other chert & & 42.3 & 19.6 & - \\
\hline Désirade red chert & & - & - & - \\
\hline Jasper & & - & - & - \\
\hline White quartz & & - & - & - \\
\hline Unidentified chert & & 3.8 & 9.8 & - \\
\hline
\end{tabular}

Table 5.24. Late Ceramic B phase. Relative amount of identified chert types by site. 


\begin{tabular}{|c|c|c|c|c|c|}
\hline Site & axes & zemis & lapidary items & use-modified rocks & other shaped tools \\
\hline $\begin{array}{l}\text { Morne Souffleur } \\
\text { (La Désirade) }\end{array}$ & $\begin{array}{l}1 \text { finished St. Martin } \\
\text { greenstone axe only }\end{array}$ & no items found & no items found & $\begin{array}{l}\text { use of igneous rock } \\
\text { for hammering and } \\
\text { abrading }\end{array}$ & no items found \\
\hline $\begin{array}{l}\text { Sugar Mill } \\
\text { (Long Island) }\end{array}$ & no items found & no items found & $\begin{array}{l}\text { no worked items } \\
\text { found, only } 1 \text { calcite } \\
\text { crystal }\end{array}$ & $\begin{array}{l}\text { one igneous } \\
\text { hammerstone only }\end{array}$ & no items found \\
\hline $\begin{array}{l}\text { Shoal Bay East } \\
\text { (Anguilla) }\end{array}$ & $\begin{array}{l}\text { greenstone axe } \\
\text { production }\end{array}$ & no items in sample ${ }^{a}$ & $\begin{array}{l}1 \text { metamorphic bead } \\
\text { pre-form }\end{array}$ & no items in sample & no items in sample \\
\hline
\end{tabular}

Table 5.25. Stone artefact use and manufacture at four Late Ceramic B phase sites within the northern Lesser Antilles. a In addition to the analysed sample for this dissertation previous survey work at Shoal Bay East by AAHS members has produced numerous zemi three pointer stones, made out of a variety of materials, such as calcite, limestone, calci-rudite and quartz (Crock \& Petersen 1999).

\section{Core tool production}

Axes and adzes

The amount of axes and axe related material is very small. Only St. Martin greenstone is associated with the use of axes during this phase (table 5.25). Similar to the earlier sites on Anguilla, Shoal Bay East yielded greenstone debitage indicating local axe fabrication. Whether greenstone axe manufacture also occurred on Saba cannot be specified yet, but it is likely, considering the occurrence of greenstone material there at Kelbey's Ridge 2. A single finished corroded example found at Morne Souffleur indicates that these tools still were traded among the northern Lesser Antilles.

Beads and pendants

Use of local mineral and rock varieties for making beads continued during this phase. Only two sites yielded bead material (see table 5.25). These are Kelbey's Ridge 2 and Shoal Bay East. At the former site, the excavation of large $4 \times 4 \mathrm{~m}$ test-units produced four diorite beads (see Hoogland 1996, 155-156, fig. 6.24a,c). The raw material resembled that of the diorite bead found at Jumby Bay and may suggest a similar provenance.

At Shoal Bay East, the later occupation levels yielded numerous calcite pieces and fragments, similar to the earlier occupation there. Most of the material either represents natural rock, or broken natural rock. As argued for the Late Ceramic A phase, this natural rock may have been collected for bead making at the site. The finding of some calcite beads suggests this. In addition to these beads, the Kelbey's Ridge 2 site yielded a slightly angular water-worn pebble, perforated at the top (Hoogland 1996, 155-156 fig. 6.24d). Both faces as well as the bottom exhibit evidence of flattening. This piece might have been worn as a pendant or it may have served as a weight for weaving cotton.

\section{Zemi three-pointer stones}

None of the samples from the studied sites include zemi or artefacts related to zemi making in stone (see table 5.25). Crock and Petersen, however, report the finding of both calci-rudite, limestone, calcite and quartz zemis at Shoal Bay East and various other Anguillian sites (Crock 2000; Crock \& Petersen 1999). These are mostly surface finds. Despite the finding of finished artefacts, the absence of evidence relating to calci-rudite making at this site may be noteworthy. This distinguishes the Shoal Bay East site from the other sites on Anguilla, that are discussed in this work. Close comparison of the material evidence and dates shows that calci-rudite material abundances decreased through time. Early sites, such as Rendezvous Bay and Sandy Ground produced a significant number of artefacts that strongly supports on-site zemi manufacture. Manufacture of zemis occurred on the somewhat later occupied Barnes Bay site as well. The Sandy Hill site, which strongly overlaps with the later period of occupation at Barnes Bay, displays a significantly lower number of the calci-rudite material. A decrease through time is tentatively supported by the near absence at Shoal Bay East, where occupation post-dates 1000 AD well into historic times (Crock 2000). 


\section{Use-modified rock and manuports}

The low number of identified use-modified pebbles only includes a few hammerstones, and an active and a passive abrading stone, all made of igneous rock (see table 5.25). Most were found at Morne Souffleur on La Désirade, where similar varieties naturally occur. The only other site that produced use-modified material for this phase was Sugar Mill, where a single nonlocal igneous pebble was used as a hammerstone. The fact that samples are small and in some cases incomplete is made clear by an absence of shaped passive grinding tools.

\subsection{Discussion}

\subsubsection{Diachronic summary}

The presentation on Pre-Columbian use of stone materials and tool productions shows that in general raw material choice and production behaviour remained relatively similar throughout the sequential phases of the Ceramic Age within the northern Lesser Antilles. Some modest and often local changes were noted, however. Only in relation to the lapidary industry a significant difference was evident, which occurred during the transition from the Early Ceramic A to Early Ceramic B phase. Tables 5.25 to 5.28 list the most important features regarding stone working and acquisition for each site within each of the four different phases. I want to emphasize that sound diachronic comparison is hampered by the fact that not all islands are represented by a site for each of the four phases. This means that in some cases sites from different islands are compared to examine diachronic variation. Considering inter-island variability in geological context, dissimilarities between sites on different islands are not necessarily indicative of changes in use and inter-island contacts through time, but they may be the result of the distinct geological conditions of the islands, and/or different distances to the exploited exotic lithic sources.

To overcome this problem of geological and geographical variability, I attempted to compare sites from the same island or from the same region within a single island. The Guadeloupe sites along the northern coast of Grande Terre form an excellent case study for this purpose, as occupation covered three of the four phases discussed in this work. Morel yielded data for the later part of the Early Ceramic A, whereas the long-term occupations at Anse à la Gourde and Anse à l'Eau covered the entire Early Ceramic B and Late Ceramic A phases. Only the last phase is not represented. Comparing the different phases shows that raw material choice overall did not change much, supporting the remark made above: similar tools were produced and used throughout the different phases. Some differences, however, are noted as well.

Among the flake tool material, Long Island flint remained the predominant rock type throughout all phases. Only the less abundant chert types exhibit diachronic variation. Within the earliest phase, white chert, for which a provenance remained to be determined, formed the second most abundant variety, whereas it totally disappeared during the later phases. The later phases displayed the use of Corbison Point flint, which was not found at Morel. Interestingly, Blackman's Point and La Désirade chert appeared in almost all phases, albeit in very small numbers.

The continued use of Long Island flint along the northern coast of Grande Terre markedly differed from a clear alteration in raw materials used at, for example, the Paso del Indio site in Puerto Rico, where long-term occupation also provided the opportunity to study diachronic changes. Rodríguez Ramos (2005) reports a significant change from the predominant use of non-local cherts within the Late Ceramic B phase toward the almost exclusive use of local igneous materials during later occupations. This example shows that interregional variability was present, suggesting that the Grande Terre case is not exemplary for the entire study area discussed here.

The diachronic comparison of the use of axes at the Grande Terre sites is somewhat hampered by the small number of items. St. Martin greenstone was present in all phases, evidently supporting its regional significance through time. In addition, igneous rock was also present during most phases. However, the material displays variation within phases and between phases. Unfortunately, incomplete knowledge about the provenances and intra-source variability severely limits a proper understanding of possible changes in lithic acquisition. Axes made of metamorphic rock exhibit more variation through time. So far, the Early Ceramic B phase did not produce a single item of such material. Considering the fact that these items are not local to the region, this may suggest more limited access to long-distance contacts during this phase.

Most significant change within this northern Grande Terre region is related to the use of certain gem stone varieties during the earliest phase, which were no longer represented during the later phases. This change was already discussed above and in this specific case, particularly applies to the use of carnelian and amethyst.

Comparison of the production and use of zemis suffers from the same low frequency of artefacts as among axe 


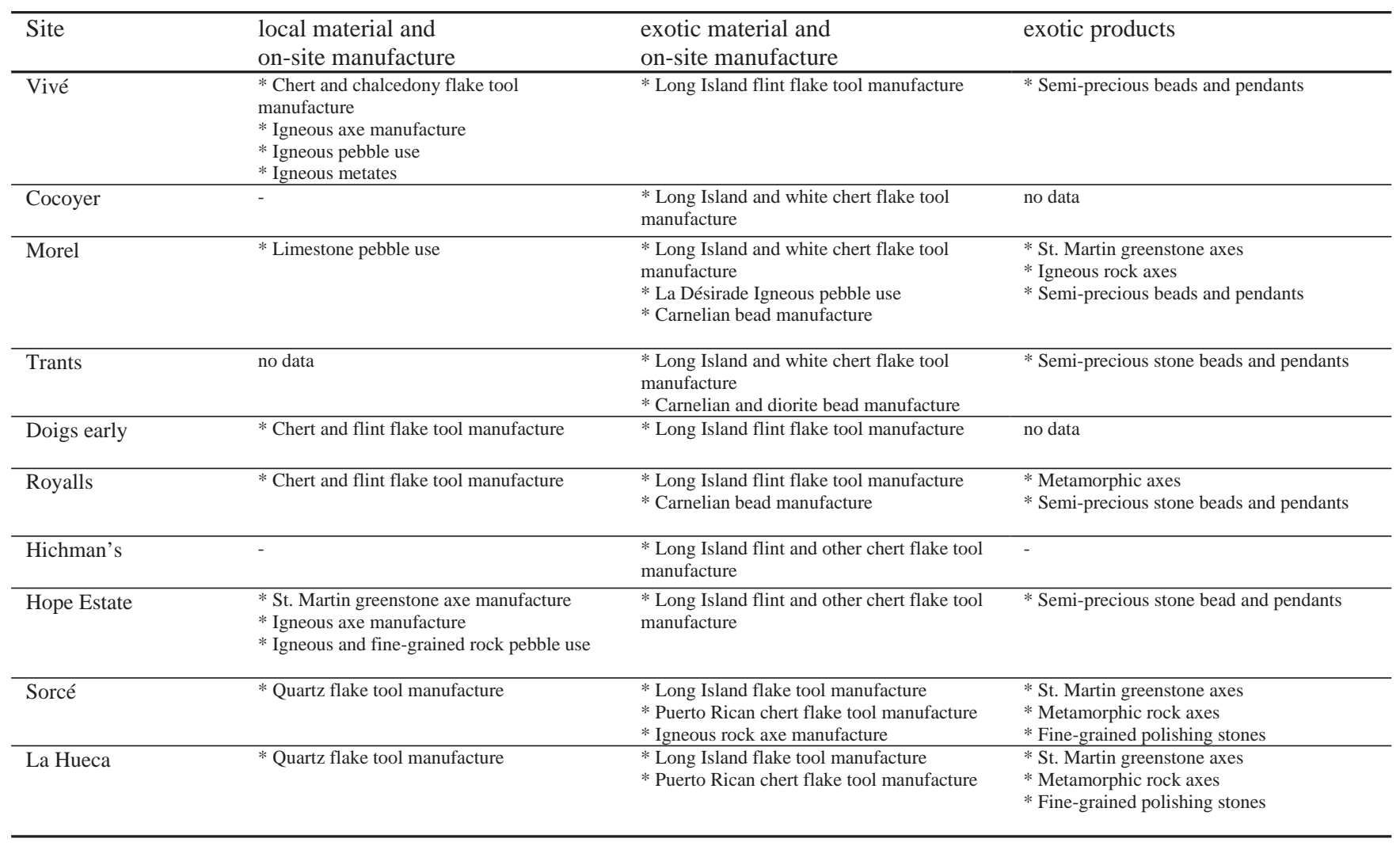

Table 5.26. Stone working and acquisition at Early Ceramic A phase sites.

\begin{tabular}{|c|c|c|c|}
\hline Site & $\begin{array}{l}\text { local material and } \\
\text { on-site manufacture }\end{array}$ & $\begin{array}{l}\text { exotic material and } \\
\text { on-site manufacture }\end{array}$ & exotic products \\
\hline Diamant & $\begin{array}{l}* \text { Chalcedony and jasper flake tool } \\
\text { manufacture } \\
* \text { Igneous rock axe manufacture } \\
* \text { Igneous rock metate use/manufacture } \\
\text { * Igneous rock pebble use }\end{array}$ & * Long Island flint flake tool manufacture (?) & * St. Martin greenstone axes \\
\hline $\begin{array}{l}\text { Anse à la Gourde } \\
\text { early }\end{array}$ & $\begin{array}{l}* \text { Beach-rock metate use/manufacture } \\
* \text { Limestone pebble use }\end{array}$ & $\begin{array}{l}\text { * Long Island flint and other chert flake tool } \\
\text { manufacture } \\
* \text { Igneous rock axe manufacture (?) }\end{array}$ & $\begin{array}{l}\text { * St. Martin greenstone axes } \\
\text { * Igneous rock metates } \\
\text { * La Désirade igneous rock pebble use }\end{array}$ \\
\hline Anse à l'Eau & - & $\begin{array}{l}* \text { Long Island flint and other chert flake tool } \\
\text { manufacture }\end{array}$ & $\begin{array}{l}\text { * Igneous rock axes } \\
\text { * Metates } \\
\text { * La Désirade igneous rock pebble use }\end{array}$ \\
\hline les Sables & * Igneous rock pebble use & no data & * Igneous rock axes \\
\hline Doigs late & * Chert flake tool manufacture & $\begin{array}{l}* \text { Long Island flint and other chert flake tool } \\
\text { manufacture }\end{array}$ & no data \\
\hline Sugar Factory Pier & $\begin{array}{l}\text { * St. Kitts flint flake tool manufacture (?) } \\
\text { * Igneous rock pebble use }\end{array}$ & $\begin{array}{l}\text { * Long Island flint flake tool manufacture } \\
\text { * St. Martin greenstone axe manufacture }\end{array}$ & $\begin{array}{l}\text { * Igneous rock axes } \\
\text { * Fine-grained axes }\end{array}$ \\
\hline Golden Rock & $\begin{array}{l}\text { * Igneous rock metate manufacture } \\
\text { * Igneous rock pebble use } \\
\text { * Pumice zemi manufacture (?) } \\
\text { * Beach-rock pebble use (?) }\end{array}$ & $\begin{array}{l}\text { * Long Island flint flake tool manufacture } \\
\text { * St. Martin greenstone axe manufacture } \\
\text { * Igneous rock axe manufacture }\end{array}$ & $\begin{array}{l}\text { * Metamorphic rock axes } \\
* \text { Fine-grained polishing stones } \\
\text { * Calci-rudite, limestone, igneous rock } \\
\text { and other rock zemis }\end{array}$ \\
\hline Kelbey's Ridge 1 & * Igneous rock pebble use & $\begin{array}{l}\text { * Long Island flint flake tool manufacture } \\
* \text { St. Martin greenstone axe manufacture }\end{array}$ & no data \\
\hline Anse des Pères & $\begin{array}{l}\text { * St. Martin greenstone axe manufacture } \\
\text { * Igneous rock axe manufacture } \\
\text { * Igneous and fine-grained rock pebble use }\end{array}$ & * Long Island flint flake tool manufacture & * Semi-precious stone beads \\
\hline
\end{tabular}

Table 5.27. Stone working and acquisition at Early Ceramic B phase sites. 


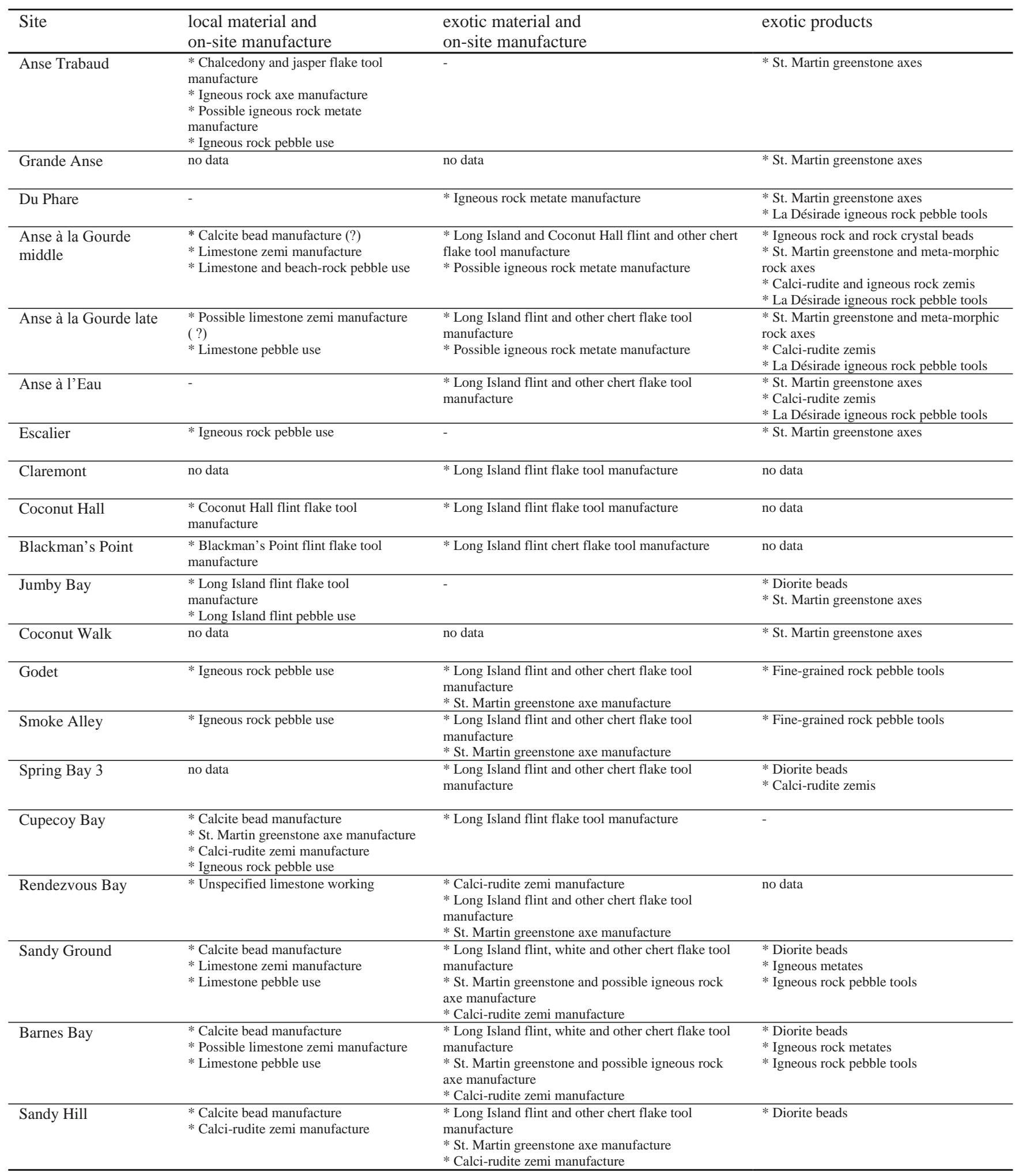

Table 5.28. Stone working and acquisition at Late Ceramic A phase sites. 
materials. Still, the fact that among the considerably larger sample from Morel only one zemi was represented signifies a change relative to the later phases, where smaller samples include more examples. The possible production and use of limestone zemis during the Late Ceramic A is worth mention, and seemingly supports the general notion that limestone became an important material during the later phases. Also the recovery of calci-rudite zemis during the Late Ceramic A phase within this region, corresponds to the evidence of clear production places during this period, which were absent during the Early Ceramic A phase.

Passive grinding/abrading stones rarely occur within the large sample of Morel. This markedly differs from the later phases, when these tools regularly turn up. This seemingly indicates a change in subsistence practices, if it is assumed that the majority of these items are related to food processing, rather than tool or bead and pendant grinding. Whether the increase of this tool type during the later phases is suggestive for the introduction of maize or the use of wild roots or panicoid seeds is speculative, but definitely needs further investigation ( $c f$. Newsom 1993).

The pebble tools and non-modified pebbles present a relatively continuous use of similar materials, probably owing to the nearby availability of these rock types. Small fine-grained igneous pebbles, including the ones displaying black residue, are found during all phases and exhibit a similar material variability, resembling rock from La Désirade. In addition, larger items of the same rock types also occur throughout all samples. Still some subtle differences are also noted. The Early Ceramic B sample from Anse à la Gourde contains relatively more granular types of igneous rock pebbles. Whether this difference can be attributed to the exploitation of different beaches on La Désirade, where the composition of pebbles is slightly distinct, or whether it points to the use of other volcanic source islands is still unclear.

\subsubsection{Organization of production}

Above, I described stone tool and artefact manufacture within the different sites for each of the four phases distinguished in this study. Still some important issues need to be addressed. These relate to the points made above in Chapter 1, particularly relative to the efficiency of the production process as an indicator of changing exchange mechanisms. In other words, it may be asked whether evidence can be found that suggests that efficiency was increased or diminished during specific phases. Torrence (1986) has argued that efficiency can be increased when production becomes more sophisticated, standardized, specialised, or simplified. In relation to sophistication and standardization, my results at the moment are too limited to obtain any clear insight. At present, the data do not suggest an increase of sophistication through the use of more subtle flaking techniques, or of a more variable tool-kit. In relation to standardization, the available evidence about greenstone axe production, however, suggests that this tool became more standardized in shape during the later phases. Comparing the Hope Estate tools, and the ones from La Hueca, Punta Candelero, and Sorcé dated to the Early Ceramic A, with the tools from later phases reveals a decrease in the number of shapes and edge types. During the later phases, the petaloid celt became the predominant axe-type. Among these later petaloid celts, variability in size and shape is still evident, as shown by the variable sized set of axes found at Anse à la Gourde (figure 5.39; see also figure 5.27).

The concept of specialization needs some additional comments, as it incorporates two aspects that are relevant to this study. On the one hand, the introduction of specialists increases the efficiency of stone tool production and on the other hand, the presence of specialists demands a different social structure. In relation to the first aspect Torrence, distinguishes craft-specialists from industrial specialists, the former being skilled craftsmen making highly individualistic products, the latter being able to make products at great efficiency. With regard to this second aspect discrimination between part-time and full-time specialists is important. The former may be able to still operate within an egalitarian society on a household or community level, whereas the latter needs to be compensated for not participating in general subsistence activities by payment from elites or participation in a market system.

Examining the different stone tool technologies within the northern Lesser Antilles relative to specialisation, a basic distinction can be made between flake tool production and core tool or core artefact production. The former production occurred at every site, whereas the latter only occurred at a limited number of sites and in particular, are related to greenstone axe and calci-rudite zemi production.

Taking a closer look at flake tool production, the evidence suggests that it remained at the household level throughout the entire Ceramic Age. This view is supported by the fact that production took place at each site and that the manufacture of tools can be classified as expedient. It is an ad-hoc means of producing a variable set of flakes, which only minimally underwent secondary modification. All signs pointing to standardization of core reduction or tool shaping are absent. As such, it can be regarded as a relatively fast and easy means of tool production not demanding much training and 

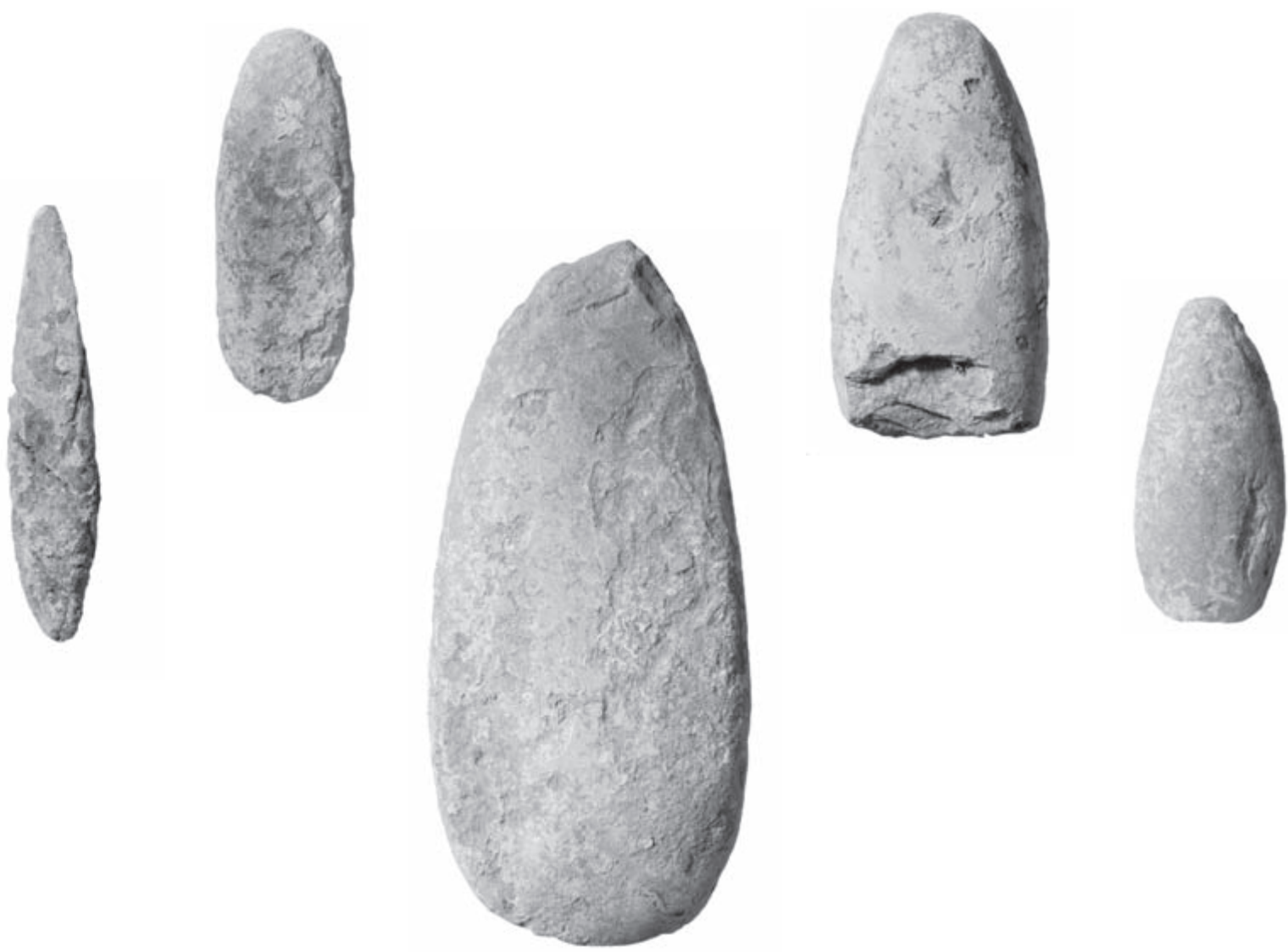

Figure 5.39. Anse à la Gourde middle and late occupation phases, Guadeloupe. Different sized and shaped St. Martin greenstone axes (scale 1:2). (Photo Ben Grishaaver)

therefore, likely to have been performed by several people in each community.

The limited number of production loci of axes and zemis, along with the general exchange to sites in the surrounding region (see below for discussion), minimally suggests a specialisation on the village level for the making of these artefacts. The variation among sizes and shapes of the imported petaloid axes at Anse à la Gourde indicates that standardization of the products only occurred to the level of a general petaloid form and that variation existed within this form. This can be either explained by the existence of craft-specialists producing individual variation among these tools, or by a household production involving a considerable number of people within each community.

I used data from a number of sites on Anguilla to obtain more insight into the number of tools produced in individual settlements. This provides an evaluation of the existence of full-time specialisation among these communities. Crock estimated the amount of St. Martin greenstone transported to these sites per year to be worked into axes on the basis of systematic shovel testing at each site (Crock 2000, 235). Using confidence intervals, his figures range from 5 to $16 \mathrm{~kg} /$ year for the Barnes Bay site and 27 to $82 \mathrm{~kg} /$ year for the Sandy Ground site. From the lithic analysis of the Sandy Ground sample, which includes the highest number of greenstone material, I found a number of 1.0 to 3.3 tools produced per one $\mathrm{kg}$ of greenstone, depending on the definition of what was a tool. ${ }^{6}$ It must be stressed that the number of tools left at Sandy Ground only represents a portion of the total number of axes made at this site, considering the fact that some were surely exchanged and others were discarded or lost elsewhere, e.g., in the forest where they were used. This means that the range of

\footnotetext{
${ }^{6}$ The lower figure only includes artefacts displaying some (portion of a) ground edge, while the higher figure includes all butt (poll) parts identified as well. The problem with classifying this latter type of artefact as a tool, lies in the fact that not all axes had completely ground butt (polls) parts, making a distinction between preform and finished tool very difficult, when only this butt (poll) portion is available.
} 
1.0 to 3.3 axes only represents the minimum range. Therefore, I used the higher figure of 3.3 axes per kg to calculate annual axe production. This gives a production rate of 87 to 265 tools per year at Sandy Ground, whereas at Barnes Bay a similar axe per mass number gives a range of 17 to 53 tools. If it is assumed that the making of an axe, including the final grinding phase, will on average not take longer than 11 hours work (one and a half days) ${ }^{7}$, then a single person working on a part-time basis is able to accomplish the entire annual production at Barnes Bay. This does not hold for the Sandy Ground production. The realisation of the maximum annual production minimally needs more than one person working on a full-time basis. This leaves the existence of full-time specialisation open, although it will be in the exceptional case of only one or two axe makers living in the village and being responsible for the maximum number of tools specified here. However, if it is assumed that five or more persons were involved in axe making, then part-time manufacture might be sufficient to produce the maximum number of tools.

Notwithstanding the fact that full-time specialisation is difficult to demonstrate on the basis of these data, the considerable axe production at Sandy Ground shows that axe making formed a significant part of daily life in this village. This significance clearly should be related to the exchange value that these tools represented (see below). Axe production clearly formed an enterprise that involved several people from a single village. Therefore, it is likely that it was organised on a community level in some way.

Neither of the other core artefact production technologies equals or exceeds the greenstone axe production in number of artefacts and amount of material, as reported for the Anguilla sites. Rare remains of igneous axe production were only identified at a very limited number of sites, as noted above. This accounts also for limestone zemi production. Only the recurrent evidence of calci-rudite zemi production on Anguilla and western St. Martin is an example of a more structured production process in space and time. Comparison of the amounts of calci-rudite with the greenstone material in this region shows that calci-rudite by no means equals the abundance of greenstone material. This is also supported by the data on the calci-rudite zemi distribution within the surrounding region (see below). This suggests that neither of these production sequences involved the participation of full-time specialists. Considering the religious significance of the stone threepointers, it is likely that the manufacture of these artefacts was allowed to only certain people within a particular village, possessing the proper religious and ritual knowledge.

\subsection{CONCLUSIONS}

The diachronic summary and detailed presentation show that stone tool technology within the northern Lesser Antilles did not experience much change with regard to the way of tool production and tools used during the four phases of the Ceramic Age. Most changes were related to the use of different materials, which likely must be associated with changing social relations. These changes either gave people the opportunity to get access to non-local sources, or forced them to be excluded from such access. Regarding this, I particularly think of the disappearance of the semi-precious bead and pendant industry, changing occurrence of metamorphic axes, and alternations in the distribution patterns of Long Island flint and St. Martin greenstone over time. Some changes may have had other causes related to changing subsistence strategies, or different cultural behaviours. In relation to the former, I refer to the possible increase of passive grinding stones during later phases. With regard to the latter I must mention the use of stone adzes in the western part of this study region (Puerto Rico and Vieques), notably during the earliest Ceramic Age phase. In the Lesser Antilles, where shell adzes appear to have been largely used, the stone equivalents are almost absent.

Stone tool and artefact production remained an activity performed on a household level or was a part-time craft specialisation, at most. On a settlement level certain sites operated as places where certain artefact types were being made, whereas others did not, but evidence does not suggest that this community specialisation involved the existence of full-time specialists. Still the considerable number of axes produced at some sites at least makes it clear that axe-manufacture formed a significant part of daily life at these settlement sites. Therefore, it may have been an activity that was organised at the village level, rather than at the individual level or single persons operating individually.

\footnotetext{
7 The time of 11 hours is a very conservative number. Experimental work on axe manufacture has shown that the grinding stage will take most of the time (Madsen 1984; Petrequin \& Jeunesse 1995). It further demonstrated that the speed of the grinding is dependent on the type of material to be ground and the material used as grinding slab. Experiments in which both harder materials were used and larger axes ground than is the case in the Lesser Antilles generally did not exceed 10 hours and in most cases were considerably shorter (Madsen 1984; Petrequin \& Jeunesse 1995).
} 


\section{Production, distribution and exchange}

\subsection{INTRODUCTION}

In preceding Chapters, I discussed various stone raw material sources within the northern Lesser Antilles region, including Puerto Rico, followed by a description of stone material use and tool production at numerous habitation sites in the same region. It became clear that the inhabitants of these islands did not solely rely on the availability of local materials, naturally occurring nearby each settlement, but in many cases they obtained rock types from neighbouring, or even more distant islands. Specific source locations for many of these rock types remain unknown. They include some of the igneous and metamorphic rock types used for making axes, fine grained rock used for polishing stones, and igneous rock used for metates, as well as some of the well-known semi-precious stones associated with the Early Ceramic A phase bead and pendant industries (Cody 1991, 1993; Watters \& Scaglion 1994; see Chapter 5). However, this does not account for three specific rock types that are discussed in this Chapter, namely flint originating from Long Island and greenstone and calci-rudite, both originating from St. Martin. As this is one of the first studies in the Caribbean that has related artefacts with specific and localized source areas, it is possible to specify the distribution of materials and see which changes occurred from their acquisition to their widest spread. In this way it will contribute to our knowledge of Pre-Columbian inter-insular exchange relationships.

The presence of exotic materials within site deposits is generally seen as indicative of exchange systems. This was not necessarily the case, however. Especially where island environments are involved, relatively large distances could be travelled more easily, and the occurrence of exotics is then explainable by the direct procurement of these non-local materials. Therefore, one of the first key-questions addressed here is to what degree exchange, the actual transfer of items between different communities, and to what degree direct access were responsible for stone distribution. If it can be clearly established that exchange played a role in material transport, the next question is how this exchange was organised, in other words what type of exchange occurred.

As outlined in Chapter 1, different approaches are used to determine the existence of exchange and relevant type of exchange. First the production transport sequence will be specified using the models outlined in Chapter 3. Secondly, fall-off curves are analysed, and thirdly, on-site production procedures are discussed. These three lines of analysis provide us with a view into the organization of production and the type of exchange that were responsible for the spread of these rock materials within the northern Lesser Antilles.

\subsection{DistribUtion OF LITHIC MATERIAL}

\subsubsection{Long Island Flint}

\section{Introduction}

The study of numerous lithic artefact collections from a series of sites in the northwestern Lesser Antilles shows that Long Island was a much used and widely distributed material. In particular for the region from Anguilla to Guadeloupe, it was the main rock type employed in the manufacture of flake tools. This was the case despite the occurrence of many other suitable fine-grained stone materials, notably on Antigua. One of the most obvious physical differences between it and other local cherts and flints on Antigua and St. Kitts, is its superior flaking characteristics, being fine-grained and lacking internal cleavage planes. ${ }^{1}$ This may well explain the heavy emphasis on this particular material. Furthermore, its easy accessibility along the shores of Long Island where large cobbles occur in high concentrations may have provided another advantage over other materials occurring at inland locations. Whether any other features may have been significant, for example, the

\footnotetext{
1 This has been confirmed by two well experienced flint knappers, Jeffery Flenniken from Washington State University (Jeff Walker, personal communications 1998) and Mikkel Sørensen from Denmark (Yvonne Lammers-Keijzers, personal communication 2001). It should be added that especially the flints within the Antigua Formation region, such as Little Cove, Soldier Point, and Blackman's Point, can also be considered as easily worked. Generally, however, they are coarser grained than Long Island flint.
} 
relatively remote location of Long Island compared to sources on the main island of Antigua, or its distinct colour is open for investigation. At least, from a technological point of view Long Island flint stands out from other materials.

This preference for Long Island flint is also noted during the Preceramic Age. Sites such as Jolly Beach on the western coast of Antigua (Davis 1993, 2000), and more remote localities on Barbuda (personal observation 2001; Watters et al. in prep), Nevis (personal observation 1995), Saba (Hofman \& Hoogland 2004), and St. Martin (Knippenberg 1995, 1999a,d) predominantly have yielded this material for Preceramic times. It may be argued that the technological superiority of Long Island flint played a more decisive role in its emphasis by the Preceramic Age people for blade manufacture, than was the case for the expedient stone tools of the later Ceramic Age.

Petrographic and geochemical characterisation discussed in Chapter 2 show that chert and flint sources are hard to separate, especially when they originate in similar geological formations. This is markedly different from obsidian sources, for example, which generally exhibit distinguishable trace element compositions (Shackley 1998). However, Long Island flint has a distinctive geochemical composition relative to most of the other sources, despite the presence of flint sources in the same geological setting. On a macroscopic level, this material is also easily recognized, especially when the investigator has some experience with identifying different local materials. Characteristic features are its typical brown colour, usually referred to as "honey brown" (e.g., Haviser 1987), and also a dark grey colour with very small white calcite inclusions dispersed as light haze among the matrix. In Chapter 2, I discussed the procedure that I used to identify artefacts originating from Long Island. This initially involved macroscopic identification, which was supported by geochemical analysis of a small sample of 13 artefacts, originating from a restricted number of sites. In all cases, the geochemical analysis confirmed the initial Long Island identification based on macroscopic analysis.

Other Antigua and St. Kitts chert and flint varieties play an insignificant role in this Chapter, because of their infrequent and highly variable occurrence. The low number of artefacts made from these materials per site in many cases inhibits a reliable macroscopic characterisation of specific rock types in question. As a result, an identification of its origin is speculative because of internal variability within some sources and similarities between others.

In addition to these difficulties with known cherts and flints, the study of the archaeological collections revealed chert varieties, which are unknown to me, particularly among the samples from Anguilla and Puerto Rico. These unknown varieties suggest the existence of other sources not included in the present research. In particular, the region of Puerto Rico and the Virgin Islands seems to host still unknown fine-grained rock sources, for example, a chalcedony and bedded chert. A full understanding of the origin of all fine grained rock materials found among lithic collections is therefore beyond the scope of this study, and needs to be addressed by future systematic search within areas where these materials may have originated. ${ }^{2}$

\section{Transport and Reduction Sequence}

Introduction

Data from the majority of studied habitation sites show that Long Island flint material was locally reduced into flake tools. The presence of flake cores, flakes, and shatter, in conjunction with utilized flakes, indicates this. This presence of cores already suggests that this material arrived in large enough pieces to be further reduced, and likely was not transported in the form of (small) flakes or flake tools in most cases. In Chapter 3, cortical count, scar count, and artefact size were introduced as the best parameters to establish which reduction stages took place at a given locality. Since the form in which lithic material was transported to different localities is of primary concern here, cortex count data are used to distinguish whether material was worked or not before its arrival at these sites.

Data from experiments in which unmodified material was reduced suggest that the percentage of flakes bearing cortex on their dorsal faces and platforms varies between $36 \%$ and $50 \%$ of the total flake assemblage (Amick et al. 1988; Shott 1996; Tomka 1989; Walker 1980a). Close examination of these past works reveals that the experiments done by Walker (1980a) were especially aimed at replicating Ceramic Age expedient flake technologies in the Lesser Antilles. Walker used Long Island flint to as closely as possible replicate the Pre-Columbian industries. Therefore, his data can be considered as most comparable to the results from this study. Walker found a mean percentage of flakes bearing cortex of $42 \%$, whereas his median value, out of ten experiments, was 36\% (Walker 1980a, 79) (Table 6.1).

${ }^{2}$ Left out of the present discussion are red and green chert varieties, which commonly occur on La Désirade, Martinique and Puerto Rico (see also Chapter 2). 


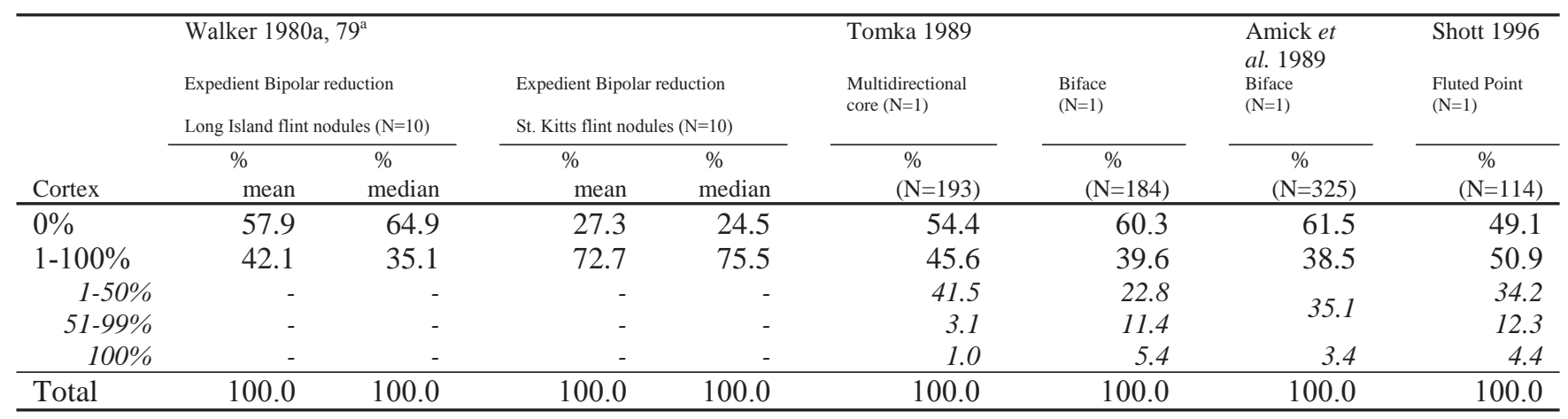

Table 6.1. Frequency distributions of cortex count on flakes found after experimentally reducing non-modified material. a Values from Walker's experiments represent average values found after reducing and counting 10 nodules each. Size range of nodules: Antigua $12.5 \times 7 \times 6 \mathrm{~cm}$ to $14.5 \times 12 \times 6 \mathrm{~cm}$; St. Kitts $4 \times 2.5 \times 1 \mathrm{~cm}$ to $9.5 \times 7 \times 4 \mathrm{~cm}$.

Detailed inspection of the cortex count data for the sites from which a large sample of Long Island flint was analysed reveals that the numbers of primary and secondary flakes (flakes with $100 \%$ and $1-99 \%$ dorsal cortex cover, respectively) are significant. In most cases, they vary between 40 and $60 \%$ (Tables $6.2-6.5$ ). This is generally higher than many of the experimentally found values. The Long Island flaked stone material from the Pre-Columbian site at Sugar Factory Pier on St. Kitts studied by Walker as part of his replication work similarly yielded on average higher percentages of cortical flakes than did his experimental data (Walker 1980a, 79, 89, 98). This minimally indicates that lithic material arrived in unmodified form and that it may have been reduced less exhaustively than was the case in the experiments. Another explanation for this higher percentage of cortical flakes in the archaeological samples relative to the experimental ones may have been the use of larger nodules during the experiments. However, this is unlikely, because the size of the Long Island flint nodules used in Walker's experiments can be considered as average. The flint nodule size of blade cores found at the Preceramic Age workshop site at Flinty Bay on Long Island, for example, is generally larger than the average nodule size found on Long Island. That the nodule size is of great significance is shown by the much higher percentages of cortical flakes generated during Walker's experimental reduction of the smaller St. Kitts flint nodules (Walker 1980a, 79).

Apart from a similar abundance of cortical flakes, the presence of flakes with complete cortex cover $(100 \%)^{3}$ is also indicative of transport of unmodified material. They are usually very low in number, between 1 and $4 \%$, and were mostly produced during the initial reduction of the material, as shown in the detailed experimental study of Shott (1996). This is in contrast to secondary flakes, that basically occur throughout the entire reduction sequence, including the later stages. Most of the larger samples used in this study contain low numbers of these primary flakes, demonstrating the arrival of unmodified material.

A few sites form a possible exception to this general pattern, given their lower percentages of cortical flakes, suggesting possible import of largely pre-worked material. In most cases this concerns very small samples, usually not larger than 25 flakes. As shown in Appendix E, these samples may be too small to provide an accurate estimation of the true relevant value, so they have to be treated with caution. Spring Bay 3 and Barnes Bay, however, include higher numbers of flakes: 86 and 40, respectively. Yet, these sites only produced 35 and $33 \%$ of flakes with cortex. These values are a little lower than the median value obtained in Walker's study, although the difference is not significant. This small difference makes it hard to disprove the arrival of unmodified material. On the other hand, the relatively low number of true core artefacts, in particular at Spring Bay 3, may indicate that some pre-worked material was transported to these sites in the form of flakes.

\footnotetext{
${ }^{3}$ In this study, the striking platform is included when estimating cortex count, unlike many other debitage studies (Shott 1996; Tomka 1989). In my case, the presence of a $100 \%$ cortex flake within a sample thus may represent the first flake removal from an unmodified flint nodule. It may be hypothesized that after removing the first flake, the following one is flaked using this first scar as the platform, as this would be most easy. This must be especially considered in the case of the expedient character of Caribbean flake tool technology. Therefore, after this first flake, all following flakes will not be $100 \%$ cortical ones according to my definition, and the number of $100 \%$ cortical flakes will be theoretically equal to the number of nodules reduced.
} 


\begin{tabular}{|c|c|c|c|c|c|c|c|}
\hline \multirow{3}{*}{$\begin{array}{l}\text { Cortex } \\
\text { All flakes }\end{array}$} & Vivé & Cocoyer & Morel & Trants & Doigs early $^{\mathrm{a}}$ & Hichman's & Sorcé \\
\hline & $\mathrm{N}=10$ & $\mathrm{~N}=16$ & $\mathrm{~N}=959$ & $\mathrm{~N}=502$ & $\mathrm{~N}=72$ & $\mathrm{~N}=18$ & $\mathrm{~N}=6$ \\
\hline & $\%$ & $\%$ & $\%$ & $\%$ & $\%$ & $\%$ & $\%$ \\
\hline $0 \%$ & 70.0 & 75.0 & 48.4 & 62.7 & 59.7 & 50.0 & 33.3 \\
\hline $1-99 \%$ & 30.0 & 25.0 & 50.9 & 36.9 & 40.3 & 50.0 & 66.6 \\
\hline $1-24 \%$ & 20.0 & 18.8 & 28.1 & 18.3 & & & 66.6 \\
\hline $25-49 \%$ & - & 6.3 & 12.7 & 11.0 & & & - \\
\hline $50-74 \%$ & 10.0 & - & 6.4 & 5.4 & & & - \\
\hline $75-99 \%$ & - & - & 3.8 & 2.2 & & & - \\
\hline $100 \%$ & - & - & 7.3 & 0.4 & - & - & - \\
\hline Total & 100.0 & 100.0 & 100.0 & 100.0 & 100.0 & 100.0 & 100.0 \\
\hline \multirow{2}{*}{$\begin{array}{l}\text { Cortex Complete } \\
\text { flakes }\end{array}$} & $\mathrm{N}=4$ & $\mathrm{~N}=5$ & $\mathrm{~N}=328$ & $\mathrm{~N}=141$ & not distinguished & sample too small & sample too small \\
\hline & $\%$ & $\%$ & $\%$ & $\%$ & $\%$ & $\%$ & $\%$ \\
\hline $0 \%$ & 75.0 & 60.0 & 37.8 & 58.9 & - & - & - \\
\hline $1-99 \%$ & 25.0 & 40.0 & 60.7 & 41.9 & - & - & - \\
\hline $1-24 \%$ & 25.0 & 40.0 & 34.1 & 23.4 & - & - & - \\
\hline $25-49 \%$ & - & - & 11.6 & 11.3 & - & - & - \\
\hline $50-74 \%$ & - & - & 9.5 & 5.7 & - & - & - \\
\hline $75-99 \%$ & - & - & 5.5 & 0.7 & - & - & - \\
\hline $100 \%$ & - & - & 1.5 & - & - & - & - \\
\hline Total & 100.0 & 100.0 & 100.0 & 100.0 & - & - & - \\
\hline
\end{tabular}

Table 6.2. Early Ceramic A phase. Number and relative amount of flakes by percentage of cortex cover on dorsal face including platform.

a The numbers and percentages given for Doigs early include all flint material, that is cores, flakes, and shatter.

\begin{tabular}{|c|c|c|c|c|c|}
\hline $\begin{array}{l}\text { Cortex } \\
\text { All flakes }\end{array}$ & $\begin{array}{c}\text { Anse à la } \\
\text { Gourde early } \\
\mathrm{N}=48\end{array}$ & $\begin{array}{c}\text { Doigs late }^{\mathrm{a}} \\
\mathrm{N}=158\end{array}$ & $\begin{array}{c}\text { Golden Rock } \\
\quad \mathrm{N}=405\end{array}$ & $\begin{array}{c}\text { Kelbey's } \\
\text { Ridge } 1 \\
\mathrm{~N}=41\end{array}$ & $\begin{array}{c}\text { Anse des } \\
\text { Pères } \\
\text { not counted }\end{array}$ \\
\hline All flakes & $\%$ & $\%$ & $\%$ & $\%$ & $\%$ \\
\hline $0 \%$ & 64.6 & 65.8 & 48.6 & 56.1 & - \\
\hline $1-99 \%$ & 35.4 & 33.5 & 49.4 & 41.5 & - \\
\hline $1-24 \%$ & 18.8 & & 24.2 & 22.0 & - \\
\hline $25-49 \%$ & 12.5 & & 13.1 & 9.8 & - \\
\hline $50-74 \%$ & 4.2 & & 7.4 & 7.3 & - \\
\hline 75-99\% & - & & 4.7 & 2.4 & - \\
\hline $100 \%$ & - & 0.6 & 2.0 & 2.4 & - \\
\hline Total & 100.0 & 100.0 & 100.0 & 100.0 & - \\
\hline \multirow{2}{*}{$\begin{array}{l}\text { Cortex } \\
\text { Complete } \\
\text { flakes }\end{array}$} & $\mathrm{N}=14$ & $\begin{array}{c}\text { not } \\
\text { distinguished }\end{array}$ & $\mathrm{N}=127$ & $\mathrm{~N}=19$ & $\mathrm{~N}=31$ \\
\hline & $\%$ & $\%$ & $\%$ & $\%$ & $\%$ \\
\hline $0 \%$ & 57.1 & - & 43.3 & 42.1 & 41.9 \\
\hline $1-99 \%$ & 42.9 & - & 53.5 & 52.6 & 58.1 \\
\hline $1-24 \%$ & 21.4 & - & 23.6 & 26.3 & 35.5 \\
\hline $25-49 \%$ & 14.3 & - & 15.0 & 15.8 & 12.9 \\
\hline $50-74 \%$ & 7.1 & - & 10.2 & 5.3 & 6.5 \\
\hline $75-99 \%$ & - & - & 4.7 & 5.3 & 3.2 \\
\hline $100 \%$ & - & - & 3.1 & 5.3 & - \\
\hline Total & 100.0 & - & 100.0 & 100.0 & 100.0 \\
\hline
\end{tabular}

Table 6.3. Early Ceramic B phase. Number and relative amount of flakes by percentage of cortex cover on dorsal face including platform. a The numbers and percentages given for Doigs late include all flint material, that is cores, flakes, and shatter.

Flint from Shoal Bay East and Vivé displays a similar low proportion of cortical flakes and the absence of core artefacts. Samples from both sites, however, are very small. Especially in the case of the Vivé lithic material may have arrived in an unmodified form. The fact that all flakes most likely originated from the same nodule, as shown by their close similarity in colour and texture, combined with their concentration and the excellent state of preservation of a related living floor suggests that the reduction of a single nodule there. As such, they represent a snapshot within the complete reduction sequence of this nodule. This contrasts to many other sites, where multiple test-units and test-pits, excavated in dense refuse deposits, are more likely to yield an average picture of flint reduction, comprising material from all reduction stages that took 


\begin{tabular}{|c|c|c|c|c|c|c|c|c|c|c|}
\hline Cortex & $\begin{array}{c}\text { Anse à la } \\
\text { Gourde } \\
\text { middle } \\
\mathrm{N}=62\end{array}$ & Claremont $^{\mathrm{a}}$ & $\begin{array}{c}\text { Blackman's } \\
\text { Point }^{\mathrm{a}}\end{array}$ & Coconut Hall $^{\mathrm{a}}$ & $\begin{array}{c}\text { Jumby } \\
\text { Bay }\end{array}$ & Godet & $\begin{array}{l}\text { Smoke } \\
\text { Alley }\end{array}$ & $\begin{array}{c}\text { Spring Bay } \\
3\end{array}$ & $\begin{array}{l}\text { Sandy } \\
\text { Ground }\end{array}$ & $\begin{array}{c}\text { Barnes } \\
\text { Bay }\end{array}$ \\
\hline All flakes & $\%$ & $\%$ & $\%$ & $\%$ & $\%$ & $\%$ & $\%$ & $\%$ & $\%$ & $\%$ \\
\hline $0 \%$ & 58.1 & 26.7 & 55.0 & 55.6 & 41.9 & 75.0 & 47.1 & 65.1 & 57.1 & 67.5 \\
\hline $1-99 \%$ & 41.9 & 73.3 & 45.0 & 42.7 & 55.9 & 25.0 & 52.9 & 33.7 & 40.0 & 32.5 \\
\hline $1-24 \%$ & 21.0 & & & & 23.2 & 12.5 & 35.3 & 22.1 & 22.9 & 25.0 \\
\hline $25-49 \%$ & 12.9 & & & & 16.3 & - & - & 8.1 & 8.6 & 5.0 \\
\hline $50-74 \%$ & 3.2 & & & & 11.8 & 12.5 & 17.6 & 1.2 & 5.7 & - \\
\hline $75-99 \%$ & 4.8 & & & & 4.7 & - & - & 2.3 & 2.9 & 2.5 \\
\hline $100 \%$ & - & - & - & 1.6 & 2.2 & - & - & 1.2 & 2.9 & - \\
\hline Total & 100.0 & 100.0 & 100.0 & 100.0 & 100.0 & 100.0 & 100.0 & 100.0 & 100.0 & 100.0 \\
\hline \multirow{2}{*}{$\begin{array}{l}\text { Cortex } \\
\text { Complete } \\
\text { flakes }\end{array}$} & $\mathrm{N}=19$ & not distinguished & not distinguished & not distinguished & $\mathrm{N}=201$ & $\begin{array}{c}\text { sample too } \\
\text { small }\end{array}$ & $\mathrm{N}=8$ & $\mathrm{~N}=34$ & $\mathrm{~N}=15$ & $\mathrm{~N}=11$ \\
\hline & $\%$ & $\%$ & $\%$ & $\%$ & $\%$ & $\%$ & $\%$ & $\%$ & $\%$ & $\%$ \\
\hline $0 \%$ & 47.4 & - & - & - & 37.3 & - & 50.0 & 70.6 & 53.3 & 63.6 \\
\hline $1-99 \%$ & 52.6 & - & - & - & 59.7 & - & 50.0 & 29.4 & 40.0 & 36.4 \\
\hline $1-24 \%$ & 21.1 & - & - & - & 25.9 & - & 25.0 & 14.7 & 26.7 & 36.4 \\
\hline $25-49 \%$ & 31.5 & - & - & - & 16.9 & - & - & 8.8 & 13.3 & - \\
\hline $50-74 \%$ & - & - & - & - & 12.4 & - & 25.0 & 2.9 & 6.7 & - \\
\hline $75-99 \%$ & - & - & - & - & 4.5 & - & - & 2.9 & - & - \\
\hline $100 \%$ & - & - & - & - & 3.0 & - & - & - & 6.7 & - \\
\hline Total & 100.0 & - & - & - & 100.0 & - & 100.0 & 100.0 & 100.0 & 100.0 \\
\hline
\end{tabular}

Table 6.4. Late Ceramic A phase. Number and relative amount of flakes by percentage of cortex cover on dorsal face including platform. a The numbers and percentages given for Claremont, Blackman's Point, and Coconut Hall include all flint material, that is cores, flakes and shatter.

\begin{tabular}{|c|c|c|c|c|}
\hline \multirow{3}{*}{\multicolumn{2}{|c|}{$\begin{array}{l}\text { Cortex } \\
\text { All flakes }\end{array}$}} & $\begin{array}{c}\text { Sugar } \\
\text { Mill }\end{array}$ & $\begin{array}{c}\text { Kelbey's } \\
\text { Ridge } 2\end{array}$ & Shoal Bay East \\
\hline & & $\mathrm{N}=207$ & $\mathrm{~N}=67$ & $\mathrm{~N}=6$ \\
\hline & & $\%$ & $\%$ & $\%$ \\
\hline $0 \%$ & & 40.1 & 64.2 & 83.3 \\
\hline $1-99 \%$ & & 56.5 & 34.3 & 16.7 \\
\hline & $1-24 \%$ & 20.3 & 19.4 & 16.7 \\
\hline & $25-49 \%$ & 15.0 & 11.9 & - \\
\hline & $50-74 \%$ & 15.0 & - & - \\
\hline & $75-99 \%$ & 7.2 & 3.0 & - \\
\hline $100 \%$ & & 3.4 & 1.5 & - \\
\hline Total & & 100.0 & 100.0 & 100.0 \\
\hline \multirow{2}{*}{\multicolumn{2}{|c|}{$\begin{array}{l}\text { Cortex } \\
\text { Complete } \\
\text { flakes }\end{array}$}} & $\mathrm{N}=69$ & $\mathrm{~N}=29$ & $\begin{array}{c}\text { sample too } \\
\text { small }\end{array}$ \\
\hline & & $\%$ & $\%$ & $\%$ \\
\hline $0 \%$ & & 30.0 & 48.3 & - \\
\hline $1-99 \%$ & & 65.2 & 48.3 & - \\
\hline & $1-24 \%$ & 30.4 & 20.7 & - \\
\hline & $25-49 \%$ & 14.5 & 20.7 & - \\
\hline & $50-74 \%$ & 13.0 & - & - \\
\hline & $75-99 \%$ & 7.2 & 6.9 & - \\
\hline $100 \%$ & & 5.8 & 3.4 & - \\
\hline Total & & 100.0 & 100.0 & - \\
\hline
\end{tabular}

Table 6.5. Late Ceramic B phase. Number and relative amount of flakes by percentage of cortex cover on dorsal face including platform.

place there. Therefore, it may be possible that the Vivé piece of flint was also reduced in other areas of the site, both before and after the removal of the studied flakes. It is minimally clear that the import of flakes is unlikely in this case.

Apart from these specific sites with small samples, none of the other small samples suggest the arrival of pre-worked material. All the latter produced evidence of local flint working in the form of flakes, shatter, and cores, as well as around $50 \%$ cortical pieces. Considering their small sample sizes, interpretations may change as more data become available. ${ }^{4}$

\footnotetext{
${ }^{4}$ The samples from all sites only represent a part of a larger assemblage. Therefore, the presence of a few artefacts made of distinct varieties of Long Island flint cannot by itself provide evidence that individual flaked pieces were imported.
} 


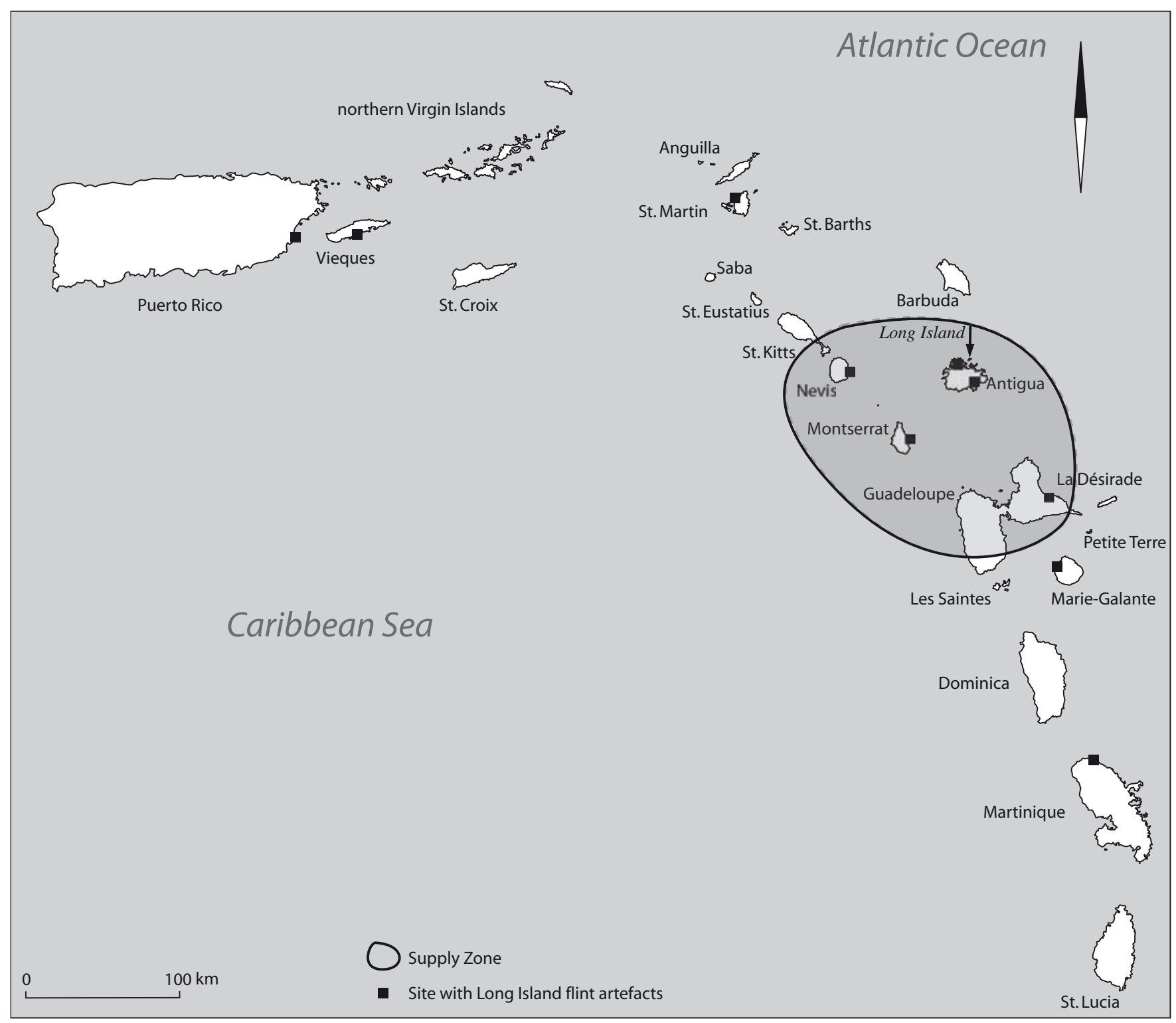

Figure 6.1. Distribution of Long Island flint and the location of the supply zone during the Early Ceramic A phase (400 BC - AD 400).

The Early Ceramic Age

Differentiating the studied sites by phase brings out the following picture. Evidence for the transport of unmodified material is strong for the area of Guadeloupe and Nevis during the Early Ceramic A phase (figure 6.1). The small sample data from sites on Vieques, Puerto Rico, and Martinique equally do not exclude import of unmodified material. Cocoyer, however, may form a possible exception to this pattern, as the percentage of cortical flakes is low, around $25 \%$. A similarly low percentage of cortical flakes is reported for the Hope Estate site (Haviser 1993, 1999). Basing himself on a high percentage (70\%) of "non-decortificated" flakes, that he defined as flakes without any cortex Haviser (1999, 195; see Haviser 1993 for definition) states that the lithic material arrived in a pre-worked state. From the discussion above, this frequency is indeed suggestive of the arrival of pre-worked material, and in any case is higher than most of my values for other sites. On the other hand, this value cannot be simply compared to my data, since Haviser does not distinguish between Long Island flint and other chert types in his cortex count. My data from other sites suggest that other chert categories usually have higher percentages of non- 
cortical flakes, increasing the overall percentage. ${ }^{5}$ Golden Rock, for example, produced a value of $49 \%$ for Long Island flint in comparison to $71 \%$ for the other chert categories. Furthermore, Haviser, did not include patinated surfaces among cortical/ outer surface types for the Long Island flint category (see Chapters 2 and 3), as he was less familiar with this flint material. This would also reduce the number of non-cortical flakes. Within the Jumby Bay and Sugar Mill samples, this would account for a $5 \%$ decrease. Combining these differences, the percentage of non-cortical flakes may be $5 \%$ to $10 \%$ lower than the figure Haviser reported, and this produces a value that falls within the range Walker (1980) found experimentally, suggesting arrival of non-modified material.

This leaves Cocoyer as the only exception to the pattern of transport of unmodified flint material. Considering the small sample of artefacts being analysed from this particular site, additional research is needed to prove or disprove the exceptional position of Cocoyer.

During the later Early Ceramic B phase, the arrival of unmodified Long Island flint material has been suggested for sites within the Guadeloupe to Saba area (figure 6.2). The larger samples from Sugar Factory Pier, Golden Rock, and Anse des Pères have produced especially high numbers of cortical flakes. The smaller samples do not differ, and therefore support this pattern. Even for the Paso del Indio site, which is situated at the largest distance from the source considered here, the common occurrence of cortical flakes indicates the arrival of unmodified material (Rodríguez Ramos, personal communication 2001). Only in the case of the Diamant site, does the recovery of a single tertiary flake leave all possibilities open. In contrast to the preceding phase, none of the Early Ceramic B sites have produced clear data that suggest arrival of pre-worked material.

The data from both phases also agree with the absence of any reduction activities attributed to the entire Early Ceramic Age at the Long Island source (see Chapter 4). This implies that the people who had direct access to the Long Island source sent out expeditions to collect unmodified material and bring it back to their settlements. However, from this pattern alone, i.e. the transport of unmodified material, it is difficult to indicate where the direct access zone actually stopped, and where inter-village exchange began. Only the Early Ceramic A phase has produced possible information in this regard. The fact that pre-worked material might have been entering the Cocoyer site points to the existence of an exchange mechanism, as special workshop sites at the source or anywhere else were not encountered or reported. In other words, if sample bias is not blurring the data, the Cocoyer community must have obtained Long Island flint from an intermediate site, where it was (pre-)worked. The fall-off data, which are discussed below, minimally support the beginning of a down-the-line mode of exchange at this distance of ca. $140 \mathrm{~km}$ from the source.

\section{The Late Ceramic Age}

The Late Ceramic A phase does not show a marked change relative to the preceding Early Ceramic B phase, except for a less extensive distribution (figure 6.3). Sites with relatively large samples, that produced high percentages of cortical flakes, and thus suggest the arrival of unmodified lithic material are Blackman's Point and Coconut Hall on Antigua, Anse à la Gourde on Guadeloupe, and Sandy Ground on Anguilla. In general, however, these percentages are lower than those found at the small settlement of Jumby Bay on Long Island. This may be attributed to a smaller average core size used or the less exhaustive reduction, considering the larger average size of the flakes at Jumby Bay. The small samples that suggest import of unmodified material include Claremont on Antigua and Smoke Alley on St. Eustatius. Only the above mentioned Spring Bay 3 and Barnes Bay sites may represent places where worked material was transported in.

In general, the more limited data associated with the Late Ceramic B phase do not markedly differ from those of the preceding phase (figure 6.4). Arrival of unmodified material was the case for Kelbey's Ridge 2. Possible indications for the import of pre-worked material, likely flakes, are only found at Shoal Bay East. The small sample from Shoal Bay East comprises many tertiary flakes and no cores.

Summarising the data for both late phases, the transport of unmodified material basically occurred within the Guadeloupe and Saba area, although differentiation is noticed for the islands of Saba and St. Eustatius, especially between the Spring Bay 3 and Kelbey’s Ridge 2 sites. Unfortunately, data from the islands between Statia and Antigua is not available.

\footnotetext{
${ }^{5}$ This higher percentage in general may be attributed to the fact that many of these chert types are not true flints and therefore lack the typical formation of a cortical rind. There are indications that some of these materials were obtained from inland surface scatters, where a very distinctive outer surface did not develop, in contrast to water-worn surfaces in river beds or on beaches, for example. This makes it more difficult to distinguish outer surface from inner surface, thereby potentially over-representing non-cortical surfaces.
} 


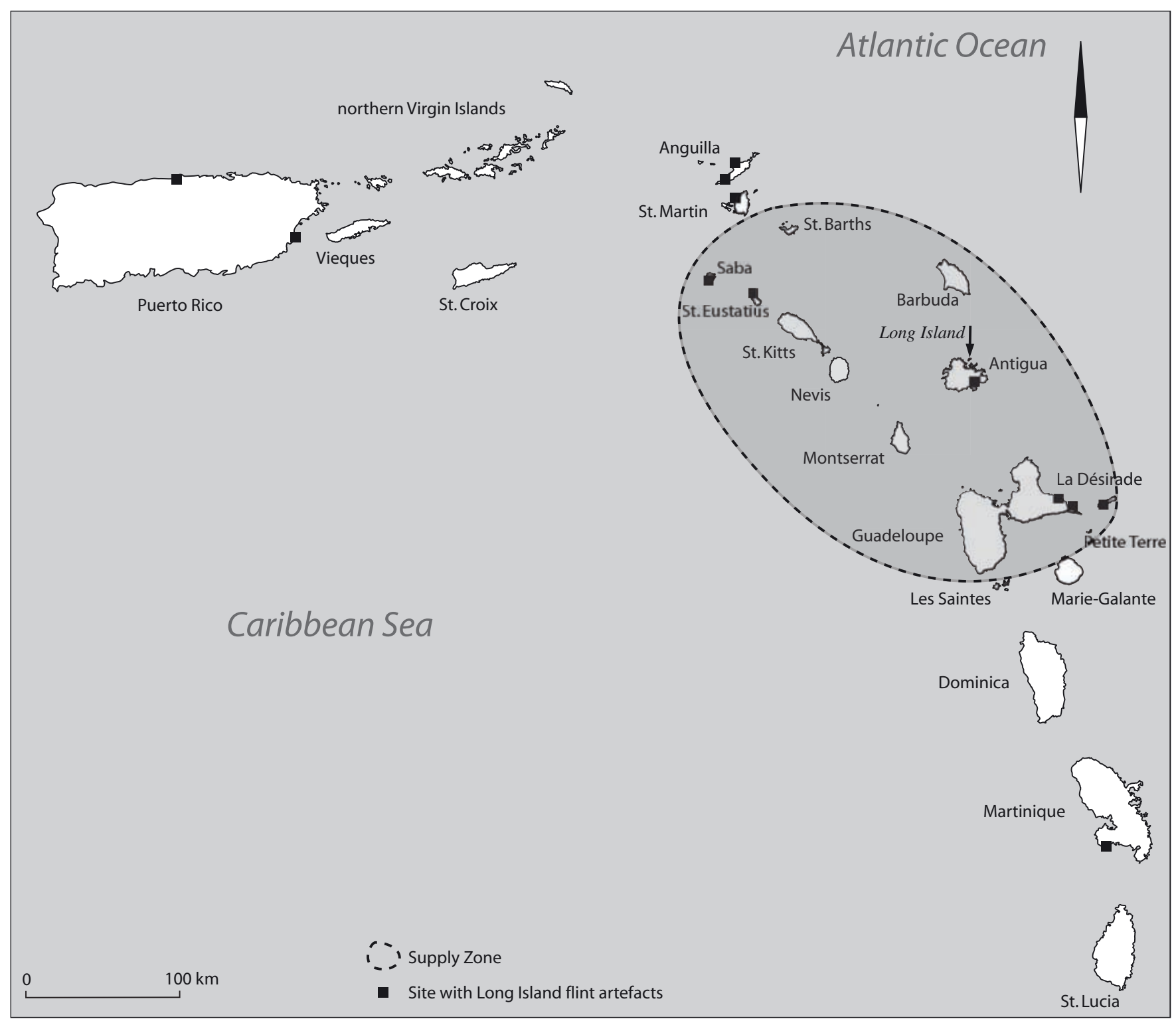

Figure 6.2. Distribution of Long Island flint and the location of the supply zone during the Early Ceramic B phase (AD 400 - 850).

Some sites on the island of Anguilla seem to have obtained material in a pre-worked form and therefore, likely received it through their exchange with neighbouring communities. The presence of exchange relationships is supported by fall-off data discussed below. Still, it is also obvious that importation of material was different on Anguilla. For example, data from the Sandy Ground site suggest import of unmodified material, whereas data from later sites seem to suggest the acquisition of pre-worked material. Whether this is related to a diachronic change is open for further study. In this respect it is interesting to point out that Long Island material was less widely distributed during the Late Ceramic Age than during the Early Ceramic Age. Combined with the possible arrival of pre-worked material at some of the more distant sites, this suggests more restricted access to the Long Island source for these later phases of the Ceramic Age (see discussion of fall-off data below). The existence of small habitation sites on Long Island (see Chapter 4) may be related to this more restricted access, since these settlements may have played a role in the possible control of this source. 


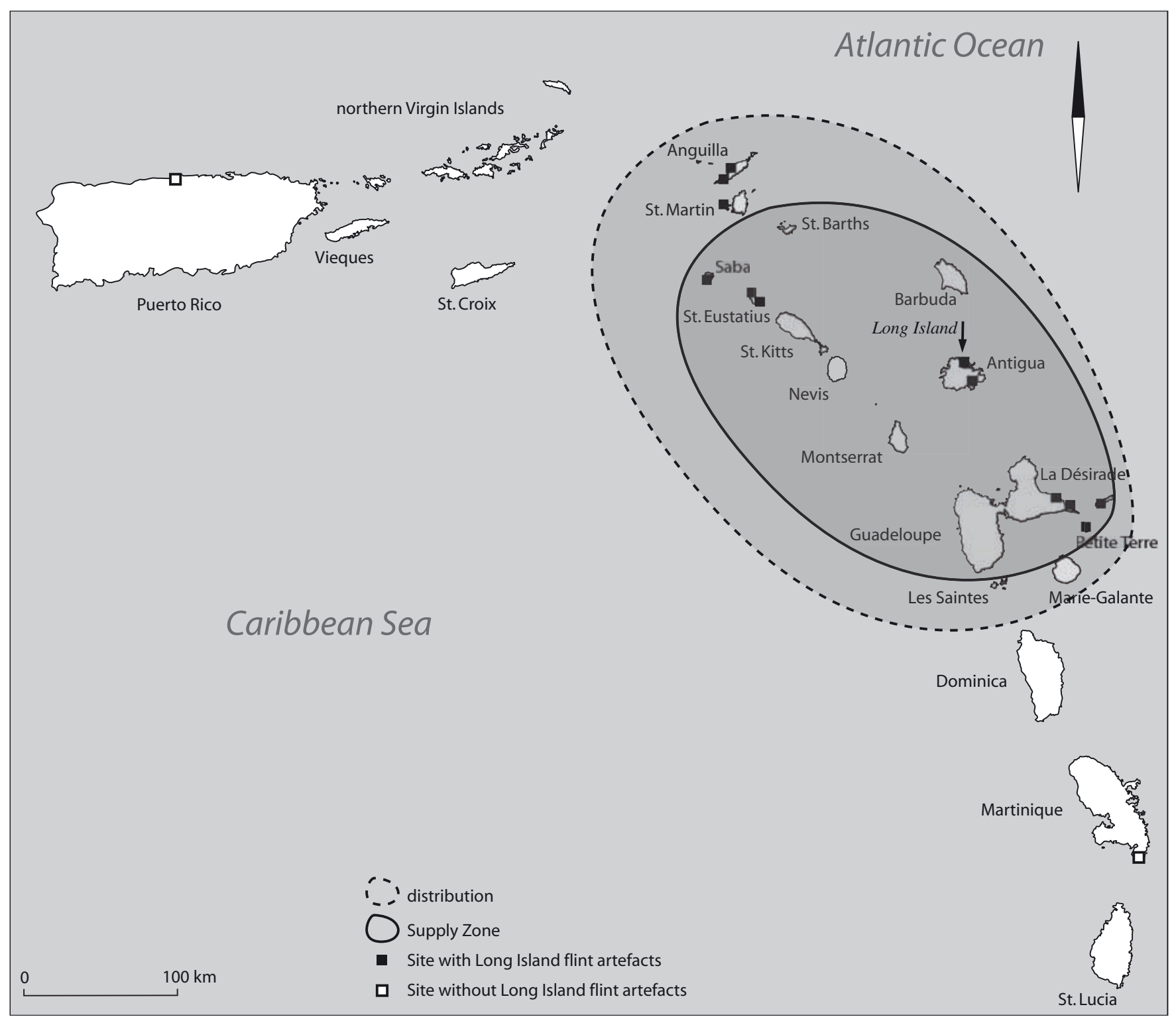

Figure 6.3. Distribution of Long Island flint and the location of the supply zone during the Late Ceramic A phase (AD 850 - 1250).

\section{Fall-off analysis}

Introduction

In Chapter 1, the concept of fall-off analysis was introduced as a base-line method for the investigation of the exchange mechanisms that were responsible for the distribution of a particular material. Fall-off curves in this case provide some additional insights, despite the difficulties that are encountered using this form of analysis (see Torrence 1986 for detailed discussion).

Some initial comments need to be made, concerning the study of fall-off. With regard to the distribution of rock materials in the Lesser Antilles, certain conditions simplify the study of fall-off patterns. First, the fact that we are dealing with an island archipelago, comprising relatively small islands, makes it very likely that transport primarily occurred by canoe. This was probably the case for not only inter-island traffic but also for traffic between villages situated on the same island. The predominant coastal location of sites, in many cases mountainous terrain, and typically dense forest cover at the 


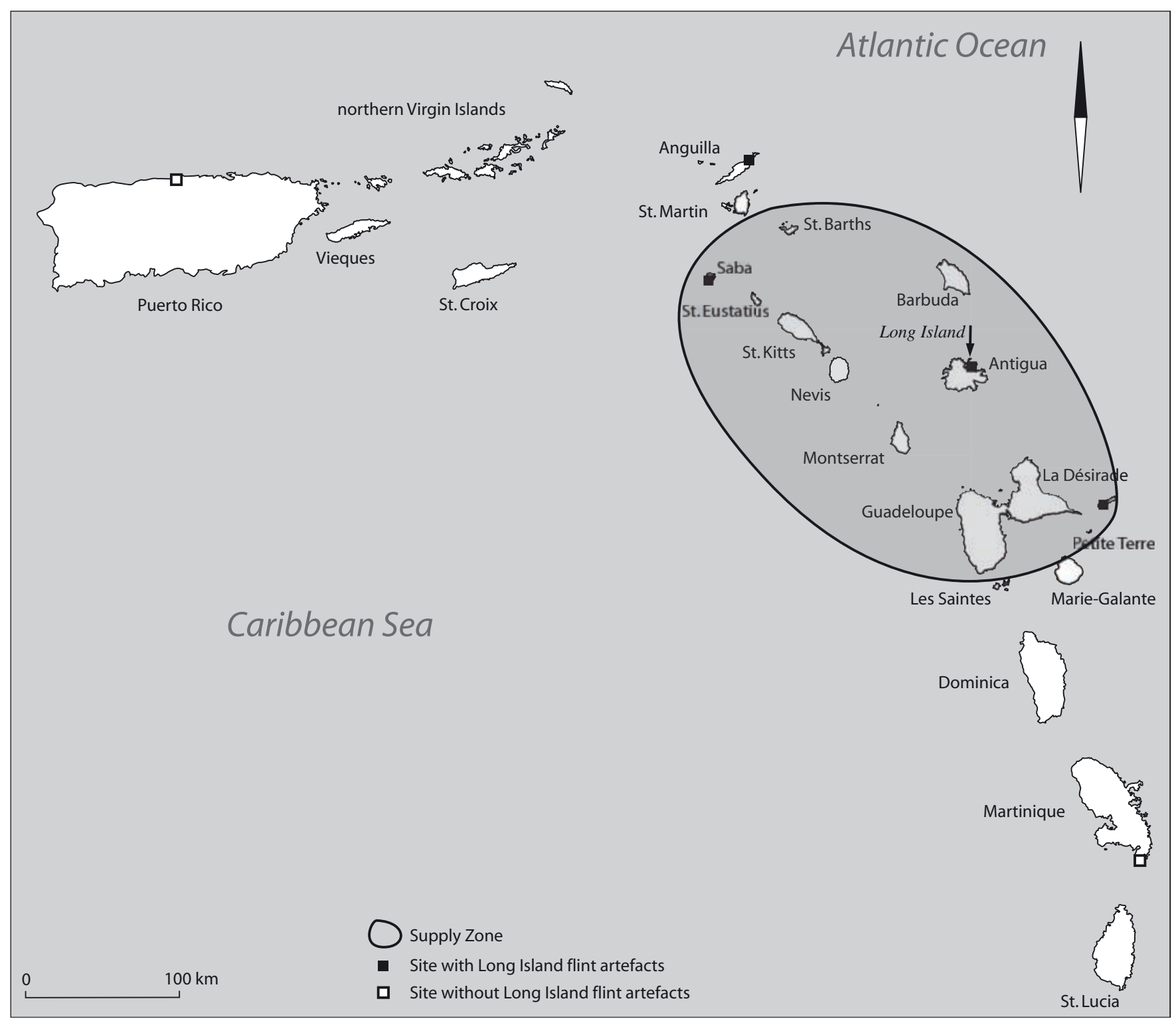

Figure 6.4. Distribution of Long Island flint and the location of the supply zone during the Late Ceramic B phase (AD 1250 - 1492).

time, would have made transport over land difficult and supports a predominant reliance on marine traffic. Therefore, the difficulty of weighing sea transport to land transport is generally not at issue here when calculating effective distance for the fall-off curves.

Furthermore, the specific shape of the Lesser Antilles island chain only leaves room for two main directions over which material can be transported. Seen from Antigua, it is either a (north)western transport in the direction of Puerto Rico or a southeastern one, heading to the Windward Islands and the South American mainland. Only Montserrat to the southwest and Barbuda to the north deviate from these two island chain routes. As such, the fall-off curve can be divided into two separate ones and each one can be considered as closely resembling a one-dimensional situation (see Chapter 1). Finally, the island nature of the study area determined that only discrete transport steps were possible, equal to the distance between the islands. The curve's effective distance is equal to the shortest distance between the islands in this case. In most cases this will be a very good approximation, since sea transport was the form of transportation. 
The percentage of Long Island flint as part of the total amount of lithic material associated with a flake tool technology (all cherts and quartz) is taken as the measure of abundance for the construction of the fall-off curve. As such, a percentage is much influenced by the availability of other lithic sources in the region. Therefore, it is not considered to be the best measure. However, a ratio in which ceramics are incorporated, assuming that ceramics were more widely available and therefore were much more constant relative to the number of users, is beyond the scope of the present research. In many cases, the exact number of pottery sherds is not known or reported, or had to be recalculated using unpublished artefact data-bases unavailable to me. A measure using the amount per excavated volume or area, which has been applied by some researchers (see Torrence 1986, 124 table 6 for an overview), is not considered a reliable parameter here, because of the high variability in intra- and inter-site artefact concentrations. In the first place there is a marked difference within individual sites between living areas and refuse areas. Also, differences within refuse area, centres and peripheries, can be distinguished. Secondly, artefact concentrations in refuse areas from different sites appear to vary significantly in material abundance.

Another drawback for the current study is the small number of sites per phase, that have been available for analysis. In many cases, data from specific micro-regions could not be obtained, notably from the area from Dominica to the southwestern portion of Guadeloupe (Basse Terre), as well as the region of the Virgin Islands. In both cases, these regions are relatively distant from the source and it appeared that beyond these areas significant changes occur, thereby hampering good insight into the shape of the fall-off curve.

\section{Results}

The fall-off curves for the different phases all conform to the Law of Monotonic Decrement (LMD) (see Chapter 1): overall material abundance clearly declines with distance (tables 6.6-6.9, figures 6.5-6.7). However, some deviations exist in comparison to the curves demonstrated in other areas of the world. Most of the fall-off curves within this study do not correspond to the expected form of high abundance near the source (the "supply zone"), and a monotonic decline with increasing distance, as has been found in the Near East by Renfrew and his colleagues, for example (Renfrew \& Dixon 1976; Renfrew et al. 1968; see also Renfrew \& Bahn 1991, 326). The deviations are mainly found near the Long Island lithic source, and can be attributed to the use of other locally available fine-grained rocks. Particularly within the Early Ceramic A and Late Ceramic A phases, significant variation exists between sites on the island of Antigua and also to some extent, Montserrat. Within the Early Ceramic A phase, white chert is one of the prevailing materials at Doigs, Trants, Morel, and Hichman's, as mentioned below in Chapter 5, but De Mille (2001) reports a significant occurrence of many other local categories for the site of Royalls as well. The Late Ceramic A phase exhibits variation, since the inhabitants of the Blackman's Point and Coconut Hall sites made significant use of local materials that are found near them. These "other" sources played only a minor role within the wider region, as is shown by predominant use of Long Island flint on Nevis, Guadeloupe, and beyond. This clearly demonstrates the higher value that was given to Long Island flint relative to other finegrained materials.

Comparison of the different phases reveals some changes. Within the Early Ceramic A and B phases the distribution was at its widest, at least all the way to Martinique to the south and the eastern and middle portions of Puerto Rico to the west. Unfortunately, sites outside of this broad region were not studied for this phase and the full limits of its extent was not established. However, it is likely that this material was not transported any further, considering the steep decline in abundance, especially in the southern direction. For the southern area, this can be attributed to the common local availability of other fine-grained rock on Martinique. These local rocks form the predominant lithic categories at the Martinican sites according to the available information. In the northwestern direction, further distribution also may have stopped at about the limit of the study, although the social situation is believed to be different there as a result of the presence of Preceramic Age groups then (Rodríguez Ramos 2001c; Rouse 1992). These latter people displayed a marked preference for Long Island flint, as noted on sites in the northern Lesser Antilles (Davis 2000; Watters et al. in prep.). Rodríguez Ramos (2005) argues that relationships must have existed between both the Ceramic and Preceramic Age people, although archaeological data for this are still scarce. Therefore, a larger zone of distribution of Long Island flint should still be considered in this general area.

Long Island flint did not reach Puerto Rico anymore during the following Late Ceramic A phase. A more contracted distribution is to some extent already noticed for the Early Ceramic B phase, which shows a decrease in Long Island flint at Punta Candelero through time. Whether this more restricted spread of flint continued to manifest itself during the latest phase of Pre-Columbian occupation cannot be tested, as studied samples are lacking for this phase in this area. Late occupation at Anse Trabaud on the other end of the region does not display the use of Long Island flint, however. Available data thus far 


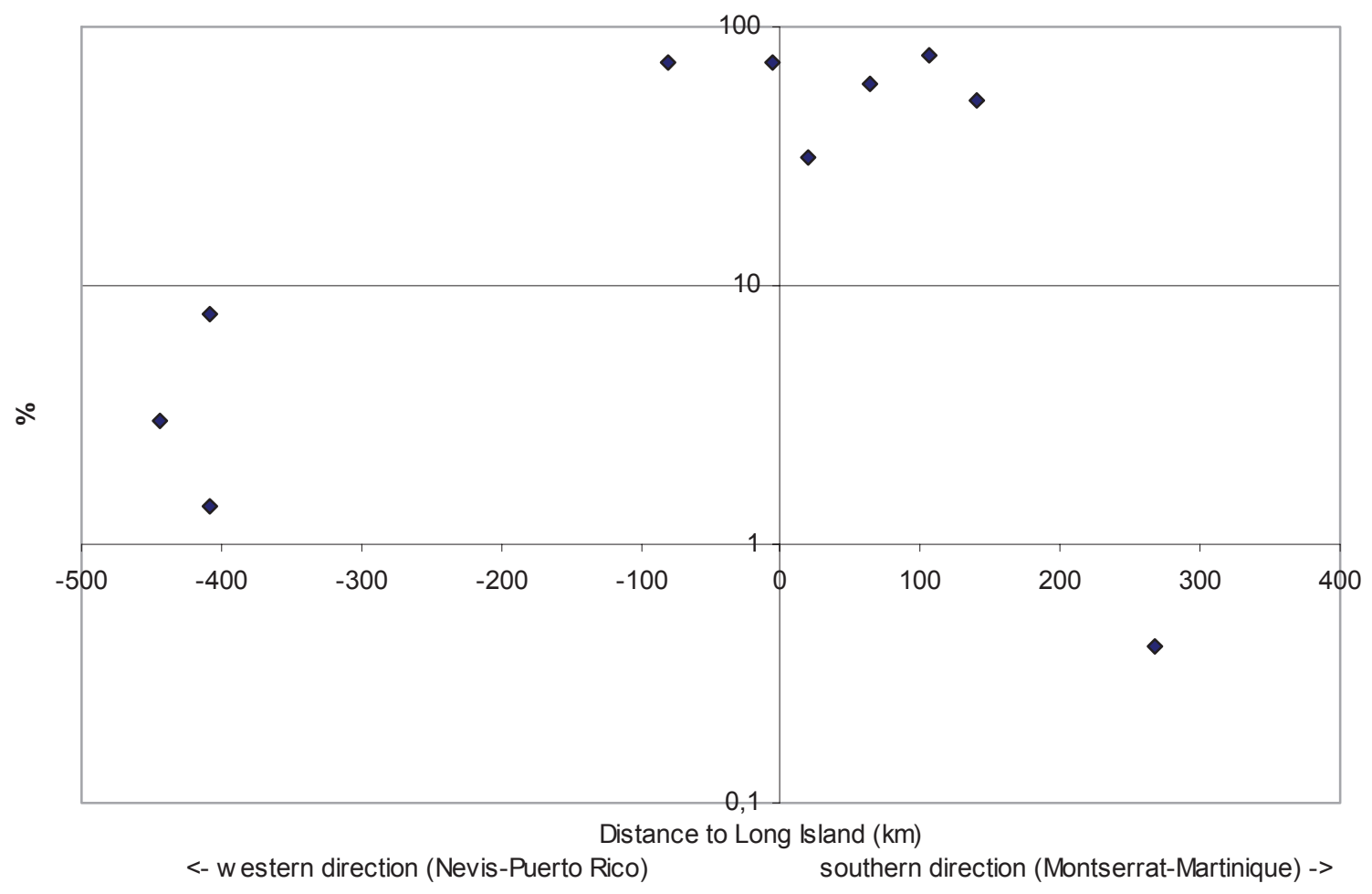

Figure 6.5. Early Ceramic A phase. Fall-off graph (logarithmic scale) showing the percentage of Long Island flint at a settlement site by distance to Long Island.

\begin{tabular}{llrrr}
\hline Site & Island & $\begin{array}{c}\text { Distance to Long } \\
\text { Island (km) }\end{array}$ & $\begin{array}{c}\text { \% Long Island } \\
\text { flint }\end{array}$ & $\begin{array}{c}\text { N Long Island } \\
\text { artefacts }\end{array}$ \\
\hline Punta Candelero $^{\mathrm{a}}$ & Puerto Rico & 444 & 3.0 & 31 \\
La Hueca $^{\mathrm{a}}$ & Vieques & 408 & 7.7 & 113 \\
Sorcé & Vieques & 408 & 1.4 & 7 \\
Hichman's & Nevis & 81 & 72.7 & 24 \\
Royalls $^{\mathrm{b}}$ & Antigua & 6 & 72.3 & 523 \\
Doigs early & Antigua & 19 & 31.6 & 74 \\
Trants & Montserrat & 63 & 60.7 & 573 \\
Morel & Guadeloupe & 107 & 78.0 & 1083 \\
Cocoyer & Marie-Galante & 141 & 52.3 & 23 \\
Vivé & Martinique & 268 & 0.4 & 1 \\
\hline
\end{tabular}

Table 6.6. Early Ceramic A phase. Percentage of Long Island flint as part of all flake tool related material by site by distance to Long Island. a after Rodríguez Ramos 2001a; b after De Mille 2001.

only point out that Long Island flint remained frequently used within the Guadeloupe-Anguilla area during the later phases of the Ceramic Age.

Renfrew et al. (1968) showed in their work on Anatolian obsidian distribution that in the region surrounding the source, the abundance of obsidian stays relatively high over time. They interpreted this area of high abundance as the supply zone, where people had direct access to the source. In the specific Anatolian case, abundance remained around $80 \%$ of the total of obsidian. Beyond a certain distance, however, the amount decreased according to an exponential curve indicative of "downthe-line” exchange. In the present study, the Early Ceramic A phase does not display a constant high abundance of Long 


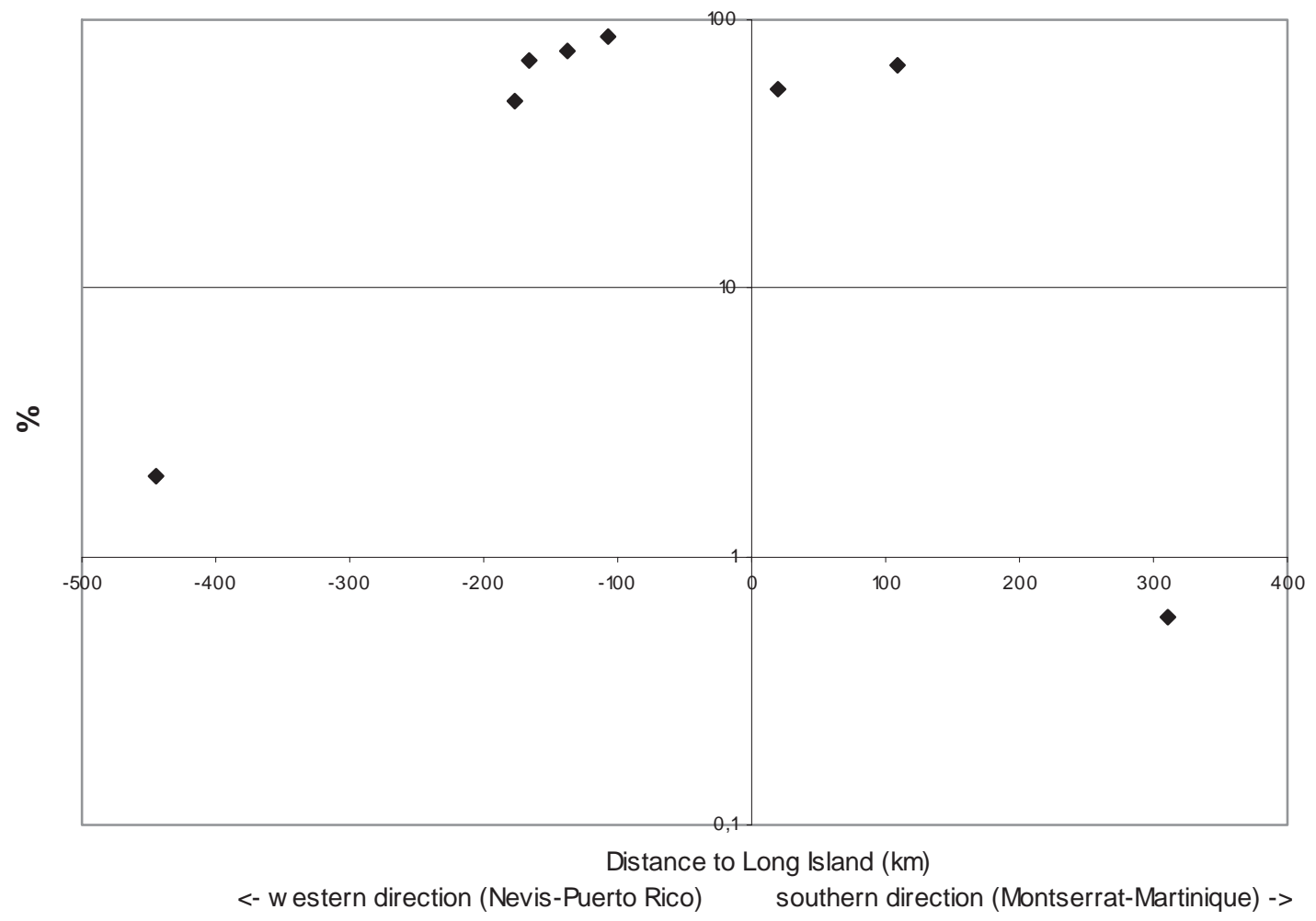

Figure 6.6. Early Ceramic B phase. Fall-off graph (logarithmic scale) showing the percentage of Long Island flint at a settlement site by distance to Long Island.

\begin{tabular}{|c|c|c|c|c|}
\hline Site & Island & $\begin{array}{l}\text { Distance to Long } \\
\text { Island }(\mathrm{km})\end{array}$ & $\begin{array}{l}\text { \% Long Island } \\
\text { flint }\end{array}$ & $\begin{array}{l}\text { N Long Island } \\
\text { artefacts }\end{array}$ \\
\hline Punta Candelero $^{\mathrm{a}}$ & Puerto Rico & 444 & 2.0 & n.s. \\
\hline Anse des Pères & St. Martin & 176 & 50.0 & 91 \\
\hline Kelbey’s Ridge 1 & Saba & 166 & 70.4 & 50 \\
\hline Golden Rock & St. Eustatius & 137 & 75.9 & 483 \\
\hline Sugar Factory Pier ${ }^{\mathrm{b}}$ & St. Kitts & 107 & 86.1 & 896 \\
\hline Doigs late & Antigua & 19 & 54.8 & 160 \\
\hline Anse à l’Eau early & Guadeloupe & 109 & 67.4 & 60 \\
\hline Anse à la Gourde early & Guadeloupe & 117 & 100.0 & 12 \\
\hline Diamant & Martinique & 310 & 0.6 & 1 \\
\hline
\end{tabular}

Table 6.7. Early Ceramic B phase. Percentage of Long Island flint as part of all flake tool related material by site by distance to Long Island. a Rodríguez Ramos personal communication (2002); b after Walker (1980a, 91).

Island flint as a result of the use of other sources on the island of Antigua. However, beyond Guadeloupe in the southern direction and beyond Nevis in the western direction, Long Island percentages exhibit a monotonic decline. Especially in case of the southern fall-off, this decline approximates exponential decay. In the western direction basically only two distance points are present, one on Nevis and one in the Vieques-eastern Puerto Rico area. If it is assumed that between these two points two exchange transactions occurred, one at Hope Estate and one in the Virgin Islands, such as Prosperity, for example, then the $60 \%$ found at Nevis becomes $7.5 \%$ at Vieques, assuming that half of the quantity is kept and the other half is passed on. This $7.5 \%$ equals the amount at La Hueca. Following the fall-off in the southeastern direction reveals that the abundance of flint on Martinique is considerably lower (less than 1\%) than would be expected if two or three exchange transactions 


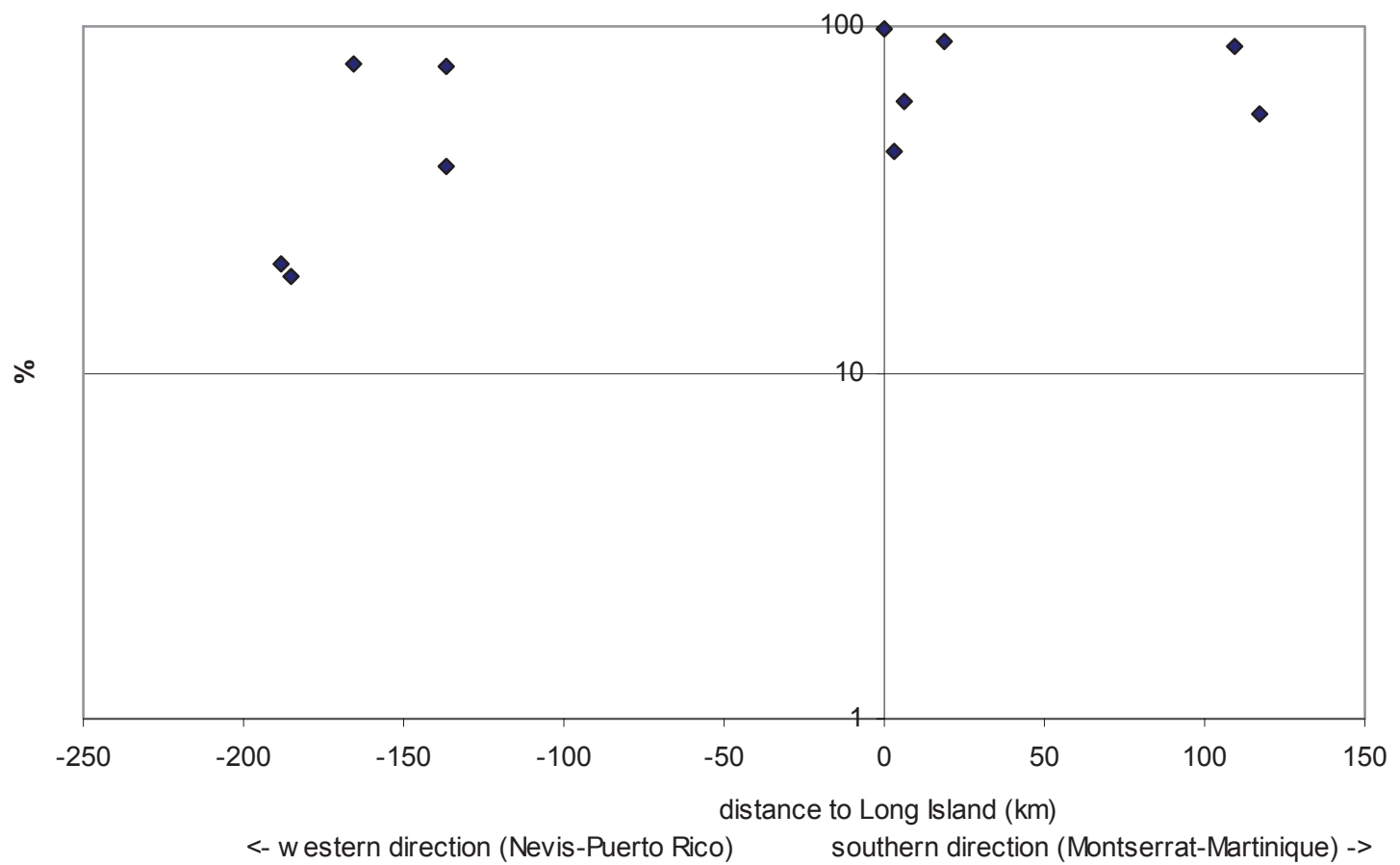

Figure 6.7. Late Ceramic A phase. Fall-off graph (logarithmic scale) showing the percentage of Long Island flint at a settlement site by distance to Long Island.

\begin{tabular}{llrrr}
\hline Site & Island & $\begin{array}{c}\text { Distance to Long } \\
\text { Island (km) }\end{array}$ & $\begin{array}{c}\text { \% Long Island } \\
\text { flint }\end{array}$ & $\begin{array}{c}\text { N Long Island } \\
\text { artefacts }\end{array}$ \\
\hline Barnes Bay & Anguilla & 188 & 20.7 & 87 \\
Sandy Ground & Anguilla & 185 & 19.0 & 59 \\
Spring Bay 3 & Saba & 166 & 78.0 & 110 \\
Smoke Alley & St. Eustatius & 137 & 76.9 & 20 \\
Godet & St. Eustatius & 137 & 39.1 & 9 \\
Claremont & Antigua & 19 & 90.0 & 32 \\
Jumby Bay & Antigua & 0 & 98.9 & 953 \\
Coconut Hall & Antigua & 6 & 61.0 & 125 \\
Blackman's Point & Antigua & 3 & 43.6 & 80 \\
Anse à l'Eau late & Guadeloupe & 109 & 87.5 & 7 \\
Anse à la Gourde middle & Guadeloupe & 117 & 55.9 & 85 \\
Anse à la Gourde late & Guadeloupe & 117 & 65.6 & 21 \\
Anse Trabaud & Martinique & 321 & 0.0 & 0 \\
\hline
\end{tabular}

Table 6.8. Late Ceramic A phase. Percentage of Long Island flint as part of all flake tool related material by site by distance to Long Island.

\begin{tabular}{llrrr}
\hline Site & Island & $\begin{array}{c}\text { Distance to Long } \\
\text { Island (km) }\end{array}$ & $\begin{array}{c}\text { \% Long Island } \\
\text { flint }\end{array}$ & $\begin{array}{c}\text { N Long Island } \\
\text { artefacts }\end{array}$ \\
\hline Anse Trabaud & Martinique & 321 & 0.0 & 0 \\
Sugar Mill & Antigua & 0 & 100.0 & 427 \\
Kelbey's Ridge 2 & Saba & 166 & 78.2 & 79 \\
Shoal Bay East & Anguilla & 185 & 56.7 & 17 \\
\hline
\end{tabular}

Table 6.9. Late Ceramic B phase. Percentage of Long Island flint as part of all flake tool related material by site by distance to Long Island. 
had occurred. This lower percentage is probably due to the local availability of good flaking materials and less of a need for imports

This suggests that the region between Nevis and the northern coast of Grande Terre (Guadeloupe) represents the supply zone. Does this also mean that the people living in this area all had direct access to the Long Island source? In other words, were the inhabitants of this area able to exploit the Long Island flint source without the interference of another community controlling it? ${ }^{6}$ In Chapter 4, I showed that during the Early Ceramic phases Long Island was not occupied in contrast to the later part of the Ceramic Age. People apparently visited the island only to collect flint then, which they brought to their villages without any systematic pre-working. So, the source itself provides no indication of control at this time.

If one searches for the closest residential site during this phase then the Royalls site on Antigua is the best candidate (De Mille 2001; Murphy 1999). Raw material data for this site differs in composition from those of, for example, Trants and Morel, located within the supply zone. At Morel and Trants, Long Island flint makes up the majority of the lithic material, with the white chert variety being the second most abundant. On the contrary, De Mille (2001), reports for Royalls a lower Long Island flint percentage and the occurrence of a number of other local chert varieties, not encountered at Trants and Morel. This means that the Trants and Morel communities did not obtain their material from this site. Otherwise, one would expect to find these other categories as well. Apparently, the Trants and Morel communities directed special trips to the relatively remote lying Long Island source. For them this material may have been more easily approached than some of the other chert sources situated on the main island of Antigua, which may have been controlled by specific villages in the immediate vicinity (figure 6.1).

For the Early Ceramic B phase the situation changes slightly relative to the Early Ceramic A phase. Sites with high percentages of flint have a more extended distribution in the northwestern direction, as data from the sites of Golden Rock and Kelbey's Ridge 1 on the newly populated islands of St. Eustatius and Saba show. Beyond these, the abundance markedly declines at Anse des Pères and Punta Candelero, suggesting down-the-line exchange. In the other direction, sites on the northern coast of Grande Terre, Anse à l'Eau and the small sample of Anse à la Gourde, still demonstrate high numbers of Long Island flint, and the supply zone apparently continued to incorporate this area (figure 6.2). Further to the south, data are very scanty, with only the site of Diamant being studied. However, this site displays an almost identical low abundance of flint as the earlier Vivé settlement. The steep decline is therefore also suggestive of down-the-line exchange in this direction.

Looking more closely at the lithic raw material composition of the sites, it is noticed that Long Island flint is the sole recurrent and predominant material within the supply zone area. This differs from the preceding phase when other materials also occurred in relatively high numbers, particularly the white chert. The only site on Antigua itself for this phase within the present analysis is the late occupation of the Doigs site. This phase produced a different flint and chert composition than sites within the supply zone, as is the case, for example at Sugar Factory Pier on St. Kitts, Golden Rock on St. Eustatius, and Kelbey's Ridge 1 on Saba. Similar to the preceding phase, this difference in composition suggests that sites within the supply zone were exploiting the Long island flint source themselves.

As already mentioned, the Late Ceramic A phase had a more restricted distribution in the western area as compared to the two Early Ceramic phases. Unfortunately, data are scanty for the eastern direction and depend on the dating of the Anse Trabaud site. This site did not produce any Long Island flint, however, although the difference with the Early Ceramic phase is not significant, considering the very low percentages of Long Island flint encountered at Vivé and Diamant, and the smaller sample studied for Anse Trabaud.

Within this less extensive distribution, the frequency pattern resembles the other one characteristic of the Early Ceramic B phase, with high percentages occurring at sites on St. Eustatius and Saba, and significantly lower values at Anguilla. Similar to the Early Ceramic B phase, the supply zone still incorporated Saba and St. Eustatius, beyond which exchange started. On the other end along the northern coast of Grande Terre, the Troumassoid 1 and 2, and Suazan Troumassoid phases of the Anse à la Gourde site produced similar percentages to the earlier sample from the Anse à l'Eau site, suggesting no change in access there as well. The supply zone, therefore, was again positioned between Saba and at least the northern part of Guadeloupe (figure 6.3).

\footnotetext{
${ }^{6}$ In both situations, direct access or exchange with a community living next to the source and controlling it, mathematically will not result in different fall-off curves, if one assumes that such a controlling community will have an infinite amount of rock material available for exchange. This means that the amount of material that reaches the supply zone sites will not be dependent on the amount at the source community, but will be dependent on the distance to the source only.
} 
The latest phase marks a slight change relative to the earlier one, as the Shoal Bay East site on Anguilla produced a significantly higher flint percentage compared to the Barnes Bay and Sandy Ground sites from the earlier phase. This suggests that the island of Anguilla may have become part of the supply zone then as well. In case of Saba, the limited data provide a similar picture to the preceding phase (figure 6.4). Kelbey's Ridge 2 has produced an equally high percentage of Long Island flint to Spring Bay 3. Contrary to this, the very small sample from Morne Souffleur on La Désirade, comprising only eight chert artefacts, did not include a single Long Island item. This is markedly different from earlier samples from the neighbouring Grande Terre sites, where Long Island formed the majority of flaked stone. The uncommon location of this La Désirade site on the high central plateau, and its distinct ceramic stylistic features, when compared to other sites in the region suggest that it fulfilled an exceptional role during Pre-Columbian times in this region, which may have also included a different social position (De Waal 2006; Hofman et al. 2004). Beyond the Anguilla - Guadeloupe area Long Island material has not been identified to the west or the south as yet, although it needs to be pointed out that the number of sites studied is very small, including only the problematic Anse Trabaud site and the latest occupation phase of Paso del Indio (Rodríguez Ramos personal communication 2001).

\section{Reduction at the site}

It has been shown above that the inhabitants of many of the regional sites either obtained non-modified cobbles through direct access to the lithic source, or imported these cobbles through their exchange with intermediate communities. Only in a few cases did the import of pre-worked material seemingly take place. Furthermore, the fall-off analysis indicates a down-the-line mode of flint exchange. In this section a closer look will be taken at on-site reduction to see if differences in the manner of treating the lithic material provides additional information about the degree of access to it. In other words, following Torrence (1986), were certain technological measures taken to increase the efficiency of production as access to material became more restricted?

In Chapter 5, I argued that the production of flake tools was undertaken in an expedient manner and that this type of technology did not change through time. This non-standardised type of flint working by itself does not leave many opportunities to increase the efficiency of its production by application of "cost-control" devices, which were discussed in Chapter 1. It is a fast and easy way to produce a set of quite variable flake tools. The evidence from the technological analysis shows that this production did not become more standardized, or sophisticated over time (see Chapter 5). Furthermore, there are no indications that the manufacture of flake tools became a specialised enterprise. Still, the data suggest that the degree of access had an effect on the efficiency of the production, with respect to flakes produced per amount of material available in particular.

I used different parameters to measure this. The definition of these parameters is complicated by the fact that the final products, the flake tools, are difficult to recognize, as formal tool types are absent. Considering the expedient fashion of the production, it is assumed that every flake is a potential tool. Therefore, the maximum dimension of a flake is taken as the measure for the length of edges, which are the potentially usable entities. This dimension has been divided by the flake weight to obtain a parameter related to the quantity of possible tools generated given a certain lithic mass, thereby indicating how efficiently the knappers used the available material.

To obtain some insight into the degree of reduction a number of variables were recorded. The first relates to the scar-count on dorsal faces of flakes, as mentioned in Chapter 3. The second is more specific to Ceramic Age technology and relates to the degree of modification and the percentage of complete flakes. In Chapter 5, it was said that apart from core reduction in many cases flakes were further modified or reduced to obtain smaller flakes. In this manner, the reduction and modification of flakes can be used as a means to more exhaustively utilize the available stone material. A result of the modification and reduction of flakes is a smaller percentage of complete flakes in the sample, particularly if one considers that complete flakes are often among the larger ones, and in many cases can still function as potential cores for the production of smaller flakes.

With respect to the maximum-dimension/weight ratio, higher values, suggesting more efficient use of lithic material, are generally apparant with increasing distance from the source, particularly if one compares the Long Island sites with the other settlements (table 6.10). ${ }^{7}$ Some deviations, however, are present. Within the Early Ceramic A phase, the Trants site produced

${ }^{7}$ When calculating these parameters, mesh-size differences were accounted for, as discussed in Chapter 3 and Appendix E. Data for only a limited number of sites were available. 


\begin{tabular}{|c|c|c|c|c|c|c|c|c|}
\hline Site & Island & $\begin{array}{l}\text { Distance } \\
\text { to Long } \\
\text { Island } \\
(\mathrm{km})\end{array}$ & \multicolumn{2}{|c|}{ flakes $>11$} & \multicolumn{2}{|c|}{ flakes $>14$} & \multicolumn{2}{|c|}{ flakes $>19$} \\
\hline \multicolumn{9}{|l|}{ Early Ceramic A } \\
\hline Trants & Montserrat & 63 & 293 & 2.32 & 194 & 1.81 & 92 & 1.00 \\
\hline Morel & Guadeloupe & 107 & - & - & 500 & 1.37 & 255 & 0.91 \\
\hline \multicolumn{9}{|l|}{ Early Ceramic B } \\
\hline Golden Rock & St. Eustaius & 137 & - & - & - & - & 274 & 0.81 \\
\hline Kelbey's Ridge 1 & Saba & 166 & 30 & 1.78 & 23 & 1.16 & 11 & 0.95 \\
\hline \multicolumn{9}{|l|}{ Late Ceramic A } \\
\hline Jumby Bay & Long Island & 0 & - & - & 351 & 1.13 & 258 & 0.74 \\
\hline Anse à la Gourde middle & Guadeloupe & 117 & 65 & 1.39 & 55 & 1.26 & - & - \\
\hline Sugar Mill & Long Island & 0 & - & - & 140 & 1.15 & 94 & 0.81 \\
\hline Kelbey's Ridge 2 & Saba & 166 & 46 & 1.78 & 29 & 1.33 & - & - \\
\hline
\end{tabular}

Table 6.10. Long Island flint flakes: (Maximum dimension)/(weight) ratio of all flakes by site, and by size class. "flakes $>11$ " represents all artefacts with maximum dimension and width both larger than $11 \mathrm{~mm}$, "flakes>14" both larger than $14 \mathrm{~mm}$, etc.

a relatively very high ratio when compared to the more distant Morel site or most of the other sites dating to the later phases. During the following phase, it is also noted that Golden Rock had a relatively low value, when compared to the small sample of Kelbey's Ridge 1 on the neighbouring island of Saba. As both sites produced lower values than Morel or Trants, it seems that lithic material was considered less scarce during this phase than during the earlier phase. The sites from the later two phases, however, conform to the expected pattern of increasing ratio with increasing distance from the source. Only Barnes Bay deviates from this pattern with its relatively low value.

Regarding the second group of variables related to percentages of modified and complete flakes, the analysis is hampered by small sample size of many of the more distant sites. Comparing only the larger samples, it is obvious that the data from the two sites close to the source of Long Island are different from the sites on the islands surrounding Antigua (tables 6.11 and 6.12). This is particularly the case with respect to the modification and reduction of flakes, suggesting that this was an important means of exhaustively using the lithic material. In this respect it is interesting to see that at Trants a high percentage of modification is found along with a relatively high percentage of complete flakes, suggesting a low portion of shatter. If we combine these figures with the high maximum-dimension/weight ratio at Trants, then this means that material was reduced in a very efficient way, i.e. a high number of flakes produced per mass.

Evaluating the scar count data, the Long Island sites exhibit larger percentages among the lower scar numbers than the settlement sites on the surrounding islands (table 6.13). This again suggests that the earlier stages of reduction are better represented than the later ones at the source sites. In other words, at the sites on the surrounding islands the material was reduced more exhaustively. Among these latter sites there is generally little variation, although a good comparison is hampered by the small sample size to some extent. A few other things can be noted, however. The Spring Bay 3 sample produced a relatively large portion of flakes with a high number of flake scars. This finding correlates well with the cortex count data, which suggested the arrival of pre-worked material there, implying that the earlier reduction stage did not occur at Spring Bay 3. Considering the low occurrence of cores and the fact that Spring Bay 3 represents a short-term camp, this may suggest that the occupants took pre-worked cores to this locality. These were further reduced for obtaining flakes to be used for tasks on-site. When leaving the site, they discarded exhausted cores and took the still reducable ones with them to be further worked at another location. 


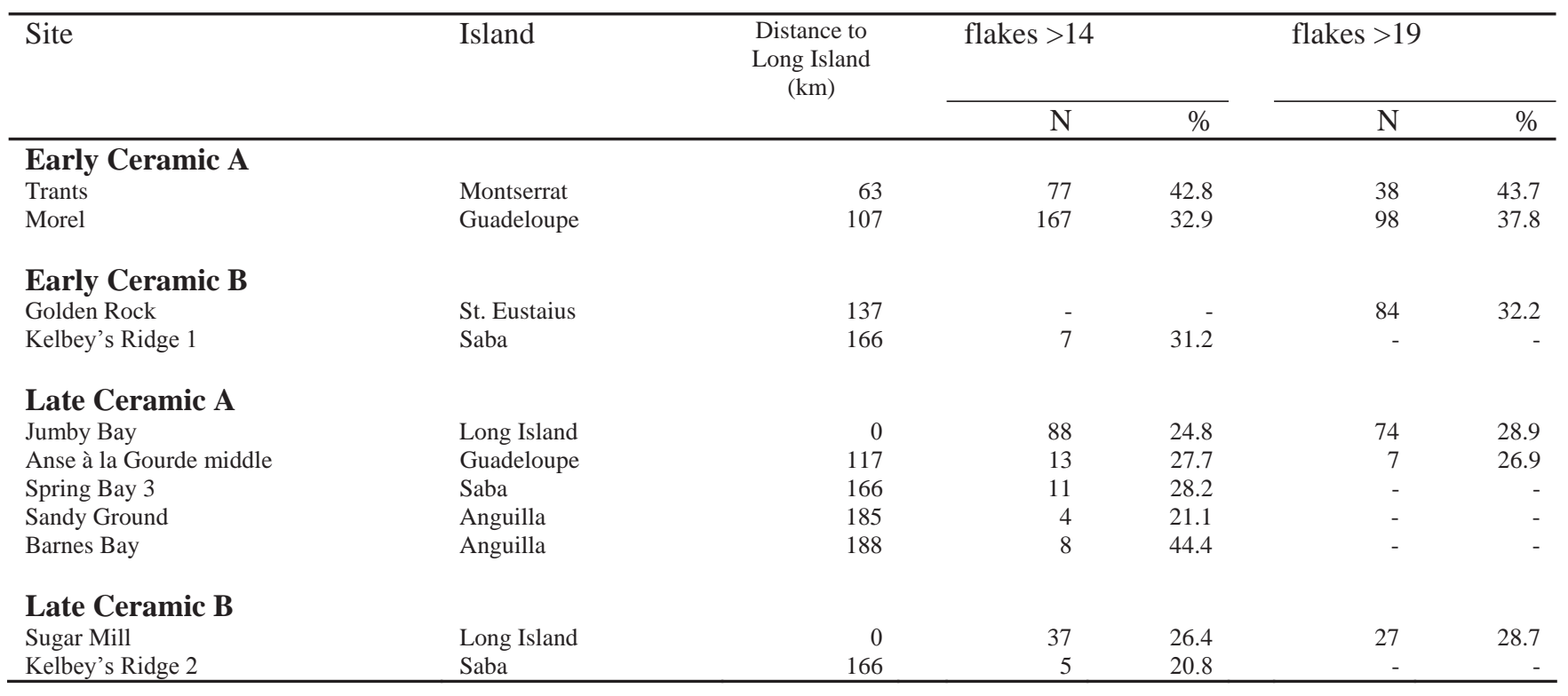

Table 6.11. Long Island flint flakes: Amount $(\mathrm{N})$ and percentage (\%) of modified flakes by site, and by size class. "flakes $>14$ " represents all artefacts with maximum dimension and width both larger than $14 \mathrm{~mm}$ and "flakes $>19$ " both larger than $19 \mathrm{~mm}$.

\begin{tabular}{|c|c|c|c|c|c|c|}
\hline \multirow[t]{2}{*}{ Site } & \multirow[t]{2}{*}{ Island } & \multirow{2}{*}{$\begin{array}{l}\text { Distance to } \\
\text { Long Island } \\
(\mathrm{km})\end{array}$} & \multicolumn{2}{|c|}{ flakes $>14$} & \multicolumn{2}{|c|}{ flakes $>19$} \\
\hline & & & $\mathrm{N}$ & $\%$ & $\mathrm{~N}$ & $\%$ \\
\hline Trants & Montserrat & 63 & 70 & 36.1 & 35 & 37.6 \\
\hline Morel & Guadeloupe & 107 & 195 & 32.9 & 109 & 36.0 \\
\hline Kelbey’s Ridge 1 & Saba & 166 & 11 & 45.5 & - & - \\
\hline \multicolumn{7}{|l|}{ Late Ceramic A } \\
\hline Jumby Bay & Long Island & 0 & 163 & 39.6 & 120 & 39.2 \\
\hline Anse à la Gourde middle & Guadeloupe & 117 & 16 & 26.9 & 12 & 40.0 \\
\hline Spring Bay 3 & Saba & 166 & 16 & 37.2 & - & - \\
\hline Sugar Mill & Long Island & 0 & 59 & 37.8 & 43 & 40.2 \\
\hline Kelbey's Ridge 2 & Saba & 166 & 16 & 59.3 & 16 & 59.3 \\
\hline
\end{tabular}

Table 6.12. Long Island flint flakes: Amount $(\mathrm{N})$ and percentage $(\%)$ of complete flakes by site, and by size class. "flakes $>14$ " represents all artefacts with maximum dimension and width both larger than $14 \mathrm{~mm}$ and "flakes $>19$ " both larger than $19 \mathrm{~mm}$.

\section{Discussion and concluding remarks}

In the previous sections it was shown, that Long Island material was transported in unmodified form based on the cortex count data. In particular, the larger samples from a number of settlement sites provide good support for this interpretation. The fall-off analysis suggests that most of these larger samples (Morel, Trants, and Golden Rock) are situated on islands, that are located within the supply zone of the Long Island flint source. These results correlate well with the data at the Long Island flint source itself, which indicate that during the Ceramic Age systematic pre-working of cores at the source did not 


\begin{tabular}{|c|c|c|c|c|c|c|c|c|c|c|}
\hline $\begin{array}{c}\text { All complete } \\
\text { flakes }\end{array}$ & $\begin{array}{l}\text { Anse à la } \\
\text { Gourde } \\
\text { middle } \\
\mathrm{N}=16\end{array}$ & $\mathrm{~N}=135$ & Jumby Bay & Sugar Mill & Golden Rock & Spring Bay 3 & $\begin{array}{l}\text { Kelbey's } \\
\text { Ridge } 1 \\
\mathrm{~N}=19\end{array}$ & $\begin{array}{c}\text { Kelbey's } \\
\text { Ridge } 2 \\
\mathrm{~N}=29\end{array}$ & $\begin{array}{c}\text { Sandy } \\
\text { Ground } \\
\mathrm{N}=14\end{array}$ & Barnes Bay \\
\hline Scar count & $\%$ & $\%$ & $\%$ & $\%$ & $\%$ & $\%$ & $\%$ & $\%$ & $\%$ & $\%$ \\
\hline 0 & - & 0.7 & 5.2 & 11.4 & 3.3 & - & 5.3 & 3.4 & 7.1 & - \\
\hline 1 & 6.3 & 14.1 & 16.1 & 25.7 & 14.0 & 8.8 & 10.5 & 13.8 & - & 11.1 \\
\hline 2 & 31.3 & 30.4 & 24.5 & 27.1 & 17.4 & 29.4 & 26.3 & 13.8 & 50.0 & 11.1 \\
\hline 3 & 18.8 & 30.4 & 27.1 & 12.9 & 28.1 & 26.5 & 36.8 & 34.5 & 28.6 & 22.2 \\
\hline 4 & 12.5 & 16.3 & 13.5 & 8.6 & 18.2 & 17.6 & 21.0 & 31.0 & 7.1 & 22.2 \\
\hline 5 & 18.8 & 5.2 & 8.3 & 8.6 & 10.7 & 11.8 & - & - & 7.1 & 11.1 \\
\hline$\geq 6$ & 12.5 & 3.0 & 5.2 & 5.7 & 8.3 & 5.9 & - & 3.4 & - & 22.2 \\
\hline total & 100.0 & 100.0 & 100.0 & 100.0 & 100.0 & 100.0 & 100.0 & 100.0 & 100.0 & 100.0 \\
\hline $\begin{array}{c}\text { Complete flakes }> \\
14 \times 14\end{array}$ & $\begin{array}{l}\text { sample } \\
\text { too small }\end{array}$ & $\mathrm{N}=72$ & $\mathrm{~N}=164$ & $\mathrm{~N}=65$ & $\begin{array}{l}\text { mesh too } \\
\text { coarse }\end{array}$ & $\mathrm{N}=19$ & $\begin{array}{l}\text { sample } \\
\text { too small }\end{array}$ & $\mathrm{N}=18$ & $\begin{array}{c}\text { sample } \\
\text { too small }\end{array}$ & $\begin{array}{l}\text { sample } \\
\text { too small }\end{array}$ \\
\hline Scar count & $\%$ & $\%$ & $\%$ & $\%$ & $\%$ & $\%$ & $\%$ & $\%$ & $\%$ & $\%$ \\
\hline 0 & - & 1.4 & 6.1 & 10.8 & - & - & - & - & - & - \\
\hline 1 & - & 13.9 & 18.3 & 26.2 & - & 10.5 & - & 16.7 & - & - \\
\hline 2 & - & 23.6 & 24.4 & 26.2 & - & 21.1 & - & 11.1 & - & - \\
\hline 3 & - & 27.8 & 22.6 & 12.3 & - & 26.3 & - & 38.9 & - & - \\
\hline 4 & - & 22.2 & 12.8 & 9.2 & - & 15.8 & - & 27.8 & - & - \\
\hline 5 & - & 5.6 & 9.8 & 9.2 & - & 21.1 & - & - & - & - \\
\hline$\geq 6$ & - & 5.6 & 6.1 & 6.1 & - & 5.3 & - & 5.3 & - & - \\
\hline total & - & 100.0 & 100.0 & 100.0 & - & 100.0 & - & 100.0 & - & - \\
\hline $\begin{array}{c}\text { Complete flakes > } \\
\text { 19x19 }\end{array}$ & $\begin{array}{l}\text { sample } \\
\text { too small }\end{array}$ & $\mathrm{N}=37$ & $\mathrm{~N}=121$ & $\mathrm{~N}=49$ & $\mathrm{~N}=79$ & $\begin{array}{l}\text { sample } \\
\text { too small }\end{array}$ & $\begin{array}{l}\text { sample } \\
\text { too small }\end{array}$ & $\begin{array}{l}\text { sample } \\
\text { too small }\end{array}$ & $\begin{array}{l}\text { sample } \\
\text { too small }\end{array}$ & $\begin{array}{l}\text { sample } \\
\text { too small }\end{array}$ \\
\hline Scar count & $\%$ & $\%$ & $\%$ & $\%$ & $\%$ & $\%$ & $\%$ & $\%$ & $\%$ & $\%$ \\
\hline 0 & - & - & 6.6 & 10.2 & 5.1 & - & - & - & - & - \\
\hline 1 & - & 8.1 & 18.2 & 28.6 & 13.9 & - & - & - & - & - \\
\hline 2 & - & 18.9 & 19.0 & 22.4 & 13.9 & - & - & - & - & - \\
\hline 3 & - & 27.0 & 22.3 & 10.2 & 24.1 & - & - & - & - & - \\
\hline 4 & - & 32.4 & 14.9 & 12.2 & 24.1 & - & - & - & - & - \\
\hline 5 & - & 8.1 & 12.4 & 10.2 & 11.4 & - & - & - & - & - \\
\hline$\geq 6$ & - & 5.4 & 6.6 & 12.2 & 7.6 & - & - & - & - & - \\
\hline total & - & 100.0 & 100.0 & 100.0 & 100.0 & - & - & - & - & - \\
\hline
\end{tabular}

Table 6.13. Long Island flint flakes: Percentage of complete flakes by site and by scar count, tabulated for different size classes.

occur. So, people were visiting the source and collected cobbles, then, which they immediately transported to their villages (unlike the evidence for Preceramic Age use of Long Island).

The Ceramic Age supply zone basically can be positioned in the Saba - (northern) Guadeloupe area for all of the different phases. This zone is only more restricted to the Nevis - (northern) Guadeloupe area during the earliest phase, the Early Ceramic A. This more restricted zone must be largely ascribed to a lower site density within the northern Lesser Antilles, with small islands such as Saba and St. Eustatius being uninhabited at this time.

Outside this zone the number of Long Island artefacts becomes low, hindering clear insight into on-site reduction. Only the Anse des Pères and the Sandy Ground sites produced relatively large samples, and cortex data for these sites also suggest the arrival of unmodified material. As these sites were beyond the supply zone, this suggests that unmodified material was not only collected by people having direct access to the source in these cases, but that they exchanged it with neighbouring communities.

On the other hand, the technological analysis of samples from the Cocoyer (Marie Galante) and Barnes Bay (Anguilla) sites shows that the percentage of cortical flakes is lower and cores are absent. This either suggests the arrival of flakes or the transport of fully worked cores, which were reduced at the site and transported or exchanged further on. A similar situation exists for the Spring Bay 3 site on Saba as well. Considering the short-term occupation at this site (Hoogland 1996), the second possibility of carrying cores to this campsite, producing flakes when needed, and taking what was left of the core to a new site, is plausible. Many of the samples from the more distant sites are too small to discriminate between the arrival of unworked or pre-worked material. In many cases local reduction could be identified, suggesting that cores, rather than finished flake tools were entering, the settlements. 


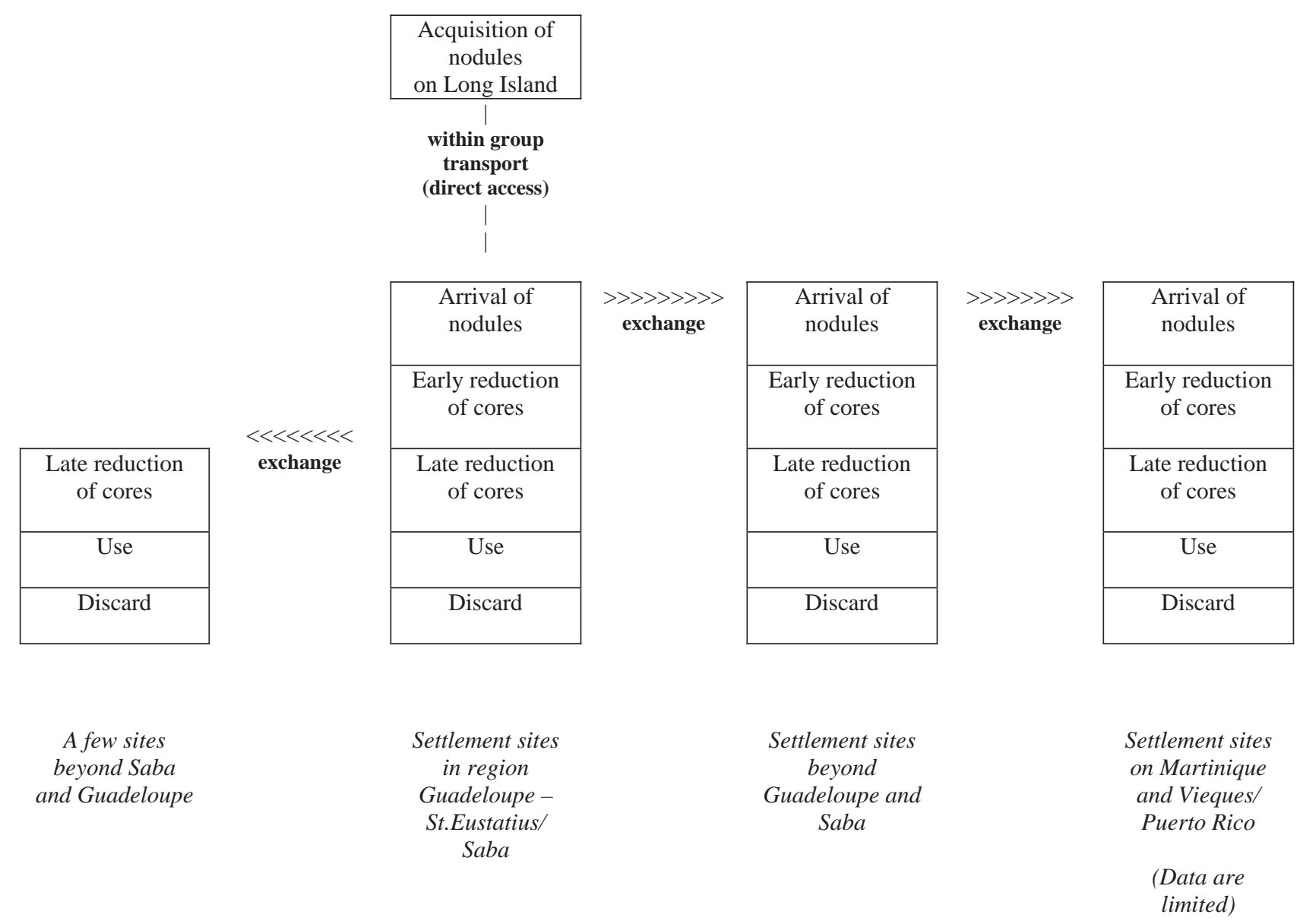

Figure 6.8. Long Island flint reduction, transport and exchange sequence during the Ceramic Age.

The Early Ceramic A and B phases produced the strongest evidence of direct procurement by communities within the supply zone. The later two Late Ceramic phases yielded clear evidence of settlement activities on Long Island itself, likely of a short-term nature. These occupation activities suggest more direct control over the Long Island flint source by communities inhabiting the northern region of Antigua. This means that direct procurement by other villages situated in the supply zone might have been prohibited then, and that these villages needed to exchange with the controlling community. Although this more limited access to the Long Island flint is not clearly visible in raw material abundances at sites within the supply zone, the generally higher efficiency ratios when compared to the Early Ceramic B phase (Golden Rock and Kelbey's Ridge 1) and reduced distribution beyond the supply zone may have been a result.

In particular, during the Early Ceramic phases the exponential decrease of Long Island flint abundance beyond the supply zone strongly supports a down-the-line-mode of exchange. During these phases, the area of distribution included the island of Puerto Rico to the west and the island of Martinique to the south. The later two Late Ceramic phases exhibit a more restricted distribution, flint not being exchanged beyond the Anegada Passage in the west and not reaching Martinique any more in the south.

Returning to the models as outlined by de Grooth (1991, 170-1 fig.9-10; see Chapter 3), the Long Island flint reduction, transport, and exchange trajectory corresponds with model D1 in general (figure 6.8). Flint knappers living in villages within the supply zone visited the Long Island flint source where they collected raw flint nodules (Early Ceramic Age) or had direct contact with the community controlling the source (Late Ceramic Age). They reduced some of the unmodified nodules for their own purposes there and exchanged the remainder with neighbouring villages. In some instance, 
such as Cocoyer, model D2 better describes the situation. Pre-worked material was probably exchanged, instead of nonmodified material. In case of Spring Bay 3, model F0 may be an option as well. Considering the short-term occupation of the site, the transport of pre-worked material may not have involved exchange, but can be explained by the movement of the same people to different sites, where they stayed for temporary periods.

\subsubsection{St. Martin greenstone}

\section{Introduction}

A second widely used and distributed material within the northern Lesser Antilles and beyond is a fine-grained, grey-green mudstone originating from St. Martin. As discussed in Chapter 2 this material can be found in the bedded geological deposits belonging to the Point Blanche Formation. Outcrops are numerous on the island, and still need to be investigated in detail. It has become clear from two inspected rock sections that the bedded sequence consists of many layers, often not exceeding $20 \mathrm{~cm}$ in thickness. These layers exhibit a wide variety of rock types, from true igneous rock to almost pure sediments with a minor volcano-clastic component. From these different varieties the Amerindian inhabitants chose specific fine-grained ones, generally grey-green in colour, which produced a conchoidal fracture similar to cherts and flints. In essence, these varieties are made up by a fine-grained matrix, in which a mixture of re-crystallised material with mud occurs, consisting of fine carbonate and clay minerals.

Within this fine-grained group some variation exists, however, as the petrological analysis of eight artefacts in this study pointed out. This variation mainly relates to the occurrence of igneous minerals and the amount of mud versus recrystallised material. It became also evident that true igneous rock was not present among the analysed samples.

Despite this minor internal variation, this rock can easily be recognised and distinguished as a result of a very characteristic weathering, which turns the outer texture into calcite, giving the rock a chalky and corroded appearance. Very wet conditions can remove this outer surface, thereby exposing non-weathered grey-green rock again. Furthermore, in some cases the rock material that was flaked consisted of layers that exhibited differentiated weathering, leaving parts less weathered or non-weathered, still preserving some of its original texture. The presence of this characteristic carbonate corroded outer surface distinguishes this rock type from other stone materials encountered among artefact samples from PreColumbian sites in the region. It must be specifically related to a chemical alteration of this grey-green rock, and is not the result of some general process in Caribbean soils through which carbonate is precipitated on rocks, which is common in some cases (Gardner et al. 2001).

Before proceeding to presentation and discussion of the distribution of this particular material, several points need to be first specified. In this work I ascribe the use of this mudstone material mainly to the Amerindian manufacture of axes, although there are indications that it was occasionally used for other purposes. In particular, this accounts for the sites where axe production was identified. These sites exhibit more variability among core artefacts. For example, the Anse des Pères site has yielded one possible pestle and a few round artefacts, that exhibit used faces, in addition to many axe preforms and axe fragments (Knippenberg 1999c, 99 fig. 8.8h,i,j). ${ }^{8}$ Although the rounded artefacts in particular point to differential use of the material, the high number of axe related core artefacts clearly indicates that the making of axes was the central purpose behind modifying this particular material. Furthermore, the distribution of axes, restricted only to the surrounding islands, shows that this stone type was primarily valued as a raw material for making these tools, and that the other core tools were only formed in rare exceptions.

Considering the cherty nature of this rock type, making it easy to produce sharp edges, it is theoretically possible that specific flakes within the debitage were used as tools for cutting or scraping, thereby operating as alternatives for flint and other fine-grained siliceous rocks. All available evidence so far, however, suggests that this was not the case. In the first place greenstone debitage is technologically and morphologically different from the flint and other flake tool related samples of debitage. For example, reduction of mudstone flakes to obtain smaller flake did not occur, as well as edge modification on flakes. This suggests that it did not function as a useful alternative to the true flake tool related materials and that, if used, it might have only been utilized to perform a restricted set of tasks, which were usually executed using these other lithic flake tools. In the second place, use-wear has not been identified on any of the non-weathered flakes. However, it should be

\footnotetext{
${ }^{8}$ It should be noted that apart from its general function as woodworking tool, many examples of axes have been found that were re-used as hammer-stones or active abrading stones, similar to the utilization of water-worn pebbles.
} 
remembered that most of the samples have undergone significant degrees of alteration, making it impossible to identify traces of use-wear. Considering these issues it is assumed that St. Martin greenstone was not used as raw material for producing flake tools and was instead solely used to manufacture axes. Given the limited data that can be obtained from the use-wear analysis of this material, future work should focus on more experimental studies. These studies should help clarify whether this material is suitable for producing flake tools, anyway. The high carbonate content, as shown by the chemical analyses (see Chapter 2), casts serious doubts about whether this material can be used as an efficient material for cutting or scraping purposes.

A considerable draw back related to the study of this material is the absence of knowledge about exploitation sites and related reduction strategies at the source. Contrary to the Long Island flint, for which the actual source has been identified, such specific location(s) is (are) still unknown for the greenstone. As already mentioned, the Pointe Blanche Formation surfaces at different places on St. Martin (see figure 2.30). Good exposures can be found at Little Bay, Point Blanche, Devils Cupper, and Cole Bay, but it is likely that the material can be obtained elsewhere on St. Martin as well. However, two past fieldsurveys on the St. Martin (Haviser 1988; Stouvenot 1999) have not located any exploitation sites. This may be the result of either incomplete coverage of the island during these surveys ${ }^{9}$, or it may suggest an absence of reduction at the exploitation sites, similar to the absence of exploitation debris at Long Island dated to the Ceramic Age (see Chapter 4).

At present, the evidence of greenstone production at settlement sites suggests that they represent the primary places of lithic reduction for this material, considering the recovery of high amounts of debitage at these habitation places. If working at the source occurred, it would have involved only minor pre-working at most, likely related to reducing large blocks to sizeable and transportable pieces.

The limited number of non-weathered artefacts bearing outer surface reveals that secondary material was collected from inland surfaces, as well as local beaches. A more detailed statistical analysis using cortex count as an indicator for the state of reduction at the particular places is impeded by the weathered nature of the artefacts and the less clear formation of typical cortical surfaces, compared to flints, for example. This makes identification of original outer cortical surfaces and counting of its coverage less reliable.

One of the other most striking features of this material is its total absence in any Preceramic Age contexts. Archaeological work at the Norman Estate site on St. Martin did not produce any of this greenstone among a sample of over 250 Preceramic Age artefacts (Knippenberg 1999d), whereas at the Ceramic Age sites on the island, such as Hope Estate and Anse des Pères, this material accounts for around 50\% of the total assemblage (Haviser 1999; Knippenberg 1999c). This may relate to the fact that during Ceramic Age times this grey-green rock was exclusively used for making axes, while stone axes during the Preceramic Age are rare, as shell was mainly used to make this type of tool (Brokke 1999b). Furthermore, the reported Preceramic Age stone axes, all made of igneous rock varieties, are in sharp contrast to the Ceramic Age petaloid celts, both in shape and size (Barbotin 1973a, b; Harris 1983). Therefore, scholars doubt whether these actually functioned as tools, considering their large sizes and blunt edges.

Another characteristic, that may explain greenstone occurrence solely within Ceramic Age contexts, relates to its green colour. For example, Boomert (1987) pointed out that the colour green played a special role in the cosmology of horticulturalists in the Amazon, as it was associated with female fertility. This importance was expressed in the making of pendants out of dense green rock, commonly encountered among the indigenous cultures of the Amazon. It is also known from Caribbean archaeological contexts dating to the Ceramic Age, where they are a recurrent feature (Cody 1991, 1993; Haviser 1999; Watters \& Scaglion 1994). Although Boomert does not pay particular attention to the use of green rock as raw material for making axes, its frequent occurrence among Ceramic Age archaeological assemblages in the Antilles is striking (Roobol \& Lee 1976; see Chapter 5), and thus suggests a very deliberate choice. In this respect, the association of axes as the primary tool used to clear agricultural fields, women being the most important persons working these fields, and the fields' "fertility" being of crucial importance to the community, may have been of significance. ${ }^{10}$ If this had been the case, it may also explain the absence of greenstone axes during the Preceramic Age, when agriculture did not play a role, since the people

${ }^{9}$ Haviser (1998) explicitly stated in his survey report that he field-walked areas that would be suitable for habitation, thereby neglecting other types of behaviour such as, for example, exploitation of stone sources. Despite this bias, he surveyed the Little Bay area, a likely place of greenstone exploitation as it is one of the good exposures of this material. He did not find any greenstone workshop sites, there. Stouvenot (1999), working for the French Government, only incorporated the French part of the island in his survey.

${ }^{10}$ Crock (2000) hypothesizes that the petaloid celts may have functioned as digging implements as well, like hoes. 
were nomadic foragers at the time.

We can further elaborate on the notion that the appearance of this type of rock had been of importance by incorporating the process of weathering as well. This distinguishes this stone from other greenstone varieties in the region. The relatively fast rate ${ }^{11}$ needed to turn it into a crumbly, chalky material makes it very likely that the indigenous peoples were familiar with the weathering process. In this respect, this change may have somehow given the material and the objects made of it additional value, as they might be viewed as "living" objects. Starting as "fertile" green specimens they eventually turn into "old" or "dead" corroded-crumbly rock. As such, they can be considered a metaphor of life. The corrosion in this respect is potentially very meaningful to its users. Hoogland (personal communication 2002) pointed out that within the cosmology of the Amerindians of the Greater Antilles the distinction between a dead but not decayed body and a decayed body is very significant, since the decay represents the departing of the dead person's spirit from the body, and therefore signifies the departure of this person from the world of the living and the entering into the world of the spirits. In this respect, the recovery of an intentionally deposited pelican decorated vessel on La Désirade containing two corroded axes (De Waal 2006; Hofman et al. 2004, 177 fig. 12) may support this relation between greenstone weathering and ideological significance.

In the following sections, the production and distribution of this material will be discussed for four consecutive phases, as was done for the Long Island flint. Unlike chert and flint materials used for making flake tools, the greenstone in many cases is very rare, biasing results when small sample sizes are represented. In many cases, therefore, its absence among analysed samples does not necessarily indicate absence of greenstone usage at that specific site. To partly overcome this sample problem, I collected data from other lithic samples I did not analyse myself. ${ }^{12}$ This enabled me to acquire a broader knowledge about the use of this material within different micro-regions in the study area. Considering this sample-size bias, I have not included fall-off analysis in this case, nor any comparison of size dimensions in the discussion of its distribution.

\section{Transport and reduction sequence}

Production

In case of the greenstone, inter-site comparison of material reduction sequences has produced much more clear-cut results than was found for the Long Island flint. In contrast to the Long Island flake tool material, the greenstone from St. Martin, was only worked at a restricted number of sites situated in settings near the source. Table 6.14 (see also figures 6.9-6.12) lists all of the sites, that yielded greenstone production remains. In general, such remains consist of large quantities of flakes, preforms, numerous unidentifiable core fragments, and fragments of axes, both the edges as well as the butts. ${ }^{13}$

The large size of the unidentifiable fragment category is a very characteristic feature of this production. In most cases, these pieces are relatively large fragments that were removed or broken from preforms, in different stages of the reduction sequence. Unlike biface and axe production sequences reported from other parts in the world, greenstone reduction seemed to follow a less standardized sequence (see Jones 1984 for a comparable example). From the analysis of preforms, the reduction in many cases only involved a few bifacial flake removals after it was reduced to a preferred size. In some cases, large flakes were also used to manufacture axes, resembling a case reported for New Guinea adze making (Jones 1984). To what degree raw material size influenced the size of the final tools cannot be answered with certainty yet due to the fact that exploited outcrops and the system of quarrying are unknown. Chauviere (1998) notes in his report on the lithic material from Hope Estate that this raw material probably included small blocks. Inspected parts of the Pointe Blanche Formation revealed that greenstone beds occur in varying sizes, and therefore the possibility exists that larger blocks were obtained as well. This would not restrict tool size if primary outcrops were quarried. In case of exploitation of secondary surface scatters, the size of cobbles might well have been more restricted.

\footnotetext{
11 François Petit, local citizen of St. Martin, directed a stone quarry company, that exploited parts of the Pointe Blanche Formation at Hope Hill. During the 1993 research on St. Martin, he told a team from Leiden University, working at Hope Estate and other sites, that certain beds within this formation were unsuitable as construction material because of its inclination to weather. He saw house walls, where this material was used that began to crumble due to its expansion within a few years after construction.

12 For this purpose, the reports and theses relating to archaeological research on St. Martin and Anguilla were consulted, as they pay particular attention to this rock type (Crock 1999, 2000; Crock \& Petersen 1999; Haviser 1987, 1988, 1991, 1993, 1999). Furthermore, I acquired information from colleagues who are familiar with the material. Reniel Rodríguez Ramos provided me with data from the following sites on Puerto Rico: La Mina, Paso del Indio, La Hueca, and Punta Candelero (see for latter two sites also Rodríguez Ramos 2001). Christy De Mille informed me about Elliot's on Antigua and Mark Nokkert informed me about the Coconut Walk and Hichman's sites on Nevis.

13 The refuse context from which most studied lithic samples originates is clearly evidenced by the absence of complete axes.
} 


\begin{tabular}{|c|c|c|c|c|}
\hline Site & Island & $\begin{array}{l}\text { Distance to } \\
\text { St. Martin }\end{array}$ & Chronometric date & Greenstone \\
\hline $\begin{array}{l}\text { Early Ceramic A } \\
\text { Hope Estate }\end{array}$ & St. Martin & $0 \mathrm{~km}$ & $\begin{array}{l}\text { cal } 400-50 \text { BC (early) } \\
\text { cal AD } 255-650 \text { (late) }\end{array}$ & $\begin{array}{l}\text { production } \\
\text { production }\end{array}$ \\
\hline $\begin{array}{l}\text { Early Ceramic F } \\
\text { Anse des Pères } \\
\text { Rendezvous Bay } \\
\text { Sandy Ground } \\
\text { Golden Rock } \\
\text { Kelbey' Ridge } 1 \\
\text { Sugar Factory Pier }\end{array}$ & $\begin{array}{l}\text { St. Martin } \\
\text { Anguilla } \\
\text { Anguilla } \\
\text { St. Eustaius } \\
\text { Saba } \\
\text { St. Kitts }\end{array}$ & $\begin{array}{l}0 \mathrm{~km} \\
9 \mathrm{~km} \\
10 \mathrm{~km} \\
55 \mathrm{~km} \\
44 \mathrm{~km} \\
85 \mathrm{~km}\end{array}$ & $\begin{array}{l}\text { cal AD } 750-950 \\
\text { AD } 400-950 \\
\text { cal AD } 650-1035 \\
\text { cal AD } 450-850 \\
\text { cal AD } 655-880 \\
\text { no chronometric dates }\end{array}$ & $\begin{array}{l}\text { production } \\
\text { production(?) } \\
\text { production } \\
\text { production } \\
\text { possible production } \\
\text { possible production }\end{array}$ \\
\hline $\begin{array}{l}\text { Late Ceramic A } \\
\text { Cupecoy Bay } \\
\text { Rendezvous Bay } \\
\text { Sandy Ground } \\
\text { Barnes Bay } \\
\text { Sandy Hill } \\
\text { Godet } \\
\text { Smoke Alley } \\
\text { Spring Bay } 3\end{array}$ & $\begin{array}{l}\text { St. Martin } \\
\text { Anguilla } \\
\text { Anguilla } \\
\text { Anguilla } \\
\text { Anguilla } \\
\text { St. Eustaius } \\
\text { St. Eustaius } \\
\text { Saba }\end{array}$ & $\begin{array}{l}1 \mathrm{~km} \\
9 \mathrm{~km} \\
10 \mathrm{~km} \\
11 \mathrm{~km} \\
10 \mathrm{~km} \\
62 \mathrm{~km} \\
62 \mathrm{~km} \\
44 \mathrm{~km}\end{array}$ & $\begin{array}{l}\text { aprox. AD } 1100-1300 \\
\text { AD } 400-950 \\
\text { cal AD } 650-1035 \\
\text { cal AD } 775-1295 \\
\text { cal AD } 1000-1350 \\
\text { no chronometric dates } \\
\text { cal AD } 1000-1160 \\
\text { cal AD } 1000-1200\end{array}$ & $\begin{array}{l}\text { production } \\
\text { production } \\
\text { production } \\
\text { production } \\
\text { production } \\
\text { production } \\
\text { production } \\
\text { possible production }\end{array}$ \\
\hline $\begin{array}{l}\text { Late Ceramic B } \\
\text { Shoal Bay East } \\
\text { Kelbey's Ridge } 2\end{array}$ & $\begin{array}{l}\text { Anguilla } \\
\text { Saba }\end{array}$ & $\begin{array}{l}14 \mathrm{~km} \\
44 \mathrm{~km}\end{array}$ & $\begin{array}{l}\text { cal AD } 1005-1640 \\
\text { cal AD } 1285-1400\end{array}$ & $\begin{array}{l}\text { production } \\
\text { possible production }\end{array}$ \\
\hline
\end{tabular}

Table 6.14. Greenstone axe production sites by period by island.

Diachronic changes are present with regard to the places where production took place (table 6.14). Furthermore, the number of production sites increased significantly from the Early Ceramic B phase onwards. During the Early Ceramic A phase, the only site that yielded clear evidence of production is Hope Estate, situated in the inner part of the island of St. Martin. The production debris and related products form a very significant part of the total lithic artefact inventory. About axe production, Haviser clearly points out that the subsequent stages of the reduction sequence from initial block reduction to final tool finishing all occurred at the site (Haviser 1999; see Chauviere 1998). Therefore, he thinks that this material probably arrived in an un-worked, natural state at Hope Estate, and probably originated somewhere from within or near the site surroundings, as the Pointe Blanche Formation is the underlying bedrock formation in this part of St. Martin. Apart from Hope Estate, no other sites with remains of greenstone production are reported for this early phase. Most of the islands surrounding St. Martin such as Anguilla, St. Eustatius, and Saba were not populated during this early portion of the Ceramic Age, and one of the nearest sites known, Hichman's on Nevis, only yielded finished products.

This localized production region extends itself during the later Early Ceramic B phase. Production has been identified for this phase at Anse des Pères (St. Martin), Golden Rock (St. Eustatius), the early phases of occupation at Sandy Ground and Rendezvous Bay (Anguilla) (Crock \& Petersen 1999), and Sugar Factory Pier (St. Kitts) (Walker 1980). In particular, the first two sites produced a significant amount of debris. Different stages of the production sequence, from initially worked preforms to finished items, are represented at these sites. Unworked material, however, is lacking. This does not necessarily suggest that pre-worked material arrived at these sites. Considering the distance of St. Eustatius from St. Martin, some effort was needed to obtain the material, making it likely that material arriving at the site would be as fully used. Some material still possessed outer surface cortex remains, which was worn to some degree, suggesting exploitation of secondary surface scatters. These scatters were probably not situated in the vicinity of streambeds or beaches because waterworn surfaces are scarce.

For the Anguilla sites, the identification of axe production in the Early Ceramic B is only based on artefacts associated with the early occupation deposits of the Sandy Ground site (Crock 2000; Chapter 5). For Rendezvous Bay such an association is not reported, but the common occurrence of greenstone at this site (Crock \& Petersen 1999), nonetheless, makes it likely that it was utilized throughout the entire site occupation. In case of Sugar Factory Pier, Walker (1980), at that time not familiar with the source on St. Martin, mentions the occurrence of flakes, core fragments, and axe parts made of a 


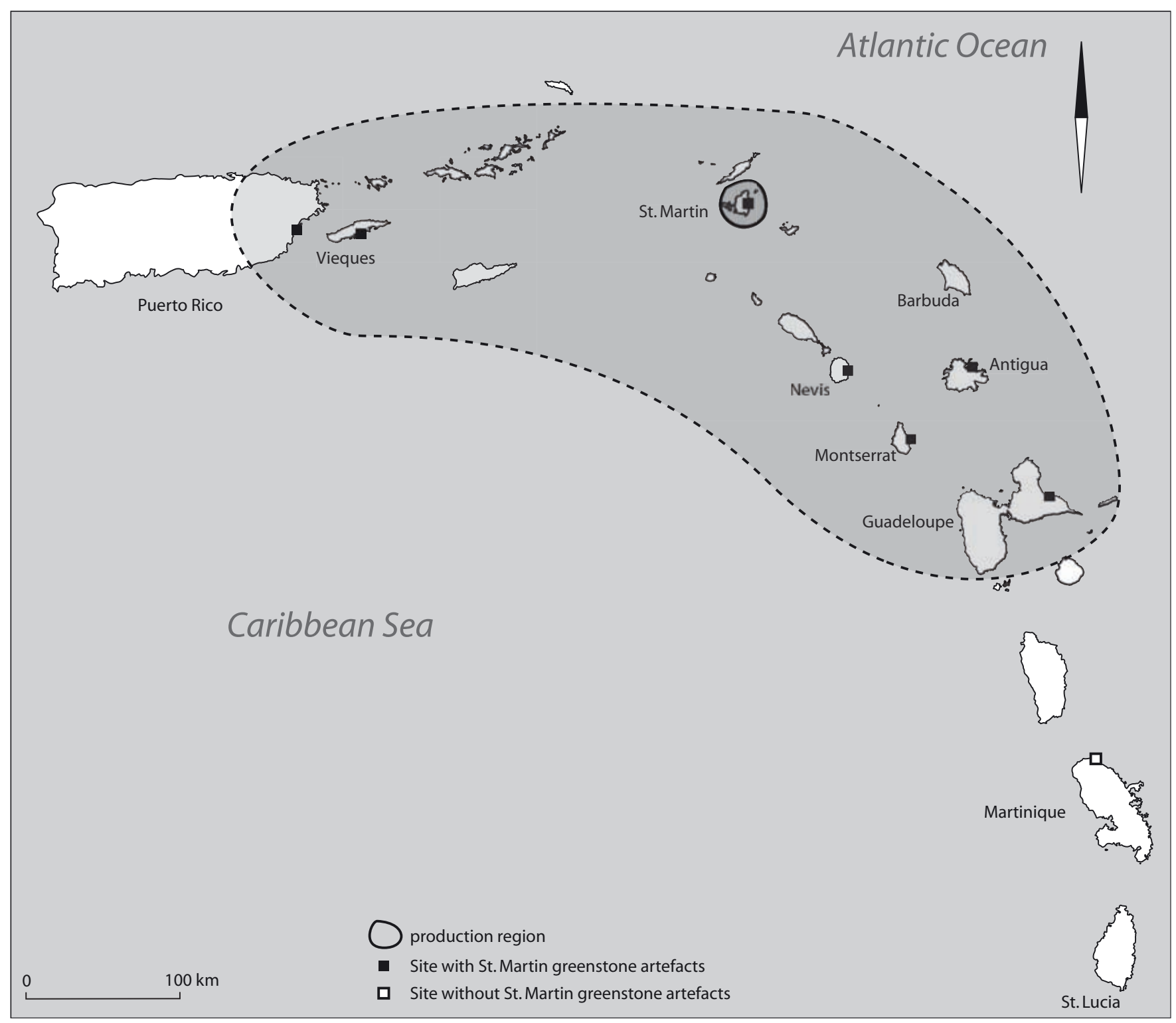

Figure 6.9. Distribution of St. Martin greenstone axes and the location of the production area during the Early Ceramic A phase (400 BC - AD 400).

corroded greenstone. Walker concluded that axes were produced at Sugar Factory Pier made of this corroded stone, although it is not clear for every artefact whether it actually is the greenstone from St. Martin. From his descriptive data, the flake to core ratio appears to be lower than among the Anse des Pères and Golden Rock sites, suggesting that already reduced material entered this site.

Considering the significant numbers of artefacts found at sites within this region, communities on the islands surrounding St. Martin must have had direct access to natural occurrences of the greenstone. People originating from various directions probably exploited different outcrops, since material can be found on many parts of the island.

With the advent of the first post-Saladoid pottery styles, the island of Anguilla, in particular, displayed a marked increase in the number and size of settlement sites (Crock 2000). The available evidence thus far suggests that the inferred population increase predominantly occurred on the island of Anguilla within the near micro-region, and apparently relates to a change in 


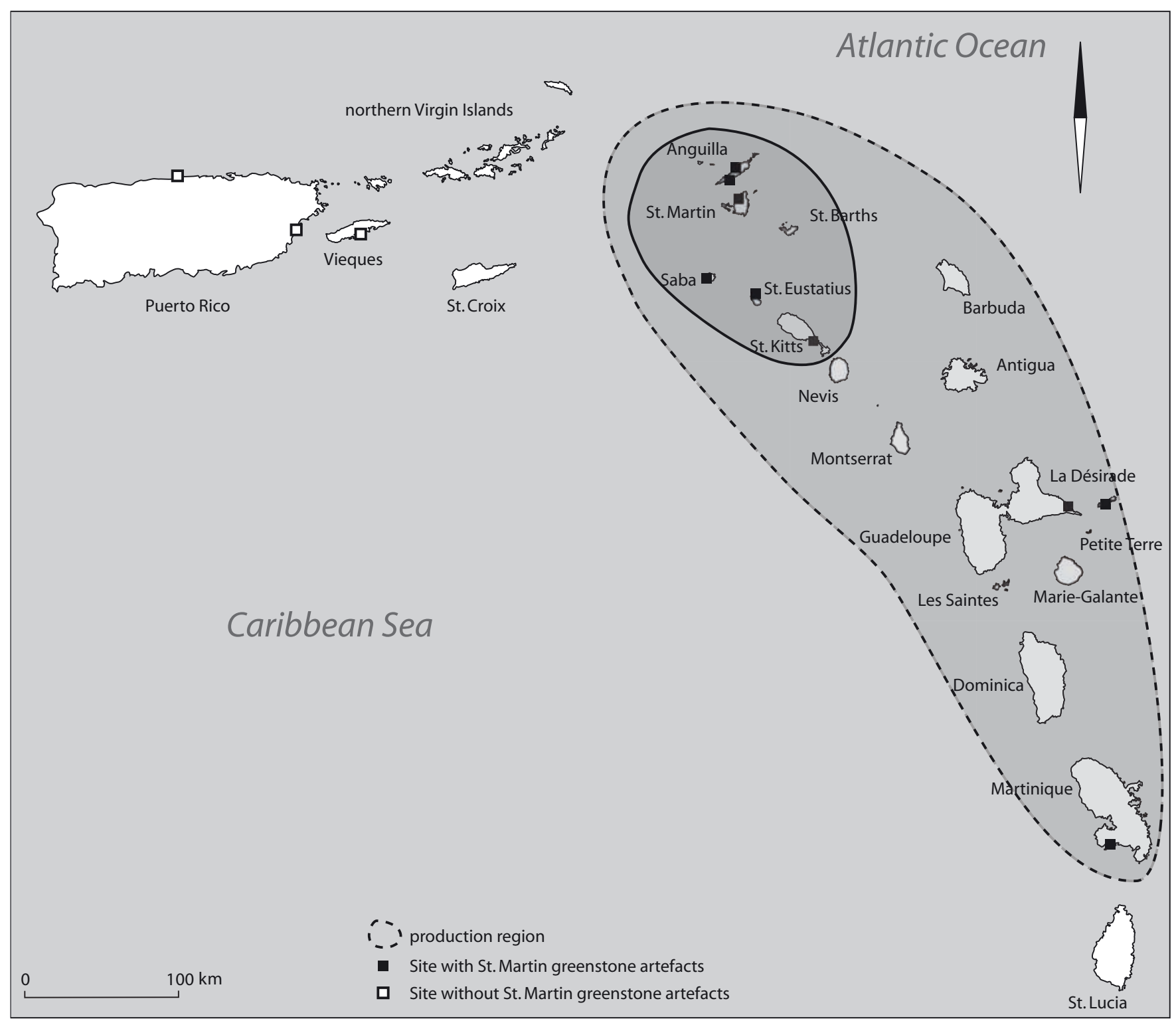

Figure 6.10. Distribution of St. Martin greenstone axes and the location of the production area during the Early Ceramic B phase (AD 400 - 850).

habitation preference towards the low lying carbonate islands. Although habitation sites are still reported on St. Martin, their sizes and probably their number are smaller than on Anguilla (Crock 2000; Haviser 1988, 1991; Stouvenot 1999). Without exception, all reported sites on both islands from this phase yielded production remains of greenstone material (Crock \& Petersen 1999; Haviser 1988), clearly pointing to an overall increase in local greenstone axe manufacture. The common occurrence on Anguilla shows that the communities living there had easy and unrestricted access to the sources. Limited data from the Godet and Smoke Alley sites on St. Eustatius and Spring Bay 1b on Saba indicate that the region where axes were being produced incorporated these islands as well. Compared to Golden Rock, however, Godet and Smoke Alley yielded a lower flake to core artefact ratio, and this may suggest that pre-worked material arrived there. The recovery of exclusively finished items at Coconut Walk on Nevis indicates that this island was not included within the area of production. Unfortunately, data from St. Kitts are absent. This latter island probably fell outside the production region as well, if notion is taken of the data from St. Eustatius, that suggest that access became more limited. 


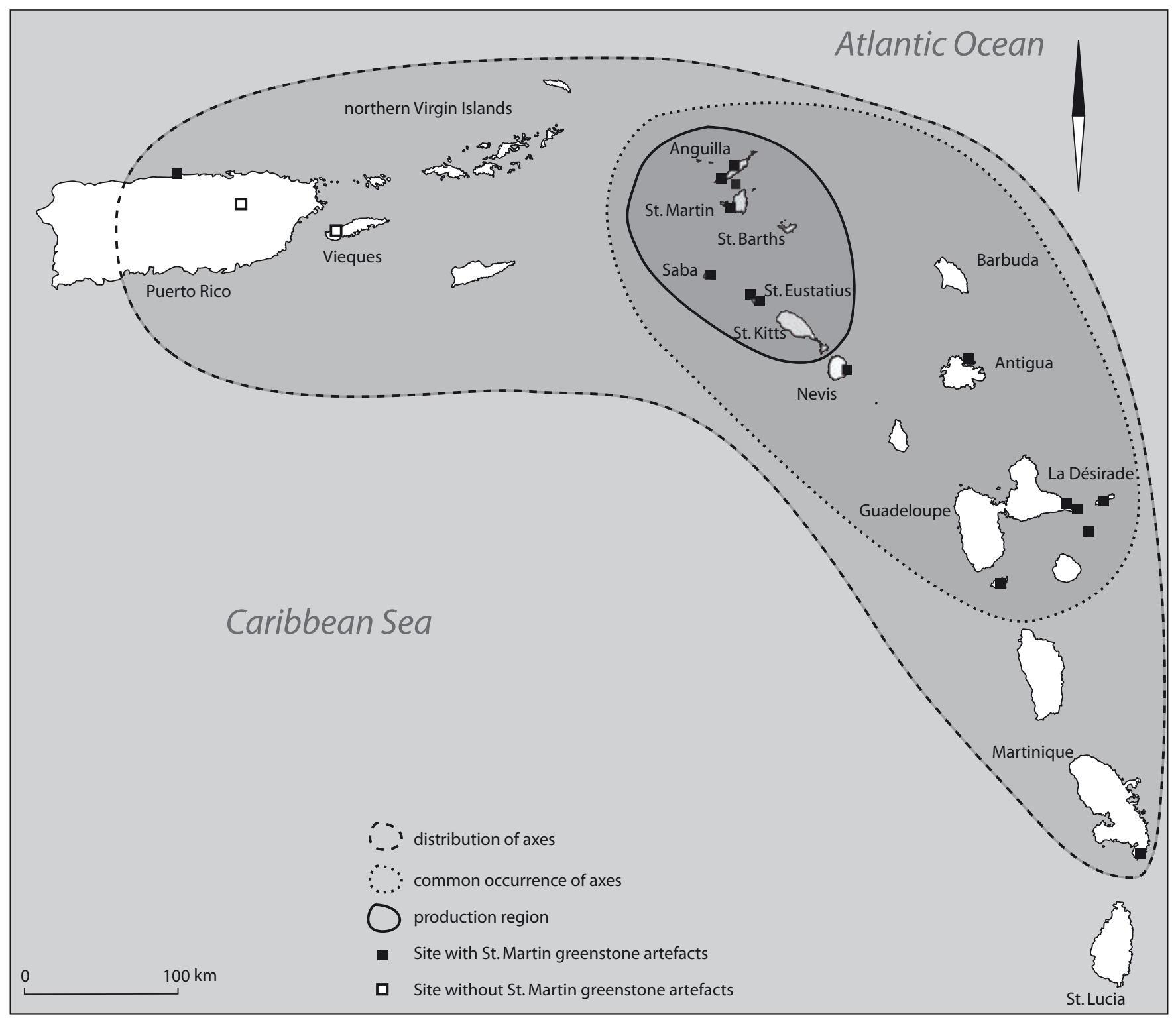

Figure 6.11. Distribution of St. Martin greenstone axes and the location of the production area during the Late Ceramic A phase (AD 850 1250).

During the latest phase of Pre-Columbian occupation, Anguilla remained a central place for greenstone celt production. For example, late occupation at Shoal Bay East yielded relatively high amounts of production debris. On St. Martin, the Baie Rouge site yielded late greenstone production as well. Unfortunately, late data on greenstone production from the surrounding islands are not presently available.

\section{Distribution}

The sites mentioned above markedly differ from the many sites found in the broader region with respect to the abundance of greenstone material and type of artefacts present. In contrast to the "production" sites, the other sites are characterised by an absence of material that can be associated with manufacture such as flakes, preforms, and unidentifiable core fragments so commonly encountered in the fabrication centres. These other sites only yielded complete ground axes, fragments of ground 


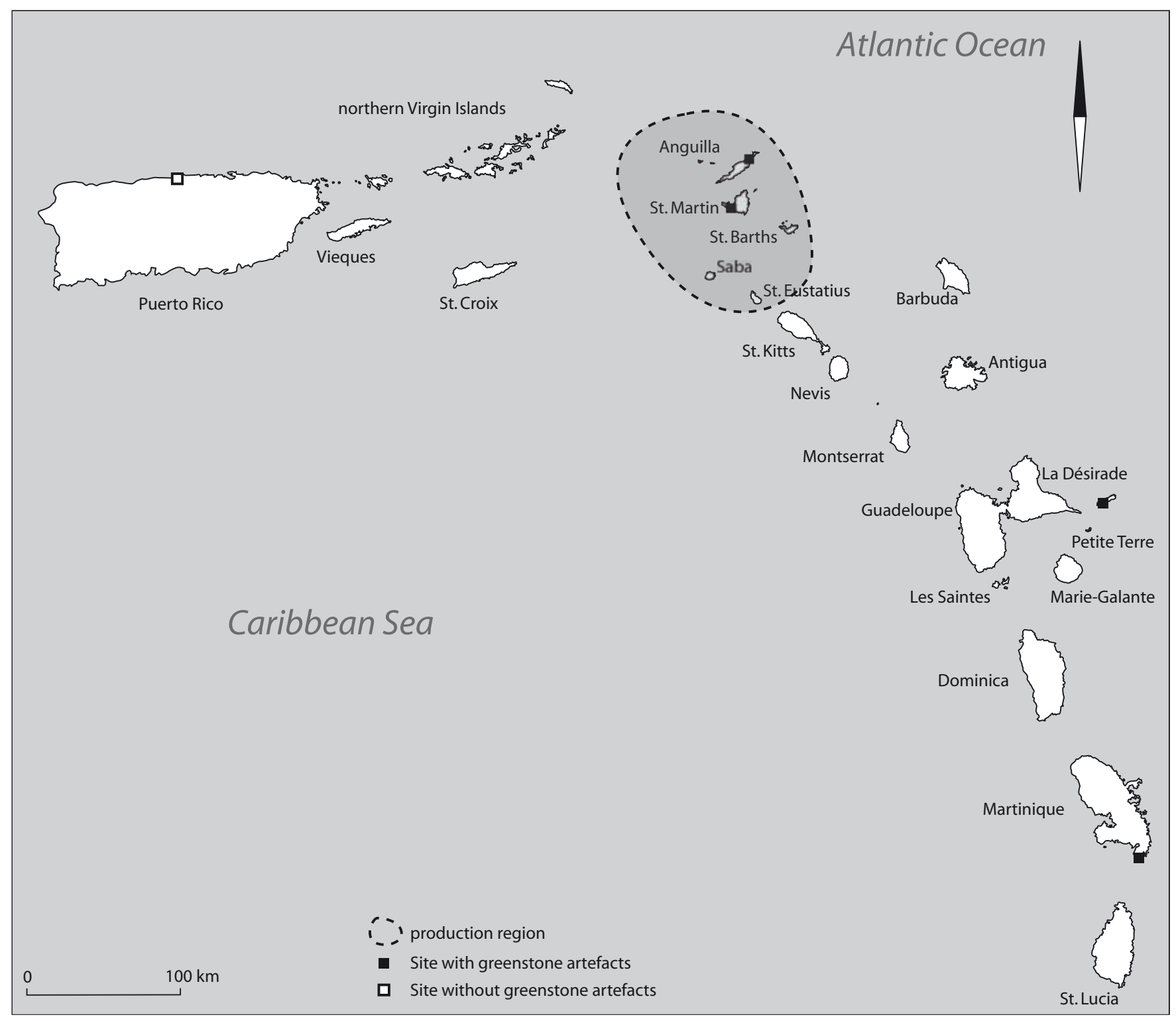

Figure 6.12. Distribution of St. Martin greenstone axes and the location of the production area during the Late Ceramic B phase (AD 1250 - 1492).

ones, or edge flakes. In some cases a very small number of other flakes was encountered as well, e.g. at Trants. These flakes do not point to actual manufacture, but rather should be related to intensive use (accidental spalls) and possible re-sharpening of axes on site, as they often exhibit ground dorsal surfaces. This absence of production related debitage indicates that the greenstone material arrived at these sites in the form of finished axes.

In theory the arrival of flaked preforms, that only needed to be ground may be considered an option as well. In the New Guinea Highlands, for example, axe preforms were commonly being exchanged (Burton 1984, 1989). The extensive evidence of production at settlement sites surrounding the source, where axes were being fully finished, combined with the absence of data on production activities at the sources itself, indicate that the production centres are the only likely candidates from which finished greenstone core tools were obtained. This variability in production and import of finished products, points to the existence of exchange relationships, in contrast to the Long Island flint material for which this is more difficult to prove. 


\begin{tabular}{|c|c|c|c|c|}
\hline Site & Island & $\begin{array}{l}\text { Distance to } \\
\text { St. Martin }\end{array}$ & Chronometric date & Greenstone \\
\hline \multicolumn{5}{|c|}{ Early Ceramic A } \\
\hline Punta Candelero & Puerto Rico & $284 \mathrm{~km}$ & cal $100 \mathrm{BC}-\mathrm{AD} 50$ & finished items \\
\hline Sorcé & Vieques & $245 \mathrm{~km}$ & cal AD $136-650$ & finished items \\
\hline Hichman's & Nevis & $110 \mathrm{~km}$ & cal $5 \mathrm{BC}-\mathrm{AD} 635$ & possibly finished items only \\
\hline Elliots & Antigua & 175 km & no chronometric dates & finished items \\
\hline Cocoyer & Marie-Galante & $293 \mathrm{~km}$ & no chronometric dates & absent \\
\hline Vivé & Martinique & $406 \mathrm{~km}$ & cal AD $144-440$ & absent \\
\hline \multicolumn{5}{|c|}{ Early Ceramic B } \\
\hline Paso del Indio & Puerto Rico & 318 km & AD $570-640$ & absent \\
\hline Punta Candelero & Puerto Rico & $284 \mathrm{~km}$ & cal AD $700-950$ & absent \\
\hline Anse à l’Eau & Guadeloupe & $267 \mathrm{~km}$ & no chronometric dates & absent \\
\hline \multicolumn{5}{|l|}{ Late Ceramic A } \\
\hline Paso del Indio & Puerto Rico & 318 km & cal AD $880-1385$ & finished item \\
\hline Jumby Bay & Long Island & $166 \mathrm{~km}$ & $\mathrm{cal}$ AD $1050-1250$ & finished item \\
\hline Muddy Bay & Antigua & $173 \mathrm{~km}$ & cal AD $1000-1300$ & absent \\
\hline Anse à l'Eau & Guadeloupe & $267 \mathrm{~km}$ & no chronometric dates & finished item \\
\hline Anse à la Gourde & Guadeloupe & 273 km & approx AD 1000-1200 & finished items (many) \\
\hline Escalier & La Désirade & $281 \mathrm{~km}$ & cal AD $1049-1243$ & finished item \\
\hline Du Phare & Petite Terre & $287 \mathrm{~km}$ & no chronometric dates & finished item \\
\hline Grande Anse & Les Saintes & $281 \mathrm{~km}$ & cal AD $1158-1278$ & finished items \\
\hline Anse Trabaud & Martinique & $465 \mathrm{~km}$ & no chronometric dates & finished items \\
\hline \multicolumn{5}{|l|}{ Late Ceramic B } \\
\hline Paso del Indio & Puerto Rico & 318 km & approx. AD $1385-1500$ & absent \\
\hline
\end{tabular}

Table 6.15. Greenstone axe distribution by period by site by island.

Comparing the distribution of axes by phase reveals subtle changes over time. Within the Early Ceramic A phase, a number of sites yielded at least one or more finished items (table 6.15; figure 6.9). They include sites on Puerto Rico and Vieques such as Punta Candelero, La Hueca, and Sorcé on the western end, and sites on Nevis (Hichman's), Antigua (Elliots) and northern Guadeloupe (Morel) on the eastern side. Only the Hope Estate site functioned as a production centre at this time. This community on St. Martin may have had direct relationships with those on the Virgin Islands for which no data are available yet, and perhaps even Vieques on the eastern part of Puerto Rico, considering the low site density during this phase, with many other islands left uninhabited. This may have been the case with Hichman's on Nevis, for example. The results from the lithic analysis of the Puerto Rican and Vieques sites indicate that this material is relatively common when compared to other axe related lithic materials.

During the following phase the distribution changed and became more oriented toward the southeast (table 6.15; figure 6.10). Material has not been reported within the later occupation phase of the Punta Candelero site on Puerto Rico. Also, the Paso del Indio site, along the central north coast of Puerto Rico did not yield any relevant artefacts. Apart from the sites mentioned here where the Early Ceramic B occupation phase can be separated from other occupations, other sites such as La Mina and Martineau where such distinction is more difficult to make, did not yield greenstone either (Rodríguez Ramos, personal communication 2002). This strengthens the notion that during this phase the inhabitants of Puerto Rico and Vieques, and possibly the Virgin Islands as well, did not have or only rarely had access to these greenstone tools. The difference is especially striking in relation to its common occurrence in the earlier phase of the Punta Candelero site and the La Hueca/ Sorcé locality. 
On the other end, a small axe from Diamant is the oldest greenstone find on Martinique. As it is the only artefact made of this material from this phase, future research focussing on both phases of the Early Ceramic Age should make clear whether this marks a significant and structural change with the earlier phase, rather than being a rare occasion in which a single item made it all the way to this southern site. Closer to the source, on Guadeloupe there is no uncertainty regarding the presence of this material, since it was found both at Anse á la Gourde (Grande Terre) and Les Sables (La Désirade).

The Late Ceramic A phase, marking the advent of more localized post-Saladoid pottery styles, displays a more common occurrence of such axes within the Anguilla-Guadeloupe area (table 6.15; figure 6.11). Greenstone axes have been identified at Grande Anse (Les Saintes), Site du Phare (Petite Terre), Éscalier (La Désirade), Anse à la Gourde, Anse à l'Eau (both Grande Terre, Guadeloupe), Jumby Bay (Long Island), and Coconut Walk (Nevis). The Troumassoid 1 and 2 phases of the Anse à la Gourde site especially produced a significant number of greenstone axes and fragments, outnumbering all other axe related materials.

Beyond this region, greenstone axe occurrence is less frequent. So far, only one fragment out of 25 other stone axe pieces was identified within the Elenan Ostionoid occupation phase at Paso del Indio on Puerto Rico with other sites on this island not producing any (Rodríguez Ramos 2005, personal communication 2002.) In relation to the southern distribution, some uncertainties exist about the date of the identified greenstone axes from Anse Trabaud. Their tentative dating between AD 1000 and 1500 leaves open the possibility that these tools can be attributed to either one of the Late Ceramic phases. Dating of greenstone axe finds, recently identified at the Lavoutte site on St. Lucia, suffer from a similarly wide time span within the Late Ceramic Age (Hofman and Hoogland, personal communication 2004).

With regard to the final phase of Pre-Columbian occupation, the available data are scanty. In addition to the possible occurrence at Anse Trabaud, greenstone axe material was only encountered at the small site of Morne Souffleur on La Désirade (table 6.15; figure 6.12).

In summary, the reduction, transport, and exchange trajectories basically conform to a single pattern through time. Looking at the models outlined by de Grooth (1991, 170 fig. 9; Chapter 3), they can be classified as closest to model D3 (figure 6.13). Stone workers in villages nearby the source, either on St. Martin itself or on the surrounding islands, exploited the outcrops and secondary surface scatters, where they collected raw material, generally in blocky form, that they took back to their villages without pre-working or only minimally pre-working it. At their habitations they fabricated axes, which they exchanged with neighbouring villages, who did not have direct access to the raw material source.

\section{Discussion and concluding remarks}

It was argued in the preceding section that the differentiation between settlement sites producing greenstone axes and those only receiving finished items provides support for the existence of exchange relationships, the latter sites interacting with the former for the acquisition of the axe blades. A closer look at the areas of production through time shows us that these areas varied in size to some extent as a result of changing population densities. Population was dispersed, in particular, during the Early Ceramic A, with only a limited number of islands inhabited. The only production site thus far identified is the Hope Estate site on St. Martin. The area reached its largest extension during the Early Ceramic B phase, including the islands between St. Kitts and Anguilla. It is assumed that the production area corresponded with the area of direct access to the sources. It is likely that communities living on neighbouring islands were able to exploit the material at the source themselves without having to interact with a local St. Martin village. The common availability of this type of rock on St. Martin makes it very difficult to exercise control over it. The most distant community still being able to exploit the source was situated on St. Kitts, c. $85 \mathrm{~km}$ from St. Martin. This distance falls within the range of distances reported for direct access distances in other parts of the world. Compared to the direct access region of the Long Island flint exploitation, however, it is considerably smaller.

Beyond this area of direct procurement, some differences in the area of distribution are noted as well. Within the Early Ceramic A phase, the axes are commonly found on Vieques and the eastern part of Puerto Rico, whereas on the southern end they do not occur on Martinique. Within the following phases, interaction beyond the Anegada Passage appears to diminish, as the material is rarely encountered on Puerto Rico. Only the Late Ceramic A occupation at Paso del Indio yielded such an axe fragment. This rare presence on Puerto Rico is in marked contrast to a common occurrence among sites within the Anguilla - Guadeloupe area and to the appearance of greenstone tools on Martinique from the Early Ceramic B phase onwards. 


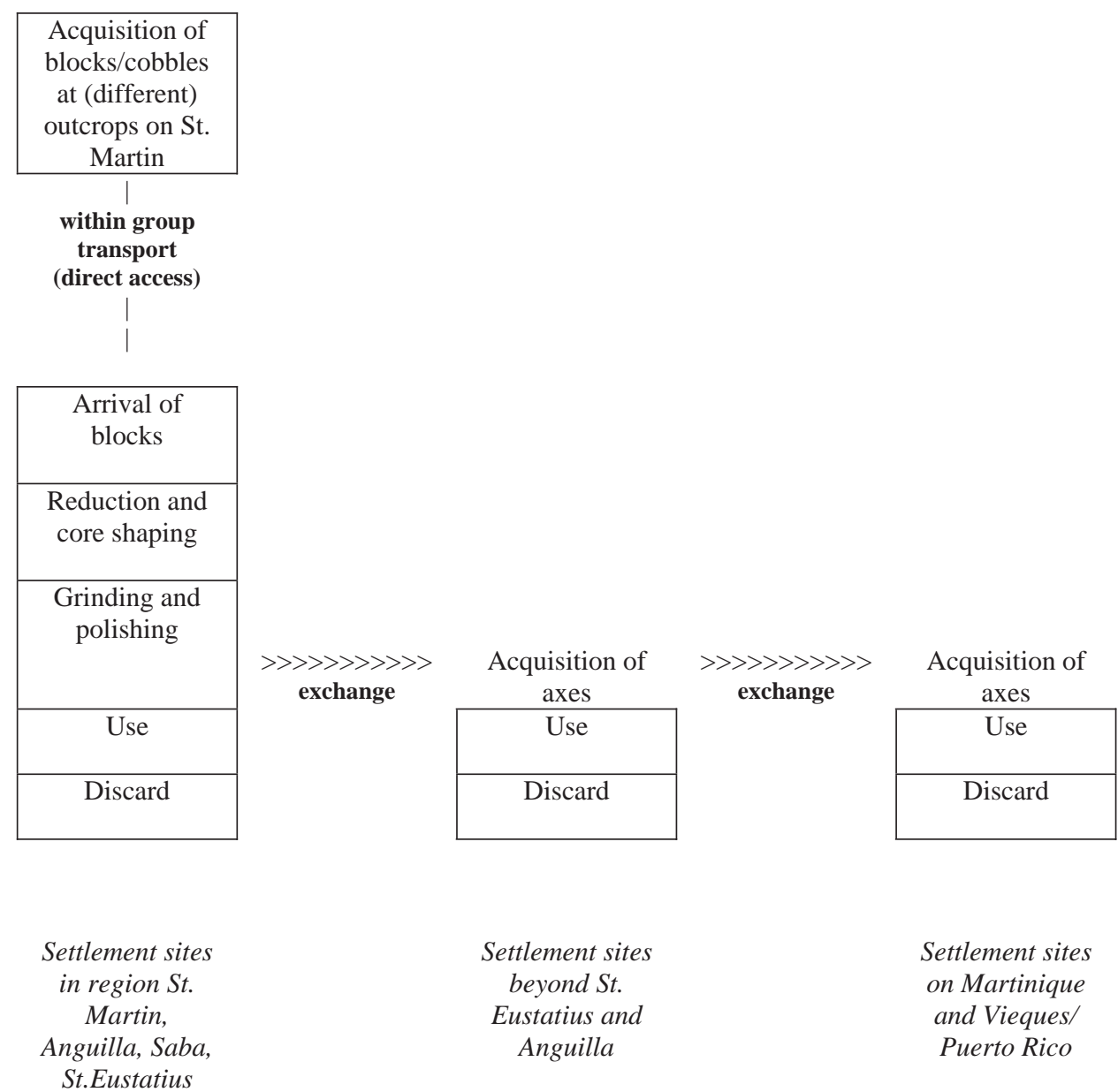

Figure 6.13. St. Martin greenstone axe production, transport, and exchange sequence during the Ceramic Age.

The type of exchange by which the material was distributed is difficult to specify from these data. This can be mainly attributed to small sample sizes, as well to the incompleteness of many of the tools, making comparison of metric values unreliable. Following the results of the flint study, a down-the-line mode of exchange seems likely, in particular during the Early Ceramic A phase. There are, however, indications that during later time, a central-place type of exchange, in which large sites operated as pooling centres, had come into existence. The Anse á la Gourde site on the northern shore of Guadeloupe might have been such a site. The large number of greenstone axes, as well as the occurrence of calci-rudite zemis (see next section), along with many other types of zemis, is quite striking. Moreover, the site experienced a long-term occupation, is the largest one in the direct surroundings, and comprised a large burial ground. Together, this suggests that it was a place of regional importance (De Waal 2001, 2006; Hofman et al. 2001). Unfortunately, the detailed information from this site is not matched among the smaller sites around it. This hinders sound comparison and leaves its relation with the smaller sites unspecified. It is unclear whether these smaller surrounding sites should be interpreted as permanent occupied settlements, or whether they functioned as special activity localities, that were visited on a temporary basis. A central place type of (re)distribution is more likely in the former case, while the smaller sites are not relevant for the study of exchange systems in the latter case. 


\subsubsection{St. Martin calci-rudite}

\section{Introduction}

In Chapter 2, a detailed description was presented for the conglomerate pack-stone, calci-rudite, which was identified as such by Van Tooren (Van Tooren \& Haviser 1999). Very characteristic particles cemented by fine-grained carbonate make this rock easily recognisable, even with the unaided eye. The study of several collections as part of the present dissertation showed that this material was exclusively used for making zemis (see Crock 2000; Crock \& Petersen 1999; Haviser 1987, 1999; Versteeg 1999), the well-known three-pointed shaped artefact, that was reported by the early Spanish chroniclers as related to veneration of the deified ancestors and magical power in general (Pané 1999; Siegel 1997). The present research has pointed out that several other materials were used for zemi manufacture besides calci-rudite. These include limestone, igneous rock, pumice, calcite, quartz, shell and coral (Chapter 5; see Crock \& Petersen 1999; Hoogland 1996; Versteeg \& Schinkel 1992).

Calci-rudite's highly characteristic appearance and its exclusive usage for making zemis are striking features and they suggest a deliberate relationship. For the St. Martin greenstone I pointed out above that the green colour and the corrosion might have been characteristics that gave this stone additional meaning and value. In the case of calci-rudite the supposed meaning behind the mottled nature of the rock is still puzzling, especially if one considers that some of other rock types and other materials used for zemi making generally do not exhibit such variety in colour. On the other hand, diorite, displaying a similar mixture of white and dark particles, is rarely reported among zemis as well (Faber Morse, personal communication 2002) and more commonly occurs among beads throughout the whole of the Ceramic Age (Watters \& Scaglion 1994; Chapter 5, this volume).

The source location itself was probably of significance as well. Pané (1999) explicitly writes about the making of wooden zemis that the tree needed to make the zemi, will reveal itself to the zemi maker. Unlike other materials, that have an unclear origin or which have a common origin (e.g. coral and shell), this rock type has a very localized source, that was exploited for considerable time.

Thus far there are no indications that zemis were made and used by the Preceramic Age inhabitants of the Caribbean. All evidence suggests that these religious items first appeared during the Early Ceramic Age. Furthermore, careful comparison of different sites shows that the first emergence of zemis within the Caribbean was not contemporary with the first arrival of horticulturalists. Early sites, such as Fond Brulé and Vivé on Martinique, and the La Hueca component on Vieques lack this typical item (Bérard, personal communication 2000; Narganes Storde 1995). Therefore, introduction of the zemis must be considered a later local Caribbean phenomenon, perhaps roughly dated at AD 300. Contemporary with the introduction of zemis, the first calci-rudite zemis turn up as well. Here I discuss in chronological order the usage of this material within the different Ceramic Age phases.

First, I need to make a few comments about my analysis of calci-rudite zemi production and distribution. Similar to the greenstone, information about local exploitation at the source outcrop itself is lacking. In contrast to the greenstone, the calci-rudite conglomerate has a much more restricted occurrence, with only one identified outcrop at Point Arago, on the western coast of St. Martin (see Chapter 2). Despite this single occurrence, no evidence of actual exploitation has been reported for Point Arago. Unlike the greenstone, where the main production occurred at the settlement sites, this could not always be established for the calci-rudite material. This results in an incomplete picture for some Ceramic Age phases, where we have some evidence of zemi-usage, but in which we lack clear identification of actual production localities. Finally, it should be noted that due to the rare occurrence of zemis in general and calci-rudite zemis in particular, similar biases exist as reported for my analysis of the greenstone axe distribution. Therefore, in this case again published site reports and colleagues were consulted for additional data.

\section{Reduction and transportation \\ Production \\ The reduction and transport sequence for calci-rudite zemis displays many similarities to the greenstone axe production described above. Again, a clear distinction can be made between habitation sites where zemis were being manufactured, situated close to the source, and those that only imported finished items. The former sites yielded clear manufacturing debris, in the form of small flakes, lots of shatter, and preforms, while the latter sites only yielded finished ground three-pointers, either complete or fragmentary. The calci-rudite case, however, exhibits more variation through time, with a clearly distinct}


period during the Late Ceramic A phase, marking the peak of its production and usage (tables 6.16 and 6.17).

As mentioned in the introduction, the earliest zemi appearance must be dated somewhere around AD 300. Early calci-rudite examples are reported from Hope Estate, Elliots, and Trants. However, these are finds from undated surface proveniences. ${ }^{14}$ Looking for production activities during this phase, we are faced with a lack of data because it has not produced clear evidence of calci-rudite zemi production, despite the occurrence of zemis at a few sites. The most likely place for zemi production would be the site of Hope Estate, which is situated on the source island of St. Martin itself. Haviser speaks of five "raw material" pieces in his 1999 report and thereby suggests local production (Haviser 1999). Chauviere (1998), on the other hand, considers these to be fragments from finished items, as they have ground surfaces, and excludes the possibility of a local production. When compared to later sites with clear production remains, such as Sandy Ground and Barnes Bay, the frequency differences are striking and support Chauviere's statement (see Chapter 5).

During the Early Ceramic B phase, indications for production are again scanty, notably on St. Martin, where the Early Ceramic B Anse des Pères site did not yield any calci-rudite material at all, out of a total of more than a 1000 artefacts (Knippenberg 1999c). The only reported sites, that had late Saladoid occupation and produced calci-rudite zemi manufacture remains are Rendezvous Bay and Sandy Ground on Anguilla (Crock 2000; Crock \& Petersen 1999). In particular, the Rendezvous Bay site has been suggested as an important zemi production place, considering the relatively large quantity of calci-rudite material. Notwithstanding the fact that calci-rudite zemis were being made at both sites, the association with the earliest occupation at both localities is less firmly established, thus far. Concerning Rendezvous Bay, the lithic materials from the stratigraphically excavated test-units yielding the earliest deposits have not been analysed. On the other hand, Crock and Petersen argue for early zemi making, as surface collected material from the site yielded a "pedestalled" zemi, which is characteristic for the Early Ceramic Age (Crock \& Petersen 1999, fig. 23). This may suggest that zemi-making was associated with the earliest occupation, starting from about AD 400 onwards.

At Sandy Ground, calci-rudite zemi material is mostly associated with the later occupation phases at the site. The test-unit sample that I analysed did not contain any calci-rudite material in the lower levels, and calci-rudite is rare in the deep deposits in general (Crock 2000). Associated dates for the upper levels place the production between AD 775 and 1035. This production may be related to the recovery of zemis at Golden Rock, roughly dated between AD 450 and 850. Furthermore these dates make the zemi-manufacture at least contemporaneous with the Anse des Pères site, which has been dated between AD 730 and 950 (Knippenberg 1999b). This brings to light an intriguing situation where a site situated only a few hundred metres from the source, Anse des Pères, lacks any production debris or zemis in general, but Sandy Ground, and Rendezvous Bay, which lie considerably further from Pointe Arago, demonstrate its production.

The first appearance of calci-rudite zemi production during the late Saladoid/early post-Saladoid transitional phase (Early Ceramic B) developed to an extensive production during the following centuries, notably the period between AD 850 and 1250. True Late Ceramic Age occupation at Sandy Ground, Barnes Bay, and Rendezvous Bay on Anguilla (Crock 2000), and Cupecoy Bay on St. Martin (Haviser 1987) yielded clear manufacture remains. Furthermore, Crock and Petersen present an extensive list of surveyed (but chronometrically undated) post-Saladoid sites on Anguilla assumed to fall within the AD 9001200 period, and that have yielded remains of calci-ruidte zemi production as well (Crock \& Petersen 1999). Close reading of Haviser's survey report on St. Martin (1988) shows that only sites on the western part of the island yielded calci-rudite debitage (see figure 5.33). Among all these sites on both islands, Rendezvous Bay stands out according to Crock and Petersen (1999), by its considerable number of production remains and finished zemis. Therefore, they tentatively interpret this site as a port of entry for this particular stone material.

Interestingly a decline in calci-rudite artefacts is noted though time, as sites, that have been dated to the later parts of the post-Saladoid period yielded considerable lower amounts of this material. For example, the Sandy Hill site, which overlaps with the later phases of occupation at Barnes Bay and Sandy Ground hardly produced any calci-rudite material at all, suggesting that production was not a significant characteristic there. A low occurrence of calci-rudite material is also noted for the Forest North site. The unconvincingly long time span suggested by radiocarbon dating for this site, however, poses difficulties where to place Forest North temporally. In particular, the Shoal Bay East site, with the latest dates for

\footnotetext{
14 The zemi from Trants was part of the Howes collection, which was gathered during the late nineteenth century (Watters \& Scaglion 1994). While fieldwalking the Elliot's site in 2000, I picked up a calci-rudite zemi fragment in an area that produced a lot of "White-on-Red" Saladoid ceramics.
} 


\begin{tabular}{|c|c|c|c|c|}
\hline Site & Island & $\begin{array}{l}\text { Distance to } \\
\text { Pointe } \\
\text { Arago }(\mathrm{km})\end{array}$ & Chronometric date & Calci-rudite \\
\hline \multicolumn{5}{|c|}{$\begin{array}{l}\text { Early Ceramic A } \\
\text { unknown }\end{array}$} \\
\hline \multicolumn{5}{|c|}{ Early Ceramic B } \\
\hline Rendezvous Bay & Anguilla & 11 km & cal AD $400-950$ & production (?) \\
\hline \multicolumn{5}{|c|}{ Late Ceramic A } \\
\hline Cupecoy Bay & St. Martin & $6 \mathrm{~km}$ & aprox. AD $1100-1300$ & production \\
\hline Rendezvous Bay & Anguilla & $11 \mathrm{~km}$ & Cal AD $400-950$ & production \\
\hline Sandy Ground & Anguilla & $13 \mathrm{~km}$ & cal AD $650-1035$ & production \\
\hline Barnes Bay & Anguilla & $12 \mathrm{~km}$ & cal AD $775-1295$ & production \\
\hline
\end{tabular}

Table 6.16. Calci-rudite zemi production sites by period by island.

Anguilla, displays an almost complete absence of calci-rudite. ${ }^{15}$

Crock (2000) does not pay any attention to the lower occurrence of calci-rudite material in the relatively later sites, suggesting disappearance of calci-rudite zemi-production through time. However, this decline is also supported by data from surveyed sites listed in Crock and Petersen (1999). ${ }^{16}$ Blackgarden Bottom, one of the few places, that may have had an occupation phase in the later post-Saladoid period (AD 1200 - 1500), is characterised by an absence of calci-rudite material. Notably, all reported sites that did yield calci-rudite debitage, are dated to the earlier half of the late Ceramic Age (AD 900 -1200). The disappearance or at least significant decline of calci-rudite zemi production must be dated somewhere between $\mathrm{AD} 1250$ and 1300 in view of the radiocarbon dates from Anguilla.

The evidence for production indicates that zemi manufacture locations may have a much more localized occurrence than was the case for greenstone axe fabrication. During its highlight, zemis were only manufactured on the western part of St. Martin and on the island of Anguilla ${ }^{17}$, whereas greenstone axe production sites can be found on Saba, St. Eustatius, and incidentally St. Kitts as well. ${ }^{18}$ This much smaller production region for the calci-rudite material suggests that fewer people had direct access to the source. This may be attributed to its more localized source on St. Martin when compared to the more broadly available greenstone material, making it easier for neighbouring communities to exercise control over and deny access to it by others. This control and restricted access may have played an important role in increasing socio-political competition within the region, in particular when the religious importance of zemis made from it is considered (Crock 2000; see Chapter 7).

\footnotetext{
15 One localized area at Shoal Bay East also yielded evidence of late Saladoid occupation, including one radiocarbon dated sample (cal AD 655 - 890), and White-on-Red ceramics (Crock 2000, 169). Unfortunately, lithic data attributed to this occupation have not been described. Furthermore, in a personal communication, John Crock pointed out that only a small amount of calci-rudite material has been surface collected at Shoal Bay East, and considering its surface provenience it may be placed within the later phases of occupation at the site. According to Crock this relates to a more general problem regarding the later Amerindian occupation on Anguilla and elsewhere, as plough disturbance has made the upper, mostly younger deposits unreliable for radiocarbon dating, biasing our knowledge of site occupation more toward the older phases (Crock, personal communication 2002).

${ }^{16}$ Crock (2000) was mainly focussed on contemporaneity between sites. As many of them were occupied for a considerable period, such co-existence was proven. To compare the sites he treated them as single entities without distinguishing specific occupation phases. Therefore, he was less interested in variation through time.

${ }_{17}$ Data from St. Barths are absent as a result of very limited archaeological work on this island (Gassies 1999). Considering the presence of production remains restricted only to sites on the western part of St. Martin and the island of Anguilla, closely corresponding with the source's location along St. Martin's western coast, suggests that St. Barths may not have been part of the production area.

${ }^{18}$ Considering the wider distribution of greenstone production sites, it is very likely that St. Barths was included within the greenstone production area as well.
} 


\begin{tabular}{|c|c|c|c|c|}
\hline Site & Island & $\begin{array}{l}\text { Distance to } \\
\text { Point } \\
\text { Arago }\end{array}$ & Chronometric date & Calci-rudite \\
\hline \multicolumn{5}{|c|}{ Early Ceramic A } \\
\hline Punta Candelero & Puerto Rico & $285 \mathrm{~km}$ & cal $100 \mathrm{BC}-\mathrm{AD} 50$ & absent \\
\hline La Hueca & Vieques & 246 km & cal AD $0-400$ & absent \\
\hline Sorcé & Vieques & $246 \mathrm{~km}$ & cal AD $136-650$ & absent \\
\hline Hope Estate & St. Martin & 4 km & $\begin{array}{l}\text { cal 400/300 - 50 BC (early) } \\
\text { cal AD 255 - } 650 \text { (late) }\end{array}$ & finished items \\
\hline Trants & Montserrat & 177 km & $500 \mathrm{cal} \mathrm{BC}-\mathrm{cal} \mathrm{AD} 400$ & finished item \\
\hline Morel & Guadeloupe & $270 \mathrm{~km}$ & AD $200-600$ & absent \\
\hline Cocoyer & Marie-Galante & $302 \mathrm{~km}$ & no chronometric dates & absent \\
\hline Vivé & Martinique & $426 \mathrm{~km}$ & cal AD $144-440$ & absent \\
\hline \multicolumn{5}{|c|}{ Early Ceramic B } \\
\hline Anse à la Gourde & Guadeloupe & 283 km & approx. AD $400-600$ & absent \\
\hline Les Sables & La Désirade & 291 km & no chronometric dates & absent \\
\hline Diamant & Martinique & $460 \mathrm{~km}$ & cal AD $415-725$ & absent \\
\hline \multicolumn{5}{|c|}{ Late Ceramic A } \\
\hline Paso del Indio & Puerto Rico & $320 \mathrm{~km}$ & cal AD $880-1385$ & finished item \\
\hline Jumby Bay & Long Island & $176 \mathrm{~km}$ & cal AD $1050-1250$ & absent \\
\hline Mill Reef & Antigua & 183 km & no chronometric dates & finished item \\
\hline Muddy Bay & Antigua & 183 km & cal AD $1000-1300$ & absent \\
\hline Anse à l'Eau & Guadeloupe & $277 \mathrm{~km}$ & no chronometric dates & finished item \\
\hline Anse à la Gourde & Guadeloupe & $283 \mathrm{~km}$ & approx AD 1000-1250 & finished items \\
\hline Escalier & La Désirade & $291 \mathrm{~km}$ & cal AD $1049-1243$ & absent \\
\hline
\end{tabular}

Table 6.17. Calci-rudite zemi distribution by period by site by island.

\section{Distribution}

The distribution of finished calci-rudite zemis rather than debitage, is very similar to that of the greenstone material. Outside the production region, calci-rudite material is only found in the form of complete or fragmented finished zemis. Debitage in the form of unworked raw material, flakes, unidentified fragments and preforms is lacking. Contrary to the greenstone axes calci-rudite zemis are relatively rare within archaeological assemblages, somewhat hampering a sound reconstruction of its distribution, however.

For the Early Ceramic A phase, data are very scanty, with zemis only reported from Hope Estate, Elliots, and Trants (table 6.17). The finished examples all came from surface collections and these pose uncertainties with regard to their precise age, in particular considering the absence of clear production sites prior to $\mathrm{AD} 400$ and the considerable size of the zemis, which are larger than the early zemis found at Golden Rock (see below).

For the following Early Ceramic B phase the distribution is even more localized, with calci-rudite zemis only found at the Golden Rock site on St. Eustatius, thus far. Out of the twelve stone zemis recovered from this site, four are made of calci-rudite material. Furthermore, all of these specimens are small in size, comparable to the other limestone, coral and igneous rock zemis from Golden Rock. This correlates well with the notion that the oldest zemis were small, and that they 


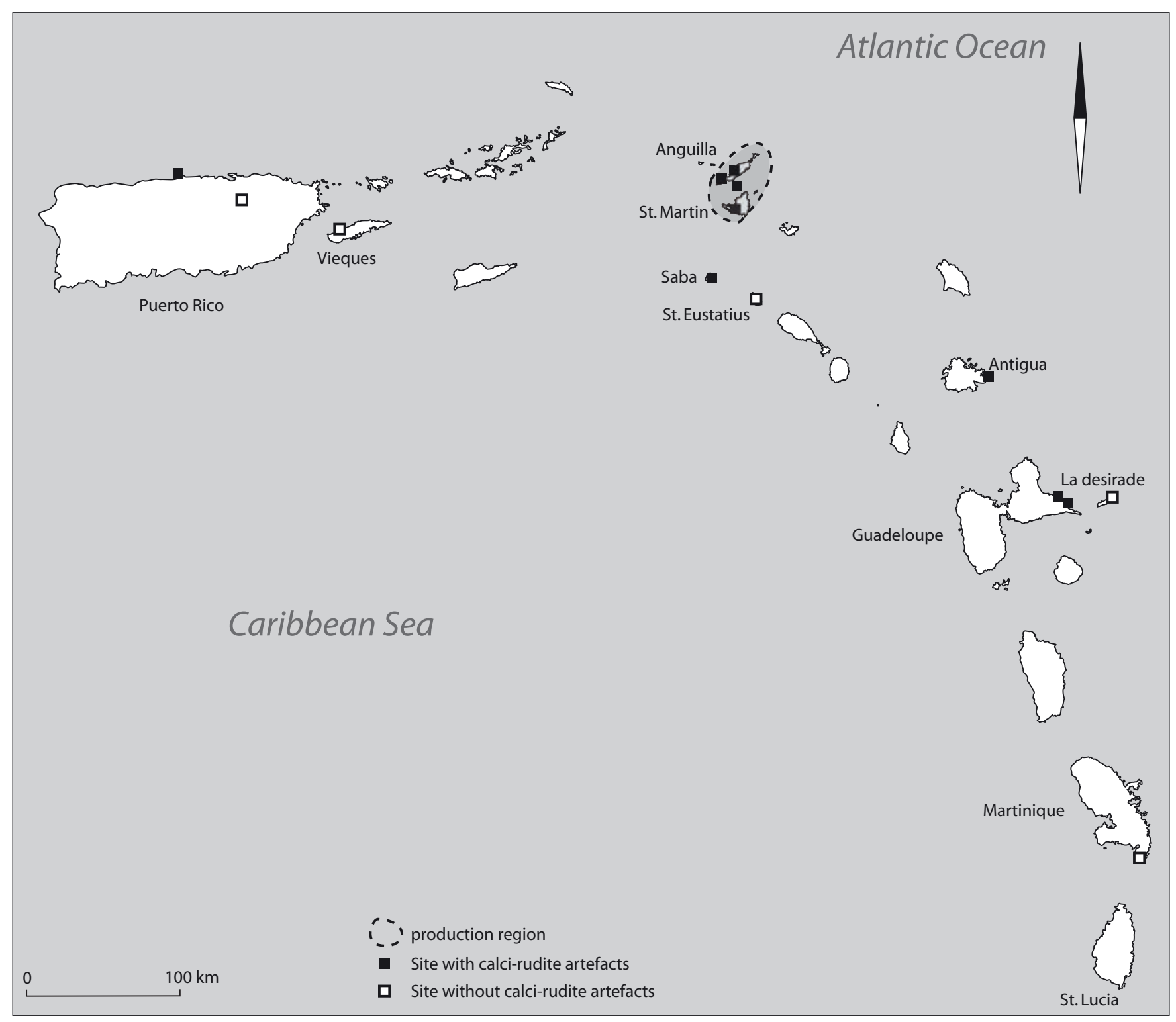

Figure 6.14. Distribution of calci-rudite zemis and the location of the production area during the Late Ceramic A phase (AD 850 - 1250).

gradually become larger through time. The place of production of the Golden Rock zemis, may well have been either at Rendezvous Bay or Sandy Ground on Anguilla, from where the items were obtained through exchange.

During the Late Ceramic A phase, the extensive evidence on the production of the calci-rudite zemis is well correlated with their higher frequency at habitation sites within the surrounding region. Complete or fragmentary items are reported at Anse à l'Eau, Anse à la Gourde (both Grande Terre, Guadeloupe), Mill Reef (Antigua), Spring Bay 3 (Saba), and Paso del Indio (Puerto Rico) (figure 6.14). This suggests a wider distribution than during the preceding phase, and notably the co-occurrence of a greenstone axe fragment and an incomplete zemi at Paso del Indio supports the notion that sites in Puerto Rico were participating in a widespread exchange network during this phase. Still, zemi frequency is generally low when compared to greenstone axes.

Moving toward the final centuries of Pre-Columbian history, reported zemis are absent, but the context sample for excavated sites is very small as well. The previously mentioned occurrence of zemis at Anse à la Gourde, dated to the Late Ceramic A phase (between AD 1200 - 1250), represents the latest known examples within the wider region. Later sites, 


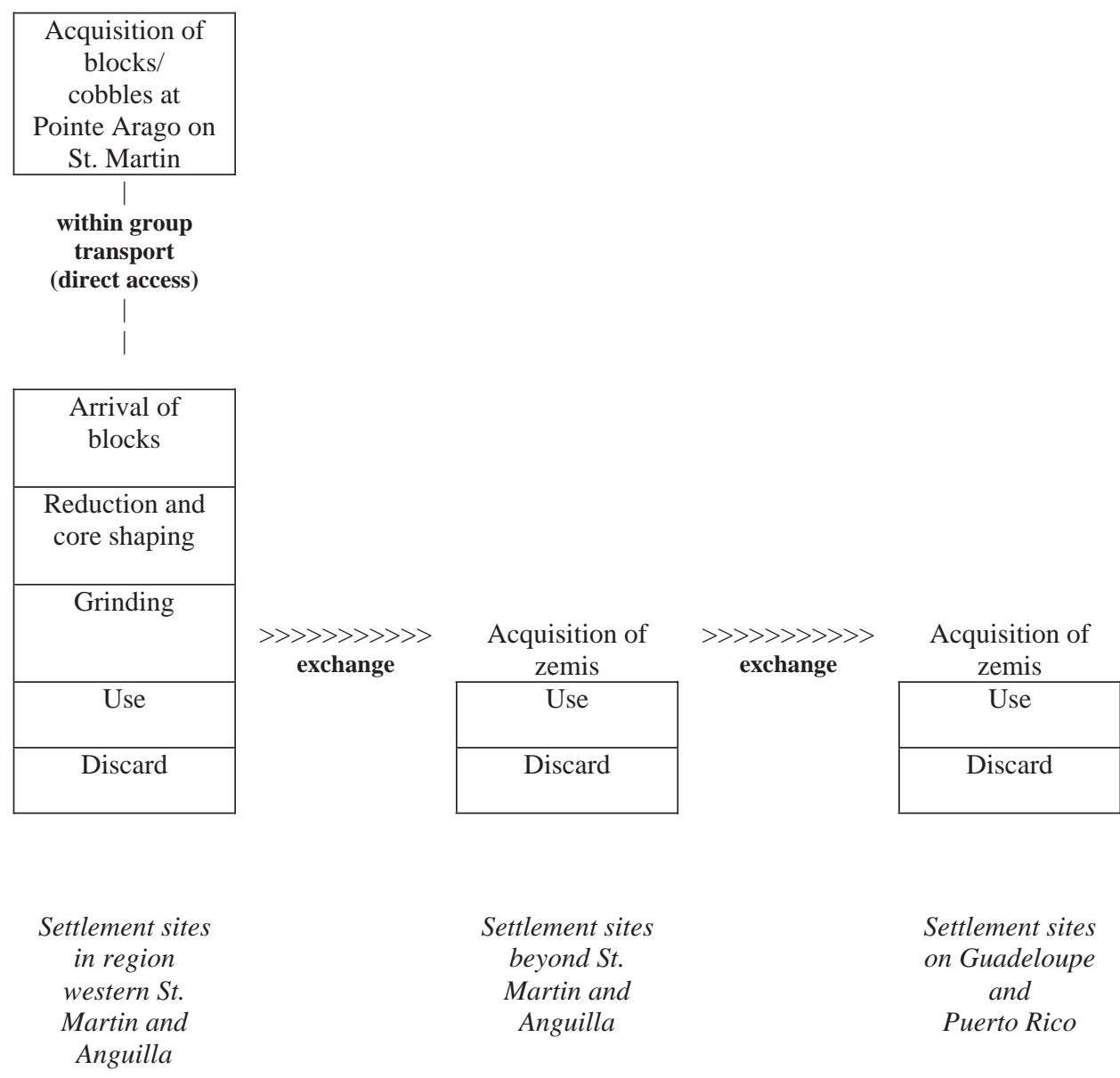

Figure 6.15. St. Martin calci-rudite zemi production, transport, and exchange sequence during the Late Ceramic A phase (AD 850 - 1250).

such as Kelbey's Ridge 2, Sugar Mill, Morne Cybele, Morne Souffleur, and the latest occupation at Paso del Indio have not yielded any examples. However, I should point out that lithic samples from the latter four sites are relatively small too. Notwithstanding this possible sample size bias, the absence of zemis at these late sites corresponds well with evidence for declining or even absent production on Anguilla, as suggested above.

\section{Discussion and concluding remarks}

Data on calci-rudite production and distribution have been discussed here through time. Thus far, it is the only zemi rock material for which production and distribution can be clearly identified, in contrast to many other materials used for zemi manufacture. In particular, these other materials include different varieties of limestone, as study of sites on Guadeloupe and Anguilla has shown. A low frequency of zemi related artefacts and large variety of rock types on an intra- as well as inter-site level hinder sound comparison and a proper identification of zemi manufacture and distribution in these cases. The available evidence for calci-rudite zemi production and distribution, however, shows that its main usage can be roughly dated between AD 800 and AD 1250. During this time, the reduction, transport, and exchange trajectory corresponds to De Grooth's model D3, similar to the greenstone case (figure 6.15) (De Grooth 1991, 170 fig.9). A number of settlements near the source had access to the calci-rudite material and were involved in zemi manufacture. These settlements exchanged the finished objects to settlements over a much wider region. 
Before AD 800, calci-rudite zemi manufacture and distribution occurred only on a small scale, whereas in the latest phase of Amerindian occupation, after AD 1250, its use seems to have disappeared. During its heyday, however, the area of production remained small, suggesting the deliberate control of access to it. In contrast to the greenstone and Long Island flint, calci-rudite zemis are relatively rare in general, probably owing to their special religious function. Nonetheless, their occurrence at sites on Puerto Rico and Guadeloupe clearly indicates that the indigenous Caribbean inhabitants valued calcirudite as raw material for these important objects.

This description has revealed two striking features that need additional discussion. One relates to the scanty evidence of actual production during the earliest phases of the Ceramic Age and the other one concerns the small size of the production region during the Late Ceramic A phase, relative to the ones for the greenstone and the Long Island flint. As became evident for the earlier Ceramic periods, in particular for the Early Ceramic A phase, clear calci-rudite zemi production sites have not been identified, despite the occurrence of calci-rudite zemis at early sites. Due to the fact that the data do not strongly favour any particular explanation I want to discuss some possible ones:

1) The Rendezvous Bay site on Anguilla may have functioned as the production locality for all the early zemis. Although major occupation at this settlement must be ascribed to the Late Ceramic A phase, radiocarbon dating as well as White-onRed ceramics in the lower deposits suggest that occupation started around AD 400, which would make it contemporaneous with the later phases of Hope Estate, and possibly Trants and Elliots as well. This would mean that a settlement on the neighbouring island of Anguilla and not a site on the source island of St. Martin itself was responsible for the introduction of calci-rudite as a zemi raw material for the manufacture of stone threepointers. This situation is intriguing when it is recognized that Anguilla became such an important island for the calci-rudite zemi manufacture. These circumstances may suggest an important aspect of calci-rudite manufacture. It shows that it was not necessarily distance to the source, but rather the relation with the first zemi producing settlement, that was decisive in who was involved in zemi manufacture and who was not. This may also explain the absence of manufacturing activities at the adjacent Anse des Pères site on St. Martin. With regard to the relationship between the Late Ceramic Age habitation sites on Anguilla, several lines of reasoning may be brought forward. These relationships may well have had a primarily social character, in which social and kinship ties between the inhabitants form the main foundation. Another viewpoint would be that the bond was more of a political nature, in which a supra-village authority connected the settlements, or that it should be sought within the spiritual-religious realm, in which a lineage of religious specialists were responsible for a communal involvement in calci-rudite zemi manufacture.

2) Zemis were manufactured at another locality, somewhere outside individual settlements during this early phase, or at another time from which the following options can be suggested:

(a) The source area was the place where calci-rudite was worked. Unfortunately data relating to remains of debitage at the source are not reported. If there are indeed no remains present there, then it is possible that such remains have been eroded away by the ocean, since it is a coastal site, with cliffs and little beach development yet. On the other hand, if we look at Long Island flint in particular, then it is evident that Ceramic Age people did not reduce this material at the source either. All evidence for the greenstone material so far indicates the same thing too, suggesting local acquisition and production were not done at the same place by these people.

(b) A special locality outside the village with "religious" significance was chosen for calci-rudite zemi manufacture. This may be a possibility, but there is no data, however, about this issue, since such sites have not been systematically searched for nor reported on St. Martin. To my knowledge, similar examples elsewhere in the region have not been described. Furthermore, this would contradict with later lithic related behaviour, when habitation sites became the places of reduction, as described above.

(c) Zemis were being made within the settlement site in one specific area, which fell outside the excavated areas at Hope Estate, for example. Although it has been shown at Rendezvous Bay that the concentration of calci-rudite material varies within the site, its presence seems to be continuous there. Considering the relatively extensive excavations at Hope Estate that produced the lithic samples studied by Haviser and Chauviere, it is unlikely that such areas would have been missed, however.

(d) It is possible that he zemis found at different early sites were later intentional deposits made by Late Ceramic Age people visiting their "ancestral" places, and should not be associated with the Saladoid occupation of these sites. Arguments in favour of this possibility include the clear evidence of extensive production of calci-rudite zemis during the Late Ceramic Age, notably on Anguilla, and to a lesser degree on St. Martin itself, as well as the relatively large 
size of the zemis found at Elliots and Trants, suggesting Late Ceramic Age manufacture. On the other hand, the excavation reports for the Hope Estate and Trants sites do not mention any evidence of post-Saladoid activities at the site. If these activities were solely involved in the intentional burial or placement of zemis, then they may have only minimally disturbed earlier deposits and this has gone unrecognised. Thus far, there are no stratigraphic indications that such was the case and although the idea of post-Saladoid visits is tempting, archaeological evidence is completely lacking.

Comparing these different possibilities, I think that options 1, 2a and 2d should be regarded as the most likely ones, given the scanty evidence. Future research should not neglect the possibility of calci-rudite working and zemi manufacture at the source, as this would be a relatively easy object of study.

Careful reading of Haviser's St. Martin survey (1988) and Crock and Petersen's Anguilla report (1999) shows that Late Ceramic A sites producing calci-rudite debitage and therefore suggesting zemi manufacture either are situated on Anguilla, or on the western part of St. Martin. These areas nicely surround the source locality situated along St. Martin's western coast and these settlements likely had direct access to Pointe Arago. Compared to, for example, greenstone or Long Island flint, this area of production and direct access is much more restricted. This seems to suggest that these nearby communities controlled this source and denied access to it for others. The important nature of the artefacts that were manufactured from calci-rudite, probably formed the primary reason for strict control of it. Furthermore, the single source occurrence of this rock material may have made it relatively easy to exercise such control, standing in sharp contrast to the greenstone, which is more widely available on St. Martin.

There are different possibilities for control and ownership. The source may have been situated within the territory belonging to a single linguistic or culturally related group, or a multi-community lineage, similar to cases found in southeastern Australia, where certain groups once possessed a rock source for centuries (McBryde 1984). Recognizing the special religious meaning of zemis, it is also possible that only certain religious specialists, similar to the behiques in Taíno society, were allowed to exploit this material, as they possessed the proper spiritual power and knowledge to handle it. It may well be possible that such specialists in the long run acquired a central ruling social position as the result of their ability to control these items and thus control the supra-natural world. This possibly provided them with the power to ultimately exclude other specialists from it and to keep its production very localised.

In relation to this, it is intriguing to note that the oldest Ceramic Age site on Anguilla, Rendezvous Bay, is also considered to be the most important zemi manufacture settlement on the island. This may imply the existence of a local hierarchy among zemi producing sites, in which the founder settlement is considered to be the most important one, as this may have been where the lineage of the first zemi makers lived.

\subsection{EXCHANGE SYSTEMS IN THE NORTHERN LESSER ANTILLES: SOME CONCLUDING REMARKS}

The study of the production and distribution of three different lithic materials has clearly shown the existence of exchange networks operating during the Ceramic Age within the northern Lesser Antilles. All three materials proved to be relatively highly valued rock types, relative to alternative materials used for the same purposes. For Long Island flint, none of the other cherts and flints available within the northern Lesser Antilles were so widely used for the making of flake tools. Similar preferences were given to St. Martin greenstone for the manufacture of axes and calci-rudite for the making of zemis. However, it should be stressed that these three rock types were collected for totally different purposes, that is, flake tools versus axes versus zemis, despite their comparable esteem relative to alternatives. This differential use has been mentioned above, but the consequences of how to evaluate the three different exchange and distribution patterns relative to each other have not been exploited yet.

Comparison of the transport and reduction sequences of these three materials through time reveals the following differences and similarities:

(a) Long Island flint was reduced at every site where it has been archaeologically recovered, while greenstone and calcirudite were only worked into axes and zemis at a restricted number of settlements in the vicinity of the source areas.

(b) Long Island flint was primarily exchanged in unmodified form as nodules, from which flake tools could be produced. In 
contrats, greenstone and calci-rudite were exchanged as finished objects.

(c) Greenstone exchange and distribution exceeded Long Island flint exchange and distribution during the Late Ceramic $\mathrm{A}$ phase and possibly during the Late Ceramic B phase. For the Early Ceramic phases, the limited data suggest that this was not the case.

(d) Long Island flint and greenstone were used and distributed throughout the entire Ceramic Age, in contrast to calcirudite, for which its usage and distribution were seemingly restricted to the Early Ceramic B and Late Ceramic A phases only. Moreover, it needs to be stressed that the latter phase clearly marks the heyday of calci-rudite zemi manufacture and distribution.

(e) Preceramic Age foragers used Long Island flint, whereas greenstone and calci-rudite clearly were only introduced by the later horticulturalists of the Ceramic Age.

These points suggest a number of things. First of all it is clear that the lithics were valued differently. This is apparent just by looking at the form of the exchanged material. Long Island flint was primarily seen as a raw material from which implements could be extracted. In this sense, its utilitarian value was emphasized, whereas for the other two materials the finished objects, with all of their associated meanings and values, were part of the exchange transaction. The additional meaning and value both incorporated the time invested in making these artefacts and all connotations surrounding their representation, usage, shape, and size.

With regard to zemis, I need not make a large argument here about the important role and the high value they entailed for their users. We know from the Spanish chronicles that they formed representations of the supernatural entities, and they played a very important role in ceremonies surrounding the fertilisation of the agricultural fields, for example (McGinnis 1997; Pané 1999; Siegel 1997).

Greenstone axes may well also have represented more than just ordinary tools. First of all, the fact that they were widely exchanged suggests something about their special value, which unlike Long Island flint does not seem to be related to the greenstone material's quality as a wood-working tool, but rather may have lain in the ideological realm. The intentionally buried pelican decorated ceramic pot containing two corroded axes found on La Désirade reveals something of the special value or meaning associated with these objects (De Waal 2006; Hofman et al. 2004). Before, I argued that the greenstone weathering may have been meaningful to its users and may have stood in relation to the decay of the dead person's body. Any possible association between the burial of the pot, the pelican decoration, and the corrosion is intriguing and awaits further investigation.

This difference in value and meaning attached to the exchanged objects certainly was of issue during the act of exchange, and therefore must have had its effect on when it was exchanged, how it was exchanged, and between whom (i.e. on which level of society). In other words, given these differences, it can be questioned whether the materials at issue were part of different exchange systems. Unfortunately, the generally small scale of most excavations and the refuse contexts from which the majority of artefacts were excavated does not allow a detailed intra-site analysis. Therefore, it is impossible to study any differential use and access to these materials within a particular community. For now, the distribution data on a site level provide the only data source by which this issue can be tackled.

The most striking differences are found when the Early Ceramic phases are set against those of the late Ceramic A phase. The St. Martin greenstone distribution became wider during this latter phase than was the Long Island flint distribution and calci-rudite zemi manufacture experienced its heyday. The first aspect suggests that Long Island flint and St. Martin greenstone had become part of different exchange systems during that period, the latter apparently being more valued and exchanged more widely. This may be an indication that levels within society became more accentuated. The axes may have operated as valuables in an elite exchange network. In the Greater Antilles, this was the period during which the first evidence appeared of growing socio-political complexity (Curet 1992).

This contrasts to the earliest Ceramic Age phase, for which the evidence suggests that the greenstone was not specifically preferred over Long Island flint. Both materials had more or less similar distributions then. Moreover, settlement data reveal a dispersed configuration of only large settlements, which operated in relative isolation. Exchange in the first place fulfilled the need for these settlements to stay in contact as a means to minimize the risks, associated with the exploration and settlement of new environments. The long-distance exchange of semi-precious stone beads and pendants during this early period should be viewed in this light as well. It was a relatively long-lasting stable network, in which each settlement seemingly played an equal role. 
The full appearance of calci-rudite zemi manufacture and distribution simultaneous with the more extensive greenstone distribution may be connected to the process of growing complexity as well. An aspect that further supports this view is the much more focussed region of calci-rudite zemi manufacture as compared to that of greenstone axes. If it indeed was the case that the use and manufacture of the zemis was reserved for spiritual specialists, or at least that specialists played an important part in this process, then the appearance of several calci-rudite zemi manufacturing sites and the zemi's distribution among the surrounding islands during the Late Ceramic A phase must be viewed as an indication that this particular social group was more explicitly propagating its position within society. It may even have been the case that these figures had become leaders within society because of their ability to control the supra-natural world, as reflected by the ownership of the calci-rudite material and their ability to create "powerful" objects, i.e. the zemis. Therefore, it may have been of crucial importance to them to keep access to the calci-rudite restricted. In relation to this, the increase in size of the zemi three pointers has been seen as an indication that public display became a more important part of zemiism (e.g. Curet 1996; Siegel 1999). Apparently, this implies that there was room for or, more strongly, there existed a need for the use of these objects in public. This may again be related to the appearance of social stratification, and that zemis were used to sanction the ruling position of the elite (Curet 1996).

It is evident from the differences in distribution patterns for these three lithic materials that despite the exchange value they share, their exchange and their changing regional distribution patterns signify different social processes. The similar spread of Long Island flint and St. Martin greenstone during the Early Ceramic A phase suggests that both materials were part of the same exchange system. This changed during the following phase because during the Late Ceramic A phase the distribution of both materials was different. At the same time, calci-rudite zemi manufacture appeared. These changes suggest that the exchange of these lithic materials took place within different systems, which may have been related to growing socio-political complexity within society, or at least related to the wish of certain social groups to strengthen their position. 


\section{$7 \quad$ Inter-island relationships}

\subsection{SUMMARY OF THE DATA}

The previous chapters showed that exchange of stone materials and artefacts formed a common means of acquiring nonlocal lithic materials and products among the communities of the northern Lesser Antilles during the different phases of the Ceramic Age (see table 7.1 for a general summary). It was also pointed out that the recovery of stone exotic to a particular island does not necessarily indicate exchange. In many instances, the acquisition of these exotics only involved withincommunity transport, in other words direct procurement at the source.

To summarize my research findings, inter-site variation is evident regarding the quantity of non-local rock found. To a large degree this can be ascribed to variation in the geological settings of the sites, varying from pure limestone surroundings, providing little useful material, to diverse settings offering numerous different lithic materials. Ignoring geological variability, local materials in general comprise water-worn rock used for different purposes. If not locally obtained many of the water-worn pebbles originate from sources relatively close to the particular settlements, where they were used. People likely obtained them by visiting the natural occurrences themselves. This may have involved short walking distances to nearby beaches, or boat-trips to nearby islands.

This contrasts to a number of other materials and artefacts, for which exchange between island settlements was responsible for their distribution, at least a part of it. This group of exchanged rock varies in artefact form and material. A low frequency in the archaeological record and unspecified provenance hinders good insight into the exact distribution and the type of exchange responsible for a considerable part of these materials. This does not account for the Long Island flint, St. Martin greenstone and calci-rudite, which were discussed in the preceding Chapter. Knowledge of their source areas, combined with their recurrent presence at a considerable number of sites, over an extensive region, has provided data for formulation of some ideas about inter-island exchange through time.

Long Island flint displays a wide distribution over the island arc, particularly during the Early Ceramic phases. A high abundance of this flint variety occurs at sites on islands surrounding Antigua, comprising the Saba - Guadeloupe region, and it indicates relatively easy access. During the early Ceramic Age, the people inhabiting this region in all probability had direct access to Long Island. From this inner sphere, Long Island flint was also widely exchanged in a down-the-line mode. This probably did not involve more than two to three exchange steps, finally resulting in a distribution from Martinique in the south to the eastern part of Puerto Rico in the west. This distribution contracted during the Late Ceramic Age, and did not transverse the Anegada passage in the west anymore, and probably did not reach Martinique to the south as well. Sites within the Saba - Guadeloupe region continued to produce high quantities, however, indicating they were still situated within the supply zone, but unlike the preceding phases, sites within the supply zone had no direct access to Long Island anymore. They had to obtain the material through exchange with people controlling the source, as suggested by settlement activity on the small islet itself.

The study of the St. Martin greenstone and calci-rudite artefacts has revealed a much clearer distinction between communities having direct access to these sources and other communities who acquired these materials by means of exchange. The former are the ones that were actually involved in the production of axes, whereas the latter interacted with them to obtain solely finished products. Comparison between the different phases shows that greenstone production was very localized during the Early Ceramic A phase, only the site of Hope Estate on St. Martin yielding evidence of axe manufacture. Finished tools, however, were relatively widely exchanged, particularly to the west. During the following phase, greenstone production expanded over the islands immediately surrounding St. Martin. The distribution to Puerto Rico and the Virgin Islands ceased and was directed more to the south. The number of production sites increased in the Late Ceramic A and the material is commonly found within the Anguilla - Guadeloupe region, while beyond this region, items are occasionally identified as well. The latest phase is still poorly known, but limited data minimally suggest that greenstone axes were still made and exchanged.

Evidence for calci-rudite zemi production and exchange is considerably more limited. In particular, the identification of zemi production sites has proven to be a problem for the two Early Ceramic phases. Zemis were definitely manufactured during the Early Ceramic B phase. However, it cannot be established where these objects were fabricated. The Rendezvous Bay site on Anguilla is the most likely candidate. Contrary to these early phases, the Late Ceramic A phase yielded clear evidence of production and distribution, marking the heyday of calci-rudite zemi usage within this region. Production was restricted to the western part of St. Martin and the neighbouring island of Anguilla, "nicely surrounding" the Point Arago source. Finished zemis, less abundant in number than the greenstone axes, were found on many of the surrounding islands, 


\begin{tabular}{|c|c|c|c|c|}
\hline & $\begin{array}{l}\text { Early Ceramic A } \\
(400 \mathrm{BC}-\mathrm{AD} 400) \\
\end{array}$ & $\begin{array}{l}\text { Early Ceramic B } \\
(\mathrm{AD} 400-850)\end{array}$ & $\begin{array}{l}\text { Late Ceramic A } \\
(\mathrm{AD} 850-1250)\end{array}$ & $\begin{array}{l}\text { Late Ceramic B } \\
(\text { AD } 1250-1492)\end{array}$ \\
\hline Beads and Pendants & $\begin{array}{l}\text { * Extensive exchange network in } \\
\text { which exotic and local varieties } \\
\text { were distributed }\end{array}$ & $\begin{array}{l}* \text { Manufacture and distribution } \\
\text { of local varieties }\end{array}$ & $\begin{array}{l}* \text { Manufacture and distribution } \\
\text { of local varieties }\end{array}$ & $\begin{array}{l}\text { * Manufacture and distribution } \\
\text { of local varieties }\end{array}$ \\
\hline Zemis & Not in use & $\begin{array}{l}\text { * First appearance of zemis } \\
\text { * Manufacture of small zemis } \\
\text { * Localised calci-rudite } \\
\text { distribution }\end{array}$ & $\begin{array}{l}* \text { Heydays of calci-rudite } \\
\text { manufacture and distribution } \\
* \text { Use of elaborate zemis }\end{array}$ & $\begin{array}{l}* \text { Termination of calci-rudite use } \\
* \text { Use of elaborate zemis }\end{array}$ \\
\hline Axes & $\begin{array}{l}\text { * Localised St. Martin } \\
\text { greenstone manufacture and } \\
\text { extensive distribution } \\
\text { * Limited manufacture of axes } \\
\text { made out of other materials }\end{array}$ & $\begin{array}{l}* \text { Extensive greenstone } \\
\text { manufacture and extensive } \\
\text { distribution } \\
* \text { Limited manufacture of axes } \\
\text { made out of other materials }\end{array}$ & $\begin{array}{l}* \text { Extensive greenstone } \\
\text { manufacture and distribution } \\
* \text { Limited manufacture of axes } \\
\text { made out of other materials }\end{array}$ & $\begin{array}{l}\text { * Possible continuation of } \\
\text { extensive greenstone } \\
\text { manufacture and distribution }\end{array}$ \\
\hline Flake tools & $\begin{array}{l}\text { * Expedient technology } \\
\text { * Extensive Long Island flint } \\
\text { distribution }\end{array}$ & $\begin{array}{l}\text { * Expedient technology } \\
\text { * Extensive Long island flint } \\
\text { distribution }\end{array}$ & $\begin{array}{l}\text { * Expedient technology } \\
\text { * Limited Long Island flint } \\
\text { distribution }\end{array}$ & $\begin{array}{l}\text { * Expedient technology } \\
\text { * Limited Long Island flint } \\
\text { distribution }\end{array}$ \\
\hline Other tools & $\begin{array}{l}* \text { Limited usage of metates } \\
* \text { Varied usage of pebble tools }\end{array}$ & $\begin{array}{l}* \text { More common usage of } \\
\text { metates and local manufacturing } \\
\text { sites } \\
* \text { Varied usage of pebble tools }\end{array}$ & $\begin{array}{l}* \text { Common usage of metates } \\
* \text { Varied usage of pebble tools }\end{array}$ & Very limited data \\
\hline
\end{tabular}

Table 7.1. Main trends in stone tool manufacture and distribution among the northern Lesser Antilles during the Ceramic Age by phase.

covering the area between Puerto Rico and Guadeloupe. Limited evidence from the latest phase thus far suggests termination of calci-rudite zemi manufacture and distribution in late prehistoric times.

A down-the-line mode of exchange, in which exchange took place on a reciprocal basis, is supported from a production point of view. Data relating to flint flake tool production suggest on-site working, most likely at the house-hold level. In particular, the overall occurrence of flake tool production, the un-standardised nature of the reduction process, and the relatively simple and ad-hoc means of making flake tools support this view. The more restricted axe and zemi making may indicate initial forms of craft-specialisation, in particular during the Late Ceramic A phase, although the data do not suggest that axes were being made by full-time specialists.

Additional variation among the transport of the different materials is seen in the form in which the rocks were exchanged. Long Island flint was generally traded as unmodified cobbles, whereas the greenstone and calci-rudite went from hand to hand as finished objects. This reveals something about how they were valued. Long Island flint was primarily seen as raw material from which utensils could be extracted. In this sense, its utilitarian value was emphasized, whereas for the other materials the finished object, with all its associated meanings and values, was centred to the exchange transaction. Above it was argued that this difference in value was most emphasized during the Late Ceramic A phase, when the distribution and production data exhibited most variation between the three materials. This Late Ceramic A change logically was associated with socio-political processes.

\subsection{INTER-ISLAND EXCHANGE NETWORKS AND SOCIO-POLITICAL ORGANISATION}

\subsubsection{Introduction}

In Chapter 1, I discussed the current views about socio-political organisation within the Caribbean, and in particular in the Lesser Antilles. A main issue under considerable debate relates to the formation of a chiefdom level of society during the Late Ceramic Age within the northern Lesser Antilles. Based on the anthropological literature, I further showed the crucial role exchange relationships can play in the processes that lead to greater complexity. Especially within more politically oriented models, much emphasis is placed on the active role people play in forming and manipulating relationships in their wish to acquire power.

The results of my study of the exchange of stone materials within the northern Lesser Antilles can now be used to contribute to the current discussion. Before proceeding, I want to stress that I realize that approaching this debate from an exchange point of view will only have limited explanatory power. The results will initially tell us something about existence 
of social relations between islands and the possible changes they underwent through time. Additional data in the form of burial practices, settlement patterns, and intra-site organisation are needed to acquire a better insight into the possible existence of socio-political stratification. Still, some of the patterns and the changes they underwent during the different phases reflect changes in the social structure and organisation within the region.

I showed that the production of the flake tools and axes and zemis occurred on a house-hold level of production throughout the whole Ceramic Age. This production may have involved craft-specialists who were stone workers among their local community and they exercised their tasks on a part-time basis. However, the data do not support the existence of full-time specialists who standardized the production process and its outcome. These features do not by themselves point to growing organisational complexity. From the changing distribution patterns through time, however, certain aspects can be elucidated that correspond with some of the views brought forward about growing socio-political complexity within the region.

\subsubsection{The Early Ceramic Age}

The first agriculturalists, the Saladoid people, rapidly explored the Lesser Antilles and settled the islands. Many have emphasized the short time-span, during which this occurred and the cultural homogeneity of the early Saladoid series over a large geographical area. Considering this, some have argued that the communities must have been organised at a level that surpassed simple egalitarian societies (Hoogland 1996; Siegel 1996; see Chapter 1). In addition, inter-island interaction apparently played an important role. Specifically, frequent inter-community contact is considered as crucial for societies exploring and settling new environments. In this way, social risks in the form of hostile encounters with neighbouring Preceramic Age foragers or keeping the birth-rate high enough in a sparsely populated region without violating any incesttaboo, could be controlled.

In relation to this, Watters (1997a) proposed the homeland model of the Lapita culture in the Pacific as a possible analogy for the Saladoid case. Kirch (1988) reports that the fast and extensive spread of the Lapita culture over the various widely spread Pacific islands coincided with the maintenance of contacts with its place of origin, as evidenced by the extensive distribution of obsidian varieties from the "homeland", rather than the exploitation of local sources on the newly settled islands. Kirch sees this contact with the homeland as an important feature of the successful Lapita colonization.

In a recent article, J. Moore (2001) tested different colonization models with regard to their success in new surroundings. Using stochastic simulations, he found that one of the crucial factors for successful colonization was the ability of the colonizing community to stay in contact with at least one socially related community. Therefore, the "string of pearls" model of colonization is as viable as other modes (J. Moore 2001, 396 fig. 3). In the "string of pearls" model, colonization expands in a line, along a river for example, connecting the communities in a one-to-one relationship, as if they belonged to a string. In most other models, the exploring community stays in contact with several communities at one time, as in a matrix. For the Saladoid case, this is an interesting viewpoint. Transferred to an island environment, this string of pearls mode can be seen as a chain of settlements populating each island, or each of the major islands. This strongly resembles the early Saladoid situation in the Lesser Antilles. Apparently the fact that contact was maintained along this chain of sparsely populated islands contributed to successful colonization.

Keegan et al. (1998) presented interesting viewpoints about the first Saladoid migrations into the Antilles, which in light of the above argumentation need some further discussion. They asserted that the first Caribbean horticulturalists were Arawakan speaking people, who had an uxorilocal rule of residence. They derived their main arguments from a theory on matrilocal residence formulated by Divale (1984), and asserted that: (a) Taíno elites had an avunculocal residence rule according to the historical sources; (b) avunculocal residence likely derives from uxorilocal residence; (c) the scanty data on the Taíno language suggest that it belongs to the Arawakan language family; and (d) nowadays Arawakan peoples, living in the Amazon, have a uxorilocal residence rule.

In short, Divale (1984) argued that matrilocal or uxorilocal residence rules only come into existence as a response to a situation of social stress. In normal circumstances, the residence rule is patrilocal, which is found among the vast majority of small-scale societies. One of these stress situations may be migration or frequent waging of external warfare (warfare against communities outside one's own society, hence with speakers of other languages). The underlying explanation relates to the existence of fraternal interest groups among patrilocal societies, which undermines internal cohesion in such societies. Competition between these interest groups results in internal warfare. In a society that is exploring new environments, or waging external warfare, men tend to be away for long periods and women are forced to cooperate among themselves for 
protection and to maintain the subsistence production. In such situations they are likely to group themselves with their closest family members, i.e. their sisters and daughters. As a result, internal cohesion is attained because the fraternal interest groups are broken. Brothers are not living together anymore, but are living with their wives, often in separate villages.

After external warfare ceases, or a society becomes settled in newly colonized surroundings, men will attempt to acquire internal control again. This will change matrilocal residence into an avunculocal one, in which descent remains matrilineal, but the residence rule groups matrilineal related men together, creating a new internal interest group, similar to fraternal interest groups in patrilocal societies. Further evolution will create virilocal residence, before society finally becomes patrilocal again. According to Keegan et al. (1998), Saladoid society corresponded with the matrilocal stage of this presented sequence. This society was externally oriented, and focussed on exploration and settlement within a new environment. As a result, the men were making long trips often with uncertain outcomes due to the threat of accidents on sea or hostile encounters with the existing population on the islands (external warfare). ${ }^{1}$

In this light, the documented long-distance semi-precious bead and pendant exchange network is typically related to the earliest phase of Saladoid occupation on the islands and it extended from the South-American mainland, the homeland, along the Lesser Antilles towards Puerto Rico. It seems to reflect existence of this important inter-community contact during the initial settlement of the islands (figure 7.1). Exchange would have been facilitated or initiated by the wish of related men (brothers), perhaps living in separate communities (i.e. with their wives family), to keep in contact.

The relatively wide distributions of Long Island flint and greenstone during this early period correlate well with the long-distance semi-precious bead and pendant exchange network. Flint and greenstone exchange likely occurred simultaneously with the handing over of the semi-precious stone items. Furthermore, it should be stressed that the population density was relatively low compared to later times, since many islands were still uninhabited. In such a situation, exchange transactions involved longer distances and a down-the-line movement of a rock material among a few communities easily produced this extensive distribution.

In regard to the homeland model introduced to the Caribbean by Watters, it has to be stressed that the Saladoid communities were not solely looking backwards to their place of origin for stone resources. They also rapidly adjusted to new island environments, shown by the very early appearance at Trants and Hope Estate of local Lesser Antilles Long Island flint and St. Martin greenstone.

\subsubsection{The Early to Late Ceramic Age transition}

From the Early Ceramic B phase onwards, the described rock materials became less common with greater distance from their sources. This is particularly evident for materials moving in a western direction to the Virgin Islands and Puerto Rico. Among the Puerto Rican sites, we see a decline in the abundance of the Long Island flint and greenstone. In case of Long Island flint, even a total disappearance may have been the case eventually from Late Ceramic A onwards. Apparently, the large stretch of ocean between Anguilla and the Virgin Islands, the Anegada Passage, corresponded with a social boundary during the later phases of Amerindian occupation. In the southeastern direction, the decline was less sharp. Data suggest that Long Island flint did not reach Martinique anymore after the Early Ceramic Age, whereas the island's inhabitants may have still obtained greenstone axes on a regular basis. On the other hand, frequency differences in Martinique compared to Guadeloupe are significant.

This less extensive distribution relates well to the disappearance of the long-distance exchange of semi-precious materials. In Chapter 5, I showed that the occurrence of stone beads and pendants was diminishing during the Early Ceramic B phase, including the disappearance of certain materials pointing to long-distance contacts. Beads and pendants become predominantly made of varieties local to the region. Furthermore, the use of commonly available shell for making decorative artefacts became more predominant later in time. This is particularly evident at the Late Saladoid and mainly post-Saladoid site of Anse à la Gourde.

It is noticed at the same time that the number of settlements increased in the region, notably during the Late Ceramic A phase, suggesting a significant population increase (e.g. Crock 2000; De Waal 2001, 2006; Wilson 1989). Alongside this

\footnotetext{
1 There is an additional aspect, not touched upon by Keegan et al. (1998), that deserves mention in relation to Divale's theory, as it provides a feature that can be tested archaeologically. Apart from a correlation between external warfare/exploration and matri/uxorilocal residence, Divale also found a correlation between larger house size and matri/uxorilocal societies, as well as the existence of men's houses among matrilocal societies. With regard to men's houses, the excavations at the Saladoid site of Golden Rock have revealed an example of such a large structure (Versteeg \& Schinkel 1992). This provides additional evidence for the existence of the matrilocal residence rule among Saladoid society.
} 


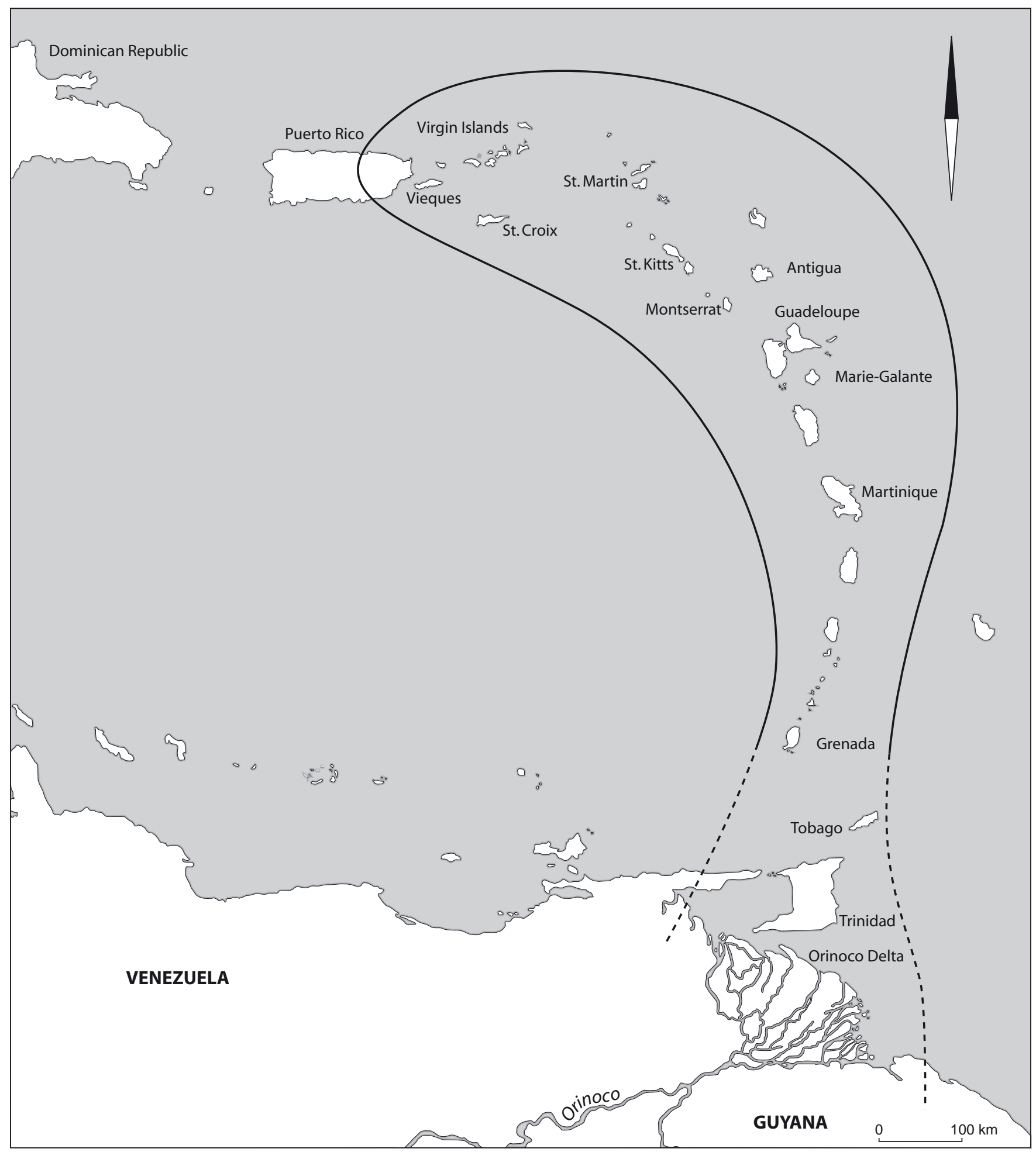

Figure 7.1. The area of the semi-precious stone bead and pendant exchange network during the Early Ceramic A phase (400 BC - AD 300$)$. 
increase, habitation became more evenly spread. This not only included settlements on previously unsettled islands, but also within already occupied islands as all available coastal areas became populated. Anguilla, for example, experienced the settlement of its first agriculturalists during the start of Early Ceramic B phase, after which it evolved towards a regionally important centre during the following Late Ceramic A phase (Crock 2000; Crock \& Petersen 1999). St. Eustatius, Saba, and Barbuda became populated as well (Hofman 1993; Hoogland 1996; Versteeg \& Schinkel 1992; Watters et al. 1991). This populating of uninhabited islands, co-occurred with the abandonment of certain long-term occupied sites, such as Hope Estate and Trants. At the same time, many of the sites, that later would become large settlements, came into existence, such as Anse à la Gourde on Guadeloupe, and Rendezvous Bay and Sandy Ground on Anguilla (Crock 2000; Crock \& Petersen 1999; Hoogland 1999; Hofman et al. 2001; Petersen 1996; Petersen et al. 1999; Watters and Petersen 1999).

Along with this population increase, the appearance of local pottery styles was notable, which clearly distinguishes different micro-style areas. Hofman and Hoogland (2004) in their synthesis of the northern Lesser Antilles speak about the formation of micro-regions during this period, including a limited number of neighbouring islands. The data of stone material distribution and exchange certainly correlate with these findings. One such micro-region can be specified for the area extending from Anguilla to Guadeloupe, as the three stone materials in this study have a relatively common occurrence there. Apparently, the increasing population on the islands resulted in the formation of sub-regions, that acted independently with respect to resource procurement, as well as social matters. Allen (1985), explaining a similar situation in Pacific history where population increased and networks became more localized over time, speaks of changing social distances in relation to geographical distances. In the earlier situation, which would correspond to the Early Ceramic A phase in this study, the social distance between geographically widely separated communities was small. During later phases, starting in the Early Ceramic B, populations expanded on the islands and socially related communities were living closer by (see Allen 1985, fig. 2).

Bringing the evidence together for stone distribution during the Late Ceramic Age, it is possible to distinguish four levels of interaction on a regional scale. The smallest region of interaction corresponds with the direct access area of the calci-rudite stone material (figure 7.2). This region included Anguilla and the western part of St. Martin. It may have hosted closely related social communities, for example, all members of a certain lineage. These communities could have fallen under the leadership of one headman and probably were operating in close cooperation, as they were controlling the calci-rudite source. The following level of interaction corresponds with the direct access area of the greenstone material and included those communities that were regularly making trips to St. Martin. Considering the larger area of direct access, it may be assumed that either control and ownership of the greenstone outcrops did not play a role, or that such control was difficult to accomplish in case of this material, which was widely available across the island. This may have facilitated direct access by communities coming from different islands. The third level of interaction included the area of common abundance of the stone material, as obtained through exchange. This suggests that within this area inter-island contact was occurring on a relatively regular basis. For the Late Ceramic phases, this was the Anguilla - Guadeloupe region. The fourth level of interaction included the entire area of a rock material's distribution and corresponds with rare inter-island contact. This was likely the Martinique - Puerto Rico area, or even beyond.

For the Early Ceramic Age, the regions for levels 3 and 4 are less clearly defined, at present. Furthermore, direct access to sources was apparently related more to distance to the source, than to definite ownership rules. For example, Hope Estate was the only Early Ceramic A phase site with greenstone production remains, as sites on most surrounding islands did not exist yet.

In line with the theory of Divale (1984), Keegan et al. (1998) argue that the transition from Early Ceramic B to Late Ceramic A may have been the time when the uxorilocal residence rule of the first settlers started to change toward an avunculocal residence rule. In this view, the formation of more densely populated micro-regions altered the perspective of society from an outward oriented one focussed on exploration toward an inward one, in which settled communities started to form multivillage polities, which competed for control over land and resources. According to Keegan et al., this new rule of residence offered great opportunities for a strong village headman (mother's brother) to easily bond a number of men to him. These were not only the sons of his sister who were living with him, but also his own sons who were living with their mother's brother family. If clever and powerful enough, the headman may have exercised rule over several communities and thereby become a man with regional leadership (a chieftain), opening the way to the development of a chiefdom proper.

The stone use and distribution data provide some additional features to support the idea of increasing internal competition between these micro-regions during the late phases of Amerindian occupation of the islands. Curet $(1992,1996)$ previously argued that the development of social complexity in the Greater Antilles was not a result of population pressure, 


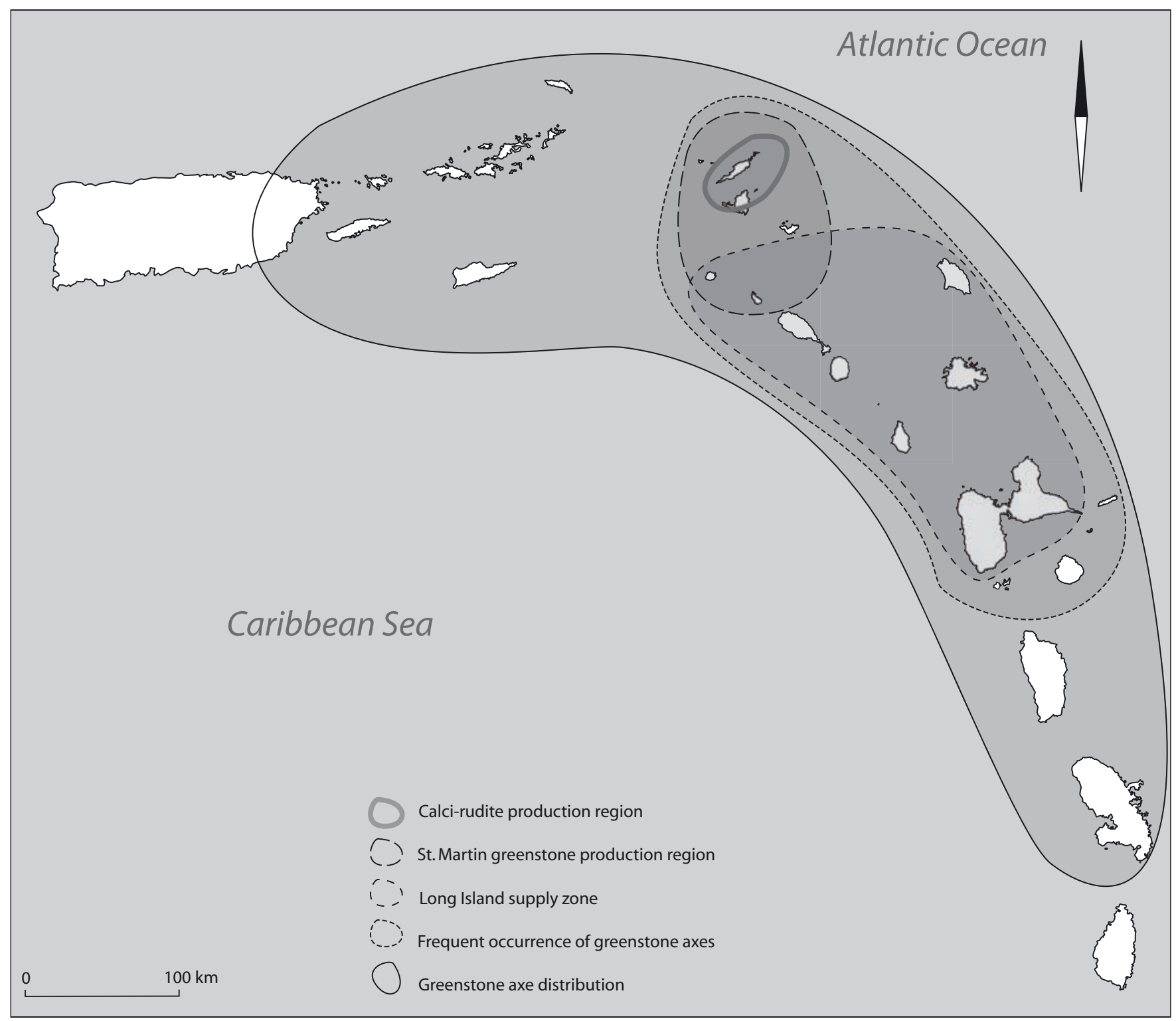

Figure 7.2. Different interaction regions among the northern Lesser Antilles during the Ceramic Age.

but rather followed a more politically motivated path, in which local leaders were able to gain regional power through the manipulation and control of ideology. In this respect, the control of the manufacture of the calci-rudite zemis, representing important religious objects, may have played a role. I demonstrated above that access to the calci-rudite source was only possible for sites on Anguilla and a few on St. Martin. Considering the very localized occurrence of this source, it must have been relatively easy for communities living nearby to exercise control over the locality and deny others access to it. By doing so, they were able to appropriate these powerful objects, which may have given them a renowned position within the region. In Chapter 1 I pointed out that within present-day Amazonian societies, the spiritual or religious specialists have the ability to become powerful figures in their society. The special place that the shaman, or behique fulfilled in Taíno society, as described in the historical documents, further supports this.

Archaeological evidence from Anguilla correlates well with the special position that the island was given during the later phases of the Ceramic Age, as the work of Crock and Petersen has shown (Crock 2000; Crock \& Petersen 1999). They 
demonstrated that the island hosted some of the largest sites in the near Lesser Antilles region, which produced a number of high-status artefacts. Access to the calci-rudite material and to a lesser degree access to the greenstone along with the island's location closest to the Greater Antilles chiefdoms, may have given the inhabitants a crucial advantage over their northern Lesser Antilles neighbours (Crock 2000). Study of the Haida and Tlingit in the Northwest Coast region of North America and the Trobianders of the Melanesian archipelago has shown that superior locations with respect to resources were crucial in the development of chiefdom societies. These locations enhanced competition among these peoples over who was the controlling figure of this superior access in relation to the neighbouring societies (Rosman \& Rubel 1989; see Keegan et al. 1998).

There is one aspect of the greenstone axe making that deserves more detailed discussion in relation to the regional importance of the island of Anguilla, and possibly the western part of St. Martin as well. The number of axe making settlements increased markedly during the Late Ceramic A (see Chapters 5 and 6). This increase was already present during the Early Ceramic B phase, when sites on the islands surrounding St. Martin became involved in greenstone axe manufacture. The number of sites per island, however, remained small, indicating that greenstone axe production was still performed in relative isolation, mirroring the Early Ceramic A phase situation. This contrasts with the Late Ceramic Age situation on Anguilla. Numerous simultaneously occupied sites there have yielded significant amounts of greenstone material, suggesting a continuously high production of greenstone tools. From the general appearance of finished greenstone axes within the wider region, it is evident that these particular settlements did not solely work to fulfil their own demands, but were also producing more widely for extensive inter-island exchange.

This structural involvement in greenstone tool manufacture among closely neighbouring villages, intended for exchange with villages on the neighbouring islands, suggests some internal cohesion between these settlements. This situation is clearly different from that in the Early Ceramic A phase, when only the Hope Estate site was seemingly involved in greenstone axe production. Rather than seeing these as communities operating on an individual basis, it can be assumed that they were organised or tied together by some supra-village level of authority (see Cobb 2000 for discussion on communal activities). This supra-village authority may have been a chieftain who was able to gain regional control by his own endeavours, or it was possibly a true ascribed chief. In this light, the small number of settlements where calci-rudite zemis were being made may have represented villages higher in the settlements hierarchy. These villages then likely hosted powerful ritual specialists (the Lesser Antilles equivalent of the Taíno behiques), or members of a chiefly lineage.

The first appearance of small settlement sites on Long Island during the Late Ceramic A phase, can be also interpreted from this perspective. In Chapter 4, I suggested that they may have represented (short-term) controlling camp sites, which were occupied by people from communities on Antigua who controlled access to the Long Island flint. Whether the more restricted distribution of Long Island flint among the surrounding islands then is a result is still open for debate. If it is true that social networks became more localized, as argued above, then this more limited distribution could be explained by the shift of social boundaries, rather than by greater difficulty in obtaining Long Island flint. The data on flint reduction at the local settlements, however, favour the scenario of more restricted access, although the proof of this is thin. Compared to sites from the Early Ceramic B phase, the following phases yielded higher efficiency ratios for sites lying at a similar distance. This would mean that flint was considered scarcer, as a result of greater difficulty of acquiring it. On the other hand, it should be pointed out that the Early Ceramic A phase sites produced the highest values in this respect. This indicates that although material abundance was relatively high during this period, material was perceived to be scarcer than during the later phases. This may be attributed to less frequent inter-island traffic and material transport between different communities, relative to later phases.

There are other features that support growing socio-political complexity. The first one relates to the finding of a St. Martin greenstone axe and calci-rudite zemi within the Late Ceramic A phase of the Paso del Indio site. It is probably one of the few sites on Puerto Rico from this phase that yielded these exotic items. The large size of this settlement and the large number of burials suggest that we are dealing with a site of regional significance. Such was the case for Anse à la Gourde as well (Hofman et al. 2001). This latter site yielded a significant number of greenstone axes and some calci-rudite zemis. Given the presence of these artefacts at these two large sites and the fact that only these two valuables from the Lesser Antilles were found at Paso del Indio and not the more commodity-like Long Island flint suggest that we are dealing with gift exchanges of highly esteemed objects, which likely occurred between the leaders of these regional centres. Wilson (1990) has mentioned the well-known case of chief Caonobo's wife, Anacaona, the sister of chief Behecchio on Hispaniola, as an example of an elite person. She accumulated numerous valuables through gift-exchanges with other chiefs. Apparently, the circulation of these valuables did not take place simultaneously with the Long Island flint distribution any more and became part of another exchange network, which extended beyond the local micro-region. This suggests that local village leaders from the Lesser 
Antilles were interacting with chiefs from the Greater Antilles. The involvement of the Lesser Antilles in one or more of the Greater Antilles elite networks may support the appearance of status variation among the Lesser Antilles.

\subsection{The Late Ceramic B phase}

Entering the latest phase of indigenous occupation of the islands, some changes occurred. In the first place, the small number of reported sites is striking. Secondly, most of the sites markedly differ from their predecessors in the ceramic styles encountered and site locations chosen, as work at Kelbey's Ridge 2, Morne Cybèle, and Morne Souffleur has shown (De Waal 1999a, 2006; Hofman 1993, 1999; Hoogland 1996). Thirdly, some long-term occupied sites, such as Anse à la Gourde were abandoned (Hofman et al. 2001). These facts suggest that the social and cultural situation of the northern Lesser Antilles islands changed, although it has to be stressed that the data are still limited as detailed knowledge for many islands is missing. Hofman and Hoogland argue on the basis of ceramic styles, foreign to the region, that new groups were entering and settling the islands, from a western as well as a southeastern origin (Hofman 1993, 1999; Hoogland 1996). Apparently, the northern Lesser Antilles micro-polities (Hofman \& Hoogland 2004), which were formed during the Early Ceramic B phase and experienced their heyday during the Late Ceramic A phase, collapsed at the time, and the central sites were abandoned, leaving room for new people to enter. Although not everyone shares this view (e.g., Crock 2000), and as data for many islands is still lacking or scanty, it may well explain the marginal position the northern Lesser Antilles received in the accounts of the Early Spanish chronicles.

The decline and possible disappearance of the calci-rudite zemi production and use during this latest phase is in accordance with this notion. Detailed analysis of calci-rudite zemi abundance on Anguilla showed that they diminished at the younger sites, being almost absent at Shoal Bay East, which has produced the latest dates for the island. The presence of these artefacts is not reported after approximately AD 1350 in the surrounding region as well. Apparently, with the collapse of Anguilla's central position, which it fulfilled during the Late Ceramic A phase, the role of calci-rudite zemi manufacture as an important means and token to acquire power faded.

In contrast to the decline and possible disappearance of calci-rudite zemi usage, greenstone and Long Island flint continue to be important materials for stone tool production during the Late Ceramic B phase. This suggests that these materials were less sensitive to socio-political or cultural changes. Probably their utilitarian value formed an important feature in addition to their religious or cognitive value, whereas the value of the zemis was primarily related to the ideological realm. Therefore, the greenstone and flint exchange was not primarily or totally dependent on gift-exchange networks between chief(tain)s or spiritual specialists, who were operating in the political arena of competing micro-polities.

Another interesting aspect is the abundance of Long Island flint at Kelbey's Ridge 2 on Saba. Hofman and Hoogland (1999; Hofman 1993; Hoogland 1996) affiliate this site with the Boca Chica ceramic style from Hispaniola and therefore, argue that Saba became part of a Taíno interaction sphere during this late phase. Notwithstanding this stylistic similarity, the abundance of Long Island flint at this site points to interaction within the northern Lesser Antilles itself, rather than maintaining contact with the presumed region of the inhabitants' origin. This favours a scenario in which the small community at Kelbey's Ridge 2 abandoned Hispaniola, for which fissioning may have been the reason, after which it settled on Saba, as this small island was not inhabited then and therefore provided enough room for occupation in contrast to, for example, Puerto Rico or the Virgin Islands, where chiefdom societies resided. Given their social affiliation with distant Hispaniola, contact with their relatives faded, and the community at Kelbey's Ridge sought interaction within its new surroundings.

This relatively abrupt change from a dynamic region where population expanded, and social complexity increased towards a marginal region where sites were abandoned and an "invasion" of new groups occurred seems to provide room for the reopening of the "Island Carib debate" again. The causes for this change need to be addressed first, before the situation in the last phase of Amerindian history can be fully understood. Important in this respect is whether the change can be explained from processes occurring within the northern Lesser Antilles societies themselves or whether outside forces or even invasion by foreign groups were the main reasons for the decline. 


\subsection{CONCLUDING REMARKS}

I attempted here to link some of the exchange and distribution patterns found within the scope of this research with some of the issues about socio-political organisation currently at stake within the northern Lesser Antilles. One of these issues is focussed on the possible development of stratified societies during the Late Ceramic Age. I have not explicitly expressed myself in favour of the existence of chiefdoms on one hand, or chieftaincies on the other. In my opinion, the data for lithic production and exchange do not necessarily prove or disprove one or the other. However, it has become clear that the Late Ceramic A phase displayed some changes relative to the Early Ceramic A phase. During the early phase, dispersed villages operating on an individual basis were involved in a long-distance interaction network that was necessary for the successful colonisation of the archipelago. By the Late Ceramic A phase, this long-distance network had disappeared and the more densely populated islands became part of relatively independent micro-regions. It was noted that competition over resources increased within the micro-regions. Furthermore, multiple villages on the same island became engaged in artefact manufacture of items with a regional significance, involving part-time craft-specialists. It was suggested that this was a communal enterprise organised by a supra-village level of authority. This contrasted notably with the single village producing greenstone axes during the earliest phase.

These changes apparently were related to increasing complexity during the Late Ceramic A phase, in particular, communal activities and competition over resources. These facts by themselves, however, do not prove stratification, as chieftaincies may be capable of accomplishing communal activities, although on a temporary basis. Furthermore, the fact that full-time specialists were not necessarily making the objects suggests that stratification likely had not (fully) developed. On the other hand, there are indications that the situation as sketched for the Late Ceramic A phase may have lasted for a few centuries at least (Crock 2000). In such a case, a supra-village level of authority cannot be explained by the presence of a chieftaincy only. Power within these societies was fluid because it was dependent on achievement and therefore, it may have alternated relatively quickly between headmen of different villages. As Redmond (1998c) has argued, a stable chieftaincy, which is ruled for a considerable period by the same lineage, will likely transform into a chiefdom over time.

These points make it clear that if chiefdom societies had come into existence within the northern Lesser Antilles during the Late Ceramic A phase, the data at least suggest that it did not evolve into a fully developed one. Considering the situation during the Late Ceramic B phase, which displays an abandonment of many central sites and intrusion from outside groups, any multi-village polity had likely disappeared at that time.

Let me end by making a few final comments on the study of stone tool production and exchange within the Caribbean. My work has clearly demonstrated that this is a fruitful line of research in this region. The presence of many small islands providing different stone resources offers a great setting for identifying stone material distributions. Within my research, I concentrated on the use and distribution of three different materials. I showed that they were widely used and exchanged among the northern Lesser Antilles throughout the major part of the Pre-Columbian era. Apart from these three materials, it is evident that the Amerindians exploited several other lithic sources. For a number of them, I was able to pinpoint possible provenances that in many instances proved to be relatively nearby sources. Still, the origin of a portion of the stone artefact assemblages remains unspecified. These include many of the semi-precious rock materials used for bead and pendant manufacture, as well as a various stone types used for making axes. Many of these materials most probably originated from very distant sources outside the present study area. Concentrating on these materials in the future may provide information on long-distance relationships, which are additional to the data obtained in this research. In this light the St. Martin greenstone exchange network needs further elaboration as well, in particular with regard to the Late Ceramic A phase. Recent identification of greenstone axes at sites on St. Lucia suggests that the distribution of this material went even further than was specified during this research (Hofman and Hoogland, personal communication 2003).

With regard to stone tool and artefact production, it is now evident that the habitation sites formed the primary places of manufacture. Still, additional research focussing on the exploited greenstone and calci-rudite source areas is needed. In relation to the greenstone axe manufacture, it is of special interest to find out whether a single source area or whether multiple outcrops on St. Martin were exploited during the different Ceramic Age phases. For the calci-rudite material, future research should attempt to identify the places of Early Ceramic Age zemi manufacture. Analysis of material from the excavations at Rendezvous Bay site, currently being done by the University of Vermont (Petersen and Crock, personal communication 2004), should receive a central role in this matter. Additionally, larger samples from both lithic materials need to be studied to obtain more accurate data on production behaviour. In combination with more accurate chronological 
assignment of the places of manufacture, this will provide a more complete view on the organisation of production through time. As such, it will first further elaborate and help close the gaps within our current picture of calci-rudite zemi manufacture and secondly, it may provide better insight into the interpretation of the involvement of different villages in the production of both artefacts. 


\section{Appendix A Chert and flint sources}

\section{A.1 INTRODUCTION}

Within this appendix, I provide a detailed description of each flint and chert source included within the present study. These descriptions are complementary to the short summary presented in Chapter 2 (section 2.3). The total number of lithic sources included in this study equals 15 . Some of these have been already reported by earlier researchers, but for a number of them this is the first time that they are being described.

The sources can be found on three islands: Antigua, St. Kitts, and Puerto Rico. I visited each of the localities at least once, except the chert occurrences at Moca, which were visited and sampled by others (Walker et al. 2001). Major attention was directed towards the flint occurrences on Antigua. Therefore I visited Antigua on three occasions in 1997, 1998, and 2000. The 1998 field-trip lasted two weeks and was primarily directed toward mapping and sampling flint and chert sources. Hans Zijlstra, a sedimentologist and geo-chemist, then working for the Earth Sciences faculty of the University of Utrecht, accompanied me during the 1998 trip. He provided help in interpreting the flint occurrences and explaining the stratigraphy. I visited St. Kitts once during a one week stay in 1994, and chert sources on Puerto Rico were inspected in 1998 during a three day trip to the southwestern region, accompanied by Jeff Walker and Reniel Rodríguez Ramos who were familiar with the chert sources in this area.

\section{A.2 Antigua}

\section{A.2.1 Long Island}

The most widely known flint occurrence within the Antigua Formation lies on Long island, a small islet about a mile to the north of the main island of Antigua (see figure 2.5). It is a very flat island, which extends about $2 \mathrm{~km}$ east-west, and $1.5 \mathrm{~km}$ north-south. The bedrock solely consists of limestone.

Long Island has been long considered as a major source of flint within the northern Lesser Antilles by Caribbean archaeologists (Bartone \& Crock 1998; Crock et al. 1993; Walker 1980a). Preliminary studies on characterisation and sourcing of this material and small-scale archaeological research on the island have supported this idea (Knippenberg 1995, 1999a; see Chapter 4 for a discussion on archaeological research there).

Despite its archaeological significance, the presence of flint is not reported in geological reports concerning Antigua (Martin-Kaye 1959; Mascle \& Westercamp 1983; Weiss 1994). Archaeologists, however, have noted the easy availability of the material several times (Nicholson 1974; Olson 1973). Van Gijn (1996) and Verpoorte (1993) were the first to provide a detailed description of the natural and prehistoric flint scatters. Based on their descriptions and my fieldwork in the seasons of 1998 and 2000, the following general characteristics of the natural occurrence can be summarized.

On Long Island, natural flints can be found in primary context; that is, as nodules in the limestone host-rock, as well as secondary deposits of eroded material on the beach and more inland, both within the dark soils and scattered on their surface. In addition, flint is commonly present in a tertiary form, evidenced by numerous flake and blade scatters spread over the island. From the present-day secondary distribution of the material, it is hard to elucidate the situation in which the prehistoric populations encountered it, as several episodes of construction and land clearing during historic times have altered the landscape, especially in the past twenty years. Large artificial piles of flint situated in the centre of the island, erected as collecting spots after clearing some areas are one of the most obvious examples of modern disturbance (Van Gijn 1996). Still, a general assumption can be made about the original distribution: basically flint occurs everywhere on the island, except on the extended rock outcrop at Cistern Point (see figure 4.1). However, flint is most rare in the southern portion, in the area below an imaginary line from Jumby Bay to Cistern Point. Although excavations there have revealed that natural flint blocks are present in the topsoil, the concentration is low and the blocks generally can be considered as poor raw material for lithic tool production. This low frequency of flint gradually changes as one moves to the north. There, flint becomes more abundant and larger in size. The surface and the topsoil within the areas just behind the Flinty Bay coast are full of different sized cobbles of flint, with a characteristic brown cortex, including many boulders suitable for flaking. The highest concentrations are located on the Flinty Bay coast itself, which literally consists of flint. Along the western and eastern coasts, it is more rare but still easy to locate. 
In addition to the enormous amounts of secondary flint, Van Gijn also describes some places where flint still resides in the limestone host rock. During the 1998 field trip, these localities were inspected. The most significant one is along the north coast between the Flinthouse and the Flinty Bay site, where exposed limestone ledges contain circle shaped, or "stirred" flint (Van Gijn 1996: 189). According to Hans Zijlstra, these flints are concentrated cylinders around mm thin and metre deep vertical syn-sedimentary burrows of Bathichnus paramoudrea (for similar examples, see Clayton 1986 and Zijlstra 1994). Another primary locality extends from the north of Pond Bay to just around the corner with Pasture Bay, where isolated nodules can be found. A third in-situ source is situated along the east coast between Cistern Point and Buckley Bay, where a shallow rock section exposes small layers with flint nodules in them.

In comparison to the secondary surface material, these in-situ sources are very restricted and few in number. This suggests that significant coastal erosion has occurred, which can be considered responsible for the almost total disappearance of all original flint bearing limestone. In this scenario, the vertical burrow flint cylinders must be seen as the lower part of the original flint-bearing limestone deposit. The eroded upper part possibly contained horizontal nodule layers. The fact that most of the limestone that nowadays surfaces at Long Island contains high amounts of foraminifers supports this view, as field inspections at other flint bearing rock sections on Antigua revealed that this specific limestone deposit always underlies more or less directly the flint bearing limestone deposits.

Long Island flint itself has a variable appearance, which mainly can be attributed to the effect of chemical weathering of the rock. Flint from a primary context displaying its original colour has a characteristic very dark grey hue defined by the colour code 10YR 3/1, 2.5Y 3/1, as described in Munsell Soil Color Charts (1990). Just underneath the cortex, it can have a very thin (2-5mm) light olive brown (2.5Y 5/3), greyish brown (10YR 5/2) to brown (10YR 5/3) coloured band. At first sight, the matrix looks homogeneous, but closer inspection reveals that the matrix of the flint exhibits a typical light coloured irregular shaped pattern or "haze", of very fine white inclusions. These appear to be remnant calcite crystals when viewed under a microscope. In secondary context, the colour can have different hues. Flint along the cobble beach of Flinty Bay predominantly keeps this dark colour, whereas within more inland soils the colour has changed. Usually this change is only restricted to an outer band, averaging $1-2 \mathrm{~cm}$ in thickness, with the core remaining dark coloured. Sometimes, the complete rock has altered colour. In general, the colour has become lighter, the hues including light grey (10YR 7/2), (very) pale brown (10YR 7/3, 6/3), (light) yellowish brown (2.5Y 6/3, 10YR 5/4), brown (10YR 5/3), light brownish grey (2.5Y 6/1), and grey/greyish brown (10YR 5/1-2). The brown to yellowish brown hues are often referred to as "honey-coloured" by some scholars (e.g., Haviser 1987).

Five predominant cortex types occur. Cortex around primary flints is clear white, chalky in appearance. ${ }^{1}$ Flint with this cortex can be found on the beach and in some inland parts of the island. A second frequent cortex type is the typical brown "rusty" cortex, which can be found on the flints that are scattered within the soils, notably in the northern part behind Flinty Bay. Seen from the outside this cortex has the typical brown colour, a result of iron staining on the rock. When cut, however, the cortex may still preserve its original white colour, although fully brown examples also occur. On the beach, the flint has a water-worn outer surface; usually the typical outer white cortex rind has disappeared and the inner flint surface is exposed. Depending on the colour of the flint, this type of cortex can have many colours.

The remaining two cortex types are actually not true cortex types, but have formed as a result of natural breakage of the rock. Within the soils of especially the northern area many examples occur of naturally broken flints. As a result of chemical weathering, two main types of patina developed on the broken surfaces. One is a white patina, also commonly encountered on the Preceramic Age artefacts, and the other is a brown patina, probably the result of iron staining. The brown patina occurs in those areas where the brown cortex has also developed, which are the dark soils just behind Flinty Bay coastline. The white patina can be found in the white clayey subsoil, the weathering horizon of the limestone bedrock. These two patina types are mentioned here, as they should be considered as a specific type of outer surface when analysing the artefacts. $^{2}$

In thin section, the matrix of the flint has a somewhat dirty appearance, with remains of calcite, fragments of fossils (bioclasts), and dark coloured particles scattered throughout the rock (see figure 2.15a,b). Such a "dirty" matrix is very typical for the limestone cherts of the Antigua Formation and indicates incomplete silification of the original carbonate host-

\footnotetext{
${ }^{1}$ Although this cortex looks like limestone, it is actually flint. Under the microscope, it is built up by the same crypto-crystalline quartz as the flint portion.

2 During the analysis of lithic artefacts from the different habitation sites on the surrounding islands, it appeared that occasionally the Amerindians collected cobbles, that were partly covered with patinated surfaces.
} 
rock. The crystal size of the crypto-crystalline quartz in the matrix is fine compared to the other sources. It exhibits a mixture of very fine quartz, with low concentrations of coarser quartz grains (up to $0.05 \mathrm{~mm}$ in size). This mixture is commonly encountered among the other Antigua Formation flint sources as well. Chalcedony (fibrous crystal variety of quartz) is rare to absent, and only occurs as filling of some fossils or fossil fragments. The concentration of calcite varies considerably. Primary samples taken from the host-rock still contain significant amounts of calcite, whereas within the majority of the secondary samples this calcite is (partly) lost due to dissolution after being exposed to chemical weathering (see figure 2.22d). Bioclasts (fossils or fragments of fossils) occur within the samples, although in varying concentrations. In general, the bioclast concentrations are low; only in those cases where flint around the burrows formed within the foraminifera-rich limestone layers is the concentration higher. Fossils can both be composed of original carbonate or re-crystallised quartz. Some samples still exhibit ghosts of ooids (oval grains commonly present in limestone), which probably were present in the original limestone host-rock. Iron in the form of oxides is predominantly visible within the secondary samples. In these samples, veins with high concentrations of iron are situated in the rim areas of the rock (see figure 2.22a,b).

\section{A.2.2 Little Cove}

The Little Cove Bay is situated on the east coast of Antigua, where steep cliffs arise from the sea (see figure 2.5). All cliffs are part of the Antigua Formation. Martin-Kaye reports the occurrence of brown flints in the limestone rock at this bay (Martin-Kaye 1959). David Watters from the Carnegie Museum of Natural History was the first who noted its possible archaeological potential. In the company of Desmond Nicholson and geologist Jack Donahue from the University of Pittsburgh, Watters visited the locality in the late 1970s and took samples as reference for the determination of the provenance of flint artefacts found on Barbuda (Watters \& Donahue 1990). ${ }^{3}$

By foot, the locality is only accessible from the south end of Half Moon Bay. After passing the Half Moon Bay resort, approximately $40 \mathrm{~m}$ of bush have to be crossed before a cobble beach in the northeastern area is reached. Unfortunately, one cannot wander to the other sides of the bay, as they are only accessible with a boat during calm weather.

The cobble beach in the northeastern area is approximately $50 \mathrm{~m}$ long and on both sides enclosed by limestone section walls. Between these sections, modern alluvium hit upon the beach. Flint can be found in primary and secondary contexts. It is still present in nodule layers in the northern limestone section, it can be found as eroded water-worn cobbles on the beach and it is also scattered within the alluvium. Upon close inspection, the limestone section revealed six mutually varying layers of flint nodules in a fine-grained carbonate mudstone. Two represent clear layers, that continue all the way through the section, and the other layers only include sparsely scattered flint nodules by approximation situated in a single layer. A striking feature is formed by a shallow cave, that has cut the section. Clear crack lines suggest a natural collapse of part of the section and the subsequent forming of the cave.

On the beach, flint predominates. It has well-rounded shapes and in most cases lacks any original chalky cortex. In the alluvial deposit, consisting of eroded clayey limestone, flint is very scarce and only occurs as irregularly sized and shaped rocks.

Any signs, that may point to the prehistoric exploitation of this flint are absent at the locality itself. On the small beach, no scatters of artefacts were identified. Also the limestone host rock did not exhibit any cut marks from taking the flint out of the limestone. However, such possible marks might have been blurred by later erosion events. Within the vicinity, one unreported prehistoric Ceramic Age site was located along the beach at the south end of Half Moon Bay. A short collection from a ploughed field in the site area produced numerous flint artefacts along with pottery and shell remains. The flints exhibit close similarity with the nearby source material. Material from other sources, in particular the Long Island source, was identified as well at this site.

The Little Cove flint generally is fine-crystalline and exhibits a dull homogeneous matrix, in which a relatively low number of inclusions can be seen. However, these are more numerous than within the Long Island flint. The primary flint is darker coloured than the secondary beach cobbles. Usually, these lighter secondary samples possess small darker coloured areas. Overall, this flint is lighter in colour than the primary Long Island material. Colour varies from (dark) brown (10YR 3/3, 4/3, $5 / 3)$ to (dark) grey $(5 \mathrm{YR} 4 / 1,5 / 1)$ for primary samples, and from light brownish grey $(2.5 \mathrm{Y} 6 / 2)$, (pale) brown (10YR 6//3-

\footnotetext{
3 The same samples were included in the 1997-series of ICPAES analyses, that I conducted to extend my earlier 1993-1995 research (see section on geochemical results).
} 
$5 / 3)$, to (dark) greyish brown (10YR4/2-4/3) for secondary samples. The cortex is white for primary samples and the waterworn samples have largely lost this cortex and exhibit water-worn flint surfaces.

In thin-section, this flint exhibits a dirty matrix similar to the Long Island samples, with the same mixture of very fine quartz crystals and coarser ones (see figure $2.15 \mathrm{c}$ ). Exceptions, however, occur in which the grain-size is finer, or in which chalcedony makes up significant parts. A sample with chalcedony also differs macroscopically from the other samples by being slightly translucent. Unlike the Long Island source, the secondary material at Little Cove does not exhibit a clear decrease in the amount of calcite compared to the primary material, either suggesting shorter exposure to weathering or less intensive forms of weathering. In general, the amount of bioclasts is low (similar to Long Island), but samples may contain higher concentrations, both in re-crystallised quartz as well as original carbonate form. These samples exhibit a dirtier matrix, in which again the original limestone structure of the rock is still preserved.

\section{A.2.3 Soldier Point}

Soldier Point is a small rock mass about $3 \mathrm{~m}$ in height, that extends clearly from the northwestern coast of Antigua (see figure 2.5). Two sandy beaches surround the rock point: Langford Bay on the south side and Blue Waters Bay on the north side. This extended rock cliff is part of the Antigua Formation. Martin Kaye (1959) reported the occurrence of flint at Soldier Point.

Flint can be found scattered on both beaches, but also in the limestone of Soldier Point itself. Unfortunately, no extended sections are accessible and only occasional nodules are discerned on the point. The flint and limestone host rock are similar in colour and texture to the varieties found at Little Cove and the quarry site of Piggot's Hill near the airport. This suggests a common origin and provides support for the restricted occurrence of limestone with flint in it.

At Blue Waters Bay the construction of a hotel, as seen progressing during the first visit in 1997, had severely reduced the beach area and blurred the original natural distribution of flint on it. There is only a small corner on the east side of the sand beach covered with pebbles among which a high concentration of flint can be seen. In addition, large limestone boulders have eroded out of the host rock and are scattered along the shoreline. These occasionally contain some flint nodules. During a second visit in 1998, the outline of the beach had further been reduced and the limestone boulders were taken away.

At Langford Bay, the situation is totally different. Due to the absence of any past or current construction activities, two limestone cliffs still enclose an undisturbed sandy beach. Only at the north side, where the beach borders Soldier Point, can water rounded flint pebbles be picked up. The distribution of flint is very limited. On the south side, flint is absent and the cliff basically consists of the limestone deposits with foraminifera in it, similar to the limestone, that underlies Long Island. The slope of the cliff, dipping in direction toward Soldier Point and its closer geographical proximity to the older Central Plain group, suggest the same stratigraphical relation of foraminifera limestone with the flint-bearing limestone, as at Piggot's Hill.

Neither at Blue Waters Bay nor at Langford Bay is there any evidence of prehistoric exploitation of flint. The major disturbing activities at Blue Watters Bay, however, may have destroyed any such evidence.

The Soldier Point flint strongly resembles the Little Cove material in colour and grain-size; only the amount of inclusions is on average higher within the Soldier Point flint. Samples exhibit a more heterogeneous matrix as well, with some large carbonate grains and bioclasts. The colour does not vary much between primary and secondary material. It ranges from dark greyish brown (10YR 4/2), greyish brown (10YR 5/2), brown (10YR 5/3) to pale brown (10YR 6/3), with the first two hues predominating. The cortex is white chalky or water-worn.

In thin-section, this material exhibits on average a dirtier matrix than the other Antigua Formation sources, with still a lot of carbonate in the form of micrite and coarser-grained calcite preserved (see figure $2.15 \mathrm{~d}$ ). The concentration of bioclasts varies. Quartz crystals in the matrix have similar size ranges to the other Antigua Formation flints, with fine grains and coarser ones mixed. One secondary sample exhibits clear voids, which were probably formed after the dissolution of calcite. 


\section{A.2.4 Blackman's Point}

Desmond Nicholson was the first to identify the natural occurrence of flint at Blackman's Point during his early 1970s archaeological fieldwork at a multi-component site situated along the northeastern coast of this extended point (see figure 2.5) (Nicholson 1976). Although he did not report it then, Nicholson later showed the archaeological site and the natural distribution of flint cobbles to the Leiden field crew working at Long Island in 1989 (see Chapter 4).

Blackman's Point is named after a mill, that is situated in the middle of this peninsula. The area is uninhabited nowadays and can be crossed by a dirt road, which runs along the eastern coast. This area of the island lacks extended sandy or cobble beaches. In general, the coastline is a low, rocky shore, that is covered by vegetation. Soils in this area are clayey, which can be probably related to the presence of former salt ponds, still existing along the eastern coast in some areas.

During two visits in 1998 and 2000, the entire eastern coastline including the salt ponds, the area in the immediate vicinity of the dirt road, and the neighbouring coast to the southeast and southwest of Blackman's Point were inspected for flint. The more inner landward parts of the "point" were only superficially looked at, as impenetrable bush and the absence of clear rock sections or outcrops made it very unproductive. It appeared that basically along the entire eastern coast natural flint rocks are scattered about. The concentration of flint differs significantly and is highest in the southern area, in the middle part of the area surrounding one of the dried salt ponds, and the northern area of the peninsula adjacent to the archaeological site. In the southern area flint cobbles are generally small, with a maximum length of $20 \mathrm{~cm}$ or less. More to the north adjacent to the archaeological site locality, flint blocks become significantly larger. Some exceed $60 \mathrm{~cm}$ in maximum length. The material there is different in nature, as the flint is lighter in colour.

Apart from Blackman's Point, flint can be also found at neighbouring Brian's Wharf parallel to a small dirt road crossing an extended dried part of its shoreline. The flint scatter is probably artificial and must be related to the foundation of the dirt road. Local Antiguans likely collected rock material from somewhere in the Blackman's Point area and dropped it on the slightly clayey bottom of the dried shoreline to preserve the road.

The absence of bedrock cross-sections as a result of flat topography in this part of the island inhibits the search for primary flint deposits and complicates its stratigraphic placement within the local limestone sequence, as identified elsewhere. Most probably, the original limestone host-rock containing flint nodules has been eroded and dissolved leaving the more persistent flint. This view is supported by the significant degree of weathering on the flint, evidenced by its coarser grain-size and lighter colour. Thin-section analysis revealed that this chemical weathering is responsible for the almost complete dissolution of the original calcite crystals making the flint more porous and hence, lighter in colour. The more extensive calcite dissolution relative to Long island flint, for example, suggests a longer period of weathering.

Close to the salt ponds possible evidence of local flint exploitation was encountered in the form of sparsely distributed artefact scatters. Further proof of the use of the local flint is found within the multi-component Blackman's Point site. Analysis of archaeological material excavated by Fuess in 1993 (Martin Fuess, personal communication 2001; see Chapters 5 and 6) showed that the Post-Saladoid inhabitants made extensive use of this local flint in addition to Long Island flint, whereas the earlier Preceramic Age people there neglected the local Blackman's Point flint and only worked Long Island flint.

Blackman's Point flint varies in appearance, including colour, texture, and the number of inclusions. In general, it is a dull flint, relatively light in colour, especially when one compares it to the dark grey Long Island flint variety. A very striking characteristic of this material is its reddish to pinkish colour on many pieces, which must be associated with an increase of iron in the rock as a result of chemical weathering, as has been shown by the geochemical analysis. The large variation in colour is clearly evident from the different hues identified among collected lithic samples. Grey varieties vary from light grey (10YR 8/2, 2.5Y 7/1), grey (10YR 6/1, 2.5Y 6/1), to dark grey (10YR 4/1). Brown-yellow flints vary from light brownish grey (2.5 6/2), pale yellow (2.5 Y 7/4), very pale brown (10YR 7/2, 7/3, 7/4), (light) yellowish brown (10YR 5/4, 6/4), to brown (10YR 5/3). The reddish and pinkish hues are pinkish grey (10YR 7/2), pink (7.5YR 7/3, 7/4), (light) reddish brown (2.5 R 5/3, 5YR 6/3), weak red (10R 4/4), and pale red (10R 6/2). These hues do not necessarily represent different groups of rock pieces. Individual flint specimens may consist of different coloured bands or areas, that have hues both within the grey, brown as well as pink to red ranges.

Blackman's Point flint generally does not contain clearly visible inclusions, giving it a homogeneous appearance. However, exceptions occur, with rare specimens containing many inclusions. Two main types of inclusions are present: round white clasts and re-crystallised fossil fragments. 
Blackman's Point flint is on average coarser grained than the other Antigua Formation flints. This is attributed to chemical weathering and the formation of voids. On the other hand however, some exhibit a fine grain-size, suggesting less alteration. The flint cortex of the flints is generally water worn and (dark) (yellowish) brown (7.5 YR 3/3, 4/4, 10YR 4/3, 4/4) in colour on the exterior.

In thin-section, Blackman's Point flint is similar to the primary Antigua flint occurrences regarding typical quartz grain-size, in which the matrix predominantly consists of very fine particles, with larger particles (up to $0.05 \mathrm{~mm}$ ) scattered through it. Blackman's Point flint differs, however, in the absence of calcite leaving clear voids, which in some cases are filled by iron oxides giving them a dark appearance in plain light, or in other cases left blank (translucent in plain light; see figure 2.22c). This makes the rock a relatively pure quartz chert. These samples also lack the typical dirty matrix seen in other Antigua flints. However, some specimens do exhibit re-crystallised bio-clasts, which are often built-up by a fibrous chalcedonic variety of quartz. No detrital minerals are present in the samples.

\section{A.2.5 Coconut Hall}

During my first field-trip to Antigua in 1997, Reg Murphy, government archaeologist on Antigua, mentioned to me the Coconut Hall locality (Reg Murphy, personal communication 1997). This locality is situated on a small peninsula on the north coast of Antigua (see figure 2.5). The area is flat, except for a small hill at the northeast end overlooking Coconut Hall and the neighbouring islet of Guard Point. Today, the little hill exposes evidence of recent quarry activities. However, this quarry was not being used during both of my field trips. The surrounding coast is very irregular, with numerous bays and inlets, covered with dense mangrove vegetation. The underlying geological formation is the Antigua Formation.

Surface inspection revealed that on the fallow grassland to the southwest of the hill and on the north side of a dirt road small concentrations of different sized flint blocks are scattered across the surface along, with chalk rock. Today dirt piles erected by local farmers to clear the land of bush, wood, and large stones, have resulted in artificial higher concentrations of flint. The extension of the scatter of flint blocks is around $100 \mathrm{~m}$ to $200 \mathrm{~m}$. The area where flint can be found is low in elevation, but moving towards the southwest, the land slowly rises and the ratio of chalk rock to flint increases significantly, with only chalk and no flint at the highest points. Unfortunately, clear bedrock sections are almost absent and can be only inspected for flint nodule layers at the quarry site. No such layers can be discerned at the quarry, however.

The flint blocks are angular in shape and do not exhibit signs of considerable erosion. This suggests that natural movement has not occurred. Local limestone bearing flint nodule layers were probably eroded, leaving the more resistant flint blocks, similar to the situation at Blackman's Point and on Long Island. This would suggest that in the higher areas the flint bearing chalk may still be in its original deposition and that with the help of excavations the flint bearing rock could be unearthed to localise its exact stratigraphic position. This would be a time consuming enterprise and therefore, was beyond the means of my field trips.

Just at the foot of the quarry hill, the remains of an extensive Amerindian settlement site can be discerned. Recently, Martin Fuess did survey work and small-scale testing at this site (Fuess 1995; Fuess, personal communication 2001). From Fuess' report, it is evident that recent bulldozing has destroyed large sections of the northern part of the site. Preliminary conclusions about the site's chronology state that it is dated to the Late Ceramic Age, two shell samples producing a calibrated date between AD 935 - 1190 (95\% confidence intervals) (Fuess 1995, personal communication 2001). Brief inspection of excavated material from Fuess' test-excavations revealed that the inhabitants of the Coconut Hall site exploited both the local flint and the Long Island material (see Chapters 5 and 6).

Coconut Hall flint varies considerably more in macroscopic and microscopic appearance than the other Antigua Formation flints. Three general varieties can be distinguished. One variety consists of semi-translucent flints that contain many inclusions, giving the rock a heterogeneous appearance. Predominant colours are dark greyish brown (10YR 4/2), brown/dark brown (10YR 4/3), brown (10YR 6/3), to pale brown (10YR 6/4). The second variety includes dull light coloured banded flints, containing small amounts of inclusions. Colours vary from yellowish brown (10YR 5/4), light brownish grey (2.5Y $6 / 2$ ), greyish brown (10YR 5/2), light grey $(2.5 \mathrm{Y} 6 / 2-7 / 2,10 \mathrm{YR} 7 / 1)$, to pale brown (10YR 6/3). The third variety is a dull, coarser grained flint, with few inclusions. It has a light colour, which ranges from grey $(2.5 \mathrm{Y} 6 / 1)$, light grey $(2.5 \mathrm{Y} 7 / 1)$, to white (5YR 8/1). This latter variety, especially distinguishes itself from the other two. 
In thin-section this latter variety appears to be a non-complete silicified flint, in which high amounts of carbonate remain (see description of St. Kitts material for other similar examples). The other varieties display diverse matrix and quartz types under a microscope. Unlike the majority of Antigua Formation flints, many of these flints do not exhibit the typical dirty matrix of fine quartz, with a small number of coarser crystals. A large group has a coarser crystal size, or significant parts of a radial fibrous chalcedony (see figure 2.17e,f and Schubel \& Simonson 1990 for a similar example of this type of chalcedony). Another recurrent and distinct feature is the presence of many veins in the Coconut Hall rock, with a distinct quartz filling within the matrix (see figure 2.15f). This quartz filling is solely chalcedony in the case of thin veins, or additionally filled with macro-quartz crystals when wider. This type of filling suggests later silicification of the veins and voids. In addition, some veined areas also contain very fine crypto-crystalline quartz.

The presence of different quartz crystal fillings suggest different phases of silicification and it clearly distinguishes Coconut Hall flint from other Antigua Formation flints. In this regard, they display some similarity to the Puerto Rican cherts. However, it is unclear how the exact trajectory of the silicification of the Coconut Hall flints can be explained. From the presence of bioclasts, it is minimally clear that silicification started as a replacement process within limestone hostrock, similar to other Antigua Formation flints. It is unclear whether the voids were formed as a result of deformation of the initially formed chert or represent areas of incomplete silicification.

\section{A.2.6 Shirley Heights}

The Shirley Heights locality is the only chert occurrence known within the Basal Volcanic Suite on Antigua (see figure 2.5) (Weiss 1994). Christman (1972) reported the occurrence of tuffs in this area. Outcrops of irregularly shaped inclusions of chert in brown and lighter coloured tuff deposits can be seen close to the road that leads to the main building of the Shirley Heights fortification and also on the northern flank of the hill adjacent to the fortification.

There, the concentration of eroded secondary cherts is very small and no signs pointing to prehistoric exploitation were discerned. Only limited field-walking was conducted in the immediate Shirley Heights region. Therefore, this means that additional outcrops may be present there. Furthermore, secondary deposits may occur in the low-lying areas surrounding the Shirley Heights hills, especially near the English Harbour Bay to the west or in the Indian Creek valley to the north.

This chert generally has a slightly translucent and light coloured appearance. Some rocks exhibit a homogenous single coloured matrix without discernable inclusions. Other samples are mottled in colour and have dark coloured inclusions. The colour can vary from white (10 YR 8/1, 2.5 Y N8) to (light) grey (7.5 YR N6/; 10 YR 5/1, 7/2; 2.5 Y N5/, 7/1-2).

In thin-section, this chert is very pure (see figure 2.16a). The matrix exclusively consists of homogeneously distributed and relatively coarse-grained crypto-crystalline quartz crystals that are clearly larger than the general crystal size among the Antigua Formation and St. Kitts flints (see below). Inclusions in the form of calcite crystals, micrite, bioclasts, iron oxides, or other lithoclasts are completely absent. The absence of bioclasts and calcite suggests formation within a noncarbonate host.

\section{A.2.7 Corbison Point}

The Corbison Point locality is an extended rock along Antigua's northeastern coast (see figure 2.5). Like Dry Hill (see below), it has been well known for a long time among geologists and rock collectors for its abundant silicified wood (K. Earle 1923; Nugent 1821; Purves 1884). In addition, a cliff there exposes several chert layers that are inter-bedded with mudstones and calcareous tuff. Weiss $(1994,17)$ reports, from study by Marek $(1981)$, that the fossils in the different rock strata point to both marine and freshwater origins, and probably the cherty layers were formed close to the coast. They represent secondary chertification with the silica probably originating from inter-bedded volcanic muds and soils, as both marine and fresh water deposits were silicified.

Corbison Point has become the geological type-site for the chert beds that can be found at numerous places within the Central Plain Group, notably at Dry Hill. Chert and petrified wood have a very restricted occurrence, basically corresponding to the extension of the rock point. Siliceous materials are absent along both the adjacent northern and southern beaches. Only on the northern side is the point accessible and samples were taken from different beds as well as from secondary material lying on the small cobble beaches. No signs of human exploitation in the form of flaking debris were identified. 
The primary chert is dull and has a (very) dark grey (7.5YR 3/1, 4/1, 10YR 3/1, 4/1) colour. Secondary material is lighter and exhibits a wider variety of colours, ranging from white (5YR 8/1), (light) grey (5YR 7/1,6/2,5/2) to pinkish grey (7.5YR 6/2). Both primary and secondary material is fine to medium grained, exhibiting a coarser size than the Antigua Formation flints. In general, these cherts contain varying amounts and types of inclusions. Some samples display clearly distinguishable and relatively large fossils, whereas in others only small white unidentifiable grains are seen. Rare samples exhibit no inclusions at all. The bedded nature of the chert is also clearly evidenced by variation in clast contents following this bedding and parallel orientation in chert samples.

The variable origin of this chert is also visible on a microscopic level. Thin-section analysis demonstrates considerable difference in quartz size, fossil content, and bedding between samples. Four groups can be distinguished on a microscopic and chemical level (see Chapter 2). These include: (A) a bioclast rich and carbonate poor chert (see figure 2.16b); (B) a bioclast rich and carbonate rich chert; (C) a pure quartz chert without inclusions; and (D) a dirty bioclast poor chert, much resembling some of the Antigua Formation flints. The last three groups each correspond with a different chert layer, suggesting significant inter-layer variation. This contrasts to the absence of such variation among flint nodule layers of the Antigua Formation flints. Furthermore, most of the secondary materials can be classified to one of these groups as well, clearly indicating that they originated from one of these layers. Only the pure quartz samples are all secondary in nature and probably originated from a layer of chert, that is currently not exposed.

\section{A.2.8 Dry Hill}

The elevated rock cliff at Dry Hill is situated only $1.5 \mathrm{~km}$ to the south of the Corbison Point locality and adjacent to the sandy beach of Fort Bay (see figure 2.5). There, an approximately $10 \mathrm{~m}$ high cliff exposes a sequence of chert layers inter-bedded with muddy limestones (Weiss 1994, 17). Martin-Kaye considered these beds to be the same as those found at Corbison Point, which is confirmed by microscopic and chemical analysis (see Chapter 2). In general, the beds are not thicker than $1 \mathrm{~m}$ at Dry Hill and I identified three beds. In addition to these beds, eroded chert material is lying at the foot of the cliff in the form of rounded and angular cobbles. No signs of human exploitation are evident along the cliff.

This material generally exhibits a close similarity to the Corbison Point cherts in macroscopic appearance. The primary chert is generally dark in colour, whereas the secondary material is lighter. In most cases, this chert is homogeneous, without clearly identifiable clasts. Some samples contain clearly distinguishable fossils. Colour ranges from (very) dark grey (10YR 3/1, 4/1), grey (10YR 5/1), greyish brown (10YR 5/2), to light brownish grey (10YR 6/2). Secondary samples display a similar range, with the lighter hues predominating.

Dry Hill chert has less variation on a microscopic level than Corbison Point. Basically, the samples correspond with groups $\mathrm{C}$ and $\mathrm{D}$ of the Corbison Point chert. These include the bioclast rich and carbonate rich variety (C), and the dirty bioclast poor chert (D) (see figure 2.16c).

\section{A.2.9 Other chert localities in the Central Plain and Basal Volcanic Suite regions}

In addition to the chert sources described above, samples were taken from two additional Antiguan localities, at Willis Freeman near the small village of Table Hill Gordon, and at the village of Buckeys and its surrounding (see figure 2.5). Both places where chert was collected expose artificial outcrops or scattering of chert material. Therefore, they were not likely exploited by Pre-Columbian Amerindians. Analysis of a limited number of samples revealed that both chert varieties macroscopically display differences with the other cherts from other geological regions of the island. Under a microscope the chert from Buckleys appears to be similar to the Shirley Heights chert in quartz matrix features and the absence of calcite and fossils. Willis Freeman chert to some degree shares these features, although one sample likely is a silicified coral, preserving some of its original structure.

These data show that chert in this part of the island is relatively variable, particularly when the Corbison Point and Dry Hill localities are set against the other cherts. A close reading of available geological reports shows that still other chert outcrops exist on Antigua, notably in the Central Plain region of the island. 


\section{A.3 ST. KITTS}

\section{A.3.1 Flint occurrences}

Though unexpected due to the island's volcanic character, natural scatters of flint occur on St. Kitts. They were first identified, mapped and described by an archaeological team of Arizona State University during several field-campaigns in the 1970s. They reported a total of five such localities (Armstrong 1978; Walker 1980a, 64). K. Earle (1924) mentions a possible sixth occurrence of chert-like rock at Goodwin Gut, in St. Kitts. Walker (1980a) however, was unable to locate this chert-like material during his fieldwork. All other sources can be considered secondary and any associated limestone hostrock is absent (Walker 1980a). Most of them, including Great Salt Pond, Banana Bay, and White House Bay, are situated on the southeastern peninsula (see figure 2.6). The other two occurrences, Sugar Factory Pier and Bird Rock are located to the east of the capital Basse Terre along the southern shore of the island, adjacent to the Amerindian site of Sugar Factory Pier. Flint at White House Bay, Banana Bay, and Sugar Factory Pier can be found in the form of small nodules scattered among volcanic pebble beaches. At Bird Rock flint is found below the cliffs forming the coastline, and at Great Salt Pond flint pebbles are lying among volcanic cobbles on an artificial dam that has been erected to divide the salt ponds. I visited St. Kitts during a short stay in 1994 and collected flint at Great Salt Pond and Sugar Factory Pier. ${ }^{4}$

Despite efforts by Walker and me to find primary flint depositions at Brimstone Hill and other limestone outcrops, the origin of the St. Kitts flint remains unclear. Except for Earle's information on the Goodwin Gut jasper, none of the geological reports mention the occurrence of flint in any of the limestone outcrops. The only additional remark on the presence of flint on the island is made by Branch, which probably relates to one of the four coastal occurrences, mentioned above, when he states that flint can be found in the "shingles of some beaches" (Branch 1907, 322).

This lack of a clear primary depositional environment raises many questions. The most important ones include: should the material be associated with limestone host-rock, or does it represent chert or chalcedony material from a volcanic origin? Is the material natural to the island, or can its occurrence be considered artificial, e.g. the dropping of ballast loads during historic times? ${ }^{5}$ If it can be considered a flint natural to St. Kitts, how is its occurrence explained within the volcanic structure of the island?

The first question regarding the type of chert can be answered straightforward. Thin-section studies (see below) clearly show that this chert material contains carbonate fossils and other biogenic clasts, and a variable amount of carbonate in the form of calcite and micrite. Such features point to a marine carbonate environment during genesis that is not found in volcanic materials. Furthermore, the occurrence of carbonate fossils excludes a non-carbonate marine environment of origin, commonly encountered among bedded cherts.

The second question can be only answered indirectly. Walker (1980a) saw a close similarity between two types of chert used at the Pre-Columbian Early Ceramic Age site of Sugar Factory Pier and the materials that he collected from different local flint localities. This implies that the flint was available to the Amerindian populations who inhabited St. Kitts before Columbus and that the flint cannot be a relict of historic activities.

Still some questions remain in relation to this issue. These include: (a) chemical analysis of two artefacts, that may be local to the island did not produce a St. Kitts origin (see Chapter 2). Furthermore, most of the Sugar Factory Pier artefacts within the small sample provided to me by Walker did not resemble the St. Kitts material more than they did some of the Antigua sources, other than Long Island. Walker did not know about these other Antigua sources at the time of his work on the Sugar Factory Pier material; (b) the percentages of flint within the archaeological collection of the Sugar Factory Pier settlement, for which Walker assumed a local origin, are five times lower than the percentages of exotic Long Island flint. Such a low percentage is strange for locally available material and they suggest that it too is exotic; (c) the Preceramic Age people at Sugar Factory Pier prior to their Saladoid successors did not use presumably local St. Kitts flint. Instead, they only used volcanic material for the production of flakes, as Armstrong reported (1978, 1980), and (d) Flaked material from other sites on surrounding islands either produced no material that resembled the St. Kitts material, or only very small amounts that were doubtfully attributed to St. Kitts. So far, I have not encountered a single site, where a significant number of artefacts can

\footnotetext{
${ }^{4}$ I did not visit Banana Bay, Bird Rock, and White House Bay, as I was unaware of the fact that flint was present there. In Walker's Proceedings article (1980b, 73), the only reference I had in my possession at that time, he mentions flint at Majors Bay, Great Salt Pond, and Sugar Factory Pier. At the latter two, I collected flint, but at Majors Bay I was not able to find any flint nodules. This absence was later confirmed by my reading of Walker's Master thesis (1980a), in which no mention is made of this location.

${ }^{5}$ See Appendix B on Hughes Bay for a possible example of an artificial flint occurrence on Antigua. Westermann (1957) and Langemeyer (1937) report an example of stone ballast droppings on St Martin.
} 
be assigned to one of the varieties that definitely belong to the St. Kitts material.

These four points cast serious doubt on a natural origin for flint on St. Kitts. However, I was not able to conclusively disprove such an origin, keeping in mind the fact that Walker, who had seen much more of the Sugar Factory Pier material, discerned strong similarities between these artefacts and the natural material. Therefore, I still consider the flint on St. Kitts natural to the island, until proven otherwise. ${ }^{6}$ Including source material with a doubtful origin may well have serious consequences in the end for understanding raw material distribution. Given the rare occurrence of artefact materials that can possibly be related to the St. Kitts sources, such consequences in this case will be only limited. Incorrect assignments will only result in slight changes of the distributions obtained and will not likely alter the overall picture of raw material procurement and exchange among the islands.

Given these conditions, and assuming that the flint is natural to the island, how should its occurrence be then explained? Definite solutions cannot be provided at present and only possible options can be suggested. It is noted that all the localities where flint is found on St. Kitts lie in the areas where the older deposits of the island are present on the surface. These belong to the southeast peninsula group of volcanic rocks. This suggests that if limestone formations were present within these areas, then they would have been subject to a longer period of erosion than elsewhere. Furthermore the later eruptions of the Mount Scenery centre may have had very disturbing effects on the visibility or availability of any such formations at present. From this the following scenarios emerge:

1) A submarine carbonate platform was present at the time of the first volcanic eruptions on St. Kitts around $2.3 \mathrm{Ma}$. These eruptions lifted part of the limestone up, after which it became exposed to weathering and erosion. The limestone was largely dissolved and the more resistant flint remained. This would mean that the carbonate platform pre-dates volcanic activity in this area, which is very unlikely considering the depths of the ocean. Usually, carbonate platforms evolved after the formation of volcanic islands, as is the case with the Brimstone Hill Formation on St. Kitts, and the White Wall Formation on St. Eustatius (Westerman \& Kiel 1961). It also accounts for the Miocene limestone formation in the St. Martin/Anguilla area and the Antigua Formation on Antigua (Christman 1953; Multer et al. 1986).

2) Therefore a logical second solution states that after the first volcanic eruptions, a submarine carbonate platform was formed in the vicinity of the newly arisen island. This marine platform was lifted by later eruptions or tectonic activity, which still predated the volcanic activity at the South East Range, Middle Range, and Mount Scenery centres, and became exposed. This uplifted limestone was later eroded, dissolved and the flint remained. Flint remained only accessible for exploitation in the southeast area of the island, where later volcanic activity did not cover the earlier formed igneous rock.

These scenarios would entail that the occurrence of flint should not be related with the present occurrence of limestone on the island, as this limestone is related to younger depositional events. Brimstone Hill, for example, was formed during the Pleistocene epoch prior to the eruptions of the Mount Scenery centre, but probably after the Middle Range eruptions (Westerman \& Kiel 1961). This younger age explains the unsuccessful attempts by Walker and me to locate the flint in the Brimstone Hill Formation.

\section{A.3.2 Macroscopic and microscopic characteristics}

After macroscopic inspection, and microscopic and geochemical analysis it became clear that the flints from the Great Salt Pond and the Sugar Factory Pier localities in St. Kitts are very similar and probably originate from the same geological setting. Therefore, the characteristics of both localities are treated here as one.

The material itself is variable in nature. Generally, the pebbles do not exceed $10 \mathrm{~cm}$ in dimension and are heavily rounded due to water erosion. Limestone cortex is lacking, although some pebbles exhibit a white outer surface. Basically, two types of flint can be distinguished macroscopically: predominantly a semi-translucent flint with a homogeneous matrix,

\footnotetext{
${ }^{6}$ A possible option to test its natural origin would be an analysis of dinoflagellates. Past study has shown that these one-celled organisms are well preserved in flint due to their resistant tests. This resistibility makes it possible to extract these tests from the flint and study them under the microscope. The analysis of European flints has shown that they may be a good stratigraphic marker (Rademakers 1995; Verhoeven 2002). This provides a good means to test a local or exotic provenance for the St. Kitts flints, as the island's geological age is much younger than the age of, for example, the European flints, Europe being the most likely origin in case of an artificial Historic occurrence of flints on St. Kitts.
} 
in which occasionally relatively large light inclusions occur. Colours range from black, (very) dark grey (2.5Y N3, 10YR $3 / 1,4 / 1)$, (very dark) greyish brown (2.5Y 4/2, 10 YR 3/2, 4/2, 5/2), brown (10YR 5/3), light olive brown (2.5Y 5/3), brownish yellow (10YR 6/8), to light yellowish brown (2.5Y 6/4, 10YR 6/4). The other type consists of light coloured dull flint, ranging from (light) grey (2.5Y N6/, 10YR 6/1) to light brownish grey, (2.5Y 6/2, 10YR 6/2). Some samples in this latter type are homogeneous, corresponding with calcite rich samples, whereas mottled ones, containing white inclusions, are more of a pure quartz type.

Under the microscope, the matrix consists of very fine crypto-crystalline quartz, which is considerably finer than the quartz within the Antigua Formation flints (see figure 2.16e). All analysed samples exhibit this fine crystal size, pointing to a similar origin. The dull light coloured rocks are actually poorly silicified flints. The samples still contain a lot of calcite homogeneously distributed throughout the rock (see figure 2.16f). The semi-translucent flints can be divided into two groups. One is a very pure chert, with only very small numbers of bioclasts (fossils), that all occur in a silicified (quartz) form. The other is a bioclast rich rock, in which both re-crystallised and carbonate fossils occur. This type also has a dirtier matrix, with more micrite preserved. The large lighter coloured inclusions under the microscope appear to be areas in which the concentration of micrite is higher.

\section{A.4 Puerto Rico}

\section{A.4.1 Cerrillos}

Pike and Pantel (1974) were the first to report on the occurrence of chert at Cerrillos. In their contribution to the Proceedings of the fifth International Congress for the study of the Pre-Columbian cultures of the Lesser Antilles, they mention the presence of a high concentration of worked chert material and natural nodules at this locality. They interpret Cerrillos as a workshop area, where knapppers collected and pre-worked flint material. Later research by Pantel showed that Cerrillos probably was visited during the Preceramic Age as is suggested by the use of a blade technology and early radiocarbon dates (Ortiz 1976).

Geologically, the locality is situated within the Guanajibo Formation dating to the Miocene, which is surrounded in this area by Tertiary Quartz Sand deposits (see figure 2.7) (Volckmann 1984b). In both geological units, the primary occurrence of chert is not mentioned. The Guanajibo Formation consists of loosely cemented calcirudite and calcacerite, while the quartz sand deposits do not contain large clasts. In a personal communication to Ortiz, Volckmann explained the occurrence of the chert at Cerrillos by the complete weathering of limestone rock after which the chert residing in it remained (Volckmann, personal communication to Ortiz, 1976).

At the time of my visit to Cerillos, it was obvious that road construction and house development during the past few decades had considerably affected the area, and only left a small portion of the original flint distribution and the archaeological work-shop site (Walker, personal communication 1998). On a small field, not extending more than a few hectares, chert material is scattered across the surface. This includes clear artefacts and natural cobbles in a moderately dense concentration. Superficial inspection revealed that the artefacts can be associated with the blade technology identified by Pantel and Ortiz (Ortiz 1976; Pike \& Pantel 1974).

A very characteristic feature of the chert material at Cerrillos is its reddish colour on the exterior, varying from yellow (10YR 7/6), reddish brown (7.5YR 6/6), to brown (7.5YR 5/4). Both the artefacts and the natural material possess this same colour. That this represents a form of iron staining on the flint, related to the high iron contents of the surrounding red soil, is evidenced by the different colour that they exhibit when freshly flaked or cut. In general, the chert is dull and exhibits variation in colour within the stone. Cut specimens expose light coloured medium-crystalline chert. Generally the matrix of the chert is heterogeneous, displaying veins of different texture and colour, as well as different coloured areas. Some specimens, however, exhibit a more homogeneous chert matrix. The boundary with the outer surface is irregular and occasionally iron minerals, probably pyrite, are visible. The colour may vary from white (10YR 8/1, 2.5Y N8/), light grey to grey (2.5Y N7/, 10YR 5/1), very pale brown (10YR7/3), pale brown (10YR6/3), light yellowish brown (10YR 6/4, 2.5Y 6/3) to brown (10YR 5/3), and in rare occasions, red (2.5YR 5/6, 4/8) occurs as well.

Thin-section analysis showed that this chert is a pure quartz chert without any carbonate, bioclasts, or lithoclasts (see figure 2.17a). The iron staining of the flint is clearly evident under microscope as a high concentration of red ironoxide in the rim area. The structural absence of carbonate and fossils does not make this a typical limestone flint, as was 
hypothesized. Also, the crypto-crystalline quartz matrix clearly differs from the ones encountered among the Antigua and St. Kitts flints. The matrix generally displays a homogeneous distribution of crystals, which are generally coarser than the Antigua flints and in particular, the St. Kitts ones. In rare areas, the rock differs in crystal size. These areas may be finer than the Antigua flints, for example, but coarser parts also occur. All rock samples are veined, in which vein filling is different from the surrounding matrix. In most cases macro-quartz fills these veins, surrounded by a chalcedony rim, which marks the boundary between the matrix and vein filling. In some cases, veins are either completely filled with chalcedony or very fine quartz similar to the St. Kitts matrix. Similar to the Coconut Hall flint, these veins represent later phases of silification relative to the matrix.

\section{A.4.2 Las Palmas}

Las Palmas is the southernmost chert occurrence, situated in-between the villages of Las Palmas and Pole Ojea and lies approximately $3.6 \mathrm{~km}$ from Puerto Rico's southern coast (see figure 2.7). A similar situation exists there relative to Cerrillos. Natural chert material is scattered over an extensive area at Las Palmas, approximately a few hectares, of slightly sloping terrain. Among many natural pieces, clearly flaked material was found as well. Artefact scatters clearly differ in concentration and density. A superficial inspection of the artefacts revealed that a blade technology was used to reduce the material. This occurrence at Las Palmas has not been studied archaeologically to my knowledge, leaving the geographical extent of the site, its function, and period of usage unclear. The presence of blades suggests that it was minimally exploited during the Preceramic Age.

From the geological map of the area, it is clear that this locality is situated within the Ponce Limestone and Juan Diaz Formation, which has an Oligocene to Miocene date (see figure 2.7) (Volckmann 1984a). Volckmann (1984a) reported about the rocks associated with this formation, including:

“(1) Yellowish-white to yellowish-orange poorly cemented, somewhat friable calcirudite and calcerenite (...). Commonly capped by 1-3 m of caliche which contains abundant fragments of underlying calcirudite and calcerenite. (2) Reddisch-brown to reddish-orange, interbedded sand and medium-to coarse-grained gravel poorly cemented with calcite and hematite. Gravel $2.4 \mathrm{~km}$ west of Las Palmas consists of rounded clasts of chert derived from the Sierra Bermeja. Gravel in the area northeast of Corozo contains clasts of limestone, volcanic rock, and chert."

The described gravel occurrence $2.4 \mathrm{~km}$ west of Las Palmas refers to the locality where we found chert pebbles and some artefacts. Although it is obvious that the area consists of limestone, Volckmann states that the chert was not formed herein, but that it likely originated from the Sierra Bermeja, more to the east, which lies within the Mariquita Chert Formation (see figure 2.7) (Lower Cretaceous and Upper Jurrasic). This formation consists of:

"Yellowish-red, brownish-red, greyish green, black or white, fine-to medium-grained bedded chert and silicified limestone (KJml)" (Volckmann 1984a). "Chert typically consists of an interlocking mosaic of microcrystalline quartz which in many areas has been partially to completely recrystallized and generally is fractured or brecciated; quartz and (or) calcite and limonite-hematite commonly fill fractures and voids between breccia fragments. Radiolaria and locally Forminifera are abundant constituents. Locally Radiolaria are completely recrystallized and may be selectively stained by iron oxide" (Volckmann 1983a).

Careful inspection and microscopic analysis of collected rock pieces demonstrated that the Las Palmas chert can be divided into two broad distinct varieties, each possessing characteristics that point to different geological origins. The large group, which is also associated with the artefacts, has a very variable macroscopic appearance. The majority has a very heterogeneously or mottled looking chert surface, displaying irregular and differently coloured and textured patterns in the matrix and veins that crosscut the rock. Less frequently occurring are more homogeneous cherts, which can be dull and slightly translucent. Many chert pieces exhibit signs of iron oxidation in the form of red coloured bands or red inclusions. The colours are broadly variable. Most fall in the range from white (10YR 8/1 8/2), light grey, light brownish grey, greyish brown (10 YR 7/2,6/2,5/2), very pale brown to pale brown (10 YR 8/3, 7/3, 6/3). Among the homogeneous cherts, dark and light colours both occur, including: dark grey (7.5YR 4/1); white (N8/); yellow (10YR7/6, 8/6); and white-pinkish white-pale red (2.5YR $8 / 1-2,7 / 2)$.

From microscopic study, it is clear that these rocks almost exclusively consist of quartz. The matrix of micro- to crypto-crystalline quartz in this chert has a heterogeneous appearance, in which coarse and fine-grained crystals co-occur, as well as significant amounts of fibrous chalcedony. These cherts strongly resemble the cherts from the other Puerto Rican 
localities in thin-section, and the secondary flint from Coconut Hall on Antigua.

The second variety macroscopically distinguishes itself by a dark grey-green colour (dark greenish grey 10BG4/1), and it is a bedded chert. Under the microscope, it exhibits a much more homogeneous quartz matrix, which consists of fine micro- to crypto-crystalline quartz. Very distinctive features of this chert are the presence of radiolarian fossils and detrital amphibole fragments. In particular, the presence of this latter mineral is not shared with any of the other cherts and flints studied in this dissertation work, and clearly suggests a different geological relation. ${ }^{7}$

Comparison of these characteristics with the description of Volckmann suggests that this latter grey-green chert originates from the Mariquita Chert Formation. Similarly coloured cherts can be found there, but more importantly an amphibolite formation underlies the Mariquita chert, clearly explaining the presence of this mineral in the present chert. Considering its distinctive green colour, this latter chert type will be left out of the following description and discussion of the macroscopic, microscopic and chemical characteristics (see objectives stated at the beginning of Chapter 2).

As already noted, the first variety of Las Palmas chert shares many similarities with the Cerrillos and the other Puerto Rican cherts under the microscope. It is a pure quartz chert without bioclasts and lithoclasts. The presence of carbonate could not be clearly identified. Similar to Cerrillos, the absence of carbonate does not suggest a common limestone flint. Iron-oxide forms a variable component of this chert.

Furthermore, the chert samples exhibit considerable variation in the quartz matrix and structure of the rock. Two samples are silicified breccias, having a texture like a graywacke. The original grain structure is still visible as different coloured quartz areas in the rock. Furthermore, the fillings between the grains have a different quartz composition (usually in the form of chalcedony) than the fillings of the grains themselves. To some extent, these cherts follow Volckmann's description of the Bermeja chert, although the presence of fossils was not identified.

Other samples are very homogeneous looking quartz chert, in which size of the crystals does not vary much. Generally, size of the quartz is coarser than among, for example, the Antigua flints; some samples even contain some areas with macro-quartz. In addition to these types of quartz, a very distinct form of chalcedony was identified, which resembles the radial fibrous type identified among the Coconut Hall flints (see figure 2.17e,f and Schubel \& Simonson 1990 for another example). Again, the chalcedony building occurs from a centre point, in contrast to length-slow chalcedony, in which chalcedony growth is along a boundary. This length-slow chalcedony was also present in vein fillings. In addition, veins can sometimes contain very fine crypto-crystalline and macro-quartz, similar to the Cerrillos chert.

\section{A.4.3 Villa Taina}

The Villa Taina locality is situated a few hundred metres from an archaeological site of the same name that was excavated by Goodwin and Walker (1975), approximately $2.5 \mathrm{~km}$ to the west of the village of Boqueron (see figure 2.7). In a small gut coming from the adjacent hill, occasional large blocks of chert are scattered on the surface. The size of the locality is small and the amount of material is low. The quality of the material is poor, because the blocks contain many irregularities in texture. Archaeological work at the nearby Late Ceramic Age settlement of Villa Taina by Goodwin and Walker (1975) showed that the inhabitants used the local material for producing flake tools (Walker, personal communication 1998).

With regard to the geological formation, the area surrounding this locality is largely covered by Boqueron Basalt, but also Cotui Limestone Formation crops out nearby, more uphill (see figure 2.7) (Volckmann 1984b). About the Boqueron Basalt, Volckmann states that some of the weathered outcrops of lava contain amygdules (cavities) filled with silica. These amygdules do not exceed $3 \mathrm{~cm}$ in size and therefore, the chert is not likely related to these filled cavities.

The Cotui limestone Formation may be a more likely origin, considering the common relation between limestone and chert. Volckmann reports that the dense bioclastic limestone contains minor constituents of authigenic quartz. It is not clear whether this authigenic quartz stands for chert nodules or it only concerns small-sized quartz grains. However, the presence of authigenic quartz makes it likely that flint was formed within this limestone formation. The gully, which cuts the slope of the hill, may have been responsible for the erosion of the chert out of the limestone bedrock.

Despite my argumentation in favour of an association with the Cotui Limestone Formation, the characteristics of the chert itself do not point to a limestone host. The most important evidence is the total absence of fossils or other features

\footnotetext{
7 The chemical analysis of one sample of this green type of chert also produced distinct values compared to the other cherts. In general, the material contains much higher concentrations of most of the elements sampled. This higher concentration is ascribed to the presence of the detrital amphibole.
} 
pointing to a biogenic carbonate formation. In this respect the chert from Villa Taina resembles the tuff cherts from Shirley Heights, as well as the other Puerto Rican cherts, more than the limestone flints.

Studied macroscopically, the rock is very heterogeneous. It is dull and relatively coarse-grained when compared to the limestone flints. The matrix of the chert exhibits variation. A closer look at some pieces reveals that they resemble a conglomeratic rock, in which rounded dull grains, still preserved in a chert matrix but for which their original nature cannot be determined, are floating in a slightly translucent chert matrix. This granular structure may represent the texture of the original host-rock. Other specimens, however, do not display this "conglomeratic" structure. The matrix in these samples can be very homogeneous, or it displays veins or veined areas. The colour is generally light. Dark rock also occurs. The colour varies from almost white (10YR 8/1), light grey (10YR 7/1-7/2), light brownish grey (10YR 6/2), to grey (10YR 5/1), and greyish brown (10YR 5/2).

Under the microscope, this rock is a pure quartz chert, with varying amounts of iron-oxide, similar to the other Puerto Rican cherts. The matrix and structure of the samples exhibit a similar variation as well. Crypto-crystalline quartz in the matrix is generally coarse (see figure $2.17 \mathrm{c}$ ), but areas with a finer size also occur. In addition, the radial fibrous type of chalcedony is present in the matrix of two samples. Furthermore, veins that have a chalcedony or macro-quartz filling in a number of samples point to different phases of silification.

One sample displays some of its original structure in non-crossed polarized light. It consists of oval to round clasts that could be ooids or peloids. If these round clasts are indeed ooids or peloids, then this original structure points to a carbonate host. On the other hand, these round clasts, alternatively may be heavily rounded detrital mineral grains.

\section{A.4.4 Pedernales}

The chert occurrence referred to as Pedernales corresponds to a relatively large scatter of chert boulders and cobbles located in the northwestern part of the Barrio Pedernales, which is indicated on the geological map of the Puerto Real quadrangle (see figure 2.7) (Volckmann 1984b). Chert material is scattered across an area of approximately $1 \mathrm{~km}^{2}$, part of which is disturbed by house development in the small village El Cerro. We inspected and sampled only a small portion of the entire surface distribution. This portion was situated toward the eastern end. Large irregularly shaped chert blocks of varying quality were encountered there. They exhibit poorly silicified as well as true chert varieties. The blocks vary in size and can reach up to $50 \mathrm{~cm}$. To Walker's knowledge, no evidence of Pre-Columbian exploitation has been identified so far and also our field inspection did not yield any artefacts (Walker, personal communication 1998).

Underlying these silica blocks is the Miocene dated Guanajibo Limestone and Gravel Formation, similar to the chert at Cerrillos (see figure 2.7). Volckmann (1984b) does not provide an explanation for its occurrence in the description accompanying the geological map. Given the association with the same limestone Formation as at Cerrillos, a similar erosion process to that of the Cerrillos chert may be responsible for this chert.

The large blocks expose a very varied textured rock, giving it a heterogeneous appearance to some degree resembling the Villa Taina cherts. Areas of clear chert material alternate with coarser and duller looking material, strongly resembling the texture of cortex rinds in limestone flint. Like these other flints the Pedernales textures consist of less completely silicified rock. The transition from chert to these areas and the outer surface is often very gradual, making it difficult to discern where the actual chert matrix starts and ends.

The chert textures are light in colour, but exhibit variation between different blocks. The material exhibits a varied grain-size, which is generally coarser than the limestone flints from Antigua, for example. The matrix is homogeneous in most cases and contains very few inclusions. The colour of the chert varies from white (10YR 8/1), light grey (10YR 7/1, light brownish grey (10YR 6/2), to brown (10YR 5/3). Other areas are generally lighter in colour, mostly resembling the (10YR 8/1) white hue.

Under the microscope this chert displays similar features to the other cherts from Puerto Rico. Again, material does not possess any clear characteristics pointing to a limestone origin, as calcite was not identified and fossils are absent. Furthermore, varied matrices occur (see figure $2.17 \mathrm{~d}$ ), consisting of a fine to coarse crypto-crystalline quartz type, and a macro-quartz or radial fibrous chalcedony type. In addition, the rock can be veined with length-slow chalcedony in it, in some cases surrounding macro-quartz filled centres. 


\section{A.4.5 Moca}

Recently, Walker et al. (2001) reported the presence of natural chert in the valley of the Culebrinas River in the municipalities of Moca, San Sebastian and Lares, all in the northwestern part of Puerto Rico (see figure 2.7). Surface inspection revealed dispersed but distinct surface scatters of chert material, varying in quality from very good to poor. Associated with these natural occurrences, flaked material was identified as well, but the artefacts could not be dated.

The researchers point to the San Sebastián Formation as the possible geological source for this chert. Dated to the Oligocene and Miocene, this formation primarily consists of clay and sand beds, with conglomerates at the base. Some limestone lenses occur as well. Three components of this formation are of interest to the chert occurrences. These include a deposit of a silica rich conglomerate, mainly built up of chert and quartz (referred to as geological unit Tscq), a clay deposit with chert cobbles (Tscc), and a (Tsch-) unit containing jasper and petrified wood (Walker et al. 2001, 14-16).

The chert is coloured brown generally, but varying in darkness. The chert matrix often displays veins and on rare occasions a clastic appearance, consisting of densely concentrated round inclusions. This probably represents the texture of the original host-rock. A portion of the samples, however, consists of a more homogenous chert matrix, slightly translucent in appearance. Colours range from white (10YR 8/1), yellowish brown (10YR 5/4), to brown (7.5YR 5/3,10YR 4/3).

Under the microscope, the Moca cherts display a very pure quartz content, although in some cases some mud of the original sediment is present. The composition of this mud could not be determined. Its dark brown colour suggests that iron in it had been oxidized. One sample originally is a layered brecciated rock or a grain-supported pack-stone, which may have been silicified during different phases. The quartz filling of the original clasts was different from the areas between the clasts (see figure 2.17b). Another sample is a veined chert, similar to some of the chert samples from the other Puerto Rican sources. The vein-fillings are very fine crypto-crystalline quartz, macro-quartz, or chalcedony. Similar to the other Puerto

Rican cherts, the Moca-samples do not contain any bioclasts or carbonate, which suggests a non-carboneous environment of formation, not related to limestone. 


\section{Appendix B Hughes Bay flint scatter, Antigua}

\section{B.1 Artificial flint Scatter at Hughes Bay}

Field-walking along the coast of Hughes Bay and Brown's Bay in northeastern Antigua, identified a cluster of large blocky flint nodules scattered on a cobble beach between these bays (see figure 2.5). This flint concentration includes many chalk pebbles as well. The shape of the flint blocks is angular and the cortex sometimes looks fresh, that is, not water-worn. A subsequent search for in-situ flint along both beaches did not produce any additional finds. Also, examination of an extended limestone rock section at Hughes Point, part of the Antigua Formation, did not yield any layers with flint nodules in it, despite a reference to it by Mascle and Westercamp (1983).

The relative angular form of the nodules, a characteristic not to be expected on a beach where rounded cobbles predominate, and the discovery of many igneous rock pebbles on the same beach, rock types unlikely in an exclusive limestone environment, are both signs of an artificial occurrence. Closer analysis of the flint revealed that it generally is very dark in colour, varying from black (7.5YR N2/) to (very) dark gray (7.5YR N3/, N4/, 10YR 3/1), which is different from other Antigua formation flints. Also, the type and size of the inclusions differ from the local flints. Furthermore comparison of geochemical data from one sample analysed with average values from Antigua Formation flints showed that $\mathrm{Al}$ and $\mathrm{K}$ values are lower. More importantly, the Hughes Bay sample has a lower $\mathrm{Al} / \mathrm{K}$ ratio, which is relatively constant among the primary flint sources on Antigua. ${ }^{1}$ This all strongly supports a non-Antiguan origin. In this light, the former habit of cargo ships being loaded with stone ballast on the way to the Caribbean islands and then dropping the ballast somewhere along their shores might explain the presence of this flint. Such a case has been reported for "de Groote Baai" on St. Martin, where exotic stones can be picked up (Langemeyer 1937; Westermann 1957).

In case of a historical origin, England would be the most likely source for the stone ballast, considering its colonial occupation of the island during $17^{\text {th }}, 18^{\text {th }}, 19^{\text {th }}$ and $20^{\text {th }}$ centuries (Murphy, personal communication 2001; Desmond Nicholson, personal communication 2001). Therefore, some samples were sent to Mark Edmonds, Sheffield University, who is familiar with English and other northwestern European flints. Edmonds stated that the material is very similar to English material, but also exhibits strong similarities with flints from the Atlantic fringe of Northwest Europe. As a consequence, he was not able to pinpoint a specific source location, but generally speaking, he supported the idea of a European, most likely English origin for this flint (Mark Edmonds personal communication 2001).

\footnotetext{
1 The trace-element concentration values from the Hughes Bay sample have not been compared with the more weathered secondary Antigua Formation flint sources, such as Blackman's Point and Coconut Hall. If the flint were natural to the island, it would have to be a relatively "freshly" eroded flint, considering the limited water rounding it demonstrates. This would make it comparable to the primary Antigua Formation flint sources.
} 


\section{Appendix C}

\section{Geo-chemical analysis and data}

\section{C.1 INTRODUCTION}

In this appendix, the results of the Inductively Coupled Plasma Emission Spectroscopy (ICPAES) analyses are listed for each rock and artefact sample (tables C.1-C.18). After collection and selection, samples were prepared following a standard procedure.

\section{C.2 SAMPLE PREPARATION AND ANALYSIS}

A small rock sample with unexposed fresh surfaces was sawn from a larger block with a diamond impregnated saw. This sample was crushed with a steel hammer into small grains. The grains were then washed for 3 minutes in aqua regia to remove any possible contamination resulting from the sawing and crushing. After this, they were washed with aquabidest four times and dried for 36 hours in an oven at $60^{\circ} \mathrm{C}$. From these small grains, $1.5 \mathrm{~g}$ was carefully weighed. This sample was then put in a Teflon pot and hydrofluoric acid $(20 \mathrm{ml}, 40 \%)$, and a mixture of nitric acid (65\%) and perchloric acid (70\%) $(10$ $\mathrm{ml})^{1}$ were added. This mixture was heated for 24 hours at a temperature of $92^{\circ} \mathrm{C}$ to dissolve the rock. The solution was next evaporated on a $180^{\circ} \mathrm{C}$ sand bath. The obtained residue was then dissolved in hydrochloric acid $(1.0 \mathrm{~N}, 25 \mathrm{ml})$ and heated for 4 hours at $92^{\circ} \mathrm{C}$. After cooling the Teflon pot containing the solution was carefully weighed and the solution was poured into a small tube for ICPAES analysis.

\section{C.3 DATA}

The following tables list the trace-element concentration values for geological samples from the different chert and flint sources discussed in this dissertation (see tables C.1-C.5, C.7-C.9, C.12-C.17). In addition, some geological samples from currently exposed rock outcrops, which were not available to the Amerindians were analysed and are tabulated as well (see tables C.6,C.10-C.11). Table C.18 lists the trace-element concentration values for a series of analysed artefacts originating at a number of archaeological sites within the studied area for comparison.

\begin{tabular}{|c|c|c|c|c|c|c|c|c|c|c|c|c|}
\hline number & $\mathrm{Al}$ & $\mathrm{K}$ & $\mathrm{Na}$ & $\mathrm{Li}$ & $\mathrm{Ti}$ & $\mathrm{Cr}$ & $\mathrm{Fe}$ & $\mathrm{Mn}$ & $\mathrm{Ca}$ & $\mathrm{Mg}$ & $\mathrm{Ba}$ & $\mathrm{V}$ \\
\hline ANLI-01.2 & 1242.26 & 399.45 & 539.13 & 11.98 & 51.73 & 5.52 & 365.58 & 1.76 & 336.04 & 26.68 & 7.09 & 2.28 \\
\hline ANLI-02.2 & 1806.17 & 511.32 & 980.88 & 13.33 & 84.73 & 10.45 & 542.99 & $<$ d.l. & 549.46 & 129.65 & 8.43 & 4.50 \\
\hline ANLI-02.2.2 & 1488.61 & 437.36 & 832.97 & 11.56 & 68.85 & 8.15 & 536.02 & 2.05 & 353.28 & 117.42 & 12.81 & 4.05 \\
\hline ANLI-03.2 & 1796.54 & 509.36 & 829.39 & 14.68 & 84.00 & 8.36 & 997.47 & $<$ d.l. & 375.62 & 97.95 & 219.06 & 5.43 \\
\hline ANLI-04.2 & 1499.61 & 410.51 & 830.68 & 12.51 & 61.02 & 5.62 & 439.49 & 2.90 & 6269.93 & 602.32 & 1.41 & 1.65 \\
\hline ANLI- 05.2 & 1062.45 & 361.54 & 649.34 & 9.52 & 46.04 & 5.30 & 333.27 & 1.89 & 576.31 & 71.41 & 45.55 & 2.51 \\
\hline ANLI-06.2 & 1588.79 & 485.48 & 848.59 & 16.89 & 72.21 & 6.28 & 776.07 & 2.55 & 1628.49 & 487.39 & 1.68 & 2.13 \\
\hline ANLI-08.2 & 1736.67 & 480.97 & 1045.85 & 12.66 & 70.39 & 7.62 & 475.91 & 3.81 & 442.59 & 167.90 & 16.62 & 3.32 \\
\hline ANLI-09 & 1606.15 & 510.30 & 694.85 & 15.36 & 67.81 & 7.17 & 313.03 & 2.33 & 711.46 & 74.50 & 9.01 & 1.98 \\
\hline ANLI-10 & 1738.32 & 556.18 & 1273.63 & 17.77 & 75.74 & 8.38 & 253.61 & 2.82 & 436.74 & 57.23 & 253.23 & 3.79 \\
\hline ANLI-11 & 2284.90 & 664.33 & 1199.16 & 19.26 & 94.49 & 9.76 & 384.46 & 2.62 & 750.65 & 235.05 & 20.46 & 3.94 \\
\hline ANLI-12 & 1693.91 & 569.25 & 705.58 & 15.96 & 73.08 & 7.47 & 320.44 & 1.01 & 292.44 & 70.38 & 77.10 & 2.74 \\
\hline ANLI-12.2 & 1704.05 & 585.30 & 741.39 & 15.35 & 78.33 & 6.95 & 460.28 & $<$ d.l. & 308.34 & 67.06 & 78.58 & 2.34 \\
\hline ANLI-25.1 (pri) & 1685.16 & 553.63 & 1124.28 & 13.85 & 70.77 & 5.77 & 638.67 & 2.06 & 4134.38 & 1492.28 & 11.00 & 3.22 \\
\hline ANLI-25.2 (pri) & 1740.02 & 541.21 & 1101.97 & 13.80 & 68.15 & 5.69 & 558.21 & 2.06 & 3904.07 & 1323.21 & 14.32 & 3.05 \\
\hline ANLI-25.3 (pri) & 1816.02 & 553.98 & 1097.43 & 14.30 & 75.51 & 6.34 & 542.70 & 2.24 & 3613.26 & 1365.43 & 6.41 & 3.28 \\
\hline ANLI-51a.1 (pri) & 1741.12 & 567.19 & 945.51 & 15.34 & 51.61 & 7.38 & 632.66 & 12.74 & 2658.83 & 181.19 & 6.16 & 2.25 \\
\hline ANLI-51a.2av (pri) & 1688.34 & 533.24 & 974.90 & 14.78 & 57.13 & 5.84 & 514.46 & 2.74 & 3352.39 & 186.63 & 13.48 & 2.03 \\
\hline ANLI-53a.1 (pri) & 881.59 & 344.34 & 942.56 & 8.63 & 41.23 & 4.81 & 432.97 & $<$ d.l. & 209.57 & 78.78 & 19.74 & 4.20 \\
\hline ANLI-53a.2 (pri) & 1059.69 & 352.75 & 811.85 & 9.66 & 46.59 & 4.83 & 237.71 & 1.22 & 198.71 & 70.78 & 10.27 & 2.92 \\
\hline ANLI-70 (pri) & 1260.13 & 399.89 & 1236.80 & 11.58 & 54.00 & 5.71 & 301.89 & 1.98 & 8352.88 & 3010.40 & 30.02 & 2.39 \\
\hline ANLI-75 & 1717.11 & 547.06 & 966.54 & 16.77 & 69.26 & 5.48 & 396.86 & 2.38 & 1889.61 & 555.89 & $<$ d.l. & 1.84 \\
\hline ANLI-76 & 1738.35 & 496.18 & 888.99 & 13.79 & 72.26 & 5.57 & 116.14 & 1.20 & 186.80 & 47.49 & 43.86 & 1.72 \\
\hline
\end{tabular}

Table C.1. Long Island, Antigua Formation, Antigua. Trace-element concentration values in flint samples (in mg/kg (ppm)). "-av" denotes average value from a multiple analysis; "pri" denotes samples from primary contex; < d.I. = value is below detection limit.

1 Volume ratio of mixture: (water)/(nitric acid)/(perchloric acid) $:(1) /(2.5) /(6.5))$. 
APPENDIX C - DATA OF GEOCHEMICAL ANALYSIS

\begin{tabular}{|c|c|c|c|c|c|c|c|c|c|c|c|c|}
\hline number & $\mathrm{Al}$ & $\mathrm{K}$ & $\mathrm{Na}$ & $\mathrm{Li}$ & $\mathrm{Ti}$ & $\mathrm{Cr}$ & $\mathrm{Fe}$ & $\mathrm{Mn}$ & $\mathrm{Ca}$ & $\mathrm{Mg}$ & $\mathrm{Ba}$ & $\mathrm{V}$ \\
\hline ANLC-01 & 968.28 & 283.09 & 452.00 & 8.43 & 25.27 & 5.25 & 100.61 & 0.60 & 1064.64 & 69.25 & 7.99 & 2.94 \\
\hline ANLC-02 & 1199.69 & 349.38 & 669.38 & 17.63 & 32.25 & 4.26 & 169.70 & 0.69 & 2124.65 & 94.03 & 38.49 & 2.35 \\
\hline ANLC-03 & 1254.36 & 374.13 & 900.74 & 13.23 & 44.23 & 6.15 & 331.94 & 0.72 & 2530.54 & 111.80 & 121.07 & 4.11 \\
\hline ANLC-04 & 1482.84 & 405.20 & 684.43 & 17.82 & 34.55 & 2.12 & 52.07 & 0.61 & 1533.00 & 102.94 & 11.92 & 2.50 \\
\hline ANLC-05 & 1323.59 & 365.26 & 701.04 & 16.20 & 33.97 & 4.21 & 153.44 & 0.54 & 948.53 & 78.28 & 14.69 & 2.27 \\
\hline ANLC-06 (pri) & 1206.10 & 368.59 & 1037.80 & 15.78 & 38.25 & 5.23 & 261.66 & 0.48 & 1055.93 & 87.32 & 73.31 & 3.33 \\
\hline ANLC-07 (pri) & 1204.11 & 362.70 & 975.44 & 16.58 & 40.50 & 5.39 & 178.03 & $<$ d.l. & 840.96 & 85.57 & 17.10 & 3.36 \\
\hline ANLC-08 (pri) & 1341.74 & 400.66 & 960.27 & 16.81 & 49.75 & 4.99 & 89.00 & 0.51 & 877.80 & 126.80 & 7.73 & 3.66 \\
\hline ANLC-09 (pri) & 558.93 & 181.66 & 320.58 & 5.78 & 23.40 & 5.09 & 107.97 & $<$ d.l. & 715.16 & 58.79 & 1.24 & 3.79 \\
\hline ANLC-10 (pri) & 534.80 & 145.19 & 327.05 & 6.40 & 11.39 & 2.88 & $<$ d.l. & $<$ d.l. & 1151.43 & 123.90 & 1.31 & 1.99 \\
\hline ANLC-20a (pri) & 1242.63 & 379.43 & 1097.36 & 14.29 & 44.94 & 4.29 & 365.31 & $<$ d.l. & 3363.17 & 112.30 & 125.80 & 2.74 \\
\hline ANLC-24a (pri) & 1099.32 & 327.94 & 943.43 & 16.25 & 37.65 & 3.77 & 309.18 & 1.35 & 11426.93 & 184.87 & 11.87 & 1.74 \\
\hline ANLC-26a (pri) & 1104.97 & 343.07 & 914.57 & 12.65 & 41.06 & 4.46 & 333.65 & $<$ d.l. & 5535.95 & 158.94 & 25.58 & 2.93 \\
\hline
\end{tabular}

Table C.2. Little Cove, Antigua Formation, Antigua. See table C.1 for description.

\begin{tabular}{|c|c|c|c|c|c|c|c|c|c|c|c|c|}
\hline number & $\mathrm{Al}$ & $\mathrm{K}$ & $\mathrm{Na}$ & $\mathrm{Li}$ & $\mathrm{Ti}$ & $\mathrm{Cr}$ & $\mathrm{Fe}$ & $\mathrm{Mn}$ & $\mathrm{Ca}$ & $\mathrm{Mg}$ & $\mathrm{Ba}$ & $\mathrm{V}$ \\
\hline ANSP-01 (pri) & 861.03 & 288.95 & 689.73 & 8.96 & 32.44 & 2.92 & 224.16 & 1.03 & 1457.39 & 82.72 & 4.02 & 1.68 \\
\hline ANSP- $02^{\mathrm{a}}$ (pri) & 1075.53 & 368.36 & 652.12 & 10.97 & 35.44 & 3.06 & 320.87 & $<$ d.l. & 888.59 & 68.84 & 5.85 & 1.29 \\
\hline ANSP-04 & 952.59 & 330.03 & 672.83 & 11.06 & 52.93 & 4.59 & 371.75 & $<$ d.l. & 1661.21 & 58.76 & 1.65 & 3.24 \\
\hline ANSP-05 & 1067.70 & 288.39 & 807.58 & 11.54 & 32.08 & 2.52 & 170.37 & 0.73 & 638.19 & 63.04 & 5.01 & 0.83 \\
\hline ANSP-06 & 657.20 & 232.90 & 500.32 & 9.55 & 27.82 & 2.96 & 200.46 & 2.18 & 3122.82 & 64.17 & 1.36 & 1.44 \\
\hline ANSP-09 (pri) & 769.82 & 288.35 & 376.53 & 14.45 & 31.89 & 3.49 & 238.65 & $<$ d.l. & 2225.81 & 59.83 & 2.55 & 1.70 \\
\hline ANSP-12 (pri) & 1066.90 & 386.19 & 439.77 & 11.57 & 44.34 & 3.39 & 222.30 & 0.86 & 562.36 & 52.93 & 3.74 & 1.99 \\
\hline ANSP-13 & 850.10 & 290.04 & 628.25 & 13.30 & 34.70 & 2.98 & 207.79 & $<$ d.1. & 3614.43 & 89.42 & 1.39 & 1.91 \\
\hline ANSP-14 & 862.51 & 273.54 & 792.83 & 11.33 & 25.69 & 5.05 & 255.66 & $<$ d.l. & 613.67 & 84.10 & 2.25 & 1.69 \\
\hline ANSP-30 (pri) & 604.17 & 152.61 & 482.05 & 10.20 & 16.62 & 3.82 & 130.17 & 1.82 & 12715.01 & 116.13 & 2.23 & 1.05 \\
\hline
\end{tabular}

Table C.3. Soldier Point, Antigua Formation, Antigua. See table C.1 for description.

\begin{tabular}{|c|c|c|c|c|c|c|c|c|c|c|c|c|}
\hline number & $\mathrm{Al}$ & $\mathrm{K}$ & $\mathrm{Na}$ & $\overline{\mathrm{Li}}$ & $\mathrm{Ti}$ & $\mathrm{Cr}$ & $\mathrm{Fe}$ & $\mathrm{Mn}$ & $\mathrm{Ca}$ & $\mathrm{Mg}$ & $\mathrm{Ba}$ & $\mathrm{V}$ \\
\hline ANBP-01.2 & 411.37 & 73.95 & 428.60 & 17.97 & 15.66 & 5.73 & 2333.40 & 18.76 & 141.40 & 43.86 & 2.80 & 2.92 \\
\hline ANBP-02.2.1 & 450.58 & 94.01 & 276.68 & 14.40 & 16.21 & 4.58 & 954.20 & 5.33 & 289.77 & 40.56 & 2.34 & 1.11 \\
\hline ANBP-02.2.2 & 560.61 & 92.46 & 271.20 & 14.39 & 13.89 & 4.14 & 793.16 & 4.23 & 261.39 & 40.48 & 1.81 & 1.08 \\
\hline ANBP-03.2 & 425.61 & 130.91 & 176.33 & 5.25 & 23.00 & 4.64 & 1334.91 & 3.03 & 138.28 & 27.97 & 4.37 & 1.69 \\
\hline ANBP-04.2 & 374.68 & 103.22 & 138.54 & 8.14 & 12.15 & 4.08 & 799.18 & 3.34 & 281.03 & 21.76 & 8.62 & 2.14 \\
\hline ANBP-05.2 & 484.66 & 137.03 & 155.30 & 2.94 & 13.61 & 4.43 & 355.51 & 1.83 & 150.21 & 28.45 & 3.76 & 1.54 \\
\hline ANBP-14 & 735.47 & 181.96 & 217.12 & 3.29 & 15.70 & 3.96 & 631.15 & 2.84 & 503.86 & 24.45 & 26.49 & 1.62 \\
\hline ANBP-17 & 1148.84 & 356.12 & 1256.35 & 11.38 & 47.36 & 3.75 & 420.23 & 1.74 & 471.17 & 86.62 & 4.86 & 2.64 \\
\hline ANBP-44 & 544.39 & 67.77 & 182.14 & 18.08 & 17.67 & 7.94 & 4978.95 & 30.32 & 165.39 & 37.47 & 17.28 & 7.83 \\
\hline ANBP-48 & 458.59 & 136.59 & 581.77 & 5.14 & 12.51 & 3.99 & 813.15 & 3.63 & 138.47 & 193.94 & 52.14 & 2.96 \\
\hline ANBP-49 & 519.74 & 175.93 & 160.77 & 5.43 & 12.55 & 4.16 & 579.70 & 1.40 & 165.68 & 19.26 & 5.91 & 2.21 \\
\hline ANBP-53 & 315.02 & 55.22 & 780.89 & 20.13 & 11.90 & 4.04 & 332.28 & 1.66 & 283.23 & 243.11 & 4.07 & 1.72 \\
\hline ANBP-60 & 319.97 & 56.21 & 575.99 & 9.46 & 11.23 & 4.03 & 322.71 & 1.48 & 476.66 & 125.25 & 2.98 & 1.30 \\
\hline
\end{tabular}

Table C.4. Blackman's Point, Antigua Formation, Antigua. See table C.1 for description. 


\begin{tabular}{|c|c|c|c|c|c|c|c|c|c|c|c|c|}
\hline number & $\overline{\mathrm{Al}}$ & $\mathrm{K}$ & $\mathrm{Na}$ & $\overline{\mathrm{Li}}$ & $\overline{\mathrm{Ti}}$ & $\mathrm{Cr}$ & $\mathrm{Fe}$ & $\mathrm{Mn}$ & $\mathrm{Ca}$ & $\mathrm{Mg}$ & $\mathrm{Ba}$ & $\mathrm{V}$ \\
\hline ANCH-01 & 296.25 & 115.28 & 160.92 & 1.41 & 7.53 & 3.41 & 637.42 & 5.29 & 120.98 & 9.82 & 9.04 & 1.00 \\
\hline ANCH-02 & 301.04 & 85.49 & 119.57 & 11.53 & 13.55 & 6.91 & 616.85 & 11.48 & 1039.35 & 21.57 & 18.11 & 1.41 \\
\hline ANCH-12 & 139.45 & 55.68 & 56.75 & $<$ d.l. & 1.22 & $<$ d.l. & 256.84 & 1.69 & 150.55 & 3.66 & 0.73 & $<$ d.l \\
\hline ANCH-17 & 162.86 & 111.86 & 146.97 & 1.44 & 5.08 & $<$ d.l. & 506.24 & 1.12 & 65.69 & 6.02 & 5.21 & 0.87 \\
\hline ANCH-24 & 444.78 & 128.71 & 148.28 & 1.47 & 16.47 & $<$ d.l. & 1116.85 & 434.98 & $<$ d.l. & 1409.91 & 1.47 & 3.85 \\
\hline ANCH-40 & 339.41 & 128.47 & 146.34 & 2.22 & 13.15 & 5.97 & 2234.83 & 6.98 & 150.45 & 20.13 & 1.20 & 1.78 \\
\hline ANCH-41 & 277.51 & 70.62 & 161.12 & $<$ d.1. & 6.13 & 1.91 & 117.88 & 2.02 & 155.99 & 9.71 & 1.12 & $<$ d.1 \\
\hline ANCH-42 & 199.82 & 40.70 & 81.15 & 2.63 & 6.24 & 3.34 & 1036.85 & 9.94 & 1121.42 & 20.07 & 6.98 & 3.77 \\
\hline ANCH- 43 & 482.77 & 137.35 & 161.98 & 6.18 & 170.35 & 5.58 & 1433.39 & 6.79 & 549.33 & 21.10 & 11.53 & 2.16 \\
\hline ANCH-44 & 737.73 & 192.21 & 256.11 & 3.74 & 80.05 & 2.99 & 1022.34 & 4.25 & 208.92 & 20.48 & 28.83 & 2.70 \\
\hline ANCH-50 & 360.47 & 76.84 & 271.98 & 2.66 & 3.54 & $<$ d.l. & 209.02 & 11.00 & 42.75 & 2.77 & 12.83 & $<$ d.l \\
\hline ANCH-51 & 287.76 & 135.82 & 152.73 & 1.62 & 12.54 & 2.26 & 276.54 & 1.74 & 101.47 & 12.74 & $<$ d.l. & $<$ d.l \\
\hline
\end{tabular}

Table C.5. Coconut Hall, Antigua Formation, Antigua. See table C.1 for description.

\begin{tabular}{|c|c|c|c|c|c|c|c|c|c|c|c|c|}
\hline number & $\mathrm{Al}$ & $\mathrm{K}$ & $\mathrm{Na}$ & $\mathrm{Li}$ & $\mathrm{Ti}$ & $\mathrm{Cr}$ & $\mathrm{Fe}$ & $\mathrm{Mn}$ & $\mathrm{Ca}$ & $\mathrm{Mg}$ & $\mathrm{Ba}$ & $\mathrm{V}$ \\
\hline ANPG-01 (pri) & 796.86 & 188.20 & 406.44 & 8.90 & 28.97 & 2.89 & 183.67 & $<$ d.l. & 2736.56 & 36.92 & 5.08 & 1.65 \\
\hline ANPG-03 (pri) & 833.14 & 194.50 & 387.35 & 6.68 & 26.41 & 3.10 & 161.74 & $<$ d.l. & 822.97 & 39.22 & 3.61 & 1.39 \\
\hline ANPG-05 (pri) & 827.64 & 237.30 & 472.41 & 7.57 & 32.07 & 2.91 & 418.63 & $<$ d.l. & 858.52 & 42.98 & 4.41 & 0.88 \\
\hline ANPG-06 (pri) & 848.03 & 267.04 & 604.65 & 6.77 & 42.25 & 4.66 & 348.50 & $<$ d.l. & 1689.21 & 63.72 & 3.53 & 1.39 \\
\hline ANPG-07a (pri) & 940.30 & 273.95 & 463.90 & 5.95 & 33.47 & 3.58 & 359.90 & $<$ d.l. & 2837.69 & 83.27 & 16.56 & 2.11 \\
\hline
\end{tabular}

Table C.6. Pigotts Hill (present-day limestone quarry site), Antigua Formation, Antigua. See table C.1 for description.

\begin{tabular}{|c|c|c|c|c|c|c|c|c|c|c|c|c|}
\hline number & $\mathrm{Al}$ & $\mathrm{K}$ & $\mathrm{Na}$ & $\mathrm{Li}$ & $\mathrm{Ti}$ & $\mathrm{Cr}$ & $\mathrm{Fe}$ & $\mathrm{Mn}$ & $\mathrm{Ca}$ & $\mathrm{Mg}$ & $\mathrm{Ba}$ & $\mathrm{V}$ \\
\hline ANSH-01 (pri) & 4168.17 & 649.80 & 576.40 & 14.16 & 133.55 & 5.24 & 198.54 & 2.46 & 489.71 & 62.72 & 76.08 & 1.58 \\
\hline ANSH-03 (pri) & 1659.95 & 331.37 & 331.25 & 8.05 & 24.95 & 0.88 & 93.13 & 3.03 & 253.96 & 45.51 & 198.87 & $<$ d.l. \\
\hline ANSH-04 (pri) & 2555.28 & 444.66 & 420.12 & 9.58 & 175.98 & 9.59 & 145.99 & 3.78 & 240.02 & 24.70 & 84.61 & 2.03 \\
\hline ANSH-06 (pri) & 910.27 & 262.79 & 341.54 & 3.36 & 26.05 & $<$ d.l. & 35.20 & 0.81 & 106.80 & 26.56 & 13.30 & $<$ d.l. \\
\hline ANSH-09 & 2192.11 & 458.93 & 410.40 & 9.09 & 126.39 & 7.48 & 93.64 & 2.53 & 227.15 & 39.84 & 42.63 & 1.57 \\
\hline ANSH-11 & 1735.30 & 374.60 & 357.56 & 6.72 & 109.90 & 3.92 & 71.06 & 2.51 & 229.23 & 36.07 & 41.36 & 0.96 \\
\hline ANSH-12a & 232.95 & 77.53 & 99.95 & 1.67 & 3.81 & $<$ d.l. & 2560.12 & 12.15 & 88.15 & 18.35 & 5.98 & 2.78 \\
\hline ANSH-12b & 278.89 & 93.92 & 97.16 & 1.44 & 2.66 & $<$ d.l. & 18.10 & 1.11 & 123.09 & 8.21 & 11.12 & $<$ d.l. \\
\hline
\end{tabular}

Table C.7. Shirley Heights, Basal Volcanic Suite, Antigua. See table C.1 for description.

\begin{tabular}{|c|c|c|c|c|c|c|c|c|c|c|c|c|}
\hline number & $\mathrm{Al}$ & $\mathrm{K}$ & $\mathrm{Na}$ & $\mathrm{Li}$ & $\mathrm{Ti}$ & $\mathrm{Cr}$ & $\mathrm{Fe}$ & $\mathrm{Mn}$ & $\mathrm{Ca}$ & $\mathrm{Mg}$ & $\mathrm{Ba}$ & $\mathrm{V}$ \\
\hline ANCP-01 & 1871.12 & 378.17 & 672.78 & 28.08 & 85.98 & 0.93 & 184.69 & 5.04 & 340.76 & 46.60 & 48.95 & 21.73 \\
\hline ANCP-02 & 773.59 & 227.34 & 488.46 & 17.22 & 113.53 & 0.89 & 532.74 & 5.85 & 695.73 & 96.00 & 69.86 & 90.74 \\
\hline ANCP-03 & 148.57 & 21.87 & 156.82 & 1.86 & 23.98 & 0.87 & $<$ d.l. & 1.59 & 80.24 & 61.57 & 13.33 & 5.22 \\
\hline ANCP-04 & 169.98 & 26.80 & 103.89 & 1.58 & 10.90 & $<$ d.l. & $<$ d.l. & 2.30 & 54.91 & 54.56 & 3.95 & 4.79 \\
\hline ANCP-05 & 2332.44 & 420.80 & 861.35 & 33.73 & 110.10 & 1.44 & 444.05 & 15.75 & 437.77 & 99.01 & 75.78 & 32.88 \\
\hline ANCP-06 & 81.08 & 12.11 & 52.78 & $<$ d.l. & $<$ d.1. & $<$ d.l. & $<$ d.l. & 1.51 & 18.27 & 14.64 & 42.78 & 1.36 \\
\hline ANCP-10 (pri) & 58.18 & 25.58 & 356.56 & 0.77 & 8.43 & $<$ d.l. & 27.66 & 13.07 & 8714.55 & 220.78 & 1.39 & 1.62 \\
\hline ANCP-11.1 (pri) & 1551.94 & 348.72 & 1077.58 & 23.81 & 82.63 & 1.78 & 950.28 & 18.70 & 6434.20 & 205.41 & 20.35 & 75.68 \\
\hline ANCP-11.2 (pri) & 1611.41 & 374.63 & 1128.09 & 25.40 & 80.17 & 1.80 & 1118.17 & 24.72 & 9579.71 & 267.19 & 14.81 & 81.05 \\
\hline ANCP-12 (pri) & 831.65 & 236.35 & 1328.97 & 12.32 & 39.26 & 1.83 & 927.02 & 26.87 & 37884.83 & 693.99 & 4.08 & 70.84 \\
\hline ANCP-13 & 570.29 & 154.08 & 1299.00 & 11.36 & 33.43 & $<$ d.l. & 108.00 & 203.40 & 30698.85 & 554.58 & 3.88 & 34.10 \\
\hline ANCP-20 & 51.76 & 29.02 & 252.78 & 0.93 & 12.02 & $<$ d.l. & 21.22 & 14.04 & 8828.38 & 238.62 & 1.53 & 1.60 \\
\hline ANCP-21 & 1393.51 & 293.44 & 641.92 & 20.97 & 107.94 & 1.66 & 583.55 & 2.77 & 329.58 & 59.60 & 129.21 & 156.98 \\
\hline
\end{tabular}

Table C.8. Corbison Point, Central Plain Group, Antigua. See table C.1 for description. 
APPENDIX C - DATA OF GEOCHEMICAL ANALYSIS

\begin{tabular}{|c|c|c|c|c|c|c|c|c|c|c|c|c|}
\hline number & $\mathrm{Al}$ & $\mathrm{K}$ & $\mathrm{Na}$ & $\mathrm{Li}$ & $\mathrm{Ti}$ & $\mathrm{Cr}$ & $\mathrm{Fe}$ & $\mathrm{Mn}$ & $\mathrm{Ca}$ & $\mathrm{Mg}$ & $\mathrm{Ba}$ & $\mathrm{V}$ \\
\hline ANDH-01 (pri) & 385.16 & 95.71 & 584.90 & 3.34 & 13.28 & $<$ d.l. & 286.55 & 8.75 & 2384.38 & 222.07 & 2.23 & 44.70 \\
\hline ANDH-02 (pri) & 332.63 & 22.40 & 586.38 & 1.93 & 4.43 & $<$ d.l. & 464.85 & 40.53 & 32548.82 & 787.52 & 4.53 & 1.53 \\
\hline ANDH-03 (pri) & 469.89 & 134.59 & 552.27 & 8.48 & 24.28 & $<$ d.1. & 95.73 & 19.80 & 4215.05 & 230.59 & 2.61 & 11.28 \\
\hline ANDH-04a (pri) & 286.68 & 86.48 & 583.20 & 9.72 & 10.94 & $<$ d.l. & 1730.72 & 716.83 & 34894.30 & 895.84 & 4.07 & 9.53 \\
\hline ANDH-04b (pri) & 395.16 & 108.01 & 749.67 & 11.24 & 18.08 & $<$ d.l. & 2784.04 & 653.86 & 34735.57 & 1050.64 & 14.61 & 13.91 \\
\hline ANDH-09 & 175.95 & 63.88 & 379.07 & 0.92 & 6.76 & $<$ d.l. & 6563.67 & 2.80 & 191.55 & 73.57 & 2.01 & 8.77 \\
\hline ANDH-11 & 204.34 & 46.16 & 165.72 & 6.41 & 5.41 & $<$ d.l. & 32.05 & 39.65 & 2280.79 & 1295.47 & 0.94 & 29.48 \\
\hline ANDH-12 & 422.18 & 164.71 & 558.28 & 1.13 & 11.69 & $<$ d.l. & 146.81 & 1.08 & 65.43 & 72.10 & 1.43 & $<$ d.l. \\
\hline ANDH-13 & 113.90 & 39.77 & 260.97 & 1.43 & 22.26 & $<$ d.l. & 229.28 & 11.40 & 4028.34 & 161.75 & 3.18 & 17.95 \\
\hline
\end{tabular}

Table C.9. Dry Hill, Central Plain Group, Antigua. See table C.1 for description.

\begin{tabular}{|c|c|c|c|c|c|c|c|c|c|c|c|c|}
\hline number & $\mathrm{Al}$ & $\mathrm{K}$ & $\mathrm{Na}$ & $\mathrm{Li}$ & $\mathrm{Ti}$ & $\mathrm{Cr}$ & $\mathrm{Fe}$ & $\mathrm{Mn}$ & $\mathrm{Ca}$ & $\mathrm{Mg}$ & $\mathrm{Ba}$ & $\mathrm{V}$ \\
\hline ANWF-02 (pri) & 728.18 & 61.16 & 324.05 & 1.74 & 5.77 & $<$ d.l. & 61.03 & 2.13 & 319.49 & 10.66 & 9.26 & $<\mathrm{d} .1$ \\
\hline ANWF-03 (pri) & 508.11 & 73.51 & 146.13 & 2.20 & 2.34 & $<$ d.l. & 48.55 & 1.42 & 226.63 & 7.16 & 2.98 & $<\mathrm{d} .1$ \\
\hline ANWF-07 (pri) & 412.74 & 73.35 & 166.87 & 4.55 & 5.40 & $<$ d.l. & 115.81 & 1.28 & 1562.72 & 7.80 & 2.96 & $<$ d.1 \\
\hline ANWF-08 (pri) & 485.52 & 103.38 & 231.61 & 1.57 & 2.91 & $<$ d.l. & 72.43 & 1.21 & 101.44 & 5.58 & $<$ d.l. & $<$ d.1. \\
\hline
\end{tabular}

Table C.10. Willis Freeman (present-day quarry site), Central Plain Group, Antigua. See table C.1 for description.

\begin{tabular}{|c|c|c|c|c|c|c|c|c|c|c|c|c|}
\hline number & $\mathrm{Al}$ & $\mathrm{K}$ & $\mathrm{Na}$ & $\mathrm{Li}$ & $\mathrm{Ti}$ & $\mathrm{Cr}$ & $\mathrm{Fe}$ & $\mathrm{Mn}$ & $\mathrm{Ca}$ & $\mathrm{Mg}$ & $\mathrm{Ba}$ & $\mathrm{V}$ \\
\hline ANBU-02 & 255.86 & 51.09 & 143.12 & 2.02 & 5.31 & $<$ d.l. & 54.36 & 1.29 & 48.90 & 5.12 & 5.75 & 1.66 \\
\hline ANBU-04 & 556.27 & 94.94 & 193.15 & 11.03 & 28.66 & $<$ d.l. & 944.74 & 8.32 & 1568.92 & 66.58 & 250.61 & 42.73 \\
\hline ANBU-20 & 448.64 & 67.60 & 222.19 & 4.69 & 20.18 & 1.25 & 67.59 & 2.59 & 335.94 & 16.88 & 7.83 & 10.25 \\
\hline ANBU-21 & 488.58 & 31.24 & 90.56 & 10.87 & 13.53 & $<$ d.l. & 580.90 & 10.20 & 1041.88 & 26.46 & 31.27 & 9.68 \\
\hline
\end{tabular}

Table C.11. Buckleys, Central Plain Group, Antigua. See table C.1 for description.

\begin{tabular}{|c|c|c|c|c|c|c|c|c|c|c|c|c|}
\hline number & $\mathrm{Al}$ & $\mathrm{K}$ & $\mathrm{Na}$ & $\mathrm{Li}$ & $\mathrm{Ti}$ & $\mathrm{Cr}$ & $\mathrm{Fe}$ & $\mathrm{Mn}$ & $\mathrm{Ca}$ & $\mathrm{Mg}$ & $\mathrm{Ba}$ & $\mathrm{V}$ \\
\hline PRCE.a-01.1.1 & 618.25 & 43.49 & 29.04 & 4.73 & 18.76 & 50.54 & 1953.11 & 18.86 & 20.30 & 311.82 & 4.88 & 7.95 \\
\hline PRCE.a-01.1.2 & 274.46 & 43.78 & 31.36 & 5.92 & 7.37 & 50.16 & 1850.27 & 10.59 & 35.29 & 302.06 & 6.07 & 8.05 \\
\hline PRCE.a-01.1.3 & 178.33 & 41.61 & 30.61 & 3.54 & 5.66 & 39.42 & 871.46 & 9.15 & 18.73 & 287.68 & 3.18 & 3.89 \\
\hline PRCE.a-01.2av & 283.68 & 35.93 & 40.88 & 5.32 & 9.83 & 48.91 & 1392.62 & 11.17 & 22.93 & 371.55 & 3.23 & 6.28 \\
\hline PRCE.a-02 & 127.48 & 45.12 & 94.49 & 1.15 & 3.97 & 39.24 & 724.39 & 5.15 & 25.72 & 326.04 & 2.90 & 4.79 \\
\hline PRCE.a-06 & 221.44 & 50.99 & 67.59 & 2.64 & 5.52 & 201.23 & 1056.47 & 8.08 & 29.98 & 186.73 & 3.40 & 7.78 \\
\hline PRCE.a-07 & 395.94 & 109.37 & 71.76 & 24.53 & 12.53 & 33.50 & 1264.54 & 8.18 & 14.24 & 1056.05 & 3.07 & 6.72 \\
\hline PRCE.a-13 & 258.97 & 69.40 & 138.17 & 1.61 & 6.69 & 1.71 & 177.82 & 3.28 & 34.71 & 109.09 & 8.37 & 1.29 \\
\hline PRCE-01 & 247.15 & 67.96 & 72.66 & 5.32 & 7.96 & 4.80 & 146.98 & 2.28 & 25.82 & 83.15 & 41.78 & 2.33 \\
\hline PRCE-04 & 507.06 & 105.06 & 77.89 & 5.42 & 22.92 & 83.67 & 5833.65 & 14.28 & 347.10 & 409.88 & 7.29 & 15.23 \\
\hline PRCE-05 & 279.65 & 48.10 & 63.25 & 3.90 & 5.86 & 26.62 & 2856.59 & 3.40 & 38.19 & 253.40 & 13.63 & 6.02 \\
\hline PRCE-06 & 272.87 & 77.09 & 58.03 & 14.89 & 9.81 & 30.45 & 1206.72 & 6.12 & 18.67 & 559.60 & 1.91 & 3.83 \\
\hline PRCE-07 & 66.99 & 20.04 & 18.15 & 4.27 & 3.86 & 4.24 & 149.76 & 2.77 & 14.53 & 331.24 & 5.11 & 2.34 \\
\hline
\end{tabular}

Table C.12. Cerrillos, Guanajibo Formation, Puerto Rico. See table C.1 for description. 
APPENDIX C - DATA OF GEOCHEMICAL ANALYSIS

\begin{tabular}{|c|c|c|c|c|c|c|c|c|c|c|c|c|}
\hline number & $\mathrm{Al}$ & $\mathrm{K}$ & $\mathrm{Na}$ & $\mathrm{Li}$ & $\mathrm{Ti}$ & $\mathrm{Cr}$ & $\mathrm{Fe}$ & $\mathrm{Mn}$ & $\mathrm{Ca}$ & $\mathrm{Mg}$ & $\mathrm{Ba}$ & $\mathrm{V}$ \\
\hline PRPE-01 & 259.00 & 124.28 & 150.65 & 3.35 & 13.89 & 25.91 & 246.95 & $<$ d.l. & 194.52 & 108.43 & 2.59 & 5.37 \\
\hline PRPE-02 & 139.28 & 63.54 & 25.33 & 4.61 & 3.27 & 2.34 & 134.92 & 1.14 & 58.84 & 22.24 & 1.17 & 1.32 \\
\hline PRPE-03 & 321.83 & 265.47 & 200.33 & $<$ d.l. & 10.41 & 4.11 & 298.41 & 1.11 & 67.96 & 35.36 & $<$ d.l. & 2.81 \\
\hline PRPE-04 & 121.53 & 72.59 & 79.69 & 0.92 & 3.51 & 7.31 & 58.35 & 1.00 & 159.54 & 93.45 & 0.89 & 4.13 \\
\hline PRPE-06 & 200.09 & 89.42 & 52.27 & 2.93 & 5.08 & 4.14 & 127.63 & 1.05 & 49.57 & 23.41 & 1.10 & 1.38 \\
\hline PRPE-07 & 176.85 & 32.17 & 38.21 & 2.41 & 26.63 & 3.21 & 380.25 & 4.31 & 487.70 & 291.99 & 10.32 & 1.84 \\
\hline PRPE-08 & 198.42 & 102.40 & 100.53 & 1.86 & 7.52 & 7.09 & 174.68 & 1.90 & 73.65 & 46.14 & 5.18 & 3.77 \\
\hline PRPE-09 & 299.95 & 144.47 & 184.80 & 1.76 & 15.27 & 6.32 & 394.05 & 5.23 & 65.57 & 71.45 & 2.15 & 8.13 \\
\hline
\end{tabular}

Table C.13. Pedernales, Guanajibo Formation, Puerto Rico. See table C.1 for description

\begin{tabular}{|c|c|c|c|c|c|c|c|c|c|c|c|c|}
\hline number & $\mathrm{Al}$ & $\mathrm{K}$ & $\mathrm{Na}$ & $\mathrm{Li}$ & $\mathrm{Ti}$ & $\mathrm{Cr}$ & $\mathrm{Fe}$ & $\mathrm{Mn}$ & $\mathrm{Ca}$ & $\mathrm{Mg}$ & $\mathrm{Ba}$ & $\mathrm{V}$ \\
\hline PRLP.a-04 & 74.22 & 93.62 & 171.88 & $<$ d.l. & 2.38 & $<$ d.l. & 177.16 & 1.30 & 67.34 & 22.70 & 1.47 & 1.18 \\
\hline PRLP.a-05 & 311.46 & 95.59 & 165.69 & 0.88 & 5.21 & 2.41 & 4453.88 & 3.53 & 136.77 & 81.67 & 4.13 & 8.57 \\
\hline PRLP.a-09 & 70.89 & 42.20 & 71.58 & 1.23 & 3.53 & 42.07 & 152.55 & 5.69 & 900.46 & 523.95 & 136.22 & 26.12 \\
\hline PRLP.a-10 & 185.40 & 104.39 & 191.24 & $<$ d.l. & 2.61 & 2.01 & 796.60 & 3.79 & 59.11 & 85.02 & 1.37 & 5.73 \\
\hline PRLP.a-11.1 & 149.36 & 83.49 & 83.18 & 2.71 & 5.48 & 22.11 & 481.91 & 4.85 & 55.96 & 28.45 & 4.52 & 3.95 \\
\hline PRLP.a-11.2av & 82.17 & 49.34 & 71.31 & 1.25 & 2.99 & 14.67 & 230.89 & 3.16 & 153.46 & 97.09 & 6.26 & 2.15 \\
\hline PRLP.a-11.3av & 354.88 & 175.17 & 132.44 & 0.88 & 34.11 & 61.88 & 824.57 & 41.95 & 119.94 & 71.96 & 55.17 & 2.99 \\
\hline PRLP.a-13 & 55.36 & 100.84 & 181.97 & 1.20 & 2.97 & 3.53 & 354.06 & 1.88 & 272.27 & 515.56 & 8.89 & 15.24 \\
\hline PRLP.a-16 & 165.04 & 47.75 & 86.32 & 3.53 & 1.71 & 9.16 & 620.84 & 2.03 & 204.91 & 116.13 & 3.88 & 1.84 \\
\hline PRLP-01 & 115.94 & 95.02 & 170.60 & $<$ d.l. & 2.17 & $<$ d.1. & 502.84 & 1.63 & 65.37 & 61.07 & 0.90 & 4.52 \\
\hline PRLP-16 & 85.21 & 51.03 & 24.34 & $<$ d.l. & 3.91 & $<$ d.1. & 59.25 & $<$ d.l. & 44.94 & 33.68 & 0.99 & $<$ d.l. \\
\hline PRLP-20 & 43.65 & 18.49 & 7.99 & $<$ d.l. & 2.83 & $<$ d.l. & 116.75 & 3.54 & 241.04 & 325.13 & 7.52 & 8.57 \\
\hline
\end{tabular}

Table C.14. Las Palmas, Ponce Formation, Puerto Rico. See table C.1 for description.

\begin{tabular}{|c|c|c|c|c|c|c|c|c|c|c|c|c|}
\hline number & $\mathrm{Al}$ & $\mathrm{K}$ & $\mathrm{Na}$ & $\mathrm{Li}$ & $\mathrm{Ti}$ & $\mathrm{Cr}$ & $\mathrm{Fe}$ & $\mathrm{Mn}$ & $\mathrm{Ca}$ & $\mathrm{Mg}$ & $\mathrm{Ba}$ & $\mathrm{V}$ \\
\hline PRVT-01 & 411.14 & 41.12 & 92.16 & 2.04 & 3.39 & 19.02 & 7641.99 & 24.09 & 140.01 & 82.24 & 10.15 & 15.59 \\
\hline PRVT-02 & 257.45 & 41.24 & 104.31 & 7.42 & 2.34 & 9.96 & 349.62 & 13.84 & 622.05 & 396.70 & 16.70 & 17.53 \\
\hline PRVT-03 & 303.93 & 47.54 & 84.22 & 5.11 & 4.74 & 16.18 & 2270.26 & 15.22 & 113.20 & 50.31 & 73.95 & 6.57 \\
\hline PRVT-04 & 243.27 & 87.80 & 110.23 & 6.55 & 4.10 & 19.46 & 560.22 & 3.52 & 85.44 & 49.93 & 8.31 & 3.00 \\
\hline PRVT-05 & 399.12 & 34.44 & 136.63 & 1.45 & 4.51 & 43.68 & 8732.00 & 38.02 & 149.89 & 137.22 & 21.59 & 22.51 \\
\hline PRVT-06 & 248.10 & 19.79 & 62.02 & 8.87 & 10.37 & 18.46 & 590.12 & 1.54 & 26.26 & 47.64 & 12.17 & 7.91 \\
\hline PRVT-07 & 359.33 & 66.04 & 122.92 & 4.80 & 4.93 & 23.60 & 4288.42 & 159.05 & 588.77 & 343.08 & 51.37 & 13.79 \\
\hline PRVT-08 & 54.79 & 47.59 & 87.27 & 1.19 & 1.73 & 27.98 & 68.72 & 1.02 & 104.19 & 492.31 & 6.21 & 3.25 \\
\hline
\end{tabular}

Table C.15. Villa Taina, Cotui Formation, Puerto Rico. See table C.1 for description.

\begin{tabular}{|c|c|c|c|c|c|c|c|c|c|c|c|c|}
\hline number & $\mathrm{Al}$ & $\mathrm{K}$ & $\mathrm{Na}$ & $\mathrm{Li}$ & $\mathrm{Ti}$ & $\mathrm{Cr}$ & $\mathrm{Fe}$ & $\mathrm{Mn}$ & $\mathrm{Ca}$ & $\mathrm{Mg}$ & $\mathrm{Ba}$ & $\mathrm{V}$ \\
\hline PRMO-04 & 62.07 & 38.41 & 148.45 & $<$ d.l. & 3.10 & 4.41 & 1427.74 & 19.65 & 331.96 & 152.23 & 2.96 & 10.60 \\
\hline PRMO-05 & 45.81 & $<$ d.l. & 20.56 & $<$ d.l. & 1.35 & 3.42 & 3405.29 & 20.13 & 76.56 & 21.03 & 10.25 & 2.74 \\
\hline PRMO-06 & 589.24 & 219.42 & 297.74 & 9.41 & 42.73 & 46.02 & 2485.20 & 33.53 & 134.97 & 193.33 & 25.22 & 7.89 \\
\hline PRMO-01 & 550.92 & 167.17 & 236.08 & 10.55 & 27.81 & 15.43 & 1909.96 & 13.05 & 77.10 & 59.21 & 28.82 & 10.43 \\
\hline PRMO-08 & 149.87 & 46.59 & 109.02 & $<$ d.l. & 2.11 & 4.13 & 1386.41 & 8.74 & 51.76 & 27.38 & 1.79 & 5.85 \\
\hline PRMO-02 & 289.31 & 95.93 & 183.75 & 4.47 & 7.60 & 12.99 & 340.89 & 4.56 & 85.29 & 663.61 & 6.01 & 8.56 \\
\hline
\end{tabular}

Table C.16. Moca, San Sebastián Formation, Puerto Rico. See table C.1 for description. 
APPENDIX C - DATA OF GEOCHEMICAL ANALYSIS

\begin{tabular}{|c|c|c|c|c|c|c|c|c|c|c|c|c|}
\hline number & $\mathrm{Al}$ & $\mathrm{K}$ & $\mathrm{Na}$ & $\mathrm{Li}$ & $\mathrm{Ti}$ & $\mathrm{Cr}$ & $\mathrm{Fe}$ & $\mathrm{Mn}$ & $\mathrm{Ca}$ & $\mathrm{Mg}$ & $\mathrm{Ba}$ & $\mathrm{V}$ \\
\hline StKGSP-01.2 & 227.33 & 181.47 & 387.94 & 1.27 & 10.67 & $<$ d.l. & 108.91 & 1.12 & 167.09 & 37.07 & $<$ d.l. & $<$ d.l. \\
\hline StKGSP-02.2 & 515.41 & 211.70 & 623.22 & 1.83 & 12.51 & 7.95 & 99.69 & 3.48 & 32269.90 & 528.28 & 0.96 & 5.13 \\
\hline StKGSP-03.2 & 351.33 & 238.35 & 408.88 & 4.73 & 11.30 & $<$ d.l. & 70.76 & 0.85 & 108.20 & 153.93 & 1.05 & $<$ d.l. \\
\hline StKGSP-04.2 & 452.95 & 296.84 & 607.53 & 1.95 & 17.89 & 0.98 & 226.76 & 1.42 & 112.32 & 94.22 & 1.67 & $<$ d.l. \\
\hline StKGSP-05 & 443.99 & 292.10 & 733.90 & 4.21 & 13.44 & $<$ d.l. & 509.17 & 1.48 & 146.75 & 195.94 & 1.48 & $<$ d.l. \\
\hline StKGSP-07 & 399.05 & 258.28 & 741.89 & 2.27 & 13.33 & 0.77 & 513.02 & 2.83 & 74.82 & 118.10 & 21.52 & 1.31 \\
\hline StKGSP-09 & 449.25 & 145.92 & 697.70 & 5.05 & 25.08 & 0.84 & 398.15 & 3.53 & 217.48 & 107.01 & 9.42 & 18.99 \\
\hline$\frac{\text { StKGSP-10 }}{\text { StKSFP-01.2 }}-$ & $\frac{316.76}{324.89}$ & $\frac{258.56}{261.79}$ & $-\frac{1061.92}{309.52}$ & $-\frac{2.06}{2.01}$ & $-\frac{13.53}{13.54}$ & $-\frac{8.89}{0.77}$ & $-\frac{103.44}{343.25}$ & $-\frac{2.05}{9.57}$ & $\frac{29297.95}{689.69}$ & $-\frac{633.28}{40.76}$ & $\frac{1.05}{3.97}$ & $-\frac{5.89}{<\text { d. } 1 .}$ \\
\hline StKSFP-02.2 & 263.06 & 166.16 & 369.15 & 2.33 & 8.31 & $<$ d.l. & 97.07 & 0.81 & 92.73 & 41.70 & 1.10 & $<$ d.l. \\
\hline StKSFP-03.2 & 983.20 & 470.68 & 529.21 & 16.62 & 40.54 & 1.55 & 128.81 & 2.29 & 79.19 & 59.59 & 7.89 & 1.26 \\
\hline StKSFP-04.2 & 385.47 & 281.60 & 442.05 & 2.50 & 15.06 & 0.93 & 116.71 & 2.41 & 306.53 & 16.48 & 3.25 & $<$ d.l. \\
\hline StKSFP-05 & 433.81 & 280.02 & 708.93 & 3.32 & 11.66 & 0.74 & 491.26 & 14.82 & 392.21 & 736.93 & 9.64 & $<$ d.l. \\
\hline StKSFP-06 & 308.17 & 195.56 & 508.76 & 2.11 & 8.01 & $<$ d.l. & 57.39 & 0.87 & 105.44 & 54.36 & 1.37 & $<$ d.l. \\
\hline$\frac{\underline{\text { StKSFP-10 }}}{\text { StK-K-1 }}-$ & $\frac{833.59}{475.41}$ & $\frac{450.04}{244.69}$ & $-\frac{664.71}{586.60}$ & $\frac{5.55}{4.08}$ & $\frac{31.19}{11.00}$ & $-\frac{1.30}{<\mathrm{d} .1 .}$ & $\frac{181.50}{565.95}$ & $-\frac{1.28}{1.15}$ & $-\frac{73.28}{56.38}$ & $-\frac{94.00}{148.99}$ & $\frac{3.42}{1.63}$ & $-\frac{1.08}{<\mathrm{d} .1 .}$. \\
\hline StK-K-2 & 467.00 & 300.20 & 471.08 & 1.55 & 17.28 & 0.91 & 164.63 & 1.42 & 171.60 & 42.25 & 1.94 & 1.02 \\
\hline StKWB-01.1av & 847.97 & 363.06 & 491.82 & 3.62 & 30.16 & 119.34 & 1217.64 & 20.38 & 1103.48 & 93.84 & 8.84 & 1.32 \\
\hline
\end{tabular}

Table C.17. Great Salt Pond and Sugar Factory Pier, St. Kitts. See table C.1 for description. 


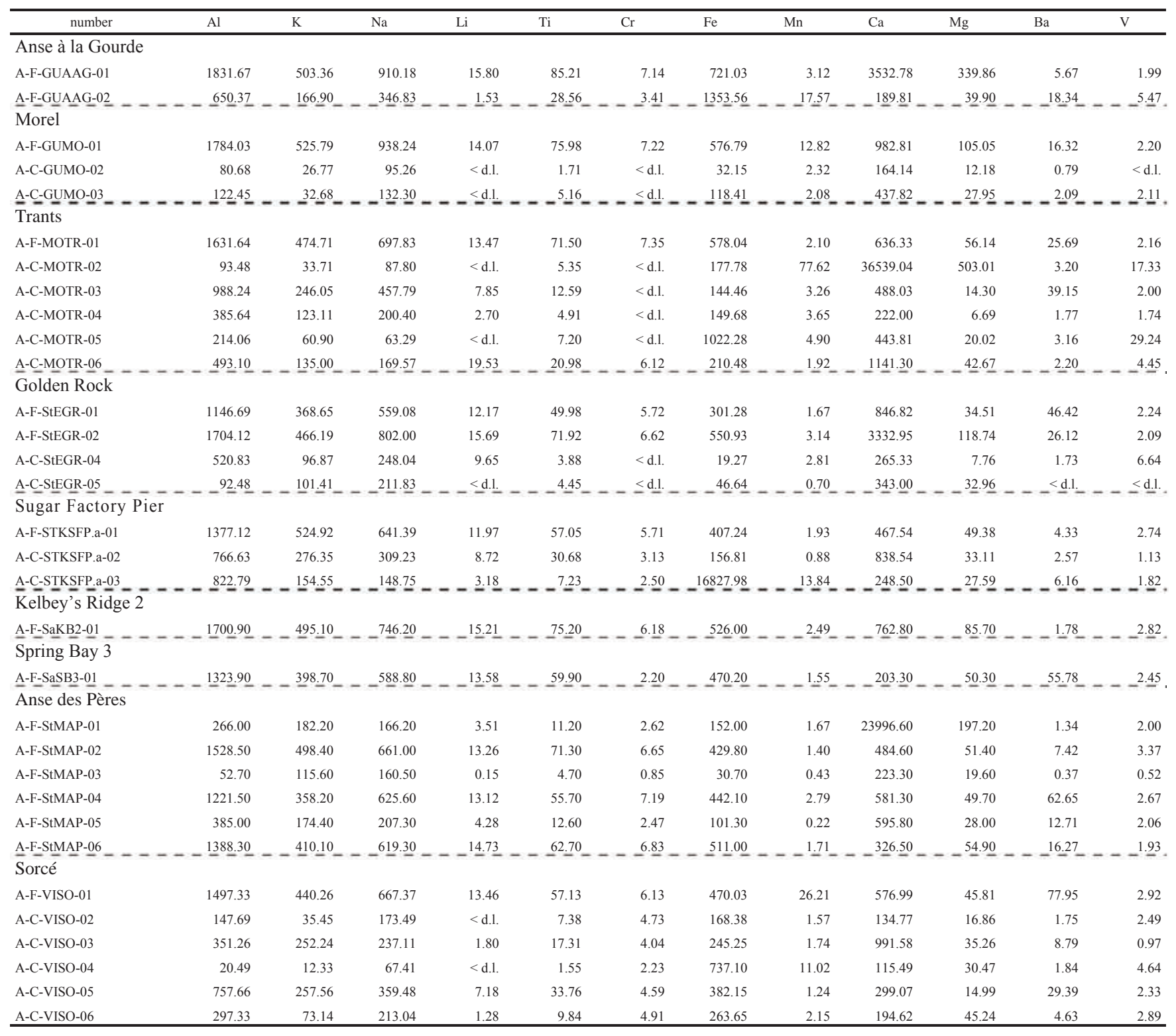

Table C.18. Trace-element concentration values (in $\mathrm{mg} / \mathrm{kg}(\mathrm{ppm})$ ) within flint and chert artefacts from different Ceramic Age sites within the northern Lesser Antilles and Puerto Rico. See table C.1 for description. 


\section{Appendix D Attribute analysis of lithic artefacts}

\section{D.1 INTRODUCTION}

As stated in Chapter 3, samples of lithic artefacts were studied following a standardised procedure that was set up at the beginning of this research. This procedure included the coding of a number of attributes for each artefact, which were chosen bearing the initial aims in mind concerning reduction stages. Not all artefacts were analysed for the same attributes, however, depending on artefact category and related technology. Therefore, during the analysis artefacts were assigned to certain groups and each of these groups was studied differently.

At the start of the analysis, each artefact was given an individual number and was analysed for the following attributes: (1) type of raw material; (2) type of artefact; (3) maximal dimension; (4) width; (5) thickness; (6) weight; (7) colour; (8) traces of burning; and (9) likely lithic source.

Then, all flakes and shatter were separated from the core artefacts. Within these flake/shatter and core categories, flake tool associated artefacts were separated from core tool associated artefacts. All flakes were studied for: (10) the amount of outer surface (cortex) on the dorsal face; (11) the type of cortex; (12) whether they were further reduced; (13) on the presence of use-wear in the form of intentional or use retouch; and (14) the location of retouch. After this, flakes that were associated with the flake tool technology were additionally analysed for: (15) the presence of patina/weathering; (16) the type of flaking technique; (17) the number of scars on dorsal face (only for complete flakes); (18) the type of striking platform; and (19) the type of distal end.

All flake cores were studied for the amount of outer surface and the flaking technique. Within the remaining core artefact and core tool group, a distinction was made between complete and non-complete items, between finished tools or artefacts, and preforms. Furthermore any signs of (20) shaping techniques present, such as flaking, pecking, or grinding were recorded. Other attributes included, if possible, the tool's overall shape (21), the edge shape (22), and its type of finishing (23). In the case of the St. Martin greenstone artefacts, the presence of weathering (24) was recorded as well.

\section{D.2 The ATTRIBUTE LIST}

Each attribute is discussed separately in the following section to provide a complete definition in each case.

(1) Type of raw material: The rock material the artefact was made is specified in this case. As the variety of rock types within the region is very large and many rock types need in-depth analysis to be fully determined, the specified rock types in this attribute follow broad geological categories and only in certain cases are very distinct materials mentioned.

1) flint (nodular chert in limestone).

2) chert (bedded chert; other types of chert).

3) jasper.

4) quartz.

5) igneous rock (hypabyssal and volcanic varieties).

6) plutonic rock.

7) sandstone.

8) limestone.

9) fine grained rock (possibly sedimentary (non-carbonate)).

10) red ochre (hematite).

11) semi-precious stone.

12) metamorphic rock.

13) pumice.

14) calcite.

15) tuff.

16) calci-rudite (zemistone).

17) unidentifiable due to burning.

18) unidentified. 
2) Artefact type: The artefact type attribute is divided into three broad groups: (a) flakes and shatter; (b) flake cores; and (c) core tools/other core artefacts. For the flake and shatter, Sullivan and Rozen's (1985) classification scheme is used. The flake core types follow Hutcheson and Callow (1986), including some additional types, and the other core artefacts/core tools category includes many common types found within Caribbean lithic assemblages.

debitage: flakes and shatter

1) complete flake/blade: any piece removed from a larger mass by the application of force. It possesses an interior surface,

a platform, and margins; a blade is flake with a length that is larger than twice its width.

2) broken flake: differs from complete flake for not having intact margins.

3) split flake: differs from complete flake for having a sheared axis of flaking.

4) flake fragment: all flakes without a platform.

5) shatter: any piece removed from a larger mass by the application of force without a discernable interior surface.

6) unidentified flake artefact: artefact in which weathering or burning has blurred technological features.

flake/blade core: an item from which flakes/blades were removed. It only bears negative percussion features, lacking positive ones

1) polyhedral: a multi-platformed core, roughly globular in shape, with flaking carried out in any direction and from any platform capable of yielding a usable flake; often exhausted, and sometimes with aretes showing signs of shattering caused by unsuccessful attempts to continue debitage.

2) shapeless/miscellaneous: core formed by a few removals without any obviously preferred orientation.

3) multiple platformed: thinner than the polyhedral cores, but rather similar in other respects (notably in the possession of two or more platforms without evidence of a systematic reduction strategy).

4) discoidal: rather flat core, with more or less radial scar patterns and removals of roughly equal size on both faces.

5) prismatic: a single platformed core. The platform is formed by a natural fracture or an early flake scar at one end of the core; from much of its circumference, parallel-sided flakes or blades were removed.

6) pyramidal/conical: from around a single flattish circular platform flakes have been removed so that their scars meet at the apex of a moderately shallow cone.

7) bipyramidal/biconical: the platform is circular, and peripheral; flaking is on both faces, and alternate, making use of one flake scar as the platform for the next.

8) single platformed, unifacial: core from which flakes have been struck on one face only, from a single platform.

9) single platformed, bifacial: flakes have been removed from two faces, from a single platform. This sometimes results in a core looking rather like a chopping tool, though with an edge too obtuse, or irregular, to be useful.

10) double platformed: core with two platforms which are opposed to each other, on the ends or sides of the cores; from these, flaking had been preformed on either the same or adjacent faces.

11) double platformed at right angles: core possessing two platforms which are perpendicular to each other, more or less adjacent: flaking has been carried out on either the same or adjacent faces. (all definitions according to Hutcheson \& Callow 1986)

12) split cobble: core possessing one bipolar flake scar on one surface and the rest of the specimen is still cortex encased (Walker 1980)

13) bidirectional (bipolar): a flat core with usually edged platforms on both ends, from which flakes have been removed in opposite directions.

Core-tools:

1) axe/adze: an implement having a range of shapes from ovoid to rectangular, produced with bifacial chipping, grinding, or polishing, with at least one end tapered to a bit that can be plano-convex or bi-convex in shape (Haviser 1993; with some modifications).

2) edge flake: a flake that possesses a part of the edge of an axe/adze on the dorsal face.

3) core-tool pre-form: an unfinished core tool, that possesses flaking scars and/or signs of pecking and/or grinding; furthermore it usually exhibits a flaw (e.g., breakage, oversized flake removal), that is why it was discarded.

4) butt-end: a ground or polished incomplete artefact with a rounded end, usually the butt of an axe.

5) hammer stone: a mass of lithic material, often round or oblong in shape, with battering on one or both ends, sides, or faces.

6) pestle: an oblong cylindrical mass of lithic material with at least one flat end.

7) anvil stone: a mass of lithic material, flat in shape, exhibiting a battered area on at least one of the faces.

8) polishing stone: mass of lithic material, usually a water-worn pebble, exhibiting areas with polish and/or striations.

9) passive abrading stone (metate, grinding stone): a flat mass of lithic material with at least one concave abraded surface; in the case of a grinding stone, the length of a pronounced abraded surface is usually significantly longer than its width. 
10) active abrading stone (manos): an oblong or elongated mass of lithic material with at least one convex abraded surface.

11) other type of abrading tool: any mass of lithic material that has an abraded surface and does not fit the other definitions.

12) water-worn pebble with a flake scar: a naturally rounded lithic item that possesses one or few flake scars and for which the purpose of flaking is unclear.

13) water-worn pebble with narrow indentations (net-weight): Pebble with bifacial flake removals in the middle of both sides to provide points for attachment.

Other core-artefacts:

1) non-modified water-worn pebble: a lithic item rounded by water erosion.

2) flint nodule: a non-modified piece of flint other than a water-worn pebble.

3) natural rock other than water-worn pebbles: unmodified rock (not shaped by flaking, pecking or grinding, and without use-wear).

4) bead: a lithic item ground or polished in a cylindrical object that is perforated.

5) bead-preform: an unfinished bead, typically lacking complete grinding or perforation .

6) pendant: a lithic item with a hole at its end or edge (Steenvoorden 1992).

7) pendant preform: unfinished pendant, typically lacking complete grinding or perforation.

8) zemi: triangular shaped object, representing one of the forms in which zemis were depicted.

9) zemi-preform: unfinished zemi, typically lacking completely ground surfaces.

10) other type of core artefact: any core artefact that does not meet any of the criteria specified above.

11) unidentified core artefact.

3a) Maximal dimension: the distance between the two most extreme points (recorded in $\mathrm{mm}$ ).

3b) Length: Length was recorded only for flakes and zemis (in $\mathrm{mm}$ ).

-flake/blade: the maximal dimension of the artefact while holding the axis of the flake parallel to the callipers. -zemi: distance between both lower points.

4) Width: Width was recorded for all artefacts (in $\mathrm{mm}$ ) according to the following criteria:

-flakes: side perpendicular to length and parallel to the dorsal and ventral plain/parallel to one of the faces. -zemi: distance between top point and base perpendicular to its length.

-other artefacts: longest side perpendicular to the maximum dimension.

5) Thickness: Thickness was recorded for all artefacts (in $\mathrm{mm}$ ) according to the following criteria:

-flake: longest distance between the ventral and dorsal sides.

-other artefacts: longest distance perpendicular to maximum dimension and width.

6) Weight: weight was recorded for all artefacts (in $0.1 \mathrm{~g}$ ).

7) Colour: the Munsell Soil Color Chart was used to determine colours. Burnt and weathered artefacts were not recorded.

8) Traces of burning: absence or presence of traces of burning.

1) no traces.

2) parent piece with the negatives of the ejected potlids. 
3) potlids: the ejected pieces.

4) structural change usually resulting in white opacity and a porcelain looking surface (after Schlanger 1992).

5) colour difference.

6) firecracked.

7) unidentified.

9) Source: All artefacts received a source designation if they were similar to source material when studied macroscopically. If not, source was specified as "unidentified". This attribute was mainly focussed on flint and chert sources, since that was the material most available to me.

Flint/chert sources:

Antigua

1) Long Island.

2) Little Cove.

3) Soldier Point.

4) Shirley Heights.

5) Hughes Bay.

6) Coconut Hall.

7) Blackman's Point.

8) Corbison Point/Dry Hill.

St.Kitts

9) Great Salt Pond.

10) Sugar Factory Pier.

11) Whitehorse Bay.

Puerto Rico

12) Cabo Rojo.

13) Las Palmas.

14) Pedernales.

15) Cerillo.

16) Villa Taina.

Other sources:

17) jasper: La Désirade.

18) greenstone: St.Martin.

19) calci-rudite: St. Martin.

20) unidentified.

10a) Amount of cortex/outer surface on the exterior face: amount of cortex/outer surface (in \%) on the exterior surface, including the striking platform.

$\begin{array}{ll}1) & 100 \% \\ 2) & 75-99 \% \\ 3) & 50-74 \% \\ 4) & 25-49 \% \\ 5) & 1-24 \% \\ 6) & 0 \%\end{array}$


10b) Amount of cortex/outer surface, including old patina on the exterior face: This attribute was included for flint and chert, as it appeared that artefacts might have a patinated surface as their outer surface. This patina formed when natural cobbles were broken, after which a patina developed on the broken surface. In addition, it was noticed in rare instances that ancient artefacts (likely dating to the Preceramic Age) were scavenged. Usually these artefacts were patinated and as such, the patinated surface had to be considered as the outer surface. Therefore within this attribute the sum of the amount of cortex/outer surface and the amount of the patina on a natural surface or patina on the exterior face of an artefact including striking platform is estimated (total in \%).

1) $100 \%$

2) $\quad 75-99 \%$

3) $\quad 50-74 \%$

4) $\quad 25-49 \%$

5) $\quad 1-24 \%$

6) $\quad 0 \%$

11) Type of cortex: nature of cortex/outer surface indicative of the collecting environment.

1) irregular: could be freshly quarried

2) worn: inland (irregular but has little worn areas).

3) water-worn.

4) unclear.

5) no cortex

12) Reduction of debitage: This attribute relates to the intentional modification of flakes, other than typical retouch.

1) non-modified.

2) modified: flake that has been modified, that is flakes have been removed from it after its formation. This could have been done to shape the flake, but also modification is included when it was not clear what the purpose of the modification was.

3) modified: core on flake: flake has been used as a core from which small flakes were removed.

4) modified: bipolarly split: flake has been rested on an anvil with the flat face (either ventral or dorsal) facing the anvil, after which it has been struck into two, leaving a (negative) of bulb of force and cone of percussion at the "broken" end.

13) Retouch: absence or presence of use or intentional retouch. A general distinction between use-wear and intentional retouch was based on the size of scars, in which use retouch is defined as a pattern of flake scars originating from an edge of a flake indicative of use wear, with scars not exceeding $1 \mathrm{~mm}$ in size. In intentional retouch, these scars are between 1 and 5 $\mathrm{mm}$ in size.

1) no retouch.

2) use retouch.

3) intentional retouch.

\section{4) Location of intentional and use retouch:}

1) unifacial.

2) bifacial.

3) at pointed end.

4) unifacial with steep edge angle.

5) unifacial at curvate edge. 
15) Patina: absence or presence of patina (naturally weathered surface).

1) not patinated.

2) patina all over.

3) patina on one face.

4) patina: flaked afterwards: reduction took places after a patina had formed.

5) differential patination: flaked in between: reduction took place after one type of patina had formed but before a second type formed.

6) unidentified.

16) Flaking technique:

1) bipolar.

2) direct freehand percussion (hard hammer).

3) direct freehand percussion (soft hammer).

4) pressure flaking.

5) unclear.

17) The number of scars on the exterior face: the number of scars larger than $2 \mathrm{~mm}$ on the exterior face, excluding the platform associated scars. The number is filled in on the sheet.

\section{8) Type of striking platform:}

1) cortical/outer surface.

2) outer surface with scar.

3) single scar.

4) two scars.

5) three scars.

6) four scars.

7) more than four scars.

8) pointed.

9) edge.

19) Distal Part: Type of flake termination.

1) feather.

2) hinge.

3) step.

4) plunge.

5) end of core

All core-tools and core artefacts are analysed for:

20) Type of modification: All human modification that has been applied with the aim of shaping the tool

1) none: water-worn rock.

2) none: natural rock (other than water-worn).

3) flaked.

4) pecked.

5) ground. 
6) flaked and pecked.

7) flaked and ground.

8) pecked and ground.

9) flaked, pecked, and ground.

10) can not be identified.

All axes/adzes are analyzed for:

21) Shape: shape of the axe/adze.

1) petaloid.

2) rectangular.

3) rectangular with indentations.

4) butterfly.

5) other.

6) unidentified.

22) Edge: shape of edge when seen from aside.

1) asymmetrical (plano-convex).

2) symmetrical.

\section{3) Type of finishing:}

1) totally ground.

2) totally polished.

3) only edge ground.

4) only edge polished.

5) edge and medial part ground.

6) edge and medial part polished.

7) partially ground.

24) Weathering: presence or absence of weathering on greenstone artefacts.

1) non-weathered.

2) partially weathered.

3) completely weathered. 


\section{Appendix E Mesh size and sample size bias}

\section{E.1 Mesh SIZE BIAS}

This study uses data on average flake or core size dimensions to compare the degree of efficiency among flake production from different sites. Therefore, it compares samples of lithic artefacts excavated at these sites. The samples were obtained using different excavation methods, of which especially the use of different mesh sizes for screening is assumed to have a significant influence on the size dimension data. Artefacts vary in shape and size and therefore, I believe that samples do not become similar just by subtracting all items with a maximal dimension, that is smaller than the largest mesh size used. Instead, to know how samples should be treated, a simple test was invented using archaeological data from this study. It was tested by using residue samples from different sized mesh-screens to assess the representation of different size classes of artefacts and therefore which ones would produce similar average results. In other words, the question was asked: from which minimum size class onwards both sample residues would contain the same numbers of artefacts, if one could duplicate the excavation of a test-unit and one would sieve the first attempt with a mesh-size of $3.2 \mathrm{~mm}$ and afterwards do the same excavation with a $6.4 \mathrm{~mm}$ mesh-size.

As such a duplicate excavation cannot be done in reality, a case was sought in which part of a test-unit was excavated using one type of mesh-size and another part of the same unit was excavated using a different type of mesh-size. This situation exists for the excavations at Anguilla sites, done by John Crock and Jim Petersen (Crock 2000; Crock et al. 1995). They systematically reserved a $0.5 \times 0.5 \mathrm{~m}$ subunit within their $1.0 \times 1.0 \mathrm{~m}$ test-units for fine mesh screening. The smaller square was sieved through a $1 / 8$ inch $(3.2 \mathrm{~mm})$ mesh, while the remainder of the unit was sieved through a $1 / 4$ inch $(6.4 \mathrm{~mm}) \mathrm{mesh}$. From their excavations, I chose the Barnes Bay site for further analysis, since the test-units at this site were excavated most systematically using this methodology and the largest number of artefacts were recorded enabling comparison of larger samples, and thereby improving reliability.

The first step was to group the artefacts into size classes. As a criterion for constructing such a class, I took the combination of maximum dimension and width (being perpendicular to maximum dimension). This combination of the largest two dimensions (thickness is in general smaller than width) was chosen because with such a combination it is possible to be certain that an object will not go through a specific mesh opening. For example, an item where both the maximal dimension and the width is larger than $10 \mathrm{~mm}$ will never pass through a round opening of $10 \mathrm{~mm}$. However, if the width is smaller, then it is possible to pass through. This does not necessarily have to be the case, if one considers, for example, a very long but narrow and thin object, which is not likely to go through due to its long maximal dimension.

I grouped the artefacts into the cumulative classes as tabulated in table E.1. In this table, $6 \times 6 \mathrm{~mm}$ stands for all items where both the maximum dimension and the width are larger than $6 \mathrm{~mm}$, and $7 \times 7 \mathrm{~mm}$ stands for all items where these dimensions are larger than $7 \mathrm{~mm}$, etc. The difference between these two classes is formed by the artefacts where both maximum dimension and width are exactly $6 \mathrm{~mm}$. This means that by increasing size the number of artefacts included will decrease. The next step was to count the number of artefacts within each mesh residue for each size class. For example, 106 artefacts were counted from the 1/8 inch mesh residue sample that had both a maximum dimension and a width larger than 6 $\mathrm{mm}$, and there are 88 artefacts for which this was $7 \mathrm{~mm}$, indicating that the number of artefacts with a maximum dimension and a width both equal to $6 \mathrm{~mm}$ being 18 . As usual the sample square $(3.2 \mathrm{~mm}$ mesh) and normal square $(6.4 \mathrm{~mm}$ mesh) were not equal in size, so the ratio of [(number within size class X from $3.2 \mathrm{~mm}) /($ number within size class $X$ from $6.4 \mathrm{~mm})]$ was calculated. Both residue samples are considered similar from the point on, when this ratio remains constant. In theory, this ratio should remain constant until the largest size class, but due to the small sample size of the large size classes, sample bias influences the outcome.

From the table it is clear that for Unit $402 / 423$ the size class from where the ratio becomes constant is (13 x 13), with class $(12 \times 12)$ being close. Unit $401 / 418$ produced somewhat different results. As the overall sample size is smaller than for unit $402 / 423$, the ratio values differ more and make it hard to draw the line. From the numbers, it is clear that the point should be between the size classes ( $10 \times 10),(11 \times 11)$, and ( $12 \times 12)$.

This means that when using both a 3.2 and $6.4 \mathrm{~mm}$ mesh size, residues become comparable from around the $12 \mathrm{x}$ $12 \mathrm{~mm}$ size class onwards, which is 5 to $6 \mathrm{~mm}$ larger than the largest mesh size. If one takes into account that for the $6.4 \mathrm{~mm}$ rectangular mesh size, the largest opening equals $9.1 \mathrm{~mm}^{1}$, which is the diagonal between the corners, then the discrepancy

1 Using Pythagoras: $(6.4)^{2}+(6.4)^{2}=(9.1)^{2}$ 


\begin{tabular}{|c|c|c|c|c|c|c|c|c|}
\hline \multirow{2}{*}{$\begin{array}{c}\text { Size } \\
\text { category }\end{array}$} & \multicolumn{4}{|c|}{ Unit 401/418 } & \multicolumn{4}{|c|}{ Unit 402/423 } \\
\hline & $\begin{array}{c}\mathrm{N} \\
3.2 \mathrm{~mm} \\
\end{array}$ & $\begin{array}{c}\mathrm{N} \\
6.4 \mathrm{~mm} \\
\end{array}$ & $\begin{array}{c}\text { Ratio } \\
(6.4) /(3.2)\end{array}$ & average $^{a}$ & $\begin{array}{c}\mathrm{N} \\
3.2 \mathrm{~mm} \\
\end{array}$ & $\begin{array}{c}\mathrm{N} \\
6.4 \mathrm{~mm}\end{array}$ & $\begin{array}{c}\text { Ratio } \\
(6.4) /(3.2)\end{array}$ & average $^{\mathrm{a}}$ \\
\hline $6 \times 6$ & 84 & 134 & 1.60 & - & 106 & 102 & 0.96 & - \\
\hline $7 x 7$ & 59 & 133 & 2.25 & 2.38 & 88 & 101 & 1.15 & 1.53 \\
\hline $8 \times 8$ & 37 & 122 & 3.30 & 2.94 & 74 & 97 & 1.31 & 1.34 \\
\hline $9 \times 9$ & 29 & 95 & 3.28 & 3.41 & 55 & 85 & 1.55 & 1.51 \\
\hline $10 \times 10$ & 22 & 80 & 3.64 & 3.55 & 44 & 73 & 1.66 & 1.78 \\
\hline $11 \times 11$ & 18 & 67 & 3.72 & 3.91 & 28 & 60 & 2.14 & 2.00 \\
\hline $12 \times 12$ & 14 & 61 & 4.36 & 3.94 & 24 & 53 & 2.21 & 2.32 \\
\hline $13 \times 13$ & 12 & 45 & 3.75 & 4.29 & 20 & 52 & 2.60 & 2.56 \\
\hline $14 \times 14$ & 8 & 35 & 4.75 & 4.50 & 17 & 49 & 2.88 & 2.72 \\
\hline $15 \times 15$ & 6 & 30 & 5.00 & 4.64 & 16 & 43 & 2.69 & 2.76 \\
\hline $16 \times 16$ & 6 & 25 & 4.17 & 4.39 & 14 & 38 & 2.71 & 2.67 \\
\hline $17 \times 17$ & 6 & 24 & 4.00 & 3.99 & 13 & 34 & 2.61 & 2.74 \\
\hline $18 \times 18$ & 5 & 19 & 3.80 & 3.87 & 11 & 32 & 2.91 & 2.81 \\
\hline $19 \times 19$ & 5 & 19 & 3.80 & 3.47 & 10 & 29 & 2.90 & 2.80 \\
\hline $20 \times 20$ & 5 & 14 & 2.80 & 3.07 & 10 & 26 & 2.60 & 2.65 \\
\hline $21 \times 21$ & 5 & 13 & 2.60 & 2.72 & 9 & 22 & 2.44 & 2.56 \\
\hline $22 x 22$ & 4 & 11 & 2.75 & 3.62 & 8 & 21 & 2.63 & 2.57 \\
\hline $23 \times 23$ & 2 & 11 & 5.50 & - & 8 & 21 & 2.63 & 2.50 \\
\hline $24 \times 24$ & - & - & - & - & 8 & 18 & 2.25 & - \\
\hline Total & 125 & 135 & & & 139 & 102 & & \\
\hline
\end{tabular}

Table E.1. Barnes Bay, Anguilla. Number of artefacts that at least is larger or similar to a certain size category within the residue of 3.2 or $6.4 \mathrm{~mm}$ mesh-screens. So $8 \times 8$ designates all artefacts that have maximum dimensions as well as widths larger than $8 \mathrm{~mm}$. For example an artefact with maximum dimension of $14 \mathrm{~mm}$ and width of $6 \mathrm{~mm}$ does not belong to this size class. ${ }^{\text {a }}$ At this column the values of three subsequent size classes are averaged.

is only $3 \mathrm{~mm}$. If, for example, a $10 \mathrm{~mm}$ mesh residue is compared to a $6.4 \mathrm{~mm}$, the largest opening would be $14.1 \mathrm{~mm}$, and preferred size class from where residues would be comparable becomes 17 x $17 \mathrm{~mm}$.

\section{E.2 SAMPLE SIZE BIAS}

This study makes use of samples of lithic artefacts to determine to what extent Long Island flint was used at a number of different sites within the northern Lesser Antilles. In relation to this aim, a number of parameters were considered to be useful, for example, the percentage of Long Island material as part of all flake tool material, or the average length or weight of a certain artefact class. To evaluate the effect of sample size (number of artefacts) on the accuracy of these parameters, and as estimators of the true population values, I decided to study this in detail for one site. The Early Ceramic Age Golden Rock site on St. Eustatius was considered most useful for this purpose. The reasons for choosing this site include: (a) the relatively large number of artefacts analysed; (b) the fact that excavation work there involved the almost complete uncovering of a distinct area used as discard location; (c) the systematic procedure in which the excavation occurred; and (d) the relatively small period during which discard was dumped in this area (Versteeg \& Schinkel 1992).

The excavators divided this area of the site into large 4 x $4 \mathrm{~m}$ units, which were then subdivided into sixteen $1 \times 1$ $\mathrm{m}$ test unit squares. Material was collected following this $1 \mathrm{x} 1 \mathrm{~m}$ grid-system. This systematic excavation procedure enabled me to quickly construct sub-samples of varying sizes in a systematic manner. For example, I could easily select only the material from the first $1 \times 1 \mathrm{~m}$ square within each $4 \times 4 \mathrm{~m}$ unit, or the material from two squares, the first and the ninth, etc.

In this manner, I constructed four types of sub-samples: (1) one square per $4 \mathrm{~m}$ unit, making up a $6 \%$ sample; (2) two squares at the same distance per $4 \mathrm{~m}$ unit, including approximately $12.5 \%$ of the total sample; (3) one $2 \times 2 \mathrm{~m}$ square (four 1 x $1 \mathrm{~m}$ squares) in each $4 \mathrm{~m}$ unit, including approximately $25 \%$ of the total sample; and (4) two $2 \times 2 \mathrm{~m}$ squares in a chess-board pattern (so eight $1 \times 1 \mathrm{~m}$ squares) within each $4 \mathrm{~m}$ unit, including approximately $50 \%$ of the total.

For each of these sub-samples, I determined four parameters: (1) percentage of Long Island flint among all flake tool 


\begin{tabular}{|c|c|c|c|c|c|c|c|c|}
\hline sample & $\begin{array}{l}\mathrm{N} \text { total } \\
\text { all flint and } \\
\text { chert }\end{array}$ & $\begin{array}{l}\% \text { LI-flint } \\
\text { (average) }\end{array}$ & $\begin{array}{c}\text { sd } \\
\text { average } \\
\% \text { LI- flint }\end{array}$ & $\begin{array}{c}\text { RSD } \\
\text { average } \\
\% \text { LI- flint }\end{array}$ & $\begin{array}{l}\text { average } \\
\text { difference with } \\
\text { value from } \\
\text { complete } \\
\text { sample }\end{array}$ & $\begin{array}{c}\text { sd } \\
\text { average } \\
\text { difference }\end{array}$ & $\begin{array}{l}\text { relative average } \\
\text { difference with } \\
\text { value from } \\
\text { complete } \\
\text { sample }\end{array}$ & $\begin{array}{l}\text { maximum } \\
\text { relative } \\
\text { difference }\end{array}$ \\
\hline complete & 672 & 71,70 & - & - & - & - & - & - \\
\hline $50 \%$ samples & approx. 336 & 71,73 & 0,38 & 0,53 & 0,28 & 0,21 & 0,38 & 0,70 \\
\hline $12,5 \%$ samples & approx. 83 & 71,68 & 5,55 & 7,75 & 4,32 & 3,18 & 6,03 & 11,85 \\
\hline $6 \%$ samples & approx. 42 & 71,80 & 7,06 & 9,83 & 6,13 & 3,13 & 8,54 & 15,06 \\
\hline
\end{tabular}

Table E.2. Golden Rock flint and chert artefacts. Comparison of artificial sub-sample values of the percentage of Long Island flint artefacts with the true value of the Golden Rock assemblage (the complete sample). RSD = Relative Standard Deviation.

\begin{tabular}{|c|c|c|c|c|c|c|c|c|}
\hline sample & $\begin{array}{c}\mathrm{N} \text { total } \\
\text { Long Island }\end{array}$ & $\begin{array}{c}\text { average } \\
\text { maximum } \\
\text { dimension } \\
\text { of debitage } \\
\text { except } \\
\text { shatter }\end{array}$ & $\begin{array}{c}\text { sd } \\
\text { average } \\
\text { maximum } \\
\text { dimension }\end{array}$ & $\begin{array}{c}\text { RSD } \\
\text { average } \\
\text { maximum } \\
\text { dimension }\end{array}$ & $\begin{array}{c}\text { average } \\
\text { difference with } \\
\text { value from } \\
\text { complete } \\
\text { sample }\end{array}$ & $\begin{array}{c}\text { sd } \\
\text { average } \\
\text { difference }\end{array}$ & $\begin{array}{l}\text { relative average } \\
\text { difference with } \\
\text { value from } \\
\text { complete } \\
\text { sample }\end{array}$ & $\begin{array}{l}\text { maximum } \\
\text { relative } \\
\text { difference }\end{array}$ \\
\hline complete & 482 & 31,49 & - & - & - & - & - & - \\
\hline $50 \%$ samples & approx. 241 & 31,49 & 0,33 & 1,05 & 0,24 & 0,18 & 0,76 & 1,27 \\
\hline $25 \%$ samples & approx. 120 & 31,49 & 0,13 & 0,43 & 0,10 & 0,07 & 0,31 & 0,64 \\
\hline $12,5 \%$ samples & approx. 59 & 31,63 & 0,67 & 2,13 & 0,49 & 0,46 & 1,54 & 4,38 \\
\hline $6 \%$ samples & approx. 30 & 31,48 & 1,65 & 5,24 & 1,28 & 0,99 & 4,06 & 8,16 \\
\hline
\end{tabular}

Table E.3. Golden Rock flint and chert artefacts. Comparison of artificial sub-sample values of the maximum dimension of Long Island flint debitage with the true value of the Golden Rock assemblage (the complete sample). RSD = Relative Standard Deviation.

related material; (2) percentage of cortical flakes among all Long Island flakes; (3) average maximum dimension of all Long Island flake material; and (4) average weight of all Long Island flake material. Following that, I calculated the absolute and relative difference of the sub-sample value with the value for the total sample. As I selected multiple sub-samples for each sub-sample type, I also determined the average relative difference and the maximum relative difference.

Tables E.2-E.5 present the different results. It is clear from these tables that the four parameters were affected differently by variation in sample size. The average maximum dimension is least affected; even in case of the smallest subsample (approximately 30 artefacts), the maximum relative difference with the total sample average is below $10 \%$, with a mean value of a little above $4 \%$. This suggests that samples of 30 artefacts in this case provide a fairly accurate estimator of the true value. The percentage of Long island flint differs more from the true value for the smaller samples, although the averages of the relative differences stay well below $10 \%$.

The other parameters are considerably more affected by sample size. In particular, the percentage of cortical flakes becomes significantly less accurate when samples below 100 artefacts are used. Looking at the average weight, it is noted that this parameter generally varies more than the other parameters. This is due to the considerable variation in weight between the different flint artefacts, indicated by a much higher standard deviation in all samples than, for example, in case of the average maximum dimension. Also, the accuracy of this parameter is poor in case of the smallest sample.

In conclusion it can be stated that samples with more than 100 artefacts provide fairly accurate results, but in the case of smaller samples, the weight values and the percentages of cortical flakes, should be treated with caution. 


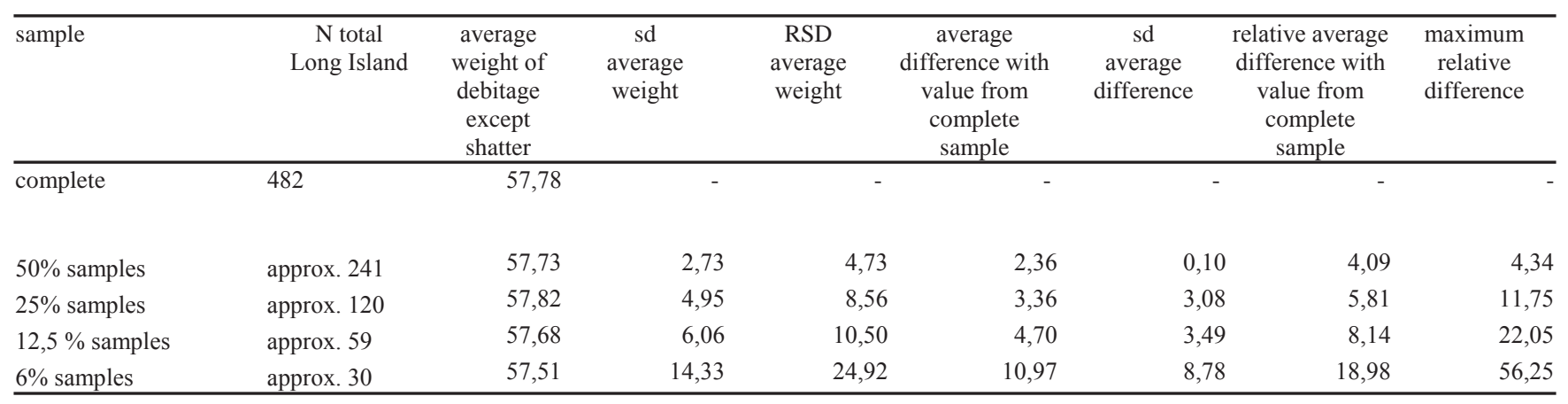

Table E.4. Golden Rock flint and chert artefacts. Comparison of artificial sub-sample values of the average weight of Long Island flint debitage with the true value of the Golden Rock assemblage (the complete sample). RSD = Relative Standard Deviation.

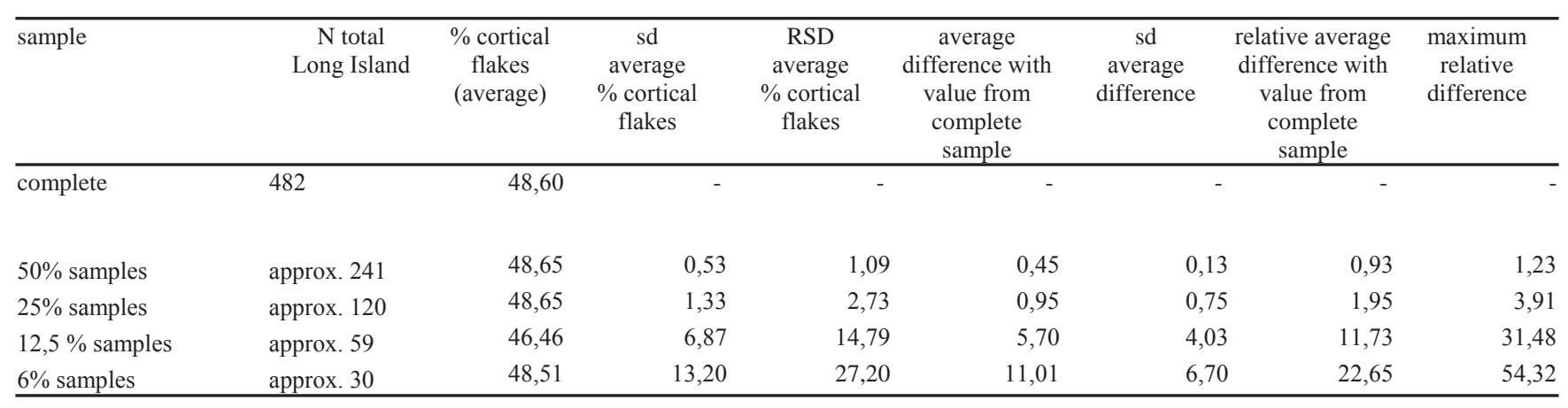

Table E.5. Golden Rock flint and chert artefacts. Comparison of artificial sub-sample values of the percentage of cortical Long Island flint flakes with the true value of the Golden Rock assemblage (the complete sample). RSD = Relative Standard Deviation. 


\section{Appendix F Archaeological sites and related lithic sample}

\section{F.1 INTRODUCTION}

In the following section, each of the archaeological sites from which a sample of stone artefacts was analysed are briefly described. In addition, the provenience of the studied sample is specified, along with the methodology employed during its excavation.

\section{F.2 Martinique}

Samples from three sites on the island of Martinique are included within this study. These are Vivé, Dizac au Diamant, and Anse Trabaud (see figure 3.12).

\section{F.2.1 Vivé}

Vivé, an early Saladoid settlement site, is situated along the fertile northeastern coast of Martinique. It is one of the oldest Ceramic Age sites on the island and it has been dated between cal AD $144-440$ (1730 $\pm 100 \mathrm{BP})$ and cal AD $400-660$ $(1530 \pm 75 \mathrm{BP})$. Vivé has been the subject of several archaeological projects, of which the one by Mattioni during 1970s and more recent research by Giraud, Bérard, and Vidal can be considered the most significant (Giraud et al.1999; Mattioni 1971, 1974). They established that Vivé was minimally occupied during two phases. The oldest one corresponds with the early date of cal AD $144-440$ (95\% confidence interval) and falls within the Early Ceramic A phase. This occupation predates an active volcanic period of Mount Pelée. Sudden volcanic eruptions surely forced the inhabitants to abandon the Vivé site. Volcanic flows also covered the area with ash and debris, protecting finds from later post-depositional processes and perfectly preserving occupation remains just prior to the eruption. The second phase is dated after AD 400, falling within the Early Ceramic B phase and corresponding with the end of the volcanic activity. People then settled on the previously deposited ash layer. Data from this second occupation phase are scanty, as recent banana growing activities have largely disturbed the remains.

In total, a sample of 327 lithic artefacts was analysed from this site (table F.1). The sample originated from two systematically screened test-units: nr. 8 and 9, excavated by Giraud and co-workers during the 1996 field-season. Only the artefacts from the oldest occupation phase below the volcanic ash deposit have been included in this study. Materials identified include flint, red and yellow varieties of jasper, chalcedony (transluscent chert), chert, igneous rock and pumice. A larger sample, including the material from these two units, was previously studied and reported by Benoit Bérard in earlier publications (Bérard 1999a,b, 2004; Bérard and Giraud 1998). 


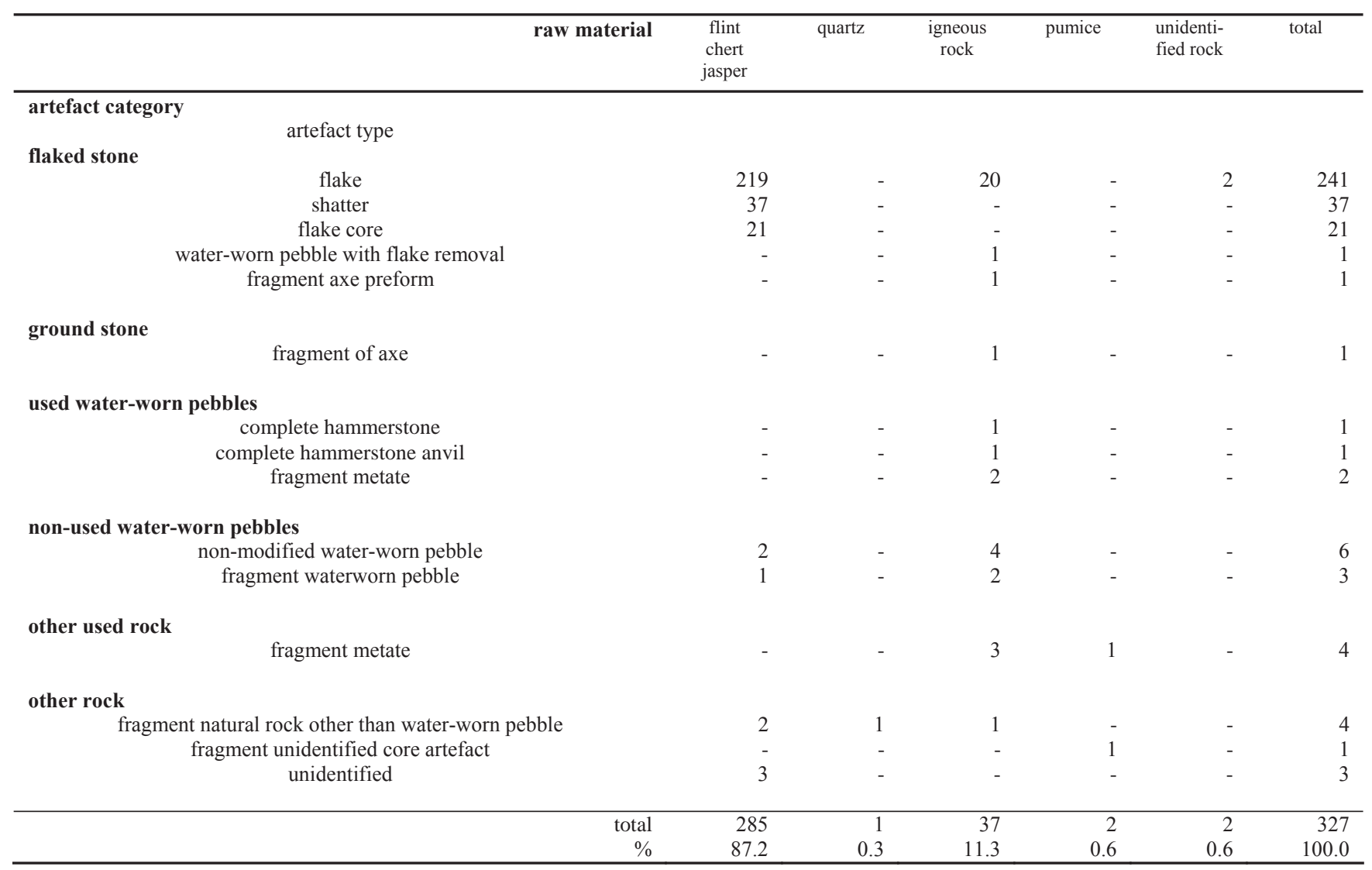

Table F.1. Vivé, Martinique. Number of lithic artefacts by raw material by artefact type. 


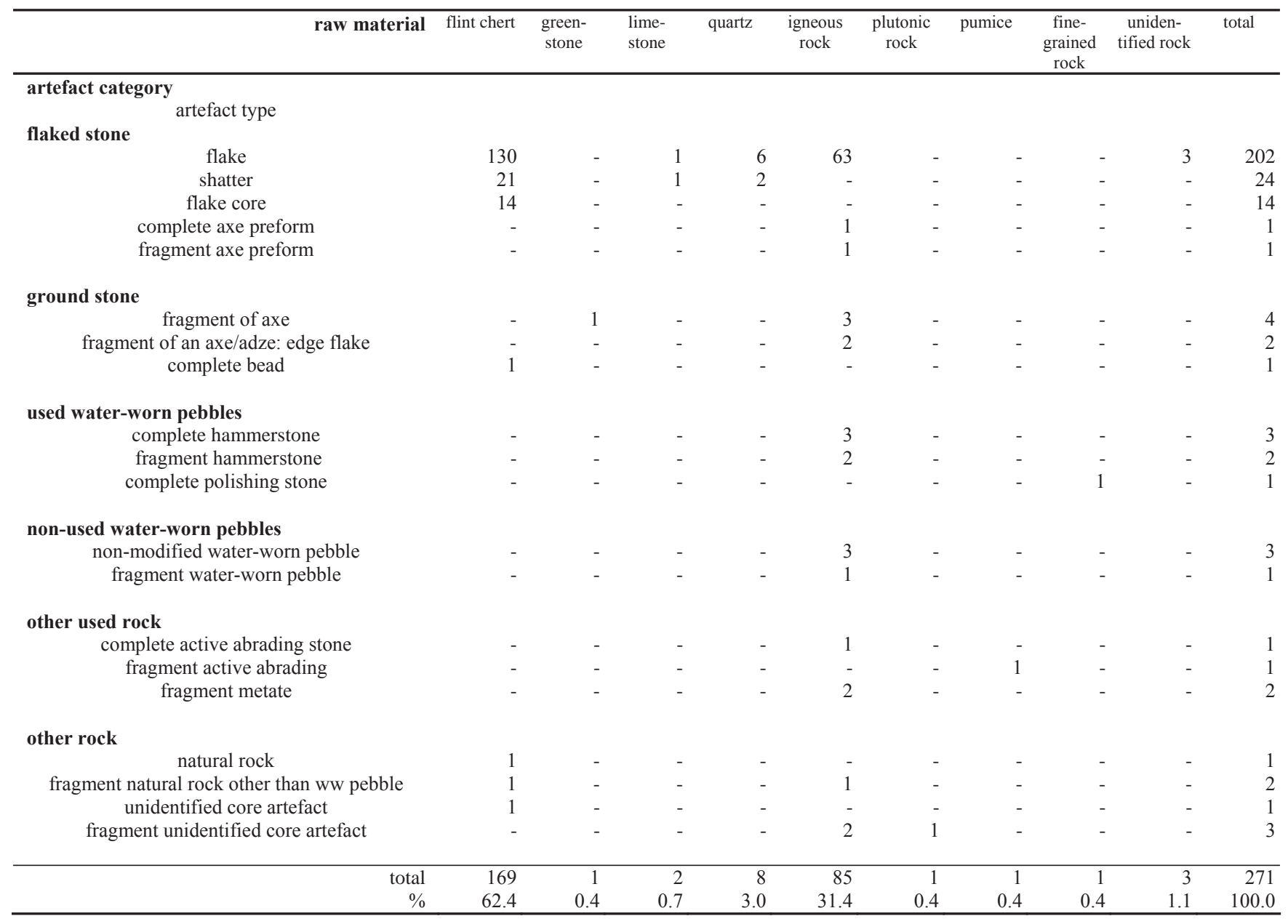

Table F.2. Dizac au Diamant, Martinique. Number of lithic artefacts by raw material by artefact type.

\section{F.2.3 Dizac au Diamant}

Dizac au Diamant, a late Saladoid settlement site, is situated along the southwestern coast of Martinique, facing the famous Rocher du Diamant. From excavations carried out by Nathalie Vidal during the early 1990s, remains belonging to an Amerindian occupation were found within an extensive dune deposit, roughly dated to the Early Ceramic B phase between AD 500 and 700. Vidal classified the site as "Modified" Saladoid based on the pottery characteristics.

The sample from this site totalled 271 lithic artefacts (table F.2). This sample originated from one large $50 \mathrm{~m}^{2}$ unit, which was excavated in 18 different arbitrarily $5 \mathrm{~cm}$ levels, using $2 \mathrm{~mm}$ mesh screens (Vidal 1992). Rock materials include flint, chert, jasper, chalcedony, dull white quartz, petrified wood, St. Martin greenstone, igneous rock, plutonic rock, tuff, pumice, limestone and fine-grained siliceous materials. 


\begin{tabular}{|c|c|c|c|c|c|}
\hline raw material & $\begin{array}{c}\text { flint and } \\
\text { chert }\end{array}$ & quartz & greenstone & igneous rock & total \\
\hline \multicolumn{6}{|l|}{ artefact category } \\
\hline flake & 37 & - & - & 5 & 42 \\
\hline shatter & 5 & - & - & - & 5 \\
\hline flake core & 5 & - & - & - & 5 \\
\hline flaked piece & - & - & - & 1 & 1 \\
\hline \multicolumn{6}{|l|}{ ground stone } \\
\hline fragment of axe & - & - & 1 & & 1 \\
\hline fragment of an axe/adze: edge flake & - & - & - & 1 & 1 \\
\hline fragment axe preform & - & - & - & 1 & 1 \\
\hline fragment polishing stone & - & - & - & 1 & 1 \\
\hline complete passive grinding stone & - & - & - & 1 & 1 \\
\hline \multicolumn{6}{|l|}{ non-used water-worn pebbles } \\
\hline non-modified water-worn pebble & - & - & - & 18 & 18 \\
\hline fragment water-worn pebble & - & - & - & 5 & 5 \\
\hline \multicolumn{6}{|l|}{ other used rock } \\
\hline fragment metate & - & - & - & 6 & 6 \\
\hline fragment other type of abrading tool & 1 & - & - & - & 1 \\
\hline \multicolumn{6}{|l|}{ other rock } \\
\hline natural rock & 1 & - & - & - & 1 \\
\hline
\end{tabular}

Table F.3. Anse Trabaud, Martinique. Number of lithic artefacts by raw material by artefact type.

\section{F.2.4 Anse Trabaud}

Anse Trabaud, a Late Ceramic Age habitation site along the southeastern coast of Martinique, is situated only a few kilometres to the east of La Savanne des Pétrifications. Louis Allaire and Mario Mattioni studied this site during two field-seasons in 1983 and 1984. Following the excavation of 16 test-units, they classified this site as Suazoid. Louis Allaire distinguished two pottery styles, one clearly Suazoid and the other somewhat distinctive from that, but late in its characteristics (Allaire 1997). Unfortunately, radiocarbon dates have not been obtained for this site to support this possible distinction. Generally, the Suazoid period is dated between AD 1000 and 1500, which extended from the later part of the Late Ceramic A phase well into the following Late Ceramic B (Hofman 1993).

From the Anse Trabaud site, 108 lithic artefacts were studied (table F.3). I only analysed the material from the 1984 field-season, including seven 1 x $1 \mathrm{~m}$ test-units, named I to O. These were excavated in arbitrary $20 \mathrm{~cm}$ levels, using $10 \mathrm{~mm}$ mesh-screens (Allaire 1997). Lithic raw materials include red and yellow jasper, St. Martin greenstone, translucent chalcedony, petrified wood, crystal quartz, tuff, and igneous rock. 


\section{F.3 GuAdELOUPE}

Samples from three sites lying on the northern island of Grande Terre in Guadeloupe were included within this study. These are Morel, Anse à la Gourde, and Anse à l'Eau (see figure 3.11).

\section{F.3.1 Morel}

Morel, a large multi-component site situated along the northern Atlantic coast of Grande Terre and near the town of le Moule, has been subject of several archaeological research campaigns. In relation to this, the excavation work of Edgar Clerc during the late 1950s and early 1960s needs mentioning since Clerc set up the first chronology of the site (Clerc 1964, 1968, 1970; see a summary for Morel in Arts 1999). From a number of test-excavations, Clerc identified a very long occupational history, which he divided into 4 phases, Morel 1 to 4. Later, Ripley and Adelaide Bullen confirmed this distinction when they performed tests at Morel (Bullen and Bullen 1973). Based on their typology, Petitjean Roget (1981) summarized the phases as follows: Insular Saladoid (Morel 1), Modified Saladoid (Morel 2), Terminal Saladoid (Morel 3), and Suazey (Morel 4), respectively. These phases formed the basis upon which the entire chronology of prehistoric Guadeloupe was founded (Rouse 1986, 1992).

Later rescue work by the Archaeological Service of Guadeloupe and Leiden University during the period from 1995 until 1999 confirmed the importance of Morel, although not all phases identified by Clerc were found. An important aspect that became clear was the significant disturbance caused by coastal erosion, which also affected other sites on the northeastern coast of Grande Terre. Erosion has been responsible for the disappearance of a large part of the archaeological remains, leaving only segments of the occupations dating to the Morel 1,2, and 3 phases.

Field-work carried out in 1999 provided the lithic sample studied in the scope of the present research (Hofman et al. 2000). The field-work in 1999 concentrated on the western part of the site still present, corresponding with the Morel 1 and 2 phases. The occupation deposit within this site area was large. It was extensively excavated. In addition to the collection of artefacts and subsistence remains, the research was also aimed at mapping posthole features and burials. Initial results indicate that this area corresponds with a habitation zone, which was located near an old saline pond. The deposits are dated somewhere between AD 200 and 600, and the ceramics exhibit both characteristics of the Huecan and Cedrosan Saladoid subseries. This places the site within the Early Ceramic A phase.

A sample of 2339 artefacts was studied from this site and only included material collected during the 1999 fieldcampaign (table F.4). Frank Stevens (2002), doing his Master's thesis work at Leiden University, analysed the sample under my supervision, following the methodology used in this dissertation. Considering my knowledge of many lithic samples and stone sources in the region, I identified the raw materials myself. The sample originated from the large units excavated at the site. These units were subdivided into 1 x $1 \mathrm{~m}$ squares, which were systematically excavated in arbitrary $10 \mathrm{~cm}$ levels using $10 \mathrm{~mm}$ mesh-screens. We identified the following raw materials: flint, chert, St. Martin greenstone, jasper, petrified wood, limestone, carnelian, amethyst, quartz, different varieties of igneous rock, pumice, plutonic rock, fine grained non-carbonate rock, metamorphic rock, and red ochre.

\section{F.3.2 Anse à la Gourde}

Anse à la Gourde is another major site along Grande Terre's northern coast, approximately $13 \mathrm{~km}$ to the east of Morel. It lies at the Anse à la Gourde Bay, which is a sandy beach protected by a shallow reef. The site itself covers parts of the sandy dune and the areas more inland. It extends over an area 500 metres by 1 kilometre in size (Hofman et al. 2001). First studied in the early 1970s by Father Barbotin and Edgar Clerc, it was the subject of several other small field campaigns during the following years, led by different researchers (e.g., Bodu 1984). These studies showed that the site is a large multi-component habitation site, with significant occupation phases during the Post-Saladoid period.

Considering its presumed significance and the constant threat of costal erosion and clandestine sand collecting, Anse à la Gourde was subject to a multi-year excavation campaign led by the local DRAC and Leiden University (Hofman et al. 2001). The first outcomes of the research showed that it experienced a long history of occupation, from the Late Saladoid, around AD 500-700 followed by three post-Saladoid phases: Troumassoid 1 (AD 700-900; Mill Reef style), Troumassoid 2 (AD 1000-1150; Mamora Bay style), and Suazan Troumassoid (AD 1250-1300) (Hofman et al. 2001; Hofman, personal communication 2001). This extensive period of settlement corresponds with the Early Ceramic B and Late Ceramic A phases. Coastal erosion had significantly affected the site, destroying large parts of the original Saladoid occupation deposits. The most significant remaining archaeological deposits are attributed to the Troumassoid 1 and 2 phases. These include a 


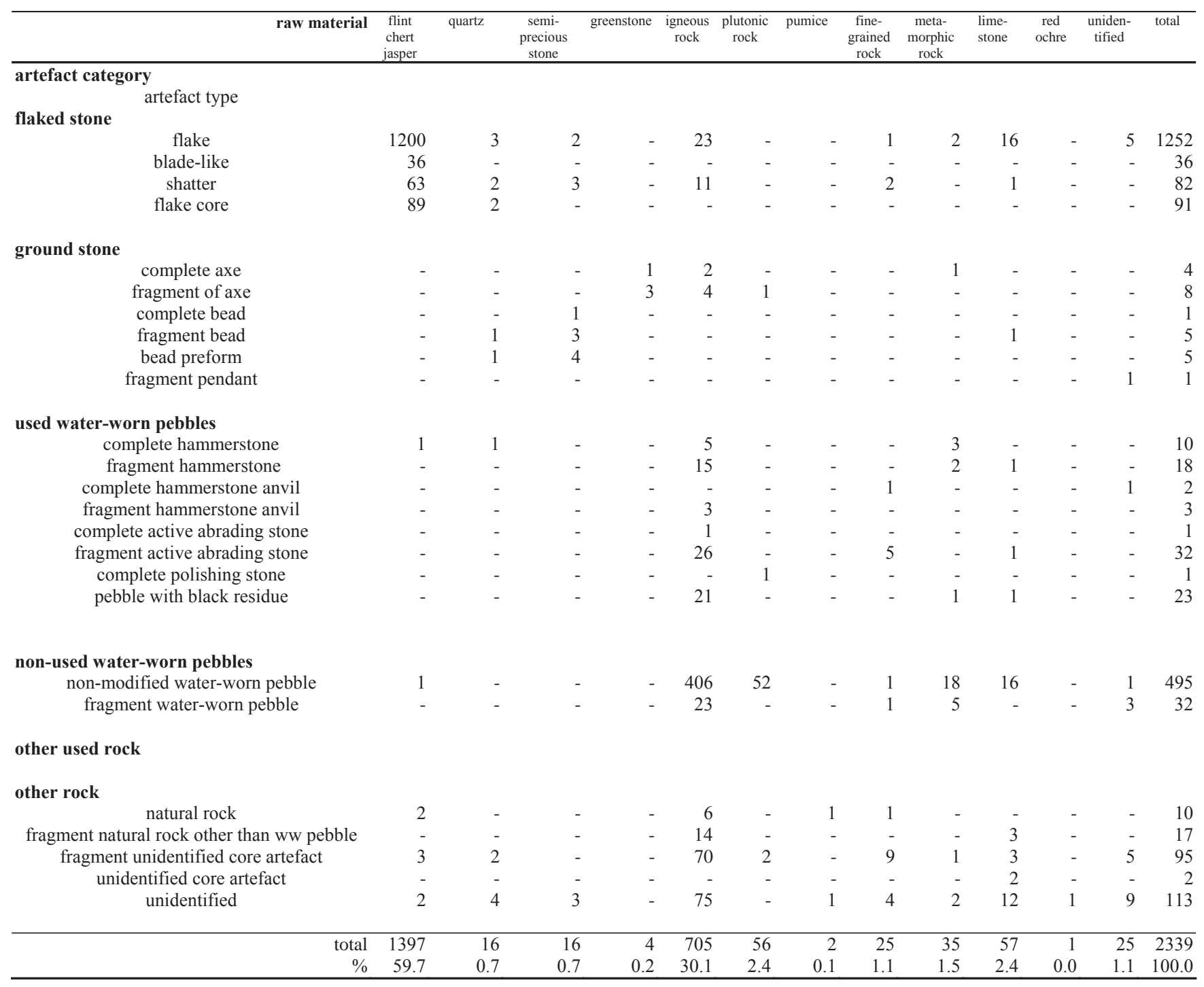

Table F.4. Morel, Guadeloupe. Number of lithic artefacts by raw material by artefact type.

habitation and burial area, where several house plans and over 80 burials were found, encircled by a donut shaped refuse zone. The remains from the latest Suazan Troumassoid phase are scanty and suggest that habitation areas were moved to a different location more inland (Dorst et al. 2001; Hoogland \& Panhuysen 2001; Jansen et al. 2001).

A sample of 1222 artefacts was studied from the Anse à la Gourde site, originating only from the systematically excavated and screened test-units. These were predominantly $2 \times 2 \mathrm{~m}$ in size, and were excavated in $10 \mathrm{~cm}$ arbitrary levels using $6.4 \mathrm{~mm}$ mesh-screens. Based on stratigraphy and ceramic typology each level within these units is attributed to one of the different occupation phases. Within some units, it was not possible to differentiate the Troumassoid 1 from the Troumassoid 2 phase. To avoid small samples by excluding mixed deposits, the artefacts from both phases have been lumped. Therefore, a distinction was made between three broad phases: the Saladoid (early phase), Troumassoid 1+2 (middle phase), and Suazan Troumassoid (late phase). Unfortunately a portion of the studied artefacts had to be excluded from further analysis, as their provenience would not let them be dated to one of these three phases exclusively. The excavation of large units for investigating post-hole and burial features yielded many more lithic artefacts. Information from these unscreened contexts was incidentally used to support existing data or provide additional data to the results from the test-units. This extra information mainly has a qualitative character. 


\begin{tabular}{|c|c|c|c|c|c|c|c|c|}
\hline raw material & $\begin{array}{l}\text { flint } \\
\text { chert }\end{array}$ & $\begin{array}{l}\text { plutonic } \\
\text { rock }\end{array}$ & $\begin{array}{l}\text { igneous } \\
\text { rock }\end{array}$ & $\begin{array}{l}\text { fine } \\
\text { grained } \\
\text { rock }\end{array}$ & limestone & $\begin{array}{l}\text { beach } \\
\text { rock }\end{array}$ & $\begin{array}{l}\text { uniden- } \\
\text { tified }\end{array}$ & total \\
\hline \multicolumn{9}{|l|}{ artefact category } \\
\hline \multicolumn{9}{|l|}{ artefact type } \\
\hline flake & 12 & - & - & - & 3 & 1 & - & 16 \\
\hline shatter & 2 & - & - & - & - & - & - & 2 \\
\hline flake core & - & - & - & - & 1 & - & - & 1 \\
\hline \multicolumn{9}{|l|}{ ground stone } \\
\hline axe & - & - & 1 & - & - & - & - & 1 \\
\hline \multicolumn{9}{|l|}{ used water-worn pebbles } \\
\hline complete hammerstone & - & - & 9 & - & 1 & - & - & 10 \\
\hline fragment hammerstone & - & 1 & - & - & - & - & - & 1 \\
\hline complete hammerstone anvil & - & - & - & - & - & - & - & \\
\hline fragment manos & - & - & 1 & - & - & - & - & 1 \\
\hline fragment metate & - & - & 4 & - & - & 1 & - & 5 \\
\hline complete passive grinding stone & - & - & 1 & - & - & - & - & 1 \\
\hline \multicolumn{9}{|l|}{ non-used water-worn pebbles } \\
\hline non-modified water-worn pebble & - & - & 22 & 1 & 9 & 1 & - & 33 \\
\hline fragment water-worn pebble & - & - & 1 & 1 & 1 & - & 1 & 4 \\
\hline \multicolumn{9}{|l|}{ other rock } \\
\hline natural rock & - & - & - & - & 3 & - & - & 3 \\
\hline fragment natural rock other than ww pebble & - & - & - & 1 & 8 & 1 & - & 10 \\
\hline fragment unidentified core artefact & - & - & - & - & 4 & 1 & - & 5 \\
\hline unidentified core artefact & - & - & - & - & - & - & 1 & 1 \\
\hline
\end{tabular}

Table F.5. Anse à la Gourde, Guadeloupe, early occupation phase (Early Ceramic B). Number of lithic artefacts by raw material by artefact type.

\section{Saladoid (early) occupation phase}

The sample of artefacts that could be ascribed to the late Saladoid occupation phase comprises only 96 lithic specimens (table F.5). ${ }^{1}$ Out of these 96 specimens, 68 can be considered definite artefacts, while the remainder include unmodified local limestone rock, for which it was not possible to determine with certainty whether they are artefacts (see Chapter 3 for definition). The sample includes the following materials: flint, beach-rock, limestone, tuff, igneous rock, plutonic rock, and siliceous sedimentary rock, along with some unidentified materials.

\section{The Troumassoid 1 and 2 (middle) occupation phases}

The excavations at Anse à la Gourde largely focused on the extensive occupational remains during these two phases. This emphasis is also evident in the larger number of lithic artefacts attributed to this phase and analysed for this study. The total number of items includes 834, of which 496 can be classified as definite artefacts (table F.6). This leaves 338 rock specimens

\footnotetext{
1 In contrast to the material from the other phases that came from clear refuse deposits, this sample originated from within an occupation floor, that was identified in the lower levels of the $2 \times 2 \mathrm{~m}$ test-units in the dune area.
} 


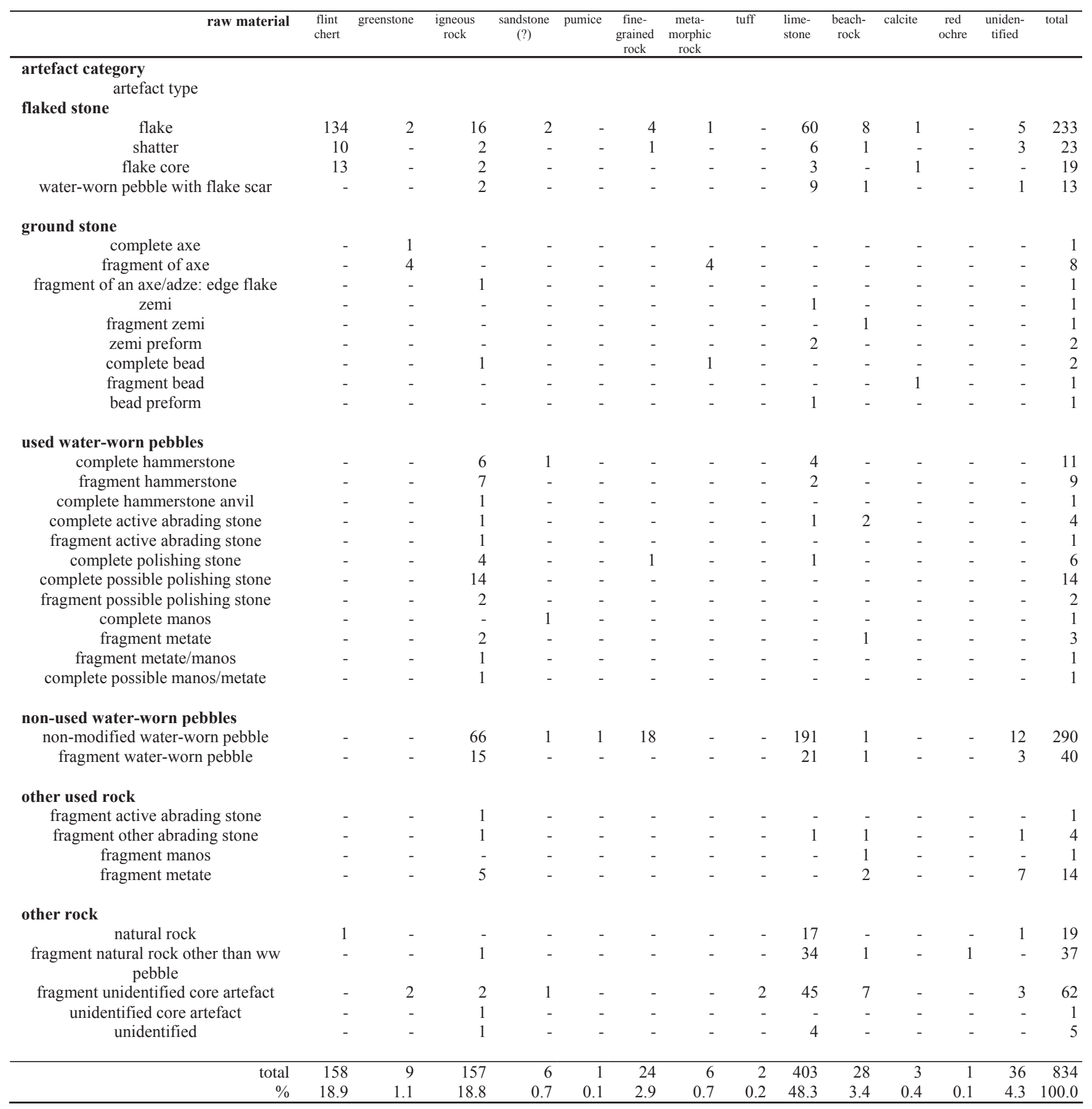

Table F.6. Anse à la Gourde, Guadeloupe, middle occupation phase (Late Ceramic A). Number of lithic artefacts by raw material by artefact type.

as disputable artefacts, of which the majority is made out of local rock and does not have any clear signs of modification. Rock materials used are for a great part similar to the ones identified within the Saladoid phase sample and include the following: flint, St. Martin greenstone, jasper, fine-grained varieties, calcite, limestone, beach-rock, red ochre, igneous rock, plutonic rock, pumice, tuff, and metamorphic rock along with a number of unidentified pieces. 


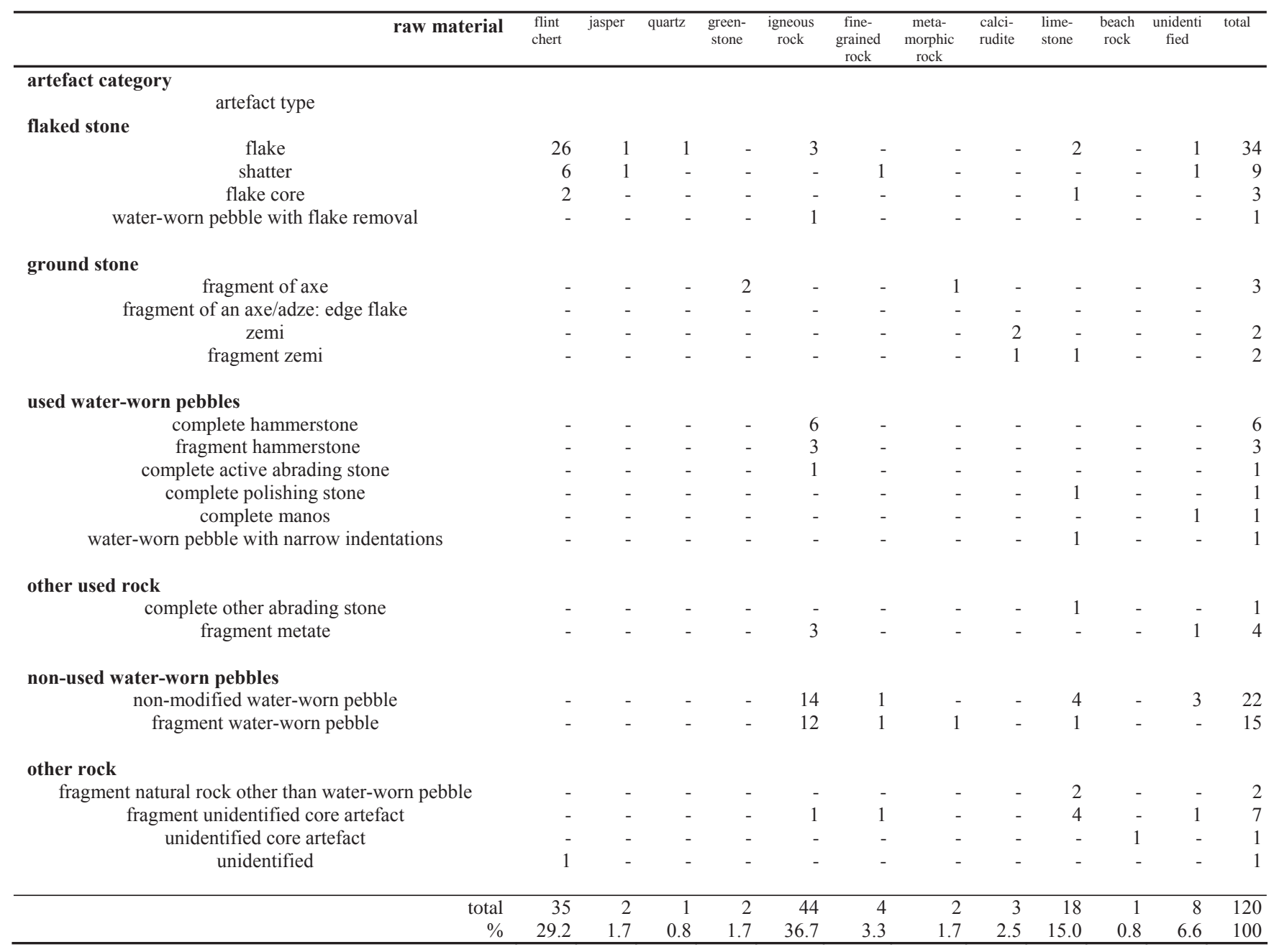

Table F.7. Anse à la Gourde, Guadeloupe, late occupation phase (Late Ceramic A). Number of lithic artefacts by raw material by artefact type.

\section{Suazan Troumassoid (late) occupation phase}

The sample that was ascribed to the Suazan Troumassoid occupation phase only includes 120 rock pieces (table F.7). I consider 108 of these as true artefacts, as the remainder is made out of local limestone and does not exhibit clear evidence of modification, either through use or through shaping of the rock. In contrast to the other two samples, the artefacts from this phase were collected from test-units exclusively ascribed to this last occupation of the site. Therefore the chance of artefacts being attributed to the wrong phase is considerably smaller. Within this sample, I identified the following materials: chert, flint, quartz, St. Martin greenstone, limestone, calci-rudite, igneous rock, metamorphic rock, and siliceous sedimentary rock. 


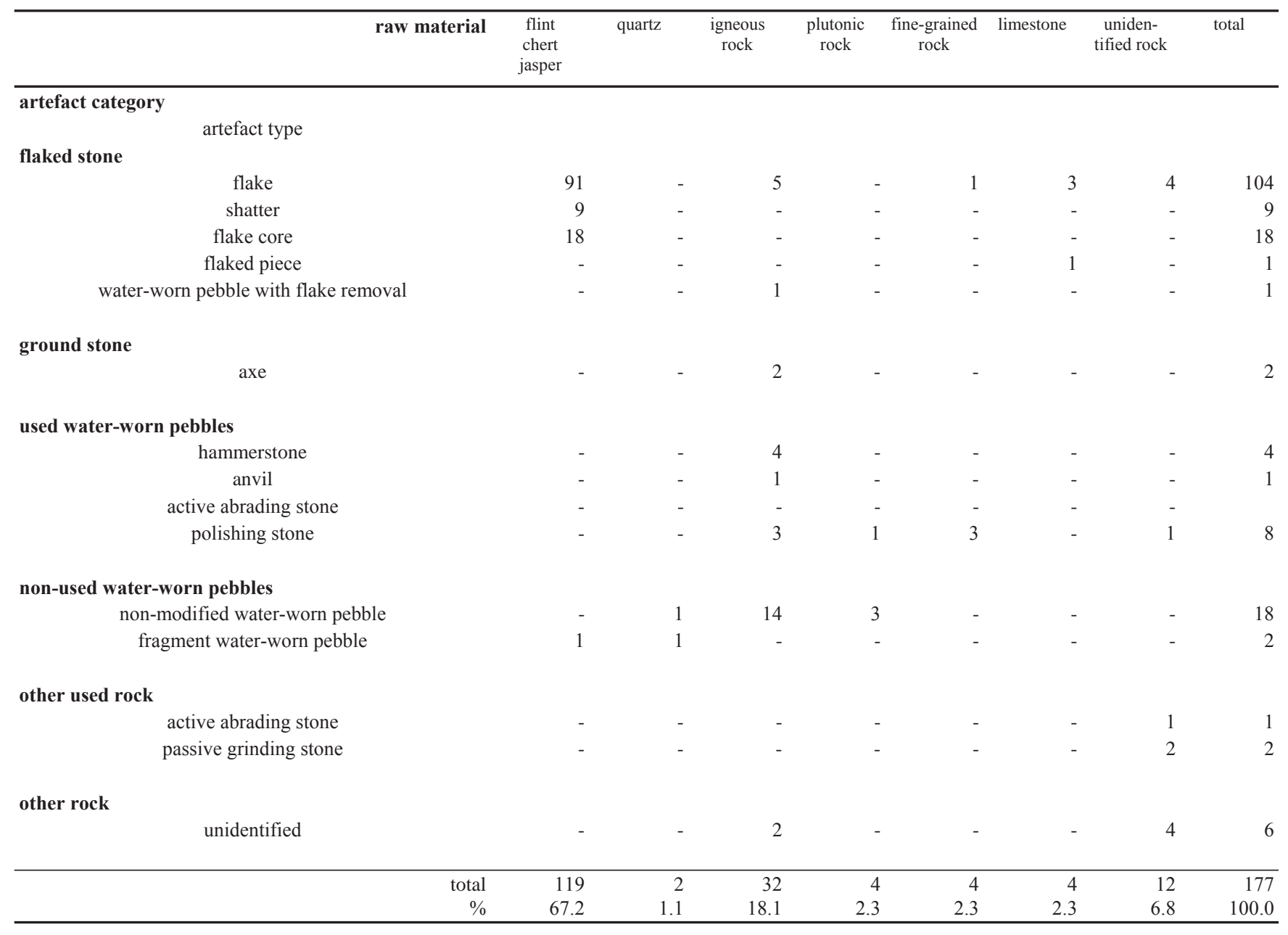

Table F.8. Anse à l'Eau, Guadeloupe, early occupation phase (Early Ceramic B). Number of lithic artefacts by raw material by artefact type.

\section{F.3.3 Anse à l'Eau}

Anse à l'Eau is the third site along Grande Terre's northern Atlantic coast included in this study. It is situated almost perfectly between the Morel and Anse à la Gourde sites. Similar to these sites, Edgar Clerc and Pierre Bodu conducted small-scale archaeological research there during the 1960s and early 1980s respectively (Bodu 1984; Clerc 1964, 1968, 1970). The identification of a significant site that was largely attributed to the Saladoid period, became the reason for planning of a sitesurvey there by four Master students from Leiden University and the University of Bonn (Boomsma \& Isendoorn 2001).

The survey included a systematic auger-test campaign (217 augers) and excavation of 23 test-units of varying size. The results showed that the site extends itself over a considerable area, approximately $80000 \mathrm{~m}^{2}$ in size. Based on pottery typology, two main phases of occupation were identified: a Saladoid (early) one in the northwestern part, roughly dated between AD 300 and 500, and a Post-Saladoid or Troumassoid (late) one in the eastern part. This latter area may also contain Saladoid material, but the small number of diagnostic artefacts impedes proper identification, however. The only radiocarbon date from this site was obtained during the fieldwork of Edgar Clerc. Its ${ }^{14} \mathrm{C}$ age of $1160 \pm 100 \mathrm{BP}$ (Rouse et al. 1985) places it somewhere in the late Saladoid/early Post-Saladoid period. Unfortunately, the exact provenience of the dated sample within the site is unknown and the most recent work did not produce new dates to supplement this single sample (Boomsma \& Isendoorn 2001). 


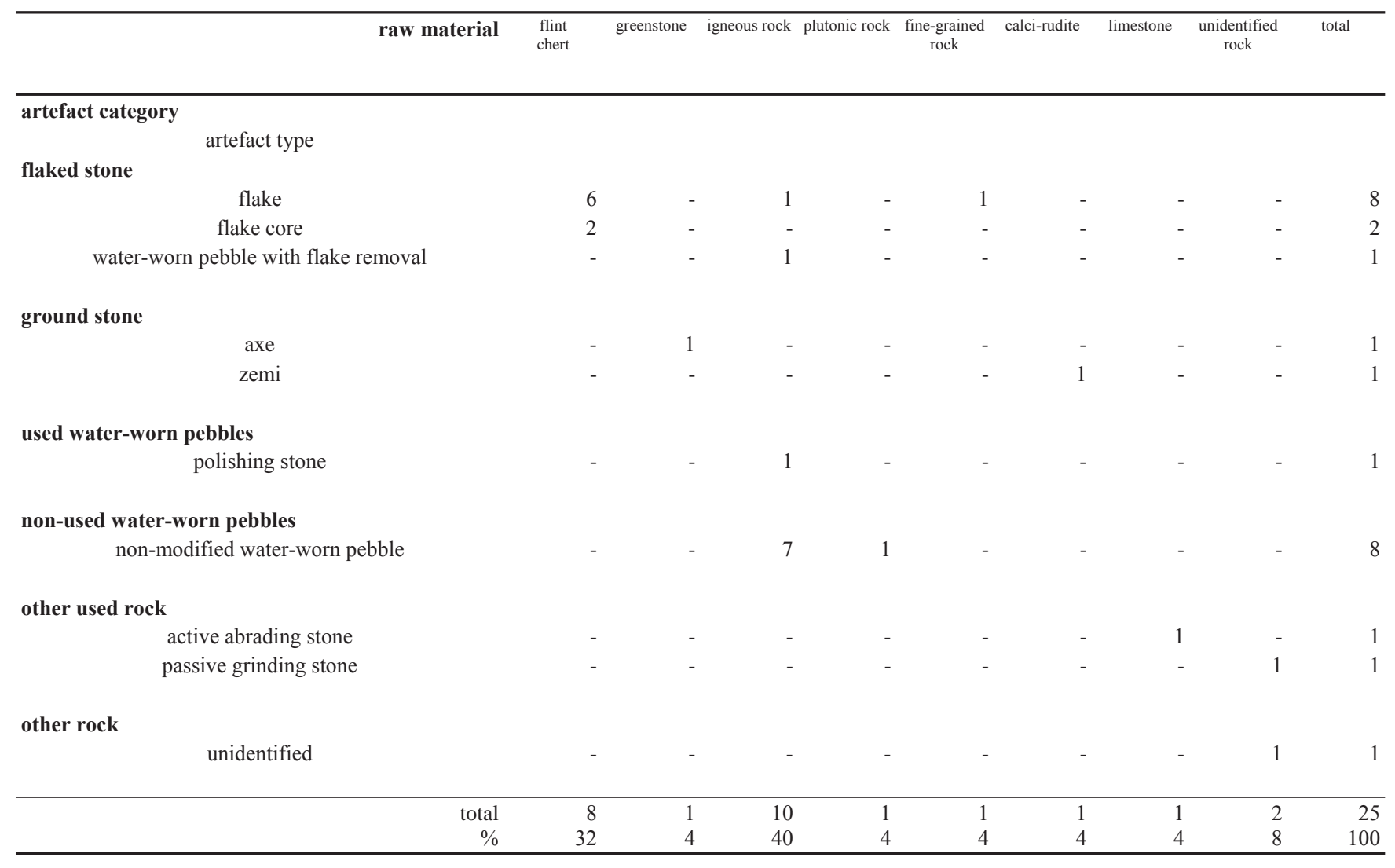

Table F.9. Anse à l'Eau, Guadeloupe, late occupation phase (Late Ceramic A). Number of lithic artefacts by raw material by artefact type.

The studied sample includes 239 lithic artefacts. It only comprises artefacts excavated within the test-units. These are the Saladoid units 3, 4, 5, 8, 9, 10,11, 12, 15, 16, 17, 18, 19, 20, 21, 22, and 23, and the post-Saladoid unit 2 (Boomsma \& Isendoorn 2001). For a detailed distribution of finds in the test-units and chronology of test-units see Knippenberg (2001c). From this total, 177 artefacts can be attributed to the Saladoid (early) occupation, including the following raw materials: flint and chert, quartz, limestone, igneous rock, plutonic rock, and other sedimentary rock. Another 25 artefacts are attributed to the Post-Saladoid (late) occupation and include flint, St. Martin greenstone, igneous rock, plutonic rock, limestone, and calcirudite (tables F.8 and F.9). The remaining 37 are from mixed contexts. These latter have been left out of the analysis. 


\begin{tabular}{|c|c|c|c|c|c|}
\hline raw material & $\begin{array}{l}\text { flint } \\
\text { chert }\end{array}$ & $\begin{array}{l}\text { igneous } \\
\text { rock }\end{array}$ & limestone & calcite & total \\
\hline \multicolumn{6}{|l|}{$\begin{array}{r}\text { artefact category } \\
\text { artefact type }\end{array}$} \\
\hline \multicolumn{6}{|l|}{ flaked stone } \\
\hline flake & 40 & - & - & - & 40 \\
\hline shatter & 15 & 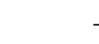 & 1 & - & 16 \\
\hline flake core & 6 & - & - & - & 6 \\
\hline \multicolumn{6}{|l|}{ used water-worn pebbles } \\
\hline complete hammerstone & - & 1 & - & - & 1 \\
\hline \multicolumn{6}{|l|}{ other rock } \\
\hline natural rock & - & - & - & 1 & 1 \\
\hline unidentified & 1 & - & - & - & 1 \\
\hline total & 62 & 1 & 1 & 1 & 65 \\
\hline$\%$ & 95 & 2 & 2 & 2 & 100 \\
\hline
\end{tabular}

Table F.10. Cocoyer, Marie Galante. Number of lithic artefacts by raw material by artefact type.

\section{F.4 Marie Galante}

\section{F.4.1 Cocoyer St. Charles}

A single site, Cocoyer St. Charles, on the island of Marie-Galante east of Guadeloupe, provided a sample of lithic artefacts for the present study (see figure 3.11). Cocoyer is situated along the west coast of Marie Galante, south of the small city of St. Louis and immediately northeast of the archaeological site of Folle Anse, which is known for its Huecan ceramics (Arts 1999). The site area itself is located between a sandy beach and a swamp area. As part of a multiple site-survey project, the same four master students working at Anse à l'Eau conducted a shovel test $(0.5 \mathrm{x} 0.5 \mathrm{~m})$ campaign followed by test-unit $(1 \mathrm{x}$ $1 \mathrm{~m}$ ) excavations within the densest artefact areas (Boomsma \& Isendoorn 2001).

Hampered by a high natural water table, they were only able to identify a single early Saladoid occupation extending over area $350 \times 200 \mathrm{~m}$ in size. Based on pottery characteristics, they assume that the site was contemporary with the early phases of the nearby site of Folle Anse, falling in the Early Ceramic A phase, although this latter site produced distinct ceramics in the form of Huecan ware. Due to the lack of radiocarbon dated samples, more precise dating is not possible.

The studied sample only includes a small number of artefacts, 65 in total, recovered from the shovel tests and from the test-units (table F.10). The large majority, 62 pieces (95\%), comprise flint and chert artefacts, and a single limestone, calcite, and igneous rock artefact. 


\begin{tabular}{|c|c|c|c|c|c|c|c|}
\hline raw material & $\begin{array}{l}\text { flint } \\
\text { chert }\end{array}$ & greenstone & limestone & plutonic rock & igneous rock & $\begin{array}{l}\text { unidentified } \\
\text { rock }\end{array}$ & total \\
\hline \multicolumn{8}{|l|}{ artefact category } \\
\hline \multicolumn{8}{|l|}{ artefact type } \\
\hline flake & 2 & - & 1 & - & 1 & - & 4 \\
\hline water-worn pebble with flake removal & - & - & . & 1 & - & 1 & 2 \\
\hline fragment of axe & - & 1 & & - & - & - & 1 \\
\hline \multicolumn{8}{|l|}{ non-used water-worn pebbles } \\
\hline non-modified water-worn pebble & - & - & & - & 2 & - & 2 \\
\hline fragment water-worn pebble & - & - & r & - & 1 & - & 1 \\
\hline \multicolumn{8}{|l|}{ other used rock } \\
\hline fragment unidentified core artefact & - & - & 1 & - & - & - & 1 \\
\hline total & 2 & 1 & 2 & 1 & 6 & 1 & 13 \\
\hline$\%$ & 15 & 8 & 15 & 8 & 46 & 8 & 100 \\
\hline
\end{tabular}

Table F.11. Du Phare, Petite Terre. Number of lithic artefacts by raw material by artefact type.

\section{F.5 Iles de la Petite Terre}

\section{F.5.1 Du Phare}

Du Phare is situated on Terre de Bas, the larger of the two islets making up Iles de la Petite Terre archipelago near Guadeloupe (see figure 3.11). It lies on "an elevated plain at some distance from the coast, extending from the east from the lighthouse towards the easternmost salina" (De Waal 2006). The site covers an area of approximately $12000 \mathrm{~m}^{2}$. Archaeological work was carried out during three different occasions over the past 30 years. Desmond Nicholson excavated a $2 \mathrm{~m}^{2}$ test unit there in 1975 (Nicholson 1975), Bodu and Petitjean-Roget performed survey work in 1985, and finally De Waal mapped archaeological surface material in the site area and subsequently did test-excavations in 1999. De Waal's 1 x 1 and $2 \times 2 \mathrm{~m}$ test-units were excavated in two densely concentrated site areas. The former only revealed a shallow archaeological deposit with a $20 \mathrm{~cm}$ thickness, while the latter uncovered a thicker deposit of $60 \mathrm{~cm}$.

Radiocarbon samples are not available for this site. Its pottery exhibits strong similarities with Post-Saladoid traditions in the area and the occupation should be placed within the Late Ceramic A phase.

The small sample of lithics only contains 13 artefacts, which originated both from the test-units and surface finds done during the 1999 work (table F.11). Igneous rock predominates within the sample, but other raw materials include chert, St. Martin greenstone, limestone, and plutonic rock. 


\begin{tabular}{|c|c|c|c|c|c|c|c|c|c|}
\hline raw material & chert & local chert & $\begin{array}{c}\text { Long } \\
\text { Island } \\
\text { flint }\end{array}$ & limestone & $\begin{array}{l}\text { plutonic } \\
\text { rock }\end{array}$ & $\begin{array}{l}\text { igneous } \\
\text { rock }\end{array}$ & $\begin{array}{l}\text { fine- } \\
\text { grained } \\
\text { rock }\end{array}$ & $\begin{array}{l}\text { uniden- } \\
\text { tified rock }\end{array}$ & total \\
\hline \multicolumn{10}{|l|}{ artefact category } \\
\hline \multicolumn{10}{|l|}{ flaked stone } \\
\hline flake & & 1 & 4 & - & - & 6 & - & - & 12 \\
\hline re-used pre-Ceramic Age blade fragment & & - & 1 & - & - & - & - & - & 1 \\
\hline \multicolumn{10}{|l|}{ ground stone } \\
\hline fragment of axe & & - & - & - & - & - & 1 & - & 1 \\
\hline fragment of an axe/adze: edge flake & & - & - & - & - & - & 1 & - & 1 \\
\hline \multicolumn{10}{|l|}{ used water-worn pebbles } \\
\hline \multicolumn{10}{|l|}{ non-used water-worn pebbles } \\
\hline non-modified water-worn pebble & & - & - & - & 1 & 31 & - & 1 & 33 \\
\hline fragment water-worn pebble & & - & - & - & - & 8 & - & - & 8 \\
\hline \multicolumn{10}{|l|}{ other used rock } \\
\hline fragment passive grinding/abrading stone & & - & - & 1 & - & 6 & - & - & 7 \\
\hline \multicolumn{10}{|l|}{ other rock } \\
\hline fragment natural rock & & - & - & - & - & 5 & - & - & 5 \\
\hline
\end{tabular}

Table F.12. Les Sables, La Désirade. Number of lithic artefacts by raw material by artefact type.

\section{F.6 LA DÉSIRADE}

Small samples from three sites lying on la Désirade, northeast of Guadeloupe, are included within this study (see figure 3.11). These are Les Sables, Escalier, and Morne Souffleur.

\section{F.6.1 Les Sables}

Les Sables is situated somewhat inland behind the Les Sables beach along the southern coast of La Désirade and to the west of the little capital of Beauséjour. Bodu discovered the site and conducted small-scale excavations in 1984. De Waal surveyed the site in 1999 and estimated its size to be $22500 \mathrm{~m}^{2}$ (De Waal 2006.). It is one of the largest Amerindian sites on the small island of La Désirade. Recent house and road construction has diminished its size and the site is clearly being affected by coastal erosion at present.

Bodu excavated a total of three test-units, including one $4 \times 4$ and two $1 \times 1 \mathrm{~m}$ squares. These excavations revealed an archaeological midden deposit varying in thickness. Unfortunately, the site has not been radiocarbon dated. The study of the pottery from the test-units, however, reveals strong similarities with late Saladoid pottery, placing this site within the Early Ceramic B phase.

The small sample of lithics includes 80 artefacts, which both originate from the test-units and the surface (table F.12). Igneous rock predominates within the sample, but other raw materials include chert, limestone, plutonic rock, and unidentified fine-grained rock. 


\begin{tabular}{|c|c|c|c|c|c|c|c|}
\hline raw material & $\begin{array}{l}\text { flint } \\
\text { chert }\end{array}$ & greenstone & limestone & calcite & igneous rock & $\begin{array}{c}\text { uniden- } \\
\text { tified rock }\end{array}$ & total \\
\hline \multicolumn{8}{|l|}{ artefact category } \\
\hline \multicolumn{8}{|l|}{ artefact type } \\
\hline flake & 8 & - & - & - & 20 & - & 28 \\
\hline flake core & - & - & - & - & 1 & - & 1 \\
\hline water-worn pebble with flake removal & - & - & - & - & 1 & - & 1 \\
\hline \multicolumn{8}{|l|}{ ground stone } \\
\hline fragment of axe & - & 1 & - & - & - & - & 1 \\
\hline \multicolumn{8}{|l|}{ used water-worn pebbles } \\
\hline hammerstone & - & - & - & - & 2 & - & 2 \\
\hline active abrading stone & - & - & 1 & - & 5 & - & 6 \\
\hline \multicolumn{8}{|l|}{ non-used water-worn pebbles } \\
\hline non-modified water-worn pebble & - & - & - & - & 57 & - & 57 \\
\hline fragment water-worn pebble & - & - & 1 & - & 12 & - & 13 \\
\hline \multicolumn{8}{|l|}{ other rock } \\
\hline fragment natural rock & - & - & - & 1 & 29 & - & 30 \\
\hline fragment unidentified core artefact & - & - & - & - & - & 1 & 1 \\
\hline total & 8 & 1 & 2 & 1 & 129 & 1 & 142 \\
\hline$\%$ & 5.6 & 0.7 & 1.4 & 0.7 & 90.8 & 0.7 & 100.0 \\
\hline
\end{tabular}

Table F.13. Escalier, La Désirade. Number of lithic artefacts by raw material by artefact type.

\section{F.6.2 Escalier}

The Escalier site is "situated in a cultivated terrain very close to the beach at the southern coastal plain of La Désirade" (De Waal 2006). Archaeological work was carried out during two different episodes. Bodu surveyed the site in 1985, and re-surveying and small test-excavations were carried out by de Waal in 1999 as part of her PhD dissertation work (De Waal 2006). De Waal estimates the site to cover an area of approximately $2400 \mathrm{~m}^{2}$. The excavation of two $2 \times 2 \mathrm{~m}$ test units revealed an $80 \mathrm{~cm}$ thick archaeological deposit, likely a midden area. Radiocarbon dates and the analysis of the ceramics position this site within the Late Ceramic A phase. Occupation of the site must have been between 1049 and 1243 cal AD, using $95 \%$ confidence intervals for a single radiocarbon date.

The sample of lithic artefacts amounts to 142 artefacts and originated from the test-units and survey work by Bodu and De Waal (table F.13). Within the sample, igneous rock predominates, but other raw materials include chert, St. Martin greenstone, limestone, and calcite. 


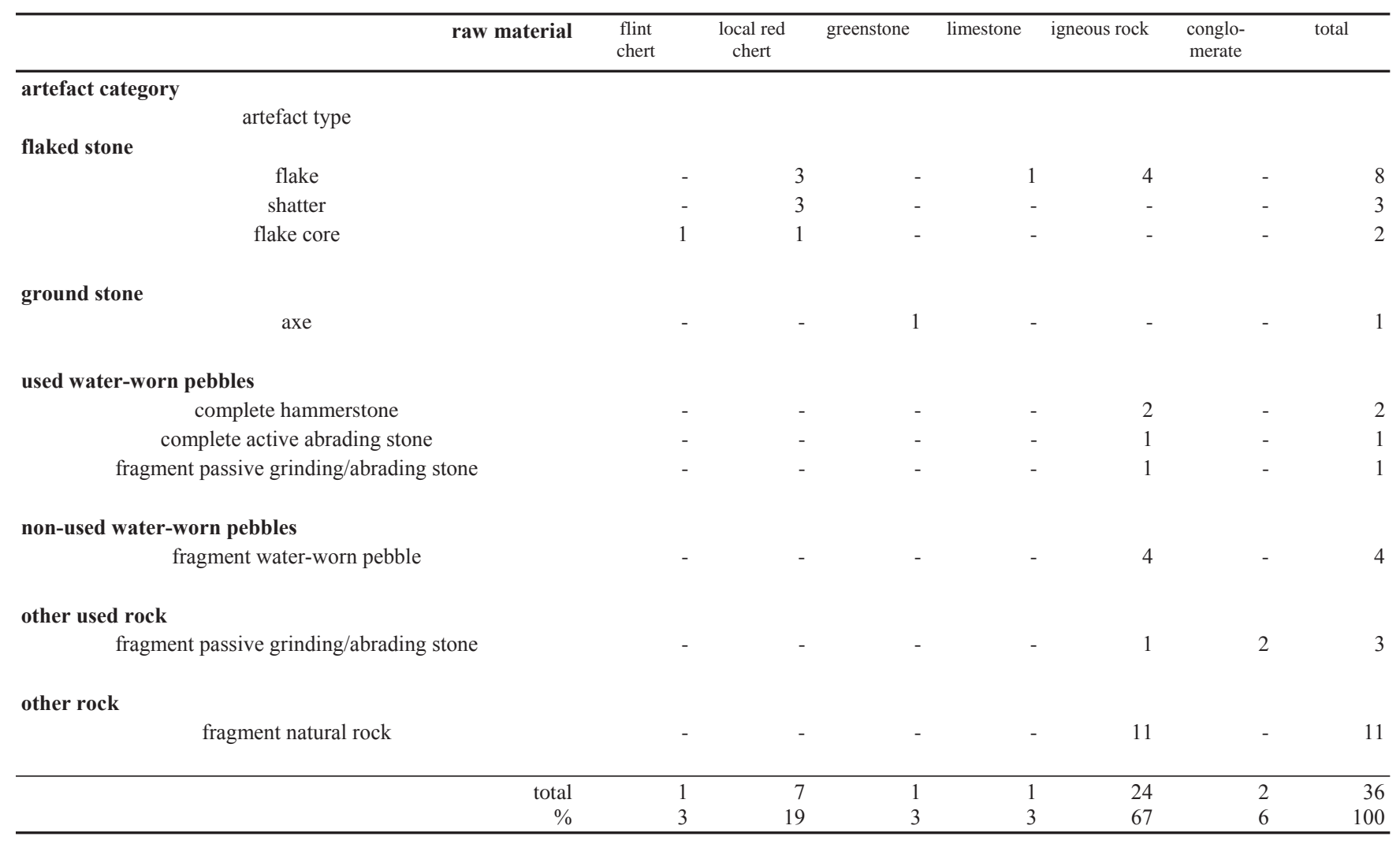

Table F.14. Morne Souffleur, La Désirade. Number of lithic artefacts by raw material by artefact type.

\section{F.6.3 Morne Souffleur}

The Morne Soufleur site is situated along the southern border of the central plateau of La Désirade and close to the terrain of the windmills (De Waal 2006). It lies approximately $1.5 \mathrm{~km}$ to the west of the earlier reported Morne Cybèle site (Hofman 1999). Morne Souffleur was discovered during survey work by De Waal in 1999. The site covers an area of approximately $3150 \mathrm{~m}^{2}$ and currently erodes along the southern edge of the plateau. Two $2 \times 2 \mathrm{~m}$ test-excavations revealed a shallow archaeological deposit, almost entirely part of the disturbed topsoil, which immediately overlies the limestone bedrock in this part of the island.

Radiocarbon samples are not available for this site. Strong similarities for its pottery are evident with the very characteristic and unique stylistic traits of the Morne Cybèle site, placing this site within the later part of the Late Ceramic B phase (Hofman et al. 2004).

The sample of lithics contains only 36 artefacts (table F.14), These were collected during test-unit excavation and surface collection. Igneous rock predominates within the sample, but other raw materials include chert, local red chert, St. Martin greenstone, limestone, and conglomerate. 


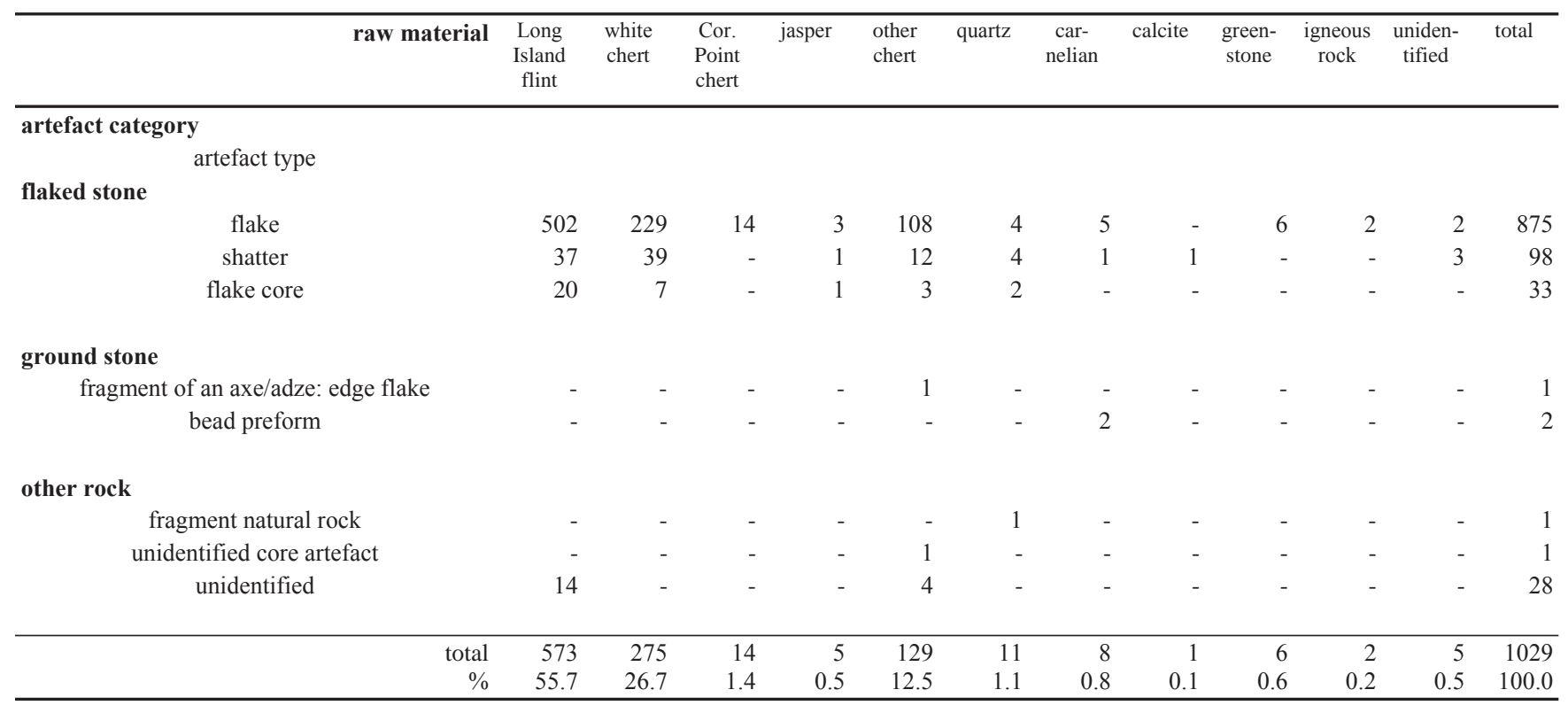

Table F.15. Trants, Montserrat. Number of lithic artefacts by raw material by artefact type, excluding 16 water-worn igneous rock pebbles.

\section{F.7 MONTSERRAT}

\section{F.7.1 Trants}

Trants is one of the oldest Ceramic Age sites within the Caribbean, dated back to 500 BC (Petersen 1996). "It is situated east of Centre Hills the only sizeable stretch of relatively flat terrain near sea level along the windward coast " of Montserrat (Watters 1994, 265; see figure 3.10). Finds originating from this site were first reported during the beginning of the $20^{\text {th }}$ century, when Harrington published on numerous beads and pendants made out of semi-precious rock materials (Harrington 1924). It was not until the late 1970s when the first archaeological excavations were performed at the Trants site. David Watters, at that time working on his $\mathrm{PhD}$ dissertation, excavated one $2 \times 2 \mathrm{~m}$ test-unit within one of the densely concentrated areas. This sounding showed extensive and well preserved occupation deposits. Threatened by plans to extend the air-strip in immediate vicinity, the site and surrounding area became the central focus of a multi-year archaeological research supervised by David Watters and Jim Petersen. The work included the mapping of the distribution of archaeological material, systematic shovel testing, followed by test-unit excavations within dense artefact areas, and the opening of large units in order to identify structural remains (Petersen 1996; Watters 1994; Watters \& Petersen 1999).

Results of this fieldwork showed that the site at least measures $62000 \mathrm{~m}^{2}$, in which a ring shaped distribution of high concentrated deposits of archaeological material enclose a more vacant plaza-like centre. This configuration resembles village lay-outs of ring-shape Amerindian settlements within the Amazonian rain forest. Multiple radiocarbon dates show that the site was occupied for a considerable time period, between $500 \mathrm{BC}$ until at least AD 400 (Petersen et al. 1999), corresponding with the period of the Cedrosan Saladoid subseries and placing the site in the Early Ceramic A phase.

A sample of 1029 lithic artefacts was analysed from this site at the Carnegie Museum of Natural History, Pittsburgh (table F.15). They originate from four 2 x 2 m test-units: N596E571, N405E571, N402E561, and N396E571. These were excavated using arbitrary $10 \mathrm{~cm}$ levels within natural stratigraphy, and using $6.4 \mathrm{~mm}(1 / 4 \mathrm{inch})$ and $3.2 \mathrm{~mm}(1 / 8 \mathrm{inch}) \mathrm{mesh}$ screens. Solely flaked stone artefacts from the $6.4 \mathrm{~mm}$ residues were analysed. These predominantly belong to flake tool and bead productions. Ground stone and use-modified core artefacts and fragments were not studied, as these were stored in Montserrat. The sample in Pittsburgh, however, contains a small number of 16 use-modified artefacts, made of igneous rock. Although they were studied, their relationship to the larger sample that was not studied, is unknown and so, they will be left out of the quantitative analysis. Material from units N596E571 and N396E571 was first included within the lithic study done by John Crock and Robert Bartone (Bartone \& Crock 1993; Crock \& Bartone 1998). Radiocarbon dates associated with the units from which material was analysed display a considerable time range, i.e. between $480 \mathrm{BC}$ and $\mathrm{AD} 410$. 


\begin{tabular}{lcccc}
\hline raw material & $\begin{array}{c}\text { Long } \\
\text { Island } \\
\text { flint }\end{array}$ & $\begin{array}{c}\text { white } \\
\text { chert }\end{array}$ & $\begin{array}{c}\text { other } \\
\text { chert and } \\
\text { flint }\end{array}$ & \\
\hline
\end{tabular}

artefact category

artefact type

flaked stone

$\begin{array}{crrrr}\text { flake } & 59 & - & - & 59 \\ \text { shatter } & 10 & - & - & 10 \\ \text { flake core } & 5 & - & - & 5\end{array}$

other rock

\begin{tabular}{lrrrrr} 
unidentified & & - & $74^{\mathrm{a}}$ & $86^{\mathrm{a}}$ & 160 \\
& & & & & \\
\hline & total & 74 & 74 & 86 & 234 \\
& $\%$ & 31.6 & 31.6 & 36.8 & 100.0 \\
\hline
\end{tabular}

Table F.16. Doigs, Antigua, Early Ceramic A occupation phase. Number of lithic artefacts by raw material by artefact type. a The artefact type for white chert and the other chert and flint group has not been determined.

\section{F.8 Antigua}

Flaked stone samples from four different sites on the island of Antigua were included in this study, along with the sites studied on Long Island (see Chapter 4). The four Antigua sites are Doigs, Claremont, Coconut Hall, and Blackman's Point (see figure 3.9).

\section{F.8.1 Doigs Amerindian}

The Doigs site is situated "within the rear of the isolated broad, coastal valley of Doigs in the southwestern volcanic district of Antigua" (Fuess, personal communication 2001). After initial site recognition by Desmond Nicholson in 1990, Martin Fuess as part of his $\mathrm{PhD}$ dissertation work excavated 29 shovel test probes along two transects to investigate the dimensions of the site. It extends approximately $400 \mathrm{~m}$ in a north-south direction by $300 \mathrm{~m}$ in an east-west direction. The shovel testing was followed by the excavation of a single $1 \times 1 \mathrm{~m}$ test-unit within a stratified midden area. The test-unit excavation revealed a $1.5 \mathrm{~m}$ deep archaeological deposit. Within this deposit, two occupation phases were distinguished. Radiocarbon dating of two shell samples produced a cal AD $110-405$ age for the early phase, corresponding with the Early Ceramic A, and a cal AD 595 - 800 age for the later phase, corresponding with the Early Ceramic B (Fuess, personal communication 2001).

A sample of 526 lithic artefacts has been studied from the Doigs site (tables F.16 and F.17). This sample originated from the $1 \times 1 \mathrm{~m}$ test-unit, which was excavated in arbitrary $10 \mathrm{~cm}$ levels, using a $3.2 \mathrm{~mm}$ mesh-screen. The sample has been divided into two sub-samples, corresponding with the two occupation phases of the site. The early phase sample consists of 292 artefacts and the late phase sample consists of 234 artefacts. The sample only includes flaked stone, almost exclusively related to the flake tool production. The sample comprises flint and cherts only. Due to time constraints, material from Doigs was only analysed for a limited number of attributes.

\begin{tabular}{|c|c|c|c|c|}
\hline raw material & $\begin{array}{l}\text { Long } \\
\text { Island } \\
\text { flint }\end{array}$ & $\begin{array}{l}\text { white } \\
\text { chert }\end{array}$ & $\begin{array}{l}\text { other } \\
\text { chert and } \\
\text { flint }\end{array}$ & total \\
\hline \multicolumn{5}{|l|}{$\begin{array}{l}\text { artefact category } \\
\qquad \text { artefact type }\end{array}$} \\
\hline \multicolumn{5}{|l|}{ flaked stone } \\
\hline flake & 136 & - & - & 136 \\
\hline shatter & 14 & - & - & 14 \\
\hline flake core & 9 & - & - & 9 \\
\hline \multirow{2}{*}{\multicolumn{5}{|c|}{$\begin{array}{l}\text { non-used water-worn pebbles } \\
\text { non-modified water-worn pebble } \\
\text { other rock }\end{array}$}} \\
\hline & & & & \\
\hline unidentified & - & $40^{\mathrm{a}}$ & $92^{\mathrm{a}}$ & 132 \\
\hline total & 160 & 40 & 92 & 292 \\
\hline$\%$ & 54.8 & 13.7 & 31.5 & 100.0 \\
\hline
\end{tabular}

Table F.17. Doigs, Antigua, Early Ceramic B occupation phase. Number of lithic artefacts by raw material by artefact type. a The artefact type for white chert and the other chert and flint group has not been determined. 


\begin{tabular}{|c|c|c|c|c|}
\hline raw material & $\begin{array}{l}\text { Long } \\
\text { Island } \\
\text { flint }\end{array}$ & other chert & quartz & total \\
\hline \multicolumn{5}{|l|}{$\begin{array}{l}\text { artefact category } \\
\text { artefact type }\end{array}$} \\
\hline \multicolumn{5}{|l|}{ flaked stone } \\
\hline flake & 28 & 1 & - & 29 \\
\hline shatter & 1 & - & 1 & 2 \\
\hline flake core & 6 & 2 & - & 8 \\
\hline \multicolumn{5}{|l|}{ non-used water-worn pebbles } \\
\hline non-modified water-worn pebble & 1 & - & - & 1 \\
\hline total & 36 & 3 & 1 & 40 \\
\hline$\%$ & 90 & 8 & 3 & 100 \\
\hline
\end{tabular}

Table F.18. Claremont, Antigua. Number of lithic artefacts by raw material by artefact type.

\section{F.8.2 Claremont}

The Claremont site is located within the confines of a broad alluvial valley that opens onto Carlisle Bay in Antigua. It is situated within a ploughed and furrowed pineapple field. The site lies approximately $2.4 \mathrm{~km}$ west of the Doigs site (Fuess, personal communication 2001). Martin Fuess conducted a surface reconnaissance and excavated a single 1 x $1 \mathrm{~m}$ test-unit there as part of his PhD dissertation work. "Based on diagnostic attributes of recovered ceramic materials a general PostSaladoid/Late Ceramic Age chronological affiliation for the site was assigned" (Fuess, personal communication 2001). The test-unit revealed a cultural stratum $60 \mathrm{~cm}$ in thickness on average.

A small sample of 40 lithic artefacts was studied from the Claremont site (table F.18). This sample originated from the $1 \mathrm{x} 1 \mathrm{~m}$ test-unit. This unit was excavated in arbitrary $10 \mathrm{~cm}$ levels using a $3.2 \mathrm{~mm}$ mesh-screen. It only includes flaked stone, almost exclusively related to the flake tool production. The sample comprises flint and chert. Due to time constraints, this material was only analysed for a limited number of attributes.

\section{F.8.3 Coconut Hall}

The site of Coconut Hall is situated on a peninsula-like point of low-lying limestone bedrock on the northeastern coast of Antigua and approximately $1.3 \mathrm{~km}$ northwest of the village of Seatons (Fuess, personal communication 2001). This segment of the point hosts one of the few natural surface scatters of flint on the main island of Antigua (see Chapter 2 and Appendix A). Fuess carried out archaeological fieldwork there as part of his PhD dissertation work (Fuess 1995, personal communication 2001). A preliminary surface reconnaissance showed that part of the site had been heavily disturbed by recent bulldozing activities related to a planned hotel construction. The undisturbed segment "may have been comprised of a series of smaller contemporaneous house clusters or shorter term intensive occupations through time" suggested by the identification of several concentrated midden areas (Fuess, personal communication 2001). Time constraints prevented the determination of the extent of the entire site. A single 1 x $1 \mathrm{~m}$ test-unit, however, was excavated within one of these midden clusters. Apart from a small number of historic artefacts, it entirely produced cultural remains related to a Post-Saladoid occupation. Two Strombus gigas shell samples supported this notion and yielded calibrated dates from cal AD 930 to 1180 (1370 \pm 60 BP; Beta 81999) and cal AD 945 to 1190 (1350 \pm 60 BP; Beta 93701), clearly positioning this site within the Late Ceramic A phase.

A sample of 229 lithic artefacts was studied from the Coconut Hall site (table F.19). This sample originated from the $1 \times 1 \mathrm{~m}$ test-unit, which has been excavated in arbitrary $10 \mathrm{~cm}$ levels using a $3.2 \mathrm{~mm}$ mesh-screen. It only includes flaked stone, almost exclusively related to the flake tool production. The sample comprises flint and cherts. Due to time constraints, the material has only analysed for a limited number of attributes. 


\begin{tabular}{|c|c|c|c|c|c|c|}
\hline raw material & $\begin{array}{l}\text { Long } \\
\text { Island } \\
\text { flint }\end{array}$ & $\begin{array}{c}\text { Coconut } \\
\text { Hall } \\
\text { flint }\end{array}$ & other chert & $\begin{array}{l}\text { burnt } \\
\text { flint and } \\
\text { chert }\end{array}$ & quartz & total \\
\hline \multicolumn{7}{|l|}{ artefact category } \\
\hline \multicolumn{7}{|l|}{ flaked stone } \\
\hline flake & 111 & 59 & 1 & - & - & 171 \\
\hline shatter & 6 & 13 & - & - & - & 19 \\
\hline flake core & 7 & 7 & - & - & - & 14 \\
\hline \multicolumn{7}{|l|}{ non-used water-worn pebbles } \\
\hline non-modified water-worn pebble & 1 & - & - & - & 1 & 2 \\
\hline \multicolumn{7}{|l|}{ other rock } \\
\hline unidentified & - & - & - & 23 & - & 23 \\
\hline total & 125 & 79 & 1 & 23 & 1 & 229 \\
\hline$\%$ & 54.6 & 34.5 & 0.4 & 10.0 & 0.4 & 100.0 \\
\hline
\end{tabular}

Table F.19. Coconut Hall, Antigua. Number of lithic artefacts by raw material by artefact type.

\section{F.8.4 Blackman's Point}

The site of Blackman's Point is situated on the eastern edge of a broad, low-lying, level, limestone bedrock peninsula in north-central Antigua (Fuess, personal communication 2001). It lies immediately to the north of the major natural surface scatter of flint in the area (see Chapter 2 and Appendix A). After earlier work by Desmond Nicholson in the 1970s (Nicholson 1976), and later by Bruce Nodine in the late 1980s and early 1990s, Martin Fuess conducted excavation work there as part of his $\mathrm{PhD}$-dissertation research. All three archaeological investigations demonstrated the unique character of the site in that it represents the only site known thus far from Antigua possessing stratified evidence for an Archaic Age occupation underlying a Late Ceramic Age cultural presence (Fuess, personal communication 2001). The site at least extends approximately $300 \mathrm{~m}$ southward along the eastern coast of the Blackman's Point peninsula and approximately $200 \mathrm{~m}$ inland.

Fuess' site survey work, which is of concern to this study, consisted of the excavation of three $1 \mathrm{x} 1 \mathrm{~m}$ test-units to establish both the extent and depth of the cultural deposits. Test-unit 3 revealed the presence of both Archaic and PostSaladoid occupations.

A sample of 395 lithic artefacts was studied from the Blackman's Point site (tables F.20-F.22). This sample originates from test-unit 3. This unit was excavated in arbitrary $10 \mathrm{~cm}$ levels using a $3.2 \mathrm{~mm}$ mesh-screen. The sample was divided into three sub-samples, corresponding with the two occupation phases and a mixed stratum at the site. The Archaic Age sample consists of 152 artefacts, the mixed sample of 31 artefacts and the Late Ceramic Age sample consists of 212 artefacts. The sample only includes flaked stone, almost exclusively related to the flake tool production. The sample only comprises flint and cherts. Due to time constraints the material has been only analysed for a limited number of attributes. 


\begin{tabular}{|c|c|c|c|}
\hline raw material & $\begin{array}{c}\text { Long Island } \\
\text { flint }^{\mathrm{a}}\end{array}$ & other chert & total \\
\hline \multicolumn{2}{|l|}{ artefact type } & & \\
\hline \multicolumn{4}{|l|}{ flaked stone } \\
\hline flake & 126 & - & 126 \\
\hline blade & 9 & - & 9 \\
\hline shatter & 7 & - & 7 \\
\hline flake/blade core & 4 & - & 4 \\
\hline \multicolumn{4}{|l|}{ other rock } \\
\hline unidentified & - & $6^{\mathrm{b}}$ & 6 \\
\hline total & 146 & 6 & 152 \\
\hline$\%$ & 96.1 & 3.9 & 100.0 \\
\hline
\end{tabular}

\begin{tabular}{|c|c|c|c|c|}
\hline raw material & $\begin{array}{l}\text { Long Island } \\
\text { flint }\end{array}$ & $\begin{array}{l}\text { Blackman's } \\
\text { Point flint }\end{array}$ & other chert & total \\
\hline \multicolumn{5}{|l|}{$\begin{array}{l}\text { artefact category } \\
\text { artefact type }\end{array}$} \\
\hline \multicolumn{5}{|l|}{ flaked stone } \\
\hline flake & 9 & 14 & 1 & 24 \\
\hline shatter & 1 & 2 & - & 3 \\
\hline flake/blade core & 2 & 2 & - & 4 \\
\hline total & $12^{\mathrm{a}}$ & 18 & 1 & 31 \\
\hline$\%$ & 39 & 58 & 3 & 100 \\
\hline
\end{tabular}

Table F.20. Blackman's Point, Antigua, Preceramic Age occupation phase. Number of lithic artefacts by raw material by artefact type. ${ }^{a}$ Long Island flint artefacts are all patinated; b The artefact type for other chert and flint group has not been determined.
Table F.21. Blackman's Point, Antigua. Number of lithic artefacts from the mixed pre-Ceramic - Ceramic Age deposit by raw material by artefact type. ${ }^{a}$ Long Island flint artefacts include Preceramic Age artefacts.

\begin{tabular}{|c|c|c|c|c|c|}
\hline raw material & $\begin{array}{l}\text { Long Island } \\
\text { flint }\end{array}$ & $\begin{array}{l}\text { Blackman's } \\
\text { Point flint }\end{array}$ & $\begin{array}{l}\text { other chert } \\
\text { and flint }\end{array}$ & $\begin{array}{l}\text { igneous } \\
\text { rock }\end{array}$ & total \\
\hline \multicolumn{6}{|l|}{ artefact type } \\
\hline \multicolumn{6}{|l|}{ flaked stone } \\
\hline flake & 65 & 88 & - & - & 153 \\
\hline shatter & 10 & 10 & - & - & 20 \\
\hline flake/blade core & 5 & 4 & - & - & 9 \\
\hline \multicolumn{6}{|l|}{ other rock } \\
\hline fragment unidentified core artefact & - & - & - & 1 & 1 \\
\hline unidentified & - & - & $29^{\mathrm{a}}$ & - & 29 \\
\hline total & 80 & 102 & 29 & 1 & 212 \\
\hline$\%$ & 37.7 & 48.1 & 13.7 & 0.5 & 100.0 \\
\hline
\end{tabular}

Table F.22. Blackman's Point, Antigua, Late Ceramic A occupation phase. Number of lithic artefacts by raw material by artefact type. ${ }^{\mathrm{a}}$ The artefact type for other chert and flint group has not been determined. 


\section{F.9 St. EUSTATIUS}

Three sites from St. Eustatius were included within this research. These are Golden Rock, Smoke Alley, and Godet (see figure 3.6).

\section{F.9.1 Golden Rock}

The Saladoid site of Golden Rock is situated in the centre of St. Eustatius on the "Cultuurvlakte" adjacent to the old air-strip. Threatened by destruction as a result of airstrip extension, Golden Rock was the subject of a large scale multi-year excavation research led by Aad Versteeg from Leiden University during the 1980s, following earlier work in the 1920s by Josselin de Jong, who attested to the significance of the site (Josseling de Jong 1947; Versteeg and Schinkel 1992). The multi-year archaeological research was aimed at investigating the intra-site structure. Large areas were opened to identify house plans and related midden areas. Results include the reconstruction of at least six house-floor plans, with associated small structures, in addition to a 25 by $16 \mathrm{~m}$ sized refuse area producing tons of shell remains, animal bone, coral, pottery, and stone artefacts. The main occupation of the site occurred between the $7^{\text {th }}$ and the $9^{\text {th }}$ century AD, placing it within the Early Ceramic B phase. Earlier activity, starting at AD 450, however, was also identified, i.e. hearths below the midden area, and must be interpreted as incipient, according to the excavators (Versteeg \& Schinkel 1992, 229).

A sample of 3238 lithic artefacts was studied from Golden Rock (tables F.23 and F.24). It includes all lithic artefacts from the following $4 \times 4$ m test-units excavated within the midden area: 3, 4, 5, 6, 7, 8, 10, 11, 12, 13, 14, 15, 16, 21, 22, 24, 25 (Schinkel 1992, 181 fig.161; Versteeg 1992a, 12 fig. 12). In addition, only the flake tool technology associated artefacts from units $1,2,18,19$, and 20 were analysed.

All units were divided in 1 x $1 \mathrm{~m}$ squares, which were excavated in arbitrary $10 \mathrm{~cm}$ levels using $12 \mathrm{~mm}$ meshscreens (Versteeg 1992b, 31-4). Residues from $2.8 \mathrm{~mm}$ mesh-screen, excavated within one sample-square of each 4 x 4 $\mathrm{m}$ unit, were not studied. The sample includes a wide variety of different raw materials. These comprise varieties of flint and chert, jasper, quartz, St. Martin greenstone, fine grained rock (possibly fine-grained igneous rock, tuffs, or mudstones), varieties of igneous rock and plutonic rock, varieties of metamorphic rock, pumice, tuff, limestone, calcite, beach-rock, calcirudite, possibly sandstone, and red ochre. 


\begin{tabular}{|c|c|c|c|c|c|c|c|c|c|c|c|}
\hline raw material & $\begin{array}{l}\text { flint chert } \\
\text { jasper }\end{array}$ & quartz & $\begin{array}{l}\text { green- } \\
\text { stone }\end{array}$ & $\begin{array}{l}\text { calci- } \\
\text { rudite }\end{array}$ & $\begin{array}{l}\text { lime- } \\
\text { stone }\end{array}$ & $\begin{array}{l}\text { beach } \\
\text { rock }\end{array}$ & calcite & $\begin{array}{l}\text { meta- } \\
\text { morphic } \\
\text { rock }\end{array}$ & $\begin{array}{c}\text { fine- } \\
\text { grained } \\
\text { rock }\end{array}$ & red ochre & $\begin{array}{l}\text { uniden- } \\
\text { tified rock }\end{array}$ \\
\hline \multicolumn{12}{|l|}{$\begin{array}{l}\text { artefact category } \\
\text { artefact type }\end{array}$} \\
\hline \multicolumn{12}{|l|}{ flaked stone } \\
\hline flake & 556 & 2 & 384 & 1 & 5 & 1 & - & 7 & 23 & - & 8 \\
\hline shatter & 57 & - & 8 & - & - & - & - & 1 & - & - & 1 \\
\hline complete axe preform & - & - & 11 & - & - & - & - & - & - & - & - \\
\hline fragment axe preform & - & - & 59 & - & - & - & - & - & - & - & - \\
\hline \multicolumn{12}{|l|}{ ground stone } \\
\hline axe & - & - & 3 & - & - & - & - & - & - & - & - \\
\hline fragment of axe & - & - & 62 & - & - & - & - & 10 & - & - & - \\
\hline fragment of an axe/adze: edge flake & - & - & 1 & - & - & - & - & 2 & - & - & - \\
\hline bead perform & - & 1 & - & - & - & - & - & 1 & - & - & - \\
\hline pendant preform & - & - & - & - & 1 & - & - & - & - & - & - \\
\hline \multicolumn{12}{|l|}{ used water-worn pebbles } \\
\hline complete hammerstone & 1 & 2 & 2 & - & 4 & - & - & - & 1 & - & 2 \\
\hline fragment hammerstone & 1 & - & 8 & - & - & - & - & 3 & - & - & 1 \\
\hline complete anvil stone & - & - & - & - & - & - & - & - & - & - & - \\
\hline fragment anvil stone & - & - & - & - & - & - & - & - & - & - & - \\
\hline complete hammerstone anvil & - & - & - & - & - & - & - & - & - & - & - \\
\hline fragment hammerstone anvil & - & - & - & - & - & - & - & - & - & - & 1 \\
\hline complete active abrading stone & - & - & - & - & - & - & - & - & 2 & - & - \\
\hline fragment active abrading stone & - & - & - & - & - & - & - & 1 & - & - & - \\
\hline complete polishing stone & - & - & - & - & - & - & - & - & 10 & - & 1 \\
\hline non-modified water-worn pebble & 2 & - & 2 & - & 14 & - & - & 1 & 8 & - & 6 \\
\hline fragment water-worn pebble & - & - & 8 & - & 8 & - & - & 1 & 10 & - & 6 \\
\hline \multicolumn{12}{|l|}{ other used rock } \\
\hline complete active abrading stone & - & - & - & - & - & - & - & - & - & - & - \\
\hline fragment active abrading stone & - & - & - & - & - & - & - & - & - & - & 3 \\
\hline fragment manos & - & - & - & - & - & - & - & - & - & - & - \\
\hline complete metate & - & - & - & - & - & - & - & - & - & - & 1 \\
\hline fragment metate & - & - & - & - & 1 & - & - & - & - & - & 6 \\
\hline possible metate & - & - & - & - & - & - & - & - & - & - & - \\
\hline complete passive grinding stone & - & - & - & - & - & - & - & - & - & - & - \\
\hline other type of abrading stone & - & - & - & - & 2 & 1 & - & - & - & - & 7 \\
\hline fragment whetstone & - & - & - & - & - & - & - & - & - & - & 1 \\
\hline \multicolumn{12}{|l|}{ other rock } \\
\hline natural rock & 1 & - & - & - & 2 & - & 1 & - & - & 4 & - \\
\hline fragment natural rock & - & 1 & - & - & 2 & - & - & 1 & - & - & 13 \\
\hline unidentified core artefact & 1 & - & 12 & - & 1 & - & - & - & - & - & 1 \\
\hline fragment unidentified core artefact & 1 & - & 49 & - & 6 & 10 & - & 1 & 3 & - & 16 \\
\hline unidentified & 6 & - & 9 & - & 4 & - & - & - & - & - & 11 \\
\hline total & 676 & 9 & 619 & 5 & 59 & 52 & 1 & 31 & 93 & 4 & 91 \\
\hline$\%$ of total (see other table) & 20.9 & 0.3 & 19.1 & 0.2 & 1.8 & 1.6 & 0.0 & 1.0 & 2.9 & 0.1 & 2.8 \\
\hline
\end{tabular}




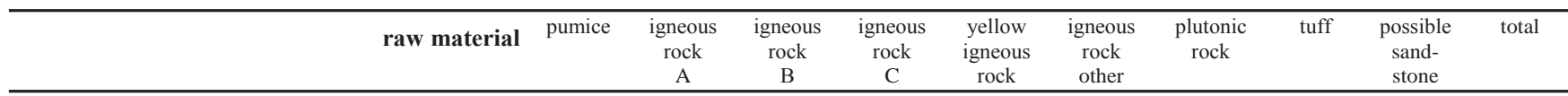

artefact category

artefact type

flaked stone

$$
\begin{gathered}
\text { flake } \\
\text { shatter } \\
\text { flake core }
\end{gathered}
$$

water-worn pebble with flake removal

complete axe preform

fragment axe preform

ground stone

axe

fragment of axe

fragment of an axe/adze: edge flake complete axe preform

$$
\text { zemi }
$$

fragment zemi

fragment bead

bead preform

pendant preform

\section{used water-worn pebbles}

complete hammerstone

fragment hammerstone

complete anvil stone

fragment anvil stone

complete hammerstone anvil

fragment hammerstone anvil

complete active abrading stone

fragment active abrading stone

complete polishing stone

fragment polishing stone

complete possible polishing stone

fragment possible polishing stone

complete metate

fragment metate

other type of abrading stone

ww pebble with narrow indentations

non-used water-worn pebbles

non-modified water-worn pebble

fragment water-worn pebble

other used rock

complete active abrading stone

fragment active abrading stone

fragment manos

complete metate

fragment metate

possible metate

complete passive grinding stone other type of abrading stone

fragment whetstone

other rock

natural rock

fragment natural rock

unidentified core artefact

fragment unidentified core artefact

unidentified

unidentified $\begin{array}{rrr}11 & 26 \\ 5 & 66 & 194\end{array}$

\begin{tabular}{rrrrr} 
unidentified & & 5 & 2 & \\
\hline & total & 66 & 194 & 442 \\
& $\%$ & 2.0 & 6.0 & 13.7
\end{tabular}




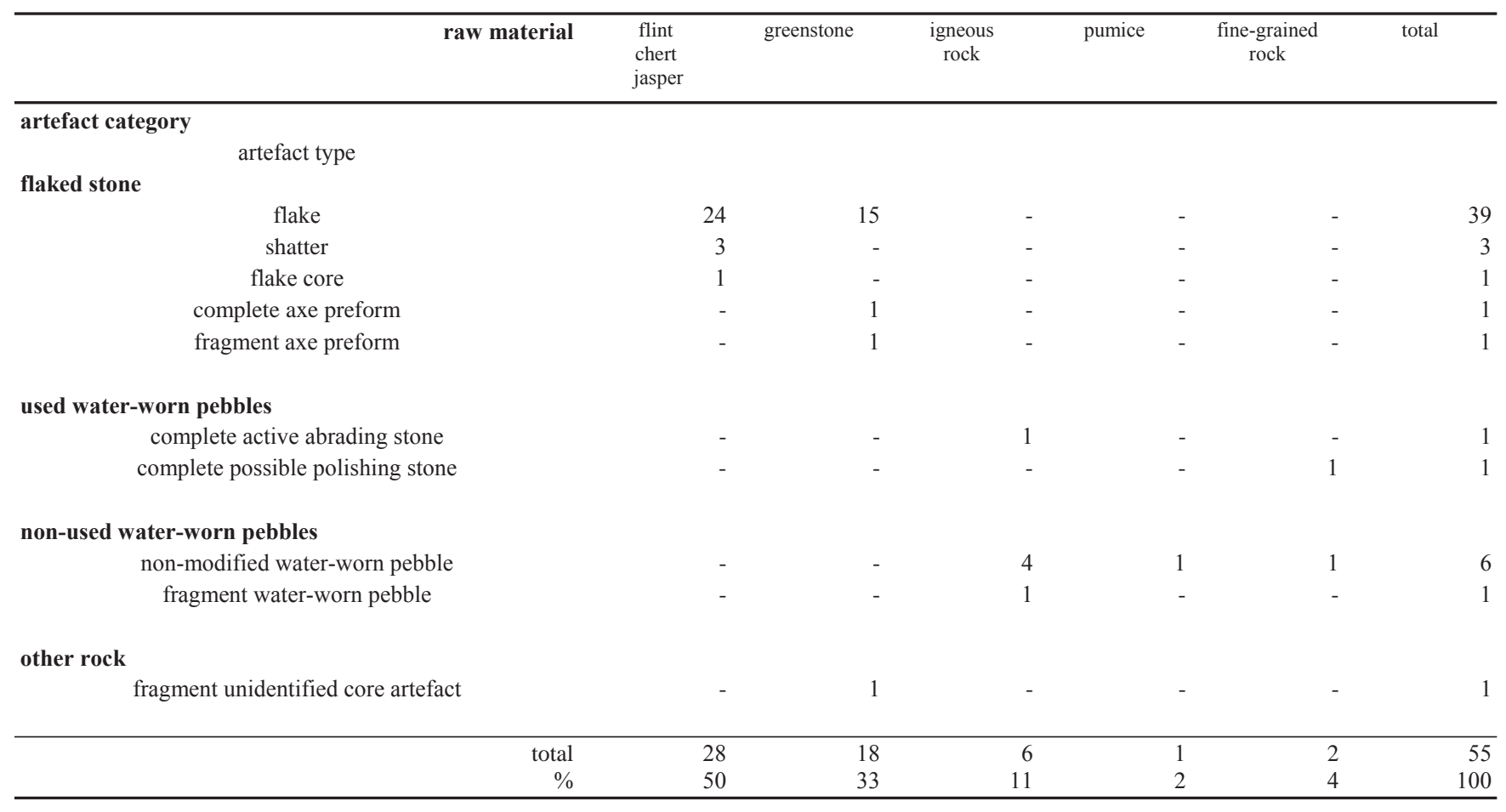

Table F.25. Smoke Alley, St. Eustatius. Number of lithic artefacts by raw material by artefact type.

\section{F.9.2 Smoke Alley}

During the different field-campaigns at the Golden Rock site, archaeological research was also undertaken at Smoke Alley, a Post-Saladoid site along the western leeward coast of the island and northwest of Oranjestad. Five 1 x $1 \mathrm{~m}$ test-units were dug to determine the extent of the midden deposit. This was followed by the excavation of a $225 \mathrm{~m}^{2}$ large area using a mechanical shovel. This work revealed the presence of an approximately 10 by $10 \mathrm{~m}$ midden area, overlying two Amerindian house structures and two burials. Radiocarbon dating suggests that the occupation started during the later part of the Early Ceramic A and lasted well into the Late Ceramic A phase. The earlier occupation must have been short considering the low amount of material that is attributed to this phase. The predominant occupation was during the Late Ceramic A phase, around cal AD 1000 -1160 (Versteeg et al. 1996).

The sample studied from Smoke Alley only includes 55 lithic artefacts (table F.25). The material originated from five $1 \times 1 \mathrm{~m}$ test-units, predominantly from the levels associated with the Late Ceramic A phase occupation. These units were excavated in $10 \mathrm{~cm}$ arbitrarily levels using $12 \mathrm{~mm}$ mesh screens (Versteeg et al. 1996). My wish to study diachronic patterns relating to the use of raw materials and production of stone tools on St. Eustatius formed the main purpose for the analysis of this small sample. Identified raw materials comprise, in order of decreasing frequency, flint, St. Martin greenstone, igneous rock, fine-grained rock, and pumice.

Table F.24 (opposite page). Golden Rock, St. Eustatius. Number of lithic artefacts by raw material and artefact type (2nd table). 


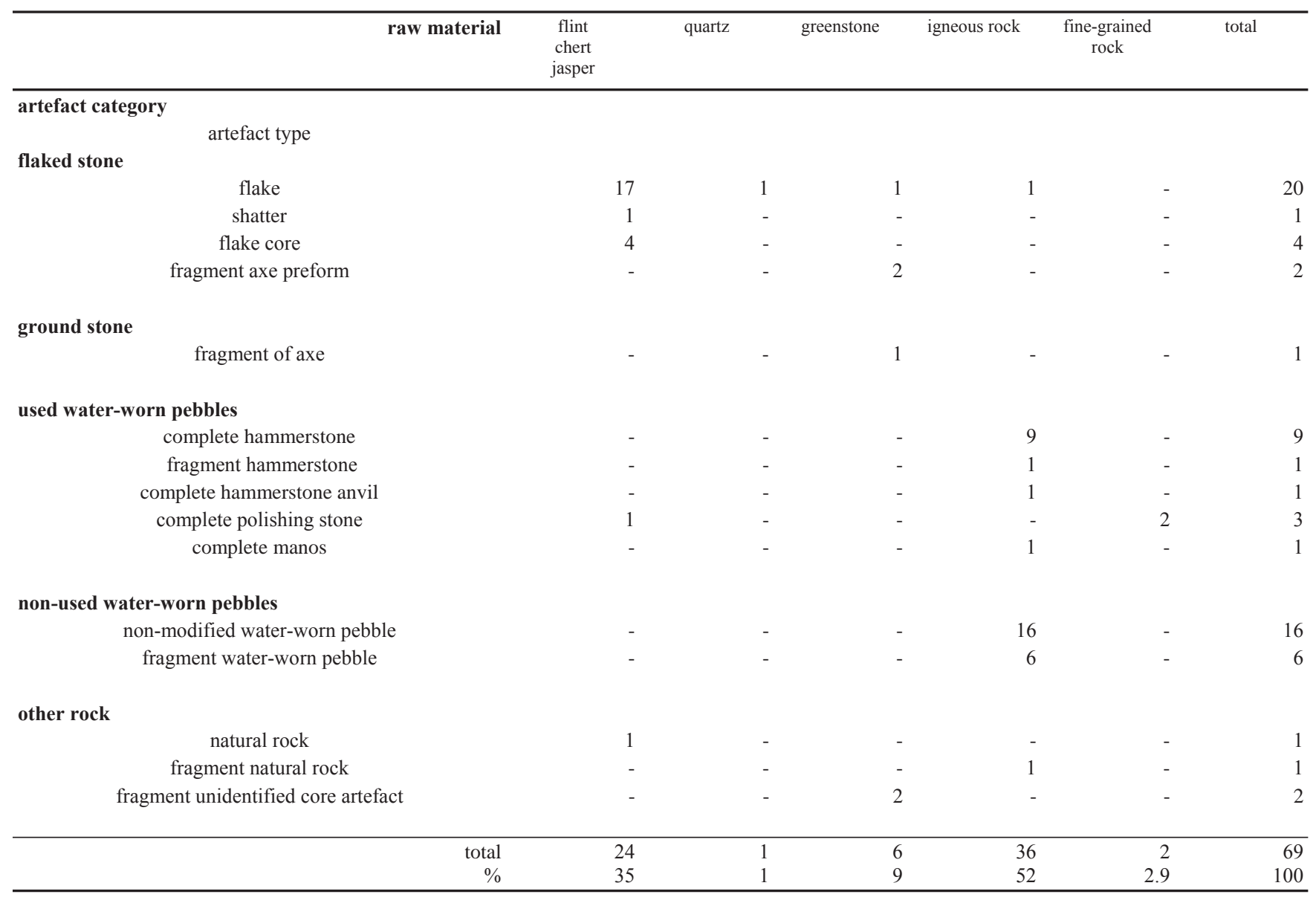

Table F.26. Godet, St. Eustatius. Number of lithic artefacts by raw material by artefact type.

\section{F.9.3 Godet}

Very limited excavation work was performed at Godet, a Post-Saladoid site in close proximity to the Smoke Alley site along Statia's western coast (Van der Valk \& Putker 1986). A single 2 x $4 \mathrm{~m}$ test-unit was excavated at Godet. Unfortunately, this site has not been radiocarbon dated. Based on ceramic features the main occupation at Godet site must be placed within the Late Ceramic A phase, around AD 800 to AD 1000. A small number of Saladoid ceramics suggest earlier activities occurred there as well.

The lithic sample from Godet only includes 69 artefacts (table F.26). The archaeological material originates from the single test-unit. The excavation methodology was similar to the Golden Rock excavations; arbitrary $10 \mathrm{~cm}$ levels were dug and dirt was sieved through $12 \mathrm{~mm}$ mesh-screens. The decision to study this small sample was based on the same grounds as the case of the Smoke Alley sample. Raw materials that were identified are, in order of decreasing frequency, igneous rock, flint, St. Martin greenstone, jasper, chert, and fine-grained rock. 


\begin{tabular}{|c|c|c|c|c|c|c|c|c|}
\hline \multicolumn{9}{|c|}{ artefact category } \\
\hline \multicolumn{9}{|l|}{ flaked stone } \\
\hline & flake & & 41 & 22 & 2 & - & - & 65 \\
\hline & shatter & & 5 & 6 & - & - & - & 11 \\
\hline & flake core & & 2 & - & - & - & - & 2 \\
\hline \multicolumn{9}{|l|}{ other rock } \\
\hline & fragment natural rock & & - & - & - & - & 1 & 1 \\
\hline & unidentified core artefact & & - & - & - & 1 & - & 1 \\
\hline & unidentified & & 2 & 2 & - & - & - & 4 \\
\hline & & total & 50 & 30 & 2 & 1 & 1 & 84 \\
\hline & & $\%$ & 60 & 36 & 2 & 1 & 1 & 100 \\
\hline
\end{tabular}

Table F.27. Kelbey's Ridge 1, Saba. Number of lithic artefacts by raw material by artefact type.

\section{F.10 SABA}

Lithic samples from three sites on Saba were studied. These include Kelbey's Ridge 1 and 2, and Spring Bay 3 (see figure 3.6).

\section{F.10.1 Kelbey's Ridge 1}

Kelbey's Ridge 1 is the smaller and older settlement of two sites that are situated in a shallow depression, roughly triangular in shape and lying to the north of a pronounced outlet of the volcanic dome, called Kelbey's Ridge (Hoogland 1996, 37-38). Corinne Hofman and Menno Hoogland performed excavations at this locality during the late 1980s and early 1990s as part of their PhD dissertation research (Hofman 1993; Hoogland 1996) The site measures only $350 \mathrm{~m}^{2}$ and is dated between cal AD 660-885, based on a single radiocarbon date. This date places Kelbey's Ridge 1 in the later part of the Early Ceramic B phase. The ceramics were classified to the Cedrosan Saladoid subseries, which makes this site one of the latest Saladoid sites in the region (Hofman 1993). Hoogland suggests that occupation must have been ephemeral considering its small size (Hoogland 1996, 122).

A lithic sample of 84 artefacts was studied from the Kelbey's Ridge 1 site (table F.27). This sample largely includes flake tool related material and some exceptional rare items. It originated from the test-units that are exclusively attributed to the Kelbey's Ridge 1 site. These include the following ones: 8, 10,11, 13, 15, 16, 17, 24, 25, 26, 27, 28, 29, 30, 31, 32, 33, and 34 (Hoogland 1996, 120 fig. 6.2). They were excavated in arbitrary $10 \mathrm{~cm}$ levels using $4 \mathrm{~mm}$ mesh-screens. The raw materials identified include flint, chert, St. Martin greenstone, igneous rock, and red ochre.

\section{F.10.2 Kelbey's Ridge 2}

Kelbey's Ridge 2 belongs to one of the larger settlement sites on the island. It lies immediately to the southeast of the Kelbey's Ridge 1 site and measures $2000 \mathrm{~m}^{2}$. The ceramics have been classified to the Chican Ostionoid subseries. The site is dated to the final two centuries of the Pre-Columbian Age, around AD 1300-1450, on the basis of 14 radiocarbon dates. This clearly positions Kelbey's Ridge 2 in the Late Ceramic B phase. Distinct refuse areas were not identified, but instead the excavations focussed on the identification of house-plans. The results suggest that a small village, consisting of four to five households occupied this area (Hoogland 1996).

A sample of 115 lithic artefacts was studied from Kelbey's Ridge 2 (table F.28). This sample only originated from systematically excavated and screened $1 \times 1 \mathrm{~m}$ test-units attributed to the Kelbey's Ridge 2 occupation. These are the following ones: 1, 2, 3, 4, 5, 6, 7, 9, 12, 19, 20, 21, 22, and 23. (see Hoogland 1996, 118 fig.6.1). The excavation methodology in the field was similar to the one used at Kelbey's Ridge 1. The lithic material only includes flaked stone, which mainly can be related to flake tool production. Materials identified are flint, chert, and St. Martin greenstone. 


\begin{tabular}{lcccc}
\hline raw material & $\begin{array}{c}\text { Long } \\
\text { Island } \\
\text { flint }\end{array}$ & $\begin{array}{c}\text { other flint } \\
\text { and chert }\end{array}$ & $\begin{array}{c}\text { green- } \\
\text { stone }\end{array}$ & total \\
& fling & & \\
\hline
\end{tabular}

\begin{tabular}{|c|c|c|c|c|c|}
\hline \multirow{2}{*}{\multicolumn{6}{|c|}{$\begin{array}{l}\text { artefact category } \\
\text { artefact type } \\
\text { flaked stone }\end{array}$}} \\
\hline & & & & & \\
\hline flake & & 67 & 25 & 1 & 93 \\
\hline shatter & & 6 & 2 & 1 & 9 \\
\hline flake core & & 5 & 2 & - & 7 \\
\hline \multicolumn{6}{|l|}{ used water-worn pebbles } \\
\hline active abrading stone & & - & - & 1 & 1 \\
\hline \multicolumn{6}{|l|}{ other rock } \\
\hline unidentified & & 1 & 4 & - & 5 \\
\hline & total & 79 & 33 & 3 & 115 \\
\hline & $\%$ & 68.7 & 28.7 & 2.6 & 100.0 \\
\hline
\end{tabular}

Table F.28. Kelbey's Ridge 2, Saba. Number of lithic artefacts by raw material by artefact type.

\section{F.10.3 Spring Bay 3}

Spring Bay 3 is a single component settlement site measuring $1000 \mathrm{~m}^{2}$ in size. It is situated along one of the few accessible bays on Saba, only $100 \mathrm{~m}$ to the east of the larger Spring Bay 1 settlement. The material is ascribed to the Mamoran Troumassoid subseries. Although the actual radiocarbon dates show a range between AD 910 and 1395 (2 sigma), Hoogland suggested on the basis of a very characteristic pottery assemblage that this site must have been occupied during a single phase, which he positioned around the second half of the eleventh century $\mathrm{AD}$, right in the middle of the Late Ceramic A phase (Hoogland 1996, 106-107).

A sample of 156 lithic artefacts was studied from the Spring Bay 3 site (table F.29). This sample originated from the test-units $31,34,36$, and 37 . These were excavated in arbitrary $10 \mathrm{~cm}$ levels using $4 \mathrm{~mm}$ mesh-screens. The sample only includes flaked stone, predominantly related to the flake tool production, in addition to some exceptional artefacts. The materials identified include flint, chert, quartz, St. Martin greenstone, and calci-rudite.

\begin{tabular}{|c|c|c|c|c|c|c|c|}
\hline & raw material & $\begin{array}{l}\text { Long Island } \\
\text { flint }\end{array}$ & $\begin{array}{l}\text { other flint and } \\
\text { chert }\end{array}$ & quartz & greenstone & calci-rudite & total \\
\hline \multicolumn{8}{|l|}{ artefact category } \\
\hline \multicolumn{8}{|l|}{ flaked stone } \\
\hline flake & & 87 & 24 & - & 3 & - & 114 \\
\hline shatter & & 20 & 11 & 1 & - & - & 32 \\
\hline \multicolumn{8}{|l|}{ ground stone } \\
\hline complete axe & & - & - & - & 1 & - & 1 \\
\hline zemi & & - & - & - & - & 1 & 1 \\
\hline \multicolumn{8}{|l|}{ used water-worn pebbles } \\
\hline \multicolumn{8}{|l|}{ other rock } \\
\hline & total & 110 & 38 & 1 & 5 & 1 & 155 \\
\hline & $\%$ & 71.0 & 24.5 & 0.6 & 3.2 & 0.6 & 100.0 \\
\hline
\end{tabular}

Table F.29. Spring Bay 3, Saba. Number of lithic artefacts by raw material by artefact type. 


\begin{tabular}{|c|c|c|c|c|c|c|c|c|c|c|c|}
\hline raw material & $\begin{array}{c}\text { flint and } \\
\text { chert }\end{array}$ & $\begin{array}{c}\text { red } \\
\text { chert } \\
\text { jasper }\end{array}$ & $\begin{array}{l}\text { dark } \\
\text { green } \\
\text { chert }\end{array}$ & $\begin{array}{l}\text { white } \\
\text { quartz }\end{array}$ & $\begin{array}{l}\text { green- } \\
\text { stone }\end{array}$ & igneous & plutonic & $\begin{array}{c}\text { fine- } \\
\text { grained } \\
\text { rock }\end{array}$ & red ochre & $\begin{array}{l}\text { uniden- } \\
\text { tified }\end{array}$ & total \\
\hline \multicolumn{12}{|l|}{ artefact category } \\
\hline \multicolumn{12}{|l|}{ flaked stone } \\
\hline flake & 135 & 1 & 15 & 8 & 229 & 123 & 2 & - & - & 24 & 537 \\
\hline shatter & 42 & - & 1 & 4 & 4 & 6 & - & - & - & - & 57 \\
\hline \multicolumn{12}{|l|}{ ground stone } \\
\hline axe & - & - & - & - & 10 & - & - & - & - & - & 10 \\
\hline butt-end & - & - & - & - & 13 & - & - & - & - & - & 13 \\
\hline axe preform & - & - & - & - & 11 & 9 & - & - & - & 1 & 21 \\
\hline \multicolumn{12}{|l|}{ used water-worn pebbles } \\
\hline active abrading stone & - & - & - & - & - & 8 & 3 & 1 & - & 1 & 13 \\
\hline polishing stone & - & - & - & - & - & 5 & - & 6 & - & 2 & 13 \\
\hline possible polishing stone & - & - & - & - & - & 4 & - & 14 & - & 9 & 27 \\
\hline possible manos/metate & - & - & - & - & - & 1 & - & - & - & - & 1 \\
\hline \multicolumn{12}{|l|}{ other used rock } \\
\hline active abrading stone & - & - & - & - & 5 & - & - & - & - & - & 5 \\
\hline other abrading stone & - & - & - & - & - & 1 & - & - & - & - & 1 \\
\hline pestle & - & - & - & - & 1 & - & - & - & - & - & 1 \\
\hline \multicolumn{12}{|l|}{ non-used water-worn pebbles } \\
\hline non-modified water-worn pebble & - & - & - & - & - & 49 & 6 & 18 & - & 12 & 85 \\
\hline \multicolumn{12}{|l|}{ other rock } \\
\hline
\end{tabular}

Table F.30. Anse des Pères, St. Martin. Number of lithic artefacts by raw material by artefact type.

\section{F.11 St. Martin}

\section{F.11.1 Anse des Pères}

Anse des Pères represents a late Saladoid habitation site situated along a cobble beach on the western coast of St. Martin between Marigot and Grande Case (see figure 3.5). A site survey, as part of Master's research work, showed that to the north of a small stream, called Ravine du Colombier, archaeological material was scattered over an area of approximately 15000 $\mathrm{m}^{2}$ including dense midden deposits (Knippenberg 1999b; Knippenberg et al. 1999). The pottery is exclusively attributed to the Cedrosan Saladoid subseries (Hamburg 1999) and ${ }^{14} \mathrm{C}$ samples produced calibrated dates between AD 750 and 950 , making it the latest Saladoid site in the region and marking the end of the Early Ceramic B phase (Knippenberg 1999b). The site is interpreted as a habitation site, where people settled during a single continuous occupation, which may have lasted around 100 years.

Only a previously analysed lithic sample from the Anse des Pères site is included in the present research (Knippenberg 1999c). It includes 906 lithic artefacts, which originated from seven randomly chosen test-units within a dense midden area (table F.30). These units were excavated in $10 \mathrm{~cm}$ levels using $10 \mathrm{~mm}$ mesh-screens (Knippenberg 1999b, 87). 
I studied this sample prior to beginning of my $\mathrm{PhD}$ research, and therefore, I used a different analysis procedure, which was described in my Master's thesis (Knippenberg 1995). In addition to this sample from the test-units, I analysed 300 artefacts from 127 systematically excavated shovel tests and 21 artefacts from haphazard surface collecting. These additional artefacts are not dealt with in the present quantitative analysis, but are mentioned in the case of rare artefact types. The materials identified include flint and chert varieties, St. Martin greenstone, jasper ${ }^{2}$, quartz, igneous rock varieties, plutonic rock, sandstone, and red ochre. The flint and chert varieties include both true flints and (bedded) cherts.

\section{F.12 Anguilla}

Samples from three sites on the island of Anguilla were chosen for a detailed technological study. These are Sandy Ground, Barnes Bay, and Shoal Bay East (see figure 3.4). Along with the Sandy Hill and Forest North sites they formed the subject of a PhD dissertation written by John Crock, at the University of Pittsburgh (Crock 2000).

\section{F.12.1 Sandy Ground}

Sandy Ground is one of the largest and first settled sites on Anguilla, situated at Road Bay along its northern coast (Crock 2000). This bay is protected from eastern tropical storms and provides a relatively deep anchorage. These optimal characteristics probably formed one of the reasons that this site is one of the first settled on Anguilla. It is estimated to cover an area of at least $75000 \mathrm{~m}^{2}$. Radiocarbon samples have provided calibrated dates that fall within $95 \%$ range from AD 610 till AD 1390, corresponding with the later part of the Early Ceramic B and the following Late Ceramic A phases. Crock considers the occupation to be continuous. Furthermore, he characterizes the ceramics as early Post-Saladoid, to some degree resembling the Mill Reef style. Typical late Saladoid or late Post-Saladoid ceramics were not found within the testexcavations, but are known in small quantities from the earlier survey work performed by the Anguilla Archaeological and Historical Society (AAHS) (Crock 2000, 59-94; see Crock \& Petersen 1999).

A sample of 789 lithic artefacts was analysed for Sandy Ground (table F.31). This sample originated from a single 1 x $3 \mathrm{~m}$ test-unit (N482 E281). It was excavated in arbitrarily $10 \mathrm{~cm}$ levels within natural stratigraphy using $3.2 \mathrm{~mm}(1 / 8 \mathrm{inch})$ and $6.4 \mathrm{~mm}(1 / 4 \mathrm{inch})$ mesh-screens. This large unit was subdivided into three $1 \mathrm{x} 1 \mathrm{~m}$ squares, of which only in the two western squares a $0.5 \times 0.5 \mathrm{~m}$ quadrant was reserved for fine screening $(3.2 \mathrm{~mm}$ ) (for description of all artefact categories, see Crock 2000, 68-91). Both mesh-size residues were studied. The materials identified include flint, St. Martin greenstone, quartz, calcite, limestone, calci-rudite, igneous rock, and fine-grained rock.

\footnotetext{
${ }^{2}$ In the 1995 and 1999 reports, this material is called red stone.
} 


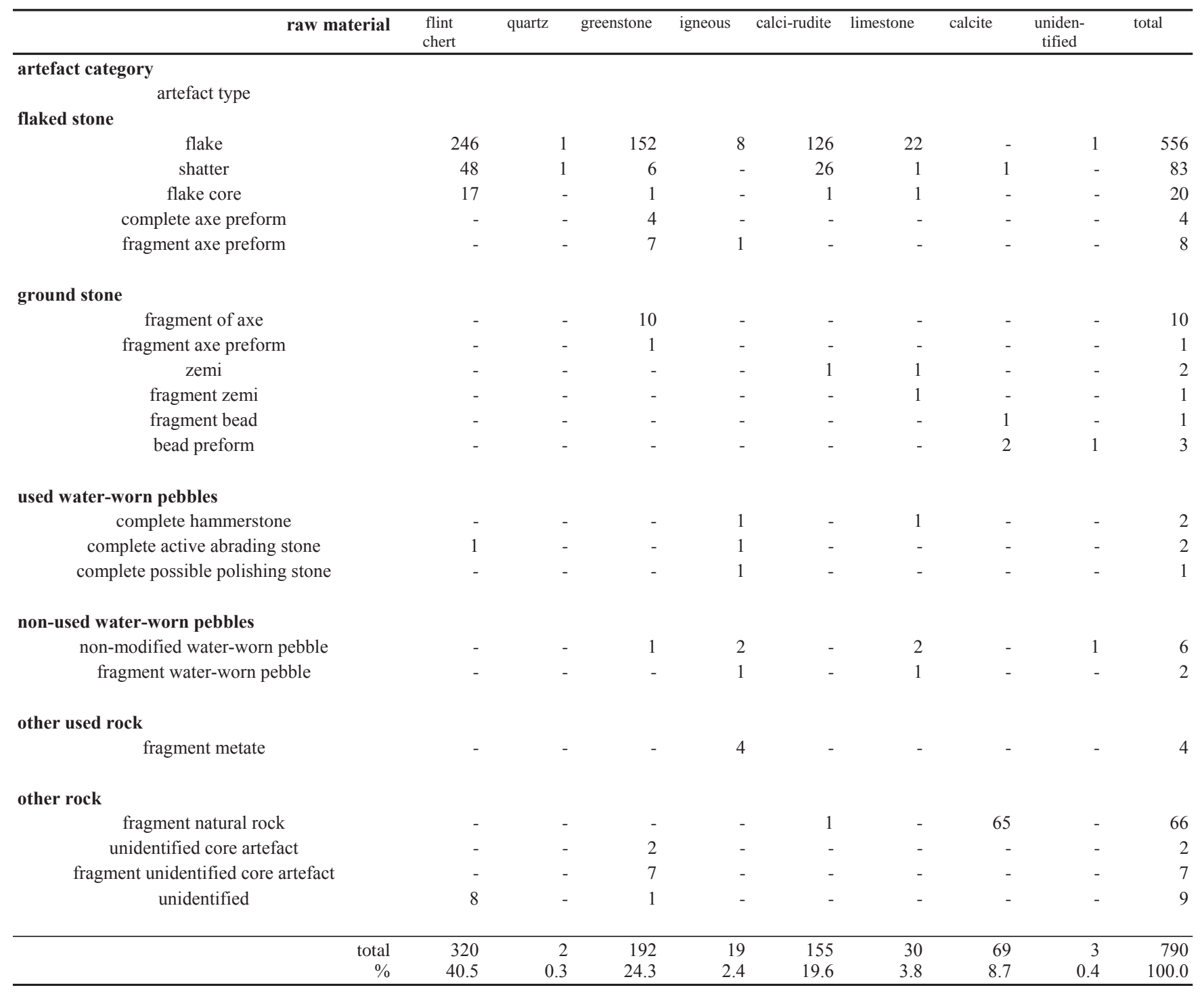

Table F.31. Sandy Ground, Anguilla. Number of lithic artefacts by raw material by artefact type. 


\begin{tabular}{|c|c|c|c|c|c|c|c|c|c|}
\hline raw material & $\begin{array}{l}\text { flint } \\
\text { chert }\end{array}$ & greenstone & $\begin{array}{l}\text { igneous } \\
\text { rock }\end{array}$ & $\begin{array}{l}\text { fine-grained } \\
\text { rock }\end{array}$ & calci-rudite & limestone & calcite & $\begin{array}{l}\text { unidentified } \\
\text { rock }\end{array}$ & total \\
\hline \multicolumn{10}{|l|}{ artefact type } \\
\hline flake & 316 & 88 & 11 & 1 & 73 & 31 & 1 & 4 & 525 \\
\hline shatter & 80 & 1 & 1 & - & 11 & 1 & 21 & - & 115 \\
\hline flake core & 18 & - & - & - & - & 1 & - & - & 19 \\
\hline fragment axe preform & - & 9 & - & - & - & - & - & - & 9 \\
\hline zemi preform & - & - & - & - & 1 & - & - & - & 1 \\
\hline \multicolumn{10}{|l|}{ ground stone } \\
\hline fragment of axe & - & 3 & 1 & - & - & - & - & - & 4 \\
\hline \multicolumn{10}{|l|}{ used water-worn pebbles } \\
\hline complete hammerstone & - & 1 & - & - & - & 2 & - & - & 3 \\
\hline fragment hammerstone & - & - & 1 & - & - & - & - & - & 1 \\
\hline fragment metate & - & - & - & - & - & 1 & - & - & 1 \\
\hline \multicolumn{10}{|l|}{ non-used water-worn pebbles } \\
\hline non-modified water-worn pebble & - & 3 & 4 & - & - & 6 & - & - & 13 \\
\hline fragment water-worn pebble & - & - & - & - & - & 1 & - & - & 1 \\
\hline \multicolumn{10}{|l|}{ other used rock } \\
\hline fragment manos & - & - & - & - & - & - & - & 1 & 1 \\
\hline fragment metate & - & - & 8 & - & - & - & - & - & 8 \\
\hline \multicolumn{10}{|l|}{ other rock } \\
\hline$\%$ & 49.5 & 12.9 & 3.2 & 0.2 & 10.1 & 5.3 & 17.8 & 0.9 & 100.0 \\
\hline
\end{tabular}

Table F.32. Barnes Bay, Anguila. Number of lithic artefacts by raw material by artefact type.

\section{F.12.2 Barnes Bay}

The settlement site of Barnes Bay is located on the western portion of Anguilla's northern coast, just inland between Barnes Bay and Mead's Bay. Threatened by destruction as a result of the expansion of the Cocoloba/Metaresort hotel, archaeological fieldwork was undertaken there in 1996. The size dimensions are not reported for this site. The calibrated radio-carbon dates suggest occupation between AD 775 and AD 1320, placing this site within the Late Ceramic A phase. The ceramics are largely attributed to the early Post-Saladoid style, possessing many similarities with the Mill Reef style from Antigua (Crock 2000, 124-160).

A sample of 850 lithic artefacts was analysed from Barnes Bay, including both residue samples from 6.4 (1/4 inch) and $3.2 \mathrm{~mm}$ (1/8 inch) mesh screens (table F.32). This sample originated from two 2 x $2 \mathrm{~m}$ test units: N401E418 and N402E423. Within each test unit, two one metre squares were chosen for analysis. These are the squares N400E417 and N401E418 from the former unit, and N401E422 and N402E423 from the latter. All squares were systematically excavated in arbitrarily $10 \mathrm{~cm}$ levels within natural stratigraphy. During the excavation of N400E417 and N401E422, only $6.4 \mathrm{~mm}$ mesh screens were used, whereas within the other two units, a $0.5 \times 0.5 \mathrm{~m}$ sample square was reserved for fine mesh screening 


\begin{tabular}{|c|c|c|c|c|c|c|c|c|c|}
\hline raw material & $\begin{array}{l}\text { flint } \\
\text { chert }\end{array}$ & greenstone & $\begin{array}{l}\text { igneous } \\
\text { rock }\end{array}$ & $\begin{array}{c}\text { meta- } \\
\text { morphic } \\
\text { rock }\end{array}$ & limestone & calcite & red ochre & $\begin{array}{l}\text { uniden- } \\
\text { tified rock }\end{array}$ & total \\
\hline \multicolumn{10}{|l|}{ artefact category } \\
\hline \multicolumn{10}{|l|}{ flaked stone } \\
\hline flake & 20 & 195 & 1 & - & 6 & 4 & - & - & 226 \\
\hline shatter & 10 & 3 & - & - & - & - & - & 1 & 14 \\
\hline \multicolumn{10}{|l|}{ ground stone } \\
\hline fragment of axe & - & 1 & - & - & - & - & - & - & 1 \\
\hline bead preform & - & - & - & 1 & - & - & - & - & 1 \\
\hline natural rock & - & - & - & - & - & 2 & - & - & 2 \\
\hline fragment natural rock & - & - & - & - & - & 41 & 1 & - & 42 \\
\hline fragment unidentified core artefact & - & - & - & - & 1 & - & - & - & 1 \\
\hline unidentified & 1 & - & - & - & - & - & - & - & 1 \\
\hline total & 31 & 206 & 2 & 1 & 7 & 48 & 1 & 1 & 297 \\
\hline$\%$ & 10.4 & 69.4 & $0 . \overline{7}$ & 0.3 & 2.4 & 16.2 & 0.3 & 0.3 & 100.0 \\
\hline
\end{tabular}

Table F.33. Shoal Bay East, Anguilla. Number of lithic artefacts by raw material by artefact type.

(Crock 2000, 128). The materials include flint, chert, St. Martin greenstone, calci-rudite, calcite, limestone, igneous rock, and unidentified fine-grained rock.

\section{F.12.3 Shoal Bay East}

The large settlement site of Shoal Bay East is situated along Anguilla's northeastern coast, to the west of Island Harbour. Along with Rendezvous Bay, Sandy Ground, and Sandy Hill, it represents one of the earliest sites on the island. Testexcavations in sandy near-beach environments revealed clearly separated occupation levels, covering an extensive period of Amerindian prehistory. The oldest date was obtained from a small test-unit situated more inland. It gave a calibrated age between AD 655 and AD 850 (95\% confidence level) (Crock 2000). From one test-unit excavated within the near beach environment, several charcoal samples and one kaolin pipe fragment provided dates that covered a period from AD 1000 till AD 1800. Main Amerindian occupation on this site is dated between AD 1000 and AD 1400. The ceramics from the excavations exclusively display Post-Saladoid traits. Only rare finds within the AAHS collection can be considered Saladoid, and support the early date from the test-pit, which did not yield any diagnostic finds, however (Crock 2000).

A sample of 297 lithic artefacts was analysed from Shoal Bay East (table F.33). This sample was obtained during the excavation of a single $2 \times 1 \mathrm{~m}$ test unit, N558E467. This unit was excavated in arbitrary $10 \mathrm{~cm}$ levels within natural stratigraphy, using a $6.4 \mathrm{~mm}(1 / 4 \mathrm{inch})$ mesh screen. Only from certain levels (corresponding to dense artefact deposits) 0.5 x $0.5 \mathrm{~m}$ sample squares were sieved through a $3.2 \mathrm{~mm}(1 / 8 \mathrm{inch})$ screen. The analysed sample comprises 297 artefacts. Identified materials include flint, chert, St. Martin greenstone, calcite, limestone, igneous rock, metamorphic rock, and red ochre. 


\section{F.13 VIEQUES}

\section{F.13.1 Sorcé}

The Sorcé site actually forms part of the multi-component settlement called La Hueca/Sorcé, where Luis Chanlatte Baik and Yvonne Narganes Storde, from the University of Rio Piedras have performed excavations over the last 30 years. Sorcé is situated around $150 \mathrm{~m}$ from the south coast near Puerto Real in the middle of the island of Vieques and extends over an area of approximately $60000 \mathrm{~m}^{2}$ (see figure 3.3). The long-term excavation project has mapped 20 mounded areas where high concentrations of archaeological material were found, interpreted as refuse dumps belonging to Amerindian settlements. In all 20 areas, systematic test-unit excavations were performed to collect samples of material remains to place the site in the regional cultural chronology. Based upon the presence of two different ceramic styles, the excavators distinguished two components within the site area: (1) The La Hueca component, which corresponds to the deposits yielding La Hueca style ceramics, basically situated in the western part of the site area; and (2) the Sorcé component, which corresponds to the deposits yielding Cedrosan Saladoid ceramics, more or less limited to the eastern area (Chanlatte Baik 1984; Narganes Storde 1991).

From the excavated mounds I chose the YTA-2 one (Narganes Storde 1991), belonging to the Sorcé component of the site, for my sample. The reasons for selecting this deposit were its relatively high artefact content and its small temporal variation based on radiocarbon dates. The calibrated dates fall between AD 135 and 620, placing it within the Early Ceramic A phase. In total, seventeen 2 × 2 m test units were chosen haphazardly from the 1980 field season, including the five units from which radiocarbon dates were obtained. All excavations were conducted according to the same procedure. Test units were excavated in arbitrarily layers of $20 \mathrm{~cm}$ each and dirt was dry sieved through a $6.4 \mathrm{~mm}(1 / 4 \mathrm{inch})$ mesh screen.

The total number of artefacts studied comprises 1018 lithic specimens (table F.34). This does not represent the entire lithic sample from these units, as artefacts associated with the lapidary industry were analysed earlier by Yvonne Narganes Storde (1995) and therefore, left out of the present study. Despite possible temporal variation within the YTA-2 refuse area, this sample has been treated as one entity with no temporal distinctions being made. This lumping is justified by the small raw material variation between units and levels in this site area.

Materials include a number of flint and chert varieties, different types of igneous rocks, quartz, jasper, St. Martin greenstone, limestone, sandstone, silicified rock, plutonic rock, metamorphic rock, red ochre, fine grained sedimentary rock, and different varieties of semi-precious stone. 


\begin{tabular}{|c|c|c|c|c|c|c|c|c|c|c|c|c|c|c|c|}
\hline raw material & $\begin{array}{l}\text { flint } \\
\text { chert }\end{array}$ & quartz & $\begin{array}{l}\text { green- } \\
\text { stone }\end{array}$ & $\begin{array}{l}\text { other } \\
\text { green } \\
\text { rock }\end{array}$ & pumice & $\begin{array}{l}\text { lime- } \\
\text { stone }\end{array}$ & $\begin{array}{l}\text { sand- } \\
\text { stone }\end{array}$ & $\begin{array}{c}\text { igneous } \\
\text { rock }\end{array}$ & $\begin{array}{c}\text { plutonic } \\
\text { rock }\end{array}$ & $\begin{array}{l}\text { meta- } \\
\text { mor- } \\
\text { phic } \\
\text { rock }\end{array}$ & $\begin{array}{c}\text { semi- } \\
\text { precious } \\
\text { stone }\end{array}$ & $\begin{array}{c}\text { fine- } \\
\text { grained } \\
\text { rock }\end{array}$ & $\begin{array}{l}\text { red } \\
\text { ochre }\end{array}$ & $\begin{array}{l}\text { uniden- } \\
\text { tified } \\
\text { rock }\end{array}$ & total \\
\hline
\end{tabular}

artefact category

artefact type

flaked stone

flake
shatter

flake core

water-worn pebble with flake scar

flaked piece

ground stone

axe

fragment of axe

adze

fragment of an adze

fragment of an axe/adze: edge flake

complete axe preform

fragment axe preform

adze preform

\section{used water-worn pebbles}

complete hammerstone

fragment hammerstone

complete hammerstone anvil

fragment hammerstone anvil

fragment anvil

active abrading stone

polishing stone

non-used water-worn pebbles

non-modified water-worn pebble

fragment water-worn pebble

\section{other used rock}

complete active abrading stone

fragment active abrading stone

\section{other rock}

natural rock

fragment natural rock

unidentified core artefact

fragment unidentified core artefact

unidentified

\begin{tabular}{|c|c|c|c|c|c|c|c|c|c|c|c|c|c|c|}
\hline 197 & 108 & - & 19 & 1 & - & - & 14 & - & 4 & - & 6 & - & 4 & 353 \\
\hline 32 & 30 & - & - & - & - & - & 1 & - & 1 & - & - & - & 2 & 66 \\
\hline 31 & 75 & - & - & - & - & - & - & - & - & - & - & - & - & 106 \\
\hline- & - & - & - & - & - & - & 2 & - & - & - & 1 & - & 1 & 4 \\
\hline- & - & - & - & - & - & - & 1 & - & - & - & 1 & - & - & ? \\
\hline
\end{tabular}




\section{References}

Alegría, R.E. 1983. Ball courts and ceremonial plazas in the West Indies. Yale University Publications in Anthropology 79, New Haven.

Allaire, L. 1983. Changements lithiques dans l'archéologie de la Martinique. Proceedings of the Tenth International Congress for the Study of the Pre-Columbian Cultures of the Lesser Antilles, 299-310.

Allaire, L. 1997. Anse Trabaud: rapport 1997. In, J.P. Giraud (ed.), Le néolithique de la Martinique dans son contexte antillais. (Projet collectif de recherche) SRA Fort de France, Martinique.

Allen, J. 1985. Comments on complexity and trade: a view from Melanesia. Archaeology in Oceania 20, 49-57.

Alminas, H.V., E.E. Foord \& R.E. Tucker 1994. Geochemistry, mineralogy, and geochronology of the U.S. Virgin Islands. U.S. Geological Survey Bulletin 2057. United States Government Printing Office, Washington.

Amick, D.A. \& R.P. Mauldin 1989. Comments on Sullivan and Rozen's “Debitage Analysis and Archaeological Interpretation”. American Antiquity 54, 166-168.

Amick, D.A. \& R.P. Mauldin 1997. Effects of raw material flake breakage patterns. Lithic Technology 22, 18-32.

Amick, D.A., R.P. Mauldin \& S.A. Tomka 1988. An evaluation of debitage produced by experimental bifacial core reduction of a Georgetown chert nodule. Lithic Technology 17, 26-36.

Ammerman, A.J. \& W. Andrefsky, Jr. 1982. Reduction sequences and the exchange of obsidian in Neolithic Calabria. In J.E. Ericson \& T.K. Earle (eds.), Contexts for prehistoric exchange. Academic Press, New York, 149-172.

Andrefsky, W. Jr. 1998. Lithics. Macroscopic approaches to analysis. (Cambridge manuals in archaeology) Cambridge University Press, Cambridge.

Andreieff, P., P. Bouysse \& D. Westercamp 1983. Révision géologique de l'île de Marie-Galante (Petites Antilles). Bulletin de la Société Géologique de France 25, 805-810.

Armstrong, D.V. 1978. Archaic shellfish gatherers of St. Kitts, Leeward Islands: A case study in subsistence and settlement patterns. (Unpublished Master's thesis) University of California, Los Angeles.

Armstrong, D.V. 1980. Shellfish gatherers of St. Kitts: a study of archaic subsistence and settlement patterns. Proceedings of the Eightth International Congress for the Study of the Pre-Columbian Cultures of the Lesser Antilles, 152-167.

Arts, J. 1999. Morel I revisited. A study of Huecan and Cedrosan Saladoid ceramics found at the site of Morel, Guadeloupe, French West Indies. (Unpublished Master's thesis) Leiden University, Leiden.

Aspinall, A. \& S.W. Feather 1972. Neutron activation analyses of prehistoric flint mine products. Archaeometry 14, 41-53.

Baker, P.E. 1968. Petrology of Mt. Misery Volcano, St. Kitts, West Indies. Lithos 1, 124-150.

Baker, P.E. 1980. Geology and geochemistry of the Mansion pyroclast fall succession, St. Kitts. Bulletin of Volcanology 43, $303-310$.

Baker, P.E. 1984. Geochemical evolution of St. Kitts and Montserrat, Lesser Antilles. Journal of the Geological Society of London 141, $401-411$.

Baldwin, S.L., T.M. Harrison \& K. Burke 1986. Fission track evidence for the source of accreted sandstones, Barbados. Tectonics 5, 457468

Barbotin, Père M. 1973. Haches de Marie-Galante. Proceedings of the Fourth International Congress for the Study of the Pre-Columbian Cultures of the Lesser Antilles, 140-151. 
REFERENCES

Barbotin, Père M. 1973. Tentative d'explication de la forme et du volume des haches Precolombiennes de Marie-Galante et quelques autres pierres. Proceedings of the Fourth International Congress for the Study of Precolumbian Cultures of the Lesser Antilles, 140-150.

Bartone, R.N. \& J.G. Crock 1993. Flaked stone industry at the early Saladoid Trants site, Montserrat, West Indies. Proceedings of the Fourteenth International Congress for Caribbean Archaeology, 124-146.

Bazelmans, J. 1996. Eén voor allen, allen voor één. (Unpublished Ph.D. dissertation) University of Amsterdam, Amsterdam.

Bérard, B. 1997. Nature et Fonction de l'outillage de pierre taillée. In J.P. Giraud (ed.), Le néolithique de la Martinique dans son contexte antillais. (Projet collectif de recherche) SRA Fort de France, Martinique.

Bérard, B. 1998. De l'occupation preceramique de la Martinique. Paper presented at 123ème congrès national des sociétés historiques et scientifiques, "Archéologie et peuplement des milieux insulaires”, Fort de France, Martinique.

Bérard, B. 1999. Gestion de materias primas silicosas y organisacion del territorio de los Amerindios de Martinica. Paper presented at "Seminario Regional sobre las Culturas Aborigenes del Caribe, FISS", Santo Domingo.

Bérard, B. 2001. Technologie lithique et caractérisation culturelle: l'exemple de l'occupation amérindienne de la Martinique. Proceedings of the Eighteenth International Congress for Caribbean Archaeology (1), 175-184.

Bérard, B. 2004. Les premières occupations agricoles de l'arc antillais, migration et insularité. Le cas de l'occupation saladoïde ancienne de la Martinique. British Archaeological Reports International Series 1299, Paris Monographs in American Archaeology 15.

Bérard, B. \& J.P. Giraud 1998. Le site Vive au Lorrain (Martinique) et les premieres establissements Saladoïdes de la Martinique. Paper presented at 123ème congrès national des sociétés historiques et scientifiques, "Archéologie et peuplement des milieux insulaires", Fort de France, Martinique.

Bérard, B. \& G. Vernet 1997. La Savane des Pétrifications, Sainte Anne. Opération de fouille programmée, AFAN. (Document final de synthèse) Service Regional de l'Archéologie, Fort de France, Martinique.

Bérard, B. \& G. Vernet 1999. Nature et fonction de l'outillage de pierre taillée. In J.P. Giraud (ed.), Le néolithique de la Martinique dans son contexte antillais. (Projet collectif de recherche) SRA Fort de France, Martinique, 40-56

Berman, M.J. 1995. A chert microlithic assemblage from an early Lucayan site on San Salvador, Bahamas. Proceedings of the Fifteenth International Congress for Caribbean Archaeology, 111-119.

Berman, M.J., A.K. Sievert \& T.R. Whyte 1999. Form and function of bipolar lithic artifacts from the Three Dog Site, San Salvador, Bahamas. Latin American Antiquity 10, 415-432.

Berman, M.J., A.K. Sievert \& T.R. Whyte 2000. An analysis of stone tools from the Three Dog Site, San Salvador. Bahamas Journal of Science 8, 2-15.

Blatt, H. 1992. Sedimentary Petrology. (2 ${ }^{\text {nd }}$ edition) Freeman and Company, New York.

Bodu, P. 1984. Deux ateliers de debitage de roches locales en Désirade. (Unpublished report) Guadeloupe.

Bodu, P. 1985. Rapport de fouille, Les Sables, Beauséjour, Désirade. (Unpublished report) Moule, Guadeloupe.

Bonneton, J.R. \& J.M. Vila 1983. Données géologiques à l'île de Saint-Martin (Petites Antilles). Bulletin de la Société Géologique de France $25,867-871$.

Boomert, A. 1979. The prehistoric stone axes of the guianas: a typological classification. Journal of Archaeology and Anthropology 2, 99-124.

Boomert, A. 1987. Gifts of the Amazons:"Greenstone" Pendants and Beads as items of ceremonial exchange in Amazonia and the Caribbean. Anthropologicia 67, 33-54. 
REFERENCES

Boomert, A. 2000. Trinidad, Tobago and the Lower Orinoco Interaction Sphere. (Ph.D. dissertation) Alkmaar.

Boomert, A. 2001a. Saladoid socio-political organisation. Proceedings of the Eighteenth International Congress for Caribbean Archaeology (2), $55-77$.

Boomert, A. 2001b. Raptorial birds as icons of shamanism in the prehistoric Caribbean and Amazonia. Proceedings of the Nineteenth International Congress for Caribbean Archaeology (2), 121-157.

Boomsma, E.A. \& A.J.D. Isendoorn 2001. Caribbean explorations. Prospections of two archaeological sites in the Guadeloupean archipelago: Cocoyer St. Charles and Anse à l'Eau. (Unpublished Master's thesis) Leiden University, Leiden.

Bouysse, P., R. Schmidt-Effing \& D. Westercamp 1983. La Desirade Island (Lesser Antilles) revisited: Lower Cretaceous radiolarian cherts and arguments against an ophiolitic origin for the basalt complex. Geology 11, 244-247.

Bradburry, A.P. \& P.J. Carr 1995. Flake typologies and alternative approaches: an experimental assessment. Lithic Technology $20,100-115$.

Branch, C.W. 1907. Aboriginal antiquities of St. Kitts and Nevis. American Anthropologist 9, 315-333

Brasier, M.D. \& J.D. Mather 1975. The stratigraphy of Barbuda, West Indies. Geological Magazine 112, 271-282.

Breton, Père R. 1978. Relations de l’ile de la Guadeloupe. tome I. (Bibliothèque d'Histoire Antillaise no.3) Basse Terre, Guadeloupe.

Brokke, A.J. 1996. Shells, past to present: shellfish gathering at Norman Estate and Anse des Pères. (Unpublished Master's thesis) Leiden University, Leiden.

Brokke, A.J. 1999a. Anse des Pères. Shell. In C.L. Hofman \& M.L.P. Hoogland (eds.), Archaeological investigations on St. Martin (Lesser Antilles). The sites of Norman Estate, Anse des Pères, and Hope Estate with a contribution to the 'La Hueca problem'. Archaeological Studies Leiden University 4, 105-110.

Brokke, A.J. 1999b. Norman Estate. Shell. In C.L. Hofman \& M.L.P. Hoogland (eds.), Archaeological investigations on St. Martin (Lesser Antilles). The sites of Norman Estate, Anse des Pères, and Hope Estate with a contribution to the 'La Hueca problem'. Archaeological Studies Leiden University 4, 47-50.

Brownlow, A.H. 1979. Geochemistry. Prentice-Hall. Englewood Cliffs, New Jersey.

Brumfiel, E.M. \& T.K. Earle 1987. Specialization, exchange, and complex societies: an introduction. In E.M. Brumfiel \& T.K. Earle, Specialization, exchange and complex societies. Cambridge University Press, Cambridge, 1-9.

Bullen, R.P. \& A.K. Bullen 1973. Stratigraphic tests at two sites on Guadeloupe. Proceedings of the Fourth In ternational Congress for the Study of Pre-columbian Cultures of the Lesser Antilles, 192-196.

Burton, J.P. 1984. Quarrying in a tribal society. World Archaeology 16, 234-247.

Burton, J.P. 1989. Repang and the salt-makers: ‘ecological trade' and stone axe production in Papua New Guinea Highlands. Man 24, 255272.

Bush, P.R. \& G. de G. Sieveking 1986. Geochemistry and the provenance of flint axes. In G. de G. Sieveking \& M.B. Hart (eds.), The scientific study of flint and chert. (Proceedings of the Fourth International Flint Symposium). Cambridge University Press, Cambridge, 133-140.

Butt Colson, A.J. 1973. Inter-tribal trade in the Guiana Highlands. Antropologica 34, 1-70.

Cackler, P.R., M.D. Glascock, H. Neff \& B.M. Chiarulli 1999a. Effects of weathering on the coloration of chert and its implications for provenance studies. Lithic Technology 24, 81-90.

Cackler, P.R., M.D. Glascock, H. Neff, H. Iceland, K.A. Pyburn, D. Hudler, T.R. Hester \& B.M. Chiarulli 1999b. Chipped stone artefacts, source areas, and provenance studies of the Northern Belize chert-bearing zone. Journal of Archaeological Science 26, $389-397$. 
REFERENCES

Carneiro, R.L. 1981. The chiefdom: precursor of the state. In G.D. Jones \& R.R. Kautz (eds.), The transition to statehood in the New World. Cambridge University Press, Cambridge, 37-79.

Carneiro, R.L. 1998. What happened at the flashpoint? Conjectures on Chiefdom Formation at the very moment of conception. In E.M. Redmond (ed.), Chiefdoms and chieftaincy in the Americas. University Press of Florida, Gainesville, 18-42.

Case, J.E. \& G. Dengo 1982. The Caribbean region. In A.R. Palmer (ed), Perspectives in regional geological synthesis: planning for the geology of North America. Geological Society of America DNAG Special Publication 1, 163-170

Case, J.E., W.D. MacDonald \& P.J. Fox 1990. Caribbean crustal provinces: seismitic and gravity evidence. In G. Dengo \& J.E. Case (eds.), The geology of North America. Volume H. The Caribbean region. Geological Society of America, Boulder, 15-36.

Chagnon, A. 1972. Yanomamo, the fierce people. Holt, Rinehart and Winston, New York.

Chanlatte Baik, L.A. 1984. Arqueología de Vieques. Centro de investigationes arqueologicas, Universidad de Puerto Rico Recinto de Rio Piedras.

Chanlatte Baik, L.A. \& Y.M. Narganes Storde 1989. La nueva arqueologia de Puerto Rico. Museo del Hombre Dominicano $22,9-51$.

Chanlatte Baik, L.A. \& Y.M. Narganes Storde 1990. La nueva arqueologia de Puerto Rico. Puerto Rico

Chapman, A. 1980. Barter as a universal mode of exchange. L'Homme 20 (3), 33-83.

Chauviere, F.X. 1998. Les industries lithiques de Hope Estate. Fouilles 1997. (Unpublished report) France.

Chernela, J.M. 1992. Social meaning and Material transaction: The Wakano-Tukano of Brazil and Colombia. Journal of Anthropological Archaeology 11, 111-124.

Christman, R.A. 1953. Geology of St. Bartholomew, St. Maarten and Anguilla. Bulletin of the Geological Society of America 64, 65-96.

Christman, R.A. 1972. Volcanic geology of Southwestern Antigua, B.W.I. Geological Society of America Memoir 132, $439-448$.

Church, T. 1994. Lithic resource studies. A source book for archaeologists. (Lithic Technology Special publication 3) University of Tulsa, Oklahoma.

Clayton, C.J. 1986. The chemical environment of flint formation in Upper Cretaceous chalks. In G. de G. Sieveking \& M.B. Hart (eds.), The scientific study of flint and chert. (Proceedings of the Fourth International Flint Symposium). Cambridge University Press, Cambridge, 43-54.

Clerc, E. 1964. Le peuplement précolombien des Antilles et ses vestiges en Guadeloupe. Bulletin de la Société d’Histoire de la Guadeloupe 2.

Clerc, E. 1968. Sites Précolombiens de la Côte nord-est de la Grande Terre de Guadeloupe. Proceedings of the Second International Congress for the Study of Pre-Columbian Cultures of the Lesser Antilles, 47-60.

Clerc, E. 1970. Recherces Archéologiques en Guadeloupe. L’Archéologie Précolombienne aux Antilles Françaises 36-37, (Parallèles, 3 et 4eme trimester), 68-88.

Cobb, C.R. 2000. From quarry to cornfield: the political economy of Mississippian hoe production. The University of Alabama Press, Tuscaloosa.

Cody, A.K. 1991. Prehistoric patterns of exchange in the Lesser Antilles: materials, models, preliminary observations. (Unpublished Master's thesis) San Diego University, San Diego.

Cody, A.K. 1993. Distribution of exotic stone artifacts through the Lesser Antilles: their implications for prehistoric interaction and exchange. Proceedings of the Fourteenth International Congress for Caribbean Archaeology, 204-225.

Collins, M.B. 1975. Lithic technology as a means of processual Inference. In E. Swanson (ed.), Lithic Technology. Mouton Publishers, The 
REFERENCES

Hague, 15-34.

Cowell, M.R. 1981. The archaeological and geochemical implications of trace elements distributions in some English, Dutch and Belgium flints.

In F.G.H. Engelsen (ed.) Third International Symposium on flint. Staringia 6, 81-84.

Craddock, P.T., M.R. Cowell, M.N. Leese \& M.J. Hughes 1983. The trace element composition of polished flint axes as indicator of source. Archaeometry 25, 135-163.

Crock, J.G. 1999. The Forest North site and post-Saladoid settlement in Anguilla. Proceedings of the Sixteenth International Congress for Caribbean Archaeology, 74-87.

Crock, J.G. 2000. Interisland interaction and the development of chiefdoms in the eastern Caribbean. (Unpublished Ph.D. dissertation)

University of Pittsburgh, Pittsburgh.

Crock, J.G. \& Bartone, R.N. 1998. Archaeology of Trants, Montserrat. Part 4. Flaked stone and stone bead industries. Annals of Carnegie Museum 67, 197-224.

Crock, J.G. \& J.B. Petersen 1999. A long and rich cultural heritage: the Anguilla archaeological project, 1992-1998. (Report prepared for the Anguilla Archaeological and Historical Society) The Valley, Anguilla.

Crock, J.G., J.B. Petersen \& N. Douglas 1995. Preceramic Anguilla: a view from the Whitehead's Bluff site. Proceedings of the Fifteenth International Congress for Caribbean Archaeology, 283-292.

Curet, L.A. 1992. The development of chiefdoms in the Greater Antilles: a regional study of the valley of Maunabo, Puerto Rico. (Unpublished Ph.D. dissertation) Arizona State University.

Curet, L.A. 1996. Ideology, chiefly power, and material culture: an example from the Greater Antilles. Latin American Antiquity 7, $114-131$.

Curet, L.A. \& J.R. Oliver 1998. Mortuary practices, social development, and ideology in Precolumbian Puerto Rico. Latin American Antiquity 9 , 217-239.

Davis, D.D. 1974. Some notes concerning the archaic occupation of Antigua. Proceedings of the Fifth International Congress for the Study of the Pre-Columbian Cultures of the Lesser Antilles, 65-71.

Davis, D.D. 1982. Archaic settlement and resource explotation in the Lesser Antilles: preliminary information of Antigua. Caribbean Journal of Science 17, 107-122.

Davis, D.D. 1993. Archaic blade production on Antigua, West Indies. American Antiquity 58, 688-697.

Davis, D.D. 2000. Jolly Beach and the preceramic occupation of Antigua, West Indies. Yale University Publications in Anthropology 84, New Haven.

De Bruin, M., P.J.M. Korthoven, C.C. Bakels \& F.C.A. Groen 1972. The use of non-destructive activation analysis and pattern recognition in the study of flint artefacts. Archaeometry 14, 55-63.

De Grooth, M.E.Th. 1991. Socio-economic aspects of neolithic flint mining: a preliminary study. Helinium 31, 153-189.

Delpuech, A. \& C.L. Hofman (eds.) 2004. Late Ceramic societies in the eastern Caribbean. British Archaeological Reports International Series 1273, Paris Monographs in American Archaeology 14.

De Mille, Ch. 1996. Analysis of the Post-Saladoid lithic assemblage, Muddy Bay (PH-14), Antigua, 1994. In A.R. Murphy, Archaeological investigations at Muddy Bay (PH-14), Antigua, West Indies: a Post-Saladoid settlement. (Unpublished Master's thesis) Trent University, Peterborough, Canada, 155-190.

De Mille, Ch. 2001. Lithic Assemblages of four ceramic sites on Antigua. Proceedings of the Eighteenth International Congress for Caribbean Archaeology (1), 225-230. 
REFERENCES

De Waal, M. 1999a. Occupations Amérindiennes dans l'Est de l'archipel Guadeloupéen. Note intermédiaire des prospections thématiques La Désirade et Petite Terre. (Unpublished report) Leiden University, Leiden.

De Waal, M. 1999b. Hope Estate. Stone tools. In C.L. Hofman \& M.L.P. Hoogland (eds.), Archaeological investigations on St. Martin (Lesser Antilles). The sites of Norman Estate, Anse des Pères, and Hope Estate with a contribution to the 'La Hueca problem'. Archaeological Studies Leiden University 4, 203-213.

De Waal, M. 2001. The Pointe Chateaux survey (1998): a preliminary report. Proceedings of the Eighteenth International Congress for Caribbean Archaeology (2), 268-276.

De Waal, M. 2002. Occupations Amérindiennes dans l'est de l'archipel Guadeloupéen. Rapport de synthèse. Tome 1. Recherches de terrain 1998-2000. (Unpublished report) Leiden University, Leiden.

De Waal, M. 2006. Pre-Columbian social organisation and interaction interpreted through the study of settlement patterns. An archaeological case-study of the Pointe des Châteaux, La Désirade and Les Îles de la Petite Terre micro-region, Guadeloupe, F.W.I. (Ph.D. dissertation) Leiden University, Leiden.

Dick, K.C., A.E. Figueredo, B. Tilden \& G.F. Tyson, Jr. 1980. Preliminary report of the first archaeological survey of Anguilla, West Indies. Journal of the Virgin Islands Society 10, 34-37.

Divale, W.T. 1984. Matrilocal residence in pre-literate society. (Studies in Cultural Anthropology 4) UMI Research Press, Ann Arbor, Michigan.

Donahue, J., D.R. Watters \& S. Millspaugh 1990. Thin section petrography of northern Lesser Antilles ceramics. Geoarchaeology 5, $229-254$.

Donnelly, T.W. 1966. Geology of St.Thomas and St. John, U.S.Virgin Islands. Geological Society of America Memoir 98, 85-176.

Donovan, S.K. \& T.A. Jackson (eds.) 1994. Caribbean Geology. An introduction. U.W.I. Publishers’ Association, Kingston.

Dorst, M. 2000. Manzanilla 1. An archaeological survey of a pre-Columbian site on Trinidad. (Unpublished Master's thesis) Leiden University, Leiden.

Dorst, M., C.L. Hofman \& A. Delpuech 2001. Méthodes et strategies de fouille. In C.L.Hofman, M.L.P. Hoogland \& A. Delpuech (eds.), Guadeloupe, Saint-François, Anse à la Gourde. Fouille programmée pluriannuelle 1995-2000. Rapport de synthèse 2000, Leiden University, 23-63.

Douglas, N. 1986. Anguilla Archaeological and Historical Society Review, 1981-1985. Anguilla Archaeological and Historical Society, The valley, Anguilla.

Douglas, N. 1991. Recent Amerindian finds on Anguilla. Proceedings of the Thirteenth International Congress for Caribbean Archaeology, 576588.

Draper, G., T.A. Jackson \& S.K. Donovan 1994. Geological provinces of the Caribbean region. In S.K. Donovan \& T.A. Jackson, Caribbean Geology. An introduction. U.W.I. Publishers' Association, Kingston, 3-12.

Drewett, P.L. 1991. Prehistoric Barbados. University College, London.

Duarte Silva, A.P. \& A. Stam 1995. Discriminant analysis. In L.G.G. Grimm \& P.R. Yarnold (eds.), Reading and understanding multivariate statistics. American Psychological Association, Washington, 277-318.

Dunham, R.J. 1962. Classification of carbonate rocks according to depositional texture. In W.E. Ham (ed.), Classification of carbonate rocks. American Association of Petroleum Geologists. Memoir 1, 108-121.

Earle, K.W. 1923. Report on the geology of Antigua. Govenrment Printing Office Leeward Islands, Antigua.

Earle, K.W. 1924. The geology of the British Virgin Islands. Geology Magazine 61, 339-351. 
REFERENCES

Earle, T.K. 1999. Production and exchange in prehistory. In G. Baker (ed.), Companions Encyclopedia of Archaeology. Routledge, London, 608635.

Ensor, H.B. and E. Roemer, jr. 1989. Comments on Sullivan and Rozen's Debitage Analysis and archaeological Interpretation. American Antiquity 54, 175-178.

Felder, W.M. \& P.W. Bosch, 1998. Vuurstenen in de St. Pietersberg. Grondboor \& Hamer 3, 65-69.

Fried, M.H. 1967. The evolution of political society. Random House, New York.

Fuess, M.T. 1995. Preliminary archaeological research of prehistoric Ameridinan sites on Antigua, Northern Lesser Antilles. Proceedings of the Fifteenth International Congress of Caribbean Archaeology, 173-180.

Fuess, M.T. 2000. Post-Saladoid age pottery in the northern Lesser Antilles: lessons learned from thin section petrography. (Unpublished Master's thesis) University of Pittsburgh, Pittsburgh.

Fuess, M.T, J.Donahue, D.R. Watters \& D. Nicholson 1993. A report on thin section petrography of the ceramics from Antigua, northern Lesser Antilles: method and theory. Proceedings of the Fourteenth International Congress for Caribbean Archaeology, 25-39.

Gardner, J.S., D.R. Watters \& J.A. Brown 2001. Conservation treatment of encrusted ceramics. Proceedings of the Eighteenth International Congress for Caribbean Archaeology (1), 75-90.

Gassies, E. 1999. Saint Barthélemy. Prospection-inventaire. In Bilan Scientifique de la région Guadeloupe 1997. Direction Régionale des Affaires Culturelles, Guadeloupe, 30-31.

Giraud, J.P. (ed.) 1997. Le néolithique de la martinique dans son contexte antillais. (Projet collectif de recherche) SRA Fort de France, Martinique.

Giraud, J.P. (ed.) 1999. Le néolithique de la martinique dans son contexte antillais. (Projet collectif de recherche) SRA Fort de France, Martinique.

Giraud, J.P., B. Bérard \& N. Vidal 1999. Le site precolombien de Vivé, Le Lourrain, Martinique. (Rapport de fouille 1998/1999) Service Regional de l'Archéologie, Fort de France, Martinique.

Glascock, M.D., G.E. Braswell \& R.H. Cobean 1998. A systematic approach to obsidian source characterisation. In M.S. Shackley (ed.), Archaeological obsidian studies. Method and theory. (Advances in Archaeological and Museum Science vol. 3) Plenum Press, New York, $15-65$.

Goodwin, R.C. 1979. The prehistoric cultural ecology of St. Kitts, West Indies: a case study in island archaeology. (Unpublished Ph.D. dissertation) Arizona State University.

Goodwin, R.C. \& J.B. Walker 1975. Villa Taina de Boqueron. Excavations of an Early Taino site in Puerto Rico. Inter American University Press. San Juan, Puerto Rico.

Grouard, S. 2002. Rapport sur les Vertébrés et les Crustacés decapods associés aux établissements post-Saladoïdes de Jumby Bay et de Sugar Mill, Long Island, Antigua. (Unpublished report) Muséum National d'Histoire Naturelle, Paris, la France.

Hamburg, T. 1999. Anse des Pères. Pottery. In C.L. Hofman \& M.L.P. Hoogland (eds.), Archaeological investigations on St. Martin (Lesser Antilles). The sites of Norman Estate, Anse des Pères, and Hope Estate. With a contribution to the 'La Hueca problem'. Archaeological Studies Leiden University 4, 73-86.

Hargett, D. 1990. Jadeite of Guatamala: a contemporary view. Gems \& Gemology 26(2), 134-141.

Harrington, M.R. 1924. A West Indian gem center. Indian notes (Museum of the American Indian, Heye Foundation, New York) 1, 184189.

Harris, P.B. O' 1983. Antillean axes/adzes: persistence of an Archaic tradidtion. Proceedings of the Ninth International Congress for the Study of 
REFERENCES

Pre-Columbian Cultures of the Lesser Antilles, 257-290.

Hauptmann, A. 1980. Feuerstein, Hornstein, Flint, Silex - eine Begriffsbestimmung. In G. Weisgerber (ed.), 5000 Jahre Feuersteinbergbau. Der Suche nach dem Stahl der Steinzeit. (Veröffentlichungen aus dem Deutschen Bergbau-Museum Bochum 22) Bochum, 7-11.

Haviser, J.B. 1987. An Archaeological excavation at the Cupecoy Bay site (SM-001), St. Maarten, Netherlands Antilles. (Report of the Archaeological and Anthropological Institute of the Netherlands Antilles No.6) Willemstad, Curaçao.

Haviser, J.B. 1988. An Archaeological survey of St. Martin- St. Maarten. (Reports of the Archaeological and Anthropological Institute of the Netherlands Antilles No.7) Willemstad, Curaçao.

Haviser, J.B. 1991. Preliminary results from test excavations at the Hope Estate Site (SM-026), St. Martin. Proceedings of the Thirteenth International Congress for Caribbean Archaeology, 647-666.

Haviser, J.B. 1991. Development of a prehistoric interaction sphere in the northern Lesser Antilles. Nieuwe West-Indische Gids 65, $129-151$.

Haviser, J.B. 1993. 1993 Lithic analysis, Hope Estate. (Unpublished report) Willemstad, Curaçao.

Haviser, J.B. 1997. Settlement strategies in the Early Ceramic age. In S.M. Wilson (ed.), The Indigeneous people of the Caribbean. University Press of Florida, Gainesville, 57-69.

Haviser, J.B. 1999. Hope Estate: Lithics. In C.L. Hofman \& M.L.P. Hoogland (eds.), Archaeological investigations on St. Martin (Lesser Antilles). The sites of Norman Estate, Anse des Pères, and Hope Estate. With a contribution to the 'La Hueca problem'. Archaeological Studies Leiden University 4, 189-202.

Hodder, I. \& C. Orton 1976. Spatial analysis in archaeology. Cambridge University Press, Cambridge.

Hoffman, Jr., C.A. 1963. Archaeological investigations on Antigua, West Indies. (Unpublished Master's thesis) University of Florida, Gainesville.

Hofman, C.L. 1993. In search of the native population of Pre-Columbian Saba, part one. (Unpublished Ph.D. dissertation) Leiden University, Leiden.

Hofman, C.L. 1995. Grande Anse, Terre-de-Bas, Guadeloupe. Rapport de fouille programmée 1995. (Unpublished report) Direction Regionale des Affaires Culturelles, Service de l'Archeologie, Guadeloupe.

Hofman, C.L. 1999. Two late prehistoric sites on la Désirade and les Saintes (Terre de Bas). Proceedings of the Sixteenth International Congress for Caribbean Archaeology, 156-167

Hofman, C.L. 1999. Hope Estate. Pottery. In C.L. Hofman \& M.L.P. Hoogland (eds.), Archaeological investigations on St. Martin (Lesser Antilles). The sites of Norman Estate, Anse des Pères, and Hope Estate with a contribution to the 'La Hueca problem'. Archaeological Studies Leiden University 4, 149-187.

Hofman, C.L. 2001. Mobilier céramique. In C.L.Hofman, M.L.P. Hoogland \& A. Delpuech (eds.), Guadeloupe, Saint-François, Anse à la Gourde. Fouille programmée pluriannuelle 1995-2000. (Rapport de synthèse 2000) Leiden University, Leiden, 155-173.

Hofman, C.L. \& M.L.P. Hoogland (eds.) 1999. Archaeological investigation on St. Martin 1993. The site of Norman Estate, Hope Estate and Anse des Pères. Archaeological Studies Leiden University 4.

Hofman, C.L. \& M.L.P. Hoogland 1999. Introduction. In C.L. Hofman \& M.L.P. Hoogland (eds.), Archaeological investigations on St. Martin (Lesser Antilles). The sites of Norman Estate, Anse des Pères, and Hope Estate with a contribution to the 'La Hueca problem'. Archaeological Studies Leiden University 4, 19-22.

Hofman, C.L. \& M.L.P. Hoogland, 2003. Plum Piece. Evidence of Archaic seasonal occupation on Saba, northern Lesser Antilles around 3300 BP. Journal of Caribbean Archaeology 4, 12-27. 
REFERENCES

Hofman, C.L. \& M.L.P. Hoogland, 2004. Social dynamics and change in Northern Lesser Antilles. In Delpuech, A. \& C.L. Hofman (eds.), Late Ceramic societies in the eastern Caribbean. British Archaeological Reports International Series 1273, Paris Monographs in American Archaeology 14, 47-58.

Hofman, C.L., M.L.P. Hoogland \& A. Delpuech 1999. New perspectives on a Huecan Saladoid assemblage on Guadeloupe: the case of Morel I. In C.L. Hofman \& M.L.P. Hoogland (eds.), Archaeological investigations on St. Martin (Lesser Antilles). The sites of Norman Estate, Anse des Pères, and Hope Estate. With a contribution to the 'La Hueca problem'. Archaeological Studies Leiden University 4, $303-312$.

Hofman, C.L., M.L.P. Hoogland \& A. Delpuech 2000. Guadeloupe, le Moule, site précolombien de Morel (no. 97117001). Fouilles archéologiques 1999. (Unpublished report) ARPAG, Basse Terre, Guadeloupe.

Hofman, C.L., M.L.P. Hoogland \& A. Delpuech (eds.) 2001b. Guadeloupe, Saint-François, Anse à la Gourde. Fouille programmée pluriannuelle 1995-2000. (Rapport de synthèse 2000) Leiden University, Leiden.

Hofman, C.L., A. Delpuech, M.L.P. Hoogland \& M. de Waal 2004. Late Ceramic Age survey of the northeastern islands of the Guadeloupen archipelago: Grande Terre, La Désirade and Petite Terre. In Delpuech, A. \& C.L. Hofman (eds.), Late Ceramic societies in the eastern Caribbean. British Archaeological Reports International Series 1273, Paris Monographs in American Archaeology 14, $159-182$.

Honeychurch, L. 1995. The Dominica Story: A history of the island. Macmillan, Basingstoke.

Honeychurch, L. 1997. Crossroads in the Caribbean: a site of encounter and exchange on Dominica. World Archaeology 28, $291-304$.

Hoogland, M.L.P. 1996. In search of the native population of Pre-Columbian Saba, part two. (Unpublished Ph.D. dissertation) Leiden University, Leiden.

Hoogland, M.P.L. 1999. Hope Estate. Method and Strategies. In C.L. Hofman \& M.P.L. Hoogland (eds.), Archaeological investigations on St. Martin (Lesser Antilles). The sites of Norman Estate, Anse des Pères, and Hope Estate. With a contribution to the 'La Hueca problem'. Archaeological Studies Leiden University 4, 129-147.

Hoogland, M.P.L. 2001. Les datations au radiocarbone. In C.L.Hofman, M.L.P. Hoogland \& A. Delpuech (eds.), Guadeloupe, Saint-François, Anse à la Gourde. Fouille programmée pluriannuelle 1995-2000. (Rapport de synthèse 2000) Leiden University, Leiden, 65-66.

Hoogland, M.P.L. \& C.L. Hofman 1999. Expansion of the Taino Cacicazgos towards the Lesser Antilles. Journal de la Société des Américanistes $85,93-113$.

Hoogland, M.P.L. \& R. Panhuysen 2001. Sépultures amérindiennes. In C.L.Hofman, M.L.P. Hoogland \& A. Delpuech (eds.), Guadeloupe, Saint-François, Anse à la Gourde. Fouille programmée pluriannuelle 1995-2000. (Rapport de synthèse 2000) Leiden University, Leiden, 73-83.

Hoopes, J.W. 1988. The complex tribe in prehistory: socio-political organization in the archaeological record. Paper presented at the 53 ${ }^{\text {rd }}$ Annual Meeting of the Society for American Archaeology.

Hughes, R.E. 1986. Diachronic variability in obsidian procurement patterns in northeastern California and southcentral Oregon. University of California Press, Berkeley.

Hutcheson, H. \& P. Callow 1986. Cores. In P. Callow \& J.M. Cronford, La Cotte de St. Brélade, Jersey. Excavations by Charles Mc. Burney 1961-1978, 240-243.

Ingbar, E.E. \& B.R. Bradley 1989. A non-typological approach to debitage analysis. In D.S. Amick \& R.P. Mauldin, Experiments in Lithic Technology. BAR International Series 528, 117-137.

Jackson, T.A. 1980. The composition and differentiation of the Volcanic rocks of Carriacou, Grenadines, West Indies. Bulletin of Volcanology 43, 311-324.

Jansen, R., R. Duin \& C.L. Hofman 2001. Faits et structures. In C.L.Hofman, M.L.P. Hoogland \& A. Delpuech (eds.), Guadeloupe, SaintFrançois, Anse à la Gourde. Fouille programmée pluriannuelle 1995-2000. (Rapport de synthèse 2000) Leiden University, Leiden, 67-72. 
REFERENCES

Johnson, G.A. 1982. Organizational structure and scalar stress. In C. Renfrew, M. Rowlands \& B. Segraves, Theory and explanation in archaeology. Academic Press, New York, 389-421.

Jones, K.L. 1984. Polynesian quarrying and flaking practices at the Samson Bay and Falls Creek argillite quarries, Tasman Bay, New Zealand. World Archaeology 16(2), 248-266.

Josselin de Jong, J.P.B. 1947. Archaeological material from Saba and St.Eustatius, Lesser Antilles. Mededelingen voor het Rijksmuseum voor Volkenkunde, No. 1, Leiden.

Kars, H., J.B.H. Jansen \& S.P. Vriend 1990. Petrography and geochemistry of flint from the Lanaye chalk (Rijkholt-St. Geertruid), and some other neolithic sources. In M.R. Séronie-Vivien \& M. Lenoir (eds.), Le silex de sa genèse à l'outil. (Actes du 5e colloque international sur le silex, Bordeaux 1987) Paris, 131-140.

Kars H, R.D. McDonnel \& J.B.H. Jansen 1993. Petrography and geochemistry of flint from six neolithic sources in southern Limburg (The Netherlands) and northern Belgium. (Unpublished typescript)

Kasper, D.C. \& D.K. Larue 1986. Paleogeographic and tectonic implications of quartzose sandstones of Barbados. Tectonics 5, 837-854.

Keegan, W.F. 1992. The people who discovered Columbus. The prehistory of the Bahamas. University Press of Florida, Gainesville.

Keegan, W.F. 1994. West Indian archaeology. 1. Overview and foragers. Journal of Archaeological Research 2, 255-284.

Keegan, W.F. 1995. Modelling dispersal in the prehistoric West Indies. World Archaeology. World Archaeology 26, 400-420.

Keegan, W.F. 1996. West Indian archaeology. 2. After Columbus. Journal of Archaeological Research 4, $265-294$.

Keegan, W.F. 1997. Haiti. Earthwatch Expedition report, July 1997. (Unpublished report) Florida Museum of Natural History, Gainesville.

Keegan, W.F. 2000. West Indian archaeology. 3. Ceramic age. Journal of Archaeological research 8, 136-169.

Keegan, W.F., M. Maclachlan \& B. Byrne 1998. Social foundations of Taino Caciques. In E.M. Redmond (ed.), Chiefdoms and chieftaincy in the Americas. University Press of Florida, Gainesville, 215-244.

Kelly, R.L. 1995. The foraging Spectrum. Smithsonian Institution Press, Washington and London.

Kelly, H. 2003. Amerindian coral tools, a pilot study in experimental archaeology on coral artefacts from Anse à la Gourde, Guadeloupe. (Unpublished Master's thesis) Leiden University, Leiden.

Kirch, P.V. 1988. Long-distance exchange and island colonization: the Lapida case. Norwegian Archaeological Review 21, $103-117$.

Kirch, P.V. 1991. Prehistoric exchange in western Melanesia. Annual review of Anthropology 20, 141-165.

Kirch, P.V. 1986. Exchange systems and inter-island contact in the transformation of an island society: the Tikopia case. In P.V. Kirch (ed.), Island societies: Archaeological approaches to evolution and transformation. Cambridge University Press, 33-41.

Klecka, W.R. 1980. Discriminant Analysis. (Sage University Paper series Quantative Applications in the Social Sciences, 07-019) Beverly Hills and London, Sage Publications.

Knippenberg, S. 1995. Norman Estate and Anse des Pères: two pre-Columbian sites on Saint Martin. (Unpublished Master's thesis) Leiden University, Leiden.

Knippenberg, S. 1997. Flint and chert on Antigua: characterisation of the Little Cove and Corbison Point sources. (Unpublished report) Amsterdam.

Knippenberg, S. 1999a. Provenance of flint within the Leeward region, West Indies. Proceedings of the Sixteenth International Congress for Caribbean Archaeology, 261-271. 
REFERENCES

Knippenberg, S. 1999b. Anse des Pères. Methods and strategies. In C.L. Hofman \& M.L.P. Hoogland (eds.), Archaeological investigations on St. Martin (Lesser Antilles). The sites of Norman Estate, Anse des Pères, and Hope Estate with a contribution to the 'La Hueca problem'. Archaeological Studies Leiden University 4, 63-72.

Knippenberg, S. 1999c. Anse des Pères. Lithics. In C.L. Hofman \& M.L.P. Hoogland (eds.), Archaeological investigations on St. Martin (Lesser Antilles). The sites of Norman Estate, Anse des Pères, and Hope Estate with a contribution to the 'La Hueca problem'. Archaeological Studies Leiden University 4, 87-104.

Knippenberg, S. 1999d. Norman Estate. Lithics. In C.L. Hofman \& M.L.P. Hoogland (eds.), Archaeological investigations on St. Martin (Lesser Antilles). The sites of Norman Estate, Anse des Pères, and Hope Estate with a contribution to the 'La Hueca problem'. Archaeological Studies Leiden University 4, 35-46.

Knippenberg, S. 2001a. Lithic procurement during the Saladoid period within the northern Lesser Antilles. Proceedings of the Eighteenth International Congress for Caribbean Archaeology (1), 262-271.

Knippenberg, S. 2001b. Artefacts lithiques. In C.L.Hofman, M.L.P. Hoogland \& A. Delpuech (eds.), Guadeloupe, Saint-François, Anse à la Gourde. Fouille programmée pluriannuelle 1995-2000. (Rapport de synthèse 2000) Leiden University, Leiden, 175-221

Knippenberg, S. 2001c. Lithic analysis. In E.A. Boomsma \& A.J.D. Isendoorn, Caribbean explorations. Prospections of two archaeological sites in the Guadeloupean archipelago: Cocoyer St. Charles and Anse à l'Eau. (Unpublished Master's thesis) Leiden University, Leiden, 203-232.

Knippenberg, S., 2001d. Flint collecting strategies on Long Island. Proceedings of the Nineteenth International Congress for Caribbean Archaeology (2), 88-98.

Knippenberg, S., M. Nokkert, A.J. Brokke \& T.D. Hamburg 1999. A late Saladoid occupation at Anse des Pères, St. Martin. Proceedings of the Sixteenth International Congress for Caribbean Archaeology, 352-371.

Kozlowski, J.K. 1974. Preceramic cultures in the Caribbean. Panstwowe Wydawnictwo Naukowe Warszawa, Kraków.

Krauskopf, K.B. 1979. Introduction to geochemistry. (2 ${ }^{\text {nd }}$ edition) McGraw-Hill, New York

Kuijt, I, W.C. Prentiss \& D.L. Pokotylo 1995. Bipolar reduction: an experimental study of debitage variability. Lithic Technology 20, 116-127.

Lammers-Keijsers, Y.M.J. 2001a. Artefacts en coquillages. In C.L.Hofman, M.L.P. Hoogland \& A. Delpuech (eds.), Guadeloupe, Saint-

François, Anse à la Gourde. Fouille programmée pluriannuelle 1995-2000. (Rapport de synthèse 2000) Leiden University, Leiden, $235-264$.

Lammers-Keijsers, Y.M.J. 2001b. Excavations at the site of Anse à la Gourde, Guadeloupe. Use wear analysis on pre-Colombian shell artefacts. Proceedings of the Eighteenth International Congress for Caribbean Archaeology (2), 179-186.

Lammers-Keijsers, Y.M.J. in prep. Tracing traces from present to past: a functional analysis of Pre-Columbian shell and stone artefacts from Anse à la Gourde and Morel, Guadeloupe. (Ph.D. dissertation) Leiden University, Leiden.

Langemeyer, F.S. 1937. Korte beschrijving van de Groote Baai van St. Maarten. West Indische Gids 18, 289-292

Larue, D.K. 1994. Puerto Rico and the Virgin Islands. In S.K. Donovan \& T.A. Jackson, Caribbean Geology. An introduction. U.W.I. Publishers' Association, Kingston, 151-165.

Lasserre, G. 1975. Atlas des Départements Français d'Outre-Mer. Tome 3: La Guadeloupe. Centre d'Etudes de Géographie Tropicale du C.N.R.S., Bordeaux-Talence.

Lavin, L. \& D.R. Prothero, D.R. 1992. Prehistoric procurement of secondary sources: the case for characterisation. North American Archaeologist 13, 97-113.

Lidiak, E.G. \& W.T. Jolly, 1998. Geochemistry of intrusive igneous rocks, St. Croix, U.S. Virgin Islands. In E.G. Lidiak \& D.K. Larue, Tectonics and Geochemistry of the Northeastern Caribbean. Geological Society of America Special Paper 322, $133-153$. 
REFERENCES

Luedtke, B.E. 1978. Chert sources and trace element analysis. American Antiquity 43, 413-423.

Luedtke, B.E. 1979. The identification of sources of chert artifacts. American Antiquity 44, 744-757.

Luedtke, B.E. 1992. An Archaeologist's guide to chert and flint. (Archaeological Research tools 7) University of California, Los Angeles.

Lundberg, E.R. 1989. Preceramic procurement patterns at Krum Bay, Virgin Islands. (Unpublished Ph.D.dissertation) University of Illinois, Urbana.

Madsen, B., 1984. Flint axe manufacture in the Neolithic: experiments with grinding and polishing of thin-butted flint axes. Journal of Danish Archaeology 3, 47-62

Magne, M.P.R. 1989. Lithic reduction stages and assemblage formation processes. In D.S. Amick \& R.P. Mauldin, Experiments in Lithic Technology. British Archaeological Reports International Series 528, 15-32.

Malinowski, B. 1984. Argonauts of the Western Pacific. Reissued by Waveland Press, Inc., Illinois.

Marek, N.J. 1981. Petrology and depositional environment of the limestone lenses of the Central Plain Group (Oligocene), Antigua, British West Indies. (Unpublished Master's thesis) Northern Illinois University.

Martin-Kaye, P.H.A. 1958a. Mineral prospects in the Leeward Islands. Report of the First Caribbean Geological Conference. Antigua, 4348.

Martin-Kaye, P.H.A. 1958b. Geology of Carriacou. Bulletins American Paleontology 38, no175, 395-407

Martin-Kaye, P.H.A. 1959. Reports on the geology of the Leeward and the British Virgin Islands. Voice Publishing Co., Ltd., St. Lucia, W.I.

Martin-Kaye, P.H.A. 1969. A summary of the geology of the Lesser Antilles. Overseas Geology and Mineral Resources 10 (2): $172-206$

Mascle, A. \& D. Westercamp 1983. Géologie d'Antigua, Petites Antilles. Bulletin de la Société géologique de France 25, 855-866.

Mattioni, M. 1971. Compte-rendue de fouilles au lieu-dit "Vivé”, Côte Nord-Est de la Martinique. (Unpublished report) Fort de France, Martinique.

Mattioni, M. 1974. Compte-rendue final de fouilles au lieu-dit “Vivé”, Côte Nord-Est de la Martinique. (Unpublished report) Fort de France, Martinique.

Mattinson, J.M., L.K. Fink, Jr. \& C.A. Hopson 1980. Geochronologic and isotopic study of the La Désirade Island basement complex; Jurrasic oceanic crust in the Lesser Antilles. Contrib.Mineral.Petrol. 71, 237-245.

Mattson, P.H. 1960. Geology of the Mayagüez Area, Puerto Rico. Bulletin of the Geological Society of America 71, 319-362.

Mauss, M. 1990. The Gift. The form and reason for exchange in archaic societies. (translated by W.D. Halls) W.W. Norton, London \& New York.

McBryde, I. 1984. Kulin greenstone quarries: the social contexts of production and distribution for the Mt Williams site. World Archaeology $16(2), 267-285$.

McGinnis, S. 1997. Zemi three-pointer stones. In F. Bercht, E. Brodsky, J.A. Farmer \& D. Taylor (eds.), Taíno. Pre-Columbian art and culture from the Caribbean. The Monacelli Press, New York, 92-105

Meijerhoff, H.A. 1926. The physiography of the Virgin Islands, Culebra and Vieques. Scientific Survey of Puerto Rico and the Virgin Islands, volume IV, 145-219.

Molengraaff, G.A.F. 1931. Saba, St.Eustatius (Statia) and St. Martin. Leidsche Geologische Mededeelingen 5, 715-739 
REFERENCES

Montgomery, H., E.A. Pessagno \& I.M. Muñoz 1992. Jurassic (Tithonian) radiolaria from la Désirade (Lesser Antilles): preliminary paleontological and tectonic implications. Tectonics 11, 1426-1432.

Moore, C. 1982. Investigation of preceramic sites on Ile à Vache, Haiti. The Florida Anthropologist 35, 186-199.

Moore, C. 1991. Cabaret: lithic workshop sites in Haiti. Proceedings of the Thirteenth International Congress for Caribbean Archaeology, 92102.

Moore, J.H. 2001. Evaluating five models of human colonization. American Anthropologist 103, 395-408.

Moreau, J.P. 1994. Un flibustier français dans la mer des Antilles. (Petite Bibliothèque Payot, Voyageurs) Éditions Seghers, Paris.

Moscoso, F. 1981. The development of tribal society in the Caribbean. (Unpublished Ph.D. dissertation) State University of New York, Binghamton.

Multer, H.G., M.P. Weiss \& D.V. Nicholson 1986. Antigua: Reefs, rocks \& highroads of history. Leeward Islands Science Associates no.1. Antigua.

Munsell Soil Color Charts 1990. (Revised edition) Baltimore, Maryland.

Murphy A.R. 1996. Archaeological investigations at Muddy Bay (PH-14), Antigua, West Indies: a Post-Saladoid settlement. (Unpublished Master's thesis) Trent University, Peterboroug.

Murphy, A.R. 1999. The prehistory of Antigua, Ceramic age: subsistence, settlement, culture, and adaptation within an insular environment. (Unpublished Ph.D. dissertation) University of Calgary, Calgary.

Murphy, A.R. \& P.F. Healy 1999. Paleoecology of the Muddy Bay (PH-14) Site, Antigua. Preliminary report. Proceedings of the Sixteenth International Congress for Caribbean Archaeology (2), 275-286.

Murphy, A.R., A.J. Hozjan, C.N. de Mille \& A.A. Levinson 2000. Pre-Columbian gems and ornamental materials from Antigua, West Indies. Gems and Gemology 36 (2), 234-245

Myers, T.P. 1981. Aborigional trade networks in Amazonia. In P.D. Francis, F.J. Kense \& P.G. Duke, Networks in the Past: regional interaction in Archaeology. University of Calgary Archaeological Association, Galgary, 19-30.

Narganes Storde, Y.M. 1991. Sequencia cronologica de dos sitios arqueologicos de Puerto Rico (Sorcé, Vieques y Tecla, Guagamilla).

Proceedings of the Thirteenth International Congress for Caribbean Archaeology, 628-646.

Narganes Storde, Y.M. 1995. La Lapidaria de la Hueca, Vieques, Puerto Rico. Proceedings of the Fifteenth International Congress for Caribbean Archaeology,

Narganes Storde, Y.M. 1999. La lapidaria Agro 2 de Sorce e Tecla, Puerto Rico. Proceedings of the Sixteenth International Congress for Caribbean Archaeology (2), 17-26.

Newcomer, M.H. 1970. Some quantitative experiments in hand-axe manufacture. World Archaeology 3, 85-93.

Newsom, L.A. 1993. Native West Indian plant use. (Unpublished Ph.D. dissertation) University of Florida, Gainesville.

Nicholson, D.V. 1974. Unpublished fieldnotes on visits to Long Island (1971-1974).

Nicholson, D.V. 1975. A possible historic Indian site on Petite Terre, Guadeloupe. (Unpublished type-script) Antigua Archaeological Society, Antigua.

Nicholson, D.V. 1976. An Antigua shell midden with ceramic and archaic components. Proceedings of the Sixth International Congress for the Study of the Pre-Columbian Cultures of the Lesser, 258-263. 
REFERENCES

Nicholson, D.V. 1994. The archaeology of Antigua and Barbuda. Museum of Antigua and Barbuda, Antigua.

Nieweg, D.C. 2000. Shells in archaeology. Part 1: archaeological shell on Trinidad and Guadeloupe: two case studies. (Unpublished Master's thesis) Leiden University, Leiden.

Nockolds, S.R., R.W.O’B. Knox \& G.A. Chimer 1978. Petrology for students. Cambridge University press, Cambridge.

Nodine, B.K. 1990. Aceramic populations in the Lesser Antilles: evidence from Antigua, West Indies. Paper presented at the society for American Archaeology, Las Vegas.

Nokkert, M., A.J. Brokke, S. Knippenberg \& T.D. Hamburg 1999. An archaic occupation at Norman Estate, St. Martin. Proceedings of the Sixteenth International Congress for Caribbean Archaeology, 333-351.

Nugent, N. 1821. A sketch of the geology of the island of Antigua. Transactions of the Geological Society 5, 459-475.

Ohnuna, K. \& C. Bergman 1982. Experimental studies in the determination of flaking mode. Bulletin of the Institute of Archaeology 19, $161-170$.

Oliver, J.R. 1999. The 'La Hueca problem' in Puerto Rico and the Caribbean: old problems, new perspectives, possible solutions. In C.L.

Hofman \& M.L.P. Hoogland (eds.), Archaeological investigations on St. Martin (Lesser Antilles). The sites of Norman Estate, Hope Estate and Anse des Pères. With a contribution to the 'La Hueca problem'. Archaeological Studies Leiden University 4, 253-298.

Olson, F. 1973. Did the Ciboney precede the Arawaks in Antigua. Proceedings of the Fourth International Congress for the Study of the PreColumbian Cultures of the Lesser Antilles, 95-102.

Ortiz, J. 1976. Excavations at the preceramic Cerillo site, Southwest Puerto Rico. Proceedings of the Sixth International Congress for the Study of Pre-Columbian Cultures of the Lesser Antilles, 269-271.

Pané, Fray R. 1999. An account of the Antiquities of the Indians. A new edition, with an introductory study, notes, and appendixes by José Juan Arrom. (Translated by Susan C. Criswold) Duke Univerisity Press, Durham \& London.

Pantel, A.G. 1976. Progress report and analysis, Barrera-Mordan complex, Azua, Dominican Republic. Proceedings of the Sixth International Congress for the Study of the Pre-Columbian Cultures of the Lesser, 253-257.

Pantel, A.G. 1988. PreColumbian flaked stone assemblages in the West-Indies. (Unpublished Ph.D. dissertation) University of Tennessee, Knoxville.

Petrequin, P., \& C. Jeunesse, 1995. La hache de pierre. Carrières vosgiennes et échanges de lames polies pendant le Néolithique (5400-2100 av. J.-C.). Editions Errance, Paris.

Petersen, J.B. 1996. Archaeology of Trants, Montserrat. Part 3. Chronology and settlement data. Annals of Carnegie Museum 65, $323-361$.

Petersen 1997. Taino, Island Carib, and prehistoric Amerindian economies in the West Indies: Tropical forest adaptations to Island Environments. In S.M. Wilson (ed.), The Indigeneous people of the Caribbean. University Press of Florida, Gainesville, 118-130. .

Petersen, J.B. \& D.R. Watters 1991. Amerindian ceramic remains from Fountain Cavern, Anguilla, West Indies. Annals of Carnegie Museum 60, 321-357.

Petersen, J.B., R.B. Bartone \& D.R. Watters 1999. Pyroclastic, storm surge and Saladoid villager deposits: the archaeological and geological stratigraphy of the Trants site, Montserrat. Proceedings of the Sixteenth International Congress for Caribbean Archaeology, 40-51.

Petersen, J.B., C.L. Hofman \& L.A. Curet 2004. Time and culture: chronology and taxonomy in the Eastern Caribbean and the Guianas. In A. Delpuech \& C.L. Hofman (eds.), Late Ceramic societies in the eastern Caribbean. British Archaeological Reports International Series 1273, Paris Monographs in American Archaeology 14, 17-32.

Petitjean Roget, H. 1981. Les populations Amérindiennes: aspects de la préhistoire Antillaise. L’Historical Antillais, Tome 1, 77-152. 
REFERENCES

Pettijohn, F.J. 1975. Sedimentary rocks. (3 $3^{\text {rd }}$ edition) Harper and Row Publishers, New York.

Pike, D.W. \& A.G. Pantel 1974. First flint worksite found in Puerto Rico. Proceedings of the Fifth International Congress for the Study of PreColumbian Cultures of the Lesser Antilles, 140-142.

Prentiss, W.C. \& E.J. Romanski 1989. Experimental evaluation of Sullivan and Rozen's debitage typology. In D.S. Amick \& R.P. Mauldin, Experiments in Lithic Technology. British Archaeological Reports, International Series 528, 89-100.

Purves, J.C. 1884. Esquisse géologique de l'ile d'Antigoa. Bulletin du Musée Royal d'Histoire Naturelle de Belgique Tome 3, $273-318$.

Rademakers, P.C.M. 1995. Hystrichosphaeridae in de vuursteenhorizonten van de Kalksteen Lanaye (Formatie van Gulpen) van het Maastrichtien in Zuid-Limburg en aangrezend Belgisch gebied. Grondboor en Hamer 6, 130-139.

Rathje, W.L. 1975. Last tango in Mayapan: a tentative trajectory of production-distribution systems. In J.A. Sabloff and C.C. LambergKarlovsky (eds.), Ancient civilization and trade. University of New Mexico Press, Albuquerque, 409-448.

Rea, W.J. 1968. Geology of the southern part of Montserrat, West Indies. Proceedings of the Geological society of London 1649, 115-116.

Rea, W.J. 1970. Andesites of the Lesser Antilles. Proceedings of the Geological Society of London 1662, 39-46

Rea, W.J. 1974. The volcanic geology and petrology of Montserrat, West Indies. Journal of the Geological Society of London 130 (4), 341366 .

Rea, W.J. \& P.E. Baker 1980. The geochemical characteristics and conditions of petrogenesis of the volcanic rock of the northern Lesser Antilles: a review. Bulletin of Volcanology 43, 325-336.

Redmond, E.M. (ed.) 1998a. Chiefdoms and chieftaincy in the Americas. University Press of Florida, Gainesville

Redmond, E.M. 1998b. Introduction: the dynamics of chieftaincy and the development of chiefdoms. In E.M. Redmond (ed.), Chiefdoms and dhieftaincy in the Americas. University Press of Florida, Gainesville, 1-17.

Redmond, E.M. 1998c. In war and peace. Alternative paths to centralized leadership. In E.M. Redmond (ed.), Chiefdoms and chieftaincy in the Americas. University Press of Florida, Gainesville, 68-103.

Reed, J.A. \& J.B. Petersen 2001. A comparison of huecan and cedrosan saladoid ceramics at the Trants site, Montserrat. Proceedings of the Eighteenth International Congress for Caribbean Archaeology (2), 253-268.

Reitz, E.J. 1989. Appendix B: Vertebrate Fauna from Krum Bay, St. Thomas, Virgin Islands. In, E.R. Lundberg, Preceramic procurement patterns at Krum Bay, Virgin Islands, 274-289. (Unpublished Ph.D. disseration) University of Illinois, Urbana.

Reitz, E.J. 1994. Archaeology of Trants, Montserrat. Part 2. Vertebrate fauna. Annals of Carnegie Museum 63, $297-317$.

Renfrew, C. 1977. Alternative models for exchange and spatial distribution. In T.K. Earle \& J.E. Ericson (eds.), Exchange systems in prehistory. Academic Press, New York, 71-90.

Renfrew, C \& P. Bahn 1991. Archaeology. Theory, methods, and practice. Thames and Hudson, London.

Renfrew, C. \& J.E. Dixon 1976. Obsidian in western Asia: a review. In G. de Sieveking, I.H. Longworth, \& K.E. Wilson (eds.), Problems in economic and social archaeology. Duckworth, London, 137-50.

Renfrew, C., J.E. Dixon \& J.R. Cann 1968. Further analysis of Near Eastern obsidian. Proceedings of the Prehistoric Society 34, $319-331$.

Robinson, E. \& P. Jung 1972. Stratigraphy and age of marine rocks, Carriacou, West Indies. The American Association of Petroleum Geologists Bulletin 56, 114-127.

Rock, N.M.S. 1988. Numerical geology. A source guide, glossary and selective bibliography to geological uses of computers and statistics. 
REFERENCES

(Lecture Notes in Earth Sciences) Springer Verlag, Berlin.

Rodriguez Lopéz, M. 1991. Arquelogia de Punta Candelero, Puerto Rico. Proceedings of the Thirteenth International Congress for Caribbean Archaeology, 605-627.

Rodríguez Lopéz, M. 1993. Early trade networks in the Caribbean. Proceedings of the Fourteenth International Congress for Caribbean Archaeology, 306-314.

Rodríguez Ramos, R. 2001a. Lithic reduction trajectories at La Hueca and Punta Candelero sites, Puerto Rico. (Unpublished Master's thesis) Texas A\&M University.

Rodríguez Ramos, R. 2001b. Lithic reduction trajectories at La Hueca and Punta Candelero sites, Puerto Rico: a preliminary report. Proceedings of the Eighteenth International Congress for Caribbean Archaeology (1), 251-261.

Rodríguez Ramos, R. 2001c. Dinámicas de intercambio en el Puerto Rico Prehispánico. (Unpublished report) San Juan, Puerto Rico.

Rodríguez Ramos, R. 2005. The crab-shell dichotomy revisited: the lithics speak out. In P. Siegel (ed.), Ancient Borinquen: archaeology and ethnohistory of native Puerto Rico. University of Alabama Press, Tuscaloosa.

Roobol, M.J. \& J.W. Lee 1976. Petrography and source of some Arawak rock artifacts from Jamaica. Proceedings of the Sixth International Congress for the Study of Pre-Columbian Cultures of the Lesser Antilles, 304-313.

Rosman, A. \& P.G. Rubel 1989. Dual organization and its development potential in two contrasting environments. In D. Matbury-Lewis \& U. Almagor (eds.), The Attraction of opposites. Thought and society in the dualistic mode. The University of Michigan Press, Ann Arbor, $209-234$.

Rostain, S. 1994. L’occupation Amerindienne ancienne du littoral de Guyane. (Unpublished Ph.D. dissertation) Paris.

Rostain, S. 1997. Tanki Flip stone material. In A. Versteeg \& S. Rostain, The Archaeology of Aruba: the Tanki Flip site. Publications of the Foundation for Scientific Research in the Caribbean Region 141, 221-250.

Rottländer, R.C.A. 1975a. Some aspects of the patination of flint. Second International Symposium on Flint. Staringia 3, 54-56.

Rottländer, R.C.A. 1975b. The formation of patina on flint. Archaeometry 17, 106-110.

Rottländer, R.C.A. 1989. Verwitterungserscheinungen an Silices und Knochen. Verlag Archaeologica Venatoria. Institut für Urgeschichte der Universität Tübingen.

Rouse, I. 1939. Prehistory in Haiti: study in method. Yale University Publications in Anthropology 21, New Haven.

Rouse, I. 1941. Culture of the Ft. Liberté region, Haiti. Yale University Publications in Anthropology 24, New Haven.

Rouse, I. 1947. Prehistory of Trinidad in relation to adjacent areas. Man 47(103), 93-98.

Rouse, I. 1952. Porto Rico prehistory. (The New York academy of Sciences, Scientific Survey of Porto Rico and the Virgin Islands, vol. 18, parts 3-4) New York.

Rouse, I. 1954. Areas and periods of culture in the Greater Antilles. Southwestern Journal of Anthropology 7, 248-256.

Rouse, I. 1964. Prehistory of the West Indies. Science 144, 499-513.

Rouse, I. 1965. Caribbean ceramics: a study of method and theory. In F.R. Matson (ed.), Ceramics and Man. Viking Fund Publications in Anthropology 41, 88-103.

Rouse, I. 1974. The Indian Creek excavations. Proceedings of the Fifth International Congress for the Study of Pre-Columbian Cultures of the Lesser Antilles, 166-76. 
REFERENCES

Rouse, I. 1977. Pattern and process in West Indian archaeology. World Archaeology 9, 1-11.

Rouse, I. 1986. Migrations in Prehistory. Inferring population movement from cultural remains. Yale University Press, New Haven.

Rouse, I. 1992. The Tainos. Rise and decline of the people who greeted Columbus. Yale University Press. New Haven.

Rouse, I. \& R.E. Alegría 1990. Excavations at María de la Cruz cave and Hacienda Grande Village site, Loiza, Puerto Rico. Yale University Publications in Anthroplogy no.80, New Haven.

Rouse, I. \& Morse, B.F. 1999. Excavations at the Indian Creek Site, Antigua, West Indies. Yale University Publications in Anthropology 82, New Haven.

Russell, R.J. 1960. Preliminary notes on Caribbean beach rock. Transactions of the Second Caribbean Geological Conference, Mayaguez, Puerto Rico, 43-49.

Schinkel, K. 1992. The Golden Rock features. In A.H. Versteeg and K. Schinkel (eds.), The archaeology of St. Eustasius. The Golden Rock site. Publication of the Foundation for Scientific Research in the Caribbean Region, no.113, 143-212.

Schins, W.J.H. 1998. Het materiaal vuursteen. In P.C.M. Rademakers, De prehistorische vuursteenmijnen van Ryckholt-St.Geertruid. Casparie, Maastricht, 163-168

Schlanger, N. 1992. Techno- en typologische analyse van Midden-Paleolithische vuursteen complexen. (Unpublished report) Leiden University, Leiden.

Schmid, F. 1986. Flint stratigraphy and its relationship to archaeology. In G. de G. Sieveking \& M.B. Hart (eds.), The scientific study of flint and chert. (Proceedings of Fourth International Flint Symposium) Cambridge University Press, Cambridge, 1-7.

Schubel, K.A. \& B.M. Simonson, 1990. Petrography and diagenesis of cherts from Lake Magadi, Kenya. Journal of Sedimentary Petrology 60, 761-776.

Serrand, N. 2001. Long distance transportation of freshwater bivalves (Unionidae) in the Lesser Antilles during the $1^{\text {st }}$ millenium AD: example from the Hope Estate Saladoid site (St. Martin). Proceedings of the Eighteenth International Congress for Caribbean Archaeology (1), $136-152$.

Shackley, M.S. (ed.) 1998. Archaeological obsidian studies. Method and theory. (Advances in Archaeological and Museum Science vol. 3) Plenum Press, New York

Sheppard, P. \& L. Pavlish 1992. Weathering of Archaeological cherts: a case study from the Solomon Islands. Geoarchaeology 7, 41-53.

Shott, M.J. 1989. Bipolar Industries: Ethnographic evidence and Archaeological Implications. North American Archaeologist 10, 1-24.

Shott, M.J. 1996. Stage versus continuum in the debris assemblage from production of a fluted biface. Lithic Technology $21,6-22$.

Siegel, P.E. 1989. Site structure, demography and social complexity in the early ceramic age of the Caribbean In P.E. Siegel (ed.). Early ceramic lifeways and adaptive strategies in the Caribbean. British Archaeological Reports, International Series 506, 193-247.

Siegel, P.E. 1996. Ideology and culture change in prehistoric Puerto Rico: A view from the community. Journal of Field Archaeology 23, 313333 .

Siegel, P.E. 1997. Ancestor worship and cosmology among the Taino. In F. Bercht, E. Brodsky, J.A. Farmer, \& D. Taylor (eds.), Taíno. PreColumbian art and culture from the Caribbean. The Monacelli Press, New York, 106-111.

Siegel, P.E. 1999. Contested places and places of contest: the evolution of social power and cermonial space in prehistoric Puerto Rico. Latin American Antiquity 10, 209-238.

Sieveking, G. de G., P. Bush, J. Ferguson, P.T. Craddock \& M.J. Hughes 1970. Characterization of prehistoric flint mine products. Nature 228, 251-254. 
REFERENCES

Sieveking, G. de G., P. Bush, J. Ferguson, P.T. Craddock, M. J. Hughes \& M.R. Cowell 1972. Prehistoric flint mines and their identification as sources. Archaeometry 14, 151-176.

Sigurdsson, H. 1973. Partly-welded pyroclast flow deposits in Dominica, Lesser Antilles. Bulletin Volcanologique 36, $148-162$.

Smith, A.L., M.J. Roobol \& B.M. Gunn 1980. The Lesser Antilles. A discussion of the island arc magmatism. Bulletin of Volcanology 43, 285302.

Spencer, Ch.S. 1998. Investigating the development of Venezuelan chiefdoms. In E.M. Redmond (ed.), Chiefdoms and dhieftaincy in the Americas. University Press of Florida, Gainesville, 104-137.

Staargaard, J.A. 1952. On igneous and metamorphic rocks and associated manganese-iron ores of Netherlands St. Martin (Lesser Antilles). Proceedings Koninklijke Nederlandse Akademie van Wetenschappen. Series B 55, 37-50.

Stevens, F. 2002. Morel rocks. A study of lithics of a La Hueca/Cedros style settlement at Morel, Guadeloupe, French West Indies. (Unpublished Master's thesis) Leiden University, Leiden.

Stouvenot, C. 1998. First hypotheses regarding the origin and distribution of the stone raw materials used by the Amerindians of Saint-Martin. Hope Estate Bulletin 7, 24-25.

Stouvenot, C. 1999. Saint Martin. Prospection inventaire. In Bilan Scientifique de la région Guadeloupe 1998. Direction Régionale des Affaires Culturelles, Guadeloupe, 36-37.

Sued Badillo, J. 1992. Searching for ethnicity: an economic contextualization. Paper presented at "The Symposium on the Native Caribbean", Leiden University, Leiden.

Sullivan, A.P. \& K.C. Rozen 1985. Debitage analysis and archaeological interpretation. American Antiquity 50, 755-779.

Taylor, D.R. \& B.J. Hoff 1980. The linguistic repertory of the Island-Carib in the seventeenth century: the men's language- a Carib pidgin? International Journal of American Linguistics 46, 201-312.

Thiry, M. \& I. Ribet 1999. Groundwater silification in Pris Basin limestones: fabrics, mechanisms, and modelling. Journal of Sedimentary Research 69 (1), 171-183

Thomas, D.J. 1972. The indigenous trade system of Southeast Estado Bolivar, Venezuela. Antropologica 33, 3-37.

Thomas, D.J. 1981. Cultural homogeneity, resource distribution and exchange patterns in the Guiana Highlands of South America. In P.D. Francis, F.J. Kense \& P.G. Duke (eds.), Networks in the Past: regional interaction in Archaeology. University of Calgary Archaeological Association, Galgary, 85-100.

Thompson, M., P.R. Bush \& J. Ferguson 1986. The analysis of flint by inductively coupled plasma atomic emission spectrometry, as a method of source determination. In G. de G. Sieveking \& M.B. Hart (eds.), The scientific study of flint and chert. (Proceedings of Fourth International Flint Symposium) Cambridge University Press, Cambridge, 243-247.

Tomka, S.A. 1989. Differentiating lithic reduction techniques: an experimental approach. In D.S. Amick \& R.P. Mauldin (eds.), Experiments in Lithic Technology. British Arachaeological Reports, International Series 528, 137-161.

Torrence, R. 1986. Production and exchange of stone tools. Cambridge University Press, Cambridge.

Trenchmann, C.T. 1932. Notes on Brimstone Hill, St. Kitts. The Geological Magazine 69, 241-265.

Troelstra, S. \& K. Beets 2001. Etudes géomorphologiques et environnementales. In C.L.Hofman, M.L.P. Hoogland \& A. Delpuech (eds.), Guadeloupe, Saint-François, Anse à la Gourde. Fouille programmée pluriannuelle 1995-2000. (Rapport de synthèse 2000) Leiden University, Leiden, 11-22.

Van der Steen, E.J. 1992. Shell artefacts of Golden Rock. In A.H. Versteeg \& K. Schinkel (eds.), The archaeology of St. Eustatius. The Golden 
REFERENCES

Rock site. Publication of the Foundation for Scientific Research in the Caribbean region no. 131. Amsterdam, 93-118.

Van der Valk, L. 1992. The physical environment of Golden Rock. In A.H. Versteeg \& K. Schinkel (eds.), The archaeology of St. Eustasius. The Golden Rock site. Publication of the Foundation for Scientific Research in the Caribbean Region, no.113, 14-30.

Van der Valk, L. \& H.J. Putker, 1986. Geological and archaeological investigations at Godet. (Unpublished report) Leiden University, Leiden.

Van Gijn, A. 1996. Flint exploitation on Long Island, Antigua, West Indies. Analecta Praehistorica Leidensia 26, $183-197$.

Van Soest, M. 2000. Sediment subduction and crustal contamination in the Lesser Antilles Island arc. (Ph.D. disseration) Free University of Amsterdam, Amsterdam.

Van Tooren, M. 1993. Appendix 1: Petrographic study of archaeological samples from St. Martin. In J.B. Haviser, 1993 Lithic analysis, Hope Estate. (Unpublished report) Willemstad, Curaçao.

Van Tooren, M. \& J.B. Haviser 1999. Petrographic analysis of lithic material recovered from Hope Estate, St. Martin, and the potential for indications of regional contact. Proceedings of the Sixteenth International Congress for Caribbean Archaeology, 251-260.

Veloz Maggiolo, M. 1991. Panorama historico del Caribe Pre- colombino. Edicion del Banco central de la Republica Dominicana.

Verhoeven, K. 2002. Herkomstbepaling van silexartefacten uit de prehistorische sites van Doel, Spiere en Eudeghien, door middel van micropaleontologisch onderzoek met dinoflagellatencysten. ("Licentiaat" thesis) University of Gent, Gent.

Verpoorte, A. 1993. Stenen op een eiland: veldverkenning van de vuursteenvoorkomens en werkplaatsen van Long Island, Antigua, West Indies. (Unpublished Master's thesis) Leiden University, Leiden.

Versteeg, A.H. 1992a. Introduction. In A.H. Versteeg \& K. Schinkel (eds.), The archaeology of St. Eustasius. The Golden Rock site. Publication of the Foundation for Scientific Research in the Caribbean Region, no.113, 36-73.

Versteeg, A.H. 1992b. The GR-1 midden: methods. In A.H. Versteeg \& K. Schinkel (eds.), The archaeology of St. Eustasius. The Golden Rock site. Publication of the Foundation for Scientific Research in the Caribbean Region, no.113, 31-35.

Versteeg, A.H. 1992. The GR-1 midden: the pottery of Golden Rock. In A.H. Versteeg \& K. Schinkel (eds.), The archaeology of St. Eustasius. The Golden Rock site. Publication of the Foundation for Scientific Research in the Caribbean Region, no.113, 36-73.

Versteeg, A.H. 1999. Archaeological records from the southern and eastern Caribbean area. How different and how similar are they? Proceedings of the Seventeenth International Congress for Caribbean Archaeology, 86-102.

Versteeg, A.H. \& K. Schinkel (eds.) 1992. The archaeology of St. Eustasius. The Golden Rock site. Publication of the Foundation for Scientific Research in the Caribbean Region, no.113.

Versteeg, A.H., K. Schinkel \& S.M. Wilson 1996. Large-scale excavations versus surveys: examples from Nevis, St. Eustatius, and St. Kitts in the Northern Caribbean. Analecta Praehistorica Leidensia 25, 138-161.

Vescelius, G.S. \& L.S. Robinson 1979. Exotic items in archaeological collections from St. Croix: prehistoric imports and their implications. Paper presented at the Eighth International Congress for the Study of the Pre-Columbian Cultures of the Lesser Antilles, St. Kitts.

Vidal, N. 1992. Diamant Martinique. Troisième campagne de fouilles, Avril-Mai-Juin-Juillet 1992. (Unpublished report) Fort de France, Martinique.

Vidal, N. 1999. Le site precolombien de la plage de Dizac au Diamant, Martinique. Proceedings of the Sixteenth International Congress for Caribbean Archeology (2), 7-17.

Volckmann, R.P. 1984a. Geologic map of Cabo Rojo and Parguera Quadrangles, Southwest Puerto Rico. U.S. Geological Survey Miscellaneous 
Investigations Series Map I-1557, scale 1:20,000.

Volckmann, R.P. 1984b. Geologic map of the Puerto Real Quadrangle, Southwest Puerto Rico. U.S. Geological Survey Miscellaneous Investigations Series Map I-1559, scale 1:20,000.

Volckmann, R.P. 1984c. Geologic map of the San German Quadrangle, Southwest Puerto Rico. U.S. Geological Survey Miscellaneous Investigations Series Map I-1558, scale 1:20,000.

Wadge, G. 1994. The Lesser Antilles. In S.K. Donovan \& T.A. Jackson, Caribbean Geology. An introduction. U.W.I. Publishers' Association, Kingston, 167-178.

Walker, J.B. 1980a. Analysis and replication of the lithic artifacts from the Sugar Factory Pier site, St. Kitts, West Indies. (Unpublished Master's thesis) Washington State University, Pullman.

Walker, J.B. 1980b. Analysis and replication of lithic artifacts from the Sugar Pier site, St. Kitts. Proceedings of the Eightth International Congress for the Study of Pre-Columbian Cultures of the Lesser, 69-79.

Walker, J.B. 1981. Use-wear analysis of Caribbean flaked stone tools. Proceedings of the Ninth International Congress for the Study of PreColumbian Cultures of the Lesser, 239-248.

Walker, J.B. 1983. A preliminary report on the lithic and osteological remains from the 1980, 1981, 1982 field seasons at Hacienda Grande. Proceedings of the Tenth International Congress for the Study of Pre-Columbian Cultures of the Lesser Antilles, 181-224.

Walker, J.B. 1985. Analysis of the lithic artifacts from El Bronce Archaeological Site, Puerto Rico. Appendix G in L.S. Robinson, E.R. Lundberg \& J.B. Walker, Archaeological data recovery at El Bronce, Puerto Rico, Final report, phase 2. Puerto Rico.

Walker, J.B. 1995. On the nature of Taino stone collars: the production technology. Proceedings of the Fifteenth International Congress for Caribbean Archaeology, 121-129.

Walker, J.B. 1997. Analysis of the lithic artifacts from the stage II testing of the Finca Valencia site, Arecibo, and the La Trocha site, Vega Baja, Puerto Rico. (Unpublished report) Puerto Rico.

Walker, J.B. 1997. Taíno stone collars, elbow stones, and three-pointers. In F. Bercht, E. Brodsky, J.A. Farmer, \& D. Taylor (eds.), Taíno. PreColumbian art and culture from the Caribbean. The Monacelli Press, New York, 80-91

Walker, J.B., E. Questell Rodríguez \& R. Rodríguez Ramos 2001. Proyecto Fuentes de lítica en el Noroeste de Puerto Rico. (Unpublished report) Oficina Estatal de Conservación Historica, Puerto Rico.

Watters, D.R. 1980. Transect surveying and Prehistoric site locations on Barbuda and Montserrat, Leeward Islands, West Indies. (Unpublished Ph.D. dissertation) University of Pittsburgh, Pittsburgh.

Watters, D.R. 1991. Archaeology of Fountain Cavern, Anguilla, West Indies. Annals of Carnegie Museum 60, 255-320

Watters, D.R. 1994. Archaeology of Trants, Montserrat. Part 1 Methods and artifact density distributions. Annals of Carnegie Museum 63, 265295.

Watters, D.R. 1997a. Maritime trade in the prehistoric Eastern Caribbean. In S.M. Wilson (ed.), The Indigeneous people of the Caribbean. University Press of Florida, Gainesville, 88-99.

Watters, D.R. 1997b. Stone beads in the prehistoric Caribbean. Bead Study Trust Newsletter 29, 7-8.

Watters, D.R. 2001. Preliminary report on the correlation of Archaic Age localities with a paleoshoreline on Barbuda. Proceedings of the Nineteenth International Congress for Caribbean Archaeology (2).

Watters, D.R. \& J. Donahue 1990. Geoarchaeological research on Barbuda, Antigua, and Montserrat. Proceedings of the Tenth International Congress for Caribbean Archaeology, 375-379. 
REFERENCES

Watters, D.R., J. Donahue \& R. Stuckenrath 1991. Paleoshorelines and the prehistory of Barbuda, West Indies. In L.L. Johnson (ed.), Paleoshorelines and prehistory: an investigation of Method. CRC Press, Boca Raton, Florida, 15-52.

Watters, D.R. \& J.B. Petersen 1993. Preliminary report on the archaeology of the Rendezvous Bay site, Anguilla. Proceedings of the Fourteenth International Congress for Caribbean Archaeology, 25-33.

Watters, D.R. \& J.B. Petersen 1999. Trants, Montserrat: the 1995 field season. Proceedings of the Sixteenth Congress for Caribbean Archaeology, 27-39.

Watters, D.R. \& J.B. Petersen 1999. Is la Hueca style pottery present at Trants? In C.L. Hofman \& M.L.P. Hoogland (eds.), Archaeological investigations on St. Martin (Lesser Antilles). The sites of Norman Estate, Anse des Pères, and Hope Estate. With a contribution to the 'La Hueca problem'. Archaeological Studies Leiden University 4, 299-301

Watters, D.R. \& R. Scaglion 1994. Beads and pendants from Trants, Montserrat: implications for the prehistoric lapidary industry of the Caribbean. Annals of the Carnegie Museum 63, 215-237.

Watters, D.R., R. Dacal Moure \& S. Knippenberg in prep. Preceramic Age occupation at Barbuda (working title).

Weaver, C.E. 1989. Clays, muds, and shales. (Developments in sedimentology 44) Elsevier, Amsterdam.

Weiss, M.P. 1994. Oligocene Limestones of Antigua, West Indies: Neptune succeeds Vulcan. Caribbean Journal of Science $30,1-29$.

Westercamp, D. \& H. Tazieff 1980. Martinique. Guadeloupe. Saint-Martin. La Désirade. Guides géologiques régionaux. Masson, Paris.

Westermann, J.H. 1957. De Geologische geschiedenis der drie Bovenwindse eilanden St.Martin, Saba en St.Eustatius. Uitgaven van de "Natuurwetenschappelijke Werkgroep Nederlandse Antillen" no.7, Curaçao.

Westermann, J.H. \& H. Kiel 1961. The geology of Saba and St. Eustatius, with notes on the geology of St. Kitts, Nevis and Montserrat (Lesser Antilles). Uitgaven Natuurwetenschappelijke Studiekring voor Suriname en de Nederlandse Antillen 24, Utrecht.

Weyl, R. 1966. Geologie der Antillen. (Beiträge zur Regionalen Geologie der Erde, Band 4) Berlin

Whetten, J.J. 1966. Geology of St. Croix, U.S. Virgin Islands. Geological Society of America Memoir 98, 177-239.

Willey, G.R. \& J.A. Sabloff 1974. A History of American Archaeology. W.H. Freeman, San Fransisco.

Wilson, S.M. 1989. The prehistoric settlement pattern of Nevis, West Indies. Journal of Field Archaeology 16, 427-440.

Wilson, S.M. 1990. Hispaniola: Caribbean chiefdoms in the age of Columbus. The University of Alabama Press, Tuscaloosa \& London.

Wilson, S.M., H. B. Iceland \& T.R.Hester 1998. Preceramic connections between Yucatan and the Caribbean. Latin American Antiquity 9 (4), 342-352.

Wing, E.S. 1991. Economy and subsistence I - Faunal remains. In P.L. Drewitt (ed.), Prehistoric Barbados. Archetype Publications LtD, Wales, 134-152.

Wing, E.S. \& E.J. Reitz 1982. Prehistoric fishing economies of the Caribbean. Journal of New World Archaeology 5 (2), $13-32$.

Yde, J. 1965. The material culture of the Waiwai. Nationalmuseets Skrifter, Ethnograf. Raekke 10, Copenhagen.

Zijlstra, J.J.P. 1994. Sedimentology of the late Cretaceous and early Tertiary (Tuffaceous) chalk of Northwest Europe. Geologica Ultraiectina no.119. Utrecht. 


\section{Samenvatting}

\section{Inleiding}

Studie naar vervaardiging en verspreiding van stenen artefacten gedurende de pre-Columbiaanse bewoning binnen de Caribische regio is slechts in geringe mate uitgevoerd binnen de archeologie van het gebied, ondanks het feit dat deze eiland archipel zich uitermate goed leent voor een dergelijk onderzoek. Het onderhavige onderzoek voorziet in deze leemte. Steenbewerking en verspreiding van artefacten temidden van de noordelijke Kleine Antillen staan centraal met als doel tot een inzicht te komen welke uitwisselingsmechanismen ten grondslag hebben gelegen aan deze verspreiding. Het onderzoek behandelt de gehele Keramische periode. Deze periode omvat de tijdspanne van 500 v. Chr tot aan de komst van de Europeanen in 1492 na Chr. Met het verkregen inzicht is een bijdrage geleverd aan de lopende discussie over de sociaalpolitieke organisatie van de inheemse samenlevingen gedurende deze periode.

Centraal in deze discussie staat of er gedurende de tweede helft van deze Keramische periode (800-1492 na Chr) hoofdschappen zijn ontstaan met een overerfbaar leiderschap, zogenaamde chiefdoms. Lang is men er vanuit gegaan dat op de Kleine Antillen de sociaal-politieke organisatie het niveau van een tribale, egalitaire samenleving nooit is ontstegen, in tegenstelling tot de Grote Antillen, waar bloeiende hoofdschappen hebben bestaan. Recent archeologisch onderzoek op de Kleine Antillen heeft echter aangetoond dat er op vindplaatsniveau gedurende de late fase van de Keramische periode duidelijk verschillen zijn waar te nemen, die mogelijk duiden op een toename aan complexiteit in sociaal-politieke organisatie. Sommigen menen hier het ontstaan van hoofdschappen in te zien, terwijl anderen niet verder gaan dan te concluderen dat binnen de tribale samenlevingen differentiatie aanwezig is die te wijten is aan regionalisatie.

Het ontstaan van hoofdschappen heeft in de antropologie altijd op veel aandacht mogen rekenen. Een belangrijk deel van de theorievorming hieromtrent is gebaseerd op antropologisch onderzoek van de samenlevingen in het Amazonegebied, samenlevingen die cultureel verwant zijn met de verdwenen Antilliaanse inheemse bevolking. Robert Carneiro, sinds de jaren 70 een van de hoofdrolspelers rond deze theorievorming, stelt dat hoofdschappen vooral politieke entiteiten zijn, meer dan alleen samenlevingen met overerfbaar leiderschap. Hij benadrukt dat het gaat om conglomeraties van dorpen, die onder het gezag staan van een hoofdman, de chief. Deze verschillen duidelijk van egalitaire samenlevingen, waar de verschillende dorpen relatief autonoom ten opzichte van elkaar opereren. Een tussenstadium wordt gevormd door de chieftaincy, een samenleving waarbij een sterk tribaal leider op basis van eigen verdiensten meerdere dorpen onder zijn gezag weet te krijgen. Een dergelijke situatie staat of valt met de capaciteiten van deze leider. Aangezien in een dergelijke samenleving leiderschap (nog) niet overerfbaar is, zal gezag sterk wisselen en kan de samenleving gemakkelijk terugvallen naar het egalitaire niveau.

Vanuit het perspectief van Carneiro gezien, vormen de onderlinge relaties van de verschillende gemeenschappen een belangrijke factor in de sociaal-politieke ontwikkeling van de desbetreffende samenleving. Deze relaties worden verankerd in uitwisseling. Immers, sinds Marcel Mauss in 1925 zijn "Essai sur le Don" publiceerde, weten we dat uitwisseling in niet-westerse samenlevingen veel meer omvat dan slechts een economisch aspect van het verkrijgen van zaken die je zelf niet kunt fabriceren. Mauss toonde aan dat in uitwisselingsrelaties naast economische ook sociale, religieuze en rituele aspecten van een samenleving verankerd liggen en dat tijdens uitwisselingsbijeenkomsten in feite de positie van de gehele gemeenschap ten opzichte van andere gemeenschappen aan de orde is.

De noordelijke Antillen vormen een regio die zich uitermate goed leent voor archeologisch onderzoek naar fabricage en verspreiding van stenen werktuigen en objecten. Niet alleen het feit dat we hier te maken hebben met een archipel van veelal kleine eilanden heeft ervoor gezorgd dat gesteentes zeer verschillend en zeer gelokaliseerd voorkomen, ook de diversiteit aan geologische opbouw van de afzonderlijke Antillen draagt hieraan bij. Hierdoor kan van een groot aantal stenen materialen die gebruikt zijn door de inheemse bevolking, in de periode voorafgaande aan de komst van de Europeanen, met redelijke precisie vastgesteld worden vanwaar de stenen oorspronkelijk afkomstig zijn.

In relatie tot het vervaardigen van stenen werktuigen en andere objecten heeft archeologe Robin Torrence met haar werk "Production and exchange of stone tools" (1986) enkele belangrijke aspecten van onderzoek naar uitwisseling in het algemeen en het vervaardigen van stenen werktuigen in het bijzonder naar voren gebracht. Ten eerste stelt ze - kort samengevat - dat de wijze waarop een artefact wordt gefabriceerd, bepaald wordt door de mate van toegang tot een materiaal, met andere woorden door het type uitwisseling. Ten tweede benadrukt ze dat de aard van het vervaardigen van stenen werktuigen reducerend (afbouwend) is, en dat daardoor elke stap binnen het vervaardigingproces zijn residu achterlaat in de vorm van bewerkingsafval. Deze aspecten bieden voor de archeoloog uitermate geschikte uitgangspunten voor onderzoek 
naar uitwisselingsnetwerken van stenen materialen en werktuigen.

Naast deze benadering, met de nadruk op de productiekant van stenen werktuigen, is er ook vruchtbaar onderzoek verricht naar de consumptiekant van het gebruik van stenen werktuigen. Zo construeerde Colin Renfrew afnamecurven (falloff curves), waarin de hoeveelheid van een materiaal is afgezet tegen de afstand tot de bron. Beide benaderingswijzen zijn gebruikt in het huidige onderzoek om tot identificatie van uitwisselingtypen te komen.

\section{Herkomstonderzoek}

In hoofdstuk 2 bespreek ik het onderzoek naar de identificatie van gesteentebronnen. Drie verschillende steensoorten passeren de revue. De meeste aandacht gaat uit naar vuursteen en gerelateerde kiezelgesteentes (cherts). Binnen de Antillen zijn er slechts enkele eilanden bekend waar deze materialen van nature voorkomen. Dit zijn de eilanden Antigua, St. Kitts en Puerto Rico. Op deze eilanden zijn vijftien bronlocaties in kaart gebracht en bemonsterd. Het betreffen weliswaar verschillende soorten kiezelhoudende gesteentes, maar in uiterlijke kenmerken vertonen ze een sterke overlap met elkaar waardoor het moeilijk is om ze met het blote oog uit elkaar te houden.

Centraal staan de bepaling en uitwerking van een methode om de vijftien bronnen van elkaar te kunnen onderscheiden op basis van objectief toetsbare karakteristieken. Uit eerder onderzoek is gebleken dat de bepaling van de concentratie van een reeks sporenelementen vruchtbare resultaten opleverde. Deze methode is verder uitgewerkt en tevens is getracht een verklaring te vinden waarom deze concentraties aan sporenelementen variëren tussen de verschillende bronnen, met het doel tot een betere onderbouwing van dit verschil te komen.

Om dit te bewerkstelligen is gekeken naar de geologische context en de fysieke hoedanigheid van de bronnen, en naar de microscopische en macroscopische kenmerken van de verschillende kiezelhoudende gesteentes. Zoals verwacht is het verschil tussen de bronnen sterk afhankelijk van de geologische context en dan in het bijzonder het moedergesteente waarin de vuursteen en kiezels zich gevormd hebben. Op Antigua was een duidelijke driedeling te maken tussen vuursteen gevormd in kalkgesteente (grofweg te vinden in het noordelijk deel), cherts gevormd in kalkhoudend tuf (in het westelijk deel) en cherts gevormd in niet kalkhoudend tuf (in het zuidoostelijk deel).

De bronnen blijken onderling het meest te verschillen wat betreft een bepaalde groep sporenelementen. Deze sporenelementen zijn afkomstig van de klei- en tufbestanddelen aanwezig in het moedergesteente. De variatie in verhoudingen toont aan dat de verschillen in ingesloten klei- en tuffracties in hoofdmate verantwoordelijk zijn voor de onderlinge variatie. Het feit dat de kalkvuurstenen aangetroffen op St. Kitts qua sporenelementsamenstelling sterk op de kalkvuurstenen van Antigua lijken, onderbouwt het gesuggereerde verband tussen moeder- en kiezelgesteente.

Naast het moedergesteente blijkt verwering een tweede grote factor te zijn die van invloed is op de samenstelling van de sporenelementen. Een vergelijking tussen vuursteen uit primaire context, dat is vuursteen vers uit de kalkafzettingen, en secundair materiaal dat lange tijd blootgesteld is geweest aan verwering, toont aan dat deze samenstelling significant verandert. Vooral verwering die optreedt in bodems heeft sterke invloed. Vuursteen lange tijd blootgesteld aan verwering in bodems verliest zijn kalkbestanddeel door oplossing en kan sterk toenemen in concentraties ijzer, afhankelijk van het omliggende ijzergehalte van de bodem. Ook de elementen geassocieerd met kleimineralen veranderen verhoudingsgewijs. In absolute concentraties is het verschil tussen primair en secundair materiaal echter veel minder significant.

Voor de discriminatie van bronnen heeft dit verkregen inzicht verschillende implicaties. Het onderscheid is het duidelijkst tussen bronnen uit verschillende moedergesteentes. Kiezelgesteentes van bronnen uit hetzelfde moedergesteente kunnen ook verschillen, maar doen dit over het algemeen minder. Daar komt bij dat verwering een negatief effect heeft op discriminatie, omdat dit zorgt voor een toename aan variatie binnen een bron. Slechts in uitzonderlijke gevallen, waarin verwering over een lange periode heeft geopereerd op een in omvang beperkte bron, kan verwering tot een betere discriminatie leiden. In het huidige onderzoek blijkt dit het geval te zijn voor vuursteen afkomstig van de Blackman's Point op Antigua. Deze bron is onder invloed van sterke verwering duidelijk verschillend geworden van de geologisch verwante en geografische nabij gelegen Long Island vuursteenbron.

Uiteindelijk is een reeks vuurstenen artefacten, afkomstig van verschillende nederzettingen op de Kleine Antillen en Puerto Rico, geanalyseerd op hun sporenelementsamenstelling en is deze met behulp van discriminant analyse (een multivariabele statistische techniek) toegekend aan de betreffende bron. Het bleek dat een groot deel van de artefacten waarvan op voorhand was verondersteld dat ze van het kleine eiland Long Island iets uit de kust ten noorden van Antigua afkomstig zijn, ook daadwerkelijk van Long Island komen. Omdat deze geanalyseerde monsters verreweg de grootste groep artefacten vertegenwoordigen, is hiermee aangetoond dat Long Island de belangrijkste bron is geweest gedurende de Keramische periode in de noordelijke Kleine Antillen. Daarnaast is duidelijk geworden dat niet alle door de inheemse 
bevolking gebruikte bronnen binnen dit onderzoek opgenomen zijn. Tenslotte, is het opvallend dat de bronnen in het zuidwesten van Puerto Rico nauwelijks van enige importantie zijn geweest voor de vindplaatsen in het oosten van dit zelfde eiland en de noordelijke Kleine Antillen.

Naast het vuursteen, en dan in het bijzonder het vuursteen van Long Island, bleken er twee andere steensoorten in de regio voor te komen die in de Pre-Columbiaanse periode belangrijk zijn geweest. Het betreft een grijsgroene siltsteen (simpelweg greenstone genoemd) en een conglomeraat gesteente (calci-rudite genoemd). Beide komen van nature voor op Sint Maarten. Aangezien beide steenvariëteiten met het blote oog zeer goed te herkennen zijn vanwege enkele specifieke karakteristieken, is in het laatste deel van hoofdstuk 2 volstaan met een goede macroscopische en microscopische beschrijving van beide materialen en een uiteenzetting waar ze van nature voorkomen op Sint Maarten.

\section{Methodologie en keuze van onderzochte vindplaatsen}

In hoofdstuk 3 komt de gehanteerde onderzoeksmethode gebruikt bij de analyse van collecties stenen artefacten afkomstig van verschillende nederzettingen aan bod en wordt er in dit hoofdstuk ingegaan op de keuze van deze collecties. Daarnaast is inzicht verschaft in de vertekeningen die aanwezig zijn als gevolg van deze keuze. Ook is gekeken naar de vertekeningen als gevolg van de verschillende opgravingmethodieken tijdens het verzamelen van het stenen materiaal en de omvang van de bestudeerde collecties. De variatie in de maaswijdte van de gebruikte zeven en het verschil in numerieke omvang van de collectie stenen spelen hierbij de grootste rol.

Tijdens het onderzoek zijn collecties van 30 vindplaatsen gelegen op 14 verschillende eilanden bestudeerd. Dit sample aan vindplaatsen voldeed in grote lijnen aan de vooropgestelde doelstellingen. De meeste zijn op basis van ${ }^{14} \mathrm{C}$ monsters absoluut gedateerd, vertegenwoordigen alle vier de fasen binnen de Keramische periode en zijn ruimtelijk regelmatig verspreid binnen de onderzoeksregio van de noordelijke Kleine Antillen en oostelijk Puerto Rico.

Wat betreft de keuze van de vindplaatsen bestaat er wel enigszins een vertekening, aangezien het met name de grotere nederzettingen betreft. Deze vertekening is geheel te wijten aan de relatief grote hoeveelheid aandacht die naar deze nederzettingen is uitgegaan binnen de Caribische archeologie.

Voortbordurend op het inzicht dat de afzonderlijke stappen van het fabricatieproces van stenen artefacten hun sporen zullen achterlaten in het archeologische bestand, heb ik vervolgens een schematisch overzicht opgesteld van deze verschillende stappen. Hierbij heb ik de momenten gespecificeerd waarop stenen materialen verplaatst en dus eventueel ook verhandeld kunnen zijn. In dit schematische overzicht maak ik een onderscheid tussen: (a) het verzamelen van ruw materiaal; (b) het voorbewerken van ruw materiaal; (c) het daadwerkelijk produceren van werktuigen; (d) het afwerken van de werktuigen; (e) het gebruik van werktuigen; en (f) het uiteindelijk weggooien van werktuigen. Voor elk type artefact heb ik een dergelijk schema opgesteld. Op basis van technologie, wijze van fabricage en manier van gebruik, onderscheid ik daarbij: (a) de productie van afslagwerktuigen; (b) de productie van kernwerktuigen en objecten, zoals bijlen, dissels, maalstenen, maar ook kralen, hangers en zemis; (c) het ad-hoc gebruik van allerlei gerolde keien; en (d) een groep artefacten, die van elders verkregen zijn, maar waarbij geen sporen van gebruik of bewerking te herkennen zijn. In de Engelstalige literatuur worden deze artefacten aangeduid met manuports.

Om een goed inzicht te krijgen in welk van de hierboven genoemde stappen voor welke artefact type plaatsvonden op de verschillende onderzochte nederzettingen heb ik een lijst met variabelen opgesteld. De systematisch analyse van de verschillende collecties stelde mij uiteindelijk in staat de nederzettingen onderling met elkaar te vergelijken en verschafte mij zo een regionaal en chronologisch overzicht.

\section{Vuursteenbewerking bij de bron: Long Island}

In hoofdstuk 4 vestig ik mijn aandacht op de belangrijkste vuursteenbron in de regio, die van Long Island. Het betreft hier vooral een secundair voorkomen van vuursteen, waar met name langs de noordkust grote hoeveelheden vuursteen eenvoudig te verzamelen zijn. De inheemse bevolking heeft dan ook niet meer dan alleen oppervlaktemateriaal verzameld, aanwijzingen voor het mijnen naar vuursteen zijn niet aangetroffen.

Vanuit de vraagstelling en methodiek besproken in hoofdstuk 1 en 3 is het van belang een goed inzicht te krijgen in hoe men het materiaal op Long Island verkregen heeft en wat men er ter plaatse precies mee heeft gedaan voordat het getransporteerd werd naar omliggende eilanden. Om deze vraag te beantwoorden is er archeologisch veldwerk uitgevoerd 
in de zomer van 2000 en zijn gegevens afkomstig uit een eerdere veldcampagne, uitgevoerd door de Universiteit Leiden in 1989, bestudeerd en opnieuw geëvalueerd.

De resultaten laten zien dat het merendeel van de aanwezige bewerkingsvindplaatsen en scatters op het eiland tot de pre-Keramische periode gerekend moeten worden. Het gaat om oppervlakte vindplaatsen waar klingkernen zijn voorbewerkt (ontdaan van hun cortex) voordat ze naar elders getransporteerd zijn. Vooral Flinty Bay langs de noordkust van het eiland is een omvangrijke voorbewerkingsvindplaats geweest. Buiten deze voorbewerkingsvindplaatsen zijn er ook sporadische resten van pre-Keramische nederzettingsvindplaatsen bekend op het eiland, waar de karakteristieken van het vuursteenmateriaal duidelijk anders zijn en duiden op het lokaal vervaardigen en gebruik van werktuigen.

Het herkennen van activiteiten uit de vroeg(e) Keramische periode (400 v. Chr tot 800 na Chr.) bleek problematisch. Bewoningsvindplaatsen uit deze periode ontbreken en ook de vuursteenscatters verspreid over het eiland vertonen geen duidelijke voor deze periode kenmerkende karakteristieken. Op basis hiervan kan gesteld worden dat gedurende deze vroege fase de menselijke activiteiten op het eiland zich hebben beperkt tot slechts het verzamelen van vuursteenmateriaal, zonder dat er systematische voorbewerking plaatsvond.

Hoewel de vuursteen scatters ook wat betreft de latere fase van de Keramische periode geen aanwijzingen opleverden dat men daar systematisch vuursteen heeft voorbewerkt, zijn er wel duidelijke archeologische aanwijzingen voor menselijke activiteit op Long Island gedurende deze periode. Ten minste twee, maar vermoedelijk vier kleine nederzettingsvindplaatsen zijn aanwezig. Al deze vier zijn tijdens de campagne van 2000 door middel van kleinschalig archeologisch veldwerk onderzocht. Bij twee vindplaatsen, Jumby Bay en Sugar Mill, zijn duidelijke afvalzones met aardewerk, vuursteen en hoge concentraties voedselresten in de vorm van schelpen en vissenbotjes aangetroffen. Bij de overige twee vindplaatsen ontbreekt een dergelijke zone en is er slechts een dunne verspreiding aardewerk, vuursteen en schelp aangetroffen. Waarschijnlijk gaat het hier om kortstondig bewoonde vindplaatsen, waarbij het verzamelen van schelpen en het vangen van vis belangrijke aspecten vormden om er te verblijven. Er zijn geen aanwijzingen aangetroffen dat vuursteen systematisch werd voorbewerkt om naar elders te worden vervoerd. Al het aanwezige vuursteen duidt op fabricage van afslagwerktuigen voor lokaal gebruik.

Hoewel dit aspect met het onderzoek op Long Island (zelf) niet aangetoond kon worden, hebben deze kleine nederzettingen vermoedelijk wel een rol gespeeld bij het toezicht houden op de vuursteenbron door een lokale gemeenschap. Onderzoek naar de verspreiding en de wijze van fabriceren van het Long Island vuursteen, dat is aangetroffen op de omliggende eilanden, heeft aangetoond dat gedurende deze late fase toegang tot het Long-Island-vuursteen het moeilijkst is geweest.

Steenbewerking en vervaardiging van artefacten binnen de nederzetting

In hoofdstuk 5 wordt het vizier op de omliggende eilanden gericht. In dit hoofdstuk bespreek ik per periode systematisch de wijze van fabricage van stenen werktuigen en objecten die geldt voor de onderzochte vindplaatsen. Het merendeel van de data is gebaseerd op de analyse van de collecties stenen artefacten afkomstig van een reeks vindplaatsen gelegen op verschillende eilanden binnen de regio Martinique en Puerto Rico, zoals besproken in hoofdstuk 3. De data zijn, waar mogelijk, aangevuld met de resultaten van onderzoek naar andere vindplaatsen door derden.

De assemblages aan stenen artefacten laten een grote verscheidenheid aan artefact typen en gebruikte steensoorten zien. Niet alleen werktuigen, zoals bijlen, klopstenen, wrijfstenen, maalstenen, slijpstenen en allerlei afslagwerktuigen, maar ook andersoortige objecten, zoals kralen en hangers en objecten met religieuze betekenis, zoals driehoekige zemi-stenen, treft men veelvuldig aan binnen de collecties van de verschillende nederzettingen uit de Keramische periode. Op basis van deze uitgebreide studie kan gesteld worden dat er gedurende de Keramische periode over het algemeen weinig veranderde in de manier waarop men stenen werktuigen fabriceerde en de materialen die men daarvoor gebruikte.

Vuursteen en ander kiezelhoudend gesteente, zoals jaspis, chert, maar ook gangkwarts werden bewerkt voor het verkrijgen van afslagwerktuigen. Deze werktuigen werden met behulp van een niet gestandaardiseerde afslagtechnologie geproduceerd. Gebruikmakend van de directe harde percussie en de aambeeldtechniek zijn afslagen vervaardigd die veelal zonder een stadium van secundaire bewerking gebruikt zijn als snij-, schraap-, boor- en raspwerktuigen. Formele werktuigtypen zijn niet aanwezig.

Veelal kristallijne gesteentes en het St. Maarten greenstone werden gebruikt voor het maken van bijlen. Daarbij is duidelijk geworden dat het St. Maarten greenstone een belangrijk gesteente geweest is voor de noordelijke Antillen. Gedurende de gehele Keramische periode heeft de bewoners dit materiaal verzameld voor het vervaardigen van bijlen. 
Nederzettingen met aanwijzingen dat bijlen lokaal gefabriceerd zijn, zijn talrijk en bevinden zich op St. Maarten zelf en de direct omliggende eilanden. Buiten deze fabricageplaatsen vinden we bijlen verspreid op de verder omliggende eilanden. In tegenstelling tot het St. Maarten greenstone zijn de plaatsen en aanwijzingen voor het vervaardigen van bijlen van lokaal kristallijngesteente veel minder talrijk. Naast deze voor de regio lokale materialen treffen we ook bijlen aan vervaardigd van exotische steensoorten, veelal groene metamorfe variëteiten.

Een breed palet aan mineralen en halfedelstenen is terug te vinden onder de gefabriceerde kralen en hangers. Allerlei kwartsvariëteiten, maar ook nefriet, calciet, bariet, serpentine, turkoois en dioriet zijn aangetroffen. De mineralen en halfedelstenen zijn deels lokaal, maar soms ook van verre afkomstig. Ook onder de zemi-stenen, de driehoekige objecten met een religieuze betekenis, is de variatie aan materialen groot. Zo zijn deze gemaakt van verschillende soorten kalksteen en verschillende soorten kristallijngesteente, maar ook kwarts, calciet en calci-rudite afkomstig van St. Maarten.

Maalstenen zijn slechts sporadisch aangetroffen en zijn voornamelijk vervaardigd van verschillende variëteiten kristallijngesteente. Over het fabricageproces van deze werktuigen tasten we nog enigszins in het duister, daar data maar summier aanwezig zijn. Onder de gebruikte, maar niet bewerkte rolkeien vinden we wederom een breed palet aan steensoorten. De variatie die aanwezig is tussen de verschillende vindplaatsen lijkt in sterke mate afhankelijk van het lokaal voorhanden zijn van rolkeien, waarbij de bewoners op de uit kalkafzettingen bestaande Antillen zich wenden tot de naburig gelegen vulkanische eilanden voor het verkrijgen van deze keien. Voor klopstenen, aambeeldstenen en wrijfstenen zijn veelal kristallijne gesteentes gebruikt. Onder de klopstenen treffen we sporadisch ook kwarts, chert en vuursteen aan. Polijststeentjes zijn veelal van fijnkorrelige steensoorten gemaakt. Dit kunnen kiezel- en andere fijne mariene afzettingsgesteentes zijn, maar ook fijne kristallijne gesteentes komen voor. Bij deze vaak kleine werktuigen zien we dat ze in enkele gevallen van relatief ver afkomstig zijn. Hierin onderscheiden deze keitjes zich duidelijk van de andere rolsteenwerktuigen.

Naast de globale continuïteit in de wijze van vervaardiging en gebruik van stenen werktuigen en objecten, zijn er toch enkele veranderingen op te merken. Deze zijn vooral gerelateerd aan het gebruik van materialen en niet zozeer terug te vinden in de wijze van fabricage. Zo is een zeer grote diversiteit aan mineralen en halfedelstenen onder kralen en hangers een in het oog springend kenmerk van de vroege Keramische periode. Veel van deze mineralen en halfedelstenen komen van bronnen van het Zuid-Amerikaanse vasteland en de aanwezigheid daarvan op de Antillen duidt op contacten over grote afstanden. Deze contacten verdwijnen rond $400 \mathrm{na}$ Chr. met als gevolg dat men genoodzaakt is deze exotische steensoorten te vervangen voor lokaal verkrijgbare mineralen en gesteentes zoals kwarts, calciet en dioriet.

De verschijning van zemis vormt een ander aspect. Deze objecten treffen we nauwelijks aan in vroeg gedateerde vindplaatsen en lijken voor het eerst te verschijnen rond 300 na Chr., waarna ze een onlosmakelijk onderdeel vormen van de pre-Columbiaanse Antilliaanse cultuur. Opmerkelijk is verder dat de vroegste exemplaren relatief klein zijn en dat de omvang duidelijk in de loop van de tijd toeneemt.

Ook het gebruik van maalstenen komt in het begin van de Keramische periode maar sporadisch voor en lijkt met de tijd toe te nemen, hoewel de data hiervoor nog summier zijn. Deze verandering houdt mogelijk verband met een veronderstelde toename aan maïs in het voedselpakket.

\section{Fabricage, verspreiding en uitwisseling}

Zoals uit de beschrijvingen in hoofdstuk 5 naar voren komt, is veel van het steenmateriaal aangetroffen binnen de nederzettingen, van elders afkomstig. Voor een deel was men genoodzaakt niet-lokale bronnen te exploiteren, omdat bruikbaar steenmateriaal lokaal gewoonweg niet voorhanden was. Vooral de bewoners van de uit kalkafzettingen bestaande Antilliaanse eilanden zagen zich veelal genoodzaakt hun gesteentes van naburige eilanden te verkrijgen. Naast deze relatief in de nabijheid verkregen materialen is er ook een reeks steensoorten aan te wijzen die op grotere afstand van de bron in een archeologische context opduiken. Dit behelst een verscheidenheid aan artefacten, gemaakt van een grote variëteit aan steensoorten, deels afkomstig van de noordelijke Antillen zelf en deels van daarbuiten.

In hoofdstuk 2 is de herkomst en herkomstbepaling van een drietal stenen aan bod gekomen. Dat zijn Long Island vuursteen, Sint Maarten greenstone en Sint Maarten calci-rudite. De drie materialen zijn veel gebruikt en komen wijdverspreid voor binnen het onderzochte gebied, soms op meer dan $450 \mathrm{~km}$ afstand van hun oorsprong. De wijze van productie van de artefacten, de vorm waarin ze getransporteerd zijn en de uiteindelijke verspreiding staan centraal in hoofdstuk 6. Aan de hand van de ideeën van Robin Torrence en met behulp van fall-off curven is getracht om op basis van deze aspecten tot uitspraken te komen over de manier van uitwisseling van deze materialen. 
De gedetailleerde analyse van het Long Island vuursteen, aangetroffen binnen de verschillende vindplaatsen, toont aan dat het materiaal bij vrijwel alle vindplaatsen als onbewerkte knollen binnen kwam. De fall-off analyse maakt duidelijk dat in de regio Saba -Guadeloupe de nederzettingen directe toegang hadden tot het bronmateriaal. In de eerste helft van de Keramische periode bezocht men Long Island zelf om het vuursteen te verzamelen. Gedurende de tweede helft van de periode stond men waarschijnlijk in contact met gemeenschappen, die de bron controleerden. In deze fase duiden de minder grote verspreiding en de efficiëntere manier van het benutten van het materiaal erop dat het materiaal moeilijker te verkrijgen was. Buiten de regio Saba-Guadeloupe is het materiaal via een down-the-line wijze uitgewisseld.

Het Sint Maarten greenstone laat een iets verschillend productie- en verspreidingsbeeld zien. Anders dan bij het vuursteen, werd geen onbewerkt ruw materiaal uitgewisseld, maar reeds vervaardigde bijlen. De bewoners van de vindplaatsen op St. Maarten en de direct omliggende eilanden waren betrokken bij de fabricage van bijlen, terwijl bewoners op de eilanden daarbuiten bijlen via uitwisseling verkregen. De ontwikkelingen in de verspreiding van deze bijlen laten een iets ander beeld zien dan in het geval van het vuursteen. In de vroegste fase van de Keramische periode is het materiaal wijdverspreid, waarna de daarop volgende fase een kleine afname te zien geeft. In zoverre loopt de ontwikkeling parallel met die van het vuursteen. Vanaf 800 na Chr. echter, breidt de verspreiding zich weer uit en tevens komt het materiaal in de regio Anguilla - Guadeloupe veelvuldig voor. In deze periode zien we dat ook het aantal vindplaatsen waar de bijlen vervaardigd zijn, het talrijkst zijn.

Net als bij het Sint Maarten greenstone, was er bij het Sint Maarten calci-rudite ook maar een beperkt aantal vindplaatsen betrokken bij de fabricage van zemi stenen. De regio waarbinnen deze stenen objecten vervaardigd werden, is echter beduidend kleiner. Slechts enkele vindplaatsen in alleen het westelijk deel van Sint Maarten en op het naburig gelegen eiland Anguilla hebben aanwijzingen voor lokale vervaardiging opgeleverd. Ook de tijdspanne waarbinnen calci-rudite zemi stenen in zwang waren, is beperkter dan in het geval van de greenstone bijlen. Zoals hierboven reeds opgemerkt verschijnen de eerste zemis pas rond 300 na Chr. Temidden van deze eerste zemis bevinden zich ook al calci-rudite exemplaren. Hoewel de productieplaatsen uit de beginperiode niet bekend zijn, is het duidelijk dat het eiland Anguilla, gelegen ten westen van St. Maarten, een centrale rol vervult in de vervaardiging van de calci-rudite zemi stenen. Waarschijnlijk vond hier de aanvang van de productie plaats. Tussen 800 en 1250 na Chr. beleefde de vervaardiging van cali-rudite zemis zijn hoogtijdagen. Het aantal productieplaatsen is in deze periode het talrijkst en de verspreiding het verst. Opmerkelijk is dat na 1250 na Chr. de fabricage van calci-rudite zemis niet meer plaatsvindt. Deze ontwikkeling lijkt parallel te lopen met het verdwijnen van enkele belangrijke nederzettingen en het verschijnen van gemeenschappen van buitenaf.

\section{Interinsulaire relaties}

In hoofdstuk 7 worden de inzichten over de fabricage van stenen artefacten en de uitwisseling van stenen materialen binnen de noordelijke Kleine Antillen in een breder sociaal-politiek perspectief geplaatst. De relatief verre verspreiding van het Long Island vuursteen en het St. Martin greenstone gedurende de vroegste fase van de Keramische periode kan geassocieerd worden met het ver reikende uitwisselingsnetwerk van kralen en hangers. Dit netwerk kan verklaard worden vanuit de kolonisatie van de eilanden door groepen afkomstig van het Zuid-Amerikaanse vaste land. Deze kolonisatie voltrok zich in een rap tempo en omvatte een omvangrijk gebied. Antropologische modellen hebben aangetoond dat het succes van een dergelijke kolonisatie sterk vergroot wordt wanneer contact tussen de verschillende sociaal verwante nederzettingen in stand gehouden blijft. Vanuit dit perspectief gezien functioneerden de uitwisselingrelaties, archeologisch waarneembaar in de aanwezigheid van exotische kralen en hangers, als het sociale verbindingsmechanisme. Vermoedelijk vertegenwoordigden de kralen en hangers de centrale geschenken en werden in het kielzog daarvan, de bijlen en de vuursteen knollen uitgewisseld.

Na 400 na Chr. zien we dat de exotische kralen en hangers van het toneel verdwijnen en er een regionalisatie optreedt waarbij verschillende eilandgroepen zich relatief onafhankelijk van elkaar ontwikkelen. Naast het verdwijnen van de exotische kralen en hangers, ontstaan er ook wat betreft de iconografie op het aardewerk duidelijke verschillen tussen de regio's. Deze regionalisatie is tevens waarneembaar binnen de verspreiding van de in dit proefschrift bestudeerde stenen materialen. De verre verspreiding neemt af, hoewel de materialen binnen de microregio's niet aan belangrijkheid inboeten. Voorts verschijnen voor het eerst zemi-stenen, waaronder exemplaren gemaakt van calci-rudite.

Naast deze ontwikkelingen op het gebied van uitwisseling en iconografie zien we ook op nederzettingsniveau enkele veranderingen optreden. Veel tot dan toe lang bewoonde nederzettingen raken verlaten en nieuwe nederzettingen met een belangrijke rol in de late Keramische periode verschijnen. Voorts vestigt men zich op tot dan toe onbewoonde eilanden, waarbij men een veel gevarieerder gebruik ging maken van de natuurlijke mogelijkheden die de eilanden boden, en lijkt een zekere site differentiatie een aanvang te nemen. Deze veranderingen zijn tot hun volle wasdom gekomen rond 800 na Chr. 
Tegelijkertijd zien we dat ook binnen de fabricage en uitwisseling van stenen artefacten differentiatie optreedt. Het gebruik van het St. Maarten greenstone en calci-rudite neemt ten opzichte van het Long Island vuursteen toe. Greenstone wordt in wijdere omtrek verhandeld dan vuursteen, iets wat in de voorgaande periodes niet het geval is geweest. Verder is de duidelijke toename aan calci-rudite productieplaatsen enerzijds en de beperkte regio waarbinnen deze religieuze objecten vervaardigd werden anderzijds, een opmerkelijke verschijning gedurende deze periode.

Deze veranderingen laten duidelijk zien dat er op sociaal-politiek niveau ontwikkelingen gaande zijn binnen de Kleine Antillen. Het is ook gedurende deze periode dat op de Grote Antillen de eerste hoofdschappen verschijnen. Hoewel differentiatie zichtbaar is binnen de Kleine Antillen, is het niet onomstotelijk bewezen dat er hoofdschappen daadwerkelijk op de Kleine Antillen zijn ontstaan. Ook de uitwisselingsdata en productiedata wijzen niet expliciet in die richting. Alle stenen artefacten werden op household niveau, dan wel door parttime specialisten vervaardigd. Een dergelijke wijze van produceren past heel goed bij samenlevingen die zich op een tribaal niveau of een niveau van chieftaincy bevinden.

Wel is duidelijk dat op het eiland Anguilla in de periode van 800 tot 1250 na Chr. binnen een aantal nederzettingen grote hoeveelheden bijlen vervaardigd werden. Deze gelijktijdige betrokkenheid bij het fabriceren van greenstone bijlen, maar ook van calci-rudite zemis duidt op een centrale aansturing. Dit suggereert dat gedurende deze periode de autonomie van de afzonderlijke nederzettingen verdwijnt en dat op zijn minst het niveau van een chieftaincy bereikt was. Tevens lijkt de productie van calci-rudite zemis onlosmakelijk verbonden te zijn met deze genoemde ontwikkelingen en is het goed mogelijk dat, gezien de religieuze connotatie van deze objecten, ze een belangrijke rol vervulden in het politieke spel van succesvolle hoofdmannen in hun poging hegemonie over een regio te bemachtigen.

Gelet op het feit dat deze situatie enkele eeuwen heeft bestaan mag het niet uitgesloten worden dat uiteindelijk hoofdschappen ontstaan zijn. Mocht dit zo zijn geweest, dan was het maar van korte duur, omdat gedurende de laatste fase van de Keramische periode, vanaf 1250 na Chr., er duidelijke veranderingen optreden. Enkele omvangrijke nederzettingen raken verlaten en kleine gemeenschappen van elders bevolken de regio. Voor wat betreft de stenen materialen komt deze verandering het best tot uitdrukking in het geheel wegvallen van de fabricage en het gebruik van calci-rudite zemis. Met het verlaten raken van de grote nederzettingen betrokken bij de fabricage van deze zemis, was kennelijk ook het sociaal-politieke platform, waarbinnen deze zemis een belangrijke rol vervulden, verdwenen.

Dit onderzoek heeft duidelijk aangetoond dat de studie naar vervaardiging en verspreiding van stenen materialen binnen de noordelijke Antilliaanse regio vruchtbare resultaten op heeft geleverd voor de kennis omtrent uitwisselingsnetwerken die operatief waren gedurende de pre-Columbiaanse periode. Uit het onderzoek blijkt ook dat veel aspecten nog onderbelicht of zelfs geheel onbekend zijn. Ik spreek daarom dan ook de hoop uit dat in de toekomst dit soort onderzoek gecontinueerd en verder uitgebouwd wordt. 


\section{Curriculum Vitae}

Sebastiaan Knippenberg was born in Amsterdam on August 1, 1970. After his secondary school education at the Spaarne Scholengemeenschap in Haarlem (1982-1988), he studied chemistry at the University of Amsterdam for two years (1988-1990). In 1989 he started his study of archaeology at Leiden University (1989-1995), obtaining the MA degree in archaeology, with specialisation in pre-Columbian archaeology in 1995. He participated in a number of archaeological field projects in the Caribbean, Germany and The Netherlands in the course of his study.

After his graduation he was employed by the Joan Willems Foundation as a field archaeologist for two years at the Late Mesolithic and Early Neolithic site of De Hoge Vaart, The Netherlands (1995-1997). He subsequently joined the Anse à la Gourde project, Guadeloupe, as a field supervisor in the summer of 1997. The next six months he worked as a field archaeologist employed by Jacobse and Burnier, a contract archaeological firm based in Amsterdam. During this period he conducted fieldwork in the area around Haarlem, The Netherlands.

In 1998 he obtained a four-year PhD research position at Leiden University partaking in the project "Pre-Columbian interinsular relationships and social organization on the Lesser Antilles. A multi-dimensional approach", which was headed by Dr. Corinne L. Hofman. The Netherlands Organisation for Scientific Research (NWO), The Hague, provided the funding for this project, which resulted in the present dissertation. Currently Sebastiaan Knippenberg is employed by Archol BV, the contract archaeological firm associated with Leiden University. During the past few years he has taken part in many archaeological projects in The Netherlands and wrote various excavation reports. 
